\title{
DIVERSITY AND ECOLOGY OF THE ROSEOBACTER \\ Clade AND OTHER MARINE MiCROBES AS REVEALED \\ BY METAGENOMIC AND METATRANSCRIPTOMIC APPROACHES
}

\author{
Dissertation \\ zur Erlangung des mathematisch-naturwissenschaftlichen \\ Doktorgrades \\ "Doctor rerum naturalium" \\ der Georg-August-Universität Göttingen \\ im Promotionsprogramm Biologie \\ der Georg-August University School of Science (GAUSS)
}

vorgelegt von

Bernd Wemheuer

aus Northeim

Göttingen, 2013 


\section{Betreuungsausschuss}

Prof. Dr. Rolf Daniel, Genomische und Angewandte Mikrobiologie und Göttinger Genomlabor, Institut für Mikrobiologie und Genetik

Prof. Dr. Stefanie Pöggeler, Genetik eukaryotischer Mikroorganismen, Institut für Mikrobiologie und Genetik

Mitglieder der Prüfungskommission

Referent: Prof. Dr. Rolf Daniel, Genomische und Angewandte Mikrobiologie und Göttinger Genomlabor, Institut für Mikrobiologie und Genetik

Korreferentin: Prof. Dr. Stefanie Pöggeler, Genetik eukaryotischer Mikroorganismen, Institut für Mikrobiologie und Genetik

Weitere Mitglieder der Prüfungskommission:

Jun.-Prof. Dr. Kai Heimel, Mikrobielle Zellbiologie, Institut für Mikrobiologie und Genetik

Prof. Dr. Burkhard Morgenstern, Bioinformatik, Institut für Mikrobiologie und Genetik

PD Dr. Christoph Scherber, Agrarökologie, Department für Nutzpflanzenwissenschaften

Prof. Dr. Stefan Vidal, Agrarentomologie, Department für Nutzpflanzenwissenschaften

Tag der mündlichen Prüfung: 21. 01. 2014 
"We have to remember that what we observe is not nature itself, but nature exposed to our method of questioning"

\section{Werner Heisenberg}

(German physicist and Noble Price laureate) 


\section{TABLE OF CONTENTS}

Table of contents iv

Abbreviations vi

List of relevant publications ix

Chapter A - Summary 1

Chapter B - General introduction 5

1 Diversity and ecology of marine microorganisms 7

1.1 Oceanic divisions 7

1.2 Study Area 8

1.3 Marine microbial ecology 9

1.4 Culture-independent analysis of marine microbial communities 10

1.5 Structure of marine microbial communities 12

2 Diversity and ecology of microorganisms in other ecosystems 14

2.1 Geothermal springs 14

2.2 Photobioreactors 14

2.3 Endophytic bacteria 15

3 Focus of this thesis 17

Chapter C - Publications 19

Study 1 20

Study 2 29

Study 3 52

Study 4 79

Study 5 98

Study 6 343

Study 7 351

Study 8 366

Study 9 388

Chapter D - General discussion 412

1 Marine Microbes 414

1.1 Microbial ecology of marine ecosystems 414

1.2 Ecology of the Roseobacter clade 415

1.3 Microbial response to a changing environment 418 
2 Further studies on microbial ecology 420

2.1 microbial diversity and ecology of two hyperthermal springs 420

2.2 Diversity, genomic potential, and function in a photobioreactor 421

2.3 Endophytic communities in three grass species 422

3 Concluding remark 424

Chapter E - General references 425

Appendix 437

Other Publications 438

Journal articles (peer-reviewed) 438

Talks and poster presentations 439

Talks at conferences 439

Posters at conferences (selection) 439

Acknowledgements 440

Curriculum Vitae 442 


\section{AbBreviations}

AAP

ACE

ANOVA

a.s.1.

BLAST

BLASTN

bp

${ }^{\circ} \mathrm{C}$

ca.

$\mathrm{cm}$

$\mathrm{CO}$

CTD

D.

DEPC

DGGE

DMSP

DMSO

DNA

DOC

DOM

E

EDTA

e.g.

EU

EU-27

F.

Fig.

Figs.

g

GOS

GrassMan aerobic anoxygenic photosynthesis

ACE richness estimator

Analysis of Variance

above sea line

Basic Local Alignment Search Tool

BLAST search using a nucleotide query

base pairs

degree Celsius

circa

centimetre

carbon monoxide

conductivity, temperature, depth

Dactylis

diethylpyrocarbonate

denaturing gradient gel electrophoresis

dimethylsulfoniopropionate

dimethyl sulphoxide

deoxyribonucleic acid

dissolved organic carbon

dissolved organic matter

East

Ethylenediaminetetraacetic acid

exempli gratia, for example

European Union

Member of the European Union

Festuca

figure

figures

gram

Global Ocean Sampling

Grassland Management Experiment 


\begin{tabular}{|c|c|}
\hline $\mathrm{h}$ & hour(s) \\
\hline ha & hectare \\
\hline i.e. & id est, that is \\
\hline $\mathrm{k}$ & kilo \\
\hline $\mathrm{L}$ & litre \\
\hline$L$. & Lolium \\
\hline $\mathrm{m}$ & meter \\
\hline$\mu$ & micro \\
\hline $\min$ & minute \\
\hline $\mathrm{mm}$ & millimetre \\
\hline mRNA & messenger RNA \\
\hline $\mathrm{N}$ & North \\
\hline NAC & North Atlantic cluster \\
\hline NCBI & National Centre for Biotechnology Information \\
\hline NGS & next generation sequencing \\
\hline $\mathrm{n}_{\max }$ & maximal OUT number \\
\hline NPK & Fertilizer containing Nitrogen, Phosphorous, and \\
\hline & Potassium \\
\hline $\mathrm{nt}$ & nucleotides \\
\hline$O$. & Octadecabacter \\
\hline ORF & open reading frame \\
\hline OTU & operational taxonomic unit \\
\hline$P$. & Planktomarina \\
\hline PCR & polymerase chain reaction \\
\hline PFLA & Phospholipid Fatty Acid \\
\hline $\mathrm{pH}$ & power of hydrogen \\
\hline POC & particulate organic carbon \\
\hline POM & particulate organic matter \\
\hline QIIME & Quantitive Insights Into Microbial Ecology \\
\hline$R$. & Roseobacter \\
\hline RCA & Roseobacter clade affiliated \\
\hline rDNA & DNA coding for ribosomal DNA \\
\hline rRNA & ribosomal RNA \\
\hline
\end{tabular}




\begin{tabular}{ll} 
PCoA & Principal Coordinate Analysis \\
PGPR & Plant Growth Promoting Rhizobacteria \\
RNA & ribonucleic acid \\
rpm & rotations per minute \\
rRNA & ribosomal RNA \\
sec & second \\
SSU & Small Subunit of the Ribosome \\
Tab. & table \\
TAE & tris-acetate-EDTA \\
Taq & Thermus aquaticus \\
TE & Tris EDTA \\
Tr. & Treatment \\
Tris & tris(hydroxymethyl)aminomeethane \\
UPGMA & Unweighted Pair Group Method with Arithmetic \\
USA & Mean \\
UV & United States of America \\
V & ultraviolet \\
vs. & volt \\
& versus \\
& year \\
\hline
\end{tabular}

Abbreviations for nucleotides
A
adenine
C
cytosine
G
guanine
$\mathrm{R}$
purines (adenine or guanine)
$\mathrm{T}$
thymine (5-methyluracil)
Y
pyrimidines (cytosine, thymine or uracil) 


\section{LIST OF RELEVANT PUBLICATIONS}

1) Wemheuer B, Wemheuer F, and Daniel R. RNA-Based Assessment of Diversity and Composition of Active Archaeal Communities in the German Bight. Archaea,vol. 2012, Article ID 695826, 8 pages, 2012. doi:10.1155/2012/695826.

2) Wemheuer B, Güllert S, Billerbeck S, Giebel H-A, Voget S, Simon M, and Daniel R (2014). Impact of a phytoplankton bloom on the diversity of the active bacterial community in the southern North Sea as revealed by metatranscriptomic approaches. FEMS Microb Ecol 87: 378-389. doi: 10.1111/1574-6941.12230

3) Wemheuer B, Meier D, Klempert P, Billerbeck S, Giebel HA, Scherber C, Simon M, and Daniel R. From Germany to Norway: simultaneous assessment of total and active bacterial community structures in the North Sea along a latitudinal gradient. (in preparation)

4) Kanukollu S, Wemheuer B, Herber J, Billerbeck S, Lucas J, Daniel R, Simon M, Cypionka H, and Engelen B: Community analysis of free-living and attached Roseobacter-affiliated bacteria indicate an overlap in diversty between matured particles and the sediment surface. (in preparation)

5) Voget S, Wemheuer B, Brinkhoff T, Vollmers J, Dietrich S, Giebel HA, Beardsley C, Bakenhus I, Billerbeck S, Daniel R, and Simon M: Adaptation of an abundant Roseobacter RCA organism to pelagic systems revealed by genomic and transcriptomic analyses. ISME J 2014 AUG 1. doi:10.1038/ismej.2014.134 
6) Simon M, Billerbeck S, Brinkhoff T, Dogs M, Müllenmeister S, Seibt M, Seidel M, Smits M, Wagner-Döbler I, Wang H, Wemheuer B, and Wurst M (2012) Composition and activity of the bacterioplankton communities in the Drake Passage and Antarctic Peninsula region with a special emphasis on the Roseobacter clade and dissolved organic matter. In: Lucassen M (ed) The expedition of the Research Vessel "Polarstern" to the Antarctic in 2012 (ANT-XXVIII/4) Reports on Polar and Marine Research 653: 49-54.

7) Sahm K, John P, Nacke H, Wemheuer B, Grote R, Daniel R, and Antranikian G (2013) High abundance of heterotrophic prokaryotes in hydrothermal springs of the Azores as revealed by a network of 16S rRNA gene-based methods. Extremophiles 17: 649-662.

8) Krohn-Molt I, Wemheuer B, Alawi M, Poehlein A, Güllert S, Schmeisser C, Pommerening-Röser A, Grundhoff A, Daniel R, Hanelt D, and Streit WR. Metagenome survey of a multispecies and algae-associated biofilm reveals key elements of bacterial-algae interactions in photobioreactors. Appl Environ Microbiol 79 (20) 6196-6206. doi: 10.1128/AEM.01641-13

9) Wemheuer F, Kretzschmar D, Wemheuer B, Daniel R, and Vidal S. Impact of grassland management regimes on bacterial endophyte diversity differs with grass species and season. (in preparation) 
Chapter A

SUMMARY 
Marine Bacteria and Archaea represent the major part of the total biodiversity on Earth. They are main drivers of biogeochemical cycles in marine environments and play an integral role in ecosystem structuring. Therefore, the understanding how marine prokaryotic communities are structured and how these communities react towards altered environmental conditions is of fundamental importance. In this thesis, the diversity and ecology of Bacteria and Archaea in the pelagic realm of the North Sea was studied using different culture-independent approaches. In particular, the abundance and ecological role of the Roseobacter clade was analyzed. Moreover, the response of the investigated prokaryotic communities to changing environmental conditions was examined.

One objective was to analyze active archaeal and bacterial community structures in the southern North Sea. Moreover, the impact of a phytoplankton bloom on prokaryotic community composition and diversity was elucidated. For this purpose, 14 marine water samples were collected in May 2010 in the German Bight in and outside of a phytoplankton bloom. Community structures were assessed by pyrotag sequencing of $16 \mathrm{~S}$ rRNA transcripts. A total of 62,045 and 211,769 16S rRNA sequences were used to examine archaeal and bacterial community composition and diversity, respectively. Different marine lineages of the Gamma- and Alphaproteobacteria including the SAR92 clade and the Roseobacter clade affiliated (RCA) cluster dominated the bacterial community. The archaeal community mainly composed of Halobacteria as well as minor proportions of Thermoplasmata and members of the Marine Group I.

Both archaeal and bacterial community structures were influenced by the presence of the examined phytoplankton bloom. In addition to structural changes, the bacterial richness was reduced in bloom presence indicating that only certain bacteria could thrive during the bloom. To exploit the impact of the phytoplankton bloom on gene expression, environmental mRNA from three samples was extracted, enriched, and sequenced resulting in a total of 988,022 sequences for all three samples. Changes in various metabolic pathways including photosynthesis and protein metabolism were recorded as response to the bloom. The observed changes were induced either directly by the bloom or indirectly by altered environmental parameters as most of these parameters were significantly correlated to bloom presence. 
Another objective was to assess the structure and diversity of total and active bacterial communities along a latitudinal gradient ranging from the German Bight to the Norwegian coast. For this purpose, surface water samples were taken in July 2011 on board of the research vessel Heincke. Community structures were examined by pyrotag sequencing of $16 \mathrm{~S}$ rRNA genes and transcripts. A total of 382,507 16s rRNA gene sequences were used to assess bacterial community structures. These communities were dominated by different groups affiliated to the Bacteroidetes and Alphaproteobacteria including the marine groups NS5, NS7, and NS9, different subclusters of the Roseobacter clade, and members of the SAR116 clade. Moreover, Cyanobacteria were found in minor abundance with Synechococcus as the dominant genus.

Total and active bacterial community structures were significantly altered along the latitudinal gradient whereas the bacterial richness was unaffected. The abundance of certain marine groups such as the Roseobacter CHAB-I-5 and NAC11-7 clusters either decreased or increased with rising latitude. The recorded changes in bacterial community structures along the studied gradient might be explained by changing environmental conditions which are probably caused by the different water currents found along the gradient. Additionally, the composition of the Rhodobacteraceae in the free-living and in the particleassociated fraction in different depths as well as in the sediment along the latitudinal gradient was investigated. The composition of this family significantly varied between the different fractions.

In addition to the overall bacterial community structure, the ecological contribution of an abundant member of the RCA cluster, Planktomarina temperata, to nutrient cycling in the pelagic realm of the North Sea was analyzed. This cluster exhibited more than $20 \%$ relative abundance in samples derived from the first sampling. Consequently, the largest mRNA dataset of this cruise and a metagenome obtained by direct sequencing of gDNA from the same sample was mapped on its genome. Around one million pyrosequencing reads were mapped in total. Large parts of the genome were retrieved by the mapping approach with approximately $86 \%$ of the genome transcribed. Active features included the photosynthetic operon, the two $\mathrm{CO}$ dehydrogenase systems, and the assimilatory sulfate reduction pathway. 
In addition to marine ecosystems, the diversity of other prokaryotic communities in three non-marine habitats was examined. In the first survey, we studied the prokaryotic community in two hyperthermal springs on the Azores. Environmental DNA was extracted from two sediment samples and further analyzed using different metagenomic methods. The first spring was dominated by heterotrophic bacterial genera including Caldicellulosiruptor, Dictyoglomus, and Fervidobacterium as well as by the chemolithoautotrophic genus Sulfurihydrogenibium. The archaeal community comprised Crenarchaeota with Thermoproteaceae and Desulfurococcaceae as the dominant families. The bacterial community in the other spring was mainly composed of the heterotrophic genus Acidicaldus and the chemolithoautotrophic genus Acidithiobacillus.

In the second study, the diversity and genomic potential of a bacterial biofilm associated with two freshwater algae, Chlorella vulgaris and Scenedesmus obliquus, in a photobioreactor was investigated. DNA was extracted from collected biofilm samples and analyzed using different metagenomic approaches. The recorded community size was rather limited with approximately 30 bacterial species. The majority of the observed Bacteria were affiliated to Alphaproteobacteria, Betaproteobacteria, and Bacteroidetes. Analysis of the genomic potential revealed a high metabolic diversity with respect to the utilization of polymers, aromatic, and non-aromatic compounds.

In the third study, the bacterial endophytic community structures in three agricultural important grasses, Dactylis glomerata, Festuca rubra, and Lolium perenne, was examined. Moreover, the response of these communities to fertilizer application, mowing frequency, and seasonal changes over two consecutive years was investigated. Endophytic community structures were studied by DGGE-based analysis of $16 \mathrm{~S}$ rRNA genes amplified from plant DNA. The communities were dominated by different members of the Firmicutes and Proteobacteria with Bacillus and Pseudomonas as the predominate genera. The studied management regimes significantly altered the endophytic communities in L.perenne and F. rubra but not in D. glomerata. On the other hand, season significantly affected the community structures in all three grasses. Moreover, as community structures were subjected to seasonal variations, the recorded impact of management regimes differed between the two investigated years. 
CHAPTER B

GENERAL INTRODUCTION 
"Ocean: A body of water occupying about two-thirds of a world made for man who has no gills."

Ambrose Bierce (American journalist and writer) 


\section{DIVERSITY AND ECOLOGY OF MARINE MICROORGANISMS}

\subsection{OCEANIC DIVISIONS}

The world ocean covers approximately $71 \%$ of the Earth's surface and contains more than $95 \%$ of the global water. Moreover, it is the planet's largest ecosystem. In general, the ocean can be divided into the pelagic realm (water column) and the benthic realm (sea floor) (Fig. 1). With respect to depth and light penetration, the pelagic realm is vertically divided into a photic and an aphotic zone. The photic zone is the zone where light is abundant, photosynthesis can occur, and thus the major part of marine primary production happens. As a consequence, life in the aphotic zone relies on other energy sources such as material sinking from the surface to the ground (marine snow) or hydrothermal vents. In addition to its vertical separation, the pelagic realm is horizontally divided into a neritic (coastal regions) and an oceanic zone (open ocean). The neritic zone exhibits a different nutrient composition and availability than the oceanic zone due to upwelling ground water or the inflow of rivers. The benthic realm is subdivided into different zones on the basis of depth, which extend from high tide to the continental shelf and deep-sea zones.

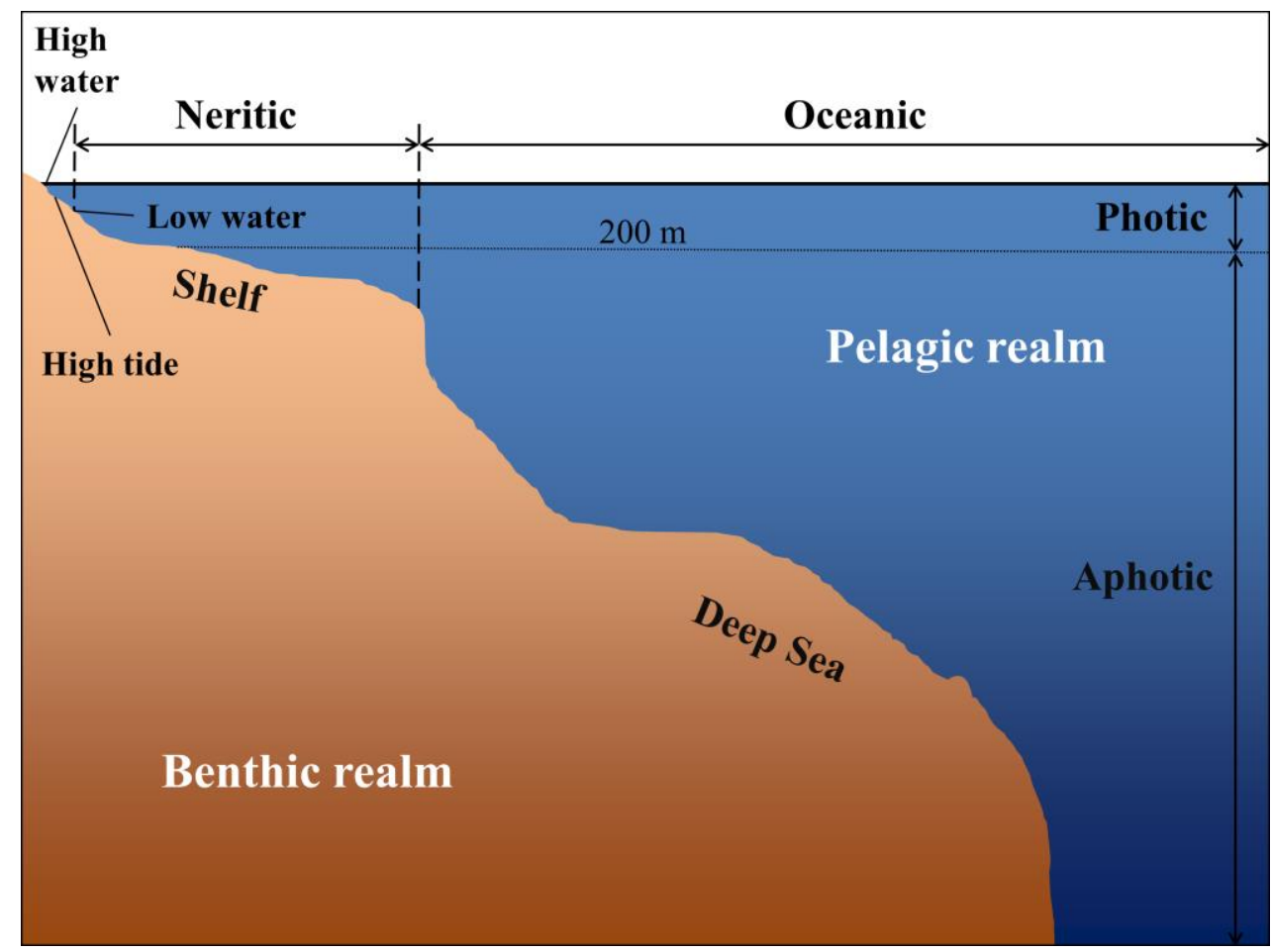

Figure 1: Oceanic divisions (ㄷ Bernd Wemheuer). 


\subsection{STUdY AREA}

The studies presented in this thesis were mainly focused on the analysis of microbial communities in the pelagic realm of the North Sea. The North Sea is a marginal of the Atlantic Ocean on the European continental shelf. Coastal shelf areas of the temperate zone are highly productive because of the continuous nutrient supply by rivers. The counter-clockwise circulation of the water masses is caused by the main currents inflowing from the English Channel and the Norwegian trench (Fig. 2). During the last 40 years, the North Sea, in particular its southern region underwent high nutrient loading and warming (McQuattersGollop et al., 2007; Wiltshire et al., 2010).
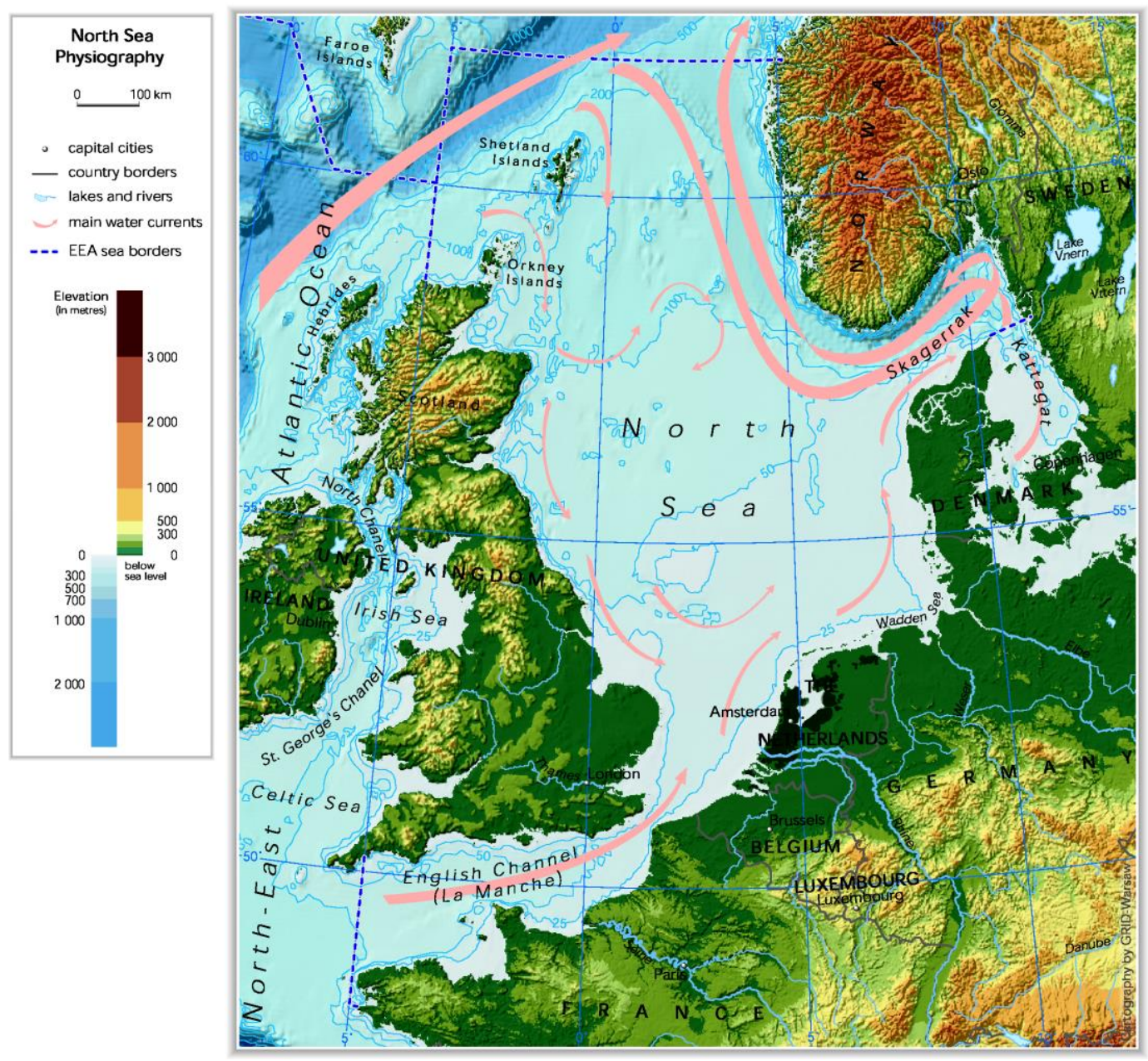

Figure 2: Physiography of the North Sea ( European Environment Agency). 


\subsection{MARINE MICROBIAL ECOLOGY}

According to the National Oceanic and Atmospheric Administration (USA), the world ocean harbors an enormous biodiversity and promotes the life of nearly 50 percent of all species on Earth (http://www.noaa.gov/ocean.html). Although all marine ecosystems are generally characterized by high salinities (around 3.5\%) and low nutrient availability, various ecological niches are formed. All of these niches are colonized by marine microbes. The biology in all marine ecosystems is strongly influenced by different factors such as temperature and salinity. Moreover, anthropogenic factors such as marine pollution or overfishing changed the structures of these ecosystems during the last century. In addition large parts, especially the deep sea, remain poorly examined.

Microbes (organisms from 0.2 to $100 \mu \mathrm{m}$ ) account for $50 \%$ of the global biomass. These bacteria, archaea, protists, and unicellular fungi are responsible for $98 \%$ of the primary production (Whitman et al., 1998) and mediate all biogeochemical cycles in the ocean (Atlas \& Bartha, 1993). One example is the microbial contribution to the carbon cycle. A large fraction of the primary products formed is dissolved (dissolved organic matter; DOM) by various mechanisms in the food web (Fig. 3). This part of the primary production is almost exclusively accessible to heterotrophic Bacteria and Archaea (Azam \& Malfatti, 2007). Therefore, marine microbes are important for global nutrient cycling. During the last years, there has been an increasing interest in the ecology of these important organisms and their active contribution to ecosystem functioning.

The overall role of marine microorganism in different marine ecosystems has been frequently addressed over the last years. However, the active contribution of single microbial clades or lineages is still poorly understood mainly due to the non-cultivability of these organisms. Currently available isolates hardly represent marine microbial diversity. Most marine microorganisms are uncharacterized both genetically and biochemically (Rusch et al., 2007). As a consequence, it is difficult to link individual organisms, clusters, or phyla to certain biogeochemical processes and ecosystem services (Heidelberg et al., 2010). 


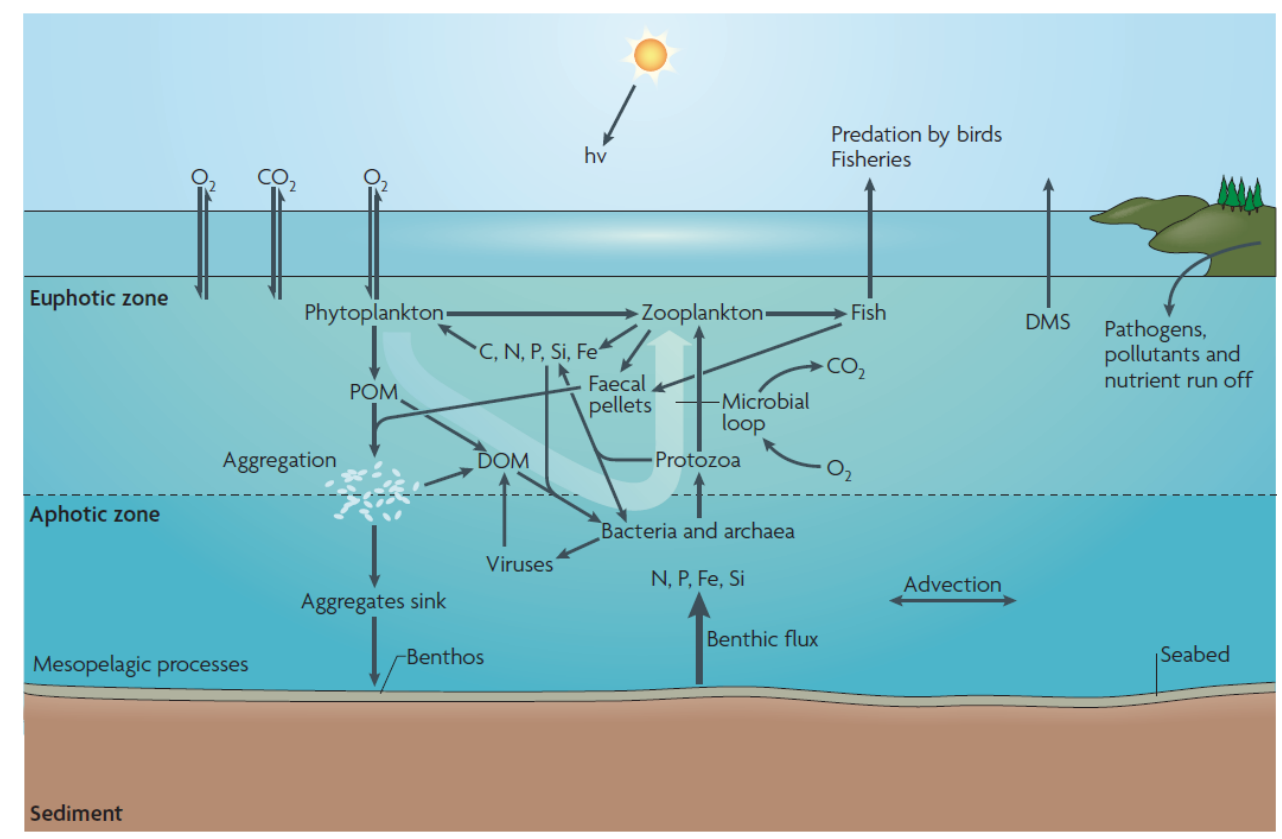

Figure 3: Microbial structuring of a marine ecosystem (taken from (Azam \& Malfatti, 2007). (DMS = dimethyle sulfide; DOM = dissolved organic matter; POM particulate organic matter)

\subsection{CUlture-INDEPENDENT ANALYSIS OF MARINE MiCrobial COMMUNITIES}

It has been calculated that one milliliter of oceanic sea water contains up to one million microorganisms (Curtis et al., 2002). Most of these organisms cannot be studied as they are reluctant to common culturing techniques. As a consequence, cultivation-independent approaches are the only possibility to assess and exploit both the diversity and the ecology of marine microbial communities. Studies using these approaches have greatly advanced our understanding of marine microbial diversity and ecology (e.g., Venter et al., 2004, Giovannoni \& Stingl, 2005). Early studies used traditional techniques such as Sanger sequencing-based analysis of $16 \mathrm{~S}$ rRNA gene libraries to examine bacterial community structures (e.g., Giovannoni et al., 1990, Britschgi \& Giovannoni, 1991). However, these studies failed to investigate the full extent of microbial diversity due the size and complexity of marine microbial communities. The advent of next-generation sequencing revolutionized metagenomic research and 
has been applied for in-depth investigation of bacterial communities in almost all marine ecosystems (e.g., Bolhuis \& Stal, 2011, Lee et al., 2011, Thompson et al., 2011)). However, most studies on marine diversity and ecology applied DNAbased approaches (e.g., Schmidt et al., 1991, Selje et al., 2004, Giebel et al., 2009). Therefore, these surveys assessed the diversity of the total microbial community but were not able to distinguish between active and inactive fraction. The application of culture-independent approaches using environmental RNA and proteins as starting material (Fig. 4) and thus targeting the active fraction of the microbial community provided novel and unique insights into diversity and ecological contribution of marine microbes (e.g., Teeling et al., 2012, Wemheuer et al., 2012, Wemheuer et al., 2013).

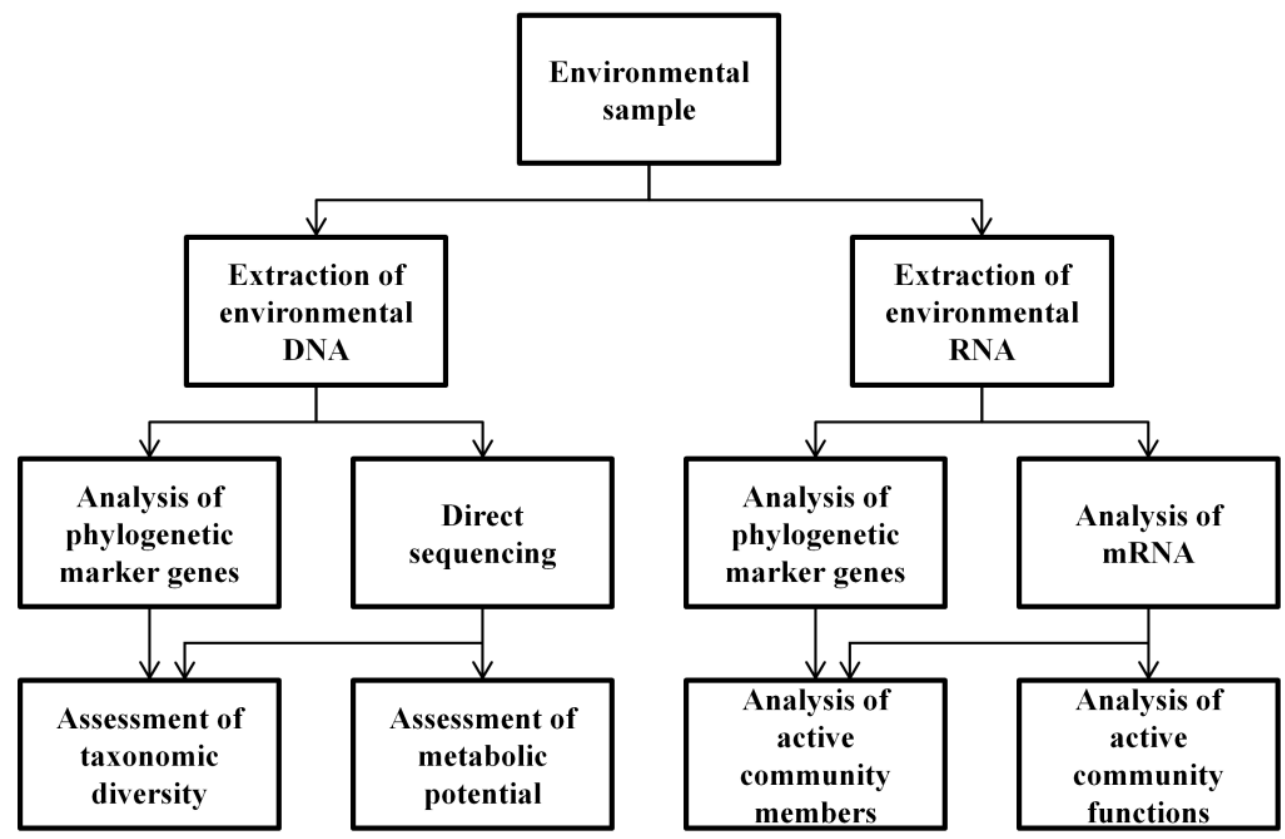

Figure 4: Metagenomic and metatranscriptomic ways to investigate environmental samples (modified from Simon \& Daniel, 2011). 


\subsection{STRUCTURE OF MARINE MICROBIAL COMMUNITIES WITH FOCUS ON THE ROSEOBACTER CLADE}

Certain marine clades are ubiquitous and abundant in almost all marine environments (Fig. 5). One of these groups is the Roseobacter clade, a monophyletic group within the Rhodobacteraceae (Alphaproteobacteria). Members of this clade have been found in almost every marine environment including polar regions (Brinkmeyer et al., 2003). They constitute up to $25 \%$ of all marine prokaryotes (Buchan et al., 2005). Members of the Roseobacter clade have been identified as biofilm-forming, free-living, or as symbionts of phytoplankton and sponges (as reviewed in Brinkhoff et al., 2008).

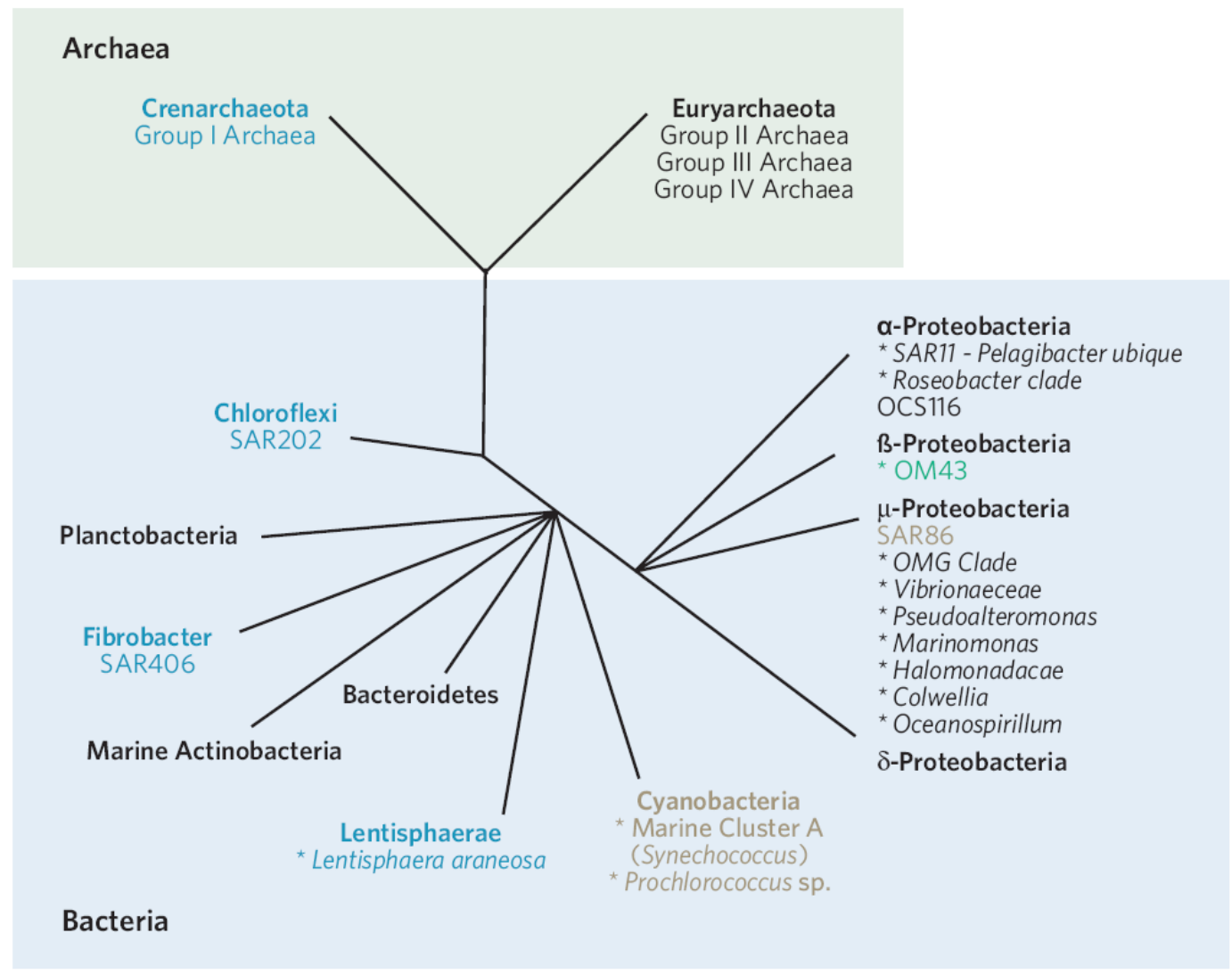

Figure 5: Main phyla of marine pelagic prokaryotes. Ubiquitous groups are written in black (Giovannoni \& Stingl, 2005). 
The use of a multitude of organic compounds, the production of secondary metabolites, and other metabolic pathways such as aerobic anoxygenic photosynthesis (AAnP) or carbon monoxide (CO) oxidation are thought to contribute to the success of the Roseobacter clade in marine environments. This knowledge is mainly based on the high numbers of available isolates and the analysis of the corresponding genomes. Several of these genomes have been investigated during the past years (Wagner-Döbler et al., 2010, Kalhoefer et al., 2011, Vollmers et al., 2013). These studies found several novel traits which might also contribute to the success of the Roseobacter clade in marine ecosystems including several potential heavy metal resistance genes and xanthorhodopsins (Kalhoefer et al., 2011, Vollmers et al., 2013). However, most of the investigated isolates do not represent the predominate subclusters of the Roseobacter clade. What is responsible for the success of this clade in marine environments is still not fully understood. 
In addition to marine ecosystems, the diversity and ecology of microbes in different natural and artificial habitats was studied, i.e., two geothermal springs derived from the Azores, a photobioreactor, and different agricultural important grass species

\subsection{GEOTHERMAL SPRINGS}

Sites of volcanic activity can be found all over the world. With regard to physicochemical conditions, they provide a variety of different ecological niches for microorganisms. These niches exhibit extreme environmental conditions, such as high temperature, low or high $\mathrm{pH}$, and the presence of toxic ions. One well studied example of such a niche are hydrothermal springs (Hugenholtz et al., 1998, MEYER-DOMBARD et al., 2005, Kvist et al., 2007, Wemheuer et al., 2013). Their extreme features are expected to lead to limited biodiversity, thus, making hydrothermal habitats ideal model systems to study principles of community structure and function (Sahm et al., 2013). Moreover, extremophilic microorganisms inhabiting hydrothermal springs are considered to be the closest living descendants of the earliest life forms on Earth (Olsen et al., 1994).

\subsection{PHOTOBIOREACTORS}

Rising carbon dioxide levels in the atmosphere and the global energy crisis resulted in an increasing demand for alternative energy sources. Algal biofuel produced by microalgae is a promising candidate to supply this demand, but the process is still some way from being carbon neutral or commercially viable (Scott et al., 2010). Microalgae comprise a large and phylogenetically very heterogeneous group of microorganisms. They perform oxygenic photosynthesis and thereby convert $\mathrm{CO}_{2}$ to high amounts of cellular lipids as potential source of biofuels (Abomohra et al., Chisti, 2007, Gouveia \& Oliveira, 2009, Williams \& 
Laurens, 2010, Wiley et al., 2011). Since photobioreactors allow the continuous cultivation of microalgae under relatively controlled conditions, they have been in the focus of many research projects often linked to large-scale biofuel production (Chisti, 2007, Ugwu et al., 2008, Scott et al., 2010, Williams \& Laurens, 2010). However, one fundamental problem of biofuel production is that there is still little background knowledge established (Scott et al., 2010). This knowledge might enable us to solve frequent problems in algal farming such as biofouling and the growth of microbial biofilms in the reactor. Moreover, it can help us to increase yield and quality of the growing algae.

\subsection{ENDOPHYTIC BACTERIA}

Almost all plant species are colonized by microorganisms including endophytic bacteria (Senthilkumar et al., 2011). Endophytic bacteria are defined as bacteria that can be isolated from within plants or from surface-disinfested plant tissue, and that have no apparent harmful effects on the plant (Hallmann et al., 1997). Endophytic bacteria have been reported to promote plant growth, plant yield, and the overall plant health by a number of mechanisms. This includes the production of phytohormones and antibiotics (Bacon \& Hinton, 2006, Compant et al., 2010) as well as enhanced nutrient availability and nitrogen fixation (Stoltzfus et al., 1997, Rosenblueth \& Martinez-Romero, 2006). Moreover, plants infected with endophytic bacteria have a higher resistance to plant pathogens (e.g., (Hallmann et al., 1998, Krechel et al., 2002, Siddiqui \& Shaukat, 2003, Compant et al., 2005) and environmental stresses (e.g., (Sturz \& Nowak, 2000, Bacon \& Hinton, 2006, Bacon \& Hinton, 2011). Many biotic factors including plant age or tissue as well as abiotic factors such as soil conditions, temperature, or crop rotation influence the bacterial endophytic community (Hallmann et al., 1997, Fuentes-Ramírez et al., 1999, Sessitsch et al., 2002, Seghers et al., 2004, Hardoim et al., 2012). Although their important role in agricultural cropping systems is frequently appreciated (e.g., (Hallmann et al., 1997, Kobayashi \& Palumbo, 2000, Bacon \& Hinton, 2006, Maksimov et al., 2011, Senthilkumar et al., 2011), the effect of 
different management regimes and seasonal changes on the overall bacterial endophytic community in different grass species has not been studied yet. 


\section{FOCUS OF THIS THESIS}

This main objective of this thesis was to investigate the diversity and ecology of microbial communities in marine ecosystems (Fig. 7). In addition, microbes in other habitats were studied (Fig. 7). To gain insights into the diversity and ecology of the examined microbial communities, different cultureindependent approaches were employed. Metagenomic (DNA-based) methods were used to assess phylogenetic structures and to exploit the genomic potential of the studied communities. In addition, metatranscriptomic (RNA-based) approaches were used to investigate the active microbial community fraction. With regard to the high diversity of the studied ecosystems, next generation sequencing techniques were employed as these approaches provide a more accurate picture of microbial community structure and potential.

The first two studies were focused on the analysis of samples taken on board of the RV Heincke in May 2010. The aim of this cruise was to examine the diversity of archaeal and bacterial communities in the southern North Sea. Moreover, the influence of a phytoplankton bloom on the ambient microbial community was studied. The next two surveys analyzed samples taken along a latitudinal gradient in the North Sea on board of the RV Heincke in July 2011. Bacterial communities were analyzed with respect to changes of environmental conditions and geographical parameters. In addition, the composition of the Roseobacter clade and other Rhodobacterales in different consortia (free-living, particle-associated, sediment) and different depths (from surface to sediment) was investigated. The fifth study investigated the abundance and ecological function of an abundant Roseobacter clade isolate, Planktomarina temperata. The sixth study is article about the sampling on board of the RV Polarstern in the Southern Ocean. The last three surveys were focused on the analysis of other, non-marine samples. In the first one, the diversity and ecology of Archaea and Bacteria in two hyperthermal springs on the Azores were studied using different metagenomic approaches. In the second one, structure and genomic potential of a bacterial community in a photobioreactor were investigated to better understand the dynamics and function of this artificial habitat. The last study aimed at assessing the bacterial endophytic community in three agricultural important grass species 
and to evaluate the impact of different management regimes and season changes on these communities.

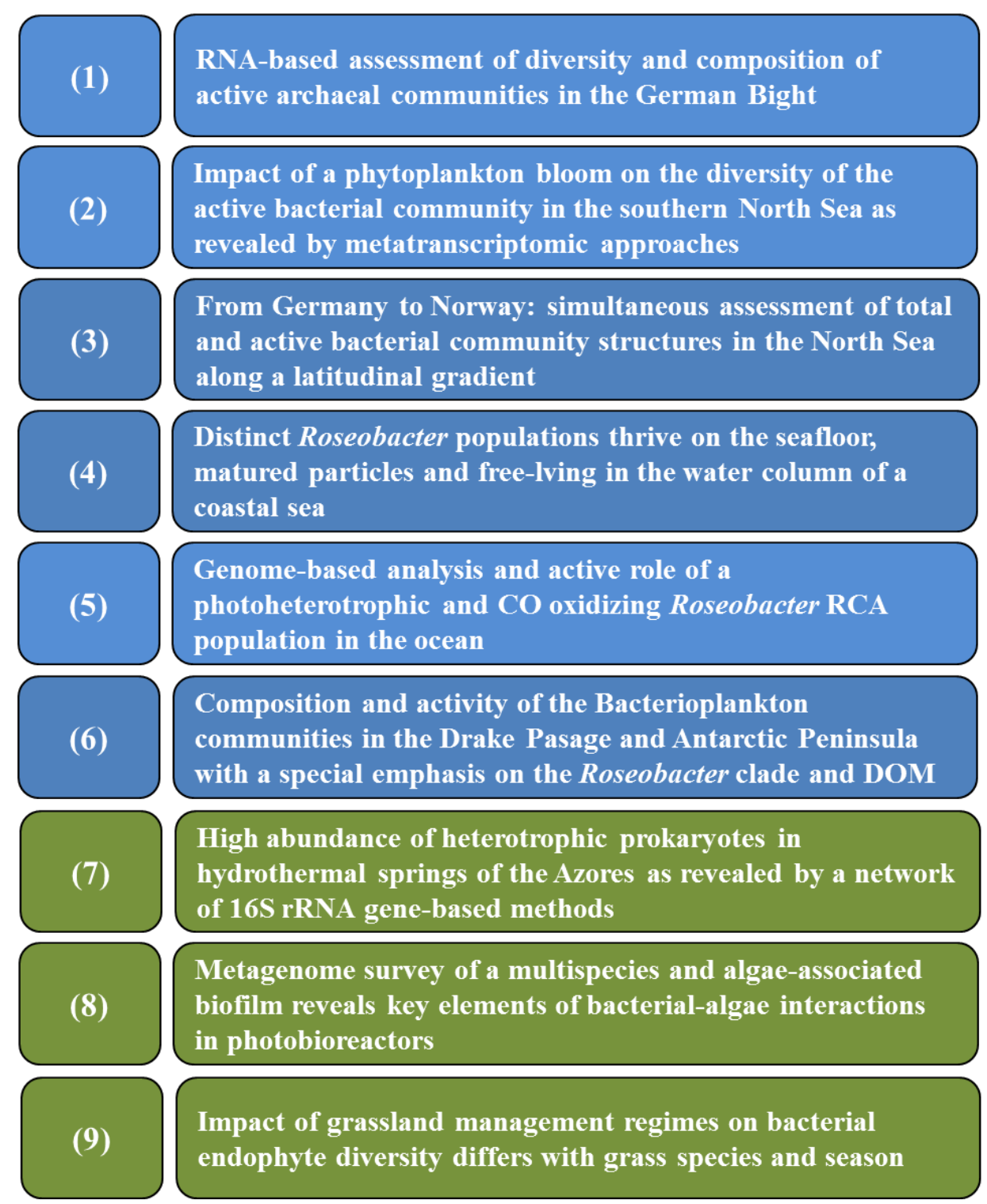

Figure 7: Overview about the studies presented in this thesis. All marine studies are highlighted in blue, non-marine studies in green. 
Chapter C

\section{Publications}




\title{
STUDY 1:
}

\section{RNA-BASED ASSESSMENT OF DIVERSITY AND COMPOSITION OF ACTIVe Archaeal Communities in The German Bight}

\author{
WEMHEUER B ${ }^{1}$, WEMHEUER $\mathrm{F}^{2}$, AND DANIEL $\mathrm{R}^{1}$
}

ARCHAEA, VOL. 2012, ARTICLE ID 695826

(doi:10.1155/2012/695826)

\footnotetext{
${ }^{1}$ Institute OF Microbiology AND GENETICS, GEORG-AUGUST-UNIVERSITY GÖTtINGEN, GRISEBACHSTR. 8, D-37077 GÖTtINGEN, GERMANY; ${ }^{2}$ DEPARTMENT FOR CROP SCIENCES, GEORG-AuguSt-University GÖTtINGEN, GRISEBACHSTR. 6, D-37077 GÖTTINGEN, GERMANY
}

Author contributions to the work:

Performed the experiments: BW

Analyzed data: BW

Contributed data on water properties and analysis of these data: BW Wrote the publication: BW, FW, RD

Conceived and designed the experiments: BW, RD 


\title{
RNA-Based Assessment of Diversity and Composition of Active Archaeal Communities in the German Bight
}

\author{
Bernd Wemheuer, ${ }^{1}$ Franziska Wemheuer, ${ }^{2}$ and Rolf Daniel ${ }^{1}$ \\ ${ }^{1}$ Department of Genomic and Applied Microbiology and Göttingen Genomics Laboratory, \\ Institute of Microbiology and Genetics, Georg-August University of Göttingen, Grisebachstraße 8, 37077 Göttingen, Germany \\ ${ }^{2}$ Section of Agricultural Entomology, Department for Crop Sciences, Georg-August University of Göttingen, Grisebachstraße 6, 37077 \\ Göttingen, Germany \\ Correspondence should be addressed to Rolf Daniel, rdaniel@gwdg.de
}

Received 6 September 2012; Accepted 2 October 2012

Academic Editor: Michael Hoppert

Copyright @ 2012 Bernd Wemheuer et al. This is an open access article distributed under the Creative Commons Attribution License, which permits unrestricted use, distribution, and reproduction in any medium, provided the original work is properly cited.

Archaea play an important role in various biogeochemical cycles. They are known extremophiles inhabiting environments such as thermal springs or hydrothermal vents. Recent studies have revealed a significant abundance of Archaea in moderate environments, for example, temperate sea water. Nevertheless, the composition and ecosystem function of these marine archaeal communities is largely unknown. To assess diversity and composition of active archaeal communities in the German Bight, seven marine water samples were taken and studied by RNA-based analysis of ribosomal 16S rRNA. For this purpose, total RNA was extracted from the samples and converted to cDNA. Archaeal community structures were investigated by pyrosequencing-based analysis of $16 \mathrm{~S}$ rRNA amplicons generated from cDNA. To our knowledge, this is the first study combining next-generation sequencing and metatranscriptomics to study archaeal communities in marine habitats. The pyrosequencing-derived dataset comprised 62,045 archaeal 16S rRNA sequences. We identified Halobacteria as the predominant archaeal group across all samples with increased abundance in algal blooms. Thermoplasmatales (Euryarchaeota) and the Marine Group I (Thaumarchaeota) were identified in minor abundances. It is indicated that archaeal community patterns were influenced by environmental conditions.

\section{Introduction}

It has been calculated that one $\mathrm{mL}$ of oceanic sea water contains up to $10^{6}$ different microorganisms [1]. These archaea, bacteria, protists, and unicellular fungi contribute $98 \%$ to the primary biomass production and are involved in almost all biogeochemical cycles [2]. It has been estimated that the global ocean harbors approximately $1.3 \times 10^{28}$ archaeal cells and $1.3 \times 10^{28}$ bacterial cells, which together constitute $63 \%$ to $90 \%$ of the entire marine picoplankton [3]. In addition, high numbers of Archaea have been found in marine sediments [4].

In contrast to their relatives living in extreme environments, little is known on marine Archaea. This is partly due to the unavailability of pure cultures. Marine Archaea might be involved in the oceanic nitrogen cycle as some marine Crenarchaeota are capable of nitrification [5]. However, our knowledge of the archaeal role in oceanic ecology is rudimentary and their influence on global biogeochemical cycles is largely unexplored [6].

Culture-independent approaches have greatly advanced our knowledge of the diversity and ecology of marine microbial communities [7-9]. Next-generation sequencing (NGS) contributed to this advancement. For example, many different ecosystems such as soil $[10,11]$ or sea water [12] have been studied by DNA-based high throughput sequencing of 16S rRNA gene fragments and analysis of the obtained sequences. The main drawback of DNA-based metagenomic approaches is the inability to distinguish between active and inactive community members.

Active members and functions of microbial communities are accessible by employing RNA-based metatranscriptomic approaches. For example, Urich et al. [13] analyzed the composition and metabolic potential of active soil microbial 
communities by sequencing of reverse transcribed total RNA. Other studies analyzed gene expression in ocean surface waters [8] or in a deep-sea hydrothermal plume [14]. However, mainly bacterial communities and their capabilities were analyzed in these studies.

In this paper, we investigated the composition of active archaeal communities in surface water derived from the southeastern part of the North Sea, the German Bight. The northwest of the German Bight is separated from the remaining North Sea by the Doggerbank, a large sandbank. Large coastal parts of the bight are shallow with water depths of approximately 2 to 12 meters. In our investigation, we collected seven water samples at different locations and depths in these shallow offshore areas.

The aim of our study was to assess the active archaeal community structures in the southern North Sea employing next-generation sequencing of $16 \mathrm{~S}$ rRNA amplicons generated by reverse transcription polymerase chain reaction (RTPCR). To our knowledge, this is the first study using this combined approach to study marine archaeal communities.

\section{Material and Methods}

2.1. Sampling and Sample Preparation. Seven marine water samples were taken for archaeal community analysis. Approximately 50 liters of sea water per sampling site were collected on board of the research vessel Heincke in May 2010 employing a conductivity, temperature, and depth (CTD) profiler. All sites were located in the German Bight. Sea water samples were prefiltered through a $10 \mu \mathrm{m}$-mesh-size nylon net and a filter sandwich consisting of a precombusted $(4 \mathrm{~h}$ at $450^{\circ} \mathrm{C}$ ) $47 \mathrm{~mm}$-diameter glass fiber filter (Whatman GF/D; Whatman, Maidstone, UK) and a $47 \mathrm{~mm}$-diameter (pore size $3.0 \mu \mathrm{m}$ ) polycarbonate filter (Nuclepore, Whatman). Bacterioplankton was harvested by filtration of $1 \mathrm{~L}$ prefiltered sea water through a filter sandwich consisting of a glass fiber filter (Whatman GF/F) and a $47 \mathrm{~mm}$-diameter (pore size $0.2 \mu \mathrm{m}$ ) polycarbonate filter (Nuclepore, Whatman).

Additionally, marine phytoplankton samples were collected by employing a plankton net (pore size $55 \mu \mathrm{m}$ ). The composition of the algal community was determined by microscopy of the collected samples.

2.2. RNA Extraction and Purification. Total RNA was extracted as described by Weinbauer et al. [15]. One $47 \mathrm{~mm}$ diameter filter (pore size $0.2 \mu \mathrm{m}$ ) was used per sample. Subsequently, RNA was purified employing the RNeasy Mini Kit as recommended by the manufacturer (Qiagen, Hilden, Germany).

To remove residual DNA from RNA samples, Ambions TURBO DNase (Invitrogen, Carlsbad, USA) was used according to the instructions of the manufacturer with one modification: subsequent to a standard reaction, $0.5 \mu \mathrm{L}$ of TURBO DNase per $10 \mu \mathrm{g}$ of RNA was added to the mixture, and incubation was performed at $37^{\circ} \mathrm{C}$ for $15 \mathrm{~min}$. Phenol/Chloroform/Isoamyl alcohol $(25: 24: 1)$ was used to inactivate the DNase.
The presence of remaining DNA was tested by PCR using the 16S rRNA gene as a target gene for amplification. The following two primer sets were employed: 8F/518R (5' - AGAGTTTGATCCTGGCTCAG-3' [16] and 5' ATTACCGCGGCTGCTGG-3' [17]) and 1055F/1378R (5' ATGGCTGTCGTCAGCT-3' [18] and 5'-CGGTGTGTACAAGGCCCGGGAACG-3' [19]).

The PCR reaction mixture $(25 \mu \mathrm{L})$ for amplification of the target gene contained $2.5 \mu \mathrm{L}$ of 10 -fold Mg-free Taq polymerase buffer (Fermentas, St. Leon-Rot, Germany), $200 \mu \mathrm{M}$ of each of the four desoxynucleoside triphosphates, $1.75 \mathrm{mM}$ $\mathrm{MgCl}_{2}, 0.4 \mu \mathrm{M}$ of each primer, $1 \mathrm{U}$ of Taq DNA polymerase (Fermentas), and approximately $100 \mathrm{ng}$ of purified RNA sample as template. The following thermal cycling scheme was used: initial denaturation at $94^{\circ} \mathrm{C}$ for $2 \mathrm{~min}, 28$ cycles of denaturation at $94^{\circ} \mathrm{C}$ for $1.5 \mathrm{~min}$, annealing at $55^{\circ} \mathrm{C}$ for $1 \mathrm{~min}$, followed by extension at $72^{\circ} \mathrm{C}$ for $40 \mathrm{~s}$. The final extension was carried out at $72^{\circ} \mathrm{C}$ for $10 \mathrm{~min}$.

2.3. Synthesis of cDNA from Total RNA. cDNA was synthesized from total RNA by employing the SuperScript Double-Stranded cDNA Synthesis Kit (Invitrogen) with modifications of the first strand synthesis protocol: $10 \mu \mathrm{L}$ of total RNA (up to $5 \mu \mathrm{g}$ ) were mixed with $1 \mu \mathrm{L}$ of random hexamer primers (Roche, Mannheim, Germany) and $1 \mu \mathrm{L}$ dNTP mixture containing $10 \mathrm{mM}$ of each of the four desoxynucleoside triphosphates. The mixture was incubated for $10 \mathrm{~min}$ at $70^{\circ} \mathrm{C}$ and chilled on ice. Four $\mu \mathrm{L} 5 \mathrm{x}$ first-strand buffer, $1 \mu \mathrm{L}$ of $0.1 \mathrm{M} \mathrm{DTT}$, and $1 \mu \mathrm{L}$ RNA protect (Fermentas) were added, and the reaction mixture was incubated for $2 \mathrm{~min}$ at $25^{\circ} \mathrm{C}$. Subsequently, $1 \mu \mathrm{L}$ of SuperScript II reverse transcriptase was added. The reaction was incubated for $10 \mathrm{~min}$ at $25^{\circ} \mathrm{C}$ and then for $1 \mathrm{~h}$ at $45^{\circ} \mathrm{C}$. The generated cDNA was subjected to $16 \mathrm{~S}$ rRNA PCR.

2.4. Amplification of $16 S \mathrm{rRNA}$ and Pyrosequencing. To analyze archaeal diversity, the V3-V5 region of the archaeal $16 \mathrm{~S}$ rRNA was amplified by PCR. The PCR reaction $(25 \mu \mathrm{L})$ contained $5 \mu \mathrm{L}$ of 5 -fold Phusion GC buffer (Finnzymes, Vantaa, Finland), $200 \mu \mathrm{M}$ of each of the four desoxynucleoside triphosphates, $1.5 \mathrm{mM} \mathrm{MgCl}_{2}, 4 \mu \mathrm{M}$ of each primer (Table 1), 2.5\% DMSO, $1 \mathrm{U}$ of Phusion High Fidelity Hot Start DNA polymerase (Finnzymes), and approximately $50 \mathrm{ng}$ of cDNA. The following thermal cycling scheme was used: initial denaturation at $98^{\circ} \mathrm{C}$ for $5 \mathrm{~min}, 25$ cycles of denaturation at $98^{\circ} \mathrm{C}$ for $45 \mathrm{~s}$, annealing at $68^{\circ} \mathrm{C}$ for $45 \mathrm{~s}$, followed by extension at $72^{\circ} \mathrm{C}$ for $30 \mathrm{~s}$. The final extension was carried out at $72^{\circ} \mathrm{C}$ for $5 \mathrm{~min}$. Negative controls were performed by using the reaction mixture without template. Primer sequences for amplification of the V3-V5 region [20] as well as 454 adaptors with the unique MIDs for each sample are listed in Table 1. The resulting PCR products were checked for appropriate size and then purified by using the peqGOLD Gel Extraction Kit (Peqlab, Erlangen, Germany) as recommended by the manufacturer. Three independent PCR reactions were performed per sample, purified by gel extraction, and pooled in equal amounts. Quantification of the PCR products was performed using the Quant-iT dsDNA 
TABLE 1: Primers used for amplification of the V3-V5 region of the archaeal 16S rRNA [20].

\begin{tabular}{lccccc}
\hline \multirow{2}{*}{ Sample } & \multirow{2}{*}{ Primer } & & \multicolumn{2}{c}{ Sequence $\left(5^{\prime}-3^{\prime}\right)$} & \\
& & 454-Adaptor (Lip-A Kit) & Key & Unique MID & Archaeal 16S rRNA specific \\
\hline 655 & ARC344F & CGTATCGCCTCCCTCGCGCCA & TCAG & ACTGTACAGT & ACGGGGYCAGCAGGCGCGA \\
658 & ARC344F & CGTATCGCCTCCCTCGCGCCA & TCAG & AGACTATACT & ACGGGGYGCAGCAGGCGCGA \\
659 & ARC344F & CGTATCGCCTCCCTCGCGCCA & TCAG & AGCGTCGTCT & ACGGGGYGCAGCAGGCGCGA \\
660 & ARC344F & CGTATCGCCTCCCTCGCGCCA & TCAG & AGTACGCTAT & ACGGGGYGCAGCAGGCGCGA \\
664 & ARC344F & CGTATCGCCTCCCTCGCGCCA & TCAG & ATAGAGTACT & ACGGGGYGCAGCAGGCGCGA \\
670 & ARC344F & CGTATCGCCTCCCTCGCGCCA & TCAG & CACGCTACGT & ACGGGGYGCAGCAGGCGCGA \\
671 & ARC344F & CGTATCGCCTCCCTCGCGCCA & TCAG & CAGTAGACGT & ACGGGGYGCAGCAGGCGCGA \\
All & ARC915R & CTATGCGCCTTGCCAGCCCGC & TCAG & ACAGTATATA & GTGCTCCCCCGCCAATTCCT \\
\hline
\end{tabular}

BR Assay Kit and a Qubit fluorometer (Invitrogen) as recommended by the manufacturer. The Göttingen Genomics Laboratory determined the sequences of the 16S rRNA by using a Roche GS-FLX 454 pyrosequencer with Titanium chemistry (Roche, Mannheim, Germany).

\subsection{Processing and Analysis of Pyrosequencing Derived Data} Sets. Sequence data were deposited in the sequence read archive of the National Center for Biotechnology Information under accession number SRA056839. Generated 16S rRNA datasets were processed and analyzed employing the QIIME 1.4 software package and other tools [21]. The sequences were initially processed according to the denoising of 454 datasets workflow. Sequences shorter than $300 \mathrm{bp}$, with an average quality value below 25 , or possessing homopolymers longer than $8 \mathrm{bp}$ were removed. Afterwards, the sequences were denoised. Cutadapt was used to truncate remaining primer sequences [22]. Chimeric sequences were removed using UCHIME and the Green Genes Gold dataset as reference database [23-25].

Remaining sequences were clustered employing the UCLUST algorithm [23] and the following QIIME scripts: pick_otus.py and pick_rep_set.py. The sequences were clustered in operational taxonomic units (OTUs) at 3\% and $1 \%$ genetic dissimilarity. Phylogenetic composition was determined using the QIIME assign_taxonmy.py script. A BLAST alignment [26] against the most recent Silva ARB database [27] was thereby performed. Sequences were classified with respect to the taxonomy of their best hit in the ARB database. Finally, OTU tables were generated.

2.6. Rarefaction Analysis and Diversity Analysis. Rarefaction curves, Shannon indices [28], and Chaol indices [29] were calculated employing QIIME scripts. In addition, the maximal number of OTUs $\left(n_{\max }\right)$ was estimated for each sample in $\mathrm{R}$ (version 2.15) [30] using the data derived from the QIIME rarefaction analysis and a nonlinear regression model based on Michaelis-Menten kinetics [31].

To compare archaeal community structures across all samples based on phylogenetic or count-based distance metrics, a principal coordinate analysis (PCoA) was performed using QIIME. The following scripts were successively used to generate a phylogenetic tree at $1 \%$ genetic distance prior to PCoA calculation: align_seqs.py (PyNAST algorithm),

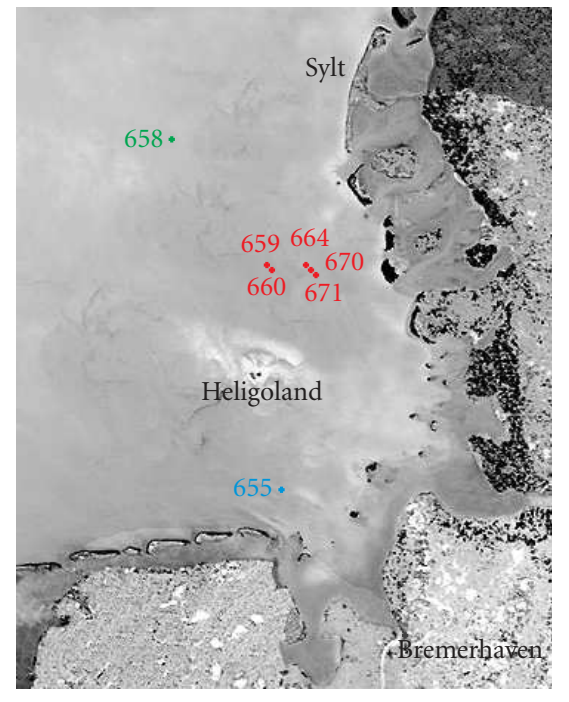

FIGURE 1: Satellite image of the German Bight showing the locations of the seven sampling sites (Image: ESA/NASA - SOHO/LASCO). Samples taken during an algal bloom (samples 659, 660, 664, 670, and 671) are shown in red. Sample 655 taken at a river outfall and sample 658 originating from outside the algal bloom in blue and green, respectively.

filter_alignment.py, and make_phylogeny.py. The tree and the respective OTU table were used to generate PCoAs employing the "beta_diversity_through_plots.py" script.

\section{Results}

3.1. Environmental Parameters. Marine water samples for archaeal community analysis were randomly collected at seven different locations in the German Bight (Figure 1, Table 2). Five samples (sites 659, 660, 664, 670, and 671) were taken in presence of an algal bloom. The other two samples derived from a river outfall (655) and from a site outside the algal bloom (658). The algal blooms observed during the sampling were mainly dominated by the genus Phaeocystis. Diatoms of the genus Rhizosolenia and some dinoflagellates were also identified but only in minor abundances. 
TABLE 2: Parameters of sampling sites analyzed in this study.

\begin{tabular}{lcccccccc}
\hline & Site & Latitude $^{\circ} \mathrm{N}$ & Longitude $^{\circ} \mathrm{E}$ & Depth $(\mathrm{m})$ & $T\left({ }^{\circ} \mathrm{C}\right)$ & Salinity $(\mathrm{psu})$ & Fluorescence $\left(\mathrm{mg} / \mathrm{m}^{3}\right)$ & Transmission $(\%)$ \\
\hline 655 & River outfall & $53^{\circ} 53.729$ & $8^{\circ} 02.979$ & 2 & 11.09 & 30.24 & 1.21 & 57.2 \\
658 & No bloom & $54^{\circ} 45.754$ & $7^{\circ} 26.780$ & 2 & 9.73 & 32.71 & 0.49 & 81.23 \\
659 & Bloom & $54^{\circ} 27.450$ & $7^{\circ} 59.360$ & 9 & 10.80 & 30.64 & 2.76 & 60.14 \\
660 & Bloom & $54^{\circ} 27.250$ & $8^{\circ} 00.110$ & 2 & 10.83 & 30.65 & 1.89 & 72.28 \\
664 & Bloom & $54^{\circ} 28.400$ & $8^{\circ} 11.830$ & 2 & 10.90 & 30.76 & 1.14 & 87.28 \\
670 & Bloom & $54^{\circ} 27.570$ & $8^{\circ} 12.420$ & 2 & 11.43 & 30.83 & - $^{*}$ & 75.72 \\
671 & Bloom & $54^{\circ} 26.940$ & $8^{\circ} 12.970$ & 2 & 11.70 & 31.04 & - $^{*}$ & 76.59 \\
\hline
\end{tabular}

* Fluorescence was not measured due to a malfunction of the profiler.

Environmental factors at all seven sampling sites were monitored employing a CTD profiler (Table 2). Temperatures and salinities ranged from 9.73 to $11.70^{\circ} \mathrm{C}$ and from 30.24 to $32.71 \mathrm{psu}$, respectively. The lowest temperature and highest salinity were measured at site 658 . All other sites showed similar conditions. Fluorescence was higher at bloom sites due to a higher chlorophyll concentration, whereas transmission was reduced due to a higher turbidity in the water.

3.2. Archaeal Community Structure Revealed by $16 S$ rRNABased Analysis. To assess archaeal community structures, total RNA was extracted from the samples. Approximately $5 \mu \mathrm{g}$ of total RNA per filter were extracted from each sample. After removal of contaminating DNA and small RNAs, 0.25 to $1.5 \mu \mathrm{g}$ of RNA were used as template for cDNA synthesis. The V3-V5 region of the 16S rRNA was amplified from the generated cDNA. The resulting PCR products were subjected to pyrosequencing. Sequence processing including quality filtering, denoising, and removal of potential chimeric sequences resulted in recovery of 62,090 high quality sequences with a read length of $\geq 300 \mathrm{bp}$ across all 7 samples. The average read length was $506 \mathrm{bp}$. The number of sequences per sample ranged from 4,301 to 23,070 . We were able to assign 62,045 sequences to the domain Archaea and to classify all of these sequences below the domain level. The classified sequences were affiliated to three archaeal phyla with twelve archaeal classes or similar phylogenetic groups. Euryarchaeota was the most abundant archaeal phylum (99.25\%) and Halobacteria the predominant class across all samples (>98.1\%) (Figure 2). Most of the sequences affiliated to the Halobacteria $(97.81 \%)$ were affiliated to uncultured members of the Deep Sea Hydrothermal Vent Group 6 (DHVEG-6) [32]. Interestingly, Halobacteria were more abundant in bloom samples than in other samples (Figure 2). Other archaeal groups present in all samples were the Marine Group I (Thaumarchaeota) [33] and the Thermoplasamata (Euryarchaeota). Sequences affiliated to the latter archaeal group belonged to the uncultured members of the CCA47 [34] group and the Marine Group II [33].

3.3. Diversity and Species Richness of Archaeal Communities. To determine the archaeal diversity and richness, rarefaction analyses were performed with QIIME [21]. Alpha diversity analysis was performed at the same level of surveying

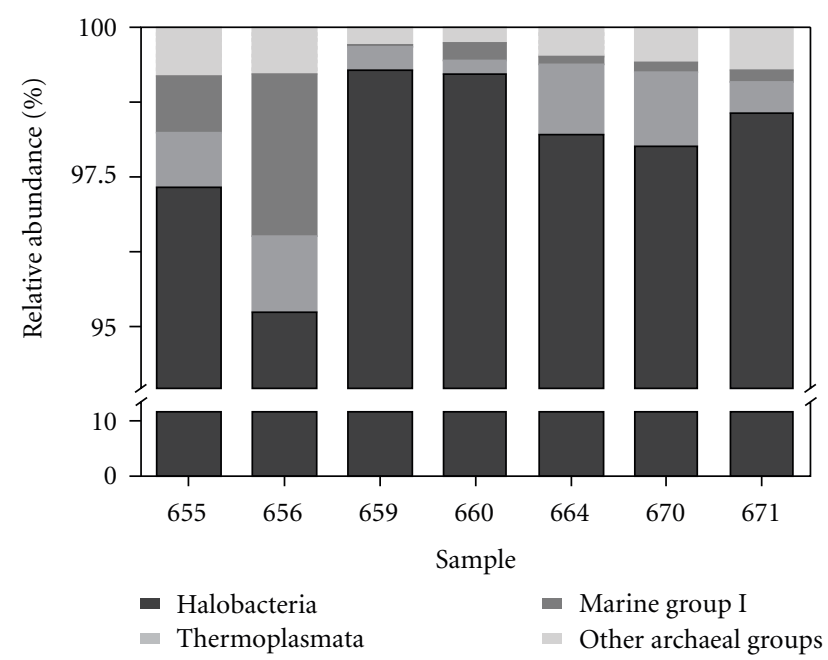

Figure 2: Relative sequence abundances of different archaeal phyla and classes. Euryarchaeota, especially Halobacteria (98.14\%), were highly abundant. Thermoplasmata $(0.75 \%)$ and the Marine Group 1 $(0.58 \%)$ were found to some extent. All archaeal classes and groups (abundance $<0.5 \%$ ) are depicted together.

effort (3100 randomly selected sequences per sample). The observed OTU number in the archaeal picoplankton ranged from 252 to 454 OTUs ( $1 \%$ genetic distance) and from 250 to 417 OTUs (3\% genetic distance) (Table 3). The maximal expectable number of clusters for every sample was determined by nonlinear regression based on the MichalisMenten equitation. The average OTU coverages were $62.3 \%$ and $62.6 \%$ at $1 \%$ and $3 \%$ genetic distance, respectively. Shannon indices ranged from 3.74 to 7.74 (1\% genetic distance) and from 3.63 to 7.62 (3\% genetic distance).

Comparison of the rarefaction analyses with the number of OTUs determined by Chaol richness estimator revealed that at $1 \%$ and $3 \%$ genetic distances the rarefaction curves (Figure 3) were not saturated and the richness estimators indicated that $41.34 \%$ to $73.41 \%$ of the estimated richness, respectively, were recovered by the sequencing effort (Table 3). Thus, we did not survey the full extent of taxonomic diversity at these genetic distances, but a substantial fraction of the archaeal diversity within individual samples was assessed at genetic divergence of $3 \%$. 
TABle 3: Archaeal diversity and richness values at $1 \%$ and $3 \%$ genetic distance. Numbers of observed OTUs as well as Shannon and Chao 1 values were calculated with QIIME [16]. The maximal OTU number $\left(n_{\max }\right)$ in each sample was calculated by nonlinear modeling. Coverage was determined based on observed OTUs and $n_{\max }$. To compare community structures, 3100 randomly selected sequences form every sample were used.

\begin{tabular}{|c|c|c|c|c|c|c|c|c|c|c|}
\hline \multirow{2}{*}{ Sample } & \multicolumn{2}{|c|}{ Observed OTUs } & \multicolumn{2}{|c|}{ Max. OTUs $\left(n_{\max }\right)$} & \multicolumn{2}{|c|}{ Coverage (\%) } & \multicolumn{2}{|c|}{ Shannon index $\left(\mathrm{H}^{\prime}\right)$} & \multicolumn{2}{|c|}{ Chaol } \\
\hline & $1 \%$ & $3 \%$ & $1 \%$ & $3 \%$ & $1 \%$ & $3 \%$ & $1 \%$ & $3 \%$ & $1 \%$ & $3 \%$ \\
\hline 655 & 293 & 268 & 510 & 468 & 57.45 & 57.26 & 4.37 & 4.02 & 530 & 470 \\
\hline 658 & 451 & 428 & 555 & 524 & 81.26 & 81.68 & 7.74 & 7.62 & 636 & 583 \\
\hline 659 & 252 & 250 & 446 & 441 & 56.50 & 56.69 & 3.74 & 3.63 & 498 & 470 \\
\hline 660 & 281 & 269 & 516 & 496 & 54.46 & 54.23 & 3.95 & 3.74 & 551 & 509 \\
\hline 664 & 346 & 327 & 516 & 488 & 67.05 & 67.01 & 4.81 & 4.65 & 569 & 486 \\
\hline 670 & 454 & 417 & 782 & 717 & 58.06 & 58.16 & 5.21 & 5.07 & 785 & 674 \\
\hline 671 & 399 & 370 & 649 & 586 & 61.48 & 63.14 & 5.09 & 4.96 & 1227 & 895 \\
\hline
\end{tabular}

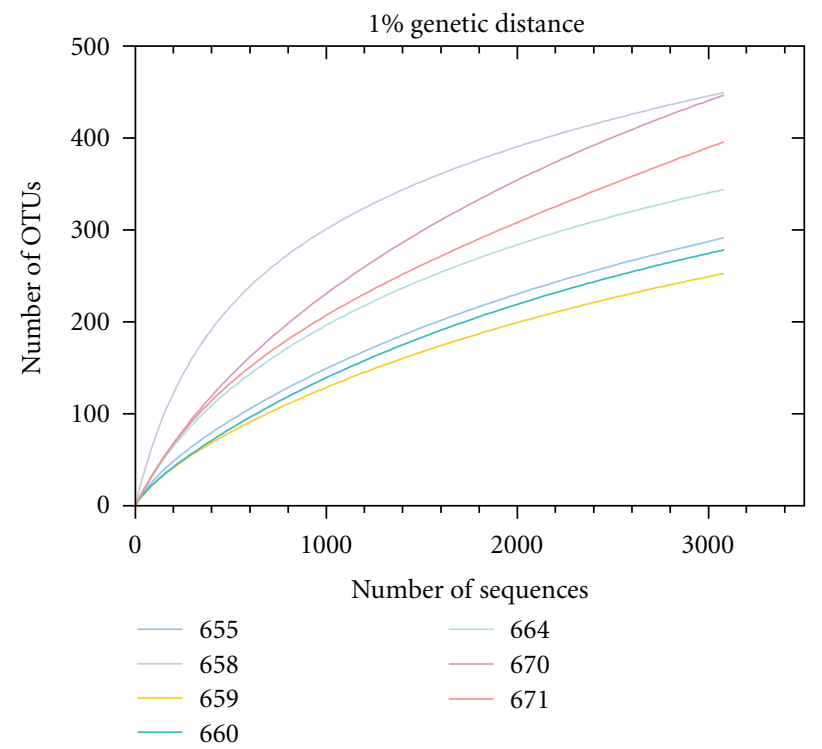

(a)

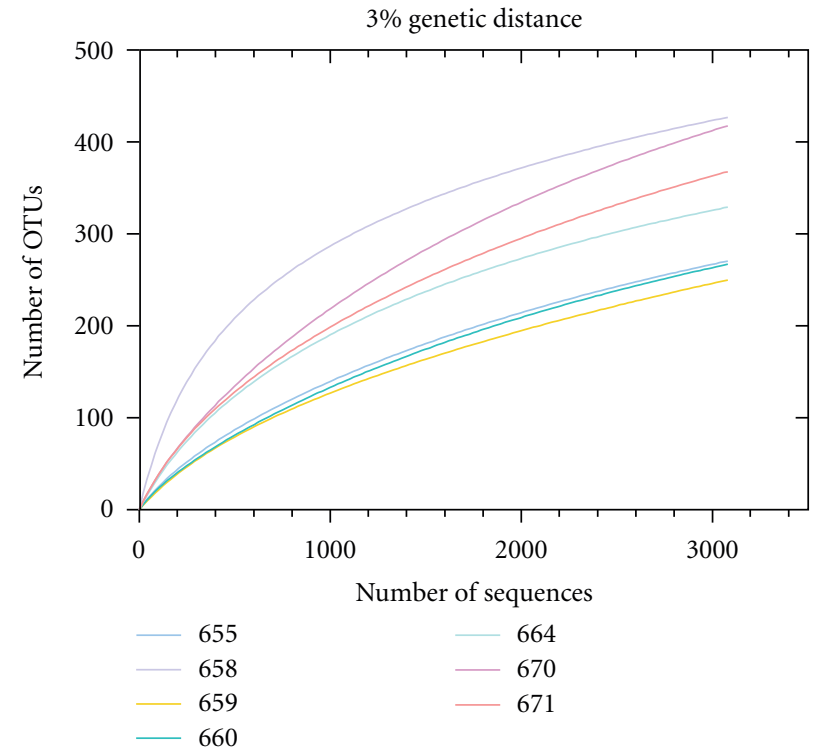

(b)

FIGURE 3: Rarefaction curves for all seven sampling sites. Curves were calculated at 1\% (a) and 3\% (b) genetic distance level employing QIIME [21]. Description of samplings sites is shown in Table 2.

3.4. Beta Diversity of the Bacterioplankton Community. Changes of the active bacterial community in response to different environmental conditions were examined by principal coordinate analysis (PCoA) (Figure 4). Surveying effort had no or little effect on diversity and community structure. However, the PCoA analysis revealed that all samples exhibiting similar environmental parameters such as temperature and salinity were assigned to one site of the plot. In addition, all bloom samples tend to cluster together. Sample 658 taken outside the algal bloom was completely separated from all other samples.

\section{Discussion}

Marine environments contain a high microbial biodiversity, and marine microbial communities play major roles in many biogeochemical cycles. Studies using culture-independent approaches have greatly contributed to our understanding of the extent of microbial diversity [35]. Most of these studies focused on marine bacteria, whereas very little is known on the diversity and ecology of marine Archaea. Recent metagenomic studies provided evidence for ammonium-oxidizing Archaea being capable of nitrification [36]. Some marine crenarchaeal lineages are thought to be important nitrifiers in planktonic marine systems [37]. These results indicate that Archaea are important players in the global nitrogen cycle. However, detailed comparative ecological studies to understand archaeal community patterns and environmental drivers that shape these communities are missing [37].

This study focused on assessing the active archaeal community structure and richness in picoplankton samples derived from the German Bight by metatranscriptomic approaches. To our knowledge, this is the first study using an RNA-based approach combined with NGS to analyze archaeal community compositions. In addition, the obtained average read length $(506 \mathrm{bp})$ is higher than in most other 


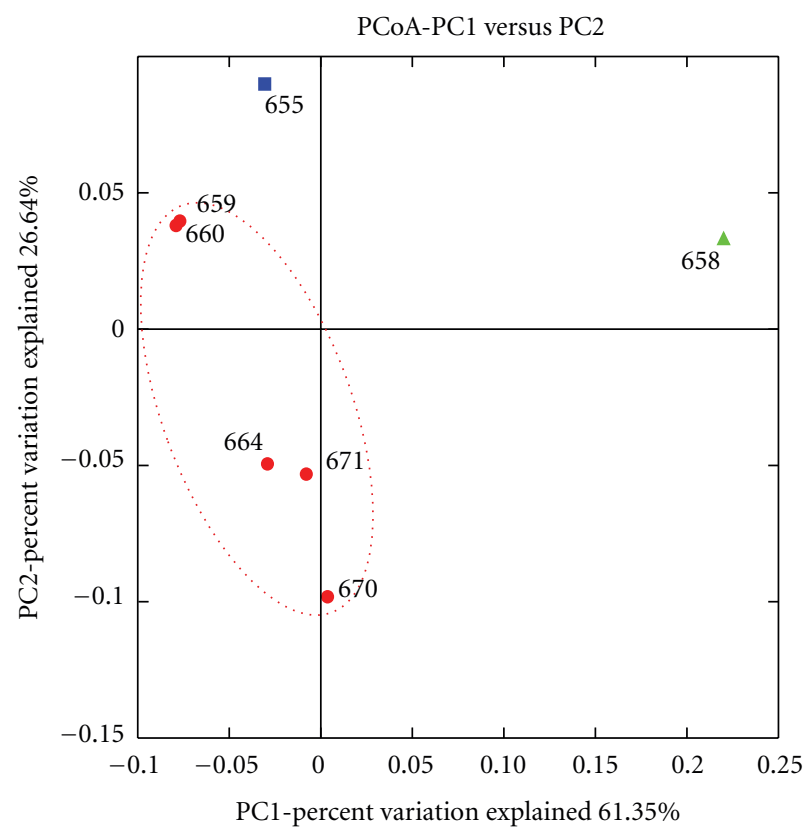

FIgUre 4: Weighted UniFrac 2D Principal Coordinate Analysis plot for beta diversity analysis. Samples taken during an algal bloom (samples 659, 660, 664, 670, and 671) are shown in red. Sample 655 taken at a river outfall and sample 658 originating from outside the algal bloom in blue and green, respectively.

studies employing NGS sequencing of 16S rRNA gene amplicons $[38,39]$. The majority of sequences obtained was affiliated to the Euryarchaeota. Sapp et al. [40] studied marine sediments derived from the Oyster Ground (North Sea) and found high abundances of members of this phylum in their samples. We identified Halobacteria as the most abundant archaeal group. Members of this group can grow aerobically as well as anaerobically. Large halobacterial blooms appear reddish due to production of retinal-containing rhodopsins. Rhodopsins are photoactive membrane proteins with a highly conserved tertiary structure [41] and may serve as an additional possibility to conserve energy. This is advantageous in marine environments, as the concentration of dissolved organic matter and other nutrients is usually low [42]. Most of the halobacterial sequences analyzed in this study were affiliated to the Deep Sea Hydrothermal Vent Euryarchaeotal Group 6 (DHVE-6). This group was originally described as a hydrothermal vent lineage [43]. It was later renamed Miscellaneous Euryarchaeotic Group, as members of this group were also found in marine sediment [44] and in soil [45]. Another archaeal group found in all samples was the Marine Group I (MG-I). It was originally identified by sequencing of environmental 16S rRNA genes derived from sea water [46, 47]. Members of MG-I account for large fractions of marine prokaryotic picoplankton and prokaryotic communities in deep sea water (below $3000 \mathrm{~m}$ ). Thermoplasmata were the third most abundant archaeal class in the investigated samples. Most sequences were affiliated to the CCA47 group. This group was originally identified by $16 \mathrm{~S}$ rRNA gene analysis of oxygen-depleted marine environments [48]. Later, Ferrer et al. [34] found members of this group in anoxic subsaline sediments. A few sequences assigned to Thermoplasmata were also affiliated to the Marine Group II. DeLong [33] suggested that members of Marine Group II (Euryarchaeota) are more abundant in temperate sea water than Marine Group I (Crenarchaeota) members. We found the opposite, as we recorded a higher abundance of Marine Group I members in the studied samples. Marine Group II members were almost absent in the investigated samples. One reason for this discrepancy might be that large parts of the German Bight are strongly influenced by tidal currents. Thus, these currents might whirl up archaeal cells from the sediment to the surface water, as most of the identified groups were originally described as inhabitants of marine sediments. Nonetheless, the number of studies targeting archaeal communities in the water column is substantially lower than that on marine sediments. Due to this knowledge gap, the habitat preference of these archaeal groups cannot be deduced definitely.

The impact of environmental conditions onto archaeal community composition and richness has been rarely studied. Auguet et al. [37] performed a general analytical approach to find community patterns of uncultured Archaea along environmental gradients or habitat types. Their results indicate that habitat types have a greater effect on archaeal community structures than other environmental conditions. All samples investigated in our study originated from almost the same habitat type, except for samples 655 and 658, which were collected at a river outfall region and outside of the algal bloom, respectively. Accordingly, all samples derived from the bloom showed an almost identical community composition. In addition, sample 655 showed a consimilar community structure. This indicates that similar environmental factors, such as temperature, salinity, and high nutrient availability during algal blooms or at river outfalls, have a similar impact onto composition of active archaeal communities.

Herfort et al. [49] studied archaeal communities in the southwestern North Sea via Denaturing Gradient Gel Electrophoresis (DGGE) and showed a positive correlation between the abundance of Euryarchaeota and chlorophyll concentrations, whereas the abundance of Crenarchaeota was negatively correlated with the chlorophyll concentration. Teeling et al. [50] investigated bacterial communities near Helgoland. They demonstrated that bacterial community structures were highly influenced by the presence of an algal bloom. In our study, we investigated the influence of algal blooms on archaeal diversity by PCoA. Sample taken in presence of a bloom shared a more similar community structure. This indicates that marine archaeal communities are also influenced by algal blooms or by environmental parameters correlated with bloom presence. We observed an increased number of Halobacteria in bloom samples. This might be correlated with the high amounts of organic matter in blooms. Halobacteria are the most active organisms with respect to organic matter degradation in hypersaline environments [37]. Thus the higher abundance of Halobacteria in algal bloom samples might indicate an involvement in marine organic matter degradation under high nutrient conditions found during algal blooms. 
Due to the lack of pure cultures and large comparative investigations, robust conclusions on contributions of marine archaeal communities to biogeochemical cycles cannot be drawn. In this study, we found highly diverse and active archaeal communities in the surface water of the German Bight. Their ecological role is unknown, and further research including analyses of expressed functional genes needs to be performed to unravel the role of marine Archaea.

\section{Acknowledgments}

The authors thank the crew of the research vessel Heincke for their valuable support and the people from Oldenburg, especially Meinhard Simon and Helge-Ansgar Giebel, for the hydrographic data and valuable help prior and during the sampling. This work was funded by the Deutsche Forschungsgemeinschaft (DFG) as part of the collaborative research center TRR 51.

\section{References}

[1] T. P. Curtis, W. T. Sloan, and J. W. Scannell, "Estimating prokaryotic diversity and its limits," Proceedings of the National Academy of Sciences of the United States of America, vol. 99, no. 16, pp. 10494-10499, 2002.

[2] M. L. Sogin, H. G. Morrison, J. A. Huber et al., "Microbial diversity in the deep sea and the underexplored "rare biosphere"," Proceedings of the National Academy of Sciences of the United States of America, vol. 103, no. 32, pp. 12115-12120, 2006.

[3] M. B. Karner, E. F. Delong, and D. M. Karl, "Archaeal dominance in the mesopelagic zone of the Pacific Ocean," Nature, vol. 409, no. 6819, pp. 507-510, 2001.

[4] H. Agogué, M. Brink, J. Dinasquet, and G. J. Herndl, "Major gradients in putatively nitrifying and non-nitrifying Archaea in the deep North Atlantic," Nature, vol. 456, no. 7223, pp. 788-792, 2008.

[5] E. F. DeLong and D. M. Karl, "Genomic perspectives in microbial oceanography," Nature, vol. 437, no. 7057, pp. 336-342, 2005.

[6] S. J. Giovannoni and U. Stingl, "Molecular diversity and ecology of microbial plankton," Nature, vol. 437, no. 7057, pp. 343-348, 2005.

[7] T. Brinkhoff, D. Fischer, J. Vollmers et al., "Biogeography and phylogenetic diversity of a cluster of exclusively marine myxobacteria," International Society for Microbial Ecology Journal, vol. 6, no. 6, pp. 1260-1272, 2012.

[8] J. Frias-Lopez, Y. Shi, G. W. Tyson et al., "Microbial community gene expression in ocean surface waters," Proceedings of the National Academy of Sciences of the United States of America, vol. 105, no. 10, pp. 3805-3810, 2008.

[9] J. C. Venter, K. Remington, J. F. Heidelberg et al., "Environmental genome shotgun sequencing of the sargasso sea," Science, vol. 304, no. 5667, pp. 66-74, 2004.

[10] H. Nacke, A. Thürmer, A. Wollherr et al., "Pyrosequencingbased assessment of bacterial community structure along different management types in German forest and grassland soils," PLoS ONE, vol. 6, no. 2, Article ID e17000, 2011.

[11] C. Will, A. Thürmer, A. Wollherr et al., "Horizon-specific bacterial community composition of german grassland soils, as revealed by pyrosequencing-based analysis of 16S rRNA genes," Applied and Environmental Microbiology, vol. 76, no. 20, pp. 6751-6759, 2010.
[12] M. Vila-Costa, J. M. Gasol, S. Sharma, and M. A. Moran, "Community analysis of high- and low-nucleic acid-containing bacteria in NW Mediterranean coastal waters using $16 \mathrm{~S}$ rDNA pyrosequencing," Environmental Microbiology, vol. 14, no. 6, pp. 1390-1402, 2012.

[13] T. Urich, A. Lanzén, J. Qi, D. H. Huson, C. Schleper, and S. C. Schuster, "Simultaneous assessment of soil microbial community structure and function through analysis of the metatranscriptome," PLoS ONE, vol. 3, no. 6, Article ID e2527, 2008.

[14] R. A. Lesniewski, S. Jain, K. Anantharaman, P. D. Schloss, and G. J. Dick, "The metatranscriptome of a deep-sea hydrothermal plume is dominated by water column methanotrophs and lithotrophs," International Society for Microbial Ecology Journal. In press.

[15] M. G. Weinbauer, I. Fritz, D. F. Wenderoth, and M. G. Höfle, "Simultaneous extraction from bacterioplankton of total RNA and DNA suitable for quantitative structure and function analyses," Applied and Environmental Microbiology, vol. 68, no. 3, pp. 1082-1087, 2002.

[16] V. I. Miteva, P. P. Sheridan, and J. E. Brenchley, "Phylogenetic and physiological diversity of microorganisms isolated from a deep greenland glacier ice core," Applied and Environmental Microbiology, vol. 70, no. 1, pp. 202-213, 2004.

[17] G. Muyzer, E. C. De Waal, and A. G. Uitterlinden, "Profiling of complex microbial populations by denaturing gradient gel electrophoresis analysis of polymerase chain reactionamplified genes coding for $16 \mathrm{~S}$ rRNA," Applied and Environmental Microbiology, vol. 59, no. 3, pp. 695-700, 1993.

[18] M. J. Ferris, A. Masztal, and D. H. Martin, "Use of speciesdirected 16S rRNA gene PCR primers for detection of Atopobium vaginae in patients with bacterial vaginosis," Journal of Clinical Microbiology, vol. 42, no. 12, pp. 5892-5894, 2004.

[19] M. Hartmann and F. Widmer, "Reliability for detecting composition and changes of microbial communities by $\mathrm{T}$ RFLP genetic profiling," FEMS Microbiology Ecology, vol. 63, no. 2, pp. 249-260, 2008.

[20] Z. Yu, R. García-González, F. L. Schanbacher, and M. Morrison, "Evaluations of different hypervariable regions of archaeal $16 \mathrm{~S}$ rRNA genes in profiling of methanogens by Archaeaspecific PCR and denaturing gradient gel electrophoresis," Applied and Environmental Microbiology, vol. 74, no. 3, pp. 889-893, 2008.

[21] J. G. Caporaso, J. Kuczynski, J. Stombaugh et al., "QIIME allows analysis of high-throughput community sequencing data," Nature Methods, vol. 7, no. 5, pp. 335-336, 2010.

[22] M. Martin, "Cutadapt removes adapter sequences from highthroughput sequencing reads," EMBnet.Journal, vol. 17, no. 1, pp. 10-12, 2011.

[23] R. C. Edgar, B. J. Haas, J. C. Clemente, C. Quince, and R. Knight, "UCHIME improves sensitivity and speed of chimera detection," Bioinformatics, vol. 27, no. 16, Article ID btr381, pp. 2194-2200, 2011.

[24] P. D. Schloss, D. Gevers, and S. L. Westcott, "Reducing the effects of PCR amplification and sequencing artifacts on $16 \mathrm{~S}$ rRNA-based studies," PloS ONE, vol. 6, no. 12, Article ID e27310, 2011.

[25] T. Z. DeSantis, P. Hugenholtz, N. Larsen et al., "Greengenes, a chimera-checked 16S rRNA gene database and workbench compatible with ARB," Applied and Environmental Microbiology, vol. 72, no. 7, pp. 5069-5072, 2006.

[26] C. Camacho, G. Coulouris, V. Avagyan et al., "BLAST+: architecture and applications," BMC Bioinformatics, vol. 10, article 421, 2009. 
[27] E. Pruesse, C. Quast, K. Knittel et al., "SILVA: a comprehensive online resource for quality checked and aligned ribosomal RNA sequence data compatible with ARB," Nucleic Acids Research, vol. 35, no. 21, pp. 7188-7196, 2007.

[28] C. E. Shannon, "A mathematical theory of communication," SIGMOBILE Mobile Computing and Communications Review, vol. 5, no. 1, pp. 3-55, 2001.

[29] A. Chao and J. Bunge, "Estimating the number of species in a stochastic abundance model," Biometrics, vol. 58, no. 3, pp. 531-539, 2002.

[30] RDevelopmentCoreTeam, R: A Language and Environment For Statistical Computing, 2012

[31] L. Michaelis and M. L. Menten, "Die kinetik der invertinwirkung," Biochemistry Zeitung, vol. 49, no. 333-369, p. 352, 1913.

[32] J. Kan, S. Clingenpeel, R. E. Macur et al., "Archaea in Yellowstone Lake," International Society for Microbial Ecology Journal, vol. 5, no. 11, pp. 1784-1795, 2011.

[33] E. F. DeLong, "Oceans of archaea," ASM News, vol. 69, no. 10, p. 9,2003

[34] M. Ferrer, M. E. Guazzaroni, M. Richter et al., "Taxonomic and functional metagenomic profiling of the microbial community in the anoxic sediment of a sub-saline shallow lake (Laguna de Carrizo, Central Spain)," Microbial Ecology, vol. 62, no. 4, pp. 824-837, 2011.

[35] C. Simon and R. Daniel, "Metagenomic analyses: past and future trends," Applied and Environmental Microbiology, vol. 77, no. 4, pp. 1153-1161, 2011.

[36] R. Cavicchioli, M. Z. DeMaere, and T. Thomas, "Metagenomic studies reveal the critical and wide-ranging ecological importance of uncultivated archaea: the role of ammonia oxidizers," BioEssays, vol. 29, no. 1, pp. 11-14, 2007.

[37] J. C. Auguet, A. Barberan, and E. O. Casamayor, "Global ecological patterns in uncultured Archaea," International Society for Microbial Ecology Journal, vol. 4, no. 2, pp. 182-190, 2010.

[38] O. O. Lee, Y. Wang, J. Yang, F. F. Lafi, A. Al-Suwailem, and P. Y. Qian, "Pyrosequencing reveals highly diverse and speciesspecific microbial communities in sponges from the Red Sea," International Society for Microbial Ecology Journal, vol. 5, no. 4, pp. 650-664, 2011.

[39] J. A. Huber, D. B. Mark Welch, H. G. Morrison et al., "Microbial population structures in the deep marine biosphere," Science, vol. 318, no. 5847, pp. 97-100, 2007.

[40] M. Sapp, E. R. Parker, L. R. Teal, and M. Schratzberger, "Advancing the understanding of biogeography-diversity relationships of benthic microorganisms in the North Sea," FEMS Microbiology Ecology, vol. 74, no. 2, pp. 410-429, 2010.

[41] J. L. Spudich, C. S. Yang, K. H. Jung, and E. N. Spudich, "Retinylidene proteins: structures and functions from archaea to humans," Annual Review of Cell and Developmental Biology, vol. 16, pp. 365-392, 2000.

[42] M. T. Madigan and T. D. Brock, Brock Biology of Microorganisms, Pearson/Benjamin Cummings, San Francisco, Calif, USA, 2010.

[43] K. Takai and K. Horikoshi, "Genetic diversity of archaea in deep-sea hydrothermal vent environments," Genetics, vol. 152, no. 4, pp. 1285-1297, 1999.

[44] K. B. SØRensen, A. Lauer, and A. Teske, "Archaeal phylotypes in a metal-rich and low-activity deep subsurface sediment of the Peru Basin, ODP Leg 201, Site 1231," Geobiology, vol. 2, no. 3, pp. 151-161, 2004.

[45] K. Takai, D. P. Moser, M. DeFlaun, T. C. Onstott, and J. K. Fredrickson, "Archaeal diversity in waters from deep South African gold mines," Applied and Environmental Microbiology, vol. 67 , no. 12 , pp. 5750-5760, 2001.
[46] E. F. DeLong, "Archaea in coastal marine environments," Proceedings of the National Academy of Sciences of the United States of America, vol. 89, no. 12, pp. 5685-5689, 1992.

[47] J. A. Fuhrman, K. McCallum, and A. A. Davis, "Novel major archaebacterial group from marine plankton," Nature, vol. 356, no. 6365, pp. 148-149, 1992.

[48] T. Stoeck and S. Epstein, "Novel eukaryotic lineages inferred from small-subunit rRNA analyses of oxygen-depleted marine environments," Applied and Environmental Microbiology, vol. 69, no. 5, pp. 2657-2663, 2003.

[49] L. Herfort, S. Schouten, B. Abbas et al., "Variations in spatial and temporal distribution of Archaea in the North Sea in relation to environmental variables," FEMS Microbiology Ecology, vol. 62, no. 3, pp. 242-257, 2007.

[50] H. Teeling, B. M. Fuchs, D. Becher et al., "Substrate-controlled succession of marine bacterioplankton populations induced by a phytoplankton bloom," Science, vol. 336, no. 6081, pp. 608-611, 2012. 


\title{
STUDY 2:
}

\section{IMPACT OF A PHYTOPLANKTON BLOOM ON THE DIVERSITY OF THE ACTIVE BACTERIAL COMMUNITY IN THE SOUTHERN NORTH SEA AS REVEALED BY METATRANSCRIPTOMIC APPROACHES}

\author{
Wemheuer B ${ }^{1}$, Güllert $S^{1,3}$, Billerbeck $S^{2}$, Giebel HA ${ }^{2}$, Voget \\ $\mathrm{S}^{1}$, SIMON $\mathrm{M}^{2}$, AND DANIEL $\mathrm{R}^{1}$
}

FEMS MicRoBiology ECOLOGY: 87: 378-389

(doi: 10.1111/1574-6941.12230)

\begin{abstract}
${ }^{1}$ Institute OF Microbiology AND Genetics, GeORG-August-UniVERSITY GÖTTINGEN, GRISEBACHSTR. 8, D-37077 GÖTTINGEN, GERMANY; ${ }^{2}$ INSTITUTE FOR ChEMISTRY AND Biology OF THE MARINE ENVIRONMENT (ICBM), CARL-VONOSSIETZKY-UNIVERSITY OF OLDENBURG, CARL-VON-OSSIETZKY-STR. 9-11, D26111 OldENBURG, GERMANY; ${ }^{3}$ PRESENT ADDRESS: BIOZENTRUM KLEIN FlottbeK, Mikrobiologie, OHNHORStSTR. 18, D-22609 HamburG, Germany
\end{abstract}

Author contributions to the work:

Performed the experiments: BW, SG

Analyzed data: BW, SG, SV

Contributed data on water properties and analysis of these data: SB, HAG, MS Wrote the publication: BW, MS, RD

Conceived and designed the experiments: BW,RD 


\title{
Impact of a phytoplankton bloom on the diversity of the active bacterial community in the southern North Sea as revealed by metatranscriptomic approaches
}

\author{
Bernd Wemheuer ${ }^{1}$, Simon Güllert ${ }^{1}$, Sara Billerbeck ${ }^{2}$, Helge-Ansgar Giebel ${ }^{2}$, Sonja Voget ${ }^{1}$, Meinhard \\ Simon $^{2}$ \& Rolf Daniel ${ }^{1}$ \\ 'Department of Genomic and Applied Microbiology and Göttingen Genomics Laboratory, Institute of Microbiology and Genetics, Georg-August- \\ University Göttingen, Göttingen, Germany; and 2Biology of Geological Processes - Aquatic Microbial Ecology, Institute for Chemistry and Biology \\ of the Marine Environment (ICBM), Carl-von-Ossietzky-University Oldenburg, Oldenburg, Germany
}

\begin{abstract}
Correspondence: Rolf Daniel, Department of Genomic and Applied Microbiology and Göttingen Genomics Laboratory, Institute of Microbiology and Genetics, Georg-August University Göttingen, Grisebachstr. 8, D-37077 Göttingen, Germany. Tel.: 0049551 393827; fax: 00495513912181 e-mail: rdaniel@gwdg.de
\end{abstract}

Present address: Simon Güllert, Microbiology and Biotechnology, Biocenter Klein Flottbek, Ohnhorststr. 18, D-22609 Hamburg, Germany

Received 21 June 2013; revised 18 September 2013; accepted 19 September 2013. Final version published online 25 October 2013.

DOI: 10.1111/1574-6941.12230

Editor: Riks Laanbroek

\section{Keywords}

bacterial diversity; bacterioplankton; pyrotag sequencing; German Bight; metatranscriptome.

\begin{abstract}
Despite their importance for ecosystem functioning, little is known about the composition of active marine bacterioplankton communities. Hence, this study was focused on assessing the diversity of these communities in the southern North Sea and examining the impact of a phytoplankton spring bloom on the ambient bacterioplankton community. Community composition in and outside the bloom was assessed in 14 samples by pyrosequencing-based analysis of $16 \mathrm{~S}$ rRNA gene amplicons generated from environmental RNA. The data set comprised of 211769 16S rRNA gene sequences. Proteobacteria were the predominant phylogenetic group with Alphaproteobacteria and Gammaproteobacteria as the most abundant classes. Actinobacteria and Bacteroidetes were identified in minor abundances. Active bacterial communities were dominated by few lineages such as the Roseobacter RCA cluster and the SAR92 clade. Community structures of three selected samples were also assessed by direct sequencing of cDNA generated from rRNA-depleted environmental RNA. Generated data sets comprised of 988202 sequences. Taxonomic assignment of the reads confirmed the predominance of Proteobacteria. The examined phytoplankton spring bloom affected the bacterioplankton community structures significantly. Bacterial richness was reduced in the bloom area, and the abundance of certain bacterial groups was affected by bloom presence. The SAR92 clade and the Roseobacter RCA cluster were significantly more abundant and active in the bloom. Functions affected by the bloom include photosynthesis, protein metabolism, and DNA metabolism.
\end{abstract}

\section{Introduction}

Cultivation-independent approaches have greatly advanced our understanding of the ecology and diversity of marine microbial communities (e.g. Venter et al., 2004; Giovannoni \& Stingl, 2005). In early DNA-based studies, traditional techniques such as Sanger sequencingbased analysis of 16S rRNA gene libraries or fingerprinting methods were used to analyze microbial community structures at different marine locations (e.g. Giovannoni et al., 1990; Schmidt et al., 1991; Muyzer et al., 1993). These approaches were often limited to the analysis of relatively small numbers of clones or samples. Taking into account the high diversity and community size of marine microbial communities, only a small fraction of the bacterial diversity was unraveled by these studies. Recent studies analyzing 16S rRNA gene fragments by nextgeneration sequencing technologies have been applied for in-depth investigation of bacterial communities in diverse ecosystems such as soil (e.g. Will et al., 2010; Nacke et al., 2011) or different marine ecosystems (e.g. Kirchman et al., 2010; Vila-Costa et al., 2012). These studies provided detailed insights into the composition of the ambient microbial communities and revealed the 
existence of many taxa not known from the previous less sensitive approaches.

Coastal shelf seas of the temperate zone are highly productive because of the continuous nutrient supply by rivers. A typical shelf sea with these characteristics is the North Sea and in particular its southern region, the German Bight, which underwent high nutrient loading and warming during the last 40 years (McQuatters-Gollop et al., 2007; Wiltshire et al., 2010). Nutrients and plankton communities have been studied intensely in this dynamic coastal sea. Studies concerning the bacterioplankton community in the German Bight show that distinct lineages of Alphaproteobacteria and Gammaproteobacteria as well as Flavobacteria constitute the majority of this community (Alderkamp et al., 2006; Rink et al., 2011; Teeling et al., 2012; Sintes et al., 2013). Archaea are also present in the prokaryotic picoplankton with dominance of Halobacteria and minor proportions of Thermoplasmata and members of the marine group I (Wemheuer et al., 2012). Among Alphaproteobacteria, the SAR11 and Roseobacter clade, especially the Roseobacter clade-affiliated (RCA) cluster, are of particular significance and constitute this bacterial class to a great extent (Selje et al., 2004; Giebel et al., 2011; Sperling et al., 2012). However, the vast majority of investigations focused on assessing total bacterioplankton community structures by DNAbased 16S rRNA gene analysis and did not consider the active members of the microbial communities (but see Teeling et al., 2012; Wemheuer et al., 2012), which can be examined, that is, by the analysis of 16S rRNA gene transcripts (e.g. West et al., 2008; Wemheuer et al., 2012).

Another approach to assess active bacterioplankton community structures and their functional response to ambient growth and environmental conditions is the application of large-scale sequencing of environmental mRNA. This approach has been applied in recent studies providing first insights into how marine bacterioplankton communities respond to nutrient inputs and changing environmental conditions (e.g. Frias-Lopez et al., 2008; Gifford et al., 2011; Lesniewski et al., 2012; Ottesen et al., 2013).

The aim of the present study was to investigate the phylogenetic composition of active bacterioplankton communities in the southern North Sea, the German Bight, and validate the impact of a phytoplankton spring bloom on the structure of these communities. We hypothesized (1) that the structure of the active bacterioplankton community is affected by the bloom, as the availability and the composition of nutrients are different between bloom and nonbloom conditions. We further hypothesized (2) that the bacterial richness is also influenced by bloom presence, as a specialized ecological niche is formed during a bloom in which only certain bacterioplankton members can thrive.

To assess bacterial community structures, we applied large-scale pyrosequencing of the $16 \mathrm{~S}$ rRNA gene V2-V3 region. Moreover, we also employed direct sequencing of cDNA derived from rRNA-depleted environmental RNA to assess bacterial community structures via subsequent phylogenetic assignment of the recovered sequences. This is the first study using RNA-based next-generation sequencing approaches to monitor the impact of a phytoplankton bloom on active bacterioplankton communities. It provides evidence for changes in structure and activity of these communities during the bloom event.

\section{Materials and methods}

\section{Sampling and sample preparation}

Fourteen water samples were collected in the southern North Sea at 13 stations in May 2010 on board RV Heincke (cruise HE327) to investigate the impact of a phytoplankton bloom on the ambient bacterial community structure (Supporting Information, Table S1). The phytoplankton bloom examined in this study was localized by satellite data. Its presence at the sampling stations was then evaluated based on chlorophyll $a$ content. Samples were taken using 5-L Niskin bottles mounted on a CTD rosette (Fig. 1, Table S1). To allow comparison with other studies using samples from the HE327 cruise, station and corresponding sample numbers were given according to the designation provided by the ICBM (Oldenburg, Germany). The water of at least eight Niskin bottles (c. $40 \mathrm{~L}$ ) was pooled in an ethanol-rinsed PE barrel. It was prefiltered through a $10-\mu \mathrm{m}$ nylon net and a filter sandwich consisting of a precombusted ( $4 \mathrm{~h}$ at $450{ }^{\circ} \mathrm{C}$ ) glass fiber filter (47 mm diameter, Whatman GF/D; Whatman, Maidstone, UK) and 3.0- $\mu \mathrm{m}$ polycarbonate filter (47 mm diameter, Nuclepore; Whatman). Bacterioplankton was harvested from a prefiltered 1-L sample on a filter sandwich consisting of a glass fiber filter (47 mm diameter, Whatman GF/F; Whatman) and $0.2-\mu \mathrm{m}$ polycarbonate filter (47 mm diameter, Nuclepore; Whatman). All filters were frozen using liquid nitrogen and stored at $-80{ }^{\circ} \mathrm{C}$ until further use. Additionally, phytoplankton samples were collected for screening of the major phytoplankton taxa employing a plankton net (pore size, $55 \mu \mathrm{m}$ ).

For the determination of Chl $a$ and phaeopigments, water samples were filtered onto glass fiber filters $(47 \mathrm{~mm}$ diameter, Whatman GF/F; Whatman), immediately wrapped into aluminum foil, and kept frozen at $-20{ }^{\circ} \mathrm{C}$ until further analysis within 2 weeks according to Giebel et al. (2011) and Nusch (1999). Water samples for the analysis of suspended particulate matter (SPM), 


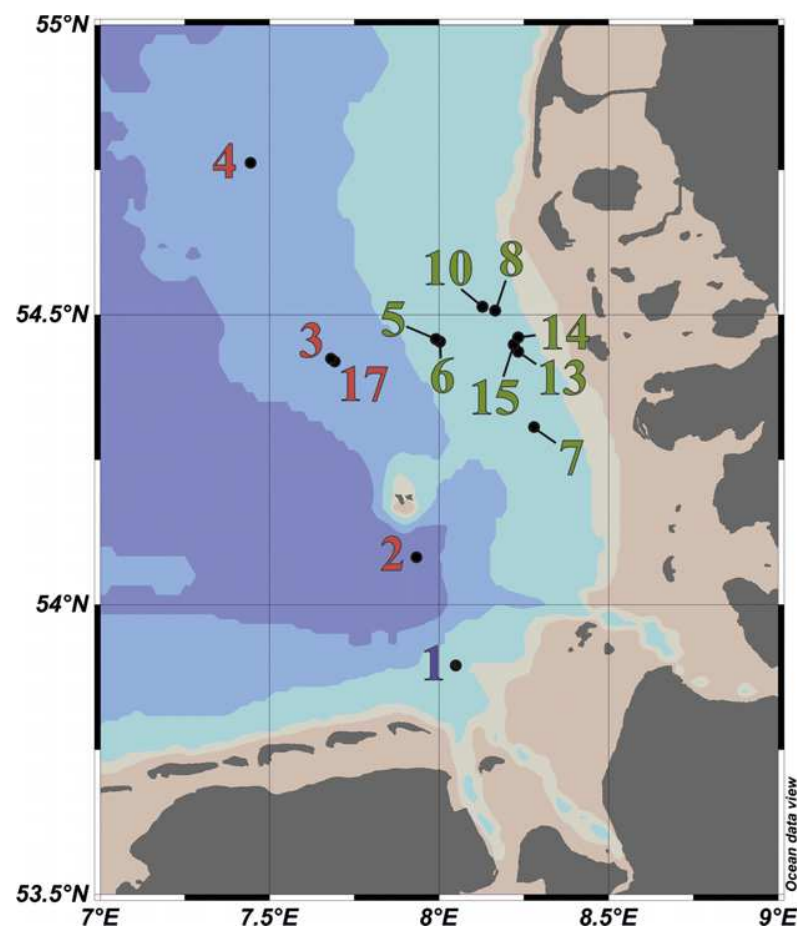

Fig. 1. Map of the German Bight showing the location of the 13 sampling stations visited in May 2010. Stations inside the examined algal bloom are depicted in green; those outside the bloom are in red. Station 1 is depicted in blue as it was located in a bloom outside of the area of the examined bloom. Bloom samples were defined as samples with $\mathrm{Chl}$ a concentrations of $>4.4 \mu \mathrm{g} \mathrm{Chl} \mathrm{a} \mathrm{L^{-1 }}$ The map was generated using the OCEAN DATA VIEW software package (Schlitzer, 2013).

particulate organic carbon (POC), and particulate organic nitrogen (PON), respectively, were filtered onto precombusted $\left(2 \mathrm{~h}, 500{ }^{\circ} \mathrm{C}\right)$ and preweighed glass fiber filter (47 mm diameter, Whatman GF/F; Whatman). Filters for SPM determination were subsequently rinsed with distilled water to remove salt. All filters were kept frozen at $-20{ }^{\circ} \mathrm{C}$ until the analysis as described in detail by Lunau et al. (2006). Samples for dissolved inorganic nutrients (nitrate, nitrite, and phosphate) were filtered through glass fiber filter (47 mm diameter, Whatman GF/F; Whatman) and measured with an autoanalyzer (Autoanalyzer Evolution 3; Alliance Instruments, Frepillon, France) following the protocol by Koroleff \& Grasshoff (1983). Detection limits were $0.3 \mu \mathrm{M}$ for $\mathrm{N}$ and $0.1 \mu \mathrm{M}$ for P. Bacterioplankton cell numbers were determined by flow cytometry (BD FACSAria ${ }^{\mathrm{TM}}$ III; BD Biosciences, San Jose, CA) using SYBR Green I staining and internal bead calibration as described previously (Giebel et al., 2009). For this purpose, water samples were taken, preserved with glutaraldehyde (final concentration 1\%), and stored at $-20{ }^{\circ} \mathrm{C}$ until further analysis. All measured environmental parameters are listed in Table S2.

\section{Extraction and purification of environmental RNA}

Total RNA was extracted as described by Weinbauer et al. (2002). One 47-mm-diameter filter (pore size, $0.2 \mu \mathrm{m}$ ) was used per sample. Subsequently, RNA was purified employing the RNeasy Mini Kit as recommended by the manufacturer (Qiagen, Hilden, Germany). Residual DNA was removed from RNA samples, and the absence of DNA was confirmed according to Wemheuer et al. (2012). Either DNA-free RNA was converted directly to cDNA for $16 \mathrm{~S}$ rRNA gene analysis or mRNA was enriched by rRNA depletion. The RiboMinus ${ }^{\mathrm{TM}}$ transcriptome isolation kit for Bacteria (Invitrogen ${ }^{\mathrm{TM}}$, Carlsbad, CA) was employed for mRNA enrichment. The removal of rRNA was performed according to the manufacturer's instructions with one modification. For initial denaturation, the RNA was incubated at $70{ }^{\circ} \mathrm{C}$ for $10 \mathrm{~min}$.

DNA was synthesized from total RNA and enriched mRNA by employing the SuperScript ${ }^{\mathrm{TM}}$ double-stranded cDNA synthesis kit (Invitrogen ${ }^{\mathrm{TM}}$ ) with slight modifications according to Wemheuer et al. (2012). Total RNA-derived cDNA was subjected to 16S rRNA gene PCR. The Göttingen Genomics Laboratory determined the sequences of the enriched mRNA-derived cDNA using a Roche GS-FLX $454^{\mathrm{TM}}$ pyrosequencer and titanium chemistry (Roche, Mannheim, Germany).

\section{Amplification and sequencing of 165 rRNA gene}

To analyze the bacterial diversity, the V2-V3 region of the bacterial $16 \mathrm{~S}$ rRNA gene was amplified by PCR. The PCR $(25 \mu \mathrm{L})$ contained $5 \mu \mathrm{L}$ of fivefold Phusion GC buffer (Finnzymes, Vantaa, Finland), $200 \mu \mathrm{M}$ of each of the four deoxynucleoside triphosphates, $1.5 \mathrm{mM} \mathrm{MgCl}_{2}$, $4 \mu \mathrm{M}$ of each primer, $2.5 \%$ DMSO, $1 \mathrm{U}$ of Phusion Hot Start DNA polymerase (Finnzymes), and c. $50 \mathrm{ng}$ of cDNA. The following thermal cycling scheme was used: initial denaturation at $98{ }^{\circ} \mathrm{C}$ for $5 \mathrm{~min}, 25$ cycles of denaturation at $98{ }^{\circ} \mathrm{C}$ for $45 \mathrm{~s}$, annealing at $68^{\circ} \mathrm{C}$ for $45 \mathrm{~s}$, followed by extension at $72{ }^{\circ} \mathrm{C}$ for $30 \mathrm{~s}$. The final extension was carried out at $72{ }^{\circ} \mathrm{C}$ for $5 \mathrm{~min}$. Negative controls were performed using the reaction mixture without template. The V2-V3 region was amplified with the following set of primers according to Nacke et al. (2011) containing the Roche 454 pyrosequencing adaptors, keys, and one unique MID per sample (underlined): V2for

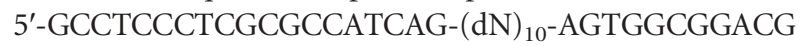
GGTGAGTAA-3' and V3rev 5'-GCCTTGCCAGCCCGCT CAGACAGTATATA-CGTATTACCGCGGCTGCTG-3'.).

The resulting PCR products were checked for appropriate size and purified by employing the peqGOLD gel 
extraction kit (Peqlab, Erlangen, Germany) as recommended by the manufacturer. Three independent PCRs were performed per sample, purified by gel extraction, and pooled in equal amounts. Quantification of the PCR products was performed using the Quant-iT dsDNA HS assay kit and a Qubit fluorometer (Invitrogen) as recommended by the manufacturer. The Göttingen Genomics Laboratory determined the 16S rRNA gene sequences using a Roche GS-FLX $454^{\mathrm{TM}}$ pyrosequencer and titanium chemistry (Roche).

\section{Processing and analysis of pyrosequencing derived data sets}

Generated 16S rRNA gene data sets were processed and analyzed employing the QIIME software package (version 1.6; Caporaso et al., 2010) and other tools. A detailed workflow is depicted and described in Fig. S1. Sequence statistics are listed in Table S3. Generated mRNA data sets were analyzed by employing the MG-RAST platform (Meyer et al., 2008). Sequence statistics are listed in Table S4. Community compositions was determined by best hit classification using the nonredundant multisource annotation database (M5NR) as annotation source and a minimum $e$-value of $1 \mathrm{e}-5$, a minimal identity of $60 \%$, and a minimum alignment length of $50 \mathrm{bp}$. The abundance of different phylogenetic groups was defined by raw sequence numbers of classified sequences. Functional analysis was performed by hierarchical classification using MG-RAST subsystems as annotation source and a minimum e-value of $1 \mathrm{e}-5$, a minimal identity of $60 \%$, and a minimum alignment length of 50 amino acids.

\section{Statistical analysis}

To validate the impact of phytoplankton bloom presence on the measured environmental parameters as well as on calculated diversity indices, we tested for significance of the parameters/index with respect to bloom presence by employing the Student's two-sample $t$-test (homogenous variances) or with the Welsh's two-sample $t$-test (heterogeneous variances) for normally distributed samples and with the Wilcoxon-Mann-Whitney test for non-normally distributed samples. The effect of the algal bloom onto relative abundances of prominent bacterial groups was tested by Dirichlet regression in $R$ using the Dirichlet Reg package (Meier, 2012). The relative abundances were thereby treated as compositional data and tested against the presence/absence of the investigated bloom. Effects were regarded as statistically significant by $P \leq 0.05$. All statistical analyses were conducted employing $\mathrm{R}$ (version 2.15.0; R Development Core Team, 2009).

\section{Deposition of sequence data}

Sequence data were deposited in the sequence read archive of the National Center for Biotechnology Information under the accession number SRA061816.

\section{Results and discussion}

\section{Study area and characteristics of sampling sites}

In this survey, we examined the impact of a phytoplankton bloom on bacterial community structures in the southern North Sea of samples taken in and outside of a phytoplankton spring bloom by assessing the metatranscriptomes using direct sequencing of rRNA-depleted RNA and especially pyrosequencing-based analysis of 16S rRNA gene transcripts. During the survey in southern North Sea, in situ temperatures ranged from 8.18 to $11.83{ }^{\circ} \mathrm{C}$ with slightly colder temperatures in the western compared with the eastern region (Table S1). Salinity ranged from 30.64 to 32.71 . Samples were taken at different locations and different depths within the German Bight (Fig. 1, Table S1). In the western region, four samples were taken at stations $2-4$ and 17 with Chl $a$ concentrations below $3.4 \mu \mathrm{g} \mathrm{Chl} a \mathrm{~L}^{-1}$. Nine samples were taken in phytoplankton bloom areas with $\mathrm{Chl} a$ concentrations of $>4.4 \mu \mathrm{g} \mathrm{Chl} a \mathrm{~L}^{-1}$ (Fig. 1, Table S2), one at the southernmost station (station 1) and eight in the northeastern region (stations 5-8, 10, and 13-15). Nine samples were collected from $2 \mathrm{~m}$ depth, and the other 5 , from 9 to $20 \mathrm{~m}$ (Table S1). At station 3, samples were collected from 2 and $12 \mathrm{~m}$. Due to the shallow water depth of $<22 \mathrm{~m}$ at 12 of the 13 stations visited (Table S1) and the weak stratification of the water column, no systematic differences between values of any parameter from $2 \mathrm{~m}$ compared with 9-20 $\mathrm{m}$ were observed.

The phytoplankton bloom examined in this study was dominated by Phaeocystis globosa and various diatoms typical for spring in the southern North Sea such as Thalassiosira spp., Chaetoceros spp., and Rhizosolenia spp. (Wiltshire et al., 2010). Mean concentrations of POC, PON, Chl $a$, and phaeopigments of stations in the bloom area were significantly higher than that outside the bloom area (Table S2). The opposite was recorded for bacterial cell numbers, which were significantly lower in bloom samples. Concentrations of SPM ranged between 2.35 and $11.3 \mathrm{mg} \mathrm{L}{ }^{-1}$ without significant differences between the bloom and nonbloom areas. The same was recorded for the nitrite concentrations, whereas nitrate and phosphate concentrations were significantly correlated with bloom presence (Table S2). 


\section{$16 S$ rRNA gene-based assessment of active bacterioplankton community structures}

Active bacterioplankton community compositions were assessed by pyrosequencing-based analysis of the V2-V3 region of the 16S rRNA gene amplified from environmental RNA by two-step RT-PCR. A total of 211769 highquality bacterial $16 \mathrm{~S}$ rRNA gene sequences were recovered across all 14 analyzed samples (Table S3). Calculated rarefaction curves as well as diversity indices revealed that the majority of the bacterial community was recovered by the surveying effort (Fig. S2, Table S5). Approximately $93 \%$ of all estimated OTUs were recovered at $1 \%$ and $3 \%$ genetic divergence. At $20 \%$ genetic divergence, the OTU coverage was $c$. $85 \%$, indicating that the majority but not all bacterial phyla were recovered by the surveying effort. Calculated Shannon indices ranged from 4.6 to 5.5, 4.4 to 5.4, and 1.4 to 2.2 at $1 \%, 3 \%$, and $20 \%$ genetic distance, respectively.

Classification of the 16S rRNA gene sequences revealed that Proteobacteria was the most abundant bacterial phylum across all samples (c. 98.6\% of all sequences). Other identified phyla present in all samples were Bacteroidetes $(0.9 \%)$ and Actinobacteria (0.3\%). The majority of all $16 \mathrm{~S}$ rRNA gene sequences (c. 95\%) were further affiliated to 13 bacterial groups, clades, and genera (Fig. 2). The low abundance of Bacteroidetes was surprising, as the prominence of this phylum in bacterioplankton communities has been shown in other studies (e.g. Jamieson et al., 2012).

Most of the sequences were assigned to Gammaproteobacteria. The SAR92 clade $(21.8 \%)$, the SAR86 clade $(5.9 \%)$, the OM60 clade $(10.3 \%)$, the OM182 clade (13.4\%), and the genus Pseudospirillum (3.5\%) were identified as the most abundant phylogenetic groups in this class (Fig. 2). Alphaproteobacteria were the second most abundant proteobacterial class in all samples. The majority of 16S rRNA gene sequences (19.5\%) were assigned to the Roseobacter RCA cluster (Newton et al., 2010; Giebel et al., 2013; Hahnke et al., 2013), the largest cluster of the Roseobacter clade (Buchan et al., 2005). It has been consistently detected at various locations and over several years in the German Bight and in the entire North Sea (Selje et al., 2004; Giebel et al., 2011; Sperling et al., 2012).

Another lineage found in all samples was the SAR11 clade (5\%) (Fig. 2), which is abundant globally in the ocean and also in the North Sea (Morris et al., 2002; Giebel et al., 2011; Teeling et al., 2012). The high abundance of the Roseobacter clade was also supported by our results, but the SAR11 clade was substantially less abundant compared with previous DNA-based studies (Giebel et al., 2011; Sperling et al., 2012; Teeling et al., 2012). The overall low abundance of SAR11 on RNA level might be explained by a low metabolic activity. Observed

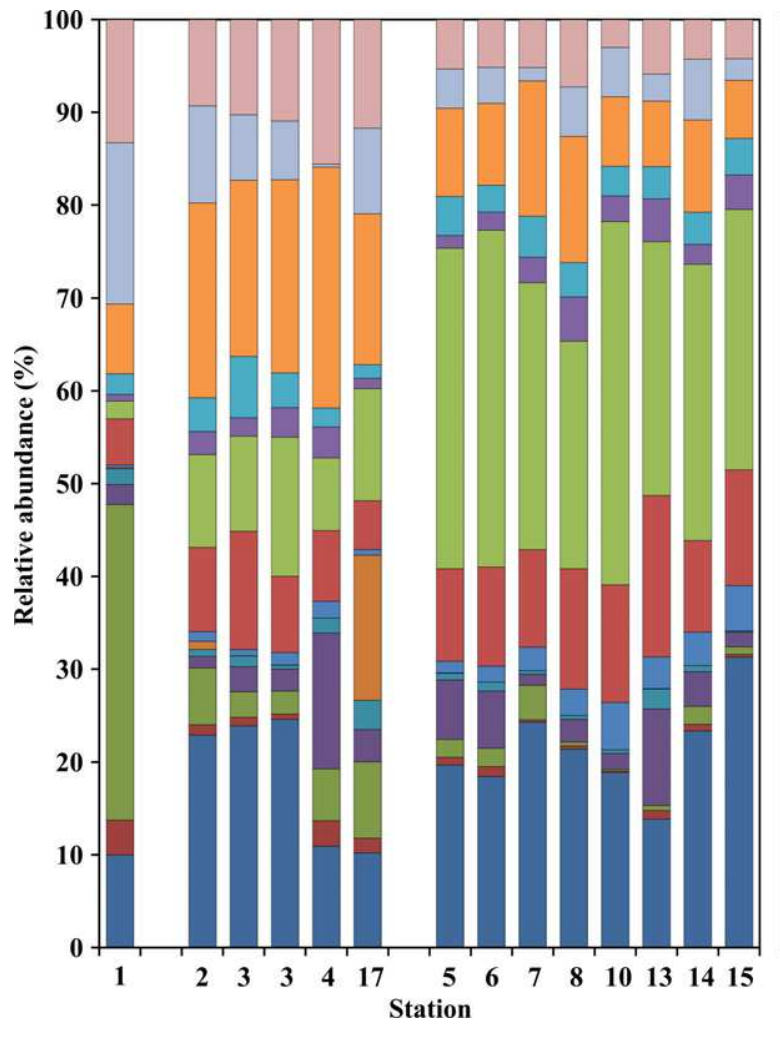

(C) 2013 Federation of European Microbiological Societies. Published by John Wiley \& Sons Ltd. All rights reserved

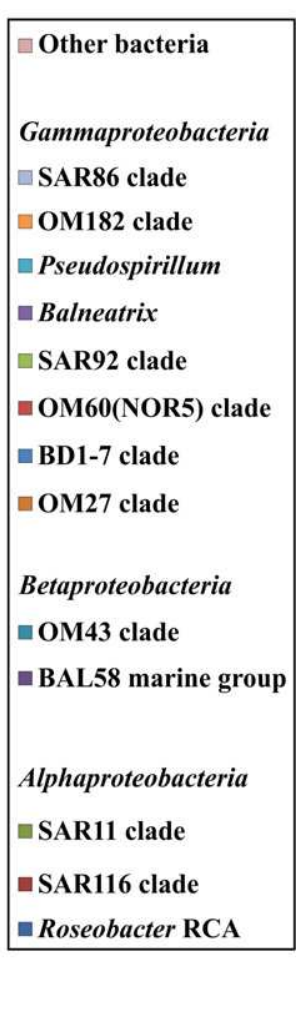

Fig. 2. Relative distribution of abundant bacterial lineages at stations outside (1-4 and 17) and inside (5-8, 10, and 13-15) the examined phytoplankton bloom. Only groups with an average abundance of more than $1 \%$ are shown. Station 1 is separated, as it was located in a bloom outside of the examined bloom. 
changes in relative abundance in RNA-based studies are not necessarily solely caused by changes in the total number of corresponding bacterial cells. These changes can also partly result from increasing or decreasing metabolic activity, which directly affects the number of ribosomes present in the cell. A low activity of SAR11 has been reported in other studies. For example, Alonso \& Pernthaler (2006) showed that SAR11 is highly abundant, but not very active in costal North Sea waters. In addition, West et al. (2008) demonstrated that SAR11 was more abundant in the Southern Ocean on DNA level than on RNA level.

The third most abundant proteobacterial class was Betaproteobacteria (5.7\%). Sequences were mainly affiliated to BAL58 marine group (4.3\%). The name of this group originated from strain BAL58, which is an obligate oligotrophic marine bacterium (Simu \& Hagström, 2004). This strain was also detected by DGGE-based analysis of the bacterioplankton community in the central Baltic Sea (Riemann et al., 2008).

\section{Assessment of bacterioplankton composition based on direct sequencing of mRNA}

To gain initial insights into gene expression patterns, three samples from nonbloom and bloom locations were selected for direct metatranscriptome sequencing and assessment of bacterioplankton community structures by phylogenetic classification of the mRNA reads: one sample at the southernmost station with high concentrations of SPM (station 1), one sample from the northeastern bloom with the highest chlorophyll a concentration (station 5), and one sample from outside the bloom (station 17). For this purpose, enriched mRNA was converted to cDNA and directly sequenced. Different from other studies (e.g. McCarren et al., 2010; Gifford et al., 2013), we omitted amplification steps prior to sequencing to avoid bias formation. Generated mRNA sets contained a total of 988202 sequences (Table S4). The amount of residual rRNA ranged from $5.8 \%$ to $76.8 \%$. Between 46238 and 360032 hits in the M5 nonredundant protein database were used for taxonomic classification.

Based on the phylogenetic affiliation of the deduced proteins, Bacteria encompassed the major fraction (Fig. S3). Alphaproteobacteria and Gammaproteobacteria were the dominant active classes (Fig. 3a). Betaproteobacteria, Actinobacteria, and Cyanobacteria were of minor abundance. Bacteroidetes encompassed $34 \%$ of the transcripts at station 5 , but $<8 \%$ at the other two stations. Alphaproteobacteria were predominant in the mRNAbased analysis of the latter samples. Different from the $16 \mathrm{~S}$ rRNA gene analysis, Gammaproteobacteria (26\%) were less abundant in the mRNA analysis than Alphaproteobacteria (a)
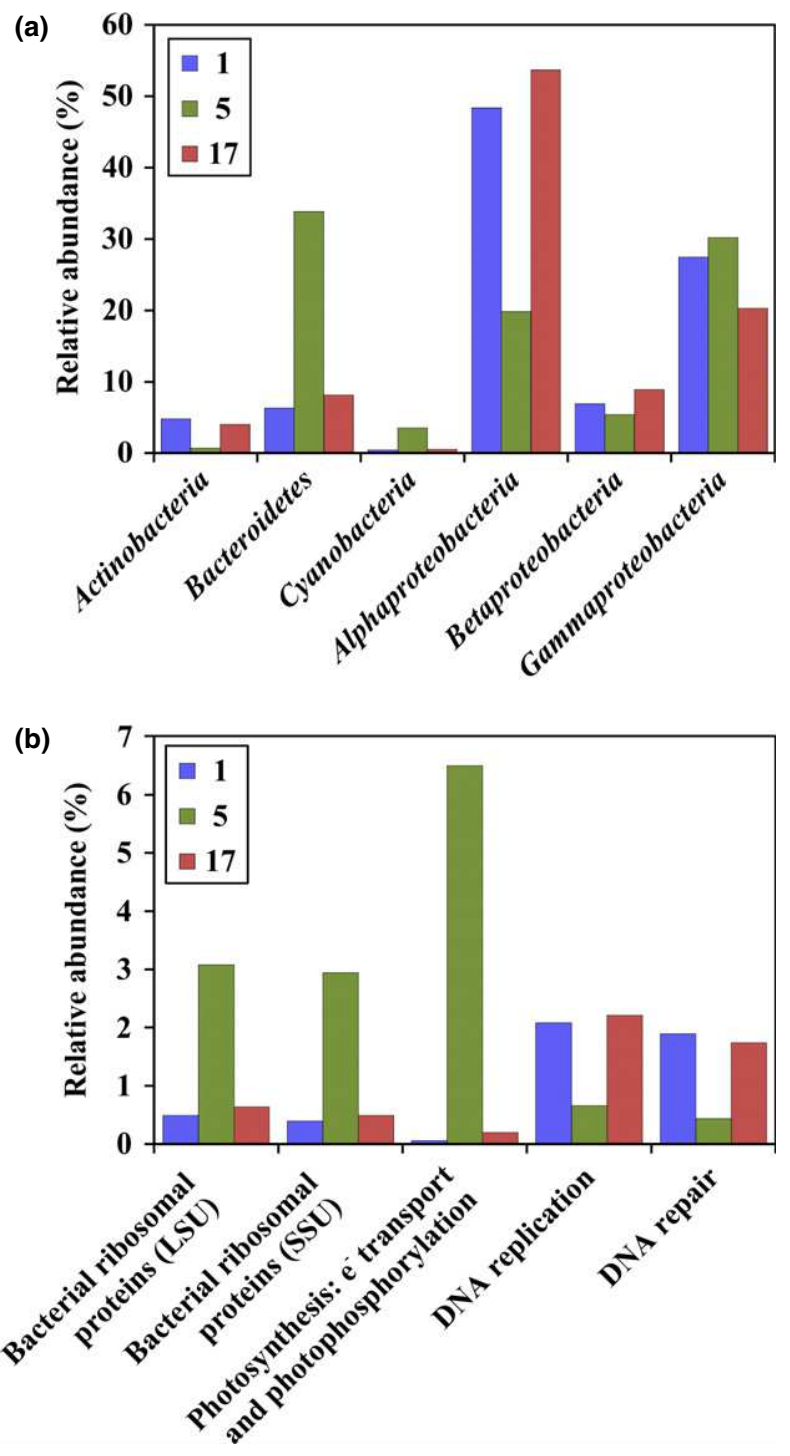

Fig. 3. MG-RAST-based phylogenetic (a) and gene expression analysis (b) of mRNA data sets derived from stations 1, 5, and 17. The sample from station 5 was taken in the center of a phytoplankton bloom with the highest chlorophyll a concentration measured during the survey $\left(11.45 \mu \mathrm{g} \mathrm{L}^{-1}\right)$. Stations 1 and 17 were taken outside the examined bloom and exhibited chlorophyll a concentration of $<4.4 \mu \mathrm{g} \mathrm{L}{ }^{-1}$.

(Fig. 3a). Almost $41 \%$ of all identified proteobacterial mRNA sequences were affiliated to the latter class.

The differences in the relative abundance of certain bacterial groups between both approaches highlight common problems of both analysis types. PCR-based methods usually result in a biased picture of bacterial communities, for example, by primer pair mismatches (Klindworth et al., 2013). Direct sequencing approaches do not introduce bias like PCR-based methods, but one disadvantage is the reliability on the corresponding and well-annotated 
entries in sequence databases. For example, the SAR11 clade was abundant in the 16S rRNA gene analysis of sample 1, but was not detected during mRNA analysis of the corresponding sample. This could be explained by the low number of entries for SAR11 in public databases. The M5NR database used by MG-RAST (Meyer et al., 2008) is an integration of many sequence databases including NCBI, RDP, and KEGG databases into one single, searchable database. Despite its size, this database harbors only 16477 entries for SAR11, of which many derive from Pelagibacter ubique. Another example for the reliability on the corresponding and well-annotated entries in sequence databases is the study by Ottesen et al. (2013). Here, the authors focused on dynamics among five abundant microbial lineages and genera in the investigated marine community, that is, Ostreococcus, Synechococcus, Pelagibacter, SAR86 cluster (Gammaproteobacteria), and the marine group II (Euryarchaeota). Interestingly, the majority of the bacterial community was not studied as $<31 \%$ of the reads with matches in the NCBI nonredundant peptide database were affiliated to the five groups. We avoided performing a phylogenetic analysis of the transcripts at high taxonomic resolution because most phylogenetic lineages detected by the $16 \mathrm{~S}$ rRNA gene amplicon sequencing approach are not represented in the M5NR protein database.

Other bacterial groups, for example, the Roseobacter clade, are relatively well represented in public databases due to the high number of physiologically diverse isolates and corresponding genome sequences (González et al., 2000; Brinkhoff et al., 2008). However, recent studies showed that also abundant Roseobacter clade members thriving in bacterioplankton communities are still largely missing in these databases, as corresponding isolates are not yet available (Luo et al., 2012). Further analysis of the mRNA data sets, however, revealed that the majority of the annotated protein hits derived from the three samples were affiliated to the Rhodobacterales and, in particular, to different members of the Roseobacter clade. The $16 \mathrm{~S}$ rRNA gene analysis of the corresponding samples revealed that c. $91 \%$ of the $16 \mathrm{~S}$ rRNA gene sequences assigned to the Rhodobacterales were affiliated to the RCA cluster. As this cluster is not represented in the genome databases so far, protein hits assigned to the Rhodobacteraceae putatively belong mainly to the RCA cluster, the predominant Roseobacter cluster in the German Bight.

\section{Impact of environmental conditions on active bacterial community structures}

We further investigated the impact of environmental conditions on active bacterioplankton community structures. For this purpose, the community structure response to different environmental parameters was examined by principal coordinate analysis (PCoA; Fig. 4).

As environmental conditions might be linked to bloom presence, we initially tested for correlations between the recorded parameters and the bloom. Only the sampling depth, the suspended particulate matter content (SPM), and the nitrite concentration exhibited no direct correlation with bloom presence and were further examined by PCoA. They exhibited no effect on diversity and community structure (data not shown). Nevertheless, PCoA with respect to bloom presence revealed that all samples taken in the presence of the phytoplankton bloom tend to cluster and, thus, indicate similarity in bacterial community composition (Fig. 4). Samples taken outside the algal bloom did not show cluster formation. Thus, these results support our first hypothesis that bacterioplankton community composition is affected by the bloom and the environmental conditions found during the bloom. Sample 1 taken in a bloom separated from the examined bloom area exhibits a different community structure than the other bloom samples.

\section{Impact of the phytoplankton bloom onto bacterioplankton composition and richness}

As bacterioplankton community structures and phytoplankton bloom presence exhibit a strong correlation in the PCoA, we investigated the effect of the bloom on bacterial richness as well as the abundances and activity of certain bacterial groups. We recorded differences in the number of OTUs by direct comparison of rarefaction curves calculated with regard to bloom presence (Fig. 5). Nonbloom samples exhibited a higher diversity at $1 \%$ and $3 \%$ genetic distance. In addition, Shannon indices calculated at all three genetic distance levels were significantly reduced in the bloom samples (Table S5). This indicates a lower bacterial diversity in the bloom than outside the bloom and confirms our second hypothesis that the bacterial richness is affected by the presence of the phytoplankton bloom. The overall reduction in diversity during the bloom indicates that certain members of the bacterioplankton community benefitted from the substrates provided by primary production of the phytoplankton species present. A specialized ecological niche is formed in which only certain members of the bacterioplankton can grow. This is in accordance with other studies (West et al., 2008; Teeling et al., 2012).

We further examined which bacterial groups were significantly affected by bloom presence using statistical analysis. In accordance with our first hypothesis, eight of the 13 identified abundant bacterial groups and genera were significantly influenced by the bloom (Table 1 ). The strongest response to phytoplankton bloom presence was 


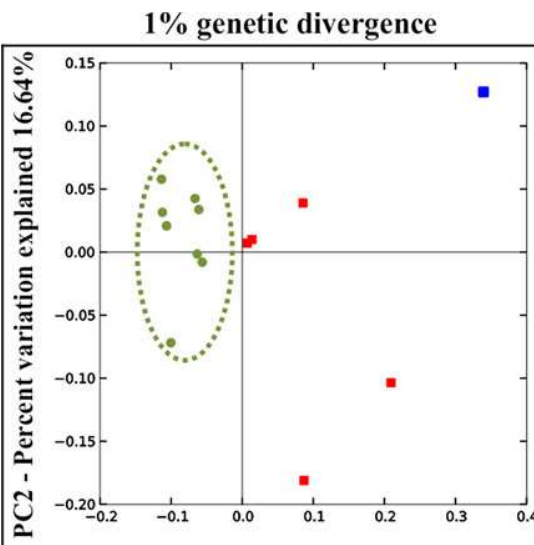

PC1 - Percent variation explained 53.74\%
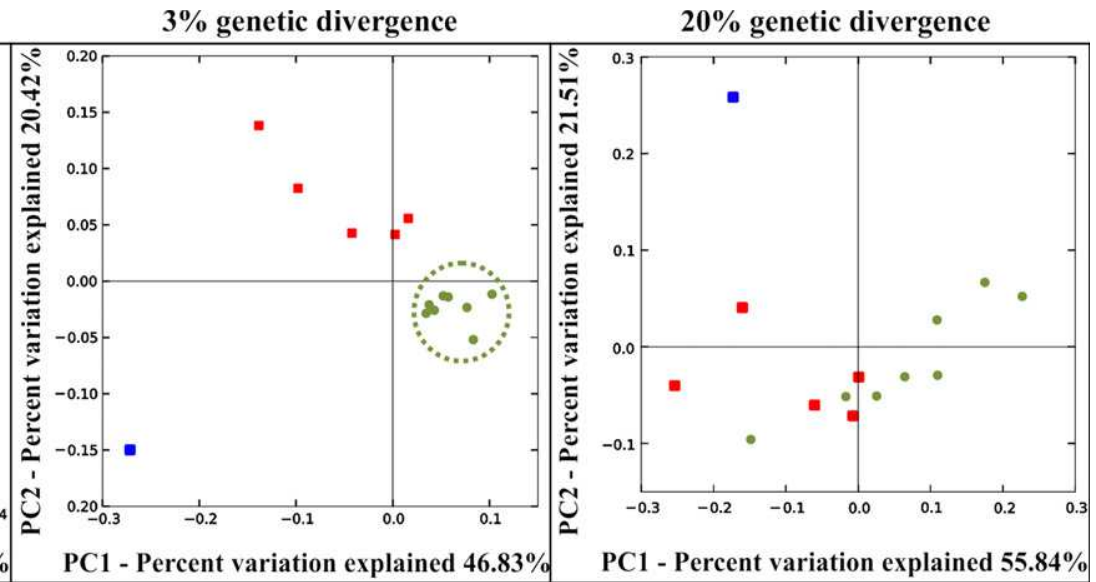

Fig. 4. Weighted UniFrac 2D PCoA plots calculated at $1 \%$ and $3 \%$ genetic distance employing QIIME (Caporaso et al., 2010). To compare community structures, 10353 randomly selected sequences from each sample were used for the calculation. Stations located inside of the phytoplankton bloom area are depicted as green dots, those outside the bloom, as red squares. Station 1 is shown as it was taken in a bloom separated from the examined bloom. Circles are drawn to better visualize putative structural similarities of the studied communities.

Fig. 5. Average rarefaction curves calculated for bloom and nonbloom samples at $1 \%, 3 \%$, and $20 \%$ genetic distance.

recorded for the SAR92 clade. On average, the relative abundance of this clade increased threefold in bloom presence. It was shown that members of the SAR92 clade benefit from nutrient-rich conditions (Stingl et al., 2007) as found during a phytoplankton bloom. Interestingly, Teeling et al. (2012) recorded no increase in abundance for the SAR92 clade during a bloom in the southern North Sea applying catalyzed reporter deposition-fluorescence in situ hybridization (CARD-FISH). This might indicate that not the number of cells, but the activity of the SAR92 clade is increased under bloom conditions.

We also recorded significantly higher abundances of the OM60 (NOR5) clade and the BD1-7 clade in the bloom area. These two clades and the SAR92 clade do belong to Oligotrophic Marine Gammaproteobacteria (OMG) group (Cho \& Giovannoni, 2004). Although genomic information on diverse OMG isolates is available (e.g. Stingl et al., 2007; Huggett \& Rappé, 2012), little is known about their ecological role.

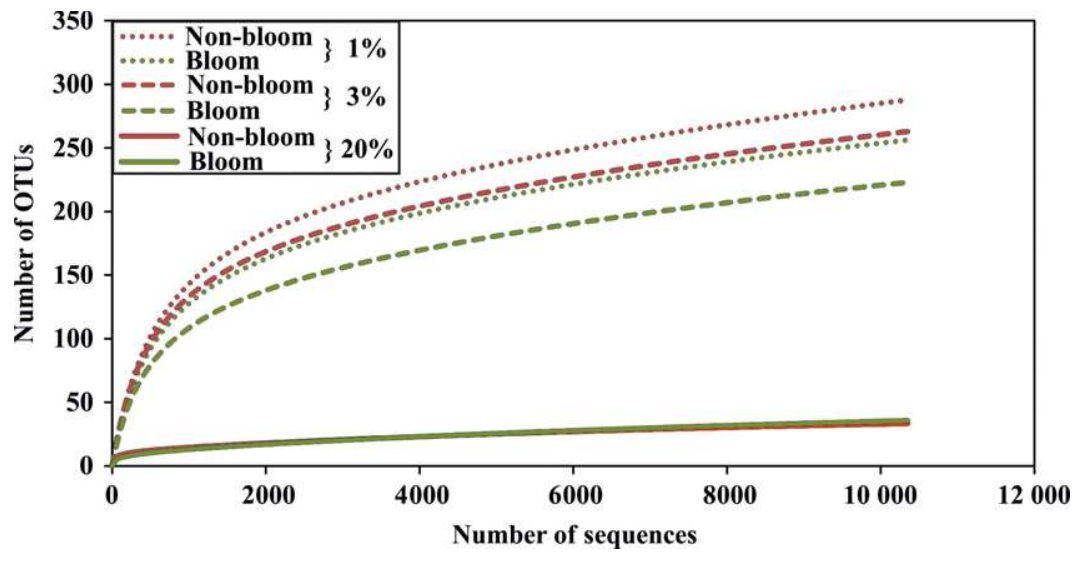

Another bacterial group positively correlated with bloom presence was the RCA cluster (Table 1). Giebel et al. (2011) and Sperling et al. (2012) showed that the abundance of the RCA cluster was positively correlated with concentrations of Chl $a$ and other biogeochemical properties characterizing phytoplankton blooms in the North Sea. Also West et al. (2008) reported that the RCA cluster was abundant in and outside of a phytoplankton bloom in the Southern Ocean. Moreover, two other Roseobacter clusters, NAC11-6 and NAC11-7, had higher relative abundances and higher activities in the bloom. González et al. (2000) showed that members of the Roseobacter clade, the SAR11 clade, and the SAR86 clade accounted for more than $50 \%$ of the bacterial $16 \mathrm{~S}$ rRNA genes in a phytoplankton bloom in the North Atlantic. Our data suggest that members of RCA cluster were slightly more abundant or active during the bloom. According to Teeling et al. (2012), the abundance of phosphorus-related ABC-type transporters affiliated to the 
Table 1. Relative abundances of dominant bacterial groups and correlations with phytoplankton bloom presence. Significance was tested by Dirichlet regression in $R$ (significance level $P \leq 0.05$ )

\begin{tabular}{|c|c|c|c|c|}
\hline \multirow[b]{2}{*}{ Bacterial group } & \multicolumn{2}{|c|}{$\begin{array}{l}\text { Mean relative abundance } \\
(\%)\end{array}$} & \multirow[b]{2}{*}{ Correlation } & \multirow[b]{2}{*}{$P$} \\
\hline & Nonbloom & Bloom & & \\
\hline \multicolumn{5}{|l|}{ Alphaproteobacteria } \\
\hline $\begin{array}{l}\text { Roseobacter } \\
\text { RCA }\end{array}$ & $18.5 \pm 7.3$ & $21.4 \pm 5.1$ & Positive & $<0.001$ \\
\hline SAR11 clade & $1.4 \pm 0.86$ & $0.58 \pm 0.35$ & - & - \\
\hline SAR116 clade & $5.0 \pm 2.4$ & $1.4 \pm 1.2$ & - & - \\
\hline \multicolumn{5}{|l|}{ Betaproteobacteria } \\
\hline $\begin{array}{l}\text { BAL58 } \\
\text { marine group }\end{array}$ & $4.9 \pm 5.5$ & $4.2 \pm 3.2$ & - & $<0.05$ \\
\hline OM43 clade & $1.4 \pm 1.1$ & $0.73 \pm 0.64$ & - & - \\
\hline \multicolumn{5}{|c|}{ Gammaproteobacteria } \\
\hline Balneatrix & $2.4 \pm 0.92$ & $3.0 \pm 1.3$ & Positive & $<0.01$ \\
\hline BD1-7 clade & $0.5 \pm 3.2$ & $1.4 \pm 0$ & Positive & $<0.001$ \\
\hline OM182 clade & $20.6 \pm 3.6$ & $9.7 \pm 3.0$ & - & - \\
\hline OM27 clade & $3.3 \pm 6.9$ & $>0.01$ & - & - \\
\hline $\begin{array}{l}\text { OM60 (NOR5) } \\
\text { clade }\end{array}$ & $8.65 \pm 2.7$ & $12.1 \pm 2.5$ & Positive & $<0.001$ \\
\hline Pseudospirillum & $3.51 \pm 2$ & $3.6 \pm 0.51$ & Positive & $<0.01$ \\
\hline SAR86 clade & $6.7 \pm 3.9$ & $4.0 \pm 1.7$ & Negative & $<0.05$ \\
\hline SAR92 clade & $11.0 \pm 2.7$ & $31.1 \pm 5.0$ & Positive & $<0.001$ \\
\hline
\end{tabular}

Rhodobacterales is enhanced in the late bloom stage, whereas the abundance of the Roseobacter clade, comprising mainly this order, was not affected. As for SAR92, not the abundance of members of the RCA cluster, but the activity might be affected by bloom presence in the German Bight. Interestingly, Teeling et al. (2012) recorded a slight decrease in SAR11 abundance during the bloom by CARD-FISH analysis. We also recorded 2.5 -fold decrease in our analysis (Table 1). However, a significant correlation between SAR11 abundance and bloom presence was not recorded.

\section{Impact of a phytoplankton bloom onto bacterial community structure and activity as assessed by direct sequencing of mRNA}

Generated mRNA data sets were further analyzed to evaluate the impact of the phytoplankton bloom on structure as well as metabolic activity of the bacterioplankton. Phylogenetic analysis of the generated mRNA data sets revealed an increase in abundance of the Bacteroidetes in the sample taken in the area of the investigated bloom (sample 5) (Fig. 3a). Bacteroidetes are widespread in marine systems and play an important role in organic matter degradation (Gomez-Pereira et al., 2010). The higher abundance of this phylum corresponds to the results of Teeling et al. (2012). They recorded a higher cell abundance of different flavobacterial genera during and after the bloom event. Therefore, Bacteroidetes seem to be one bacterial group benefitting from the conditions provided by the investigated phytoplankton bloom.

Functional analysis of the generated mRNA data sets also revealed differences between samples collected at stations with low and high Chl a concentrations. As expected, expression levels of genes affiliated to photosynthesis were enhanced at station 5, inside the examined bloom (Figs $3 \mathrm{~b}$ and S4). More than $80 \%$ of these were further affiliated to different genes encoding proteins of the photosystem II such as PsbA, PsbB, PsbC, PsbD, and PspE (data not shown).

The number of transcripts assigned to protein metabolism was higher at this station compared with the other two stations (Fig. S4). A deeper analysis revealed that especially the number of transcripts affiliated to bacterial ribosomal protein-encoding genes was higher (Fig. 3b). An increased number of ribosomal proteins indicates an increased ribosome formation, which in turn might correspond to a higher bacterial activity during the bloom event. Interestingly, the number of transcripts affiliated to DNA metabolism, in particular DNA replication and repair (Fig. 3b), as well as the number of transcripts assigned to the cell cycle (Fig. S4) was lower at station 5. This might indicate a reduced bacterioplankton growth rate within the bloom and complies with the lower bacterial numbers inside the bloom area relative to outside the bloom. This corresponds to our second hypothesis and also to the hypothesis proposed by Teeling et al. (2012) that specialized ecological niches are formed during a phytoplankton bloom in which only certain members of the bacterioplankton can grow, whereas others are inhibited.

In conclusion, the investigated active bacterial communities in the southern North Sea were dominated by only a few marine groups such as the SAR92 clade and Roseobacter RCA cluster. The metatranscriptomic approaches revealed that most of the environmentally occurring abundant and active marine groups found in the bacterioplankton are underrepresented by isolates or type strains and correspondingly by reference genome sequences. In addition, the number of field studies targeting the active bacterial community either by metatranscriptomic or by metaproteomic approaches is limited. This study provides first insights into structural and functional changes in the active bacterioplankton community as response to a phytoplankton bloom. More studies targeting active bacterioplankton communities in combination with isolation and characterization of environmentally relevant strains are required to unravel the ecological role and ecosystem function of bacterioplankton community members in different marine ecosystems. 


\section{Acknowledgements}

We thank the crew of RV Heincke for their valuable support; B. Schmidt from the Experimental and Applied Mineralogy Department of the Geoscience Center Göttingen for providing his muffle furnace; B. Kuerzel, A. Schlingloff, and R. Weinert for analysis of chlorophyll, SPM, POC, and PON, as well as M. Wurst, N. Händel, G. Wienhausen, and M. Wolterink for analysis of inorganic nutrients. This work was funded by Deutsche Forschungsgemeinschaft (DFG) within the Collaborative Research Center TRR 51.

\section{References}

Alderkamp A-C, Sintes E \& Herndl GJ (2006) Abundance and activity of major groups of prokaryotic plankton in the coastal North Sea during spring and summer. Aquat Microb Ecol 45: 237-246.

Alonso C \& Pernthaler J (2006) Roseobacter and SAR11 dominate microbial glucose uptake in coastal North Sea waters. Environ Microbiol 8: 2022-2030.

Brinkhoff T, Giebel HA \& Simon M (2008) Diversity, ecology, and genomics of the Roseobacter clade: a short overview. Arch Microbiol 189: 531-539.

Buchan A, Gonzalez JM \& Moran MA (2005) Overview of the marine Roseobacter lineage. Appl Environ Microbiol 71: 5665-5677.

Caporaso JG, Kuczynski J, Stombaugh J et al. (2010) QIIME allows analysis of high-throughput community sequencing data. Nat Methods 7: 335-336.

Cho J-C \& Giovannoni SJ (2004) Cultivation and growth characteristics of a diverse group of oligotrophic marine gammaproteobacteria. Appl Environ Microbiol 70: 432-440.

Frias-Lopez J, Shi Y, Tyson GW, Coleman ML, Schuster SC, Chisholm SW \& DeLong EF (2008) Microbial community gene expression in ocean surface waters. P Natl Acad Sci USA 105: 3805-3810.

Giebel HA, Brinkhoff T, Zwisler W, Selje N \& Simon M (2009) Distribution of Roseobacter RCA and SAR11 lineages and distinct bacterial communities from the subtropics to the Southern Ocean. Environ Microbiol 11: 2164-2178.

Giebel HA, Kalhoefer D, Lemke A, Thole S, Gahl-Janssen R, Simon M \& Brinkhoff $\mathrm{T}$ (2011) Distribution of Roseobacter RCA and SAR11 lineages in the North Sea and characteristics of an abundant RCA isolate. ISME J 5: 8-19.

Giebel HA, Kalhoefer D, Gahl-Janssen R et al. (2013)

Planktomarina temperata gen. nov., sp. nov., belonging to the globally distributed RCA cluster of the marine Roseobacter clade, isolated from the German Wadden Sea. Int J Syst Evol Microbiol, DOI: 10.1099/ijs.0.053249-0 [Epub ahead of print].

Gifford SM, Sharma S, Rinta-Kanto JM \& Moran MA (2011) Quantitative analysis of a deeply sequenced marine microbial metatranscriptome. ISME J 5: 461-472.
Gifford SM, Sharma S, Booth M \& Moran MA (2013) Expression patterns reveal niche diversification in a marine microbial assemblage. ISME J 7: 281-298.

Giovannoni SJ \& Stingl U (2005) Molecular diversity and ecology of microbial plankton. Nature 437: 343-348.

Giovannoni SJ, Britschgi TB, Moyer CL \& Field KG (1990) Genetic diversity in Sargasso Sea bacterioplankton. Nature 345: 60-63.

Gomez-Pereira PR, Fuchs BM, Alonso C, Oliver M, van Beusekom J \& Amann R (2010) Distribution patterns and diversity of planktonic Flavobacterial clades in contrasting water masses of the North Atlantic Ocean. ISME J 4: 472-487.

González JM, Simó R, Massana R, Covert JS, Casamayor EO, Pedrós-Alió C \& Moran MA (2000) Bacterial community structure associated with a dimethylsulfoniopropionate-producing North Atlantic algal bloom. Appl Environ Microbiol 66: 4237-4246.

Hahnke S, Brock NL, Zell C, Simon M, Dickschat JS \& Brinkhoff T (2013) Physiological diversity of Roseobacter clade bacteria co-occurring during a phytoplankton bloom in the North Sea. Syst Appl Microbiol 36: 39-48.

Huggett MJ \& Rappé MS (2012) Genome sequence of strain HIMB55, a novel marine gammaproteobacterium of the OM60/NOR5 clade. J Bacteriol 194: 2393-2394.

Jamieson RE, Rogers AD, Billett DS, Smale DA \& Pearce DA (2012) Patterns of marine bacterioplankton biodiversity in the surface waters of the Scotia Arc, Southern Ocean. FEMS Microbiol Ecol 80: 452-468.

Kirchman DL, Cottrell MT \& Lovejoy C (2010) The structure of bacterial communities in the western Arctic Ocean as revealed by pyrosequencing of $16 \mathrm{~S}$ rRNA genes. Environ Microbiol 12: 1132-1143.

Klindworth A, Pruesse E, Schweer T, Peplies J, Quast C, Horn M \& Glöckner FO (2013) Evaluation of general 16S ribosomal RNA gene PCR primers for classical and next-generation sequencing-based diversity studies. Nucleic Acids Res 41: e1.

Koroleff F \& Grasshoff K (1983) Determination of nutrients. Methods of Seawater Analysis, Vol. 2 (Grasshoff K, Ehrhardt M \& Kremling K, eds), pp. 125-188. Verlag Chemie, Weinheim, Germany.

Lesniewski RA, Jain S, Anantharaman K, Schloss PD \& Dick GJ (2012) The metatranscriptome of a deep-sea hydrothermal plume is dominated by water column methanotrophs and lithotrophs. ISME J 6: 2257-2268.

Lunau M, Lemke A, Dellwig O \& Simon M (2006) Physical and biogeochemical controls of microaggregate dynamics in a tidally affected coastal ecosystem. Limnol Oceanogr 51: $847-859$.

Luo H, Löytynoja A \& Moran MA (2012) Genome content of uncultivated marine Roseobacters in the surface ocean. Environ Microbiol 14: 41-51.

McCarren J, Becker JW, Repeta DJ, Shi Y, Young CR, Malmstrom RR, Chisholm SW \& DeLong EF (2010) Microbial community transcriptomes reveal microbes and 
metabolic pathways associated with dissolved organic matter turnover in the sea. P Natl Acad Sci USA 107: 16420-16427.

McQuatters-Gollop A, Raitsos DE, Edwards M, Pradhan Y, Mee LD, Lavender SJ \& Attrill MJ (2007) A long-term chlorophyll data set reveals regime shift in North Sea phytoplankton biomass unconnected to nutrient trends. Limnol Oceanogr 52: 635-648.

Meier MJ (2012) DirichletReg. Available at: http://cran. r-project.org/web/packages/DirichletReg.

Meyer F, Paarmann D, D'Souza M et al. (2008) The metagenomics RAST server - a public resource for the automatic phylogenetic and functional analysis of metagenomes. BMC Bioinformatics 9: 386.

Morris RM, Rappe MS, Connon SA, Vergin KL, Siebold WA \& Carlson CA (2002) SAR11 clade dominates ocean surface bacterioplankton communities. Nature 420: 806-810.

Muyzer G, de Waal EC \& Uitterlinden AG (1993) Profiling of complex microbial populations by denaturing gradient gel electrophoresis analysis of polymerase chain reaction-amplified genes coding for 16S rRNA. Appl Environ Microbiol 59: 695-700.

Nacke H, Thurmer A, Wollherr A, Will C, Hodac L, Herold N, Schoning I, Schrumpf M \& Daniel R (2011) Pyrosequencing-based assessment of bacterial community structure along different management types in German forest and grassland soils. PLoS ONE 6: e17000.

Newton RJ, Griffin LE, Bowles KM et al. (2010) Genome characteristics of a generalist marine bacterial lineage. ISME J 4: 784-798.

Nusch EA (1999) Chlorophyllbestimmung. Biologische Gewässeruntersuchung (von Tuempling W \& Friedrich G, eds), pp. 368-375. G Fischer, Stuttgart, Germany.

Ottesen EA, Young CR, Eppley JM, Ryan JP, Chavez FP, Scholin CA \& DeLong EF (2013) Pattern and synchrony of gene expression among sympatric marine microbial populations. P Natl Acad Sci USA 110: 488-497.

R Development Core Team (2009) R: A Language and Environment for Statistical Computing. R Foundation for Statistical Computing, Vienna, Austria.

Riemann L, Leitet C, Pommier T, Simu K, Holmfeldt K, Larsson U \& Hagström $\AA$ (2008) The native bacterioplankton community in the Central Baltic Sea is influenced by freshwater bacterial species. Appl Environ Microbiol 74: 503-515.

Rink B, Seeberger S, Martens T, Duerselen C-D, Simon M \& Brinkhoff T (2011) Regional patterns of bacterial community composition and biogeochemical properties in the southern North Sea. Aquat Microb Ecol 63: 207-222.

Schlitzer R (2013) Ocean data view. Available at: http://odv. awi.de.

Schmidt TM, DeLong EF \& Pace NR (1991) Analysis of a marine picoplankton community by $16 \mathrm{~S}$ rRNA gene cloning and sequencing. J Bacteriol 173: 4371-4378.

Selje N, Simon M \& Brinkhoff T (2004) A newly discovered Roseobacter cluster in temperate and polar oceans. Nature 427: 445-448.
Simu K \& Hagström A (2004) Oligotrophic bacterioplankton with a novel single-cell life strategy. Appl Environ Microbiol 70: 2445-2451.

Sintes E, Witte H, Stodderegger K, Steiner P \& Herndl GJ (2013) Temporal dynamics in the free-living bacterial community composition in the coastal North Sea. FEMS Microbiol Ecol 83: 413-424.

Sperling M, Giebel HA, Rink B, Grayek S, Staneva J, Stanev E \& Simon M (2012) Differential effects of hydrographic and biogeochemical properties on the SAR11 clade and Roseobacter RCA cluster in the North Sea. Aquat Microb Ecol 67: 25-34.

Stingl U, Desiderio RA, Cho JC, Vergin KL \& Giovannoni SJ (2007) The SAR92 clade: an abundant coastal clade of culturable marine bacteria possessing proteorhodopsin. Appl Environ Microbiol 73: 2290-2296.

Teeling H, Fuchs BM, Becher D et al. (2012) Substrate-controlled succession of marine bacterioplankton populations induced by a phytoplankton bloom. Science 336: 608-611.

Venter JC, Remington K, Heidelberg JF et al. (2004) Environmental genome shotgun sequencing of the Sargasso Sea. Science 304: 66-74.

Vila-Costa M, Gasol JM, Sharma S \& Moran MA (2012) Community analysis of high- and low-nucleic acid-containing bacteria in NW Mediterranean coastal waters using $16 \mathrm{~S}$ rDNA pyrosequencing. Environ Microbiol 14: 1390-1402.

Weinbauer MG, Fritz I, Wenderoth DF \& Höfle MG (2002) Simultaneous extraction from bacterioplankton of total RNA and DNA suitable for quantitative structure and function analyses. Appl Environ Microbiol 68: 1082-1087.

Wemheuer B, Wemheuer F \& Daniel R (2012) RNA-based assessment of diversity and composition of active archaeal communities in the German Bight. Archaea 2012: 695826 .

West NJ, Obernosterer I, Zemb O \& Lebaron P (2008) Major differences of bacterial diversity and activity inside and outside of a natural iron-fertilized phytoplankton bloom in the Southern Ocean. Environ Microbiol 10: 738-756.

Will C, Thurmer A, Wollherr A, Nacke H, Herold N, Schrumpf M, Gutknecht J, Wubet T, Buscot F \& Daniel R (2010) Horizon-specific bacterial community composition of German grassland soils, as revealed by pyrosequencing-based analysis of $16 \mathrm{~S}$ rRNA genes. Appl Environ Microbiol 76: 6751-6759.

Wiltshire K, Kraberg A, Bartsch I, Boersma M, Franke H-D, Freund J, Gebühr C, Gerdts G, Stockmann K \& Wichels A (2010) Helgoland roads, North Sea: 45 years of change. Estuaries Coasts 33: 295-310.

\section{Supporting Information}

Additional Supporting Information may be found in the online version of this article: 
Fig. S1. Processing of amplicon-based 454 pyrosequencing reads with QIIME and other tools.

Fig. S2. Rarefaction curves for all 14 samples at $1 \%$ (a), $3 \%$ (b), and 20\% (c) genetic divergence.

Fig. S3. MG-RAST-based taxonomic assignment of mRNA reads derived from stations 1,5 and 17 .

Fig. S4. MG-RAST-based hierarchical protein annotation using subsystems as annotation source.

Table S1. Sampling time and position as well as CTD measured parameters of the sampling sites.
Table S2. Environmental parameters determined for the samples.

Table S3. Sequence statistics of the 16S rRNA gene data sets.

Table S4. Statistics of the mRNA analysis according to MG-RAST (Meyer et al., 2008).

Table S5. Bacterial diversity and richness at 1\%, 3\% and $20 \%$ genetic distance. 


\section{SUPPORTING INFORMATION FOR STUDY 2}

\section{Contents:}

Fig. S1. Processing of amplicon-based 454 pyrosequencing reads with QIIME and other tools.

Fig. S2. Rarefaction curves for all 14 samples at 1\% (a), 3\% (b), and 20\% (c) genetic divergence.

Fig. S3. MG-RAST-based taxonomic assignment of mRNA reads derived from stations 1, 5 and 17.

Fig. S4. MG-RAST-based hierarchical protein annotation using subsystems as annotation source.

Table S1. Sampling time and position as well as CTD measured parameters of the sampling sites.

Table S2. Environmental parameters determined for the samples.

Table S3. Sequence statistics of the 16S rRNA gene data sets.

Table S4. Statistics of the mRNA analysis according to MG-RAST (Meyer et al., 2008).

Table S5. Bacterial diversity and richness at 1\%, 3\% and 20\% genetic distance. 


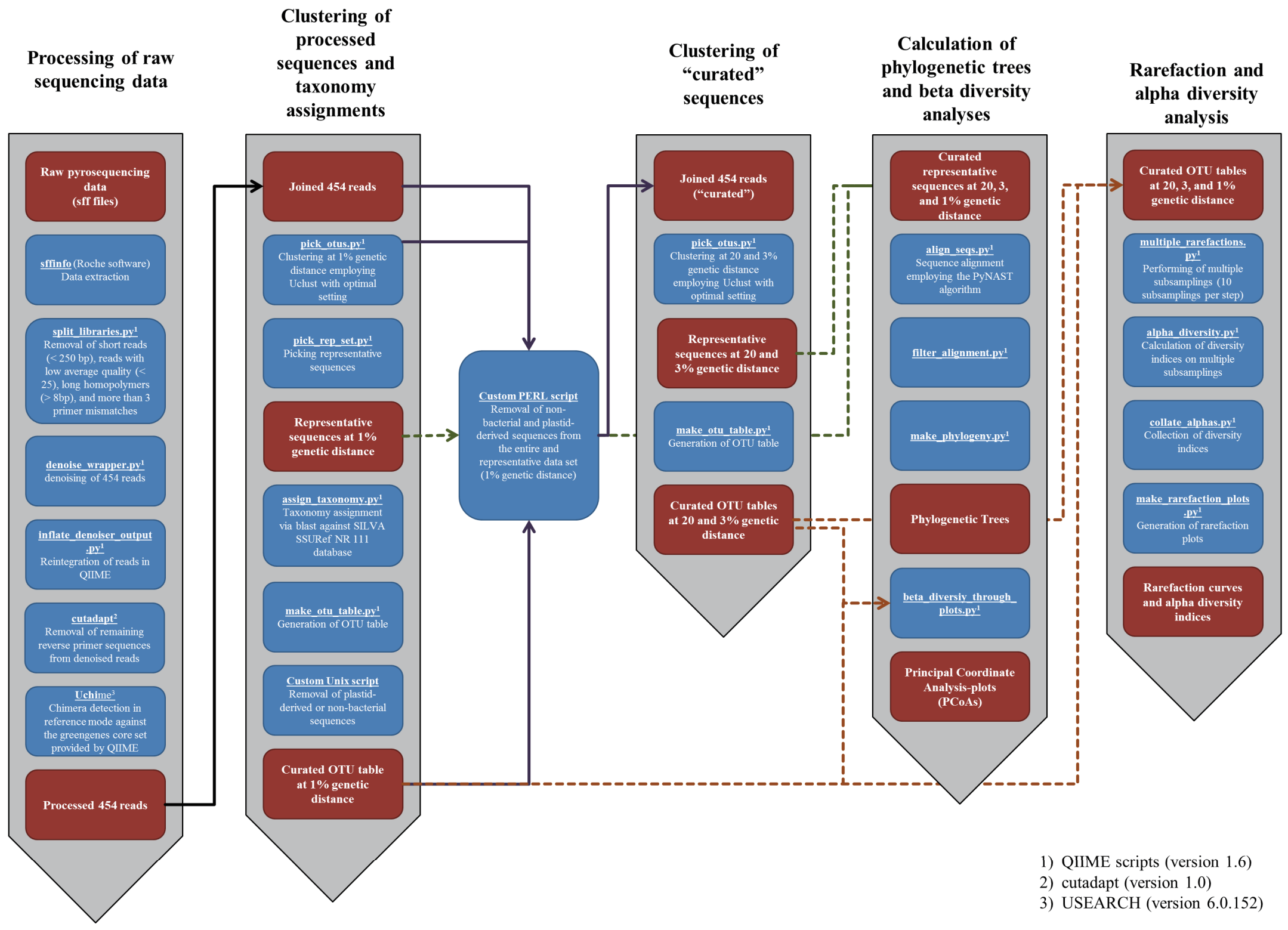


Fig. S1. Processing of amplicon-based 454 pyrosequencing reads with QIIME and other tools. After raw data extraction, reads shorter than $250 \mathrm{bp}$, with an average quality value below 25 , possessing long homopolymer stretches ( $>8 \mathrm{bp}$ ), or primer mismatches ( $>3)$ were removed. Subsequently, sequences were denoised employing QIIME (Caporaso et al.. 2010). Remaining primer sequences were truncated employing cutadapt (Martin. 2011). Chimeric sequences were removed using UCHIME and the most recent Greengenes core set as reference dataset (DeSantis et al.. 2006. Edgar et al.. 2011). Processed sequences of all samples were joined, sorted by decreasing length, and clustered employing the UCLUST algorithm (Edgar 2010). Sequences were clustered in operational taxonomic units (OTUs) at $1 \%, 3 \%$ and $20 \%$ genetic dissimilarity according to Simon et al. (2009). OTUs at 3 and 20\% sequence divergence represent species and phylum level, respectively (Schloss \& Handelsman. 2005). Phylogenetic composition was determined using the QIIME assign taxonmy.py script. A BLAST alignment against the Silva SSURef 111 NR database (Pruesse et al. 2007) was thereby performed. Sequences were classified with respect to the silva taxonomy of their best hit. Rarefaction curves, Shannon indices (Shannon, 2001) and Chaol indices (Chao \& Bunge. 2002) were calculated. In addition, the maximal number of OTUs $\left(\mathrm{n}_{\max }\right)$ was estimated for each sample using the Michaelis-Menten-fit alpha diversity metrics included in the QIIME software package. To compare bacterial community structures across all samples based on phylogenetic or count-based distance metrics, Principal Coordinate Analysis (PCoA) plots were generated. A phylogenetic tree was calculated prior to PCoA generation. For this purpose, sequences were aligned using the PyNAST algorithm. The phylogenetic tree and the corresponding OTU table were subsequently used to generate PCoA plots.

\section{References}

Caporaso JG, Kuczynski J, Stombaugh J, et al. (2010) QIIME allows analysis of high-throughput community sequencing data. Nat methods 7: $335-336$.

Chao A \& Bunge J (2002) Estimating the number of species in a stochastic abundance model. Biometrics 58: 531-539.

DeSantis TZ, Hugenholtz P, Larsen N, Rojas M, Brodie EL, Keller K, Huber T, Dalevi D, Hu P \& Andersen GL (2006) Greengenes. a chimerachecked 16S rRNA gene database and workbench compatible with ARB. Appl Environ Microbiol 72: 5069-5072.

Edgar RC, Haas BJ, Clemente JC, Quince C \& Knight R (2011) UCHIME improves sensitivity and speed of chimera detection. Bioinformatics 27: 2194-2200.

Martin M (2011) Cutadapt removes adapter sequences from high-throughput sequencing reads. EMBnet.journal 17: 10-12.

Pruesse E, Quast C, Knittel K, Fuchs BM, Ludwig W, Peplies J \& Glockner FO (2007) SILVA: a comprehensive online resource for quality checked and aligned ribosomal RNA sequence data compatible with ARB. Nucleic Acids Res 35: 7188-7196.

Schloss PD \& Handelsman J (2005) Introducing DOTUR. a computer program for defining operational taxonomic units and estimating species richness. Appl Environ Microbiol 71: 1501-1506.

Shannon CE (2001) A mathematical theory of communication. SIGMOBILE Mob Comput Commun Rev 5: 3-55.

Simon C, Wiezer A, Strittmatter AW \& Daniel R (2009) Phylogenetic diversity and metabolic potential revealed in a glacier ice metagenome. Appl Environ Microbiol 75: 7519-7526. 

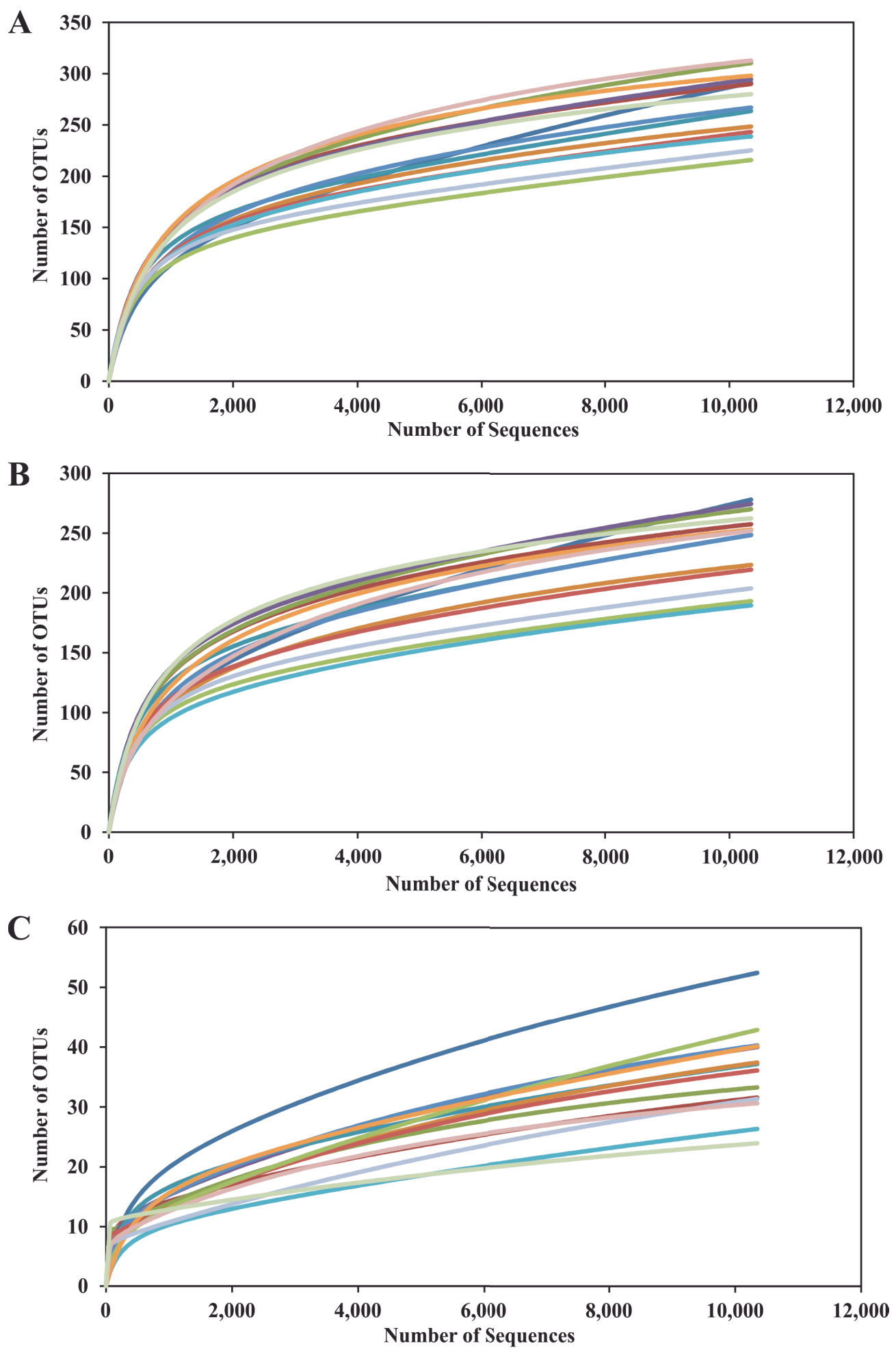

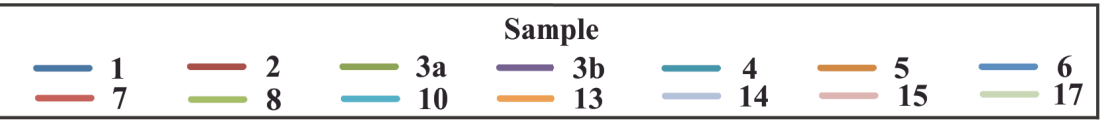

Fig. S2. Rarefaction curves for all 14 samples at 1 (A), 3 (B), and 20\% (C) genetic divergence. Rarefaction analysis was performed with QIIME (Caporaso et al.. 2010).

\section{References}

Caporaso JG, Kuczynski J, Stombaugh J, et al. (2010) QIIME allows analysis of high-throughput community sequencing data. Nat Methods 7: 335-336. 


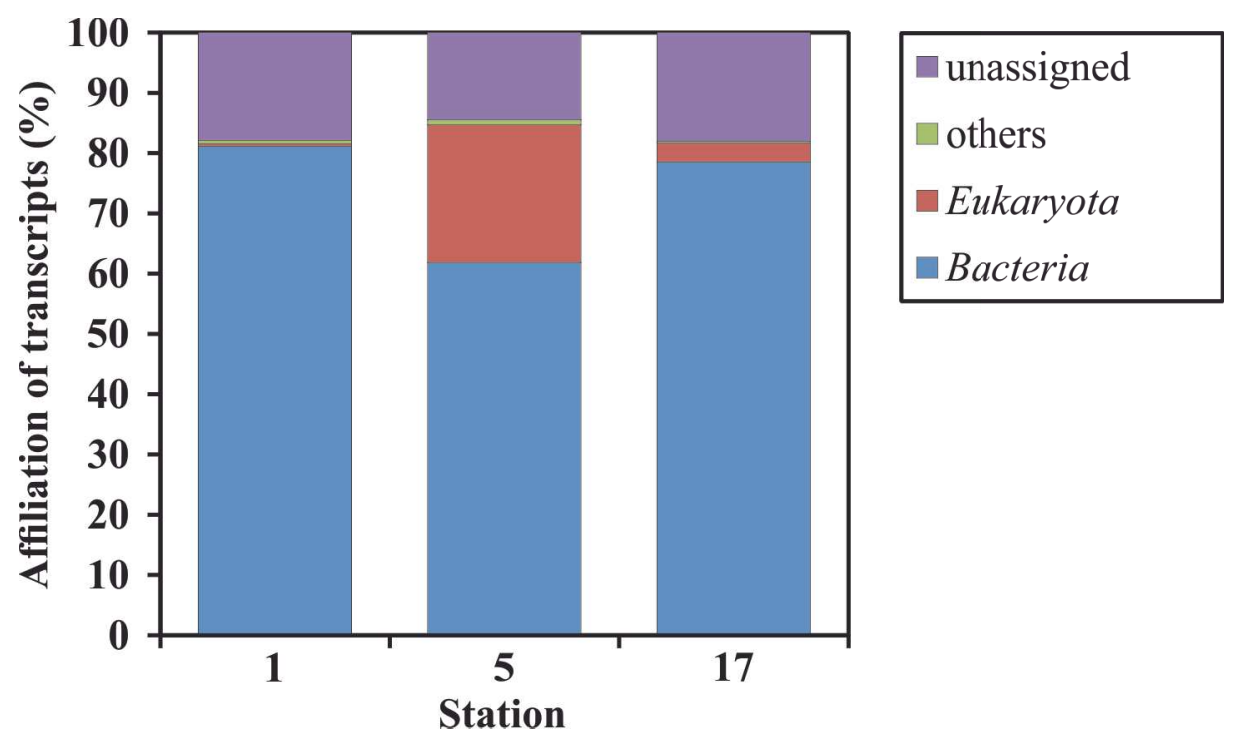

Fig. S3. MG-RAST-based taxonomic assignment of mRNA reads derived from stations 1, 5 and 17. The bioinformatic tools used were all part of MG-RAST (Meyer et al., 2008). Sample from station 5 was taken in the center of a phytoplankton bloom with the highest chlorophyll $a$ concentration measured during the survey $\left(11.45 \mu \mathrm{g} \mathrm{L}^{-1}\right)$. Stations 1 and 17 were taken outside the examined bloom and exhibited chlorophyll $a$ concentrations $<4.4 \mu \mathrm{g} \mathrm{L}^{-1}$.

\section{Reference}

Meyer F, Paarmann D, D'Souza M, et al. (2008) The metagenomics RAST server - a public resource for the automatic phylogenetic and functional analysis of metagenomes. $B M C$ Bioinformatics 9: 386. 


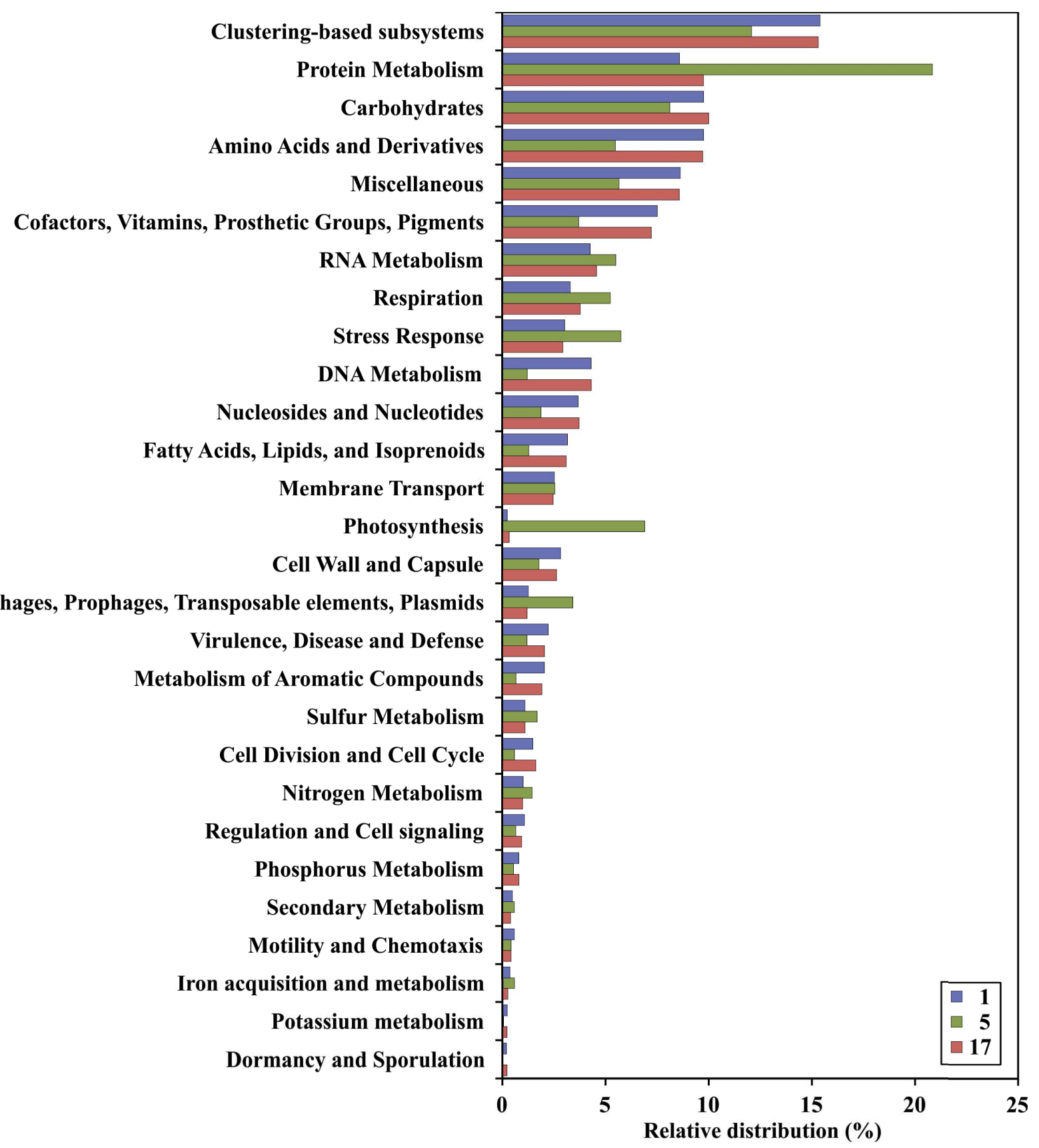

Fig. S4. MG-RAST-based hierarchical protein annotation using subsystems as annotation source. The bioinformatic tools used were all part of MG-RAST (Meyer et al., 2008). The sample from station 5 (green) was taken in the center of a phytoplankton bloom with the maximum chlorophyll $a$ concentration of all samples analyzed in this survey $\left(11.45 \mu \mathrm{g} \mathrm{L}^{-1}\right)$. The samples from stations 1 and 17 exhibited chlorophyll $a$ concentrations $<4.4 \mu \mathrm{g} \mathrm{L}^{-1}$ and were taken outside the examined bloom.

\section{Reference}

Meyer F, Paarmann D, D'Souza M, et al. (2008) The metagenomics RAST server - a public resource for the automatic phylogenetic and functional analysis of metagenomes. $B M C$ Bioinformatics 9: 386. 
Table S1. Sampling time and position as well as CTD measured parameters of the sampling sites. Significant differences between bloom and non-bloom samples are shown in bold type. The significance was tested either with the Student's two-sample t-test (homogenous variances) or with the Welsh Two Sample t-test (heterogeneous variances) for normally distributed samples and with the Wilcoxon-Mann-Whitney test for not-normally distributed samples. Sample 1 was excluded from statistical testing as it was taken in a bloom different to the examined phytoplankton bloom.

\begin{tabular}{|c|c|c|c|c|c|c|c|c|c|c|c|}
\hline Sample & $\begin{array}{l}\text { Ship } \\
\text { station }\end{array}$ & Date & $\begin{array}{l}\text { Latitude } \\
\left({ }^{\circ} \mathrm{N}\right)\end{array}$ & $\begin{array}{l}\text { Longitude } \\
\left({ }^{\circ} \mathrm{E}\right)\end{array}$ & $\begin{array}{l}\text { Depth } \\
\text { (m) }\end{array}$ & $\begin{array}{c}\text { Bottom } \\
\text { Depth (m) }\end{array}$ & $\begin{array}{c}\text { Temperature } \\
\left({ }^{\circ} \mathrm{C}\right)\end{array}$ & $\begin{array}{l}\text { Salinity } \\
\text { (psu) }\end{array}$ & $\begin{array}{c}\text { Fluorescence } \\
(\mathrm{FU})\end{array}$ & $\begin{array}{c}\text { Transmission } \\
(\%)\end{array}$ & $\begin{array}{c}\text { Density } \\
(\mathrm{g} / \mathrm{L})\end{array}$ \\
\hline 1 & 655 & $05 / 25 / 2010$ & 53.8955 & 8.0496 & 2 & 15.5 & 11.09 & 30.24 & 1.21 & 57.20 & 1023.10 \\
\hline \multicolumn{12}{|c|}{ Non-bloom } \\
\hline 2 & 656 & $05 / 25 / 2010$ & 54.0813 & 7.9338 & 12 & 34.5 & 9.96 & 30.81 & 0.27 & 84.74 & 1023.77 \\
\hline $3 a$ & 657 & $05 / 26 / 2010$ & 54.4223 & 7.6833 & 2 & 22.1 & 9.43 & 31.42 & 0.20 & 87.98 & 1024.27 \\
\hline $3 b$ & 657 & $05 / 26 / 2010$ & 54.4223 & 7.6833 & 12 & 22.1 & 8.18 & 32.01 & 0.77 & 84.83 & 1024.93 \\
\hline 4 & 658 & $05 / 26 / 2010$ & 54.7626 & 7.4463 & 2 & 20 & 9.73 & 32.71 & 0.49 & 81.23 & 1025.20 \\
\hline 17 & 673 & $05 / 30 / 2010$ & 54.4202 & 7.6922 & 2 & 22 & 10.75 & 31.6 & $\mathrm{NA}(*)$ & 87.74 & 1024.20 \\
\hline Mean & - & - & - & - & - & - & 9.61 & 31.71 & 0.43 & 85.30 & 1024.47 \\
\hline SD & - & - & - & - & - & - & 0.94 & 0.71 & 0.26 & 2.75 & 0.58 \\
\hline $\mathrm{CV}$ & - & - & - & - & - & - & 0.10 & 0.02 & 0.59 & 0.03 & 0.00 \\
\hline \multicolumn{12}{|l|}{ Bloom } \\
\hline 5 & 659 & $05 / 26 / 2010$ & 54.4575 & 7.9893 & 9 & 12.5 & 10.80 & 30.64 & 2.76 & 60.14 & 1023.50 \\
\hline 6 & 660 & $05 / 27 / 2010$ & 54.4542 & 8.0018 & 2 & 12.5 & 10.83 & 30.65 & 1.89 & 72.78 & 1023.40 \\
\hline 7 & 661 & $05 / 27 / 2010$ & 54.3054 & 8.2807 & 10 & 13.5 & 11.37 & 30.68 & 2.19 & 66.10 & 1023.40 \\
\hline 8 & 663 & $05 / 27 / 2010$ & 54.5065 & 8.1645 & 2 & 12 & 11.31 & 31.05 & 2.39 & 73.92 & 1023.67 \\
\hline 10 & 665 & $05 / 28 / 2010$ & 54.5135 & 8.128 & 2 & 11 & 11.40 & 31.11 & 2.27 & 74.79 & 1023.70 \\
\hline 13 & 668 & $05 / 29 / 2010$ & 54.4365 & 8.2328 & 10 & 12 & 11.83 & 31.18 & 2.80 & 67.83 & 1023.70 \\
\hline 14 & 670 & 05/29/2010 & 54.4595 & 8.2328 & 2 & 11 & 11.43 & 30.83 & $\mathrm{NA}(*)$ & 75.72 & 1023.50 \\
\hline 15 & 671 & $05 / 30 / 2010$ & 54.449 & 8.22 & 2 & 12 & 11.70 & 31.04 & $\mathrm{NA}(*)$ & 76.59 & 1023.60 \\
\hline Mean & - & - & - & - & - & - & 11.33 & 30.90 & 2.38 & 70.98 & 1023.56 \\
\hline SD & - & - & - & - & - & - & 0.37 & 0.22 & 0.35 & 5.75 & 0.13 \\
\hline $\mathrm{CV}$ & - & - & - & - & - & - & 0.03 & 0.01 & 0.15 & 0.08 & 0.00 \\
\hline
\end{tabular}

(*) not measured. 
Table S2. Environmental parameters determined for the samples. Significant differences between bloom and non-bloom samples are shown in bold type. The significance was tested either with the Student's two-sample t-test (homogenous variances) or with the Welsh Two Sample t-test (heterogeneous variances) for normally distributed samples and with the Wilcoxon-Mann-Whitney test for not-normally distributed samples. Sample 1 was excluded from statistical testing as it was taken in a bloom different to the examined phytoplankton bloom.

\begin{tabular}{|c|c|c|c|c|c|c|c|c|c|c|c|}
\hline Station & $\begin{array}{c}\text { Chlorophyll a } \\
\left(\mu \mathrm{g} \mathrm{L}^{-1}\right)\end{array}$ & $\begin{array}{l}\text { Phaeo- } \\
\text { pigments } \\
\left(\mu \mathrm{g} \mathrm{L}^{-1}\right)\end{array}$ & $\begin{array}{c}\text { Phaeo- } \\
\text { pigments } \\
(\% \text { total } \mathrm{Chl})\end{array}$ & $\begin{array}{l}\text { Bacterial } \\
\text { abundance } \\
\left(10^{6} \mathrm{~mL}^{-1}\right)\end{array}$ & $\begin{array}{c}\text { Suspended } \\
\text { particulate } \\
\text { matter } \\
\left(\mathrm{mg} \mathrm{L}^{-1}\right)\end{array}$ & $\begin{array}{c}\text { Particulate } \\
\text { organic } \\
\text { carbon } \\
\left(\mu \mathrm{g} \mathrm{L}^{-1}\right)\end{array}$ & $\begin{array}{c}\text { Particulate } \\
\text { organic } \\
\text { nitrogen } \\
\left(\mu \mathrm{g} \mathrm{L}^{-1}\right)\end{array}$ & $\begin{array}{l}\text { Nitrate } \\
(\mu \mathrm{M})\end{array}$ & $\begin{array}{l}\text { Nitrite } \\
(\mu \mathrm{M})\end{array}$ & $\begin{array}{c}\text { Mono- } \\
\text { nitrogen } \\
\text { oxides } \\
(\mu \mathrm{M})\end{array}$ & $\begin{array}{l}\text { Phosphate } \\
(\mu \mathrm{M})\end{array}$ \\
\hline 1 & 4.38 & 2.11 & 32.5 & 4.00 & 9.80 & 997.4 & 152.1 & 8.5 & 0.19 & 8.65 & \\
\hline \multicolumn{12}{|c|}{ Non-bloom } \\
\hline 2 & 1.01 & 0.37 & 26.8 & 1.96 & 8.73 & 282.4 & 42.0 & 9.8 & 0.28 & 10.07 & 0.050 \\
\hline $3 a$ & 1.12 & 0.25 & 18.3 & 2.57 & 4.60 & 291.2 & 43.0 & 7.4 & 0.25 & 7.65 & 0.020 \\
\hline $3 b$ & 3.37 & 1.08 & 24.3 & 2.54 & 7.15 & 496.4 & 82.2 & 5.9 & 0.27 & 6.17 & 0.040 \\
\hline 4 & 2.55 & 0.37 & 12.7 & $0.83(*)$ & 6.15 & 290.4 & 46.9 & 6.2 & 0.24 & 6.41 & 0.030 \\
\hline 17 & 1.07 & 0.18 & 14.4 & 2.22 & 2.35 & 332.2 & 49.4 & 7.6 & 0.19 & 7.76 & 0.040 \\
\hline Mean & 1.82 & 0.45 & 19.30 & 2.02 & 5.80 & 338.52 & 52.70 & 7.36 & 0.25 & 7.61 & 0.036 \\
\hline SD & 1.08 & 0.36 & 6.12 & 0.71 & 2.44 & 90.37 & 16.76 & 1.54 & 0.04 & 1.55 & 0.011 \\
\hline $\mathrm{CV}$ & 0.59 & 0.80 & 0.32 & 0.35 & 0.42 & 0.27 & 0.32 & 0.21 & 0.14 & 0.20 & 0.317 \\
\hline \multicolumn{12}{|l|}{ Bloom } \\
\hline 5 & 11.45 & 7.03 & 38.0 & 1.84 & 3.27 & 1673.0 & 213.6 & 5.0 & 0.24 & 5.27 & 0.100 \\
\hline 6 & 7.34 & 2.77 & 27.4 & 2.00 & 11.30 & 728.2 & 106.2 & 9.1 & 0.42 & 9.53 & 0.080 \\
\hline 7 & 7.28 & 2.91 & 28.6 & 1.82 & 7.50 & 1079.9 & 133.8 & 2.7 & 0.30 & 3 & 0.060 \\
\hline 8 & 6.81 & 2.18 & 24.3 & 1.12 & 10.40 & 958.0 & 174.1 & 3.6 & 0.29 & 3.86 & 0.060 \\
\hline 10 & 6.93 & 2.10 & 23.3 & 1.21 & 7.50 & 737.5 & 95.3 & 3.7 & 0.29 & 3.98 & 0.070 \\
\hline 13 & 5.53 & 3.16 & 36.4 & 1.66 & 9.91 & 936.5 & 123.5 & 2.1 & 0.21 & 2.29 & 0.100 \\
\hline 14 & 4.44 & 1.43 & 24.4 & 2.00 & 9.05 & 638.4 & 80.1 & 3.2 & 0.21 & 3.37 & 0.070 \\
\hline 15 & 5.33 & 1.58 & 22.9 & 1.37 & 6.25 & 624.4 & 83.9 & 3.0 & 0.30 & 3.27 & 0.080 \\
\hline Mean & 6.89 & 2.90 & 28.16 & 1.66 & 8.15 & 921.99 & 126.31 & 4.04 & 0.28 & 4.32 & 0.078 \\
\hline SD & 2.12 & 1.78 & 5.93 & 0.36 & 2.60 & 344.56 & 46.70 & 2.22 & 0.07 & 2.28 & 0.016 \\
\hline $\mathrm{CV}$ & 0.31 & 0.62 & 0.21 & 0.22 & 0.32 & 0.37 & 0.37 & 0.55 & 0.24 & 0.53 & 0.204 \\
\hline
\end{tabular}

$(*)$ excluded as outlier. 
Table S3. Sequence statistics of the 16S rRNA datasets.

\begin{tabular}{|c|c|c|c|c|c|c|}
\hline \multirow[t]{2}{*}{ Sample } & \multicolumn{2}{|c|}{ Before preprocessing } & \multicolumn{2}{|c|}{ After preprocessing } & \multicolumn{2}{|c|}{$\begin{array}{l}\text { After denoising and removal of non- } \\
\text { bacterial or chimeric sequences }\end{array}$} \\
\hline & $\begin{array}{c}\text { No. of } \\
\text { sequences }\end{array}$ & $\begin{array}{l}\text { Average } \\
\text { length }\end{array}$ & $\begin{array}{c}\text { No. of } \\
\text { sequences }\end{array}$ & $\begin{array}{l}\text { Average } \\
\text { length }\end{array}$ & $\begin{array}{c}\text { No. of } \\
\text { sequences }\end{array}$ & $\begin{array}{l}\text { Average } \\
\text { length }\end{array}$ \\
\hline 1 & 23,400 & $355.2 \mathrm{bp}$ & 15,958 & $424.2 \mathrm{bp}$ & 12,202 & $398.8 \mathrm{bp}$ \\
\hline 2 & 34,759 & $342.6 \mathrm{bp}$ & 23,176 & $433.9 \mathrm{bp}$ & 17,866 & $404.3 \mathrm{bp}$ \\
\hline $3 a$ & 31,754 & $349.3 \mathrm{bp}$ & 21,727 & $434.4 \mathrm{bp}$ & 15,882 & $406.1 \mathrm{bp}$ \\
\hline $3 b$ & 24,831 & $364.2 \mathrm{bp}$ & 18,074 & $434.3 \mathrm{bp}$ & 13,189 & $406.8 \mathrm{bp}$ \\
\hline 4 & 25,020 & $358.2 \mathrm{bp}$ & 16,908 & $431.8 \mathrm{bp}$ & 11,529 & $408.7 \mathrm{bp}$ \\
\hline 5 & 23,768 & $359.5 \mathrm{bp}$ & 16,330 & $432.0 \mathrm{bp}$ & 12,963 & $407.8 \mathrm{bp}$ \\
\hline 6 & 21,200 & $360.3 \mathrm{bp}$ & 14,584 & $432.3 \mathrm{bp}$ & 10,710 & $409.1 \mathrm{bp}$ \\
\hline 7 & 20,507 & $358.9 \mathrm{bp}$ & 14,495 & $436.2 \mathrm{bp}$ & 11,827 & $408.4 \mathrm{bp}$ \\
\hline 8 & 17,318 & $361.3 \mathrm{bp}$ & 12,368 & $437.5 \mathrm{bp}$ & 10,354 & $408.2 \mathrm{bp}$ \\
\hline 10 & 26,104 & $356.7 \mathrm{bp}$ & 15,865 & $439.4 \mathrm{bp}$ & 13,075 & $408.9 \mathrm{bp}$ \\
\hline 13 & 43,113 & $355.5 \mathrm{bp}$ & 28,777 & $439.5 \mathrm{bp}$ & 21,798 & $413.4 \mathrm{bp}$ \\
\hline 14 & 21,040 & $368.0 \mathrm{bp}$ & 14,618 & $433.6 \mathrm{bp}$ & 10,633 & 406.9 bp \\
\hline 15 & 80,326 & $349.8 \mathrm{bp}$ & 54,407 & $437.0 \mathrm{bp}$ & 32,574 & $406.3 \mathrm{bp}$ \\
\hline 17 & 34,917 & $373.3 \mathrm{bp}$ & 25,973 & $435.0 \mathrm{bp}$ & 17,167 & $404.7 \mathrm{bp}$ \\
\hline Sum & 428,057 & $357 \mathrm{bp}$ & 293,260 & $435 \mathrm{bp}$ & 211,769 & $407 \mathrm{bp}$ \\
\hline
\end{tabular}


Table S4. Statistics of the mRNA analysis according to MG-RAST (Meyer et al.. 2008).

\begin{tabular}{lccccc}
\hline Sample & $\begin{array}{c}\text { Number of } \\
\text { sequences }\end{array}$ & $\begin{array}{c}\text { Total number of } \\
\text { basepairs }\end{array}$ & $\begin{array}{c}\text { Average read } \\
\text { length (bp) }\end{array}$ & $\begin{array}{c}\text { Number of ribosomal } \\
\text { RNAs }\end{array}$ & $\begin{array}{c}\text { Number of bacterial hits in the } \\
\text { M5NR database used for } \\
\text { taxonomic classification }\end{array}$ \\
\hline 1 & 478,024 & $173,971,335$ & 363 & $27,926(5.8 \%)$ & 359,387 \\
5 & 389,593 & $139,023,923$ & 357 & $299,333(76.8 \%)$ & 46,238 \\
17 & 120,585 & $39,448,347$ & 327 & $8,884(7.4 \%)$ & 62,389 \\
\hline
\end{tabular}

\section{Reference}

Meyer F, Paarmann D, D'Souza M, et al. (2008) The metagenomics RAST server - a public resource for the automatic phylogenetic and functional analysis of metagenomes. BMC Bioinformatics 9: 386. 


\title{
STUDY 3:
}

\section{FROM GERMANY TO NORWAY: SIMULTANEOUS ASSESSMENT OF TOTAL AND ACTIVE BACTERIAL COMMUNITY STRUCTURES IN THE NORTH SEA ALONG A LATITUDINAL GRADIENT}

\author{
Wemheuer B ${ }^{1}$, Meier $\mathrm{D}^{1,4}$, BILlerbeck $\mathrm{S}^{2}$, Giebel HA ${ }^{2}$, \\ SCHERBER $\mathrm{C}^{3}$, SIMON $\mathrm{M}^{2}$, AND DANIEL $\mathrm{R}^{1}$
}

(IN PREPARATION)

${ }^{1}$ Institute of Microbiology And Genetics, GeORG-August-University GÖTtINGEN, GRISEBACHSTR. 8, D-37077 GÖtTINGEN, GERMANY; ${ }^{2}$ InSTITUTE FOR Chemistry AND Biology OF THE MARINE ENVIRONMENT (ICBM), CARL-VONOSSIETZKY-UNIVERSITY OF OLDENBURG, CARL-VON-OSSIETZKY-STR. 9-11, D26111 OldENBURG, GERMANY; ${ }^{3}$ DEPARTMENT FOR CROP SCIENCES, GEORGAugust-University GötTINGEN, GRISEBACHSTR. 6, D-37077 GÖTTINGEN, GERMANY; ${ }^{4}$ PrESENT ADDRESS: MAX PlanCK INSTITUTE FOR MARINE Microbiology, Celsiusstrasse 1, D-28359 Bremen, Germany

\footnotetext{
Author contributions to the work:

Performed the experiments: BW, DM

Analyzed data: BW, DM, CS

Contributed data on water properties and analysis of these data: SB, HAG, MS

Wrote the publication: BW, RD

Conceived and designed the experiments: BW, RD
} 


\section{ABSTRACT}

Marine bacterioplankton communities play major roles in many ecological important pathways and nutrient cycles. However, the contribution of many marine groups to ecosystem functioning is largely unexplored. Little is known about the active community members, as most studies were mainly focused on structure of total bacterial communities. In this survey, we assessed total and active bacterial community structures in North Sea water samples along a latitudinal gradient from Germany to Norway by pyrosequencing-based analysis of $16 \mathrm{~S}$ rRNA amplicons generated from environmental DNA and RNA, respectively. The generated $16 \mathrm{~S}$ rRNA gene datasets comprised 382,507 sequences across all 13 samples with an average read length of 519 bp. Proteobacteria and Bacteroidetes were identified as the most abundant phylogenetic groups across all samples. Cyanobacteria and Verrucomicrobia were found in minor abundances. Sequences were mainly affiliated to different flavobacterial groups and genera such as the marine groups NS5 and NS7, different clusters of the Roseobacter clade such as CHAB-I-5 and NAC117, the SAR116 clade, and the genus Synechococcus. Although the bacterial richness remained almost constant along the gradient, the abundance of several of these bacterial groups was significantly affected by latitudinal change. A comparison of both DNA-based and RNA-based approach revealed significant differences between total and active bacterial community structures. The number of phylotypes at 1,3, and $20 \%$ genetic distance was significantly higher on RNA level than on DNA level. Thus, the diversity of active members in marine bacterioplankton communities appears to be underestimated by previous DNA-based studies.

\section{IMPORTANCE}

The ecological importance of marine microbial communities is generally accepted, as they are major components of global nutrient cycles. Understanding the factors controlling their distribution and versatile ways of nutrient transformations is a major challenge in marine microbiology. Moreover, the ecological role of single marine groups or lineages is still largely unexplored, as the majority of field studies targeted the total community (active and inactive) but not in particular the active community members. This study provides a yet unique insight into compositional variations of marine bacterial communities along a latitudinal gradient as total and active bacterial community structures were simultaneously assessed. The bacterial diversity of the active community was higher compared to the total community. Consequently, the number of active members contributing to ecosystem functioning might have been underestimated by previous DNA-based studies.

\section{INTRODUCTION}

Oceans cover more than $70 \%$ of the world's surface. According to the National Oceanic and Atmospheric Administration (http://www.noaa.gov/ocean.html), they harbor an enormous biodiversity and support the life of nearly 50 percent of all species on Earth. Recent estimates revealed that up to $10^{6}$ different microorganisms inhabit $1 \mathrm{ml}$ of oceanic seawater (1). These archaea, bacteria, protists, and unicellular fungi contribute $98 \%$ to the primary biomass production. Moreover, marine plankton is a major component of global nutrient cycles $(2,3)$. Culture-independent approaches have greatly advanced our understanding of the diversity of marine microbial communities (4). Early studies used traditional techniques such as Sanger sequencing-based analysis of $16 \mathrm{~S}$ rRNA gene libraries to assess bacterial community structures $(5,6)$. In this way, due to the richness and size of marine microbial communities, only a small fraction of the diversity was unraveled. The application of next-generation sequencing revolutionized this field of research. Novel sequencing techniques have been applied for in-depth investigation of bacterial communities in diverse ecosystems such as soil $(7,8)$ or seawater $(9,10)$. However, metagenomic approaches fail to distinguish between total and active bacterial communities as environmental DNA is used as starting material. Thus, the vast majority of investigations targeting marine microbial communities did not focus on the active members (but see 11, 12), which can be investigated, i.e., by analysis of 16S rRNA transcripts (e.g., 11, 13).

A recent study investigated community patterns of marine planktonic bacteria worldwide by amplified ribosomal intergenic spacer analysis (ARISA) (14). Geographic patterns similar to those of higher organisms were recorded. The authors concluded that the kinetics of metabolisms strongly influenced bacterial diversity and global distribution (14). Other studies focused on assessing bacterial communities structures along latitudinal gradients. Two recent studies analyzing bacterial community 
structures along such gradients found high numbers of Proteobacteria in coastal bacterioplankton communities in Latin America (15) and the SAR11 clade and the genus Prochlorococcus as dominant phylogenetic groups in oceanic surface waters from South Africa to the English Channel (16).

Coastal shelf seas of the temperate zone are highly productive because of the continuous nutrient supply by rivers. The North Sea, a typical costal shelf sea, is connected to the Atlantic Ocean via the English Channel in the South and the Norwegian Sea in the North. The water depth of the southern part is less than $50 \mathrm{~m}$ and is subjected to strong tidal currents. Nutrient suspension from the sediment and loss of water stratification are results of tides. This region underwent high nutrient loading and warming during the last 40 years (17, 18). The northern part of the North Sea is deeper (up to $725 \mathrm{~m}$ ) and strong tidal currents are not occurring. Studies concerning the bacterioplankton community in the North Sea showed that distinct lineages of Alphaproteobacteria and Gammaproteobacteria as well as Flavobacteria constitute the major parts of these communities (12, 19-21).

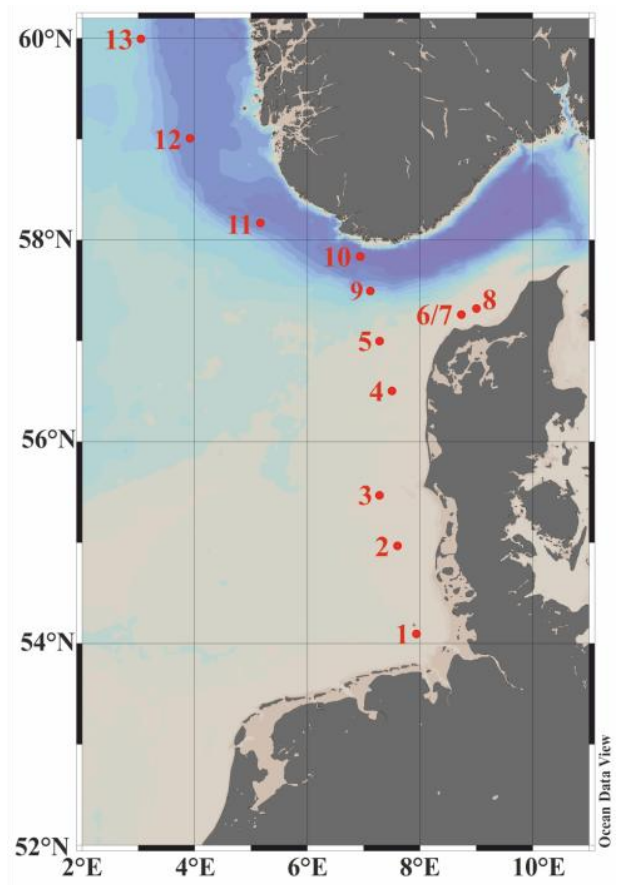

FIG 1 Map of the North Sea showing the positions of all 13 samplings sites. The map was generated using the Ocean Data View software package (version 4.5.2, Alfred Wegener Institute, Bremerhaven, Germany, [http://odv.awi.de/]).
In this study, we simultaneously investigated entire and active bacterioplankton community structures in the North Sea along a latitudinal gradient from Germany to Norway. Community structures were assessed by large-scale pyrosequencing-based analysis of the V3-V5 region of the $16 \mathrm{~S}$ rRNA amplified by gene-specific PCR or RT-PCR using environmental DNA and RNA as template, respectively. We hypothesized that total and active bacterial communities undergo significant structural changes along the studied gradient. We further hypothesized that community structures of the total bacterial community assessed by DNA-based analysis differ from those of the active bacterial community assessed by RNA-based analysis. To our knowledge, this is the first investigation using both 16S rRNA and 16S rRNA gene analysis combined with large-scale next-generation sequencing to study total and active bacterioplankton community structures simultaneously.

\section{RESULTS AND DISCUSSION}

\section{Sampling and sampling site characteristics}

In this survey, we examined the bacterial community composition of thirteen marine water samples derived from the North Sea. All analyzed samples were taken at $3 \mathrm{~m}$ or $4 \mathrm{~m}$ depth within 6 days (see Table S1 in the supplemental material). Samples were taken on a latitudinal gradient from Germany to Norway. Five samples (1, 2, 3, 4, and 5) were taken near the German and Danish coast, three samples $(6,7$, and 8) in the Skagerrak, and 5 samples $(9,10,11,12$, and 13) in the Norwegian trench (Fig. 1). Temperature and salinity ranged from $14.5^{\circ} \mathrm{C}$ to $18.3^{\circ} \mathrm{C}$ and from 29.8 psu to 33.4 psu, respectively. Fluorescence varied from 0.36 to $1.54 \mathrm{mg} / \mathrm{m}^{3}$ and oxygen content from 5.3 to 6.1 $\mathrm{mL} / \mathrm{L}$ (see Table $\mathrm{S} 1$ in the supplemental material). As samples were taken along a North-South gradient, we tested for correlations between latitude and other measured environmental parameters. Temperature, bacterial cell counts, biomass production (BP), as well as turnover of glucose and dissolved free amino acids were significantly correlated to the latitudinal change and decreased with rising latitude (see Table $\mathrm{S} 2$ in the supplemental material). In addition, dissolved organic carbon (DOC) and total nitrogen (TN) content decreased in northern samples (Osterholz $\mathrm{H}$ and Dittmar T, \{personal communication\}). 
To assess total and active bacterioplankton community structures, DNA-based and RNA-based analysis, respectively, of 16S rRNA sequences were performed. For this purpose, DNA and RNA were extracted from the samples. The isolated DNA and the cDNA generated from the RNA served as templates for the amplification of the V3 to V5 region of $16 \mathrm{~S}$ rRNA gene region. Amplification of the V3-V5 region is commonly used for DGGE analysis of marine bacterial communities and allows a high coverage and taxonomic resolution of bacterial phylogenetic groups $(22,23)$. The high coverage was supported by analysis with TestPrime (24). After quality filtering, denoising, and removal of potential chimeras and non-bacterial sequences, 382,507 high-quality sequences with an average read length of 519 bp (DNA 155,919 sequences, RNA 226,588 sequences) were used to study total and active bacterial community compositions (see Table S3 in the supplemental material). The number of sequences per sample ranged from 4,762 to 20,981 (DNA-based) and 1,798 to 37,444 (RNAbased). We were able classify all sequences below phylum level.

Calculated rarefaction curves as well as diversity indices revealed that the majority of the bacterial community was covered by the surveying effort (see Table S4 and Fig. S1 in the supplemental material). On DNA level, more than $80 \%$ of all estimated OTUs were regained at 1, 3, and $20 \%$ genetic distance. On RNA level, almost $88 \%$ of all OTUs at $20 \%$ genetic distance and $67 \%$ of all OTUs at 1 and $3 \%$ genetic distance were recovered. Classification of the sequences revealed the presence of 18 and 22 bacterial phyla and candidate divisions on DNA and RNA level, respectively. Proteobacteria were predominant across all samples (DNA 50.03\%, RNA 54.83\%). Bacteroidetes (DNA 38.36\%, RNA 36.31\%) and Cyanobacteria (DNA 7.66\%, RNA 5.96\%) were the second and third most abundant bacterial phyla. Other abundant bacterial phyla, present in all samples, were Actinobacteria (DNA $1.60 \%$, RNA $0.19 \%$ ), Deferribacteres (DNA $0.49 \%$, RNA $0.10 \%$ ), and Verrucomicrobia (DNA $1.45 \%$, RNA $2.54 \%$ ).

Alphaproteobacteria were the most abundant bacterial class in all samples (DNA $44.02 \%$, RNA $50.10 \%$ ). Sequences were mainly assigned to the Rhodobacterales, in particular, to different clusters of the Roseobacter clade (Fig. 2), i.e., the CHAB.I5, the RCA (25), the NAC11-6, and the NAC11-7 clusters. These four clusters comprised almost $30 \%$ of the bacterial community (DNA $25.59 \%$, RNA
$27.54 \%$ ). The marine Roseobacter clade is the only marine lineage of which cultured representatives are closely related to environmental clones (26). Members of the Roseobacter clade play important roles in the global carbon and sulfur cycles, as they are capable of diverse metabolic traits such as aerobic anoxygenic photosynthesis or carbon monoxide oxidation. The high abundance of this clade in the North Sea is in accordance previous studies (27).

In a previous study, Giebel et al. investigated the abundances of the Roseobacter RCA cluster and the SAR11 clade by qPCR along a similar gradient in the North Sea employing specific primers for RCA and SAR11 (28). The RCA cluster accounted for approximately $4.4 \%$ of the total bacterial community, which corresponds to our results (DNA $3.69 \%$, RNA $5.58 \%$ ). The abundance of the SAR 11 clade was also analyzed and constituted approximately $20 \%$ of the total bacterial community. In another study from 2009 SAR11 abundances of up to $40 \%$ in the North Atlantic have been detected by CARD-FISH analysis (29). Surprisingly, we only found members of the SAR11 clade in low abundances $(<1 \%)$. This difference could be due to the different detection method employed or seasonal effects (30). Giebel et al. analyzed samples taken in late 2005 and early 2006, whereas our samples were taken in summer 2011. We also studied samples taken in the German Bight in May 2010 in which SAR11 was highly abundant in only one of 14 analyzed samples (data not shown). Thus, seasonal changes are most likely not the reason for this discrepancy. Primer evaluation of the V3-V5 primer set used in this study revealed that more than $93 \%$ of the SAR11 clade should be covered (SSURef 114, 95.8\%; SSURef114 NR, $93.8 \%$ ). This is even higher as the coverage calculated for the entire Bacteroidetes and the Proteobacteria (data not shown). Interestingly, evaluation of the SAR11 clade-specific primer used by Giebel et al. (28) revealed that only $31.1 \%$ (SSURef 114NR) and 19\% (SSURef 114) of the SAR11 clade were theoretically covered. 
A
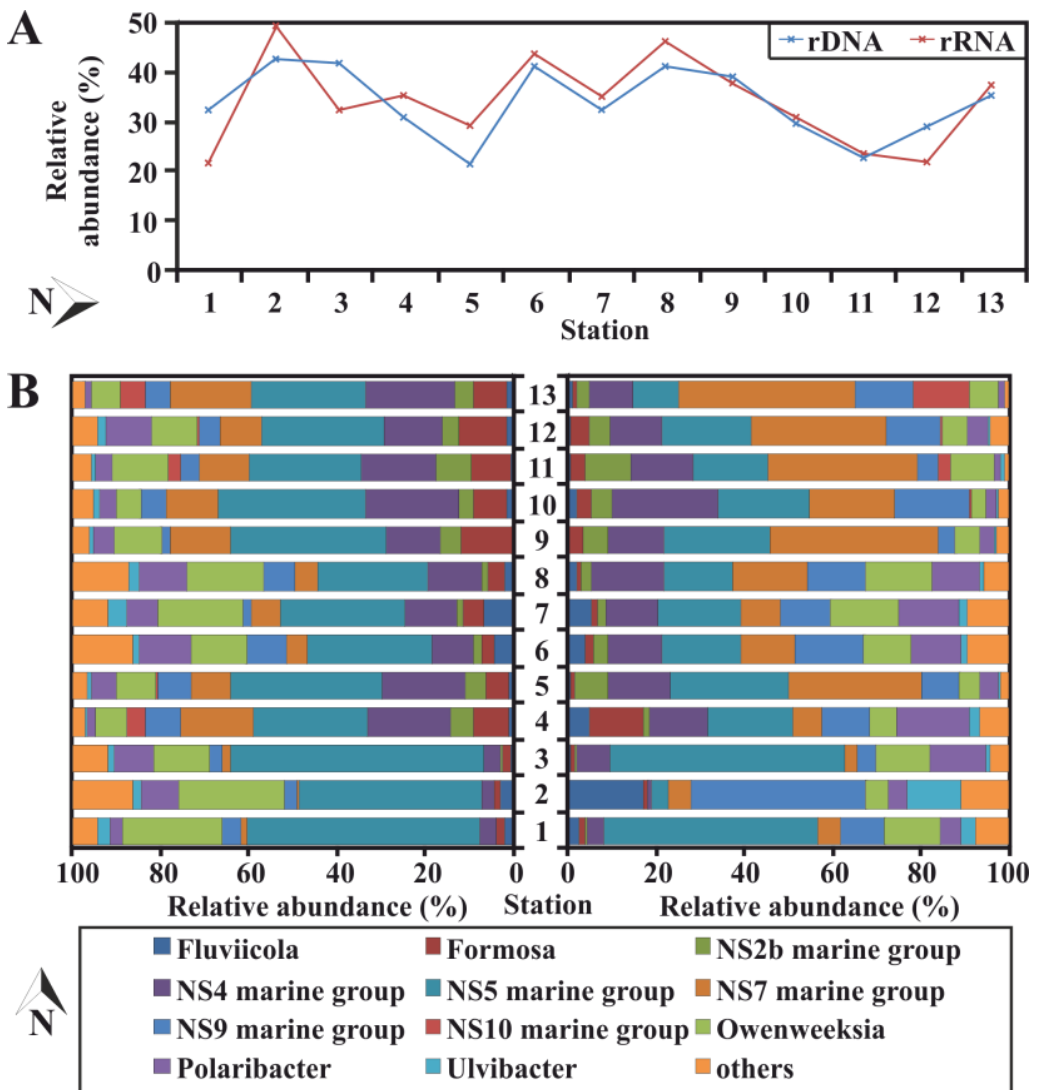

FIG 2 Relative abundance (A) and composition (B) of the Rhodobacterales along the latitudinal gradient. The Roseobacter NAC11-6 and NAC11-7 lineages were significantly correlated to latitude. The abundance of the Roseobacter clade affiliated (RCA) and CHAB-I-5 clusters were correlated to nucleic acid type (DNA/RNA). Significance was tested by Dirichlet regression in R.
Almost $10 \%$ of all sequences were affiliated to members of the Rickettsiales with the SAR116 clade as the most abundant marine group (DNA $7.02 \%$, RNA $11.81 \%$ ). This clade has been described as ubiquitous in marine environments (31). Members of SAR116 were found as a major fraction of the bacterioplankton in coastal regions as well as in the open ocean (32). Interestingly, the abundances of the clade were reported to be relatively low $(<5 \%)$ compared to those of SAR11 or Bacteroidetes in the Sargasso Sea (4). Only a few isolates of SAR116 exist with first genomes published in 2010 and $2011(33,34)$. Members of the SAR116 clade are proposed to be metabolic generalists in ocean nutrient cycling, as the genome sequences of the SAR116 member Candidatus Puniceispirillum marinum contains genes for proteorhodopsin, aerobic-type carbon monoxide dehydrogenase, dimethylsulfoniopropionate demethylase, and metabolism of $\mathrm{C} 1$ compounds (33). Another abundant bacterial group was the genus Synechococcus comprising the major fraction of the Cyanobacteria.

Sequences affiliated to the Bacteroidetes were mainly affiliated to different genera and marine groups within the Flavobacteriales (Fig. 3). Bacteroidetes are well known as one of the main groups of marine bacteria. Members are present in various habitats from the Southern Ocean (35) to the North Atlantic (36). Bacteroidetes are heterotrophs and important for the degradation of organic matter in the oceans. Their activity increases after algal blooms, as these organisms are able to effectively degrade algal remains (37). As genome sequences of isolates contain high numbers of genes involved in $\mathrm{CO}_{2}$ fixation (38), Bacteroidetes might play an important role in the global carbon cycle. However, a lack between diversity of Bacteroidetes assessed by culturedependent and independent approaches has been previously reported. All available isolates have not yet been found in studies using culture-independent approaches (39). In our study, less than $1 \%$ of all sequences were affiliated to known cultured members of the Bacteroidetes.

\section{Impact of the latitudinal gradient on bacterial community composition}

As samples for community analysis were taken along a latitudinal gradient from Germany to Norway, we further studied the composition of the bacterial communities along the gradient. We initially tested for correlations between calculated diversity indices and latitude. None of the calculated diversity indices was affected by latitudinal change.

As $16 \mathrm{~S}$ rRNA sequences were mainly affiliated to the two bacterial orders 

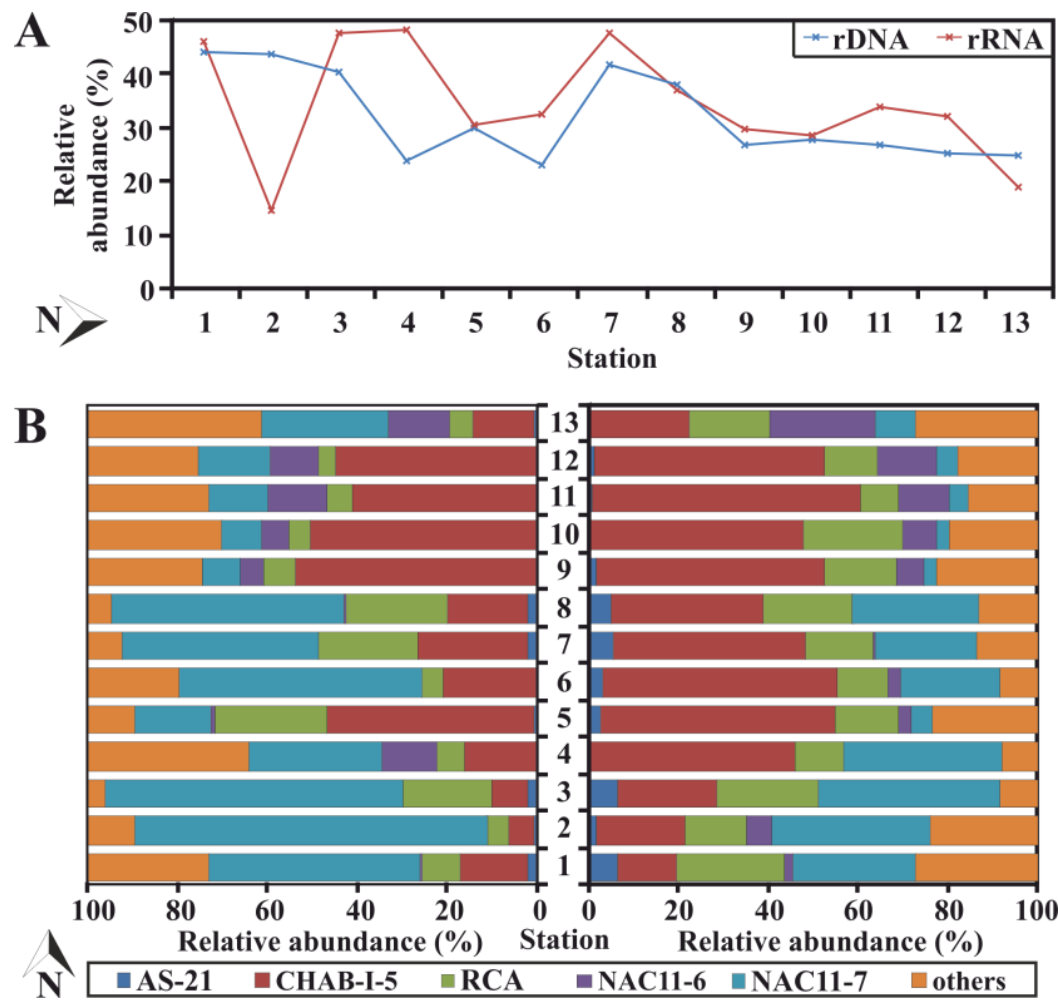

FIG 3 Relative abundance (A) and composition (B) of the Flavobacterales along the latitudinal gradient. Only the genera Fluviicola and Ulvibacter showed no correlation to latitude or nucleic acid type (DNA/RNA). The NS2b, NS7, NS9 and NS10 marine groups were correlated to latidutinal change, whereas the NS5 marine group and the genera Owenweeksia and Polaribacter were significantly affected by nucleic acid type. The genus Formosa and the NS4 marine group were significantly correlated to both parameters. Significance was tested by Dirichlet regression in R.
Flavobacteriales and Rhodobacterales, we further examined compositional changes of these groups along the latitudinal gradient (Figs. 2 and 3). Analysis of the composition of the Rhodobacterales revealed that the abundance of two of the five abundant groups was significantly correlated to latitude. The Roseobacter NAC11-7 cluster was more abundant in the southern samples whereas the abundance of the NAC11-6 cluster increased in northern samples. A similar result was recorded for the Flavobacteriales (Fig. 3). Six marine groups and genera, namely the genus Formosa, and the NS2b, NS4, NS7, NS9, and NS10 marine groups, were significantly correlated to latitudinal change.

In other studies, variations in community structures were correlated to alterations of environmental parameters. Schattenhofer et al. recorded changes in community structures with the latitude by studying a large South-North transect in the Atlantic (16). However, the surface water temperatures as well as other environmental factors drastically altered along the latitudinal gradient. The in our study recorded temperature decrease of approximately $1{ }^{\circ} \mathrm{C}$ from North to South might not explain the changes in bacterial community structures across the latitudinal gradient. As samples 6 to 13 were taken in the Skagerrak and Norwegian trench, the general circulation in the North Sea might explain latitudinal changes. Due to the topography of this area, a large inflow of Atlantic seawater occurs (40). The anti-clockwise circulation of the North
Sea causes most of the water in the North Sea to pass through this area. Moreover, all the water from the Baltic Sea passes this area as well. Therefore, recorded changes in bacterial community structures might be explained by regional differences as water masses differ between the southern and northern sampling sites. These different water masses have different nutrient availabilities, as indicated, for example, in the recorded decrease of DOC and TN with arising latitude (Osterholz $\mathrm{H}$ and Dittmar $\mathrm{T}$, \{personal communication\}). Structural changes in bacterioplankton communities caused by changes of DOC and nutrient availability have been reported previously (e.g., 41). In a study on a phytoplankton bloom in the Southern Ocean, the Roseobacter NAC11-6 and NAC11-7 clusters were found as an active part of the bloom community but dwell in different stages of the bloom (42). The authors suggested that both clusters are important contributors to carbon cycling. In this study, NAC11-7 was more abundant in the southern samples compared to the northern samples. The opposite was recorded for NAC11-6. The presence in different bloom stages reported by West et al. (13) might indicate that both groups are adapted to the different nutrient availabilities, which are also found along latitudinal gradients. 


\section{Comparision between RNA-based and DNA-based approch}

We assessed bacterial community structures and relative abundances of phylogenetic groups by simultaneous $16 \mathrm{~S}$ rRNA and $16 \mathrm{~S}$ rRNA gene analysis. The advantage of the RNA-based approach is the ability to gain insight into active part of a microbial community whereas DNA-based approach allows assessment of structure of the total microbial community present in an environment (43). We recorded a lower diversity coverage on RNA level than on DNA level (see Table S4 in the supplemental material). To further evaluate this discrepancy, we caluculated rarefaction curves with respect to RNA and DNA (see Fig. S2 in the supplemental material). Curves calculated for RNA samples at all three genetic distance levels were less saturated than the corresponding curves generated for DNA samples. This indicates a higher bacterial diversity on RNA level. Further analysis revealed that the calculated genetic richness (number of operational taxonomic units (OUTs)) was significantly higher at all three genetic distances on RNA level (see Table S4 in the supplemental material). This is in accordance with the result of the rarefaction analysis and indicates a higher diversity of the active bacterial community.

The number of large comparative studies analyzing both active and total microbial communities is limited. Baldrian et al. used a similar approach to study microbial communities in forest soils (44). Similarities between total and active community structure were identified. Moreover, a higher fungal diversity on RNA level was recorded. Around $18 \%$ of the fungal OTUs identified in the forest soil were exclusively found in the active community. The higher genetic richness is in accordance with our findings. The active bacterial communities showed a higher richness and diversity compared to the total community. Although similar major groups were identified in the active and total community, many rare groups were exclusively identified on RNA level as indicated by the increased number of singleton OTUs with only one affiliated sequence (see Table S3 in the supplemental material).

We further examined compositional changes of the two abundant orders with respect to DNA-based and RNA-based analysis. This analysis revealed that the abundances of many predominant bacterial groups significantly differed between total (DNAbased) and active (RNA-based) bacterial community (Figs. 2 and 3). The Roseobacter CHAB-I-5 and RCA clusters as well as the genera Formosa, Owenweeksia, and Polaribacter and the
NS4 marine group were significantly affected by nucleic acid type. For example, the RCA cluster was more abundant on RNA level than on DNA leve, indicating a higher activity.

Whereas abundance on DNA level is linked to cell abundance and to the number of rRNA operons in the genome, the abundance on RNA level is linked to cell abundance and to the number of rRNA transcripts. In Escherichia coli, rRNA promoter activity is regulated by a negative-feedback control loop responding to the translation activity (45). Consequently, low cell activity leads to a lower rRNA transcription rate in the cell and, thus, to a decreased number of rRNA transcripts. Thus, even rare species can be detected on RNA level as long as they are highly active. Moreover, the number of 16S rRNA copies in a PCR reaction is higher when RNA is used as starting material as $16 \mathrm{~S}$ rRNA transcripts constitute a major fraction of the total RNA. As a consequence, the detection limit for single species in a PCR reaction is lower in RNAbased studies than in DNA-based metagenomic approaches.

Metagenomic studies greatly advanced our knowledge on the composition of bacterial communities in diverse habitats. However, the results of this study suggest that the diversity of marine bacterial communities and especially of the active members contributing to ecosystem functioning might be higher as previously reported by DNA-based studies. Consequently, the richness and diversity of marine communities, especially of the rare biosphere, might still be largely unexplored.

\section{MATERIAL AND METHODS}

\section{Sampling and sample preparation}

Water samples for community analyses were collected in the North Sea along a latitudinal gradient from Germany to Norway at 13 stations in July 2011 on board RV Heincke by 5 1-Niskin bottles mounted on a CTD (conductivity, temperature, and depth) rosette (Fig. 1, see Table $\mathrm{S} 1$ in the supplemental material). The water of at least 8 Niskin bottles (approximately 40 liters) was pooled in an ethanol-rinsed PE barrel. It was prefiltered through a $10-\mu \mathrm{m}$ nylon net and a precombusted $\left(4 \mathrm{~h}\right.$ at $\left.450^{\circ} \mathrm{C}\right)$ glass fiber filter $(142$ $\mathrm{mm}$ diameter, Whatman GF/D, Whatman, Maidstone, UK). Bacterioplankton was harvested from a prefiltered 10 liter sample using a filter sandwich consisting of a glass fiber filter $(142 \mathrm{~mm}$ diameter, Whatman GF/F, Whatman) and $0.2-\mu \mathrm{m}$ 
polycarbonate filter (142 $\mathrm{mm}$ diameter, Nuclepore, Whatman).

For determination of chlorophyll $a$ (Chl $a$ ) and phaeopigments, water samples were filtered onto glass fiber filters (47 mm diameter, Whatman GF/F, Whatman), immediately wrapped into aluminum foil and kept frozen at $-20^{\circ} \mathrm{C}$ until further analysis within two weeks according to (28) and (46). Biomass production (BP) of heterotrophic prokaryotes was determined employing the ${ }^{14} \mathrm{C}$ leucine incorporation method as described in (28) and (47). Turnover rates of free amino acids and glucose were determined by the radiotracer technique according to (28) and (48). Subsamples for DFAA analysis were filtered on board through $0.2 \mu \mathrm{m}$ low protein binding filters (Tuffrin Acrodisc, Whatman) and kept frozen at $-20^{\circ} \mathrm{C}$ until analysis. Bacterioplankton cell numbers were determined by flow cytometry (BD Accuri ${ }^{\mathrm{TM}}$ C6, BD Biosciences, Heidelberg, Germany) using SybrGreen I staining and internal bead calibration as described previously (28). For this purpose, water samples were taken, preserved with glutardialdehyde (final concentration 1\%), and stored at $-20^{\circ} \mathrm{C}$ until further analysis.

\section{Extraction and purification of environmental DNA and RNA}

Total DNA and RNA were extracted using acidic phenol as described by Weinbauer et al. (49). One sixth of a filter (pore size $0.2 \mu \mathrm{m}$ ) was used per sample in the extraction. Subsequently, RNA was purified employing the RNeasy Mini kit as recommended by the manufacturer (Qiagen, Hilden, Germany). Residual DNA was removed from RNA samples by treatment with Turbo ${ }^{\mathrm{TM}}$ DNase treatment (Ambion) and the absence of DNA was confirmed by $16 \mathrm{~S}$ rRNA gene PCR according to Wemheuer et al. (11). Purified RNA was converted to cDNA by employing the SuperScript ${ }^{\mathrm{TM}}$ double-stranded cDNA synthesis kit (Invitrogen ${ }^{\mathrm{TM}}$ ) as modified by Wemheuer et al. (11). Total DNA was purified employing the peqGOLD Gel extraction kit (Peqlab, Erlangen Germany).

\section{Amplification and sequencing of 16S rRNA}

To assess bacterial community structures, the V3V5 region of the bacterial 16S rRNA was amplified by PCR. The PCR reaction $(50 \mu \mathrm{l})$ contained $10 \mu \mathrm{l}$ of 5-fold Phusion HF buffer (Finnzymes, Vantaa, Finland), $200 \mu \mathrm{M}$ of each of the four desoxynucleoside triphosphates, $1.5 \mathrm{mM} \mathrm{MgCl}_{2}, 4$ $\mu \mathrm{M}$ of each primer, $2.5 \%$ DMSO, $2 \mathrm{U}$ of Phusion high fidelity hot start DNA polymerase (Finnzymes), and approximately $50 \mathrm{ng}$ of DNA or $25 \mathrm{ng}$ of cDNA as template. The following thermal cycling scheme was used: initial denaturation at $98^{\circ} \mathrm{C}$ for $5 \mathrm{~min}, 25$ cycles of denaturation at $98^{\circ} \mathrm{C}$ for $45 \mathrm{~s}$, annealing at $63^{\circ} \mathrm{C}$ for $45 \mathrm{~s}$, followed by extension at $72^{\circ} \mathrm{C}$ for $30 \mathrm{~s}$. The final extension was carried out at $72^{\circ} \mathrm{C}$ for $5 \mathrm{~min}$. Negative controls were performed by using the reaction mixture without template. The V3-V5 region was amplified with the following set of primers according to Muyzer et al. (50) containing the Roche 454 pyrosequencing adaptors, keys and one unique MID per sample (underlined): 341f 5'CCATCTCATCCCTGCGTGTCTCCGAC-TCAG$(\mathrm{dN})_{10}$-CCTACGGRAGGCAGCAG-3' and 907r 5'CCTATCCCCTGTGTGCCTTGGCAGTC-TCAGCCGTCAATTCMTTTGAGT-3'. Primer coverage was evaluated using TestPrime (24) with a maximum number of 0 mismatches and the most recent Silva database (SSURef 114 and SSURef NR) as reference (51). Obtained PCR products were checked for appropriate size and then purified by using the peqGOLD gel extraction kit (Peqlab) as recommended by the manufacturer. Three independent PCR reactions were performed per sample, purified by gel extraction, and pooled in equal amounts. Quantification of the PCR products was performed using the Quant-iT dsDNA HS assay kit and a Qubit fluorometer (Invitrogen) as recommended by the manufacturer. The Göttingen Genomics Laboratory determined the sequences by using a Roche GS-FLX+ 454 pyrosequencer with Titanium chemistry (Roche, Mannheim, Germany).

\section{Processing and analysis of datasets}

Sequence data were deposited in the sequence read archive of the National Center for Biotechnology Information under the accession number SRA082674. Generated 16S rRNA gene and rRNA datasets were processed and further analyzed employing the QIIME 1.6.0 software package (52) and other tools. A detailed workflow is depicted in Fig. S3 in the supplemental material.

After raw data extraction, reads shorter than $300 \mathrm{bp}$, with an average quality value below 25 , possessing long homopolymer stretches (> $8 \mathrm{bp}$ ), or primer mismatches (>3) were removed. Subsequently, sequences were denoised employing QIIME. Remaining primer sequences were truncated employing cutadapt (53). Chimeric sequences were removed using UCHIME and the most recent Greengenes core set as reference dataset $(54,55)$. 
Processed sequences of all samples were joined, sorted by decreasing length, and clustered employing the UCLUST algorithm (56). Sequences were clustered in operational taxonomic units (OTUs) at 1\%, 3\% and 20\% genetic dissimilarity according to (57). OTUs at 3 and 20\% sequence divergence represent species and phylum level, respectively (58). Phylogenetic composition was determined using the QIIME assign_taxonmy.py script. A BLAST alignment against a modified version of the Silva SSURef 111 NR database (51) was thereby performed. Modification included the integration and/or reclassification of sequences affiliated to the Roseobacter OCT lineage, which consists of the Roseobacter NAC1-2, NAC11-6, and CHAB-I-5 clusters (see Table S5 in the supplemental material). Sequences were classified with respect to the modified Silva taxonomy of their best hit. Rarefaction curves, Shannon indices (59) and Chaol indices (60) were calculated. In addition, the maximal number of OTUs $\left(\mathrm{n}_{\max }\right)$ was estimated for each sample using the MichaelisMenten-fit alpha diversity metrics included in the QIIME software package.

\section{Statistical analysis}

All statistical analyses were conducted employing R (version 2.15.0; R Development Core Team 2011 [http://cran.r-project.org/]). Comparisons of community structures were performed at the same level of surveying effort (4,762 randomly selected sequences). The RNA sample derived from station 6 (sample 4) was excluded from the analysis and any statistical testing, as it contains less than 1800 sequences. Possible correlations between latitude and other environmental parameters were determined by linear modeling in $\mathrm{R}$ ( $\mathrm{lm}$ function). Possible impacts of latitude or nucleic acid type (DNA/RNA) on bacterial richness and diversity were tested by Analysis of Covariance (ANCOVA). Changes in the composition of the two abundant orders with respect to nucleic acid type and latitude were further examined by Dirichlet regression in $\mathrm{R}$ using the Dirichlet Reg package. Effects were assumed as statistically significant when $\mathrm{P} \leq 0.05$.

\section{ACKNOWLEDGEMENTS}

We thank the crew of RV Heincke for their valuable support and B. Schmidt from the Experimental and Applied Mineralogy Department of the Geoscience Center Göttingen for providing his muffle furnace as well as Helena Osterholz and Thorsten Dittmar from the Marine Geochemistry
Group of the Max Planck Institute for Marine Microbiology in Bremen (Germany) for providing information about DOC and TN. This work was funded by Deutsche Forschungsgemeinschaft (DFG) within the Collaborative Research Center TRR 51.

\section{REFERENCES}

1. Curtis TP, Sloan WT, Scannell JW. 2002. Estimating prokaryotic diversity and its limits. P. Natl. Acad. Sci. USA 99:10494-10499.

2. Sogin ML, Morrison HG, Huber JA, Mark Welch D, Huse SM, Neal PR, Arrieta JM, Herndl GJ. 2006. Microbial diversity in the deep sea and the underexplored "rare biosphere". P. Natl. Acad. Sci. USA 103:12115-12120.

3. Arrigo KR. 2005. Marine microorganisms and global nutrient cycles. Nature 437:349-355.

4. Venter JC, Remington K, Heidelberg JF, Halpern AL, Rusch D, Eisen JA, Wu D, Paulsen I, Nelson KE, Nelson W, Fouts DE, Levy S, Knap AH, Lomas MW, Nealson K, White O, Peterson J, Hoffman J, Parsons R, Baden-Tillson $\mathrm{H}$, Pfannkoch C, Rogers YH, Smith HO. 2004. Environmental genome shotgun sequencing of the Sargasso Sea. Science 304:66-74.

5. Giovannoni SJ, Britschgi TB, Moyer CL, Field KG. 1990. Genetic diversity in Sargasso Sea bacterioplankton. Nature 345:60-63.

6. Schmidt TM, DeLong EF, Pace NR. 1991. Analysis of a marine picoplankton community by $16 \mathrm{~S}$ rRNA gene cloning and sequencing. J. Bacteriol. 173:43714378.

7. Will C, Thurmer A, Wollherr A, Nacke H, Herold N, Schrumpf M, Gutknecht J, Wubet T, Buscot F, Daniel R. 2010. Horizon-specific bacterial community composition of German grassland soils, as revealed by pyrosequencing-based analysis of $16 \mathrm{~S}$ rRNA genes. Appl. Environ. Microb. 76:6751-6759.

8. Nacke H, Thurmer A, Wollherr A, Will C, Hodac L, Herold N, Schoning I, Schrumpf M, Daniel R. 2011. Pyrosequencing-based assessment of 
bacterial community structure along different management types in German forest and grassland soils. PloS one 6:e17000.

9. Vila-Costa M, Gasol JM, Sharma S, Moran MA. 2012. Community analysis of high- and low-nucleic acid-containing bacteria in NW Mediterranean coastal waters using $16 \mathrm{~S}$ rDNA pyrosequencing. Environ. Microbiol. 14:1390-1402.

10. Kirchman DL, Cottrell MT, Lovejoy C. 2010. The structure of bacterial communities in the western Arctic Ocean as revealed by pyrosequencing of $16 \mathrm{~S}$ rRNA genes. Environ. Microbiol. 12:1132-1143.

11. Wemheuer B, Wemheuer F, Daniel $\mathbf{R}$. 2012. RNA-Based Assessment of Diversity and Composition of Active Archaeal Communities in the German Bight. Archaea 2012:8.

12. Teeling H, Fuchs BM, Becher D, Klockow C, Gardebrecht A, Bennke CM. 2012. Substrate-controlled succession of marine bacterioplankton populations induced by a phytoplankton bloom. Science 336:608-611.

13. West NJ, Obernosterer I, Zemb O, Lebaron P. 2008. Major differences of bacterial diversity and activity inside and outside of a natural iron-fertilized phytoplankton bloom in the Southern Ocean. Environ. Microbiol. 10:738-756.

14. Fuhrman JA, Steele JA, Hewson I, Schwalbach MS, Brown MV, Green JL, Brown JH. 2008. A latitudinal diversity gradient in planktonic marine bacteria. P. Natl. Acad. Sci. USA 105:7774-7778.

15. Thompson F, Bruce T, Gonzalez A, Cardoso A, Clementino M, Costagliola M, Hozbor C, Otero E, Piccini C, Peressutti S, Schmieder R, Edwards R, Smith M, Takiyama L, Vieira R, Paranhos R, Artigas L. 2011. Coastal bacterioplankton community diversity along a latitudinal gradient in Latin America by means of V6 tag pyrosequencing. Arch. Microbiol. 193:105-114.

16. Schattenhofer M, Fuchs BM, Amann R, Zubkov MV, Tarran GA, Pernthaler J. 2009. Latitudinal distribution of prokaryotic picoplankton populations in the Atlantic Ocean. Environ. Microbiol. 11:2078-2093.

17. Wiltshire K, Kraberg A, Bartsch I, Boersma M, Franke H-D, Freund J, Gebühr C, Gerdts G, Stockmann K, Wichels A. 2010. Helgoland Roads, North Sea: 45 Years of Change. Estuar. Coasts. 33:295-310.

18. McQuatters-Gollop A, Raitsos DE, Edwards M, Pradhan Y, Mee LD, Lavender SJ, Attrill MJ. 2007. A longterm chlorophyll data set reveals regime shift in North Sea phytoplankton biomass unconnected to nutrient trends. Limnol. Oceanogr. 52:635-648.

19. Alderkamp AC, Sintes E, Herndl GJ. 2006. Abundance and activity of major groups of prokaryotic plankton in the coastal North Sea during spring and summer. Aquat. Microb. Ecol. 45:237246.

20. Rink B, Seeberger S, Martens T, Duerselen C-D, Simon M, Brinkhoff T. 2011. Regional patterns of bacterial community composition and biogeochemical properties in the southern North Sea. Aquat. Microb. Ecol. 63:207222.

21. Sintes E, Witte $\mathbf{H}$, Stodderegger $\mathbf{K}$, Steiner P, Herndl GJ. 2013. Temporal dynamics in the free-living bacterial community composition in the coastal North Sea. FEMS Microbiol. Ecol. 83:413-424.

22. Muyzer G, Brinkhoff T, Nübel U, Santegoeds C, Schäfer H, Wawer C. 2004. Denaturing gradient gel electrophoresis (DGGE) in microbial ecology, p. 743-769. Kluwer Academic Publishers, Dordrecht.

23. Sánchez O, Gasol JM, Massana R, Mas J, Pedrós-Alió C. 2007. Comparison of Different Denaturing Gradient Gel Electrophoresis Primer Sets for the Study of Marine Bacterioplankton Communities. Appl. Environ. Microb. 73:5962-5967.

24. Klindworth A, Pruesse E, Schweer T, Peplies J, Quast C, Horn M, Glöckner FO. 2013. Evaluation of general 16S ribosomal RNA gene PCR primers for classical and next-generation sequencingbased diversity studies. Nucleic Acids Res. 41:e1-e1. 
25. Newton RJ, Griffin LE, Bowles KM, Meile C, Gifford S, Givens CE, Howard EC, King E, Oakley CA, Reisch CR, Rinta-Kanto JM, Sharma S, Sun S, Varaljay V, Vila-Costa M, Westrich JR, Moran MA. 2010. Genome characteristics of a generalist marine bacterial lineage. ISME J 4:784-798.

26. Wagner-Dobler I, Biebl H. 2006. Environmental biology of the marine Roseobacter lineage. Annu. Rev. Microbiol. 60:255-280.

27. González JM, Simó R, Massana R, Covert JS, Casamayor EO, Pedrós-Alió C, Moran MA. 2000. Bacterial Community Structure Associated with a Dimethylsulfoniopropionate-Producing

North Atlantic Algal Bloom. Appl. Environ. Microb. 66:4237-4246.

28. Giebel HA, Kalhoefer D, Lemke A, Thole S, Gahl-Janssen R, Simon M, Brinkhoff T. 2011. Distribution of Roseobacter RCA and SAR11 lineages in the North Sea and characteristics of an abundant RCA isolate. ISME journal 5:819.

29. Schattenhofer M, Fuchs BM, Amann R, Zubkov MV, Tarran GA, Pernthaler J. 2009. Latitudinal distribution of prokaryotic picoplankton populations in the Atlantic Ocean. Environ Microbiol. 11:2078-2093.

30. Giovannoni SJ, Vergin KL. 2012. Seasonality in ocean microbial communities. Science 335:671-676.

31. Oh HM, Kwon KK, Kang I, Kang SG, Lee JH, Kim SJ, Cho JC. 2010. Complete genome sequence of "Candidatus Puniceispirillum marinum" IMCC1322, a representative of the SAR116 clade in the Alphaproteobacteria. J. Bacteriol. 192:3240-3241.

32. Morris RM, Frazar CD, Carlson CA. 2012. Basin-scale patterns in the abundance of SAR11 subclades, marine Actinobacteria (OM1), members of the Roseobacter clade and OCS116 in the South Atlantic. Environ. Microbiol. 14:1133-1144.

33. Oh HM, Kwon KK, Kang I, Kang SG, Lee JH, Kim SJ, Cho JC. 2010. Complete genome sequence of "Candidatus Puniceispirillum marinum" IMCC1322, a representative of the
SAR116 clade in the Alphaproteobacteria. J. Bacteriol. 192:3240-3241.

34. Grote J, Bayindirli C, Bergauer K, Carpintero de Moraes $\mathbf{P}$, Chen $\mathbf{H}$, D'Ambrosio L, Edwards B, FernándezGómez B, Hamisi M, Logares R, Nguyen D, Rii YM, Saeck E, Schutte C, Widner B, Church MJ, Steward GF, Karl DM, Delong EF, Eppley JM, Schuster SC, Kyrpides NC, Rappé MS. 2011. Draft genome sequence of strain HIMB100, a cultured representative of the SAR116 clade of marine Alphaproteobacteria. Stand. Genomic Sci. 5:269-278.

35. Jamieson RE, Rogers AD, Billett DS, Smale DA, Pearce DA. 2012. Patterns of marine bacterioplankton biodiversity in the surface waters of the Scotia Arc, Southern Ocean. FEMS Microbiol. Ecol. 80:452468.

36. Gómez-Pereira PR, Schüler M, Fuchs BM, Bennke C, Teeling H, Waldmann J, Richter M, Barbe V, Bataille E, Glöckner FO, Amann R. 2012. Genomic content of uncultured Bacteroidetes from contrasting oceanic provinces in the North Atlantic Ocean. Environ. Microbiol. 14:52-66.

37. Teeling H, Fuchs BM, Becher D, Klockow C, Gardebrecht A, Bennke CM, Kassabgy M, Huang S, Mann AJ, Waldmann J, Weber M, Klindworth A, Otto A, Lange J, Bernhardt J, Reinsch C, Hecker M, Peplies J, Bockelmann FD, Callies U, Gerdts G, Wichels A, Wiltshire KH, Glöckner FO, Schweder T, Amann R. 2012. Substrate-controlled succession of marine bacterioplankton populations induced by a phytoplankton bloom. Science 336:608-611.

38. Fernandez-Gomez B, Richter $\mathbf{M}$, Schuler M, Pinhassi J, Acinas SG, Gonzalez JM, Pedros-Alio C. 2013. Ecology of marine Bacteroidetes: a comparative genomics approach. ISME J, in press.

39. Alonso C, Warnecke F, Amann R, Pernthaler J. 2007. High local and global diversity of Flavobacteria in marine plankton. Environ. Microbiol. 9:12531266. 
40. OSPAR commission. 2000. Quality Status Report 2000; Region II - Greater North Sea. OSPAR Commission, London.

41. Morris RM, Frazar CD, Carlson CA. 2012. Basin-scale patterns in the abundance of SAR11 subclades, marine Actinobacteria (OM1), members of the Roseobacter clade and OCS116 in the South Atlantic. Environ. Microbiol. 14:1133-1144.

42. West NJ, Obernosterer I, Zemb O, Lebaron P. 2008. Major differences of bacterial diversity and activity inside and outside of a natural iron-fertilized phytoplankton bloom in the Southern Ocean. Environ. Microbiol. 10:738-756.

43. Simon C, Daniel R. 2011. Metagenomic analyses: past and future trends. Appl. Environ. Microbiol. 77:1153-1161.

44. Baldrian P, Kolarik M, Stursova M, Kopecky J, Valaskova V, Vetrovsky T, Zifcakova L, Snajdr J, Ridl J, Vlcek C, Voriskova J. 2012. Active and total microbial communities in forest soil are largely different and highly stratified during decomposition. ISME J 6:248-258.

45. Schneider DA, Gourse RL. 2003. Changes in Escherichia coli rRNA Promoter Activity Correlate with Changes in Initiating Nucleoside Triphosphate and Guanosine 5' Diphosphate 3'-Diphosphate Concentrations after Induction of Feedback Control of Ribosome Synthesis. J. Bacteriol. 185:6185-6191.

46. Nusch EA. 1999. Chlorophyllbestimmung. In: von Tuempling W, Friedrich G. (eds). Biologische Gewässeruntersuchung. G Fischer, Stuttgart; Germany.

47. Simon M, Rosenstock B, Zwisler, W. 2004. Coupling of epipelagic and mesopelagic heterotrophic picoplankton production to phytoplankton biomass in the Antarctic Polar Frontal Region. Limnol. Oceanogr. 49: 1035-1043.

48. Simon, M, Rosenstock, B. 2007. Different coupling of dissolved amino acid, protein, and carbohydrate turnover to heterotrophic picoplankton production in the Southern Ocean in austral summer and fall. Limnol. Oceanogr. 52:85-95.

49. Weinbauer MG, Fritz I, Wenderoth DF, Höfle MG. 2002. Simultaneous extraction from bacterioplankton of total RNA and DNA suitable for quantitative structure and function analyses. Appl. Environ. Microbiol. 68:1082-1087.

50. Muyzer G, Teske A, Wirsen CO, Jannasch HW. 1995. Phylogenetic relationships of Thiomicrospira species and their identification in deep-sea hydrothermal vent samples by denaturing gradient gel electrophoresis of $16 \mathrm{~S}$ rDNA fragments. Arch. Microbiol. 164:165-172.

51. Pruesse E, Quast C, Knittel K, Fuchs BM, Ludwig W, Peplies J. 2007. SILVA: a comprehensive online resource for quality checked and aligned ribosomal RNA sequence data compatible with ARB. Nucleic Acids Res. 35:7188-7196.

52. Caporaso JG, Kuczynski J, Stombaugh J, Bittinger K, Bushman FD, Costello EK, Fierer N, Pena AG, Goodrich JK, Gordon JI, Huttley GA, Kelley ST, Knights D, Koenig JE, Ley RE, Lozupone CA, McDonald D, Muegge BD, Pirrung M, Reeder J, Sevinsky JR, Turnbaugh PJ, Walters WA, Widmann J, Yatsunenko T, Zaneveld J, Knight R. 2010. QIIME allows analysis of highthroughput community sequencing data. Nature methods 7:335-336.

53. Martin M. 2011. Cutadapt removes adapter sequences from high-throughput sequencing reads. EMBnet.journal 17:1012.

54. Edgar RC, Haas BJ, Clemente JC, Quince C, Knight R. 2011. UCHIME improves sensitivity and speed of chimera detection. Bioinformatics 27:2194-2200.

55. DeSantis TZ, Hugenholtz P, Larsen N, Rojas M, Brodie EL, Keller K, Huber T, Dalevi D, Hu P, Andersen GL. 2006. Greengenes, a chimera-checked 16S rRNA gene database and workbench compatible with ARB. Appl. Environ. Microbiol. 72:5069-5072.

56. Edgar RC. 2010. Search and clustering orders of magnitude faster than BLAST. Bioinformatics 26:2460-2461.

57. Simon C, Wiezer A, Strittmatter AW, Daniel R. 2009. Phylogenetic diversity and metabolic potential revealed in a glacier ice metagenome. Appl. Environ. Microbiol. 75:7519-7526.

58. Schloss PD, Handelsman J. 2005. Introducing DOTUR, a computer program for defining operational taxonomic units 
and estimating species richness. Appl. Environ. Microbiol. 71:1501-1506.

59. Shannon CE. 2001. A mathematical theory of communication. SIGMOBILE Mob. Comput. Commun. Rev. 5:3-55.

60. Chao A, Bunge J. 2002. Estimating the number of species in a stochastic abundance model. Biometrics 58:531-539. 


\section{SUPPORTING INFORMATION FOR STUDY 3}

\section{CONTENTS:}

FIG S1 Rarefaction curves at 1 (A,B), 3 (C,D), and 20\% (E,F) genetic divergence calculated for DNA-based (A,C,E) and RNA-based (B, D, F) approaches.

FIG S2 Rarefaction analysis with respect to nucleic acid type used for 16S rRNA analysis.

FIG S3 Processing of 454 pyrosequencing reads with QIIME (1) and other tools.

TABLE S1 CTD measured parameters for the sampling sites.

TABLE S2 Environmental parameters measured for the sampling stations.

TABLE S3 Statistics of the 16S rRNA sequence datasets.

TABLE S4 Bacterial diversity and richness at 1\%,3\%, and 20\% genetic distance.

TABLE S5 16S rRNA gene sequences used to modify the Silva SSURef 111 NR database. 

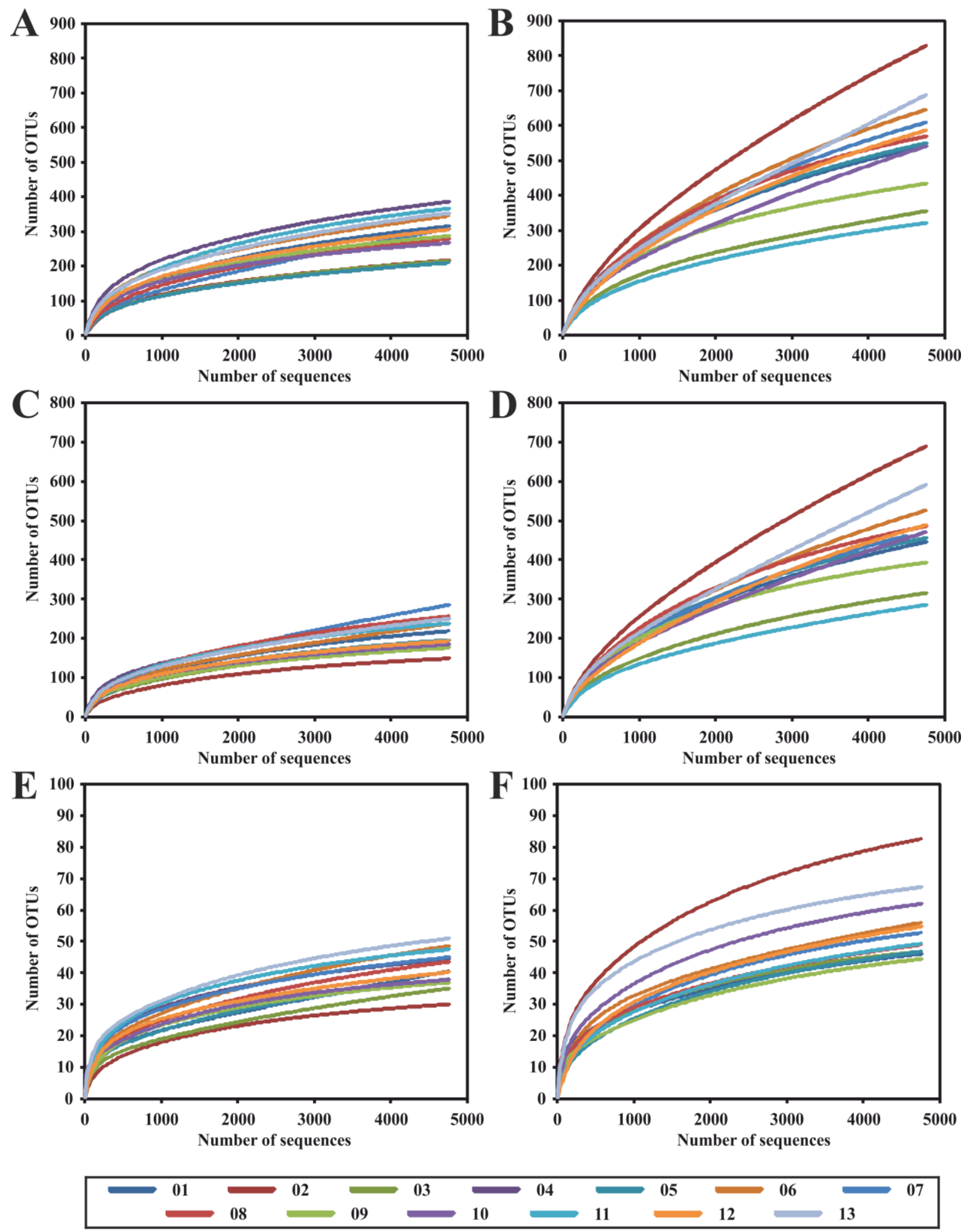

FIG S1 Rarefaction curves at 1 (A,B), 3 (C,D), and 20\% (E,F) genetic divergence calculated for DNA-based (A,C,E) and RNA-based (B, D, F) approaches. Rarefaction analysis was performed with QIIME (1). 


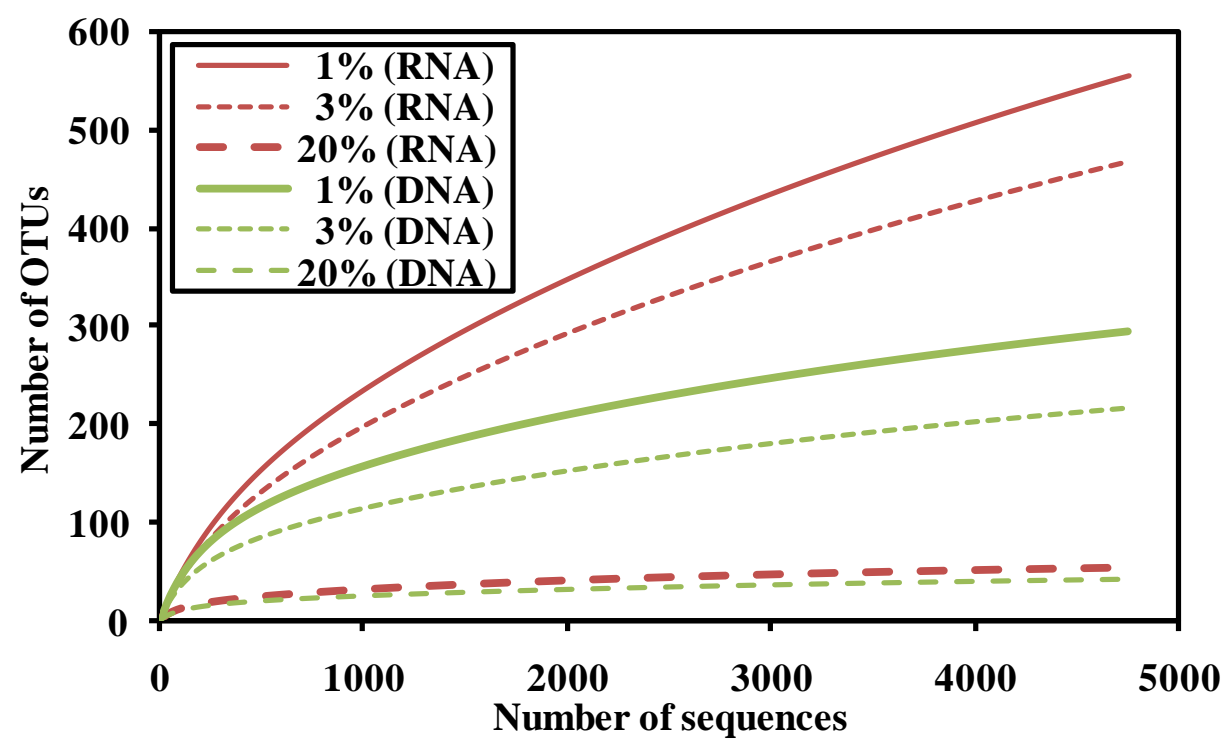

FIG S2 Rarefaction analysis with respect to nucleic acid type used for 16S rRNA analysis. Curves were calculated at 1, 3 and $20 \%$ genetic divergence. Rarefaction analysis was performed with QIIME (1). 


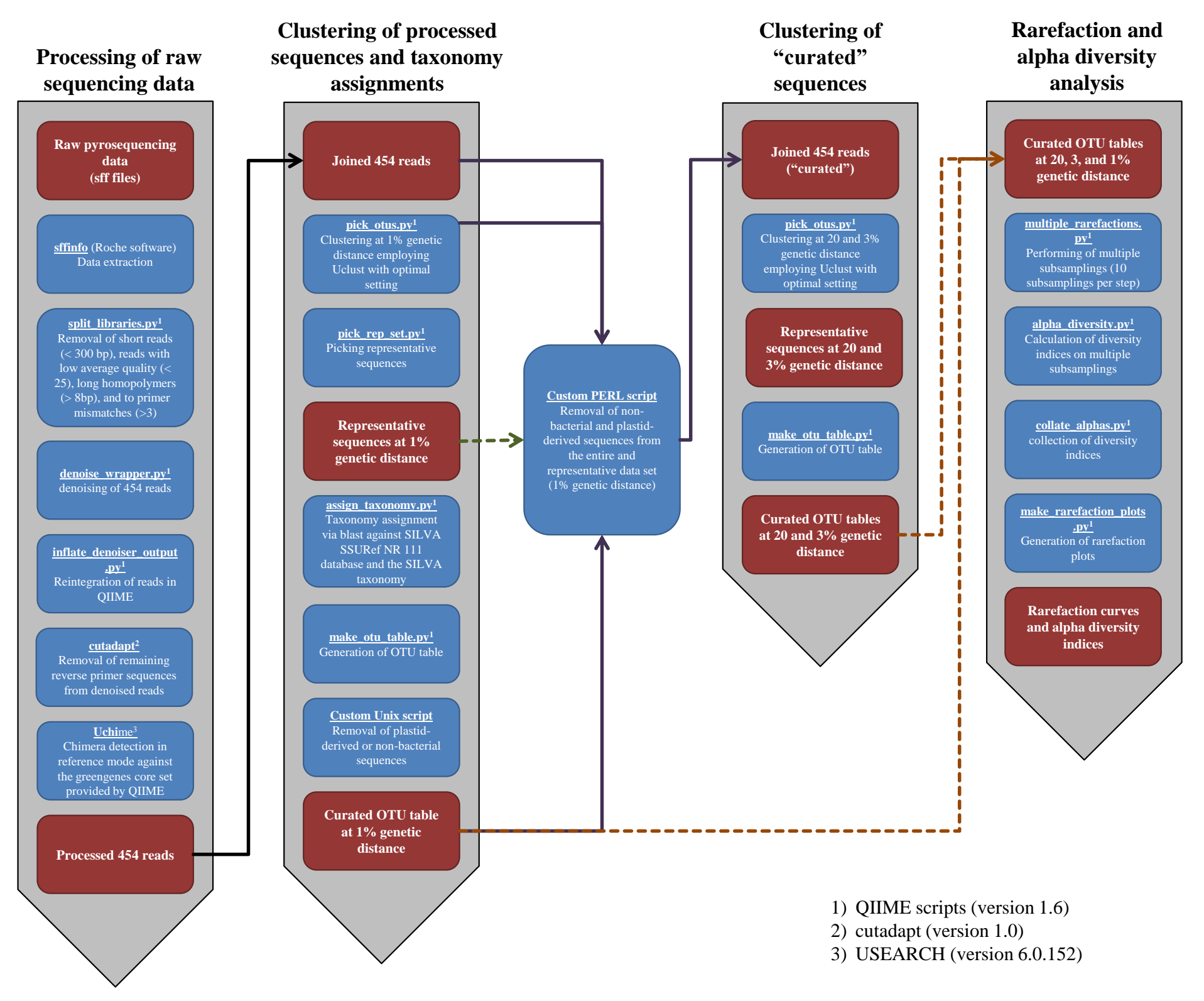


FIG S3 Processing of 454 pyrosequencing reads with QIIME (1) and other tools. After raw data extraction, reads shorter than 300 bp, with an average quality value below 25 , possessing long homopolymer stretches (> $8 \mathrm{bp}$ ), or primer mismatches (>3) were removed. Subsequently, sequences were denoised employing QIIME. Remaining primer sequences were truncated employing cutadapt (2). Chimeric sequences removed using UCHIME and the most recent Greengenes core set as reference dataset (3, 4). Processed sequences of all samples were joined, sorted by decreasing length, and clustered employing the UCLUST algorithm (5). Sequences were clustered in operational taxonomic units (OTUs) at 1\%,3\% and 20\% genetic dissimilarity according to Simon et al (6). Phylogenetic composition was determined using the QIIME assign_taxonmy.py script. A BLAST alignment against a modified version of the Silva SSURef 111 NR database (7) was thereby performed. Modification included the integration and/or reclassification of sequences affiliated to the Roseobacter OCT lineage, which consist of the Roseobacter NAC1-2, NAC11-6, and CHAB-I-5 clusters (see Table S4 in the supplemental material). Sequences were classified with respect to the modified Silva taxonomy of their best hit. Rarefaction curves, Shannon indices (8) and Chao1 indices (9) were calculated. In addition, the maximal number of OTUs (nmax) was estimated for each sample using the Michaelis-Menten-fit alpha diversity metrics included in the QIIME software package. 
TABLE S1 CTD measured parameters for the sampling sites.

\begin{tabular}{|c|c|c|c|c|c|c|c|c|c|c|c|}
\hline Sample & Ship station & $\begin{array}{c}\text { Date } \\
\text { (dd.mm.yyyy) }\end{array}$ & $\begin{array}{c}\text { Latitude } \\
\left({ }^{\circ} \mathrm{N}\right)\end{array}$ & $\begin{array}{l}\text { Longitude } \\
\left({ }^{\circ} \mathrm{E}\right)\end{array}$ & $\begin{array}{c}\text { Depth } \\
(m)\end{array}$ & $\begin{array}{c}\text { Bottom depth } \\
(\mathrm{m})\end{array}$ & $\begin{array}{c}\text { Temperature } \\
\left({ }^{\circ} \mathrm{C}\right)\end{array}$ & $\begin{array}{c}\text { Salinity } \\
(p s u)\end{array}$ & $\begin{array}{c}\text { Transmission } \\
(\%)\end{array}$ & $\begin{array}{c}\text { Fluorescence } \\
\left(\mathrm{mg} / \mathrm{m}^{3}\right)\end{array}$ & $\begin{array}{c}\text { Oxygen } \\
(m L / L)\end{array}$ \\
\hline 1 & 01 & 15.07 .2011 & 54.0893 & 7.9327 & 3 & 32 & 18.308 & 29.826 & 78.563 & 0.757 & 6.118 \\
\hline 2 & 02 & 15.07.2011 & 54.9667 & 7.6058 & 3 & 21 & 15.804 & 32.248 & 92.506 & 0.621 & 5.314 \\
\hline 3 & 03 & 16.07.2011 & 55.4662 & 7.2852 & 3 & 25 & 14.775 & 33.420 & 93.706 & 0.377 & 5.277 \\
\hline 4 & 06 & 16.07 .2011 & 56.5018 & 7.5015 & 3 & 29 & 15.700 & 33.225 & 90.844 & 0.388 & 5.718 \\
\hline 5 & 07 & 16.07 .2011 & 56.994 & 7.2925 & 3 & 32 & 15.192 & 33.110 & 92.886 & 0.391 & 5.730 \\
\hline 6 & 08 & 17.07.2011 & 57.261 & 8.732 & 3 & 23 & 14.782 & 33.408 & 83.597 & 1.490 & 5.943 \\
\hline 7 & 10 & 17.07.2011 & 57.3173 & 9.0008 & 3 & 23 & 15.335 & 33.169 & 77.244 & 1.540 & 5.874 \\
\hline 8 & 11 & 18.07.2011 & 57.2575 & 8.7438 & 3 & 24 & 15.252 & 33.259 & 82.817 & 1.366 & 5.696 \\
\hline 9 & 12 & 18.07.2011 & 57.4887 & 7.1 & 3 & 181 & 15.453 & 31.873 & 92.874 & 0.361 & 5.696 \\
\hline 10 & 13 & 19.07.2011 & 57.8305 & 6.9185 & 3 & 384 & 16.506 & 30.062 & 93.006 & 0.504 & 5.586 \\
\hline 11 & 14 & 19.07.2011 & 58.1657 & 5.1693 & 4 & 290 & 14.652 & 32.566 & 90.982 & 0.572 & 5.751 \\
\hline 12 & 15 & 20.07.2011 & 58.9985 & 3.9232 & 3 & 275 & 14.559 & 31.857 & 92.501 & 0.405 & 5.752 \\
\hline 13 & 16 & 20.07.2011 & 59.9848 & 3.036 & 4 & 119 & 14.507 & 32.167 & 91.153 & 0.466 & 5.861 \\
\hline
\end{tabular}


TABLE S2 Environmental parameters measured for the sampling stations.

\begin{tabular}{|c|c|c|c|c|c|c|}
\hline$\overline{\text { Station }}$ & $\begin{array}{c}\text { Chlorophyll a } \\
(\mu g / L)\end{array}$ & $\begin{array}{c}\text { Phaeopigments } \\
(\mu \mathrm{g} / \mathrm{l})\end{array}$ & $\begin{array}{l}\text { No. bacterial cells } \\
\quad\left(10^{9} \text { cells } / L\right)\end{array}$ & $\begin{array}{c}\text { Bacterial biomass } \\
\text { production } \\
(\mu g C / L * h)\end{array}$ & $\begin{array}{c}\text { Glucose } \\
\text { turnover } \\
\left(\text { day }^{-1}\right)\end{array}$ & $\begin{array}{l}\text { Dissolved free amino } \\
\text { acids turnover }\left(\text { day }^{-1}\right)\end{array}$ \\
\hline 1 & 2.013 & 0.788 & 1.66 & 712.7 & 2.68 & 0.17 \\
\hline 2 & 1.302 & 0.492 & 1.60 & 321.6 & 3.08 & 0.29 \\
\hline 3 & 0.533 & 0.382 & 0.76 & 155.2 & 3.49 & 0.29 \\
\hline 4 & 0.789 & 0.251 & 0.97 & 420.0 & 3.91 & 0.27 \\
\hline 5 & 0.281 & 0.187 & 0.86 & 149.4 & 0.92 & 0.06 \\
\hline 6 & 1.598 & 0.606 & 0.72 & 252.6 & 0.67 & 0.16 \\
\hline 7 & 3.157 & 0.462 & 0.67 & 316.4 & 1.95 & 0.20 \\
\hline 8 & 2.625 & 0.121 & 0.86 & - & - & - \\
\hline 9 & 0.222 & 0.132 & 0.58 & 161.8 & 0.92 & 0.10 \\
\hline 10 & 0.474 & 0.026 & 0.82 & 147.0 & 1.01 & 0.10 \\
\hline 11 & 0.612 & 0.065 & 1.10 & 108.3 & 0.19 & 0.05 \\
\hline 12 & 0.304 & 0.100 & 0.91 & 183.6 & 1.37 & 0.11 \\
\hline 13 & 0.459 & 0.040 & 1.14 & 196.8 & 1.08 & 0.09 \\
\hline
\end{tabular}

-, not measured 
TABLE S3 Statistics of the 16S rRNA sequence datasets.

\begin{tabular}{|c|c|c|c|c|c|c|}
\hline Sample & $\begin{array}{c}\text { No. of } \\
\text { sequences }\end{array}$ & $\begin{array}{l}\text { Average } \\
\text { length } \\
(\text { bp })\end{array}$ & $\begin{array}{c}\text { No. of } \\
\text { centroids }\end{array}$ & $\begin{array}{c}\text { No. of } \\
\text { centroids } \\
\text { /10,000 } \\
\text { sequences }\end{array}$ & No. of singeltons & $\begin{array}{c}\text { No. of singeltons } \\
/ 10,000 \\
\text { sequences }\end{array}$ \\
\hline \multicolumn{7}{|c|}{ DNA-based } \\
\hline 1 & 14,360 & 515 & 270 & 188.0 & 208 & 144.8 \\
\hline 2 & 11,566 & 522 & 189 & 163.4 & 105 & 90.8 \\
\hline 3 & 20,981 & 508 & 189 & 90.1 & 230 & 109.6 \\
\hline 4 & 11,536 & 505 & 325 & 281.7 & 213 & 184.6 \\
\hline 5 & 9,509 & 513 & 159 & 167.2 & 116 & 122.0 \\
\hline 6 & 13,133 & 509 & 276 & 210.2 & 253 & 192.6 \\
\hline 7 & 4,762 & 452 & 108 & 226.8 & 200 & 420.0 \\
\hline 8 & 13,260 & 505 & 212 & 159.9 & 237 & 178.7 \\
\hline 9 & 12,094 & 516 & 253 & 209.2 & 145 & 119.9 \\
\hline 10 & 12,930 & 504 & 234 & 181.0 & 141 & 109.0 \\
\hline 11 & 9,657 & 502 & 301 & 311.7 & 169 & 175.0 \\
\hline 12 & 10,976 & 508 & 255 & 232.3 & 154 & 140.3 \\
\hline 13 & 11,155 & 486 & 250 & 224.1 & 282 & 252.8 \\
\hline Sum/Avg & 155,919 & 506.2 & 188.7 & 203.5 & 232.4 & 172.3 \\
\hline \multicolumn{7}{|c|}{ RNA-based } \\
\hline 1 & 22,110 & 535 & 558 & 252.4 & 473 & 213.9 \\
\hline 2 & 7,816 & 518 & 339 & 433.7 & 829 & 1060.6 \\
\hline 3 & 15,171 & 538 & 244 & 160.8 & 422 & 278.2 \\
\hline 4 & 1,798 & 513 & 101 & 561.7 & 86 & 478.3 \\
\hline 5 & 16,779 & 534 & 471 & 280.7 & 499 & 297.4 \\
\hline 6 & 33,857 & 516 & 693 & 204.7 & 1224 & 361.5 \\
\hline 7 & 37,444 & 518 & 558 & 149.0 & 1469 & 392.3 \\
\hline 8 & 23,986 & 542 & 574 & 239.3 & 574 & 239.3 \\
\hline 9 & 16,363 & 544 & 397 & 242.6 & 265 & 162.0 \\
\hline 10 & 11,087 & 505 & 222 & 200.2 & 778 & 701.7 \\
\hline 11 & 14,748 & 532 & 220 & 149.2 & 387 & 262.4 \\
\hline 12 & 17,472 & 533 & 457 & 261.6 & 820 & 469.3 \\
\hline 13 & 7,957 & 507 & 218 & 274.0 & 801 & 1006.7 \\
\hline Sum/Avg & 226,588 & 527.2 & 388.6 & 262.3 & 663.6 & 455.7 \\
\hline
\end{tabular}


TABLE S4 Bacterial diversity and richness at 1\%, 3\%, and $20 \%$ genetic distance. Coverage was determined based on observed clusters and $\mathrm{n}_{\text {max }}$. To compare community structures 4,762 randomly selected sequences from each sample were used for calculation. RNA sample 4 was removed from analysis, as it comprised only 1800 sequences. Significant differences between RNA and DNA samples are indicated by bold type. Significant correlations between any calculated diversity index and latitude were not observed. Significance was tested by Analysis of Covariance (ANCOVA). Diversity inices were calculated

\begin{tabular}{|c|c|c|c|c|c|c|c|c|c|c|c|c|c|c|c|}
\hline \multirow[t]{2}{*}{ Sample } & \multicolumn{3}{|c|}{ Observed clusters } & \multicolumn{3}{|c|}{ Max. clusters $\left(n_{\max }\right)$} & \multicolumn{3}{|c|}{ Coverage (\%) } & \multicolumn{3}{|c|}{ Shannon index (H') } & \multicolumn{3}{|c|}{ Chaol } \\
\hline & $1 \%$ & $3 \%$ & $20 \%$ & $1 \%$ & $3 \%$ & $20 \%$ & $1 \%$ & $3 \%$ & $20 \%$ & $1 \%$ & $3 \%$ & $20 \%$ & $1 \%$ & $3 \%$ & $20 \%$ \\
\hline \multicolumn{16}{|l|}{$D N A$} \\
\hline 1 & 311.4 & 216.3 & 38.5 & 388.1 & 267.3 & 44.3 & 80.23 & 80.93 & 86.83 & 4.10 & 3.33 & 1.42 & 465.3 & 351.2 & 62.7 \\
\hline 2 & 216.0 & 150.5 & 30.5 & 262.0 & 183.0 & 35.3 & 82.43 & 82.23 & 86.42 & 3.33 & 2.79 & 1.19 & 304.7 & 229.0 & 45.8 \\
\hline 3 & 213.0 & 182.8 & 34.7 & 257.9 & 219.9 & 40.2 & 82.59 & 83.14 & 86.31 & 3.41 & 3.23 & 1.34 & 336.4 & 296.1 & 66.6 \\
\hline 4 & 386.5 & 248.0 & 45.8 & 452.9 & 288.9 & 48.3 & 85.34 & 85.85 & 94.79 & 4.94 & 4.22 & 2.18 & 605.6 & 445.9 & 67.3 \\
\hline 5 & 207.6 & 197.7 & 37.6 & 250.8 & 238.6 & 42.2 & 82.78 & 82.87 & 89.05 & 3.24 & 3.19 & 1.74 & 324.7 & 303.9 & 47.7 \\
\hline 6 & 340.1 & 232.5 & 48.4 & 395.8 & 286.1 & 56.1 & 85.93 & 81.26 & 86.25 & 4.48 & 3.74 & 1.87 & 624.7 & 463.3 & 81.1 \\
\hline 7 & 308.0 & 286.0 & 45.0 & 447.8 & 396.1 & 48.7 & 68.78 & 72.21 & 92.38 & 3.78 & 3.72 & 1.83 & 1634.7 & 870.5 & 54.4 \\
\hline 8 & 281.3 & 262.3 & 44.2 & 350.0 & 326.0 & 50.2 & 80.37 & 80.46 & 88.08 & 3.87 & 3.78 & 1.68 & 511.7 & 454.3 & 89.0 \\
\hline 9 & 288.8 & 175.1 & 36.2 & 343.7 & 201.5 & 39.8 & 84.03 & 86.90 & 91.06 & 4.22 & 3.63 & 1.66 & 434.5 & 251.8 & 42.4 \\
\hline 10 & 266.8 & 185.6 & 39.0 & 308.1 & 210.9 & 42.6 & 86.59 & 87.99 & 91.59 & 4.14 & 3.67 & 1.82 & 405.6 & 276.6 & 53.1 \\
\hline 11 & 367.0 & 238.9 & 46.8 & 449.8 & 283.5 & 50.5 & 81.59 & 84.28 & 92.75 & 4.53 & 3.81 & 1.93 & 530.7 & 333.5 & 64.9 \\
\hline 12 & 302.2 & 191.4 & 39.5 & 356.5 & 221.9 & 41.9 & 84.76 & 86.26 & 94.17 & 4.30 & 3.59 & 1.84 & 465.8 & 296.0 & 51.4 \\
\hline 13 & 356.0 & 249.3 & 51.5 & 427.0 & 301.3 & 56.2 & 83.37 & 82.75 & 91.58 & 4.71 & 4.09 & 2.21 & 753.8 & 523.1 & 69.3 \\
\hline Mean & 295.7 & 216.6 & 41.4 & 360.8 & 263.5 & 45.9 & 82.21 & 82.86 & 90.10 & 4.21 & 3.66 & 1.79 & 569.1 & 391.9 & 61.2 \\
\hline$S D$ & 58.8 & 39.7 & 6.1 & 74.1 & 59.0 & 6.4 & 4.49 & 3.99 & 3.09 & 0.53 & 0.39 & 0.30 & 345.1 & 170.5 & 13.8 \\
\hline$C V$ & 0.20 & 0.18 & 0.15 & 0.21 & 0.22 & 0.14 & 0.05 & 0.05 & 0.03 & 0.13 & 0.11 & 0.17 & 0.61 & 0.43 & 0.23 \\
\hline
\end{tabular}


TABLE S4 continued

\begin{tabular}{|c|c|c|c|c|c|c|c|c|c|c|c|c|c|c|c|}
\hline \multirow[t]{2}{*}{ Sample } & \multicolumn{3}{|c|}{ Observed clusters } & \multicolumn{3}{|c|}{ Max. clusters $\left(n_{\max }\right)$} & \multicolumn{3}{|c|}{ Coverage (\%) } & \multicolumn{3}{|c|}{ Shannon index ( $\left.H^{\prime}\right)$} & \multicolumn{3}{|c|}{ Chao1 } \\
\hline & $1 \%$ & $3 \%$ & $20 \%$ & $1 \%$ & $3 \%$ & $20 \%$ & $1 \%$ & $3 \%$ & $20 \%$ & $1 \%$ & $3 \%$ & $20 \%$ & $1 \%$ & $3 \%$ & $20 \%$ \\
\hline \multicolumn{16}{|l|}{ RNA } \\
\hline 1 & 537.1 & 440.5 & 45.1 & 755.5 & 618.0 & 50.0 & 71.10 & 71.28 & 90.24 & 4.60 & 4.07 & 1.52 & 849.0 & 710.0 & 65.3 \\
\hline 2 & 830.2 & 684.9 & 82.8 & 1541.4 & 1226.4 & 94.0 & 53.86 & 55.85 & 88.13 & 5.05 & 4.71 & 2.48 & 3465.6 & 2115.1 & 105.1 \\
\hline 3 & 353.8 & 317.3 & 46.4 & 477.8 & 424.4 & 52.2 & 74.05 & 74.76 & 88.89 & 3.86 & 3.67 & 1.45 & 772.1 & 658.7 & 62.2 \\
\hline 4 & 548.9 & 456.9 & 47.7 & 765.1 & 642.1 & 57.7 & 71.74 & 71.16 & 82.64 & 4.47 & 4.15 & 1.68 & 937.1 & 834.4 & 64.9 \\
\hline 5 & 650.4 & 512.9 & 55.3 & 1041.3 & 798.9 & 62.3 & 62.46 & 64.20 & 88.77 & 4.70 & 4.31 & 1.91 & 1242.3 & 1042.7 & 77.5 \\
\hline 6 & 603.5 & 476.2 & 54.8 & 896.3 & 713.6 & 64.3 & 67.33 & 66.73 & 85.29 & 4.63 & 4.08 & 1.59 & 1165.8 & 1096.8 & 74.4 \\
\hline 7 & 578.5 & 487.9 & 49.1 & 820.8 & 678.0 & 56.6 & 70.48 & 71.96 & 86.70 & 4.58 & 4.33 & 1.60 & 903.7 & 820.0 & 62.7 \\
\hline 8 & 431.4 & 387.2 & 44.6 & 558.6 & 499.5 & 51.2 & 77.23 & 77.52 & 87.12 & 4.28 & 4.12 & 1.64 & 625.2 & 524.3 & 66.6 \\
\hline 9 & 535.6 & 474.1 & 61.8 & 843.9 & 761.5 & 69.6 & 63.47 & 62.26 & 88.85 & 4.46 & 4.18 & 1.99 & 3465.0 & 2121.1 & 92.3 \\
\hline 10 & 318.6 & 283.6 & 50.8 & 423.9 & 384.0 & 61.0 & 75.16 & 73.85 & 83.32 & 3.66 & 3.53 & 1.50 & 735.6 & 606.1 & 65.6 \\
\hline 11 & 587.0 & 494.9 & 54.3 & 970.7 & 854.8 & 64.5 & 60.47 & 57.90 & 84.14 & 4.14 & 3.91 & 1.77 & 1324.4 & 1137.9 & 65.6 \\
\hline 12 & 683.5 & 585.4 & 65.9 & 1310.3 & 1088.9 & 70.7 & 52.16 & 53.76 & 93.24 & 4.73 & 4.44 & 2.37 & 5208.8 & 2872.1 & 75.4 \\
\hline Mean & 554.9 & 466.8 & 54.9 & 867.1 & 724.2 & 62.8 & 66.63 & 66.77 & 87.28 & 4.49 & 4.17 & 1.85 & 1724.6 & 1211.6 & 73.1 \\
\hline$S D$ & 140.7 & 107.9 & 11.0 & 325.0 & 249.6 & 11.9 & 8.20 & 7.92 & 3.07 & 0.39 & 0.32 & 0.34 & 1478.9 & 747.1 & 13.2 \\
\hline$C V$ & 0.25 & 0.23 & 0.20 & 0.37 & 0.34 & 0.19 & 0.12 & 0.12 & 0.04 & 0.09 & 0.08 & 0.18 & 0.86 & 0.62 & 0.18 \\
\hline
\end{tabular}


TABLE S5 16S rRNA gene sequences used to modify the Silva SSURef 111 NR database. Sequences were integrated and/or reassigned to the respective Roseobacter subclusters CHAB-I-5, NAC1-2, and NAC11-6, to resolve the Roseobacter OCT lineage, which does not represents a single lineage but mainly comprises the three subclusters mentioned.

\begin{tabular}{|c|c|c|}
\hline $\begin{array}{l}\text { Taxonomic affiliation } \\
\text { (Roseobacter }\end{array}$ & Name & Accession \\
\hline CHAB-I-5 & Uncultured alpha proteobacterium KTc0993 & AF235129 \\
\hline CHAB-I-5 & Uncultured alpha proteobacterium CHAB-I-5 & AJ240910 \\
\hline CHAB-I-5 & Uncultured Roseobacter sp. & AY627366 \\
\hline CHAB-I-5 & Uncultured Roseobacter sp. & AY627371 \\
\hline CHAB-I-5 & Uncultured marine bacterium & DQ009284 \\
\hline CHAB-I-5 & Uncultured marine bacterium & DQ071080 \\
\hline CHAB-I-5 & Uncultured alpha proteobacterium & DQ810318 \\
\hline CHAB-I-5 & Uncultured alpha proteobacterium & EF016462 \\
\hline CHAB-I-5 & Uncultured bacterium & EF645958 \\
\hline CHAB-I-5 & Uncultured alpha proteobacterium & EU268090 \\
\hline CHAB-I-5 & Uncultured alpha proteobacterium & EU268095 \\
\hline CHAB-I-5 & Uncultured bacterium & EU799191 \\
\hline CHAB-I-5 & Uncultured bacterium & EU799372 \\
\hline CHAB-I-5 & Uncultured bacterium & EU799470 \\
\hline CHAB-I-5 & Uncultured bacterium & EU799319 \\
\hline CHAB-I-5 & Uncultured bacterium & EU799544 \\
\hline CHAB-I-5 & Uncultured bacterium & EU799596 \\
\hline CHAB-I-5 & Uncultured bacterium & EU799604 \\
\hline CHAB-I-5 & Uncultured bacterium & EU799640 \\
\hline CHAB-I-5 & Uncultured bacterium & EU799809 \\
\hline CHAB-I-5 & Uncultured bacterium & EU799837 \\
\hline CHAB-I-5 & Uncultured bacterium & EU799994 \\
\hline CHAB-I-5 & Uncultured bacterium & EU800023 \\
\hline CHAB-I-5 & Uncultured bacterium & FJ545513 \\
\hline CHAB-I-5 & Uncultured bacterium & FJ545522 \\
\hline CHAB-I-5 & Uncultured bacterium & FJ545623 \\
\hline CHAB-I-5 & Uncultured Sulfitobacter sp. & FJ744918 \\
\hline CHAB-I-5 & Uncultured Sulfitobacter sp. & FJ745272 \\
\hline CHAB-I-5 & Uncultured marine bacterium & FJ826232 \\
\hline CHAB-I-5 & Uncultured marine bacterium & FJ826260 \\
\hline CHAB-I-5 & Uncultured marine bacterium & FJ826501 \\
\hline CHAB-I-5 & Uncultured alpha proteobacterium & GQ347827 \\
\hline CHAB-I-5 & Uncultured alpha proteobacterium & GQ347863 \\
\hline CHAB-I-5 & Uncultured alpha proteobacterium & GQ347787 \\
\hline CHAB-I-5 & Uncultured alpha proteobacterium & GQ347819 \\
\hline CHAB-I-5 & Uncultured alpha proteobacterium & GQ347872 \\
\hline CHAB-I-5 & Uncultured alpha proteobacterium & GQ348856 \\
\hline CHAB-I-5 & Uncultured alpha proteobacterium & GQ348786 \\
\hline CHAB-I-5 & Uncultured alpha proteobacterium & GQ348929 \\
\hline CHAB-I-5 & Uncultured marine bacterium & GU204725 \\
\hline CHAB-I-5 & Uncultured alpha proteobacterium & HM057611 \\
\hline CHAB-I-5 & Uncultured alpha proteobacterium & HM057744 \\
\hline CHAB-I-5 & Uncultured bacterium & HQ166724 \\
\hline CHAB-I-5 & Uncultured Rhodobacteraceae bacterium & HQ242009 \\
\hline CHAB-I-5 & Uncultured Rhodobacteraceae bacterium & HQ241992 \\
\hline CHAB-I-5 & Uncultured Rhodobacteraceae bacterium & HQ242334 \\
\hline CHAB-I-5 & Uncultured Roseobacter sp. & JN233137 \\
\hline CHAB-I-5 & Uncultured bacterium & JQ013156 \\
\hline NAC1-2 & Uncultured Roseobacter NAC1-2 & AF245615 \\
\hline NAC1-2 & Marine bacterium SRF2 & AJ002564 \\
\hline
\end{tabular}


TABLE S5 continued

\begin{tabular}{|c|c|c|}
\hline $\begin{array}{l}\text { Taxonomic affiliation } \\
\text { (Roseobacter subcluster) }\end{array}$ & Name & Accession \\
\hline NAC1-2 & Marine bacterium SRF1 & AJ002563 \\
\hline NAC1-2 & Uncultured organism & DQ395765 \\
\hline NAC1-2 & Uncultured organism & DQ395728 \\
\hline NAC1-2 & Uncultured organism & DQ395731 \\
\hline NAC1-2 & Uncultured organism & DQ395864 \\
\hline NAC1-2 & Uncultured organism & DQ395872 \\
\hline NAC1-2 & Uncultured bacterium & EF645949 \\
\hline NAC $1-2$ & Uncultured bacterium & EF646123 \\
\hline NAC1-2 & Uncultured bacterium & EU799025 \\
\hline NAC1-2 & Uncultured bacterium & EU799081 \\
\hline NAC1-2 & Uncultured bacterium & EU799101 \\
\hline NAC1-2 & Uncultured bacterium & EU799272 \\
\hline NAC $1-2$ & Uncultured bacterium & EU799264 \\
\hline NAC1-2 & Uncultured bacterium & EU800060 \\
\hline NAC1-2 & Uncultured bacterium & FJ545544 \\
\hline NAC1-2 & Uncultured bacterium & FJ545545 \\
\hline NAC $1-2$ & Uncultured alpha proteobacterium & FJ615109 \\
\hline NAC1-2 & Uncultured marine bacterium & FJ825934 \\
\hline NAC1-2 & Uncultured marine bacterium & FJ826325 \\
\hline NAC1-2 & Uncultured alpha proteobacterium & GQ347547 \\
\hline NAC1-2 & Uncultured alpha proteobacterium & GQ347978 \\
\hline NAC1-2 & Uncultured alpha proteobacterium & GQ348093 \\
\hline NAC1-2 & Uncultured alpha proteobacterium & GQ348318 \\
\hline NAC1-2 & Uncultured alpha proteobacterium & GQ348563 \\
\hline NAC $1-2$ & Uncultured alpha proteobacterium & GQ348588 \\
\hline NAC1-2 & Uncultured alpha proteobacterium & GQ349293 \\
\hline NAC1-2 & Uncultured alpha proteobacterium & GQ350465 \\
\hline NAC1-2 & Uncultured bacterium & GU061348 \\
\hline NAC1-2 & Uncultured bacterium & GU061367 \\
\hline NAC1-2 & Uncultured alpha proteobacterium & HQ163162 \\
\hline NAC1-2 & Uncultured Rhodobacteraceae bacterium & HQ242021 \\
\hline NAC1-2 & Uncultured Rhodobacteraceae bacterium & HQ242013 \\
\hline NAC1-2 & Uncultured Rhodobacteraceae bacterium & HQ241978 \\
\hline NAC $1-2$ & Uncultured Rhodobacteraceae bacterium & HQ242010 \\
\hline NAC1-2 & Uncultured Rhodobacteraceae bacterium & HQ242028 \\
\hline NAC1-2 & Uncultured Rhodobacteraceae bacterium & HQ241980 \\
\hline NAC1-2 & Uncultured Rhodobacteraceae bacterium & HQ242039 \\
\hline NAC1-2 & Uncultured Rhodobacteraceae bacterium & HQ242038 \\
\hline NAC1-2 & Uncultured Rhodobacteraceae bacterium & HQ242201 \\
\hline NAC1-2 & Uncultured Rhodobacteraceae bacterium & HQ242215 \\
\hline NAC1-2 & Uncultured Rhodobacteraceae bacterium & HQ242314 \\
\hline NAC1-2 & Uncultured bacterium & HQ671914 \\
\hline NAC1-2 & Uncultured bacterium & HQ672014 \\
\hline NAC1-2 & Uncultured bacterium & HQ672039 \\
\hline NAC1-2 & Uncultured bacterium & HQ671987 \\
\hline NAC1-2 & Uncultured bacterium & HQ672179 \\
\hline NAC11-6 & Uncultured Roseobacter NAC11-6 & AF245634 \\
\hline NAC11-6 & Roseobacter sp. 3008 & AM110967 \\
\hline NAC11-6 & Uncultured alpha proteobacterium MB11C09 & AY033324 \\
\hline NAC11-6 & Uncultured organism & DQ395766 \\
\hline NAC11-6 & Uncultured organism & DQ395672 \\
\hline NAC11-6 & Uncultured organism & DQ395823 \\
\hline NAC11-6 & Uncultured organism & DQ395796 \\
\hline NAC11-6 & Uncultured organism & DQ395871 \\
\hline NAC11-6 & Uncultured organism & DQ395831 \\
\hline NAC11-6 & Uncultured alpha proteobacterium & EF016465 \\
\hline NAC11-6 & Uncultured marine bacterium & EU005826 \\
\hline
\end{tabular}




\begin{tabular}{lll}
\hline $\begin{array}{l}\text { Taxonomic affiliation } \\
\text { (Roseobacter subcluster })\end{array}$ & Name & Accession \\
\hline NAC11-6 & Uncultured bacterium & EU035836 \\
NAC11-6 & Uncultured bacterium & EU265946 \\
NAC11-6 & Uncultured bacterium & EU570893 \\
NAC11-6 & Uncultured bacterium & EU799357 \\
NAC11-6 & Uncultured bacterium & EU799376 \\
NAC11-6 & Uncultured bacterium & EU799567 \\
NAC11-6 & Uncultured bacterium & FJ545521 \\
NAC11-6 & Uncultured bacterium & FJ545602 \\
NAC11-6 & Uncultured marine bacterium & FJ826399 \\
NAC11-6 & Uncultured Rhodobacteraceae bacterium & FM958453 \\
NAC11-6 & Uncultured Rhodobacteraceae bacterium & FN582321 \\
NAC11-6 & Uncultured Roseobacter sp. & FR681767 \\
NAC11-6 & Uncultured Roseobacter sp. & FR681768 \\
NAC11-6 & Uncultured Roseobacter sp. & FR681769 \\
NAC11-6 & Uncultured marine bacterium & FR683592 \\
NAC11-6 & Uncultured Roseobacter sp. & FR681770 \\
NAC11-6 & Uncultured alpha proteobacterium & GQ348520 \\
NAC11-6 & Uncultured alpha proteobacterium & GQ348598 \\
NAC11-6 & Uncultured alpha proteobacterium & GQ348534 \\
NAC11-6 & Uncultured alpha proteobacterium & GQ348722 \\
NAC11-6 & Uncultured alpha proteobacterium & GQ349969 \\
NAC11-6 & Uncultured alpha proteobacterium & GQ350050 \\
NAC11-6 & Uncultured alpha proteobacterium & GU061261 \\
NAC11-6 & Uncultured marine bacterium & GU235686 \\
NAC11-6 & Uncultured marine bacterium & GU235651 \\
NAC11-6 & Uncultured bacterium & HQ671749 \\
NAC11-6 & Uncultured bacterium & HQ671894 \\
NAC11-6 & Uncultured bacterium & JF451313 \\
NAC11-6 & Uncultured alpha proteobacterium & JN177665 \\
NAC11-6 & Uncultured bacterium & JX016532 \\
NAC11-6 & Uncultured bacterium & JX206779 \\
\hline
\end{tabular}




\section{References}

1. Caporaso JG, Kuczynski J, Stombaugh J, Bittinger K, Bushman FD, Costello EK, Fierer N, Pena AG, Goodrich JK, Gordon JI, Huttley GA, Kelley ST, Knights D, Koenig JE, Ley RE, Lozupone CA, McDonald D, Muegge BD, Pirrung M, Reeder J, Sevinsky JR, Turnbaugh PJ, Walters WA,Widmann J, Yatsunenko T, Zaneveld J, Knight R. 2010. QIIME allows analysis of high-throughput community sequencing data. Nature methods 7:335-336.

2. Martin M. 2011. Cutadapt removes adapter sequences from high-throughput sequencing reads. (2011) EMBnet.journal 17:10-12.

3. DeSantis TZ, Hugenholtz P, Larsen N, Rojas M, Brodie EL, Keller K, Huber T, Dalevi D, Hu P, Andersen GL. 2006. Greengenes, a chimera-checked 16S rRNA gene database and workbench compatible with ARB. Appl Environ Microbiol 72:5069-5072.

4. Edgar RC, Haas BJ, Clemente JC, Quince C, Knight R. 2011. UCHIME improves sensitivity and speed of chimera detection. Bioinformatics 27:2194-2200.

5. Edgar RC. 2010. Search and clustering orders of magnitude faster than BLAST. Bioinformatics 26:2460-2461

6. Simon C, Wiezer A, Strittmatter AW, Daniel R. 2009. Phylogenetic diversity and metabolic potential revealed in a glacier ice metagenome. Appl Environ Microbiol 75:7519-7526.

7. Pruesse E, Quast C, Knittel K, Fuchs BM, Ludwig W, Peplies J. 2007. SILVA: a comprehensive online resource for quality checked and aligned ribosomal RNA sequence data compatible with ARB. Nucleic Acids Res 35:7188-7196.

8. Shannon CE. 2001. A mathematical theory of communication. SIGMOBILE Mob. Comput. Commun. Rev. 5:3-55.

9. Chao A, Bunge J. 2002. Estimating the Number of Species in a Stochastic Abundance Model. Biometrics 58:531-539 


\title{
STUDY 4:
}

\section{COMMUNITY ANALYSIS OF FREE-LIVING AND ATTACHED \\ ROSEOBACTER-AFFILIATED BACTERIA INDICATE AN OVERLAP IN DIVERSTY BETWEEN MATURED PARTICLES AND THE SEDIMENT SURFACE}

\begin{abstract}
Kanukollu $\mathrm{S}^{1}$, Wemheuer B ${ }^{2}$, Herber $\mathbf{J}^{1}$, Billerbeck $\mathrm{S}^{1}$, LuCAS $\mathbf{J}^{1}$, DANIEL $\mathrm{R}^{2}$, SIMON $\mathrm{M}^{1}$, CYPIONKA $\mathrm{H}^{1}$, AND ENGELEN B ${ }^{1}$
\end{abstract}

(IN PREPARATION)

${ }^{1}$ INSTITUTE FOR CHEMISTRY AND BIOLOGY OF THE MARINE ENVIRONMENT (ICBM), CARL-VON-OSSIETZKY-UNIVERSITY OF OLDENBURG, CARL-VONOSSIETZKY-STR. 9-11, D-26111 OLDENBURG, GERMANY; ${ }^{2}$ INSTITUTE OF Microbiology and Genetics, GeOrG-August-University Göttingen,

GRISEBACHSTR. 8, D-37077 GÖTTINGEN, GERMANY; ${ }^{3}$ PRESENT ADDRESS: Biological Institute Helgoland, KuRPRomenade 201, D-27498 HelgOland, GERMANY

Author contributions to the work:

Performed the experiments: SV, BW, HG, CB

Analyzed data: SV, MS, BW, HG, CB, JV, SD

Contributed data on water properties and analysis of these data: BW, TB, HG, $\mathrm{CB}, \mathrm{IB}, \mathrm{SB}$

Wrote the publication: SV, MS, TB, RD 


\section{Abstract}

In this study, we compared the diversity of the Roseobacter clade within sediment and water samples from the eastern North Sea by cultivationindependent and cultivation-based methods. Cluster analysis of DGGE patterns revealed specific localizations of free-living and attached populations. Roseobacter communities from surface-near particles (3 m depth), clustered separately, while matured particles $(10-40 \mathrm{~m})$ and sediment surfaces $(23-181 \mathrm{~m})$ showed similar compositions. These results were confirmed by amplicon-based analysis of $16 \mathrm{~S}$ rRNA gene sequences, indicating an increasing diversity of Roseobacter-populations from the sea surface to the seafloor. As roseobacters are known to contribute to sulfur transformations, MPN experiments were set up with media containing either dimethyl sulfide (DMS), dimethyl sulfonium propionate (DMSP) or dimethyl sulfoxide (DMSO). While anoxic, DMSO-containing enrichments showed highest MPN numbers for the sediment surface (up to $2.1 \mathrm{x}$ $10^{7}$ roseobacters $/ \mathrm{cm}^{3}$ ), growth of sediment-dwelling roseobacters was specifically stimulated in all DMSP and half of the DMS-containing dilution series. A total of 20 roseobacters (12 from sediments) was isolated from all oxic enrichments, representing $0.55 \%$ of all Rhodobacteraceae in the pyrosequence dataset. Thus, the isolates could be quantified in the environmental samples avoiding the laborious design of specific primer sets or probes for quantification.

\section{INTRODUCTION}

The Roseobacter clade is a major marine bacterial lineage (3) representing a significant part of pelagic and benthic microbial communities $(4,14,38)$. The majority of Roseobacter affiliated bacteria (short: roseobacters) was detected in the water column as members of free-living and particle associated bacterial communities in various marine ecosystems and in different geographic regions. They can comprize more than $20 \%$ of all bacteria in coastal oceans (4). Additionally, about $3 \%$ of all roseobacter clones in $16 \mathrm{~S}$ rRNA gene libraries originate from marine surface sediments $(20,26)$. The fact that marine sediments are a relevant but understudied environment for roseobacters is further documented by the observation that approximately $10 \%$ of all available pure cultures are derived from benthic origins (4). However, so far no systematic study was performed which examines differences among the roseobacters in the free-living, particle-associated and sedimentdwelling bacterial communities. Because of the great habitat diversity, roseobacters exhibit a broad metabolic versatility (47). At least 12 of the 41 major Roseobacter lineages are involved in sulfur transformation reactions $(27,52)$. For example, it has been shown that DMSP-degrading roseobacters live in symbiotic relationships with DMSPproducing dinoflagellates (25). While some of the DMSP is cleaved, most of it is demethylated, and a fraction of the volatile degradation product DMS is oxidized by pelagic bacteria (19). As high concentrations of DMSP are associated with decaying (and sinking) algal blooms (47), it is most likely, that this compound is a possible substrate for sediment-dwelling roseobacters. Interestingly, some of the benthic roseobacters were detected in permanently anoxic sediment layers, indicating an anaerobic metabolism $(18,28)$. An adaptation at least to periodic anaerobiosis was detected for Dinoroseobacter shibae DFL $12^{\mathrm{T}}$ by the analysis of its genome showing the presence of a DMSOreductase gene and pathways for denitrification and fermentation (49). However, it is still unknown whether roseobacters are adapted to and are able to dwell in permanently anoxic sediments.

The overall goal of our study was to evaluate the occurrence and diversity of free 72 living and particle-attached roseobacters in the water column and in both, oxic and anoxic sediments of a coastal sea. We hypothesized that distinct differences exist in the roseobacter communities from the near surface waters to deeper waters and in the sediment-dwelling microbial communities. Roseobacter-specific DGGE analyses gave a first overview on their distribution patterns. Pyrosequencing-based analysis of 16S rRNA gene amplicons allowed deeper insights into their diversity and relative abundance. Additionally, cultivation experiments were carried out with special emphasis on sulfur transformation reactions. Thus, serial dilution cultures were set up to quantify their most probable number (MPN) and isolate roseobacters that are involved in aerobic DMS and DMSP utilization or/and anaerobic DMSO reduction. The combination of microbiological and advanced molecular techniques allowed to determine the relevance of these isolates within the different compartments. 


\section{MATERIAL AND METHODS}

\section{Sample origin}

The samples were collected in July 2011 during a cruise with RV 'Heincke' (expedition HE361) to the eastern North Sea (Fig. 1). Six sampling sites were chosen to be analyzed in detail by cultivation, DGGE and pyrosequencing. They represent two shallow sites (water depth: 35 and 26 meters below sea level; mbsl) at the German/Danish coast (station 36: $7^{\circ} 93.57^{\prime} \mathrm{E}, \quad 54^{\circ} 09.02^{\prime} \mathrm{N}$ and station 5: $\left.7^{\circ} 69.02^{\prime} \mathrm{E}, 56^{\circ} 01.18^{\prime} \mathrm{N}\right)$, a shallow ( $\left.23 \mathrm{mbsl}\right)$ and a deep site (114 mbsl) in the Skagerrak area (station 8: $\quad 8^{\circ} 73.20^{\prime} \mathrm{E}, \quad 57^{\circ} 26.10^{\prime} \mathrm{N}$ and station 27 : $8^{\circ} 35.41^{\prime} \mathrm{E}, 57^{\circ} 36.77^{\prime} \mathrm{N}$ ), as well as two deep sites (181 and $119 \mathrm{mbsl}$ ) within the Norwegian trench (station $12: 7^{\circ} 10.00^{\prime} \mathrm{E}, 57^{\circ} 48.87^{\prime} \mathrm{N}$ and station 16 : $3^{\circ} 03.60^{\prime} \mathrm{E}, 59^{\circ} 98.48^{\prime} \mathrm{N}$ ). Intermediate sites (stations $1-3,6,7,10,11,13-15)$ were analyzed by pyrosequencing of $3 \mathrm{~m}$ deep surface waters, only. Sediment samples and bottom seawater directly above the seafloor were taken by a multi-core sampler (MUC). Aliquots of the samples were transferred to cultivation media or stored at $-20^{\circ} \mathrm{C}$ for further molecular analyses in the home lab. Other water samples were obtained from corresponding locations by 5 1-Niskin bottles mounted on a rosette and equipped with a conductivity-temperature-depth (CTD) probe. These samples were taken from the turbidity maxima at $3 \mathrm{mbsl}$ and deep water layers between 23 and $181 \mathrm{mbsl}$, respectively. Up to several liters of water (depending on sample turbidity) were first filtered through 5- $\mu \mathrm{m}$ Nuclepore filters (to collect particle-associated bacteria) and then through $0.2104 \mu \mathrm{m}$ Nuclepore filters (to collect free-living bacteria). All filters were stored at $-80^{\circ} \mathrm{C}$ until further processing.

\section{Cultivation}

Immediately after sampling, water and sediments from all stations (Table 1) were inoculated in artificial seawater media (44). The media were slightly modified as $\mathrm{Na} 2 \mathrm{SO} 4$ was substituted by $\mathrm{NaCl}$. Four media variations were set up by adding i) DMS $(100 \mu \mathrm{M})$ and lactate $(5 \mathrm{mM})$, ii) DMS (500 $\mu \mathrm{M})$, iii) DMSP $(5 \mathrm{mM})$. and iv) DMSO $(100 \mu \mathrm{M})$ and lactate $(5 \mathrm{mM})$. For each station, water samples from the near surface and bottom seawater, as well as sediment samples from the seafloor $(0-1 \mathrm{cmbsf})$ and the oxic/anoxic transition zone $(4-5 \mathrm{cmbsf})$ were incubated in serial dilutions of the four media described above.

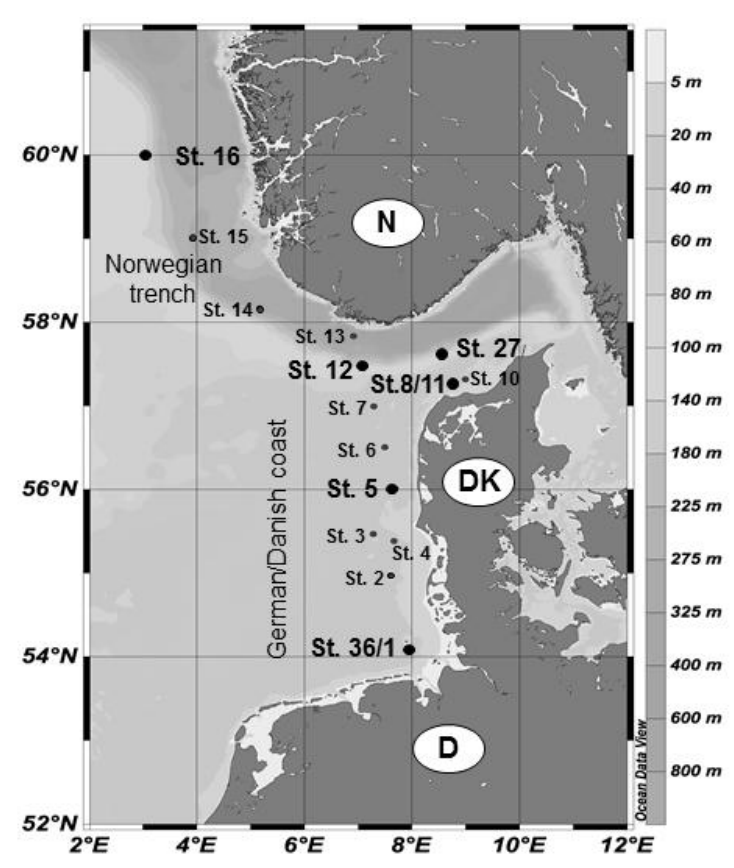

Fig. 1. Track of the Heincke cruise HE361 (June 2011). Samples were taken at six stations along the German/Danish coast and the Norwegian trench. The map was created with Ocean Data View (Schlitzer, R., Ocean Data View, httn://odv.awi-hremerhaven.de. 2004).

The dilutions were performed stepwise in three paralells from $10^{-2}$ to $10^{-7}$ in polypropylene 96deepwell plates (Beckman, Fullerton, CA). Every well was filled with $900 \mu \mathrm{l}$ medium, to which 100 $\mu \mathrm{l}$ inoculum was added. The plates containing media i-iii were incubated under oxic conditions and those containing medium iv were incubated anoxically for six months in the dark at $4^{\circ} \mathrm{C}$ as described in Süß et al (44).

\section{Analysis of MPN series}

Growth was tested according to Martens-Habbena and Sass (23). The cells within each well were stained with SYBR Green I (Molecular Probes, Eugene, OR) and growth was detected by using a microtiter plate reader (FLUOstar OPTIMA bMG, Offenburg/Germany). All MPN counts were calculated as described by de Man (10) and corrected for the values obtained from sample-free dilution series. Dilutions indicating growth were further subjected to DNA extraction and PCR to determine Roseobacter-specific MPN values. Additionally, grown dilution cultures served as isolation source for indigenous bacteria.

\section{Isolation of bacteria}

Aliquots $(100 \mu \mathrm{l})$ from the MPN wells that were tested positive for growth of roseobacters were 
spread on agar plates or transferred to deep-agar dilutions containing the respective media. The agar plates and tubes were incubated in the dark at $15^{\circ} \mathrm{C}$ under oxic and anoxic conditions for more than 2 and 6 months, respectively. Colonies from the agar plates were picked and further subcultivated at least 3 times to obtain pure cultures. Colonies from the anoxic agar tubes were picked and are under process to further subcultivations.

\section{DNA extractions}

For sediments, the DNA was extracted from $0.25 \mathrm{~g}$ of the samples, using the MoBio Power Soil DNA Isolation Kit (Carlsbad, California), following the manufacturer's instructions. PCR141 grade water was used to elute the purified DNA of the spin columns for downstream applications. The DNA of filtered water and particles was isolated after bead beating, phenol143 chloroform extraction, and isopropanol precipitation as described previously $(22,42)$. Treatment by sodium-dodecyl-sulfate (SDS, $1.75 \%$ of a $25 \%$ solution) was applied instead of lysozyme (43), precipitation was done with $30 \mu \mathrm{l} \mathrm{NaAc}$ and $750 \mu \mathrm{l}$ isopropanol at $-20^{\circ} \mathrm{C}$ overnight and $50 \mu \mathrm{l}$ of PCR-grade water (Eppendorf, Hamburg, Germany) was used for resuspension at $4^{\circ} \mathrm{C}$ overnight. For cultivated samples, a freeze-thaw extraction protocol was used. From each well of the dilution series that was tested positively for growth, $100 \mu$ were transferred into 1.5-ml reaction tubes (Eppendorf, Hamburg, Germany). The tubes were repeatedly heated to $60^{\circ} \mathrm{C}$ for $5 \mathrm{~min}$, and then frozen in liquid nitrogen for $1 \mathrm{~min}$ for 4 cycles. The cell lysate was stored at $20^{\circ} \mathrm{C}$ and used for further molecular analysis.

\section{Amplification of $16 S$ rRNA genes from environmental samples and enrichment cultures}

PCR was used to amplify 16S rRNA gene fragments for DGGE analysis. For calculating Roseobacter-specific MPN from the serial dilution series, the microtiter wells that showed growth were tested for amplifiable DNA by using a general Bacteria-specific PCR according to Wilms et al. (49). To specifically target the Roseobacter clade in cultures and in environmental samples, the primer pair RoseoGC536f/GrB735r (15) was used. The PCR reaction mixture $(50 \mu \mathrm{l})$ contained $0.2 \mathrm{mM}$ dNTP's, $1.5 \mathrm{mM} \mathrm{MgCl} 2,0.2 \mathrm{mM}$ of each primer, 1 $\mathrm{x}$ Red Taq Buffer (Sigma, Munich, Germany), 0.2 ng $\mu \mathrm{l}^{-1}$ BSA, $2 \mathrm{U}$ Red Taq DNA polymerase (Sigma, Munich, Germany) and 2-4 $\mu$ lemplate DNA (2-6 ng $\left.\mu \mathrm{l}^{-1}\right)$. The PCR was performed in a thermal cycler (Mastercycler, Eppendorf, Hamburg,
Germany) for 10 cycles under the following conditions: $94^{\circ} \mathrm{C}$ for four minutes, $94^{\circ} \mathrm{C}$ for 30 seconds, $65^{\circ} \mathrm{C}$ for one minute, $72^{\circ} \mathrm{C}$ for one minute. After that, the samples were run for another 33 cycles with an annealing temperature of $63^{\circ} \mathrm{C}$, followed by a final elongation step at $72^{\circ} \mathrm{C}$ for ten minutes. After amplification, the PCR products were visualized on a $1.5 \%(\mathrm{w} / \mathrm{v})$ agarose gel.

\section{DGGE analysis}

DGGE was carried out as described by Süß et al. (44) using an INGENYphorU-2 system (Ingeny, Leiden, The Netherlands). The amplicons (ca. 200 bp) obtained by the Roseobacter- specific PCR were mixed with loading buffer (40 \% [wt/vol] glycerol, $60 \%$ [wt/vol] $1 x$ Tris-acetate-EDTA [TAE], bromphenol blue) in a ratio of 1:2. PCR products were loaded onto polyacrylamide gels $(6 \%$ $\mathrm{wt} / \mathrm{vol}$ ) stored in $1 \mathrm{x}$ TAE (40 mmol $\mathrm{l}^{-1}$ Tris, 20 mmol $\mathrm{l}^{-1}$ acetate, 1 mmol $\mathrm{l}^{-1}$ EDTA), with a denaturing gradient from $50 \%$ to $70 \% \quad(100 \%$ denaturant correspond to $7 \mathrm{~mol} \mathrm{l}^{-1}$ urea and $40 \%$ formamide). DGGE-gels were run at a constant voltage of $100 \mathrm{~V}$ and at a temperature of $60{ }^{\circ} \mathrm{C}$ for 20 h. After electrophoresis, gels were stained for 2 h with $1 \times$ SYBRGold (Molecular Probes, Leiden, Netherlands) and destained in water for $20 \mathrm{~min}$ in distilled water prior to UV transillumination.

\section{Cluster analysis of DGGE community patterns}

The software package GelComparII, version 6.5 (Applied Maths, St-Martens-Latem, Belgium) was used for cluster analysis according to Wilms et al. (49). Since all lanes of a DGGE gel contain a characteristic degree of smear, a background subtraction was performed to make different lanes comparable. Therefore, a background scale of $20 \%$ was applied in the software package. The densitometric curves were compared using the Pearson coefficient (31). A position tolerance optimization was performed to fit the curves to the best possible match. Dendrograms were generated, using the UPGMA method (41).

\section{Sequence analysis of DGGE bands and pure cultures}

To identify the phylogenetic affiliation of pure cultures, genomic DNA was extracted from picked colonies. The cell pellet was resuspended in $100 \mu \mathrm{l}$ of PCR-grade water (Eppendorf, Hamburg, Germany) and then treated by the freeze and thaw procedure as described above. Two $\mu$ l of the final extract were added to $48 \mu \mathrm{l}$ of PCR mixture. Nearly full-length bacterial 16S rRNA gene sequences 
were amplified using the Bacteria-specific primers 8f/1492r according to Overmann and Tuschak (30). For sequence analysis of DGGE bands, those were excised, subjected to $50 \mu \mathrm{l}$ of PCR-water and incubated over night at $4^{\circ} \mathrm{C}$ to elute the DNA. $2 \mu \mathrm{l}$ of the DNA elute were taken for reamplification by using the Roseobacter-specific primer pair as described above without containing the GC-clamp. The reamplification comprised 26 PCR cycles (annealing temperature $55^{\circ} \mathrm{C}$ ). All PCR products were purified using the QIAquick PCR purification Kit (Qiagen $\mathrm{GmbH}$, Hilden, Germany) and were commercially sequenced (GATC, Köln, Germany). The Göttingen Genomics Laboratory determined the sequences of the isolates. The partial 16S rRNA sequences were compared to those in GenBank using the BLAST function (1). All partial 16S rRNA gene sequences of DGGE bands and isolates have been deposited in the EMBL database under accession numbers HG423215 - HG423283.

\section{Pyrosequencing of 16S rRNA genes}

All 27 water, particle and sediment samples from this study were subjected to pyrosequencing. The V3-V5 region of the environmental DNA (50 ng/ $\mu \mathrm{l})$ was amplified with 15 different forward primers according to Schneider et al. (36) containing the Roche 454 pyrosequencing adaptors (underlined), the key (italic), one unique MID per sample and a template specific sequence: Forward primer V3forMID-137-151: 5'-CCA TCT CAT CCC TGC GTG TCT CCG AC-T CAG-MID(137-151)-TAC GGR AGG CAG CAG-3' and reverse primer V5rev: 5' CCT ATC CCC TGT GTG CCT TGG CAG TC- $T$ $C A G-\mathrm{CCG}$ TCA ATT CMT TTG AGT-3'. The PCR reactions were set up according to the manufacturer's instructions of the Phusion PCR Master Mix Kit (Thermo Scientific, Bremen, Germany). The reaction mixture $(50 \mu \mathrm{l})$ contained $15.5 \mu \mathrm{l}$ of PCR H2O, $25 \mu \mathrm{l}$ of $2 \mathrm{x}$ Phusion Master Mix with HF Buffer, $2 \mu$ of BSA, $1.5 \mu$ l of $100 \%$ DMSO, $2.5 \mu \mathrm{l}$ of primers and $1 \mu \mathrm{l}$ of template. The PCR was performed in a thermal cycler (Mastercycler, Eppendorf, Hamburg, Germany) under the following conditions: $98^{\circ} \mathrm{C}$ for 4 minutes, 26 cycles with $98^{\circ} \mathrm{C}$ for 30 seconds, $60^{\circ} \mathrm{C}$ for one minute, $72^{\circ} \mathrm{C}$ for one minute followed by a final elongation step at $72^{\circ} \mathrm{C}$ for 5 minutes. After amplification, the complete PCR mixture $(50 \mu \mathrm{l})$ was loaded on $1 \%(\mathrm{w} / \mathrm{v})$ agarose gels and excised by using peqGOLD Gel Extraction Kit (PEQLAB Biotechnologie $\mathrm{GmbH}$, Erlangen, Germany) according to the manufacturer's instructions. The concentration and purity of the DNA samples were analyzed by using Nanodrop (Thermo Scientific, Bremen, Germany). For further sequencing, $5 \mathrm{ng} / \mu \mathrm{l}$ of DNA was required, if the desired concentration was not reached, the procedure was repeated for those samples. If necessary, 2-5 PCR reaction mixtures were pooled before purification. Finally, the samples were subjected to pyrosequencing at the Institute für Mikrobiologie und Genetik (Göttingen, Germany). Raw data of all 27 samples generated in this study were deposited in the NCBI Short Read Archive under accession SRA096062. Data from the 13 surface samples $(3 \mathrm{~m})$ were obtained from Wemheuer et al. (B. Wemheuer, D. Meier, P. Klembert, S. Billerbeck, H.-A. Giebel, C. Scherber, M. Simon, and R. Daniel, submitted for publication) and were deposited under accession number SRA082674.

\section{Processing and analysis of pyrosequencing- derived datasets}

After raw data extraction, reads shorter than $300 \mathrm{bp}$, with an average quality value below 25 , possessing long homopolymer stretches (> $8 \mathrm{bp}$ ), or primer mismatches (> 5) were removed. Subsequently, sequences were denoised employing Acacia (2). Remaining primer sequences were truncated employing cutadapt (24). Chimeric sequences removed using UCHIME and the most recent greengenes core set as reference dataset $(11,13)$. Processed sequences of all samples were joined, sorted by decreasing length, and clustered employing the UCLUST algorithm (12). Sequences were clustered in operational taxonomic units (OTUs) at $1 \%, 3 \%$ and $20 \%$ genetic dissimilarity according to Simon et al. (40). OTUs at 3 and $20 \%$ sequence divergence represent species and phylum level, respectively (35). Phylogenetic composition was determined using the QIIME assign_taxonmy.py script (5). A BLAST alignment against the Silva SSURef 111 NR database (32) was thereby performed. Sequences were classified with respect to the silva taxonomy of their best hit. Rarefaction curves, Shannon indices (39) and Chao1 indices (7) were calculated. In addition, the maximal number of OTUs (nmax) was estimated for each sample using the Michaelis-Menten249 fit alpha diversity metrics included in the QIIME software package. To compare bacterial community structures across all samples based on phylogenetic or count-based distance metrics, Principal Coordinate Analysis (PCoA) plots were generated and a phylogenetic tree was calculated prior to PCoA generation. For this purpose, sequences were aligned using the PyNAST algorithm. The 
phylogenetic tree and the corresponding OTU table were subsequently used to generate PCoA plots.

\section{RESULTS}

Free-living and particle-associated roseobacters show different diversity patterns

North Sea samples from the German/Danish coast and the Norwegian trench (Fig. 1) were analyzed by Roseobacter-specific DGGE to identify an overlap between free-living, particle260 associated and sediment-dwelling communities. Cluster analysis of DGGE patterns revealed specific differences between free-living and attached roseobacters (Fig. 2). Interestingly, particle-associated Roseobactercommunities from surface-near waters $(3 \mathrm{~m}$, young particles) clustered separately, while the community composition of matured particles from waters at the bottom of the mixed layer (10 to $30 \mathrm{~m}$ ) showed high similarities to that of the sediment surface. Sequencing of representative DGGE bands indicated the presence of specific Roseobacter populations within the different pelagic and benthic compartments (Figs. S1, S2 and Tables S1, S2).
Some bacteria such as relatives of Sulfitobacter donghicola were part of all free-living and particleassociated communities. Bacteria affiliated to Nereida ignava occurred in the entire water column down to the seafloor, whereas relatives of Phaeobacter caeruleus only occurred in shallow waters and sequences related to Thalassobius mediterraneus were exclusively detected in bottom waters. The material taken from the young particles (3 mbsl) was most notably different from the rest of the samples. Still some bacteria occurred on all particles, e.g. affiliates of Sulfitobacter dubius, whereas others were exclusively present in either the sediment such as relatives of Roseovarius crassostreae or the shallow water samples from the chlorophyll a maximum (bloom) like Sulfitobacter pontiacus affiliates. As the DGGE analysis gave a limited phylogenetic resolution (amplicon size: 200 bp), pyrosequencing was performed on the same material to obtain a more detailed insight into the Roseobacter community structures. A total of app. 452,000 high quality 16S rRNA gene sequences were obtained by amplicon-based pyrosequencing of all sites and compartments.

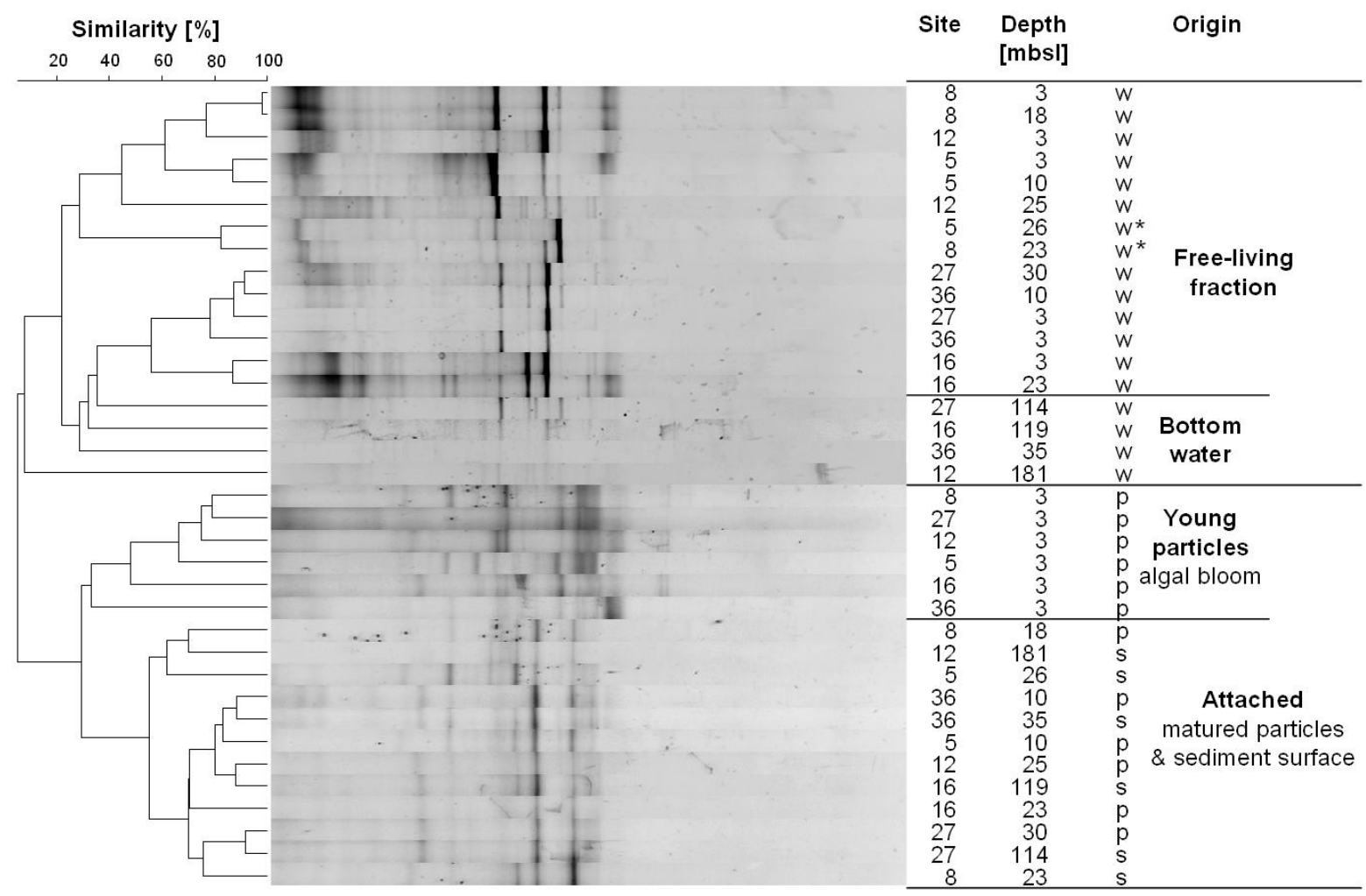

Fig. 2. Cluster analysis of Roseobacter-specific DGGE patterns. The densitometric curves of the DGGE community profiles were obtained by applying GelComparII and compared using the Pearson coefficient. The dendrogram was generated using the UPGMA method. Sampling sites, water depth in meters below sea level (mbsl) and origin ( $\mathrm{w}=$ water, $\mathrm{p}=$ particles, $\mathrm{s}=$ sediments $)$ are indicated. $*=$ two bottom water samples (St. 5 \& 8) clustering with other deep and surface waters. 


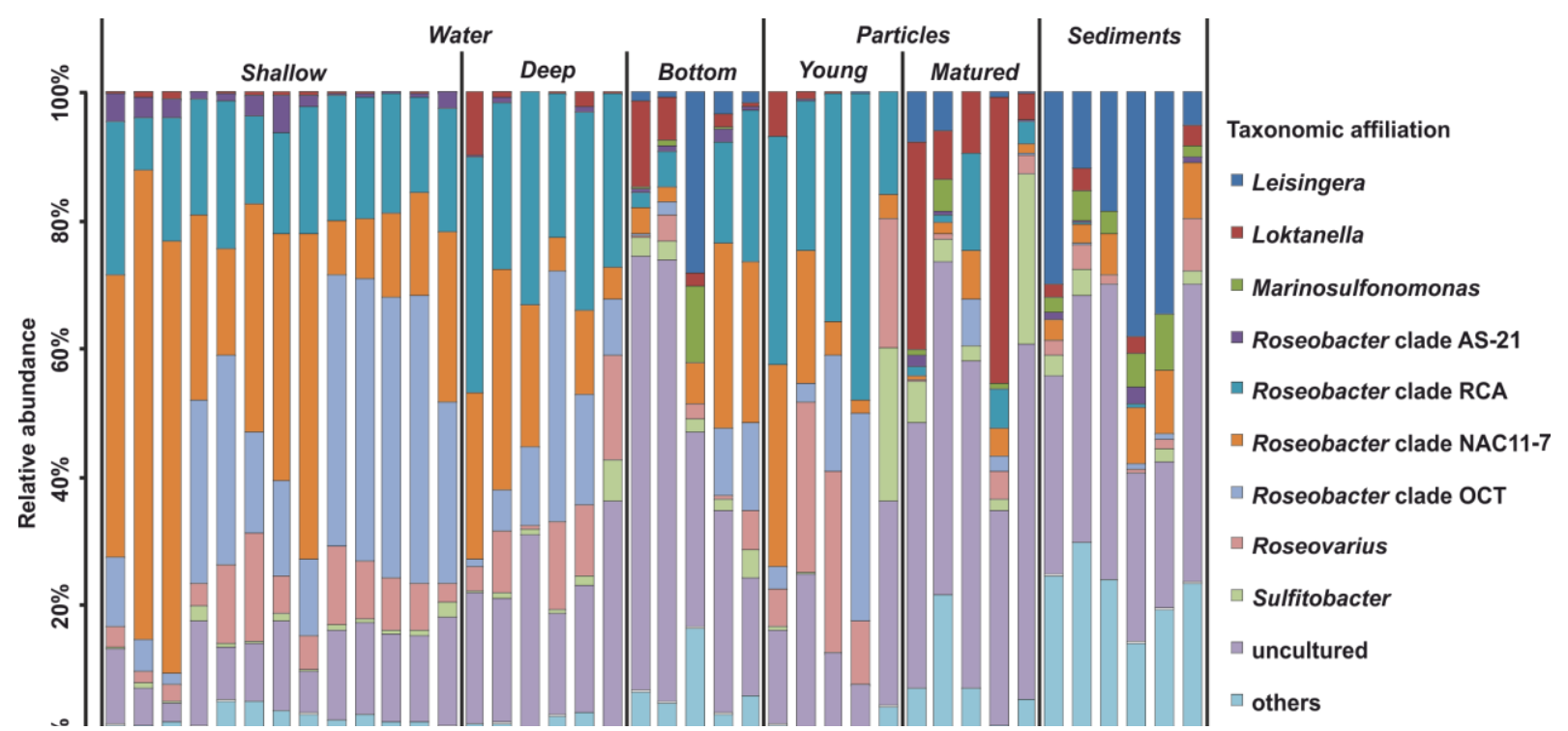

Fig. 3. Amplicon-based diversity patterns of Rhodobacteraceae within the different free-living and attached fractions. The sequences that were affiliated to the Rhodobacteraceae (93.000) were assigned to operational taxonomic units (OTUs) on a 99\% sequence similarity level. The samples are named by sampling site (1-27), compartment $(\mathrm{w}=$ water, $\mathrm{p}=$ particles, $\mathrm{s}=$ sediment $)$ and water depth $(3-181 \mathrm{mbsl})$.

About 93,000 sequences were affiliated to the Rhodobacteraceae with an average of approximately $20 \%$ per sample. While approximately $25 \%$ of the free 283 living fraction was affiliated to the Rhodobacteraceae, a proportion of about $19 \%$ and $2 \%$ were determined for particles and sediments, respectively. To display diversity patterns for this phylogenetic group in the different compartments, the sequences were assigned to operational taxonomic units (OTUs) on a $99 \%$ sequence similarity level. In general, the diversity of Roseobacter populations of sediments and matured particles was generally much higher than that of water samples and young particles (Fig. 3). Diversity patterns indicate increasing numbers of uncultured roseobacters from the sea surface to the seafloor. Water samples were dominated by members of the Roseobacter subcluster NAC 11-7, the Roseobacter Clade Affiliated (RCA) cluster, and the OCT lineage comprising the cluster NAC12, NAC11-6 (19) and CHAB-I-5. Sediments and matured particles harbored a variety of other lineages including Sulfitobacter and Roseovarius species. Matured particles were dominated by Loktanella species. In contrast, Leisingera species dominated sediments, only. One exception for the general separation of free-living and particleassociated roseobacters was the bottom water sample from station 16 . The respective community composition was highly similar to that of the underlying sediment surface. This indicates a probable mixing during sample recovery which was not visible in the DGGE cluster analysis.

\section{Next-generation sequencing confirms DGGE results}

The composition of Rhodobacteraceae-related phylotypes from the pyrosequencing analysis that was identified for the different compartments was used to perform a principle coordinate analysis (PCoA). In this calculation, we have integrated an additional set of water samples from a depth of three meters that were recovered during the same sampling campaign (small black dots in Fig. 1). Two end-members of the Rhodobacteraceae community composition can be identified along the first principle coordinate (PC1) that explains 52\% of the variation (Fig. 4). One comprises samples from shallow waters, the other is a combination of samples from sediments, matured particles and bottom waters. The samples from young particles and deep waters fall in between. While the shallow water samples are widespread along PC2 (11\% of variation), indicating subtle differences among the free-living Rhodobacteraceae communities near the sea surface, the other end-member shows less variations. This was already indicated by the diversity plot shown in Figure 3. This general trend is in accordance to the clustering of DGGE community profiles of Roseobacter populations.

However, the clear separation between most bottom waters and the rest of the free-living fraction, as seen in the DGGE clusters is not as visible in the PCoA. 


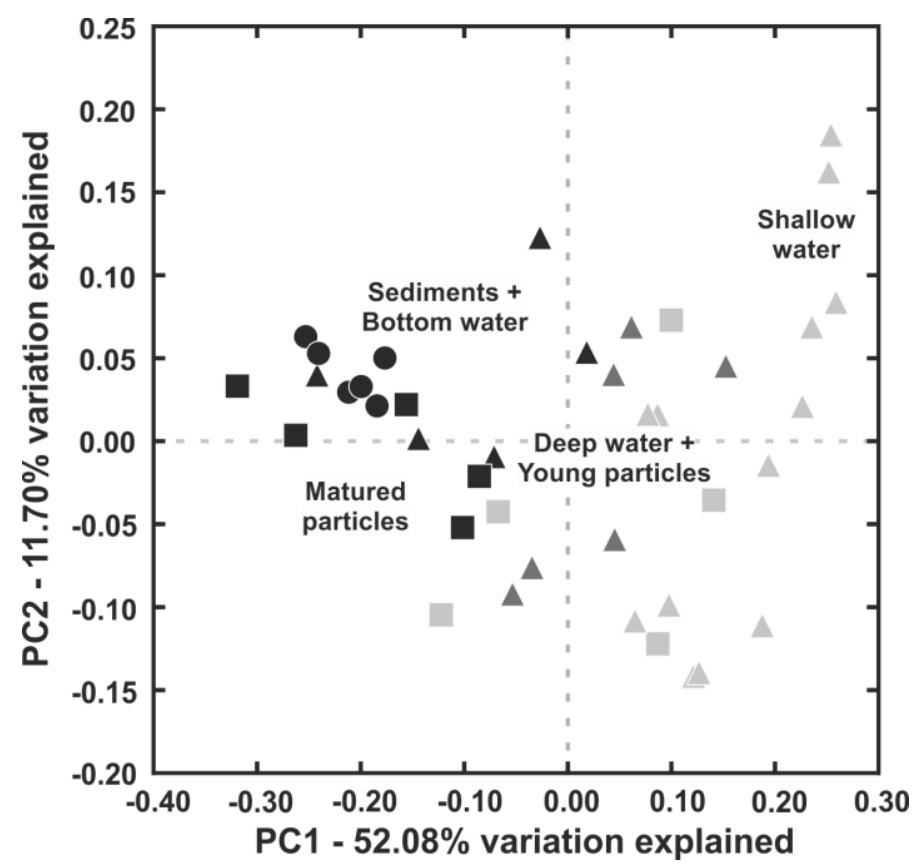

Fig. 4. Principle coordinate analysis of Rhodobacteraceae community compositions. Water samples are displayed as triangles (light gray $=$ shallow, gray $=$ deep, black $=$ bottom), particles are displayed as squares (light gray = young, black $=$ matured), sediments are shown as black circles.

High numbers of roseobacters were enriched in media amended with methylated sulfur compounds

Apart from the cultivation-independent methods, a subset of samples was inoculated in serial dilution cultures. These enrichments were performed with water samples of the chlorophyll a maximum (bloom) and bottom seawater, as well as with sediments from the upper centimeter of the seafloor and the oxic/anoxic transition zone between 4 and 10 centimeter below seafloor (cmbsf). The media

were amended with DMS, DMSP or DMSO to quantify the amount of roseobacters utilizing organic sulfur compounds. In one medium, lactate was provided as a carbon source, while DMS served as electron donor. Two other media contained either DMS or DMSP as the only substrates. Here, the sulfur compounds served as both, electron donor and carbon source. In the fourth medium, DMSO was added as electron acceptor for anaerobic respiration. Due to technical problems during sampling, samples from station 36

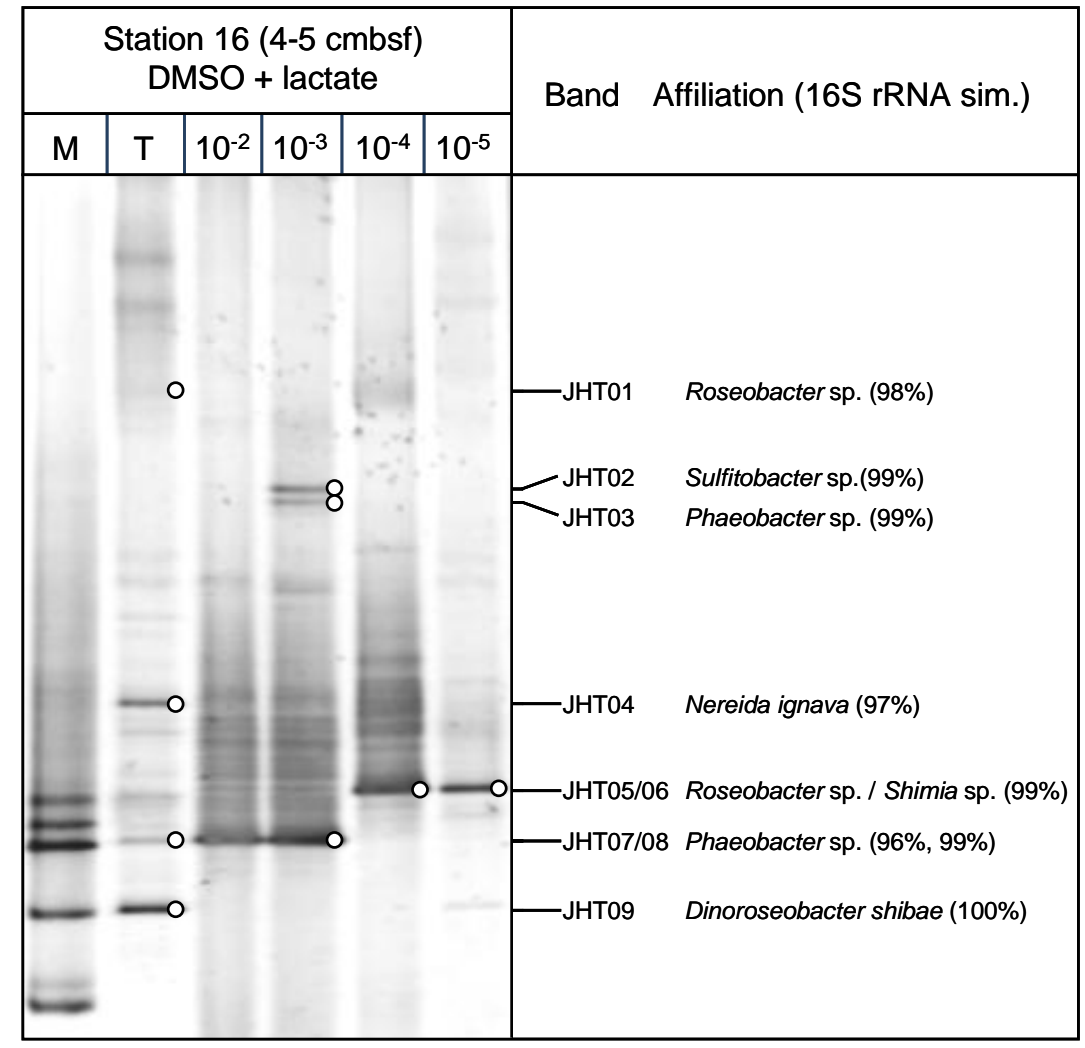

Fig. 5. DGGE analysis of one anoxic serial dilution series from the oxic/anoxic transition zone (4-5 cmbsf) of station 16. PCR amplicons ( 200 bp) were generated by using Roseobacterspecific primers. Representative DGGE bands (white circles) were excised and sequenced. The next relatives in GenBank are indicated. $\mathrm{M}=$ marker, $\mathrm{T}=$ original sediment 
Table 1: MPN analysis of pelagic and benthic North Sea samples. Samples were take from the chlorophyll a maximum (Bloom), bottom waters above the seafloor (Bottom), the sediment surface (Seafloor) and the oxicanoxic transition zone (Transition) at six different stations. Media were amended with DMS and DMSP and DMSO as organic sulfur compounds. MPN numbers are given in $10^{3}$ cells per milliliter which refers to $10^{3}$ cells per $\mathrm{cm}^{3}$ of sediment.

\begin{tabular}{|c|c|c|c|c|c|c|c|c|c|c|}
\hline \multirow[t]{2}{*}{ Station } & \multirow{2}{*}{$\begin{array}{c}\text { Origin } \\
\text { Bloom }\end{array}$} & \multirow{2}{*}{$\begin{array}{c}\text { Depth } \\
3 \mathrm{mbsl}\end{array}$} & \multicolumn{2}{|c|}{$\begin{array}{l}\text { DMS+lactate } \\
{\left[10^{3} \text { cells } / \mathrm{ml}\right]}\end{array}$} & \multicolumn{2}{|c|}{$\begin{array}{c}\text { DMS } \\
{\left[10^{3} \text { cells } / \mathrm{ml}\right]}\end{array}$} & \multicolumn{2}{|c|}{$\begin{array}{c}\text { DMSP } \\
{\left[10^{3} \text { cells } / \mathrm{ml}\right]}\end{array}$} & \multicolumn{2}{|c|}{$\begin{array}{c}\text { DMS0+lactate } \\
{\left[10^{3} \text { cells } / \mathrm{ml}\right]}\end{array}$} \\
\hline & & & 14 & 9 & 9 & 9 & 0.4 & 0 & - & - \\
\hline \multirow{4}{*}{36} & Bottom & $35 \mathrm{mbsl}$ & 300 & 0 & 0.4 & 0.4 & 0.15 & 0 & - & - \\
\hline & Seafloor & $0-1 \mathrm{cmbsf}$ & 150 & 40 & 9 & 9 & 0.9 & 0.9 & - & - \\
\hline & Transition & $4-5 \mathrm{cmbsf}$ & 9 & 4 & 0.9 & 0.4 & 0.023 & 0.023 & - & - \\
\hline & Bloom & $3 \mathrm{mbsl}$ & 4 & 0.4 & 0 & 0 & 0 & 0 & 2000 & 1100 \\
\hline \multirow{3}{*}{5} & Bottom & $26 \mathrm{mbsl}$ & 2.3 & 0.4 & 0.9 & 0 & 4 & 0 & 700 & 700 \\
\hline & Seafloor & $0-1 \mathrm{cmbsf}$ & 1.5 & 1.1 & 4.3 & 4.3 & 0.4 & 0.4 & 7500 & 7500 \\
\hline & Transition & $5-6 \mathrm{cmbsf}$ & 4 & 4 & 1.5 & 1.5 & 40 & 0 & 2000 & 2000 \\
\hline \multirow{4}{*}{8} & Bloom & $3 \mathrm{mbsl}$ & 0.4 & 0.4 & 300 & 0 & 0 & 0 & 2000 & 1100 \\
\hline & Bottom & $23 \mathrm{mbsl}$ & 0.4 & 0.4 & 0.4 & 0 & 0 & 0 & 15 & 7 \\
\hline & Seafloor & $0-1 \mathrm{cmbsf}$ & 70 & 70 & 9 & 9 & 0.023 & 0.023 & 15000 & 2800 \\
\hline & Transition & $5-6 \mathrm{cmbsf}$ & 4 & 4 & 0.9 & 0.9 & 0.023 & 0.023 & 230 & 230 \\
\hline \multirow{4}{*}{27} & Bloom & $30 \mathrm{mbsl}$ & 7 & 7 & 0.4 & 0 & 3 & 0 & - & - \\
\hline & Bottom & $114 \mathrm{mbsl}$ & 2.3 & 2.3 & 0.9 & 0.9 & 30 & 0 & - & - \\
\hline & Seafloor & $0 \mathrm{cmbsf}$ & 200 & 200 & 70 & 70 & 0.023 & 0.023 & - & - \\
\hline & Transition & $10-11 \mathrm{cmbsf}$ & 700 & 700 & 0.4 & 0.4 & 0.9 & 0.9 & - & - \\
\hline \multirow{4}{*}{12} & Bloom & $25 \mathrm{mbsl}$ & 0 & 0 & 0.9 & 0.9 & 0 & 0 & 300 & 300 \\
\hline & Bottom & $181 \mathrm{mbsl}$ & 0 & 0 & 0.023 & 0.023 & 0 & 0 & 15 & 15 \\
\hline & Seafloor & $0-1 \mathrm{cmbsf}$ & 40 & 40 & 0.43 & 0.15 & 0.23 & 0.23 & 21000 & 21000 \\
\hline & Transition & $5-6 \mathrm{cmbsf}$ & 40 & 40 & 2.4 & 0.43 & 0.023 & 0.023 & 1200 & 750 \\
\hline \multirow{4}{*}{16} & Bloom & $23 \mathrm{mbsl}$ & 40 & 0 & 0.4 & 0 & 0 & 0 & 0 & 0 \\
\hline & Bottom & $119 \mathrm{mbsl}$ & 0.4 & 0.4 & 400 & 0 & 0 & 0 & 4 & 4 \\
\hline & Seafloor & $0-1 \mathrm{cmbsf}$ & 40 & 40 & 90 & 90 & 0.023 & 0.023 & 110000 & 300 \\
\hline & Transition & $5-6 \mathrm{cmbsf}$ & 4 & 4 & 30 & 30 & 4 & 0 & 11000 & 30 \\
\hline
\end{tabular}

Table 2: Origin and closest type strains of Roseobacter-affiliated isolates.

\begin{tabular}{|c|c|c|c|c|c|c|c|}
\hline $\begin{array}{c}\text { Strain } \\
\text { affiliation }\end{array}$ & Station & $\begin{array}{l}\text { Water } \\
\text { Depth } \\
\text { [mbsl] }\end{array}$ & $\begin{array}{c}\text { Sediment } \\
\text { Depth } \\
\text { [cmbsf] }\end{array}$ & Origin & Medium & Closest type strain & $\begin{array}{c}\text { Max } \\
\text { Ident. } \\
{[\%]}\end{array}$ \\
\hline SK003/38 & 36 & 3 & & Bloom & DMS+Lactate & Sulfitobacter dubius & $98-99$ \\
\hline SK025 & 36 & 3 & & Bloom & DMS+Lactate & Sulfitobacter pontiacus & 97 \\
\hline SK024/29 & 36 & 35 & & Bottom & DMS & Loktanella salsilacus & 99 \\
\hline SK009/10 & 36 & 35 & $0-1$ & Seafloor & DMS+Lactate & Loktanella rosea & $98-99$ \\
\hline SK031/32 & 36 & 35 & $4-5$ & Transition & DMS & Celeribacter neptunius & 96 \\
\hline SK040 & 5 & 26 & $5-6$ & Transition & DMSP & Phaeobacter arcticus & 99 \\
\hline SK042 & 5 & 26 & $5-6$ & Transition & DMSP & Phaeobacter inhibens & 97 \\
\hline SK002/23 & 8 & 23 & & Bottom & DMS+Lactate & Shimia isoporae & 99 \\
\hline SK012 & 8 & 23 & $0-1$ & Seafloor & DMS+Lactate & Sulfitobacter mediterraneus & 98 \\
\hline SK013 & 27 & 114 & $0-1$ & Seafloor & DMS+Lactate & Shimia isoporae & 97 \\
\hline SK015/21 & 12 & 181 & $0-1$ & Seafloor & DMS+Lactate & Loktanella agnita & 93 \\
\hline SK033 & 12 & 181 & $0-1$ & Seafloor & DMS & Roseobacter litoralis & 94 \\
\hline SK045 & 12 & 181 & $0-1$ & Seafloor & DMS & Loktanella koreensis & 94 \\
\hline SK011 & 16 & 119 & & Bottom & DMS+Lactate & Sulfitobacter delicatus & 98 \\
\hline
\end{tabular}


and 27 could not be inoculated in the anoxic medium. All dilution series were screened for the diversity of roseobacters and used for their isolation. After detecting growth in the dilution series by using a SYBR Green I assay (23), all positive enrichments were analyzed by Roseobacter-specific PCR. The results were used to estimate most probable numbers of roseobacters for the different environmental samples (Table 1). Interestingly, the anoxic enrichments with DMSO as electron acceptor showed the highest MPN with $1.1 \times 10^{8}$ bacterial cells $/ \mathrm{cm}^{3}$ for the sediment surface of station 16 and up to $2.1 \times 10^{7}$ Roseobacter-affiliated cells $/ \mathrm{cm}^{3} \quad$ (station 12, seafloor). All dilution series containing DMSP and half of the series containing DMS as sole carbon source stimulated growth of sediment-dwelling roseobacters, only.

\section{Several roseobacters were enriched and isolated from serial dilution cultures}

A total of 263 isolates was obtained from the oxic enrichments. From these strains, 45 showed a positive result by PCR-screening using Roseobacter-specific primers. These isolates were subcultivated on agar plates containing their respective media. After sequencing and BLAST analysis, 20 strains turned out to be affiliated to the Roseobacter

clade (Table 2). Some strains from the same samples but different dilution steps were affiliated to the same species. More than half of the isolates (12 strains) derived from sediment samples and most of them (6 strains) from media containing DMS + lactate. Seven strains belonged to four different species within the genus Loktanella. Strains affiliated to L. rosea, L. agnita, L. koreensis were isolated from the seafloor and L. salsilacus was obtained from bottom waters. Five strains were related to four different species of the genus Sulfitobacter (S. dubius, $S$. pontiacus, $S$. medietrraneus, $S$. delicatus). Those were obtained from both, water and sediment samples (bloom, bottom water and seafloor). Other isolates were affiliated to Shimia isoporae, Roseobacter litoralis and Celeribacter neptunius. The latter and two affiliates of the genus Phaeobacter were isolated from the oxic/anoxic transition zone. Interestingly, the two strains affiliated to $P$. arcticus and $P$. inhibens, isolated from the DMSP medium, were not found in sediments before. Genetic signatures of the isolates from the oxic enrichments were detected in low percentages in the pyrosequencing dataset. On average, their relative abundance in the environmental samples was $0.03 \%$ of the bacterial communities and $0.55 \%$ of the Rhodobacteraceae. Interestingly, their percentage for all detected Rhodobacteraceae within the sediment samples was much higher $(2.45 \%)$. This was mainly due to strains SK033 and SK045 (affiliates of $R$. litoralis and L. koreensis, respectively) that were both isolated from the seafloor of site 12. In this sample, they comprised $2.9 \%$ of all detected Rhodobacteraceae. They seem to be typical members of the seafloor bacterial community as they were found in all sediment samples with up to $6.2 \%$ of all Rhodobacteraceae at site 27. Initial anoxic enrichments which showed a Roseobacterspecific PCR signal were subcultivated in deep-agar dilutions and additionally analyzed for their diversity by DGGE. Sequencing of DGGE bands revealed growth of various roseobacters in the different dilution steps. For instance, bands of the original sample from the oxic/anoxic transition zone of station 16 were affiliated to species of Roseobacter, Shimia, Sulfitobacter, Phaeobacter, Nereida ignava, and Dinoroseobacter shibae (Fig. 5). While a species affiliated to Nereida ignava did not grow in the dilution cultures, the Phaeobacter species was specifically enriched in dilutions of $10^{-2}$ and $10^{-3}$. Additional bands that were affiliated to another Phaeobacter and a Sulfitobacter species showed up in the $10^{-3}$ dilution step. The last two dilution steps $\left(10^{-4}\right.$ and $\left.10^{-5}\right)$ were dominated by relatives of Roseobacter / Shimia species and showed faint bands affiliated to D. shibae. This example displays the dilution to extinction of fastgrowing, but less abundant species along serial dilution cultures. However, as roseobacters were not the majority within the entire microbial community, many colonies were present in the respective agar tubes. Unfortunately, after six months of incubation, no roseobacters were among the first 84 picked colonies of the anoxic enrichments as indicated by preliminary sequencing of the first subcultivation step.

\section{DISCUSSION}

As main outcome of our study, both, DGGE analysis and amplicon-based sequencing of $16 \mathrm{~S}$ rRNA genes indicated a broad overlap of Roseobacter populations thriving on matured particles and the sediment surface which were clearly distinct from the free-living communities dwelling in the water column. The attached fraction 
of roseobacters was much more diverse than the free-living fraction. A variety of roseobacters was enriched and isolated from all sampling sites and compartments with media containing different organic sulfur compounds.

Habitat specific characteristics trigger the separation of pelagic and benthic roseobacters.

Specific differences between free-living, particleassociated and sediment-associated bacterial fractions in the southern North Sea were previously identified by Stevens et al (43). Focusing on freeliving, aggregate-associated and sediment-dwelling microbial communities from intertidal flat regions of the German Wadden Sea, distinctive patterns for the different compartments were obtained. In conclusion, particles represent an intermediate habitat that is characterized by bacterial transformation processes occurring in both, the water column and at the sediment surface. Also, Rink et al $(33,34)$ detected differences between free living and particle-associated bacterial communities in the southern North Sea by DGGE analysis and showed, by applying Alphaprotebacteria and Roseobacter-specific primer sets, a higher number of bands in the particle-associated relative to the free-living bacterial communties. So far, however, the present study is the first one which examines specifically differences in the composition of Roseobacter communities among the free-living, particle-and sediment-associated bacterial communities. The low diversity of roseobacters we have detected within surface water samples is in accordance with previous investigations on phytoplankton blooms $(45,48)$. Even though there is a significant difference between the free-living and the attached lifestyle, an overlap in microbial diversity between both compartments is visible. The release of algal exudates triggers growth of highly specialized microbial communities on the phytoplankton-born particles (17). As surface-near, young particles are composed of fresh algal material, the associated communities are mainly degrading their exudates (9). It was shown that roseobacters exhibit mutualistic interactions with planktonic algae and dinoflagellates $(16,47)$. In contrast, matured particles in deeper layers are constituted of decaying algal material and thus harbor different microbial communities (37, 51). Environmental conditions such as high nutrient concentrations and a complex organic-matter composition are comparable to those found at the sediment surface. Thus, both compartments exhibit similar microbial community patterns $(21,29)$. The recalcitrant organic matter found on matured particles and the sediment surface stimulates highly diverse, slowgrowing microbial communities with various metabolic capacities. The variety of available ecological niches and interactions between different microbial community members is reflected in the high proportion of roseobacters that are assigned as "uncultured". This type of environment is hard to be mimicked under laboratory conditions, which results in a lack of respective isolates.

\section{A variety of roseobacters are involved in the utilization of organic sulfur compounds.}

DMSP is an osmolyte that is produced by marine macro- and microalgae (50). This compound is released from lysed, dead or grazed algae and subsequently degraded by various bacteria. High concentrations of DMSP are associated to algal blooms that in turn attract high numbers of roseobacters (16) which were among the first bacteria isolated from DMSP-containing media (47). Sedimenting algal material might lead to an enrichment of DMSP-consuming Roseobacter species at the seafloor. In our cultivation experiments, growth of roseobacters was mainly stimulated in sediment samples when DMSP and DMS were provided as a sole carbon source. Apart from several isolates that were obtained from DMScultures we have isolated two Phaeobacter species from DMSP-enrichments from this compartment. Unfortunately, several DMSP-enrichments were lost during subcultivation. When DMSP is demethylated, the degradation product DMS is oxidized to DMSO. The high numbers of Roseobacter-affiliated isolates we have obtained from DMS-amended media indicate their role in this degradation process. On matured particles and especially in sediments, oxic and anoxic microniches are present in close proximity. If aerobically produced DMSO diffuses into anoxic regions, this can be used as electron acceptor under anoxic conditions. In our enrichments, we found high numbers of roseobacters reducing DMSO in water and sediment samples. This indicates either the presence of facultative anaerobic roseobacters in both, oxic and anoxic compartments, or the existence of microniches. For the next relatives of some of our oxic isolates, e.g. S. pontiacus, it is known that they can perform aerobic and anaerobic respiration (e.g. nitrate reduction) and harbor the gene for DMSO reduction (6). The fact that Sulfitobacter species were isolated from aerobic cultures and detected to grow in anaerobic 
enrichments points to their ability to switch between the two lifestyles. To prove this, we are currently subcultivating further colonies from our anoxic enrichments. Additionally, growth experiments with the aerobic isolates under anoxic conditions will reveal their potential for DMSO reduction.

\section{Cultivation of Roseobacter-affiliated bacteria} matches the results of the molecular investigations

The fact that sequences of all our isolates showed a match in the pyrosequence database was used to quantify their relative abundance in the different compartments. Due to their relatively low percentages, this would have not been possible by using DGGE as fingerprinting technique, only. In general, both molecular methods exhibited a similar grouping of Roseobacter populations from environmental samples with some exceptions. In both approaches, sediments and matured particles were separated from the water samples but clustering of free-living and attached roseobacters was much clearer in the DGGE analysis. However, the primers used in this study are specific for roseobacters but also target a limited number of Rhodobacteraceae and other Alphaproteobacteria. Additionally, they produce a PCR product with a length of app. $200 \mathrm{bp}$ which only gives a low phylogenetic resolution. These limitations can be minimized by amplicon-based sequencing of $16 \mathrm{~S}$ rRNA genes using universal primers to digitally extract information on certain groups from the whole dataset. In contrast to DGGE, pyrosequencing has a higher capacity to explore the entire bacterial richness including rare species (8). Even though pyrosequencing requires a high amount of data-processing and analytical expertise, the possibility to detect and determine the relative abundance of cultured organisms (46) is a big advantage over other techniques. Following this approach, the laborious design and testing of specific primers and probes for quantitative PCR or fluorescence in-situ hybridization (FISH) is circumvented. However, screening of enrichments by DGGE allows to specifically target strains that are growing in these cultures. A molecularly guided cultivation will lead to the isolation of strains even if their colonies are hidden under a broad diversity of other colonies within the subcultures.

\section{ACKNOWLEDGEMENTS}

We thank the crew and the scientific party of RV Heincke (expedition HE361) for their help during sampling. Michael Pilzen, Sonja Standfest, Thomas Schirdewahn and Nawras Ghanem are acknowledged for technical assistance during sample preparation and subcultivation. This work was financially supported by Deutsche Forschungsgemeinschaft (DFG) within the Transregional Collaborative Research Center TRR51.

\section{REFERENCES}

1. Altschul, S. F., T. L. Madden, A. A. Schäffer, J. Zhang, Z. Zhang, W. Miller, andD. J. Lipman. 1997. Gapped BLAST and PSI-BLAST: a new generation of protein database search programs. Nucleic Acids Res 25:3389-3402.

2. Bragg, L., G. Stone, M. Imelfort, P. Hugenholtz, and G. W. Tyson. 2012. Fast,accurate error-correction of amplicon pyrosequences using Acacia. Nature Methods 9:425-426.

3. Brinkhoff, T., H.-A. Giebel, and M. Simon. 2008. Diversity, ecology, and genomics of the Roseobacter clade: a short overview. Archives of Microbiology 189:531-539.

4. Buchan, A., J. M. Gonzalez, and M. A. Moran. 2005. Overview of the marineRoseobacter lineage. Appl Environ Microbiol 71:5665-77.

5. Caporaso, J. G., J. Kuczynski, J. Stombaugh, K. Bittinger, F. D. Bushman, E. K.Costello, N. Fierer, A. G. Pena, J. K. Goodrich, J. I. Gordon, G. A. Huttley, S. T.Kelley, D. Knights, J. E. Koenig, R. E. Ley, C. A. Lozupone, D. McDonald, B. D. Muegge, M. Pirrung, J. Reeder, J. R. Sevinsky, P. J. Turnbaugh, W. A. Walters,J. Widmann, T. Yatsunenko, J. Zaneveld, and R. Knight. 2010. QIIME allows analysis of high-throughput community sequencing data. Nat Methods 7:335-6.

6. Caspi, R., T. Altman, K. Dreher, C. A. Fulcher, P. Subhraveti, I. M. Keseler, A.Kothari, M. Krummenacker, M. Latendresse, L. A. Mueller, Q. Ong, S. Paley, A.Pujar, A. G. Shearer, M. Travers, D. Weerasinghe, P. Zhang, and P. D. Karp.2012. The MetaCyc database of metabolic pathways and enzymes and the BioCyc collection of pathway/genome databases. Nucleic Acids Research 40:D742D753.

7. Chao, A., and J. Bunge. 2002. Estimating the number of species in a stochastic abundance model. Biometrics 58:531-9.

8. Chau, J. F., A. C. Bagtzoglou, and M. R. Willig. 2011. The effect of soil texture onrichness and diversity of bacterial 
communities. Environmental Forensics 12:333-341.

9. Cole, J. J. 1982. Interactions between bacteria and algae in aquatic ecosystems.Annual Review of Ecology and Systematics 13:291314.

10. de Man, J. C. 1977 . MPN tables for more than one test. European J. Appl. Microbiol.4:307310 .

11. DeSantis, T. Z., P. Hugenholtz, N. Larsen, M. Rojas, E. L. Brodie, K. Keller, T.Huber, D. Dalevi, P. Hu, and G. L. Andersen. 2006. Greengenes, a chimera-checked 16S rRNA gene database and workbench compatible with ARB. Appl Environ Microbiol 72:5069-72.

12. Edgar, R. C. 2010. Search and clustering orders of magnitude faster than BLAST. Bioinformatics 26:2460-2461.

13. Edgar, R. C., B. J. Haas, J. C. Clemente, C. Quince, and R. Knight. 2011.UCHIME improves sensitivity and speed of chimera detection. Bioinformatics 27:2194-200.

14. Eilers, H., J. Pernthaler, J. Peplies, F. O. Glockner, G. Gerdts, and R. Amann.2001. Isolation of novel pelagic bacteria from the German bight and their seasonal contributions to surface picoplankton. Appl Environ Microbiol 67:5134-42.

15. Giebel, H.-A., T. Brinkhoff, W. Zwisler, N. Selje, and M. Simon. 2009. Distributionof Roseobacter RCA and SAR11 lineages and distinct bacterial communities from the subtropics to the Southern Ocean. Environmental Microbiology 11:2164-2178.

16. Gonzalez, J. M., R. Simo, R. Massana, J. S. Covert, E. O. Casamayor, C. Pedros-Alio, and M. A. Moran. 2000. Bacterial community structure associated with adimethylsulfoniopropionate-producing North Atlantic algal bloom. Applied andEnvironmental Microbiology 66:42374246.

17. Grossart, H. P., F. Levold, M. Allgaier, M. Simon, and T. Brinkhoff. 2005. Marinediatom species harbour distinct bacterial communities. Environmental Microbiology 7:860-873.

18. Inagaki, F., M. Suzuki, K. Takai, H. Oida, T. Sakamoto, K. Aoki, K. H. Nealson, and K. Horikoshi. 2003. Microbial communities associated with geological horizons in coastal subseafloor sediments from the Sea of Okhotsk. Applied andEnvironmental Microbiology 69:7224-7235.

19. Kiene, R. P. 1990. Dimethyl sulfide production from dimethylsulfoniopropionate incoastal seawater samples and bacterial cultures. Appl Environ Microbiol 56:3292-7.

20. Lenk, S., C. Moraru, S. Hahnke, J. Arnds, M. Richter, M. Kube, R. Reinhardt, T.Brinkhoff, J. Harder, R. Amann, and M. Mussmann. 2012. Roseobacter clade bacteria are abundant in coastal sediments and encode a novel combination of sulfuroxidation genes. Isme J 6:2178-87.

21. Llobet-Brossa, E., R. Rossello-Mora, and R. Amann. 1998. Microbial community composition of Wadden Sea sediments as revealed by fluorescence in situhybridization. Applied and Environmental Microbiology 64:2691-2696.

22. MacGregor, B. J., D. P. Moser, E. W. Alm, K. H. Nealson, and D. A. Stahl. 1997.Crenarchaeota in Lake Michigan sediment. Appl Environ Microbiol 63:117881.

23. Martens-Habbena, W., and H. Sass. 2006. Sensitive determination of microbial growth by nucleic acid staining in aqueous suspension. Appl Environ Microbiol 72:87-95.

24. Martin, M. 2011. Cutadapt removes adapter sequences from high-throughput sequencing reads. Bioinformatics in Action 17:10-12.

25. Miller, T. R., and R. Belas. 2004. Dimethylsulfoniopropionate metabolism by Pfiesteria-associated Roseobacter spp. Applied and Environmental Microbiology70:33833391.

26. Mills, H. J., C. Hodges, K. Wilson, I. R. MacDonald, and P. A. Sobecky. 2003. Microbial diversity in sediments associated with surface-breaching gas hydratemounds in the Gulf of Mexico. Fems Microbiology Ecology 46:39-52.

27. Moran, M. A., R. Belas, M. A. Schell, J. M. Gonzalez, F. Sun, S. Sun, B. J. Binder, J. Edmonds, W. Ye, B. Orcutt, E. C. Howard, C. Meile, W. Palefsky, A.Goesmann, Q. Ren, I. Paulsen, L. E. Ulrich, L. S. Thompson, E. Saunders, and A.Buchan. 2007. Ecological genomics of marine Roseobacters. Appl Environ Microbiol 73:4559-69.

28. Mouné, S., P. Caumette, R. Matheron, and J. C. Willison. 2003. Molecularsequence analysis of prokaryotic diversity in the anoxic sediments underlyingcyanobacterial mats of two hypersaline ponds in Mediterranean salterns. FEMSMicrobiology Ecology 44:117130.

29. Novitsky, J. A. 1990. Evidence for sedimenting particles as the origin of the microbialcommunity in a coastal marine sediment. Marine Ecology Progress Series 60:161-167.

30. Overmann, J., and C. Tuschak. 1997. Phylogeny and molecular fingerprinting ofgreen sulfur bacteria. Archives of Microbiology 167:302-309.

31. Pearson, K. 1926. On the coefficient of racial likeness. Biometrika 18:105-117.

32. Pruesse, E., C. Quast, K. Knittel, B. M. Fuchs, W. Ludwig, J. Peplies, and F. $O$. Glockner. 2007. SILVA: a comprehensive 
online resource for quality checked andaligned ribosomal RNA sequence data compatible with ARB. Nucleic Acids Res35:7188-96.

33. Rink, B., N. Gruener, T. Brinkhoff, K. Ziegelmueller, and M. Simon. 2011.Regional patterns of bacterial community composition and biogeochemical properties in the southern North Sea. Aquatic Microbial Ecology 63:207222.

34. Rink, B., S. Seeberger, T. Martens, C.-D. Duerselen, M. Simon, and T. Brinkhoff.2007. Effects of phytoplankton bloom in a coastal ecosystem on the composition ofbacterial communities. Aquatic Microbial Ecology 48:47-60.

35. Schloss, P. D., and J. Handelsman. 2005. Introducing DOTUR, a computer program for defining operational taxonomic units and estimating species richness. Applied and Environmental Microbiology 71:1501-1506.

36. Schneider, D., G. Arp, A. Reimer, J. Reitner, and R. Daniel. 2013. Phylogenetic analysis of a microbialite-forming microbial mat from a hypersaline lake of thekiritimati atoll, central pacific. PLoS One 8:e66662.

37. Schweitzer, B., I. Huber, R. Amann, W. Ludwig, and M. Simon. 2001. Alpha- and beta-Proteobacteria control the consumption and release of amino acids on lake snow aggregates. Applied and Environmental Microbiology 67:632-645.

38. Selje, N., M. Simon, and T. Brinkhoff. 2004. A newly discovered Roseobacter cluster in temperate and polar oceans. Nature 427:445-8.

39. Shannon, C. E. 2001. A mathematical theory of communication. SIGMOBILE Mob. Comput. Commun. Rev. 5:3-55.

40. Simon, C., A. Wiezer, A. W. Strittmatter, and R. Daniel. 2009. Phylogenetic diversity and metabolic potential revealed in a glacier ice metagenome. Applied and Environmental Microbiology 75:7519-7526.

41. Sogin, M. L., and J. H. Gunderson. 1987. Structural diversity of eukaryotic small subunit ribosomal RNAs. Annals of the New York Academy of Sciences 503:125-139.

42. Stahl, D. A., B. Flesher, H. R. Mansfield, and L. Montgomery. 1988. Use of phylogenetically based hybridization probes for studies of ruminal microbial ecology. Applied \& Environmental Microbiology 54:1079-1084.

43. Stevens, H., T. Brinkhoff, and M. Simon. 2005. Composition of free-living, aggregateassociated and sediment surface-associated bacterial communities in the German Wadden Sea. Aquatic Microbial Ecology 38:15-30.

44. Süß, J., B. Engelen, H. Cypionka, and H. Sass. 2004. Quantitative analysis of bacterial communities from Mediterranean sapropels based on cultivation-dependent methods. FEMS Microbiol Ecol 51:109-21.
45. Teeling, H., B. M. Fuchs, D. Becher, C. Klockow, A. Gardebrecht, C. M. Bennke, M. Kassabgy, S. Huang, A. J. Mann, J. Waldmann, M. Weber, A. Klindworth, A. Otto, J. Lange, J. Bernhardt, C. Reinsch, M. Hecker, J. Peplies, F. D. Bockelmann, U. Callies, G. Gerdts, A. Wichels, K. H. Wiltshire, F. O. Glöckner, T. Schweder, and R. Amann. 2012. Substrate-controlled succession of marine bacterioplankton populations induced by a phytoplankton bloom. Science 336:608619 611 .

46. Vaz-Moreira, I., C. Egas, O. C. Nunes, and C. M. Manaia. 2011. Culture-dependent and culture-independent diversity surveys target different bacteria: a case study in a freshwater sample. Antonie Van Leeuwenhoek International Journal of General and Molecular Microbiology 100:245-257.

47. Wagner-Döbler, I., and H. Biebl. 2006. Environmental biology of the marine Roseobacter lineage. Annu Rev Microbiol 60:255-80.

48. West, N. J., I. Obernosterer, O. Zemb, and P. Lebaron. 2008. Major differences of bacterial diversity and activity inside and outside of a natural iron-fertilized phytoplankton bloom in the Southern Ocean. Environmental Microbiology 10:738629 756.

49. Wilms, R., H. Sass, B. Kopke, H. Koster, H. Cypionka, and B. Engelen. 2006. Specific bacterial, archaeal, and eukaryotic communities in tidal-flat sediments along a vertical profile of several meters. Applied and Environmental Microbiology 72:2756633 2764.

50. Yoch, D. C. 2002. Dimethylsulfoniopropionate: its sources, role in the marine food web, and biological degradation to dimethylsulfide. Appl Environ Microbiol 68:5804636 15.

51. Zhu, M., G. Zhu, L. Zhao, X. Yao, Y. Zhang, G. Gao, and B. Qin. 2013. Influence of algal bloom degradation on nutrient release at the sediment-water interface in Lake Taihu, China. Environ Sci Pollut Res Int 20:1803-11.

52. Zubkov, M. V., B. M. Fuchs, S. D. Archer, R. P. Kiene, R. Amann, and P. H. Burkill. 2002. Rapid turnover of dissolved DMS and DMSP by defined bacterioplankton communities in the stratified euphotic zone of the North Sea. Deep643 Sea Research Part IiTopical Studies in Oceanography 49:30173038. 


\section{SUPPORTING INFORMATION FOR STUDY 4}

\section{Contents:}

Fig. S1. DGGE community patterns of free-living roseobacters.

Fig. S2. DGGE community patterns of particle-associated and sediment-dwelling roseobacters.

Table S1. Free-living fraction of Roseobacter-affiliated phylotypes detected by sequencing of DGGE bands (o) from the gel displayed in Figure S1.

Table S2. Particle-asssociated fraction of Roseobacter-affiliated phylotypes detected by sequencing of DGGE bands (o) from the gel displayed in Figure S2. 


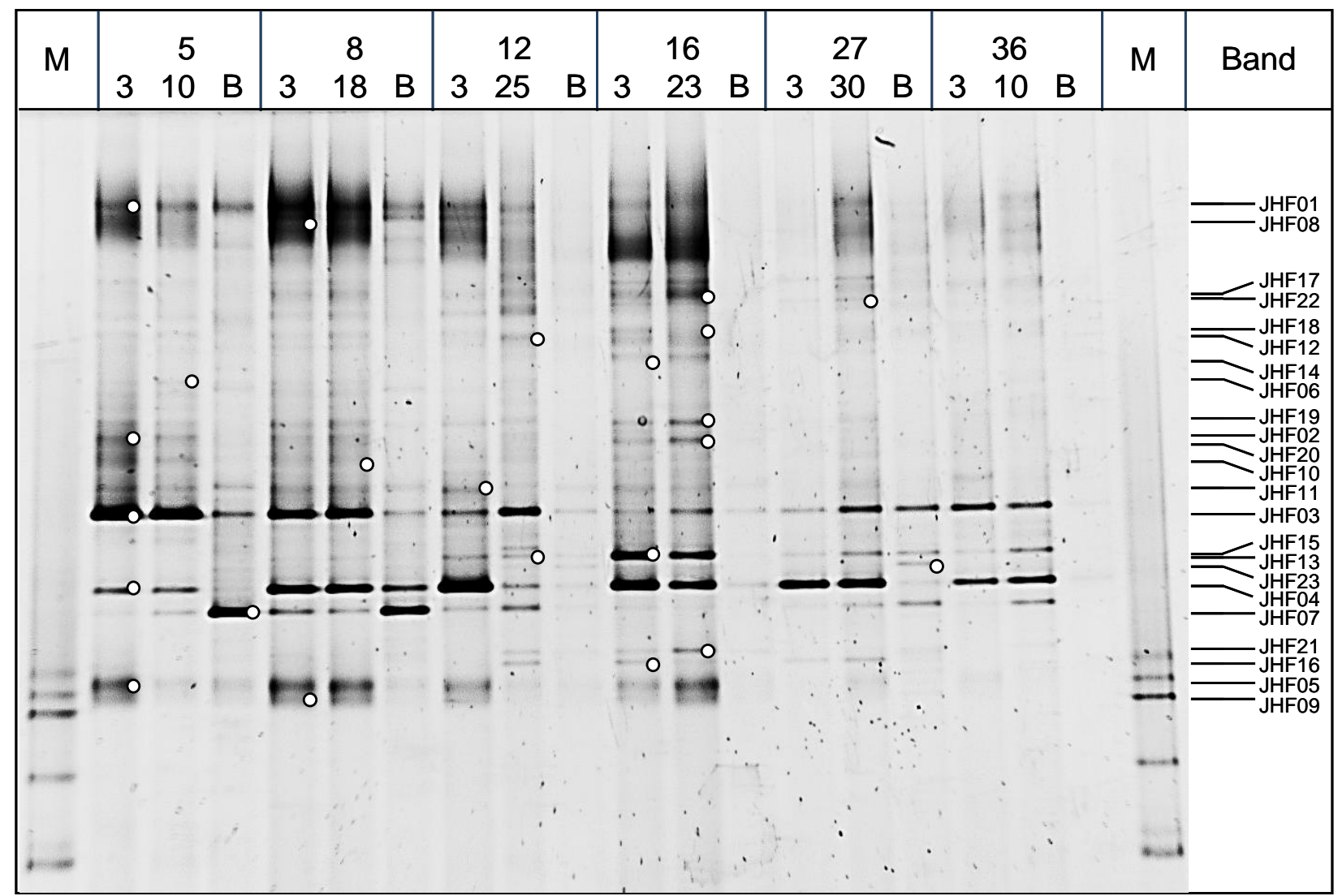

Fig. S1. DGGE community patterns of free-living roseobacters. Samples were obtained from surface waters (3 mbsl), deep waters (10-30 mbsl) and bottom waters (depth: see material and methods section). PCR amplicons ( $200 \mathrm{bp})$ were generated by using Roseobacter-specific primers. Representative DGGE bands (white circles) were excised and sequenced. Phylogenetic affiliation and distribution, see table $\mathrm{S} 1$. $\mathrm{M}=$ marker, $\mathrm{B}=$ bottom water 


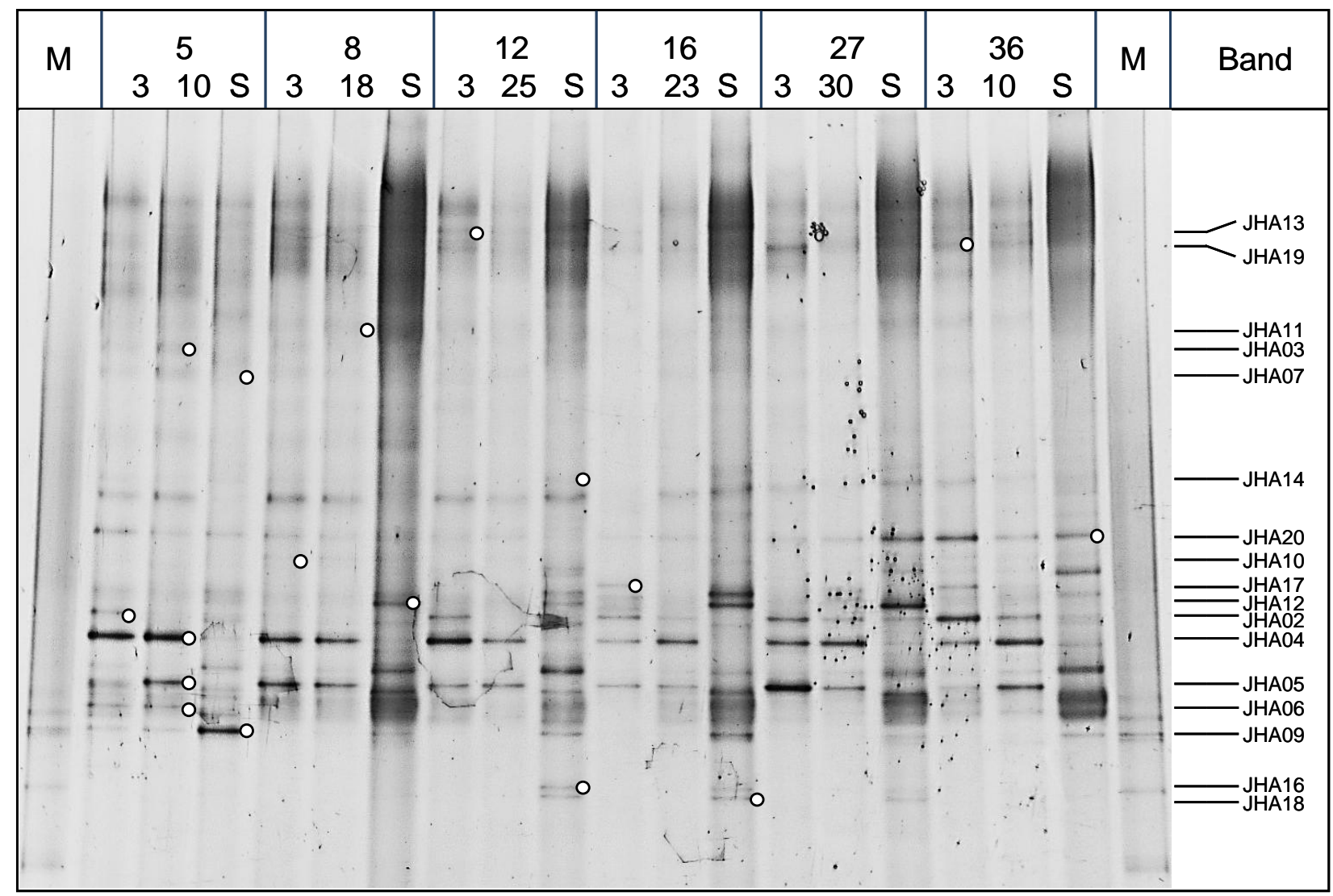

Fig. S2. DGGE community patterns of particle-associated and sediment-dwelling roseobacters. Samples were obtained from young particles (3 mbsl), matured particles (10-30 mbsl) and the sediment surface (depth: see material and methods section). PCR amplicons ( 200 bp) were generated by using Roseobacter-specific primers. Representative DGGE bands (white circles) were excised and sequenced. Phylogenetic affiliation and distribution, see table $\mathrm{S} 2 . \mathrm{M}=$ marker, $\mathrm{S}=$ seafloor 
Table S1. Free-living fraction of Roseobacter-affiliated phylotypes detected by sequencing of DGGE bands (o) from the gel displayed in Figure S1. Site and depths related distribution is indicated by the presence of corresponding DGGE bands in other lanes (+).

\begin{tabular}{|c|c|c|c|c|c|c|c|c|c|c|c|c|c|c|c|c|c|c|c|c|}
\hline \multirow[t]{3}{*}{$\begin{array}{l}\text { Band } \\
\text { No. }\end{array}$} & \multirow[t]{3}{*}{ Affiliation } & \multirow{3}{*}{$\begin{array}{l}\text { Sim } \\
{[\%]}\end{array}$} & \multicolumn{18}{|c|}{ Station and Depth [mbsl] } \\
\hline & & & \multicolumn{3}{|c|}{5} & \multicolumn{3}{|c|}{8} & \multicolumn{3}{|c|}{12} & \multicolumn{3}{|c|}{16} & \multicolumn{3}{|c|}{27} & \multicolumn{3}{|c|}{36} \\
\hline & & & 3 & 10 & B & 3 & 18 & B & 3 & 25 & B & 3 & 23 & B & 3 & 30 & B & 3 & 10 & B \\
\hline JHF01 & Sulfitobacter donghicola & 92 & o & + & + & + & + & + & + & + & & + & + & & & + & + & + & + & \\
\hline JHF02 & Nautella italica & 99 & o & + & + & + & + & + & & & & + & + & & & & & & & \\
\hline JHF03 & Nereida ignava & 100 & o & + & + & + & + & + & + & + & + & & + & + & + & + & + & + & + & + \\
\hline JHF04 & Sulfitobacter pontiacus & 99 & o & + & & + & + & + & + & + & + & + & + & & + & + & & + & + & \\
\hline JHF05 & Nereida ignava & 100 & o & + & + & + & + & & + & & & + & + & & & & & & & \\
\hline JHF06 & Roseovarius crassostreae & 99 & & o & & & & & & & & & & & & & & & & \\
\hline JHF07 & Roseovarius aestuarii & 100 & & + & o & + & + & + & + & + & & & & & & + & + & & + & \\
\hline JHF08 & Thalassobacter stenotrophicus & 100 & + & + & & o & + & & + & & & & & & & & & & & \\
\hline JHF09 & Thalassobacter stenotrophicus & 99 & + & + & + & o & + & & + & & & + & + & & & & & & & \\
\hline JHF10 & Thalassobius mediterraneus & 100 & + & + & + & + & $\mathrm{o}$ & + & + & + & & + & + & & & & & & & \\
\hline JHF11 & Sulfitobacter pontiacus & 96 & + & + & + & + & + & + & o & + & & + & + & & + & + & + & + & + & + \\
\hline JHF12 & Thalassobacter stenotrophicus & 97 & + & + & + & + & + & + & + & $\mathrm{o}$ & & & & & & & & & & \\
\hline JHF13 & Thalassobacter stenotrophicus & 97 & & & & & & & + & o & & + & + & & + & + & + & + & + & + \\
\hline JHF14 & Sulfitobacter pontiacus & 95 & & & & & & & & & & o & + & & & & & & & \\
\hline JHF15 & Nereida ignava & 98 & & & & & & & + & + & & o & + & & + & + & + & + & + & + \\
\hline JHF16 & Rhodobacteraceae bacterium & 95 & & & & & & & & + & & o & & & & & & & & \\
\hline JHF17 & Nereida ignava & 98 & & & & & & & & + & & + & o & & & & & & & \\
\hline JHF18 & Sulfitobacter marinus & 95 & & & & & & & & & & & o & & & & & & & \\
\hline JHF19 & Phaeobacter caeruleus & 97 & + & + & & + & + & & + & + & & + & $\mathrm{o}$ & & & & & & & \\
\hline JHF20 & Rhodobacteraceae bacterium & 94 & + & + & + & + & + & + & & & & + & $\mathrm{o}$ & & & & & & & \\
\hline JHF21 & Sulfitobacter pontiacus & 98 & & & & & & & & + & & + & $\mathrm{o}$ & & & & & & & \\
\hline JHF22 & Thalassobacter stenotrophicus & 98 & & & & & & & & + & & + & + & & & o & & & & \\
\hline JHF23 & Thalassobius mediterraneus & 98 & & & & & & & & & + & & & & & & $\mathrm{o}$ & & & \\
\hline
\end{tabular}

B: Bottom seawater (depth see material and methods section) 
Table S2. Particle-asssociated fraction of Roseobacter-affiliated phylotypes detected by sequencing of DGGE bands (o) from the gel displayed in Figure S2. Site and depths related distribution is indicated by the presence of corresponding DGGE bands in other lanes (+).

\begin{tabular}{|c|c|c|c|c|c|c|c|c|c|c|c|c|c|c|c|c|c|c|c|c|}
\hline \multirow{3}{*}{$\begin{array}{l}\text { Band } \\
\text { No. }\end{array}$} & \multirow[t]{3}{*}{ Affiliation } & \multirow{3}{*}{$\begin{array}{l}\text { Sim } \\
{[\%]}\end{array}$} & \multicolumn{18}{|c|}{ Station and Depth [mbsl] } \\
\hline & & & \multicolumn{3}{|c|}{5} & \multicolumn{3}{|c|}{8} & \multicolumn{3}{|c|}{12} & \multicolumn{3}{|c|}{16} & \multicolumn{3}{|c|}{27} & \multicolumn{3}{|c|}{36} \\
\hline & & & 3 & 10 & $\mathbf{S}$ & 3 & 18 & $\mathbf{S}$ & 3 & 10 & $\mathbf{S}$ & 3 & 18 & $\mathbf{S}$ & 3 & 10 & $\mathbf{S}$ & 3 & 18 & $\mathbf{S}$ \\
\hline JHA02 & Sulfitobacter pontiacus & 99 & $\mathrm{O}$ & + & + & & & & + & & & + & & & + & & & + & + & \\
\hline JHA03 & Phaeobacter inhibens & 97 & & o & & & & & & & & & & & & & & & & \\
\hline JHA04 & Loktanella rosea & 97 & + & o & & + & + & & + & + & & + & + & & + & + & & + & + & \\
\hline JHA05 & Pseudoruegeria aquimaris & 96 & + & o & & + & + & & + & + & & + & + & & + & + & & + & + & \\
\hline JHA06 & Roseovarius crassostreae & 97 & + & o & & + & + & + & + & & + & & & + & & & + & & & \\
\hline JHA07 & Leisingera aquimarina & 97 & & & o & & & & & & & & & & & & & & & \\
\hline JHA09 & Tateyamaria omphalii & 99 & & & o & & & & & & & & & & & & & & & \\
\hline JHA10 & Jannaschia pohangensis & 96 & + & + & + & o & + & + & + & + & + & + & + & + & + & + & + & + & + & + \\
\hline JHA11 & Jannaschia pohangensis & 94 & & & & & o & + & & & & & & & & & & & & \\
\hline JHA12 & Nereida ignava & 98 & & & & & & o & & & + & & & & & & + & & & \\
\hline JHA13 & Pelagicola litoralis & 94 & & & & & & & o & & & & & & & & & + & & \\
\hline JHA14 & Nautella italica & 98 & & & & & & & & & o & & & + & & & + & + & + & + \\
\hline JHA16 & Phaeobacter inhibens & 100 & & & & & & & & & o & & & + & & & & & & \\
\hline JHA17 & Thalassobacter stenotrophicus & 98 & + & & & & & & & & & o & & & & & & + & & \\
\hline JHA18 & Dinoroseobacter shibae & 100 & & & & & & & & & + & & & o & & & & & & \\
\hline JHA19 & Sulfitobacter dubius & 95 & + & + & + & + & + & + & + & + & + & + & + & + & + & + & + & o & + & + \\
\hline JHA20 & Nereida ignava & 97 & + & + & + & + & + & + & + & + & + & & + & & + & + & + & + & + & $\mathrm{o}$ \\
\hline
\end{tabular}

S: Seafloor (depth: see material and methods section) 


\section{STUDY 5:}

\section{Adaptation of AN ABUNdant Roseobacter RCA ORGanisM to PELAGIC SYSTEMS REVEALED BY GENOMIC AND TRANSCRIPTOMIC} ANALYSES

Voget $\mathrm{S}^{1}$, WeMheuer B ${ }^{1}$, Brinkhoff $\mathrm{T}^{2}$, Vollmers $\mathrm{J}^{1}$, Dietrich $\mathrm{S}^{1}$, GIEBEl HA ${ }^{2}$, BEARdsley $\mathrm{C}^{2}$, BAKENHUS I ${ }^{2}$, BILlERBECK $\mathrm{S}^{2}$, DANIEL $\mathrm{R}^{1}$, AND SIMON $\mathrm{M}^{2}$

ISME J 2014 AUG 1. (DOI: 10.1038/ISMEJ.2014.134)

${ }^{1}$ Institute OF Microbiology And Genetics, GeORG-August-University GÖTTINGEN, GRISEBACHSTR. 8, D-37077 GÖTTINGEN, GERMANY; ${ }^{2}$ INSTITUTE FOR Chemistry And Biology of THE MARine EnVIRONMENT (ICBM), CARL-VONOSSIETZKY-UNIVERSITY OF OLDENBURG, CARL-VON-OSSIETZKY-STR. 9-11, D26111 OldENBURG, GERMANY; ${ }^{3}$ PRESENT ADDRESS: BIOZENTRUM KLEIN Flottbek, Mikrobiologie, OHnhorststr. 18, D-22609 Hamburg, Germany

Author contributions to the work:

Performed the experiments: SV, BW, HG, CB

Analyzed data: SV, MS, BW, HG, CB, JV, SD

Contributed data on water properties and analysis of these data: BW, TB, HAG, $\mathrm{CB}, \mathrm{IB}, \mathrm{SB}$

Wrote the publication: SV, MS, TB, RD

Conceived and designed the experiments:SV, MS, TB, RD 


\title{
Adaptation of an abundant Roseobacter RCA organism to pelagic systems revealed by genomic and transcriptomic analyses
}

\author{
Sonja Voget ${ }^{1}$, Bernd Wemheuer ${ }^{1}$, Thorsten Brinkhoff ${ }^{2}$, John Vollmers ${ }^{1}$, Sascha Dietrich ${ }^{1}$, \\ Helge-Ansgar Giebel², Christine Beardsley², Carla Sardemann², Insa Bakenhus², \\ Sara Billerbeck ${ }^{2}$, Rolf Daniel ${ }^{1}$ and Meinhard Simon ${ }^{2}$ \\ ${ }^{1}$ Institute of Microbiology and Genetics, Genomic and Applied Microbiology and Göttingen Genomics \\ Laboratory, University of Göttingen, Göttingen, Germany and ${ }^{2}$ Institute for Chemistry and Biology of the \\ Marine Environment, University of Oldenburg, Oldenburg, Germany
}

\begin{abstract}
The RCA (Roseobacter clade affiliated) cluster, with an internal 16S rRNA gene sequence similarity of $>98 \%$, is the largest cluster of the marine Roseobacter clade and most abundant in temperate to (sub)polar oceans, constituting up to $35 \%$ of total bacterioplankton. The genome analysis of the first described species of the RCA cluster, Planktomarina temperata RCA23, revealed that this phylogenetic lineage is deeply branching within the Roseobacter clade. It shares not $>65.7 \%$ of homologous genes with any other organism of this clade. The genome is the smallest of all closed genomes of the Roseobacter clade, exhibits various features of genome streamlining and encompasses genes for aerobic anoxygenic photosynthesis (AAP) and CO oxidation. In order to assess the biogeochemical significance of the RCA cluster we investigated a phytoplankton spring bloom in the North Sea. This cluster constituted $5.1 \%$ of the total, but $10-31 \%$ (mean $18.5 \%$ ) of the active bacterioplankton. A metatranscriptomic analysis showed that the genome of $\boldsymbol{P}$. temperata RCA23 was transcribed to $94 \%$ in the bloom with some variations during day and night. The genome of $\boldsymbol{P}$. temperata RCA23 was also retrieved to $84 \%$ from metagenomic data sets from a Norwegian fjord and to $82 \%$ from stations of the Global Ocean Sampling expedition in the northwestern Atlantic. In this region, up to $6.5 \%$ of the total reads mapped on the genome of $P$. temperata RCA23. This abundant taxon appears to be a major player in ocean biogeochemistry.

The ISME Journal advance online publication, 1 August 2014; doi:10.1038/ismej.2014.134
\end{abstract}

\section{Introduction}

Our understanding of the role of abundant individual taxa in ocean biogeochemistry is hampered by the fact that so far very few of such taxa have been isolated and are available to genomic and postgenomic analyses (Yooseph et al., 2010). It is extremely difficult to obtain representative isolates of the major players and only novel approaches made this effort more successful (Giovannoni and Stingl, 2007). However, still today detailed information on the role of abundant individual taxa in oceanic cycling of matter is available only for Prochlorococcus and for Cand. Pelagibacter ubique of the SAR11 clade. Pelagibacter ubique of the SAR11 clade (Giovannoni et al., 2005; Tripp et al., 2008; Sowell et al., 2009; Thompson et al., 2011). Isolates of these taxa are available, their genomes

Correspondence: M Simon, Institute for Chemistry and Biology of the Marine Environment, University of Oldenburg, C v Ossietzky Str 9-11, Oldenburg D-26111, Germany.

E-mail:m.simon@icbm.de

Received 24 April 2014; revised 17 June 2014; accepted 21 June 2014 have been sequenced and thus form a basis for postgenomic studies and relating metagenomic and, more importantly, metatranscriptomic and metaproteomic information to individual taxa.

The Roseobacter and SAR11 clades are the most prominent subdivisions of Alphaproteobacteria in the ocean's near surface waters (Giovannoni and Stingl, 2005). The RCA (Roseobacter clade affiliated) cluster with an internal sequence similarity of the $16 \mathrm{~S}$ rRNA gene of at least $98 \%$, constitutes up to $35 \%$ of total bacterioplankton and is most abundant in temperate to (sub)polar oceans, but absent in tropical and subtropical regions (Selje et al., 2004; Giebel et al., 2009; Giebel et al., 2011). It is divided into a subcluster with sequences from temperate regions and one with sequences of subpolar and polar origin (Giebel et al., 2011). Because of the high abundance and distinct biogeography of the RCA cluster, there is great interest to elucidate its functional role and biogeochemical significance. However, no information on the genomic data and features of organisms of this important cluster are yet available because RCA organisms defy isolation and cultivation greatly. 
An isolate of this cluster, retrieved from the southern North Sea, became recently available and was characterized as type species of the first described species of the genus Planktomarina, Planktomarina temperata RCA23 (Giebel et al., 2013). In the North Sea, P. temperata RCA23 represents the most abundant ribotype of the RCA cluster that comprises persistently between $2 \%$ and $20 \%$ of total bacterioplankton (Selje et al., 2004; Giebel et al., 2011; Teeling et al., 2012) and is a major representative of the Roseobacter clade in the active bacterioplankton (Wemheuer et al., 2014). Based on these observations we hypothesized that the genome of this organism exhibits distinct features of its adaptation to life in the nutrient-poor pelagic environment with respect to genome organization and metabolic potential. Further, we hypothesized that the genome of $P$. temperata RCA23 is well represented in metagenomic and metatranscriptomic data in the North Sea because of its high abundance and activity. Therefore, we sequenced the genome of $P$. temperata RCA23 to elucidate its metabolic potential. In addition, we assessed its significance and functional role during a phytoplankton spring bloom in the southern North Sea by applying a metatranscriptomic approach. Finally, metagenomic data sets of pelagic marine systems were mined for the presence, abundance and genomic features of this organism.

\section{Materials and methods}

Origin and growth of P. temperata RCA23

$P$. temperata RCA23 was originally isolated from a water sample collected in the southern North Sea (Giebel et al., 2011, 2013). It was grown in liquid culture of autoclaved sea water amended with marine broth (40\% of peptone and yeast extract; Giebel et al., 2013 ) to an optical density of 0.2 . Biomass was harvested by $20 \mathrm{~min}$ centrifugation (Beckman JA10, Krefeld, Germany) at 7500 r.p.m. and $4{ }^{\circ} \mathrm{C}$ and DNA was extracted using the MasterPure DNA Purification Kit (Epicentre, Madison, Wisconsin, USA) according to the manufacturer's protocol.

\section{Sequence determination, gene annotation and} phylogenetic analyses

To sequence the genome of $P$. temperata RCA23 a pyrosequencing run was performed using a Roche GS-FLX 454 sequencer (Branford, CT, USA) with Titanium chemistry. All sequencing steps were performed according to the manufacturer's protocols and recommendations. In total 411932 reads were generated and assembled to 78 contigs bigger than $500 \mathrm{bp}$ with a 26-fold coverage. Furthermore, 576 fosmid Sanger-sequences were added to the data set to identify the contig order. Gap closure and polishing were carried out using the Staden software package (Staden, 1996) and PCR-based techniques on genomic DNA. Open reading frames were identified using YACOP (Tech and Merkl, 2003) and GLIMMER (Delcher et al., 2007). The open reading frame finding was inspected manually with Artemis and open reading frames were corrected by checking the GC frame plot, ribosomal binding site and blast hits against the NCBI nr database.

Orthologous protein sequences were identified using reciprocal BLASTp-analysis combined with global alignments based on the Needleman-Wunsch algorithm. Only hits with $e$-values $<1 e-20$ were considered and additionally filtered, based on sequence identity cutoffs of the respective global alignments. A cutoff value of $30 \%$ sequence identity was chosen to identify orthologs. For multilocus sequence analysis, protein sequences of 162 genes, for which one ortholog but no paralog was found in every comparison strain, were concatenated. The multilocus sequence analysis tree was constructed using ARB v5.1 (Ludwig et al., 2004) and the evolutionary history was inferred using the neighbor-joining method and recovered reproducibly with the maximum-likelihood method (Figure 1).

\section{Study area, sample collection and chlorophyll}

The significance of the RCA cluster was investigated during a phytoplankton spring bloom in the southern North Sea. Samples were collected at 11 stations at $2 \mathrm{~m}$ depth between 25 and 31 May 2010 on board RV Heincke by 41 Niskin bottles mounted on a CTD rosette (Sea-Bird, Bellevue, WA, USA). For pyrosequencing, metagenomic and metatranscriptomic analyses, 501 of sea water were prefiltered through a 10$\mu \mathrm{m}$ nylon net and a filter sandwich consisting of a precombusted glass fiber and $3-\mu \mathrm{m}$ polycarbonate filter $(47 \mathrm{~mm}$ diameter). Bacterioplankton was harvested from a prefiltered 1-liter sample on a filter sandwich consisting of a glass fiber and $0.2-\mu \mathrm{m}$ polycarbonate filter $(47 \mathrm{~mm})$. One filter sandwich was used for RNA extraction. For gene expression analysis and metagenome sequencing, at least four filter sandwiches were subjected to RNA and DNA extraction. Chlorophyll a concentrations were determined as described (Giebel et al., 2011).

Enumeration of bacteria, CARD-FISH and BrdU-FISH Bacterial cell numbers were determined by flow cytometry after staining of subsamples with SybrGreen I (Sigma-Aldrich, Munich, Germany), preserved with glutardialdehyde (final concentration $1 \%$ ) and stored at $-80{ }^{\circ} \mathrm{C}$ until further analysis as described Giebel et al. (2011). The abundance of RCA cells was determined by catalyzed reporter deposition fluorescence in situ hybridization (CARD-FISH) and the proportion of DNA-synthesizing RCA cells by incorporation of BrdU ( $4 \mathrm{~h}$ incubation) according to Pernthaler et al. (2002) and applying an RCA-specific probe set (RCA996, C Beardsley and I Bakenhus, unpublished data). Cells were counted via epifluorescence microscopy using $\times 1000$ magnification and suitable filter sets for DAPI-stained total cells, Alexa ${ }_{488}$-stained RCA cells, 


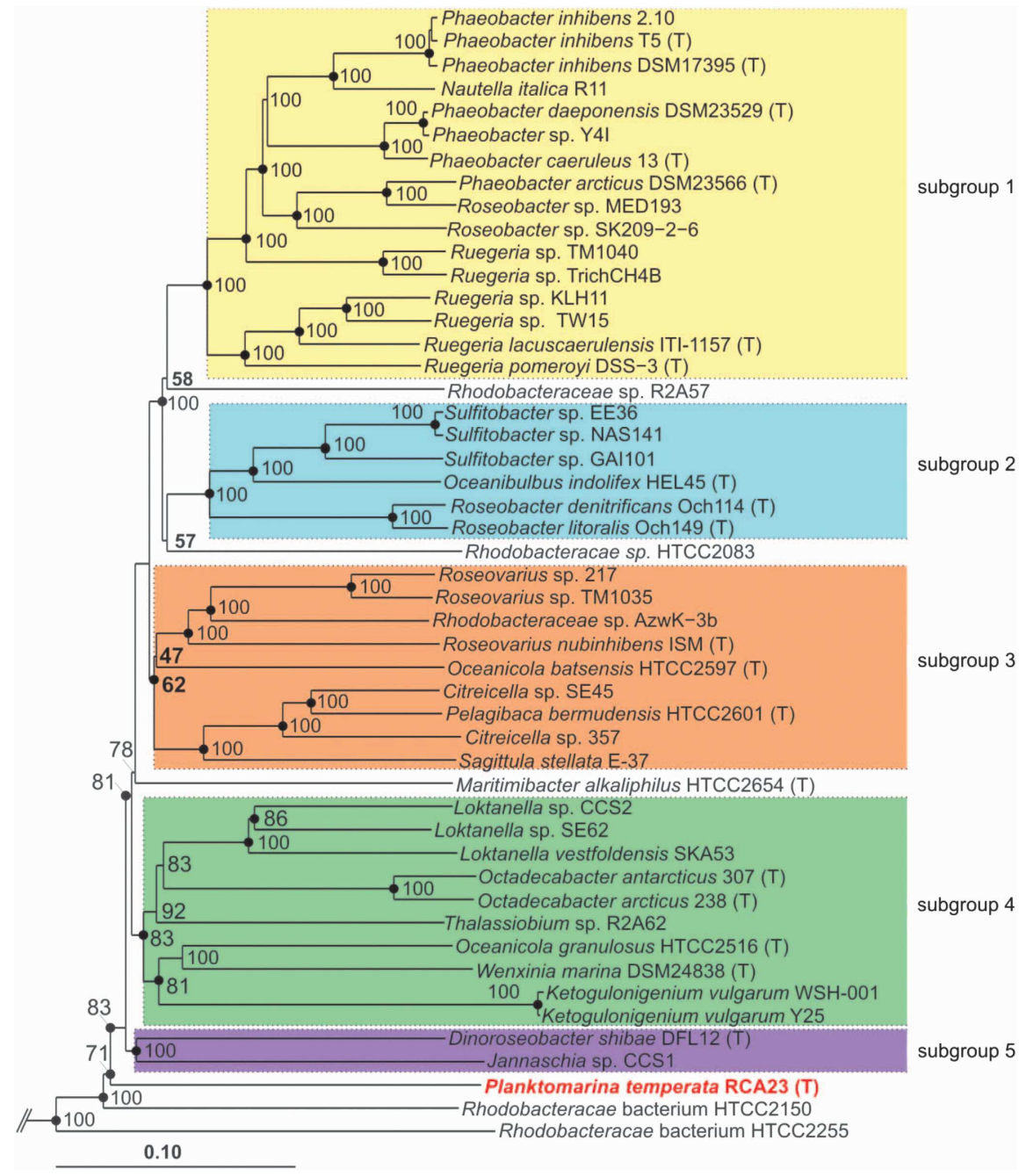

Figure 1 Neighbor-joining tree based on multilocus sequence analysis (MLSA) of genome-sequenced organisms of the Roseobacter clade. The tree was constructed using ARB v5.1 and is based on a similar tree of Newton et al. (2010) but includes additional genome sequences and an extended gene set. Filled circles indicate nodes also recovered reproducibly with maximum-likelihood calculation. Numbers at the nodes are bootstrap values (only $>50 \%$ are shown) from 1000 replicates. Subclades of the Roseobacter clade are marked by different colors. (T) indicates type strains. Escherichia coli K12 MG1655 was used as outgroup.

and Cy3-stained (Perkin Elmer, Waltham, MA, USA) BrdU-positive cells, respectively.

$16 S$ rRNA gene amplicons, metagenomics and transcriptomics

Environmental DNA and RNA were coextracted and the composition of the active bacterial community was assessed by $16 \mathrm{~S}$ rRNA PCRs as described before Wemheuer et al. (2014). For metagenomic and metatranscriptomic analyses DNA and cDNA were sequenced on an Illumina/Solexa GAIIx system (San Diego, CA, USA). In total, 54334282 pairedend sequences of $100 \mathrm{bp}$ were generated for the metagenomic and 78042122 single-read sequences of $75-100 \mathrm{bp}$ for the metatranscriptomic data sets, respectively (Supplementary Table S1). The sequences were quality trimmed and the Illumina adapter sequences were removed with Trimmomatic v0.30 (Bolger et al., 2014) using the following parameters: adapter:2:40:15 leading:3 trailing:3 slidingwindow:4:15 minlen:50. Reads derived from ribosomal RNA gene fragments were filtered with SortMeRNA (Kopylova et al., 2012). The remaining sequences were mapped with Bowtie 2 (Langmead and Salzberg, 2012) using the implemented end-toend mode, which requires that the entire read align from one end to the other.

To compare the RNA-Seq results, the read counts were normalized to remove biases like the length of the transcript and the sequencing depth of a sample. We used the Nucleotide activity Per Kilobase of exon model per million Mapped reads (NPKM), a derivate of RPKM (reads per kilo base per million), as a normalized read count value (Wiegand et al., 2013).

\section{Data deposition}

The genome sequence of $P$. temperata RCA23 has been deposited at the NCBI GenBank database with the accession number CP003984. The metagenomic 
and metatranscriptomic data sets have been deposited at MG-Rast with the accession numbers: 4548721.3 (Station 3 gDNA), 4550305.3 (Station 3 cDNA), 4548722.3 (Station 9 gDNA), 4550303.3 (Station 9 cDNA), 4548723.3 (Station 13 gDNA) and 4550304.3 (Station 13 cDNA).

\section{Results and discussion}

Genomic features of P. temperata RCA23

$P$. temperata RCA23 is deeply branching within the Roseobacter clade, not affiliated to any of the known subclades, as shown by multilocus sequence analysis (Figure 1). The genome of $P$. temperata RCA23 encompasses $3.29 \mathrm{Mbp}$ and carries 3101 genes of which 3054 encode proteins (Supplementary Table S2). It is the smallest of all closed and the third smallest of all genomes of the Roseobacter clade and carries the second lowest number of genes of all organisms of this clade (Figure 2a and Supplementary Table S2). The only organism of this clade with a significantly smaller genome is
Rhodobacterales bacterium HTCC2255 (Luo et al., 2013). Further, partial genomes of two other organisms of the Roseobacter clade with estimated genome sizes of $<3 \mathrm{Mbp}$ were recently reported from sequence analyses of single amplified genomes retrieved from coastal and oceanic surface waters (Swan et al., 2013; Luo et al., 2014). Members of the Roseobacter clade with a genome size of $<3.8 \mathrm{Mbp}$ are exclusively of pelagic origin (Figure 2a and Supplementary Table S2). The mean genome sizes of the pelagic members of this clade is $4.06 \mathrm{Mbp}$ and $0.5 \mathrm{Mbp}$ smaller than that of members associated to other organisms, surfaces or sediments (Figure $2 \mathrm{~b}$ and Supplementary Table S3). The relatively small genome of $P$. temperata RCA23 and other pelagic members of the Roseobacter clade and the reduction in genomic traits is consistent with genomic streamlining and adaptation to nutrient-poor pelagic marine ecosystems (see below; Giovannoni et al., 2005; Luo et al., 2013; Swan et al., 2013). The genomic difference between both groups of the Roseobacter clade obviously reflects the divergent evolutionary history of this clade with genomic
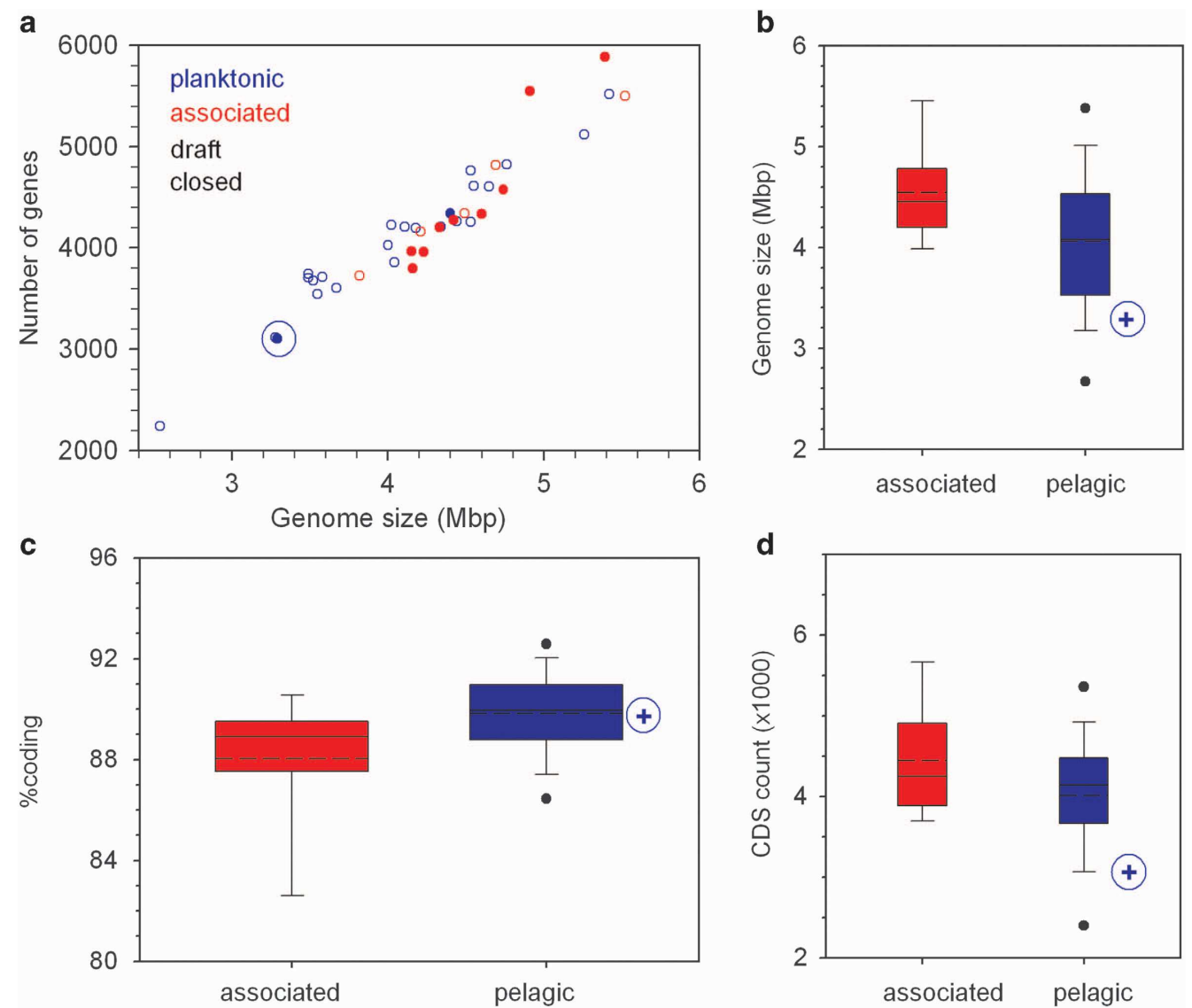

Figure 2 Genomic traits of P. temperata RCA23 in comparison to other organisms of the Roseobacter clade. Relation between genome size and number of genes (a). Box-Whisker plot of the GC content (b), percentage coding genes (c) and CDS (coding DNA sequences) count (d) of 14 members of the Roseobacter clade associated to other organisms, surfaces or sediments and of 24 members with a pelagic life style listed in Supplementary Table S2. Data include 12 closed and 26 draft genomes. Blue circle and + : P. temperata RCA23. The boxes show the median (solid line), mean (dashed line), the 25th and 75th percentile and the whiskers the 10th and 90 th percentiles. •: Outlayers. For further details see Supplementary Tables S2 and S3. 
streamlining of at least several pelagic members and gained genomic content by the associated members (Luo et al., 2013). The much larger genome size of $P$. temperata RCA23 and other pelagic members of the Roseobacter clade, however, harbour genomes much larger than highly streamlined marine pelagic bacteria such as Cand. P. ubique of the SAR11 clade. This feature points out that, besides streamlining, distinct aspects of their life history and adaptation to their niche in the marine pelagic realm were also important in shaping the evolution of these pelagic members of the Roseobacter clade (Giovannoni et al., 2014). These authors have identified a low number of $\sigma$-factors as a feature to distinguish between streamlined and non-streamlined genomes of bacteria with a more complex life style. The genome of $P$. temperata RCA23 harbors six $\sigma$-factors, a value much lower than that of other members of the Roseobacter clade and in the same range as that of many typical streamlined genomes of a size of $<2 \mathrm{Mb}$ (Giovannoni et al., 2014).

The GC content of $54 \%$ of P. temperata RCA23 is lower than that of all associated (mean $=60.07 \pm$ $3.58 \%, N=14$ ) and the fifth lowest of the 24 pelagic members of the Roseobacter clade included in this analysis $\quad($ mean $=59.28 \pm 6.82 \%$; Supplementary Tables S2 and S3). However it is substantially higher than the genomic GC content of many other marine bacteria, ranging below $40 \%$, such as Rhodobacterales bacterium HTCC2255 (Supplementary Table S2), Cand. $P$. ubique and pelagic bacteria subjected to single cell genome sequencing (Swan et al., 2013; Luo et al., 2014). It has been speculated that a reduced genomic GC content may be an adaptation to nitrogen limitation in marine systems (Swan et al., 2013), but clear-cut evidence is still missing, also because it is still unclear whether pelagic heterotrophic bacteria are carbon- or nitrogenlimited. The percentage of coding DNA of $P$. temperata RCA23 is very similar to the mean of all pelagic members of the Roseobacter clade which, however, is significantly higher than the mean of the organisms of this clade associated to other organisms, surfaces or sediment (Figure 2c and Supplementary Table S3).

The genome of $P$. temperata RCA23 shares not $>65.7 \%$ of homologous genes (2009) with other members of the Roseobacter clade (Supplementary Tables S2 and S4). It harbors no prophage, which is consistent with the fact that prophage induction using mitomycin C and UV light was unsuccessful (H-A Giebel, unpublished data). Further, the genome carries no plasmid, no complete GTA (gene transfer agent) cluster (Supplementary Table S4) and no CRISPR (clustered regularly interspaced small palindromic repeats). CRISPR are uncommon in the genomes of most organisms of the Roseobacter clade and were so far detected in only two members of this clade, Dinoroseobacter shibae and Maritimibacter alkaliphilus HTCC2654. The lack of plasmids in the genome of $P$. temperata RCA23 and other pelagic members of this clade with a genome size of $<3.5 \mathrm{Mb}$ (Supplementary Table S2) appears to be an adaptation to the pelagic life style and exhibits another feature of streamlining not considered yet in other analyses. In contrast, plasmids are common genomic elements of all members of the Roseobacter clade associated to other organisms, surfaces and sediments and constitute between $2 \%$ and $33 \%$ of the genomic content (Supplementary Table S2; Pradella et al., 2010).

GTAs have been detected in Alphaproteobacteria and all genomes of the Roseobacter clade except in Rhodobacterales bacteria HTCC2083 and HTCC2255 (Zhao et al., 2009; Newton et al., 2010). GTA-related gene transfer was suggested as a potential adaptation mechanism of these bacteria to maintain the metabolic flexibility in the dynamic marine environment (Biers et al., 2008). The fact that the genome of $P$. temperata RCA23 encodes only three putative GTA-related genes (c18030, c18040 and c18050; Supplementary Table S4) implies that this mode of gene transfer was discarded during adaptation to the pelagic life style, presumably because of little benefits by this type of genetic exchange in the nutrient-poor pelagic environment. Hence, the mentioned missing genomic features, the absence of plasmids and GTA in the genome of $P$. temperata RCA23 indicate a less diversified genomic organization as compared to other organisms of the Roseobacter clade and suggests reduced genetic exchange with other members of this clade.

In comparison to typical groups of other Roseobacter clade organisms (Newton et al., 2010) 10 genomic islands (GIs), harboring $22.6 \%$ of all genes, are present in the genome of $P$. temperata RCA23 (Supplementary Figure S1). This bacterium encodes genes for chemotaxis, possesses a monotrichous flagellum and is motile (Table 1; Giebel et al., 2013). Phylogenetic analysis of the flagella synthesis cluster present in GI 3 shows that the flagellar gene sets of the Roseobacter clade are divided into two distinct groups (Supplementary Figure S2). The flagella genes of the majority of the Roseobacter clade organisms fall into group I, but those of $P$. temperata RCA23 into group II. This group contains relatively few sequences of Roseobacter clade members but additionally includes strains of the SAR116 clade and of Rhodobacter sphaeroides. The existence of these two groups of flagella gene clusters obviously reflects the evolutionary history of the Roseobacter clade with substantial lateral gene transfer (Luo et al., 2013). GI 5 harbours the genes for the group I CO dehydrogenase (coxI; Supplementary Table S4). The existence of the coxI gene cluster enables members of the Roseobacter clade to oxidize CO (Cunliffe, 2011).

The genome of $P$. temperata RCA23 encodes all basic metabolic functions. Carbohydrates are metabolized via the Entner-Doudoroff pathway that appears typical for the Roseobacter clade and also for the SAR11 clade (Giovannoni et al., 2005; Fuerch 
Table 1 Comparison of selected biosynthetic/catabolic genes and pathways of representative members of the Roseobacter clade

\begin{tabular}{|c|c|c|c|c|c|c|c|c|c|c|c|c|c|c|c|c|c|c|c|c|}
\hline & & 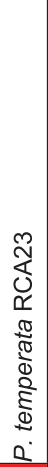 & 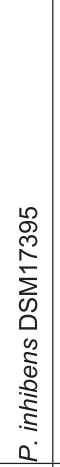 & 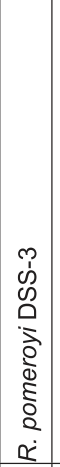 & 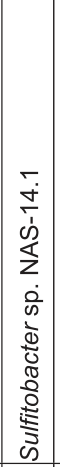 & 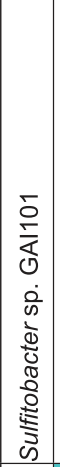 & 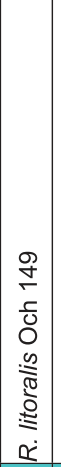 & 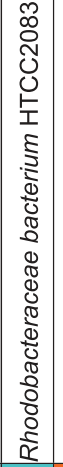 & 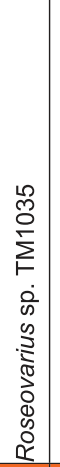 & 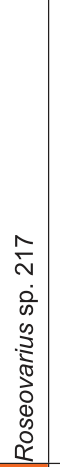 & 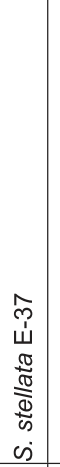 & 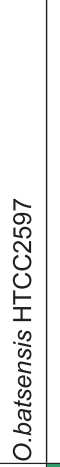 & 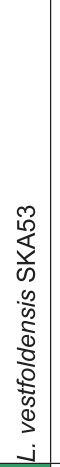 & 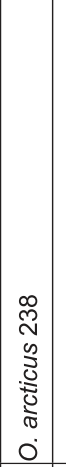 & 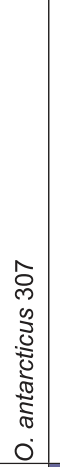 & 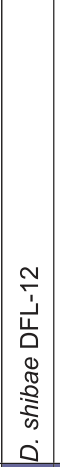 & 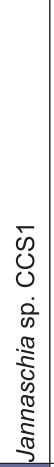 & 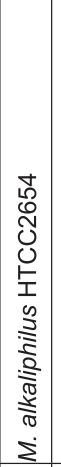 & 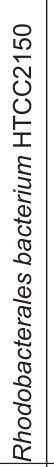 & 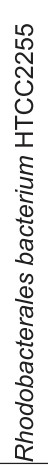 \\
\hline \multirow{5}{*}{$\begin{array}{l}\text { Trophic } \\
\text { strategy }\end{array}$} & photosynthesis cluster & & & & & & & & & & & & & & & & & & & \\
\hline & rhodopsin & & & & & & & & & & & & & & & & & & & \\
\hline & $\mathrm{H}_{2}$ oxidation & & & & & & & & & & & & & & & & & & & \\
\hline & & & & & & & & & & & & & & & & & & & & \\
\hline & gene transfer agents & & & & & & & & & & & & & & & & & & & \\
\hline & & & & & & & & & & & & & & & & & & & & \\
\hline \multirow{6}{*}{$\begin{array}{l}\text { Aromatic } \\
\text { degradation }\end{array}$} & B-ketoadipate & & & & & & & & & & & & & & & & & & & \\
\hline & gentisate pathway & & & & & & & & & & & & & & & & & & & \\
\hline & benzoate & & & & & & & & & & & & & & & & & & & \\
\hline & phenylacetic acid & & & & & & & & & & & & & & & & & & & \\
\hline & homoprotocatechuate & & & & & & & & & & & & & & & & & & & \\
\hline & homogentisate pathway & & & & & & & & & & & & & & & & & & & \\
\hline & & & & & & & & & & & & & & & & & & & & \\
\hline \multirow{2}{*}{$\begin{array}{l}\text { Carbon } \\
\text { monoxide } \\
\text { utilization }\end{array}$} & group I CO DH & & & & & & & & & & & & & & & & & & & \\
\hline & group II CO DH & & & & & & & & & & & & & & & & & & & \\
\hline & & & & & & & & & & & & & & & & & & & & \\
\hline \multirow{5}{*}{$\begin{array}{l}\text { C1 } \\
\text { compound } \\
\text { utilization }\end{array}$} & C1 incorp (serine) & & & & & & & & & & & & & & & & & & & \\
\hline & $\mathrm{MeOH}$ oxidation & & & & & & & & & & & & & & & & & & & \\
\hline & TMA oxidation & & & & & & & & & & & & & & & & & & & \\
\hline & formaldehyde oxidation & & & & & & & & & & & & & & & & & & & \\
\hline & formate oxidation & & & & & & & & & & & & & & & & & & & \\
\hline & & & & & & & & & & & & & & & & & & & & \\
\hline \multirow{2}{*}{$\begin{array}{l}\text { C2 } \\
\text { compound } \\
\text { utilization }\end{array}$} & ethylmalonyl pathway & & & & & & & & & & & & & & & & & & & \\
\hline & glyoxylate shunt & & & & & & & & & & & & & & & & & & & \\
\hline \multirow{5}{*}{$\begin{array}{l}\text { Motility, } \\
\text { sensing, } \\
\text { and } \\
\text { attachment }\end{array}$} & chemotactic ability & & & & & & & & & & & & & & & & & & & \\
\hline & motility & & & & & & & & & & & & & & & & & & & \\
\hline & flp pilus (type IV) & & & & & & & & & & & & & & & & & & & \\
\hline & lux quorum sensing & & & & & & & & & & & & & & & & & & & \\
\hline & virB syst (type IV SS) & & & & & & & & & & & & & & & & & & & \\
\hline & & & & & & & & & & & & & & & & & & & & \\
\hline $\begin{array}{l}\text { Secondary } \\
\text { metabolite }\end{array}$ & $\begin{array}{l}\text { antibiotic production } \\
\text { (TDA) }\end{array}$ & & & & & & & & & & & & & & & & & & & \\
\hline
\end{tabular}

Abbreviations: CO DH, carbon monoxide dehydrogenase; DMSP, dimethylsulphonium propionate; NRPS, non-ribosomal peptide synthase; PKS, polyketide synthetase; TDA, tropodithietic acid; TMA, trimethylamine. Colored boxes represent the presence of a gene or pathway within a genome. Data for $P$. temperata RCA23 were generated in this study; the data for representative members of the Roseobacter clade are taken from Newton et al. (2010) and colored according to the different subclades in Figure 1. 
Table 1 (Continued)

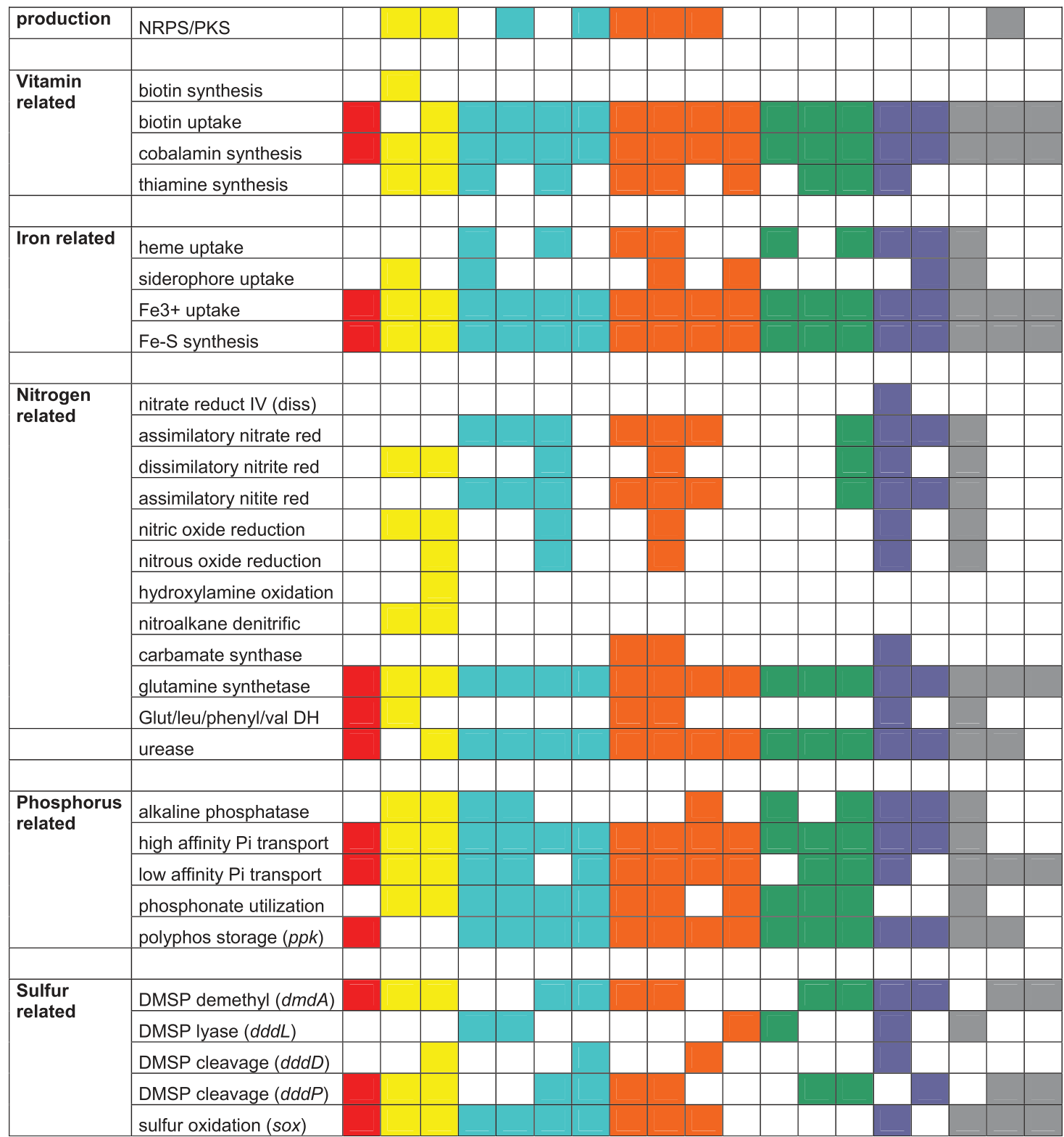

et al., 2009). Dimethylsulphonium propionate can be degraded via the demethylation and the cleavage pathway (Table 1 and Supplementary Table S4) and enhances growth of $P$. temperata RCA23 when added additionally to the medium (Giebel et al., 2013). This organism is able to carry out AAP (Giebel et al., 2013). The organization of the photosynthetic operon, however, differs from that of other members of the Roseobacter clade (Supplementary Figure S3 and Supplementary Table S4). In accordance to many other Roseobacter clade organisms, nitrogen can only be taken up in reduced form as the genome harbors no genes encoding enzymes for reducing nitrate and nitrite, but gene clusters encoding enzymes for uptake of ammonium, amino acids, putrescine/spermidine and to utilize urea (Table 1 and Supplementary Table S4). These genomic features are in line with growth tests of $P$. temperata RCA23 (Giebel et al., 2013). Whether oxidized sulfur compounds can be reduced is unclear because a putative gene cluster for assimilatory sulfate reduction exists (c14410-c14360), but lacks the typical $c y s H$ gene known from other organisms of the Roseobacter clade. Instead a smaller variant harboring a phosphoadenosine phosphosulfate reductase domain was found (c14380).

The genome of $P$. temperata RCA23 encodes 287 transport proteins, a number lower than the mean of 
the pelagic members of the Roseobacter clade (Supplementary Figure S4A and B; Supplementary Tables S2 and S3). A total of 208 transport proteins of $P$. temperata RCA23 belongs to the ATP-binding cassette (ABC) family (Supplementary Figure S4B and C; Supplementary Table S2). This number is lower than the mean of the pelagic members of the Roseobacter clade, whereas the proportion of ABC transporters of P. temperata RCA23 $(72.5 \%)$ is very close to and the number of ABC transporters per $\mathrm{Mb}$ of P. temperata RCA23 (63.2) identical to the mean of all pelagic members (Supplementary Table S2). Interestingly, the other two deeply branching pelagic members of the Roseobacter clade, Rhodobacterales bacteria HTCC2255 and HTCC 2150, have the lowest numbers of ABC transporters per $\mathrm{Mb}$ of all roseobacters, 47.6 and 50.2, values close to that of Cand. P. ubique, 51.1 (Supplementary Table S2). The mean of the absolute numbers of ABC transporters of the pelagic members is significantly lower than that of the associated Roseobacter clade members (Student's $t$-test; $P=0.014$; Supplementary Table S3), presumably a result of the different evolutionary history of both groups of this clade with respect to gene acquisition and loss (Luo et al., 2013). A high proportion of ABC transporters, which exhibit high substrate affinities, was interpreted as an adaptation of pelagic bacteria to the nutrient-poor oceanic environment (Giovannoni et al., 2005; Lauro et al., 2009). As all members of the Roseobacter clade exhibit a rather high percentage of ABC transporters, this feature may not be an adaptation to the nutrientpoor oceanic environment. It may also reflect the generally highly dynamic nutrient supply to members of this clade, considered as opportunistic marine bacteria and being able to adapt to a variety of nutrient conditions (Brinkhoff et al., 2008; Teeling et al., 2012; Luo et al., 2013). The number of tripartite ATP-independent periplasmic transporters of P. temperata RCA23 is lower than the mean of the pelagic as well as associated members of the Roseobacter clade (Figure 3d and Supplementary Table S3). The great majority of tripartite ATP-independent periplasmic transporters of P. temperata RCA23 mediates uptake of dicarboxylic acids (Supplementary Table S4). Physiological tests showed that $P$. temperata RCA23 is able to grow on a large variety of organic substrates including amino acids, monosaccharides and short-chain fatty acids (Giebel et al., 2013). This high versatility appears to reflect the high number of transporter proteins.

Even though quite a few genomic features are similar to those of other members of the Roseobacter clade, the genome of $P$. temperata RCA23 is distinct in lacking genes encoding the Flp pilus (type IV) for attachment, the VirB system for discharge of genetic material and protein, and genes encoding enzymes for quorum sensing and synthesizing other secondary metabolites (Table 1). The only other organism of the Roseobacter clade also missing the genes encoding attachment properties is Rhodobacterales bacterium HTCC2255 (Table 1). In Octadecabacter arcticus these genes are present but fragmented into three partial clusters and not arranged homologously to the other organisms of this clade (Table 1; Vollmers et al., 2013). The lacking feature for attachment in $P$. temperata RCA23 is consistent with the observation that the RCA cluster has not been detected in the fraction of particle-associated bacteria in the North Sea (Giebel et al., 2011) and that growth on agar plates is weak and unreliable (Giebel et al., 2013). This lacking attachment ability, however, is in contrast to the life style of another RCA cluster isolate, strain LE17, retrieved from Californian coastal waters that lives associated with a dinoflagellate (Mayali et al., 2008).

In order to distinguish between genomic features of copiotrophic and oligotrophic bacteria Lauro et al. (2009) compared Photobacterium angustum S14 (copiotrophic; genome size $5.10 \mathrm{Mbp}$ ), and Sphingopyxis alaskensis RB 2256 (oligotrophic; genome size 3.37 Mbp). These authors found that categories of clusters of orthologous groups (COG) for motility (N), transcription (K), defense mechanisms (V) and signal transduction (T) constitute lower and COG categories for lipid transport and metabolism (I) and secondary metabolites, biosynthesis, transport and catabolism (Q) higher fractions in the oligotrophic as compared to the copiotrophic bacterium. The fractions of COG categories $\mathrm{K}, \mathrm{V}$ and $\mathrm{T}$ in the genome of $P$. temperata RCA23 constitute even smaller fractions and COG categories I and Q higher fractions than in $S$. alaskensis (Supplementary Table S5), confirming the finding by Lauro et al. (2009) and emphasizing that P. temperata RCA23 is a truly oligotrophic bacterium in these respects. Interestingly, COG category I (lipid transport and metabolism) of the pelagic members of the Roseobacter clade constitutes a significantly higher fraction relative to the associated members (Supplementary Table S5) and P. temperata RCA23 has the third highest fraction of this COG category of all pelagic roseobacters (Supplementary Table S5). Genes affiliated to this COG category include shortchain fatty acid dehydrogenases, hydratases, dehydratases and acetyltransferases (Supplementary Table S4). The COG category of cell motility (N) of $P$. temperata RCA23 has a fraction not as low as that of $S$. alaskensis, suggesting that this feature is of adaptive significance for the life style of $P$. temperata RCA23 in the pelagic environment. The respective means of the associated and pelagic groups of the Roseobacter clade do not exhibit such a clear-cut difference between these COG categories and thus may reflect that members of this clade in general are more adapted to nutrient-poor environments than $P$. angustum (Supplementary Table S5).

Occurrence of the RCA cluster and P. temperata RCA23 in the North Sea

In order to assess the significance of the RCA cluster and $P$. temperata RCA23 among the active microbial 
a

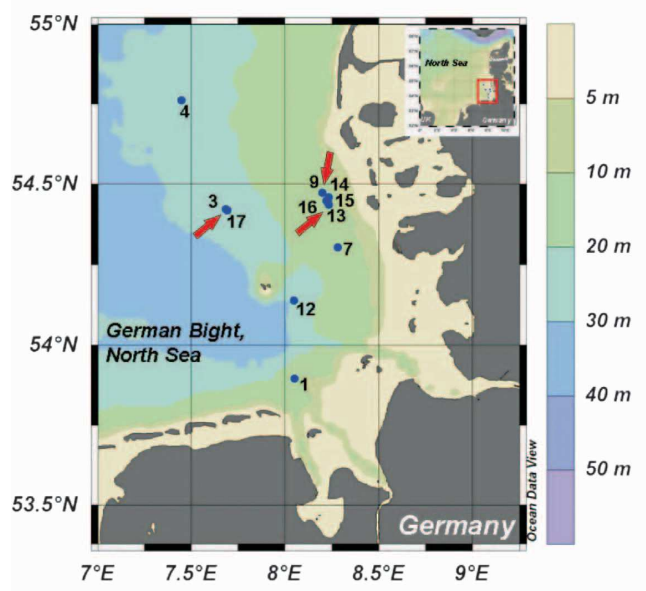

b
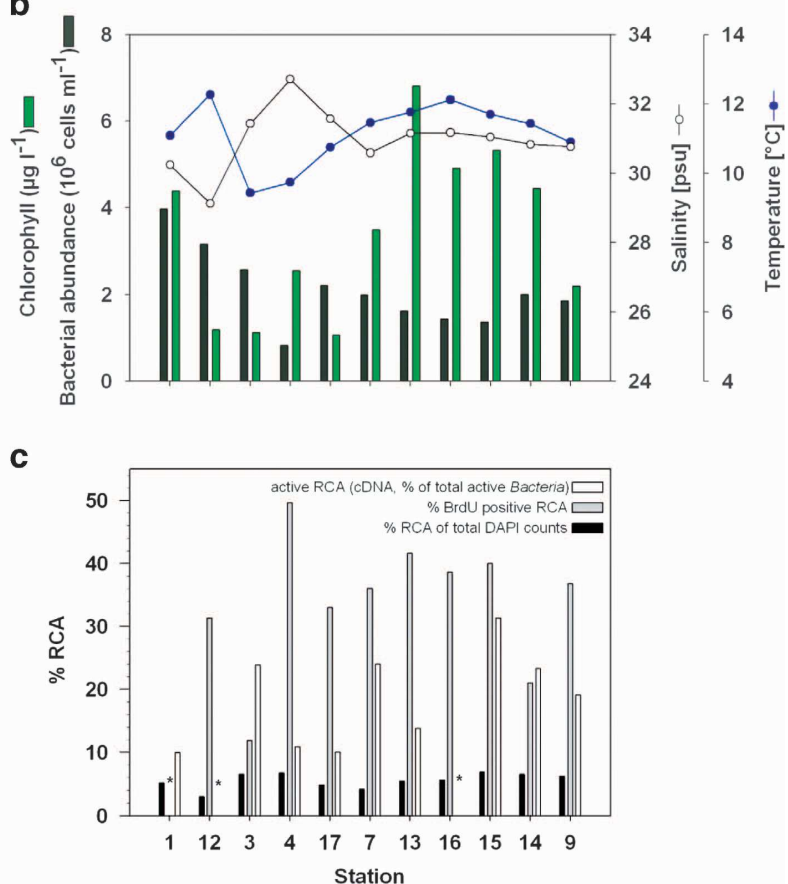

Figure 3 (a) Bathymetry of the southern North Sea (German Bight) and sampling stations in May 2010. Arrows indicate stations where the samples for the metagenomic and transcriptomic analyses were collected. (b) Chlorophyll $a$, bacterial abundance, salinity and temperature at $2 \mathrm{~m}$ depth. (c) Percentages of the RCA cluster as detected by CARD-FISH with an RCA-specific probe, of DNA-synthesizing RCA cells (BrdU positive) and of active RCA (cDNA). Samples in (b) and (c) are ordered as inside and outside the bloom except station 1, which was a separate bloom in the southernmost area. ${ }^{*}$ : Missing data.

players in the southern North Sea, we investigated bacterioplankton abundance, composition and activity in and outside a diatom-dominated phytoplankton spring bloom in the German Bight (Figure 3). The RCA cluster dominated the Roseobacter clade by $>90 \%$ (Wemheuer et al., 2014), constituted $3.0-6.5 \% \quad($ mean $=5.1 \pm 1.2 \%)$ of total bacterioplankton and the active bacterioplankton community to even higher proportions, to $10-31.3 \%$ (mean $=18.5 \pm 7.7 \%$ ), as determined by the cDNA derived from the 16S rRNA (Figure 3c; Wemheuer et al., 2014). Between $11.9 \%$ and $49.6 \%$ (mean $=34.0 \pm 10.7 \%$ ) of the RCA cells were actively dividing as determined by incorporation of bromodeoxyuridine (BrdU; Figure 3c).

One sample collected outside (station 3) and two samples collected inside the bloom, during day (1100 hours; station 13) and at night (0330 hours; station 9), were subjected to a metagenomic and metatranscriptomic analysis. The genome of P. temperata RCA23 was retrieved from the metagenomes to $>96 \%$ and accounted for $7.8-15.4 \%$ of total reads (Table 2; Figure 4). It was also retrieved from the metatranscriptomes, to $17.3 \%$ outside and to at least $93.4 \%$ inside the bloom (Table 2; Figure 4). Inside the bloom it accounted for 6.7\% of total metatranscriptomic reads during night and for $8 \%$ during day (Table 2). These data, in line with the other above-mentioned data, show that $P$. temperata RCA23 was an abundant and in the bloom also highly active member of the bacterioplankton in the southern North Sea.

For comparison and to validate our genome mapping approach, we carried out similar genomic mappings in the metagenomes and transcriptomes for organisms of the SAR11 clade and SAR92 cluster, phylogenetic lineages also abundant at these stations (Wemheuer et al., 2014). The genomes of Cand. P. ubique HTCC1062 of the SAR11 clade and of the Gammaproteobacterium HTCC2207 of the SAR92 cluster were retrieved to $92.7 \%$ and $44.6 \%$ in the metagenome outside the bloom, and to $50.2 \%$ and $95.6 \%$ inside the bloom, with some differences between day and night (Table 2). Both genomes accounted for not $>1.7 \%$ of total metagenomic reads. The genome of Cand. P. ubique HTCC1062 had already been retrieved to $96 \%$ from metagenomic data of a North Sea phytoplankton spring bloom, but only from the pooled data of all combined samples (Teeling et al., 2012). We retrieved the genomes of Cand. P. ubique HTCC1062 and of Gammaproteobacterium HTCC2207 also from metatranscriptomic reads, in the bloom sample collected during the day to $40.9 \%$ and $89.1 \%$, respectively, and at night to $42.6 \%$ and $34.1 \%$, respectively. These data show little variations between day and night for the transcriptome of Cand. P. ubique HTCC1062, but a much lower fraction of the genome of HTCC2207 transcribed at night. The transcriptomic reads of both organisms 
Table 2 Days of sampling, mapped reads, percentage of genomic coverage and percentage of total reads of $P$. temperata RCA23, Cand. Pelagibacter ubique HTCC1062 of the SAR11 clade and of Gammaproteobacterium HTCC2207 of the SAR92 cluster of the metagenome (DNA) and metatranscriptome (RNA) retrieved at stations outside (non-bloom) and inside the phytoplankton spring bloom during day (1100 hours) and night (0330 hours)

\begin{tabular}{|c|c|c|c|c|c|c|}
\hline Station & Target & No. of reads & Organism (lineage) & Mapped reads & $\begin{array}{c}\text { Percentage of } \\
\text { genome coverage }\end{array}$ & $\begin{array}{c}\text { Percentage of } \\
\text { total reads }\end{array}$ \\
\hline \multicolumn{7}{|l|}{3} \\
\hline Non-bloom & DNA & 23381812 & P. temperata RCA23 & 1819024 & 97.1 & 7.8 \\
\hline \multirow{5}{*}{26 May 2010} & & & Cand. P. ubique HTCC1062 (SAR11) & 407611 & 92.7 & 1.7 \\
\hline & & & HTCC2207 (SAR92) & 50361 & 44.6 & 0.2 \\
\hline & RNA & 2223804 & P. temperata RCA23 & 19435 & 17.3 & 0.9 \\
\hline & & & Cand. P. ubique HTCC1062 (SAR11) & 16947 & 17.9 & 0.8 \\
\hline & & & HTCC2207 (SAR92) & 4021 & 2.6 & 0.2 \\
\hline \multicolumn{7}{|l|}{9} \\
\hline bloom, night & DNA & 12671944 & P. temperata RCA23 & 1783951 & 96.4 & 14.1 \\
\hline \multirow[t]{5}{*}{29 May 2010} & & & Cand. P. ubique HTCC1062 (SAR11) & 112728 & 89.0 & 0.9 \\
\hline & & & HTCC2207 (SAR92) & 45926 & 50.2 & 0.4 \\
\hline & RNA & 8101537 & P. temperata RCA23 & 543596 & 93.4 & 6.7 \\
\hline & & & Cand. P. ubique HTCC1062 (SAR11) & 35853 & 42.6 & 0.4 \\
\hline & & & HTCC2207 (SAR92) & 35853 & 34.1 & 0.3 \\
\hline \multicolumn{7}{|l|}{13} \\
\hline bloom, day & DNA & 16156091 & P. temperata RCA23 & 2480608 & 96.0 & 15.4 \\
\hline \multirow[t]{5}{*}{29 May 2010} & & & Cand. P. ubique HTCC1062 (SAR11) & 23806 & 66.3 & 0.1 \\
\hline & & & HTCC2207 (SAR92) & 238054 & 95.5 & 1.5 \\
\hline & RNA & 15349574 & P. temperata RCA23 & 1222858 & 94.6 & 8.0 \\
\hline & & & Cand. P. ubique HTCC1062 (SAR11) & 27026 & 40.9 & 0.2 \\
\hline & & & HTCC2207 (SAR92) & 179429 & 89.1 & 1.2 \\
\hline GOS02-13 & DNA & 1083836 & P. temperata RCA23 & 12254 & 81.9 & 1.1 \\
\hline \multirow[t]{2}{*}{ Norwegian fjord } & DNA & 863687 & P. temperata RCA23 & 54895 & 83.9 & 6.4 \\
\hline & RNA & 256537 & & 4176 & 23.7 & 1.6 \\
\hline
\end{tabular}

For exact locations of the stations see Figure 3a.

accounted for not $>1.2 \%$ of total metatranscriptomic reads, indicating that these organisms were far less abundant and active than P. temperata RCA23.

The fact that at least $93 \%$ of the genome of P. temperata RCA23 were transcribed in the bloom is remarkable because it reflects that the population of this abundant organism was highly active and used basically the entire potential of its metabolic properties. The largest fraction of the remaining unmapped regions refers to hypothetical proteins mostly located in GIs (Figure 4). To the best of our knowledge this is the first report of such a high fraction of the genome of an abundant marine bacterium transcribed and retrieved from a metatranscriptome. A similarly high genome coverage in a metatranscriptome analysis was recently found in a sediment-derived microbial community degrading hexadecane under anoxic conditions. The genome of Smithella spec., largely dominating this community, was transcribed to 94\% (Embree et al., 2014). Transcribed genomic fractions of $52-95 \%$ have been reported from pure culture experiments with various bacteria such as Helicobacter pylori (Sharma et al., 2010), Bacillus anthracis (Passalacqua et al., 2009), Bacillus subtilis (Nicolas et al., 2012) and Prochlorococcus MED4 (Wang et al., 2014). Hence, the high fraction of the genome of $P$. temperata RCA23 transcribed is in line with these reports but may indicate that the ambient population of this organism consisted of cells in different metabolic stages with respect to growth and substrate utilization.

A more detailed analysis of the transcriptomic patterns of $P$. temperata RCA23 shows that transcripts of COG category E (amino-acid transport and metabolism) exhibited the highest NPKMnormalized reads of all COG categories, followed by COG category $\mathrm{R}$ (general function) and J (translation, ribosomal structure and biogenesis) (Table 3, Supplementary Table S6). The high values of normalized transcripts of amino-acid and carbohydrate transport and metabolism (categories E and G) appear to reflect the significance of these substrates for growth of $P$. temperata RCA23, and is consistent with the broad substrate spectrum of this organism (Giebel et al., 2013). Pronounced differences between the day and night transcriptome occurred in COG categories for translation, ribosomal structure and biogenesis (category J) and for cell motility, but not for chemotaxis (both category N), with higher fractions at night than at day (Supplementary Table S6). Further, the genes c29660, c29670 and c29760, encoding the lightharvesting protein B-870 beta chain PufB and alpha chain PufA and cytochrome c551, respectively, were highly overexpressed at night (Supplementary Figure S5 and Supplementary Table S6). This observation is in line with the well-known fact that bacteriochlorophyll $a$ is only produced during night in AAP bacteria (Wagner-Döbler and Biebl, 2006). 


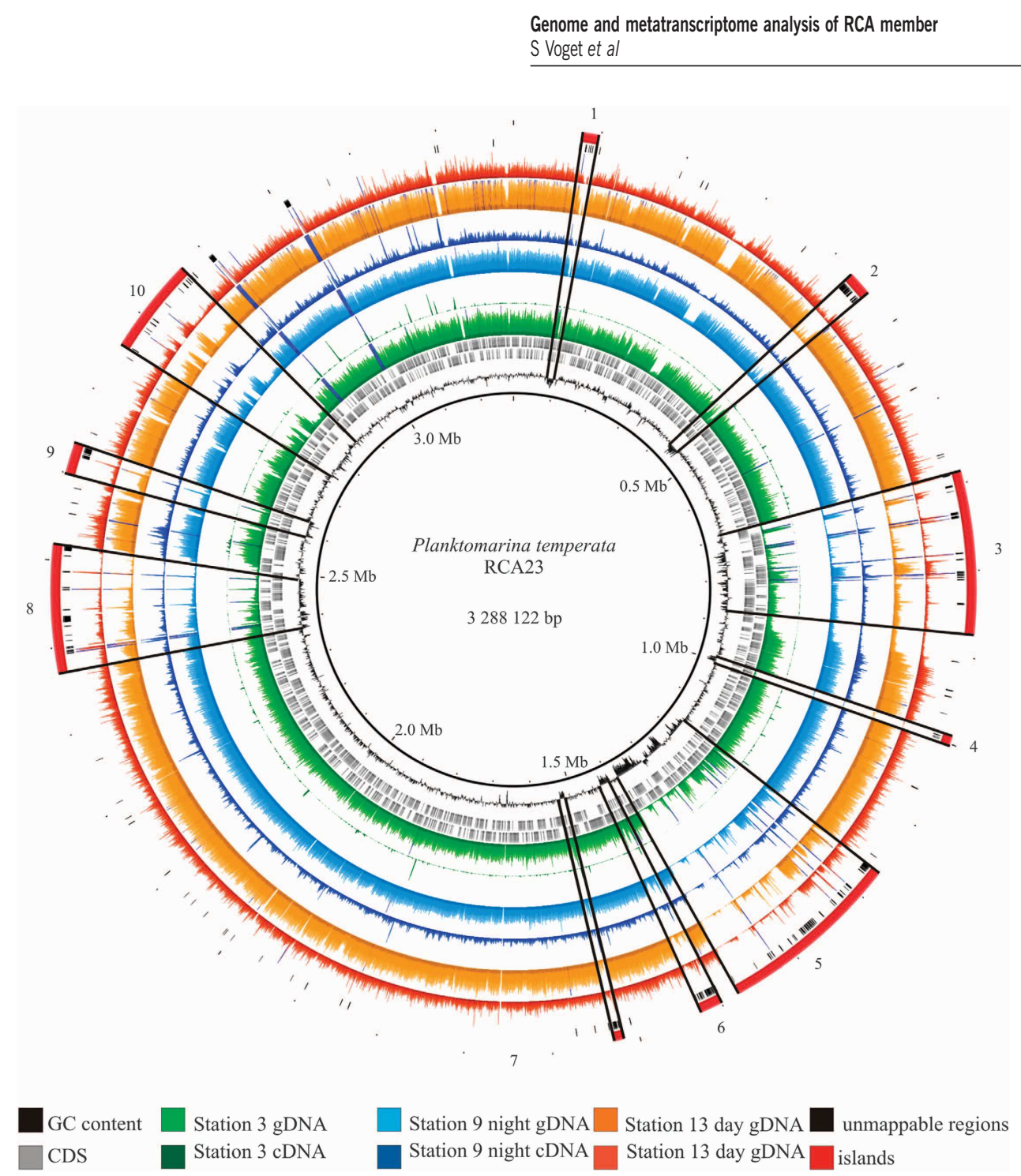

Figure 4 Circular plot of metagenome and transcriptome read mappings onto the genome of $P$. temperata RCA23. Read counts from the Bowtie 2 mappings are shown. From innermost to outer circle: GC content, CDS counts, stations 3, 9 and 13 (DNA and cDNA), unmappable regions and genomic islands.

Genes encoding small heat-shock protein IbpA (c1240, c20690), RNA polymerase $\sigma-32$ factors RpoH1 and RpoH2 (c9960, c21310), chaperonin GroEL (c20740), GroS (c20750) and chaperone protein DnaK (c30090) were also highly overexpressed at night. The small heat-shock protein DnaK and chaperonin GroS, GroEL are important in preventing stress-induced aggregation of various proteins in the cytosol of bacteria (Mogk et al., 2003; Stolyar et al., 2007; Ting et al., 2010). Hence, $P$. temperata RCA23 obviously undergoes some stress during night. So far we have no clue about a more specific type of stress that upregulates the transcription of these genes during night.

As a conclusion from this analysis the population of $P$. temperata RCA23 undergoes intense metabolic reconstruction during night including protein synthesis and stress response, but also enhances the synthesis of flagella proteins. This intense metabolic reconstruction may be a result of the different modes of energy conservation of this AAP bacterium during day and night. It has been shown that Roseobacter litoralis, another AAP bacterium of the Roseobacter clade, changes its proteome drastically, mainly by downregulating protein synthesis, when shifted from dark to light conditions (Zong and Zhao, 2012). Hence the mode of energy conservation appears to have a pronounced effect on the global regulation of metabolic networks in AAP bacteria of the Roseobacter clade, and presumably beyond, with implications of their diurnal participation in turnover of organic matter in marine ecosystems.

Global and biogeochemical significance of the RCA cluster and P. temperata RCA23

Because of the known global distribution of the RCA cluster (Selje et al., 2004) we examined publicly available metagenomic data sets for the presence of genomic features of $P$. temperata RCA23. The photosynthetic operon was present in an 
Table 3 NPKM-normalized reads in the COG categories with type of metabolism of the genome of $P$. temperata RCA23 retrieved in the metatranscriptome at stations 9 and 13 in the German Bight of the North Sea

\begin{tabular}{|c|c|c|c|}
\hline COG category & Type of metabolism & $\begin{array}{c}\text { Station } 9 \text { (night) } \\
\text { NPKM }\end{array}$ & $\begin{array}{c}\text { Station } 13 \text { (day) } \\
\text { NPKM }\end{array}$ \\
\hline $\mathrm{B}$ & Chromatin structure and dynamics & 661 & 954 \\
\hline $\mathrm{C}$ & Energy production and conversion & 61408 & 57017 \\
\hline $\mathrm{D}$ & Cell cycle control, cell division and chromosome partitioning & 7190 & 7533 \\
\hline $\mathrm{E}$ & Amino acid transport and metabolism & 101802 & 107628 \\
\hline $\mathrm{F}$ & Nucleotide transport and metabolism & 24455 & 26003 \\
\hline $\mathrm{G}$ & Carbohydrate transport and metabolism & 59872 & 59448 \\
\hline $\mathrm{H}$ & Coenzyme transport and metabolism & 36820 & 42486 \\
\hline I & Lipid transport and metabolism & 45455 & 49575 \\
\hline $\mathrm{J}$ & Translation, ribosomal structure and biogenesis & 71558 & 59835 \\
\hline K & Transcription & 44710 & 41837 \\
\hline $\mathrm{L}$ & Replication, recombination and repair & 36761 & 39159 \\
\hline M & Cell wall/membrane/envelope biogenesis & 37299 & 39404 \\
\hline $\mathrm{N}$ & Cell motility & 8425 & 4975 \\
\hline $\mathrm{O}$ & Post-translational modification, protein turnover and chaperones & 50598 & 45863 \\
\hline $\mathrm{P}$ & Inorganic ion transport and metabolism & 32016 & 32078 \\
\hline Q & Secondary metabolites biosynthesis, transport and catabolism & 16285 & 16089 \\
\hline$\widehat{\mathrm{R}}$ & General function prediction only & 84440 & 90432 \\
\hline $\mathrm{S}$ & Function unknown & 68057 & 68212 \\
\hline $\mathrm{T}$ & Signal transduction mechanisms & 20797 & 19875 \\
\hline $\mathrm{U}$ & Intracellular trafficking, secretion and vesicular transport & 7431 & 7254 \\
\hline $\mathrm{V}$ & Defense mechanisms & 8258 & 8799 \\
\hline
\end{tabular}

Abbreviations: COG, clusters of orthologous groups; NPKM, Nucleotide activity Per Kilobase of exon model per million Mapped reads.

environmental bacterial artificial chromosome clone derived from Californian coastal waters (Supplementary Figure S3; Béjà et al., 2002; Yutin and Béjà, 2005) and in metagenomic data sets from a Norwegian fjord, the western English Channel, the western coastal Atlantic visited during the Global Ocean Sampling expedition (GOS), and in the eastern (Monterey Bay) and southwestern Pacific in Australian waters (Rusch et al., 2007; Yutin et al., 2007; Gilbert et al., 2008, 2010; Thomas et al., 2010; Rich et al., 2011).

The genome of $P$. temperata RCA23 was retrieved from metagenomic and metatranscriptomic data of a Norwegian fjord to $83.9 \%$ and $23.7 \%$, respectively (Gilbert et al., 2008; Table 2). At the GOS stations, the genome of $P$. temperata RCA23 was retrieved from the metagenomic data to $81.9 \%$ (Table 2) and accounted for $0.7 \%$ to $6.5 \%$ of the mapped reads (Supplementary Figure S6B). This finding, together with the observation that the structure of the photosynthetic operon of the AAP bacteria at these stations was similar to that of P. temperata RCA23 (see above), is consistent with the assumption that this organism constituted largely the AAP communities at these stations. In the GOS and the Norwegian fjord data sets, $80 \%$ and $81 \%$, respectively, of the genes of $P$. temperata RCA23 showed a coverage of $\geqslant 80 \%$. In contrast, $62.5 \%$ of the genes of the GIs were not mapped or showed a low coverage (Supplementary Table S7).

\section{Conclusion}

This study, on the basis of the sequenced genome of P. temperata RCA23 and the North Sea metagenome and metatranscriptome, sheds new light on the significance of the RCA cluster for biogeochemical processes in marine pelagic systems, considering the high abundances of this organism and the entire RCA cluster in temperate to polar oceans (Selje et al., 2004; West et al., 2008; Giebel et al., 2009, 2011; Wemheuer et al., 2014). It appears to carry out a life style well adapted to the nutrient- and energypoor marine pelagic realm. The entire population of this organism, and possibly even single cells, simultaneously transcribe almost the entire genome during phytoplankton bloom situations and convert complementary energy by harvesting light. This versatile physiology together with the wealth of high-affinity transporter proteins, despite the absence of distinct genomic and metabolic traits typical for the Roseobacter clade, and a streamlined genome relative to other Roseobacter clade organisms, helps to explain the success of this abundant taxon in temperate and presumably also (sub)polar marine systems. Our findings illustrate how important it is to dissect the role of individual taxa for better understanding their participation in processing organic and inorganic matter in pelagic marine systems.

\section{Conflict of Interest}

The authors declare no conflict of interest.

\section{Acknowledgements}

We thank Renate Gahl-Janssen for growing P. temperata RCA23 and harvesting biomass for DNA extraction, Melissa Büngener for technical assistance in sequence analyses, the crew of RV Heincke and M Wolterink for 
helping with sample collection and processing during the North Sea cruise and the prophage induction experiment. This work was supported by grants from the Volkswagen Foundation in Lower Saxony, Germany, and by TRR51 of Deutsche Forschungsgemeinschaft.

\section{References}

Béjà O, Suzuki MT, Heidelberg JF, Nelson WC, Preston CM, Hamada T et al. (2002). Unsuspected diversity among marine aerobic anoxygenic phototrophs. Nature 415: 630-633.

Biers EJ, Wang K, Pennington C, Belas R, Chen F, Moran MA. (2008). Occurrence and expression of gene transfer agent (GTA) genes in marine bacterioplankton. Appl Environ Microbiol 74: 2933-2939.

Bolger AM, Lohse M, Usadel B. (2014). Trimmomatic: a flexible trimmer for Illumina sequence data. Bioinformatics; e-pub ahead of print 28 April 2014; doi:10.1093/bioinformatics/btu170.

Brinkhoff T, Giebel HA, Simon M. (2008). Diversity, ecology, and genomics of the Roseobacter clade: a short overview. Arch Microbiol 189: 531-539.

Cunliffe M. (2011). Correlating carbon monoxide oxidation with cox genes in the abundant Marine Roseobacter Clade. ISME J 5: 685-691.

Delcher AL, Bratke KA, Powers EC, Salzberg SL. (2007). Identifying bacterial genes and endosymbiont DNA with Glimmer. Bioinformatics 23: 673-679.

Embree M, Nagarajan H, Movahedi N, Chitsaz H, Zengler K. (2014). Single-cell genome and metatranscriptome sequencing reveal metabolic interactions of an alkane-degrading methanogenic community. ISME J. 8: 757-767.

Fuerch T, Preusse M, Tomasch J, Zech H, Wagner-Döbler I, Rabus R et al. (2009). Metabolic fluxes in the central carbon metabolism of Dinoroseobacter shibae and Phaeobacter gallaeciensis, two members of the marine Roseobacter clade. BMC Microbiol 9: 209.

Giebel HA, Brinkhoff T, Zwisler W, Selje N, Simon M. (2009). Distribution of Roseobacter RCA and SAR11 lineages and distinct bacterial communities from the subtropics to the Southern Ocean. Environ Microbiol 11: $2164-2178$.

Giebel HA, Kalhoefer D, Lemke A, Thole S, Gahl-Janssen R, Simon M et al. (2011). Distribution of Roseobacter RCA and SAR11 lineages in the North Sea and characteristics of an abundant RCA isolate. ISME J 5: 8-19.

Giebel HA, Kalhoefer D, Gahl-Janssen R, Choo YJ, Lee K, Cho JC et al. (2013). Planktomarina temperata gen. nov., sp. nov., belonging to the globally distributed RCA cluster of the marine Roseobacter clade, isolated from the German Wadden Sea. Int J Syst Evol Microbiol 63: $4207-4217$.

Gilbert JA, Field D, Huang Y, Edwards R, Weizhong L, Gilna $\mathrm{R}$ et al. (2008). Detection of large numbers of novel sequences in the metatranscriptomes of complex marine microbial communities. PLoS One 3: e3042.

Gilbert JA, Field D, Swift P, Thomas S, Cummings D, Temperton B et al. (2010). The taxonomic and functional diversity of microbes at a temperate coastal site: a 'multi-omic' study of seasonal and diel temporal variation. PLoS One 5: e15545.
Giovannoni SJ, Tripp HJ, Givan S, Podar M, Vergin KL, Baptista D et al. (2005). Genome streamlining in a cosmopolitan oceanic bacterium. Science 309: 1242-1245.

Giovannoni SJ, Stingl U. (2007). The importance of culturing bacterioplankton in the 'omics' age. Nat Rev Microbiol 5: 820-826.

Giovannoni SJ, Stingl U. (2005). Molecular diversity and ecology of microbial plankton. Nature 437: 343-348.

Giovannoni SJ, Cameron Thrash J, Temperton B. (2014). Implications of streamlining theory for microbial ecology. ISME J; e-pub ahead of print 17 April 2014; doi:10.1038/ismej.2014.60.

Kopylova E, Noé L, Touzet H. (2012). SortMeRNA: fast and accurate filtering of ribosomal RNAs in metatranscriptomic data. Bioinformatics 28: 3211-3217.

Langmead B, Salzberg S. (2012). Fast gapped-read alignment with Bowtie 2. Nat Methods 9: 357-359.

Lauro FM, McDougald D, Thomas T, Williams TJ, Egan S, Rice $S$ et al. (2009). The genomic basis of trophic strategy in marine bacteria. Proc Natl Acad Sci USA 106: $15527-15533$.

Ludwig W, Strunk O, Westram R, Richter L, Meier H, Yadhukumar et al. (2004). ARB: a software environment for sequence data. Nucleic Acids Res 32: 1363-1371.

Luo H, Csu M, Hughes A, Moran MA. (2013). Evolution of divergent life history strategies in marine Alphaproteobacteria. mbio 4: e00373-13.

Luo H, Swan BK, Stepanauskas R, Hughes A, Moran MA. (2014). Evolutionary analysis of a streamlined lineage of surface ocean Roseobacters. ISME J 8: 1428-1439.

Mayali X, Franks PS, Azam F. (2008). Cultivation and ecosystem role of a marine Roseobacter clade-affiliated cluster bacterium. Appl Environ Microbiol 74: 2595-2603.

Mogk A, Deuerling E, Vorderwülbecke S, Vierling E, Bukau B. (2003). Small heat shock proteins, ClpB and the DnaK system form a functional triade in reversing protein aggregation. Mol Microbiol 50: 585-595.

Newton RJ, Griffin LE, Bowles KM, Meile C, Gifford S, Givens CE et al. (2010). Genome characteristics of a generalist marine bacterial lineage. ISME $J$ 4: 784-798.

Nicolas P, Mäder U, Dervyn E, Rochat T, Léduc A et al. (2012). Condition-dependent transcriptome reveals high-level regulatory architecture in Bacillus subtilis. Science 335: 1103-1106.

Passalacqua KD, Varadarajan A, Ondov BD, Okou DT, Zwick ME, Bergman NH. (2009). Structure and complexity of a bacterial transcriptome. J Bacteriol 191: 3203-3211.

Pernthaler A, Pernthaler J, Schattenhofer M, Amann R. (2002). Identification of DNA-synthesizing bacterial cells in coastal North Sea plankton. Appl Environ Microbiol 68: 5728-5736.

Pradella S, Päuker O, Petersen J. (2010). Genome organization of the marine Roseobacter clade member Marinovum algicola. Arch Microbiol 192: 115-126.

Rich VI, Pham VD, Eppley JM, Shi Y, DeLong EF. (2011). Time-series analyses of Monterey Bay coastal microbial picoplankton using a 'genome proxy' microarray. Environ Microbiol 13: 116-134.

Rusch DB, Halpern A, Sutton G, Heidelberg KB, Williamson S, Yooseph S et al. (2007). The Sorcerer II Global Ocean Sampling expedition: northwest Atlantic through eastern tropical Pacific. PLoS Biol 5: e77. 
Selje N, Simon M, Brinkhoff T. (2004). A newly discovered Roseobacter cluster in temperate and polar oceans. Nature 427: 445-448.

Sharma CM, Hoffmann S, Darfeuille F, Reignier J, Findeiss S, Sittka A et al. (2010). The primary transcriptome of the major human pathogen Helicobacter pylori. Nature 460: 250-254.

Sowell SM, Wilhelm LJ, Norbeck AD, Lipton LS, Nicora CD, Barofsky DF et al. (2009). Transport functions dominate the SAR11 metaproteome at low-nutrient extremes in the Sargasso Sea. ISME J 3: 93-105.

Staden R. (1996). The Staden sequence analysis package. Mol Biotech 5: 233-241.

Stolyar S, He Q, Joachimiak MP, He ZL, Yang ZK, Borglin $\mathrm{SE}$ et al. (2007). Response of Desulfovibrio vulgaris to alkaline stress. J Bacteriol 189: 8944-8952.

Swan BK, Tupper B, Sczyrba A, Lauro FM, Martinez-Garcia M, González JM et al. (2013). Prevalent genome streamlining and latitudinal divergence of planktonic bacteria in the surface ocean. Proc Natl Acad Sci USA 110: 11463-11468.

Tech M, Merkl R. (2003). YACOP: Enhanced gene prediction obtained by a combination of existing methods. In Silico Biology 3: 441-451.

Teeling H, Fuchs BM, Becher D, Klockow C, Gardebrecht A, Bennke CM et al. (2012). Substratecontrolled succession of marine bacterioplankton populations induced by a phytoplankton bloom. Science 336: 608-611.

Thomas T, Rusch D, DeMaere MZ, Yung PY, Lewis M, Halpern A et al. (2010). Functional genomic signatures of sponge bacteria reveal unique and shared features of symbiosis. ISME J 4: 1557-1567.

Thompson AW, Huang K, Saito MA, Chisholm SW. (2011). Transcriptome response of high- and low-lightadapted Prochlorococcus strains to changing iron availability. ISME J 5: 1580-1594.

Ting L, Williams TJ, Cowley MJ, Lauro FM, Guilhaus M, Raftery MJ et al. (2010). Cold adaptation in the marine bacterium, Sphingopyxis alaskensis, assessed using quantitative proteomics. Environ Microbiol 12: 2658-2676.

Tripp HJ, Kitner JB, Schwalbach MS, Dacey JWH, Wilhelm LJ, Giovannoni SJ. (2008). SAR11 marine bacteria require exogenous reduced sulphur for growth. Nature 452: 741-744.

Vollmers J, Voget S, Dietrich S, Gollnow K, Smits M, Meyer K et al. (2013). Poles apart: extreme genome plasticity and a new xanthorhodopsin-like gene family in the genomes of Octadecabacter arcticus 238 and Octadecabacter antarcticus 307. PLoS One 8: e63422.

Wagner-Döbler I, Biebl H. (2006). Environmental biology of the marine Roseobacter lineage. Ann Rev Microbiol 60: $255-280$.

Wang B, Lu L, Lv H, Jiang H, Qu G, Tian C et al. (2014). The transcriptome landscape of Prochlorococcus MED4 and the factors for stabilizing the core genome. BMC Microbiol 14: 11.

Wemheuer B, Güllert S, Billerbeck S, Giebel H-A, Voget S, Simon $\mathrm{M}$ et al. (2014). Impact of a phytoplankton bloom on the diversity of the active bacterial community in the southern North Sea as revealed by metatranscriptomic approaches. FEMS Microbiol Ecol 87: 378-389.

West NJ, Obernosterer I, Zemb Lebaron P. (2008). Major differences of bacterial diversity and activity inside and outside of a natural iron-fertilized phytoplankton bloom in the Southern Ocean. Environ Microbiol 10: 738-756.

Wiegand S, Dietrich S, Hertel R, Bongaerts J, Evers S, Volland S et al. (2013). RNA-Seq of Bacillus licheniformis: active regulatory RNA features expressed within a productive fermentation. BMC Genomics 14: 667.

Yooseph S, Nealson KH, Rusch DB, McCrown JP, Dupont CL, Kim M et al. (2010). Genomic and functional adaptation in surface ocean planktonic prokaryotes. Nature 468: 60-67.

Yutin N, Béjà O. (2005). Putative novel photosynthetic reaction centre organizations in marine aerobic anoxygenic photosynthetic bacteria: insights from metagenomics and environmental genomics. Environ Microbiol 7: 2027-2033.

Yutin N, Suzuki MT, Teeling H, Weber M, Venter JC, Rusch DB et al. (2007). Assessing diversity and biogeography of aerobic anoxygenic phototrophic bacteria in surface waters of the Atlantic and Pacific Oceans using the Global Ocean Sampling expedition metagenomes. Environ Microbiol 9: 1464-1475.

Zhao Y, Wang K, Budinoff C, Buchan A, Lang A, Jiao $N$ et al. (2009). Gene transfer agent (GTA) genes reveal diverse and dynamic Roseobacter and Rhodobacter populations in the Chesapeake Bay. ISME J 3: 364-373.

Zong R, Zhao N. (2012). Proteomic responses of Roseobacter litoralis OCh149 to starvation and light regimen. Microbes Environ 27: 430-442.

Supplementary Information accompanies this paper on The ISME Journal website (http://www.nature.com/ismej) 


\section{Supplementary Information to:}

\section{Adaptation of an abundant Roseobacter RCA organism to pelagic systems revealed by genomic and transcriptomic analyses}

Sonja Voget ${ }^{1}$, Bernd Wemheuer ${ }^{1}$, Thorsten Brinkhoff ${ }^{2}$, John Vollmers ${ }^{1}$, Sascha Dietrich ${ }^{1}$, HelgeA. Giebel ${ }^{2}$, Christine Beardsley ${ }^{2}$, Carla Sardemann ${ }^{2}$, Insa Bakenhus ${ }^{2}$, Sara Billerbeck ${ }^{2}$, Rolf Daniel ${ }^{1}$, Meinhard Simon ${ }^{2} *$

${ }^{1}$ Institute of Microbiology \& Genetics, Genomic \& Applied Microbiology and Göttingen Genomics Laboratory, University of Göttingen, D-37077 Göttingen, Germany.

${ }^{2}$ Institute for Chemistry and Biology of the Marine Environment, University of Oldenburg, D26111 Oldenburg, Germany.

* corresponding author.m.simon@icbm.de

Supplementary information includes 4 Figures with the circular representation of the genome of Planktomarina temperata RCA23 (S1), the flagellar genes (S2), the photosynthesis gene cluster of P. temperata RCA23 and other organisms affiliated to the Roseobacter clade (S3), expression patterns of the photosynthesis gene cluster of P. temperata RCA23 during day and night during a phytoplankton spring bloom in the North Sea (S4) and 7 Tables with genomic and metagenomic data on this organism and others of the Roseobacter clade. For Tables S4, S6 and S7 see extra files. 


\section{Figure legends}

Figure S1: Circular representation of the genome of Planktomarina temperata RCA23. From the outer to the innermost circle: 1. Genomic islands (GIs, red). 2 and 3: Leading and lagging strand colored according to the assigned Clusters of Orthologous Groups (COG) categories. 4: transposases/integrases (red), rRNA genes (purple). 5: tRNAs. 6-22: Homologs to genes in 17 organisms of the Roseobacter clade as listed in Table S3, colored according to subclades like in Fig. 1. ORFs of $P$. temperata were determined by reciprocal BLAST-analysis with global alignments (see Methods) against the proteome datasets of the 17 organisms. Query organisms: Rhodobacterales bacterium HTCC2150, Maritimibacter alkaliphilus HTCC2654, Jannaschia sp. CCS1, Dinoroseobacter shibae DFL12, Loktanella vestfoldensis SKA53, Octadecabacter antarcticus 307, Octadecabacter arcticus 238, Roseovarius sp. TM1035, Roseovarius sp. 217 , Sagittula stellata E-37, Oceanicola batsensis HTCC2597, Sulfitobacter NAS-14.1, Sulfitobacter sp. GAI101, Roseobacter litoralis Och149, Rhodobacterales bacterium HTCC2083, Phaeobacter inhibens DSM17395, Ruegeria pomeroyi DSS-3. 23: G+C-content of the chromosome of $P$. temperata with violet areas below average and olive areas above average.

Figure S2 Neighbor-joining phylogeny of flagellar gene sets in Roseobacter clade members (marked in red) and related gene sets in other Alpha- and Gammaproteobacteria based on concatenated protein sequences. The subtree containing flagellar protein sequences of Gammaproteobacteria was collapsed. Bootstrap values are given for major nodes. The resulting phylogenetic tree shows that the flagellar gene sets of the Roseobacter clade are divided into two distinct groups (group I and II) which are more closely related to gene sets of Gammaproteobacteria than to each other. The flagellar genes of P. temperata (marked in bold) fall into group II which contains relatively few sequences of Roseobacter clade members but includes strains of the SAR116 clade (Cand. Puniceispirillum marinum IMCC1322, Alphaproteobacterium HIMB 100) and of Rhodobacter sphaeroides. In contrast, the majority of flagella gene sets in the Roseobacter clade belong to group I.

For the phylogenetic relationship of the flagellar gene sets, genes belonging to the flagellar cluster were identified in the genomes of 38 Roseobacter clade members based on existing annotations and on reciprocal BLASTp analyses. Related gene sets from other bacterial taxa (displayed in black) were obtained by BLASTp analyses of the NCBI nt database using multiple flagellar proteins as query. When multiple flagellar gene sets were present in the same genome, numbers were assigned to the individual sets (indicated by square parentheses). For each gene set, alignments of 15 shared flagellar proteins (FlgA, FlgB, FlgC, FlgD, FlgF, FlgG, FlgH, FlgI, FlhA, FlhB, FliE, FliI, FliL, FliQ, and FliR) were produced using clustalW v1.83. The alignments were concatenated and imported into ARB v5.1 where a filter was created to remove gapped sites and the remaining 3,673 alignment positions per concatenated sequence were subjected to neighbor-joining analysis.

Figure S3 Photosynthesis gene cluster (PGC) of P. temperata RCA23, a BAC clone and other organisms affiliated to the Roseobacter clade. Shown is the different organization of the PGC of members of the Roseobacter clade and environmental clone BAC-60D04 (NCBI Accession AE008921) derived from Californian coastal waters (Béjà et al., 2002). Homologous regions are indicated by blue shaded vertical areas and black lines, respectively. Re-arrangements are marked by red shaded areas. Genes are colored according to biological categories: green, 
bacteriochlorophyll biosynthesis (bch); orange, carotenoid biosynthesis (crt); red, light harvesting and photosynthesis reaction center (puf); blue, cytochrome c2; grey, accessory genes.

Figure S4 Transporter proteins of $P$. temperata RCA23 in comparison to those of other organisms of the Roseobacter clade. Relation between total numbers of transporters and $\mathrm{ABC}$ transporters (A). Box-Whisker plot of $\mathrm{ABC}$ transporters (B), $\mathrm{ABC}$-/total transporters (C) and TRAP transporters (D) of 14 members of the Roseobacter clade associated to other organisms, surfaces or sediment and of 24 members with a pelagic life style listed in supplementary Table S2. Data include 12 closed and 26 draft genomes. Blue circle and +: P. temperata RCA23. The boxes show the median (solid line), mean (dashed line), the $25^{\text {th }}$ and $75^{\text {th }}$ percentile and the whiskers the $10^{\text {th }}$ and $90^{\text {th }}$ percentiles. $\bullet$ outlayers. For further details see supplementary Tables S2 and S3.

Figure S5 Expression patterns of the photosynthesis gene cluster of $P$. temperata RCA23 at station 13 during day and station 9 at night during a phytoplankton spring bloom in the southern North Sea in May 2010. Genes are colored according to biological categories: green, bacteriochlorophyll biosynthesis (bch); orange, carotenoid biosynthesis (crt); red, light harvesting and photosynthesis reaction center (puf).

Figure S6 Representation of the genome of Planktomarina temperata RCA23 in metagenomic data sets of the north-western Atlantic Ocean. (A) Overview of the stations visited by the Global Ocean Sampling (GOS) expedition in the western coastal Atlantic Ocean (Rusch et al., 2007). (B) Salinity, temperature, chlorophyll and mapped reads (bar) of the genome of $P$. temperata RCA23 at the stations shown above. 


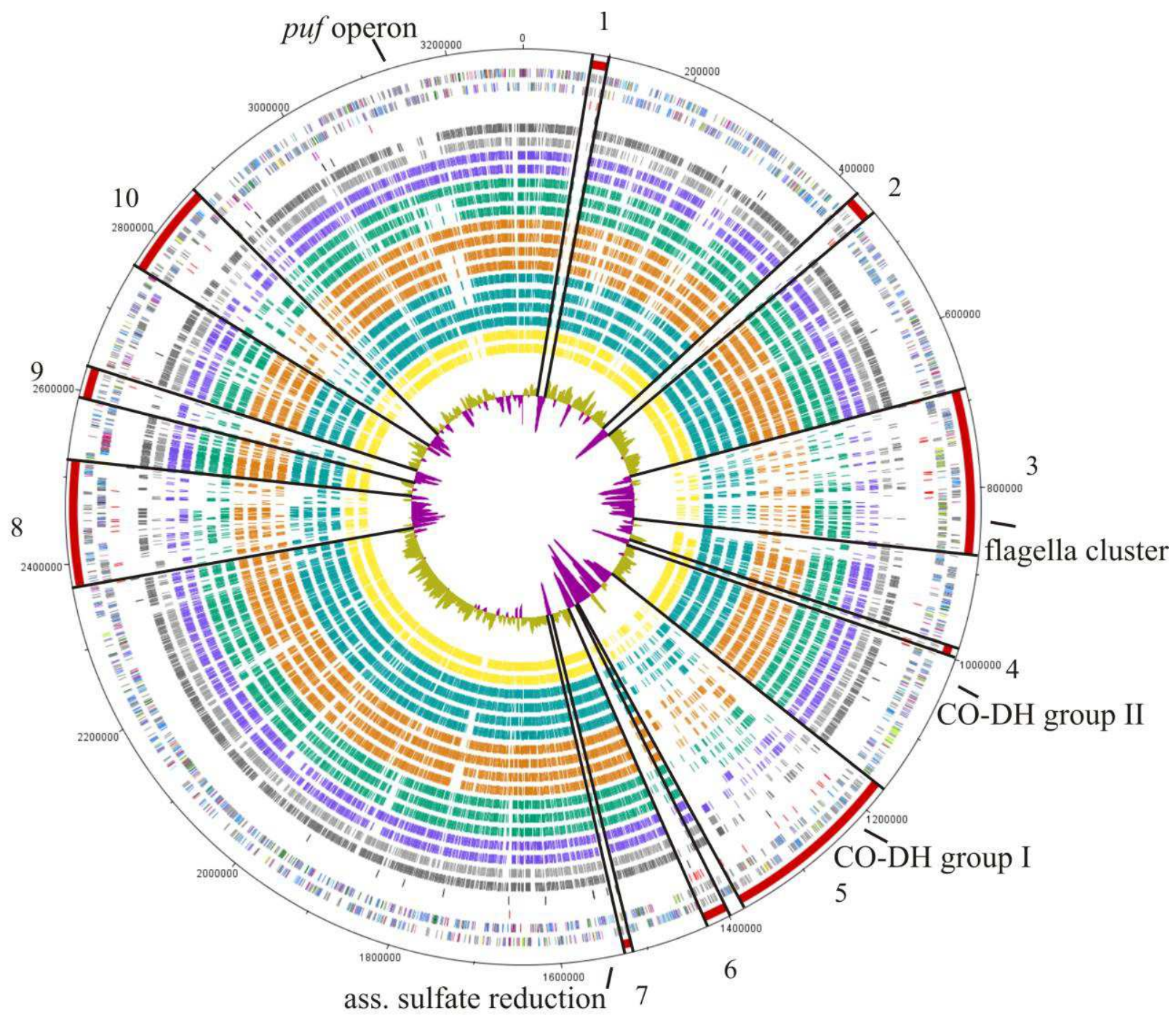

Figure S1. 


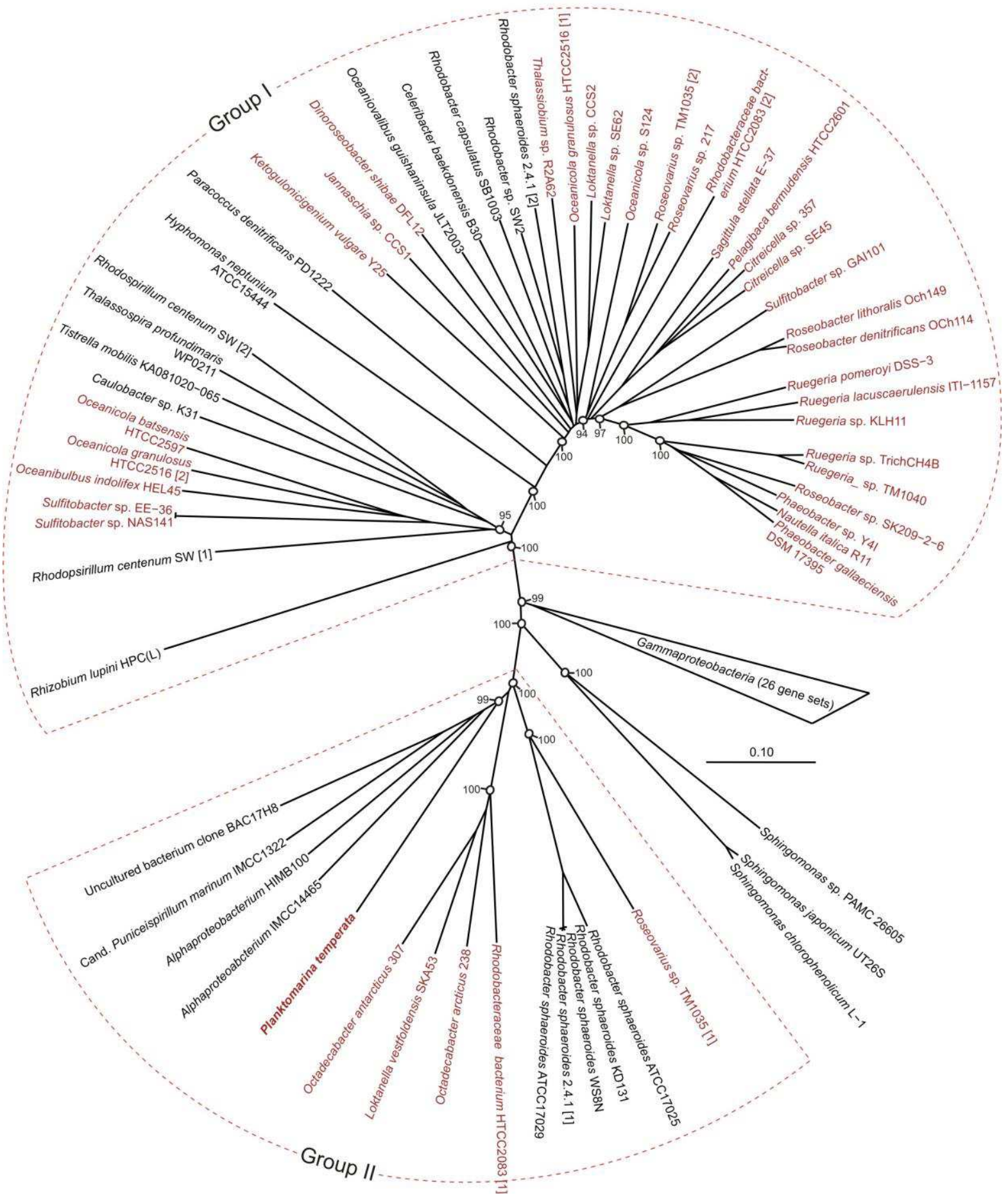

Figure S2 


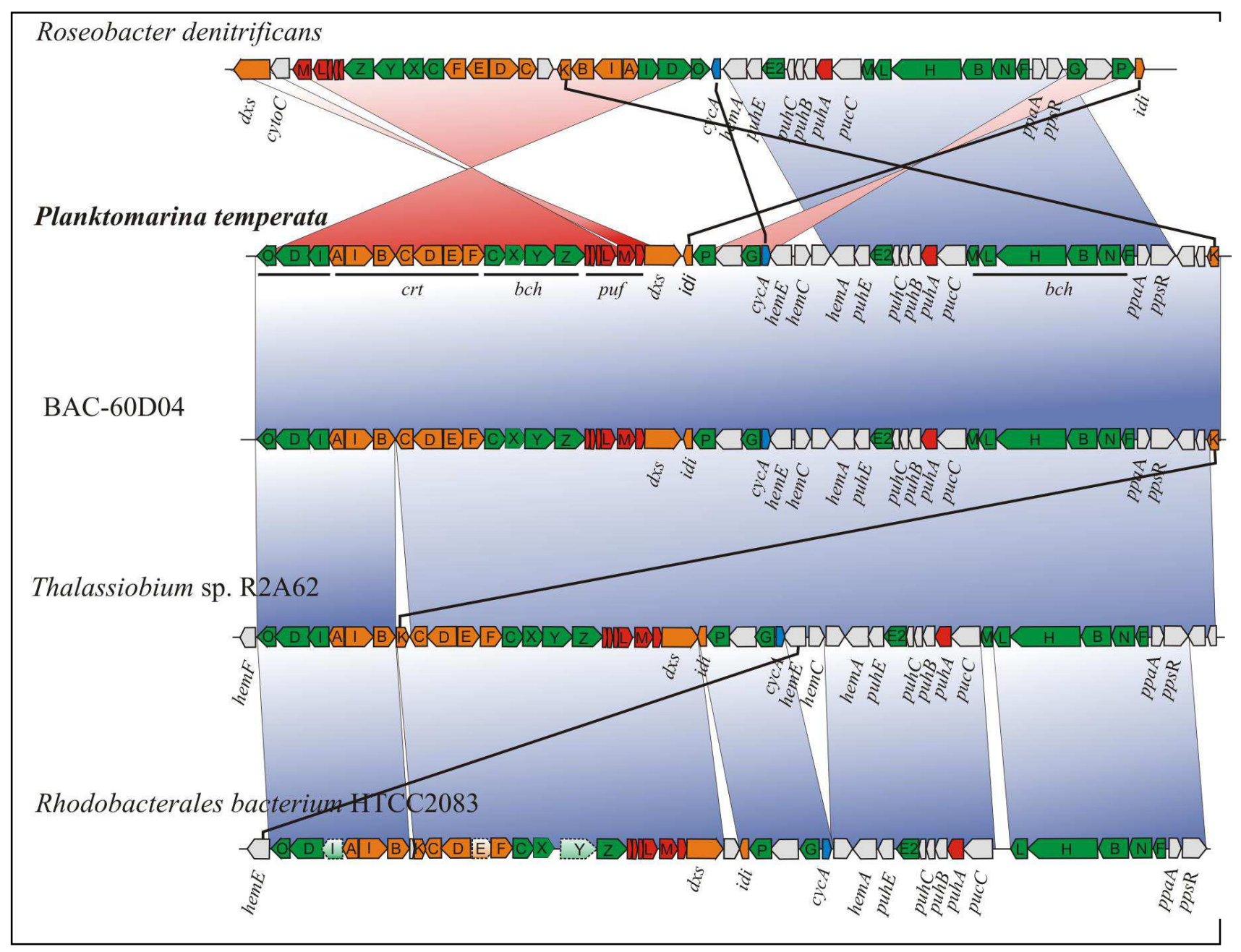

Figure S3 

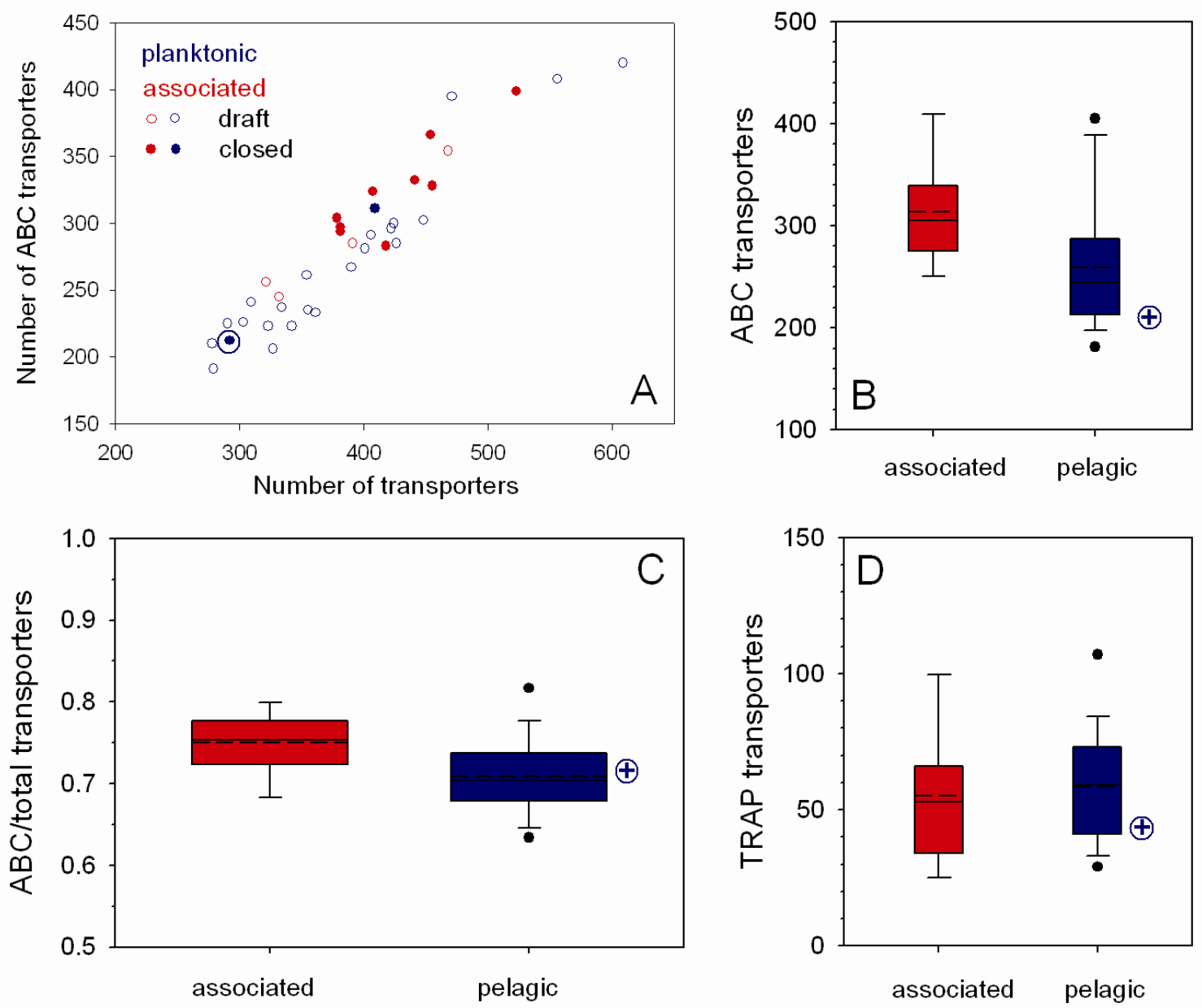

Fiı 
Station 13, bloom-day

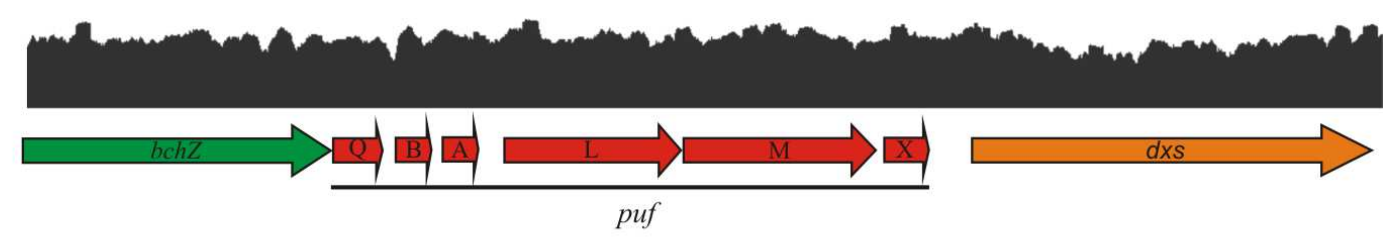

Station 9, bloom-night

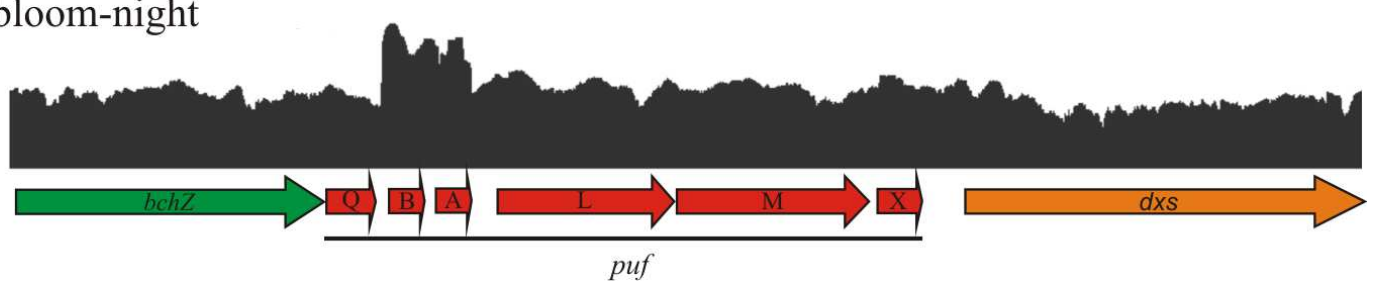

Figure S5 Voget et al 

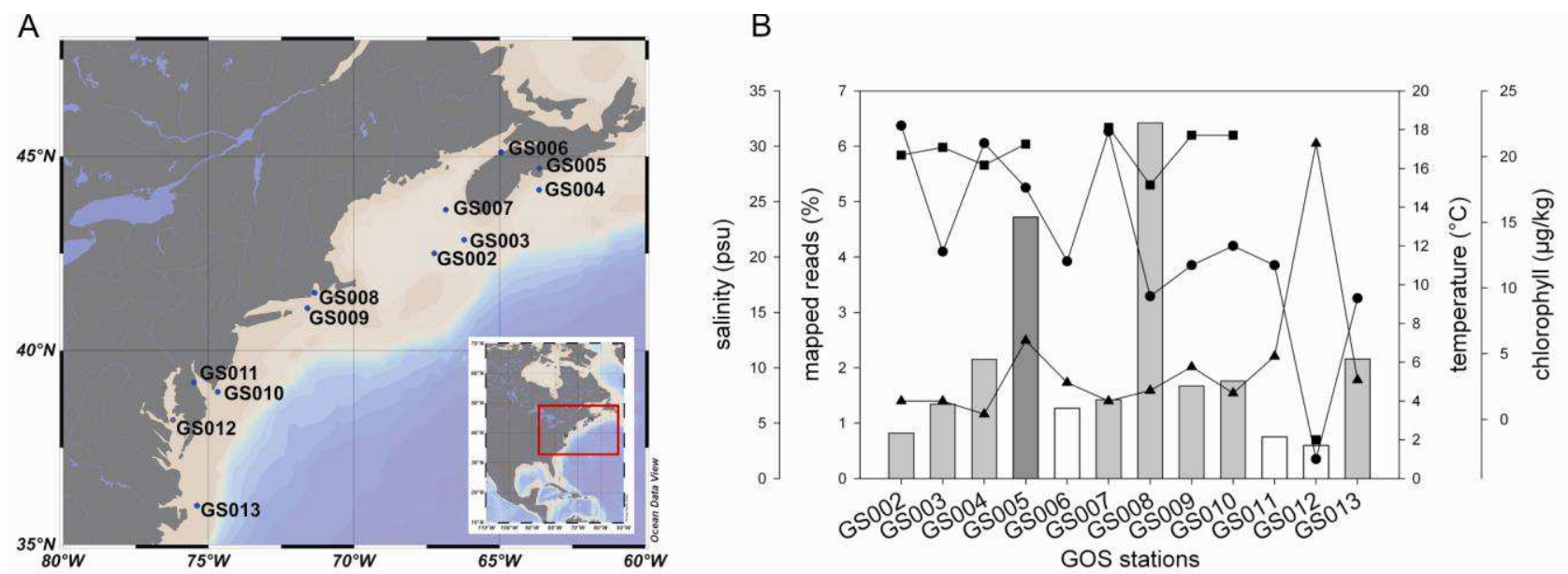

Figure S6 
Table S1. Overview of metagenomic and metatranscriptomic datasets used in this study.

\begin{tabular}{lccrrr}
\hline $\begin{array}{c}\text { Data sets used in this } \\
\text { study }\end{array}$ & type & $\begin{array}{c}\text { Sequencing } \\
\text { technology }\end{array}$ & Raw-reads & $\begin{array}{c}\text { No. of reads } \\
\text { (trimmed, } \\
\text { rRNA free) }\end{array}$ & Reference \\
\hline Station 3, non-bloom & DNA & Illumina & 24331052 & 23381812 & This study \\
& RNA & Illumina & 24879579 & 2223804 & \\
Station 9, bloom-night & DNA & Illumina & 13125978 & 12671944 & This study \\
& RNA & Illumina & 26176832 & 8101537 & \\
Station 13, bloom-day & DNA & Illumina & 16877252 & 16156091 & This study \\
& RNA & Illumina & 26985711 & 15349574 & \\
northwestern Atlantic & DNA & Sanger & 1083836 & - & Rusch et al. \\
(stations GOS02-13) & & & & & Gilbert et al \\
Norwegian fjord & DNA & 454 & 863687 & - &
\end{tabular}

Rusch DB, et al. (2007). The Sorcerer II Global Ocean Sampling expedition: northwest Atlantic through eastern tropical Pacific. PLoS Biology 5:e77.

Gilbert JA, et al. (2008). Detection of large numbers of novel sequences in the metatranscriptomes of complex marine microbial communities. PLoS One 3:e3042. 
Table S2. Overview of genome characteristics and general genome comparisons of organisms of the Roseobacter clade isolated from associations (assoc) with various organisms, surfaces or sediment and from pelagic environments and ordered according to genome size. For comparison respective data of Cand. Pelagibacter ubique HTCC1062 are also given. The number of plasmids was derived from plasmid replication systems. Data were taken from the Integrated Microbial Genomes and Metagenomes (IMG; http://img.jgi.doe.gov/) platform.

F: finished genomes; D: draft genomes. nd: not determined.

CDS: Coding DNA sequences; COG: Cluster of orthologous groups; ABC: ATP-binding cassette;

TRAP: Tripartite ATP-independent periplasmic.

\begin{tabular}{|c|c|c|c|c|c|c|c|c|c|c|c|c|c|c|c|c|c|c|}
\hline \multirow[t]{2}{*}{$\begin{array}{l}\text { Sta- } \\
\text { tus }\end{array}$} & \multirow[t]{2}{*}{ Genome Name } & \multirow[t]{2}{*}{ type } & \multirow[t]{2}{*}{$\begin{array}{c}\text { Scaf } \\
\text { fold } \\
\text { Cou } \\
\text { nt } \\
\\
\\
\text { total } \\
\end{array}$} & \multirow[t]{2}{*}{$\begin{array}{r}\mathbf{G C} \\
\\
\\
\\
\\
\\
\end{array}$} & \multirow[t]{2}{*}{$\begin{array}{c}\text { geno } \\
\text { me } \\
\text { size } \\
\\
\mathrm{Mb} \\
\end{array}$} & \multirow[t]{2}{*}{$\begin{array}{l}\% \\
\text { codi } \\
\text { ng } \\
\\
\\
\% \\
\end{array}$} & \multirow[t]{2}{*}{$\begin{array}{c}\text { Gene } \\
\text { Count } \\
\text { total }\end{array}$} & \multirow[t]{2}{*}{$\begin{array}{c}\text { CDS } \\
\text { Count } \\
\\
\text { total }\end{array}$} & \multirow[t]{2}{*}{$\begin{array}{c}\text { COG } \\
\\
\\
\% \\
\end{array}$} & \multicolumn{2}{|c|}{$\begin{array}{c}\text { Homolog } \\
\text { CDSs } \\
\text { (alignment } \\
\text { min. 30\% } \\
\text { and e-value } \\
<1 \mathrm{e}-20 \text { ) }\end{array}$} & \multicolumn{2}{|c|}{$\begin{array}{l}\text { trans-port } \\
\text { proteins }\end{array}$} & \multicolumn{2}{|c|}{$\begin{array}{l}\text { ABC-type } \\
\text { transport } \\
\text { proteins }\end{array}$} & \multirow[t]{2}{*}{$\begin{array}{c}\text { TRAP } \\
\text {-type } \\
\text { trans } \\
\text { port } \\
\text { protei } \\
\text { ns } \\
\text { total } \\
\end{array}$} & \multirow[t]{2}{*}{$\begin{array}{c}\text { amino } \\
\text { acid } \\
\text { transpo } \\
\mathbf{r t} \\
\text { proteins } \\
\\
\text { total }\end{array}$} & \multirow[t]{2}{*}{$\begin{array}{l}\text { Plas- } \\
\text { mids } \\
\\
\text { total }\end{array}$} \\
\hline & & & & & & & & & & total & $\%$ & total & per Mb & total & per Mb & & & \\
\hline $\mathrm{F}$ & $\begin{array}{l}\text { Cand. Pelagibacter } \\
\text { ubique HTCC } 1062\end{array}$ & pelagic & 1 & 30 & 1.31 & 96.1 & 1394 & 1354 & 81.13 & 847 & 27.7 & 95 & 73 & 67 & 51.1 & 9 & 31 & 0 \\
\hline $\mathrm{F}$ & Nautella italica $\mathrm{R} 11$ & assoc & 2 & 60 & 3.82 & 88.7 & 3725 & 3656 & & 1860 & 60.9 & 321 & 84 & 256 & 67.0 & 27 & 63 & 1 \\
\hline $\mathrm{F}$ & $\begin{array}{l}\text { Ruegeria sp. } \\
\text { TM1040 }\end{array}$ & assoc & 3 & 60 & 4.15 & 89.0 & 3964 & 3870 & 75.45 & 1825 & 59.7 & 375 & 90 & 289 & 69.6 & 42 & 51 & 4 \\
\hline $\mathrm{F}$ & $\begin{array}{l}\text { Phaeobacter } \\
\text { inhibens } 2.10\end{array}$ & assoc & 4 & 60 & 4.16 & 88.0 & 3798 & 3729 & 82.52 & 1894 & 62.0 & 371 & 89 & 289 & 69.5 & 27 & 74 & 3 \\
\hline $\mathrm{D}$ & $\begin{array}{l}\text { Roseovarius sp. } \\
\text { TM1035 }\end{array}$ & assoc & 15 & 61 & 4.21 & 91.1 & 4158 & 4102 & 73.42 & 1847 & 60.4 & 380 & 90 & 275 & 65.3 & 53 & 100 & 1 \\
\hline $\mathrm{F}$ & $\begin{array}{c}\text { Phaeobacter } \\
\text { inhibens DSM17395 } \\
\text { Roseobacter }\end{array}$ & assoc & 4 & 60 & 4.23 & 88.8 & 3960 & 3891 & 80.03 & 1891 & 61.9 & 369 & 87 & 297 & 70.2 & 22 & 69 & 3 \\
\hline $\mathrm{F}$ & $\begin{array}{c}\text { denitrificans OCh } \\
114\end{array}$ & assoc & 5 & 59 & 4.33 & 89.4 & 4201 & 4146 & 73.22 & 1923 & 62.9 & 432 & 100 & 324 & 74.8 & 64 & 72 & 4 \\
\hline $\mathrm{F}$ & $\begin{array}{l}\text { Dinoroseobacter } \\
\text { shibae DFL-12, } \\
\text { DSM } 16493\end{array}$ & assoc & 6 & 66 & 4.42 & 89.9 & 4271 & 4219 & 74.29 & 1861 & 60.9 & 407 & 92 & 273 & 61.8 & 78 & 55 & 5 \\
\hline $\mathrm{D}$ & Ruegeria sp. KLH11 & assoc & 6 & 58 & 4.49 & 86.4 & 4338 & 4274 & 68.88 & 1797 & 58.8 & 327 & 73 & 241 & 53.7 & 34 & 51 & 2 \\
\hline $\mathrm{F}$ & $\begin{array}{c}\text { Ruegeria pomeroyi } \\
\text { DSS-3 }\end{array}$ & assoc & 2 & 64 & 4.60 & 90.0 & 4355 & 4283 & 78.05 & 1941 & 63.5 & 447 & 97 & 321 & 69.8 & 72 & 114 & 1 \\
\hline $\mathrm{D}$ & $\begin{array}{c}\text { Silicibacter sp. } \\
\text { TrichCH4B }\end{array}$ & assoc & 8 & 59 & 4.69 & 89.1 & 4814 & 4735 & 68.92 & 1821 & 59.6 & 461 & 98 & 348 & 74.2 & 55 & 45 & nd \\
\hline $\mathrm{F}$ & $\begin{array}{c}\text { Roseobacter litoralis } \\
\text { Och } 149\end{array}$ & assoc & 4 & 57 & 4.74 & 89.1 & 4577 & 4537 & 77.91 & 1982 & 64.9 & 509 & 107 & 387 & 81.6 & 66 & 95 & 3 \\
\hline $\mathrm{F}$ & $\begin{array}{l}\text { Octadecabacter } \\
\text { antarcticus } 307\end{array}$ & assoc & 18 & 55 & 4.91 & 83.4 & 5544 & 5495 & 58.75 & 1906 & 62.4 & 428 & 87 & 339 & 69.0 & 48 & 58 & 1 \\
\hline $\mathrm{F}$ & $\begin{array}{l}\text { Octadecabacter } \\
\text { arcticus } 238\end{array}$ & assoc & 8 & 55 & 5.39 & 81.8 & 5883 & 5834 & 60.58 & 1888 & 61.8 & 395 & 73 & 305 & 56.6 & 50 & 80 & 2 \\
\hline $\mathrm{D}$ & Citreicella sp. SE45 & assoc & 9 & 67 & 5.52 & 87.9 & 5499 & 5427 & 71.65 & 1721 & 56.3 & 644 & 117 & 443 & 80.3 & 132 & 103 & 3 \\
\hline
\end{tabular}




\begin{tabular}{|c|c|c|c|c|c|c|c|c|c|c|c|c|c|c|c|c|c|c|}
\hline \multirow[t]{2}{*}{$\begin{array}{l}\text { Sta- } \\
\text { tus }\end{array}$} & \multirow[t]{2}{*}{ Genome Name } & \multirow[t]{2}{*}{ type } & \multirow[t]{2}{*}{$\begin{array}{c}\text { Scaf } \\
\text { fold } \\
\text { Cou } \\
\text { nt } \\
\\
\\
\text { total } \\
\end{array}$} & \multirow[t]{2}{*}{$\begin{array}{r}\text { GC } \\
\\
\\
\\
\\
\% \\
\end{array}$} & \multirow[t]{2}{*}{$\begin{array}{c}\text { geno } \\
\text { me } \\
\text { size } \\
\\
\\
\mathrm{Mb} \\
\end{array}$} & \multirow[t]{2}{*}{$\begin{array}{l}\begin{array}{l}\text { \% } \\
\text { codi } \\
\text { ng }\end{array} \\
\\
\\
\% \\
\end{array}$} & \multirow[t]{2}{*}{$\begin{array}{c}\text { Gene } \\
\text { Count } \\
\\
\text { total } \\
\end{array}$} & \multirow[t]{2}{*}{$\begin{array}{c}\text { CDS } \\
\text { Count } \\
\\
\text { total } \\
\end{array}$} & \multirow[t]{2}{*}{$\begin{array}{c}\text { COG } \\
\\
\\
\\
\% \\
\end{array}$} & \multicolumn{2}{|c|}{$\begin{array}{l}\text { Homolog } \\
\text { CDSs } \\
\text { (alignment } \\
\text { min. 30\% } \\
\text { and e-value } \\
<1 \mathrm{e}-20 \text { ) }\end{array}$} & \multicolumn{2}{|c|}{$\begin{array}{l}\text { trans-port } \\
\text { proteins }\end{array}$} & \multicolumn{2}{|c|}{$\begin{array}{c}\text { ABC-type } \\
\text { transport } \\
\text { proteins }\end{array}$} & \multirow[t]{2}{*}{$\begin{array}{c}\text { TRAP } \\
\text {-type } \\
\text { trans } \\
\text { port } \\
\text { protei } \\
\text { ns } \\
\text { total } \\
\end{array}$} & \multirow[t]{2}{*}{$\begin{array}{c}\text { amino } \\
\text { acid } \\
\text { transpo } \\
\mathbf{r t} \\
\text { proteins } \\
\\
\text { total } \\
\end{array}$} & \multirow[t]{2}{*}{$\begin{array}{l}\text { Plas } \\
\text { mids } \\
\\
\text { total }\end{array}$} \\
\hline & & & & & & & & & & total & $\%$ & total & per $\mathrm{Mb}$ & total & per $\mathrm{Mb}$ & & & \\
\hline $\mathrm{D}$ & $\begin{array}{l}\text { Rhodobacterales } \\
\text { sp.HTCC2255 }\end{array}$ & pelagic & 12 & 37 & 2.54 & 92.7 & 2240 & 2177 & 87.46 & 1565 & 51,2 & 247 & 111 & 179 & 47.6 & 38 & 54 & 0 \\
\hline $\mathrm{D}$ & $\begin{array}{c}\text { Loktanella } \\
\text { vestfoldensis SKA53 }\end{array}$ & pelagic & 14 & 60 & 3.06 & 91.9 & 3117 & 3068 & 75.01 & 1843 & 60.3 & 272 & 89 & 205 & 67.0 & 34 & 45 & 0 \\
\hline F & $\begin{array}{c}\text { Planktomarina } \\
\text { temperata } \text { RCA23 }\end{array}$ & pelagic & 1 & 54 & 3.29 & 89.8 & 3101 & 3056 & 83.23 & l & I & 287 & 87 & 208 & 63.2 & 43 & 53 & $\mathbf{0}$ \\
\hline $\mathrm{D}$ & Loktanella sp. CCS2 & pelagic & 11 & 55 & 3.49 & 92.2 & 3703 & 3660 & 69.46 & 1841 & 60.2 & 300 & 86 & 234 & 67.0 & 35 & 46 & 0 \\
\hline $\mathrm{D}$ & $\begin{array}{l}\text { Thalassiobium sp. } \\
\text { R2A62 }\end{array}$ & pelagic & 1 & 55 & 3.49 & 90.1 & 3744 & 3696 & 67.68 & 1913 & 62.6 & 285 & 82 & 221 & 63.3 & 31 & 48 & 0 \\
\hline $\mathrm{D}$ & $\begin{array}{c}\text { Ruegeriar } \\
\text { lacuscaerulensis ITI- } \\
1157\end{array}$ & pelagic & 2 & 63 & 3.52 & 90.9 & 3677 & 3611 & 72.97 & 1828 & 59.8 & 298 & 85 & 222 & 63.1 & 28 & 44 & 1 \\
\hline $\mathrm{D}$ & $\begin{array}{l}\text { Sulfitobacter sp. EE- } \\
36\end{array}$ & pelagic & 15 & 60 & 3.55 & 91.0 & 3542 & 3474 & 76.31 & 1764 & 57.7 & 333 & 94 & 215 & 60.6 & 73 & 54 & 2 \\
\hline D & $\begin{array}{c}\text { Rhodobacterales sp. } \\
\text { HTCC } 2150\end{array}$ & pelagic & 25 & 49 & 3.58 & 91.6 & 3713 & 3667 & 70.11 & 1943 & 63.6 & 273 & 76 & 186 & 52.0 & 53 & 59 & 3 \\
\hline D & $\begin{array}{c}\text { Roseovarius } \\
\text { nubinhibens ISM }\end{array}$ & pelagic & 10 & 64 & 3.67 & 89.8 & 3605 & 3547 & 74.84 & 1737 & 56.8 & 322 & 88 & 202 & 55.0 & 76 & 70 & 1 \\
\hline D & $\begin{array}{l}\text { Sulfitobacter sp. } \\
\text { NAS-14.1 }\end{array}$ & pelagic & 27 & 60 & 4.00 & 90.1 & 4026 & 3962 & 73.7 & 1788 & 58.5 & 348 & 87 & 229 & 57.3 & 65 & 53 & 5 \\
\hline D & $\begin{array}{c}\text { Rhodobacterales sp. } \\
\text { HTCC } 2083\end{array}$ & pelagic & 5 & 53 & 4.02 & 87.6 & 4226 & 4179 & 69.12 & 2009 & 65.7 & 347 & 86 & 255 & 63.4 & 66 & 76 & 1 \\
\hline $\mathrm{D}$ & $\begin{array}{l}\text { Oceanicola } \\
\text { granulosus } \\
\text { HTCC2516 }\end{array}$ & pelagic & 85 & 70 & 4.04 & 91.5 & 3855 & 3792 & 77.12 & 1736 & 56.8 & 459 & 114 & 384 & 95.0 & 35 & 52 & 2 \\
\hline D & $\begin{array}{c}\text { Oceanibulbus } \\
\text { indolifex HEL-45 }\end{array}$ & pelagic & 105 & 60 & 4.11 & 89.4 & 4208 & 4153 & 73.31 & 1780 & 58.2 & 411 & 100 & 286 & 69.6 & 68 & 79 & 1 \\
\hline D & $\begin{array}{l}\text { Roseobacter sp. } \\
\text { AzwK-3b }\end{array}$ & pelagic & 31 & 62 & 4.18 & 88.8 & 4197 & 4145 & 69.67 & 1825 & 59.7 & 325 & 78 & 229 & 54.8 & 59 & 78 & 0 \\
\hline $\mathrm{F}$ & $\begin{array}{l}\text { Jannaschia sp. } \\
\text { CCS1 }\end{array}$ & pelagic & 2 & 62 & 4.40 & 90.8 & 4339 & 4283 & 73.17 & 1917 & 62.7 & 400 & 91 & 303 & 68.9 & 59 & 39 & 1 \\
\hline $\mathrm{D}$ & $\begin{array}{c}\text { Rhodobacterales sp. } \\
\text { Y4I }\end{array}$ & pelagic & 5 & 64 & 4.34 & 86.2 & 4206 & 4133 & 73.3 & 1782 & 58.3 & 317 & 73 & 218 & 50.2 & 42 & 73 & 2 \\
\hline $\mathrm{D}$ & $\begin{array}{c}\text { Oceanicola batsensis } \\
\text { HTCC } 2597\end{array}$ & pelagic & 23 & 66 & 4.44 & 89.2 & 4261 & 4212 & 75.1 & 1739 & 56.9 & 437 & 98 & 293 & 66.0 & 82 & 108 & 4 \\
\hline $\mathrm{D}$ & $\begin{array}{c}\text { Maritimibacter } \\
\text { alkaliphilus } \\
\text { HTCC2654 }\end{array}$ & pelagic & 46 & 64 & 4.53 & 90.1 & 4763 & 4712 & 67.86 & 1751 & 57.3 & 381 & 84 & 260 & 57.4 & 64 & 88 & 3 \\
\hline
\end{tabular}




\begin{tabular}{|c|c|c|c|c|c|c|c|c|c|c|c|c|c|c|c|c|c|c|}
\hline \multirow[t]{2}{*}{$\begin{array}{l}\text { Sta- } \\
\text { tus }\end{array}$} & \multirow[t]{2}{*}{ Genome Name } & \multirow[t]{2}{*}{ type } & \multirow[t]{2}{*}{$\begin{array}{c}\text { Scaf } \\
\text { fold } \\
\text { Cou } \\
\text { nt } \\
\\
\\
\text { total }\end{array}$} & \multirow[t]{2}{*}{$\begin{array}{r}\text { GC } \\
\\
\\
\% \\
\end{array}$} & \multirow[t]{2}{*}{$\begin{array}{c}\text { geno } \\
\text { me } \\
\text { size } \\
\\
\mathrm{Mb} \\
\end{array}$} & \multirow[t]{2}{*}{$\begin{array}{l}\begin{array}{l}\text { \% } \\
\text { codi } \\
\text { ng }\end{array} \\
\\
\\
\% \\
\end{array}$} & \multirow[t]{2}{*}{$\begin{array}{c}\text { Gene } \\
\text { Count } \\
\\
\text { total } \\
\end{array}$} & \multirow[t]{2}{*}{$\begin{array}{c}\text { CDS } \\
\text { Count } \\
\\
\text { total } \\
\end{array}$} & \multirow[t]{2}{*}{$\begin{array}{c}\text { COG } \\
\\
\\
\\
\%\end{array}$} & \multicolumn{2}{|c|}{$\begin{array}{l}\text { Homolog } \\
\text { CDSs } \\
\text { (alignment } \\
\text { min. 30\% } \\
\text { and e-value } \\
<1 \mathrm{e}-20 \text { ) }\end{array}$} & \multicolumn{2}{|c|}{$\begin{array}{c}\text { trans-port } \\
\text { proteins }\end{array}$} & \multicolumn{2}{|c|}{$\begin{array}{c}\text { ABC-type } \\
\text { transport } \\
\text { proteins }\end{array}$} & \multirow[t]{2}{*}{$\begin{array}{c}\text { TRAP } \\
\text {-type } \\
\text { trans } \\
\text { port } \\
\text { protei } \\
\text { ns } \\
\text { total } \\
\end{array}$} & \multirow[t]{2}{*}{$\begin{array}{c}\text { amino } \\
\text { acid } \\
\text { transpo } \\
\text { rt } \\
\text { proteins } \\
\\
\text { total } \\
\end{array}$} & \multirow[t]{2}{*}{$\begin{array}{l}\text { Plas- } \\
\text { mids } \\
\\
\text { total }\end{array}$} \\
\hline & & & & & & & & & & total & $\%$ & total & per $\mathrm{Mb}$ & total & per $\mathrm{Mb}$ & & & \\
\hline $\mathrm{D}$ & $\begin{array}{c}\text { Sulfitobacter sp. } \\
\text { GAI101 }\end{array}$ & pelagic & 9 & 59 & 4.53 & 87.2 & 4258 & 4203 & 76.33 & 1857 & 60.8 & 414 & 91 & 291 & 64.2 & 74 & 59 & 3 \\
\hline $\mathrm{D}$ & $\begin{array}{l}\text { Roseobacter sp. } \\
\text { SK209-2-6 }\end{array}$ & pelagic & 29 & 57 & 4.55 & 88.8 & 4610 & 4537 & 71.13 & 1851 & 60.6 & 394 & 87 & 276 & 60.7 & 59 & 86 & 3 \\
\hline $\mathrm{D}$ & $\begin{array}{l}\text { Roseobacter sp. } \\
\quad \text { MED193 }\end{array}$ & pelagic & 19 & 57 & 4.65 & 89.1 & 4605 & 4535 & 71.9 & 1901 & 62.2 & 395 & 85 & 281 & 60.4 & 51 & 80 & 2 \\
\hline $\mathrm{D}$ & Roseovarius sp. 217 & pelagic & 37 & 61 & 4.76 & 90.2 & 4823 & 4772 & 72.53 & 1842 & 60.3 & 417 & 88 & 277 & 58.2 & 73 & 100 & 2 \\
\hline $\mathrm{D}$ & $\begin{array}{c}\text { Sagittula stellata E- } \\
37 \\
\text { Pelagihasa }\end{array}$ & pelagic & 39 & 65 & 5.26 & 88.3 & 5121 & 5067 & 72.66 & 1908 & 62.4 & 546 & 104 & 399 & 75.9 & 90 & 89 & 3 \\
\hline $\mathrm{D}$ & $\begin{array}{l}\text { bermudensis } \\
\text { HTCC2601 }\end{array}$ & pelagic & 103 & 66 & 5.42 & 88.6 & 5519 & 5452 & 70.95 & 1830 & 59.9 & 596 & 110 & 408 & 75.3 & 116 & 87 & 3 \\
\hline
\end{tabular}


Table S3. Mean values $\underline{+}$ standard deviation of genomic features and COG categories indicated of the members of the Roseobacter clade associated to other organisms, surfaces and sediment and with a pelagic life style listed in supplementary Table S4, Planktomarina temperata RCA23 and of Photobacterium angustum and Sphingopyxis alaskensis. *: significantly different means as tested by Student's t-test $(P<0.03$; genome size, \% coding genes, ABC/total transporters, COG V) or Mann Whitney Rank Sum test $(P<0.015$; ABC transporters, COG I). N: number of organism of the subgroup; CDS: Coding DNA Sequences. Data of $P$. angustum and S. alaskensis are from Lauro et al. (2009) and the Integrated Microbial Genomes and Metagenomes (IMG; http://img.jgi.doe.gov/) platform.

\begin{tabular}{lccccc}
\hline Feature & Associated & Pelagic & P. temperata & P. angustum & S. alaskensis \\
\hline $\mathrm{N}$ & 14 & 24 & 1 & 1 & 1 \\
GC content (\%) & $60.07 \pm 3.58$ & $59.28 \pm 6.82$ & 54 & 39.69 & 65.46 \\
Genome size (Mb) & $4547 \pm 478$ & $4059 \pm 681 *$ & 3.29 & 5.10 & 3.37 \\
\% coding genes & $88.05 \pm 2.57$ & $89.82 \pm 1.62 *$ & 89.75 & 85.19 & 90.63 \\
CDS & $4442.7 \pm 689.2$ & $4003.9 \pm 699.8$ & 3056 & 4558 & 3208 \\
Transporter proteins & $419.0 \pm 82.5$ & $366.8 \pm 86.0$ & 287 & 293 & 116 \\
ABC transporters & $313.4 \pm 53.6$ & $260.9 \pm 63.5 *$ & 208 & 182 & 50 \\
ABC/total & $0.75 \pm 0.04$ & $0.71 \pm 0.05 *$ & 0.72 & 0.62 & 0.43 \\
ABC/Mb & $68.8 \pm 7.9$ & $63.2 \pm 9.8$ & 63.2 & 36.7 & 14.9 \\
TRAP transporters & $55.0 \pm 28.1$ & $58.9+21.3$ & 43 & 4 & 0 \\
COG N (cell motility; \%) & $1.53 \pm 0.44$ & $1.22 \pm 0.54$ & 1.71 & 3.31 & 1.01 \\
COG K (transcription; \%) & $8.03 \pm 1.01$ & $7.53 \pm 0.99$ & 6.15 & 7.53 & 6.62 \\
COG V (defense; \%) & $1.37 \pm 0.20$ & $1.14 \pm 0.18 *$ & 1.01 & 1.47 & 1.24 \\
COG T (signal transduction ; \%) & $4.45 \pm 0.79$ & $4.16 \pm 0.85$ & 2.72 & 7.07 & 3.63 \\
COG I (lipid transport and metabolism; \%) & $4.58 \pm 0.47$ & $5.34 \pm 0.86 *$ & 6.18 & 2.96 & 4.41 \\
COG Q (secondary metabolites, biosynthesis, & $3.52 \pm 0.44$ & $3.87 \pm 0.65$ & 4.63 & 2.17 & 3.54 \\
$\quad$ transport and catabolism, \%) & & & & &
\end{tabular}


Table S4. Complete CDS list of $P$. temperata RCA23 and combined results of the reciprocal blast comparisons against 39 Roseobacter genomes. Orthologous genes with an e-value of the corresponding blast hit $<1 \mathrm{e}-20$ and min. global alignment of $30 \%$ are colored.

See extra file! 
Table S5. Percent of COG categories N (cell motility), K (transcription), V (defense), T (signal transduction), I (lipid transport and metabolism) and Q (secondary metabolites, biosynthesis, transport and catabolism) of organisms of the Roseobacter clade isolated from associations with various organisms, surfaces or sediment and from pelagic environments. For comparison respective data of Cand. Pelagibacter ubique are also given. Data were taken from the Integrated Microbial Genomes and Metagenomes (IMG; http://img.jgi.doe.gov/) platform.

\begin{tabular}{|l|c|c|c|c|c|c|}
\hline \multicolumn{1}{|c|}{ Genome Name } & N & K & V & T & I & Q \\
\hline & & & & & & $\%$ \\
\hline Associated & & & & & & \\
\hline Dinoroseobacter shibae DFL-12, DSM 16493 & 1.14 & 6.86 & 1.26 & 3.89 & 4.37 & 3.65 \\
\hline Nautella italica R11 & 1.82 & 8.07 & 1.46 & 5.17 & 4.68 & 3.39 \\
\hline Octadecabacter antarcticus 307 & 1.32 & 7.11 & 1.23 & 3.51 & 4.71 & 3.45 \\
\hline Octadecabacter arcticus 238, DSM 13978 & 1.21 & 6.25 & 0.83 & 2.90 & 3.60 & 2.63 \\
\hline Phaeobacter inhibens 2.10 & 1.69 & 8.62 & 1.40 & 4.98 & 4.75 & 3.73 \\
\hline Phaeobacter inhibens DSM 17395 & 1.64 & 8.30 & 1.33 & 4.67 & 4.86 & 3.63 \\
\hline Roseobacter denitrificans OCh 114 & 1.43 & 7.15 & 1.72 & 4.52 & 4.52 & 3.38 \\
\hline Roseobacter litoralis Och 149 & 1.35 & 7.63 & 1.40 & 4.37 & 4.21 & 3.56 \\
\hline Ruegeria pomeroyi DSS-3 & 0.85 & 9.89 & 1.44 & 4.15 & 5.74 & 4.50 \\
\hline Ruegeria sp. TM1040 & 2.17 & 9.29 & 1.34 & 6.08 & 4.61 & 3.28 \\
\hline Citreicella sp. SE45 & 1.27 & 8.60 & 1.37 & 4.19 & 4.29 & 3.86 \\
\hline Roseovarius sp. TM1035 & 2.46 & 7.73 & 1.51 & 4.59 & 4.65 & 3.93 \\
\hline Ruegeria sp. KLH11 & 1.17 & 7.97 & 1.54 & 4.05 & 4.75 & 3.38 \\
\hline Ruegeria sp. TrichCH4B & 1.90 & 9.07 & 1.33 & 5.21 & 4.31 & 2.95 \\
\hline & & & & & & \\
& & & & & & \\
\end{tabular}




\begin{tabular}{|c|c|c|c|c|c|c|}
\hline & $\mathbf{N}$ & $\mathbf{K}$ & $\mathbf{V}$ & $\mathbf{T}$ & $\mathbf{I}$ & $\mathbf{Q}$ \\
\hline \multicolumn{7}{|l|}{ Pelagic } \\
\hline Planktomarina temperata RCA23 & 1.71 & 6.15 & 1.01 & 2.72 & 6.18 & 4.63 \\
\hline Jannaschia sp. CCS1 & 1.32 & 8.31 & 0.94 & 4.19 & 5.01 & 4.03 \\
\hline Loktanella sp. CCS2 & 1.17 & 7.23 & 1.17 & 4.04 & 4.94 & 2.92 \\
\hline Loktanella vestfoldensis SKA53 & 1.97 & 6.46 & 1.20 & 4.15 & 5.09 & 3.55 \\
\hline Maritimibacter alkaliphilus HTCC2654 & 0.53 & 7.74 & 0.93 & 4.02 & 6.96 & 4.36 \\
\hline Oceanibulbus indolifex HEL-45 & 1.04 & 7.52 & 0.91 & 5.38 & 4.93 & 3.57 \\
\hline Oceanicola batsensis HTCC2597 & 1.13 & 7.06 & 1.03 & 3.47 & 8.00 & 4.94 \\
\hline Oceanicola granulosus HTCC2516 & 2.25 & 7.27 & 1.21 & 3.77 & 4.57 & 3.80 \\
\hline Pelagibaca bermudensis HTCC2601 & 1.86 & 7.99 & 1.02 & 4.16 & 4.75 & 3.80 \\
\hline Rhodobacterales bacterium HTCC2083 & 1.64 & 6.95 & 1.06 & 2.91 & 5.92 & 4.62 \\
\hline Rhodobacterales bacterium HTCC2150 & 0.31 & 6.80 & 1.23 & 3.73 & 5.38 & 4.80 \\
\hline Rhodobacterales bacterium Y4I & 1.78 & 8.27 & 1.39 & 6.23 & 4.57 & 3.60 \\
\hline Rhodobacterales bacterium HTCC2255 & 0.21 & 5.80 & 0.93 & 2.48 & 4.35 & 2.69 \\
\hline Roseobacter sp. AzwK-3b & 0.75 & 6.94 & 1.57 & 4.58 & 4.75 & 3.08 \\
\hline Roseobacter sp. MED193 & 0.97 & 9.21 & 1.27 & 4.92 & 5.83 & 4.08 \\
\hline Roseobacter sp. SK209-2-6 & 1.62 & 10.09 & 1.04 & 5.15 & 4.79 & 3.54 \\
\hline Roseovarius nubinhibens ISM & 0.26 & 8.67 & 0.93 & 3.82 & 5.00 & 4.04 \\
\hline Roseovarius sp. 217 & 1.17 & 8.66 & 1.03 & 4.43 & 5.32 & 3.72 \\
\hline Sagittula stellata $\mathrm{E}-37$ & 1.45 & 7.87 & 1.10 & 4.97 & 5.29 & 4.27 \\
\hline Ruegeria lacuscaerulensis ITI-1157 & 1.16 & 7.38 & 1.30 & 4.21 & 5.03 & 3.24 \\
\hline Sulfitobacter sp. EE-36 & 1.33 & 7.33 & 1.26 & 4.00 & 6.10 & 4.14 \\
\hline Sulfitobacter sp. GAI101 & 1.51 & 6.68 & 1.45 & 4.86 & 5.97 & 4.95 \\
\hline Sulfitobacter sp. NAS-14.1 & 1.01 & 7.48 & 1.15 & 3.81 & 4.95 & 3.67 \\
\hline Thalassiobium sp. R2A62 & 1.10 & 6.91 & 1.26 & 3.75 & 4.38 & 2.88 \\
\hline
\end{tabular}


Table S6. Normalized read counts (NPKM) of the transcripts at stations 9 (bloom, night) and 13 (bloom, day) and differences between night and day

\section{See extra file!}

Table S7 Coverage of $P$. temperata RC23 genes from combined stations GS012-13 of the GOS data set and the Norwegian fjord metagenome.

\section{See extra file!}




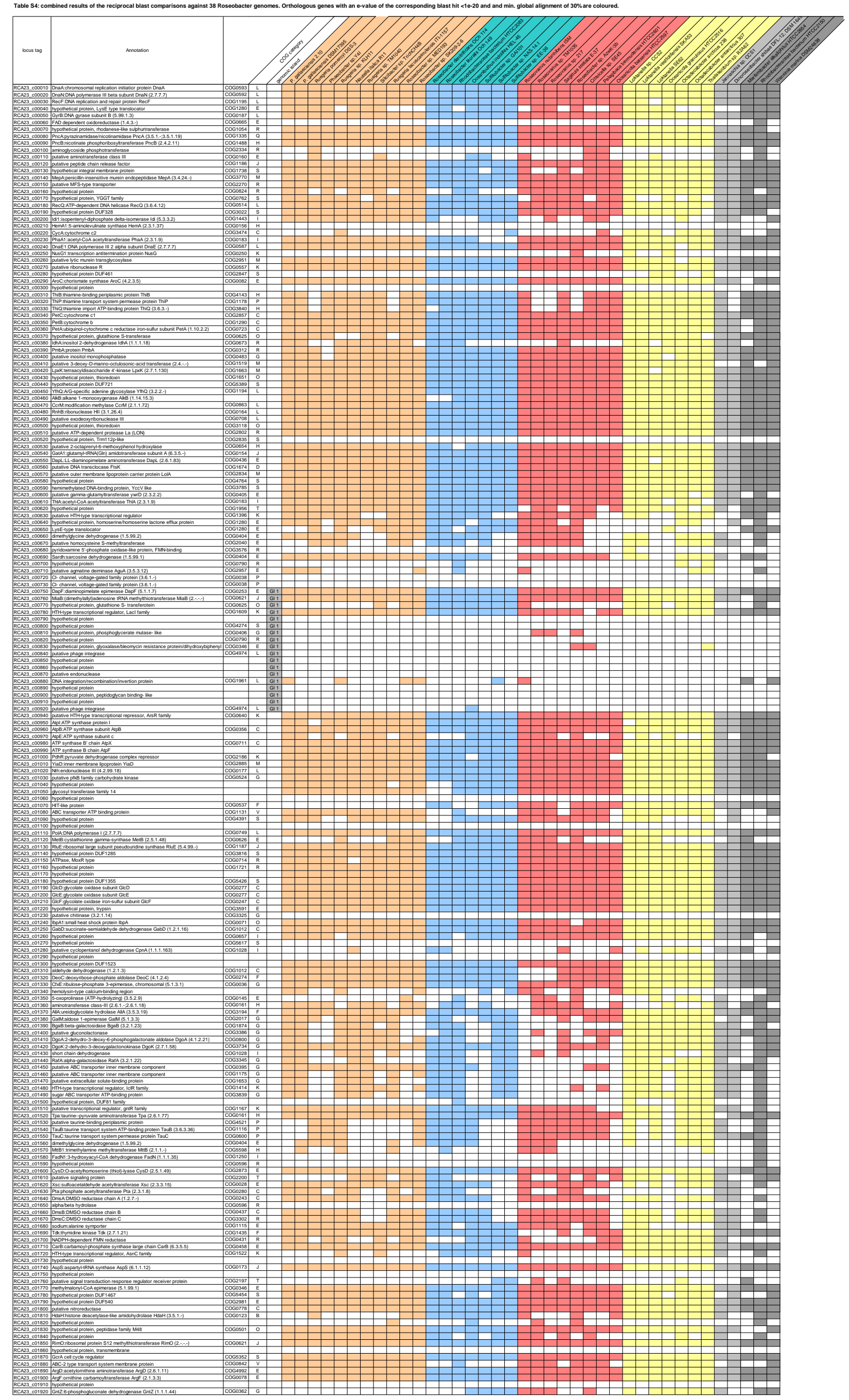




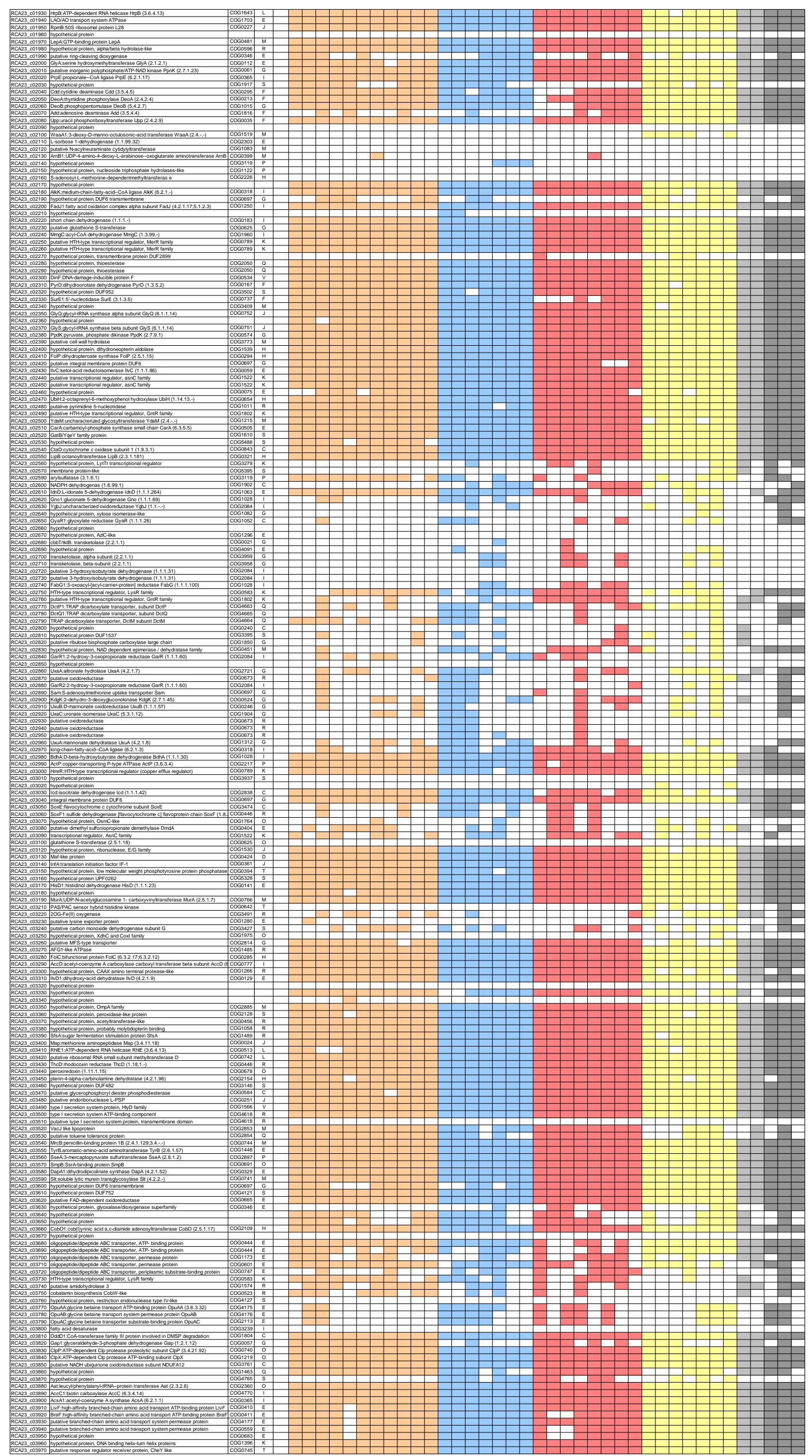









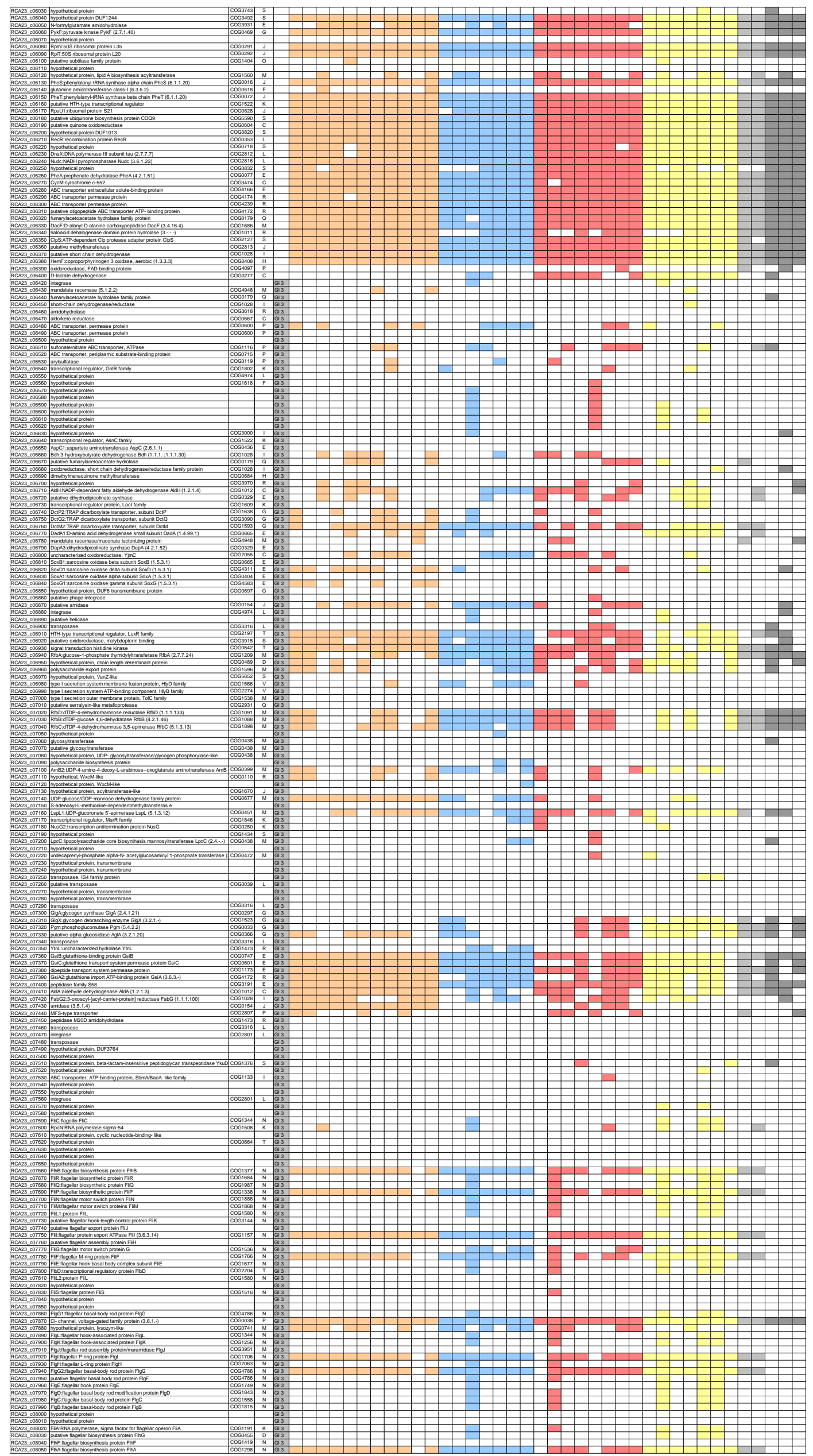




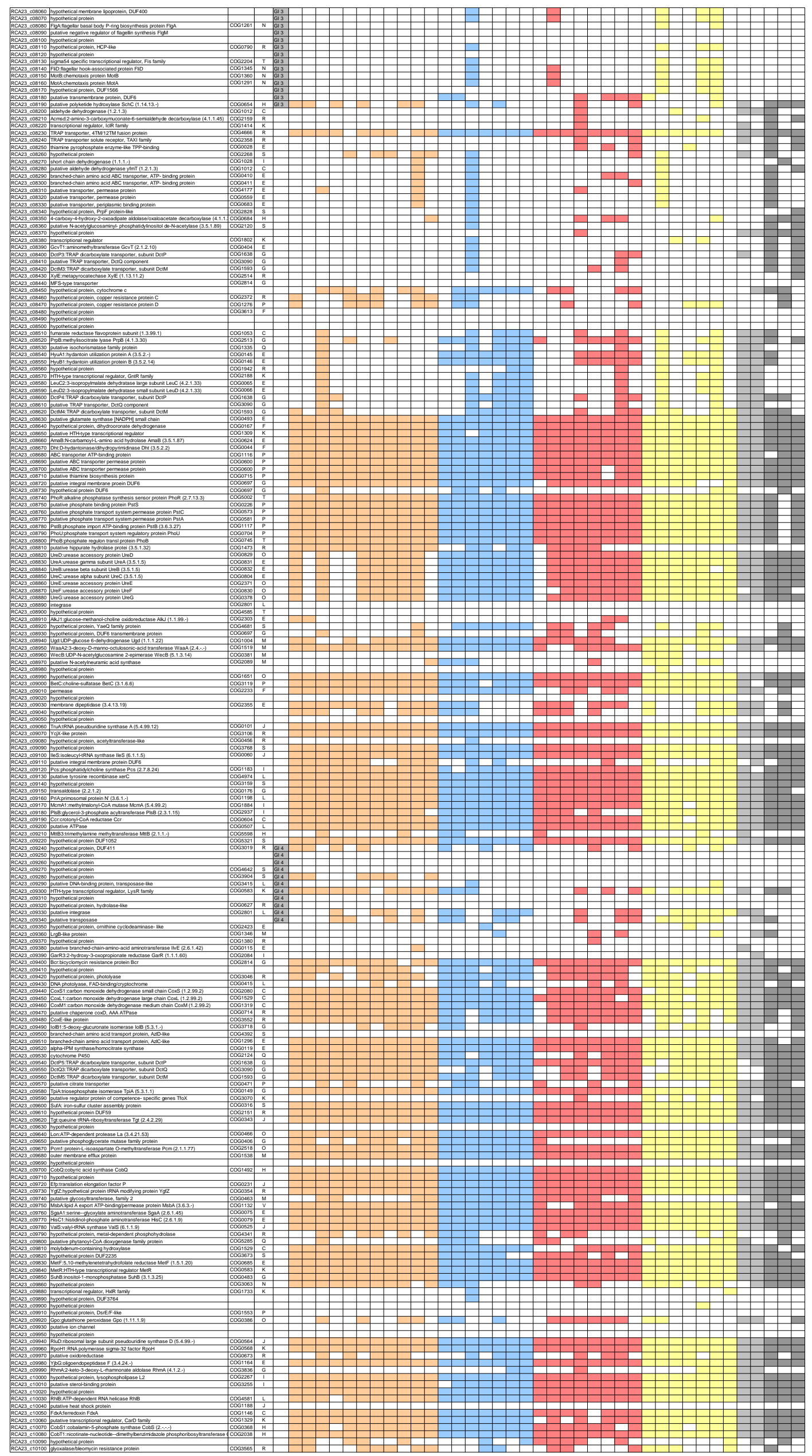




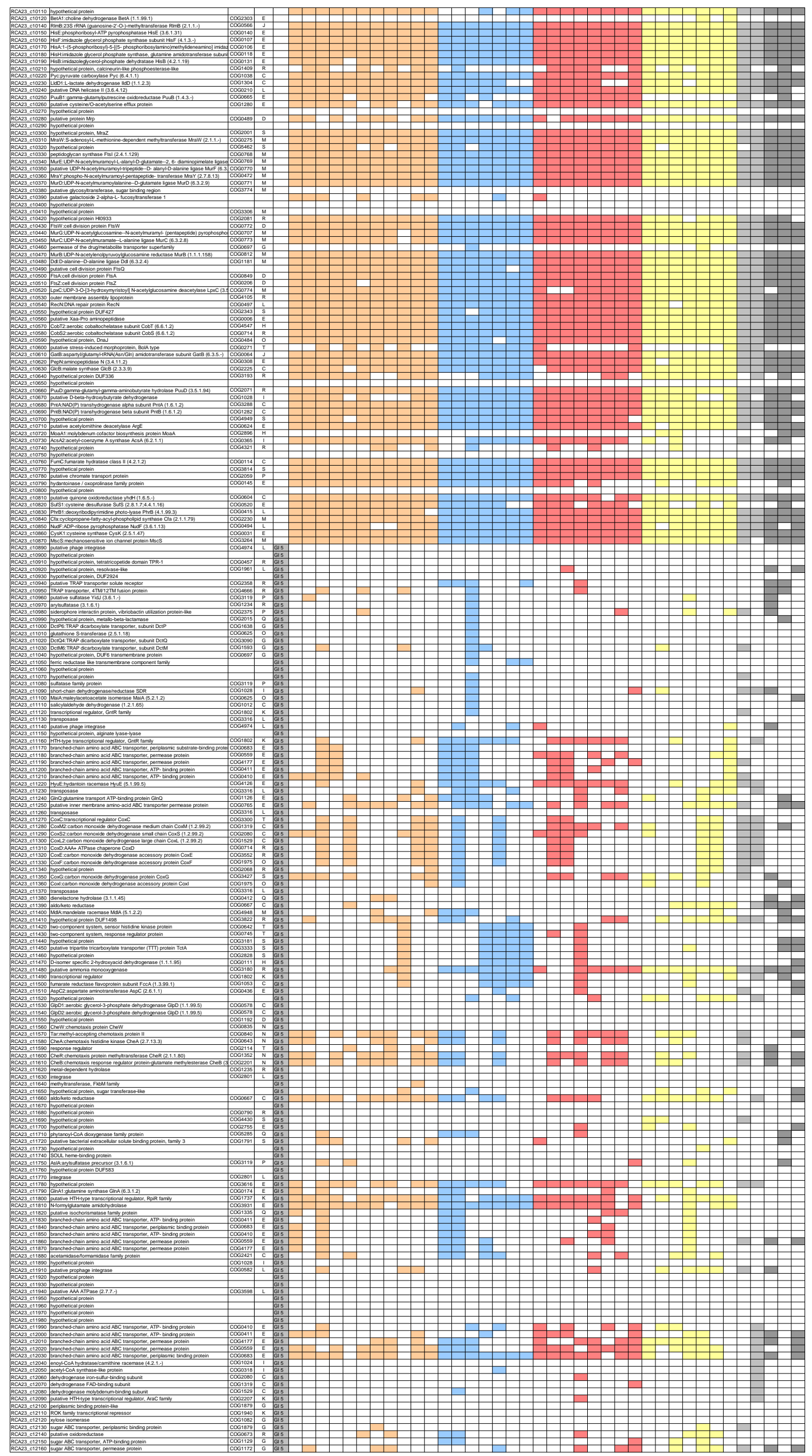




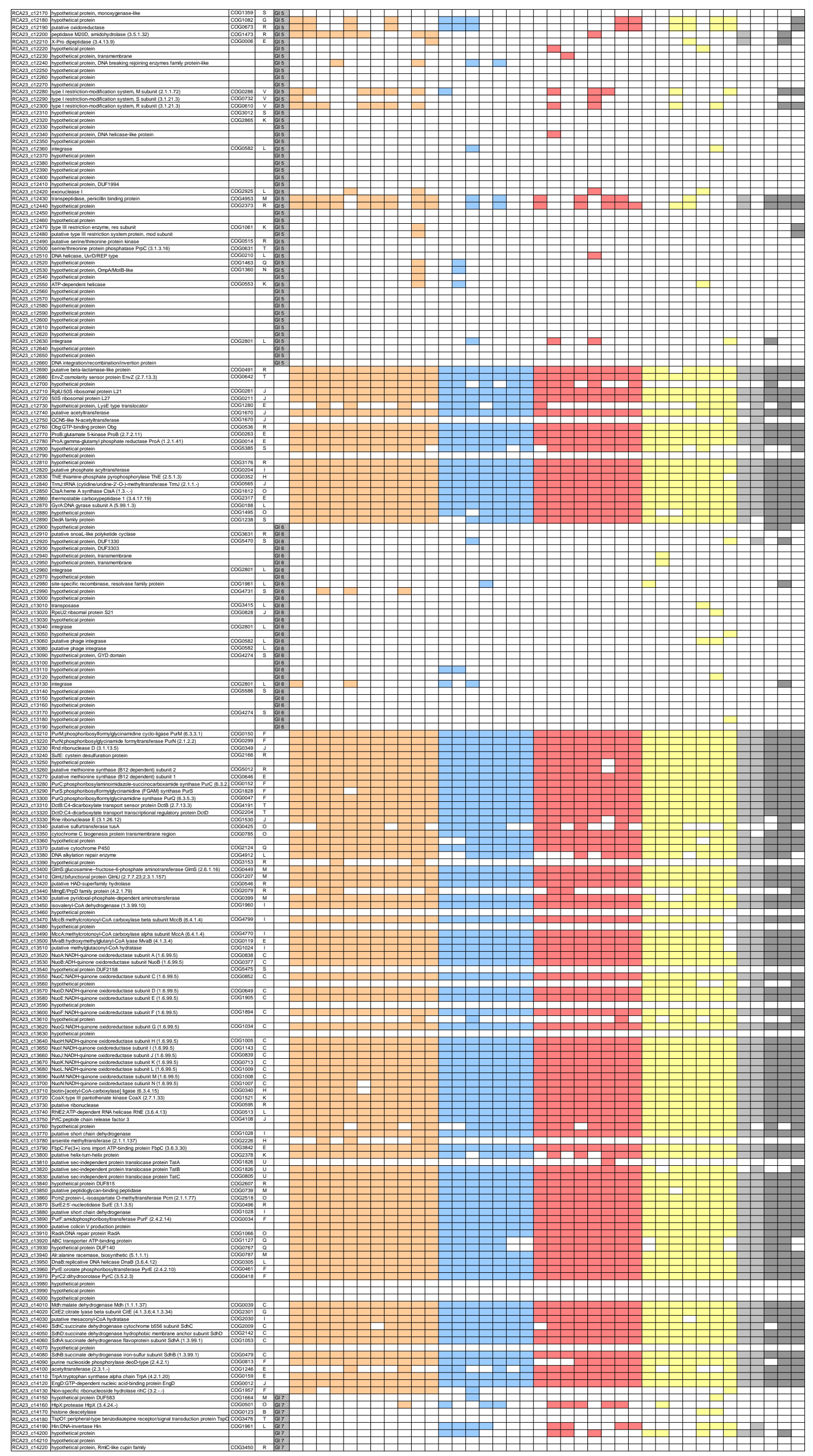




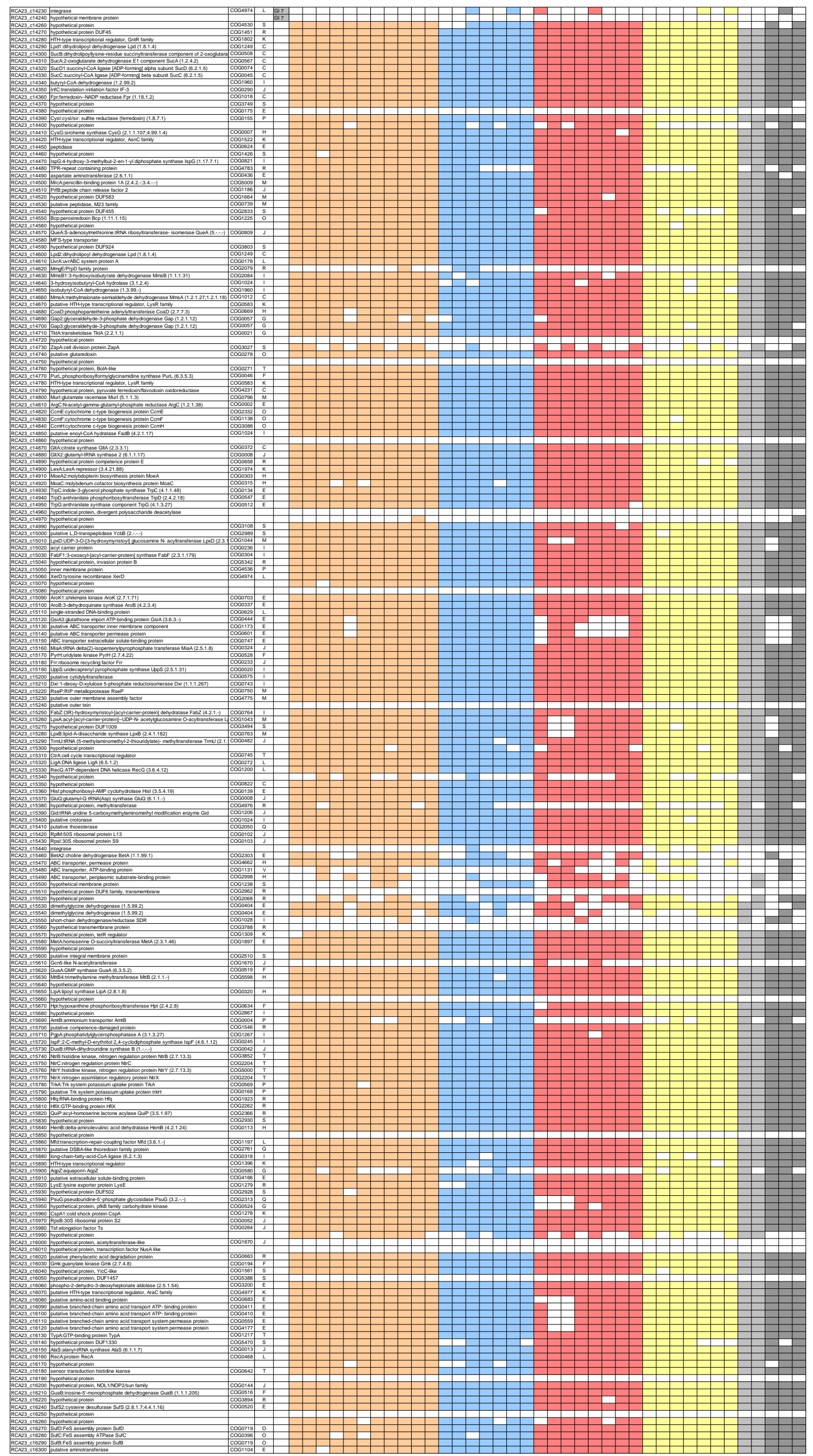




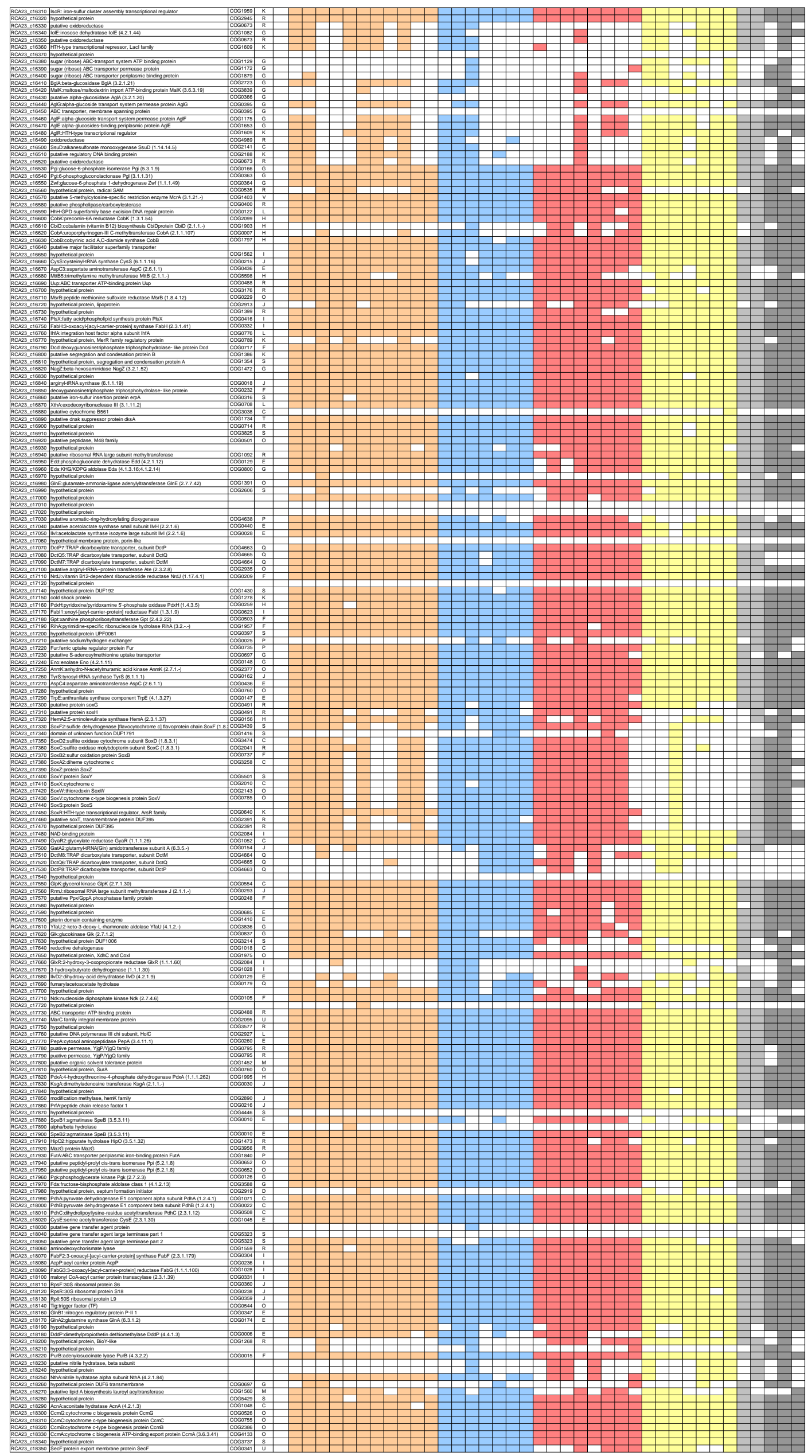




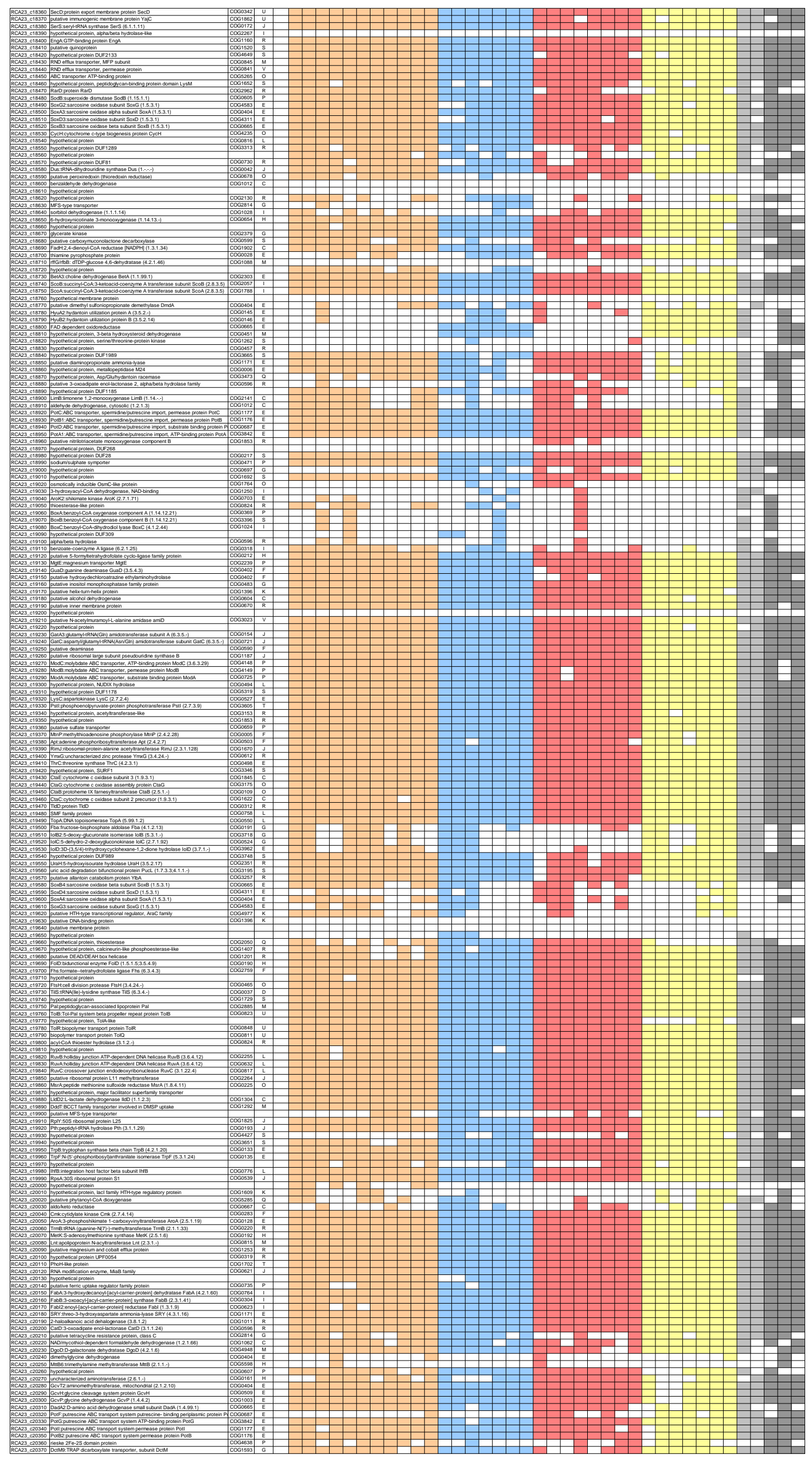




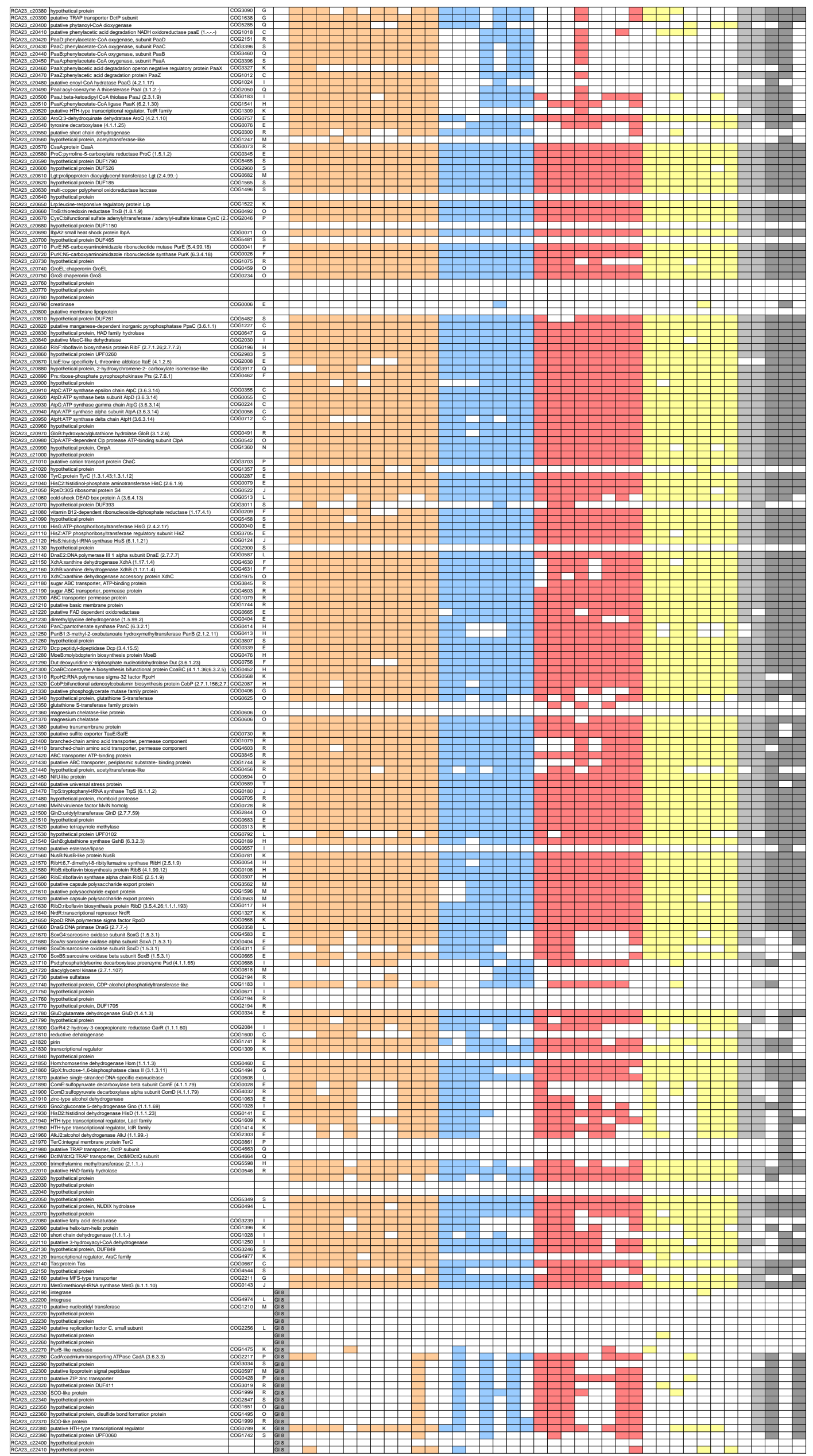




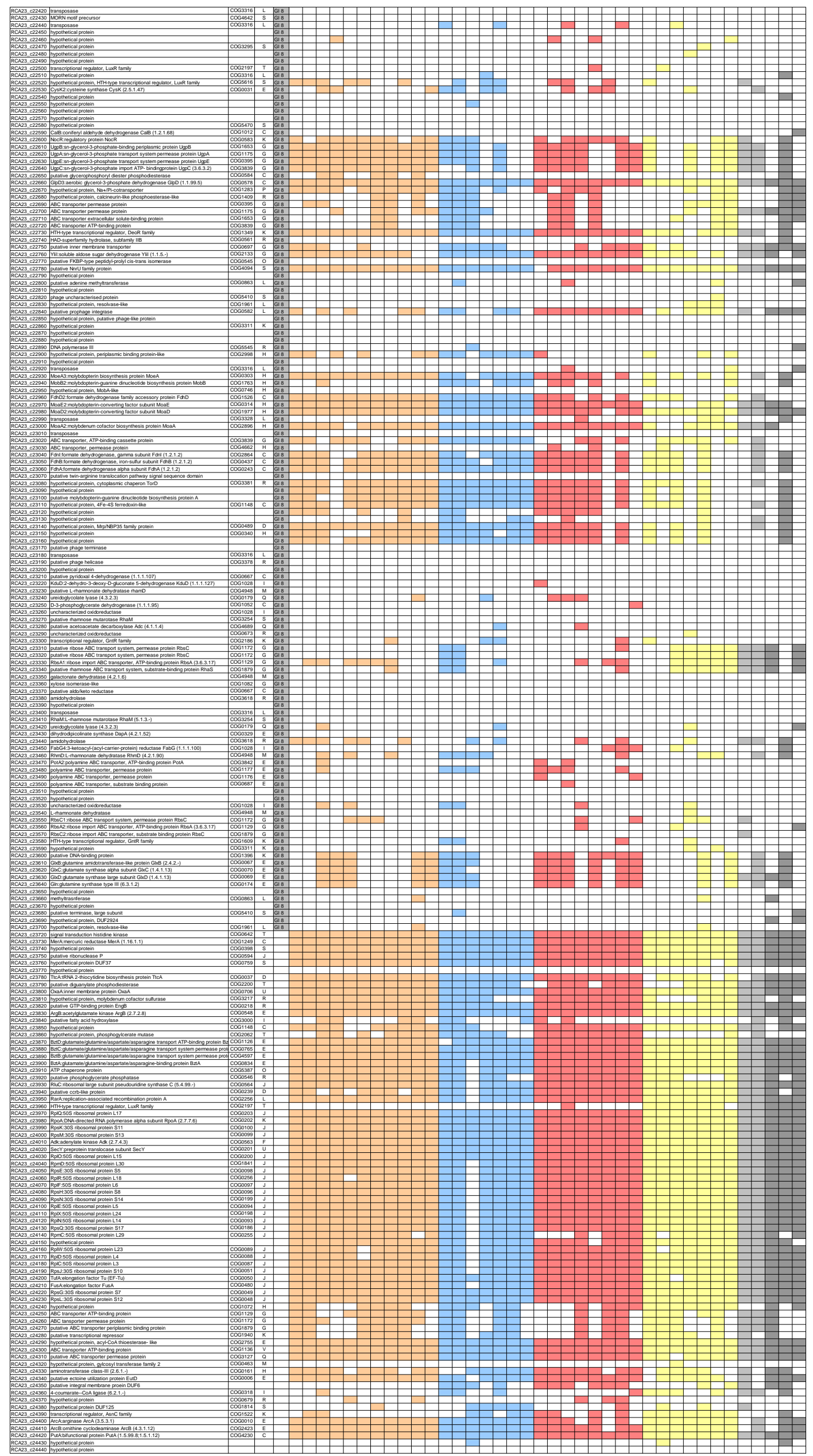




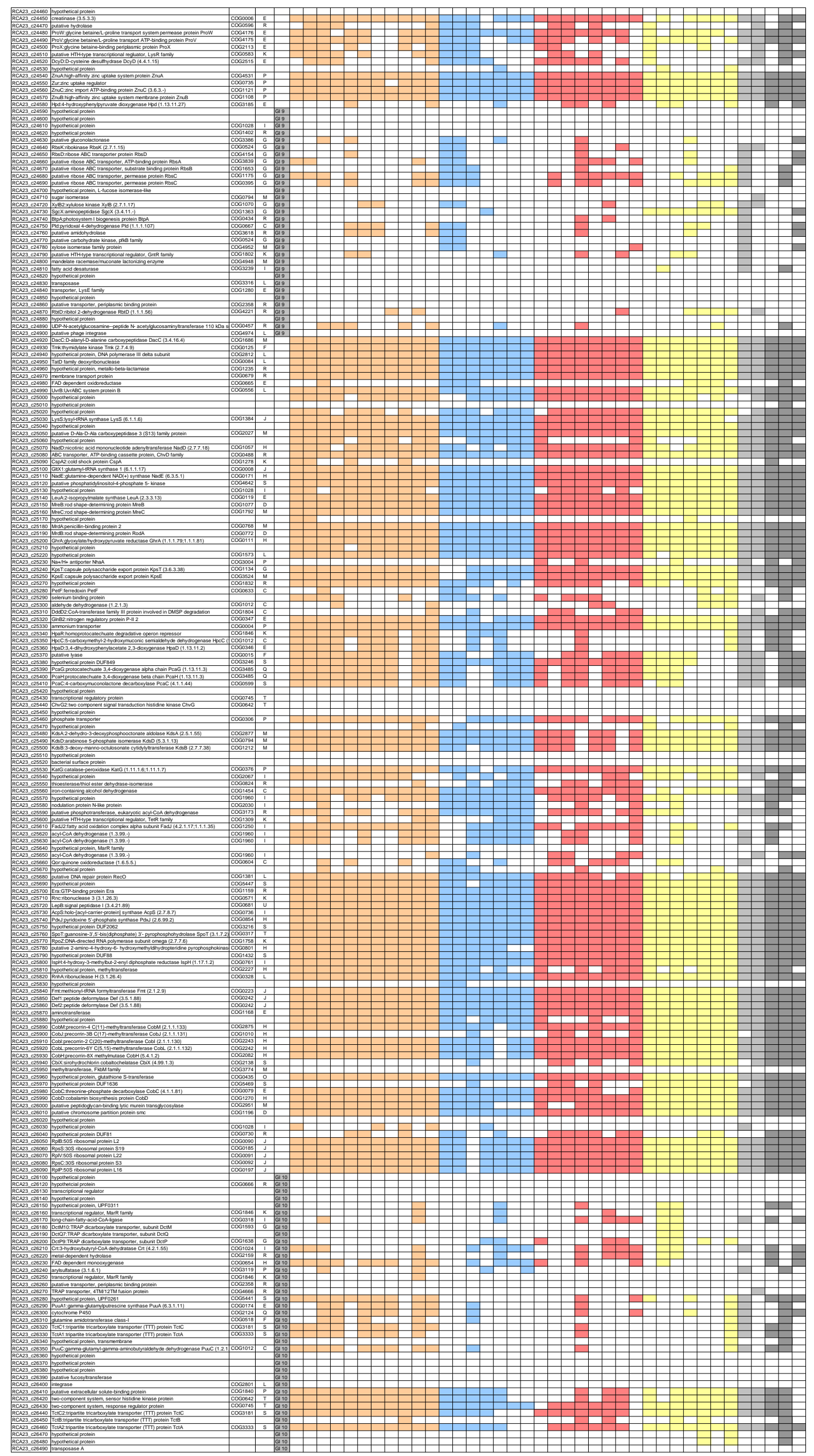




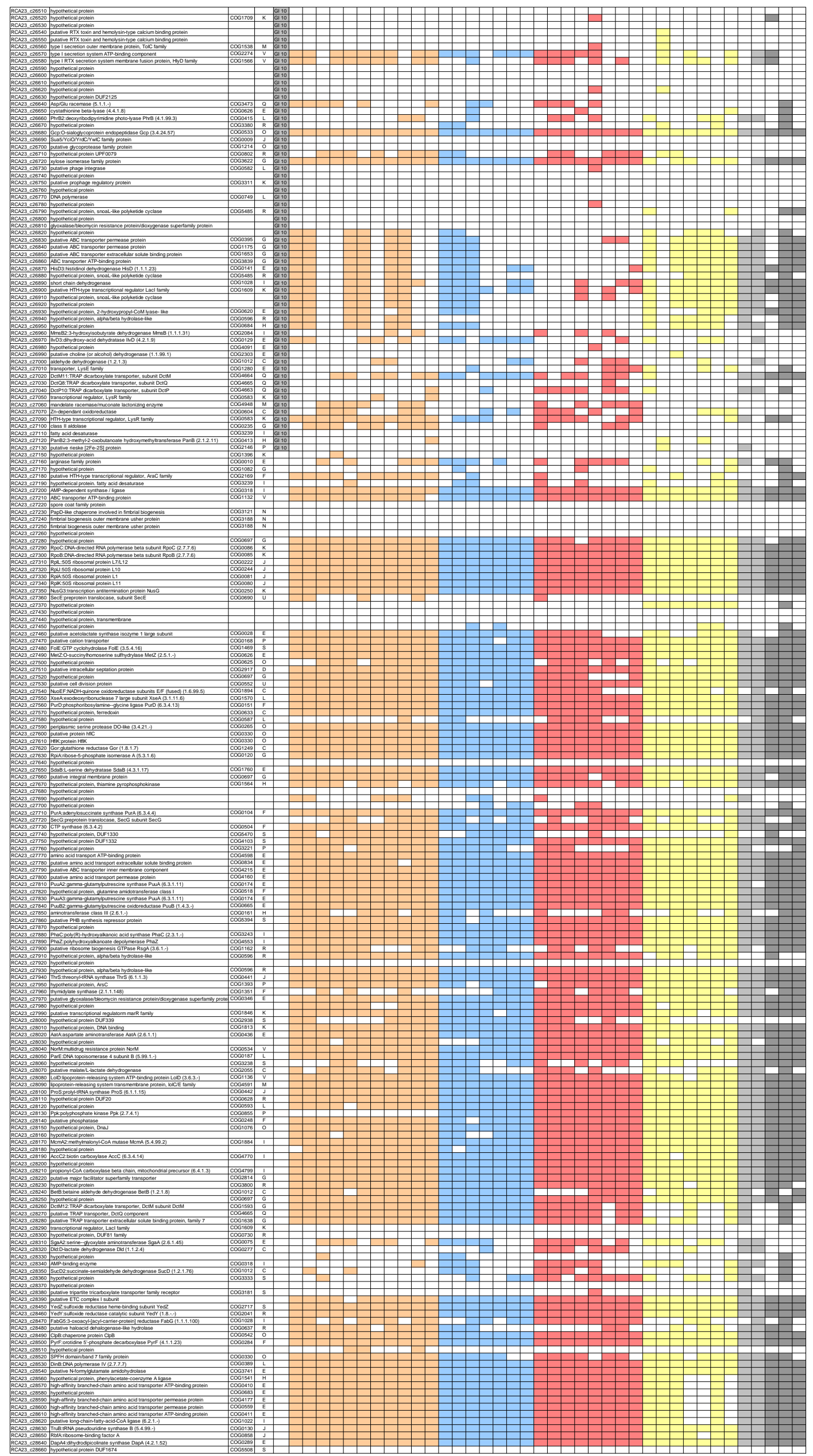




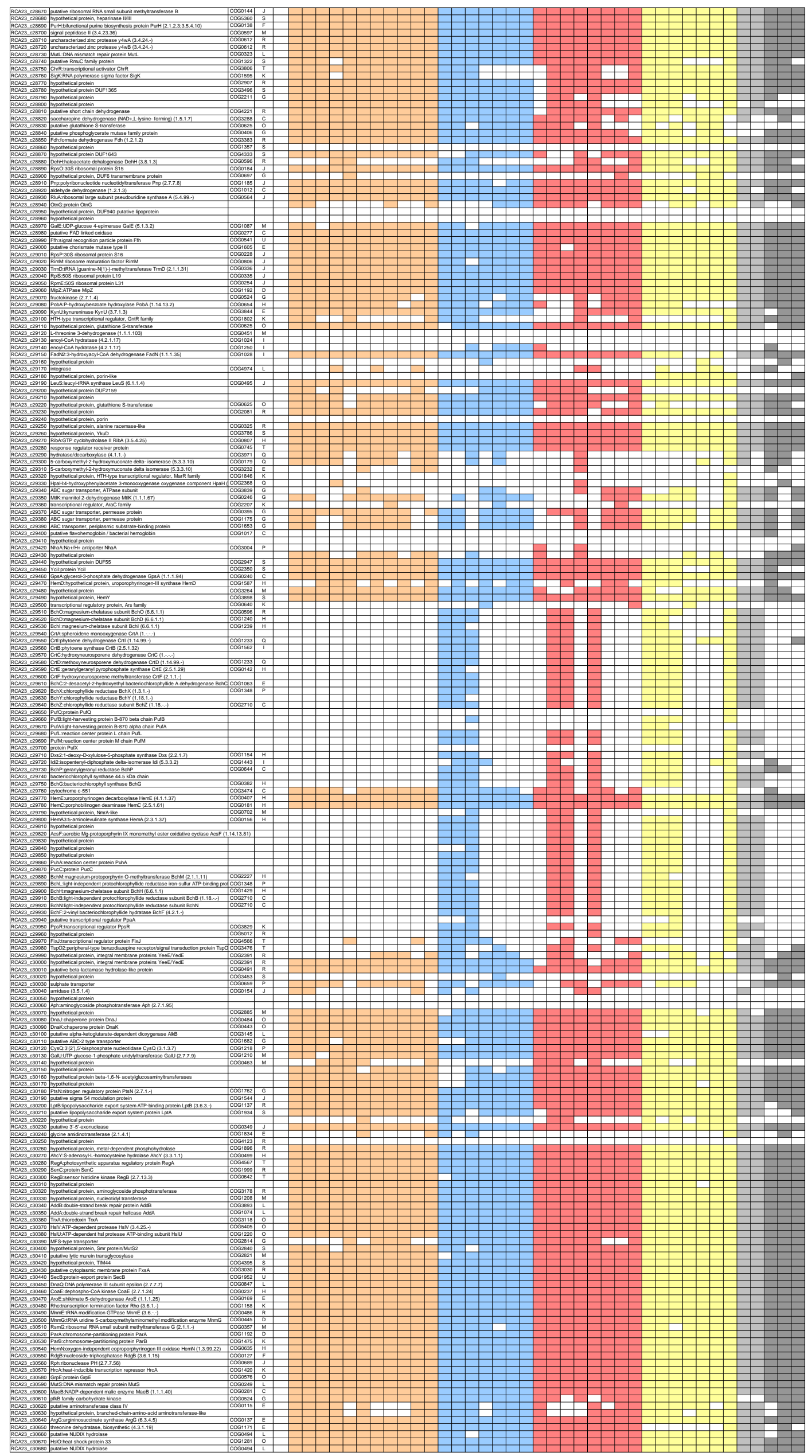




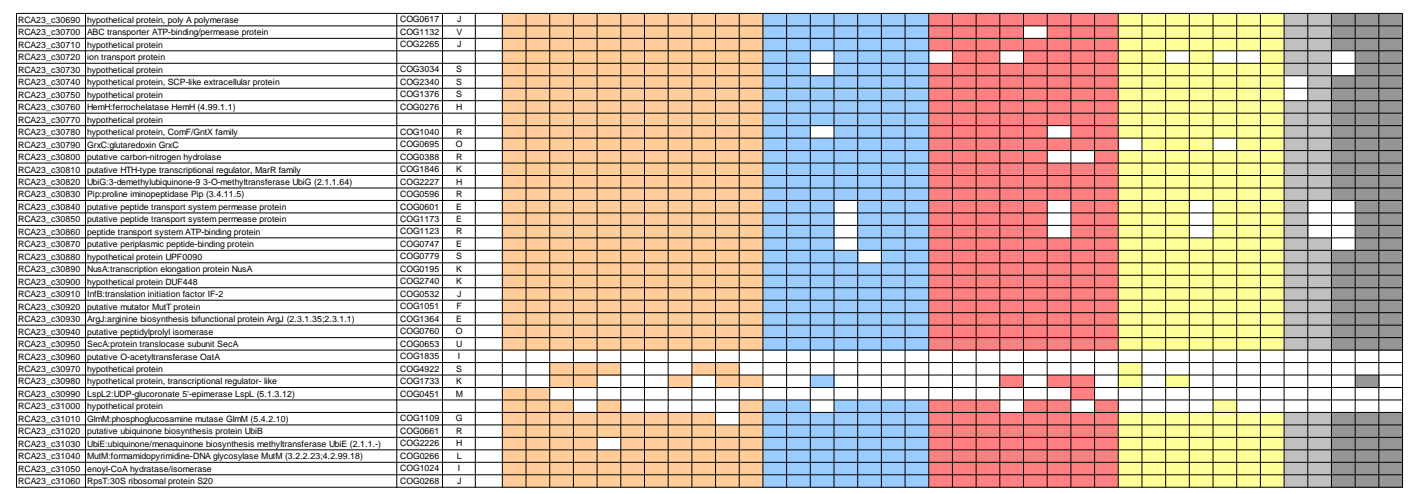


Table S6: COG categories, genomic islands, normalized read counts (NPKM) of the transcripts at stations 9 (bloom, night) and 13 (bloom, day) and differences between night and day

\begin{tabular}{|c|c|c|c|c|c|c|c|c|c|}
\hline locus_tag & start & stop & annotation & COG ID & $\begin{array}{c}\text { COG } \\
\text { category }\end{array}$ & $\begin{array}{l}\text { genomic } \\
\text { island }\end{array}$ & $\begin{array}{c}\text { NPKM } \\
\text { station } 9 \\
\text { bloom- } \\
\text { night }\end{array}$ & $\begin{array}{c}\text { NPKM } \\
\text { station } 13 \\
\text { bloom-day }\end{array}$ & $\begin{array}{c}\text { NPKM } \\
\text { difference } \\
\text { night-day }\end{array}$ \\
\hline RCA23_c00010 & 101 & 1447 & chromosomal replication initiatior protein $\mathrm{DnaA}$ & COG0593 & $\mathrm{L}$ & & 617 & 502 & 115 \\
\hline RCA23_c00020 & 1550 & 2668 & DNA polymerase III beta subunit DnaN & COG0592 & $\mathrm{L}$ & & 605 & 575 & 30 \\
\hline RCA23_c00030 & 2778 & 3800 & DNA replication and repair protein RecF & COG1195 & $\mathrm{L}$ & & 358 & 419 & -61 \\
\hline RCA23_c00040 & 3797 & 4417 & hypothetical protein, LysE type translocator & COG1280 & $\mathrm{E}$ & & 455 & 635 & -180 \\
\hline RCA23_c00050 & 4567 & 6984 & DNA gyrase subunit B & COG0187 & $\mathrm{L}$ & & 599 & 596 & 3 \\
\hline RCA23_c00060 & 7002 & 8384 & FAD dependent oxidoreductase & COG0665 & $\mathrm{E}$ & & 339 & 421 & -82 \\
\hline RCA23_c00070 & 9282 & 8392 & hypothetical protein, rhodanese-like sulphurtransferase & COG1054 & $\mathrm{R}$ & & 414 & 392 & 22 \\
\hline RCA23_c00080 & 9413 & 10003 & pyrazinamidase/nicotinamidase PncA & COG1335 & Q & & 456 & 502 & -46 \\
\hline RCA23_c00090 & 10003 & 11295 & nicotinate phosphoribosyltransferase PncB & COG1488 & $\mathrm{H}$ & & 608 & 548 & 60 \\
\hline RCA23_c00100 & 12224 & 11292 & aminoglycoside phosphotransferase & COG2334 & $\mathrm{R}$ & & 392 & 456 & -64 \\
\hline RCA23_c00110 & 13477 & 12221 & putative aminotransferase class III & COG0160 & $\mathrm{E}$ & & 255 & 339 & -84 \\
\hline RCA23_c00120 & 13889 & 13467 & putative peptide chain release factor & COG1186 & $\mathrm{J}$ & & 432 & 659 & -227 \\
\hline RCA23_c00130 & 14772 & 14128 & hypothetical integral membrane protein & COG1738 & $\mathrm{S}$ & & 378 & 472 & -94 \\
\hline RCA23_c00140 & 15799 & 14879 & penicillin-insensitive murein endopeptidase MepA & COG3770 & $\mathrm{M}$ & & 424 & 459 & -35 \\
\hline RCA23_c00150 & 17181 & 15796 & putative MFS-type transporter & COG2270 & $\mathrm{R}$ & & 588 & 535 & 53 \\
\hline RCA23_c00160 & 17672 & 17241 & hypothetical protein & COG0824 & $\mathrm{R}$ & & 354 & 357 & -3 \\
\hline RCA23_c00170 & 17836 & 18201 & hypothetical protein, YGGT family & COG0762 & $\mathrm{S}$ & & 446 & 469 & -23 \\
\hline RCA23_c00180 & 18217 & 20277 & ATP-dependent DNA helicase RecQ & COG0514 & $\mathrm{L}$ & & 362 & 427 & -65 \\
\hline RCA23_c00190 & 20300 & 21073 & hypothetical protein DUF328 & COG3022 & $\mathrm{S}$ & & 375 & 423 & -48 \\
\hline RCA23_c00200 & 21576 & 21070 & isopentenyl-diphosphate delta-isomerase Idi & COG1443 & I & & 495 & 470 & 25 \\
\hline RCA23_c00210 & 21812 & 23056 & 5-aminolevulinate synthase HemA & COG0156 & $\mathrm{H}$ & & 577 & 477 & 100 \\
\hline RCA23_c00220 & 23097 & 23540 & cytochrome c2 & COG3474 & $\mathrm{C}$ & & 489 & 500 & -11 \\
\hline RCA23_c00230 & 24777 & 23602 & acetyl-CoA acetyltransferase PhaA & COG0183 & I & & 276 & 293 & -17 \\
\hline RCA23_c00240 & 24942 & 27992 & DNA polymerase III 2 alpha subunit DnaE & COG0587 & $\mathrm{L}$ & & 333 & 404 & -71 \\
\hline
\end{tabular}




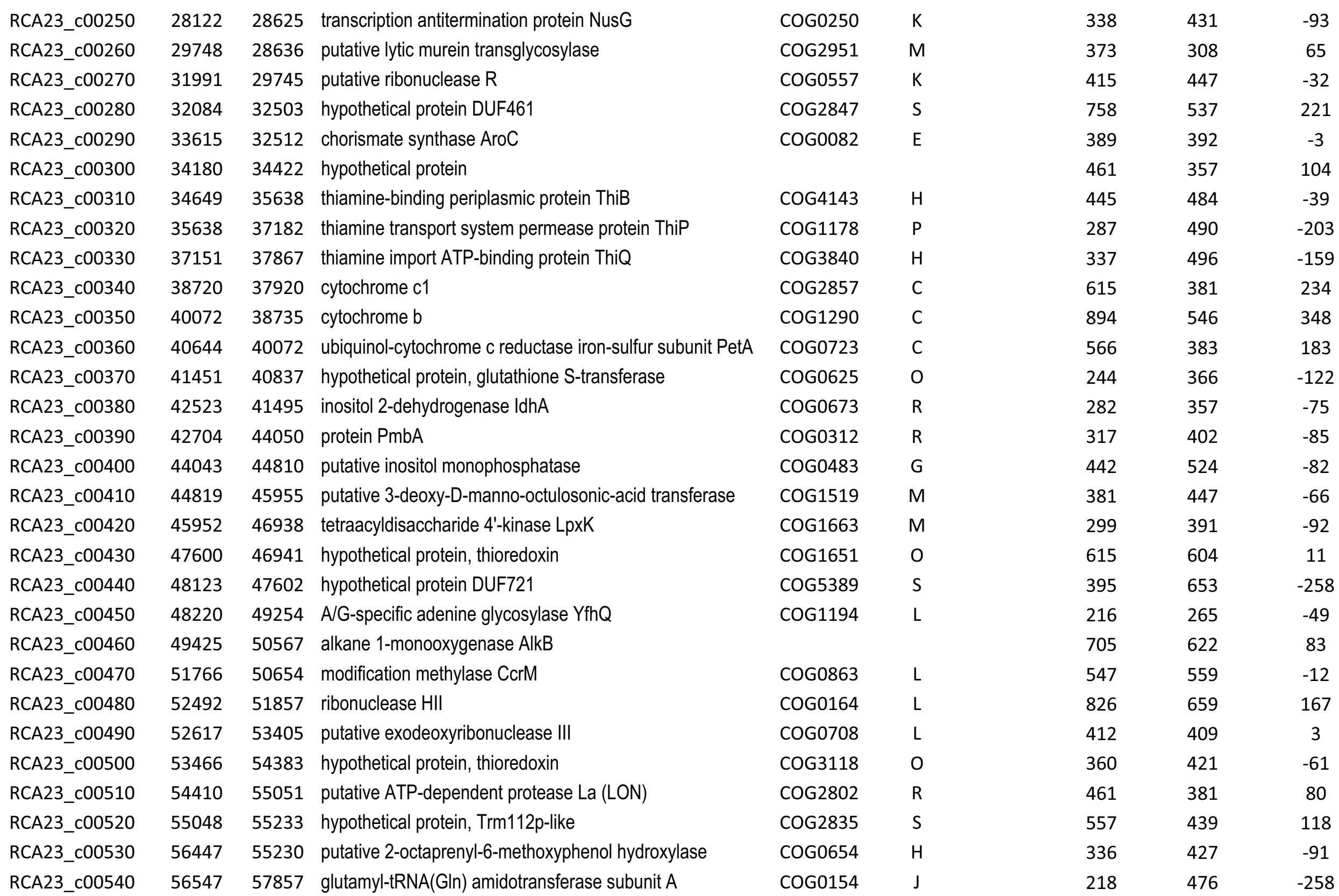




\begin{tabular}{|c|c|c|c|c|c|c|c|c|c|}
\hline RCA23_c00550 & 57922 & 59085 & LL-diaminopimelate aminotransferase DapL & COG0436 & $E$ & & 518 & 488 & 30 \\
\hline RCA23_c00560 & 59099 & 61888 & putative DNA transclocase FtsK & COG1674 & $\mathrm{D}$ & & 506 & 510 & -4 \\
\hline RCA23_c00580 & 63223 & 62720 & hypothetical protein & COG4764 & $\mathrm{S}$ & & 478 & 353 & 125 \\
\hline RCA23_c00600 & 65410 & 63833 & putative gamma-glutamyltransferase ywrD & COG0405 & $E$ & & 253 & 306 & -53 \\
\hline RCA23_c00610 & 65571 & 66749 & acetyl-CoA acetyltransferase ThIA & COG0183 & 1 & & 289 & 358 & -69 \\
\hline RCA23_c00620 & 66761 & 67216 & hypothetical protein & COG1956 & $\mathrm{T}$ & & 801 & 697 & 104 \\
\hline RCA23_c00640 & 67871 & 68488 & hypothetical protein, homoserine/homoserine lactone efflux & COG1280 & $E$ & & 417 & 485 & -68 \\
\hline RCA23_c00650 & 68502 & 69128 & LysE-type translocator & COG1280 & $\mathrm{E}$ & & 274 & 391 & -117 \\
\hline RCA23_c00660 & 69140 & 71587 & dimethylglycine dehydrogenase & COG0404 & $E$ & & 513 & 451 & 62 \\
\hline RCA23_c00670 & 71603 & 72469 & putative homocysteine S-methyltransferase & COG2040 & $E$ & & 334 & 377 & -43 \\
\hline RCA23_c00680 & 72474 & 72929 & pyridoxamine 5'-phosphate oxidase-like protein, FMN-bindir & COG3576 & $\mathrm{R}$ & & 400 & 404 & -4 \\
\hline RCA23_c00690 & 72966 & 75419 & sarcosine dehydrogenase & COG0404 & $\mathrm{E}$ & & 503 & 505 & -2 \\
\hline RCA23_c00730 & 79210 & 78368 & Cl- channel, voltage-gated family protein & COG0038 & $\mathrm{P}$ & & 284 & 229 & 55 \\
\hline RCA23_c00750 & 79638 & 80468 & diaminopimelate epimerase DapF & COG0253 & $\mathrm{E}$ & GI 1 & 356 & 453 & -97 \\
\hline RCA23_c00760 & 80465 & 81721 & (dimethylallyl)adenosine tRNA methylthiotransferase MiaB & COG0621 & $\mathrm{J}$ & GI 1 & 300 & 392 & -92 \\
\hline RCA23_c00770 & 81775 & 82368 & hypothetical protein, glutathione S-transferotein & COG0625 & 0 & GI 1 & 340 & 473 & -133 \\
\hline RCA23_c00780 & 83403 & 82369 & HTH-type transcriptional regulator, Lacl family & COG1609 & $\mathrm{K}$ & GI 1 & 392 & 377 & 15 \\
\hline RCA23_c00790 & 84698 & 84859 & hypothetical protein & & & GI 1 & 512 & 328 & 184 \\
\hline RCA23_c00800 & 85627 & 85304 & hypothetical protein & COG4274 & $\mathrm{S}$ & GI 1 & 503 & 298 & 205 \\
\hline RCA23_c00810 & 86298 & 86852 & hypothetical protein, phosphoglycerate mutase-like & COG0406 & G & GI 1 & 577 & 360 & 217 \\
\hline RCA23_c00820 & 86971 & 87357 & hypothetical protein & COG0790 & $\mathrm{R}$ & GI 1 & 602 & 405 & 197 \\
\hline RCA23_c00830 & 87971 & 87558 & hypothetical protein, glyoxalase/bleomycin resistance protei & COG0346 & $\mathrm{E}$ & GI 1 & 350 & 319 & 31 \\
\hline RCA23_c00840 & 88760 & 88251 & putative phage integrase & COG4974 & $\mathrm{L}$ & GI 1 & 284 & 247 & 37 \\
\hline
\end{tabular}




\begin{tabular}{|c|c|c|c|c|c|c|c|c|c|}
\hline RCA23_c00860 & 89849 & 90679 & hypothetical protein & & & GI 1 & 44 & 43 & 1 \\
\hline RCA23_c00870 & 92517 & 91066 & putative endonuclease & & & GI 1 & 1 & 0 & 1 \\
\hline RCA23_c00880 & 93431 & 93994 & DNA integration/recombination/invertion protein & COG1961 & $\mathrm{L}$ & GI 1 & 253 & 243 & 10 \\
\hline RCA23_c00890 & 94002 & 94223 & hypothetical protein & & & GI 1 & 529 & 399 & 130 \\
\hline RCA23_c00910 & 95706 & 96575 & hypothetical protein & & & GI 1 & 28 & 29 & -1 \\
\hline RCA23_c00920 & 98235 & 96589 & putative phage integrase & COG4974 & $\mathrm{L}$ & GI 1 & 54 & 35 & 19 \\
\hline RCA23_c00960 & 99360 & 100142 & ATP synthase subunit AtpB & COG0356 & $\mathrm{C}$ & & 361 & 248 & 113 \\
\hline RCA23_c00970 & 100189 & 100425 & ATP synthase subunit $c$ & & & & 766 & 349 & 417 \\
\hline RCA23_c01000 & 102506 & 101736 & pyruvate dehydrogenase complex repressor & COG2186 & $\mathrm{K}$ & & 376 & 382 & -6 \\
\hline RCA23_c01010 & 103165 & 102623 & inner membrane lipoprotein YiaD & COG2885 & M & & 265 & 319 & -54 \\
\hline RCA23_c01020 & 103461 & 104105 & endonuclease III & COG0177 & $\mathrm{L}$ & & 351 & 403 & -52 \\
\hline RCA23_c01070 & 107628 & 108008 & HIT-like protein & COG0537 & $\mathrm{F}$ & & 461 & 501 & -40 \\
\hline RCA23_c01080 & 108944 & 108024 & ABC transporter ATP binding protein & COG1131 & $\mathrm{V}$ & & 655 & 495 & 160 \\
\hline RCA23_c01090 & 109004 & 109222 & hypothetical protein & COG4391 & $\mathrm{S}$ & & 754 & 472 & 282 \\
\hline RCA23_c01100 & 109664 & 109233 & hypothetical protein & & & & 564 & 410 & 154 \\
\hline RCA23_c01110 & 109753 & 112548 & DNA polymerase I & COG0749 & $\mathrm{L}$ & & 456 & 441 & 15 \\
\hline RCA23_c01120 & 112575 & 113720 & cystathionine gamma-synthase MetB & COG0626 & $\mathrm{E}$ & & 208 & 301 & -93 \\
\hline RCA23_c01130 & 113714 & 114265 & ribosomal large subunit pseudouridine synthase RluE & COG1187 & $\mathrm{J}$ & & 276 & 499 & -223 \\
\hline RCA23_c01140 & 114879 & 114286 & hypothetical protein DUF1285 & COG3816 & $\mathrm{S}$ & & 371 & 533 & -162 \\
\hline RCA23_c01150 & 114939 & 115946 & ATPase, MoxR type & COG0714 & $\mathrm{R}$ & & 192 & 243 & -51 \\
\hline RCA23_c01160 & 115943 & 116806 & hypothetical protein & COG1721 & $\mathrm{R}$ & & 276 & 277 & -1 \\
\hline RCA23_c01170 & 116803 & 119550 & hypothetical protein & & & & 224 & 357 & -133 \\
\hline
\end{tabular}




$\begin{array}{llll}\text { RCA23_c01190 } & 122292 & 123830 & \text { glycolate oxidase subunit GlcD } \\ \text { RCA23_c01200 } & 123827 & 124996 & \text { glycolate oxidase subunit GIcE } \\ \text { RCA23_c01210 } & 124996 & 126312 & \text { glycolate oxidase iron-sulfur subunit GlcF } \\ \text { RCA23_c01220 } & 126476 & 127198 & \text { hypothetical protein, trypsin } \\ \text { RCA23_c01230 } & 128473 & 127643 & \text { putative chitinase } \\ \text { RCA23_c01240 } & 129159 & 129614 & \text { small heat shock protein IbpA } \\ \text { RCA23_c01250 } & 131155 & 129680 & \text { succinate-semialdehyde dehydrogenase GabD } \\ \text { RCA23_c01260 } & 131221 & 132024 & \text { hypothetical protein } \\ \text { RCA23_c01270 } & 132344 & 132021 & \text { hypothetical protein } \\ \text { RCA23_c01280 } & 133081 & 132341 & \text { putative cyclopentanol dehydrogenase CpnA } \\ \text { RCA23_c01290 } & 133264 & 133566 & \text { hypothetical protein } \\ \text { RCA23_c01300 } & 133661 & 134278 & \text { hypothetical protein DUF1523 } \\ \text { RCA23_c01310 } & 136598 & 134286 & \text { aldehyde dehydrogenase } \\ \text { RCA23_c01320 } & 137589 & 136603 & \text { deoxyribose-phosphate aldolase DeoC } \\ \text { RCA23_c01330 } & 137692 & 138366 & \text { ribulose-phosphate 3-epimerase, chromosomal } \\ \text { RCA23_c01340 } & 140190 & 138385 & \text { hemolysin-type calcium-binding region } \\ \text { RCA23_c01350 } & 140316 & 143915 & \text { 5-oxoprolinase (ATP-hydrolyzing) } \\ \text { RCA23_c01360 } & 145374 & 144022 & \text { aminotransferase class-III } \\ \text { RCA23_c01370 } & 145865 & 145371 & \text { ureidoglycolate hydrolase AllA } \\ \text { RCA23_c01380 } & 146898 & 145891 & \text { aldose 1-epimerase GalM } \\ \text { RCA23_c01390 } & 148778 & 146898 & \text { beta-galactosidase BgaB } \\ \text { RCA23_c01400 } & 149622 & 148786 & \text { putative gluconolactonase } \\ \text { RCA23_c01410 } & 150218 & 149616 & \text { 2-dehydro-3-deoxy-6-phosphogalactonate aldolase DgoA } \\ \text { RCA23_c01420 } & 151120 & 150215 & \text { 2-dehydro-3-deoxygalactonokinase DgoK } \\ \text { RCA23_c01430 } & 151884 & 151117 & \text { short chain dehydrogenase } \\ \text { RCA23_c01440 } & 154013 & 151929 & \text { alpha-galactosidase RafA } \\ \text { RCA23_c01450 } & 154942 & 154043 & \text { putative ABC transporter inner membrane component } \\ \text { RCA23_c01460 } & 155930 & 154920 & \text { putative ABC transporter inner membrane component } \\ \text { RCA23_c01470 } & 157438 & 156014 & \text { putative extracellular solute-binding protein } \\ \text { RCA23_c01480 } & 157460 & 158245 & \text { HTH-type transcriptional regulator, IcIR family } \\ & & & \end{array}$

$\begin{array}{llccc}\text { COG0277 } & \text { C } & 492 & 613 & -121 \\ \text { COG0277 } & \text { C } & 449 & 505 & -56 \\ \text { COG0247 } & \text { C } & 438 & 414 & 24 \\ \text { COG3591 } & \text { E } & 379 & 640 & -261 \\ \text { COG3325 } & \text { G } & 43 & 18 & 25 \\ \text { COG0071 } & \text { O } & 1.541 & 759 & 782 \\ \text { COG1012 } & \text { C } & 335 & 398 & -63 \\ \text { COG0657 } & \text { I } & 241 & 333 & -92 \\ \text { COG5617 } & \text { S } & 233 & 327 & -94 \\ \text { COG1028 } & \text { I } & 381 & 387 & -6 \\ & & 287 & 356 & -69 \\ & & 469 & 370 & 99 \\ \text { COG1012 } & \text { C } & 256 & 353 & -97 \\ \text { COG0274 } & \text { F } & 287 & 273 & 14 \\ \text { COG0036 } & \text { G } & 290 & 386 & -96 \\ & & 322 & 456 & -134 \\ \text { COG0145 } & \text { E } & 257 & 381 & -124 \\ \text { COG0161 } & \text { H } & 314 & 322 & -8 \\ \text { COG3194 } & \text { F } & 551 & 501 & 50 \\ \text { COG2017 } & \text { G } & 273 & 397 & -124 \\ \text { COG1874 } & \text { G } & 225 & 271 & -46 \\ \text { COG3386 } & \text { G } & 260 & 321 & -61 \\ \text { COG0800 } & \text { G } & 205 & 303 & -98 \\ \text { COG3734 } & \text { G } & 202 & 287 & -85 \\ \text { COG1028 } & \text { I } & 245 & 234 & 11 \\ \text { COG3345 } & \text { G } & 239 & 275 & -36 \\ \text { COG0395 } & \text { G } & 388 & 341 & 47 \\ \text { COG1175 } & \text { G } & 389 & 289 & 100 \\ \text { COG1653 } & \text { G } & 365 & 261 & 104 \\ \text { COG1414 } & \text { K } & 141 & 131 & 10\end{array}$




\begin{tabular}{|c|c|c|c|c|c|c|c|c|}
\hline RCA23_c01490 & 158266 & 159324 & sugar $A B C$ transporter ATP-binding protein & COG3839 & G & 231 & 267 & -36 \\
\hline RCA23_c01500 & 160108 & 159344 & Sulfite exporter TauE/SafE & & & 177 & 299 & -122 \\
\hline RCA23_c01520 & 163233 & 161716 & taurine--pyruvate aminotransferase Tpa & COG0161 & $\mathrm{H}$ & 341 & 283 & 58 \\
\hline RCA23_c01540 & 164690 & 165496 & taurine $A B C$ transport system ATP-binding protein TauB & COG1116 & $\mathrm{P}$ & 614 & 476 & 138 \\
\hline RCA23_c01550 & 165493 & 166803 & taurine $A B C$ transport system permease protein TauC & COG0600 & $\mathrm{P}$ & 618 & 484 & 134 \\
\hline RCA23_c01560 & 169252 & 166847 & dimethylglycine dehydrogenase & COG0404 & $\mathrm{E}$ & 324 & 431 & -107 \\
\hline RCA23_c01580 & 173231 & 170928 & 3-hydroxyacyl-CoA dehydrogenase FadN & COG1250 & 1 & 294 & 374 & -80 \\
\hline RCA23_c01590 & 174034 & 173246 & hypothetical protein & COG0596 & $\mathrm{R}$ & 346 & 339 & 7 \\
\hline RCA23_c01600 & 175440 & 174031 & O-acetylhomoserine (thiol)-lyase CysD & COG2873 & $\mathrm{E}$ & 375 & 470 & -95 \\
\hline RCA23_c01610 & 175521 & 177014 & putative signaling protein & COG2200 & $\mathrm{T}$ & 515 & 534 & -19 \\
\hline RCA23_c01620 & 177159 & 178928 & sulfoacetaldehyde acetyltransferase Xsc & COG0028 & $\mathrm{E}$ & 486 & 430 & 56 \\
\hline RCA23_c01630 & 178940 & 179944 & phosphate acetyltransferase Pta & COG0280 & C & 250 & 314 & -64 \\
\hline RCA23_c01670 & 184402 & 185274 & DMSO reductase chain $C$ & COG3302 & $\mathrm{R}$ & 342 & 514 & -172 \\
\hline RCA23_c01680 & 186741 & 185380 & sodium:alanine symporter & COG1115 & $\mathrm{E}$ & 347 & 371 & -24 \\
\hline RCA23_c01690 & 187519 & 186917 & thymidine kinase Tdk & COG1435 & $\mathrm{F}$ & 259 & 365 & -106 \\
\hline RCA23_c01700 & 187650 & 188366 & NADPH-dependent FMN reductase & COG0431 & $\mathrm{R}$ & 400 & 533 & -133 \\
\hline RCA23_c01710 & 191838 & 188422 & carbamoyl-phosphate synthase large chain CarB & COG0458 & $\mathrm{E}$ & 371 & 400 & -29 \\
\hline RCA23_c01720 & 192331 & 191858 & HTH-type transcriptional regulator, AsnC family & COG1522 & K & 562 & 484 & 78 \\
\hline RCA23_c01730 & 192395 & 192673 & hypothetical protein & & & 876 & 934 & -58 \\
\hline RCA23_c01740 & 192769 & 194544 & aspartyl-tRNA synthase AspS & COG0173 & J & 459 & 475 & -16 \\
\hline RCA23_c01750 & 194967 & 194602 & hypothetical protein & & & 335 & 405 & -70 \\
\hline RCA23_c01760 & 195297 & 195013 & putative signal transduction response regulator receiver pro & COG2197 & $\mathrm{T}$ & 358 & 337 & 21 \\
\hline RCA23_c01770 & 195361 & 195822 & methylmalonyl-CoA epimerase & COG0346 & $E$ & 605 & 483 & 122 \\
\hline
\end{tabular}




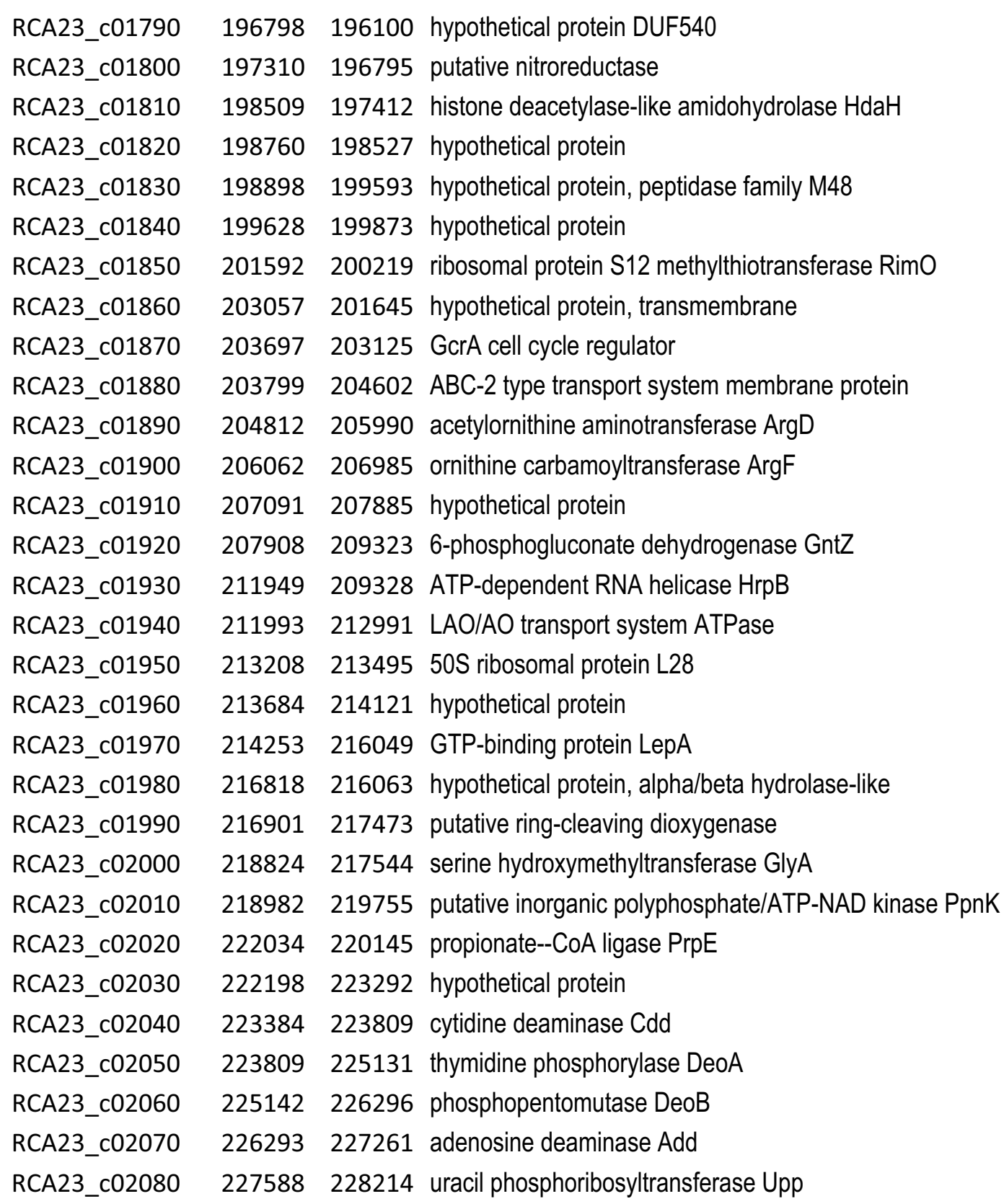

$\begin{array}{lllll}\text { COG2981 } & \text { E } & 452 & 400 & 52 \\ \text { COG0778 } & \text { C } & 264 & 302 & -38 \\ \text { COG0123 } & \text { B } & 254 & 420 & -166 \\ & & 331 & 417 & -86 \\ \text { COG0501 } & \text { O } & 218 & 295 & -77 \\ & & 216 & 359 & -143 \\ \text { COG0621 } & \text { J } & 203 & 311 & -108 \\ & & 183 & 253 & -70 \\ \text { COG5352 } & \text { S } & 261 & 323 & -62 \\ \text { COG0842 } & \text { V } & 589 & 598 & -9 \\ \text { COG4992 } & \text { E } & 327 & 501 & -174 \\ \text { COG0078 } & \text { E } & 299 & 408 & -109 \\ & & 277 & 502 & -225 \\ \text { COG0362 } & \text { G } & 254 & 365 & -111 \\ \text { COG1643 } & \text { L } & 228 & 291 & -63 \\ \text { COG1703 } & \text { E } & 204 & 314 & -110 \\ \text { COG0227 } & \text { J } & 729 & 469 & 260 \\ & & 684 & 509 & 175 \\ \text { COG0481 } & \text { M } & 566 & 504 & 62 \\ \text { COG0596 } & \text { R } & 269 & 374 & -105 \\ \text { COG0346 } & \text { E } & 435 & 594 & -159 \\ \text { COG0112 } & \text { E } & 425 & 364 & 61 \\ \text { COG0061 } & \text { G } & 432 & 438 & -6 \\ \text { COG0365 } & \text { I } & 297 & 361 & -64 \\ \text { COG1917 } & \text { S } & 290 & 425 & -135 \\ \text { COG0295 } & \text { F } & 257 & 367 & -110 \\ \text { COG0213 } & \text { F } & 209 & 351 & -142 \\ \text { COG1015 } & \text { G } & 241 & 350 & -109 \\ \text { COG1816 } & \text { F } & 392 & 461 & -69 \\ \text { COG0035 } & \text { F } & 717 & 465 & 252 \\ & & & & \end{array}$


RCA23 02090

RCA23_c02100

RCA23_c02110

RCA23_c02120

RCA23_c02130

RCA23_C02140

RCA23_C02150

RCA23_c02160

RCA23_c02170

RCA23_c02180

RCA23_c02190

RCA23_C02200

RCA23_C02210

RCA23_C02220

RCA23_C02230

RCA23_C02240

RCA23_c02250

RCA23_c02260

RCA23_c02270

RCA23_c02280

RCA23_c02290

RCA23_c02300

RCA23_c02310

RCA23_c02320

RCA23_c02330

RCA23_c02340

RCA23_C02350

RCA23_c02360

RCA23_C02370

RCA23_c02380
228449228868 hypothetical protein

2302342289003 3-deoxy-D-manno-octulosonic-acid transferase WaaA

231721230234 L-sorbose 1-dehydrogenase

232388231708 putative $\mathrm{N}$-acylneuraminate cytidylyltransferase

233528232392 UDP-4-amino-4-deoxy-L-arabinose--oxoglutarate aminotrar

236514234343 hypothetical protein

237421236696 hypothetical protein, nucleoside triphosphate hydrolases-lik

238069237422 S-adenosyl-L-methionine-dependent methyltransferase

239306238389 hypothetical protein

241023239398 medium-chain-fatty-acid--CoA ligase AlkK

241093241995 hypothetical protein DUF6 transmembrane

244207242024 fatty acid oxidation complex alpha subunit FadJ

244632244219 hypothetical protein

245865244654 short chain dehydrogenase

246509245877 putative glutathione S-transferase

248334246553 acyl-CoA dehydrogenase MmgC

248746248357 putative HTH-type transcriptional regulator, MerR family

249251248883 putative HTH-type transcriptional regulator, MerR family

250441249299 hypothetical protein, transmembrane protein DUF2899

250528250956 hypothetical protein, thioesterase

250953251453 hypothetical protein, thioesterase

251446252768 DNA-damage-inducible protein $F$

253850252789 dihydroorotate dehydrogenase PyrD

254185253847 hypothetical protein DUF952

$254360255892 \quad 5$ '-nucleotidase SurE

257694255964 hypothetical protein

257885258799 glycyl-tRNA synthase alpha subunit GlyQ

258799259317 hypothetical protein

259317261374 glycyl-tRNA synthase beta subunit GlyS

261437263977 pyruvate, phosphate dikinase PpdK

$\begin{array}{lc}\text { COG1519 } & \text { M } \\ \text { COG2303 } & \text { E } \\ \text { COG1083 } & \text { M } \\ \text { COG0399 } & \text { M } \\ \text { COG3119 } & \text { P } \\ \text { COG1122 } & \text { P } \\ \text { COG2226 } & \text { H } \\ & \\ \text { COG0318 } & \text { I } \\ \text { COG0697 } & \text { G } \\ \text { COG1250 } & \text { I } \\ & \\ \text { COG0183 } & \text { I } \\ \text { COG0625 } & \text { O } \\ \text { COG1960 } & \text { I } \\ \text { COG0789 } & \text { K } \\ \text { COG0789 } & \text { K } \\ & \\ \text { COG2050 } & \text { Q } \\ \text { COG2050 } & \text { Q } \\ \text { COG0534 } & \text { V } \\ \text { COG0167 } & \text { F } \\ \text { COG3502 } & \text { S } \\ \text { COG0737 } & \text { F } \\ \text { COG3409 } & \text { M } \\ \text { COG0752 } & \text { J } \\ \text { COG0751 } & \text { J } \\ \text { COG0574 } & \text { G } \\ & \end{array}$




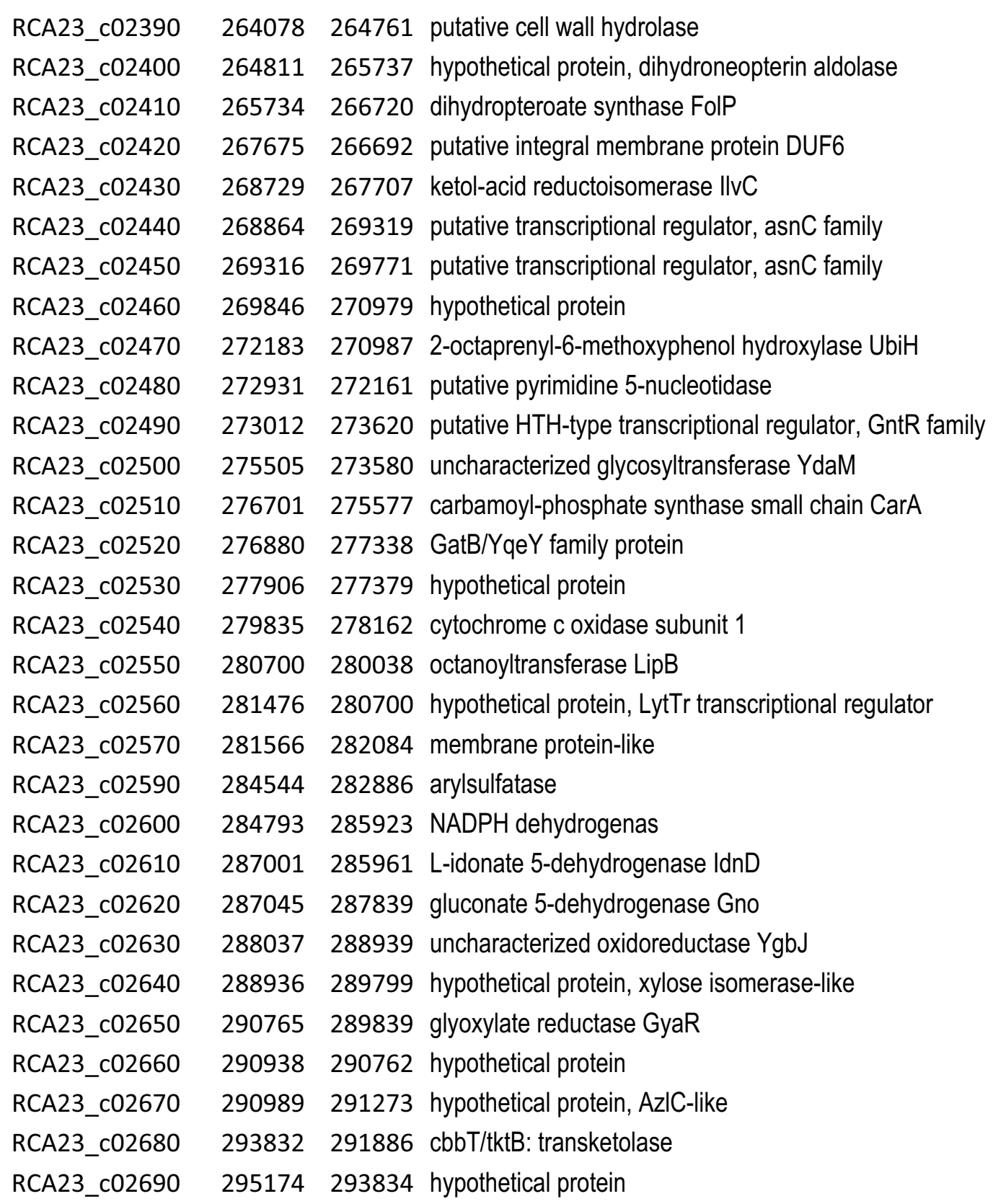

$\begin{array}{lllll}\text { COG3773 } & \text { M } & 429 & 521 & -92 \\ \text { COG1539 } & \text { H } & 326 & 427 & -101 \\ \text { COG0294 } & \text { H } & 218 & 368 & -150 \\ \text { COG0697 } & \text { G } & 277 & 365 & -88 \\ \text { COG0059 } & \text { E } & 455 & 347 & 108 \\ \text { COG1522 } & \text { K } & 260 & 420 & -160 \\ \text { COG1522 } & \text { K } & 255 & 394 & -139 \\ \text { COG0075 } & \text { E } & 378 & 383 & -5 \\ \text { COG0654 } & \text { H } & 210 & 332 & -122 \\ \text { COG1011 } & \text { R } & 348 & 434 & -86 \\ \text { COG1802 } & \text { K } & 242 & 345 & -103 \\ \text { COG1215 } & \text { M } & 317 & 431 & -114 \\ \text { COG0505 } & \text { E } & 362 & 363 & -1 \\ \text { COG1610 } & \text { S } & 554 & 518 & 36 \\ \text { COG5488 } & \text { S } & 343 & 384 & -41 \\ \text { COG0843 } & \text { C } & 599 & 404 & 195 \\ \text { COG0321 } & \text { H } & 284 & 374 & -90 \\ \text { COG3279 } & \text { K } & 157 & 207 & -50 \\ \text { COG5395 } & \text { S } & 319 & 344 & -25 \\ \text { COG3119 } & \text { P } & 331 & 339 & -8 \\ \text { COG1902 } & \text { C } & 211 & 275 & -64 \\ \text { COG1063 } & \text { E } & 214 & 271 & -57 \\ \text { COG1028 } & \text { I } & 244 & 357 & -113 \\ \text { COG2084 } & \text { I } & 282 & 358 & -76 \\ \text { COG1082 } & \text { G } & 259 & 421 & -162 \\ \text { COG1052 } & \text { C } & 275 & 373 & -98 \\ \text { COG1296 } & \text { E } & 401 & 386 & 15 \\ \text { COG0021 } & \text { G } & 119 & 114 & 5 \\ \text { COG4091 } & \mathrm{E} & 35 & 55 & -20 \\ & & 45 & 80 & -35\end{array}$


RCA23 02700

RCA23_C02710

RCA23_C02720

RCA23_C02730

RCA23_C02740

RCA23_c02750

RCA23_c02760

RCA23_C02770

RCA23_c02780

RCA23_c02800

RCA23_c02810

RCA23_C02820

RCA23_c02830

RCA23_C02840

RCA23_c02850

RCA23_C02860

RCA23_C02870

RCA23_C02880

RCA23_C02890

RCA23_C02900

RCA23_c02910

RCA23_C02920

RCA23_C02930

RCA23_c02940

RCA23_c02950

RCA23_c02960

RCA23_c02970

RCA23_c02980

RCA23_C02990

RCA23_c03000
295374296207 transketolase, alpha subunit

296204297247 transketolase, beta-subunit

297249297809 putative 3-hydroxyisobutyrate dehydrogenase

297809298171 putative 3-hydroxyisobutyrate dehydrogenase

2981682989203 3-oxoacyl-[acyl-carrier-protein] reductase FabG

$299907298930 \mathrm{HTH}$-type transcriptional regulator, LysR family

300726300040 putative HTH-type transcriptional regulator, GntR family

300938301951 TRAP dicarboxylate transporter, subunit DctP

302000302872 TRAP dicarboxylate transporter, subunit DctQ

304513305322 hypothetical protein

305336306664 hypothetical protein DUF1537

306661307920 putative ribulose bisphosphate carboxylase large chain

308882307917 hypothetical protein, NAD dependent epimerase / dehydratc

309016309939 2-hydroxy-3-oxopropionate reductase GarR

310592310035 hypothetical protein

310977312479 altronate hydrolase UxaA

312455313480 putative oxidoreductase

313516314403 2-hydroxy-3-oxopropionate reductase GarR

314406315287 S-adenosylmethionine uptake transporter Sam

315284316147 2-dehydro-3-deoxygluconokinase KdgK

317333316134 D-mannonate oxidoreductase UxuB

318704317334 uronate isomerase $\mathrm{UxaC}$

318798319817 putative oxidoreductase

319829320809 putative oxidoreductase

320806321861 putative oxidoreductase

321849323057 mannonate dehydratase UxuA

323103324641 long-chain-fatty-acid--CoA ligase

324634325440 D-beta-hydroxybutyrate dehydrogenase BdhA

325531327783 copper-transporting P-type ATPase ActP

$327811328200 \mathrm{HTH}$-type transcriptional regulator (copper efflux regulator)

\begin{tabular}{|c|c|}
\hline COG3959 & \\
\hline COG3958 & \\
\hline COG2084 & \\
\hline COG2084 & \\
\hline COG1028 & \\
\hline COG0583 & \\
\hline COG1802 & \\
\hline COG4663 & \\
\hline COG4665 & \\
\hline COG0240 & \\
\hline COG3395 & \\
\hline COG1850 & \\
\hline COG0451 & \\
\hline COG2084 & \\
\hline $\operatorname{COG} 2721$ & \\
\hline COG0673 & \\
\hline COG2084 & \\
\hline COG0697 & \\
\hline COG0524 & \\
\hline COG0246 & \\
\hline COG1904 & \\
\hline COG0673 & \\
\hline COG0673 & \\
\hline COG0673 & \\
\hline COG1312 & \\
\hline COG0318 & \\
\hline COG1028 & \\
\hline COG 2217 & \\
\hline COG0789 & \\
\hline
\end{tabular}

64

33

23

41

63

53

134

153

180

83

99

55

98

65

69

287

374

370

714

444

274

271

175

304

242

216

230

247

292

384
$-20$

$-24$

$-75$

$-37$

$-18$

25

54

46

$-15$

$-20$

$-33$

5

$-24$

1

$-26$

$-18$

12

130

25

$-79$

$-31$

$-63$

$-41$

$-30$

$-68$

$-110$

$-201$

$-165$

$-130$ 


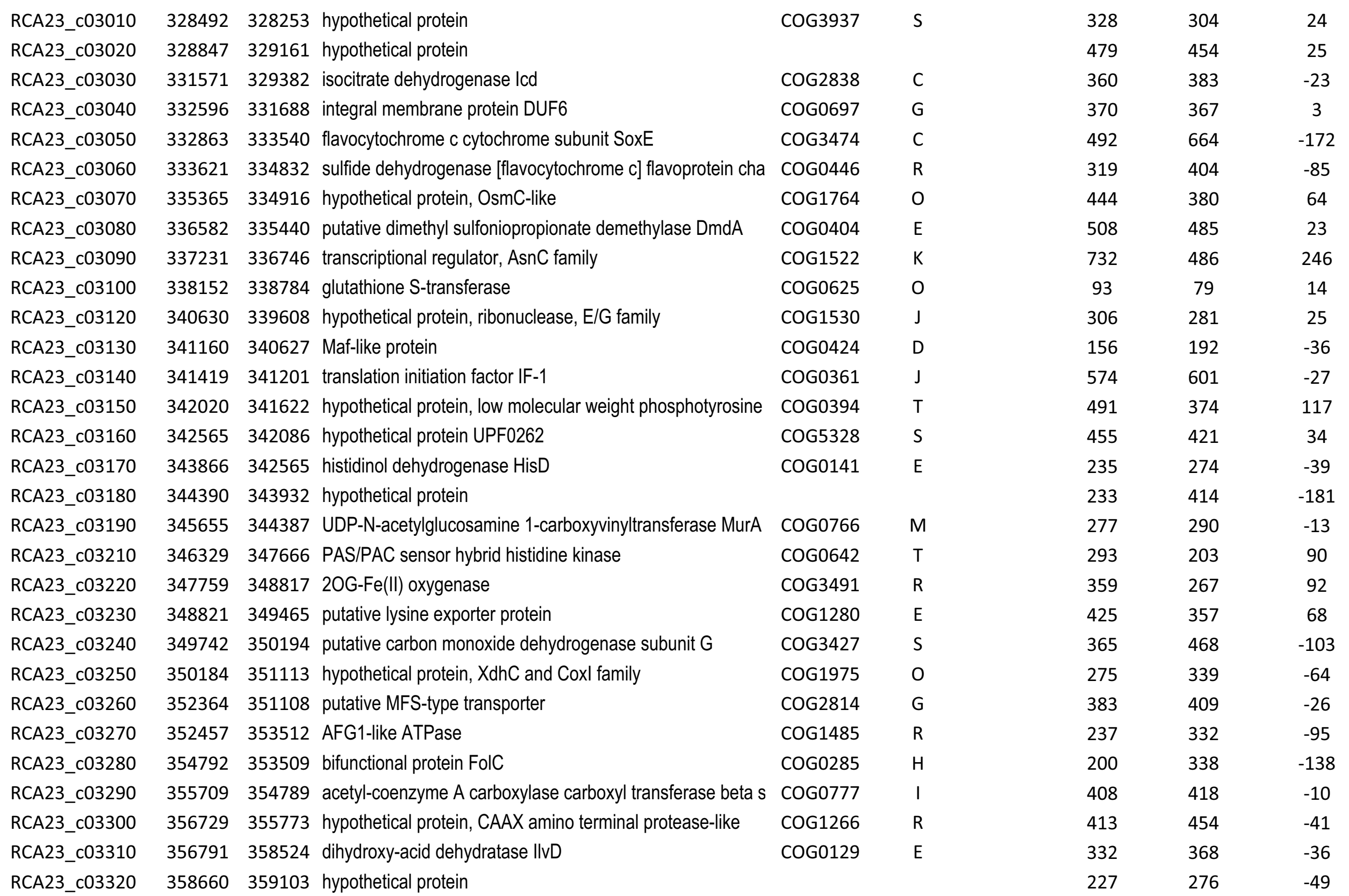


RCA23_c03330

RCA23_c03340

RCA23_c03350

RCA23_c03360

RCA23_c03370

RCA23_c03380

RCA23_c03390

RCA23_C03400

RCA23_c03410

RCA23_c03420

RCA23_c03430

RCA23_C03440

RCA23_c03450

RCA23_C03460

RCA23_c03470

RCA23_c03480

RCA23_c03490

RCA23_c03500

RCA23_C03510

RCA23_c03520

RCA23_c03530

RCA23_C03540

RCA23_c03550

RCA23_c03560

RCA23_c03570

RCA23_C03580

RCA23_c03590

RCA23_c03600

RCA23_C03610

RCA23_c03620
359279360058 hypothetical protein

360076360423 hypothetical protein

361268360426 hypothetical protein, OmpA family

361905361339 hypothetical protein, peroxidase-like protein

362627361902 hypothetical protein, acetyltransferase-like

363346362624 hypothetical protein, probably molybdopterin binding

363392364114 sugar fermentation stimulation protein SfsA

364191365000 methionine aminopeptidase Map

366577365054 ATP-dependent RNA helicase RhIE

367398366829 putative ribosomal RNA small subunit methyltransferase D

368600367395 rhodocoxin reductase ThcD

368681369172 peroxiredoxin

369613369326 pterin-4-alpha-carbinolamine dehydratase

370797369610 hypothetical protein DUF482

371604370849 putative glycerophosphoryl diester phosphodiesterase

372065371601 putative endoribonuclease L-PSP

373364372132 type I secretion system protein, HlyD family

374871373411 type I secretion system ATP-binding component

375137374874 putative type I secretion system protein, transmembrane do

375269376000 VacJ like lipoprotein

375984376589 putative toluene tolerance protein

378789376654 penicillin-binding protein 1B

380155378971 aromatic-amino-acid aminotransferase TyrB

3810123801553 3-mercaptopyruvate sulfurtransferase SseA

381576381100 SsrA-binding protein SmpB

382567381680 dihydrodipicolinate synthase DapA

382609384669 soluble lytic murein transglycosylase SIt

385589384717 hypothetical protein DUF6 transmembrane

386248385586 hypothetical protein DUF752

386288387352 putative FAD-dependent oxidoreductase

\begin{tabular}{|c|c|c|c|c|}
\hline & & 249 & 344 & -95 \\
\hline & & 380 & 445 & -65 \\
\hline COG2885 & $M$ & 332 & 403 & -71 \\
\hline COG2128 & $S$ & 428 & 461 & -33 \\
\hline COG0456 & $\mathrm{R}$ & 256 & 347 & -91 \\
\hline COG1058 & $\mathrm{R}$ & 218 & 322 & -104 \\
\hline COG1489 & $\mathrm{R}$ & 302 & 425 & -123 \\
\hline COG0024 & $\mathrm{J}$ & 369 & 393 & -24 \\
\hline COG0513 & $\mathrm{L}$ & 275 & 300 & -25 \\
\hline COG0742 & $\mathrm{L}$ & 236 & 306 & -70 \\
\hline COG0446 & $\mathrm{R}$ & 286 & 329 & -43 \\
\hline COG0678 & 0 & 574 & 527 & 47 \\
\hline COG2154 & $\mathrm{H}$ & 559 & 495 & 64 \\
\hline COG3146 & $S$ & 291 & 351 & -60 \\
\hline COG0584 & $\mathrm{C}$ & 398 & 441 & -43 \\
\hline COG0251 & $\mathrm{J}$ & 345 & 507 & -162 \\
\hline COG1566 & $\mathrm{V}$ & 257 & 378 & -121 \\
\hline COG4618 & $\mathrm{R}$ & 195 & 310 & -115 \\
\hline COG4618 & $\mathrm{R}$ & 484 & 480 & 4 \\
\hline COG2853 & $M$ & 564 & 440 & 124 \\
\hline COG2854 & $Q$ & 423 & 353 & 70 \\
\hline COG0744 & $M$ & 283 & 374 & -91 \\
\hline COG1448 & $\mathrm{E}$ & 343 & 390 & -47 \\
\hline COG2897 & $P$ & 307 & 316 & -9 \\
\hline COG0691 & 0 & 752 & 622 & 130 \\
\hline COG0329 & $\mathrm{E}$ & 245 & 271 & -26 \\
\hline COG0741 & $M$ & 231 & 304 & -73 \\
\hline COG0697 & G & 244 & 358 & -114 \\
\hline COG4121 & $S$ & 268 & 375 & -107 \\
\hline COG0665 & E & 279 & 439 & -160 \\
\hline
\end{tabular}


RCA23 003630

RCA23_c03640

RCA23_c03650

RCA23_c03660

RCA23_c03670

RCA23_c03680

RCA23_C03690

RCA23_c03700

RCA23_c03710

RCA23_c03720

RCA23_c03730

RCA23_c03740

RCA23_c03750

RCA23_c03760

RCA23_c03770

RCA23_c03780

RCA23_c03790

RCA23_c03800

RCA23_c03810

RCA23_c03820

RCA23_c03830

RCA23_c03840

RCA23_C03850

RCA23_c03860

RCA23_c03870

RCA23_c03880

RCA23_c03890

RCA23_c03900

RCA23_C03910

RCA23_C03920
387390387752 hypothetical protein, glyoxalase/dioxygenase superfamily

COG0346

388138387773 hypothetical protein

388488388135 hypothetical protein

389111388503 cob(l)yrinic acid a,c-diamide adenosyltransferase CobO COG2109

389202389606 hypothetical protein

390600389629 oligopeptide/dipeptide ABC transporter, ATP-binding proteir COG0444

391589390600 oligopeptide/dipeptide ABC transporter, ATP-binding proteir COG0444

392467391586 oligopeptide/dipeptide $A B C$ transporter, permease protein

393441392464 oligopeptide/dipeptide $A B C$ transporter, permease protein

395073393502 oligopeptide/dipeptide $A B C$ transporter, periplasmic substra

396231395302 HTH-type transcriptional regulator, LysR family

396411397982 putative amidohydrolase 3

397979398881 cobalamin biosynthesis CobW-like

398992400035 hypothetical protein, restriction endonuclease type IV-like

401165400095 glycine betaine transport ATP-binding protein OpuAA

COG1173

COG0601

COG0747

COG0583

COG1574

COG0523

COG4127

COG4175

402193401162 glycine betaine transport system permease protein OpuAB COG4176

403226402258 glycine betaine transporter substrate-binding protein OpuAC COG2113

403626404708 fatty acid desaturase

COG3239

405832404717 CoA-transferase family III protein involved in DMSP degradi COG1804

405843406949 glyceraldehyde-3-phosphate dehydrogenase Gap

407067407687 ATP-dependent Clp protease proteolytic subunit ClpP

COG0057

COG0740

407812409077 ATP-dependent Clp protease ATP-binding subunit ClpX COG1219

409209409592 putative NADH ubiquinone oxidoreductase subunit NDUFA COG3761

409597410043 ABC-type transport system involved in resistance to organic COG1463

410043410402 Uncharacterized protein conserved in bacteria (DUF2155) COG4765

411007410366 leucyl/phenylalanyl-tRNA--protein transferase Aat

COG2360

412356411004 biotin carboxylase AccC

COG4770

COG0365

414969413026 acetyl-coenzyme A synthase AcsA

$\begin{array}{llll}415768 & 415037 \text { high-affinity branched-chain amino acid transport ATP-bindi } & \text { COG0410 } \\ 416529 & 415771 & \text { high-affinity branched-chain amino acid transport ATP-bindi } & \text { COG0411 }\end{array}$

\section{$E$}

217

350

529

496

210

260

238

262

439

379

497

232

249

241

439

459

364

370

286

320

732

680

786

548

308

466

318

265

232

513

$\begin{array}{lc}367 & -150 \\ 445 & -95 \\ 416 & 113 \\ 404 & 92 \\ 318 & -108 \\ 314 & -54 \\ 350 & -112 \\ 357 & -95 \\ 395 & 44 \\ 323 & 56 \\ 494 & 3 \\ 346 & -114 \\ 331 & -82 \\ 213 & 28 \\ 469 & -30 \\ 546 & -87 \\ 379 & -15 \\ 432 & -62 \\ 378 & -92 \\ 495 & -175 \\ 497 & 235 \\ 551 & 129 \\ 483 & 303 \\ 559 & -11 \\ 397 & -89 \\ 513 & -47 \\ 325 & -7 \\ 296 & -31 \\ 342 & -110 \\ 381 & 132\end{array}$


RCA23_c03930

RCA23_c03940

RCA23_c03950

RCA23_c03960

RCA23_c03970

RCA23_c03980

RCA23_c03990

RCA23_c04000

RCA23_c04010

RCA23_c04020

RCA23_c04030

RCA23_c04040

RCA23_c04060

RCA23_c04070

RCA23_c04080

RCA23_c04090

RCA23_c04100

RCA23_c04110

RCA23_c04120

RCA23_c04130

RCA23 c04140

RCA23_c04150

RCA23_c04160

RCA23_c04170

RCA23_c04180

RCA23_c04190

RCA23_c04200

RCA23_c04210

RCA23_c04220

RCA23_c04230
417743416541 putative branched-chain amino acid transport system perme COG4177

418779417748 putative branched-chain amino acid transport system perme COG0559

420231418885 hypothetical protein

420457421773 hypothetical protein, DNA binding helix-turn helix proteins

421836422207 putative response regulator receiver protein, CheY like

422204422473 hypothetical protein

422474425128 sensor protein kinase WalK

425546425109 hypothetical protein DUF442

425805425593 hypothetical protein

425917426168 hypothetical protein

427065426184 hypothetical protein

427159428790 putative $\mathrm{Fe}(3+)$-transport system protein SfuB

428970430124 integrase

430197430778 hypothetical protein

434845431570 hypothetical protein

434910437174 UDP-N-acetylglucosamine--peptide N-acetylglucosaminyltŕ

440084439434 esterase, SGNH hydrolase-type

440656440258 hypothetical protein

441029441403 hypothetical protein, tetratricopeptide repeat

441971441678 hypothetical protein

442447442121 hypothetical protein

442788442444 hypothetical protein

443599443222 hypothetical protein, RmIC-like cupin family

444724444101 hypothetical protein

445304444918 hypothetical protein, DUF3127

446438445509 putative nucleoside triphosphate hydrolase, ATPase domail coG1066

447532449187 zinc-dependent metalloprotease

$449574449230 \mathrm{HTH}$-type transcriptional regulator, AsnC family

450860449781 integrase

COG2931

COG1522

COG2801

COG0683

COG1396

COG0745

COG0591

COG3453

$\operatorname{coG} 3750$

COG1178

COG0582

COG3945

COG0457

COG 2755

COG0790

COG3450

453456452530 putative ion channel
E 


\begin{tabular}{|c|c|c|c|c|c|c|c|c|c|}
\hline RCA23_c04240 & 454720 & 453746 & integrase & COG4974 & $\mathrm{L}$ & GI 2 & 326 & 288 & 38 \\
\hline RCA23_c04250 & 455125 & 455838 & Gcn5-like N-acetyltransferase & COG1670 & $\mathrm{J}$ & GI 2 & 8 & 1 & 7 \\
\hline RCA23_c04260 & 457797 & 456643 & integrase & COG0582 & $\mathrm{L}$ & GI 2 & 166 & 139 & 27 \\
\hline RCA23_c04280 & 458139 & 459119 & hypothetical protein, NAD dependent epimerase / dehydrat‘́ & COG0702 & M & & 246 & 375 & -129 \\
\hline RCA23_c04300 & 460124 & 461578 & glutamate synthase [NADPH] small chain GItD & COG0493 & $\mathrm{E}$ & & 382 & 340 & 42 \\
\hline RCA23_c04310 & 461639 & 466186 & glutamate synthase [NADPH] large chain GltB & COG0069 & $\mathrm{E}$ & & 343 & 411 & -68 \\
\hline RCA23_c04340 & 467733 & 468776 & putative electron transport protein yjeS & COG1600 & $\mathrm{C}$ & & 231 & 349 & -118 \\
\hline RCA23_c04360 & 469585 & 468773 & hypothetical protein & COG5266 & $P$ & & 307 & 349 & -42 \\
\hline RCA23_c04350 & 469584 & 470741 & hypothetical protein & & & & 351 & 560 & -209 \\
\hline RCA23_c04370 & 471709 & 470840 & branched-chain-amino-acid aminotransferase IlvE & COG0115 & $\mathrm{E}$ & & 279 & 331 & -52 \\
\hline RCA23_c04380 & 471872 & 472384 & HTH-type transcriptional regulator PetP & COG1846 & $\mathrm{K}$ & & 317 & 270 & 47 \\
\hline RCA23_c04430 & 475200 & 477101 & 1-deoxy-D-xylulose-5-phosphate synthase Dxs & COG1154 & $\mathrm{H}$ & & 238 & 320 & -82 \\
\hline RCA23_c04440 & 478007 & 477105 & hypothetical protein, NAD dependent epimerase/dehydratas & COG0451 & M & & 220 & 302 & -82 \\
\hline RCA23_c04450 & 478232 & 478657 & hypothetical protein & & & & 298 & 338 & -40 \\
\hline RCA23_c04460 & 478753 & 479079 & hypothetical protein & & & & 446 & 435 & 11 \\
\hline RCA23_c04470 & 479921 & 479142 & carnitinyl-CoA dehydratase CaiD & COG1024 & 1 & & 337 & 370 & -33 \\
\hline RCA23_c04480 & 481945 & 479918 & hypothetical protein, CoA-binding & COG1042 & C & & 232 & 293 & -61 \\
\hline RCA23_c04490 & 483157 & 481997 & putative acyl-CoA dehydrogenase YngJ & COG1960 & 1 & & 288 & 270 & 18 \\
\hline RCA23_c04500 & 483234 & 484166 & transcriptional regulator, AraC family & COG4977 & $\mathrm{K}$ & & 204 & 299 & -95 \\
\hline RCA23_c04510 & 484951 & 484196 & class II aldolase & COG0235 & G & & 278 & 347 & -69 \\
\hline RCA23_c04520 & 485442 & 485014 & arsenate reductase $\mathrm{ArsC}$ & COG1393 & $P$ & & 218 & 288 & -70 \\
\hline RCA23_c04530 & 485529 & 487343 & adenine deaminase Ade & COG1001 & $\mathrm{F}$ & & 223 & 310 & -87 \\
\hline
\end{tabular}




\begin{tabular}{|c|c|c|c|c|c|c|c|c|}
\hline RCA23_c04550 & 488882 & 489214 & DNA-binding protein $\mathrm{HU}$ & COG0776 & $\mathrm{L}$ & 749 & 586 & 163 \\
\hline RCA23_c04580 & 491039 & 491449 & hypothetical protein, thioredoxin & COG0526 & 0 & 398 & 399 & -1 \\
\hline RCA23_c04600 & 493168 & 492038 & succinyl-diaminopimelate desuccinylase DapE & COG0624 & $\mathrm{E}$ & 242 & 273 & -31 \\
\hline RCA23_c04610 & 493554 & 493168 & hypothetical protein & & & 369 & 407 & -38 \\
\hline RCA23_c04620 & 494478 & 493591 & 2,3,4,5-tetrahydropyridine-2,6-dicarboxylate N-succinyltrans & COG2171 & $E$ & 248 & 351 & -103 \\
\hline RCA23_c04640 & 496617 & 495427 & ribosomal RNA large subunit methyltransferase $\mathrm{N}$ & COG0820 & $\mathrm{R}$ & 322 & 367 & -45 \\
\hline RCA23_c04650 & 497212 & 496688 & hypothetical protein & & & 320 & 378 & -58 \\
\hline RCA23_c04660 & 497318 & 498349 & L-asparaginase II & COG4448 & $E$ & 194 & 300 & -106 \\
\hline RCA23_c04670 & 499288 & 498410 & phosphoserine phosphatase SerB & COG0560 & $E$ & 220 & 310 & -90 \\
\hline RCA23_c04680 & 499417 & 499902 & hypothetical protein & & & 382 & 415 & -33 \\
\hline RCA23_c04690 & 500025 & 501251 & phosphoserine aminotransferase SerC & COG1932 & $\mathrm{H}$ & 301 & 441 & -140 \\
\hline RCA23_c04730 & 505467 & 504130 & carboxy-terminal-processing protease CtpA & COG0793 & $\mathrm{M}$ & 363 & 371 & -8 \\
\hline RCA23_c04740 & 507182 & 505665 & 2,3-bisphosphoglycerate-independent phosphoglycerate mı & COG0696 & G & 294 & 331 & -37 \\
\hline RCA23_c04750 & 507362 & 508978 & putative protein ImuB & & & 218 & 304 & -86 \\
\hline RCA23_c04760 & 509201 & 509545 & hypothetical protein & & & 401 & 555 & -154 \\
\hline RCA23_c04770 & 510291 & 509542 & hypothetical protein, NIpC/P60 & COG0791 & M & 244 & 388 & -144 \\
\hline RCA23_c04780 & 511667 & 510288 & putative cytosol aminopeptidase PepA & COG0260 & $\mathrm{E}$ & 203 & 280 & -77 \\
\hline RCA23_c04790 & 512156 & 511782 & hypothetical protein & & & 280 & 370 & -90 \\
\hline RCA23_c04800 & 512302 & 512970 & carbonic anhydrase CynT & COG0288 & $\mathrm{P}$ & 701 & 454 & 247 \\
\hline RCA23_c04810 & 514074 & 513052 & aspartate-semialdehyde dehydrogenase Asd & COG0136 & $\mathrm{E}$ & 777 & 529 & 248 \\
\hline RCA23_c04820 & 515330 & 514140 & MFS-type transporter & COG2223 & $P$ & 321 & 277 & 44 \\
\hline RCA23_c04830 & 515444 & 516199 & short chain dehydrogenase & COG4221 & $\mathrm{R}$ & 260 & 362 & -102 \\
\hline
\end{tabular}




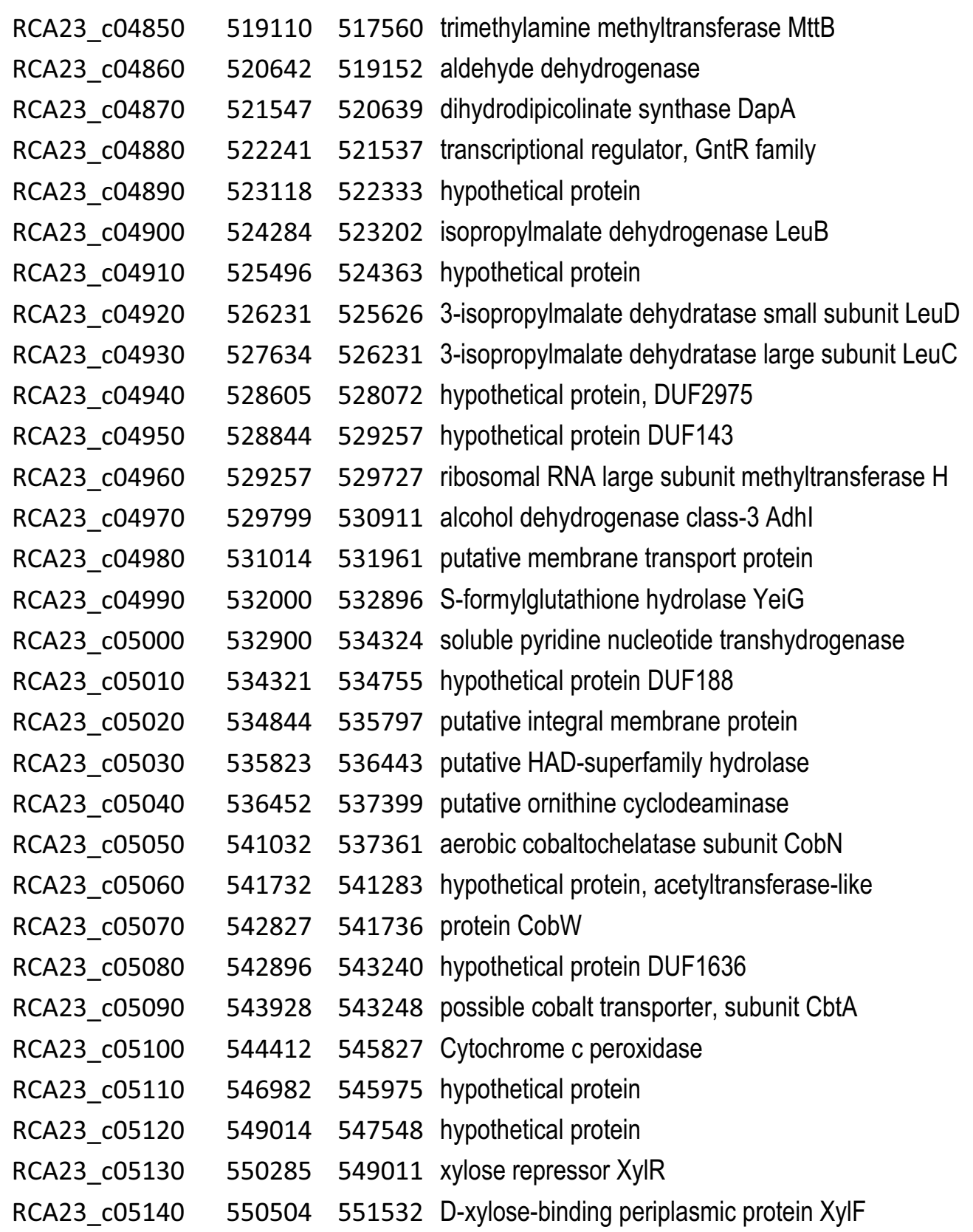

\begin{tabular}{|c|c|c|c|c|}
\hline COG5598 & $\mathrm{H}$ & 269 & 395 & -126 \\
\hline COG1012 & C & 229 & 319 & -90 \\
\hline COG0329 & $\mathrm{E}$ & 277 & 336 & -59 \\
\hline \multirow[t]{2}{*}{ COG1802 } & $\mathrm{K}$ & 322 & 303 & 19 \\
\hline & & 258 & 358 & -100 \\
\hline \multirow[t]{2}{*}{ COG0473 } & C & 304 & 357 & -53 \\
\hline & & 267 & 377 & -110 \\
\hline COG0066 & $\mathrm{E}$ & 458 & 387 & 71 \\
\hline \multirow[t]{2}{*}{ COG0065 } & $\mathrm{E}$ & 288 & 275 & 13 \\
\hline & & 207 & 247 & -40 \\
\hline COG0799 & $\mathrm{s}$ & 450 & 364 & 86 \\
\hline COG1576 & $S$ & 245 & 311 & -66 \\
\hline COG1062 & C & 294 & 435 & -141 \\
\hline COG0679 & $\mathrm{R}$ & 233 & 422 & -189 \\
\hline COG0627 & $\mathrm{R}$ & 250 & 354 & -104 \\
\hline COG1249 & $\mathrm{C}$ & 327 & 370 & -43 \\
\hline COG1671 & $S$ & 235 & 386 & -151 \\
\hline COG0697 & G & 439 & 594 & -155 \\
\hline COG1011 & $\mathrm{R}$ & 270 & 379 & -109 \\
\hline COG2423 & $\mathrm{E}$ & 225 & 304 & -79 \\
\hline COG1429 & $\mathrm{H}$ & 208 & 291 & -83 \\
\hline COG0456 & $\mathrm{R}$ & 273 & 241 & 32 \\
\hline COG0523 & $\mathrm{R}$ & 298 & 352 & -54 \\
\hline COG5469 & $S$ & 269 & 436 & -167 \\
\hline COG5446 & $S$ & 213 & 300 & -87 \\
\hline COG1858 & $P$ & 296 & 759 & -463 \\
\hline \multirow[t]{2}{*}{ COG4188 } & $\mathrm{R}$ & 350 & 299 & 51 \\
\hline & & 258 & 381 & -123 \\
\hline COG1940 & $\mathrm{K}$ & 245 & 284 & -39 \\
\hline COG4213 & G & 906 & 544 & 362 \\
\hline
\end{tabular}




\begin{tabular}{|c|c|c|c|c|c|c|c|c|}
\hline RCA23_c05150 & 551693 & 553006 & xylose transport system permease protein $\mathrm{XylH}$ & COG4214 & G & 453 & 505 & -52 \\
\hline RCA23_c05180 & 555316 & 556617 & xylose isomerase XylA & COG2115 & G & 393 & 363 & 30 \\
\hline RCA23_c05200 & 559391 & 558144 & malonyl-CoA decarboxylase & & & 373 & 355 & 18 \\
\hline RCA23_c05210 & 561272 & 559614 & acyl-CoA dehydrogenase & COG1960 & 1 & 256 & 352 & -96 \\
\hline RCA23_c05220 & 561381 & 562196 & hypothetical protein DUF81 & & & 360 & 365 & -5 \\
\hline RCA23_c05240 & 564119 & 564820 & two component signal transduction response regulator rece & COG0745 & $\mathrm{T}$ & 486 & 575 & -89 \\
\hline RCA23_c05250 & 564856 & 566508 & two component signal transduction histidine kinase ChvG & COG0642 & $\mathrm{T}$ & 217 & 329 & -112 \\
\hline RCA23_c05260 & 566513 & 566974 & hypothetical protein, HPr serine kinase & COG1493 & $\mathrm{T}$ & 220 & 332 & -112 \\
\hline RCA23_c05270 & 566967 & 567878 & putative P-loop containing ATPase & COG1660 & $\mathrm{R}$ & 307 & 374 & -67 \\
\hline RCA23_c05280 & 567875 & 568264 & hypothetical protein, PTS system mannose-specific EIIA co & COG2893 & G & 251 & 493 & -242 \\
\hline RCA23_c05290 & 568274 & 568540 & phosphocarrier protein NPr & COG1925 & G & 259 & 480 & -221 \\
\hline RCA23_c05330 & 572154 & 571324 & putative short chain dehydrogenase & COG4221 & $\mathrm{R}$ & 327 & 465 & -138 \\
\hline RCA23_c05340 & 572337 & 574667 & DNA topoisomerase 4 subunit $A$ & COG0188 & $\mathrm{L}$ & 319 & 408 & -89 \\
\hline RCA23_c05350 & 574828 & 576000 & hypothetical protein DUF898 & COG4269 & $\mathrm{S}$ & 147 & 227 & -80 \\
\hline RCA23_c05360 & 576002 & 577117 & peptidase M48 Ste24p & COG4783 & $\mathrm{R}$ & 216 & 344 & -128 \\
\hline RCA23_c05370 & 577197 & 577787 & hypothetical protein & & & 310 & 426 & -116 \\
\hline RCA23_c05380 & 577907 & 579082 & elongation factor Tu (EF-Tu) & COG0050 & $\mathrm{J}$ & 14 & 5 & 9 \\
\hline RCA23_c05400 & 580699 & 579374 & hypothetical protein, DUF560 & & & 336 & 441 & -105 \\
\hline RCA23_c05410 & 582022 & 580856 & hippurate hydrolase HipO & COG1473 & $\mathrm{R}$ & 256 & 365 & -109 \\
\hline RCA23_c05420 & 583851 & 582037 & glutathione import ATP-binding protein GsiA & COG1123 & $\mathrm{R}$ & 260 & 312 & -52 \\
\hline RCA23_c05430 & 584120 & 585829 & oligopeptide-binding protein AppA & COG0747 & $\mathrm{E}$ & 394 & 382 & 12 \\
\hline RCA23_c05440 & 585905 & 586912 & oligopeptide transport system permease protein $\mathrm{AppB}$ & COG0601 & $\mathrm{E}$ & 420 & 433 & -13 \\
\hline
\end{tabular}


RCA23_c05460

RCA23_c05470

RCA23_c05480

RCA23_c05490

RCA23_c05500

RCA23_C05510

RCA23_C05520

RCA23_C05530

RCA23_c05540

RCA23_c05550

RCA23_c05560

RCA23_c05570

RCA23_C05580

RCA23_C05590

RCA23_c05600

RCA23_c05610

RCA23_c05620

RCA23_c05630

RCA23_c05640

RCA23_c05650

RCA23_c05660

RCA23_c05670

RCA23_c05680

RCA23_C05690

RCA23_c05700

RCA23_c05710

RCA23_c05720

RCA23_c05730

RCA23_c05740

RCA23_c05750
587971588900 ABC transporter ATP-binding protein

588897589658 inner membrane transport permease

589709590494 hypothetical protein, peptidase family S49

590678591637 putative sodium/calcium exchanger protein

591649592425 putative short cprotein

592554594575 UvrABC system protein C

594704595360 CDP-diacylglycerol--glycerol-3-phosphate 3-phosphatidyltra

595366595617 molybdopterin-converting factor subunit MoaD

595619596086 molybdopterin synthase catalytic subunit MoaE

596425596096 hypothetical protein

598304596418 hypothetical protein, OmpA

599317598358 UbiA prenyltransferase

599330600049 RNA methyltransferase

600046600558 hypothetical protein

600631602001 glutamate--cysteine ligase

602642602034 glycerol-3-phosphate acyltransferase PlsY

603898602639 dihydroorotase PyrC

604984604040 aspartate carbamoyltransferase PyrB

605144605956 uracil DNA glycosylase family protein

605953606495 molybdenum cofactor biosynthesis protein MoaB

606597608030 putative efflux transporter, RND family, membrane fusion pr

608034611426 transporter, AcrB/AcrD/AcrF family

612217611423 hypothetical protein

612351612965 hypothetical protein DUF179

613054614754 acyl-CoA dehydrogenase

614764615792 putative metallo-beta-lactamase family protein

616040616657 hypothetical protein

616959616630 putative branched-chain amino acid transport protein

617657616956 protein AzIC

617712618581 formate dehydrogenase accessory protein FdhD

$\begin{array}{ll}\text { COG1131 } & \text { V } \\ \text { COG0842 } & \text { V } \\ \text { COG0616 } & \text { O } \\ \text { COG0530 } & \mathrm{P} \\ \text { COG1028 } & \mathrm{I} \\ \text { COG0322 } & \mathrm{L} \\ \text { COG0558 } & \mathrm{I} \\ \text { COG1977 } & \mathrm{H} \\ \text { COG0314 } & \mathrm{H} \\ & \\ \text { COG2885 } & \mathrm{M} \\ \text { COG0382 } & \mathrm{H} \\ \text { COG1385 } & \mathrm{S} \\ & \\ \text { COG3572 } & \mathrm{H} \\ \text { COG0344 } & \mathrm{S} \\ \text { COG0044 } & \mathrm{F} \\ \text { COG0540 } & \mathrm{F} \\ \text { COG1573 } & \mathrm{L} \\ \text { COG0521 } & \mathrm{H} \\ \text { COG1566 } & \mathrm{V} \\ \text { COG0841 } & \mathrm{V} \\ \text { COG4233 } & \mathrm{O} \\ \text { COG1678 } & \mathrm{K} \\ \text { COG1960 } & \mathrm{I} \\ \text { COG0491 } & \mathrm{R} \\ \text { COG4392 } & \mathrm{S} \\ \text { COG1296 } & \mathrm{E} \\ \text { COG1526 } & \mathrm{C}\end{array}$

711

476

644

235

729

594

399

366

372

788

349

385

362

263

237

221

265

440

259

245

333

152

237

265

347

221

253

300

238

369

293

276

297

456

85

138

$-90$

$403-37$

374

670

$-2$

118

$-66$

$-79$

84

$-35$

$-90$

$-38$

$-57$

49

$-59$

$-16$

$-215$

$-76$

$-58$

$-40$

$-99$

$-98$

$-109$

$-39$

$-187$

$-51$

$-73$

$-99$

$-97$ 
RCA23_c05760

RCA23_c05770

RCA23_c05780

RCA23_c05790

RCA23_c05800

RCA23_c05810

RCA23_c05820

RCA23_c05830

RCA23_c05840

RCA23_c05850

RCA23_c05860

RCA23_c05870

RCA23_c05880

RCA23_c05890

RCA23_c05900

RCA23_c05910

RCA23_c05920

RCA23_c05930

RCA23_c05940

RCA23_c05950

RCA23_c05960

RCA23_c05970

RCA23_c05980

RCA23_c05990

RCA23_c06000

RCA23_c06010

RCA23_c06020

RCA23_c06030

RCA23_c06040

RCA23_c06050
618578619183 molybdopterin-guanine dinucleotide biosynthesis protein Mc COG0746

619180619677 molybdopterin-guanine dinucleotide biosynthesis protein Mc COG1763

619674620930 molybdopterin biosynthesis protein MoeA

621450620965 transcription elongation factor GreA

621745623397 electron transfer flavoprotein-ubiquinone oxidoreductase

623502625211 tetratricopeptide repeat-containing protein

625201626028 4-diphosphocytidyl-2C-methyl-D-erythritol 2-phosphate synt

627043626045 octaprenyl-diphosphate synthase IspB

627656628066 hypothetical protein, methyltransferase

629161628439 acetoacetyl-CoA reductase PhaB

630460629267 acetyl-CoA acetyltransferase PhaA

631425630640 signaling protein

631516632085 DNA-3-methyladenine glycosylase 1

632617632066 thiol:disulfide interchange protein TIpA

632642634030 argininosuccinate lyase ArgH

634155634472 hypothetical protein

634558635823 diaminopimelate decarboxylase LysA

635848638316 hypothetical protein

639228639956 putative acyltransferase

640216640605 glyoxalase/bleomycin resistance protein

640646641269 hypothetical protein, pyridoxamine 5'-phosphate oxidase

642246641284 acetyl-coenzyme A carboxylase carboxyl transferase alpha

643307642348 malyl-CoA ligase

643594644595 hypothetical protein DUF1611

644712645674 L-Ala-D/L-Glu epimerase YcjG

645679646539 D-alanine aminotransferase Dat

646631648778 hypothetical, OmpA-like

648803649246 hypothetical protein

649545649243 hypothetical protein DUF1244

$650297649542 \mathrm{~N}$-formylglutamate amidohydrolase

\section{COG0303}

COG0782

COG0644

COG0457

COG1947

COG0142

COG4123

COG1028

COG0183

COG2200

COG2818

COG0526

COG0165

COG0019

COG1196

COG0204

COG2764

COG3576

COG0825

COG2301

COG3367

COG4948

COG0115

COG3743

COG3492

COG3931

\section{H}

$\mathrm{H}$

$\mathrm{H}$

K

C

R

I

$\mathrm{H}$

R

I

I

T

L

O

E

E

D

I

$\mathrm{S}$

R

I

G

$S$

$M$

E

S

$S$

E

$\begin{array}{llc}193 & 329 & -136 \\ 159 & 338 & -179 \\ 162 & 269 & -107 \\ 496 & 392 & 104 \\ 384 & 446 & -62 \\ 227 & 360 & -133 \\ 217 & 334 & -117 \\ 264 & 336 & -72 \\ 203 & 250 & -47 \\ 301 & 347 & -46 \\ 348 & 300 & 48 \\ 475 & 385 & 90 \\ 457 & 429 & 28 \\ 277 & 392 & -115 \\ 259 & 303 & -44 \\ 386 & 409 & -23 \\ 332 & 435 & -103 \\ 232 & 318 & -86 \\ 437 & 429 & 8 \\ 365 & 382 & -17 \\ 273 & 303 & -30 \\ 360 & 382 & -22 \\ 231 & 247 & -16 \\ 277 & 316 & -39 \\ 259 & 446 & -187 \\ 337 & 480 & -143 \\ 226 & 313 & -87 \\ 411 & 402 & 9 \\ 260 & 392 & -132 \\ 349 & 368 & -19\end{array}$




$\begin{array}{llll}\text { RCA23_c06060 } & 650384 & 651832 & \text { pyruvate kinase PykF } \\ \text { RCA23_c06070 } & 651832 & 652062 & \text { hypothetical protein } \\ \text { RCA23_c06080 } & 652176 & 652376 & 50 \text { S ribosomal protein L35 } \\ \text { RCA23_c06090 } & 652391 & 652753 & 50 \text { S ribosomal protein L20 } \\ \text { RCA23_c06100 } & 652996 & 655311 & \text { putative subtilase family protein } \\ \text { RCA23_c06110 } & 655323 & 655715 & \text { hypothetical protein } \\ \text { RCA23_c06120 } & 655813 & 656757 & \text { hypothetical protein, lipid A biosynthesis acyltransferase } \\ \text { RCA23_c06130 } & 656869 & 657942 & \text { phenylalanyl-tRNA synthase alpha chain PheS } \\ \text { RCA23_c06140 } & 657976 & 658701 & \text { glutamine amidotransferase class-I } \\ \text { RCA23_c06150 } & 658701 & 661094 & \text { phenylalanyl-tRNA synthase beta chain PheT } \\ \text { RCA23_c06160 } & 661282 & 661740 & \text { putative HTH-type transcriptional regulator } \\ \text { RCA23_c06170 } & 662019 & 661819 & \text { ribsomal protein S21 } \\ \text { RCA23_c06180 } & 662122 & 662802 & \text { putative ubiquinone biosynthesis protein COQ9 } \\ \text { RCA23_c06190 } & 662830 & 663807 & \text { putative quinone oxidoreductase } \\ \text { RCA23_c06200 } & 663977 & 664744 & \text { hypothetical protein DUF1013 } \\ \text { RCA23_c06210 } & 665637 & 665044 & \text { recombination protein RecR } \\ \text { RCA23_c06220 } & 665998 & 665654 & \text { hypothetical protein } \\ \text { RCA23_c06230 } & 667857 & 666067 & \text { DNA polymerase III subunit tau } \\ \text { RCA23_c06240 } & 668143 & 669114 & \text { NADH pyrophosphatase Nudc } \\ \text { RCA23_c06250 } & 669178 & 669648 & \text { hypothetical protein } \\ \text { RCA23_c06260 } & 670475 & 669645 & \text { prephenate dehydratase PheA } \\ \text { RCA23_c06270 } & 670580 & 671113 & \text { cytochrome c-552 } \\ \text { RCA23_c06280 } & 671321 & 673186 & \text { ABC transporter extracellular solute-binding protein } \\ \text { RCA23_c06290 } & 673188 & 674267 & \text { ABC transporter permease protein } \\ \text { RCA23_c06300 } & 674264 & 675379 & \text { ABC transporter permease protein } \\ \text { RCA23_c06310 } & 675376 & 676956 & \text { putative oligopeptide ABC transporter ATP-binding protein } \\ \text { RCA23_c06320 } & 677633 & 676953 & \text { fumarylacetoacetate hydrolase family protein } \\ \text { RCA23_c06330 } & 679120 & 677702 & \text { D-alanyl-D-alanine carboxypeptidase DacF } \\ \text { RCA23_c06340 } & 680015 & 679311 & \text { haloacid dehalogenase domain protein hydrolase } \\ \text { RCA23_c06350 } & 680085 & 680423 & \text { ATP-dependent Clp protease adapter protein ClpS } \\ & & & \end{array}$

$\begin{array}{ll}\text { COG0469 } & \text { G } \\ \text { COG0291 } & \text { J } \\ \text { COG0292 } & \text { J } \\ \text { COG1404 } & \text { O } \\ & \\ \text { COG1560 } & \mathrm{M} \\ \text { COG0016 } & \mathrm{J} \\ \text { COG0518 } & \mathrm{F} \\ \text { COG0072 } & \mathrm{J} \\ \text { COG1522 } & \mathrm{K} \\ \text { COG0828 } & \mathrm{J} \\ \text { COG5590 } & \mathrm{S} \\ \text { COG0604 } & \mathrm{C} \\ \text { COG3820 } & \mathrm{S} \\ \text { COG0353 } & \mathrm{L} \\ \text { COG0718 } & \mathrm{S} \\ \text { COG2812 } & \mathrm{L} \\ \text { COG2816 } & \mathrm{L} \\ \text { COG3832 } & \mathrm{S} \\ \text { COG0077 } & \mathrm{E} \\ \text { COG3474 } & \mathrm{C} \\ \text { COG4166 } & \mathrm{E} \\ \text { COG4174 } & \mathrm{R} \\ \text { COG4239 } & \mathrm{R} \\ \text { COG4172 } & \mathrm{R} \\ \text { COG0179 } & \mathrm{Q} \\ \text { COG1686 } & \mathrm{M} \\ \text { COG1011 } & \mathrm{R} \\ \text { COG2127 } & \mathrm{S}\end{array}$

$\begin{array}{ccc}393 & 434 & -41 \\ 624 & 591 & 33 \\ 871 & 606 & 265 \\ 873 & 409 & 464 \\ 455 & 421 & 34 \\ 809 & 570 & 239 \\ 291 & 395 & -104 \\ 304 & 451 & -147 \\ 224 & 306 & -82 \\ 331 & 354 & -23 \\ 798 & 641 & 157 \\ 1.005 & 915 & 90 \\ 271 & 315 & -44 \\ 276 & 335 & -59 \\ 569 & 525 & 44 \\ 391 & 437 & -46 \\ 517 & 458 & 59 \\ 205 & 268 & -63 \\ 277 & 428 & -151 \\ 389 & 485 & -96 \\ 256 & 261 & -5 \\ 552 & 407 & 145 \\ 474 & 456 & 18 \\ 595 & 473 & 122 \\ 319 & 447 & -128 \\ 373 & 488 & -115 \\ 215 & 253 & -38 \\ 158 & 204 & -46 \\ 406 & 341 & 65 \\ 541 & 439 & 102 \\ & & \\ 315\end{array}$




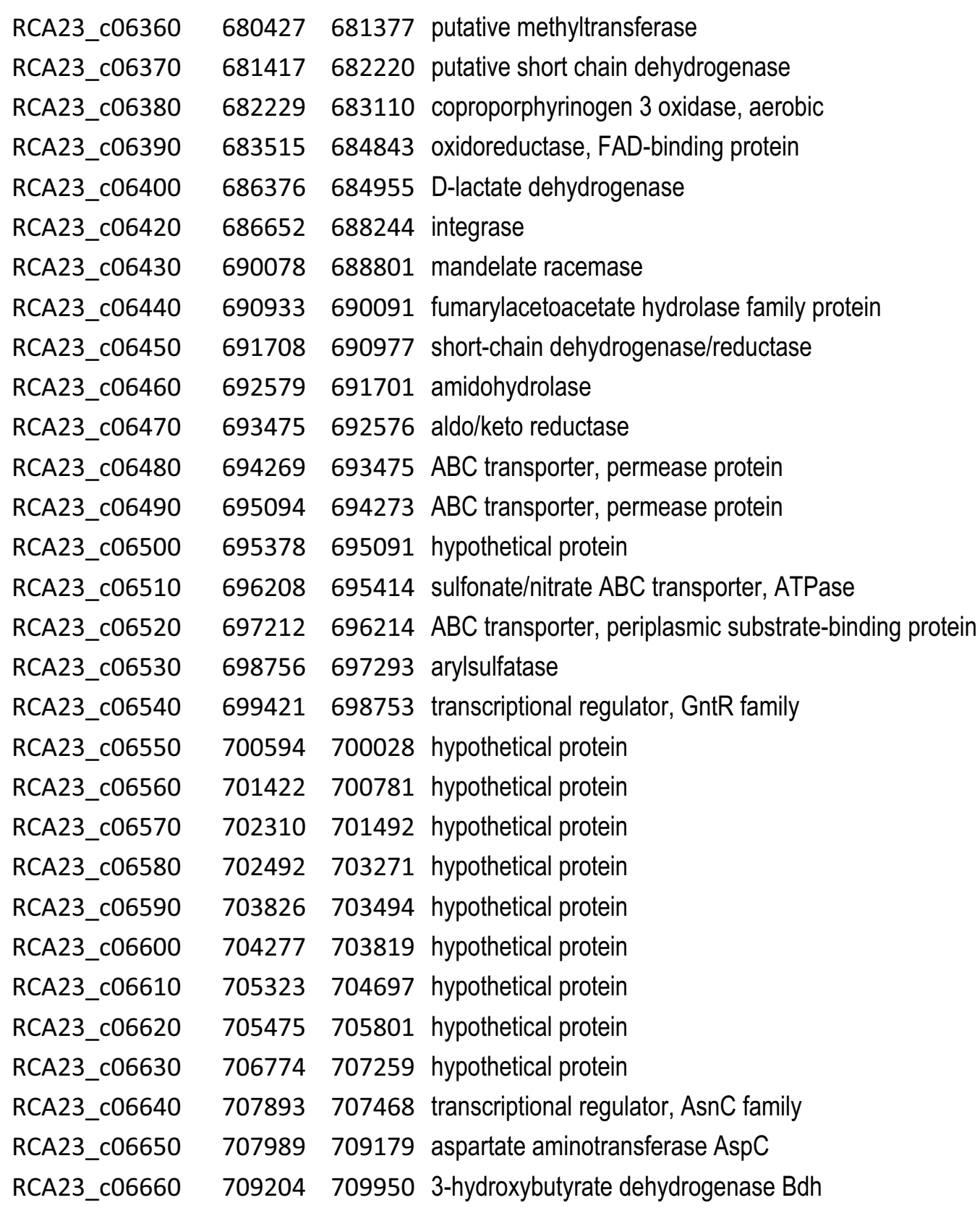

\begin{tabular}{|c|c|c|c|c|c|}
\hline COG2813 & J & & 262 & 313 & -51 \\
\hline COG1028 & 1 & & 340 & 389 & -49 \\
\hline COG0408 & $\mathrm{H}$ & & 253 & 334 & -81 \\
\hline COG4097 & $P$ & & 282 & 382 & -100 \\
\hline \multirow[t]{2}{*}{ COG0277 } & C & & 399 & 414 & -15 \\
\hline & & GI 3 & 177 & 118 & 59 \\
\hline COG4948 & M & GI 3 & 36 & 16 & 20 \\
\hline COG0179 & Q & GI 3 & 11 & 14 & -3 \\
\hline COG1028 & 1 & GI 3 & 29 & 17 & 12 \\
\hline COG3618 & $\mathrm{R}$ & GI 3 & 20 & 19 & 1 \\
\hline COG0667 & C & GI 3 & 5 & 12 & -7 \\
\hline COG0600 & $P$ & GI 3 & 26 & 17 & 9 \\
\hline \multirow[t]{2}{*}{ COG0600 } & $P$ & GI 3 & 32 & 16 & 16 \\
\hline & & GI 3 & 18 & 11 & 7 \\
\hline CoG1116 & $P$ & GI 3 & 12 & 10 & 2 \\
\hline COG0715 & $P$ & GI 3 & 37 & 10 & 27 \\
\hline COG3119 & $P$ & GI 3 & 18 & 10 & 8 \\
\hline COG1802 & $\mathrm{K}$ & $\mathrm{Gl} 3$ & 18 & 11 & 7 \\
\hline COG4974 & $\mathrm{L}$ & GI 3 & 18 & 32 & -14 \\
\hline \multirow[t]{7}{*}{ COG1618 } & $\mathrm{F}$ & GI 3 & 59 & 54 & 5 \\
\hline & & GI 3 & 393 & 273 & 120 \\
\hline & & GI 3 & 142 & 92 & 50 \\
\hline & & GI 3 & 885 & 731 & 154 \\
\hline & & GI 3 & 675 & 432 & 243 \\
\hline & & GI 3 & 515 & 372 & 143 \\
\hline & & GI 3 & 472 & 348 & 124 \\
\hline COG3000 & 1 & GI 3 & 9 & 7 & 2 \\
\hline COG1522 & $\mathrm{K}$ & GI 3 & 31 & 39 & -8 \\
\hline COG0436 & $E$ & GI 3 & 8 & 32 & -24 \\
\hline COG1028 & 1 & GI 3 & 5 & 26 & -21 \\
\hline
\end{tabular}


RCA23 066670

RCA23_c06680

RCA23_c06690

RCA23_c06700

RCA23_c06710

RCA23_c06720

RCA23_C06730

RCA23_c06740

RCA23_c06750

RCA23_c06760

RCA23_c06770

RCA23_c06780

RCA23_c06790

RCA23_c06800

RCA23_c06810

RCA23_c06820

RCA23_c06830

RCA23_c06840

RCA23_c06850

RCA23_c06860

RCA23_c06870

RCA23_c06880

RCA23_c06890

RCA23_c06900

RCA23_c06910

RCA23_c06920

RCA23_c06930

RCA23_c06940

RCA23_C06950

RCA23_c06960
709963710817 putative fumarylacetoacetate hydrolase

710820711548 oxidoreductase, short chain dehydrogenase/reductase fami COG1028

711582712247 dimethylmenaquinone methyltransferase

712286713434 hypothetical protein

713447714952 NADP-dependent fatty aldehyde dehydrogenase AldH

714981715886 putative dihydrodipicolinate synthase

716879716205 transcriptional regulator protein, Lacl family

717413718414 TRAP dicarboxylate transporter, subunit DctP

718496719083 TRAP dicarboxylate transporter, subunit DctQ

719077720369 TRAP dicarboxylate transporter, subunit DctM

720515721783 D-amino acid dehydrogenase small subunit DadA

721815722963 mandelate racemase/muconate lactonizing protein

722960723874 dihydrodipicolinate synthase DapA

723995725005 uncharacterized oxidoreductase, YjmC

725230726555 sarcosine oxidase beta subunit SoxB

726567726854 sarcosine oxidase delta subunit SoxD

726851729808 sarcosine oxidase alpha subunit SoxA

729801730364 sarcosine oxidase gamma subunit SoxG

730372731262 hypothetical protein, DUF6 transmembrane protein

732526734097 putative phage integrase

734370735797 putative amidase

736558735992 integrase

737386736745 putative helicase

737522738220 transposase

739014738397 HTH-type transcriptional regulator, LuxR family

739172739651 putative oxidoreductase, molybdopterin binding

739769742216 signal transduction histidine kinase

742420743505 glucose-1-phosphate thymidylyltransferase RfbA

743565745631 hypothetical protein, chain length determinant protein

745621747042 polysaccharide export protein

\begin{tabular}{|c|c|c|}
\hline COG1028 & & \\
\hline COG0684 & $\mathrm{H}$ & GI 3 \\
\hline COG3970 & $\mathrm{R}$ & GI 3 \\
\hline COG1012 & C & GI 3 \\
\hline COG0329 & E & GI 3 \\
\hline COG1609 & K & GI 3 \\
\hline COG1638 & G & GI 3 \\
\hline COG3090 & G & $\mathrm{Gl} 3$ \\
\hline COG1593 & G & GI 3 \\
\hline COG0665 & $E$ & GI 3 \\
\hline COG4948 & $\mathrm{M}$ & GI 3 \\
\hline COG0329 & $\mathrm{E}$ & GI 3 \\
\hline COG2055 & $\mathrm{C}$ & GI 3 \\
\hline COG0665 & $\mathrm{E}$ & GI 3 \\
\hline COG4311 & $\mathrm{E}$ & GI 3 \\
\hline COG0404 & $\mathrm{E}$ & GI 3 \\
\hline COG4583 & $\mathrm{E}$ & GI 3 \\
\hline COG0697 & G & GI 3 \\
\hline & & \\
\hline COG0154 & J & GI 3 \\
\hline COG4974 & L & GI 3 \\
\hline & & $\mathrm{Gl} 3$ \\
\hline COG3316 & L & GI 3 \\
\hline COG2197 & $\mathrm{T}$ & GI 3 \\
\hline COG3915 & $S$ & GI 3 \\
\hline COG0642 & $\mathrm{T}$ & GI 3 \\
\hline COG1209 & $M$ & $\mathrm{Gl} 3$ \\
\hline COG0489 & $\mathrm{D}$ & GI 3 \\
\hline COG1596 & $M$ & GI 3 \\
\hline
\end{tabular}

9

43

$-34$

$-34$

$-21$

3

1

1

$-20$

0

$-4$

$-2$

$-11$

$-24$

$-11$

$-12$

$-17$

$-11$

$-16$

2

$-19$

0

23

14

16

$-110$

$-2$

12

17

13

$-4$

1 
RCA23_c06970

RCA23_c06980

RCA23_c06990

RCA23_c07000

RCA23_c07010

RCA23_c07020

RCA23_c07030

RCA23_c07040

RCA23_c07050

RCA23_c07060

RCA23_c07070

RCA23_c07080

RCA23_c07090

RCA23_C07100

RCA23_C07110

RCA23_c07120

RCA23_c07130

RCA23_c07140

RCA23_C07150

RCA23_C07160

RCA23_c07170

RCA23_C07180

RCA23_c07190

RCA23_c07200

RCA23_c07210

RCA23_c07220

RCA23_c07230

RCA23_c07240

RCA23_C07250

RCA23_c07260
747621748013 hypothetical protein, VanZ-like

749389748190 type I secretion system membrane fusion protein, HlyD fam COG1566

751598749475 type I secretion system ATP-binding component, HlyB famil COG2274

752950751595 type I secretion outer membrane protein, TolC family COG1538

754718752955 putative serralysin-like metalloprotease

755773754919 dTDP-4-dehydrorhamnose reductase RfbD

756831755770 dTDP-glucose 4,6-dehydratase RfbB

757401756838 dTDP-4-dehydrorhamnose 3,5-epimerase RfbC

758505757435 hypothetical protein

759584758505 glycosyltransferase

761170759905 putative glycosyltransferase

COG2931

COG1091

COG1088

COG1898

COG0438

COG0438

762479761430 hypothetical protein, UDP-glycosyltransferase/glycogen phc COG0438

764009762492 polysaccharide biosynthesis protein

765109764015 UDP-4-amino-4-deoxy-L-arabinose--oxoglutarate aminotrar COG0399

765867765106 hypothetical, WxcM-like

766099765860 hypothetical protein, WxcM-like

766651766103 hypothetical protein, acyltransferase-like COG1670

767913766648 UDP-glucose/GDP-mannose dehydrogenase family protein COG0677

768637767906 S-adenosyl-L-methionine-dependent methyltransferase

769668768634 UDP-glucoronate 5'-epimerase LspL

770090769713 transcriptional regulator, MarR family

770490771002 transcription antitermination protein NusG

COG0451

COG1846

COG0250

COG1434

771959771234 hypothetical protein

COG0438

773130771961 lipopolysaccharide core

773759773974 hypothetical protein

774136775224 undecaprenyl-phosphate alpha-N-acetylglucosaminyl 1-pho COG0472

775393775839 hypothetical protein, transmembrane

775844776335 hypothetical protein, transmembrane

777374776907 transposase, IS4 family protein

777803777396 putative transposase
COG0472

COG3039

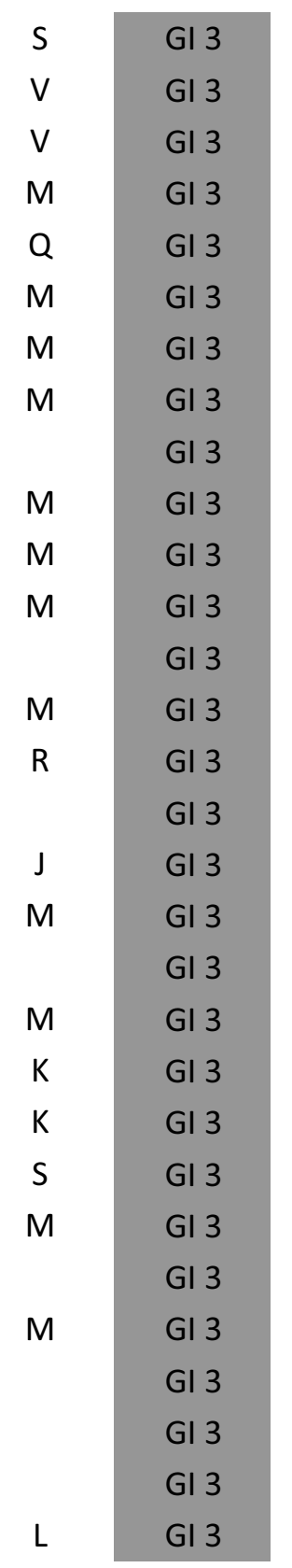

100

76

96

63

104

20

19

22

148

33

38

10

33

24

13

46

42

73

28

105

42

53

9

10

21

54

8

5

31

20
24

1

5

4

$-18$

$-13$

$-23$

$-18$

$-75$

$-10$

13

$-18$

$-23$

$-27$

$-22$

$-31$

$-4$

$-99$

$-20$

$-62$

$-21$

$-9$

$-19$

$-24$

$-26$

$-14$

$-2$

$-7$

$-34$

$-23$ 
RCA23 c07270

RCA23_c07280

RCA23_c07290

RCA23_c07300

RCA23_c07310

RCA23_c07320

RCA23_c07330

RCA23_c07340

RCA23 c07350

RCA23_c07360

RCA23_c07370

RCA23_c07380

RCA23_c07390

RCA23_c07400

RCA23_c07410

RCA23_c07420

RCA23_c07430

RCA23_c07440

RCA23_c07450

RCA23_c07460

RCA23 c07470

RCA23_c07480

RCA23_c07490

RCA23_c07500

RCA23_c07510

RCA23_c07520

RCA23_c07530

RCA23_c07540

RCA23_c07550

RCA23_c07560
778001778423 hypothetical protein, transmembrane

778428778958 hypothetical protein, transmembrane

779627780334 transposase

780406780888 glycogen synthase GlgA

780903782972 glycogen debranching enzyme GlgX

783008784639 phosphoglucomutase Pgm

786248784641 putative alpha-glucosidase AgIA

786430787128 transposase

787553788764 uncharacterized hydrolase YtnL

789242790729 glutathione-binding protein GsiB

790792791688 glutathione transport system permease protein GsiC

791735792535 dipeptide transport system permease protein

792532794106 glutathione import ATP-binding protein GsiA

794103795125 peptidase family S58

795122796576 aldehyde dehydrogenase AldA

796585797325 3-oxoacyl-[acyl-carrier-protein] reductase FabG

797368798825 amidase

800908799691 MFS-type transporter

801403802311 peptidase M20D amidohydrolase

802343802858 transposase

802913803992 integrase

804013804228 transposase

804774804520 hypothetical protein, DUF3764

805349804861 hypothetical protein

805760806716 hypothetical protein, beta-lactam-insensitive peptidoglycan · COG1376

807253807663 hypothetical protein

809049807802 ABC transporter, ATP-binding protein, SbmA/BacA-like fam COG1133

809116809526 hypothetical protein

809659809790 hypothetical protein

810944809865 integrase

\begin{tabular}{|c|c|}
\hline COG3316 & $\mathrm{L}$ \\
\hline COG0297 & G \\
\hline COG1523 & G \\
\hline COG0033 & G \\
\hline COG0366 & G \\
\hline COG3316 & $\mathrm{L}$ \\
\hline COG1473 & $\mathrm{R}$ \\
\hline COG0747 & $E$ \\
\hline COG0601 & $E$ \\
\hline COG1173 & $E$ \\
\hline COG4172 & $\mathrm{R}$ \\
\hline CoG3191 & $E$ \\
\hline COG1012 & C \\
\hline COG1028 & I \\
\hline COG0154 & $\mathrm{J}$ \\
\hline COG2807 & $P$ \\
\hline COG1473 & $\mathrm{R}$ \\
\hline COG3316 & $\mathrm{L}$ \\
\hline \multirow[t]{4}{*}{ COG2801 } & $\mathrm{L}$ \\
\hline & \\
\hline & \\
\hline & \\
\hline \multirow[t]{2}{*}{ COG1376 } & $S$ \\
\hline & \\
\hline \multirow[t]{3}{*}{ COG1133 } & I \\
\hline & \\
\hline & \\
\hline COG2801 & $\mathrm{L}$ \\
\hline
\end{tabular}




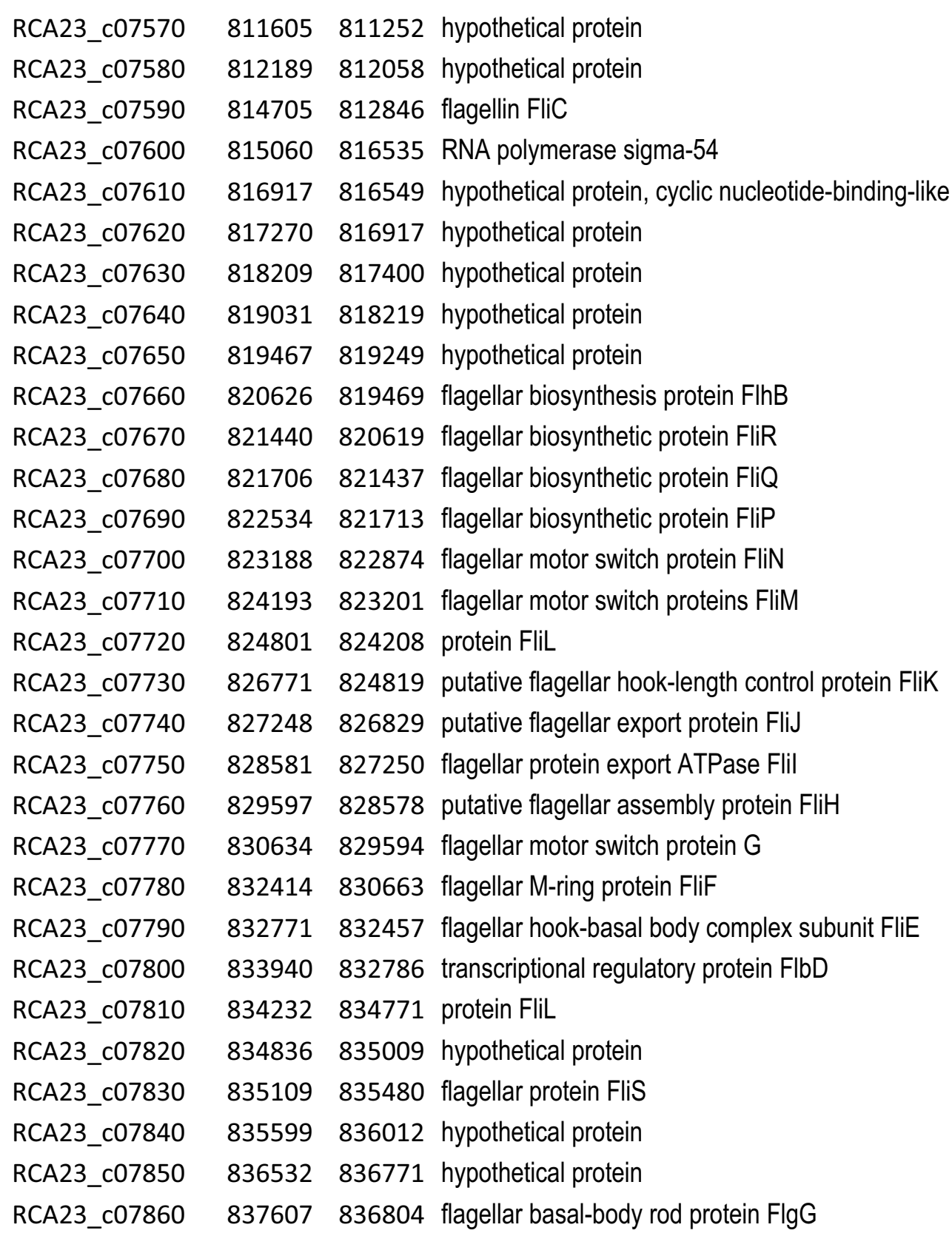

$\begin{array}{lccccc} & & \text { Gl } 3 & 8 & 5 & 3 \\ \text { COG1344 } & \text { N } & \text { Gl 3 } & 26 & 6 & 20 \\ \text { COG1508 } & \mathrm{K} & \mathrm{Gl} & 26 & 16 & 10 \\ & & \mathrm{Gl} 3 & 135 & 86 & 49 \\ \text { COG0664 } & \mathrm{T} & \mathrm{Gl} 3 & 141 & 82 & 59 \\ & & \mathrm{Gl} 3 & 213 & 115 & 98 \\ & & \mathrm{Gl} 3 & 368 & 158 & 210 \\ & & \mathrm{Gl} 3 & 386 & 127 & 259 \\ \text { COG1377 } & \mathrm{N} & \mathrm{Gl} 3 & 257 & 130 & 127 \\ \text { COG1684 } & \mathrm{N} & \mathrm{Gl} 3 & 329 & 132 & 197 \\ \text { COG1987 } & \mathrm{N} & \mathrm{Gl} 3 & 317 & 104 & 213 \\ \text { COG1338 } & \mathrm{N} & \mathrm{Gl} 3 & 239 & 115 & 124 \\ \text { COG1886 } & \mathrm{N} & \mathrm{Gl} 3 & 289 & 124 & 165 \\ \text { COG1868 } & \mathrm{N} & \mathrm{Gl} 3 & 246 & 108 & 138 \\ \text { COG1580 } & \mathrm{N} & \mathrm{Gl} 3 & 391 & 159 & 232 \\ \text { COG3144 } & \mathrm{N} & \mathrm{Gl} 3 & 140 & 72 & 68 \\ & & \mathrm{Gl} 3 & 144 & 84 & 60 \\ \text { COG1157 } & \mathrm{N} & \mathrm{Gl} 3 & 114 & 77 & 37 \\ & & \mathrm{Gl} 3 & 127 & 93 & 34 \\ \text { COG1536 } & \mathrm{N} & \mathrm{Gl} 3 & 199 & 111 & 88 \\ \text { COG1766 } & \mathrm{N} & \mathrm{Gl} 3 & 232 & 111 & 121 \\ \text { COG1677 } & \mathrm{N} & \mathrm{Gl} 3 & 213 & 77 & 136 \\ \text { COG2204 } & \mathrm{T} & \mathrm{Gl} 3 & 241 & 104 & 137 \\ \text { COG1580 } & \mathrm{N} & \mathrm{Gl} 3 & 61 & 56 & 5 \\ & & \mathrm{Gl} 3 & 115 & 56 & 59 \\ \text { COG1516 } & \mathrm{N} & \mathrm{Gl} 3 & 167 & 93 & 74 \\ & & \mathrm{Gl} 3 & 232 & 133 & 99 \\ \text { COG4786 } & \mathrm{N} & \mathrm{Gl} 3 & 93 & 80 & 13 \\ & & \mathrm{Gl} 3 & 112 & 62 & 50\end{array}$


RCA23_c07870

RCA23_c07880

RCA23_c07890

RCA23_c07900

RCA23_c07910

RCA23_C07920

RCA23_c07930

RCA23_c07940

RCA23_c07950

RCA23_c07960

RCA23_c07970

RCA23_c07980

RCA23_c07990

RCA23_c08000

RCA23_c08010

RCA23_c08020

RCA23_c08030

RCA23_c08040

RCA23_c08050

RCA23_c08060

RCA23_c08070

RCA23_c08080

RCA23_c08090

RCA23_c08100

RCA23_c08110

RCA23_c08120

RCA23_c08130

RCA23_c08140

RCA23_c08150

RCA23_c08160
$837665839437 \mathrm{Cl}$ - channel, voltage-gated family protein

840278839442 hypothetical protein, lysozym-like

841546840275 flagellar hook-associated protein FlgL

845822841581 flagellar hook-associated protein FlgK

846175845825 flagellar rod assembly protein/muramidase FlgJ

847324846188 flagellar P-ring protein Flgl

847901847338 flagellar L-ring protein FlgH

848820848032 flagellar basal-body rod protein FlgG

849559848882 putative flagellar basal body rod protein FlgF

853429849668 flagellar hook protein FlgE

854213853497 flagellar basal body rod modification protein FlgD

854630854214 flagellar basal-body rod protein FlgC

855018854632 flagellar basal-body rod protein FlgB

855113855655 hypothetical protein

855658856014 hypothetical protein

856748856023 RNA polymerase, sigma factor for flagellar operon FliA

857551856745 putative flagellar biosynthesis protein FlhG

858864857548 flagellar biosynthesis protein FlhF

861023858861 flagellar biosynthesis protein FlhA

861272861865 hypothetical membrane lipoprotein, DUF400

861871863016 hypothetical protein

863013863753 flagellar basal body P-ring biosynthesis protein FlgA

863767864087 putative negative regulator of flagellin synthesis FlgM

864117864407 hypothetical protein

865057864425 hypothetical protein, HCP-like

865443865054 hypothetical protein

865619866770 sigma54 specific transcriptional regulator, Fis family

868379866742 flagellar hook-associated protein FliD

869677868454 chemotaxis protein MotB

870477869716 chemotaxis protein MotA

$\begin{array}{lccccc}\text { COG0038 } & \mathrm{P} & \mathrm{Gl} 3 & 104 & 68 & 36 \\ \text { COG0741 } & \mathrm{M} & \mathrm{Gl} 3 & 195 & 92 & 103 \\ \text { COG1344 } & \mathrm{N} & \mathrm{Gl} 3 & 211 & 119 & 92 \\ \text { COG1256 } & \mathrm{N} & \mathrm{Gl} 3 & 153 & 98 & 55 \\ \text { COG3951 } & \mathrm{M} & \mathrm{Gl} 3 & 135 & 104 & 31 \\ \text { COG1706 } & \mathrm{N} & \mathrm{Gl} 3 & 94 & 71 & 23 \\ \text { COG2063 } & \mathrm{N} & \mathrm{Gl} 3 & 244 & 102 & 142 \\ \text { COG4786 } & \mathrm{N} & \mathrm{Gl} 3 & 249 & 113 & 136 \\ \text { COG4786 } & \mathrm{N} & \mathrm{Gl} 3 & 295 & 125 & 170 \\ \text { COG1749 } & \mathrm{N} & \mathrm{Gl} 3 & 209 & 100 & 109 \\ \text { COG1843 } & \mathrm{N} & \mathrm{Gl} 3 & 181 & 100 & 81 \\ \text { COG1558 } & \mathrm{N} & \mathrm{Gl} 3 & 213 & 123 & 90 \\ \text { COG1815 } & \mathrm{N} & \mathrm{Gl} 3 & 313 & 132 & 181 \\ & & \mathrm{Gl} 3 & 220 & 107 & 113 \\ & & \mathrm{Gl} 3 & 197 & 80 & 117 \\ \text { COG1191 } & \mathrm{K} & \mathrm{Gl} 3 & 268 & 92 & 176 \\ \text { COG0455 } & \mathrm{D} & \mathrm{Gl} 3 & 198 & 108 & 90 \\ \text { COG1419 } & \mathrm{N} & \mathrm{Gl} 3 & 195 & 100 & 95 \\ \text { COG1298 } & \mathrm{N} & \mathrm{Gl} 3 & 263 & 115 & 148 \\ & & \mathrm{Gl} 3 & 172 & 125 & 47 \\ & & \mathrm{Gl} 3 & 101 & 55 & 46 \\ \text { COG1261 } & \mathrm{N} & \mathrm{Gl} 3 & 126 & 70 & 56 \\ & & \mathrm{Gl} 3 & 206 & 93 & 113 \\ \text { COG0790 } & \mathrm{R} & \mathrm{Gl} 3 & 258 & 96 & 162 \\ & & \mathrm{Gl} 3 & 235 & 100 & 135 \\ \text { COG2204 } & \mathrm{T} & \mathrm{Gl} 3 & 143 & 71 & 72 \\ \text { COG1291 } & \mathrm{N} & 203 & 110 & 93 \\ & \mathrm{~N} & \mathrm{Gl} 3 & 223 & 93 & 130 \\ \mathrm{~N} & \mathrm{Gl} 3 & 231 & 134 & 97 \\ & & & & 109 & 190\end{array}$


RCA23 08170

RCA23_c08180

RCA23_c08190

RCA23_c08200

RCA23 08210

RCA23_C08220

RCA23_c08230

RCA23_c08240

RCA23_c08250

RCA23_c08260

RCA23_c08270

RCA23_c08280

RCA23_c08290

RCA23_c08300

RCA23_c08310

RCA23_c08320

RCA23_c08330

RCA23_c08340

RCA23_c08350

RCA23_c08360

RCA23_c08370

RCA23 c08380

RCA23_c08390

RCA23_c08400

RCA23_c08410

RCA23_c08420

RCA23_c08430

RCA23_c08440

RCA23_c08450

RCA23_c08460
870634871101 hypothetical protein, DUF1566

872040871126 putative transmembrane protein, DUF6

874242872701 putative polyketide hydroxylase SchC

875672874248 aldehyde dehydrogenase

876685875669 2-amino-3-carboxymuconate-6-semialdehyde decarboxylas COG2159

877470876682 transcriptional regulator, ICIR family

879401877467 TRAP transporter, 4TM/12TM fusion protein

880430879408 TRAP transporter solute receptor, TAXI family

880496882190 thiamine pyrophosphate enzyme-like TPP-binding

883788882265 hypothetical protein

884588883800 short chain dehydrogenase

886066884591 putative aldehyde dehydrogenase yfmT

887201886068 branched-chain amino acid ABC transporter, ATP-binding $p$

887913887194 branched-chain amino acid ABC transporter, ATP-binding $p$

888863887931 putative transporter, permease protein

889732888860 putative transporter, permease protein

890937889783 putative transporter, periplasmic binding protein

892154891102 hypothetical protein, PrpF protein-like

892833892168 4-carboxy-4-hydroxy-2-oxoadipate aldolase/oxaloacetate dt

893753893019 putative N-acetylglucosaminyl-phosphatidylinositol de-N-acı

894248894994 hypothetical protein

895147895896 transcriptional regulator

895914897314 aminomethyltransferase GcvT

897391898368 TRAP dicarboxylate transporter, subunit DctP

898371898883 TRAP dicarboxylate transporter, subunit DctQ

898880900184 TRAP dicarboxylate transporter, subunit DctM

900268901209 metapyrocatechase XylE

901273902451 MFS-type transporter

902749903183 hypothetical protein, cytochrome c

903218903562 hypothetical protein, copper resistance protein C

$\begin{array}{llcccc} & & \text { GI } 3 & 266 & 154 & 112 \\ & & \text { GI } 3 & 397 & 243 & 154 \\ \text { COG0654 } & \text { H } & \text { GI } 3 & 97 & 68 & 29 \\ \text { COG1012 } & \text { C } & & 60 & 52 & 8 \\ \text { COG2159 } & \text { R } & & 118 & 61 & 57 \\ \text { COG1414 } & \text { K } & & 66 & 69 & -3 \\ \text { COG4666 } & \text { R } & 129 & 84 & 45 \\ \text { COG2358 } & \text { R } & 86 & 70 & 16 \\ \text { COG0028 } & \text { E } & 76 & 72 & 4 \\ \text { COG2268 } & \text { S } & 86 & 60 & 26 \\ \text { COG1028 } & \text { I } & & 72 & 42 & 30 \\ \text { COG1012 } & \text { C } & 119 & 66 & 53 \\ \text { COG0410 } & \text { E } & & 113 & 70 & 43 \\ \text { COG0411 } & \text { E } & 146 & 96 & 50 \\ \text { COG4177 } & \text { E } & 173 & 81 & 92 \\ \text { COG0559 } & \text { E } & 110 & 69 & 41 \\ \text { COG0683 } & \text { E } & 122 & 74 & 48 \\ \text { COG2828 } & \text { S } & 55 & 59 & -4 \\ \text { COG0684 } & \text { H } & 56 & 60 & -4 \\ \text { COG2120 } & \text { S } & 107 & 67 & 40 \\ & & 161 & 125 & 36 \\ \text { COG1802 } & \text { K } & 93 & 88 & 5 \\ \text { COG0404 } & \text { E } & 185 & 101 & 84 \\ \text { COG1638 } & \text { G } & 97 & 61 & 36 \\ \text { COG3090 } & \text { G } & 178 & 92 & 86 \\ \text { COG1593 } & \text { G } & 153 & 93 & 60 \\ \text { COG2514 } & \text { R } & 158 & 84 & 74 \\ & \text { G } & 111 & 95 & 16 \\ & & 155 & 79 & 64 \\ & & 96 & 59\end{array}$


RCA23_c08470

RCA23_c08480

RCA23_c08490

RCA23_c08500

RCA23_c08510

RCA23_c08520

RCA23_c08530

RCA23_c08540

RCA23_c08550

RCA23_c08560

RCA23_c08570

RCA23_c08580

RCA23_c08590

RCA23_c08600

RCA23_c08610

RCA23_c08620

RCA23_c08630

RCA23_c08640

RCA23_C08650

RCA23_c08660

RCA23_c08670

RCA23_c08680

RCA23_c08690

RCA23_c08700

RCA23_c08710

RCA23_c08720

RCA23_c08730

RCA23_c08740

RCA23_c08750

RCA23_c08760
903559904410 hypothetical protein, copper resistance protein D

904753905184 hypothetical protein

906165905899 hypothetical protein

906640906996 hypothetical protein

908415907033 fumarate reductase flavoprotein subunit

909253908387 methylisocitrate lyase PrpB

909870909250 putative isochorismatase family protein

911929909872 hydantoin utilization protein A

913620911926 hydantoin utilization protein B

914183913617 hypothetical protein

914328915128 HTH-type transcriptional regulator, GntR family

9151259165313 -isopropylmalate dehydratase large subunit LeuC

916558917142 3-isopropylmalate dehydratase small subunit LeuD

917203918216 TRAP dicarboxylate transporter, subunit DctP

918309918773 TRAP transporter, subunit DctQ

918773920080 TRAP dicarboxylate transporter, subunit DctM

920337921674 putative glutamate synthase [NADPH] small chain

921674922978 hypothetical protein, dihydrooronate dehydrogenase

923623923021 putative HTH-type transcriptional regulator

923793925058 N-carbamoyl-L-amino acid hydrolase AmaB

925095926549 D-hydantoinase/dihydropyrimidinase Dht

926592927374 ABC transporter ATP-binding protein

927402928322 putative $A B C$ transporter permease protein

928319929161 putative ABC transporter permease protein

929210930205 putative thiamine biosynthesis protein

931297930413 putative integral membrane proein DUF6

932791931913 hypothetical protein DUF6

933010934104 alkaline phosphatase synthesis sensor protein PhoR

934233935270 putative phosphate binding protein PstS

935370936857 putative phosphate transport system permease protein PstC COG0573

$\begin{array}{ll}\text { COG1276 } & \text { P } \\ \text { COG3613 } & \text { F } \\ & \\ \text { COG1053 } & \text { C } \\ \text { COG2513 } & \text { G } \\ \text { COG1335 } & \text { Q } \\ \text { COG0145 } & \text { E } \\ \text { COG0146 } & \text { E } \\ \text { COG1942 } & \text { R } \\ \text { COG2188 } & \text { K } \\ \text { COG0065 } & \text { E } \\ \text { COG0066 } & \text { E } \\ \text { COG1638 } & \text { G } \\ \text { COG3090 } & \text { G } \\ \text { COG1593 } & \text { G } \\ \text { COG0493 } & \text { E } \\ \text { COG0167 } & \text { F } \\ \text { COG1309 } & \text { K } \\ \text { COG0624 } & \text { E } \\ \text { COG0044 } & \text { F } \\ \text { COG1116 } & \text { P } \\ \text { COG0600 } & \text { P } \\ \text { COG0600 } & \text { P } \\ \text { COG0715 } & \text { P } \\ \text { COG0697 } & \text { G } \\ \text { COG0697 } & \text { G } \\ \text { COG5002 } & \text { T } \\ \text { COG0226 } & \text { P } \\ \text { COG0573 } & \text { P }\end{array}$

$\begin{array}{lcc}165 & 111 & 54 \\ 132 & 101 & 31 \\ 227 & 118 & 109 \\ 170 & 169 & 1 \\ 185 & 220 & -35 \\ 240 & 253 & -13 \\ 229 & 231 & -2 \\ 178 & 191 & -13 \\ 229 & 209 & 20 \\ 249 & 209 & 40 \\ 138 & 206 & -68 \\ 226 & 214 & 12 \\ 214 & 212 & 2 \\ 530 & 304 & 226 \\ 514 & 328 & 186 \\ 622 & 381 & 241 \\ 375 & 303 & 72 \\ 574 & 518 & 56 \\ 816 & 569 & 247 \\ 600 & 475 & 125 \\ 586 & 467 & 119 \\ 627 & 416 & 211 \\ 660 & 505 & 155 \\ 913 & 619 & 294 \\ 713 & 465 & 248 \\ 967 & 590 & 377 \\ 693 & 436 & 257 \\ 428 & 407 & 21 \\ 488 & 443 & 45 \\ 413 & 525 & -112 \\ & & \end{array}$




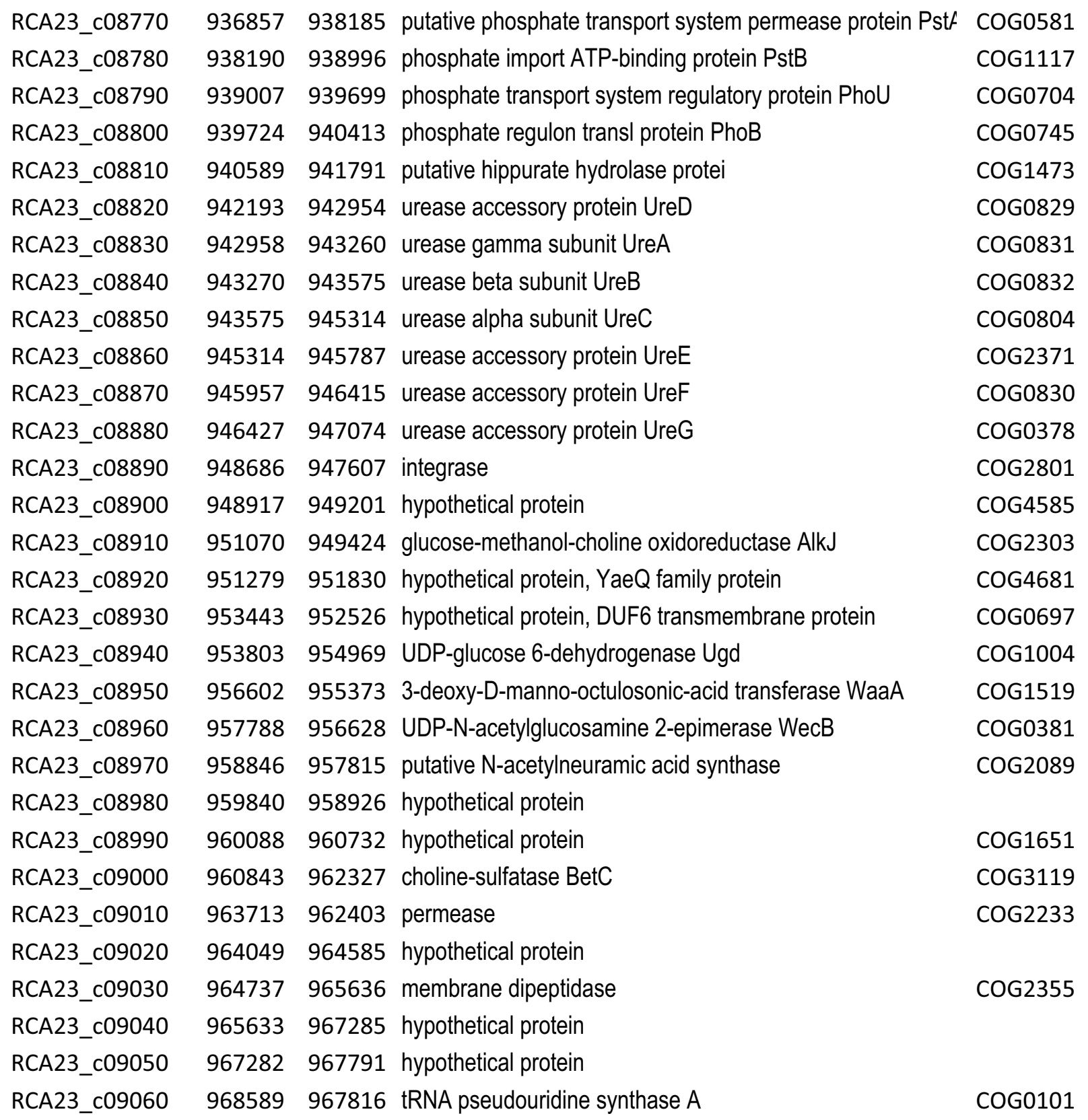

936857938185 putative phosphate transport system permease protein Pst/ COG0581

938190938996 phosphate import ATP-binding protein PstB

939007939699 phosphate transport system regulatory protein PhoU

939724940413 phosphate regulon transl protein PhoB

940589941791 putative hippurate hydrolase protei

942193942954 urease accessory protein UreD

942958943260 urease gamma subunit UreA

943270943575 urease beta subunit UreB

943575945314 urease alpha subunit UreC

945314945787 urease accessory protein UreE

945957946415 urease accessory protein UreF

946427947074 urease accessory protein UreG

948686947607 integrase

948917949201 hypothetical protein

951070949424 glucose-methanol-choline oxidoreductase AlkJ

951279951830 hypothetical protein, YaeQ family protein

953443952526 hypothetical protein, DUF6 transmembrane protein

953803954969 UDP-glucose 6-dehydrogenase Ugd

956602955373 3-deoxy-D-manno-octulosonic-acid transferase WaaA

957788956628 UDP-N-acetylglucosamine 2-epimerase WecB

958846957815 putative N-acetylneuramic acid synthase

959840958926 hypothetical protein

960088960732 hypothetical protein

960843962327 choline-sulfatase BetC

963713962403 permease

964049964585 hypothetical protein

964737965636 membrane dipeptidase

965633967285 hypothetical protein

967282967791 hypothetical protein

968589967816 tRNA pseudouridine synthase A

COG1117

COG0704

COG0745

COG1473

COG0829

COG0831

COG0832

COG0804

COG2371

COG0830

COG0378

COG2801

COG4585

COG2303

COG4681

COG0697

COG1004

COG1519

COG0381

COG2089

COG1651

COG3119

COG2233

COG2355

COG0101
E

$P$
$P$
$P$
$T$
$R$
$O$
$E$
$E$
$E$
$O$
$O$
$O$
$L$
$T$
$E$
$S$
$G$
$M$
$M$
$M$
$M$

P

$P$

T

O

E

E

0

0

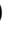

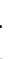

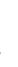

S

G

$M$

$M$

M

O

$P$

F

\begin{tabular}{|c|c|c|}
\hline 472 & 478 & -6 \\
\hline 497 & 610 & -113 \\
\hline 608 & 544 & 64 \\
\hline 1.061 & 623 & 438 \\
\hline 206 & 127 & 79 \\
\hline 648 & 456 & 192 \\
\hline 478 & 528 & -50 \\
\hline 217 & 341 & -124 \\
\hline 415 & 369 & 46 \\
\hline 361 & 376 & -15 \\
\hline 517 & 461 & 56 \\
\hline 698 & 524 & 174 \\
\hline 0 & 0 & 0 \\
\hline 780 & 501 & 279 \\
\hline 382 & 383 & -1 \\
\hline 731 & 502 & 229 \\
\hline 592 & 558 & 34 \\
\hline 456 & 389 & 67 \\
\hline 251 & 308 & -57 \\
\hline 421 & 408 & 13 \\
\hline 556 & 454 & 102 \\
\hline 595 & 416 & 179 \\
\hline 387 & 414 & -27 \\
\hline 445 & 476 & -31 \\
\hline 269 & 317 & -48 \\
\hline 249 & 294 & -45 \\
\hline 283 & 328 & -45 \\
\hline 232 & 375 & -143 \\
\hline 138 & 237 & -99 \\
\hline 255 & 224 & \\
\hline
\end{tabular}




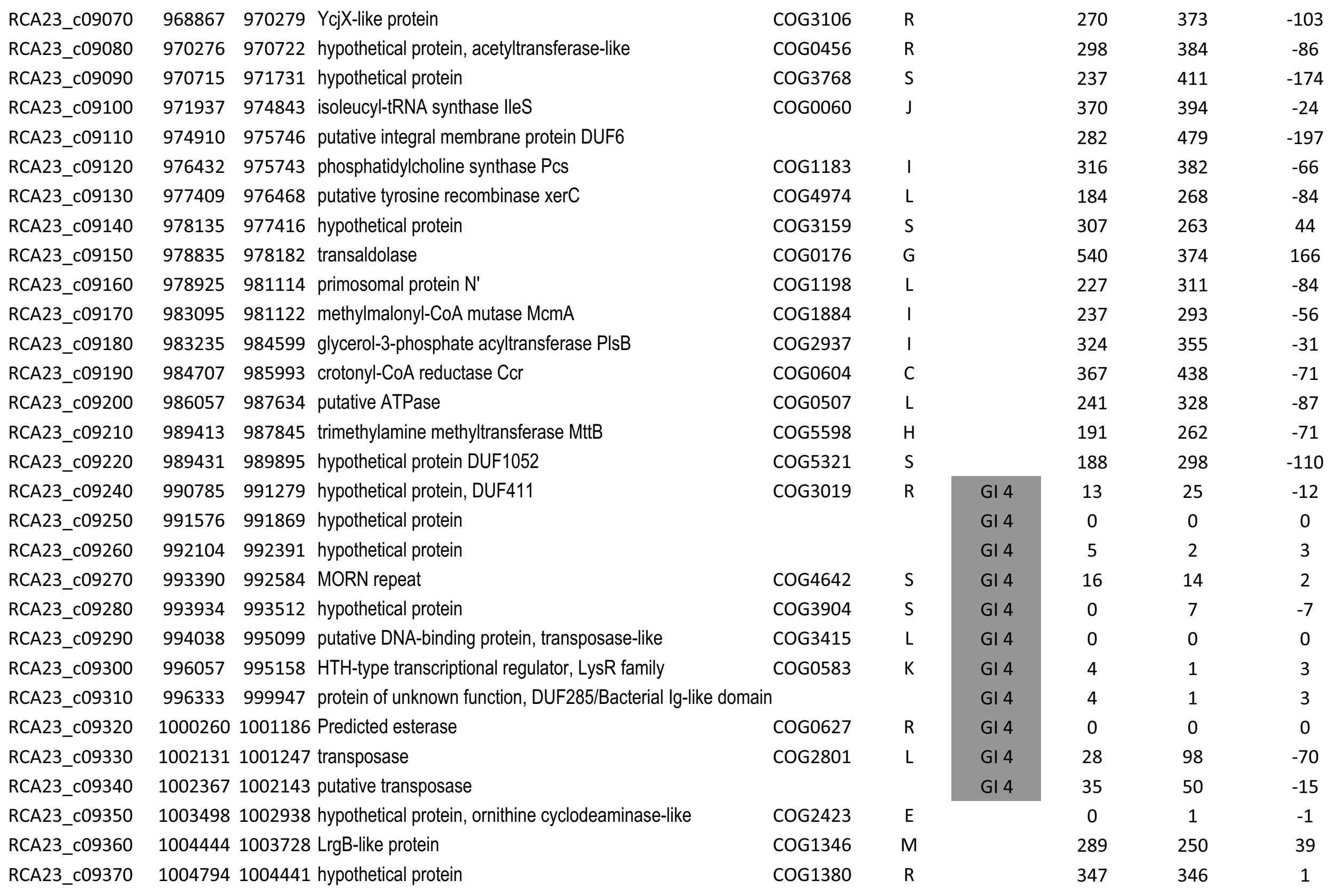


RCA23_c09380

RCA23_C09390

RCA23_C09400

RCA23_C09410

RCA23_C09420

RCA23_c09430

RCA23_C09440

RCA23_c09450

RCA23_C09460

RCA23_c09470

RCA23_C09480

RCA23_C09490

RCA23_C09500

RCA23_C09510

RCA23_C09520

RCA23_c09530

RCA23_C09540

RCA23_c09550

RCA23_c09560

RCA23_c09570

RCA23_c09580

RCA23_c09590

RCA23_c09600

RCA23_c09610

RCA23_c09620

RCA23_c09630

RCA23_c09640

RCA23_c09650

RCA23_c09670

RCA23_c09680
10058151004916 putative branched-chain-amino-acid aminotransferase llvE COG0115

10067611005865 2-hydroxy-3-oxopropionate reductase GarR

10081131006908 bicyclomycin resistance protein Bcr

10086601008187 hypothetical protein

10101981008657 hypothetical protein, photolyase

10103701011587 DNA photolyase, FAD-binding/cryptochrome

10119441012426 carbon monoxide dehydrogenase small chain CoxS

10124381014798 carbon monoxide dehydrogenase large chain CoxL

10148111015602 carbon monoxide dehydrogenase medium chain CoxM

10156451016556 MoxR-like ATPase

10165561017776 CoxE-like protein

10178821018688 5-deoxy-glucuronate isomerase lolB

10190391018707 branched-chain amino acid transport protein, AzID-like

10197431019036 branched-chain amino acid transport protein, AzlC-like

10214621019804 alpha-IPM synthase/homocitrate synthase

10226561021499 cytochrome P450

10228101023811 TRAP dicarboxylate transporter, subunit DctP

10239661024568 TRAP dicarboxylate transporter, subunit DctQ

10245731026420 TRAP dicarboxylate transporter, subunit DctM

10264861028369 putative citrate transporter

10290971028366 triosephosphate isomerase TpiA

10294541029137 putative regulator protein of competence-specific genes Tfo

10298161029451 hypothetical protein, iron-sulfur cluster assembly protein

10304451029936 hypothetical protein DUF59

10304691031599 queuine tRNA-ribosyltransferase Tgt

10320991031611 hypothetical protein

10323741034782 ATP-dependent protease La

10348231035461 putative phosphoglycerate mutase family protein

10357771036430 protein-L-isoaspartate O-methyltransferase Pcm

10364661037830 outer membrane efflux protein
COG2084

COG2814

E

I

G

COG3046

COG0415

COG 2080

COG1529

COG1319

COG0714

COG3552

COG3718

COG4392

COG1296

COG0119

COG2124

COG1638

COG3090

COG1593

COG0471

COG0149

COG3070

COG0316

COG2151

COG0343

COG0466

COG0406

COG 2518

COG1538 
RCA23_c09690

RCA23_C09700

RCA23_c09710

RCA23_c09720

RCA23_c09730

RCA23_c09740

RCA23_c09750

RCA23_c09760

RCA23_c09770

RCA23_c09780

RCA23_c09790

RCA23_c09800

RCA23_c09810

RCA23_c09820

RCA23_c09830

RCA23_c09840

RCA23_c09850

RCA23_c09860

RCA23_c09880

RCA23_c09890

RCA23_c09900

RCA23_c09910

RCA23_c09920

RCA23_c09930

RCA23_c09950

RCA23_c09940

RCA23_c09960

RCA23_c09970

RCA23_c09980

RCA23_c09990
10379051038228 hypothetical protein

10397191038262 cobyric acid synthase CobQ

10402281039917 hypothetical protein

10404451041008 translation elongation factor $P$

10417361041005 hypothetical protein tRNA modifying protein YgfZ

10417971042474 putative glycosyltransferase, family 2

10442991042530 lipid A export ATP-binding/permease protein MsbA

10444031045608 serine--glyoxylate aminotransferase SgaA

10467191045610 histidinol-phosphate aminotransferase HisC

10496821046755 valyl-tRNA synthase ValS

10503401049744 hypothetical protein, metal-dependent phosphohydrolase

10512091050337 putative phytanoyl-CoA dioxygenase family protein

10513511053636 molybdenum-containing hydroxylase

10536431054722 hypothetical protein DUF2235

10560461055225 5,10-methylenetetrahydrofolate reductase MetF

$10561431057048 \mathrm{HTH}$-type transcriptional regulator MetR

10571341057898 inositol-1-monophosphatase SuhB

10579861058552 hypothetical protein

10592771058798 transcriptional regulator, HXIR family

10594471059785 hypothetical protein, DUF3764

10598391060168 hypothetical protein

10602041060566 hypothetical protein, DsrE/F-like

10612591060684 glutathione peroxidase Gpo

10622491061521 putative ion channel

10632011062944 hypothetical protein

10632481064246 ribosomal large subunit pseudouridine synthase D

10643741065270 RNA polymerase sigma-32 factor RpoH

10653511066337 putative oxidoreductase

10683321066503 oligoendopeptidase F

10685201069284 2-keto-3-deoxy-L-rhamnonate aldolase RhmA

$\begin{array}{llccc} & & 190 & 242 & -52 \\ \text { COG1492 } & \mathrm{H} & 274 & 372 & -98 \\ & & 1.161 & 530 & 631 \\ \text { COG0231 } & \mathrm{J} & 447 & 318 & 129 \\ \text { COG0354 } & \mathrm{R} & 362 & 405 & -43 \\ \text { COG0463 } & \mathrm{M} & 225 & 395 & -170 \\ \text { COG1132 } & \mathrm{V} & 290 & 354 & -64 \\ \text { COG0075 } & \mathrm{E} & 201 & 278 & -77 \\ \text { COG0079 } & \mathrm{E} & 210 & 281 & -71 \\ \text { COG0525 } & \mathrm{J} & 332 & 382 & -50 \\ \text { COG4341 } & \mathrm{R} & 276 & 359 & -83 \\ \text { COG5285 } & \mathrm{Q} & 412 & 427 & -15 \\ \text { COG1529 } & \mathrm{C} & 264 & 374 & -110 \\ \text { COG3673 } & \mathrm{S} & 304 & 419 & -115 \\ \text { COG0685 } & \mathrm{E} & 229 & 270 & -41 \\ \text { COG0583 } & \mathrm{K} & 226 & 312 & -86 \\ \text { COG0483 } & \mathrm{G} & 292 & 283 & 9 \\ \text { COG3063 } & \mathrm{N} & 278 & 328 & -50 \\ \text { COG1733 } & \mathrm{K} & 534 & 437 & 97 \\ & & 523 & 370 & 153 \\ & & 293 & 227 & 66 \\ \text { COG1553 } & \mathrm{P} & 359 & 278 & 81 \\ \text { COG0386 } & \mathrm{O} & 225 & 261 & -36 \\ & & 421 & 440 & -19 \\ \text { COG0564 } & \mathrm{J} & 347 & 292 & 55 \\ \text { COG0568 } & \mathrm{K} & 255 & 339 & -84 \\ \text { COG0673 } & \mathrm{R} & 1.034 & 612 & 422 \\ \text { COG3836 } & \mathrm{G} & 384 & 351 & 33 \\ & & 273 & 331 & -58\end{array}$


RCA23_c10000

RCA23_c10010

RCA23_c10020

RCA23_c10030

RCA23_c10040

RCA23_c10050

RCA23_c10060

RCA23_c10070

RCA23_c10080

RCA23_c10090

RCA23_c10100

RCA23_c10110

RCA23_c10120

RCA23_c10140

RCA23_c10150

RCA23_c10160

RCA23_c10170

RCA23_c10180

RCA23_c10190

RCA23_c10210

RCA23_c10220

RCA23_c10230

RCA23_c10240

RCA23_c10250

RCA23_c10260

RCA23_c10270

RCA23_c10280

RCA23_c10290

RCA23_C10300

RCA23_c10310
10702161069269 hypothetical protein, lysophospholipase L2

10705061070216 putative sterol-binding protein

10705801071140 hypothetical protein

10711601073967 ATP-dependent RNA helicase RhIB

10740511074341 putative heat shock protein

10744101074748 ferredoxin FdxA

10749011075419 putative transcriptional regulator, CarD family

10762421075490 cobalamin-5-phosphate synthase CobS

10763261077339 nicotinate-nucleotide--dimethylbenzimidazole phosphoribos

10793871077345 hypothetical protein

10795921080008 glyoxalase/bleomycin resistance protein

10809981080018 hypothetical protein

10812351082887 choline dehydrogenase BetA

10834251084330 23S rRNA (guanosine-2'-O-)-methyltransferase RImB

10846471084342 phosphoribosyl-ATP pyrophosphatase HisE

10853781084644 imidazole glycerol phosphate synthase subunit HisF

10861501085434 1-(5-phosphoribosyl)-5-[(5-phosphoribosylamino)methylider 10868181086180 imidazole glycerol phosphate synthase, glutamine amidotra 10874101086823 imidazoleglycerol-phosphate dehydratase HisB

10887511087954 hypothetical protein, calcineurin-like phosphoesterase-like

10922181088778 pyruvate carboxylase Pyc

10935221092374 L-lactate dehydrogenase IIdD

10936551096048 putative DNA helicase II

10961331097425 gamma-glutamylputrescine oxidoreductase PuuB

10980461097444 putative cysteine/O-acetylserine efflux protein

10980561098466 hypothetical protein

10986221099686 putative protein Mrp

10997131099967 hypothetical protein

11003151100818 hypothetical protein, MraZ

11008211101810 S-adenosyl-L-methionine-dependent methyltransferase Mra
COG2267

COG3255

COG4581

COG1188

COG1146

COG1329

COG0368

COG2038

COG3565

COG2303

COG0566

COG0140

COG0107

COG0106

COG0118

COG0131

COG1409

COG1038

COG1304

COG0210

COG0665

COG1280

COG0489

COG2001

COG0275
278

284

335

1

289

291

350

$260 \quad 318$

$158 \quad 222$

$427 \quad 421$

$344 \quad 315$

$135 \quad 170$

$180 \quad 268$

$166 \quad 262$

$433 \quad 479$

$392 \quad 375$

$290 \quad 336$

$274 \quad 297$

$293 \quad 375$

$188 \quad 248$

$179 \quad 178$

$345 \quad 348$

$327 \quad 348$

$418 \quad 358$

$237 \quad 292$

$281 \quad 304$

$226 \quad 333$

$199 \quad 255$

$283 \quad 451$

$1.083 \quad 672$

$232 \quad 370$

$599 \quad 383$

$449 \quad 455$

$231 \quad 309$
$-11$

$-7$

$-15$

$-58$

$-64$

6

29

$-35$

$-88$

$-96$

$-46$

17

$-46$

$-23$

$-82$

$-60$

1

$-3$

$-21$

60

$-55$

$-23$

$-107$

$-56$

$-168$

411

$-138$

216

$-6$

$-78$ 


\begin{tabular}{|c|c|c|c|c|c|c|}
\hline RCA23_c10320 & 11018071102151 hypothetical protein & COG5462 & $\mathrm{S}$ & 369 & 361 & 8 \\
\hline RCA23_c10350 & 11054301106848 putative UDP-N-acetylmuramoyl-tripeptide--D-alanyl-D-alan & COG0770 & M & 223 & 280 & -57 \\
\hline RCA23_c10370 & 11080051109384 UDP-N-acetylmuramoylalanine--D-glutamate ligase MurD & COG0771 & M & 241 & 377 & -136 \\
\hline RCA23_c10380 & 11094711110160 putative glycosyltransferase, sugar binding region & COG3774 & M & 549 & 438 & 111 \\
\hline RCA23_c10390 & 11108341110157 putative galactoside 2-alpha-L-fucosyltransferase 1 & & & 675 & 419 & 256 \\
\hline RCA23_c10410 & 11111621111935 hypothetical protein & COG3306 & M & 476 & 358 & 118 \\
\hline RCA23_c10420 & 11131531111963 hypothetical protein HI0933 & COG2081 & $\mathrm{R}$ & 190 & 222 & -32 \\
\hline RCA23_c10430 & 11132291114434 cell division protein FtsW & COG0772 & $\mathrm{D}$ & 301 & 420 & -119 \\
\hline RCA23_c10440 & 11144241115530 UDP-N-acetylglucosamine--N-acetylmuramyl-(pentapeptide & COG0707 & M & 176 & 275 & -99 \\
\hline RCA23_c10450 & 11155301116921 UDP-N-acetylmuramate--L-alanine ligase MurC & COG0773 & M & 264 & 342 & -78 \\
\hline RCA23_c10460 & 11178031116925 permease of the drug/metabolite transporter superfamily & COG0697 & G & 226 & 272 & -46 \\
\hline RCA23_c10500 & 11207481122082 cell division protein FtsA & COG0849 & $\mathrm{D}$ & 275 & 404 & -129 \\
\hline RCA23_c10510 & 11222361123780 cell division protein FtsZ & COG0206 & $\mathrm{D}$ & 341 & 361 & -20 \\
\hline RCA23_c10520 & 11239921124912 UDP-3-O-[3-hydroxymyristoyl] N-acetylglucosamine deacet' & COG0774 & M & 325 & 407 & -82 \\
\hline RCA23_c10530 & 11250201125835 outer membrane assembly lipoprotein & COG4105 & $\mathrm{R}$ & 458 & 485 & -27 \\
\hline RCA23_c10540 & 11258521127504 DNA repair protein RecN & COG0497 & $\mathrm{L}$ & 240 & 362 & -122 \\
\hline RCA23_c10550 & 11278631127501 hypothetical protein DUF427 & $\operatorname{COG} 2343$ & $\mathrm{~S}$ & 394 & 461 & -67 \\
\hline RCA23_c10560 & 11296691127879 putative Xaa-Pro aminopeptidase & COG0006 & $E$ & 249 & 396 & -147 \\
\hline RCA23_c10570 & 11316301129756 aerobic cobaltochelatase subunit CobT & COG4547 & $\mathrm{H}$ & 258 & 346 & -88 \\
\hline RCA23_c10580 & 11326541131668 aerobic cobaltochelatase subunit CobS & COG0714 & $\mathrm{R}$ & 585 & 452 & 133 \\
\hline RCA23_c10590 & 11334711132833 hypothetical protein, DnaJ & COG0484 & $\mathrm{O}$ & 694 & 495 & 199 \\
\hline RCA23_c10600 & 11335141133801 putative stress-induced morphoprotein, BolA type & COG0271 & $\mathrm{T}$ & 335 & 420 & -85 \\
\hline
\end{tabular}


RCA23_c10620

RCA23_c10630

RCA23_c10640 11403961140824 hypothetical protein DUF336

RCA23_c10650 11409061141109 hypothetical protein

RCA23_c10660 11411191141883 gamma-glutamyl-gamma-aminobutyrate hydrolase PuuD

RCA23_c10670 11426351141880 putative D-beta-hydroxybutyrate dehydrogenase

RCA23_c10680 11427941144365 NAD(P) transhydrogenase alpha subunit PntA

RCA23_c10690 11443791145812 NAD(P) transhydrogenase beta subunit PntB

RCA23_c10700 11458801147163 hypothetical protein

RCA23_c10710 11472111148374 putative acetylornithine deacetylase ArgE

RCA23_c10720 11493751148371 molybdenum cofactor biosynthesis protein MoaA

RCA23_c10730 11495761151222 acetyl-coenzyme A synthase AcsA

RCA23_c10740 11513971151173 hypothetical protein

RCA23_c10750 11515731151397 hypothetical protein

RCA23_c10760 11529611151570 fumarate hydratase class II

RCA23_c10770 11535001153036 hypothetical protein

RCA23_c10780 11548401153572 putative chromate transport protein

RCA23_c10790 11551891157231 hydantoinase / oxoprolinase family protein

RCA23_c10800 11573311157729 hypothetical protein

RCA23_c10810 11582171159203 putative quinone oxidoreductase yhdH

RCA23_c10820 11593061160529 cysteine desulfurase SufS

RCA23_c10830 11605501161962 deoxyribodipyrimidine photo-lyase PhrB

RCA23_c10840 11620371163245 cyclopropane-fatty-acyl-phospholipid synthase Cfa

RCA23_c10850 11632531164371 ADP-ribose pyrophosphatase NudF

RCA23_c10860 11644171165454 cysteine synthase CysK

RCA23_c10870 11654411167759 mechanosensitive ion channel protein MscS

RCA23_c10890 11681021169268 putative phage integrase

RCA23_c10900 11731551169922 hypothetical protein

RCA23_c10910 11732201175214 hypothetical protein, tetratricopetide domain TPR-1

RCA23_c10920 11778611176257 hypothetical protein, resolvase-like

\begin{tabular}{|c|c|c|c|c|c|}
\hline COG0308 & $E$ & & 257 & 346 & -89 \\
\hline COG2225 & C & & 371 & 390 & -19 \\
\hline \multirow[t]{2}{*}{ COG3193 } & $\mathrm{R}$ & & 225 & 350 & -125 \\
\hline & & & 218 & 311 & -93 \\
\hline COG2071 & $\mathrm{R}$ & & 209 & 324 & -115 \\
\hline COG1028 & 1 & & 198 & 280 & -82 \\
\hline COG3288 & C & & 325 & 332 & -7 \\
\hline COG1282 & C & & 435 & 457 & -22 \\
\hline COG4949 & $S$ & & 357 & 421 & -64 \\
\hline COG0624 & $E$ & & 296 & 398 & -102 \\
\hline COG2896 & $\mathrm{H}$ & & 223 & 295 & -72 \\
\hline COG0365 & 1 & & 196 & 332 & -136 \\
\hline \multirow[t]{2}{*}{ COG4321 } & $\mathrm{R}$ & & 261 & 309 & -48 \\
\hline & & & 286 & 384 & -98 \\
\hline COG0114 & C & & 301 & 362 & -61 \\
\hline COG3814 & $\mathrm{S}$ & & 562 & 428 & 134 \\
\hline COG2059 & $P$ & & 332 & 384 & -52 \\
\hline \multirow[t]{2}{*}{ COG0145 } & $E$ & & 170 & 273 & -103 \\
\hline & & & 647 & 502 & 145 \\
\hline COG0604 & C & & 214 & 264 & -50 \\
\hline COG0520 & $\mathrm{E}$ & & 246 & 312 & -66 \\
\hline COG0415 & L & & 227 & 252 & -25 \\
\hline COG2230 & M & & 546 & 408 & 138 \\
\hline COG0494 & $\mathrm{L}$ & & 289 & 351 & -62 \\
\hline COG0031 & $\mathrm{E}$ & & 402 & 390 & 12 \\
\hline COG3264 & M & & 353 & 377 & -24 \\
\hline \multirow[t]{2}{*}{ COG4974 } & L & GI 5 & 13 & 11 & 2 \\
\hline & & GI 5 & 18 & 15 & 3 \\
\hline COG0457 & $\mathrm{R}$ & GI 5 & 22 & 11 & 11 \\
\hline COG1961 & $\mathrm{L}$ & GI 5 & 799 & 557 & 242 \\
\hline
\end{tabular}


RCA23_c10930 11783101177858 hypothetical protein, DUF2924

RCA23_c10940 11788711179848 putative TRAP transporter solute receptor

\begin{tabular}{|c|c|c|c|c|c|}
\hline & & GI 5 & 237 & 234 & 3 \\
\hline COG2358 & $\mathrm{R}$ & GI 5 & 239 & 214 & 25 \\
\hline COG4666 & $\mathrm{R}$ & GI 5 & 386 & 349 & 37 \\
\hline COG3119 & $\mathrm{P}$ & GI 5 & 325 & 398 & -73 \\
\hline COG1234 & $\mathrm{R}$ & GI 5 & 306 & 236 & 70 \\
\hline COG2375 & $P$ & GI 5 & 477 & 318 & 159 \\
\hline COG2015 & $Q$ & GI 5 & 550 & 453 & 97 \\
\hline COG1638 & G & GI 5 & 417 & 318 & 99 \\
\hline COG0625 & 0 & GI 5 & 357 & 294 & 63 \\
\hline COG3090 & G & GI 5 & 459 & 306 & 153 \\
\hline COG1593 & G & GI 5 & 284 & 244 & 40 \\
\hline \multirow[t]{4}{*}{ COG0697 } & G & GI 5 & 228 & 198 & 30 \\
\hline & & GI 5 & 221 & 170 & 51 \\
\hline & & GI 5 & 458 & 332 & 126 \\
\hline & & GI 5 & 378 & 282 & 96 \\
\hline COG3119 & $P$ & GI 5 & 477 & 324 & 153 \\
\hline COG1028 & I & GI 5 & 479 & 340 & 139 \\
\hline COG0625 & 0 & GI 5 & 545 & 391 & 154 \\
\hline COG1012 & C & GI 5 & 411 & 357 & 54 \\
\hline COG1802 & K & GI 5 & 419 & 355 & 64 \\
\hline COG3316 & L & GI 5 & 2 & 12 & -10 \\
\hline \multirow[t]{2}{*}{ COG4974 } & $\mathrm{L}$ & GI 5 & 1 & 1 & 0 \\
\hline & & GI 5 & 2 & 3 & -1 \\
\hline COG1802 & K & GI 5 & 339 & 300 & 39 \\
\hline COG0683 & $E$ & GI 5 & 438 & 334 & 104 \\
\hline COG0559 & $E$ & GI 5 & 327 & 313 & 14 \\
\hline COG4177 & $\mathrm{E}$ & GI 5 & 497 & 346 & 151 \\
\hline COG0411 & $E$ & GI 5 & 414 & 325 & 89 \\
\hline COG0410 & $\mathrm{E}$ & GI 5 & 408 & 292 & 116 \\
\hline COG4126 & E & GI 5 & 395 & 264 & 131 \\
\hline
\end{tabular}


RCA23_c11230

RCA23_c11240 12137851212979 glutamine transport ATP-binding protein GInQ

RCA23_c11250 12145001213802 putative inner membrane amino-acid ABC transporter perm RCA23_c11260 12148051215512 transposase

RCA23_c11270 12160481217244 transcriptional regulator CoxC

RCA23_c11280 12173601218214 carbon monoxide dehydrogenase medium chain CoxM

RCA23_c11290 12182251218719 carbon monoxide dehydrogenase small chain CoxS

RCA23_c11300 12187161221142 carbon monoxide dehydrogenase large chain CoxL

RCA23_c11310 12211881222063 AAA+ ATPase chaperone CoxD

RCA23_c11320 12220601223241 carbon monoxide dehydrogenase accessory protein CoxE

RCA23_c11330 12232381224017 carbon monoxide dehydrogenase accessory protein CoxF

RCA23_c11340 12240101224600 hypothetical protein

RCA23_c11350 12247271225182 carbon monoxide dehydrogenase protein CoxG

RCA23_c11360 12251871226101 carbon monoxide dehydrogenase accessory protein Coxl

RCA23_c11370 12263111226796 transposase

RCA23_c11380 12270611227807 dienelactone hydrolase

RCA23_c11390 12288501227804 aldo/keto reductase

RCA23_c11400 12302231229126 mandelate racemase MdIA

RCA23_c11410 12311891230335 hypothetical protein DUF1498

RCA23_c11420 12325981231231 two-component system, sensor histidine kinase protein

RCA23_c11430 12332991232595 two-component system, response regulator protein

RCA23_c11440 12334041234510 hypothetical protein

RCA23_c11450 12345931236608 putative tripartite tricarboxylate transporter (TTT) protein Tc

RCA23_c11460 12366051237696 hypothetical protein

RCA23_c11470 12377241238692 D-isomer specific 2-hydroxyacid dehydrogenase

RCA23_c11480 12397931238756 putative ammonia monooxygenase

RCA23_c11490 12404401239790 transcriptional regulator

RCA23_c11500 12404891241970 fumarate reductase flavoprotein subunit FccA

RCA23_c11510 12421881243363 aspartate aminotransferase AspC

RCA23_c11520 12441651243431 hypothetical protein

\begin{tabular}{|c|c|c|c|c|c|}
\hline COG3316 & $\mathrm{L}$ & GI 5 & 66 & 52 & 14 \\
\hline COG1126 & $\mathrm{E}$ & GI 5 & 32 & 11 & 21 \\
\hline COG0765 & $\mathrm{E}$ & GI 5 & 46 & 11 & 35 \\
\hline COG3316 & $\mathrm{L}$ & GI 5 & 10 & 6 & 4 \\
\hline COG3300 & $\mathrm{T}$ & GI 5 & 224 & 150 & 74 \\
\hline COG1319 & C & GI 5 & 83 & 69 & 14 \\
\hline COG2080 & C & GI 5 & 77 & 78 & -1 \\
\hline COG1529 & C & GI 5 & 130 & 117 & 13 \\
\hline COG0714 & $\mathrm{R}$ & GI 5 & 129 & 129 & 0 \\
\hline COG3552 & $\mathrm{R}$ & GI 5 & 68 & 81 & -13 \\
\hline COG1975 & 0 & GI 5 & 63 & 69 & -6 \\
\hline COG2068 & $\mathrm{R}$ & GI 5 & 75 & 70 & 5 \\
\hline COG3427 & $\mathrm{S}$ & GI 5 & 111 & 80 & 31 \\
\hline COG1975 & $\mathrm{O}$ & GI 5 & 120 & 110 & 10 \\
\hline COG3316 & $\mathrm{L}$ & GI 5 & 34 & 32 & 2 \\
\hline COG0412 & Q & GI 5 & 337 & 347 & -10 \\
\hline COG0667 & C & GI 5 & 243 & 227 & 16 \\
\hline COG4948 & M & GI 5 & 299 & 385 & -86 \\
\hline COG3822 & $\mathrm{R}$ & GI 5 & 363 & 506 & -143 \\
\hline COG0642 & $\mathrm{T}$ & GI 5 & 218 & 328 & -110 \\
\hline COG0745 & $\mathrm{T}$ & GI 5 & 255 & 357 & -102 \\
\hline COG3181 & $\mathrm{S}$ & GI 5 & 441 & 342 & 99 \\
\hline COG3333 & $\mathrm{S}$ & GI 5 & 543 & 448 & 95 \\
\hline COG2828 & $S$ & GI 5 & 288 & 325 & -37 \\
\hline COG0111 & $\mathrm{H}$ & GI 5 & 297 & 421 & -124 \\
\hline COG3180 & $\mathrm{R}$ & GI 5 & 263 & 351 & -88 \\
\hline COG1802 & $\mathrm{K}$ & GI 5 & 194 & 307 & -113 \\
\hline COG1053 & C & GI 5 & 282 & 318 & -36 \\
\hline \multirow[t]{2}{*}{ COG0436 } & $E$ & GI 5 & 321 & 400 & -79 \\
\hline & & GI 5 & 269 & 385 & -116 \\
\hline
\end{tabular}




\begin{tabular}{|c|c|c|c|c|c|c|c|}
\hline RCA23_c11530 & 12448071244235 aerobic glycerol-3-phosphate dehydrogenase GlpD & COG0578 & $\mathrm{C}$ & GI 5 & 198 & 314 & -116 \\
\hline RCA23_c11540 & 12458241244865 aerobic glycerol-3-phosphate dehydrogenase GlpD & COG0578 & $\mathrm{C}$ & GI 5 & 239 & 288 & -49 \\
\hline RCA23_c11560 & 12479281249136 chemotaxis protein CheW & COG0835 & $\mathrm{N}$ & GI 5 & 27 & 26 & 1 \\
\hline RCA23_c11580 & 12510911254051 chemotaxis histidine kinase CheA & COG0643 & $\mathrm{N}$ & GI 5 & 40 & 20 & 20 \\
\hline RCA23_c11590 & 12540481256066 response regulator $\mathrm{CheY}$ & COG2114 & $\mathrm{T}$ & GI 5 & 36 & 14 & 22 \\
\hline RCA23_c11600 & 12560781256908 chemotaxis protein methyltransferase CheR & COG1352 & $\mathrm{N}$ & GI 5 & 0 & 6 & -6 \\
\hline RCA23_c11620 & 12585411259149 metal-dependent hydrolase & COG1235 & $\mathrm{R}$ & GI 5 & 125 & 59 & 66 \\
\hline RCA23_c11630 & 12606671259588 integrase & COG2801 & L & GI 5 & 0 & 0 & 0 \\
\hline RCA23_c11640 & 12615531260729 methyltransferase, FkbM family & & & GI 5 & 13 & 25 & -12 \\
\hline RCA23_c11650 & 12626111261847 hypothetical protein, sugar transferase-like & & & GI 5 & 33 & 35 & -2 \\
\hline RCA23_c11660 & 12636861262811 aldo/keto reductase & COG0667 & C & GI 5 & 35 & 36 & -1 \\
\hline RCA23_c11670 & 12646421264917 hypothetical protein & & & GI 5 & 44 & 45 & -1 \\
\hline RCA23_c11710 & 12686991269586 phytanoyl-CoA dioxygenase family protein & COG5285 & Q & GI 5 & 343 & 209 & 134 \\
\hline RCA23_c11720 & 12702431270815 putative bacterial extracellular solute binding protein, family & COG1791 & $\mathrm{S}$ & GI 5 & 67 & 79 & -12 \\
\hline RCA23_c11730 & 12710311271468 hypothetical protein & & & GI 5 & 73 & 29 & 44 \\
\hline RCA23_c11740 & 12727981272199 SOUL heme-binding protein & & & GI 5 & 321 & 247 & 74 \\
\hline RCA23_c11750 & 12734781274995 arylsulfatase precursor & COG3119 & $\mathrm{P}$ & GI 5 & 113 & 132 & -19 \\
\hline RCA23_c11760 & 12752321275627 hypothetical protein DUF583 & & & GI 5 & 7 & 10 & -3 \\
\hline RCA23_c11770 & 12758041276883 integrase & COG2801 & $\mathrm{L}$ & GI 5 & 0 & 0 & 0 \\
\hline RCA23_c11780 & 12779851276918 hypothetical protein & COG3616 & $\mathrm{E}$ & GI 5 & 368 & 281 & 87 \\
\hline RCA23_c11790 & 12798101278509 glutamine synthase GInA type I & COG0174 & $\mathrm{E}$ & GI 5 & 3 & 7 & -4 \\
\hline RCA23_c11800 & 12806521279807 putative HTH-type transcriptional regulator, RpiR family & COG1737 & K & GI 5 & 11 & 5 & 6 \\
\hline RCA23_c11810 & $12807331281500 \mathrm{~N}$-formylglutamate amidohydrolase & COG3931 & $\mathrm{E}$ & GI 5 & 9 & 7 & 2 \\
\hline
\end{tabular}


RCA23_c11830 12821311282853 branched-chain amino acid ABC transporter, ATP-binding p COG0411

RCA23_c11840 12828821284033 branched-chain amino acid ABC transporter, periplasmic bil COG0683

RCA23_c11850 12840851284783 branched-chain amino acid ABC transporter, ATP-binding p coG0410

RCA23_c11860 12847831285679 branched-chain amino acid ABC transporter, permease pro COG0559

RCA23_c11870 12857541286698 branched-chain amino acid ABC transporter, permease pro COG4177

RCA23_c11880 12867081287646 acetamidase/formamidase family protein

$\operatorname{COG} 2421$

RCA23_c11890 12881921288902 hypothetical protein

RCA23_c11910 12895501290728 putative prophage integrase

COG1028

COG0582

RCA23_c11920 12907251291072 hypothetical protein

RCA23_c11930 12914271292068 hypothetical protein

RCA23_c11940 12921851293384 putative AAA ATPase

RCA23_c11950 12940401293531 hypothetical protein

RCA23_c11960 12948941294163 hypothetical protein

RCA23_c11970 12951391295579 hypothetical protein

RCA23_c11980 12955791295947 hypothetical protein

RCA23_c11990 12969081296210 branched-chain amino acid ABC transporter, ATP-binding p COG0410

RCA23_c12000 12976541296914 branched-chain amino acid ABC transporter, ATP-binding p COG0411

RCA23_c12010 12986341297651 branched-chain amino acid ABC transporter, permease pro coG4177

RCA23_c12020 12995591298666 branched-chain amino acid ABC transporter, permease pro COG0559

RCA23_c12030 13007331299567 branched-chain amino acid ABC transporter, periplasmic bil COG0683

RCA23_c12040 13015681300768 enoyl-CoA hydratase/carnithine racemase

RCA23_C12040 13015681300768 enoyl-CoA hydratase/carnithine racemase

COG1024

COG0318

COG2080

RCA23_c12060 13036321303123 dehydrogenase iron-sulfur-binding subunit

COG1319

COG1529

RCA23_c12080 13073801304441 dehydrogenase molybdenum-binding subunit

COG2207

COG1879

COG1940

COG1082

COG1879

GI 5
GI 5
GI 5
GI 5
GI 5
GI 5
GI 5
GI 5
GI 5
GI 5
GI 5
GI 5
GI 5
GI 5
GI 5
GI 5
GI 5
GI 5
GI 5
GI 5
GI 5
GI 5
GI 5
GI 5
GI 5
GI 5
GI 5
GI 5
GI 5
GI 5

7

1

6

10

4

7

15

1

468

13

16

79

82

4

16

76

33

45

45

76

66

53

36

55

49

26

41

71

18

9

8

RCA23_c12130 13125041313622 sugar ABC transporter, periplasmic binding protein 
RCA23_c12140

RCA23_c12160 13164181317386 sugar ABC transporter, permease protein

RCA23_c12170 13173891317691 hypothetical protein, monoxygenase-like

RCA23_c12180 13178051318863 hypothetical protein

RCA23_c12190 13188671320018 putative oxidoreductase

RCA23_c12200 13206891321837 peptidase M20D, amidohydrolase

RCA23_c12210 13218401322985 X-Pro dipeptidase

RCA23_c12220 13242961323853 hypothetical protein

RCA23_c12230 13250691324293 hypothetical protein, transmembrane

RCA23_c12240 13258321327037 hypothetical protein, DNA breaking rejoining enzymes family protein-like

RCA23_c12250 13271371328645 hypothetical protein

RCA23_c12260 13287291329205 hypothetical protein

RCA23_c12270 13295531329744 hypothetical protein

RCA23_c12280 13300881331644 type I restriction-modification system, M subunit

RCA23_c12290 13316371332842 type I restriction-modification system, S subunit

RCA23_c12300 13328421335937 type I restriction-modification system, R subunit

RCA23_c12310 13360261337000 hypothetical protein

RCA23_c12320 13371421338152 hypothetical protein

RCA23_c12330 13387621338241 hypothetical protein

RCA23_c12340 13407731338905 hypothetical protein, DNA helicase-like protein

RCA23_c12350 13409701341416 hypothetical protein

RCA23_c12360 13415571342156 integrase

RCA23_c12370 13425971342181 hypothetical protein

RCA23_c12380 13432111342702 hypothetical protein

RCA23_c12390 13433821344026 hypothetical protein

RCA23_c12400 13444891344037 hypothetical protein

RCA23_c12410 13461901345639 hypothetical protein, DUF1994

RCA23_c12420 13475751346172 exonuclease I

RCA23_c12430 13495481347575 transpeptidase, penicillin binding protein

\begin{tabular}{|c|c|c|c|c|c|}
\hline COG0673 & $\mathrm{R}$ & GI 5 & 11 & 16 & -5 \\
\hline COG1129 & G & GI 5 & 11 & 11 & 0 \\
\hline COG1172 & G & GI 5 & 12 & 24 & -12 \\
\hline COG1359 & $S$ & GI 5 & 18 & 23 & -5 \\
\hline COG1082 & G & GI 5 & 30 & 18 & 12 \\
\hline COG0673 & $\mathrm{R}$ & GI 5 & 29 & 25 & 4 \\
\hline COG1473 & $\mathrm{R}$ & GI 5 & 229 & 226 & 3 \\
\hline \multirow[t]{3}{*}{ COG0006 } & E & GI 5 & 289 & 228 & 61 \\
\hline & & GI 5 & 18 & 9 & 9 \\
\hline & & GI 5 & 12 & 12 & 0 \\
\hline \multirow[t]{4}{*}{ protein-like } & & GI 5 & 37 & 26 & 11 \\
\hline & & GI 5 & 1 & 0 & 1 \\
\hline & & GI 5 & 10 & 5 & 5 \\
\hline & & GI 5 & 0 & 13 & -13 \\
\hline COG0286 & V & GI 5 & 10 & 4 & 6 \\
\hline COG0732 & $\mathrm{V}$ & GI 5 & 8 & 2 & 6 \\
\hline COG0610 & $\mathrm{V}$ & GI 5 & 0 & 4 & -4 \\
\hline COG3012 & $\mathrm{S}$ & GI 5 & 0 & 0 & 0 \\
\hline \multirow[t]{4}{*}{ COG2865 } & $\mathrm{K}$ & GI 5 & 0 & 0 & 0 \\
\hline & & GI 5 & 0 & 0 & 0 \\
\hline & & GI 5 & 2 & 0 & 2 \\
\hline & & GI 5 & 0 & 0 & 0 \\
\hline \multirow[t]{6}{*}{ COG0582 } & $\mathrm{L}$ & GI 5 & 0 & 1 & -1 \\
\hline & & GI 5 & 0 & 0 & 0 \\
\hline & & GI 5 & 0 & 0 & 0 \\
\hline & & GI 5 & 9 & 2 & 7 \\
\hline & & GI 5 & 2 & 1 & 1 \\
\hline & & GI 5 & 386 & 183 & 203 \\
\hline COG2925 & $\mathrm{L}$ & GI 5 & 154 & 111 & 43 \\
\hline COG4953 & $M$ & GI 5 & 127 & 64 & 63 \\
\hline
\end{tabular}


RCA23_c12440

RCA23_c12450 13550671354687 hypothetical protein

RCA23_c12460 13553221355774 hypothetical protein

RCA23_c12470 13574921355828 type III restriction enzyme, res subunit

RCA23_c12480 13580341357498 putative type III restriction system protein, mod subunit

RCA23_c12490 13580971359374 putative serine/threonine protein kinase

RCA23_c12500 13593621360081 serine/threonine protein phosphatase PrpC

RCA23_c12510 13622721360134 DNA helicase, UvrD/REP type

RCA23_c12520 13622741364124 hypothetical protein

RCA23_c12530 13641211365416 hypothetical protein, OmpA/MotB-like

RCA23_c12540 13654161367443 hypothetical protein

RCA23_c12550 13674571370579 ATP-dependent helicase

RCA23_c12560 13714101370973 hypothetical protein

RCA23_c12570 13720981371616 hypothetical protein

RCA23_c12580 13725941372277 hypothetical protein

RCA23_c12590 13728811373252 hypothetical protein

RCA23_c12600 13733061374205 hypothetical protein

RCA23_c12610 13745161374866 hypothetical protein

RCA23_c12620 13749711375435 hypothetical protein

RCA23_c12630 13756741376117 integrase

RCA23_c12640 13773041376135 hypothetical protein

RCA23_c12650 13778931377396 hypothetical protein

RCA23_c12660 13782001377955 DNA integration/recombination/invertion protein

RCA23_c12690 13797691378858 putative beta-lactamase-like protein

RCA23_c12680 13797681381060 osmolarity sensor protein EnvZ

RCA23_c12700 13811301381954 hypothetical protein

RCA23_c12710 1382060138273150 S ribosomal protein L21

RCA23_c12720 13827381383007 50S ribosomal protein L27

RCA23_c12730 13830921383730 hypothetical protein, LysE type translocator

RCA23_c12740 13837271384263 putative acetyltransferase

\begin{tabular}{|c|c|c|c|c|c|}
\hline \multirow[t]{3}{*}{ COG2373 } & $\mathrm{R}$ & GI 5 & 122 & 64 & 58 \\
\hline & & GI 5 & 63 & 63 & 0 \\
\hline & & GI 5 & 12 & 9 & 3 \\
\hline \multirow[t]{2}{*}{ COG1061 } & $\mathrm{K}$ & GI 5 & 36 & 25 & 11 \\
\hline & & GI 5 & 25 & 14 & 11 \\
\hline COG0515 & $\mathrm{R}$ & GI 5 & 10 & 16 & -6 \\
\hline COG0631 & $\mathrm{T}$ & GI 5 & 12 & 14 & -2 \\
\hline COG0210 & $\mathrm{L}$ & GI 5 & 6 & 6 & 0 \\
\hline COG1463 & $Q$ & GI 5 & 4 & 4 & 0 \\
\hline \multirow[t]{2}{*}{ COG1360 } & $N$ & GI 5 & 1 & 2 & -1 \\
\hline & & GI 5 & 2 & 1 & 1 \\
\hline \multirow[t]{8}{*}{ COG0553 } & $\mathrm{K}$ & GI 5 & 5 & 5 & 0 \\
\hline & & GI 5 & 7 & 3 & 4 \\
\hline & & GI 5 & 11 & 7 & 4 \\
\hline & & GI 5 & 4 & 4 & 0 \\
\hline & & GI 5 & 14 & 2 & 12 \\
\hline & & GI 5 & 9 & 5 & 4 \\
\hline & & GI 5 & 0 & 0 & 0 \\
\hline & & GI 5 & 0 & 0 & 0 \\
\hline \multirow[t]{4}{*}{ COG2801 } & $\mathrm{L}$ & GI 5 & 376 & 216 & 160 \\
\hline & & GI 5 & 2 & 0 & 2 \\
\hline & & GI 5 & 0 & 0 & 0 \\
\hline & & GI 5 & 0 & 21 & -21 \\
\hline COG0491 & $\mathrm{R}$ & & 250 & 305 & -55 \\
\hline \multirow[t]{2}{*}{ COG0642 } & $T$ & & 253 & 396 & -143 \\
\hline & & & 591 & 515 & 76 \\
\hline COG0261 & $\mathrm{J}$ & & 514 & 314 & 200 \\
\hline COG0211 & $\mathrm{J}$ & & 403 & 469 & -66 \\
\hline COG1280 & $E$ & & 245 & 351 & -106 \\
\hline COG1670 & $\mathrm{J}$ & & 321 & 372 & -51 \\
\hline
\end{tabular}


RCA23_c12750 138

RCA23_c12760

RCA23_c12770

RCA23_c12780

RCA23_c12800

RCA23_c12790

RCA23_c12810

RCA23_c12820

RCA23_c12830

RCA23_c12840

RCA23_c12850

RCA23_c12860

RCA23_c12870

RCA23_c12880

RCA23_c12890

RCA23_c12900

RCA23_c12910 14018101401337 putative snoaL-like polyketide cyclase

RCA23_c12920 14021641402454 hypothetical protein, DUF1330

RCA23_c12930 14028831403188 hypothetical protein, DUF3303

RCA23_c12940 14039861403495 hypothetical protein, transmembrane

RCA23_c12950 14042781403991 hypothetical protein, transmembrane

RCA23_c12960 14044221405501 integrase

RCA23_c12970 14060681406265 hypothetical protein

RCA23_c12980 14068631406288 site-specific recombinase, resolvase family protein

RCA23_c12990 14070721407455 hypothetical protein

RCA23_c13000 14077811407981 hypothetical protein

RCA23_c13010 14091831408122 transposase

RCA23_c13020 14102371410437 ribsomal protein S21

RCA23_c13030 14105721410739 hypothetical protein

RCA23_c13040 14107941411873 integrase

\begin{tabular}{|c|c|c|c|c|c|}
\hline COG1670 & J & & 202 & 299 & -97 \\
\hline COG0536 & $\mathrm{R}$ & & 389 & 466 & -77 \\
\hline COG0263 & $E$ & & 322 & 395 & -73 \\
\hline COG0014 & $\mathrm{E}$ & & 246 & 337 & -91 \\
\hline \multirow[t]{2}{*}{ COG5385 } & $S$ & & 346 & 369 & -23 \\
\hline & & & 186 & 377 & -191 \\
\hline COG3176 & $\mathrm{R}$ & & 184 & 338 & -154 \\
\hline COG0204 & 1 & & 235 & 353 & -118 \\
\hline COG0352 & $\mathrm{H}$ & & 312 & 391 & -79 \\
\hline COG0565 & J & & 302 & 372 & -70 \\
\hline COG1612 & 0 & & 363 & 447 & -84 \\
\hline COG2317 & $\mathrm{E}$ & & 450 & 426 & 24 \\
\hline COG0188 & L & & 289 & 359 & -70 \\
\hline COG1495 & 0 & & 189 & 308 & -119 \\
\hline \multirow[t]{2}{*}{ COG1238 } & $S$ & & 295 & 288 & 7 \\
\hline & & GI 6 & 458 & 361 & 97 \\
\hline COG3631 & $\mathrm{R}$ & GI 6 & 222 & 195 & 27 \\
\hline \multirow[t]{4}{*}{ COG5470 } & $S$ & GI 6 & 264 & 216 & 48 \\
\hline & & GI 6 & 110 & 73 & 37 \\
\hline & & GI 6 & 27 & 27 & 0 \\
\hline & & GI 6 & 11 & 14 & -3 \\
\hline \multirow[t]{2}{*}{ COG2801 } & L & GI 6 & 0 & 0 & 0 \\
\hline & & GI 6 & 0 & 0 & 0 \\
\hline COG1961 & $\mathrm{L}$ & GI 6 & 149 & 119 & 30 \\
\hline \multirow[t]{2}{*}{ COG4731 } & $S$ & GI 6 & 437 & 256 & 181 \\
\hline & & GI 6 & 17 & 6 & 11 \\
\hline COG3415 & L & GI 6 & 0 & 0 & 0 \\
\hline \multirow[t]{2}{*}{ COG0828 } & $\mathrm{J}$ & GI 6 & 301 & 250 & 51 \\
\hline & & GI 6 & 484 & 243 & 241 \\
\hline COG2801 & L & GI 6 & 0 & 0 & 0 \\
\hline
\end{tabular}


RCA23_c13050

RCA23_c13060 14143371413294 putative phage integrase

RCA23_c13080 14148221415982 putative phage integrase

RCA23_c13090 14176471417237 hypothetical protein, GYD domain

RCA23_c13100 14179421418304 hypothetical protein

RCA23_c13110 14188561418572 hypothetical protein

RCA23_c13120 14191781420584 hypothetical protein

RCA23_c13130 14206451421724 integrase

RCA23_c13140 14222701422037 hypothetical protein

RCA23_c13150 14228681422398 hypothetical protein

RCA23_c13160 14237631423269 hypothetical protein

RCA23_c13170 14246251424954 hypothetical protein

RCA23_c13180 14251311425541 hypothetical protein

RCA23_c13190 14255531425708 hypothetical protein

RCA23_c13210 14258491426889 phosphoribosylformylglycinamidine cyclo-ligase PurM

RCA23_c13220 14268861427464 phosphoribosylglycinamide formyltransferase PurN

RCA23_c13230 14275431428700 ribonuclease D

RCA23_c13240 14287361429146 SufE-like protein

RCA23_c13250 14297451429143 hypothetical protein

RCA23_c13260 14305781429871 putative methionine synthase (B12 dependent) subunit 2

RCA23_c13270 14317451430717 putative methionine synthase (B12 dependent) subunit 1

RCA23_c13280

RCA23_c13290

RCA23_c13300

RCA23_c13310

RCA23_c13320 14355151436849 C4-dicarboxylate transport transcriptional regulatory protein

RCA23_c13330 14373251440108 ribonuclease E

RCA23_c13340 14404111440178 putative sulfurtransferase tusA

RCA23_c13350 14406151441367 cytochrome C biogenesis protein transmembrane region

RCA23_c13360

\begin{tabular}{|c|c|c|c|c|c|}
\hline & & GI 6 & 524 & 297 & 227 \\
\hline COG0582 & $\mathrm{L}$ & GI 6 & 476 & 307 & 169 \\
\hline COG0582 & $\mathrm{L}$ & GI 6 & 243 & 165 & 78 \\
\hline \multirow[t]{4}{*}{ COG4274 } & $S$ & GI 6 & 33 & 42 & -9 \\
\hline & & GI 6 & 4 & 0 & 4 \\
\hline & & GI 6 & 224 & 134 & 90 \\
\hline & & GI 6 & 92 & 69 & 23 \\
\hline COG2801 & $\mathrm{L}$ & GI 6 & 0 & 0 & 0 \\
\hline \multirow[t]{3}{*}{ COG5586 } & $S$ & GI 6 & 138 & 77 & 61 \\
\hline & & GI 6 & 83 & 93 & -10 \\
\hline & & GI 6 & 217 & 204 & 13 \\
\hline \multirow[t]{3}{*}{ COG4274 } & $S$ & GI 6 & 458 & 401 & 57 \\
\hline & & GI 6 & 484 & 312 & 172 \\
\hline & & GI 6 & 314 & 205 & 109 \\
\hline COG0150 & $\mathrm{F}$ & & 228 & 287 & -59 \\
\hline COG0299 & $\mathrm{F}$ & & 356 & 390 & -34 \\
\hline COG0349 & $\mathrm{J}$ & & 533 & 523 & 10 \\
\hline \multirow[t]{2}{*}{ COG2166 } & $\mathrm{R}$ & & 396 & 545 & -149 \\
\hline & & & 328 & 397 & -69 \\
\hline COG5012 & $\mathrm{R}$ & & 318 & 404 & -86 \\
\hline COG0646 & $E$ & & 255 & 293 & -38 \\
\hline COG0152 & $\mathrm{F}$ & & 544 & 497 & 47 \\
\hline COG1828 & $\mathrm{F}$ & & 429 & 477 & -48 \\
\hline COG0047 & $\mathrm{F}$ & & 256 & 362 & -106 \\
\hline COG4191 & $\mathrm{T}$ & & 424 & 436 & -12 \\
\hline COG2204 & $\mathrm{T}$ & & 309 & 329 & -20 \\
\hline COG1530 & $\mathrm{J}$ & & 255 & 309 & -54 \\
\hline COG0425 & $\mathrm{O}$ & & 247 & 389 & -142 \\
\hline \multirow[t]{2}{*}{ COG0785 } & 0 & & 246 & 383 & -137 \\
\hline & & & 167 & 250 & -83 \\
\hline
\end{tabular}




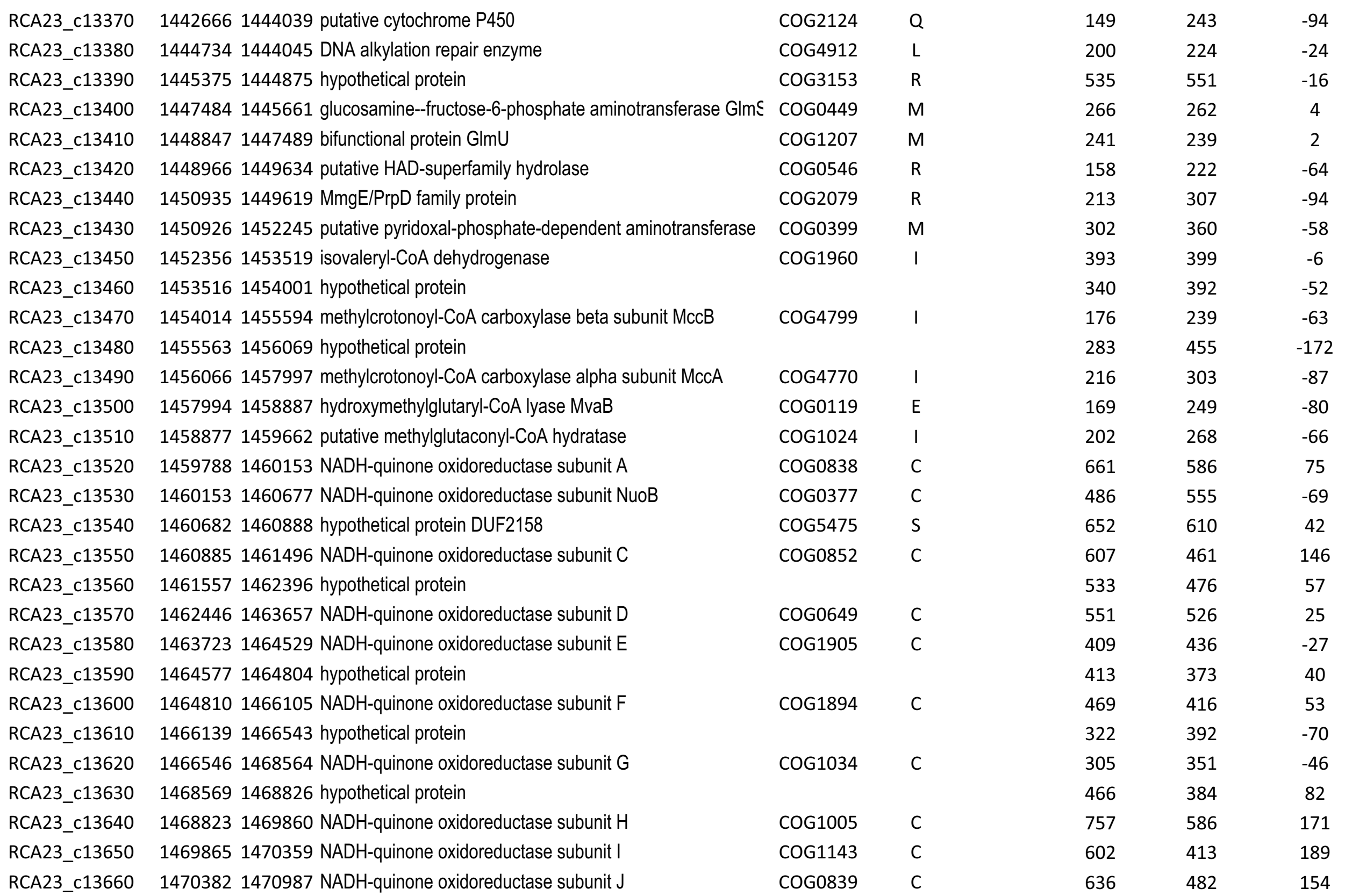


RCA23_c13670

RCA23_C13680

RCA23_C13690

RCA23_C13700

RCA23_C13710

RCA23_c13720

RCA23_C13730

RCA23_c13740 14814651479801 ATP-dependent RNA helicase RhIE

RCA23_c13750 14832321481634 peptide chain release factor 3

RCA23_c13760 14842601483316 hypothetical protein

RCA23_c13770 14844701485249 putative short chain dehydrogenase

RCA23_C13780 14853691486409 arsenite methyltransferase

RCA23_c13790 $14864651487541 \mathrm{Fe}(3+)$ ions import ATP-binding protein FbpC

RCA23_c13800 14883671487555 putative helix-turn-helix protein

RCA23_c13810 14883881488582 sec-independent protein translocase protein TatA

RCA23_c13820 14886181489190 sec-independent protein translocase protein TatB

RCA23_c13830 14891871490077 sec-independent protein translocase protein TatC

RCA23_c13840 14900741490913 hypothetical protein DUF815

RCA23_c13850 14920651490932 putative peptidoglycan-binding peptidase

RCA23_c13860 14927511492104 protein-L-isoaspartate O-methyltransferase Pcm

RCA23_c13870 14935041492755 5'-nucleotidase SurE

RCA23_c13880 14942931493628 putative short chain dehydrogenase

RCA23_c13890 14957971494328 amidophosphoribosyltransferase PurF

RCA23_c13900 14964691495963 putative colicin V production protein

RCA23_c13910 14978991496541 DNA repair protein RadA

RCA23_c13920 14987231497977 ABC transporter ATP-binding protein

RCA23_c13930 14995081498720 hypothetical protein DUF140

RCA23_c13940 15005481499505 alanine racemase, biosynthetic

RCA23_c13950 15021201500630 replicative DNA helicase DnaB

RCA23_c13960 15030311502354 orotate phosphoribosyltransferase PyrE

\begin{tabular}{|c|c|c|c|c|}
\hline COG0713 & $C$ & 821 & 637 & 184 \\
\hline COG1009 & $\mathrm{C}$ & 437 & 408 & 29 \\
\hline COG1008 & $C$ & 532 & 545 & -13 \\
\hline COG1007 & $\mathrm{C}$ & 401 & 459 & -58 \\
\hline COG0340 & $\mathrm{H}$ & 229 & 269 & -40 \\
\hline COG1521 & $\mathrm{K}$ & 366 & 445 & -79 \\
\hline COG0595 & $\mathrm{R}$ & 374 & 437 & -63 \\
\hline COG0513 & $\mathrm{L}$ & 354 & 399 & -45 \\
\hline \multirow[t]{2}{*}{ COG4108 } & $\mathrm{J}$ & 313 & 275 & 38 \\
\hline & & 571 & 437 & 134 \\
\hline COG1028 & 1 & 262 & 331 & -69 \\
\hline COG2226 & $\mathrm{H}$ & 400 & 459 & -59 \\
\hline COG3842 & $E$ & 250 & 357 & -107 \\
\hline COG2378 & $\mathrm{K}$ & 292 & 291 & 1 \\
\hline COG1826 & $U$ & 505 & 457 & 48 \\
\hline COG1826 & $U$ & 330 & 343 & -13 \\
\hline COG0805 & $U$ & 517 & 496 & 21 \\
\hline COG2607 & $\mathrm{R}$ & 258 & 376 & -118 \\
\hline COG0739 & $M$ & 224 & 279 & -55 \\
\hline COG2518 & 0 & 271 & 340 & -69 \\
\hline COG0496 & $\mathrm{R}$ & 249 & 361 & -112 \\
\hline COG1028 & 1 & 171 & 181 & -10 \\
\hline \multirow[t]{2}{*}{ COG0034 } & $\mathrm{F}$ & 308 & 326 & -18 \\
\hline & & 695 & 461 & 234 \\
\hline COG1066 & 0 & 241 & 276 & -35 \\
\hline COG1127 & $Q$ & 240 & 329 & -89 \\
\hline COG0767 & $Q$ & 233 & 367 & -134 \\
\hline COG0787 & $M$ & 293 & 329 & -36 \\
\hline COG0305 & $\mathrm{L}$ & 362 & 394 & -32 \\
\hline COG0461 & $\mathrm{F}$ & 442 & 359 & 83 \\
\hline
\end{tabular}


RCA23_c13970

RCA23_c13980

RCA23_c13990

RCA23_c14000

RCA23_c14010

RCA23_c14020

RCA23_c14030

RCA23_c14040

RCA23_c14050

RCA23_c14060

RCA23_c14070

RCA23_c14080

RCA23_c14090

RCA23_c14100

RCA23_c14110

RCA23_c14120

RCA23_c14130

RCA23_c14150

RCA23_c14160

RCA23_c14170

RCA23_c14180

RCA23_c14190

RCA23_c14200

RCA23_c14210

RCA23_c14220

RCA23_c14230

RCA23_c14240

RCA23_c14260

RCA23_c14270

RCA23_c14280
15040981503058 dihydroorotase PyrC

15042071504548 hypothetical protein

15046591504880 hypothetical protein

15057321504914 hypothetical protein

15071071506076 malate dehydrogenase Mdh

15072131508112 citrate lyase beta subunit CitE

15083121509337 putative mesaconyl-CoA hydratase

15095781509898 succinate dehydrogenase cytochrome b556 subunit SdhC

15099111510282 succinate dehydrogenase hydrophobic membrane anchor s

15103011512106 succinate dehydrogenase flavoprotein subunit SdhA

15121061512408 hypothetical protein

15125061513285 succinate dehydrogenase iron-sulfur subunit SdhB

15140721513368 purine nucleoside phosphorylase deoD-type

15145171514077 acetyltransferase

15153601514536 tryptophan synthase alpha chain TrpA

15155061516603 GTP-dependent nucleic acid-binding protein EngD

15166471517570 Non-specific ribonucleoside hydrolase rihC

15180981518574 hypothetical protein DUF583

15194561518554 protease HtpX

15213951520490 histone deacetylase

15214661521981 peripheral-type benzodiazepine receptor/signal transductior

15221561522710 DNA-invertase Hin

15235341524067 hypothetical protein

15242591524588 hypothetical protein

15261251525748 hypothetical protein, RmIC-like cupin family

15276291526337 integrase

15284301529155 hypothetical membrane protein

15300331529710 hypothetical protein

15301311530841 hypothetical protein DUF45

15309141531564 HTH-type transcriptional regulator, GntR family
COG0418

F

$s$

\begin{tabular}{|c|c|c|c|c|c|}
\hline & & & 487 & 337 & 150 \\
\hline & & & 1.964 & 903 & 1.061 \\
\hline & & & 387 & 351 & 36 \\
\hline COG0039 & C & & 211 & 210 & 1 \\
\hline COG2301 & G & & 312 & 379 & -67 \\
\hline COG2030 & 1 & & 265 & 408 & -143 \\
\hline COG2009 & C & & 557 & 392 & 165 \\
\hline COG2142 & $\mathrm{C}$ & & 433 & 353 & 80 \\
\hline COG1053 & $C$ & & 278 & 316 & -38 \\
\hline & & & 327 & 285 & 42 \\
\hline COG0479 & C & & 697 & 511 & 186 \\
\hline COG0813 & $\mathrm{F}$ & & 306 & 402 & -96 \\
\hline COG1246 & $E$ & & 267 & 373 & -106 \\
\hline COG0159 & $E$ & & 426 & 401 & 25 \\
\hline COG0012 & $\mathrm{J}$ & & 325 & 304 & 21 \\
\hline COG1957 & $\mathrm{F}$ & & 193 & 264 & -71 \\
\hline COG1664 & $M$ & GI 7 & 165 & 88 & 77 \\
\hline COG0501 & 0 & GI 7 & 279 & 171 & 108 \\
\hline COG0123 & B & GI 7 & 75 & 50 & 25 \\
\hline COG3476 & $\mathrm{T}$ & GI 7 & 102 & 83 & 19 \\
\hline COG1961 & $\mathrm{L}$ & GI 7 & 122 & 64 & 58 \\
\hline & & GI 7 & 24 & 29 & -5 \\
\hline & & GI 7 & 272 & 263 & 9 \\
\hline COG3450 & $\mathrm{R}$ & GI 7 & 126 & 63 & 63 \\
\hline COG4974 & $\mathrm{L}$ & GI 7 & 158 & 126 & 32 \\
\hline & & GI 7 & 498 & 284 & 214 \\
\hline COG4530 & $S$ & & 830 & 585 & 245 \\
\hline COG1451 & $\mathrm{R}$ & & 190 & 223 & -33 \\
\hline COG1802 & $\mathrm{K}$ & & 187 & 228 & -41 \\
\hline
\end{tabular}




$\begin{array}{llc}466 & 368 & 98 \\ 303 & 288 & 15 \\ 473 & 404 & 69 \\ 358 & 285 & 73 \\ 690 & 360 & 330 \\ 341 & 300 & 41 \\ 630 & 362 & 268 \\ 336 & 418 & -82 \\ 253 & 220 & 33 \\ 232 & 182 & 50 \\ 294 & 400 & -106 \\ 228 & 310 & -82 \\ 185 & 248 & -63 \\ 378 & 390 & -12 \\ 247 & 316 & -69 \\ 263 & 283 & -20 \\ 231 & 303 & -72 \\ 216 & 239 & -23 \\ 243 & 353 & -110 \\ 262 & 302 & -40 \\ 431 & 474 & -43 \\ 284 & 384 & -100 \\ 336 & 341 & -5 \\ 240 & 368 & -128 \\ 290 & 273 & 17 \\ 277 & 331 & -54 \\ 222 & 302 & -80 \\ 516 & 456 & 60 \\ 230 & 272 & -42 \\ 446 & 363 & 83\end{array}$


RCA23_c14610

RCA23_C14620

RCA23_c14630 15754591574587 3-hydroxyisobutyrate dehydrogenase MmsB

RCA23_c14640 15764981575461 3-hydroxyisobutyryl-CoA hydrolase

RCA23_c14650 15776701576495 isobutyryl-CoA dehydrogenase

RCA23_c14660 15792641577765 methylmalonate-semialdehyde dehydrogenase MmsA

RCA23_c14670 15793591580273 putative HTH-type transcriptional regulator, LysR family

RCA23_c14680 15803591580856 phosphopantetheine adenylyltransferase CoaD

RCA23_c14690 15818841580877 glyceraldehyde-3-phosphate dehydrogenase Gap

RCA23_c14700 15830561582103 glyceraldehyde-3-phosphate dehydrogenase Gap

RCA23_c14710 15853111583296 transketolase TktA

RCA23_c14720 15855111585894 hypothetical protein

RCA23_c14730 15858871586291 cell division protein ZapA

RCA23_c14740 15867191586354 putative glutaredoxin

RCA23_c14750 15869691586709 hypothetical protein

RCA23_c14760 15872131586971 hypothetical protein, BolA-like

RCA23_c14770 15895131587267 phosphoribosylformylglycinamidine synthase PurL

RCA23_c14780 15906341589726 HTH-type transcriptional regulator, LysR family

RCA23_c14790 15907631594146 hypothetical protein, pyruvate ferredoxin/flavodoxin oxidoreı

RCA23_c14800 15942361595048 glutamate racemase Murl

RCA23_c14810 15951201596148 N-acetyl-gamma-glutamyl-phosphate reductase ArgC

RCA23_c14820 15961481596600 cytochrome c-type biogenesis protein CcmE

RCA23_c14830 15967071598668 cytochrome c-type biogenesis protein CcmF

RCA23_c14840 15987221599117 cytochrome c-type biogenesis protein CcmH

RCA23_c14850 15991591599935 putative enoyl-CoA hydratase FadB

RCA23_c14860 16002581600728 hypothetical protein

RCA23_c14870 16021341600809 citrate synthase GItA

RCA23_c14880 16035611602152 glutamyl-tRNA synthase 2

RCA23_c14890 16036191605670 hypothetical protein competence protein E

RCA23_c14900 16063741605667 LexA repressor

\begin{tabular}{|c|c|c|c|c|}
\hline COG0178 & $\mathrm{L}$ & 350 & 381 & -31 \\
\hline COG2079 & $\mathrm{R}$ & 259 & 359 & -100 \\
\hline COG2084 & 1 & 182 & 158 & 24 \\
\hline COG1024 & I & 249 & 295 & -46 \\
\hline COG1960 & 1 & 231 & 285 & -54 \\
\hline COG1012 & C & 289 & 334 & -45 \\
\hline COG0583 & $\mathrm{K}$ & 195 & 319 & -124 \\
\hline COG0669 & $\mathrm{H}$ & 397 & 393 & 4 \\
\hline COG0057 & G & 443 & 402 & 41 \\
\hline COG0057 & G & 317 & 344 & -27 \\
\hline \multirow[t]{2}{*}{ COG0021 } & G & 257 & 307 & -50 \\
\hline & & 236 & 322 & -86 \\
\hline COG3027 & $S$ & 366 & 260 & 106 \\
\hline \multirow[t]{2}{*}{ COG0278 } & 0 & 643 & 378 & 265 \\
\hline & & 556 & 382 & 174 \\
\hline COG0271 & $\mathrm{T}$ & 488 & 401 & 87 \\
\hline COG0046 & $F$ & 254 & 340 & -86 \\
\hline COG0583 & $\mathrm{K}$ & 322 & 383 & -61 \\
\hline COG4231 & $C$ & 194 & 266 & -72 \\
\hline COG0796 & $M$ & 356 & 334 & 22 \\
\hline COG0002 & $E$ & 564 & 441 & 123 \\
\hline COG2332 & 0 & 291 & 279 & 12 \\
\hline COG1138 & 0 & 404 & 410 & -6 \\
\hline COG3088 & 0 & 315 & 462 & -147 \\
\hline \multirow[t]{2}{*}{ COG1024 } & 1 & 285 & 353 & -68 \\
\hline & & 544 & 317 & 227 \\
\hline COG0372 & $\mathrm{C}$ & 642 & 370 & 272 \\
\hline COG0008 & $\mathrm{J}$ & 390 & 320 & 70 \\
\hline COG0658 & $\mathrm{R}$ & 263 & 389 & -126 \\
\hline COG1974 & $\mathrm{K}$ & 337 & 368 & -31 \\
\hline
\end{tabular}


RCA23_C14910

RCA23_c14930 16089161608104 indole-3-glycerol phosphate synthase TrpC

RCA23_c14940 16099521608933 anthranilate phosphoribosyltransferase TrpD

RCA23_c14950 16105301609949 anthranilate synthase component TrpG

RCA23_c14960 16106791611788 hypothetical protein, divergent polysaccharide deacetylase

RCA23_c14970 16127821611811 hypothetical protein

RCA23_c14990 16137961613200 hypothetical protein

RCA23_c15000 16140951615693 putative L,D-transpeptidase YcbB

RCA23_c15010 16157231616820 UDP-3-O-[3-hydroxymyristoyl] glucosamine N-acyltransfera

RCA23_c15020 16168401617097 acyl carrier protein

RCA23_c15030 16171011618309 3-oxoacyl-[acyl-carrier-protein] synthase FabF

RCA23_c15040 16189131618323 hypothetical protein, invasion protein B

RCA23_c15050 16205851619287 inner membrane protein

RCA23_c15060 16215051620585 tyrosine recombinase XerD

RCA23_c15070 16229561621502 hypothetical protein

RCA23_c15080 16231671622958 hypothetical protein

RCA23_c15090 16232121623763 shikimate kinase AroK

RCA23_c15100 16237601624878 3-dehydroquinate synthase AroB

RCA23_c15110 16254621624944 single-stranded DNA-binding protein

RCA23_c15120 16277721625688 glutathione import ATP-binding protein GsiA

RCA23_c15130 16293781627777 putative ABC transporter inner membrane component

RCA23_c15140 16304321629392 putative ABC transporter permease protein

RCA23_c15150 16321781630532 ABC transporter extracellular solute-binding protein

RCA23_c15160 16334231632533 tRNA delta(2)-isopentenylpyrophosphate transferase MiaA

RCA23_c15170 16335221634253 uridylate kinase PyrH

RCA23_c15180 16342751634841 ribosome recycling factor Frr

RCA23_c15190 16348561635563 undecaprenyl pyrophosphate synthase UppS

RCA23_c15200 16355601636345 putative cytidylyltransferase

RCA23_c15210 16363451637505 1-deoxy-D-xylulose 5-phosphate reductoisomerase Dxr

$\begin{array}{lllll}\text { COG0303 } & \text { H } & 152 & 180 & -28 \\ \text { COG0315 } & \text { H } & 261 & 210 & 51 \\ \text { COG0134 } & \text { E } & 180 & 257 & -77 \\ \text { COG0547 } & \text { E } & 184 & 199 & -15 \\ \text { COG0512 } & \text { E } & 229 & 330 & -101 \\ & & 278 & 342 & -64 \\ & & 318 & 371 & -53 \\ \text { COG3108 } & \text { S } & 294 & 342 & -48 \\ \text { COG2989 } & \text { S } & 337 & 409 & -72 \\ \text { COG1044 } & \text { M } & 307 & 313 & -6 \\ \text { COG0236 } & \text { I } & 752 & 635 & 117 \\ \text { COG0304 } & \text { I } & 360 & 368 & -8 \\ \text { COG5342 } & \text { R } & 470 & 365 & 105 \\ \text { COG4536 } & \text { P } & 535 & 395 & 140 \\ \text { COG4974 } & \text { L } & 356 & 425 & -69 \\ & & 267 & 381 & -114 \\ \text { COG0703 } & \text { E } & 401 & 504 & -103 \\ \text { COG0337 } & \text { E } & 556 & 623 & -67 \\ \text { COG0629 } & \text { L } & 227 & 392 & -165 \\ \text { COG0444 } & \text { E } & 285 & 427 & -142 \\ \text { COG1173 } & \text { E } & 341 & 366 & -25 \\ \text { COG0601 } & \text { E } & 271 & 317 & -46 \\ \text { COG0747 } & \text { E } & 407 & 407 & 0 \\ \text { COG0324 } & \text { J } & 250 & 204 & 46 \\ \text { COG0528 } & \mathrm{F} & 194 & 325 & -131 \\ \text { COG0233 } & \text { J } & 352 & 335 & 17 \\ \text { COG0020 } & \text { I } & 393 & 363 & 30 \\ \text { COG0575 } & \text { I } & 318 & 350 & -32 \\ \text { COG0743 } & \text { I } & 183 & 309 & -126 \\ & & 155 & 311 & -156\end{array}$


RCA23_c15220 16374981638829 RIP metalloprotease RseP

RCA23_c15230 16389491641297 putative outer membrane assembly factor

RCA23_c15240 16413991641863 putative outer tein

RCA23_c15250 16419721642433 (3R)-hydroxymyristoyl-[acyl-carrier-protein] dehydratase Fal c0G0764

RCA23_c15260 16424301643227 acyl-[acyl-carrier-protein]--UDP-N-acetylglucosamine O-acy COG1043

RCA23_c15270 16432321644035 hypothetical protein DUF1009

RCA23_c15280 16440321645186 lipid-A-disaccharide synthase LpxB

RCA23_c15290

RCA23_c15300

RCA23_c15310 16468021647515 cell cycle transcriptional regulator

RCA23_c15320 16477661649886 DNA ligase LigA

RCA23_c15330 16498831651973 ATP-dependent DNA helicase RecG

RCA23_c15340 16532861652261 hypothetical protein

RCA23_c15350 16538421653390 hypothetical protein

RCA23_c15360 16539101654266 phosphoribosyl-AMP cyclohydrolase Hisl

RCA23_c15370 16551531654284 glutamyl-Q tRNA(Asp) synthase GluQ

RCA23_c15380 16557311655150 hypothetical protein, methyltransferase

RCA23_c15390 16571491655812 tRNA uridine 5-carboxymethylaminomethyl modification enż

RCA23_c15400 16579781657190 putative crotonase

RCA23_c15410 16580331658455 putative thioesterase

RCA23_c15420 16586001659058 50S ribosomal protein L13

RCA23_c15430 16590621659550 30S ribosomal protein S9

RCA23_c15440 16597631661193 integrase

RCA23_c15460 16636231661959 choline dehydrogenase BetA

RCA23_c15470 16638851664619 ABC transporter, permease protein

RCA23_c15480 16646131665329 ABC transporter, ATP-binding protein

RCA23_c15490 16653261666123 ABC transporter, periplasmic substrate-binding protein

RCA23_c15500 16661301666561 hypothetical membrane protein

RCA23_c15510 16665761667487 hypothetical protein DUF6 family, transmembrane

RCA23_c15520 16680781667497 hypothetical protein

\begin{tabular}{|c|c|c|c|c|}
\hline COG0750 & $M$ & 293 & 380 & -87 \\
\hline \multirow[t]{2}{*}{ COG4775 } & $M$ & 444 & 390 & 54 \\
\hline & & 412 & 324 & 88 \\
\hline COG0764 & 1 & 326 & 374 & -48 \\
\hline COG1043 & $\mathrm{M}$ & 283 & 369 & -86 \\
\hline COG3494 & $S$ & 199 & 315 & -116 \\
\hline COG0763 & $M$ & 225 & 289 & -64 \\
\hline \multirow[t]{2}{*}{ COG0482 } & $J$ & 270 & 301 & -31 \\
\hline & & 191 & 235 & -44 \\
\hline COG0745 & $\mathrm{T}$ & 662 & 573 & 89 \\
\hline COG0272 & $\mathrm{L}$ & 331 & 351 & -20 \\
\hline \multirow[t]{2}{*}{ COG1200 } & $\mathrm{L}$ & 233 & 326 & -93 \\
\hline & & 341 & 418 & -77 \\
\hline COG0822 & $C$ & 206 & 275 & -69 \\
\hline COG0139 & $E$ & 288 & 223 & 65 \\
\hline COG0008 & $J$ & 175 & 221 & -46 \\
\hline COG4976 & $\mathrm{R}$ & 245 & 288 & -43 \\
\hline COG1206 & $J$ & 217 & 276 & -59 \\
\hline COG1024 & 1 & 321 & 314 & 7 \\
\hline COG2050 & $Q$ & 219 & 259 & -40 \\
\hline COG0102 & $J$ & 681 & 369 & 312 \\
\hline \multirow[t]{2}{*}{ COG0103 } & $J$ & 324 & 197 & 127 \\
\hline & & 1 & 0 & 1 \\
\hline COG2303 & $E$ & 197 & 307 & -110 \\
\hline COG4662 & $\mathrm{H}$ & 250 & 357 & -107 \\
\hline COG1131 & V & 208 & 301 & -93 \\
\hline COG2998 & $\mathrm{H}$ & 273 & 269 & 4 \\
\hline COG1238 & $S$ & 257 & 388 & -131 \\
\hline COG2962 & $\mathrm{R}$ & 263 & 325 & -62 \\
\hline COG2068 & $\mathrm{R}$ & 284 & 389 & -105 \\
\hline
\end{tabular}


RCA23_c15530

RCA23_c15540

RCA23_c15550

RCA23_c15560

RCA23_c15570

RCA23_c15580

RCA23_c15590

RCA23_c15600

RCA23_c15610

RCA23_c15620

RCA23_c15630

RCA23_c15650

RCA23_c15660

RCA23_c15670

RCA23_C15680

RCA23_C15690

RCA23_C15700

RCA23_c15710

RCA23_c15720 16907231689581 2-C-methyl-D-erythritol 2,4-cyclodiphosphate synthase IspF

RCA23_c15730 16909341691875 tRNA-dihydrouridine synthase B

RCA23_c15740 16918721692936 histidine kinase, nitrogen regulation protein NtrB

RCA23_c15750 16930551694299 nitrogen regulation protein NtrC

RCA23_c15760 16943751696633 histidine kinase, nitrogen regulation protein NtrY

RCA23_c15770 16966301698030 nitrogen assimilation regulatory protein NtrX

RCA23_c15780 16981081699484 Trk system potassium uptake protein TrkA

RCA23_c15790 16994871700971 putative Trk system potassium uptake protein trkH

RCA23_c15800 17010801701313 RNA-binding protein Hfq

RCA23_c15810 17013191702623 GTP-binding protein HfIX

RCA23_c15820 17050601702583 acyl-homoserine lactone acylase QuiP

$\begin{array}{llllc}\text { COG0404 } & \mathrm{E} & 282 & 264 & 18 \\ \text { COG0404 } & \mathrm{E} & 272 & 341 & -69 \\ \text { COG1028 } & \mathrm{I} & 334 & 424 & -90 \\ \text { COG3788 } & \mathrm{R} & 458 & 440 & 18 \\ \text { COG1309 } & \mathrm{K} & 206 & 240 & -34 \\ \text { COG1897 } & \mathrm{E} & 361 & 398 & -37 \\ & & 409 & 301 & 108 \\ \text { COG2510 } & \mathrm{S} & 444 & 337 & 107 \\ \text { COG1670 } & \mathrm{J} & 276 & 171 & 105 \\ \text { COG0519 } & \mathrm{F} & 282 & 260 & 22 \\ \text { COG5598 } & \mathrm{H} & 243 & 240 & 3 \\ & & 313 & 290 & 23 \\ \text { COG0320 } & \mathrm{H} & 597 & 400 & 197 \\ & & 488 & 401 & 87 \\ \text { COG0634 } & \mathrm{F} & 754 & 569 & 185 \\ \text { COG2867 } & \mathrm{I} & 446 & 375 & 71 \\ \text { COG0004 } & \mathrm{P} & 357 & 340 & 17 \\ \text { COG1546 } & \mathrm{R} & 144 & 266 & -122 \\ \text { COG1267 } & \mathrm{I} & 217 & 316 & -99 \\ \text { COG0245 } & \mathrm{I} & 197 & 251 & -54 \\ \text { COG0042 } & \mathrm{J} & 294 & 356 & -62 \\ \text { COG3852 } & \mathrm{T} & 361 & 518 & -157 \\ \text { COG2204 } & \mathrm{T} & 515 & 426 & 89 \\ \text { COG5000 } & \mathrm{T} & 356 & 352 & 4 \\ \text { COG2204 } & \mathrm{T} & 504 & 383 & 121 \\ \text { COG0569 } & \mathrm{P} & 427 & 389 & 38 \\ \text { COG0168 } & \mathrm{P} & 482 & 534 & -52 \\ \text { COG1923 } & \mathrm{R} & 693 & 491 & 202 \\ \text { COG2262 } & \mathrm{R} & 414 & 423 & -9 \\ \text { COG2366 } & \mathrm{R} & 244 & 335 & -91\end{array}$


RCA23_c15830

RCA23_c15840 17067851705775 delta-aminolevulinic acid dehydratase HemB

RCA23_c15850 17068831707368 hypothetical protein

RCA23_c15860 17073951710835 transcription-repair-coupling factor Mfd

RCA23_c15870 17114731710832 putative DSBA-like thioredoxin family protein

RCA23_c15880 17129661711470 long-chain-fatty-acid-CoA ligase

RCA23_c15890 $17130071713654 \mathrm{HTH}$-type transcriptional regulator

RCA23_c15900 17143101713651 aquaporin AqpZ

RCA23_c15910 17162011714342 putative extracellular solute-binding protein

RCA23_c15920 17169811716376 lysine exporter protein LysE

RCA23_c15930 17176761716978 hypothetical protein DUF502

RCA23_c15940 17186741717751 pseudouridine-5'-phosphate glycosidase PsuG

RCA23_c15950 17195921718678 hypothetical protein, pfkB family carbohydrate kinase

RCA23_c15960 17198321720038 cold shock protein CspA

RCA23_c15970 17204081721112 30S ribosomal protein S2

RCA23_c15980 17211861722061 elongation factor Ts

RCA23_c15990 17232021722168 hypothetical protein

RCA23_c16000 17237121723203 hypothetical protein, acetyltransferase-like

RCA23_c16010 17241271723705 hypothetical protein, transcription factor NusA like

RCA23_c16020 17249611724428 putative phenylacetic acid degradation protein

RCA23_c16030 17255921724951 guanylate kinase Gmk

RCA23_c16040 17264661725597 hypothetical protein, YicC-like

RCA23_c16050 17266451727271 hypothetical protein, DUF1457

RCA23_c16060 17286611727291 phospho-2-dehydro-3-deoxyheptonate aldolase

RCA23_c16070 17288241729837 putative HTH-type transcriptional regulator, AraC family

RCA23_c16080 17299691731150 putative amino-acid binding protein

RCA23_c16090 17312261732005 putative branched-chain amino acid transport ATP-binding | COG0411

RCA23_c16100 17320021732715 putative branched-chain amino acid transport ATP-binding | COG0410

RCA23_c16110 17327191733732 putative branched-chain amino acid transport system permt COG0559

RCA23_c16120 17337291735063 putative branched-chain amino acid transport system permє COG4177

$\begin{array}{llllc}\text { COG2930 } & \text { S } & 247 & 295 & -48 \\ \text { COG0113 } & \text { H } & 238 & 353 & -115 \\ & & 400 & 448 & -48 \\ \text { COG1197 } & \text { L } & 287 & 350 & -63 \\ \text { COG2761 } & \text { Q } & 297 & 350 & -53 \\ \text { COG0318 } & \text { I } & 183 & 288 & -105 \\ \text { COG1396 } & \text { K } & 344 & 355 & -11 \\ \text { COG0580 } & \text { G } & 476 & 472 & 4 \\ \text { COG4166 } & \text { E } & 453 & 381 & 72 \\ \text { COG1279 } & \text { R } & 534 & 383 & 151 \\ \text { COG2928 } & \text { S } & 372 & 301 & 71 \\ \text { COG2313 } & \text { Q } & 184 & 280 & -96 \\ \text { COG0524 } & \text { G } & 194 & 242 & -48 \\ \text { COG1278 } & \text { K } & 361 & 291 & 70 \\ \text { COG0052 } & \text { J } & 423 & 286 & 137 \\ \text { COG0264 } & \text { J } & 443 & 397 & 46 \\ & & 215 & 203 & 12 \\ \text { COG1670 } & \text { J } & 194 & 134 & 60 \\ & & 194 & 156 & 38 \\ \text { COG0663 } & \text { R } & 265 & 270 & -5 \\ \text { COG0194 } & \mathrm{F} & 475 & 457 & 18 \\ \text { COG1561 } & \text { S } & 323 & 347 & -24 \\ \text { COG5388 } & \text { S } & 144 & 183 & -39 \\ \text { COG3200 } & \text { E } & 330 & 309 & 21 \\ \text { COG4977 } & \mathrm{K} & 326 & 340 & -14 \\ \text { COG0683 } & \mathrm{E} & 196 & 180 & 16 \\ \text { COG0411 } & \mathrm{E} & 241 & 251 & -10 \\ \text { COG0410 } & \mathrm{E} & 163 & 218 & -55 \\ \text { COG0559 } & \mathrm{E} & 255 & 366 & -111 \\ \text { COG4177 } & \mathrm{E} & 234 & 308 & -74\end{array}$




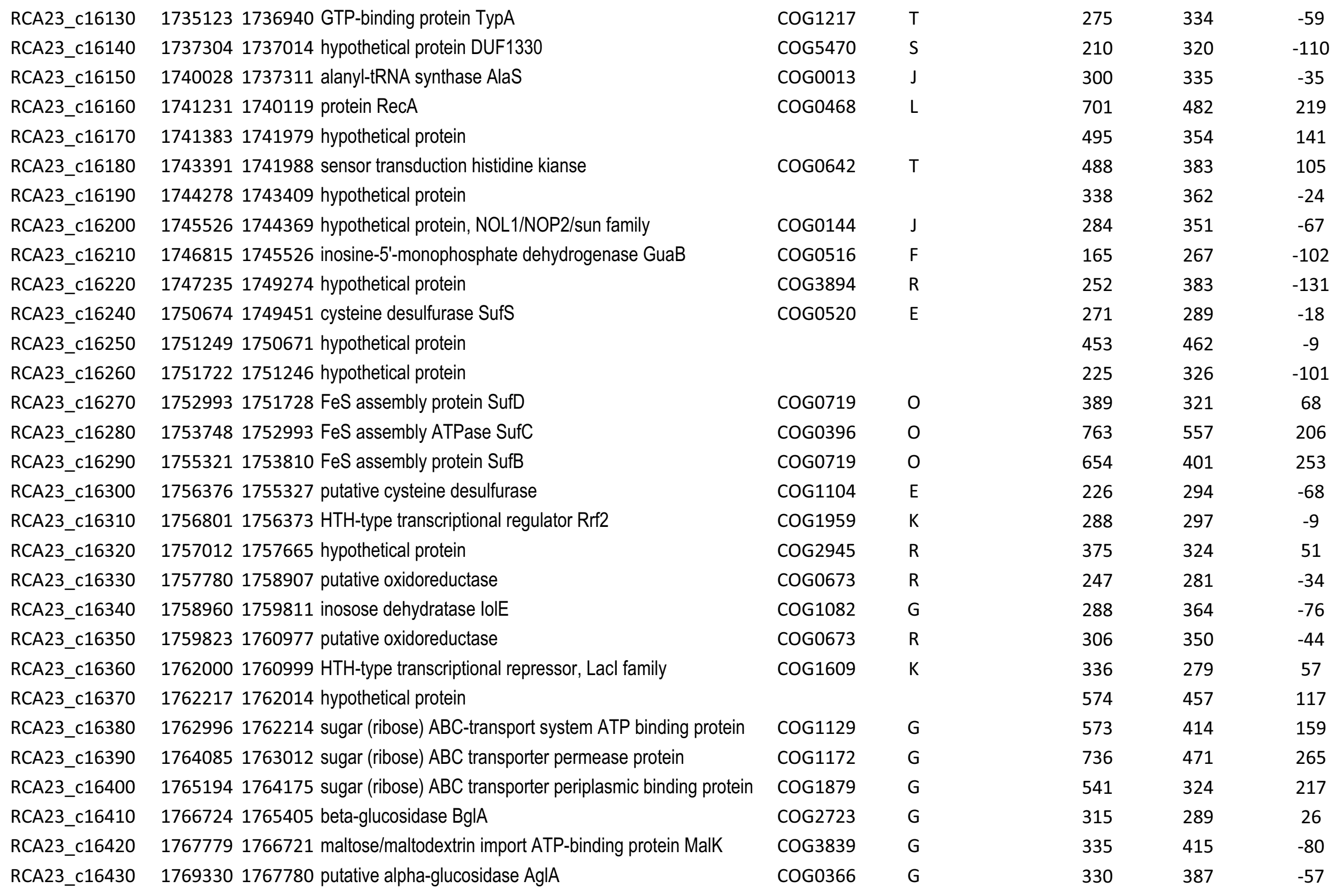


RCA23_c16440 17700251769333 alpha-glucoside transport system permease protein AglG RCA23_c16450 17705581770022 ABC transporter, membrane spanning protein

RCA23_c16460 17718231770570 alpha-glucoside transport system permease protein AgIF RCA23_c16470 17732621771922 alpha-glucosides-binding periplasmic protein AgIE

RCA23_c16480 17736351774675 HTH-type transcriptional regulator

RCA23_c16490 17755661774682 oxidoreductase

RCA23_c16500 17767231775566 alkanesulfonate monooxygenase SsuD

RCA23_c16510 17767871777521 putative regulatory DNA binding protein

RCA23_c16520 17775311778616 putative oxidoreductase

RCA23_c16530 17802021778613 glucose-6-phosphate isomerase Pgi

RCA23_c16540 17808891780212 6-phosphogluconolactonase Pgl

RCA23_c16550 17823401780889 glucose-6-phosphate 1-dehydrogenase Zwf

RCA23_c16560 17825181783450 hypothetical protein, radical SAM

RCA23_c16570 17840311783447 putative 5-methylcytosine-specific restriction enzyme McrA

RCA23_c16580 17847861784112 putative phospholipase/carboxylesterase

RCA23_c16590 17854061784783 HhH-GPD superfamily base excision DNA repair protein

RCA23_c16600 17861281785397 precorrin-6A reductase CobK

RCA23_c16610 17871441786125 cobalamin (vitamin B12) biosynthesis CbiDprotein CbiD

RCA23_c16620 17872651788116 uroporphyrinogen-III C-methyltransferase CobA

RCA23_c16630 17881131789378 cobyrinic acid A,C-diamide synthase CobB

RCA23_c16640 17893971790620 putative major facilitator superfamily transporter

RCA23_c16650 17913691790629 hypothetical protein

RCA23_c16660 17927301791366 cysteinyl-tRNA synthase CysS

RCA23_c16670 17929391794108 aspartate aminotransferase AspC

RCA23_c16680 17943101795845 trimethylamine methyltransferase MttB

RCA23_c16690 17976831795869 ABC transporter ATP-binding protein Uup

RCA23_c16700 17982211797715 hypothetical protein

RCA23_c16710 17985631798961 peptide methionine sulfoxide reductase MsrB

RCA23_c16720 17992901798958 hypothetical protein, lipoprotein

RCA23_c16730 17995411800038 hypothetical protein

$\begin{array}{lllll}\text { COG0395 } & \text { G } & 485 & 419 & 66 \\ \text { COG0395 } & \text { G } & 344 & 327 & 17 \\ \text { COG1175 } & \text { G } & 696 & 565 & 131 \\ \text { COG1653 } & \text { G } & 753 & 462 & 291 \\ \text { COG1609 } & \text { K } & 265 & 360 & -95 \\ \text { COG4989 } & \text { R } & 197 & 228 & -31 \\ \text { COG2141 } & \text { C } & 310 & 287 & 23 \\ \text { COG2188 } & \text { K } & 311 & 294 & 17 \\ \text { COG0673 } & \text { R } & 256 & 312 & -56 \\ \text { COG0166 } & \text { G } & 219 & 289 & -70 \\ \text { COG0363 } & \text { G } & 228 & 320 & -92 \\ \text { COG0364 } & \text { G } & 280 & 364 & -84 \\ \text { COG0535 } & \text { R } & 211 & 260 & -49 \\ \text { COG1403 } & \text { V } & 336 & 360 & -24 \\ \text { COG0400 } & \text { R } & 320 & 433 & -113 \\ \text { COG0122 } & \text { L } & 201 & 319 & -118 \\ \text { COG2099 } & \text { H } & 207 & 313 & -106 \\ \text { COG1903 } & \text { H } & 234 & 296 & -62 \\ \text { COG0007 } & \text { H } & 228 & 319 & -91 \\ \text { COG1797 } & \text { H } & 219 & 233 & -14 \\ & & 279 & 340 & -61 \\ \text { COG1562 } & \text { I } & 196 & 257 & -61 \\ \text { COG0215 } & \text { J } & 268 & 283 & -15 \\ \text { COG0436 } & \text { E } & 174 & 265 & -91 \\ \text { COG5598 } & \text { H } & 206 & 357 & -151 \\ \text { COG0488 } & \text { R } & 291 & 374 & -83 \\ \text { COG3176 } & \text { R } & 334 & 381 & -47 \\ \text { COG0229 } & \text { O } & 307 & 366 & -59 \\ \text { COG2913 } & \text { J } & 179 & 299 & -120 \\ \text { COG1399 } & \text { R } & 327 & 476 & -149\end{array}$


RCA23_c16740

RCA23_c16750

RCA23_c16760

RCA23_c16770

RCA23_c16790

RCA23_c16800

RCA23_c16810

RCA23_c16820

RCA23_c16830

RCA23_c16840

RCA23_c16850

RCA23_c16860

RCA23_c16870

RCA23_c16880

RCA23_c16890

RCA23_c16900

RCA23_c16910

RCA23_c16920

RCA23_c16930

RCA23_c16940

RCA23_c16950

RCA23_c16960

RCA23_c16970

RCA23_c16980

RCA23_c16990

RCA23_c17000

RCA23_c17010

RCA23_c17020

RCA23_c17030

RCA23_c17040
18004831801568 fatty acid/phospholipid synthesis protein PIsX

18015711802533 3-oxoacyl-[acyl-carrier-protein] synthase FabH

18026381802916 integration host factor alpha subunit IhfA

18029221803605 hypothetical protein, MerR family regulatory protein

18038021804875 deoxyguanosinetriphosphate triphosphohydrolase-like prote

18057461805078 putative segregation and condesation protein B

18065241805739 hypothetical protein, segregation and condensation protein

18075191806524 beta-hexosaminidase NagZ

18084201807533 hypothetical protein

18102361808491 arginyl-tRNA synthase

18114271810285 deoxyguanosinetriphosphate triphosphohydrolase-like prot $\epsilon$ COG0232

18115041811830 putative iron-sulfur insertion protein erpA

18118761812664 exodeoxyribonuclease III

18131491812685 putative cytochrome B561

18137551813333 putative dnak suppressor protein dksA

18139111814750 hypothetical protein

18149701816151 hypothetical protein

18162641816953 putative peptidase, M48 family

18174811816948 hypothetical protein

18186771817481 putative ribosomal RNA large subunit methyltransferase

18188001820605 phosphogluconate dehydratase Edd

18206311821248 KHG/KDPG aldolase Eda

18215071821208 hypothetical protein

18242171821497 glutamate-ammonia-ligase adenylyltransferase GInE

18242961824769 hypothetical protein

18248581825280 hypothetical protein

18255581825782 hypothetical protein

18260611825840 hypothetical protein

18272171826054 putative aromatic-ring-hydroxylating dioxygenase

18279321827375 putative acetolactate synthase small subunit IlvH

\begin{tabular}{|c|c|c|c|c|}
\hline COG0416 & 1 & 370 & 356 & 14 \\
\hline COG0332 & I & 321 & 335 & -14 \\
\hline COG0776 & $\mathrm{L}$ & 908 & 657 & 251 \\
\hline COG0789 & $\mathrm{K}$ & 363 & 366 & -3 \\
\hline COG0717 & $\mathrm{F}$ & 284 & 273 & 11 \\
\hline COG1386 & $\mathrm{K}$ & 292 & 333 & -41 \\
\hline COG1354 & $\mathrm{S}$ & 264 & 347 & -83 \\
\hline \multirow[t]{2}{*}{ COG1472 } & G & 233 & 290 & -57 \\
\hline & & 203 & 222 & -19 \\
\hline COG0018 & $\mathrm{J}$ & 357 & 365 & -8 \\
\hline COG0232 & $\mathrm{F}$ & 269 & 313 & -44 \\
\hline COG0316 & $S$ & 581 & 371 & 210 \\
\hline COG0708 & $\mathrm{L}$ & 439 & 421 & 18 \\
\hline COG3038 & $C$ & 276 & 347 & -71 \\
\hline COG1734 & $\mathrm{T}$ & 459 & 450 & 9 \\
\hline COG0714 & $\mathrm{R}$ & 623 & 506 & 117 \\
\hline COG3825 & $S$ & 326 & 385 & -59 \\
\hline \multirow[t]{2}{*}{ COG0501 } & 0 & 364 & 324 & 40 \\
\hline & & 233 & 300 & -67 \\
\hline COG1092 & $\mathrm{R}$ & 266 & 302 & -36 \\
\hline COG0129 & $E$ & 268 & 330 & -62 \\
\hline \multirow[t]{2}{*}{ COG0800 } & G & 181 & 211 & -30 \\
\hline & & 267 & 405 & -138 \\
\hline COG1391 & $\mathrm{O}$ & 227 & 331 & -104 \\
\hline \multirow[t]{4}{*}{ COG2606 } & $S$ & 270 & 333 & -63 \\
\hline & & 1.898 & 707 & 1.191 \\
\hline & & 304 & 243 & 61 \\
\hline & & 247 & 200 & 47 \\
\hline COG4638 & $P$ & 320 & 342 & -22 \\
\hline COG0440 & $E$ & 419 & 452 & -33 \\
\hline
\end{tabular}


RCA23_c17050 RCA23_c17060 RCA23_c17070 RCA23_c17080 RCA23_c17090 RCA23_c17100 RCA23_c17110 RCA23_c17120 RCA23_c17140 RCA23_c17150 RCA23_c17160 RCA23_c17170 RCA23_c17180 RCA23_c17190 RCA23_c17200 RCA23_c17210 RCA23_c17220 RCA23_c17230 RCA23_c17240 RCA23_c17250 18521351851050 anhydro-N-acetylmuramic acid kinase AnmK RCA23_c17260 18522021853452 tyrosyl-tRNA synthase TyrS

RCA23_c17270 18534491854615 aspartate aminotransferase AspC

RCA23_c17280 18546801856539 hypothetical protein

RCA23_c17290 18565451858056 anthranilate synthase component TrpE

RCA23_c17300 18581871859110 protein soxG

RCA23_c17310 18591141860058 protein soxH

RCA23_c17320 18612931860073 5-aminolevulinate synthase HemA

RCA23_c17330 18617471861295 sulfide dehydrogenase flavoprotein chain SoxF

RCA23_c17340 18622111861777 domain of unknown function DUF1791

RCA23_c17350 18633251862297 sulfite oxidase cytochrome subunit SoxD

$\begin{array}{llllc}\text { COG0028 } & \mathrm{E} & 380 & 318 & 62 \\ & & 724 & 550 & 174 \\ \text { COG4663 } & \mathrm{Q} & 407 & 376 & 31 \\ \text { COG4665 } & \mathrm{Q} & 711 & 490 & 221 \\ \text { COG4664 } & \mathrm{Q} & 337 & 395 & -58 \\ \text { COG2935 } & \mathrm{O} & 448 & 457 & -9 \\ \text { COG0209 } & \mathrm{F} & 477 & 377 & 100 \\ & & 175 & 144 & 31 \\ \text { COG1430 } & \mathrm{S} & 474 & 371 & 103 \\ \text { COG1278 } & \mathrm{K} & 334 & 425 & -91 \\ \text { COG0259 } & \mathrm{H} & 276 & 337 & -61 \\ \text { COG0623 } & \mathrm{I} & 385 & 443 & -58 \\ \text { COG0503 } & \mathrm{F} & 270 & 379 & -109 \\ \text { COG1957 } & \mathrm{F} & 181 & 247 & -66 \\ \text { COG0397 } & \mathrm{S} & 227 & 261 & -34 \\ \text { COG0025 } & \mathrm{P} & 328 & 487 & -159 \\ \text { COG0735 } & \mathrm{P} & 556 & 482 & 74 \\ \text { COG0697 } & \mathrm{G} & 301 & 356 & -55 \\ \text { COG0148 } & \mathrm{G} & 302 & 407 & -105 \\ \text { COG2377 } & \mathrm{O} & 202 & 334 & -132 \\ \text { COG0162 } & \mathrm{J} & 477 & 463 & 14 \\ \text { COG0436 } & \mathrm{E} & 258 & 354 & -96 \\ \text { COG0760 } & \mathrm{O} & 297 & 306 & -9 \\ \text { COG0147 } & \mathrm{E} & 224 & 249 & -25 \\ \text { COG0491 } & \mathrm{R} & 323 & 315 & 8 \\ \text { COG0491 } & \mathrm{R} & 362 & 449 & -87 \\ \text { COG0156 } & \mathrm{H} & 337 & 393 & -56 \\ \text { COG3439 } & \mathrm{S} & 404 & 468 & -64 \\ \text { COG1416 } & \mathrm{S} & 351 & 361 & -10 \\ \text { COG3474 } & \mathrm{C} & 410 & 350 & 60\end{array}$


RCA23_c17360

18663111864608 sulfur oxidation protein SoxB

RCA23_c17380 18672481866412 diheme cytochrome C

RCA23_c17390 18676051867276 protein SoxZ

RCA23_c17400 18680531867631 protein SoxY

RCA23_c17410 18685321868083 cytochrome C

RCA23_c17420 18692061868649 thioredoxin SoxW

RCA23_c17430 18699591869219 cytochrome c-type biogenesis protein SoxV

RCA23_c17440 18700301870389 protein SoxS

RCA23_c17450 18704661870801 HTH-type transcriptional regulator, ArsR family

RCA23_c17460 18708111871866 putative soxT, transmembrane protein DUF395

RCA23_c17470 18720741873135 hypothetical protein DUF395

RCA23_c17480 18740651873184 NAD-binding protein

RCA23_c17490 18750451874071 glyoxylate reductase GyaR

RCA23_c17500 18765731875236 glutamyl-tRNA(GIn) amidotransferase subunit A

RCA23_c17510 18779491876570 TRAP dicarboxylate transporter, subunit DctM

RCA23_c17520 18785811877964 TRAP dicarboxylate transporter, subunit DctQ

RCA23_c17530 18797451878651 TRAP dicarboxylate transporter, subunit DctP

RCA23_c17540 18807591880388 hypothetical protein

RCA23_c17550 18830141881539 glycerol kinase GlpK

RCA23_c17560 18837971883087 ribosomal RNA large subunit methyltransferase J

RCA23_c17570 18849191883804 putative Ppx/GppA phosphatase family protein

RCA23_c17580 18851661885453 hypothetical protein

RCA23_c17590 18854911886417 hypothetical protein

RCA23_c17600 18864301887494 pterin domain containing enzyme

RCA23_c17610 $18883071887537 \mathrm{HpcH} / \mathrm{Hpal}$ aldolase family protein

RCA23_c17620 18884661889464 glucokinase Glk

RCA23_c17630 18894511890644 hypothetical protein DUF1006

RCA23_c17640 18938591890659 reductive dehalogenase

RCA23_c17650 18948591893852 hypothetical protein, XdhC and Coxl

\begin{tabular}{|c|c|c|c|c|}
\hline COG2041 & $\mathrm{R}$ & 409 & 366 & 43 \\
\hline COG0737 & $\mathrm{F}$ & 518 & 409 & 109 \\
\hline \multirow[t]{2}{*}{ COG3258 } & $C$ & 536 & 298 & 238 \\
\hline & & 570 & 470 & 100 \\
\hline COG5501 & $S$ & 301 & 243 & 58 \\
\hline COG2010 & C & 404 & 363 & 41 \\
\hline COG2143 & 0 & 639 & 479 & 160 \\
\hline \multirow[t]{2}{*}{ COG0785 } & 0 & 588 & 396 & 192 \\
\hline & & 435 & 382 & 53 \\
\hline COG0640 & $\mathrm{K}$ & 321 & 345 & -24 \\
\hline COG2391 & $\mathrm{R}$ & 242 & 311 & -69 \\
\hline COG2391 & $\mathrm{R}$ & 383 & 379 & 4 \\
\hline COG2084 & 1 & 184 & 255 & -71 \\
\hline COG1052 & $C$ & 161 & 206 & -45 \\
\hline COG0154 & $\mathrm{J}$ & 174 & 225 & -51 \\
\hline COG4664 & $\mathrm{Q}$ & 358 & 314 & 44 \\
\hline COG4665 & $\mathrm{Q}$ & 460 & 318 & 142 \\
\hline \multirow[t]{2}{*}{ COG4663 } & $\mathrm{Q}$ & 421 & 267 & 154 \\
\hline & & 351 & 196 & 155 \\
\hline COG0554 & $C$ & 190 & 274 & -84 \\
\hline COG0293 & $J$ & 286 & 438 & -152 \\
\hline \multirow[t]{2}{*}{ COG0248 } & $\mathrm{F}$ & 321 & 343 & -22 \\
\hline & & 298 & 453 & -155 \\
\hline COG0685 & $E$ & 250 & 310 & -60 \\
\hline COG1410 & $\mathrm{E}$ & 257 & 263 & -6 \\
\hline COG3836 & $\mathrm{G}$ & 262 & 427 & -165 \\
\hline COG0837 & $\mathrm{G}$ & 320 & 380 & -60 \\
\hline COG3214 & $S$ & 188 & 320 & -132 \\
\hline COG1018 & $C$ & 279 & 315 & -36 \\
\hline COG1975 & 0 & 205 & 328 & -123 \\
\hline
\end{tabular}


RCA23_c17660

RCA23_c17670

RCA23_C17680

RCA23_C17690

RCA23_c17700

RCA23_c17710 19005911900169 nucleoside diphosphate kinase Ndk

RCA23_c17720 19007441902597 hypothetical protein

RCA23_c17730 19026291904470 ABC transporter ATP-binding protein

RCA23_c17740 19044631905104 MarC family integral membrane protein

RCA23_c17750 19051381905722 hypothetical protein

RCA23_c17760 19061911905760 putative DNA polymerase III chi subunit, HolC

RCA23_c17770 19077131906223 cytosol aminopeptidase PepA

RCA23_c17780 19078351908953 puative permease, YjgP/YjgQ family

RCA23_c17790 19089501910047 puative permease, YjgP/YjgQ family

RCA23_c17800 19100781912183 putative organic solvent tolerance protein

RCA23_c17810 19121961913395 hypothetical protein, SurA

RCA23_c17820 19134621914475 4-hydroxythreonine-4-phosphate dehydrogenase PdxA

RCA23_c17830 19144651915301 dimethyladenosine transferase KsgA

RCA23_c17840 19160861915556 hypothetical protein

RCA23_c17850 19171671916316 modification methylase, hemK family

RCA23_c17860 19182131917164 peptide chain release factor 1

RCA23_c17870 19186601918274 hypothetical protein

RCA23_c17880 19197091918672 agmatinase SpeB

RCA23_c17890 19199321920441 alpha/beta hydrolase

RCA23_c17900 19214511920480 agmatinase SpeB

RCA23_c17910 19226181921452 hippurate hydrolase HipO

RCA23_c17920 19226681923480 protein MazG

RCA23_c17930 19235461924556 ABC transporter periplasmic iron-binding protein FutA

RCA23_c17940 19251791924631 putative peptidyl-prolyl cis-trans isomerase Ppi

RCA23_c17950 19256841925172 putative peptidyl-prolyl cis-trans isomerase Ppi

\begin{tabular}{|c|c|c|c|c|}
\hline COG2084 & 1 & 232 & 253 & -21 \\
\hline COG1028 & 1 & 356 & 301 & 55 \\
\hline COG0129 & $\mathrm{E}$ & 259 & 298 & -39 \\
\hline \multirow[t]{2}{*}{ COG0179 } & $Q$ & 276 & 301 & -25 \\
\hline & & 128 & 158 & -30 \\
\hline \multirow[t]{2}{*}{ COG0105 } & $\mathrm{F}$ & 455 & 256 & 199 \\
\hline & & 97 & 96 & 1 \\
\hline COG0488 & $\mathrm{R}$ & 222 & 265 & -43 \\
\hline COG2095 & $U$ & 403 & 394 & 9 \\
\hline COG3577 & $\mathrm{R}$ & 305 & 350 & -45 \\
\hline COG2927 & L & 209 & 241 & -32 \\
\hline COG0260 & $\mathrm{E}$ & 268 & 371 & -103 \\
\hline COG0795 & $\mathrm{R}$ & 524 & 334 & 190 \\
\hline COG0795 & $\mathrm{R}$ & 326 & 382 & -56 \\
\hline COG1452 & M & 375 & 389 & -14 \\
\hline COG0760 & 0 & 287 & 313 & -26 \\
\hline COG1995 & $\mathrm{H}$ & 207 & 256 & -49 \\
\hline \multirow[t]{2}{*}{ COG0030 } & J & 179 & 238 & -59 \\
\hline & & 300 & 334 & -34 \\
\hline COG2890 & J & 353 & 442 & -89 \\
\hline COG0216 & J & 222 & 312 & -90 \\
\hline COG4446 & $S$ & 205 & 218 & -13 \\
\hline \multirow[t]{2}{*}{ COG0010 } & $E$ & 232 & 318 & -86 \\
\hline & & 162 & 268 & -106 \\
\hline COG0010 & $\mathrm{E}$ & 226 & 300 & -74 \\
\hline COG1473 & $\mathrm{R}$ & 195 & 320 & -125 \\
\hline COG3956 & $\mathrm{R}$ & 366 & 371 & -5 \\
\hline COG1840 & $P$ & 270 & 407 & -137 \\
\hline COG0652 & 0 & 284 & 433 & -149 \\
\hline COG0652 & 0 & 415 & 489 & -74 \\
\hline
\end{tabular}


RCA23_c17960

RCA23_c17970

RCA23_c17980

RCA23_c17990

RCA23_c18000

RCA23_C18010

RCA23_c18020

RCA23_c18030

RCA23_c18040

RCA23_c18050

RCA23_c18060

RCA23_c18070

RCA23_c18080

RCA23_C18090

RCA23_c18100

RCA23_c18110

RCA23_c18120

RCA23_c18130

RCA23_c18140

RCA23_c18160

RCA23_c18170

RCA23_c18190

RCA23_c18180

RCA23_c18200

RCA23_c18210

RCA23_c18220

RCA23_c18230

RCA23_C18240

RCA23_C18250

RCA23_c18260
19258051926983 phosphoglycerate kinase Pgk

19270911927984 fructose-bisphosphate aldolase class 1

19280741928373 hypothetical protein, septum formation initiator

19284911929489 pyruvate dehydrogenase E1 component alpha subunit Pdht COG1071

19294931930863 pyruvate dehydrogenase E1 component beta subunit PdhB COG0022

19308741932154 dihydrolipoyllysine-residue acetyltransferase PdhC

19330341932237 serine acetyltransferase CysE

19342501933132 putative gene transfer agent protein

19351481934639 putative gene transfer agent large terminase part 1

19360441935133 putative gene transfer agent large terminase part 2

19375431936392 aminodeoxychorismate lyase

19387741937545 3-oxoacyl-[acyl-carrier-protein] synthase FabF

19391801938947 acyl carrier protein AcpP

19401361939399 3-oxoacyl-[acyl-carrier-protein] reductase FabG

19411231940194 malonyl CoA-acyl carrier protein transacylase

19414091941774 30S ribosomal protein S6

19417881942015 30S ribosomal protein S18

1942052194264550 S ribosomal protein L9

19441851942854 trigger factor (TF)

19446351944973 nitrogen regulatory protein P-|I 1

19450001946403 glutamine synthase GlnA type I

19472741946483 hypothetical protein

19472531948665 dimethylpropiothetin dethiomethylase DddP

19493381948739 Biotin transporter BioY

19498821949370 hypothetical protein

19499911951268 adenylosuccinate lyase PurB

19513521951684 putative nitrile hydratase, beta subunit

19516811951938 hypothetical protein

19519381952600 nitrile hydratase alpha subunit NthA

19525971953469 hypothetical protein DUF6 transmembrane
COG0126

COG3588

COG0508

COG1045

COG5323 S

COG5323 S

COG1559 R

COG0304

COG0236

COG1028

COG0331

COG0360

COG0238

COG0359

COG0544

COG0347

COG0174

COG0006 E

COG1268

COG0015

COG0697

G

$\begin{array}{ccc}223 & 274 & -51 \\ 219 & 411 & -192 \\ 299 & 324 & -25 \\ 443 & 418 & 25 \\ 414 & 346 & 68 \\ 253 & 284 & -31 \\ 711 & 414 & 297 \\ 109 & 156 & -47 \\ 8 & 55 & -47 \\ 121 & 191 & -70 \\ 246 & 282 & -36 \\ 379 & 520 & -141 \\ 739 & 630 & 109 \\ 252 & 290 & -38 \\ 204 & 295 & -91 \\ 443 & 354 & 89 \\ 560 & 410 & 150 \\ 546 & 404 & 142 \\ 758 & 494 & 264 \\ 931 & 485 & 446 \\ 786 & 431 & 355 \\ 262 & 401 & -139 \\ 254 & 366 & -112 \\ 244 & 323 & -79 \\ 250 & 326 & -76 \\ 256 & 334 & -78 \\ 324 & 231 & 93 \\ 218 & 264 & -46 \\ 166 & 214 & -48 \\ 213 & 283 & -70 \\ & & \end{array}$




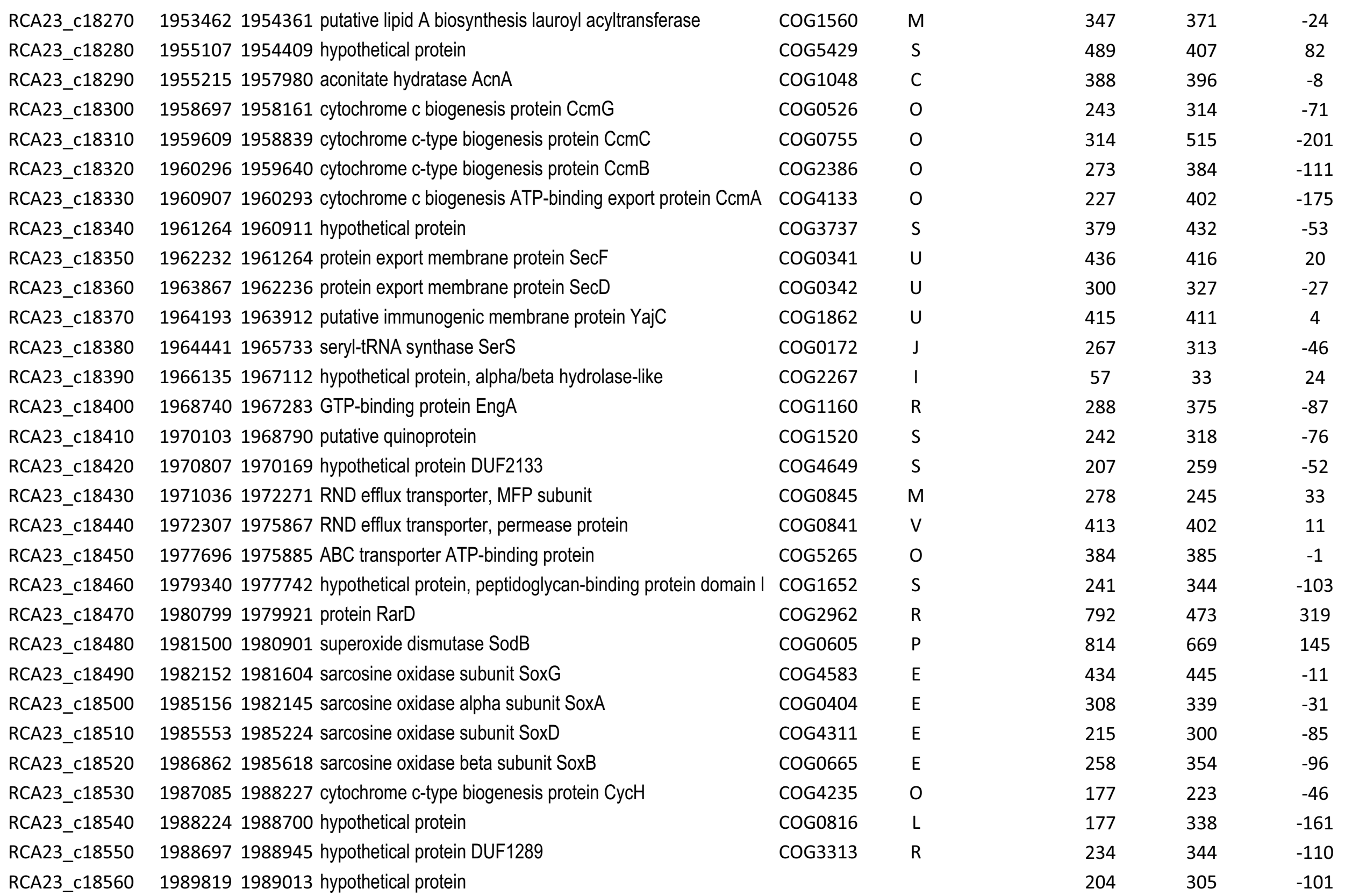


RCA23_c18570

RCA23_C18580

RCA23_c18590 19923841991857 putative peroxiredoxin (thioredoxin reductase)

RCA23_c18600 19934731992418 benzaldehyde dehydrogenase

RCA23_c18610 19941441993836 hypothetical protein

RCA23_c18620 19954541994423 hypothetical protein

RCA23_c18630 19956761996863 MFS-type transporter

RCA23_c18640 19969891997762 sorbitol dehydrogenase

RCA23_c18650 19977731999044 6-hydroxynicotinate 3-monooxygenase

RCA23_c18660 19996551999212 hypothetical protein

RCA23_c18670 20010361999702 glycerate kinase

RCA23_c18680 20010932001482 putative carboxymuconolactone decarboxylase

RCA23_c18690 20015632003575 2,4-dienoyl-CoA reductase [NADPH]

RCA23_c18700 20052392003572 thiamine pyrophosphate protein

RCA23_c18710 20063142005394 rffG/rfbB: dTDP-glucose 4,6-dehydratase

RCA23_c18720 20074892006419 hypothetical protein

RCA23_c18730 20075062009269 choline dehydrogenase BetA

RCA23_c18740 20101312009487 succinyl-CoA:3-ketoacid-coenzyme A transferase subunit S COG2057

RCA23_c18750 20108262010131 succinyl-CoA:3-ketoacid-coenzyme A transferase subunit S COG1788

RCA23_c18760 20112952011669 hypothetical membrane protein

RCA23_c18770 20128572011751 putative dimethyl sulfoniopropionate demethylase DmdA

RCA23_c18780

RCA23_c18790

RCA23_c18800

RCA23_c18810

RCA23_c18820

RCA23_c18830

RCA23_c18840

RCA23_c18850

RCA23_c18860
20131302015229 hydantoin utilization protein A

20152262016950 hydantoin utilization protein B

20169512018159 FAD dependent oxidoreductase

20181592018995 hypothetical protein, 3-beta hydroxysteroid dehydrogenase

20190842019956 hypothetical protein, serine/threonine-protein kinase

20211042019980 hypothetical protein

20221022021257 hypothetical protein DUF1989

20222032023267 putative diaminopropionate ammonia-lyase

20232672024406 hypothetical protein, metallopeptidase M24

\begin{tabular}{|c|c|c|c|c|}
\hline COG0730 & $\mathrm{R}$ & 187 & 292 & -105 \\
\hline COG0042 & $J$ & 192 & 241 & -49 \\
\hline COG0678 & 0 & 16 & 6 & 10 \\
\hline \multirow[t]{2}{*}{ COG1012 } & C & 10 & 6 & 4 \\
\hline & & 22 & 7 & 15 \\
\hline COG2130 & $\mathrm{R}$ & 336 & 356 & -20 \\
\hline COG2814 & $\mathrm{G}$ & 221 & 315 & -94 \\
\hline COG1028 & 1 & 202 & 295 & -93 \\
\hline \multirow[t]{2}{*}{ COG0654 } & $\mathrm{H}$ & 179 & 183 & -4 \\
\hline & & 176 & 334 & -158 \\
\hline COG2379 & $\mathrm{G}$ & 170 & 266 & -96 \\
\hline COG0599 & $S$ & 406 & 540 & -134 \\
\hline COG1902 & $C$ & 246 & 338 & -92 \\
\hline COG0028 & $E$ & 182 & 231 & -49 \\
\hline \multirow[t]{2}{*}{ COG1088 } & $M$ & 332 & 308 & 24 \\
\hline & & 322 & 352 & -30 \\
\hline COG2303 & $\mathrm{E}$ & 198 & 304 & -106 \\
\hline COG2057 & 1 & 338 & 422 & -84 \\
\hline \multirow[t]{2}{*}{ COG1788 } & 1 & 799 & 597 & 202 \\
\hline & & 419 & 471 & -52 \\
\hline COG0404 & $E$ & 288 & 455 & -167 \\
\hline COG0145 & $E$ & 214 & 300 & -86 \\
\hline COG0146 & $E$ & 190 & 304 & -114 \\
\hline COG0665 & $\mathrm{E}$ & 250 & 294 & -44 \\
\hline COG0451 & $M$ & 280 & 321 & -41 \\
\hline COG1262 & $S$ & 160 & 199 & -39 \\
\hline COG0457 & $\mathrm{R}$ & 168 & 236 & -68 \\
\hline COG3665 & $S$ & 128 & 236 & -108 \\
\hline COG1171 & $E$ & 156 & 175 & -19 \\
\hline COG0006 & $\mathrm{E}$ & 270 & 264 & 6 \\
\hline
\end{tabular}


RCA23_c18870

RCA23_c18880

RCA23_c18890

RCA23_c18900

RCA23_c18910

RCA23_c18920

RCA23_c18930

RCA23_c18940

RCA23_c18950

RCA23_c18960

RCA23_c18970

RCA23_c18980

RCA23_c18990

RCA23_c19000

RCA23_c19010

RCA23_c19020

RCA23_c19030

RCA23_c19040

RCA23_c19050

RCA23_c19060

RCA23_c19070

RCA23_c19080

RCA23_c19090

RCA23_c19100

RCA23_c19110

RCA23_c19120 20526302052070 putative 5 -formyltetrahydrofolate cyclo-ligase family protein

RCA23_c19130 20540002052627 magnesium transporter MgtE

RCA23_c19140 20540722055358 guanine deaminase GuaD

RCA23_c19150 20567652055422 putative hydroxydechloroatrazine ethylaminohydrolase

RCA23_c19160 20575822056758 putative inositol monophosphatase family protein

20265492025953 hypothetical protein DUF1185

20276342026561 limonene 1,2-monooxygenase LimB
COG3473

20259602025172 putative 3-oxoadipate enol-lactonase 2, alpha/beta hydrolas COG0596

COG2141

COG1012

20303362029185 ABC transporter, spermidine/putrescine import, permease $p$ COG1177

20316822030432 ABC transporter, spermidine/putrescine import, permease $p$ COG1176

20328422031745 ABC transporter, spermidine/putrescine import, substrate bi COG0687

20340102032913 ABC transporter, spermidine/putrescine import, ATP-bindin! COG3842

COG1853

Q

$\mathrm{R}$

224

239

$-15$

$268 \quad 310$

$387 \quad 557$

$291 \quad 316$

$197 \quad 267$

$398 \quad 447$

$339 \quad 358$

$397 \quad 254$

$529 \quad 415$

$273 \quad 303$

$334 \quad 290$

$633 \quad 385$

COG0217

COG0471

COG0697

COG1692

338

338

237

COG1764

COG1250

COG0703

COG0824

COG0369

COG3396

COG1024

COG0596

COG0318

COG0212

COG2239

COG0402

COG0402

COG0483 
RCA23 c19170

RCA23_c19180

RCA23_c19190

RCA23_c19200

RCA23_c19210

RCA23_c19220

RCA23_c19230

RCA23_c19240

RCA23_c19250

RCA23_c19260

RCA23_C19270

RCA23_c19280

RCA23_c19290

RCA23_c19300

RCA23_c19310

RCA23_c19320

RCA23_c19330

RCA23_c19340

RCA23_c19350

RCA23_c19360

RCA23_c19370

RCA23_c19380

RCA23_c19390

RCA23_c19400

RCA23_c19410

RCA23_c19420

RCA23_c19430

RCA23_c19440

RCA23_c19450

RCA23_c19460
20579842057688 putative helix-turn-helix protein

20583652059330 putative alcohol dehydrogenase

20594412060259 putative inner membrane protein

20606152061193 hypothetical protein

20619602061328 putative N-acetylmuramoyl-L-alanine amidase amiD

20625502062017 hypothetical protein

20640752062591 glutamyl-tRNA(GIn) amidotransferase subunit A

20643622064075 aspartyl/glutamyl-tRNA(Asn/GIn) amidotransferase subunit

20648832064449 putative deaminase

20649472065729 putative ribosomal large subunit pseudouridine synthase B 20668112065744 molybdate ABC transporter, ATP-binding protein ModC

20674942066808 molybdate ABC transporter, pemease protein ModB

20683182067491 molybdate ABC transporter, substrate binding protein Mod $A$

20683282068789 hypothetical protein, NUDIX hydrolase

20688662069288 hypothetical protein DUF1178

20693882070611 aspartokinase LysC

20706262072872 phosphoenolpyruvate-protein phosphotransferase Pstl

20735082073008 hypothetical protein, acetyltransferase-like

20735812074186 hypothetical protein

20758482074217 putative sulfate transporter

20760312076906 methylthioadenosine phosphorylase MtnP

20769632077523 adenine phosphoribosyltransferase Apt

20781042077520 ribosomal-protein-alanine acetyltransferase RimJ

20793702078108 uncharacterized zinc protease YmxG

20807522079367 threonine synthase ThrC

20814732080763 hypothetical protein, SURF1

20823282081525 cytochrome c oxidase subunit 3

20829162082347 cytochrome c oxidase assembly protein CtaG

20840332083098 protoheme IX farnesyltransferase CtaB

20849042084056 cytochrome c oxidase subunit 2 precursor

$\begin{array}{ll}\text { COG1396 } & \text { K } \\ \text { COG0604 } & \text { C } \\ \text { COG0670 } & \text { R } \\ & \\ \text { COG3023 } & \text { V } \\ & \\ \text { COG0154 } & \text { J } \\ \text { COG0721 } & \text { J } \\ \text { COG0590 } & \mathrm{F} \\ \text { COG1187 } & \mathrm{J} \\ \text { COG4148 } & \mathrm{P} \\ \text { COG4149 } & \mathrm{P} \\ \text { COG0725 } & \mathrm{P} \\ \text { COG0494 } & \mathrm{L} \\ \text { COG5319 } & \mathrm{S} \\ \text { COG0527 } & \mathrm{E} \\ \text { COG3605 } & \mathrm{T} \\ \text { COG3153 } & \mathrm{R} \\ \text { COG1853 } & \mathrm{R} \\ \text { COG0659 } & \mathrm{P} \\ \text { COG0005 } & \mathrm{F} \\ \text { COG0503 } & \mathrm{F} \\ \text { COG1670 } & \mathrm{J} \\ \text { COG0612 } & \mathrm{R} \\ \text { COG0498 } & \mathrm{E} \\ \text { COG3346 } & \mathrm{S} \\ \text { COG1845 } & \mathrm{C} \\ \text { COG3175 } & \mathrm{O} \\ \text { COG0109 } & \mathrm{O} \\ \text { COG1622 } & \mathrm{C}\end{array}$

318

258

331

60

$-63$

$\begin{array}{lll}1.541 & 607 & 934\end{array}$

$1.346 \quad 656 \quad 690$

$151 \quad 239 \quad-88$

$243 \quad 299 \quad-56$

$294 \quad 350 \quad-56$

$232 \quad 432 \quad-200$

$205 \quad 227 \quad-22$

$199 \quad 273 \quad-74$

$209 \quad 359 \quad-150$

$241 \quad 332 \quad-91$

$231 \quad 310 \quad-79$

$206 \quad 453 \quad-247$

$451 \quad 394 \quad 57$

$283 \quad 299 \quad-16$

$212 \quad 271 \quad-59$

$164 \quad 260 \quad-96$

$202 \quad 219 \quad-17$

$264 \quad 369 \quad-105$

$204 \quad 304 \quad-100$

$276 \quad 337 \quad-61$

$\begin{array}{lll}240 & 287 & -47\end{array}$

$351 \quad 418 \quad-67$

$301 \quad 345 \quad-44$

$\begin{array}{lll}421 & 448 & -27\end{array}$

$694 \quad 471 \quad 223$

$694 \quad 524 \quad 170$

$436 \quad 515 \quad-79$

$\begin{array}{lll}794 & 480 & 314\end{array}$ 
RCA23_c19470

RCA23_c19480

RCA23_c19490

RCA23_c19500

RCA23_c19510

RCA23_c19520

RCA23_c19530

RCA23_c19540

RCA23_c19550

RCA23_c19560

RCA23_c19570

RCA23_c19580

RCA23_c19590

RCA23_c19600

RCA23_c19610

RCA23_C19620

RCA23_c19630

RCA23_C19640

RCA23_c19650

RCA23_c19660

RCA23_c19670

RCA23_c19680

RCA23_c19690

RCA23_c19700

RCA23_c19710

RCA23_c19720

RCA23_c19730

RCA23_c19740

RCA23_c19750

RCA23_c19760
20850932086514 protein TldD

20866482087799 SMF family protein

20878892090483 DNA topoisomerase TopA

20913322090493 fructose-bisphosphate aldolase Fba

20921712091329 5-deoxy-glucuronate isomerase lolB

20931642092175 5-dehydro-2-deoxygluconokinase lolC

20950382093167 3D-(3,5/4)-trihydroxycyclohexane-1,2-dione hydrolase loID

20963662095143 hypothetical protein DUF989

20967312096378 5-hydroxyisourate hydrolase UraH

20967942098206 uric acid degradation bifunctional protein PucL

20991612098337 putative allantoin catabolism protein YlbA

20993792100608 sarcosine oxidase beta subunit SoxB

21006222100909 sarcosine oxidase subunit SoxD

21009062103860 sarcosine oxidase alpha subunit SoxA

21038532104413 sarcosine oxidase subunit SoxG

21054502104446 putative HTH-type transcriptional regulator, AraC family

21055192106172 putative DNA-binding protein

21065992106183 putative membrane protein

21070642107477 hypothetical protein

21082272107835 hypothetical protein, thioesterase

21088922108230 hypothetical protein, calcineurin-like phosphoesterase-like

21113602108931 putative DEAD/DEAH box helicase

21123022111400 bidunctional enzyme FolD

21140642112388 formate--tetrahydrofolate ligase Fhs

21149592114357 hypothetical protein

21169372115018 cell division protease FtsH

21182542117031 tRNA(lle)-lysidine synthase TilS

21190392118251 hypothetical protein

21195392119039 peptidoglycan-associated lipoprotein Pal

21209162119594 Tol-Pal system beta propeller repeat protein TolB
COG0312 R

COG0758 L

COG0550 L

COG0191 G

COG3718 G

COG0524

COG3962

COG3748

COG2351

COG3195

COG3257

COG0665

COG4311

COG0404

COG4583

COG4977

COG1396

COG2050

COG1407

COG1201

COG0190

COG2759

COG0465

COG0037

COG1729

COG 2885

COG0823

$\begin{array}{lll}190 & 276 & -86 \\ 160 & 264 & -104 \\ 240 & 343 & -103 \\ 226 & 349 & -123 \\ 378 & 459 & -81 \\ 203 & 302 & -99 \\ 218 & 303 & -85 \\ 398 & 405 & -7 \\ 330 & 328 & 2 \\ 210 & 248 & -38 \\ 252 & 300 & -48 \\ 248 & 344 & -96 \\ 235 & 330 & -95 \\ 185 & 228 & -43 \\ 217 & 262 & -45 \\ 207 & 326 & -119 \\ 275 & 407 & -132 \\ 218 & 337 & -119 \\ 576 & 510 & 66 \\ 412 & 379 & 33 \\ 271 & 407 & -136 \\ 207 & 359 & -152 \\ 301 & 440 & -139 \\ 356 & 344 & 12 \\ 275 & 383 & -108 \\ 464 & 415 & 49 \\ 188 & 268 & -80 \\ 214 & 219 & -5 \\ 189 & 256 & -67 \\ 269 & 322 & -53\end{array}$


RCA23_c19770 21219082120913 hypothetical protein, TolA-like

RCA23_c19780 21225202122056 biopolymer transport protein TolR

RCA23_c19790 21232042122530 biopolymer transport protein TolQ

RCA23_c19800 21236402123296 acyl-CoA thioester hydrolase

RCA23_c19810 21243112123682 hypothetical protein

RCA23_c19820 21254472124398 holliday junction ATP-dependent DNA helicase RuvB

RCA23_c19830 21261182125444 holliday junction ATP-dependent DNA helicase RuvA

RCA23_c19840 21266212126115 crossover junction endodeoxyribonuclease RuvC

RCA23_c19850 21280582127186 putative ribosomal protein L11 methyltransferase

RCA23_c19860 21288422128189 peptide methionine sulfoxide reductase MsrA

RCA23_c19870 21301392128931 hypothetical protein, major facilitator superfamily transporter

RCA23_c19880

RCA23_c19890

RCA23_c19900

RCA23_c19910

RCA23_c19920

RCA23_c19930

RCA23_c19940

RCA23_c19950

RCA23_c19960

RCA23_c19970

RCA23_c19980

RCA23_c19990

RCA23_c20000

RCA23_c20010

RCA23_c20020

RCA23_c20030

RCA23_c20040

RCA23_c20050

RCA23_c20060
21302892131452 L-lactate dehydrogenase IIdD

21333772131542 BCCT family transporter involved in DMSP uptake

21348412133696 putative MFS-type transporter

2134970213560550 S ribosomal protein L25

21357322136418 peptidyl-tRNA hydrolase Pth

21364152137437 hypothetical protein

21374392137810 hypothetical protein

21390682137836 tryptophan synthase beta chain TrpB

21397892139151 N-(5'-phosphoribosyl)anthranilate isomerase TrpF

21401212139786 hypothetical protein

21404222140141 integration host factor beta subunit IhfB

2142345214068430 S ribosomal protein S1

21426052142934 hypothetical protein

21439682142946 hypothetical protein, lacl family HTH-type regulatory protein

21440502145192 putative phytanoyl-CoA dioxygenase

21461372145199 aldo/keto reductase

21468552146184 cytidylate kinase Cmk

21482012146852 3-phosphoshikimate 1-carboxyvinyltransferase AroA

21489972148275 tRNA (guanine-N(7)-)-methyltransferase TrmB

\begin{tabular}{|c|c|}
\hline COG0848 & U \\
\hline COG0811 & $U$ \\
\hline COG0824 & $\mathrm{R}$ \\
\hline COG2255 & $\mathrm{L}$ \\
\hline COG0632 & $\mathrm{L}$ \\
\hline COG0817 & $\mathrm{L}$ \\
\hline COG2264 & $\mathrm{J}$ \\
\hline COG0225 & $\mathrm{O}$ \\
\hline COG1304 & C \\
\hline COG1292 & $M$ \\
\hline COG1825 & $\mathrm{J}$ \\
\hline COG0193 & $\mathrm{J}$ \\
\hline COG4427 & $\mathrm{S}$ \\
\hline COG3651 & $\mathrm{S}$ \\
\hline COG0133 & $E$ \\
\hline COG0135 & $E$ \\
\hline COG0776 & $\mathrm{L}$ \\
\hline COG0539 & J \\
\hline COG1609 & K \\
\hline COG5285 & $\mathrm{Q}$ \\
\hline COG0667 & C \\
\hline COG0283 & $F$ \\
\hline COG0128 & $E$ \\
\hline COG0220 & $\mathrm{R}$ \\
\hline
\end{tabular}

$\begin{array}{llc}194 & 283 & -89 \\ 204 & 389 & -185 \\ 243 & 362 & -119 \\ 206 & 269 & -63 \\ 225 & 325 & -100 \\ 212 & 330 & -118 \\ 241 & 443 & -202 \\ 211 & 426 & -215 \\ 199 & 331 & -132 \\ 470 & 535 & -65 \\ 568 & 531 & 37 \\ 384 & 429 & -45 \\ 415 & 398 & 17 \\ 335 & 395 & -60 \\ 907 & 573 & 334 \\ 315 & 395 & -80 \\ 189 & 250 & -61 \\ 233 & 303 & -70 \\ 369 & 326 & 43 \\ 185 & 217 & -32 \\ 393 & 402 & -9 \\ 601 & 452 & 149 \\ 695 & 460 & 235 \\ 405 & 426 & -21 \\ 159 & 288 & -129 \\ 353 & 567 & -214 \\ 253 & 316 & -63 \\ 198 & 213 & -15 \\ 215 & 383 & -168 \\ 237 & 310 & -73\end{array}$


RCA23_c20070

RCA23_c20080

RCA23_c20090

RCA23_c20100

RCA23_c20110

RCA23_c20120

RCA23_c20130

RCA23_c20140

RCA23_c20150

RCA23_c20160

RCA23_c20170

RCA23_c20180

RCA23_c20190

RCA23_c20200

RCA23_c20210

RCA23_c20220

RCA23_c20230

RCA23_c20240

RCA23_c20250

RCA23_c20260

RCA23_c20270

RCA23_c20280

RCA23_c20290

RCA23_c20300

RCA23_c20310

RCA23_c20320

RCA23_c20330

RCA23_c20340

RCA23_c20350

RCA23_c20360
21502232149042 S-adenosylmethionine synthase MetK

21517672150271 apolipoprotein N-acyltransferase Lnt

21526412151742 putative magnesium and cobalt efflux protein

21531412152638 hypothetical protein UPF0054

21541362153138 PhoH-like protein

21555642154233 RNA modification enzyme, MiaB family

21556292156543 hypothetical protein

21569862156552 putative ferric uptake regulator family protein

21571432157652 3-hydroxydecanoyl-[acyl-carrier-protein] dehydratase FabA

21576672158896 3-oxoacyl-[acyl-carrier-protein] synthase FabB

21589012159689 enoyl-[acyl-carrier-protein] reductase Fabl

21607152159738 threo-3-hydroxyaspartate ammonia-lyase SRY

21614022160719 2-haloalkanoic acid dehalogenase

21614602162248 3-oxoadipate enol-lactonase CatD

21622682163494 putative tetracycline resistance protein, class C

21635102164649 NAD/mycothiol-dependent formaldehyde dehydrogenase

21647042165945 D-galactonate dehydratase DgoD

21684332165986 dimethylglycine dehydrogenase

21700442168488 trimethylamine methyltransferase MttB

21701932170597 hypothetical protein

21706292171999 uncharacterized aminotransferase

21721542173251 aminomethyltransferase, mitochondrial

21732652173630 glycine cleavage system protein GcvH

21736792176525 glycine dehydrogenase GcvP

21778472176510 D-amino acid dehydrogenase small subunit DadA

21779272178970 putrescine $A B C$ transport system putrescine-binding peripla

21802462179164 putrescine ABC transport system ATP-binding protein PotG

21810582180243 putrescine $A B C$ transport system permease protein Potl

21818882181055 putrescine $A B C$ transport system permease protein PotB

21831332181934 rieske $2 \mathrm{Fe}-2 \mathrm{~S}$ domain protein

$\begin{array}{ll}\text { COG0192 } & \text { H } \\ \text { COG0815 } & \text { M } \\ \text { COG1253 } & \text { R } \\ \text { COG0319 } & \text { R } \\ \text { COG1702 } & \text { T } \\ \text { COG0621 } & \text { J } \\ & \\ \text { COG0735 } & \text { P } \\ \text { COG0764 } & \text { I } \\ \text { COG0304 } & \text { I } \\ \text { COG0623 } & \text { I } \\ \text { COG1171 } & \text { E } \\ \text { COG1011 } & \text { R } \\ \text { COG0596 } & R \\ \text { COG2814 } & \text { G } \\ \text { COG1062 } & \text { C } \\ \text { COG4948 } & \text { M } \\ \text { COG0404 } & \text { E } \\ \text { COG5598 } & \text { H } \\ \text { COG0607 } & \text { P } \\ \text { COG0161 } & \text { H } \\ \text { COG0404 } & \text { E } \\ \text { COG0509 } & \text { E } \\ \text { COG1003 } & \text { E } \\ \text { COG0665 } & \text { E } \\ \text { COG0687 } & \text { E } \\ \text { COG3842 } & \text { E } \\ \text { COG1177 } & \text { E } \\ \text { COG1176 } & \text { E } \\ \text { COG4638 } & \text { P }\end{array}$

$\begin{array}{llc}360 & 341 & 19 \\ 237 & 319 & -82 \\ 383 & 427 & -44 \\ 368 & 393 & -25 \\ 275 & 401 & -126 \\ 275 & 292 & -17 \\ 513 & 459 & 54 \\ 537 & 555 & -18 \\ 376 & 331 & 45 \\ 361 & 339 & 22 \\ 292 & 375 & -83 \\ 167 & 199 & -32 \\ 258 & 323 & -65 \\ 289 & 372 & -83 \\ 193 & 322 & -129 \\ 189 & 249 & -60 \\ 320 & 382 & -62 \\ 269 & 340 & -71 \\ 270 & 344 & -74 \\ 248 & 216 & 32 \\ 325 & 341 & -16 \\ 364 & 312 & 52 \\ 591 & 456 & 135 \\ 291 & 292 & -1 \\ 184 & 266 & -82 \\ 343 & 375 & -32 \\ 257 & 331 & -74 \\ 470 & 610 & -140 \\ 607 & 570 & 37 \\ 465 & 415 & 50\end{array}$


RCA23_c20370

RCA23_c20380

RCA23_c20390

RCA23_c20400

RCA23_c20410

RCA23_c20420

RCA23_c20430

RCA23_c20440

RCA23_c20450

RCA23_c20460

RCA23_c20470

RCA23_c20480

RCA23_c20490

RCA23_c20500

RCA23_c20510

RCA23_c20520 219

RCA23_c20530

RCA23_c20540

RCA23_c20550

RCA23_c20560 22023892201403 hypothetical protein, acetyltransferase-like

RCA23_c20570

RCA23_c20580 22036012202786 pyrroline-5-carboxylate reductase ProC

RCA23_c20590 22041382203635 hypothetical protein DUF1790

RCA23_c20600 22047112204427 hypothetical protein DUF526

RCA23_c20610 22048592205740 prolipoprotein diacylglyceryl transferase Lgt

RCA23_c20620 22057072206798 hypothetical protein DUF185

RCA23_c20630 22067952207550 multi-copper polyphenol oxidoreductase laccase

RCA23_c20640 22087282207769 hypothetical protein

RCA23_c20650 22094822208988 leucine-responsive regulatory protein Lrp

RCA23_c20660 22096682210609 thioredoxin reductase TrxB

\begin{tabular}{|c|c|c|c|c|}
\hline COG1593 & G & 441 & 547 & -106 \\
\hline COG3090 & G & 521 & 546 & -25 \\
\hline COG1638 & G & 328 & 358 & -30 \\
\hline COG5285 & $Q$ & 167 & 221 & -54 \\
\hline COG1018 & $C$ & 203 & 273 & -70 \\
\hline COG2151 & $\mathrm{R}$ & 161 & 250 & -89 \\
\hline COG3396 & $S$ & 230 & 299 & -69 \\
\hline COG3460 & $Q$ & 272 & 347 & -75 \\
\hline COG3396 & $S$ & 292 & 384 & -92 \\
\hline COG3327 & $\mathrm{K}$ & 194 & 338 & -144 \\
\hline COG1012 & C & 200 & 257 & -57 \\
\hline COG1024 & 1 & 157 & 198 & -41 \\
\hline COG2050 & $Q$ & 207 & 193 & 14 \\
\hline COG0183 & 1 & 159 & 218 & -59 \\
\hline COG1541 & $\mathrm{H}$ & 258 & 377 & -119 \\
\hline COG1309 & $\mathrm{K}$ & 255 & 313 & -58 \\
\hline COG0757 & $E$ & 480 & 484 & -4 \\
\hline COG0076 & $E$ & 256 & 302 & -46 \\
\hline COG0300 & $\mathrm{R}$ & 180 & 216 & -36 \\
\hline COG1247 & $M$ & 188 & 325 & -137 \\
\hline COG0073 & $\mathrm{R}$ & 280 & 393 & -113 \\
\hline COG0345 & $E$ & 179 & 341 & -162 \\
\hline COG5465 & $S$ & 484 & 467 & 17 \\
\hline COG2960 & $S$ & 356 & 344 & 12 \\
\hline COG0682 & $M$ & 217 & 274 & -57 \\
\hline COG1565 & $S$ & 183 & 256 & -73 \\
\hline \multirow[t]{2}{*}{ COG1496 } & $S$ & 267 & 296 & -29 \\
\hline & & 176 & 115 & 61 \\
\hline COG1522 & $\mathrm{K}$ & 252 & 363 & -111 \\
\hline COG0492 & 0 & 277 & 273 & 4 \\
\hline
\end{tabular}


RCA23_c20670

RCA23_c20680

RCA23_c20690

RCA23_c20700

RCA23_c20710

RCA23_c20720

RCA23_c20730

RCA23_c20740

RCA23_c20750

RCA23_c20760

RCA23_c20770

RCA23_c20780

RCA23_c20790

RCA23_c20800 22228472223821 putative membrane lipoprotein

RCA23_c20810 22245472223837 hypothetical protein DUF261

RCA23_c20820 22246002225517 putative manganese-dependent inorganic pyrophosphatase

RCA23_c20830 22255352226407 hypothetical protein, HAD family hydrolase

RCA23_c20840 22264922226935 putative MaoC-like dehydratase

RCA23_c20850 22269972227944 riboflavin biosynthesis protein RibF

RCA23_c20860 22279412228405 hypothetical protein UPF0260

RCA23_c20870 22284092229458 low specificity L-threonine aldolase ItaE

RCA23_c20880 22301572229510 hypothetical protein, 2-hydroxychromene-2-carboxylate isor

RCA23_c20890

RCA23_c20900

RCA23_c20910

RCA23_20920

RCA23_ 2092022335192232095 ATP synthase beta subunit AtpD

RCA23 20940 22359532234418 ATP synthase gamma chain AlpG

RCA23_c20950 22365202235954 ATP synthase delta chain AtpH

RCA23_c20960 22375062236745 hypothetical protein
COG2046

COG0071

COG5481

COG0041

COG0026

COG1075

COG0459

COG0234

COG0006

E

COG5482

COG1227

COG0647

COG2030

COG0196

COG2983

COG2008

COG3917

COG0462

COG0355

COG0055

COG0224

COG0056

COG0712
P

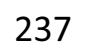

237
755

293

497

$739 \quad 516$

$416 \quad 481$

$324 \quad 250$

$192 \quad 252$

$302 \quad 371$

$1.092 \quad 481$

$1.580 \quad 549$

$272 \quad 228$

$311 \quad 282$

$256 \quad 251$

$207 \quad 242$

$262 \quad 439$

$192 \quad 370$

$323 \quad 325$

$261 \quad 348$

$300 \quad 344$

$281 \quad 423$

$370 \quad 349$

$279 \quad 242$

$254 \quad 239$

$351 \quad 337$

$339 \quad 407$

$217 \quad 213$

$765 \quad 423$

$785 \quad 455$

$653 \quad 400$

$742 \quad 430$

$238 \quad 284$
$-56$

258

223

$-65$

74

$-60$

$-69$

611

1.031

44

29

5

$-35$

$-177$

$-178$

$-2$

$-87$

$-44$

$-142$

21

37

15

14

$-68$

4

342

330

253

312

$-46$ 
RCA23_c20970

RCA23_c20980

RCA23_c20990

RCA23_c21000

RCA23_c21010

RCA23_c21020

RCA23_c21030

RCA23_c21040

RCA23_c21050

RCA23_c21060

RCA23_c21070

RCA23_c21080 22545942252333 vitamin B12-dependent ribonucleoside-diphosphate reducta

RCA23_c21090 22547542255152 hypothetical protein

RCA23_c21100 22558302255156 ATP-phosphoribosyltransferase HisG

RCA23_c21110 22568732255827 ATP phosphoribosyltransferase regulatory subunit HisZ

RCA23_c21120 22583752256870 histidyl-tRNA synthase HisS

RCA23_c21130 22584242258699 hypothetical protein

RCA23_c21140 22622382258738 DNA polymerase III 1 alpha subunit DnaE

RCA23_c21150 22626292263969 xanthine dehydrogenase XdhA

RCA23_c21160 22639662266269 xanthine dehydrogenase XdhB

RCA23_c21170 22662662267186 xanthine dehydrogenase accessory protein XdhC

RCA23_c21180 22671832268688 sugar ABC transporter, ATP-binding protein

RCA23_c21190 22686752269760 sugar ABC transporter, permease protein

RCA23_c21200 22697412270742 ABC transporter permease protein

RCA23_c21210 22707702271849 putative basic membrane protein

RCA23_c21220 22719332273012 putative FAD dependent oxidoreductase

RCA23_c21230 22755632273065 dimethylglycine dehydrogenase

RCA23_c21240 22757722276626 pantothenate synthase PanC

RCA23_c21250 22766232277435 3-methyl-2-oxobutanoate hydroxymethyltransferase PanB

RCA23_c21260 22774692277984 hypothetical protein

\begin{tabular}{|c|c|c|c|c|}
\hline COG0491 & $\mathrm{R}$ & 203 & 292 & -89 \\
\hline COG0542 & 0 & 394 & 338 & 56 \\
\hline \multirow[t]{2}{*}{ COG1360 } & $\mathrm{N}$ & 305 & 321 & -16 \\
\hline & & 257 & 346 & -89 \\
\hline COG3703 & $P$ & 210 & 316 & -106 \\
\hline COG1357 & $S$ & 297 & 248 & 49 \\
\hline COG0287 & $E$ & 207 & 274 & -67 \\
\hline COG0079 & $E$ & 204 & 333 & -129 \\
\hline COG0522 & $J$ & 558 & 359 & 199 \\
\hline COG0513 & $\mathrm{L}$ & 271 & 328 & -57 \\
\hline COG3011 & $S$ & 295 & 410 & -115 \\
\hline COG0209 & $\mathrm{F}$ & 354 & 420 & -66 \\
\hline COG5458 & $S$ & 170 & 273 & -103 \\
\hline COG0040 & $E$ & 238 & 409 & -171 \\
\hline COG3705 & $E$ & 159 & 258 & -99 \\
\hline COG0124 & $J$ & 253 & 369 & -116 \\
\hline COG2900 & $S$ & 209 & 308 & -99 \\
\hline COG0587 & $\mathrm{L}$ & 327 & 386 & -59 \\
\hline COG4630 & $\mathrm{F}$ & 236 & 242 & -6 \\
\hline COG4631 & $\mathrm{F}$ & 224 & 287 & -63 \\
\hline COG1975 & 0 & 208 & 245 & -37 \\
\hline COG3845 & $\mathrm{R}$ & 202 & 224 & -22 \\
\hline COG4603 & $\mathrm{R}$ & 330 & 307 & 23 \\
\hline COG1079 & $\mathrm{R}$ & 283 & 408 & -125 \\
\hline COG1744 & $\mathrm{R}$ & 455 & 356 & 99 \\
\hline COG0665 & $E$ & 164 & 201 & -37 \\
\hline COG0404 & $E$ & 264 & 326 & -62 \\
\hline COG0414 & $\mathrm{H}$ & 240 & 384 & -144 \\
\hline COG0413 & $\mathrm{H}$ & 307 & 438 & -131 \\
\hline COG3807 & $S$ & 226 & 318 & -92 \\
\hline
\end{tabular}


RCA23_c21270 22800102277986 peptidyl-dipeptidase Dcp

RCA23_c21280 22810462279997 molybdopterin biosynthesis protein MoeB

RCA23_c21290 22815042281043 deoxyuridine 5'-triphosphate nucleotidohydrolase Dut

RCA23_c21300 22826912281501 coenzyme A biosynthesis bifunctional protein CoaBC

RCA23_c21310 22836262282748 RNA polymerase sigma-32 factor RpoH

RCA23_c21320 22837162284249 bifunctional adenosylcobalamin biosynthesis protein CobP

RCA23_c21330 22842462284818 putative phosphoglycerate mutase family protein

RCA23_c21340 22848822285307 hypothetical protein, glutathione S-transferase

RCA23_c21350 22853232285757 glutathione S-transferase family protein

RCA23_c21360 22858292286233 magnesium chelatase-like protein

RCA23_c21370 22862302287420 magnesium chelatase

RCA23_c21380 22881092287342 putative transmembrane protein

RCA23_c21390 22890262288109 putative sulfite exporter TauE/SafE

RCA23_c21400 22902742289135 branched-chain amino acid transporter, permease compone

RCA23_c21410 22913402290279 branched-chain amino acid transporter, permease compont

RCA23_c21420 22929162291381 ABC transporter ATP-binding protein

RCA23_c21430 22939902292992 putative ABC transporter, periplasmic substrate-binding pro

RCA23_c21440 22945872294177 hypothetical protein, acetyltransferase-like

RCA23_c21450 22951612294598 NifU-like protein

RCA23_c21460 22957622295250 putative universal stress protein

RCA23_c21470 22968782295862 tryptophanyl-tRNA synthase TrpS

RCA23_c21480 22969522297626 hypothetical protein, rhomboid protease

RCA23_c21490 22991732297638 virulence factor MviN homolg

RCA23_c21500 23019382299170 uridylyltransferase GlnD

RCA23_c21510 23031312301941 hypothetical protein

RCA23_c21520 23031642304075 putative tetrapyrrole methylase

RCA23_c21530 23040802304448 hypothetical protein UPF0102

RCA23_c21540 23045472305485 glutathione synthase GshB

RCA23_c21550 23063302305503 putative esterase/lipase

RCA23_c21560 23068062306327 NusB-like protein NusB

$\begin{array}{lllll}\text { COG0339 } & \mathrm{E} & 227 & 267 & -40 \\ \text { COG0476 } & \mathrm{H} & 211 & 292 & -81 \\ \text { COG0756 } & \mathrm{F} & 194 & 283 & -89 \\ \text { COG0452 } & \mathrm{H} & 292 & 263 & 29 \\ \text { COG0568 } & \mathrm{K} & 992 & 490 & 502 \\ \text { COG2087 } & \mathrm{H} & 179 & 216 & -37 \\ \text { COG0406 } & \mathrm{G} & 125 & 238 & -113 \\ \text { COG0625 } & \mathrm{O} & 225 & 320 & -95 \\ & & 215 & 332 & -117 \\ \text { COG0606 } & \mathrm{O} & 225 & 250 & -25 \\ \text { COG0606 } & \mathrm{O} & 163 & 269 & -106 \\ & & 338 & 385 & -47 \\ \text { COG0730 } & \mathrm{R} & 370 & 455 & -85 \\ \text { COG1079 } & \mathrm{R} & 267 & 471 & -204 \\ \text { COG4603 } & \mathrm{R} & 290 & 336 & -46 \\ \text { COG3845 } & \mathrm{R} & 317 & 388 & -71 \\ \text { COG1744 } & \mathrm{R} & 354 & 382 & -28 \\ \text { COG0456 } & \mathrm{R} & 209 & 279 & -70 \\ \text { COG0694 } & \mathrm{O} & 409 & 435 & -26 \\ \text { COG0589 } & \mathrm{T} & 518 & 514 & 4 \\ \text { COG0180 } & \mathrm{J} & 372 & 400 & -28 \\ \text { COG0705 } & \mathrm{R} & 167 & 212 & -45 \\ \text { COG0728 } & \mathrm{R} & 237 & 404 & -167 \\ \text { COG2844 } & \mathrm{O} & 288 & 413 & -125 \\ \text { COG0683 } & \mathrm{E} & 173 & 274 & -101 \\ \text { COG0313 } & \mathrm{R} & 201 & 203 & -2 \\ \text { COG0792 } & \mathrm{L} & 245 & 322 & -77 \\ \text { COG0189 } & \mathrm{H} & 319 & 394 & -75 \\ \text { COG0657 } & \mathrm{I} & 327 & 376 & -49 \\ \text { COG0781 } & \mathrm{K} & 272 & 421 & -149\end{array}$


RCA23_c21570

RCA23_C21580

RCA23_C21590

RCA23_C21600

RCA23_c21610

RCA23_c21620 23117502313762 putative capsule polysaccharide export protein

RCA23_c21630 23148532313759 riboflavin biosynthesis protein RibD

RCA23_c21640 23153172314850 transcriptional repressor NrdR

RCA23_c21650 23174852315515 RNA polymerase sigma factor RpoD

RCA23_c21660 23195482317602 DNA primase DnaG

RCA23_c21670 23201082319557 sarcosine oxidase subunit SoxG

RCA23_c21680 23230312320101 sarcosine oxidase alpha subunit SoxA

RCA23_c21690 23232702323034 sarcosine oxidase subunit SoxD

RCA23_c21700 23246112323358 sarcosine oxidase beta subunit SoxB

RCA23_c21710 23254162324724 phosphatidylserine decarboxylase proenzyme Psd

RCA23_c21720 23258102325421 diacylglycerol kinase

RCA23_c21730 23273992325807 putative sulfatase

RCA23_c21740 23281222327421 hypothetical protein, CDP-alcohol phosphatidyltransferase-I

RCA23_c21750 23287182328254 hypothetical protein

RCA23_c21760 23294212328897 hypothetical protein

RCA23_c21770 23303562329541 hypothetical protein, DUF1705

RCA23_c21780 23319192330483 glutamate dehydrogenase GluD

RCA23_c21790 23324952331998 hypothetical protein

RCA23_c21800 23335292332585 2-hydroxy-3-oxopropionate reductase GarR

RCA23_c21810 23335442334782 reductive dehalogenase

RCA23_c21820 23348392335750 pirin

RCA23_c21830 23363332335734 transcriptional regulator

RCA23_c21840 23364132336667 hypothetical protein

RCA23_c21850 23367872338076 homoserine dehydrogenase Hom

RCA23_c21860 23382092339174 fructose-1,6-bisphosphatase class II

$\begin{array}{lllll}\text { COG0054 } & \mathrm{H} & 240 & 301 & -61 \\ \text { COG0108 } & \mathrm{H} & 374 & 499 & -125 \\ \text { COG0307 } & \mathrm{H} & 371 & 609 & -238 \\ \text { COG3562 } & \mathrm{M} & 318 & 279 & 39 \\ \text { COG1596 } & \mathrm{M} & 203 & 186 & 17 \\ \text { COG3563 } & \mathrm{M} & 150 & 241 & -91 \\ \text { COG0117 } & \mathrm{H} & 190 & 222 & -32 \\ \text { COG1327 } & \mathrm{K} & 348 & 414 & -66 \\ \text { COG0568 } & \mathrm{K} & 608 & 437 & 171 \\ \text { COG0358 } & \mathrm{L} & 355 & 423 & -68 \\ \text { COG4583 } & \mathrm{E} & 231 & 384 & -153 \\ \text { COG0404 } & \mathrm{E} & 196 & 307 & -111 \\ \text { COG4311 } & \mathrm{E} & 308 & 398 & -90 \\ \text { COG0665 } & \mathrm{E} & 245 & 350 & -105 \\ \text { COG0688 } & \mathrm{I} & 550 & 425 & 125 \\ \text { COG0818 } & \mathrm{M} & 881 & 641 & 240 \\ \text { COG2194 } & \mathrm{R} & 919 & 638 & 281 \\ \text { COG1183 } & \mathrm{I} & 809 & 632 & 177 \\ \text { COG0671 } & \mathrm{I} & 526 & 430 & 96 \\ \text { COG2194 } & \mathrm{R} & 558 & 446 & 112 \\ \text { COG2194 } & \mathrm{R} & 624 & 467 & 157 \\ \text { COG0334 } & \mathrm{E} & 314 & 332 & -18 \\ & & 258 & 365 & -107 \\ \text { COG2084 } & \mathrm{I} & 329 & 359 & -30 \\ \text { COG1600 } & \mathrm{C} & 264 & 315 & -51 \\ \text { COG1741 } & \mathrm{R} & 430 & 440 & -10 \\ \text { COG1309 } & \mathrm{K} & 274 & 419 & -145 \\ & & 261 & 359 & -98 \\ \text { COG0460 } & \mathrm{E} & 298 & 326 & -28 \\ \text { COG1494 } & \mathrm{G} & 221 & 267 & -46\end{array}$


RCA23_c21870

RCA23_c21890 23418842341321 sulfopyruvate decarboxylase beta subunit ComE

RCA23_c21900 23423622341886 sulfopyruvate decarboxylase alpha subunit ComD

RCA23_c21910 23433772342394 zinc-type alcohol dehydrogenase

RCA23_c21920 23441442343386 gluconate 5-dehydrogenase Gno

RCA23_c21930 23454642344148 histidinol dehydrogenase HisD

RCA23_c21940 23455182346576 HTH-type transcriptional regulator, Lacl family

RCA23_c21950 23473692346614 HTH-type transcriptional regulator, IcIR family

RCA23_c21960 23475142349115 alcohol dehydrogenase AlkJ

RCA23_c21970 23491492349817 integral membrane protein TerC

RCA23_c21980 23499362351048 putative TRAP transporter, DctP subunit

RCA23_c21990 23511682353642 TRAP transporter, DctM/DctQ subunit

RCA23_c22000 23554282353818 trimethylamine methyltransferase

RCA23_c22010 23561562355458 putative HAD-family hydrolase

RCA23_c22020 23564372356156 hypothetical protein

RCA23_c22030 23567662356512 hypothetical protein

RCA23_c22040 23570792356789 hypothetical protein

RCA23_c22050 23572612357656 hypothetical protein

RCA23_c22060 23577412358352 hypothetical protein, NUDIX hydrolase

RCA23_c22070 23592312358332 hypothetical protein

RCA23_c22080 23601462359235 putative fatty acid desaturase

RCA23_c22090 23602332361102 putative helix-turn-helix protein

RCA23_c22100 23618542361099 short chain dehydrogenase

RCA23_c22110 23633202361851 putative 3-hydroxyacyl-CoA dehydrogenase

RCA23_c22130 23643642363357 hypothetical protein, DUF849

RCA23_c22120 23643452365316 transcriptional regulator, AraC family

RCA23_c22140 23663652365322 protein Tas

RCA23_c22150 23664652367088 hypothetical protein

RCA23_c22160 23671822368417 putative MFS-type transporter

RCA23_c22170 23684752370187 methionyl-tRNA synthase MetG

\begin{tabular}{|c|c|c|c|c|}
\hline COG0608 & $\mathrm{L}$ & 211 & 311 & -100 \\
\hline COG0028 & $\mathrm{E}$ & 560 & 522 & 38 \\
\hline COG4032 & $\mathrm{R}$ & 797 & 611 & 186 \\
\hline COG1063 & E & 316 & 480 & -164 \\
\hline COG1028 & I & 200 & 301 & -101 \\
\hline COG0141 & $\mathrm{E}$ & 306 & 379 & -73 \\
\hline COG1609 & K & 291 & 268 & 23 \\
\hline COG1414 & K & 263 & 354 & -91 \\
\hline COG2303 & $\mathrm{E}$ & 278 & 286 & -8 \\
\hline COG0861 & $\mathrm{P}$ & 322 & 278 & 44 \\
\hline COG4663 & $Q$ & 464 & 312 & 152 \\
\hline COG4664 & $Q$ & 296 & 253 & 43 \\
\hline COG5598 & $\mathrm{H}$ & 411 & 403 & 8 \\
\hline \multirow[t]{4}{*}{ COG0546 } & $\mathrm{R}$ & 278 & 354 & -76 \\
\hline & & 306 & 534 & -228 \\
\hline & & 187 & 301 & -114 \\
\hline & & 143 & 183 & -40 \\
\hline COG5349 & $S$ & 172 & 246 & -74 \\
\hline \multirow[t]{2}{*}{ COG0494 } & $\mathrm{L}$ & 185 & 264 & -79 \\
\hline & & 240 & 315 & -75 \\
\hline COG3239 & 1 & 238 & 271 & -33 \\
\hline COG1396 & K & 271 & 380 & -109 \\
\hline COG1028 & 1 & 199 & 337 & -138 \\
\hline COG1250 & 1 & 222 & 316 & -94 \\
\hline COG3246 & $S$ & 198 & 375 & -177 \\
\hline COG4977 & K & 181 & 300 & -119 \\
\hline COG0667 & C & 249 & 289 & -40 \\
\hline COG4544 & $S$ & 139 & 266 & -127 \\
\hline COG2211 & G & 250 & 323 & -73 \\
\hline COG0143 & $\mathrm{J}$ & 246 & 334 & -88 \\
\hline
\end{tabular}


RCA23_c22190

RCA23_c22200

RCA23_c22210

RCA23_c22220

RCA23_c22230

RCA23_c22240

RCA23_c22250

RCA23_c22260

RCA23_c22270

RCA23_c22280

RCA23_c22290

RCA23_c22300

RCA23_c22310

RCA23_c22320

RCA23_c22330

RCA23_c22340

RCA23_c22350

RCA23_c22360

RCA23_c22370

RCA23_c22380

RCA23_c22390

RCA23_c22400

RCA23_c22410

RCA23_c22420

RCA23_c22430

RCA23_c22440

RCA23_c22450

RCA23_c22460

RCA23_c22470

RCA23_c22480
23706892372218 integrase

23726852372215 integrase

23731392373477 putative nucleotidyl transferase

23751422374411 hypothetical protein

23758732375142 hypothetical protein

23764332375873 putative replication factor C, small subunit

23774322376614 hypothetical protein

23776432378410 hypothetical protein

23805402379620 ParB-like nuclease

23806792383024 cadmium-transporting ATPase CadA

23831902383600 hypothetical protein

23840252383591 putative lipoprotein signal peptidase

23848262384065 putative ZIP zinc transporter

23852902384874 hypothetical protein DUF411

23859432385320 SCO-like protein

23863202385943 hypothetical protein

23870892386430 hypothetical protein

23875112387086 hypothetical protein, disulfide bond formation protein

23880802387508 SCO-like protein

23882772388705 putative HTH-type transcriptional regulator

23887082389034 hypothetical protein UPF0060

23891052389329 hypothetical protein

23902642389434 hypothetical protein

23924062391699 transposase

23935152392478 MORN motif precursor

23945922393885 transposase

23949532394711 hypothetical protein

23955282395211 hypothetical protein

23964642395883 hypothetical protein

23972012396467 hypothetical protein

$\begin{array}{lccccc} & & \mathrm{Gl} 8 & 337 & 236 & 101 \\ \text { COG4974 } & \mathrm{L} & \mathrm{Gl} 8 & 417 & 345 & 72 \\ \text { COG1210 } & \mathrm{M} & \mathrm{Gl} 8 & 343 & 199 & 144 \\ & & \mathrm{Gl} 8 & 371 & 226 & 145 \\ & & \mathrm{Gl} 8 & 424 & 250 & 174 \\ \text { COG2256 } & \mathrm{L} & \mathrm{Gl} 8 & 578 & 315 & 263 \\ & & \mathrm{Gl} 8 & 378 & 220 & 158 \\ & & \mathrm{Gl} 8 & 363 & 260 & 103 \\ \text { COG1475 } & \mathrm{K} & \mathrm{Gl} 8 & 484 & 357 & 127 \\ \text { COG2217 } & \mathrm{P} & \mathrm{Gl} 8 & 160 & 160 & 0 \\ \text { COG3034 } & \mathrm{S} & \mathrm{Gl} 8 & 193 & 223 & -30 \\ \text { COG0597 } & \mathrm{M} & \mathrm{Gl} 8 & 324 & 287 & 37 \\ \text { COG0428 } & \mathrm{P} & \mathrm{Gl} 8 & 206 & 270 & -64 \\ \text { COG3019 } & \mathrm{R} & \mathrm{Gl} 8 & 365 & 300 & 65 \\ \text { COG1999 } & \mathrm{R} & \mathrm{Gl} 8 & 251 & 222 & 29 \\ \text { COG2847 } & \mathrm{S} & \mathrm{Gl} 8 & 208 & 146 & 62 \\ \text { COG1651 } & \mathrm{O} & \mathrm{Gl} 8 & 162 & 177 & -15 \\ \text { COG1495 } & \mathrm{O} & \mathrm{Gl} 8 & 213 & 286 & -73 \\ \text { COG1999 } & \mathrm{R} & \mathrm{Gl} 8 & 225 & 229 & -4 \\ \text { COG0789 } & \mathrm{K} & \mathrm{Gl} 8 & 204 & 271 & -67 \\ \text { COG1742 } & \mathrm{S} & \mathrm{Gl} 8 & 176 & 169 & 7 \\ & & \mathrm{Gl} 8 & 272 & 193 & 79 \\ \text { COG3316 } & \mathrm{L} & \mathrm{Gl} 8 & 84 & 88 & -4 \\ \text { COG4642 } & \mathrm{S} & \mathrm{Gl} 8 & 283 & 186 & 97 \\ \text { COG3316 } & \mathrm{L} & \mathrm{Gl} 8 & 8 & 0 & 8 \\ & & \mathrm{Gl} 8 & 13 & 0 & 13 \\ \text { COG3295 } & \mathrm{S} & \mathrm{Gl} 8 & 2.261 & 1.424 & 837 \\ & & \mathrm{Gl} 8 & 42 & 18 & 24 \\ \mathrm{Gl} 8 & 64 & 18 & 46\end{array}$


RCA23_c22490

RCA23_c22500 23981052398617 transcriptional regulator, LuxR family

COG2197

COG3316

RCA23_c22510 23995032398796 hypothetical protein

COG5616

RCA23_c22520

RCA23_c22530

24010192399598 hypothetical protein, HTH-type transcriptional regulator, Lux

24013092402388 cysteine synthase CysK

COG0031

RCA23_c22540 24026682402847 hypothetical protein

RCA23_c22550 24029042403158 hypothetical protein

RCA23_c22560 24032662403550 hypothetical protein

RCA23_c22570 24037312404039 hypothetical protein

RCA23_c22580 24041652404464 hypothetical protein

RCA23_c22590 24049002406312 coniferyl aldehyde dehydrogenase CalB

(1)

RCA23_c22600 24073392406443 regulatory protein NocR

RCA23_c22610 24074782408791 sn-glycerol-3-phosphate-binding periplasmic protein UgpB

RCA23_c22620 24088672409748 sn-glycerol-3-phosphate transport system permease proteir

RCA23 c22630

24097902410626 sn-glycerol-3-phosphate transport system permease proteir

RCA23_c22640

24106342411680 sn-glycerol-3-phosphate import ATP-bindingprotein UgpC

RCA23_c22650 24116802412570 putative glycerophosphoryl diester phosphodiesterase

RCA23_c22660 24147042413001 aerobic glycerol-3-phosphate dehydrogenase GIpD

RCA23_c22670 24164222414794 hypothetical protein, Na+/Pi-cotransporter

RCA23_c22680 24172692416478 hypothetical protein, calcineurin-like phosphoesterase-like

RCA23_c22690 24180752417266 ABC transporter permease protein

RCA23_c22700 24189652418072 ABC transporter permease protein

RCA23_c22710 24203182419050 ABC transporter extracellular solute-binding protein

RCA23_c22720 24213802420382 ABC transporter ATP-binding protein

RCA23_c22730 24222582421398 HTH-type transcriptional regulator, DeoR family

RCA23_c22740 24225992423399 HAD-superfamily hydrolase, subfamily IIB

RCA23_c22750 24239212424865 putative inner membrane transporter

RCA23_c22760 24249872426117 soluble aldose sugar dehydrogenase Ylil

RCA23_c22770 24263012427080 putative FKBP-type peptidyl-prolyl cis-trans isomerase

RCA23_c22780 24271172427665 putative NnrU family protein

\begin{tabular}{|c|c|}
\hline COG5470 & $S$ \\
\hline COG1012 & C \\
\hline COG0583 & K \\
\hline COG1653 & G \\
\hline COG1175 & G \\
\hline COG0395 & G \\
\hline COG3839 & G \\
\hline COG0584 & C \\
\hline COG0578 & C \\
\hline COG1283 & $\mathrm{P}$ \\
\hline COG1409 & $\mathrm{R}$ \\
\hline COG0395 & G \\
\hline COG1175 & G \\
\hline COG1653 & G \\
\hline COG3839 & G \\
\hline COG1349 & K \\
\hline COG0561 & $\mathrm{R}$ \\
\hline COG0697 & G \\
\hline COG2133 & G \\
\hline COG0545 & $\mathrm{O}$ \\
\hline COG4094 & $S$ \\
\hline
\end{tabular}

0
24
5
40
64
137
135
150
67
91
349
256
431
568
590
527
368
212
144
166
173
166
305
233
194
192
285
223
37
65




\begin{tabular}{|c|c|c|c|c|c|}
\hline & & GI 8 & 23 & 19 & 4 \\
\hline \multirow[t]{2}{*}{ COG0863 } & $\mathrm{L}$ & GI 8 & 71 & 54 & 17 \\
\hline & & GI 8 & 33 & 23 & 10 \\
\hline COG5410 & $S$ & GI 8 & 38 & 24 & 14 \\
\hline COG1961 & $\mathrm{L}$ & GI 8 & 34 & 19 & 15 \\
\hline \multirow[t]{2}{*}{ COG0582 } & $\mathrm{L}$ & GI 8 & 0 & 3 & -3 \\
\hline & & GI 8 & 0 & 0 & 0 \\
\hline \multirow[t]{3}{*}{ COG3311 } & $K$ & GI 8 & 15 & 3 & 12 \\
\hline & & GI 8 & 3 & 3 & 0 \\
\hline & & GI 8 & 85 & 61 & 24 \\
\hline COG5545 & $\mathrm{R}$ & GI 8 & 168 & 114 & 54 \\
\hline \multirow[t]{2}{*}{ COG2998 } & $\mathrm{H}$ & GI 8 & 14 & 7 & 7 \\
\hline & & GI 8 & 126 & 134 & -8 \\
\hline COG3316 & $\mathrm{L}$ & GI 8 & 1 & 0 & 1 \\
\hline COG0303 & $\mathrm{H}$ & GI 8 & 53 & 66 & -13 \\
\hline COG1763 & $\mathrm{H}$ & GI 8 & 82 & 88 & -6 \\
\hline COG0746 & $\mathrm{H}$ & GI 8 & 207 & 166 & 41 \\
\hline COG1526 & C & GI 8 & 171 & 128 & 43 \\
\hline COG0314 & $\mathrm{H}$ & GI 8 & 65 & 59 & 6 \\
\hline COG1977 & $\mathrm{H}$ & GI 8 & 163 & 66 & 97 \\
\hline COG3328 & $\mathrm{L}$ & GI 8 & 158 & 124 & 34 \\
\hline \multirow[t]{2}{*}{ COG2896 } & $\mathrm{H}$ & GI 8 & 105 & 125 & -20 \\
\hline & & GI 8 & 163 & 189 & -26 \\
\hline COG3839 & G & GI 8 & 113 & 81 & 32 \\
\hline COG4662 & $\mathrm{H}$ & GI 8 & 107 & 61 & 46 \\
\hline COG2864 & C & GI 8 & 213 & 101 & 112 \\
\hline COG0437 & C & GI 8 & 155 & 92 & 63 \\
\hline COG0243 & C & GI 8 & 116 & 75 & 41 \\
\hline domain & & GI 8 & 62 & 49 & 13 \\
\hline COG3381 & $\mathrm{R}$ & GI 8 & 126 & 84 & 42 \\
\hline
\end{tabular}


RCA23 c23090

RCA23_c23100

RCA23_c23110

RCA23_c23120

RCA23_C23130

RCA23_c23140

RCA23_c23150

RCA23_c23160

RCA23_c23170

RCA23_c23180

RCA23_c23190

RCA23_c23200

RCA23_c23210

RCA23_c23220

RCA23_c23230

RCA23_c23240

RCA23_c23250

RCA23_c23260

RCA23_c23270

RCA23_c23280

RCA23_c23290

RCA23_c23300

RCA23_c23310

RCA23_c23320

RCA23_c23330

RCA23_c23340

RCA23_c23350

RCA23_c23360

RCA23_c23370

RCA23_c23380
24589492458320 hypothetical protein

24594762458946 putative molybdopterin-guanine dinucleotide biosynthesis protein A

24598072461798 hypothetical protein, $4 \mathrm{Fe}-4 \mathrm{~S}$ ferredoxin-like

COG1148

24625172461792 hypothetical protein

24626132462804 hypothetical protein

24628052463860 hypothetical protein, Mrp/NBP35 family protein

24638572464570 hypothetical protein

24645722465081 hypothetical protein

24660572465644 putative phage terminase

24670572466350 transposase

24671312467988 putative phage helicase

24685812468237 hypothetical protein

24689972470031 putative pyridoxal 4-dehydrogenase

24708452470078 2-dehydro-3-deoxy-D-gluconate 5-dehydrogenase KduD

24719942470855 putative L-rhamnonate dehydratase rhamD

24728262471987 ureidoglycolate lyase

24738122472823 D-3-phosphoglycerate dehydrogenase

24745582473809 uncharacterized oxidoreductase

24748722474555 putative rhamnose mutarotase RhaM

24756362474872 putative acetoacetate decarboxylase Adc

24766592475637 uncharacterized oxidoreductase

24774162476673 transcriptional regulator, GntR family

COG0489

COG0340

24784082477413 putative ribose ABC transport system, permease protein Rc COG1172

24794722478405 putative ribose $A B C$ transport system, permease protein Rk COG1172

24809802479472 ribose import ABC transporter, ATP-binding protein RbsA COG1129

24820932481056 putative rhamnose ABC transport system, substrate-bindinc COG1879

24823102483446 galactonate dehydratase

24834612484276 xylose isomerase-like

24844192484691 putative aldo/keto reductase

COG4948

COG1082

COG0667

COG3618
117

51

81

89

86

67

92

15

1

70

73

57

75

64

90

68

35

51

88

77

81

111

87

68

47

46

66

56

56

75
135 
RCA23_C23390

RCA23_c23400 24876352486928 transposase

RCA23_c23410 24880602487743 L-rhamnose mutarotase RhaM

RCA23_c23420 24893472488439 ureidoglycolate lyase

RCA23_c23430 24903602489458 dihydrodipicolinate synthase DapA

RCA23_c23440 24914042490508 amidohydrolase

RCA23_c23450 24922282491446 3-ketoacyl-(acyl-carrier-protein) reductase FabG

RCA23_c23460 24935592492393 L-rhamnonate dehydratase RhmD

RCA23_c23470 24947112493587 polyamine ABC transporter, ATP-binding protein PotA

RCA23_c23480 24955712494786 polyamine ABC transporter, permease protein

RCA23_c23490 24965612495575 polyamine ABC transporter, permease protein

RCA23_c23500 24977432496676 polyamine ABC transporter, substrate binding protein

RCA23_c23510 24983852498131 hypothetical protein

RCA23_c23520 24987242498401 hypothetical protein

RCA23_c23530 24995062498760 uncharacterized oxidoreductase

RCA23_c23540 25008182499526 L-rhamnonate dehydratase

RCA23_c23550 25018382500861 ribose ABC transport system, permease protein RbsC

RCA23_c23560 25026562501835 ribose import ABC transporter, ATP-binding protein RbsA

RCA23_c23570 25037522502640 ribose import $A B C$ transporter, substrate binding protein $R b$

RCA23_c23580 25039242504961 HTH-type transcriptional regulator, GntR family

RCA23_c23590 25051042505304 hypothetical protein

RCA23_c23600 25061632506816 putative DNA-binding protein

RCA23_c23610 25073672508263 glutamine amidotransferase-like protein GlxB

RCA23_c23620 25082652508942 glutamate synthase alpha subunit GIXC

RCA23_c23630 25089542510294 glutamate synthase large subunit GIXD

RCA23_c23640 25103642511698 glutamine synthase GInA type III

RCA23_c23650 25124092513053 hypothetical protein

RCA23_c23660 25132212514510 methyltrasnferase

RCA23_c23670 25145072514890 hypothetical protein

RCA23_c23680 25148802516313 putative terminase, large subunit

\begin{tabular}{|c|c|c|c|c|c|}
\hline & & GI 8 & 58 & 21 & 37 \\
\hline COG3316 & $\mathrm{L}$ & GI 8 & 31 & 25 & 6 \\
\hline COG3254 & $S$ & GI 8 & 80 & 22 & 58 \\
\hline COG0179 & $Q$ & GI 8 & 23 & 20 & 3 \\
\hline COG0329 & $E$ & GI 8 & 43 & 31 & 12 \\
\hline COG3618 & $\mathrm{R}$ & GI 8 & 67 & 20 & 47 \\
\hline COG1028 & 1 & GI 8 & 85 & 52 & 33 \\
\hline COG4948 & $M$ & Gl 8 & 28 & 27 & 1 \\
\hline COG3842 & $\mathrm{E}$ & GI 8 & 14 & 8 & 6 \\
\hline COG1177 & $E$ & GI 8 & 22 & 19 & 3 \\
\hline COG1176 & $E$ & GI 8 & 21 & 7 & 14 \\
\hline \multirow[t]{3}{*}{ COG0687 } & $\mathrm{E}$ & GI 8 & 13 & 9 & 4 \\
\hline & & GI 8 & 21 & 11 & 10 \\
\hline & & GI 8 & 12 & 4 & 8 \\
\hline COG1028 & 1 & GI 8 & 31 & 16 & 15 \\
\hline COG4948 & $M$ & GI 8 & 25 & 20 & 5 \\
\hline COG1172 & G & GI 8 & 5 & 21 & -16 \\
\hline COG1129 & $\mathrm{G}$ & GI 8 & 17 & 16 & 1 \\
\hline COG1879 & G & Gl 8 & 14 & 13 & 1 \\
\hline COG1609 & $\mathrm{K}$ & GI 8 & 18 & 19 & -1 \\
\hline COG3311 & $\mathrm{K}$ & GI 8 & 39 & 9 & 30 \\
\hline COG1396 & $\mathrm{K}$ & GI 8 & 29 & 12 & 17 \\
\hline COG0067 & $E$ & GI 8 & 41 & 12 & 29 \\
\hline COG0070 & $E$ & GI 8 & 20 & 3 & 17 \\
\hline COG0069 & $E$ & GI 8 & 18 & 6 & 12 \\
\hline \multirow[t]{2}{*}{ COG0174 } & $E$ & GI 8 & 17 & 8 & 9 \\
\hline & & GI 8 & 48 & 23 & 25 \\
\hline \multirow[t]{2}{*}{ COG0863 } & $\mathrm{L}$ & GI 8 & 66 & 37 & 29 \\
\hline & & GI 8 & 38 & 17 & 21 \\
\hline COG5410 & $\mathrm{S}$ & GI 8 & 31 & 15 & 16 \\
\hline
\end{tabular}


RCA23_c23690 25163952516823 hypothetical protein, DUF2924

RCA23_c23700 25168202518436 hypothetical protein, resolvase-like

RCA23_c23720 25202492518873 signal transduction histidine kinase

RCA23_c23730 25216842520269 mercuric reductase MerA

RCA23_c23740 25224182521687 hypothetical protein

RCA23_c23750 25228032523192 putative ribonuclease P

RCA23_c23760 25231892523428 hypothetical protein DUF37

RCA23_c23770 25237492523964 hypothetical protein

RCA23_c23780 25240202524874 tRNA 2-thiocytidine biosynthesis protein TtcA

RCA23_c23790 25249282525959 putative diguanylate phosphodiesterase

RCA23_c23800 25260672527851 inner membrane protein OxaA

RCA23_c23810 25278532528602 hypothetical protein, molybdenum cofactor sulfurase

RCA23_c23820 25285992529249 putative GTP-binding protein EngB

RCA23_c23830 25293432530209 acetylglutamate kinase ArgB

RCA23_c23840 25302242531015 putative fatty acid hydroxylase

RCA23_c23850 25310122531632 hypothetical protein

RCA23_c23860 25316442532126 hypothetical protein, phosphogylcerate mutase

RCA23_c23870 25329142532150 glutamate/glutamine/aspartate/asparagine transport ATP-bi

RCA23_c23880

RCA23_c23890

RCA23_c23900

RCA23_c23910

RCA23_c23920

RCA23_c23930

RCA23_c23940

RCA23_c23950

RCA23_c23960

RCA23_c23970

RCA23_c23980

RCA23_c23990
25342202532928 glutamate/glutamine/aspartate/asparagine transport system COG0765

25353912534222 glutamate/glutamine/aspartate/asparagine transport system COG4597

25365942535548 glutamate/glutamine/aspartate/asparagine-binding protein E COG0834

25374822536778 ATP chaperone protein

25381472537479 putative phosphoglycerate phosphatase

25391902538144 ribosomal large subunit pseudouridine synthase C

25395582539181 putative ccrb-like protein

25409032539590 replication-associated recombination protein A

$25415812540970 \mathrm{HTH}$-type transcriptional regulator, LuxR family

2542163254181050 S ribosomal protein L17

2543849254346030 S ribosomal protein S11
COG5387

COG0546

COG0564

COG0239

COG2256

COG2197

COG0203

COG0202

COG0100
25434902542336 DNA-directed RNA polymerase alpha subunit RpoA
GI 8

GI 8

42

19

324

253

532

226

269

216

246

373

371

301

261

288

407

236

239

530

785

312

743

326

309

228

321

230

227

383

941

1.196 
RCA23_c24000 2544228254386030 S ribosomal protein S13

RCA23_c24010 25450482544407 adenylate kinase Adk

RCA23_c24020 25464032545045 preprotein translocase subunit SecY

RCA23_c24030 25469752546508 50S ribosomal protein L15

RCA23_c24040 25473972547209 50S ribosomal protein L30

RCA23_c24050 25480082547409 30S ribosomal protein S5

RCA23_c24060 25484452548086 50S ribosomal protein L18

RCA23_c24070 2548990254845750 S ribosomal protein L6

RCA23_c24080 25493922549000 30S ribosomal protein S8

RCA23_c24090 25497102549405 30S ribosomal protein S14

RCA23_c24100 25502822549722 50S ribosomal protein L5

RCA23_c24110 25505872550282 50S ribosomal protein L24

RCA23_c24120 25509572550589 50S ribosomal protein L14

RCA23_c24130 25512552551025 30S ribosomal protein S17

RCA23_c24140 25514672551261 50S ribosomal protein L29

RCA23_c24150 25516922552312 hypothetical protein

RCA23_c24160 25527032552407 50S ribosomal protein L23

RCA23_c24170 25533172552700 50S ribosomal protein L4

RCA23_c24180 2554045255331450 S ribosomal protein L3

RCA23_c24190 25543682554060 30S ribosomal protein S10

RCA23_c24200 25556492554474 elongation factor Tu (EF-Tu)

RCA23_c24210 25578512555734 elongation factor FusA

RCA23_c24220 25583432557873 30S ribosomal protein S7

RCA23_c24230 2558583255835630 S ribosomal protein S12

RCA23_c24240 25597062559092 hypothetical protein

RCA23_c24250 25604432559703 ABC transporter ATP-binding protein

RCA23_c24260 25615522560479 ABC tansporter permease protein

RCA23_c24270 25626762561672 putative ABC transporter periplasmic binding protein

RCA23_c24280

RCA23_c24290
25628582564048 putative transcriptional repressor

25648002564060 hypothetical protein, acyl-CoA thioesterase-like

$\begin{array}{llccc}\text { COG0099 } & \text { J } & 1.607 & 755 & 852 \\ \text { COG0563 } & \text { F } & 470 & 419 & 51 \\ \text { COG0201 } & \text { U } & 515 & 462 & 53 \\ \text { COG0200 } & \text { J } & 648 & 387 & 261 \\ \text { COG1841 } & \text { J } & 495 & 458 & 37 \\ \text { COG0098 } & \text { J } & 562 & 385 & 177 \\ \text { COG0256 } & \text { J } & 613 & 407 & 206 \\ \text { COG0097 } & \text { J } & 960 & 459 & 501 \\ \text { COG0096 } & \text { J } & 851 & 363 & 488 \\ \text { COG0199 } & \text { J } & 1.103 & 430 & 673 \\ \text { COG0094 } & \text { J } & 1.295 & 531 & 764 \\ \text { COG0198 } & \text { J } & 1.045 & 441 & 604 \\ \text { COG0093 } & \text { J } & 1.214 & 626 & 588 \\ \text { COG0186 } & \text { J } & 1.128 & 542 & 586 \\ \text { COG0255 } & \text { J } & 919 & 575 & 344 \\ & & 491 & 514 & -23 \\ \text { COG0089 } & \text { J } & 913 & 531 & 382 \\ \text { COG0088 } & \text { J } & 843 & 572 & 271 \\ \text { COG0087 } & \text { J } & 919 & 565 & 354 \\ \text { COG0051 } & \text { J } & 561 & 460 & 101 \\ \text { COG0050 } & \text { J } & 41 & 15 & 26 \\ \text { COG0480 } & \text { J } & 997 & 541 & 456 \\ \text { COG0049 } & \text { J } & 558 & 374 & 184 \\ \text { COG0048 } & \text { J } & 966 & 883 & 83 \\ \text { COG1072 } & \text { H } & 197 & 222 & -25 \\ \text { COG1129 } & \text { G } & 377 & 332 & 45 \\ \text { COG1172 } & \text { G } & 316 & 328 & -12 \\ \text { COG1879 } & \text { G } & 376 & 304 & 72 \\ \text { COG1940 } & \text { K } & 257 & 274 & -17 \\ \text { COG2755 } & \text { E } & 330 & 432 & -102\end{array}$


RCA23_c24300

RCA23_c24310

RCA23_c24320

RCA23_c24330

RCA23_c24340

RCA23_c24350

RCA23_c24360

RCA23_c24370

RCA23_c24380

RCA23_c24390

RCA23_c24400

RCA23_c24410

RCA23_c24420

RCA23_c24430

RCA23_c24440

RCA23_c24460

RCA23_c24450

RCA23_c24470

RCA23_c24480

RCA23_c24490

RCA23_c24500

RCA23_c24510

RCA23_c24520

RCA23_c24530

RCA23_c24540

RCA23_c24550

RCA23_c24560

RCA23_c24570

RCA23_c24580

RCA23_c24590
25649212565451 ABC transporter ATP-binding protein

25654482567970 putative ABC transporter permease protein

25683282569251 hypothetical protein, gylcosyl transferase family 2

25706392569266 aminotransferase class-III

25718792570683 putative ectoine utilization protein EutD

25720182572968 putative integral membrane proein DUF6

25730672574635 4-coumarate--CoA ligase

25756722574737 hypothetical protein

25765722575760 hypothetical protein DUF125

25770152576587 transcriptional regulator, AsnC family

25771332578062 arginase ArcA

25780642579122 ornithine cyclodeaminase ArcB

25791192582481 bifunctional protein PutA

25831442582581 hypothetical protein

25834062583128 hypothetical protein

25838632583615 hypothetical protein

25838342585051 creatinase

25859982585276 putative hydrolase

25875482585995 glycine betaine/L-proline transport system permease proteir

25886002587545 glycine betaine/L-proline transport ATP-binding protein Prol

25896352588670 glycine betaine-binding periplasmic protein ProX

25898792590763 putative HTH-type transcriptional regluator, LysR family

25918552590770 D-cysteine desulfhydrase DcyD

25919952592351 hypothetical protein

25932982592375 high-affinity zinc uptake system protein ZnuA

25933552593870 zinc uptake regulator

25938672594616 zinc import ATP-binding protein ZnuC

25946162595410 high-affinity zinc uptake system membrane protein ZnuB

25955342597435 4-hydroxyphenylpyruvate dioxygenase Hpd

25984362598104 hypothetical protein

$\begin{array}{llccc}\text { COG1136 } & \text { V } & 271 & 378 & -107 \\ \text { COG3127 } & \text { Q } & 212 & 276 & -64 \\ \text { COG0463 } & \text { M } & 218 & 237 & -19 \\ \text { COG0161 } & \text { H } & 358 & 316 & 42 \\ \text { COG0006 } & \text { E } & 406 & 426 & -20 \\ & & 260 & 386 & -126 \\ \text { COG0318 } & \text { I } & 229 & 302 & -73 \\ \text { COG0679 } & \mathrm{R} & 315 & 415 & -100 \\ \text { COG1814 } & \text { S } & 191 & 301 & -110 \\ \text { COG1522 } & \text { K } & 269 & 276 & -7 \\ \text { COG0010 } & \mathrm{E} & 294 & 304 & -10 \\ \text { COG2423 } & \mathrm{E} & 294 & 233 & 61 \\ \text { COG4230 } & \mathrm{C} & 254 & 302 & -48 \\ & & 459 & 415 & 44 \\ & & 349 & 222 & 127 \\ & & 249 & 201 & 48 \\ \text { COG0006 } & \mathrm{E} & 209 & 197 & 12 \\ \text { COG0596 } & \mathrm{R} & 44 & 43 & 1 \\ \text { COG4176 } & \mathrm{E} & 108 & 62 & 46 \\ \text { COG4175 } & \mathrm{E} & 112 & 59 & 53 \\ \text { COG2113 } & \mathrm{E} & 102 & 46 & 56 \\ \text { COG0583 } & \mathrm{K} & 244 & 166 & 78 \\ \text { COG2515 } & \mathrm{E} & 285 & 248 & 37 \\ & & 794 & 435 & 359 \\ \text { COG4531 } & \mathrm{P} & 270 & 294 & -24 \\ \text { COG0735 } & \mathrm{P} & 213 & 353 & -140 \\ \text { COG1121 } & \mathrm{P} & 361 & 352 & 9 \\ \text { COG1108 } & \mathrm{P} & 234 & 351 & -117 \\ \text { COG3185 } & \mathrm{E} & 358 & 304 & 54 \\ & & 626 & 538 & 88\end{array}$


RCA23_c24600

RCA23_c24610 25990412599844 hypothetical protein

RCA23_c24620 25998632600606 hypothetical protein

RCA23_c24630 26015682600642 putative gluconolactonase

RCA23_c24640 26029672602047 ribokinase RbsK

RCA23_c24650 26034162602964 ribose ABC transporter protein RbsD

RCA23_c24660 26045562603489 putative ribose ABC transporter, ATP-binding protein RbsA

RCA23_c24670

RCA23_c24680

RCA23_c24690

RCA23_c24700

RCA23_c24710

RCA23_c24720

RCA23_c24730

RCA23_c24740

RCA23_c24750

RCA23_c24760

RCA23_c24770

RCA23_c24780

RCA23_c24790

RCA23_c24800

RCA23_c24810

RCA23_c24820

RCA23_c24830

RCA23_c24840

RCA23_c24850

RCA23_c24860

RCA23_c24870

RCA23_c24880

RCA23_c24890

26048592606439 putative ribose ABC transporter substrate binding protein $F$ COG1653 26065092607615 putative ribose $A B C$ transporter, permease protein $\mathrm{RbsC}$

26076172608534 putative ribose $A B C$ transporter, permease protein RbsC

26100242608537 hypothetical protein, L-fucose isomerase-like

26106262610162 sugar isomerase

26122062610716 xylulose kinase XylB

26132732612203 aminopeptidase SgcX

26140732613270 photosystem I biogenesis protein BtpA

26141662615188 pyridoxal 4-dehydrogenase Pld

26151852616021 putative amidohydrolase

26167912616009 putative carbohydrate kinase, pfkB family

26177532616854 xylose isomerase family protein

26185292617822 putative HTH-type transcriptional regulator, GntR family

26200642618739 mandelate racemase/muconate lactonizing enzyme

26207222621792 fatty acid desaturase

2621892 hypothetical protein

26230762622369 transposase

26240762623558 transporter, LysE family

26245312624851 hypothetical protein

26259982624925 putative transporter, periplasmic binding protein

26269482627676 ribitol 2-dehydrogenase RbtD

26318552628631 hypothetical protein

\begin{tabular}{|c|c|c|}
\hline & & GI 9 \\
\hline COG1028 & 1 & GI 9 \\
\hline COG1402 & $\mathrm{R}$ & GI 9 \\
\hline COG3386 & $\mathrm{G}$ & GI 9 \\
\hline COG0524 & G & GI 9 \\
\hline COG4154 & $\mathrm{G}$ & GI 9 \\
\hline COG3839 & $\mathrm{G}$ & GI 9 \\
\hline COG1653 & $\mathrm{G}$ & GI 9 \\
\hline COG1175 & G & GI 9 \\
\hline COG0395 & $\mathrm{G}$ & GI 9 \\
\hline & & GI 9 \\
\hline COG0794 & $M$ & GI 9 \\
\hline COG1070 & $\mathrm{G}$ & GI 9 \\
\hline COG1363 & G & GI 9 \\
\hline COG0434 & $\mathrm{R}$ & GI 9 \\
\hline COG0667 & $\mathrm{C}$ & GI 9 \\
\hline COG3618 & $\mathrm{R}$ & GI 9 \\
\hline COG0524 & $\mathrm{G}$ & GI 9 \\
\hline COG4952 & $M$ & GI 9 \\
\hline COG1802 & $\mathrm{K}$ & GI 9 \\
\hline COG4948 & $M$ & GI 9 \\
\hline COG3239 & 1 & Gl 9 \\
\hline & & GI 9 \\
\hline COG3316 & $\mathrm{L}$ & GI 9 \\
\hline COG1280 & $E$ & GI 9 \\
\hline & & Gl 9 \\
\hline COG2358 & $\mathrm{R}$ & GI 9 \\
\hline COG 4221 & $\mathrm{R}$ & GI 9 \\
\hline & & GI 9 \\
\hline COG0457 & $\mathrm{R}$ & GI 9 \\
\hline
\end{tabular}

0

3

138

$-3$

169

102

198

95

166

$266 \quad 185$

185

$\begin{array}{ll}233 & 166 \\ 298 & 217\end{array}$

217
184

$\begin{array}{ll}236 & 184 \\ 314 & 141\end{array}$

141
152

231

$\begin{array}{ll}155 & 137 \\ 162 & 121\end{array}$

121
157

199

223

193

$253 \quad 182$

$294 \quad 224$

$205 \quad 195$

$131 \quad 162$

$185 \quad 163$

$254 \quad 163$

$222 \quad 159$

$209 \quad 154$

16

43

0

26

8

50

26

52

\section{5}

27

1

35 
RCA23_c24960 26406492641437 hypothetical protein, metallo-beta-lactamase

COG1235

RCA23_c24970 26414392642368 membrane transport protein

RCA23_c24980 26434572642372 FAD dependent oxidoreductase

COG0679

COG0665

RCA23_c24990 26436452645834 UvrABC system protein B

COG0556

RCA23_c25000 26476272645909 hypothetical protein

RCA23_c25010 26482472647642 hypothetical protein

RCA23_c25020 26487322648331 hypothetical protein

RCA23_c25030 26503702648796 lysyl-tRNA synthase LysS

RCA23_c25040 26505102650884 hypothetical protein

RCA23_c25050 26523332650876 putative D-Ala-D-Ala carboxypeptidase 3 (S13) family prote COG2027

RCA23_c25070 26539672653365 nicotinic acid mononucleotide adenyltransferase NadD COG1057

RCA23_c25080 26541282655756 ABC transporter, ATP-binding cassette protein, ChvD famil) COG0488

RCA23_c25090 26559992656205 cold shock protein CspA

RCA23_c25100 26576462656327 glutamyl-tRNA synthase 1

RCA23_c25110 26593512657714 glutamine-dependent NAD(+) synthase NadE

RCA23_c25120 26595552660997 putative phosphatidylinositol-4-phosphate 5-kinase

RCA23_c25130 26617722661011 hypothetical protein

RCA23_c25140 26619352663500 2-isopropylmalate synthase LeuA

RCA23_c25150 26636412664678 rod shape-determining protein MreB

RCA23_c25160 26647092665593 rod shape-determining protein MreC

COG1278

COG0008

COG0171

COG4642

COG1028

COG0119

COG1077

COG1792

$\begin{array}{ll}\text { RCA23_c25170 } & 26655902666129 \text { hypothetical protein } \\ \text { RCA23_c25180 } & 26661262668078 \text { penicillin-binding protein } 2\end{array}$

RCA23_c25190 26680752669226 rod shape-determining protein RodA

RCA23_c25200 26692232670152 glyoxylate/hydroxypyruvate reductase GhrA 
RCA23_c25210

RCA23_c25220 26715452670925 hypothetical protein

RCA23_c25230 $26715922672890 \mathrm{Na}+/ \mathrm{H}+$ antiporter NhaA

RCA23_c25240 26730622673721 capsule polysaccharide export protein KpsT

RCA23_c25250 26736992675342 capsule polysaccharide export protein KpsE

RCA23_c25270 26759942675545 hypothetical protein

RCA23_c25280 26763532675997 ferredoxin PetF

RCA23_c25290 26777022676350 selenium binding protein

RCA23_c25300 26792282677789 aldehyde dehydrogenase

RCA23_c25310 26804352679296 CoA-transferase family III protein involved in DMSP degradi

RCA23_c25320 26806982681036 nitrogen regulatory protein P-II 2

RCA23_c25330 26810362682373 ammonium transporter

RCA23_c25340 26828872682426 homoprotocatechuate degradative operon repressor

RCA23_c25350 26830072684515 5-carboxymethyl-2-hydroxymuconic semialdehyde dehydro!

RCA23_c25360 26845392685522 3,4-dihydroxyphenylacetate 2,3-dioxygenase HpaD

RCA23_c25370 26865382685534 3-carboxy-cis,cis-muconate cycloisomerase PcaB

RCA23_c25380 26873772686535 hypothetical protein DUF849

RCA23_c25390 26879302687370 protocatechuate 3,4-dioxygenase alpha chain PcaG

RCA23_c25400 26886582687930 protocatechuate 3,4-dioxygenase beta chain PcaH

RCA23_c25410 26890412688655 4-carboxymuconolactone decarboxylase PcaC

RCA23_c25420 26894512689260 hypothetical protein

RCA23_c25430 26894982690184 transcriptional regulatory protein

RCA23_c25440 26901902691731 two component signal transduction histidine kinase ChvG

RCA23_c25450 26919802691744 hypothetical protein

RCA23_c25460 $26940292692536 \mathrm{Na}(+)$-phosphate symporter Pit

RCA23_c25470 26944222694246 hypothetical protein

RCA23_c25480 269533626944912 2-dehydro-3-deoxyphosphooctonate aldolase KdsA

RCA23_c25490 26954802696481 arabinose 5-phosphate isomerase KdsD

RCA23_c25500 26972972696491 3-deoxy-manno-octulosonate cytidylyltransferase KdsB

RCA23_c25510 26984452697384 hypothetical protein

$\begin{array}{llllc} & & 226 & 269 & -43 \\ \text { COG1573 } & \mathrm{L} & 248 & 272 & -24 \\ \text { COG3004 } & \mathrm{P} & 338 & 391 & -53 \\ \text { COG1134 } & \mathrm{G} & 568 & 561 & 7 \\ \text { COG3524 } & \mathrm{M} & 361 & 359 & 2 \\ \text { COG1832 } & \mathrm{R} & 412 & 456 & -44 \\ \text { COG0633 } & \mathrm{C} & 421 & 371 & 50 \\ & & 596 & 556 & 40 \\ \text { COG1012 } & \mathrm{C} & 264 & 321 & -57 \\ \text { COG1804 } & \mathrm{C} & 268 & 406 & -138 \\ \text { COG0347 } & \mathrm{E} & 654 & 505 & 149 \\ \text { COG0004 } & \mathrm{P} & 507 & 419 & 88 \\ \text { COG1846 } & \mathrm{K} & 311 & 282 & 29 \\ \text { COG1012 } & \mathrm{C} & 402 & 427 & -25 \\ \text { COG0346 } & \mathrm{E} & 355 & 344 & 11 \\ \text { COG0015 } & \mathrm{F} & 222 & 260 & -38 \\ \text { COG3246 } & \mathrm{S} & 286 & 319 & -33 \\ \text { COG3485 } & \mathrm{Q} & 216 & 313 & -97 \\ \text { COG3485 } & \mathrm{Q} & 172 & 217 & -45 \\ \text { COG0599 } & \mathrm{S} & 193 & 228 & -35 \\ & & 343 & 373 & -30 \\ \text { COG0745 } & \mathrm{T} & 365 & 418 & -53 \\ \text { COG0642 } & \mathrm{T} & 479 & 455 & 24 \\ \text { COG0306 } & \mathrm{P} & 545 & 451 & 94 \\ \text { COG2877 } & \mathrm{M} & 375 & 421 & -46 \\ \text { COG0794 } & \mathrm{M} & 625 & 496 & 129 \\ \text { COG1212 } & \mathrm{M} & 308 & 347 & -39 \\ & & 281 & 328 & -47 \\ & & 476 & 394 & 82 \\ & & 122 & 146 & -24\end{array}$


RCA23_c25520

RCA23_c25530 27039482706137 catalase-peroxidase KatG

RCA23_c25540 27063532707432 hypothetical protein

RCA23_c25550 27079082707480 thioesterase/thiol ester dehydrase-isomerase

RCA23_c25560 27090592707905 iron-containing alcohol dehydrogenase

RCA23_c25570 27103102709075 hypothetical protein

RCA23_c25580 27104032710906 nodulation protein N-like protein

RCA23_c25590 27109032711943 putative phosphotransferase, eukaryotic acyl-CoA dehydros

RCA23_c25600 27119402712548 putative HTH-type transcriptional regulator, TetR family

RCA23_c25610 27126232714713 fatty acid oxidation complex alpha subunit FadJ

RCA23_c25620 27147182715914 acyl-CoA dehydrogenase

RCA23_c25630 27159182717012 acyl-CoA dehydrogenase

RCA23_c25640 27172312717998 hypothetical protein, MarR family

RCA23_c25650 27180862719246 acyl-CoA dehydrogenase

RCA23_c25660 27202822719305 quinone oxidoreductase (1.6.5.5.)

RCA23_c25670 27204002720990 hypothetical protein

RCA23_c25680 27217192720952 putative DNA repair protein RecO

RCA23_c25690 27221552721823 hypothetical protein

RCA23_c25700 27230602722152 GTP-binding protein Era

RCA23_c25710 27237402723057 ribonuclease 3

RCA23_c25720 27246362723767 signal peptidase I

RCA23_c25730 27251012724688 holo-[acyl-carrier-protein] synthase AcpS

RCA23_c25740 27258412725098 pyridoxine 5'-phosphate synthase PdxJ

RCA23_c25750 27265152725865 hypothetical protein DUF2062

RCA23_c25760 27286732726508 guanosine-3',5'-bis(diphosphate) 3'-pyrophosphohydrolase

RCA23_c25770 27290392728686 DNA-directed RNA polymerase subunit omega

RCA23_c25780 27297192729135 putative 2-amino-4-hydroxy-6-hydroxymethyldihydropteridin

RCA23_c25790

RCA23_c25800 27304532731418 4-hydroxy-3-methylbut-2-enyl diphosphate reductase IspH

RCA23_c25810

$\begin{array}{ll}\text { COG0376 } & \mathrm{P} \\ \text { COG2067 } & \mathrm{I} \\ \text { COG0824 } & \mathrm{R} \\ \text { COG1454 } & \mathrm{C} \\ \text { COG1960 } & \mathrm{I} \\ \text { COG2030 } & \mathrm{I} \\ \text { COG3173 } & \mathrm{R} \\ \text { COG1309 } & \mathrm{K} \\ \text { COG1250 } & \mathrm{I} \\ \text { COG1960 } & \mathrm{I} \\ \text { COG1960 } & \mathrm{I} \\ & \\ \text { COG1960 } & \mathrm{I} \\ \text { COG0604 } & \mathrm{C} \\ & \\ \text { COG1381 } & \mathrm{L} \\ \text { COG5447 } & \mathrm{S} \\ \text { COG1159 } & \mathrm{R} \\ \text { COG0571 } & \mathrm{K} \\ \text { COG0681 } & \mathrm{U} \\ \text { COG0736 } & \mathrm{I} \\ \text { COG0854 } & \mathrm{H} \\ \text { COG3216 } & \mathrm{S} \\ \text { COG0317 } & \mathrm{T} \\ \text { COG1758 } & \mathrm{K} \\ \text { COG0801 } & \mathrm{H} \\ \text { COG1432 } & \mathrm{S} \\ \text { COG0761 } & \mathrm{I} \\ \text { COG2227 } & \mathrm{H}\end{array}$


RCA23_c25820

RCA23_c25830

RCA23_c25840

RCA23_c25850

RCA23_c25860

RCA23_c25870

RCA23_c25880

RCA23_c25890

RCA23_c25900

RCA23_c25910

RCA23_c25920

RCA23_c25930

RCA23_c25940

RCA23_c25950

RCA23_c25960

RCA23_c25970

RCA23_c25980

RCA23_c25990

RCA23_c26000

RCA23_c26010

RCA23_c26020

RCA23_c26030

RCA23_c26040

RCA23_c26050

RCA23_c26060

RCA23_c26070

RCA23_c26080

RCA23_c26090

RCA23_c26100

RCA23_c26120
27319912732443 ribonuclease $\mathrm{H}$

27324672732703 hypothetical protein

27335842732700 methionyl-tRNA formyltransferase Fmt

27340842733590 peptide deformylase Def

27347102734081 peptide deformylase Def

27347432735909 aminotransferase

27362722735922 hypothetical protein

27371332736360 precorrin-4 C(11)-methyltransferase CobM

27389712737130 precorrin-3B C(17)-methyltransferase CobJ

27396632738962 precorrin-2 C(20)-methyltransferase Cobl

27408592739660 precorrin-6Y C(5,15)-methyltransferase CobL

27414942740856 precorrin-8X methylmutase $\mathrm{CobH}$

27426532741541 sirohydrochlorin cobaltochelatase CbiX

27432572744771 methyltransferase, FkbM family

27448802745842 hypothetical protein, glutathione S-transferase

27459202746291 hypothetical protein DUF1636

27462912747238 threonine-phosphate decarboxylase CobC

27472352748140 cobalamin biosynthesis protein CobD

27482102749349 putative peptidoglycan-binding lytic murein transglycosylase

27529602749505 putative chromosome partition protein smc

27533542753145 hypothetical protein

27535242754378 hypothetical protein

27544342755204 hypothetical protein DUF81

2755268275627250 S ribosomal protein L2

2756318275655430 S ribosomal protein S19

2756558275693850 S ribosomal protein L22

2756938275765730 S ribosomal protein S3

2757702275808250 S ribosomal protein L16

27587632758521 hypothetical protein

27605962759328 hypothetcial protein

\begin{tabular}{|c|c|c|}
\hline COG0328 & $\mathrm{L}$ & \\
\hline COG0223 & $\mathrm{J}$ & \\
\hline COG0242 & $J$ & \\
\hline COG0242 & $\mathrm{J}$ & \\
\hline COG1168 & $E$ & \\
\hline COG2875 & $\mathrm{H}$ & \\
\hline COG1010 & $\mathrm{H}$ & \\
\hline COG2243 & $\mathrm{H}$ & \\
\hline COG2242 & $\mathrm{H}$ & \\
\hline COG2082 & $\mathrm{H}$ & \\
\hline COG2138 & $S$ & \\
\hline COG3774 & $M$ & \\
\hline COG0435 & $\mathrm{O}$ & \\
\hline COG5469 & $S$ & \\
\hline COG0079 & $E$ & \\
\hline COG1270 & $\mathrm{H}$ & \\
\hline COG2951 & $M$ & \\
\hline COG1196 & $D$ & \\
\hline COG1028 & 1 & \\
\hline COG0730 & $\mathrm{R}$ & \\
\hline COG0090 & $\mathrm{J}$ & \\
\hline COG0185 & $\mathrm{J}$ & \\
\hline COG0091 & $\mathrm{J}$ & \\
\hline COG0092 & $\mathrm{J}$ & \\
\hline \multirow[t]{2}{*}{ COG0197 } & $\mathrm{J}$ & \\
\hline & & GI 10 \\
\hline COG0666 & $\mathrm{R}$ & GI 10 \\
\hline
\end{tabular}

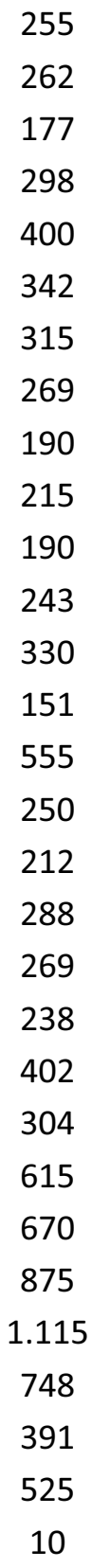

\section{6}

428

313

457

459

372

306

297

309

381

368

357

408

145

486

284

334

321

370

324

371

334

430

458

505

598

364

269

482

9
$-131$

$-166$

$-136$

$-159$

$-59$

$-30$

9

$-28$

$-119$

$-166$

$-178$

$-114$

$-78$

6

69

$-34$

$-122$

$-33$

$-101$

$-86$

31

$-30$

185

212

370

517

384

122

43

1 
RCA23_c26130

RCA23_C26140

RCA23_c26150

RCA23_c26160

RCA23_c26170

RCA23_c26180 27658532764525 TRAP dicarboxylate transporter, subunit DctM

RCA23_c26190 27663662765854 TRAP dicarboxylate transporter, subunit DctQ

RCA23_c26200 27674642766427 TRAP dicarboxylate transporter, subunit DctP

RCA23_c26210 27682962767511 3-hydroxybutyryl-CoA dehydratase Crt

RCA23_c26220 27683722769280 metal-dependent hydrolase

RCA23_c26230 27694382770715 FAD dependent monooxygenase

RCA23_c26240 27724372770791 arylsulfatase

RCA23_c26250 27729402772434 transcriptional regulator, MarR family

RCA23_c26260 27730672774122 putative transporter, periplasmic binding protein

RCA23_c26270 27741862776480 TRAP transporter, 4TM/12TM fusion protein

RCA23_c26280 27780812776852 hypothetical protein, UPF0261

RCA23_c26290 27795132778236 gamma-glutamylputrescine synthase PuuA

RCA23_c26300 27807502779515 cytochrome P450

RCA23_c26310 27814712780740 glutamine amidotransferase class-I

RCA23_c26320 27825042781536 tripartite tricarboxylate transporter (TTT) protein TctC

RCA23_c26330 27839972782504 tripartite tricarboxylate transporter (TTT) protein TctA

RCA23_c26340 27847422784008 hypothetical protein, transmembrane

RCA23_c26350 27862742784739 gamma-glutamyl-gamma-aminobutyraldehyde dehydrogené COG1012

RCA23_c26360 27869922787321 hypothetical protein

RCA23_c26370 27875692787901 hypothetical protein

RCA23_c26380 27879032788388 hypothetical protein

RCA23_c26390 27890432790062 putative fucosyltransferase

RCA23_c26400 27903982790138 integrase

RCA23_c26410 27915282790497 putative extracellular solute-binding protein

RCA23_c26420 27928892791498 two-component system, sensor histidine kinase protein

\begin{tabular}{|c|c|c|c|c|c|}
\hline & & GI 10 & 245 & 94 & 151 \\
\hline & & GI 10 & 158 & 107 & 51 \\
\hline & & GI 10 & 298 & 163 & 135 \\
\hline COG1846 & $\mathrm{K}$ & GI 10 & 324 & 211 & 113 \\
\hline COG0318 & 1 & GI 10 & 171 & 159 & 12 \\
\hline \multirow[t]{2}{*}{ COG1593 } & $\mathrm{G}$ & GI 10 & 163 & 218 & -55 \\
\hline & & GI 10 & 225 & 194 & 31 \\
\hline COG1638 & G & GI 10 & 171 & 138 & 33 \\
\hline COG1024 & 1 & GI 10 & 128 & 207 & -79 \\
\hline COG2159 & $\mathrm{R}$ & GI 10 & 381 & 230 & 151 \\
\hline COG0654 & $\mathrm{H}$ & GI 10 & 204 & 180 & 24 \\
\hline COG3119 & $\mathrm{P}$ & GI 10 & 137 & 165 & -28 \\
\hline COG1846 & $\mathrm{K}$ & GI 10 & 149 & 189 & -40 \\
\hline COG2358 & $\mathrm{R}$ & GI 10 & 113 & 141 & -28 \\
\hline COG4666 & $\mathrm{R}$ & GI 10 & 256 & 221 & 35 \\
\hline COG5441 & $\mathrm{S}$ & GI 10 & 500 & 428 & 72 \\
\hline COG0174 & $E$ & GI 10 & 493 & 386 & 107 \\
\hline COG2124 & $Q$ & GI 10 & 546 & 377 & 169 \\
\hline COG0518 & $\mathrm{F}$ & GI 10 & 630 & 421 & 209 \\
\hline COG3181 & $S$ & GI 10 & 491 & 360 & 131 \\
\hline \multirow[t]{2}{*}{ COG3333 } & $\mathrm{S}$ & GI 10 & 471 & 384 & 87 \\
\hline & & GI 10 & 794 & 831 & -37 \\
\hline \multirow[t]{5}{*}{ COG1012 } & $\mathrm{C}$ & GI 10 & 526 & 374 & 152 \\
\hline & & GI 10 & 20 & 18 & 2 \\
\hline & & GI 10 & 52 & 13 & 39 \\
\hline & & GI 10 & 18 & 11 & 7 \\
\hline & & GI 10 & 54 & 41 & 13 \\
\hline COG2801 & $\mathrm{L}$ & GI 10 & 156 & 153 & 3 \\
\hline COG1840 & $\mathrm{P}$ & GI 10 & 271 & 192 & 79 \\
\hline COG0642 & $\mathrm{T}$ & GI 10 & 137 & 118 & 19 \\
\hline
\end{tabular}


RCA23_c26430

RCA23_c26440

RCA23_c26450

RCA23_c26460

RCA23_c26470

RCA23_c26480

RCA23_c26490

RCA23_c26510

RCA23_c26520

RCA23_c26530

RCA23_c26540

RCA23_c26550

RCA23_c26560

RCA23_c26570

RCA23_c26580

RCA23_c26590

RCA23_c26600

RCA23_c26610

RCA23_c26620

RCA23_c26630

RCA23_c26640

RCA23_c26650

RCA23_c26660

RCA23_c26670

RCA23_c26680

RCA23_c26690

RCA23_c26700

RCA23_c26710

RCA23_c26720

RCA23_c26730
27935542792886 two-component system, response regulator protein

27936562794624 tripartite tricarboxylate transporter (TTT) protein TctC

27946242795112 tripartite tricarboxylate transporter (TTT) protein TctB

27951142796619 tripartite tricarboxylate transporter (TTT) protein TctA

27966212797979 hypothetical protein

27979722798277 hypothetical protein

27984192798775 transposase A

27997132799357 hypothetical protein

28009342801293 hypothetical protein

28025432802343 hypothetical protein

28063192802786 putative RTX toxin and hemolysin-type calcium binding protein

28096392806427 putative RTX toxin and hemolysin-type calcium binding protein

28099432811319 type I secretion outer membrane protein, TolC family

28113162813484 type I secretion system ATP-binding component

COG1538

COG2274

28135002814810 type I RTX secretion system membrane fusion protein, Hly[ COG1566

28148532815215 hypothetical protein

28153942815645 hypothetical protein

28156552815879 hypothetical protein

28158982816089 hypothetical protein

28162112817194 hypothetical protein DUF2125

28176832818480 Asp/Glu racemase

28185772819731 cystathionine beta-lyase

28200222821635 deoxyribodipyrimidine photo-lyase PhrB

28218212822804 hypothetical protein

28237982822806 O-sialoglycoprotein endopeptidase Gcp

28244202823791 Sua5/YciO/YrdC/YwIC family protein

28250702824417 putative glycoprotease family protein

28255792825061 hypothetical protein UPF0079

28257952826562 xylose isomerase family protein

28268232828073 putative phage integrase

\begin{tabular}{|c|c|c|c|c|c|}
\hline COG0745 & $\mathrm{T}$ & GI 10 & 214 & 156 & 58 \\
\hline \multirow[t]{2}{*}{ COG3181 } & $S$ & GI 10 & 713 & 468 & 245 \\
\hline & & GI 10 & 634 & 402 & 232 \\
\hline \multirow[t]{5}{*}{ COG3333 } & $S$ & GI 10 & 592 & 369 & 223 \\
\hline & & GI 10 & 474 & 353 & 121 \\
\hline & & GI 10 & 592 & 419 & 173 \\
\hline & & GI 10 & 341 & 254 & 87 \\
\hline & & GI 10 & 1 & 0 & 1 \\
\hline \multirow[t]{4}{*}{ COG1709 } & $\mathrm{K}$ & GI 10 & 0 & 4 & -4 \\
\hline & & GI 10 & 0 & 0 & 0 \\
\hline & & Gl 10 & 1 & 2 & -1 \\
\hline & & GI 10 & 89 & 22 & 67 \\
\hline COG1538 & $M$ & GI 10 & 267 & 163 & 104 \\
\hline COG2274 & $\mathrm{V}$ & Gl 10 & 378 & 289 & 89 \\
\hline \multirow[t]{6}{*}{ COG1566 } & $\mathrm{V}$ & GI 10 & 493 & 289 & 204 \\
\hline & & GI 10 & 680 & 516 & 164 \\
\hline & & GI 10 & 1.043 & 506 & 537 \\
\hline & & GI 10 & 1.033 & 554 & 479 \\
\hline & & GI 10 & 1.041 & 460 & 581 \\
\hline & & GI 10 & 666 & 361 & 305 \\
\hline COG3473 & $Q$ & GI 10 & 500 & 349 & 151 \\
\hline COG0626 & $E$ & GI 10 & 549 & 536 & 13 \\
\hline COG0415 & $L$ & GI 10 & 921 & 514 & 407 \\
\hline COG3380 & $\mathrm{R}$ & GI 10 & 564 & 376 & 188 \\
\hline COG0533 & 0 & GI 10 & 284 & 330 & -46 \\
\hline COG0009 & $\mathrm{J}$ & GI 10 & 299 & 317 & -18 \\
\hline COG1214 & 0 & GI 10 & 294 & 484 & -190 \\
\hline COG0802 & $\mathrm{R}$ & GI 10 & 267 & 388 & -121 \\
\hline COG3622 & G & GI 10 & 264 & 388 & -124 \\
\hline COG0582 & $\mathrm{L}$ & GI 10 & 171 & 127 & 44 \\
\hline
\end{tabular}


RCA23 c26740

RCA23_c26750 28287932828993 putative prophage regulatory protein

RCA23_c26760 28289902829565 hypothetical protein

RCA23_c26770 28296912831313 DNA polymerase

RCA23_c26780 28322932831898 hypothetical protein

RCA23_c26790 28338902832826 hypothetical protein, snoaL-like polyketide cyclase

RCA23_c26800 28344722834092 hypothetical protein

RCA23_c26810 28348412834566 glyoxalase/bleomycin resistance protein/dioxygenase superfamily protein

RCA23_c26820

RCA23_c26830

RCA23_c26840

RCA23_c26850

RCA23_c26860

RCA23_c26870

RCA23_c26880

RCA23_c26890

RCA23_c26900

RCA23_c26910

RCA23_c26920

RCA23_c26930

RCA23_c26940

RCA23_c26950

RCA23_c26960

RCA23_c26970

RCA23_c26980

RCA23_c26990

RCA23_c27000

RCA23_c27010

RCA23_c27020

RCA23_c27030
28359712834964 hypothetical protein

28368592835975 putative ABC transporter permease protein

28378372836863 putative $A B C$ transporter permease protein

28392292837985 putative $A B C$ transporter extracellular solute binding protein

28395092840555 ABC transporter ATP-binding protein

28406062841937 histidinol dehydrogenase HisD

28419342842959 hypothetical protein, snoaL-like polyketide cyclase

28429802843720 short chain dehydrogenase

28437202844733 putative HTH-type transcriptional regulator Lacl family

28447302845731 hypothetical protein, snoaL-like polyketide cyclase

28457282846693 hypothetical protein

28468262847896 hypothetical protein, 2-hydroxypropyl-CoM lyase-like

28478932848561 hypothetical protein, alpha/beta hydrolase-like

28485672849259 hypothetical protein

28502692851174 3-hydroxyisobutyrate dehydrogenase MmsB

28511712852874 dihydroxy-acid dehydratase IlvD

28528842854224 hypothetical protein

28542642855901 putative choline (or alcohol) dehydrogenase

28559262857404 aldehyde dehydrogenase

28580202857418 transporter, LysE family

28595462858080 TRAP dicarboxylate transporter, subunit DctM
28601092859546 TRAP dicarboxylate transporter, subunit DctQ

\begin{tabular}{|c|c|c|c|c|c|}
\hline & & GI 10 & 240 & 116 & 124 \\
\hline \multirow[t]{2}{*}{ COG3311 } & $\mathrm{K}$ & GI 10 & 75 & 92 & -17 \\
\hline & & GI 10 & 99 & 70 & 29 \\
\hline \multirow[t]{2}{*}{ COG0749 } & $\mathrm{L}$ & GI 10 & 144 & 96 & 48 \\
\hline & & GI 10 & 65 & 51 & 14 \\
\hline \multirow[t]{2}{*}{ COG5485 } & $\mathrm{R}$ & GI 10 & 73 & 81 & -8 \\
\hline & & GI 10 & 105 & 69 & 36 \\
\hline \multirow[t]{2}{*}{ amily protein } & & GI 10 & 58 & 114 & -56 \\
\hline & & GI 10 & 55 & 74 & -19 \\
\hline COG0395 & G & GI 10 & 92 & 82 & 10 \\
\hline COG1175 & G & GI 10 & 79 & 120 & -41 \\
\hline COG1653 & G & GI 10 & 74 & 71 & 3 \\
\hline COG3839 & G & GI 10 & 64 & 75 & -11 \\
\hline COG0141 & $\mathrm{E}$ & GI 10 & 55 & 65 & -10 \\
\hline COG5485 & $\mathrm{R}$ & GI 10 & 39 & 67 & -28 \\
\hline COG1028 & I & GI 10 & 32 & 52 & -20 \\
\hline \multirow[t]{3}{*}{ COG1609 } & $\mathrm{K}$ & GI 10 & 46 & 72 & -26 \\
\hline & & GI 10 & 44 & 75 & -31 \\
\hline & & GI 10 & 58 & 93 & -35 \\
\hline COG0620 & $E$ & GI 10 & 53 & 79 & -26 \\
\hline COG0596 & $\mathrm{R}$ & GI 10 & 80 & 90 & -10 \\
\hline COG0684 & $\mathrm{H}$ & GI 10 & 49 & 85 & -36 \\
\hline COG2084 & I & GI 10 & 171 & 236 & -65 \\
\hline COG0129 & $\mathrm{E}$ & GI 10 & 91 & 124 & -33 \\
\hline COG4091 & $E$ & GI 10 & 80 & 132 & -52 \\
\hline COG2303 & $E$ & GI 10 & 82 & 154 & -72 \\
\hline COG1012 & C & GI 10 & 132 & 164 & -32 \\
\hline COG1280 & $E$ & GI 10 & 78 & 82 & -4 \\
\hline COG4664 & $Q$ & GI 10 & 186 & 208 & -22 \\
\hline COG4665 & $Q$ & GI 10 & 193 & 194 & -1 \\
\hline
\end{tabular}


RCA23 c27040 RCA23_c27050

RCA23_c27060

RCA23_c27070

RCA23_c27090

RCA23_c27100

RCA23_c27110

RCA23_c27120

RCA23_c27130

RCA23_c27150

RCA23_c27160

RCA23_c27170

RCA23_c27180

RCA23_c27190

RCA23_c27200

RCA23_c27210

RCA23_c27220

RCA23_c27230

RCA23_c27240

RCA23_c27250

RCA23_c27260

RCA23_c27280

RCA23_c27290

RCA23_c27300

RCA23_c27310

RCA23_c27320

RCA23_c27330

RCA23_c27340

RCA23_c27350

RCA23_c27360
28612352860195 TRAP dicarboxylate transporter, subunit DctP

28621062861444 transcriptional regulator, LysR family

28641322863029 mandelate racemase/muconate lactonizing enzyme

28652412864129 Zn-dependant oxidoreductase

28668702865992 HTH-type transcriptional regulator, LysR family

28669842867739 class II aldolase

28677422868770 fatty acid desaturase

28687722869620 3-methyl-2-oxobutanoate hydroxymethyltransferase PanB

28696512869959 putative rieske [2Fe-2S] protein

28715272870697 hypothetical protein

28721692873122 arginase family protein

28739722873130 hypothetical protein

28743112875399 putative HTH-type transcriptional regulator, AraC family

28763472875367 hypothetical protein. fatty acid desaturase

28783232876440 AMP-dependent synthase / ligase

28802122878422 ABC transporter ATP-binding protein

28806502881150 spore coat family protein

28813702882092 PapD-like chaperone involved in fimbrial biogenesis

28822792884033 fimbrial biogenesis outer membrane usher protein

28840432884906 fimbrial biogenesis outer membrane usher protein

28850612885357 hypothetical protein

28864732885598 hypothetical protein

28908512886601 DNA-directed RNA polymerase beta subunit RpoC

28950442890911 DNA-directed RNA polymerase beta subunit RpoB

2895693289531650 S ribosomal protein L7/L12

2896250289576250 S ribosomal protein L10

2897346289664850 S ribosomal protein L1

2897821289734850 S ribosomal protein L11

28984762897928 transcription antitermination protein NusG

28988932898627 preprotein translocase, subunit SecE

\begin{tabular}{|c|c|c|c|c|c|}
\hline COG4663 & Q & GI 10 & 219 & 154 & 65 \\
\hline COG0583 & $\mathrm{K}$ & GI 10 & 265 & 258 & 7 \\
\hline COG4948 & M & GI 10 & 75 & 142 & -67 \\
\hline COG0604 & C & GI 10 & 72 & 182 & -110 \\
\hline COG0583 & $\mathrm{K}$ & GI 10 & 109 & 112 & -3 \\
\hline COG0235 & G & GI 10 & 127 & 145 & -18 \\
\hline COG3239 & I & GI 10 & 59 & 122 & -63 \\
\hline COG0413 & $\mathrm{H}$ & GI 10 & 113 & 150 & -37 \\
\hline COG2146 & $\mathrm{P}$ & GI 10 & 181 & 173 & 8 \\
\hline COG1396 & $\mathrm{K}$ & & 597 & 445 & 152 \\
\hline COG0010 & $E$ & & 371 & 394 & -23 \\
\hline COG1082 & G & & 609 & 538 & 71 \\
\hline COG2169 & $\mathrm{F}$ & & 277 & 286 & -9 \\
\hline COG3239 & I & & 497 & 509 & -12 \\
\hline COG0318 & I & & 392 & 482 & -90 \\
\hline \multirow[t]{2}{*}{ COG1132 } & V & & 279 & 330 & -51 \\
\hline & & & 310 & 326 & -16 \\
\hline COG3121 & $\mathrm{N}$ & & 313 & 228 & 85 \\
\hline COG3188 & $\mathrm{N}$ & & 235 & 333 & -98 \\
\hline \multirow[t]{2}{*}{ COG3188 } & $\mathrm{N}$ & & 320 & 412 & -92 \\
\hline & & & 275 & 288 & -13 \\
\hline COG0697 & G & & 437 & 532 & -95 \\
\hline COG0086 & $\mathrm{K}$ & & 605 & 404 & 201 \\
\hline COG0085 & $\mathrm{K}$ & & 596 & 421 & 175 \\
\hline COG0222 & J & & 1.149 & 666 & 483 \\
\hline COG0244 & $\mathrm{J}$ & & 1.251 & 786 & 465 \\
\hline COG0081 & J & & 541 & 451 & 90 \\
\hline COG0080 & J & & 723 & 502 & 221 \\
\hline COG0250 & $\mathrm{K}$ & & 711 & 380 & 331 \\
\hline COG0690 & $U$ & & 366 & 293 & 73 \\
\hline
\end{tabular}


RCA23_c27370

RCA23_c27430

RCA23_c27440 29064492906021 hypothetical protein, transmembrane

RCA23_c27450 29071372906511 hypothetical protein

RCA23_c27460 29087202907134 putative acetolactate synthase isozyme 1 large subunit

RCA23_c27470 29101682908720 putative cation transporter

RCA23_c27480 29112282910209 GTP cyclohydrolase FolE

RCA23_c27490 29125752911334 O-succinylhomoserine sulfhydrylase MetZ

RCA23_c27500 29127512913443 hypothetical protein

RCA23_c27510 29141302913531 putative intracellular septation protein

RCA23_c27520 29150482914146 hypothetical protein

RCA23_c27530 29162262915045 putative cell division protein

RCA23_c27540 29180082916323 NADH-quinone oxidoreductase subunits E/F (fused)

RCA23_c27550 29196862918133 exodeoxyribonuclease 7 large subunit XseA

RCA23_c27560 29197572921019 phosphoribosylamine--glycine ligase PurD

RCA23_c27570 29213982921075 hypothetical protein, ferredoxin

RCA23_c27580 29215022921894 hypothetical protein

RCA23_c27590 29234432921956 periplasmic serine protease DO-like

RCA23_c27600 29246682923781 putative protein hflC

RCA23_c27610 29258492924668 protein HflK

RCA23_c27620 29272712925913 glutathione reductase Gor

RCA23_c27630 29280552927336 ribose-5-phosphate isomerase A

RCA23_c27640 29283552928125 hypothetical protein

RCA23_c27650 29284192929792 L-serine dehydratase SdaB

RCA23_c27660 29298232930707 putative integral membrane protein

RCA23_c27670 29313462930672 hypothetical protein, thiamine pyrophosphokinase

RCA23_c27680 29314802931917 hypothetical protein

RCA23_c27690 29323392933484 hypothetical protein

RCA23_c27700 29337792933552 hypothetical protein

RCA23_c27710 29350712933779 adenylosuccinate synthase PurA

$\begin{array}{llccc} & & 315 & 334 & -19 \\ & & 433 & 427 & 6 \\ & & 477 & 559 & -82 \\ \text { COG0028 } & \text { E } & 166 & 344 & -178 \\ \text { COG0168 } & \text { P } & 255 & 334 & -79 \\ \text { COG1469 } & \text { S } & 535 & 514 & 21 \\ \text { COG0626 } & \text { E } & 454 & 382 & 72 \\ \text { COG0625 } & \text { O } & 484 & 552 & -68 \\ \text { COG2917 } & \text { D } & 355 & 420 & -65 \\ \text { COG0697 } & \text { G } & 725 & 845 & -120 \\ \text { COG0552 } & \text { U } & 373 & 538 & -165 \\ \text { COG1894 } & \text { C } & 244 & 359 & -115 \\ \text { COG1570 } & \text { L } & 257 & 373 & -116 \\ \text { COG0151 } & \text { F } & 243 & 310 & -67 \\ \text { COG0633 } & \text { C } & 245 & 400 & -155 \\ \text { COG0587 } & \text { L } & 495 & 375 & 120 \\ \text { COG0265 } & \text { O } & 158 & 249 & -91 \\ \text { COG0330 } & \text { O } & 449 & 643 & -194 \\ \text { COG0330 } & \text { O } & 553 & 459 & 94 \\ \text { COG1249 } & \text { C } & 588 & 454 & 134 \\ \text { COG0120 } & \text { G } & 302 & 406 & -104 \\ \text { COG1760 } & \text { E } & 357 & 434 & -77 \\ \text { COG0697 } & \text { G } & 300 & 310 & -10 \\ \text { COG1564 } & \text { H } & 239 & 300 & -61 \\ & & 437 & 492 & -55 \\ \text { COG0104 } & \mathrm{F} & 326 & 453 & -127 \\ & & 176 & 341 & -165 \\ & & 312 & 344 & 168 \\ & & 362 & -27 \\ & 436 & 466 & -30\end{array}$


RCA23_C27720

29353132935666 preprotein translocase, SecG subunit SecG

RCA23_c27730 29358192937462 CTP synthase

$\begin{array}{ll}\text { COG0504 } & \text { F } \\ \text { COG5470 } & \text { S } \\ \text { COG4103 } & \text { S } \\ \text { COG3221 } & \text { P } \\ \text { COG4598 } & \text { E } \\ \text { COG0834 } & \text { E } \\ \text { COG4215 } & \text { E } \\ \text { COG4160 } & \text { E } \\ \text { COG0174 } & \text { E } \\ \text { COG0518 } & \text { F } \\ \text { COG0174 } & \text { E } \\ \text { COG0665 } & \text { E } \\ \text { COG0161 } & H \\ \text { COG5394 } & \text { S }\end{array}$

RCA23 c27740 29374812937774 hypothetical protein, DUF1330

29378742938227 hypothetical protein DUF1332

RCA23_c27760 29382322938948 hypothetical protein

RCA23_c27770 29390272939800 amino acid transport ATP-binding protein

29398342940547 putative amino acid transport extracellular solute binding prı

RCA23_c27780 29407622941547 putative ABC transporter inner membrane component

RCA23_c27790 29415442942347 putative amino acid transport permease protein

RCA23_c27810 29423442943621 gamma-glutamylputrescine synthase PuuA

RCA23_c27820 29436822944383 hypothetical protein, glutamine amidotransferase class I

RCA23_c27830 29443802945732 gamma-glutamylputrescine synthase PuuA

RCA23_c27840 29457252947029 gamma-glutamylputrescine oxidoreductase PuuB

RCA23_c27850 29472272948594 aminotransferase class III

RCA23_c27860 29491022948632 putative PHB synthesis repressor protein

$\operatorname{cog} 3243$

COG4553 I

RCA23_c27880 29515922949850 poly(R)-hydroxyalkanoic acid synthase PhaC

COG1162

COG0596

$\begin{array}{llc}324 & 415 & -91 \\ 449 & 408 & 41 \\ 276 & 315 & -39 \\ 274 & 238 & 36 \\ 184 & 292 & -108 \\ 412 & 570 & -158 \\ 476 & 436 & 40 \\ 351 & 411 & -60 \\ 271 & 371 & -100 \\ 366 & 351 & 15 \\ 410 & 506 & -96 \\ 319 & 376 & -57 \\ 194 & 296 & -102 \\ 481 & 435 & 46 \\ 616 & 440 & 176 \\ 962 & 483 & 479 \\ 772 & 600 & 172 \\ 424 & 429 & -5 \\ 273 & 335 & -62 \\ 295 & 397 & -102 \\ 640 & 594 & 46 \\ 489 & 563 & -74 \\ 302 & 309 & -7 \\ 275 & 345 & -70 \\ 515 & 437 & 78 \\ 379 & 413 & -34 \\ 489 & 471 & 18 \\ 717 & 600 & 117 \\ 807 & 701 & 106 \\ 611 & 550 & 61 \\ & & \end{array}$

RCA23_c27900 29529492953992 putative ribosome biogenesis GTPase RsgA

RCA23_c27910 29546942953999 hypothetical protein, alpha/beta hydrolase-like

COG0596

COG0441 J

COG1393 P

COG1351

COG0346

COG1846

COG2938

COG1813

611

61 
RCA23_c28020

RCA23_c28030

RCA23_c28040

RCA23_c28050

RCA23_c28060

RCA23_c28070

RCA23_c28080

RCA23_c28090

RCA23_c28100

RCA23_c28110

RCA23_c28120

RCA23_c28130

RCA23_c28140

RCA23_c28150

RCA23_c28160

RCA23_c28170

RCA23_c28180

RCA23_c28190

RCA23_c28200

RCA23_c28210

RCA23_c28220

RCA23_c28230

RCA23_c28240

RCA23_c28250

RCA23_c28260

RCA23_c28270

RCA23_c28280

RCA23_c28290

RCA23_c28300

RCA23_c28310
29623442963546 aspartate aminotransferase AatA

29636962963965 hypothetical protein

29653112963962 multidrug resistance protein NorM

29653472967407 DNA topoisomerase 4 subunit B

29674322967866 hypothetical protein

29688652967876 putative malate/L-lactate dehydrogenase

29696232968946 lipoprotein-releasing system ATP-binding protein LoID

29709382969616 lipoprotein-releasing system transmembrane protein, IoIC/E

29723222970991 prolyl-tRNA synthase ProS

29724792973552 hypothetical protein DUF20

29735812974198 hypothetical protein

29742612976429 polyphosphate kinase Ppk

29765022978046 putative phosphatase

29787582978078 hypothetical protein, DnaJ

29794202978806 hypothetical protein

29815682979442 methylmalonyl-CoA mutase McmA

29816922982117 hypothetical protein

29841792982182 biotin carboxylase AccC

29847882984429 hypothetical protein

29864262984807 propionyl-CoA carboxylase beta chain, mitochondrial precul

29866142987720 putative major facilitator superfamily transporter

29877522989146 hypothetical protein

29906292989175 betaine aldehyde dehydrogenase BetB

29915192990626 hypothetical protein

29929712991571 TRAP dicarboxylate transporter, subunit DctM

29936002992971 TRAP dicarboxylate transporter, subunit DctQ

29946982993682 TRAP dicarboxylate transporter, subunit DctP

29951252994823 transcriptional regulator, Lacl family

29960932995341 hypothetical protein, DUF81 family

29972402996074 serine--glyoxylate aminotransferase SgaA

\section{COG0436}

E

COG0534

COG0187

COG3238

COG2055

COG1136

COG4591

COG0442

COG0628

COG0593

COG0855

COG0248

COG1076

COG1884 I

$\operatorname{COG} 4770$

COG4799 ।

COG2814 G

COG3800

COG1012

COG0697

COG1593

COG4665

COG1638

COG1609

COG0730

COG0075

$\begin{array}{llc}538 & 517 & 21 \\ 520 & 538 & -18 \\ 289 & 371 & -82 \\ 401 & 416 & -15 \\ 246 & 456 & -210 \\ 232 & 307 & -75 \\ 324 & 503 & -179 \\ 391 & 420 & -29 \\ 552 & 522 & 30 \\ 376 & 457 & -81 \\ 404 & 491 & -87 \\ 432 & 474 & -42 \\ 329 & 415 & -86 \\ 357 & 406 & -49 \\ 360 & 363 & -3 \\ 438 & 453 & -15 \\ 443 & 452 & -9 \\ 463 & 438 & 25 \\ 688 & 418 & 270 \\ 431 & 395 & 36 \\ 324 & 367 & -43 \\ 268 & 299 & -31 \\ 271 & 382 & -111 \\ 358 & 670 & -312 \\ 456 & 452 & 4 \\ 526 & 453 & 73 \\ 773 & 495 & 278 \\ 194 & 295 & -101 \\ 642 & 487 & 155 \\ 671 & 457 & 214\end{array}$


COG0277

\section{C}

RCA23_c28330 30001083000872 hypothetical protein

RCA23_c28340 30023593000869 AMP-binding enzyme

RCA23_c28350 30037413002356 succinate-semialdehyde dehydrogenase SucD

COG0318

COG1012 C

RCA23_c28360 30052633003773 hypothetical protein

COG3333 S

RCA23_c28370 30058153005270 hypothetical protein

RCA23_c28380 30068993005886 putative tripartite tricarboxylate transporter family receptor COG3181

RCA23_c28390 30081743007812 putative ETC complex I subunit

RCA23_c28450 30149463014311 sulfoxide reductase heme-binding subunit YedZ

$\operatorname{COG} 2717 \quad S$

RCA23_c28460 30159703015032 sulfoxide reductase catalytic subunit YedY

COG2041 R

RCA23_c28470 30160843016839 3-oxoacyl-[acyl-carrier-protein] reductase FabG

COG1028 I

RCA23_c28480 30174843016816 putative haloacid dehalogenase-like hydrolase

COG0637

COG0542

RCA23_c28490 30201583017549 chaperone protein ClpB

RCA23_c28500 30203823021098 orotidine 5'-phosphate decarboxylase PyrF

COG0284

RCA23_c28510 30213763021095 hypothetical protein

RCA23_c28520 30222663021376 SPFH domain/band 7 family protein

COG0330 O

RCA23_c28530 30223993023655 DNA polymerase IV

RCA23_c28540 30245833023660 putative N-formylglutamate amidohydrolase

COG0389 L

COG3741 E

COG1541 H

RCA23_c28560 30262363025031 hypothetical protein, phenylacetate-coenzyme A ligase

RCA23_c28570 30270953026262 high-affinity branched-chain amino acid transporter ATP-bin

RCA23_c28580 30284263027146 hypothetical protein

COG0410

COG0683

RCA23_c28590

30295673028491 high-affinity branched-chain amino acid transporter permea: COG4177

RCA23_c28600

30306313029630 high-affinity branched-chain amino acid transporter permea: COG0559

RCA23_c28610

30315173030699 high-affinity branched-chain amino acid transporter ATP-bin cOG0411

RCA23_c28620

30335303031569 putative long-chain-fatty-acid-CoA ligase

COG1022

COG0130

COG0858

RCA23_c28650

30346113033706 tRNA pseudouridine synthase B

COG0289

30351833035992 dihydrodipicolinate synthase DapA

RCA23_c28660 30362423036039 hypothetical protein DUF1674

COG5508

RCA23_c28670 30363043037596 putative ribosomal RNA small subunit methyltransferase B COG0144

$\begin{array}{llc}433 & 316 & 117 \\ 591 & 406 & 185 \\ 627 & 378 & 249 \\ 714 & 387 & 327 \\ 551 & 345 & 206 \\ 566 & 428 & 138 \\ 478 & 291 & 187 \\ 483 & 380 & 103 \\ 606 & 414 & 192 \\ 699 & 498 & 201 \\ 217 & 388 & -171 \\ 241 & 355 & -114 \\ 571 & 466 & 105 \\ 231 & 360 & -129 \\ 303 & 257 & 46 \\ 332 & 320 & 12 \\ 244 & 376 & -132 \\ 220 & 384 & -164 \\ 354 & 468 & -114 \\ 388 & 363 & 25 \\ 356 & 266 & 90 \\ 514 & 348 & 166 \\ 662 & 420 & 242 \\ 616 & 480 & 136 \\ 540 & 469 & 71 \\ 444 & 471 & -27 \\ 390 & 589 & -199 \\ 232 & 307 & -75 \\ 308 & 405 & -97 \\ 319 & 342 & -23\end{array}$


RCA23_c28680

RCA23 c28690

RCA23_c28700

RCA23_c28710

RCA23_c28720

RCA23_c28730

RCA23_c28740

RCA23_c28750

RCA23 c28760

RCA23_c28770

RCA23_c28780

RCA23_c28790

RCA23_c28800

RCA23_c28810

RCA23_c28820

RCA23_c28830

RCA23_c28840

RCA23_c28850

RCA23_c28860

RCA23_c28870

RCA23_c28880

RCA23_c28890

RCA23_c28900

RCA23_c28910

RCA23_c28920

RCA23_c28930

RCA23_c28940

RCA23_c28950

RCA23_c28960

RCA23_c28970
30377623039378 hypothetical protein, heparinase II/III

30394203041006 bifunctional purine biosynthesis protein $\mathrm{PurH}$

30410083041490 signal peptidase II

30415643042898 uncharacterized zinc protease y4wA

30428953044199 uncharacterized zinc protease $y 4 \mathrm{wB}$

30442343046045 DNA mismatch repair protein MutL

30460423047181 putative RmuC family protein

30478263047176 transcriptional activator ChrR

30484733047823 RNA polymerase sigma factor SigK

30485953049896 hypothetical protein

30498933050648 hypothetical protein DUF1365

30506453051886 hypothetical protein

30518833052434 hypothetical protein

30524413053175 putative short chain dehydrogenase

30542423053181 saccharopine dehydrogenase (NAD+,L-lysine-forming)

30548383054239 putative glutathione S-transferase

30555183054859 putative phosphoglycerate mutase family protein

30556783058473 formate dehydrogenase Fdh

30596843058476 hypothetical protein

30598453060351 hypothetical protein DUF1643

30603483061232 haloacetate dehalogenase DehH

3061378306164730 S ribosomal protein S15

30617633062671 hypothetical protein, DUF6 transmembrane protein

30628373064972 polyribonucleotide nucleotidyltransferase Pnp

30652973066739 aldehyde dehydrogenase

30675143066870 ribosomal large subunit pseudouridine synthase A

30676413068903 protein OtnG

30689523069767 hypothetical protein, DUF940 putative lipoprotein

30697703070432 hypothetical protein

30704513071461 UDP-glucose 4-epimerase GalE

\begin{tabular}{|c|c|c|c|c|}
\hline COG5360 & $\mathrm{S}$ & 307 & 415 & -108 \\
\hline COG0138 & $\mathrm{F}$ & 334 & 417 & -83 \\
\hline COG0597 & $M$ & 444 & 466 & -22 \\
\hline COG0612 & $\mathrm{R}$ & 259 & 271 & -12 \\
\hline COG0612 & $\mathrm{R}$ & 343 & 387 & -44 \\
\hline COG0323 & $\mathrm{L}$ & 277 & 394 & -117 \\
\hline COG1322 & $S$ & 453 & 493 & -40 \\
\hline COG3806 & $\mathrm{T}$ & 328 & 336 & -8 \\
\hline COG1595 & $\mathrm{K}$ & 815 & 442 & 373 \\
\hline COG2907 & $\mathrm{R}$ & 645 & 423 & 222 \\
\hline COG3496 & $S$ & 321 & 368 & -47 \\
\hline \multirow[t]{2}{*}{ COG2211 } & G & 246 & 374 & -128 \\
\hline & & 338 & 406 & -68 \\
\hline COG4221 & $\mathrm{R}$ & 338 & 412 & -74 \\
\hline COG3288 & C & 244 & 380 & -136 \\
\hline COG0625 & 0 & 410 & 462 & -52 \\
\hline COG0406 & G & 408 & 433 & -25 \\
\hline COG3383 & $\mathrm{R}$ & 256 & 355 & -99 \\
\hline COG1357 & $\mathrm{S}$ & 149 & 173 & -24 \\
\hline COG4333 & $S$ & 165 & 251 & -86 \\
\hline COG0596 & $\mathrm{R}$ & 216 & 302 & -86 \\
\hline COG0184 & $\mathrm{J}$ & 532 & 436 & 96 \\
\hline COG0697 & G & 291 & 363 & -72 \\
\hline COG1185 & $\mathrm{J}$ & 566 & 452 & 114 \\
\hline COG1012 & C & 367 & 317 & 50 \\
\hline \multirow[t]{4}{*}{ COG0564 } & $\mathrm{J}$ & 330 & 420 & -90 \\
\hline & & 239 & 284 & -45 \\
\hline & & 460 & 502 & -42 \\
\hline & & 502 & 397 & 105 \\
\hline COG1087 & $M$ & 409 & 393 & 16 \\
\hline
\end{tabular}


RCA23_c28980

RCA23_c28990

RCA23_c29000

RCA23_c29010

RCA23_c29020

RCA23_c29030

RCA23_c29040

RCA23_c29050

RCA23_c29060

RCA23_c29070

RCA23_c29080

RCA23_c29090

RCA23_c29100

RCA23_c29110

RCA23_c29120

RCA23_c29130

RCA23_c29140

RCA23_c29150

RCA23_c29160

RCA23_c29170

RCA23_c29180

RCA23_c29190

RCA23_c29200

RCA23_c29210

RCA23_c29220 30953253095912 hypothetical protein, glutathione S-transferase

RCA23_c29230 30971083095885 hypothetical protein

RCA23_c29240 30982433097311 hypothetical protein, porin

RCA23_c29250 30984813099143 hypothetical protein, alanine racemase-like

RCA23_c29260

RCA23_c29270

30729183071458 putative FAD linked oxidase

30732073074703 signal recognition particle protein Ffh

30747353075031 putative chorismate mutase type II

3075077307546330 S ribosomal protein S16

30755993076204 ribosome maturation factor RimM

30762013076983 tRNA (guanine-N(1)-)-methyltransferase TrmD

3077274307764550 S ribosomal protein L19

3077657307787850 S ribosomal protein L31

30780553078864 ATPase MipZ

30797933078861 fructokinase

30800093081187 P-hydroxybenzoate hydroxylase PobA

30812513082447 kynureninase KynU

$30830413083694 \mathrm{HTH}$-type transcriptional regulator, GntR family

30837613084600 hypothetical protein, glutathione S-transferase

30847013085639 L-threonine 3-dehydrogenase

30856503086444 enoyl-CoA hydratase

30873863086463 enoyl-CoA hydratase

30881633087396 3-hydroxyacyl-CoA dehydrogenase FadN

30882983088942 hypothetical protein

30899253088969 integrase

0900523091107 hypothetical protein, porin-like

30912543093845 leucyl-tRNA synthase LeuS

30939043094302 hypothetical protein DUF2159

30996443099150 hypothetical protein, YkuD

31006963099641 GTP cyclohydrolase II RibA

\begin{tabular}{|c|c|c|c|c|}
\hline COG0277 & $\mathrm{C}$ & 266 & 432 & -166 \\
\hline COG0541 & $U$ & 323 & 360 & -37 \\
\hline COG1605 & $E$ & 471 & 593 & -122 \\
\hline COG0228 & $\mathrm{J}$ & 454 & 521 & -67 \\
\hline COG0806 & $\mathrm{J}$ & 531 & 440 & 91 \\
\hline COG0336 & $\mathrm{J}$ & 262 & 287 & -25 \\
\hline COG0335 & $\mathrm{J}$ & 1.180 & 564 & 616 \\
\hline COG0254 & $\mathrm{J}$ & 843 & 515 & 328 \\
\hline COG1192 & $D$ & 467 & 427 & 40 \\
\hline COG0524 & G & 353 & 434 & -81 \\
\hline COG0654 & $\mathrm{H}$ & 481 & 429 & 52 \\
\hline COG3844 & $E$ & 389 & 318 & 71 \\
\hline COG1802 & $\mathrm{K}$ & 449 & 308 & 141 \\
\hline COG0625 & 0 & 529 & 404 & 125 \\
\hline COG0451 & $M$ & 348 & 353 & -5 \\
\hline COG1024 & 1 & 185 & 255 & -70 \\
\hline COG1250 & I & 205 & 333 & -128 \\
\hline \multirow[t]{2}{*}{ COG1028 } & 1 & 242 & 312 & -70 \\
\hline & & 381 & 386 & -5 \\
\hline \multirow[t]{2}{*}{ COG4974 } & $\mathrm{L}$ & 458 & 427 & 31 \\
\hline & & 520 & 390 & 130 \\
\hline \multirow[t]{3}{*}{ COG0495 } & $\mathrm{J}$ & 433 & 380 & 53 \\
\hline & & 571 & 462 & 109 \\
\hline & & 274 & 392 & -118 \\
\hline COG0625 & 0 & 500 & 442 & 58 \\
\hline \multirow[t]{2}{*}{ COG2081 } & $\mathrm{R}$ & 237 & 270 & -33 \\
\hline & & 1.707 & 409 & 1.298 \\
\hline COG0325 & $\mathrm{R}$ & 273 & 282 & -9 \\
\hline COG3786 & $S$ & 218 & 327 & -109 \\
\hline COG0807 & $\mathrm{H}$ & 321 & 376 & -55 \\
\hline
\end{tabular}


RCA23_c29280

RCA23_c29300 31034303102573 fumarylacetoacetate hydrolase family protein

RCA23_c29310 31038343103427 5-carboxymethyl-2-hydroxymuconate isomerase

RCA23_c29320 31040093104446 homoprotocatechuate degradation operon regulator $\mathrm{HpaR}$

RCA23_c29330 31044433105903 4-hydroxyphenylacetate 3-monooxygenase oxygenase com

RCA23_c29340 31069783105926 ABC sugar transporter, ATPase subunit

RCA23_c29350 31083783106966 mannitol 2-dehydrogenase MtIK

RCA23_c29360 31092773108384 transcriptional regulator, AraC family

RCA23_c29370 31101793109343 ABC sugar transporter, permease protein

RCA23_c29380 31111283110190 ABC sugar transporter, permease protein

RCA23_c29390 31125203111240 ABC transporter, periplasmic substrate-binding protein

RCA23_c29400 31130453113410 putative flavohemoglobin / bacterial hemoglobin

RCA23_c29410 31135703113848 hypothetical protein

RCA23_c29420 $31150533113854 \mathrm{Na}+/ \mathrm{H}+$ antiporter NhaA

RCA23_c29430 31155553115160 hypothetical protein

RCA23_c29440 31160463115633 hypothetical protein DUF55

RCA23_c29450 31163183116046 protein Ycil

RCA23_c29460 31172833116318 glycerol-3-phosphate dehydrogenase GpsA

RCA23_c29470 31173833118087 hypothetical protein, uroporophyrinogen-III synthase HemD

RCA23_c29480 31181123119260 hypothetical protein

RCA23_c29490 31192713120746 hypothetical protein, HemY

RCA23_c29500 31210653120736 transcriptional regulatory protein, Ars family

RCA23_c29510 31220553121183 magnesium-chelatase subunit BchO

RCA23_c29520 31237073122055 magnesium-chelatase subunit BchD

RCA23_c29530 31247163123709 magnesium-chelatase subunit Bchl

RCA23_c29540 31254593124713 spheroidene monooxygenase CrtA

RCA23_c29550 31255143127076 phytoene dehydrogenase Crtl

RCA23_c29560 31270733128113 phytoene synthase CrtB

RCA23_c29570 31290223128114 hydroxyneurosporene dehydrogenase CrtC

$\begin{array}{llllc}\text { COG0745 } & \text { T } & 801 & 648 & 153 \\ \text { COG3971 } & \text { Q } & 378 & 339 & 39 \\ \text { COG0179 } & \text { Q } & 416 & 428 & -12 \\ \text { COG3232 } & \text { E } & 367 & 337 & 30 \\ \text { COG1846 } & \text { K } & 513 & 682 & -169 \\ \text { COG2368 } & \text { Q } & 396 & 413 & -17 \\ \text { COG3839 } & \text { G } & 417 & 427 & -10 \\ \text { COG0246 } & \text { G } & 541 & 470 & 71 \\ \text { COG2207 } & \text { K } & 845 & 568 & 277 \\ \text { COG0395 } & \text { G } & 673 & 486 & 187 \\ \text { COG1175 } & \text { G } & 627 & 368 & 259 \\ \text { COG1653 } & \text { G } & 482 & 349 & 133 \\ \text { COG1017 } & \text { C } & 172 & 151 & 21 \\ & & 357 & 239 & 118 \\ \text { COG3004 } & \text { P } & 869 & 651 & 218 \\ & & 343 & 377 & -34 \\ \text { COG2947 } & \text { S } & 575 & 446 & 129 \\ \text { COG2350 } & \text { S } & 444 & 407 & 37 \\ \text { COG0240 } & \text { C } & 295 & 365 & -70 \\ \text { COG1587 } & \text { H } & 261 & 373 & -112 \\ \text { COG3264 } & \text { M } & 297 & 444 & -147 \\ \text { COG3898 } & \text { S } & 255 & 322 & -67 \\ \text { COG0640 } & \text { K } & 351 & 449 & -98 \\ \text { COG0596 } & \text { R } & 368 & 539 & -171 \\ \text { COG1240 } & \text { H } & 228 & 347 & -119 \\ \text { COG1239 } & \text { H } & 259 & 357 & -98 \\ \text { COG1233 } & \text { Q } & 327 & 471 & -144 \\ \text { COG1562 } & \text { I } & 248 & 310 & -62 \\ & & 282 & 412 & -130 \\ & & 315 & 427 & -112\end{array}$


RCA23_c29580

RCA23_c29590

RCA23_c29600

$\begin{array}{ll}\text { RCA23_c29620 } & 31336823134686 \text { chlorophyllide reductase BchX } \\ \text { RCA23_c29630 } & 31346793136250 \text { chlorophyllide reductase BchY }\end{array}$

RCA23_c29640 31362503137710 chlorophyllide reductase subunit BchZ

RCA23_c29650 31377073137940 protein PufQ

RCA23_c29660 31380873138242 light-harvesting protein B-870 beta chain PufB

RCA23_c29670 31382593138411 light-harvesting protein B-870 alpha chain PufA

RCA23_c29680 31385313139361 reaction center protein L chain PufL

RCA23_c29690 31393753140298 reaction center protein M chain PufM

RCA23_c29700 31403233140562 protein PufX

RCA23_c29710 31407483142640 1-deoxy-D-xylulose-5-phosphate synthase Dxs

RCA23_c29720 31431773142659 isopentenyl-diphosphate delta-isomerase Idi

RCA23_c29730 31443553143177 geranylgeranyl reductase BchP

RCA23_c29740 31456503144358 bacteriochlorophyll synthase $44.5 \mathrm{kDa}$ chain

RCA23_c29750 31465463145647 bacteriochlorophyll synthase BchG

RCA23_c29760 31466993147133 cytochrome c-551

RCA23_c29770 31482043147191 uroporphyrinogen decarboxylase HemE

RCA23_c29780 31483833149273 porphobilinogen deaminase HemC

RCA23_c29790 31492543150213 hypothetical protein, NmrA-like

RCA23_c29800 31514243150210 5-aminolevulinate synthase HemA

RCA23_c29810 31522203151414 hypothetical protein

RCA23_c29820 31533473152220 aerobic Mg-protoporphyrin IX monomethyl ester oxidative cyclase AcsF

RCA23_c29830 31536403153344 hypothetical protein

RCA23_c29840 31541243153657 hypothetical protein

RCA23_c29850 31547683154130 hypothetical protein

RCA23_c29860 31556003154827 reaction center protein PuhA

RCA23_c29870 31570463155619 protein PucC

\begin{tabular}{|c|c|c|c|c|}
\hline COG1233 & $Q$ & 258 & 382 & -124 \\
\hline \multirow[t]{2}{*}{ COG0142 } & $\mathrm{H}$ & 317 & 337 & -20 \\
\hline & & 351 & 342 & 9 \\
\hline COG1063 & $E$ & 357 & 361 & -4 \\
\hline \multirow[t]{2}{*}{ COG1348 } & $P$ & 519 & 502 & 17 \\
\hline & & 341 & 319 & 22 \\
\hline \multirow[t]{7}{*}{ COG2710 } & C & 536 & 488 & 48 \\
\hline & & 537 & 427 & 110 \\
\hline & & 6.978 & 500 & 6.478 \\
\hline & & 6.270 & 527 & 5.743 \\
\hline & & 874 & 581 & 293 \\
\hline & & 677 & 578 & 99 \\
\hline & & 968 & 617 & 351 \\
\hline COG1154 & $\mathrm{H}$ & 354 & 396 & -42 \\
\hline COG1443 & 1 & 410 & 573 & -163 \\
\hline \multirow[t]{2}{*}{ COG0644 } & C & 323 & 416 & -93 \\
\hline & & 331 & 411 & -80 \\
\hline COG0382 & $\mathrm{H}$ & 279 & 365 & -86 \\
\hline COG3474 & C & 2.610 & 694 & 1.916 \\
\hline COG0407 & $\mathrm{H}$ & 678 & 490 & 188 \\
\hline COG0181 & $\mathrm{H}$ & 296 & 376 & -80 \\
\hline COG0702 & $M$ & 262 & 383 & -121 \\
\hline \multirow[t]{2}{*}{ COG0156 } & $\mathrm{H}$ & 552 & 474 & 78 \\
\hline & & 439 & 465 & -26 \\
\hline \multirow[t]{6}{*}{ /clase AcsF } & & 646 & 487 & 159 \\
\hline & & 666 & 516 & 150 \\
\hline & & 392 & 356 & 36 \\
\hline & & 466 & 594 & -128 \\
\hline & & 424 & 380 & 44 \\
\hline & & 416 & 549 & -133 \\
\hline
\end{tabular}


RCA23_c29910 31637173162173 light-independent protochlorophyllide reductase subunit Bct COG2710 RCA23_c29920 31649463163714 light-independent protochlorophyllide reductase subunit Bct COG2710 
RCA23_c30180

RCA23_c30190

RCA23 c30200 31929153192157 lipopolysaccharide export system ATP-t

RCA23_c30210 31934033192915 putative lipopolysaccharide export system protein LptA

RCA23_c30220 31940203193412 hypothetical protein

RCA23_c30230 31946623194048 putative 3'-5'-exonuclease

RCA23_c30240 31948503195968 glycine amidinotransferase

RCA23_c30250 31968173196053 hypothetical protein

RCA23_c30260 31974813196918 hypothetical protein, metal-dependent phosphohydrolase

RCA23_c30270 31976343199025 S-adenosyl-L-homocysteine hydrolase AhcY

RCA23_c30280 31998903199339 photosynthetic apparatus regulatory protein RegA

RCA23_c30290 32005703199947 protein SenC

RCA23_c30300 32006493202016 sensor histidine kinase RegB

RCA23_c30310 32020733203299 hypothetical protein

RCA23_c30320 32034503204445 hypothetical protein, aminoglycoside phosphotransferase

RCA23_c30330 32044453205107 hypothetical protein, nucleotidyl transferase

RCA23_c30340 32051003208018 double-strand break repair protein AddB

RCA23_c30350 32080153211371 double-strand break repair helicase AddA

RCA23_c30360 32114303211750 thioredoxin TrxA

RCA23_c30370 32118583212415 ATP-dependent protease HsIV

RCA23_c30380 32124123213719 ATP-dependent hsl protease ATP-binding subunit HsIU

RCA23_c30390 32137573214968 MFS-type transporter

RCA23_c30400 32155433214965 hypothetical protein, Smr protein/MutS2

RCA23_c30410 32165743215546 putative lytic murein transglycosylase

RCA23_c30420 32172453216571 hypothetical protein, TIM44

RCA23_c30430 32173333217791 putative cytoplasmic membrane protein FxsA

RCA23_c30440 32178473218353 protein-export protein SecB

RCA23_c30450 32190453218350 DNA polymerase III subunit epsilon

RCA23_c30460 32196313219038 dephospho-CoA kinase CoaE

RCA23_c30470 32210433219628 shikimate 5-dehydrogenase AroE

$\begin{array}{lc}\text { COG1762 } & \text { G } \\ \text { COG1544 } & \text { J } \\ \text { COG1137 } & \text { R } \\ \text { COG1934 } & \text { S } \\ & \\ \text { COG0349 } & \text { J } \\ \text { COG1834 } & \text { E } \\ \text { COG4123 } & \text { R } \\ \text { COG1896 } & \text { R } \\ \text { COG0499 } & \text { H } \\ \text { COG4567 } & \text { T } \\ \text { COG1999 } & \text { R } \\ \text { COG0642 } & \text { T } \\ & \\ \text { COG3178 } & \text { R } \\ \text { COG1208 } & \text { M } \\ \text { COG3893 } & \text { L } \\ \text { COG1074 } & \text { L } \\ \text { COG3118 } & \text { O } \\ \text { COG5405 } & \text { O } \\ \text { COG1220 } & \text { O } \\ \text { COG2814 } & \text { G } \\ \text { COG2840 } & \text { S } \\ \text { COG2821 } & \text { M } \\ \text { COG4395 } & \text { S } \\ \text { COG3030 } & \text { R } \\ \text { COG1952 } & \text { U } \\ \text { COG0847 } & \text { L } \\ \text { COG0237 } & \text { H } \\ \text { COG0169 } & \text { E } \\ & \end{array}$

$\begin{array}{ccc}462 & 459 & 3 \\ 716 & 558 & 158 \\ 444 & 438 & 6 \\ 280 & 352 & -72 \\ 689 & 490 & 199 \\ 741 & 509 & 232 \\ 521 & 526 & -5 \\ 631 & 493 & 138 \\ 457 & 580 & -123 \\ 603 & 490 & 113 \\ 407 & 550 & -143 \\ 543 & 578 & -35 \\ 358 & 402 & -44 \\ 342 & 444 & -102 \\ 494 & 540 & -46 \\ 458 & 486 & -28 \\ 333 & 483 & -150 \\ 483 & 495 & -12 \\ 926 & 781 & 145 \\ 570 & 616 & -46 \\ 505 & 486 & 19 \\ 450 & 609 & -159 \\ 359 & 384 & -25 \\ 516 & 462 & 54 \\ 603 & 469 & 134 \\ 1.292 & 879 & 413 \\ 980 & 584 & 396 \\ 740 & 456 & 284 \\ 607 & 420 & 187 \\ 384 & 325 & 59\end{array}$


RCA23 c30480

RCA23_c30490

32245973226456 tRNA uridine 5-carboxymethylaminomethyl modification enż

RCA23_c30510 32264533227076 ribosomal RNA small subunit methyltransferase G

RCA23_c30520 32270633227839 chromosome-partitioning protein ParA

RCA23_c30530 32279133228749 chromosome-partitioning protein ParB

RCA23_c30540 32298943228746 oxygen-independent coproporphyrinogen Ill oxidase HemN

RCA23_c30550 32305023229894 nucleoside-triphosphatase RdgB

RCA23_c30560 32312123230502 ribonuclease PH

RCA23_c30570 32313093232340 heat-inducible transcription repressor HrcA

RCA23_c30580 32323473232901 protein GrpE

RCA23_c30590 32357343232948 DNA mismatch repair protein MutS

RCA23_c30600 32358473238102 NADP-dependent malic enzyme MaeB

RCA23_c30610 32380993238974 pfkB family carbohydrate kinase

RCA23_c30620 32390643239972 putative aminotransferase class IV

RCA23 c30630 32399693240679 hypothetical protein, branched-chain-amino-acid aminotransferase-like

RCA23_c30640 32419143240697 argininosuccinate synthase ArgG

RCA23_c30650 32420763243311 threonine dehydratase, biosynthetic

RCA23_c30660 32437603243320 putative NUDIX hydrolase

RCA23_c30670 32438413244851 heat shock protein 33

RCA23_c30680 32448323245428 putative NUDIX hydrolase

RCA23_c30690 32454253246585 hypothetical protein, poly A polymerase

RCA23_c30700 32466673248505 ABC transporter ATP-binding/permease protein

RCA23_c30710 32485053249719 hypothetical protein

RCA23_c30720 32497263250487 ion transport protein

RCA23_c30730 32505473251041 hypothetical protein

RCA23_c30740 32515893251068 hypothetical protein, SCP-like extracellular protein

RCA23_c30750 32517403252339 hypothetical protein

RCA23_c30760 32537883252730 ferrochelatase HemH

RCA23_c30770 32546543253839 hypothetical protein

\begin{tabular}{|c|c|}
\hline COG1158 & $\mathrm{K}$ \\
\hline COG0486 & $\mathrm{R}$ \\
\hline COG0445 & $\mathrm{D}$ \\
\hline COG0357 & $M$ \\
\hline COG1192 & $D$ \\
\hline COG1475 & $\mathrm{K}$ \\
\hline COG0635 & $\mathrm{H}$ \\
\hline COG0127 & $\mathrm{F}$ \\
\hline COG0689 & $J$ \\
\hline COG1420 & $\mathrm{K}$ \\
\hline COG0576 & $\mathrm{O}$ \\
\hline COG0249 & $\mathrm{L}$ \\
\hline COG0281 & C \\
\hline COG0524 & G \\
\hline COG0115 & $E$ \\
\hline
\end{tabular}

$\begin{array}{llc}799 & 587 & 212 \\ 677 & 610 & 67 \\ 754 & 479 & 275 \\ 923 & 624 & 299 \\ 715 & 536 & 179 \\ 590 & 401 & 189 \\ 502 & 365 & 137 \\ 443 & 404 & 39 \\ 433 & 583 & -150 \\ 677 & 565 & 112 \\ 715 & 541 & 174 \\ 382 & 470 & -88 \\ 751 & 604 & 147 \\ 385 & 437 & -52 \\ 420 & 511 & -91 \\ 281 & 358 & -77 \\ 456 & 465 & -9 \\ 565 & 492 & 73 \\ 859 & 585 & 274 \\ 563 & 552 & 11 \\ 312 & 397 & -85 \\ 231 & 347 & -116 \\ 582 & 671 & -89 \\ 472 & 532 & -60 \\ 613 & 593 & 20 \\ 812 & 587 & 225 \\ 495 & 433 & 62 \\ 713 & 514 & 199 \\ 912 & 584 & 328 \\ 409 & 512 & -103\end{array}$


RCA23_c30780 RCA23_c30790

RCA23_c30800

RCA23_c30810

RCA23_c30820

RCA23_c30830

RCA23_c30840

RCA23_c30850

RCA23_c30860

RCA23_c30870

RCA23_c30880

RCA23_c30890

RCA23_c30900

RCA23_c30910

RCA23_c30920

RCA23_c30930

RCA23_c30940

RCA23_c30950

RCA23_c30960

RCA23_c30970

RCA23_c30980

RCA23_c30990

RCA23_c31000

RCA23_c31010

RCA23_c31020

RCA23_c31030 32856213284845 ubiquinone/menaquinone biosynthesis methyltransferase U

RCA23_c31040 32856803286531 formamidopyrimidine-DNA glycosylase MutM

RCA23_c31050 32865943287370 enoyl-CoA hydratase/isomerase

RCA23_c31060 32875193287782 30S ribosomal protein S20

$\begin{array}{ll}\text { COG1040 } & \text { R } \\ \text { COG0695 } & \text { O } \\ \text { COG0388 } & \text { R } \\ \text { COG1846 } & \text { K } \\ \text { COG2227 } & \text { H } \\ \text { COG0596 } & \text { R } \\ \text { COG0601 } & \text { E } \\ \text { COG1173 } & \text { E } \\ \text { COG1123 } & \text { R } \\ \text { COG0747 } & \text { E } \\ \text { COG0779 } & \text { S } \\ \text { COG0195 } & \text { K } \\ \text { COG2740 } & \text { K } \\ \text { COG0532 } & \text { J } \\ \text { COG1051 } & \mathrm{F} \\ \text { COG1364 } & \text { E } \\ \text { COG0760 } & \text { O } \\ \text { COG0653 } & \text { U } \\ \text { COG1835 } & \text { I } \\ \text { COG } 4922 & \text { S } \\ \text { COG1733 } & \text { K } \\ \text { COG0451 } & \text { M } \\ \text { COG1109 } & \text { G } \\ \text { COG0661 } & \text { R } \\ \text { COG2226 } & \text { H } \\ \text { COG0266 } & \text { L } \\ \text { COG1024 } & \text { I } \\ \text { COG0268 } & \text { J } \\ & \end{array}$


Table S7: COG categories, genomic islands and coverage of $P$. temperata RC23 genes from combined stations GS02-13

of the GOS data set and Norwegian fjord metagenome (Gilbert et al. 2008).

Coverages of $<80 \%$ are marked pink and genomic islands gray

\begin{tabular}{|c|c|c|c|c|c|c|}
\hline locus_tag & annotation & COG id & $\begin{array}{c}\text { COG } \\
\text { category }\end{array}$ & $\begin{array}{c}\text { genomic } \\
\text { islands }\end{array}$ & $\begin{array}{c}\text { GOS stations } \\
\text { GS02-GS13 } \\
\text { gene coverage } \\
{[\%]}\end{array}$ & $\begin{array}{l}\text { Fjord gDNA } \\
\text { gene } \\
\text { coverage [\%] }\end{array}$ \\
\hline RCA23_c00010 & chromosomal replication initiatior protein DnaA & COG0593 & $\bar{L}$ & & 100.00 & 100.00 \\
\hline RCA23_c00020 & DNA polymerase III beta subunit DnaN & COG0592 & $\mathrm{L}$ & & 100.00 & 99.55 \\
\hline RCA23_c00030 & DNA replication and repair protein RecF & COG1195 & $\mathrm{L}$ & & 100.00 & 100.00 \\
\hline RCA23_c00040 & hypothetical protein, LysE type translocator & COG1280 & E & & 100.00 & 100.00 \\
\hline RCA23_c00050 & DNA gyrase subunit B & COG0187 & $\mathrm{L}$ & & 100.00 & 99.92 \\
\hline RCA23_c00060 & FAD dependent oxidoreductase & COG0665 & $\mathrm{E}$ & & 100.00 & 100.00 \\
\hline RCA23_c00070 & hypothetical protein, rhodanese-like sulphurtransferase & COG1054 & $\mathrm{R}$ & & 100.00 & 100.00 \\
\hline RCA23_c00080 & pyrazinamidase/nicotinamidase PncA & COG1335 & Q & & 100.00 & 100.00 \\
\hline RCA23_c00090 & nicotinate phosphoribosyltransferase PncB & COG1488 & $\mathrm{H}$ & & 100.00 & 100.00 \\
\hline RCA23_c00100 & aminoglycoside phosphotransferase & COG2334 & $\mathrm{R}$ & & 100.00 & 100.00 \\
\hline RCA23_c00110 & putative aminotransferase class III & COG0160 & E & & 100.00 & 100.00 \\
\hline RCA23_c00120 & putative peptide chain release factor & COG1186 & J & & 100.00 & 100.00 \\
\hline RCA23_c00130 & hypothetical integral membrane protein & COG1738 & $\mathrm{S}$ & & 100.00 & 100.00 \\
\hline RCA23_c00140 & penicillin-insensitive murein endopeptidase MepA & COG3770 & M & & 100.00 & 99.57 \\
\hline RCA23_c00150 & putative MFS-type transporter & COG2270 & $\mathrm{R}$ & & 100.00 & 100.00 \\
\hline RCA23_c00160 & hypothetical protein & COG0824 & $\mathrm{R}$ & & 100.00 & 100.00 \\
\hline RCA23_c00170 & hypothetical protein, YGGT family & COG0762 & $\mathrm{S}$ & & 100.00 & 100.00 \\
\hline RCA23_c00180 & ATP-dependent DNA helicase RecQ & COG0514 & $\mathrm{L}$ & & 100.00 & 100.00 \\
\hline RCA23_c00190 & hypothetical protein DUF328 & COG3022 & $\mathrm{S}$ & & 100.00 & 100.00 \\
\hline RCA23_c00200 & isopentenyl-diphosphate delta-isomerase Idi & COG1443 & 1 & & 100.00 & 100.00 \\
\hline RCA23_c00210 & 5-aminolevulinate synthase HemA & COG0156 & $\mathrm{H}$ & & 100.00 & 100.00 \\
\hline RCA23_c00220 & cytochrome c2 & COG3474 & C & & 100.00 & 100.00 \\
\hline RCA23_c00230 & acetyl-CoA acetyltransferase PhaA & COG0183 & 1 & & 100.00 & 100.00 \\
\hline RCA23_c00240 & DNA polymerase III 2 alpha subunit DnaE & COG0587 & $\mathrm{L}$ & & 100.00 & 100.00 \\
\hline
\end{tabular}


RCA23_c00250

RCA23_c00260

RCA23_c00270

RCA23 c00280

RCA23_c00290

RCA23_c00300

RCA23 c00310

RCA23_c00320

RCA23_c00330

RCA23_c00340

RCA23_c00350

RCA23_c00360

RCA23_c00370

RCA23_c00380

RCA23_c00390

RCA23_c00400

RCA23 c00410

RCA23_c00420

RCA23_c00430

RCA23_c00440

RCA23_c00450

RCA23_c00460

RCA23_c00470

RCA23_c00480

RCA23_c00490

RCA23 c00500

RCA23_c00510

RCA23_c00520

RCA23_c00530

RCA23_c00540

RCA23_c00550

RCA23_c00560

RCA23 c00570 transcription antitermination protein NusG

putative lytic murein transglycosylase

putative ribonuclease $R$

hypothetical protein DUF461

chorismate synthase AroC

hypothetical protein

thiamine-binding periplasmic protein ThiB

thiamine transport system permease protein ThiP

thiamine import ATP-binding protein ThiQ

cytochrome c1

cytochrome b

ubiquinol-cytochrome c reductase iron-sulfur subunit PetA

hypothetical protein, glutathione S-transferase

inositol 2-dehydrogenase IdhA

protein PmbA

putative inositol monophosphatase

putative 3-deoxy-D-manno-octulosonic-acid transferase

tetraacyldisaccharide 4'-kinase LpxK

hypothetical protein, thioredoxin

hypothetical protein DUF721

$A / G$-specific adenine glycosylase $Y f h Q$

alkane 1-monooxygenase AlkB

modification methylase CcrM

ribonuclease HII

putative exodeoxyribonuclease III

hypothetical protein, thioredoxin

putative ATP-dependent protease La (LON)

hypothetical protein, Trm112p-like

putative 2-octaprenyl-6-methoxyphenol hydroxylase

glutamyl-tRNA(GIn) amidotransferase subunit A

LL-diaminopimelate aminotransferase DapL

putative DNA transclocase FtsK

putative outer membrane lipoprotein carrier protein LolA

\begin{tabular}{|c|c|}
\hline COG0250 & \\
\hline COG2951 & \\
\hline COG0557 & \\
\hline COG2847 & \\
\hline COG0082 & \\
\hline COG4143 & \\
\hline COG1178 & \\
\hline COG3840 & \\
\hline COG2857 & \\
\hline COG1290 & \\
\hline COG0723 & \\
\hline COG0625 & \\
\hline COG0673 & \\
\hline COG0312 & \\
\hline COG0483 & \\
\hline COG1519 & \\
\hline COG1663 & \\
\hline COG1651 & \\
\hline COG5389 & \\
\hline COG1194 & \\
\hline COG0863 & \\
\hline COG0164 & \\
\hline COG0708 & \\
\hline COG3118 & \\
\hline COG2802 & \\
\hline COG2835 & \\
\hline COG0654 & \\
\hline COG0154 & \\
\hline COG0436 & \\
\hline COG1674 & \\
\hline COG2834 & \\
\hline
\end{tabular}

100.00

100.00

100.00

100.00

100.00

100.00

100.00

100.00

100.00

100.00

100.00

100.00

100.00

100.00

100.00

100.00

100.00

100.00

100.00

100.00

100.00

100.00

100.00

100.00

100.00

100.00

100.00

100.00

100.00

100.00

100.00

100.00

100.00
100.00

100.00

99.24

100.00

100.00

100.00

100.00

100.00

100.00

100.00

97.53

100.00

100.00

100.00

100.00

100.00

100.00

100.00

100.00

100.00

100.00

100.00

100.00

100.00

100.00

100.00

100.00

100.00

100.00

98.02

100.00

100.00

93.55 
RCA23_c00580 hypothetical protein

RCA23_c00590 hemimethylated DNA-binding protein, YccV like

RCA23_c00600 putative gamma-glutamyltransferase ywrD

RCA23_c00610 acetyl-CoA acetyltransferase ThIA

RCA23_c00620 hypothetical protein

RCA23_c00630 putative HTH-type transcriptional regulator

RCA23_c00640 hypothetical protein, homoserine/homoserine lactone efflux protein

RCA23_c00650 LysE-type translocator

RCA23_c00660 dimethylglycine dehydrogenase

RCA23_c00670 putative homocysteine S-methyltransferase

RCA23_c00680 pyridoxamine 5'-phosphate oxidase-like protein, FMN-binding

RCA23_c00690 sarcosine dehydrogenase

RCA23_c00700 hypothetical protein

RCA23_c00710 putative agmatine deiminase AguA

RCA23_c00720 Cl- channel, voltage-gated family protein

RCA23_c00730 Cl-channel, voltage-gated family protein

RCA23 c00750 diaminopimelate epimerase DapF

RCA23_c00760 (dimethylallyl)adenosine tRNA methylthiotransferase MiaB

RCA23_c00770 hypothetical protein, glutathione S-transferotein

RCA23_c00780 HTH-type transcriptional regulator, Lacl family

RCA23_c00790 hypothetical protein

RCA23_c00800 hypothetical protein

RCA23_c00810 hypothetical protein, phosphoglycerate mutase-like

RCA23_c00820 hypothetical protein

RCA23_c00830 hypothetical protein, glyoxalase/bleomycin resistance protein/dihydroxybiph€

RCA23_c00840 putative phage integrase

RCA23_c00850 hypothetical protein

RCA23_c00860 hypothetical protein

RCA23_c00870 putative endonuclease

RCA23_c00880 DNA integration/recombination/invertion protein

RCA23_c00890 hypothetical protein

RCA23_c00900 hypothetical protein, peptidoglycan binding-like

RCA23_c00910 hypothetical protein

\begin{tabular}{|c|c|c|c|c|}
\hline COG4764 & $S$ & & 100.00 & 100.00 \\
\hline COG3785 & $S$ & & 100.00 & 100.00 \\
\hline COG0405 & $E$ & & 100.00 & 100.00 \\
\hline COG0183 & 1 & & 100.00 & 98.13 \\
\hline COG1956 & $\mathrm{T}$ & & 100.00 & 100.00 \\
\hline COG1396 & $\mathrm{K}$ & & 100.00 & 100.00 \\
\hline COG1280 & $E$ & & 100.00 & 100.00 \\
\hline COG1280 & $E$ & & 100.00 & 87.72 \\
\hline COG0404 & $E$ & & 100.00 & 95.83 \\
\hline COG2040 & $E$ & & 100.00 & 100.00 \\
\hline COG3576 & $\mathrm{R}$ & & 100.00 & 99.34 \\
\hline COG0404 & $E$ & & 100.00 & 100.00 \\
\hline COG0790 & $\mathrm{R}$ & & 100.00 & 100.00 \\
\hline COG2957 & $E$ & & 100.00 & 100.00 \\
\hline COG0038 & $P$ & & 100.00 & 85.75 \\
\hline COG0038 & $P$ & & 100.00 & 89.68 \\
\hline COG0253 & $E$ & Gl 1 & 100.00 & 100.00 \\
\hline COG0621 & $\mathrm{J}$ & Gl 1 & 100.00 & 100.00 \\
\hline COG0625 & 0 & GI 1 & 100.00 & 100.00 \\
\hline \multirow[t]{2}{*}{ COG1609 } & $\mathrm{K}$ & Gl 1 & 71.79 & 100.00 \\
\hline & & Gl 1 & 100.00 & 100.00 \\
\hline COG4274 & $\mathrm{S}$ & Gl 1 & 100.00 & 100.00 \\
\hline COG0406 & G & Gl 1 & 95.68 & 100.00 \\
\hline COG0790 & $\mathrm{R}$ & GI 1 & 100.00 & 100.00 \\
\hline COG0346 & $E$ & GI 1 & 100.00 & 100.00 \\
\hline \multirow[t]{4}{*}{ COG4974 } & $\mathrm{L}$ & GI 1 & 100.00 & 100.00 \\
\hline & & Gl 1 & 0.00 & 67.44 \\
\hline & & GI 1 & 0.00 & 32.85 \\
\hline & & GI 1 & 0.00 & 0.00 \\
\hline \multirow[t]{4}{*}{ COG1961 } & $\mathrm{L}$ & GI 1 & 0.00 & 100.00 \\
\hline & & Gl 1 & 0.00 & 100.00 \\
\hline & & GI 1 & 0.00 & 0.00 \\
\hline & & GI 1 & 0.00 & 0.00 \\
\hline
\end{tabular}




\begin{tabular}{|c|c|}
\hline RCA23_c00920 & putative phage integrase \\
\hline RCA23_c00940 & putative HTH-type transcriptional repressor, ArsR family \\
\hline RCA23_c00950 & ATP synthase protein I \\
\hline RCA23_c00960 & ATP synthase subunit AtpB \\
\hline RCA23_c00970 & ATP synthase subunit c \\
\hline RCA23_c01000 & pyruvate dehydrogenase complex repressor \\
\hline RCA23_c01010 & inner membrane lipoprotein YiaD \\
\hline RCA23_c01020 & endonuclease III \\
\hline RCA23_c01030 & putative pfkB family carbohydrate kinase \\
\hline RCA23_c01040 & hypothetical protein \\
\hline RCA23_c01050 & glycosyl transferase family 14 \\
\hline RCA23_c01060 & hypothetical protein \\
\hline RCA23_c01070 & HIT-like protein \\
\hline RCA23_c01080 & $A B C$ transporter ATP binding protein \\
\hline RCA23_c01090 & hypothetical protein \\
\hline RCA23_c01100 & hypothetical protein \\
\hline RCA23_c01110 & DNA polymerase I \\
\hline RCA23_c01120 & cystathionine gamma-synthase MetB \\
\hline RCA23_c01130 & ribosomal large subunit pseudouridine synthase RluE \\
\hline RCA23_c01140 & hypothetical protein DUF1285 \\
\hline RCA23_c01150 & ATPase, MoxR type \\
\hline RCA23_c01160 & hypothetical protein \\
\hline RCA23_c01170 & hypothetical protein \\
\hline RCA23_c01180 & hypothetical protein DUF1355 \\
\hline RCA23_c01190 & glycolate oxidase subunit GlcD \\
\hline RCA23_c01200 & glycolate oxidase subunit GlcE \\
\hline RCA23_c01210 & glycolate oxidase iron-sulfur subunit GlcF \\
\hline RCA23_c01220 & hypothetical protein, trypsin \\
\hline RCA23_c01230 & putative chitinase \\
\hline RCA23_c01240 & small heat shock protein IbpA \\
\hline RCA23_c01250 & succinate-semialdehyde dehydrogenase GabD \\
\hline RCA23_c01260 & hypothetical protein \\
\hline RCA23_c01270 & hypothetical protein \\
\hline
\end{tabular}

\begin{tabular}{|c|c|c|c|c|}
\hline COG4974 & L & GI 1 & 0.00 & 50.33 \\
\hline \multirow[t]{2}{*}{ COG0640 } & $\mathrm{K}$ & & 100.00 & 100.00 \\
\hline & & & 100.00 & 100.00 \\
\hline \multirow[t]{2}{*}{ COG0356 } & C & & 100.00 & 100.00 \\
\hline & & & 100.00 & 100.00 \\
\hline COG2186 & $\mathrm{K}$ & & 100.00 & 100.00 \\
\hline COG2885 & M & & 100.00 & 100.00 \\
\hline COG0177 & $\mathrm{L}$ & & 100.00 & 100.00 \\
\hline \multirow[t]{4}{*}{ COG0524 } & G & & 100.00 & 100.00 \\
\hline & & & 100.00 & 100.00 \\
\hline & & & 100.00 & 100.00 \\
\hline & & & 100.00 & 100.00 \\
\hline COG0537 & $\mathrm{F}$ & & 100.00 & 100.00 \\
\hline COG1131 & V & & 100.00 & 96.42 \\
\hline \multirow[t]{2}{*}{ COG4391 } & $S$ & & 100.00 & 100.00 \\
\hline & & & 100.00 & 100.00 \\
\hline COG0749 & $\mathrm{L}$ & & 100.00 & 100.00 \\
\hline COG0626 & $\mathrm{E}$ & & 100.00 & 100.00 \\
\hline COG1187 & $\mathrm{J}$ & & 100.00 & 100.00 \\
\hline COG3816 & $S$ & & 100.00 & 100.00 \\
\hline COG0714 & $\mathrm{R}$ & & 100.00 & 100.00 \\
\hline \multirow[t]{2}{*}{ COG1721 } & $\mathrm{R}$ & & 100.00 & 94.56 \\
\hline & & & 100.00 & 100.00 \\
\hline COG5426 & $S$ & & 100.00 & 100.00 \\
\hline COG0277 & $C$ & & 100.00 & 80.83 \\
\hline COG0277 & $C$ & & 100.00 & 100.00 \\
\hline COG0247 & C & & 100.00 & 100.00 \\
\hline COG3591 & $E$ & & 100.00 & 100.00 \\
\hline COG3325 & G & & 15.64 & 33.69 \\
\hline COG0071 & 0 & & 100.00 & 100.00 \\
\hline COG1012 & C & & 100.00 & 100.00 \\
\hline COG0657 & 1 & & 100.00 & 100.00 \\
\hline 17 & $\mathrm{~S}$ & & 100.00 & 100.0 \\
\hline
\end{tabular}


RCA23 c01280

RCA23_c01290

RCA23_c01300

RCA23_c01310

RCA23_c01320

RCA23_c01330

RCA23 c01340

RCA23_c01350

RCA23_c01360

RCA23_c01370

RCA23_c01380

RCA23_c01390

RCA23_c01400

RCA23_c01410

RCA23_c01420

RCA23_c01430

RCA23_c01440

RCA23_c01450

RCA23_c01460

RCA23_c01470

RCA23_c01480

RCA23_c01490

RCA23_c01500

RCA23_c01510

RCA23_c01520

RCA23_c01530

RCA23_c01540

RCA23_c01550

RCA23_c01560

RCA23_c01570

RCA23_c01580

RCA23_c01590

RCA23_c01600 putative cyclopentanol dehydrogenase CpnA

hypothetical protein

hypothetical protein DUF1523

aldehyde dehydrogenase

deoxyribose-phosphate aldolase DeoC

ribulose-phosphate 3-epimerase, chromosomal

hemolysin-type calcium-binding region

5-oxoprolinase (ATP-hydrolyzing)

aminotransferase class-III

ureidoglycolate hydrolase AllA

aldose 1-epimerase GalM

beta-galactosidase $\mathrm{BgaB}$

putative gluconolactonase

2-dehydro-3-deoxy-6-phosphogalactonate aldolase DgoA

2-dehydro-3-deoxygalactonokinase DgoK

short chain dehydrogenase

alpha-galactosidase RafA

putative $A B C$ transporter inner membrane component

putative $A B C$ transporter inner membrane component

putative extracellular solute-binding protein

HTH-type transcriptional regulator, IcIR family

sugar ABC transporter ATP-binding protein

Sulfite exporter TauE/SafE

putative transcriptional regulator, gntR family

taurine--pyruvate aminotransferase Tpa

taurine $A B C$ transporter, periplasmic binding protein TauA

taurine $A B C$ transport system ATP-binding protein TauB

taurine $A B C$ transport system permease protein TauC

dimethylglycine dehydrogenase

trimethylamine methyltransferase MttB

3-hydroxyacyl-CoA dehydrogenase FadN

hypothetical protein

O-acetylhomoserine (thiol)-lyase CysD
COG1028

I

100.00

100.00

100.00

100.00

100.00

100.00

100.00

95.58

100.00

100.00

100.00

100.00

100.00

100.00

100.00

100.00

100.00

100.00

100.00

COG1175

COG1653

COG1414

COG3839

COG1167

COG0161

COG4521

COG1116

COG0600

COG0404

COG5598

COG1250

COG0596

COG2873
42.04

51.78

100.00

100.00

100.00

95.52

100.00

94.55

100.00

100.00

100.00

100.00

100.00

100.00
100.00

100.00

100.00

100.00

100.00

100.00

100.00

99.00

100.00

100.00

100.00

96.33

100.00

100.00

100.00

100.00

100.00

98.89

100.00

70.25

84.73

87.72

100.00

100.00

95.92

100.00

100.00

100.00

99.21

100.00

100.00

100.00

97.02 


\begin{tabular}{|c|c|}
\hline RCA23_c01610 & putative signaling protein \\
\hline RCA23_c01620 & sulfoacetaldehyde acetyltransferase Xsc \\
\hline RCA23_c01630 & phosphate acetyltransferase Pta \\
\hline RCA23_c01640 & DMSO reductase chain $A$ \\
\hline RCA23_c01650 & alpha/beta hydrolase \\
\hline RCA23_c01660 & DMSO reductase chain $B$ \\
\hline RCA23_c01670 & DMSO reductase chain $\mathrm{C}$ \\
\hline RCA23_c01680 & sodium:alanine symporter \\
\hline RCA23_c01690 & thymidine kinase Tdk \\
\hline RCA23_c01700 & NADPH-dependent FMN reductase \\
\hline RCA23_c01710 & carbamoyl-phosphate synthase large chain CarB \\
\hline RCA23_c01720 & HTH-type transcriptional regulator, AsnC family \\
\hline RCA23_c01730 & hypothetical protein \\
\hline RCA23_c01740 & aspartyl-tRNA synthase AspS \\
\hline RCA23_c01750 & hypothetical protein \\
\hline RCA23_c01760 & putative signal transduction response regulator receiver protein \\
\hline RCA23_c01770 & methylmalonyl-CoA epimerase \\
\hline RCA23_c01780 & hypothetical protein DUF1467 \\
\hline RCA23_c01790 & hypothetical protein DUF540 \\
\hline RCA23_c01800 & putative nitroreductase \\
\hline RCA23_c01810 & histone deacetylase-like amidohydrolase $\mathrm{HdaH}$ \\
\hline RCA23_c01820 & hypothetical protein \\
\hline RCA23_c01830 & hypothetical protein, peptidase family M48 \\
\hline RCA23_c01840 & hypothetical protein \\
\hline RCA23_c01850 & ribosomal protein S12 methylthiotransferase RimO \\
\hline RCA23_c01860 & hypothetical protein, transmembrane \\
\hline RCA23_c01870 & GcrA cell cycle regulator \\
\hline RCA23_c01880 & ABC-2 type transport system membrane protein \\
\hline RCA23_c01890 & acetylornithine aminotransferase ArgD \\
\hline RCA23_c01900 & ornithine carbamoyltransferase ArgF \\
\hline RCA23_c01910 & hypothetical protein \\
\hline RCA23_c01920 & 6-phosphogluconate dehydrogenase GntZ \\
\hline RCA23_c01930 & ATP-dependent RNA helicase HrpB \\
\hline
\end{tabular}

$\begin{array}{llrr}\text { COG2200 } & \text { T } & 100.00 & 100.00 \\ \text { COG0028 } & \text { E } & 100.00 & 100.00 \\ \text { COG0280 } & \text { C } & 100.00 & 100.00 \\ \text { COG0243 } & \text { C } & 100.00 & 98.54 \\ \text { COG0596 } & \text { R } & 100.00 & 93.42 \\ \text { COG0437 } & \text { C } & 100.00 & 100.00 \\ \text { COG3302 } & \text { R } & 100.00 & 100.00 \\ \text { COG1115 } & \text { E } & 100.00 & 100.00 \\ \text { COG1435 } & \text { F } & 100.00 & 100.00 \\ \text { COG0431 } & \text { R } & 100.00 & 100.00 \\ \text { COG0458 } & \text { E } & 73.66 & 100.00 \\ \text { COG1522 } & \text { K } & 44.51 & 100.00 \\ & & 100.00 & 100.00 \\ \text { COG0173 } & \text { J } & 100.00 & 100.00 \\ & & 100.00 & 100.00 \\ \text { COG2197 } & \text { T } & 100.00 & 64.91 \\ \text { COG0346 } & \text { E } & 100.00 & 100.00 \\ \text { COG5454 } & \text { S } & 100.00 & 100.00 \\ \text { COG2981 } & \text { E } & 39.77 & 100.00 \\ \text { COG0778 } & \text { C } & 100.00 & 100.00 \\ \text { COG0123 } & \text { B } & 100.00 & 100.00 \\ & & 100.00 & 100.00 \\ \text { COG0501 } & \text { O } & 100.00 & 100.00 \\ & & 100.00 & 100.00 \\ \text { COG0621 } & \text { J } & 100.00 & 100.00 \\ & & 100.00 & 100.00 \\ \text { COG5352 } & \text { S } & 100.00 & 96.34 \\ \text { COG0842 } & \text { V } & 100.00 & 100.00 \\ \text { COG4992 } & \text { E } & 100.00 & 100.00 \\ \text { COG0078 } & \text { E } & 100.00 & 100.00 \\ \text { COG0362 } & \text { G } & 100.00 & 100.00 \\ \text { COG1643 } & \text { L } & 100.00 & 100.00 \\ & & 100.00 & 98.78\end{array}$


RCA23 c01940

RCA23_c01950

RCA23_c01960

RCA23_c01970

RCA23_c01980

RCA23_c01990

RCA23 c02000

RCA23_c02010

RCA23_c02020

RCA23_c02030

RCA23_c02040

RCA23_c02050

RCA23_c02060

RCA23_c02070

RCA23_c02080

RCA23_c02090

RCA23_c02100

RCA23_c02110

RCA23_c02120

RCA23_c02130 UDP-4-amino-4-deoxy-L-arabinose--oxoglutarate aminotransferase ArnB

RCA23_c02140 hypothetical protein

RCA23_c02150 hypothetical protein, nucleoside triphosphate hydrolases-like

RCA23_c02160 S-adenosyl-L-methionine-dependent methyltransferase

RCA23_c02170 hypothetical protein

RCA23_c02180 medium-chain-fatty-acid--CoA ligase AlkK

RCA23_c02190 hypothetical protein DUF6 transmembrane

RCA23_c02200 fatty acid oxidation complex alpha subunit FadJ

RCA23_c02210 hypothetical protein

RCA23_c02220 short chain dehydrogenase

RCA23_c02230 putative glutathione S-transferase

RCA23_c02240 acyl-CoA dehydrogenase MmgC

RCA23_c02250 putative HTH-type transcriptional regulator, MerR family

RCA23_c02260 putative HTH-type transcriptional regulator, MerR family

\begin{tabular}{|c|c|c|c|}
\hline COG1703 & $E$ & 100.00 & 100.00 \\
\hline \multirow[t]{2}{*}{ COG0227 } & $\mathrm{J}$ & 100.00 & 100.00 \\
\hline & & 100.00 & 100.00 \\
\hline COG0481 & $\mathrm{M}$ & 100.00 & 93.71 \\
\hline COG0596 & $\mathrm{R}$ & 100.00 & 100.00 \\
\hline COG0346 & $E$ & 100.00 & 100.00 \\
\hline COG0112 & $E$ & 100.00 & 100.00 \\
\hline COG0061 & G & 100.00 & 100.00 \\
\hline COG0365 & I & 100.00 & 100.00 \\
\hline COG1917 & $S$ & 86.94 & 100.00 \\
\hline COG0295 & $\mathrm{F}$ & 100.00 & 100.00 \\
\hline COG0213 & $\mathrm{F}$ & 100.00 & 93.50 \\
\hline COG1015 & $\mathrm{G}$ & 100.00 & 91.69 \\
\hline COG1816 & $\mathrm{F}$ & 100.00 & 100.00 \\
\hline \multirow[t]{2}{*}{ COG0035 } & $\mathrm{F}$ & 100.00 & 100.00 \\
\hline & & 100.00 & 100.00 \\
\hline COG1519 & $M$ & 100.00 & 100.00 \\
\hline COG2303 & $E$ & 100.00 & 100.00 \\
\hline COG1083 & $M$ & 100.00 & 100.00 \\
\hline COG0399 & $M$ & 100.00 & 100.00 \\
\hline COG3119 & $P$ & 0.00 & 77.21 \\
\hline COG1122 & $P$ & 0.00 & 69.70 \\
\hline \multirow[t]{2}{*}{ COG2226 } & $\mathrm{H}$ & 0.00 & 100.00 \\
\hline & & 100.00 & 99.89 \\
\hline COG0318 & I & 100.00 & 100.00 \\
\hline COG0697 & G & 100.00 & 100.00 \\
\hline \multirow[t]{2}{*}{ COG1250 } & I & 100.00 & 100.00 \\
\hline & & 100.00 & 96.38 \\
\hline COG0183 & I & 100.00 & 100.00 \\
\hline COG0625 & 0 & 100.00 & 100.00 \\
\hline COG1960 & I & 100.00 & 100.00 \\
\hline COG0789 & K & 100.00 & 100.00 \\
\hline COG0789 & $\mathrm{K}$ & 100.00 & 100.00 \\
\hline
\end{tabular}


RCA23_c02270 hypothetical protein, transmembrane protein DUF2899

RCA23_c02280 hypothetical protein, thioesterase

hypothetical protein, thioesterase

COG2050

COG2050

RCA23_c02300

RCA23_c02310

RCA23_c02320

RCA23_c02330

RCA23_c02340

RCA23_c02350

RCA23_c02360

RCA23_c02370

RCA23_c02380

RCA23_c02390

RCA23_c02400

RCA23_c02410

RCA23_c02420

RCA23_c02430

RCA23_c02440

RCA23_c02450

RCA23_c02460

RCA23_c02470

RCA23_c02480

RCA23_c02490

RCA23_c02500

RCA23_c02510

RCA23_c02520

RCA23_c02530

RCA23_c02540

RCA23_c02550

RCA23_c02560

RCA23_c02570

RCA23_c02590

RCA23_c02600
DNA-damage-inducible protein $\mathrm{F}$

dihydroorotate dehydrogenase PyrD

hypothetical protein DUF952

5'-nucleotidase SurE

hypothetical protein

glycyl-tRNA synthase alpha subunit GlyQ

hypothetical protein

glycyl-tRNA synthase beta subunit Glys

hypothetical protein, dihydroneopterin aldolase

dihydropteroate synthase FolP

putative integral membrane protein DUF6

ketol-acid reductoisomerase IlvC

putative transcriptional regulator, asnC family

putative transcriptional regulator, asnC family

hypothetical protein

2-octaprenyl-6-methoxyphenol hydroxylase UbiH

putative pyrimidine 5-nucleotidase

putative HTH-type transcriptional regulator, GntR family

uncharacterized glycosyltransferase YdaM

carbamoyl-phosphate synthase small chain CarA

GatB/YqeY family protein

hypothetical protein

cytochrome c oxidase subunit 1

octanoyltransferase LipB

hypothetical protein, LytTr transcriptional regulator

membrane protein-like

arylsulfatase

NADPH dehydrogenas pyruvate, phosphate dikinase PpdK

putative cell wall hydrolase
COG0534

COG0167

COG3502

COG0737

COG3409

COG0752

COG0751

COG0574

COG3773

COG0294

COG0697

COG0059

COG1522

COG1522

COG0075

COG0654

COG1011

COG1802

COG1215

COG0505

COG1610

COG5488

COG0843

COG0321

COG3279

COG5395

COG3119

COG1902
COG1539
100.00

100.00

100.00

100.00

100.00

100.00

100.00

100.00

100.00

100.00

100.00

100.00

100.00

100.00

100.00

100.00

100.00

100.00

100.00

94.44

100.00

100.00

100.00

100.00

100.00

100.00

100.00

100.00

100.00

100.00

100.00

100.00

100.00
100.00

100.00

100.00

100.00

100.00

100.00

97.26

100.00

100.00

100.00

100.00

98.35

100.00

100.00

100.00

100.00

100.00

100.00

100.00

100.00

100.00

100.00

100.00

96.52

100.00

100.00

100.00

100.00

100.00

99.61

100.00

100.00

100.00 

glyoxylate reductase GyaR

100.00

100.00

RCA23 C02650

hypothetical protein

RCA23_c02670 hypothetical protein, AzIC-like

RCA23_c02680 cbbT/tktB: transketolase

100.00

100.00

100.00

100.00

RCA23_c02690

hypothetical protein

RCA23_c02700 transketolase, alpha subunit

RCA23_c02710 transketolase, beta-subunit

RCA23_C02720 putative 3-hydroxyisobutyrate dehydrogenase

43.25

100.00

RCA23_c02730 putative 3-hydroxyisobutyrate dehydrogenase

RCA23_c02740 3-oxoacyl-[acyl-carrier-protein] reductase FabG

RCA23_c02750 HTH-type transcriptional regulator, LysR family

RCA23_c02760 putative HTH-type transcriptional regulator, GntR family

RCA23_c02770 TRAP dicarboxylate transporter, subunit DctP

RCA23_c02780 TRAP dicarboxylate transporter, subunit DctQ

RCA23_C02800 hypothetical protein

RCA23_c02810 hypothetical protein DUF1537

RCA23_C02820 putative ribulose bisphosphate carboxylase large chain

RCA23_c02830 hypothetical protein, NAD dependent epimerase / dehydratase family

RCA23_c02840 2-hydroxy-3-oxopropionate reductase GarR

RCA23_c02850 hypothetical protein

RCA23_c02860 altronate hydrolase UxaA

RCA23_c02870 putative oxidoreductase

RCA23_c02880 2-hydroxy-3-oxopropionate reductase GarR

\begin{tabular}{rr}
\hline 43.25 & 14.48 \\
0.00 & 0.00 \\
43.65 & 0.00 \\
100.00 & 22.22 \\
49.38 & 0.00 \\
100.00 & 22.31 \\
100.00 & 0.00 \\
100.00 & 0.10 \\
100.00 & 15.72 \\
14.10 & 0.00 \\
100.00 & 44.33 \\
100.00 & 0.00 \\
46.88 & 0.00 \\
72.70 & 0.00 \\
100.00 & 0.00 \\
100.00 & 26.84 \\
7.71 & 0.00 \\
31.20 & 94.15 \\
100.00 & 100.00 \\
100.00 & 98.20 \\
100.00 & 100.00 \\
100.00 & 100.00 \\
100.00 & 100.00 \\
100.00 & 100.00 \\
100.00 & 100.00 \\
100.00 & 100.00 \\
\hline & \\
\hline
\end{tabular}

S-adenosylmethionine uptake transporter Sam

RCA23_c02900 2-dehydro-3-deoxygluconokinase KdgK

RCA23_c02910 D-mannonate oxidoreductase UxuB

100.00

100.00 
RCA23_c02950 putative oxidoreductase

RCA23_c02960 mannonate dehydratase UxuA

RCA23_c02970 long-chain-fatty-acid--CoA ligase

RCA23_c02980 D-beta-hydroxybutyrate dehydrogenase BdhA

RCA23_c02990 copper-transporting P-type ATPase ActP

RCA23_c03000 HTH-type transcriptional regulator (copper efflux regulator)

RCA23_c03010 hypothetical protein

RCA23_c03020 hypothetical protein

RCA23_c03030 isocitrate dehydrogenase Icd

RCA23_c03040 integral membrane protein DUF6

RCA23_c03050 flavocytochrome c cytochrome subunit SoxE

RCA23_c03060 sulfide dehydrogenase [flavocytochrome c] flavoprotein chain SoxF

RCA23_c03070 hypothetical protein, OsmC-like

RCA23_c03080 putative dimethyl sulfoniopropionate demethylase DmdA

RCA23_c03090 transcriptional regulator, AsnC family

RCA23_c03100 glutathione S-transferase

RCA23_c03120 hypothetical protein, ribonuclease, E/G family

RCA23_c03130 Maf-like protein

RCA23_c03140 translation initiation factor IF-1

RCA23_c03150 hypothetical protein, low molecular weight phosphotyrosine protein phospha

RCA23_c03160 hypothetical protein UPF0262

RCA23_c03170 histidinol dehydrogenase HisD

RCA23_c03180 hypothetical protein

RCA23_c03190 UDP-N-acetylglucosamine 1-carboxyvinyltransferase MurA

RCA23_c03210 PAS/PAC sensor hybrid histidine kinase

RCA23_c03220 20G-Fe(II) oxygenase

RCA23_c03230 putative lysine exporter protein

RCA23_c03240 putative carbon monoxide dehydrogenase subunit G

RCA23_c03250 hypothetical protein, XdhC and Coxl family

RCA23_c03260 putative MFS-type transporter

RCA23_c03270 AFG1-like ATPase

RCA23_c03280 bifunctional protein FolC

RCA23_c03290 acetyl-coenzyme A carboxylase carboxyl transferase beta subunit AccD

\begin{tabular}{|c|c|}
\hline COG0673 & \\
\hline COG1312 & \\
\hline COG0318 & \\
\hline COG1028 & \\
\hline COG2217 & \\
\hline COG0789 & \\
\hline COG3937 & \\
\hline COG2838 & \\
\hline COG0697 & \\
\hline COG3474 & \\
\hline COG0446 & \\
\hline COG1764 & \\
\hline COG0404 & \\
\hline COG1522 & \\
\hline COG0625 & \\
\hline COG1530 & \\
\hline COG0424 & \\
\hline COG0361 & \\
\hline COG0394 & \\
\hline COG5328 & \\
\hline COG0141 & \\
\hline COG0766 & \\
\hline COG0642 & \\
\hline COG3491 & \\
\hline COG1280 & \\
\hline COG3427 & \\
\hline COG1975 & \\
\hline COG2814 & \\
\hline COG1485 & \\
\hline COG0285 & \\
\hline COG0777 & \\
\hline
\end{tabular}

100.00

100.00

100.00

100.00

100.00

100.00

100.00

100.00

91.78

100.00

100.00

100.00

100.00

100.00

100.00

$\begin{array}{rrr}100.00 & 100.00 \\ 0.00 & 0.00 \\ 87.39 & 100.00 \\ 100.00 & 100.00 \\ 100.00 & 100.00 \\ 76.44 & 100.00 \\ 32.08 & 100.00 \\ 100.00 & 100.00 \\ 100.00 & 100.00 \\ 100.00 & 100.00 \\ 100.00 & 95.59 \\ 99.62 & 85.93 \\ 77.52 & 67.91 \\ 100.00 & 100.00 \\ 100.00 & 95.16 \\ 93.00 & 100.00 \\ 73.77 & 89.30 \\ 100.00 & 100.00 \\ 100.00 & 100.00\end{array}$

100.00

100.00

100.00

100.00

100.00

100.00

100.00

100.00

100.00

100.00

100.00

100.00

100.00

99.83

00.00

00.00

00.00

100.00

00.00

00.00

95.59

8.93

00.00

0.00

89.30

100.00 
RCA23_c03300 hypothetical protein, CAAX amino terminal protease-like

COG1266

dihydroxy-acid dehydratase IlvD

RCA23_C03310

RCA23_c03320

RCA23 03330

RCA23 03340

RCA23_c03350

RCA23 c03360

RCA23_c03370

RCA23_c03380

RCA23_c03390

RCA23_c03400

RCA23_c03410

RCA23_c03420

RCA23 c03430

RCA23_c03440

RCA23_c03450

RCA23 c03460

RCA23_c03470

RCA23_c03480

RCA23_c03490

RCA23_c03500

RCA23_c03510

RCA23_c03520

RCA23_c03530

RCA23_c03540

RCA23 c03550

RCA23_c03560

RCA23_03570

RCA23_c03580

RCA23_c03590

RCA23_c03600

RCA23_c03610

RCA23 c03620 hypothetical protein

hypothetical protein

hypothetical protein

hypothetical protein, OmpA family

hypothetical protein, peroxidase-like protein

hypothetical protein, acetyltransferase-like

hypothetical protein, probably molybdopterin binding

sugar fermentation stimulation protein SfsA

methionine aminopeptidase Map

ATP-dependent RNA helicase RhIE

putative ribosomal RNA small subunit methyltransferase $D$

rhodocoxin reductase $T h C D$

peroxiredoxin

pterin-4-alpha-carbinolamine dehydratase

hypothetical protein DUF482

putative glycerophosphoryl diester phosphodiesterase

putative endoribonuclease L-PSP

type I secretion system protein, HlyD family

type I secretion system ATP-binding component

putative type I secretion system protein, transmembrane domain

VacJ like lipoprotein

putative toluene tolerance protein

penicillin-binding protein $1 \mathrm{~B}$

aromatic-amino-acid aminotransferase TyrB

3-mercaptopyruvate sulfurtransferase SseA

SsrA-binding protein SmpB

dihydrodipicolinate synthase DapA

soluble lytic murein transglycosylase SIt

hypothetical protein DUF6 transmembrane

hypothetical protein DUF752

putative FAD-dependent oxidoreductase
COG0129

R

E

100.00

100.00

100.00

100.00

100.00

100.00

100.00

100.00

100.00

100.00

100.00

100.00

100.00

100.00

100.00

100.00

100.00

100.00

100.00

100.00

100.00

100.00

100.00

100.00

100.00

100.00

100.00

100.00

100.00

100.00

100.00

100.00

100.00
100.00

96.08

100.00

100.00

100.00

100.00

100.00

100.00

100.00

100.00

100.00

100.00

100.00

100.00

100.00

100.00

97.64

100.00

100.00

87.35

100.00

100.00

100.00

98.18

97.57

100.00

100.00

100.00

100.00

100.00

100.00

97.44

100.00 
RCA23_c03630

RCA23_c03640

RCA23_c03650

RCA23_c03660

RCA23_c03670

RCA23_c03680

RCA23 c03690

RCA23_c03700

RCA23_c03710

RCA23_c03720

RCA23_c03730

RCA23_c03740

RCA23_c03750

RCA23 c03760

RCA23_c03770

RCA23_c03780

RCA23_c03790

RCA23_c03800

RCA23_c03810

RCA23_c03820

RCA23_c03830

RCA23_c03840

RCA23_c03850

RCA23_c03860

RCA23_c03870

RCA23 c03880

RCA23_c03890

RCA23_c03900

RCA23_c03910

RCA23_c03920

RCA23_c03930

RCA23_c03940

RCA23 c03950 hypothetical protein, glyoxalase/dioxygenase superfamily

hypothetical protein

hypothetical protein

cob(I)yrinic acid a,c-diamide adenosyltransferase CobO

hypothetical protein

oligopeptide/dipeptide $A B C$ transporter, ATP-binding protein

oligopeptide/dipeptide ABC transporter, ATP-binding protein

oligopeptide/dipeptide $A B C$ transporter, permease protein

oligopeptide/dipeptide $A B C$ transporter, permease protein

oligopeptide/dipeptide $A B C$ transporter, periplasmic substrate-binding proteir

HTH-type transcriptional regulator, LysR family

putative amidohydrolase 3

cobalamin biosynthesis CobW-like

hypothetical protein, restriction endonuclease type IV-like

glycine betaine transport ATP-binding protein OpuAA

glycine betaine transport system permease protein OpuAB

glycine betaine transporter substrate-binding protein OpuAC

fatty acid desaturase

CoA-transferase family III protein involved in DMSP degradation

glyceraldehyde-3-phosphate dehydrogenase Gap

ATP-dependent Clp protease proteolytic subunit ClpP

ATP-dependent Clp protease ATP-binding subunit CIpX

putative NADH ubiquinone oxidoreductase subunit NDUFA12

ABC-type transport system involved in resistance to organic solvents, periplas।

Uncharacterized protein conserved in bacteria (DUF2155)

leucyl/phenylalanyl-tRNA--protein transferase Aat

biotin carboxylase AccC

acetyl-coenzyme A synthase AcsA

high-affinity branched-chain amino acid transport ATP-binding protein LivF

high-affinity branched-chain amino acid transport ATP-binding protein BraF

putative branched-chain amino acid transport system permease protein

putative branched-chain amino acid transport system permease protein

hypothetical protein
COG0346

\section{$E$}

100.00

100.00

100.00

100.00

100.00

100.00

100.00

100.00

100.00

100.00

100.00

100.00

100.00

100.00

100.00

95.35

100.00

100.00

100.00

100.00

91.95

100.00

100.00

100.00

100.00

100.00

100.00

100.00

100.00

COG0410

COG0411

COG4177

COG0559

COG0683 
RCA23 c03960 hypothetical protein, DNA binding helix-turn helix proteins

RCA23_c03970 putative response regulator receiver protein, CheY like

RCA23_c03980 hypothetical protein

RCA23_c03990 sensor protein kinase WalK

RCA23_c04000 hypothetical protein DUF442

RCA23_c04010 hypothetical protein

RCA23 c04020 hypothetical protein

RCA23_c04030 hypothetical protein

RCA23_c04040 putative Fe(3+)-transport system protein SfuB

RCA23_c04060 integrase

RCA23_c04070 hypothetical protein

RCA23_c04080 hypothetical protein

RCA23_c04090 UDP-N-acetylglucosamine--peptide N-acetylglucosaminyltransferase subunit

RCA23 c04100 esterase, SGNH hydrolase-type

RCA23_c04110 hypothetical protein

RCA23_c04120 hypothetical protein, tetratricopeptide repeat

RCA23 c04130 hypothetical protein

RCA23_c04140 hypothetical protein

RCA23_c04150 hypothetical protein

RCA23_c04160 hypothetical protein, RmIC-like cupin family

RCA23_c04170 hypothetical protein

RCA23_c04180 hypothetical protein, DUF3127

RCA23_c04190 putative nucleoside triphosphate hydrolase, ATPase domain

RCA23_c04200 zinc-dependent metalloprotease

RCA23_c04210 HTH-type transcriptional regulator, AsnC family

RCA23_c04220 integrase

RCA23_c04230 putative ion channel

RCA23_c04240 integrase

RCA23_c04250 Gcn5-like N-acetyltransferase

RCA23_c04260 integrase

RCA23_c04280 hypothetical protein, NAD dependent epimerase / dehydratase family

RCA23_c04290 undecaprenyl-diphosphatase UppP

RCA23 c04300 glutamate synthase [NADPH] small chain GItD

\begin{tabular}{|c|c|c|c|c|}
\hline COG1396 & \multicolumn{2}{|l|}{$\mathrm{K}$} & 100.00 & 100.00 \\
\hline \multirow{2}{*}{ COG0745 } & \multirow{2}{*}{\multicolumn{2}{|c|}{$\mathrm{T}$}} & 100.00 & 100.00 \\
\hline & & & 100.00 & 100.00 \\
\hline COG0591 & \multicolumn{2}{|l|}{$E$} & 100.00 & 100.00 \\
\hline \multirow{2}{*}{ COG3453 } & \multirow[t]{2}{*}{$\mathrm{S}$} & & 100.00 & 100.00 \\
\hline & & & 100.00 & 100.00 \\
\hline \multirow[t]{2}{*}{ COG3750 } & \multirow[t]{2}{*}{$\mathrm{S}$} & & 100.00 & 100.00 \\
\hline & & & 100.00 & 100.00 \\
\hline COG1178 & $P$ & & 100.00 & 100.00 \\
\hline COG0582 & $\mathrm{L}$ & GI 2 & 33.16 & 20.26 \\
\hline \multirow[t]{2}{*}{ COG3945 } & \multirow[t]{2}{*}{$S$} & GI 2 & 0.00 & 0.00 \\
\hline & & GI 2 & 0.00 & 22.80 \\
\hline COG0457 & $\mathrm{R}$ & Gl 2 & 0.00 & 15.98 \\
\hline \multirow[t]{2}{*}{ COG2755 } & \multirow[t]{2}{*}{$E$} & GI 2 & 0.00 & 0.00 \\
\hline & & GI 2 & 0.00 & 97.49 \\
\hline \multirow[t]{4}{*}{ COG0790 } & \multirow[t]{4}{*}{$\mathrm{R}$} & GI 2 & 0.00 & 47.47 \\
\hline & & GI 2 & 100.00 & 89.46 \\
\hline & & GI 2 & 100.00 & 100.00 \\
\hline & & GI 2 & 100.00 & 100.00 \\
\hline \multirow[t]{3}{*}{ COG3450 } & \multirow[t]{3}{*}{$\mathrm{R}$} & GI 2 & 0.00 & 39.42 \\
\hline & & GI 2 & 0.00 & 71.47 \\
\hline & & GI 2 & 0.00 & 100.00 \\
\hline COG1066 & $\mathrm{O}$ & GI 2 & 0.00 & 29.78 \\
\hline COG2931 & $Q$ & GI 2 & 65.16 & 41.30 \\
\hline COG1522 & $\mathrm{K}$ & GI 2 & 100.00 & 100.00 \\
\hline \multirow[t]{2}{*}{ COG2801 } & \multirow[t]{2}{*}{$\mathrm{L}$} & GI 2 & 0.00 & 0.00 \\
\hline & & GI 2 & 96.98 & 100.00 \\
\hline COG4974 & $\mathrm{L}$ & GI 2 & 100.00 & 72.51 \\
\hline COG1670 & $\mathrm{J}$ & GI 2 & 0.00 & 0.00 \\
\hline COG0582 & $\mathrm{L}$ & GI 2 & 36.10 & 94.11 \\
\hline COG0702 & $M$ & & 100.00 & 100.00 \\
\hline COG1968 & V & & 100.00 & 100.00 \\
\hline COG0493 & $E$ & & 100.00 & 100.00 \\
\hline
\end{tabular}


RCA23_c04310 glutamate synthase [NADPH] large chain GltB

RCA23_c04320 monofunctional biosynthetic peptidoglycan transglycosylase MtgA

RCA23_c04330

RCA23_c04340

RCA23 04360

RCA23_c04350

RCA23_c04370

RCA23_c04380

RCA23_c04390

RCA23_c04400

RCA23_c04410

RCA23_c04420

RCA23_c04430

RCA23 c04440

RCA23_c04450

RCA23_c04460

RCA23_c04470

RCA23_c04480

RCA23_c04490

RCA23_c04500

RCA23_c04510

RCA23_c04520

RCA23 c04530

RCA23_c04540

RCA23_c04550

RCA23 c04560

RCA23_c04570

RCA23_04580

RCA23_c04590

RCA23_c04600

RCA23_c04610

RCA23_c04620

RCA23 c04630

putative glutathione S-transferase

putative electron transport protein yjeS

hypothetical protein

hypothetical protein

branched-chain-amino-acid aminotransferase IlvE

$\mathrm{HTH}$-type transcriptional regulator PetP

protein PetR

putative deacytelase, histone deacetylase superfamily protein-like

exodeoxyribonuclease 7 small subunit XseB

geranyltranstransferase IspA

1-deoxy-D-xylulose-5-phosphate synthase Dxs

hypothetical protein, NAD dependent epimerase/dehydratase

hypothetical protein

hypothetical protein

carnitinyl-CoA dehydratase CaiD

hypothetical protein, CoA-binding

putative acyl-CoA dehydrogenase YngJ

transcriptional regulator, AraC family

class II aldolase

arsenate reductase ArsC

adenine deaminase Ade

AMP nucleosidase Amn

DNA-binding protein $\mathrm{HU}$

inner membrane protein DUF6

hypothetical protein, cytochrome $\mathrm{C}$ biogenesis protein

hypothetical protein, thioredoxin

hypothetical protein

succinyl-diaminopimelate desuccinylase DapE

hypothetical protein

2,3,4,5-tetrahydropyridine-2,6-dicarboxylate N-succinyltransferase DapD

L-threonine ammonia-lyase

\begin{tabular}{|c|c|c|c|}
\hline COG0069 & $E$ & 100.00 & 99.98 \\
\hline COG0744 & $M$ & 100.00 & 97.45 \\
\hline COG0625 & 0 & 100.00 & 100.00 \\
\hline COG1600 & $\mathrm{C}$ & 100.00 & 100.00 \\
\hline \multirow[t]{2}{*}{ COG5266 } & $\mathrm{P}$ & 100.00 & 100.00 \\
\hline & & 100.00 & 100.00 \\
\hline COG0115 & $E$ & 100.00 & 100.00 \\
\hline COG1846 & $\mathrm{K}$ & 100.00 & 100.00 \\
\hline COG0745 & $\mathrm{T}$ & 100.00 & 100.00 \\
\hline COG0123 & B & 100.00 & 100.00 \\
\hline COG1722 & $\mathrm{L}$ & 100.00 & 100.00 \\
\hline COG0142 & $\mathrm{H}$ & 91.64 & 100.00 \\
\hline COG1154 & $\mathrm{H}$ & 100.00 & 97.90 \\
\hline \multirow[t]{3}{*}{ COG0451 } & $M$ & 100.00 & 100.00 \\
\hline & & 100.00 & 100.00 \\
\hline & & 100.00 & 100.00 \\
\hline COG1024 & 1 & 100.00 & 100.00 \\
\hline COG1042 & $\mathrm{C}$ & 100.00 & 98.47 \\
\hline COG1960 & 1 & 100.00 & 100.00 \\
\hline COG4977 & $\mathrm{K}$ & 100.00 & 100.00 \\
\hline COG0235 & G & 100.00 & 100.00 \\
\hline COG1393 & $\mathrm{P}$ & 100.00 & 100.00 \\
\hline COG1001 & $\mathrm{F}$ & 100.00 & 100.00 \\
\hline COG0775 & $\mathrm{F}$ & 100.00 & 92.89 \\
\hline COG0776 & $\mathrm{L}$ & 100.00 & 100.00 \\
\hline COG0697 & G & 100.00 & 100.00 \\
\hline COG0785 & 0 & 100.00 & 100.00 \\
\hline COG0526 & 0 & 100.00 & 100.00 \\
\hline COG3222 & $S$ & 100.00 & 100.00 \\
\hline \multirow[t]{2}{*}{ COG0624 } & $E$ & 100.00 & 98.32 \\
\hline & & 100.00 & 100.00 \\
\hline COG2171 & $E$ & 100.00 & 100.00 \\
\hline COG1171 & $E$ & 100.00 & 100.00 \\
\hline
\end{tabular}


RCA23_c04640

RCA23_c04650

RCA23_c04660

RCA23_c04670

RCA23_c04680

RCA23_c04690

RCA23_c04700

RCA23_c04710

RCA23_c04720

RCA23_c04730

(tpA

RCA23_c04750 putative protein ImuB

RCA23_c04760 hypothetical protein

RCA23_c04770 hypothetical protein, NIpC/P60

RCA23_c04780 putative cytosol aminopeptidase PepA

RCA23_c04790 hypothetical protein

RCA23_c04800 carbonic anhydrase CynT

RCA23_c04810 aspartate-semialdehyde dehydrogenase Asd

RCA23_c04820 MFS-type transporter

RCA23_c04830 short chain dehydrogenase

RCA23_c04840 FAD dependent oxidoreductase

RCA23_c04850 trimethylamine methyltransferase MttB

RCA23_c04860 aldehyde dehydrogenase

RCA23_c04870 dihydrodipicolinate synthase DapA

RCA23_c04880 transcriptional regulator, GntR family

RCA23_c04890 hypothetical protein

RCA23_c04900 isopropylmalate dehydrogenase LeuB

RCA23_c04910 hypothetical protein

RCA23_c04920 3-isopropylmalate dehydratase small subunit LeuD

RCA23_c04930 3-isopropylmalate dehydratase large subunit LeuC

RCA23_c04940 hypothetical protein, DUF2975

RCA23_c04950 hypothetical protein DUF143

RCA23_c04960 ribosomal RNA large subunit methyltransferase H

\begin{tabular}{|c|c|c|c|}
\hline \multirow{2}{*}{ COG0820 } & $\mathrm{R}$ & 100.00 & 100.00 \\
\hline & & 100.00 & 100.00 \\
\hline COG4448 & $E$ & 100.00 & 100.00 \\
\hline \multirow[t]{2}{*}{ COG0560 } & $E$ & 100.00 & 100.00 \\
\hline & & 100.00 & 100.00 \\
\hline COG1932 & $\mathrm{H}$ & 100.00 & 100.00 \\
\hline \multirow[t]{2}{*}{ COG0111 } & $\mathrm{H}$ & 100.00 & 100.00 \\
\hline & & 100.00 & 100.00 \\
\hline COG0494 & $\mathrm{L}$ & 100.00 & 100.00 \\
\hline COG0793 & $\mathrm{M}$ & 100.00 & 100.00 \\
\hline \multirow[t]{3}{*}{ COG0696 } & $G$ & 100.00 & 100.00 \\
\hline & & 100.00 & 100.00 \\
\hline & & 100.00 & 100.00 \\
\hline COG0791 & $\mathrm{M}$ & 100.00 & 100.00 \\
\hline \multirow[t]{2}{*}{ COG0260 } & $E$ & 100.00 & 100.00 \\
\hline & & 100.00 & 100.00 \\
\hline COG0288 & $P$ & 100.00 & 100.00 \\
\hline COG0136 & $E$ & 100.00 & 100.00 \\
\hline COG2223 & $P$ & 100.00 & 93.28 \\
\hline COG4221 & $\mathrm{R}$ & 100.00 & 100.00 \\
\hline COG0665 & $\mathrm{E}$ & 100.00 & 100.00 \\
\hline COG5598 & $\mathrm{H}$ & 100.00 & 100.00 \\
\hline COG1012 & $C$ & 100.00 & 100.00 \\
\hline COG0329 & $E$ & 100.00 & 100.00 \\
\hline \multirow[t]{2}{*}{ COG1802 } & $\mathrm{K}$ & 100.00 & 100.00 \\
\hline & & 100.00 & 100.00 \\
\hline \multirow[t]{2}{*}{ COG0473 } & $C$ & 100.00 & 100.00 \\
\hline & & 100.00 & 100.00 \\
\hline COG0066 & $E$ & 100.00 & 100.00 \\
\hline \multirow[t]{2}{*}{ COG0065 } & $E$ & 100.00 & 99.50 \\
\hline & & 100.00 & 92.13 \\
\hline COG0799 & $S$ & 100.00 & 100.00 \\
\hline COG1576 & $S$ & 100.00 & 100.00 \\
\hline
\end{tabular}


RCA23 c04970

RCA23_c04980 putative membrane transport protein

RCA23_c04990 S-formylglutathione hydrolase YeiG

RCA23_c05000 soluble pyridine nucleotide transhydrogenase

RCA23_c05010 hypothetical protein DUF188

RCA23_c05020 putative integral membrane protein

RCA23_c05030 putative HAD-superfamily hydrolase

RCA23_c05040 putative ornithine cyclodeaminase

RCA23_c05050 aerobic cobaltochelatase subunit CobN

RCA23_c05060 hypothetical protein, acetyltransferase-like

RCA23_c05070 protein CobW

RCA23_c05080 hypothetical protein DUF1636

RCA23_c05090 possible cobalt transporter, subunit CbtA

RCA23_c05100 Cytochrome c peroxidase

RCA23_c05110 hypothetical protein

RCA23_c05120 hypothetical protein

RCA23_c05130 xylose repressor XyIR

RCA23_c05140 D-xylose-binding periplasmic protein XylF

RCA23_c05150 xylose transport system permease protein XylH

RCA23_c05160 xylose ABC transporter, ATP-binding protein XylG

RCA23_c05170 xylulose kinase XylB

RCA23_c05180 xylose isomerase XylA

RCA23_c05190 long-chain-fatty-acid--CoA ligase LcfB

RCA23_c05200 malonyl-CoA decarboxylase

RCA23_c05210 acyl-CoA dehydrogenase

RCA23_c05220 hypothetical protein DUF81

RCA23_c05230 phosphoenolpyruvate carboxykinase PckA

RCA23_c05240 two component signal transduction response regulator receiver protein Chvl

RCA23_c05250 two component signal transduction histidine kinase ChvG

RCA23_c05260 hypothetical protein, HPr serine kinase

RCA23_c05270 putative P-loop containing ATPase

RCA23_c05280 hypothetical protein, PTS system mannose-specific EllA component

RCA23_c05290 phosphocarrier protein NPr

\begin{tabular}{|c|c|c|c|}
\hline COG1062 & $\mathrm{C}$ & 100.00 & 100.00 \\
\hline COG0679 & $\mathrm{R}$ & 100.00 & 100.00 \\
\hline COG0627 & $\mathrm{R}$ & 100.00 & 100.00 \\
\hline COG1249 & $C$ & 100.00 & 100.00 \\
\hline COG1671 & $\mathrm{S}$ & 100.00 & 100.00 \\
\hline COG0697 & G & 100.00 & 100.00 \\
\hline COG1011 & $\mathrm{R}$ & 100.00 & 100.00 \\
\hline COG2423 & $E$ & 100.00 & 97.47 \\
\hline COG1429 & $\mathrm{H}$ & 100.00 & 100.00 \\
\hline COG0456 & $\mathrm{R}$ & 100.00 & 100.00 \\
\hline COG0523 & $\mathrm{R}$ & 100.00 & 91.48 \\
\hline COG5469 & $\mathrm{S}$ & 100.00 & 100.00 \\
\hline COG5446 & $\mathrm{S}$ & 100.00 & 100.00 \\
\hline COG1858 & $P$ & 100.00 & 100.00 \\
\hline \multirow[t]{2}{*}{ COG4188 } & $\mathrm{R}$ & 100.00 & 87.50 \\
\hline & & 42.94 & 100.00 \\
\hline COG1940 & $\mathrm{K}$ & 90.90 & 100.00 \\
\hline COG4213 & G & 100.00 & 100.00 \\
\hline COG4214 & G & 100.00 & 100.00 \\
\hline COG1129 & G & 100.00 & 100.00 \\
\hline COG1070 & G & 100.00 & 100.00 \\
\hline COG2115 & G & 100.00 & 95.85 \\
\hline \multirow[t]{2}{*}{ COG0318 } & 1 & 100.00 & 98.16 \\
\hline & & 100.00 & 98.72 \\
\hline \multirow[t]{2}{*}{ COG1960 } & 1 & 100.00 & 98.98 \\
\hline & & 100.00 & 99.63 \\
\hline COG1866 & $C$ & 100.00 & 98.71 \\
\hline COG0745 & $\mathrm{T}$ & 100.00 & 96.15 \\
\hline COG0642 & $\mathrm{T}$ & 100.00 & 100.00 \\
\hline COG1493 & $\mathrm{T}$ & 100.00 & 76.41 \\
\hline COG1660 & $\mathrm{R}$ & 100.00 & 100.00 \\
\hline COG2893 & G & 100.00 & 100.00 \\
\hline COG1925 & G & 100.00 & 100.00 \\
\hline
\end{tabular}


RCA23_c05300

RCA23_c05320 cob(I)yrinic acid a,c-diamide adenosyltransferase CobO

RCA23_c05330 putative short chain dehydrogenase

RCA23_c05340 DNA topoisomerase 4 subunit A

RCA23_c05350 hypothetical protein DUF898

RCA23_c05360 peptidase M48 Ste24p

RCA23_c05370 hypothetical protein

RCA23_c05380 elongation factor Tu (EF-Tu)

RCA23_c05400 hypothetical protein, DUF560

RCA23_c05410 hippurate hydrolase HipO

RCA23_c05420 glutathione import ATP-binding protein GsiA

RCA23_c05430 oligopeptide-binding protein AppA

RCA23_c05440 oligopeptide transport system permease protein AppB

RCA23_c05450 oligopeptide transport system permease protein AppC

RCA23_c05460 ABC transporter ATP-binding protein

RCA23_c05470 inner membrane transport permease

RCA23_c05480 hypothetical protein, peptidase family S49

RCA23_c05490 putative sodium/calcium exchanger protein

RCA23_c05500 putative short cprotein

RCA23_c05510 UvrABC system protein C

RCA23_c05520 CDP-diacylglycerol--glycerol-3-phosphate 3-phosphatidyltransferase

RCA23_c05530 molybdopterin-converting factor subunit MoaD

RCA23_c05540 molybdopterin synthase catalytic subunit MoaE

RCA23_c05550 hypothetical protein

RCA23_c05560 hypothetical protein, OmpA

RCA23_c05570 UbiA prenyltransferase

RCA23_c05580 RNA methyltransferase

RCA23_c05590 hypothetical protein

RCA23_c05600 glutamate--cysteine ligase

RCA23_c05610 glycerol-3-phosphate acyltransferase PIsY

RCA23_c05620 dihydroorotase PyrC

RCA23_c05630 aspartate carbamoyltransferase PyrB

\begin{tabular}{|c|c|}
\hline COG2025 & \\
\hline COG2086 & \\
\hline COG2096 & \\
\hline COG4221 & \\
\hline COG0188 & \\
\hline COG4269 & \\
\hline COG4783 & \\
\hline COG0050 & \\
\hline COG1473 & \\
\hline COG1123 & \\
\hline COG0747 & \\
\hline COG0601 & \\
\hline COG1173 & \\
\hline COG1131 & \\
\hline COG0842 & \\
\hline COG0616 & \\
\hline COG0530 & \\
\hline COG1028 & \\
\hline COG0322 & \\
\hline COG0558 & \\
\hline COG1977 & \\
\hline COG0314 & \\
\hline COG2885 & \\
\hline COG0382 & \\
\hline COG1385 & \\
\hline COG3572 & \\
\hline COG0344 & \\
\hline COG0044 & \\
\hline COG0540 & \\
\hline
\end{tabular}

100.00

100.00

100.00

100.00

100.00

54.73

96.95

100.00

100.00

100.00

100.00

100.00

100.00

100.00

100.00

100.00

100.00

100.00

100.00

100.00

100.00

100.00

100.00

100.00

100.00

100.00

100.00

100.00

100.00

100.00

100.00

100.00

100.00
93.66

100.00

100.00

100.00

100.00

98.47

93.73

100.00

34.35

100.00

98.89

90.41

100.00

100.00

100.00

100.00

95.54

99.75

100.00

100.00

100.00

100.00

100.00

100.00

89.09

100.00

100.00

100.00

100.00

100.00

100.00

95.87

100.00 
RCA23_c05640

RCA23_c05650

RCA23_c05660

RCA23_c05670

RCA23 c05680

RCA23_c05690

RCA23 c05700

RCA23_c05710

RCA23_c05720

RCA23_c05730

RCA23_c05740

RCA23_c05750

RCA23_c05760 molybdopterin-guanine dinucleotide biosynthesis protein MobA

RCA23_c05770 molybdopterin-guanine dinucleotide biosynthesis protein MobB

RCA23_c05780 molybdopterin biosynthesis protein MoeA

RCA23_c05790 transcription elongation factor GreA

RCA23_c05800 electron transfer flavoprotein-ubiquinone oxidoreductase

RCA23_c05810 tetratricopeptide repeat-containing protein

RCA23_c05820 4-diphosphocytidyl-2C-methyl-D-erythritol 2-phosphate synthase IspE

RCA23_c05830 octaprenyl-diphosphate synthase IspB

RCA23_c05840 hypothetical protein, methyltransferase

RCA23_c05850 acetoacetyl-CoA reductase PhaB

RCA23_c05860 acetyl-CoA acetyltransferase PhaA

RCA23_c05870 signaling protein

RCA23_c05880 DNA-3-methyladenine glycosylase 1

RCA23_c05890 thiol:disulfide interchange protein TIpA

RCA23_c05900 argininosuccinate lyase ArgH

RCA23_c05910 hypothetical protein

RCA23_c05920 diaminopimelate decarboxylase LysA

RCA23_c05930 hypothetical protein

RCA23_c05940 putative acyltransferase

RCA23_c05950 glyoxalase/bleomycin resistance protein

RCA23_c05960 hypothetical protein, pyridoxamine 5'-phosphate oxidase

\begin{tabular}{|c|c|c|c|}
\hline COG1573 & $\mathrm{L}$ & 100.00 & 100.00 \\
\hline COG0521 & $\mathrm{H}$ & 100.00 & 100.00 \\
\hline COG1566 & V & 100.00 & 100.00 \\
\hline COG0841 & V & 100.00 & 98.97 \\
\hline COG4233 & $\mathrm{O}$ & 100.00 & 100.00 \\
\hline COG1678 & $\mathrm{K}$ & 100.00 & 100.00 \\
\hline COG1960 & 1 & 100.00 & 98.18 \\
\hline \multirow[t]{2}{*}{ COG0491 } & $\mathrm{R}$ & 100.00 & 100.00 \\
\hline & & 100.00 & 100.00 \\
\hline COG4392 & $\mathrm{S}$ & 100.00 & 100.00 \\
\hline COG1296 & $\mathrm{E}$ & 100.00 & 85.33 \\
\hline COG1526 & $\mathrm{C}$ & 100.00 & 100.00 \\
\hline COG0746 & $\mathrm{H}$ & 100.00 & 100.00 \\
\hline COG1763 & $\mathrm{H}$ & 100.00 & 97.79 \\
\hline COG0303 & $\mathrm{H}$ & 54.18 & 100.00 \\
\hline COG0782 & $\mathrm{K}$ & 100.00 & 100.00 \\
\hline COG0644 & C & 100.00 & 100.00 \\
\hline COG0457 & $\mathrm{R}$ & 100.00 & 100.00 \\
\hline COG1947 & I & 100.00 & 100.00 \\
\hline COG0142 & $\mathrm{H}$ & 100.00 & 99.80 \\
\hline COG4123 & $\mathrm{R}$ & 100.00 & 100.00 \\
\hline COG1028 & I & 100.00 & 100.00 \\
\hline COG0183 & 1 & 100.00 & 100.00 \\
\hline COG2200 & $\mathrm{T}$ & 100.00 & 100.00 \\
\hline COG2818 & $\mathrm{L}$ & 100.00 & 100.00 \\
\hline COG0526 & $\mathrm{O}$ & 100.00 & 100.00 \\
\hline \multirow[t]{2}{*}{ COG0165 } & $E$ & 100.00 & 100.00 \\
\hline & & 100.00 & 100.00 \\
\hline COG0019 & $E$ & 100.00 & 100.00 \\
\hline COG1196 & D & 86.19 & 99.92 \\
\hline COG0204 & I & 100.00 & 100.00 \\
\hline COG2764 & $S$ & 100.00 & 100.00 \\
\hline COG3576 & $\mathrm{R}$ & 100.00 & 100.00 \\
\hline
\end{tabular}


RCA23 c05970

RCA23 c05980

RCA23_c05990

RCA23_c06000

RCA23_c06010

RCA23_c06020

RCA23_c06030

RCA23_c06040

RCA23_c06050

RCA23_c06060

RCA23_c06070

RCA23_c06080

RCA23_c06090

RCA23_c06100

RCA23_c06110

RCA23_c06120

RCA23_c06130

RCA23_c06140

RCA23_c06150

RCA23_c06160

RCA23_c06170

RCA23_c06180

RCA23_c06190

RCA23_c06200

RCA23_c06210

RCA23_c06220

RCA23_c06230

RCA23_c06240

RCA23_c06250

RCA23_c06260

RCA23_c06270

RCA23_c06280

RCA23_c06290 acetyl-coenzyme A carboxylase carboxyl transferase alpha subunit AccA

malyl-CoA ligase

hypothetical protein DUF1611

L-Ala-D/L-Glu epimerase YcjG

$D$-alanine aminotransferase Dat

hypothetical, OmpA-like

hypothetical protein

hypothetical protein DUF1244

$\mathrm{N}$-formylglutamate amidohydrolase

pyruvate kinase PykF

hypothetical protein

50 S ribosomal protein L35

$50 S$ ribosomal protein $\mathrm{L} 20$

putative subtilase family protein

hypothetical protein

hypothetical protein, lipid A biosynthesis acyltransferase

phenylalanyl-tRNA synthase alpha chain PheS

glutamine amidotransferase class-I

phenylalanyl-tRNA synthase beta chain PheT

putative HTH-type transcriptional regulator

ribsomal protein $\mathrm{S} 21$

putative ubiquinone biosynthesis protein COQ9

putative quinone oxidoreductase

hypothetical protein DUF1013

recombination protein $\mathrm{Rec} R$

hypothetical protein

DNA polymerase III subunit tau

NADH pyrophosphatase Nudc

hypothetical protein

prephenate dehydratase PheA

cytochrome c-552

$A B C$ transporter extracellular solute-binding protein

$A B C$ transporter permease protein

\begin{tabular}{|c|c|}
\hline COG0825 & \\
\hline COG2301 & \\
\hline COG3367 & \\
\hline COG4948 & \\
\hline COG0115 & \\
\hline COG3743 & \\
\hline COG3492 & \\
\hline COG3931 & \\
\hline COG0469 & \\
\hline COG0291 & \\
\hline COG0292 & \\
\hline COG1404 & \\
\hline COG1560 & \\
\hline COG0016 & \\
\hline COG0518 & \\
\hline COG0072 & \\
\hline COG1522 & \\
\hline COG0828 & \\
\hline COG5590 & \\
\hline COG0604 & \\
\hline COG3820 & \\
\hline COG0353 & \\
\hline COG0718 & \\
\hline COG2812 & \\
\hline COG2816 & \\
\hline COG3832 & \\
\hline COG0077 & \\
\hline COG3474 & \\
\hline COG4166 & \\
\hline COG4174 & \\
\hline
\end{tabular}

100.00

100.00

100.00

100.00

100.00

93.16

100.00

100.00

100.00

100.00

100.00

100.00

100.00

74.74

100.00

100.00

100.00

100.00

100.00

100.00

100.00

100.00

100.00

100.00

100.00

100.00

100.00

100.00

100.00

100.00

100.00

100.00

100.00
100.00

92.08

100.00

100.00

100.00

100.00

100.00

98.35

100.00

100.00

100.00

100.00

100.00

100.00

100.00

94.50

91.34

100.00

100.00

100.00

100.00

100.00

100.00

93.10

100.00

100.00

98.44

100.00

100.00

100.00

100.00

100.00

100.00 
RCA23_c06300

RCA23 c06310

RCA23_c06320

RCA23 c06330

RCA23_c06340

RCA23_c06350

RCA23 c06360

RCA23_c06370

RCA23_c06380

RCA23_c06390

RCA23_c06400

RCA23_c06420

RCA23_c06430

RCA23 c06440

RCA23_c06450

RCA23_c06460

RCA23 c06470

RCA23_c06480

RCA23_c06490

RCA23_c06500

RCA23_c06510

RCA23_c06520

RCA23_c06530

RCA23_c06540

RCA23_c06550

RCA23_c06560

RCA23_c06570

RCA23_c06580

RCA23_c06590

RCA23_c06600

RCA23_c06610

RCA23_c06620

RCA23_c06630
$A B C$ transporter permease protein

putative oligopeptide $A B C$ transporter ATP-binding protein

fumarylacetoacetate hydrolase family protein

D-alanyl-D-alanine carboxypeptidase DacF

haloacid dehalogenase domain protein hydrolase

ATP-dependent Clp protease adapter protein ClpS

putative methyltransferase

putative short chain dehydrogenase

coproporphyrinogen 3 oxidase, aerobic

oxidoreductase, FAD-binding protein

$D$-lactate dehydrogenase

\section{integrase}

mandelate racemase

fumarylacetoacetate hydrolase family protein

short-chain dehydrogenase/reductase

amidohydrolase

aldo/keto reductase

$A B C$ transporter, permease protein

$A B C$ transporter, permease protein

hypothetical protein

sulfonate/nitrate $A B C$ transporter, ATPase

$A B C$ transporter, periplasmic substrate-binding protein

arylsulfatase

transcriptional regulator, GntR family

hypothetical protein

hypothetical protein

hypothetical protein

hypothetical protein

hypothetical protein

hypothetical protein

hypothetical protein

hypothetical protein

hypothetical protein

\begin{tabular}{|c|c|c|c|c|}
\hline COG4239 & \multicolumn{2}{|l|}{$\mathrm{R}$} & 100.00 & 100.00 \\
\hline COG4172 & \multicolumn{2}{|l|}{$\mathrm{R}$} & 100.00 & 98.99 \\
\hline COG0179 & \multicolumn{2}{|l|}{$\mathrm{Q}$} & 100.00 & 98.68 \\
\hline COG1686 & \multicolumn{2}{|l|}{$M$} & 100.00 & 100.00 \\
\hline COG1011 & \multicolumn{2}{|l|}{$\mathrm{R}$} & 100.00 & 100.00 \\
\hline COG2127 & \multicolumn{2}{|l|}{$S$} & 100.00 & 100.00 \\
\hline COG2813 & \multicolumn{2}{|l|}{$J$} & 100.00 & 100.00 \\
\hline COG1028 & \multicolumn{2}{|l|}{1} & 100.00 & 99.50 \\
\hline COG0408 & \multicolumn{2}{|l|}{$\mathrm{H}$} & 100.00 & 100.00 \\
\hline COG4097 & \multicolumn{2}{|l|}{$P$} & 100.00 & 93.60 \\
\hline \multirow[t]{2}{*}{ COG0277 } & \multirow[t]{2}{*}{ C } & & 100.00 & 100.00 \\
\hline & & GI 3 & 98.18 & 62.52 \\
\hline COG4948 & M & Gl 3 & 0.00 & 0.00 \\
\hline COG0179 & $Q$ & GI 3 & 0.00 & 0.00 \\
\hline COG1028 & I & GI 3 & 0.00 & 0.00 \\
\hline COG3618 & $\mathrm{R}$ & GI 3 & 0.00 & 0.00 \\
\hline COG0667 & C & GI 3 & 0.00 & 0.00 \\
\hline COG0600 & $P$ & GI 3 & 0.00 & 0.00 \\
\hline \multirow[t]{2}{*}{ COG0600 } & \multirow[t]{2}{*}{$P$} & Gl 3 & 0.00 & 0.00 \\
\hline & & Gl 3 & 0.00 & 0.00 \\
\hline COG1116 & $P$ & Gl 3 & 0.00 & 0.00 \\
\hline COG0715 & $P$ & GI 3 & 0.00 & 0.00 \\
\hline COG3119 & $P$ & GI 3 & 51.23 & 0.00 \\
\hline COG1802 & $\mathrm{K}$ & GI 3 & 100.00 & 0.00 \\
\hline COG4974 & $\mathrm{L}$ & GI 3 & 1.94 & 0.00 \\
\hline \multirow[t]{7}{*}{ COG1618 } & \multirow[t]{7}{*}{$\mathrm{F}$} & GI 3 & 100.00 & 0.00 \\
\hline & & GI 3 & 100.00 & 99.63 \\
\hline & & GI 3 & 100.00 & 56.03 \\
\hline & & GI 3 & 100.00 & 89.19 \\
\hline & & Gl 3 & 94.99 & 100.00 \\
\hline & & GI 3 & 100.00 & 100.00 \\
\hline & & GI 3 & 100.00 & 100.00 \\
\hline COG3000 & I & GI 3 & 0.00 & 72.84 \\
\hline
\end{tabular}


RCA23_c06640

RCA23_c06650

RCA23_c06660

RCA23_c06670

RCA23_c06680

RCA23_c06690

RCA23_c06700

RCA23 c06710

RCA23_c06720

RCA23_c06730

RCA23_c06740

RCA23_c06750

RCA23_c06760

RCA23 066770

RCA23_c06780

RCA23_c06790

RCA23_c06800

RCA23_c06810

RCA23_c06820

RCA23_c06830

RCA23_c06840

RCA23_c06850

RCA23_c06860

RCA23_c06870

RCA23_c06880

RCA23_c06890

RCA23_c06900

RCA23_c06910

RCA23_c06920

RCA23_c06930

RCA23_c06940

RCA23_c06950

RCA23_c06960 transcriptional regulator, AsnC family

aspartate aminotransferase AspC

3-hydroxybutyrate dehydrogenase Bdh

putative fumarylacetoacetate hydrolase

oxidoreductase, short chain dehydrogenase/reductase family protein

dimethylmenaquinone methyltransferase

hypothetical protein

NADP-dependent fatty aldehyde dehydrogenase AldH

putative dihydrodipicolinate synthase

transcriptional regulator protein, Lacl family

TRAP dicarboxylate transporter, subunit DctP

TRAP dicarboxylate transporter, subunit DctQ

TRAP dicarboxylate transporter, subunit DctM

D-amino acid dehydrogenase small subunit DadA

mandelate racemase/muconate lactonizing protein

dihydrodipicolinate synthase DapA

uncharacterized oxidoreductase, YjmC

sarcosine oxidase beta subunit SoxB

sarcosine oxidase delta subunit SoxD

sarcosine oxidase alpha subunit SoxA

sarcosine oxidase gamma subunit SoxG

hypothetical protein, DUF6 transmembrane protein

putative phage integrase

putative amidase

integrase

putative helicase

transposase

HTH-type transcriptional regulator, LuxR family

putative oxidoreductase, molybdopterin binding

signal transduction histidine kinase

glucose-1-phosphate thymidylyltransferase RfbA

hypothetical protein, chain length determinant protein

polysaccharide export protein

\begin{tabular}{|c|c|c|c|c|}
\hline COG1522 & $\mathrm{K}$ & GI 3 & 100.00 & 100.00 \\
\hline COG0436 & $E$ & GI 3 & 100.00 & 94.71 \\
\hline COG1028 & 1 & GI 3 & 99.20 & 100.00 \\
\hline COG0179 & $Q$ & GI 3 & 0.00 & 67.72 \\
\hline COG1028 & 1 & GI 3 & 0.00 & 75.17 \\
\hline COG0684 & $\mathrm{H}$ & GI 3 & 0.00 & 98.95 \\
\hline COG3970 & $\mathrm{R}$ & GI 3 & 0.00 & 94.60 \\
\hline COG1012 & $\mathrm{C}$ & GI 3 & 0.00 & 75.96 \\
\hline COG0329 & $E$ & GI 3 & 0.00 & 70.75 \\
\hline COG1609 & $\mathrm{K}$ & GI 3 & 0.00 & 73.33 \\
\hline COG1638 & G & GI 3 & 0.00 & 80.34 \\
\hline COG3090 & G & GI 3 & 0.00 & 62.24 \\
\hline COG1593 & G & GI 3 & 0.00 & 78.96 \\
\hline COG0665 & $E$ & GI 3 & 0.00 & 83.92 \\
\hline COG4948 & $M$ & GI 3 & 53.61 & 78.24 \\
\hline COG0329 & $E$ & GI 3 & 100.00 & 64.59 \\
\hline COG2055 & $C$ & GI 3 & 57.07 & 88.13 \\
\hline COG0665 & $E$ & GI 3 & 82.58 & 81.90 \\
\hline COG4311 & $E$ & GI 3 & 0.00 & 100.00 \\
\hline COG0404 & $E$ & GI 3 & 41.21 & 75.69 \\
\hline COG4583 & $E$ & GI 3 & 100.00 & 77.66 \\
\hline \multirow[t]{2}{*}{ COG0697 } & $\mathrm{G}$ & GI 3 & 100.00 & 78.68 \\
\hline & & GI 3 & 46.25 & 27.23 \\
\hline COG0154 & $\mathrm{J}$ & GI 3 & 0.00 & 0.00 \\
\hline \multirow[t]{2}{*}{ COG4974 } & $\mathrm{L}$ & GI 3 & 100.00 & 55.20 \\
\hline & & GI 3 & 48.29 & 0.00 \\
\hline COG3316 & $\mathrm{L}$ & GI 3 & 0.00 & 99.00 \\
\hline COG2197 & $\mathrm{T}$ & GI 3 & 0.00 & 100.00 \\
\hline COG3915 & $S$ & GI 3 & 0.00 & 100.00 \\
\hline COG0642 & $\mathrm{T}$ & GI 3 & 0.00 & 73.12 \\
\hline COG1209 & $M$ & GI 3 & 0.00 & 61.33 \\
\hline COG0489 & $\mathrm{D}$ & GI 3 & 0.00 & 69.96 \\
\hline COG1596 & $\mathrm{M}$ & GI 3 & 0.00 & 79.68 \\
\hline
\end{tabular}




\begin{tabular}{|c|c|}
\hline RCA23_c06970 & hypothetical protein, VanZ-like \\
\hline RCA23_c06980 & type I secretion system membrane fusion protein, HlyD family \\
\hline RCA23_c06990 & type I secretion system ATP-binding component, HlyB family \\
\hline RCA23_c07000 & type I secretion outer membrane protein, TolC family \\
\hline RCA23_c07010 & putative serralysin-like metalloprotease \\
\hline RCA23_c07020 & dTDP-4-dehydrorhamnose reductase RfbD \\
\hline RCA23_c07030 & dTDP-glucose 4,6-dehydratase RfbB \\
\hline RCA23_c07040 & dTDP-4-dehydrorhamnose 3,5-epimerase RfbC \\
\hline RCA23_c07050 & hypothetical protein \\
\hline RCA23_c07060 & glycosyltransferase \\
\hline RCA23_c07070 & putative glycosyltransferase \\
\hline RCA23_c07080 & hypothetical protein, UDP-glycosyltransferase/glycogen phosphorylase-like \\
\hline RCA23_c07090 & polysaccharide biosynthesis protein \\
\hline RCA23_c07100 & UDP-4-amino-4-deoxy-L-arabinose--oxoglutarate aminotransferase ArnB \\
\hline RCA23_c07110 & hypothetical, WxcM-like \\
\hline RCA23_c07120 & hypothetical protein, WxcM-like \\
\hline RCA23_c07130 & hypothetical protein, acyltransferase-like \\
\hline RCA23_c07140 & UDP-glucose/GDP-mannose dehydrogenase family protein \\
\hline RCA23_c07150 & S-adenosyl-L-methionine-dependent methyltransferase \\
\hline RCA23_c07160 & UDP-glucoronate 5'-epimerase LspL \\
\hline RCA23_c07170 & transcriptional regulator, MarR family \\
\hline RCA23_c07180 & transcription antitermination protein NusG \\
\hline RCA23_c07190 & hypothetical protein \\
\hline RCA23_c07200 & lipopolysaccharide core biosynthesis mannosyltransferase LpcC \\
\hline RCA23_c07210 & hypothetical protein \\
\hline RCA23_c07220 & undecaprenyl-phosphate alpha-N-acetylglucosaminyl 1-phosphate transferas \\
\hline RCA23_c07230 & hypothetical protein, transmembrane \\
\hline RCA23_c07240 & hypothetical protein, transmembrane \\
\hline RCA23_c07250 & transposase, IS4 family protein \\
\hline RCA23_c07260 & putative transposase \\
\hline RCA23_c07270 & hypothetical protein, transmembrane \\
\hline RCA23_c07280 & hypothetical protein, transmembrane \\
\hline RCA23_c07290 & transposase \\
\hline
\end{tabular}

\begin{tabular}{|c|c|c|c|c|}
\hline COG5652 & $S$ & GI 3 & 0.00 & 100.00 \\
\hline COG1566 & V & GI 3 & 0.00 & 22.42 \\
\hline COG2274 & V & GI 3 & 0.00 & 67.28 \\
\hline COG1538 & $M$ & GI 3 & 0.00 & 52.58 \\
\hline COG2931 & $Q$ & GI 3 & 0.00 & 26.87 \\
\hline COG1091 & $M$ & GI 3 & 0.00 & 79.65 \\
\hline COG1088 & $M$ & GI 3 & 0.00 & 23.63 \\
\hline \multirow[t]{2}{*}{ COG1898 } & $\mathrm{M}$ & GI 3 & 0.00 & 88.30 \\
\hline & & GI 3 & 0.00 & 80.02 \\
\hline COG0438 & $\mathrm{M}$ & GI 3 & 0.00 & 21.48 \\
\hline COG0438 & $M$ & GI 3 & 0.00 & 46.21 \\
\hline \multirow[t]{2}{*}{ COG0438 } & $M$ & GI 3 & 0.00 & 23.52 \\
\hline & & GI 3 & 0.00 & 31.69 \\
\hline COG0399 & $\mathrm{M}$ & GI 3 & 0.00 & 0.00 \\
\hline \multirow[t]{2}{*}{ COG0110 } & $\mathrm{R}$ & GI 3 & 0.00 & 53.54 \\
\hline & & GI 3 & 0.00 & 0.00 \\
\hline COG1670 & $\mathrm{J}$ & GI 3 & 0.00 & 0.00 \\
\hline \multirow[t]{2}{*}{ COG0677 } & $M$ & GI 3 & 0.00 & 68.17 \\
\hline & & GI 3 & 0.00 & 25.41 \\
\hline COG0451 & $M$ & GI 3 & 0.00 & 53.53 \\
\hline COG1846 & $\mathrm{K}$ & GI 3 & 0.00 & 62.43 \\
\hline COG0250 & $\mathrm{K}$ & GI 3 & 0.00 & 87.33 \\
\hline COG1434 & $S$ & GI 3 & 0.00 & 81.82 \\
\hline \multirow[t]{2}{*}{ COG0438 } & $M$ & GI 3 & 0.00 & 69.74 \\
\hline & & GI 3 & 0.00 & 100.00 \\
\hline \multirow[t]{4}{*}{ COG0472 } & $M$ & GI 3 & 0.00 & 80.44 \\
\hline & & GI 3 & 0.00 & 84.12 \\
\hline & & GI 3 & 0.00 & 68.70 \\
\hline & & GI 3 & 0.00 & 100.00 \\
\hline \multirow[t]{3}{*}{ COG3039 } & $\mathrm{L}$ & GI 3 & 0.00 & 56.86 \\
\hline & & GI 3 & 0.00 & 74.94 \\
\hline & & GI 3 & 0.00 & 49.34 \\
\hline COG3316 & $\mathrm{L}$ & GI 3 & 0.00 & 0.00 \\
\hline
\end{tabular}




$\begin{array}{ll}\text { RCA23_c07300 } & \text { glycogen synthase GlgA } \\ \text { RCA23_c07310 } & \text { glycogen debranching enzyme GlgX } \\ \text { RCA23_c07320 } & \text { phosphoglucomutase Pgm } \\ \text { RCA23_c07330 } & \text { putative alpha-glucosidase AgIA } \\ \text { RCA23_c07340 } & \text { transposase } \\ \text { RCA23_c07350 } & \text { uncharacterized hydrolase YtnL } \\ \text { RCA23_c07360 } & \text { glutathione-binding protein GsiB } \\ \text { RCA23_c07370 } & \text { glutathione transport system permease protein GsiC } \\ \text { RCA23_c07380 } & \text { dipeptide transport system permease protein } \\ \text { RCA23_c07390 } & \text { glutathione import ATP-binding protein GsiA } \\ \text { RCA23_c07400 } & \text { peptidase family S58 } \\ \text { RCA23_c07410 } & \text { aldehyde dehydrogenase AldA } \\ \text { RCA23_c07420 } & \text { 3-oxoacyl-[acyl-carrier-protein] reductase FabG } \\ \text { RCA23_c07430 } & \text { amidase } \\ \text { RCA23_c07440 } & \text { MFS-type transporter } \\ \text { RCA23_c07450 } & \text { peptidase M20D amidohydrolase } \\ \text { RCA23_c07460 } & \text { transposase } \\ \text { RCA23_C07470 } & \text { integrase } \\ \text { RCA23_c07480 } & \text { transposase } \\ \text { RCA23_c07490 } & \text { hypothetical protein, DUF3764 } \\ \text { RCA23_c07500 } & \text { hypothetical protein } \\ \text { RCA23_c07510 } & \text { hypothetical protein, beta-lactam-insensitive peptidoglycan transpeptidase Yk } \\ \text { RCA23_c07520 } & \text { hypothetical protein } \\ \text { RCA23_c07530 } & \text { ABC transporter, ATP-binding protein, SbmA/BacA-like family } \\ \text { RCA23_c07540 } & \text { hypothetical protein } \\ \text { RCA23_c07550 } & \text { hypothetical protein } \\ \text { RCA23_c07560 } & \text { integrase } \\ \text { RCA23_c07570 } & \text { hypothetical protein } \\ \text { RCA23_c07580 } & \text { hypothetical protein } \\ \text { RCA23_c07590 } & \text { flagellin Flic } \\ \text { RCA23_c07600 } & \text { RNA polymerase sigma-54 } \\ \text { RCA23_c07610 } & \text { hypothetical protein, cyclic nucleotide-binding-like } \\ \text { RCA23_c07620 } & \text { hypothetical protein } \\ & \end{array}$

\begin{tabular}{|c|c|c|c|c|}
\hline & & & & \\
\hline COG0297 & G & GI 3 & 0.00 & 49.69 \\
\hline COG1523 & G & GI 3 & 0.00 & 35.65 \\
\hline COG0033 & G & GI 3 & 0.00 & 32.35 \\
\hline COG0366 & G & GI 3 & 0.00 & 45.27 \\
\hline COG3316 & L & GI 3 & 0.00 & 100.00 \\
\hline COG1473 & $\mathrm{R}$ & GI 3 & 100.00 & 62.38 \\
\hline COG0747 & $\mathrm{E}$ & GI 3 & 89.85 & 100.00 \\
\hline COG0601 & $\mathrm{E}$ & GI 3 & 100.00 & 94.20 \\
\hline COG1173 & $\mathrm{E}$ & GI 3 & 100.00 & 100.00 \\
\hline COG4172 & $\mathrm{R}$ & GI 3 & 100.00 & 97.59 \\
\hline COG3191 & $\mathrm{E}$ & GI 3 & 100.00 & 100.00 \\
\hline COG1012 & C & GI 3 & 100.00 & 100.00 \\
\hline COG1028 & I & GI 3 & 100.00 & 97.71 \\
\hline COG0154 & $\mathrm{J}$ & GI 3 & 100.00 & 98.01 \\
\hline COG2807 & $P$ & GI 3 & 100.00 & 82.51 \\
\hline COG1473 & $\mathrm{R}$ & GI 3 & 0.00 & 0.00 \\
\hline COG3316 & L & GI 3 & 0.00 & 0.00 \\
\hline COG2801 & L & GI 3 & 0.00 & 0.00 \\
\hline & & GI 3 & 0.00 & 0.00 \\
\hline & & GI 3 & 67.84 & 28.63 \\
\hline & & GI 3 & 100.00 & 0.00 \\
\hline COG1376 & $\mathrm{S}$ & GI 3 & 100.00 & 56.43 \\
\hline & & GI 3 & 100.00 & 100.00 \\
\hline COG1133 & I & GI 3 & 100.00 & 62.26 \\
\hline & & GI 3 & 100.00 & 50.36 \\
\hline & & GI 3 & 0.00 & 0.00 \\
\hline COG2801 & L & GI 3 & 0.00 & 0.00 \\
\hline & & GI 3 & 0.00 & 0.00 \\
\hline & & GI 3 & 0.00 & 0.00 \\
\hline COG1344 & $\mathrm{N}$ & GI 3 & 0.00 & 0.00 \\
\hline COG1508 & K & GI 3 & 84.01 & 49.32 \\
\hline & & GI 3 & 100.00 & 0.00 \\
\hline COG0664 & $\mathrm{T}$ & GI 3 & 100.00 & 51.13 \\
\hline
\end{tabular}




\begin{tabular}{|c|c|}
\hline RCA23_c07630 & hypothetical protein \\
\hline RCA23_c07640 & hypothetical protein \\
\hline RCA23_c07650 & hypothetical protein \\
\hline RCA23_c07660 & flagellar biosynthesis protein FlhB \\
\hline RCA23_c07670 & flagellar biosynthetic protein FliR \\
\hline RCA23_c07680 & flagellar biosynthetic protein FliQ \\
\hline RCA23_c07690 & flagellar biosynthetic protein FliP \\
\hline RCA23_c07700 & flagellar motor switch protein FliN \\
\hline RCA23_c07710 & flagellar motor switch proteins FliM \\
\hline RCA23_c07720 & protein FliL \\
\hline RCA23_c07730 & putative flagellar hook-length control protein Flik \\
\hline RCA23_c07740 & putative flagellar export protein FliJ \\
\hline RCA23_c07750 & flagellar protein export ATPase Flil \\
\hline RCA23_c07760 & putative flagellar assembly protein FliH \\
\hline RCA23_c07770 & flagellar motor switch protein $\mathrm{G}$ \\
\hline RCA23_c07780 & flagellar M-ring protein FliF \\
\hline RCA23_c07790 & flagellar hook-basal body complex subunit FliE \\
\hline RCA23_c07800 & transcriptional regulatory protein FlbD \\
\hline RCA23_c07810 & protein FliL \\
\hline RCA23_c07820 & hypothetical protein \\
\hline RCA23_c07830 & flagellar protein FliS \\
\hline RCA23_c07840 & hypothetical protein \\
\hline RCA23_c07850 & hypothetical protein \\
\hline RCA23_c07860 & flagellar basal-body rod protein FlgG \\
\hline RCA23_c07870 & Cl- channel, voltage-gated family protein \\
\hline RCA23_c07880 & hypothetical protein, lysozym-like \\
\hline RCA23_c07890 & flagellar hook-associated protein FlgL \\
\hline RCA23_c07900 & flagellar hook-associated protein FlgK \\
\hline RCA23_c07910 & flagellar rod assembly protein/muramidase FlgJ \\
\hline RCA23_c07920 & flagellar P-ring protein Flgl \\
\hline RCA23_c07930 & flagellar L-ring protein FlgH \\
\hline RCA23_c07940 & flagellar basal-body rod protein FlgG \\
\hline RCA23_c07950 & putative flagellar basal body rod protein FlgF \\
\hline
\end{tabular}

\begin{tabular}{|c|c|c|c|c|}
\hline & & & & \\
\hline & & GI 3 & 0.00 & 21.60 \\
\hline & & GI 3 & 0.00 & 33.83 \\
\hline & & GI 3 & 0.00 & 59.36 \\
\hline COG1377 & $\mathrm{N}$ & GI 3 & 69.34 & 29.88 \\
\hline COG1684 & $\mathrm{N}$ & GI 3 & 100.00 & 67.52 \\
\hline COG1987 & $\mathrm{N}$ & GI 3 & 100.00 & 56.30 \\
\hline COG1338 & $\mathrm{N}$ & GI 3 & 100.00 & 0.00 \\
\hline COG1886 & $\mathrm{N}$ & GI 3 & 100.00 & 34.92 \\
\hline COG1868 & $\mathrm{N}$ & GI 3 & 100.00 & 42.20 \\
\hline COG1580 & $\mathrm{N}$ & GI 3 & 100.00 & 59.26 \\
\hline COG3144 & $\mathrm{N}$ & GI 3 & 45.98 & 38.66 \\
\hline & & GI 3 & 0.00 & 45.00 \\
\hline COG1157 & $\mathrm{N}$ & GI 3 & 0.00 & 78.38 \\
\hline & & GI 3 & 45.29 & 41.18 \\
\hline COG1536 & $\mathrm{N}$ & GI 3 & 100.00 & 48.70 \\
\hline COG1766 & $\mathrm{N}$ & GI 3 & 26.08 & 71.29 \\
\hline COG1677 & $\mathrm{N}$ & GI 3 & 0.00 & 59.68 \\
\hline COG2204 & $\mathrm{T}$ & GI 3 & 40.95 & 29.18 \\
\hline COG1580 & $\mathrm{N}$ & GI 3 & 100.00 & 66.48 \\
\hline & & GI 3 & 100.00 & 71.26 \\
\hline COG1516 & $\mathrm{N}$ & GI 3 & 36.83 & 43.01 \\
\hline & & GI 3 & 33.33 & 0.00 \\
\hline & & GI 3 & 100.00 & 0.00 \\
\hline COG4786 & $\mathrm{N}$ & GI 3 & 100.00 & 14.18 \\
\hline COG0038 & $P$ & GI 3 & 89.79 & 12.80 \\
\hline COG0741 & M & GI 3 & 100.00 & 17.44 \\
\hline COG1344 & $\mathrm{N}$ & GI 3 & 96.70 & 40.02 \\
\hline COG1256 & $\mathrm{N}$ & GI 3 & 95.40 & 20.46 \\
\hline COG3951 & M & GI 3 & 100.00 & 71.51 \\
\hline COG1706 & $\mathrm{N}$ & GI 3 & 100.00 & 54.35 \\
\hline COG2063 & $\mathrm{N}$ & GI 3 & 100.00 & 45.74 \\
\hline COG4786 & $\mathrm{N}$ & GI 3 & 45.75 & 38.28 \\
\hline COG4786 & $\mathrm{N}$ & GI 3 & 0.00 & 40.41 \\
\hline
\end{tabular}




$\begin{array}{ll}\text { RCA23_c07960 } & \text { flagellar hook protein FlgE } \\ \text { RCA23_c07970 } & \text { flagellar basal body rod modification protein FlgD } \\ \text { RCA23_c07980 } & \text { flagellar basal-body rod protein FlgC } \\ \text { RCA23_c07990 } & \text { flagellar basal-body rod protein FlgB } \\ \text { RCA23_c08000 } & \text { hypothetical protein } \\ \text { RCA23_c08010 } & \text { hypothetical protein } \\ \text { RCA23_c08020 } & \text { RNA polymerase, sigma factor for flagellar operon FliA } \\ \text { RCA23_c08030 } & \text { putative flagellar biosynthesis protein FlhG } \\ \text { RCA23_c08040 } & \text { flagellar biosynthesis protein FlhF } \\ \text { RCA23_c08050 } & \text { flagellar biosynthesis protein FlhA } \\ \text { RCA23_c08060 } & \text { hypothetical membrane lipoprotein, DUF400 } \\ \text { RCA23_c08070 } & \text { hypothetical protein } \\ \text { RCA23_c08080 } & \text { flagellar basal body P-ring biosynthesis protein FlgA } \\ \text { RCA23_c08090 } & \text { putative negative regulator of flagellin synthesis FlgM } \\ \text { RCA23_c08100 } & \text { hypothetical protein } \\ \text { RCA23_c08110 } & \text { hypothetical protein, HCP-like } \\ \text { RCA23_c08120 } & \text { hypothetical protein } \\ \text { RCA23_c08130 } & \text { sigma54 specific transcriptional regulator, Fis family } \\ \text { RCA23_c08140 } & \text { flagellar hook-associated protein FliD } \\ \text { RCA23_c08150 } & \text { chemotaxis protein MotB } \\ \text { RCA23_c08160 } & \text { chemotaxis protein MotA } \\ \text { RCA23_c08170 } & \text { hypothetical protein, DUF1566 } \\ \text { RCA23_c08180 } & \text { putative transmembrane protein, DUF6 } \\ \text { RCA23_c08190 } & \text { putative polyketide hydroxylase SchC } \\ \text { RCA23_c08200 } & \text { aldehyde dehydrogenase } \\ \text { RCA23_c08210 } & \text { 2-amino-3-carboxymuconate-6-semialdehyde decarboxylase } \\ \text { RCA23_c08220 } & \text { transcriptional regulator, IclR family } \\ \text { RCA23_c08230 } & \text { TRAP transporter, 4TM/12TM fusion protein } \\ \text { RCA23_c08240 } & \text { TRAP transporter solute receptor, TAXI family } \\ \text { RCA23_c08250 } & \text { thiamine pyrophosphate enzyme-like TPP-binding } \\ \text { RCA23_c08260 } & \text { hypothetical protein } \\ \text { RCA23_c08270 } & \text { short chain dehydrogenase } \\ \text { RCA23_c08280 } & \text { putative aldehyde dehydrogenase yfmT } \\ & \end{array}$

\begin{tabular}{|c|c|c|c|c|}
\hline COG1749 & $N$ & GI 3 & 52.92 & 46.57 \\
\hline COG1843 & $N$ & GI 3 & 100.00 & 71.27 \\
\hline COG1558 & $N$ & GI 3 & 83.45 & 49.16 \\
\hline \multirow[t]{3}{*}{ COG1815 } & $N$ & GI 3 & 0.00 & 63.31 \\
\hline & & GI 3 & 0.00 & 68.88 \\
\hline & & GI 3 & 0.00 & 68.35 \\
\hline COG1191 & K & GI 3 & 13.77 & 44.08 \\
\hline COG0455 & D & GI 3 & 100.00 & 64.44 \\
\hline COG1419 & $N$ & GI 3 & 91.12 & 25.89 \\
\hline \multirow[t]{3}{*}{ COG1298 } & $N$ & GI 3 & 100.00 & 47.99 \\
\hline & & GI 3 & 46.46 & 9.26 \\
\hline & & GI 3 & 0.00 & 58.90 \\
\hline \multirow[t]{3}{*}{ COG1261 } & $N$ & GI 3 & 95.68 & 41.84 \\
\hline & & GI 3 & 100.00 & 94.39 \\
\hline & & GI 3 & 100.00 & 40.89 \\
\hline \multirow[t]{2}{*}{ COG0790 } & $\mathrm{R}$ & GI 3 & 100.00 & 60.82 \\
\hline & & GI 3 & 100.00 & 0.00 \\
\hline COG2204 & $\mathrm{T}$ & GI 3 & 100.00 & 70.49 \\
\hline COG1345 & $N$ & GI 3 & 15.63 & 57.75 \\
\hline COG1360 & $\mathrm{N}$ & GI 3 & 68.55 & 24.59 \\
\hline \multirow[t]{3}{*}{ COG1291 } & $N$ & GI 3 & 42.13 & 35.70 \\
\hline & & GI 3 & 7.69 & 25.85 \\
\hline & & GI 3 & 100.00 & 100.00 \\
\hline COG0654 & $\mathrm{H}$ & GI 3 & 67.51 & 100.00 \\
\hline COG1012 & C & & 100.00 & 64.07 \\
\hline COG2159 & $\mathrm{R}$ & & 100.00 & 89.09 \\
\hline COG1414 & K & & 100.00 & 100.00 \\
\hline COG4666 & $\mathrm{R}$ & & 100.00 & 92.04 \\
\hline COG2358 & $\mathrm{R}$ & & 100.00 & 81.43 \\
\hline COG0028 & $\mathrm{E}$ & & 95.75 & 89.62 \\
\hline COG2268 & $S$ & & 100.00 & 67.72 \\
\hline COG1028 & I & & 100.00 & 62.23 \\
\hline COG1012 & C & & 4.67 & 92.95 \\
\hline
\end{tabular}




\begin{tabular}{|c|c|}
\hline RCA23_c08290 & branched-chain amino acid ABC transporter, ATP-binding protein \\
\hline RCA23_c08300 & branched-chain amino acid ABC transporter, ATP-binding protein \\
\hline RCA23_c08310 & putative transporter, permease protein \\
\hline RCA23_c08320 & putative transporter, permease protein \\
\hline RCA23_c08330 & putative transporter, periplasmic binding protein \\
\hline RCA23_c08340 & hypothetical protein, PrpF protein-like \\
\hline RCA23_c08350 & 4-carboxy-4-hydroxy-2-oxoadipate aldolase/oxaloacetate decarboxylase \\
\hline RCA23_c08360 & putative $\mathrm{N}$-acetylglucosaminyl-phosphatidylinositol de-N-acetylase, \\
\hline RCA23_c08370 & hypothetical protein \\
\hline RCA23_c08380 & transcriptional regulator \\
\hline RCA23_c08390 & aminomethyltransferase GcvT \\
\hline RCA23_c08400 & TRAP dicarboxylate transporter, subunit DctP \\
\hline RCA23_c08410 & TRAP dicarboxylate transporter, subunit DctQ \\
\hline RCA23_c08420 & TRAP dicarboxylate transporter, subunit DctM \\
\hline RCA23_c08430 & metapyrocatechase XylE \\
\hline RCA23_c08440 & MFS-type transporter \\
\hline RCA23_c08450 & hypothetical protein, cytochrome c \\
\hline RCA23_c08460 & hypothetical protein, copper resistance protein $C$ \\
\hline RCA23_c08470 & hypothetical protein, copper resistance protein $D$ \\
\hline RCA23_c08480 & hypothetical protein \\
\hline RCA23_c08490 & hypothetical protein \\
\hline RCA23_c08500 & hypothetical protein \\
\hline RCA23_c08510 & fumarate reductase flavoprotein subunit \\
\hline RCA23_c08520 & methylisocitrate lyase PrpB \\
\hline RCA23_c08530 & putative isochorismatase family protein \\
\hline RCA23_c08540 & hydantoin utilization protein $\mathrm{A}$ \\
\hline RCA23_c08550 & hydantoin utilization protein B \\
\hline RCA23_c08560 & hypothetical protein \\
\hline RCA23_c08570 & HTH-type transcriptional regulator, GntR family \\
\hline RCA23_c08580 & 3-isopropylmalate dehydratase large subunit LeuC \\
\hline RCA23_c08590 & 3-isopropylmalate dehydratase small subunit LeuD \\
\hline RCA23_c08600 & TRAP dicarboxylate transporter, subunit DctP \\
\hline RCA23_c08610 & TRAP transporter, subunit DctQ \\
\hline
\end{tabular}

COG0410
COG0411
COG4177
COG0559
COG2828
COG0684
COG2120
COG1802
COG0404
COG1638
COG3090
COG1593
COG2514
COG2814
COG2372
COG1276
COG3613
COG06065
COG1053
COG2513
COG1335
COG0145
COG 14098

\begin{tabular}{rr}
0.00 & 100.00 \\
0.00 & 80.97 \\
28.51 & 89.92 \\
100.00 & 80.18 \\
0.00 & 75.58 \\
63.44 & 99.81 \\
67.87 & 63.96 \\
26.67 & 73.47 \\
44.71 & 100.00 \\
0.00 & 100.00 \\
92.15 & 95.36 \\
100.00 & 85.38 \\
100.00 & 59.65 \\
71.26 & 100.00 \\
78.34 & 86.31 \\
100.00 & 87.79 \\
100.00 & 100.00 \\
100.00 & 100.00 \\
24.18 & 100.00 \\
100.00 & 100.00 \\
100.00 & 100.00 \\
100.00 & 100.00 \\
100.00 & 100.00 \\
100.00 & 99.54 \\
100.00 & 93.56 \\
84.74 & 100.00 \\
79.94 & 99.76 \\
\hline 100.00 & 100.00 \\
100.00 & 91.76 \\
100.00 & 100.00 \\
100.00 & 100.00 \\
100.00 & 100.00 \\
100.00 & 100.00 \\
\hline & \\
\hline
\end{tabular}


RCA23_c08620 TRAP dicarboxylate transporter, subunit DctM

RCA23_c08630 putative glutamate synthase [NADPH] small chain

RCA23_c08640 hypothetical protein, dihydrooronate dehydrogenase

RCA23_c08650 putative HTH-type transcriptional regulator

RCA23_c08660 N-carbamoyl-L-amino acid hydrolase AmaB

RCA23_c08670 D-hydantoinase/dihydropyrimidinase Dht

RCA23_c08680 ABC transporter ATP-binding protein

RCA23_c08690 putative ABC transporter permease protein

RCA23_c08700 putative $A B C$ transporter permease protein

RCA23_c08710 putative thiamine biosynthesis protein

RCA23_c08720 putative integral membrane proein DUF6

RCA23_c08730 hypothetical protein DUF6

RCA23_c08740 alkaline phosphatase synthesis sensor protein PhoR

RCA23_c08750 putative phosphate binding protein PstS

RCA23_c08760 putative phosphate transport system permease protein PstC

RCA23_c08770 putative phosphate transport system permease protein PstA

RCA23_c08780 phosphate import ATP-binding protein PstB

RCA23_c08790 phosphate transport system regulatory protein PhoU

RCA23_c08800 phosphate regulon transl protein PhoB

RCA23_c08810 putative hippurate hydrolase protei

RCA23_c08820 urease accessory protein UreD

RCA23_c08830 urease gamma subunit UreA

RCA23_c08840 urease beta subunit UreB

RCA23_c08850 urease alpha subunit UreC

RCA23_c08860 urease accessory protein UreE

RCA23_c08870 urease accessory protein UreF

RCA23_c08880 urease accessory protein UreG

RCA23_c08890 integrase

RCA23_c08900 hypothetical protein

RCA23_c08910 glucose-methanol-choline oxidoreductase AlkJ

RCA23_c08920 hypothetical protein, YaeQ family protein

RCA23_c08930 hypothetical protein, DUF6 transmembrane protein

RCA23_c08940 UDP-glucose 6-dehydrogenase Ugd

\begin{tabular}{|c|c|c|c|}
\hline COG1593 & $\mathrm{G}$ & 100.00 & 100.00 \\
\hline COG0493 & $E$ & 100.00 & 100.00 \\
\hline COG0167 & $F$ & 100.00 & 98.93 \\
\hline COG1309 & $\mathrm{K}$ & 100.00 & 100.00 \\
\hline COG0624 & $E$ & 100.00 & 100.00 \\
\hline COG0044 & $\mathrm{F}$ & 100.00 & 99.59 \\
\hline COG1116 & $P$ & 100.00 & 100.00 \\
\hline COG0600 & $P$ & 100.00 & 100.00 \\
\hline COG0600 & $P$ & 100.00 & 100.00 \\
\hline COG0715 & $P$ & 100.00 & 100.00 \\
\hline COG0697 & G & 100.00 & 100.00 \\
\hline COG0697 & G & 100.00 & 100.00 \\
\hline COG5002 & $\mathrm{T}$ & 100.00 & 100.00 \\
\hline COG0226 & $P$ & 100.00 & 97.50 \\
\hline COG0573 & $P$ & 93.28 & 100.00 \\
\hline COG0581 & $P$ & 100.00 & 100.00 \\
\hline COG1117 & $P$ & 100.00 & 100.00 \\
\hline COG0704 & $P$ & 100.00 & 96.83 \\
\hline COG0745 & $\mathrm{T}$ & 100.00 & 100.00 \\
\hline COG1473 & $\mathrm{R}$ & 100.00 & 49.13 \\
\hline COG0829 & 0 & 100.00 & 100.00 \\
\hline COG0831 & $E$ & 100.00 & 100.00 \\
\hline COG0832 & $E$ & 100.00 & 100.00 \\
\hline COG0804 & $E$ & 100.00 & 98.62 \\
\hline COG2371 & $\mathrm{O}$ & 100.00 & 100.00 \\
\hline COG0830 & 0 & 2.83 & 100.00 \\
\hline COG0378 & 0 & 0.00 & 100.00 \\
\hline COG2801 & $\mathrm{L}$ & 0.00 & 0.00 \\
\hline COG4585 & $\mathrm{T}$ & 53.33 & 100.00 \\
\hline COG2303 & $E$ & 92.11 & 100.00 \\
\hline COG4681 & $S$ & 100.00 & 100.00 \\
\hline COG0697 & G & 100.00 & 100.00 \\
\hline COG1004 & $M$ & 100.00 & 100.00 \\
\hline
\end{tabular}


RCA23 c08950 3-deoxy-D-manno-octulosonic-acid transferase WaaA

RCA23_c08960 UDP-N-acetylglucosamine 2-epimerase WecB

RCA23_c08970 putative $\mathrm{N}$-acetylneuramic acid synthase

RCA23_c08980 hypothetical protein

RCA23 c08990 hypothetical protein

RCA23_c09000 choline-sulfatase BetC

RCA23_c09010 permease

RCA23_c09020 hypothetical protein

RCA23_c09030 membrane dipeptidase

RCA23_c09040 hypothetical protein

RCA23_c09050 hypothetical protein

RCA23_c09060 tRNA pseudouridine synthase A

RCA23_c09070 YcjX-like protein

RCA23_c09080 hypothetical protein, acetyltransferase-like

RCA23_c09090 hypothetical protein

RCA23_c09100 isoleucyl-tRNA synthase IleS

RCA23_c09110 putative integral membrane protein DUF6

RCA23_c09120 phosphatidylcholine synthase PcS

RCA23_c09130 putative tyrosine recombinase xerC

RCA23_c09140 hypothetical protein

RCA23 c09150 transaldolase

RCA23_c09160 primosomal protein N'

RCA23_c09170 methylmalonyl-CoA mutase McmA

RCA23_c09180 glycerol-3-phosphate acyltransferase PIsB

RCA23_c09190 crotonyl-CoA reductase Ccr

RCA23_c09200 putative ATPase

RCA23_c09210 trimethylamine methyltransferase MttB

RCA23_c09220 hypothetical protein DUF1052

RCA23_c09240 hypothetical protein, DUF411

RCA23_c09250 hypothetical protein

RCA23_c09260 hypothetical protein

RCA23_c09270 hypothetical protein

RCA23_c09280 hypothetical protein

\begin{tabular}{|c|c|c|c|c|}
\hline COG1519 & $M$ & & 100.00 & 100.00 \\
\hline COG0381 & $M$ & & 100.00 & 100.00 \\
\hline \multirow[t]{2}{*}{ COG2089 } & \multirow{2}{*}{$M$} & & 42.44 & 100.00 \\
\hline & & & 67.65 & 100.00 \\
\hline COG1651 & $\mathrm{O}$ & & 100.00 & 100.00 \\
\hline COG3119 & \multicolumn{2}{|l|}{$P$} & 100.00 & 94.68 \\
\hline \multirow[t]{2}{*}{ COG2233 } & \multirow[t]{2}{*}{$\mathrm{F}$} & & 100.00 & 100.00 \\
\hline & & & 100.00 & 100.00 \\
\hline \multirow[t]{3}{*}{ COG2355 } & \multirow[t]{3}{*}{$E$} & & 100.00 & 100.00 \\
\hline & & & 100.00 & 100.00 \\
\hline & & & 100.00 & 100.00 \\
\hline COG0101 & $\mathrm{J}$ & & 100.00 & 96.38 \\
\hline COG3106 & $\mathrm{R}$ & & 100.00 & 93.14 \\
\hline COG0456 & $\mathrm{R}$ & & 100.00 & 100.00 \\
\hline COG3768 & $S$ & & 100.00 & 92.33 \\
\hline \multirow[t]{2}{*}{ COG0060 } & \multirow[t]{2}{*}{$J$} & & 100.00 & 100.00 \\
\hline & & & 100.00 & 100.00 \\
\hline COG1183 & I & & 100.00 & 100.00 \\
\hline COG4974 & $\mathrm{L}$ & & 100.00 & 100.00 \\
\hline COG3159 & $S$ & & 100.00 & 100.00 \\
\hline COG0176 & G & & 100.00 & 100.00 \\
\hline COG1198 & $\mathrm{L}$ & & 100.00 & 100.00 \\
\hline COG1884 & 1 & & 100.00 & 93.52 \\
\hline COG2937 & I & & 100.00 & 98.68 \\
\hline COG0604 & C & & 100.00 & 100.00 \\
\hline COG0507 & $\mathrm{L}$ & & 100.00 & 98.61 \\
\hline COG5598 & $\mathrm{H}$ & & 100.00 & 100.00 \\
\hline COG5321 & $S$ & & 100.00 & 100.00 \\
\hline \multirow[t]{3}{*}{ COG3019 } & \multirow[t]{3}{*}{$\mathrm{R}$} & GI 4 & 0.00 & 0.00 \\
\hline & & GI 4 & 0.00 & 0.00 \\
\hline & & GI 4 & 0.00 & 0.00 \\
\hline COG4642 & $\mathrm{S}$ & GI 4 & 0.00 & 0.00 \\
\hline COG3904 & $\mathrm{S}$ & Gl 4 & 0.00 & 0.00 \\
\hline
\end{tabular}




\begin{tabular}{|c|c|}
\hline RCA23_c09290 & putative DNA-binding protein, transposase-like \\
\hline RCA23_c09300 & HTH-type transcriptional regulator, LysR family \\
\hline RCA23_c09310 & hypothetical protein \\
\hline RCA23_c09320 & hypothetical protein, hydrolase-like \\
\hline RCA23_c09330 & putative integrase \\
\hline RCA23_c09340 & putative transposase \\
\hline RCA23_c09350 & hypothetical protein, ornithine cyclodeaminase-like \\
\hline RCA23_c09360 & LrgB-like protein \\
\hline RCA23_c09370 & hypothetical protein \\
\hline RCA23_c09380 & putative branched-chain-amino-acid aminotransferase IlvE \\
\hline RCA23_c09390 & 2-hydroxy-3-oxopropionate reductase GarR \\
\hline RCA23_c09400 & bicyclomycin resistance protein Bcr \\
\hline RCA23_c09410 & hypothetical protein \\
\hline RCA23_c09420 & hypothetical protein, photolyase \\
\hline RCA23_c09430 & DNA photolyase, FAD-binding/cryptochrome \\
\hline RCA23_c09440 & carbon monoxide dehydrogenase small chain CoxS \\
\hline RCA23_c09450 & carbon monoxide dehydrogenase large chain CoxL \\
\hline RCA23_c09460 & carbon monoxide dehydrogenase medium chain CoxM \\
\hline RCA23_c09470 & MoxR-like ATPase \\
\hline RCA23_c09480 & CoxE-like protein \\
\hline RCA23_c09490 & 5-deoxy-glucuronate isomerase lolB \\
\hline RCA23_c09500 & branched-chain amino acid transport protein, AzID-like \\
\hline RCA23_c09510 & branched-chain amino acid transport protein, AzIC-like \\
\hline RCA23_c09520 & alpha-IPM synthase/homocitrate synthase \\
\hline RCA23_c09530 & cytochrome P450 \\
\hline RCA23_c09540 & TRAP dicarboxylate transporter, subunit DctP \\
\hline RCA23_c09550 & TRAP dicarboxylate transporter, subunit DctQ \\
\hline RCA23_c09560 & TRAP dicarboxylate transporter, subunit DctM \\
\hline RCA23_c09570 & putative citrate transporter \\
\hline RCA23_c09580 & triosephosphate isomerase TpiA \\
\hline RCA23_c09590 & putative regulator protein of competence-specific genes TfoX \\
\hline RCA23_c09600 & hypothetical protein, iron-sulfur cluster assembly protein \\
\hline RCA23_c09610 & hypothetical protein DUF59 \\
\hline
\end{tabular}

\begin{tabular}{|c|c|c|c|c|}
\hline COG3415 & $\mathrm{L}$ & GI 4 & 0.00 & 0.00 \\
\hline \multirow[t]{2}{*}{ COG0583 } & K & GI 4 & 0.00 & 0.00 \\
\hline & & GI 4 & 0.00 & 0.00 \\
\hline COG0627 & $\mathrm{R}$ & GI 4 & 0.00 & 0.00 \\
\hline \multirow[t]{2}{*}{ COG2801 } & $\mathrm{L}$ & GI 4 & 0.00 & 44.52 \\
\hline & & GI 4 & 0.00 & 100.00 \\
\hline COG2423 & $E$ & & 0.00 & 0.00 \\
\hline COG1346 & $M$ & & 100.00 & 100.00 \\
\hline COG1380 & $\mathrm{R}$ & & 100.00 & 100.00 \\
\hline COG0115 & $\mathrm{E}$ & & 100.00 & 100.00 \\
\hline COG2084 & I & & 100.00 & 100.00 \\
\hline \multirow[t]{2}{*}{ COG2814 } & G & & 100.00 & 100.00 \\
\hline & & & 100.00 & 71.10 \\
\hline COG3046 & $\mathrm{R}$ & & 100.00 & 97.08 \\
\hline COG0415 & $\mathrm{L}$ & & 100.00 & 91.30 \\
\hline COG2080 & C & & 100.00 & 100.00 \\
\hline COG1529 & C & & 100.00 & 100.00 \\
\hline COG1319 & C & & 100.00 & 100.00 \\
\hline COG0714 & $\mathrm{R}$ & & 100.00 & 100.00 \\
\hline COG3552 & $\mathrm{R}$ & & 100.00 & 89.68 \\
\hline COG3718 & G & & 100.00 & 100.00 \\
\hline COG4392 & $\mathrm{S}$ & & 100.00 & 100.00 \\
\hline COG1296 & $E$ & & 100.00 & 100.00 \\
\hline COG0119 & $E$ & & 100.00 & 95.84 \\
\hline COG2124 & $Q$ & & 93.18 & 94.13 \\
\hline COG1638 & G & & 100.00 & 100.00 \\
\hline COG3090 & G & & 100.00 & 100.00 \\
\hline COG1593 & G & & 100.00 & 99.40 \\
\hline COG0471 & $P$ & & 100.00 & 100.00 \\
\hline COG0149 & G & & 100.00 & 100.00 \\
\hline COG3070 & K & & 100.00 & 98.11 \\
\hline COG0316 & $S$ & & 100.00 & 100.00 \\
\hline COG2151 & $\mathrm{R}$ & & 100.00 & 100.00 \\
\hline
\end{tabular}


RCA23_c09620

RCA23_c09630

RCA23_c09640

RCA23_c09650

RCA23 c09670

RCA23_c09680

RCA23 c09690

RCA23_c09700

RCA23_c09710

RCA23_c09720

RCA23_c09730

RCA23_c09740

RCA23_c09750

RCA23_c09760

RCA23_c09770

RCA23_c09780

RCA23 c09790

RCA23 c09800

RCA23_c09810

RCA23 c09820

RCA23_c09830

RCA23_c09840

RCA23_c09850

RCA23_c09860

RCA23_c09880

RCA23_c09890

RCA23_c09900

RCA23_c09910

RCA23_c09920

RCA23_c09930

RCA23_c09950

RCA23_c09940

RCA23_c09960 queuine tRNA-ribosyltransferase Tgt

hypothetical protein

ATP-dependent protease La

putative phosphoglycerate mutase family protein

protein-L-isoaspartate O-methyltransferase $\mathrm{Pcm}$

outer membrane efflux protein

hypothetical protein

cobyric acid synthase CobQ

hypothetical protein

translation elongation factor $P$

hypothetical protein tRNA modifying protein YgfZ

putative glycosyltransferase, family 2

lipid A export ATP-binding/permease protein MsbA

serine--glyoxylate aminotransferase SgaA

histidinol-phosphate aminotransferase HisC

valyl-tRNA synthase ValS

hypothetical protein, metal-dependent phosphohydrolase

putative phytanoyl-CoA dioxygenase family protein

molybdenum-containing hydroxylase

hypothetical protein DUF2235

5,10-methylenetetrahydrofolate reductase MetF

HTH-type transcriptional regulator MetR

inositol-1-monophosphatase SuhB

hypothetical protein

transcriptional regulator, HxIR family

hypothetical protein, DUF3764

hypothetical protein

hypothetical protein, DsrE/F-like

glutathione peroxidase Gpo

putative ion channel

hypothetical protein

ribosomal large subunit pseudouridine synthase D

RNA polymerase sigma-32 factor $\mathrm{RpoH}$

\begin{tabular}{|c|c|c|c|}
\hline \multirow[t]{2}{*}{ COG0343 } & \multirow[t]{2}{*}{$\mathrm{J}$} & 100.00 & 100.00 \\
\hline & & 100.00 & 100.00 \\
\hline COG0466 & $\mathrm{O}$ & 100.00 & 99.83 \\
\hline COG0406 & G & 100.00 & 100.00 \\
\hline COG2518 & $\mathrm{O}$ & 100.00 & 100.00 \\
\hline \multirow[t]{2}{*}{ COG1538 } & \multirow[t]{2}{*}{$M$} & 100.00 & 100.00 \\
\hline & & 100.00 & 100.00 \\
\hline \multirow[t]{2}{*}{ COG1492 } & \multirow[t]{2}{*}{$\mathrm{H}$} & 100.00 & 100.00 \\
\hline & & 100.00 & 100.00 \\
\hline COG0231 & $\mathrm{J}$ & 100.00 & 100.00 \\
\hline COG0354 & $\mathrm{R}$ & 100.00 & 100.00 \\
\hline COG0463 & $M$ & 100.00 & 100.00 \\
\hline COG1132 & $\mathrm{V}$ & 100.00 & 100.00 \\
\hline COG0075 & $E$ & 100.00 & 93.37 \\
\hline COG0079 & $E$ & 100.00 & 100.00 \\
\hline COG0525 & $\mathrm{J}$ & 100.00 & 98.26 \\
\hline COG4341 & $\mathrm{R}$ & 100.00 & 100.00 \\
\hline COG5285 & $Q$ & 100.00 & 96.68 \\
\hline COG1529 & $\mathrm{C}$ & 100.00 & 99.43 \\
\hline COG3673 & $\mathrm{S}$ & 100.00 & 100.00 \\
\hline COG0685 & $\mathrm{E}$ & 100.00 & 100.00 \\
\hline COG0583 & K & 100.00 & 100.00 \\
\hline COG0483 & G & 100.00 & 100.00 \\
\hline COG3063 & $\mathrm{N}$ & 100.00 & 100.00 \\
\hline \multirow[t]{3}{*}{ COG1733 } & \multirow[t]{3}{*}{$\mathrm{K}$} & 100.00 & 100.00 \\
\hline & & 100.00 & 100.00 \\
\hline & & 100.00 & 100.00 \\
\hline COG1553 & $P$ & 100.00 & 100.00 \\
\hline \multirow[t]{3}{*}{ COG0386 } & \multirow[t]{3}{*}{0} & 100.00 & 100.00 \\
\hline & & 100.00 & 100.00 \\
\hline & & 34.50 & 100.00 \\
\hline COG0564 & $\mathrm{J}$ & 100.00 & 91.09 \\
\hline COG0568 & $\mathrm{K}$ & 100.00 & 100.00 \\
\hline
\end{tabular}


RCA23 c09970

RCA23_c09980 oligoendopeptidase $F$

RCA23_c09990 2-keto-3-deoxy-L-rhamnonate aldolase RhmA

RCA23_c10000 hypothetical protein, lysophospholipase L2

RCA23_c10010 putative sterol-binding protein

RCA23_c10020 hypothetical protein

RCA23_c10030 ATP-dependent RNA helicase RhIB

RCA23_c10040 putative heat shock protein

RCA23_c10050 ferredoxin FdxA

RCA23_c10060 putative transcriptional regulator, CarD family

RCA23_c10070 cobalamin-5-phosphate synthase CobS

RCA23_c10080 nicotinate-nucleotide--dimethylbenzimidazole phosphoribosyltransferase Cob

RCA23_c10090 hypothetical protein

RCA23_c10100 glyoxalase/bleomycin resistance protein

RCA23_c10110 hypothetical protein

RCA23_c10120 choline dehydrogenase BetA

RCA23_c10140 23S rRNA (guanosine-2'-O-)-methyltransferase RImB

RCA23_c10150 phosphoribosyl-ATP pyrophosphatase HisE

RCA23_c10160 imidazole glycerol phosphate synthase subunit HisF

RCA23_c10170 1-(5-phosphoribosyl)-5-[(5-phosphoribosylamino)methylideneamino] imidazo

RCA23 c10180 imidazole glycerol phosphate synthase, glutamine amidotransferase subunit $\vdash$

RCA23_c10190 imidazoleglycerol-phosphate dehydratase HisB

RCA23_c10210 hypothetical protein, calcineurin-like phosphoesterase-like

RCA23_c10220 pyruvate carboxylase Pyc

RCA23_c10230 L-lactate dehydrogenase IldD

RCA23_c10240 putative DNA helicase II

RCA23_c10250 gamma-glutamylputrescine oxidoreductase PuuB

RCA23_c10260 putative cysteine/O-acetylserine efflux protein

RCA23_c10270 hypothetical protein

RCA23_c10280 putative protein Mrp

RCA23_c10290 hypothetical protein

RCA23_c10300 hypothetical protein, MraZ

RCA23_c10310 S-adenosyl-L-methionine-dependent methyltransferase MraW

\begin{tabular}{|c|c|c|c|}
\hline COG0673 & $\mathrm{R}$ & 100.00 & 100.00 \\
\hline COG1164 & $E$ & 100.00 & 97.87 \\
\hline COG3836 & $\mathrm{G}$ & 100.00 & 100.00 \\
\hline COG2267 & 1 & 100.00 & 100.00 \\
\hline \multirow[t]{2}{*}{ COG3255 } & 1 & 100.00 & 100.00 \\
\hline & & 100.00 & 86.99 \\
\hline COG4581 & $\mathrm{L}$ & 100.00 & 99.79 \\
\hline COG1188 & $\mathrm{J}$ & 100.00 & 100.00 \\
\hline COG1146 & $C$ & 87.02 & 100.00 \\
\hline COG1329 & $\mathrm{K}$ & 19.08 & 100.00 \\
\hline COG0368 & $\mathrm{H}$ & 100.00 & 100.00 \\
\hline \multirow[t]{2}{*}{ COG2038 } & $\mathrm{H}$ & 100.00 & 100.00 \\
\hline & & 100.00 & 99.41 \\
\hline \multirow[t]{2}{*}{ COG3565 } & $\mathrm{R}$ & 100.00 & 100.00 \\
\hline & & 100.00 & 100.00 \\
\hline COG2303 & $E$ & 100.00 & 100.00 \\
\hline COG0566 & $\mathrm{J}$ & 100.00 & 67.11 \\
\hline COG0140 & $E$ & 100.00 & 100.00 \\
\hline COG0107 & $E$ & 100.00 & 100.00 \\
\hline COG0106 & $E$ & 100.00 & 100.00 \\
\hline COG0118 & $E$ & 100.00 & 87.64 \\
\hline COG0131 & $E$ & 100.00 & 100.00 \\
\hline COG1409 & $\mathrm{R}$ & 100.00 & 100.00 \\
\hline COG1038 & $\mathrm{C}$ & 100.00 & 98.75 \\
\hline COG1304 & C & 100.00 & 100.00 \\
\hline COG0210 & $\mathrm{L}$ & 100.00 & 100.00 \\
\hline COG0665 & $E$ & 100.00 & 100.00 \\
\hline \multirow[t]{2}{*}{ COG1280 } & $E$ & 100.00 & 100.00 \\
\hline & & 100.00 & 100.00 \\
\hline \multirow[t]{2}{*}{ COG0489 } & $D$ & 100.00 & 100.00 \\
\hline & & 100.00 & 100.00 \\
\hline COG2001 & $\mathrm{S}$ & 100.00 & 100.00 \\
\hline COG0275 & $M$ & 100.00 & 100.00 \\
\hline
\end{tabular}


RCA23_c10340 UDP-N-acetylmuramoyl-L-alanyl-D-glutamate--2,6-diaminopimelate ligase Mu RCA23_c10350 putative UDP-N-acetylmuramoyl-tripeptide--D-alanyl-D-alanine ligase MurF

COG0770

RCA23_c10370 UDP-N-acetylmuramoylalanine--D-glutamate ligase MurD

RCA23_c10380 putative glycosyltransferase, sugar binding region

COG0472

COG0771

COG3774

100.00

100.00

100.00

RCA23_c10390 putative galactoside 2-alpha-L-fucosyltransferase 1

100.00

100.00

100.00

100.00

RCA23_c10400 hypothetical protein

RCA23_c10420 hypothetical protein HI0933

COG3306

COG2081

RCA23_c10430

cell division protein FtsW

COG0772

RCA23_c10440 UDP-N-acetylglucosamine--N-acetylmuramyl-(pentapeptide) pyrophosphoryl-

COG0707

RCA23_c10450

UDP-N-acetylmuramate--L-alanine ligase MurC

COG0773

RCA23_c10460

permease of the drug/metabolite transporter superfamily

COG0697

RCA23_c10470 UDP-N-acetylenolpyruvoylglucosamine reductase MurB

RCA23_c10480 D-alanine--D-alanine ligase Ddl

COG0812

COG1181

RCA23 c10490 putative cell division protein FtsQ

RCA23_c10500 cell division protein FtsA

RCA23_c10510 cell division protein FtsZ

COG0849

COG0206

RCA23_c10520 UDP-3-O-[3-hydroxymyristoyl] N-acetylglucosamine deacetylase LpxC

COG0774

COG4105

RCA23_c10530

outer membrane assembly lipoprotein

RCA23_c10540 DNA repair protein RecN

COG0497

RCA23_c10550 hypothetical protein DUF427

COG2343

COG0006

RCA23_c10560 putative Xaa-Pro aminopeptidase

RCA23_c10570 aerobic cobaltochelatase subunit CobT

COG4547

RCA23_c10580 aerobic cobaltochelatase subunit CobS

cog 0714

RCA23_c10590 hypothetical protein, DnaJ

COG0484

RCA23_c10600 putative stress-induced morphoprotein, BolA type

RCA23_c10610 aspartyl/glutamyl-tRNA(Asn/GIn) amidotransferase subunit GatB

COG0271

COG0064

COG0308

COG2225

RCA23_c10630 malate synthase GlcB

RCA23_c10640 hypothetical protein DUF336

COG3193

100.00

100.00

100.00

100.00

100.00

100.00

100.00

100.00

100.00

57.96

82.02

100.00

100.00

100.00

100.00

100.00

100.00

100.00

100.00

100.00

54.17

95.11

95.06

100.00

100.00
100.00

100.00

100.00

100.00

100.00

96.64

100.00

100.00

100.00

100.00

85.96

100.00

100.00

100.00

100.00

100.00

100.00

100.00

100.00

100.00

100.00

100.00

100.00

100.00

90.54

95.89

97.29

100.00 
RCA23_c10650 hypothetical protein

RCA23_c10660 gamma-glutamyl-gamma-aminobutyrate hydrolase PuuD

RCA23_c10670 putative D-beta-hydroxybutyrate dehydrogenase

100.00

100.00

RCA23_c10680 NAD(P) transhydrogenase alpha subunit PntA

100.00

100.00

RCA23_c10690 NAD(P) transhydrogenase beta subunit PntB

COG1028

COG3288

RCA23_c10700 hypothetical protein

RCA23_c10710 putative acetylornithine deacetylase ArgE

RCA23_c10720 molybdenum cofactor biosynthesis protein MoaA

COG1282

100.00

COG4949

100.00

COG0624

100.00

COG2896

RCA23_c10730 acetyl-coenzyme A synthase AcsA

COG0365

100.00

100.00

COG4321

RCA23_c10740 hypothetical protein

RCA23_c10750 hypothetical protein

COG0114

RCA23_c10760 fumarate hydratase class II

COG3814

RCA23_c10770 hypothetical protein

RCA23_c10780 putative chromate transport protein

COG2059

RCA23_c10790 hydantoinase / oxoprolinase family protein

COG0145

RCA23_c10800 hypothetical protein

RCA23_c10810 putative quinone oxidoreductase yhdH

COG0604

COG0520

RCA23_c10820 cysteine desulfurase SufS

COG0415

RCA23_c10830 deoxyribodipyrimidine photo-lyase PhrB

RCA23_c10840 cyclopropane-fatty-acyl-phospholipid synthase Cfa

RCA23_c10850 ADP-ribose pyrophosphatase NudF

$\operatorname{COG} 2230$

RCA23_c10860 cysteine synthase CysK

RCA23_c10870 mechanosensitive ion channel protein MscS

RCA23_c10890 putative phage integrase

RCA23_c10900 hypothetical protein

RCA23_c10910 hypothetical protein, tetratricopetide domain TPR-1

RCA23_c10920 hypothetical protein, resolvase-like

RCA23_c10930 hypothetical protein, DUF2924

RCA23_c10940 putative TRAP transporter solute receptor

RCA23_c10950 TRAP transporter, 4TM/12TM fusion protein

RCA23_c10960 putative sulfatase YidJ

RCA23_c10970 arylsulfatase

RCA23_c10980 siderophore interactin protein, vibriobactin utilization protein-like

COG0494

COG0031

COG3264

COG4974

COG0457

COG1961

COG2358

COG4666

COG3119

COG1234

COG2375 


\begin{tabular}{|c|c|}
\hline RCA23_c10990 & hypothetical protein, metallo-beta-lactamase \\
\hline RCA23_c11000 & TRAP dicarboxylate transporter, subunit DctP \\
\hline RCA23_c11010 & glutathione S-transferase \\
\hline RCA23_c11020 & TRAP dicarboxylate transporter, subunit DctQ \\
\hline RCA23_c11030 & TRAP dicarboxylate transporter, subunit DctM \\
\hline RCA23_c11040 & hypothetical protein, DUF6 transmembrane protein \\
\hline RCA23_c11050 & ferric reductase like transmembrane component family \\
\hline RCA23_c11060 & hypothetical protein \\
\hline RCA23_c11070 & hypothetical protein \\
\hline RCA23_c11080 & sulfatase family protein \\
\hline RCA23_c11090 & short-chain dehydrogenase/reductase SDR \\
\hline RCA23_c11100 & maleylacetoacetate isomerase MaiA \\
\hline RCA23_c11110 & salicylaldehyde dehydrogenase \\
\hline RCA23_c11120 & transcriptional regulator, GntR family \\
\hline RCA23_c11130 & transposase \\
\hline RCA23_c11140 & putative phage integrase \\
\hline RCA23_c11150 & hypothetical protein, alginate lyase-lyase \\
\hline RCA23_c11160 & HTH-type transcriptional regulator, GntR family \\
\hline RCA23_c11170 & branched-chain amino acid $A B C$ transporter, periplasmic substrate-binding pro \\
\hline RCA23_c11180 & branched-chain amino acid $A B C$ transporter, permease protein \\
\hline RCA23_c11190 & branched-chain amino acid $A B C$ transporter, permease protein \\
\hline RCA23_c11200 & branched-chain amino acid ABC transporter, ATP-binding protein \\
\hline RCA23_c11210 & branched-chain amino acid ABC transporter, ATP-binding protein \\
\hline RCA23_c11220 & hydantoin racemase HyuE \\
\hline RCA23_c11230 & transposase \\
\hline RCA23_c11240 & glutamine transport ATP-binding protein GlnQ \\
\hline RCA23_c11250 & putative inner membrane amino-acid $A B C$ transporter permease protein \\
\hline RCA23_c11260 & transposase \\
\hline RCA23_c11270 & transcriptional regulator CoxC \\
\hline RCA23_c11280 & carbon monoxide dehydrogenase medium chain CoxM \\
\hline RCA23_c11290 & carbon monoxide dehydrogenase small chain CoxS \\
\hline RCA23_c11300 & carbon monoxide dehydrogenase large chain CoxL \\
\hline RCA23_c11310 & AAA+ ATPase chaperone CoxD \\
\hline
\end{tabular}

\begin{tabular}{|c|c|c|c|c|}
\hline COG2015 & Q & GI 5 & 97.10 & 63.07 \\
\hline COG1638 & G & GI 5 & 64.31 & 47.69 \\
\hline COG0625 & 0 & GI 5 & 99.55 & 62.01 \\
\hline COG3090 & G & GI 5 & 100.00 & 19.67 \\
\hline COG1593 & G & GI 5 & 100.00 & 20.78 \\
\hline \multirow[t]{4}{*}{ COG0697 } & G & GI 5 & 100.00 & 34.32 \\
\hline & & GI 5 & 100.00 & 60.14 \\
\hline & & GI 5 & 100.00 & 72.69 \\
\hline & & GI 5 & 100.00 & 67.93 \\
\hline COG3119 & $P$ & GI 5 & 12.09 & 49.51 \\
\hline COG1028 & I & GI 5 & 3.29 & 35.31 \\
\hline COG0625 & 0 & GI 5 & 100.00 & 8.30 \\
\hline COG1012 & $C$ & GI 5 & 100.00 & 42.59 \\
\hline COG1802 & K & GI 5 & 100.00 & 47.91 \\
\hline COG3316 & L & GI 5 & 4.66 & 0.00 \\
\hline \multirow[t]{2}{*}{ COG4974 } & $\mathrm{L}$ & GI 5 & 0.00 & 0.00 \\
\hline & & GI 5 & 0.00 & 0.00 \\
\hline COG1802 & K & GI 5 & 100.00 & 80.77 \\
\hline COG0683 & $E$ & GI 5 & 5.22 & 76.60 \\
\hline COG0559 & $E$ & GI 5 & 91.81 & 90.14 \\
\hline COG4177 & $E$ & GI 5 & 100.00 & 71.25 \\
\hline COG0411 & $\mathrm{E}$ & GI 5 & 77.12 & 44.58 \\
\hline COG0410 & $E$ & GI 5 & 0.00 & 43.98 \\
\hline CoG4126 & $E$ & GI 5 & 0.00 & 62.57 \\
\hline COG3316 & $\mathrm{L}$ & GI 5 & 0.00 & 79.66 \\
\hline COG1126 & $E$ & GI 5 & 0.00 & 0.00 \\
\hline COG0765 & $\mathrm{E}$ & GI 5 & 0.00 & 0.00 \\
\hline COG3316 & $\mathrm{L}$ & GI 5 & 0.00 & 0.00 \\
\hline COG3300 & $\mathrm{T}$ & GI 5 & 43.53 & 100.00 \\
\hline COG1319 & C & GI 5 & 100.00 & 100.00 \\
\hline COG2080 & $C$ & GI 5 & 100.00 & 91.11 \\
\hline COG1529 & $C$ & GI 5 & 89.29 & 98.06 \\
\hline COG0714 & $\mathrm{R}$ & GI 5 & 95.43 & 92.47 \\
\hline
\end{tabular}


RCA23 c11320

RCA23_c11330

RCA23_c11340

RCA23_c11350

RCA23_c11360

RCA23_c11370

RCA23_c11380

RCA23_c11390

RCA23_c11400

RCA23_c11410

RCA23_c11420

RCA23_c11430

RCA23_c11440

RCA23_c11450

RCA23_c11460

RCA23_c11470

RCA23_c11480

RCA23_c11490

RCA23_c11500 fumarate reductase flavoprotein subunit FccA

RCA23_c11510 aspartate aminotransferase AspC

RCA23_c11520 hypothetical protein

RCA23_c11530 aerobic glycerol-3-phosphate dehydrogenase GIpD

RCA23_c11540 aerobic glycerol-3-phosphate dehydrogenase GIpD

RCA23_c11550 hypothetical protein

RCA23_c11560 chemotaxis protein CheW

RCA23_c11570 methyl-accepting chemotaxis protein II

RCA23_c11580 chemotaxis histidine kinase CheA

RCA23_c11590 response regulator CheY

RCA23_c11600 chemotaxis protein methyltransferase CheR

RCA23_c11610 chemotaxis response regulator protein-glutamate methylesterase CheB

RCA23_c11620 metal-dependent hydrolase

RCA23_c11630 integrase

RCA23_c11640 methyltransferase, FkbM family

\begin{tabular}{|c|c|c|c|c|}
\hline COG3552 & $\mathrm{R}$ & GI 5 & 100.00 & 100.00 \\
\hline COG1975 & $\mathrm{O}$ & GI 5 & 100.00 & 91.92 \\
\hline COG2068 & $\mathrm{R}$ & GI 5 & 100.00 & 100.00 \\
\hline COG3427 & $\mathrm{S}$ & GI 5 & 100.00 & 100.00 \\
\hline COG1975 & $\mathrm{O}$ & GI 5 & 100.00 & 86.99 \\
\hline COG3316 & $\mathrm{L}$ & GI 5 & 100.00 & 0.00 \\
\hline COG0412 & Q & GI 5 & 0.00 & 96.25 \\
\hline COG0667 & C & GI 5 & 94.94 & 97.52 \\
\hline COG4948 & $\mathrm{M}$ & GI 5 & 100.00 & 91.07 \\
\hline COG3822 & $\mathrm{R}$ & GI 5 & 100.00 & 100.00 \\
\hline COG0642 & $\mathrm{T}$ & GI 5 & 100.00 & 100.00 \\
\hline COG0745 & $\mathrm{T}$ & GI 5 & 100.00 & 100.00 \\
\hline COG3181 & $S$ & GI 5 & 100.00 & 100.00 \\
\hline COG3333 & $S$ & GI 5 & 100.00 & 99.40 \\
\hline COG2828 & $\mathrm{S}$ & GI 5 & 100.00 & 90.66 \\
\hline COG0111 & $\mathrm{H}$ & GI 5 & 100.00 & 94.32 \\
\hline COG3180 & $\mathrm{R}$ & GI 5 & 100.00 & 100.00 \\
\hline COG1802 & $\mathrm{K}$ & GI 5 & 100.00 & 100.00 \\
\hline COG1053 & C & GI 5 & 100.00 & 100.00 \\
\hline \multirow[t]{2}{*}{ COG0436 } & $E$ & GI 5 & 100.00 & 100.00 \\
\hline & & GI 5 & 100.00 & 100.00 \\
\hline COG0578 & C & GI 5 & 100.00 & 98.78 \\
\hline COG0578 & C & GI 5 & 100.00 & 100.00 \\
\hline COG1192 & $\mathrm{D}$ & GI 5 & 0.00 & 0.00 \\
\hline COG0835 & $\mathrm{N}$ & GI 5 & 64.10 & 0.00 \\
\hline COG0840 & $\mathrm{N}$ & GI 5 & 99.09 & 0.00 \\
\hline COG0643 & $\mathrm{N}$ & GI 5 & 0.00 & 0.00 \\
\hline COG2114 & $\mathrm{T}$ & GI 5 & 0.00 & 0.00 \\
\hline COG1352 & $\mathrm{N}$ & GI 5 & 0.00 & 0.00 \\
\hline COG2201 & $\mathrm{N}$ & GI 5 & 0.00 & 0.00 \\
\hline COG1235 & $\mathrm{R}$ & GI 5 & 0.00 & 0.00 \\
\hline \multirow[t]{2}{*}{ COG2801 } & $\mathrm{L}$ & GI 5 & 0.00 & 0.00 \\
\hline & & GI 5 & 0.00 & 0.00 \\
\hline
\end{tabular}




\begin{tabular}{|c|c|}
\hline RCA23_c11650 & hypothetical protein, sugar transferase-like \\
\hline RCA23_c11660 & aldo/keto reductase \\
\hline RCA23_c11670 & hypothetical protein \\
\hline RCA23_c11680 & hypothetical protein \\
\hline RCA23_c11690 & hypothetical protein \\
\hline RCA23_c11700 & hypothetical protein \\
\hline RCA23_c11710 & phytanoyl-CoA dioxygenase family protein \\
\hline RCA23_c11720 & putative bacterial extracellular solute binding protein, family 3 \\
\hline RCA23_c11730 & hypothetical protein \\
\hline RCA23_c11740 & SOUL heme-binding protein \\
\hline RCA23_c11750 & arylsulfatase precursor \\
\hline RCA23_c11760 & hypothetical protein DUF583 \\
\hline RCA23_c11770 & integrase \\
\hline RCA23_c11780 & hypothetical protein \\
\hline RCA23_c11790 & glutamine synthase GInA type I \\
\hline RCA23_c11800 & putative HTH-type transcriptional regulator, RpiR family \\
\hline RCA23_c11810 & $\mathrm{N}$-formylglutamate amidohydrolase \\
\hline RCA23_c11820 & putative isochorismatase family protein \\
\hline RCA23_c11830 & branched-chain amino acid ABC transporter, ATP-binding protein \\
\hline RCA23_c11840 & branched-chain amino acid $A B C$ transporter, periplasmic binding protein \\
\hline RCA23_c11850 & branched-chain amino acid $A B C$ transporter, ATP-binding protein \\
\hline RCA23_c11860 & branched-chain amino acid $A B C$ transporter, permease protein \\
\hline RCA23_c11870 & branched-chain amino acid $A B C$ transporter, permease protein \\
\hline RCA23_c11880 & acetamidase/formamidase family protein \\
\hline RCA23_c11890 & hypothetical protein \\
\hline RCA23_c11910 & putative prophage integrase \\
\hline RCA23_c11920 & hypothetical protein \\
\hline RCA23_c11930 & hypothetical protein \\
\hline RCA23_c11940 & putative AAA ATPase \\
\hline RCA23_c11950 & hypothetical protein \\
\hline RCA23_c11960 & hypothetical protein \\
\hline RCA23_c11970 & hypothetical protein \\
\hline RCA23_c11980 & hypothetical protein \\
\hline
\end{tabular}

\begin{tabular}{|c|c|c|c|c|}
\hline & & GI 5 & 0.00 & 63.40 \\
\hline \multirow[t]{2}{*}{ COG0667 } & C & GI 5 & 0.00 & 35.84 \\
\hline & & GI 5 & 0.00 & 92.39 \\
\hline COG0790 & $\mathrm{R}$ & GI 5 & 0.00 & 0.00 \\
\hline COG4430 & $S$ & GI 5 & 0.00 & 73.65 \\
\hline COG2755 & $\mathrm{E}$ & GI 5 & 0.00 & 0.00 \\
\hline COG5285 & $Q$ & GI 5 & 100.00 & 100.00 \\
\hline \multirow[t]{3}{*}{ CoG1791 } & $S$ & GI 5 & 0.00 & 92.32 \\
\hline & & GI 5 & 0.00 & 6.62 \\
\hline & & GI 5 & 99.67 & 100.00 \\
\hline \multirow[t]{2}{*}{ COG3119 } & $\mathrm{P}$ & GI 5 & 96.71 & 96.71 \\
\hline & & GI 5 & 0.00 & 0.00 \\
\hline COG2801 & $\mathrm{L}$ & GI 5 & 0.00 & 0.00 \\
\hline COG3616 & $\mathrm{E}$ & GI 5 & 79.40 & 94.19 \\
\hline COG0174 & $\mathrm{E}$ & GI 5 & 0.00 & 0.00 \\
\hline COG1737 & $\mathrm{K}$ & GI 5 & 0.00 & 0.00 \\
\hline COG3931 & $E$ & GI 5 & 0.00 & 0.00 \\
\hline COG1335 & Q & GI 5 & 0.00 & 0.00 \\
\hline COG0411 & $\mathrm{E}$ & GI 5 & 70.26 & 0.00 \\
\hline COG0683 & $\mathrm{E}$ & GI 5 & 100.00 & 0.00 \\
\hline COG0410 & $E$ & GI 5 & 0.00 & 0.00 \\
\hline COG0559 & $\mathrm{E}$ & GI 5 & 0.00 & 0.00 \\
\hline COG4177 & $\mathrm{E}$ & GI 5 & 0.00 & 3.49 \\
\hline COG2421 & C & GI 5 & 0.00 & 18.96 \\
\hline COG1028 & I & GI 5 & 100.00 & 100.00 \\
\hline \multirow[t]{3}{*}{ COG0582 } & $\mathrm{L}$ & GI 5 & 0.00 & 20.44 \\
\hline & & GI 5 & 0.00 & 0.00 \\
\hline & & GI 5 & 0.00 & 73.21 \\
\hline \multirow[t]{5}{*}{ COG3598 } & $\mathrm{L}$ & GI 5 & 0.00 & 73.00 \\
\hline & & GI 5 & 0.00 & 0.00 \\
\hline & & GI 5 & 0.00 & 0.00 \\
\hline & & GI 5 & 0.00 & 100.00 \\
\hline & & GI 5 & 0.00 & 32.25 \\
\hline
\end{tabular}




\begin{tabular}{|c|c|}
\hline RCA23_c11990 & branched-chain amino acid ABC transporter, ATP-binding protein \\
\hline RCA23_c12000 & branched-chain amino acid ABC transporter, ATP-binding protein \\
\hline RCA23_c12010 & branched-chain amino acid $A B C$ transporter, permease protein \\
\hline RCA23_c12020 & branched-chain amino acid $A B C$ transporter, permease protein \\
\hline RCA23_c12030 & branched-chain amino acid $A B C$ transporter, periplasmic binding protein \\
\hline RCA23_c12040 & enoyl-CoA hydratase/carnithine racemase \\
\hline RCA23_c12050 & acetyl-CoA synthase-like protein \\
\hline RCA23_c12060 & dehydrogenase iron-sulfur-binding subunit \\
\hline RCA23_c12070 & dehydrogenase FAD-binding subunit \\
\hline RCA23_c12080 & dehydrogenase molybdenum-binding subunit \\
\hline RCA23_c12090 & putative HTH-type transcriptional regulator, AraC family \\
\hline RCA23_c12100 & periplasmic binding protein-like \\
\hline RCA23_c12110 & ROK family transcriptional repressor \\
\hline RCA23_c12120 & xylose isomerase \\
\hline RCA23_c12130 & sugar $\mathrm{ABC}$ transporter, periplasmic binding protein \\
\hline RCA23_c12140 & putative oxidoreductase \\
\hline RCA23_c12150 & sugar $A B C$ transporter, ATP-binding protein \\
\hline RCA23_c12160 & sugar $A B C$ transporter, permease protein \\
\hline RCA23_c12170 & hypothetical protein, monoxygenase-like \\
\hline RCA23_c12180 & hypothetical protein \\
\hline RCA23_c12190 & putative oxidoreductase \\
\hline RCA23_c12200 & peptidase M20D, amidohydrolase \\
\hline RCA23_c12210 & X-Pro dipeptidase \\
\hline RCA23_c12220 & hypothetical protein \\
\hline RCA23_c12230 & hypothetical protein, transmembrane \\
\hline RCA23_c12240 & hypothetical protein, DNA breaking rejoining enzymes family protein-like \\
\hline RCA23_c12250 & hypothetical protein \\
\hline RCA23_c12260 & hypothetical protein \\
\hline RCA23_c12270 & hypothetical protein \\
\hline RCA23_c12280 & type I restriction-modification system, $\mathrm{M}$ subunit \\
\hline RCA23_c12290 & type I restriction-modification system, S subunit \\
\hline RCA23_c12300 & type I restriction-modification system, R subunit \\
\hline RCA23_c12310 & hypothetical protein \\
\hline
\end{tabular}

\begin{tabular}{|c|c|c|c|c|}
\hline COG0410 & $E$ & GI 5 & 100.00 & 75.68 \\
\hline COG0411 & $\mathrm{E}$ & GI 5 & 100.00 & 0.00 \\
\hline COG4177 & $E$ & GI 5 & 100.00 & 46.14 \\
\hline COG0559 & $E$ & GI 5 & 92.06 & 14.54 \\
\hline COG0683 & $\mathrm{E}$ & GI 5 & 0.00 & 45.84 \\
\hline COG1024 & I & GI 5 & 0.00 & 14.86 \\
\hline COG0318 & I & GI 5 & 77.41 & 47.70 \\
\hline COG2080 & C & GI 5 & 100.00 & 23.73 \\
\hline COG1319 & C & GI 5 & 92.00 & 25.70 \\
\hline COG1529 & C & GI 5 & 0.00 & 12.86 \\
\hline COG2207 & K & GI 5 & 0.00 & 0.00 \\
\hline COG1879 & G & GI 5 & 0.00 & 0.00 \\
\hline COG1940 & K & GI 5 & 0.00 & 8.48 \\
\hline COG1082 & G & GI 5 & 0.00 & 0.00 \\
\hline COG1879 & G & GI 5 & 0.00 & 0.00 \\
\hline COG0673 & $\mathrm{R}$ & GI 5 & 0.00 & 0.00 \\
\hline COG1129 & G & GI 5 & 0.00 & 6.98 \\
\hline COG1172 & G & GI 5 & 0.00 & 0.00 \\
\hline COG1359 & $S$ & GI 5 & 0.00 & 0.00 \\
\hline COG1082 & G & GI 5 & 0.00 & 62.23 \\
\hline COG0673 & $\mathrm{R}$ & GI 5 & 0.00 & 11.02 \\
\hline COG1473 & $\mathrm{R}$ & GI 5 & 100.00 & 27.15 \\
\hline \multirow[t]{7}{*}{ COG0006 } & $\mathrm{E}$ & GI 5 & 46.86 & 29.93 \\
\hline & & GI 5 & 0.00 & 0.00 \\
\hline & & GI 5 & 0.00 & 0.00 \\
\hline & & GI 5 & 88.64 & 0.00 \\
\hline & & GI 5 & 0.00 & 0.00 \\
\hline & & GI 5 & 0.00 & 17.82 \\
\hline & & GI 5 & 0.00 & 0.00 \\
\hline COG0286 & v & GI 5 & 0.00 & 0.00 \\
\hline COG0732 & v & GI 5 & 0.00 & 0.00 \\
\hline COG0610 & v & GI 5 & 0.00 & 3.78 \\
\hline COG3012 & $S$ & GI 5 & 0.00 & 0.00 \\
\hline
\end{tabular}




\begin{tabular}{|c|c|}
\hline RCA23_c12320 & hypothetical protein \\
\hline RCA23_c12330 & hypothetical protein \\
\hline RCA23_c12340 & hypothetical protein, DNA helicase-like protein \\
\hline RCA23_c12350 & hypothetical protein \\
\hline RCA23_c12360 & integrase \\
\hline RCA23_c12370 & hypothetical protein \\
\hline RCA23_c12380 & hypothetical protein \\
\hline RCA23_c12390 & hypothetical protein \\
\hline RCA23_c12400 & hypothetical protein \\
\hline RCA23_c12410 & hypothetical protein, DUF1994 \\
\hline RCA23_c12420 & exonuclease I \\
\hline RCA23_c12430 & transpeptidase, penicillin binding protein \\
\hline RCA23_c12440 & hypothetical protein \\
\hline RCA23_c12450 & hypothetical protein \\
\hline RCA23_c12460 & hypothetical protein \\
\hline RCA23_c12470 & type III restriction enzyme, res subunit \\
\hline RCA23_c12480 & putative type III restriction system protein, mod subunit \\
\hline RCA23_c12490 & putative serine/threonine protein kinase \\
\hline RCA23_c12500 & serine/threonine protein phosphatase PrpC \\
\hline RCA23_c12510 & DNA helicase, UvrD/REP type \\
\hline RCA23_c12520 & hypothetical protein \\
\hline RCA23_c12530 & hypothetical protein, OmpA/MotB-like \\
\hline RCA23_c12540 & hypothetical protein \\
\hline RCA23_c12550 & ATP-dependent helicase \\
\hline RCA23_c12560 & hypothetical protein \\
\hline RCA23_c12570 & hypothetical protein \\
\hline RCA23_c12580 & hypothetical protein \\
\hline RCA23_c12590 & hypothetical protein \\
\hline RCA23_c12600 & hypothetical protein \\
\hline RCA23_c12610 & hypothetical protein \\
\hline RCA23_c12620 & hypothetical protein \\
\hline RCA23_c12630 & integrase \\
\hline RCA23_c12640 & hypothetical protein \\
\hline
\end{tabular}

\begin{tabular}{|c|c|c|c|c|}
\hline \multirow{4}{*}{ COG2865 } & $\mathrm{K}$ & GI 5 & 0.00 & 0.00 \\
\hline & & GI 5 & 0.00 & 0.00 \\
\hline & & GI 5 & 0.00 & 0.00 \\
\hline & & GI 5 & 0.00 & 0.00 \\
\hline \multirow[t]{6}{*}{ COG0582 } & $\mathrm{L}$ & GI 5 & 0.00 & 0.00 \\
\hline & & GI 5 & 0.00 & 0.00 \\
\hline & & GI 5 & 0.00 & 0.00 \\
\hline & & GI 5 & 0.00 & 0.00 \\
\hline & & GI 5 & 0.00 & 0.00 \\
\hline & & GI 5 & 100.00 & 47.10 \\
\hline COG2925 & $\mathrm{L}$ & GI 5 & 100.00 & 70.01 \\
\hline COG4953 & $M$ & GI 5 & 28.88 & 44.78 \\
\hline \multirow[t]{3}{*}{ COG2373 } & $\mathrm{R}$ & GI 5 & 22.49 & 26.91 \\
\hline & & GI 5 & 0.00 & 24.93 \\
\hline & & GI 5 & 0.00 & 0.00 \\
\hline \multirow[t]{2}{*}{ COG1061 } & $\mathrm{K}$ & GI 5 & 0.00 & 31.71 \\
\hline & & GI 5 & 0.00 & 53.63 \\
\hline COG0515 & $\mathrm{R}$ & GI 5 & 0.00 & 20.27 \\
\hline COG0631 & $\mathrm{T}$ & GI 5 & 0.00 & 37.50 \\
\hline COG0210 & $\mathrm{L}$ & GI 5 & 0.00 & 0.00 \\
\hline COG1463 & $Q$ & GI 5 & 0.00 & 0.00 \\
\hline \multirow[t]{2}{*}{ COG1360 } & $\mathrm{N}$ & GI 5 & 0.00 & 0.00 \\
\hline & & GI 5 & 0.00 & 0.00 \\
\hline \multirow[t]{8}{*}{ COG0553 } & $\mathrm{K}$ & GI 5 & 0.00 & 0.00 \\
\hline & & GI 5 & 0.00 & 0.00 \\
\hline & & GI 5 & 0.00 & 0.00 \\
\hline & & GI 5 & 0.00 & 0.00 \\
\hline & & GI 5 & 49.19 & 0.00 \\
\hline & & GI 5 & 89.56 & 0.00 \\
\hline & & GI 5 & 0.00 & 0.00 \\
\hline & & GI 5 & 0.00 & 0.00 \\
\hline \multirow[t]{2}{*}{ COG2801 } & $\mathrm{L}$ & GI 5 & 0.00 & 100.00 \\
\hline & & GI 5 & 0.00 & 0.00 \\
\hline
\end{tabular}




$\begin{array}{ll}\text { RCA23_c12650 } & \text { hypothetical protein } \\ \text { RCA23_c12660 } & \text { DNA integration/recombination/invertion protein } \\ \text { RCA23_c12690 } & \text { putative beta-lactamase-like protein } \\ \text { RCA23_c12680 } & \text { osmolarity sensor protein EnvZ } \\ \text { RCA23_c12700 } & \text { hypothetical protein } \\ \text { RCA23_c12710 } & \text { 50S ribosomal protein L21 } \\ \text { RCA23_c12720 } & \text { 50S ribosomal protein L27 } \\ \text { RCA23_c12730 } & \text { hypothetical protein, LysE type translocator } \\ \text { RCA23_c12740 } & \text { putative acetyltransferase } \\ \text { RCA23_c12750 } & \text { GCN5-like N-acetyltransferase } \\ \text { RCA23_c12760 } & \text { GTP-binding protein Obg } \\ \text { RCA23_c12770 } & \text { glutamate 5-kinase ProB } \\ \text { RCA23_c12780 } & \text { gamma-glutamyl phosphate reductase ProA } \\ \text { RCA23_c12800 } & \text { hypothetical protein } \\ \text { RCA23_c12790 } & \text { hypothetical protein } \\ \text { RCA23_c12810 } & \text { hypothetical protein } \\ \text { RCA23_c12820 } & \text { putative phosphate acyltransferase } \\ \text { RCA23_c12830 } & \text { thiamine-phosphate pyrophosphorylase ThiE } \\ \text { RCA23_c12840 } & \text { tRNA (cytidine/uridine-2'-O-)-methyltransferase TrmJ } \\ \text { RCA23_c12850 } & \text { heme A synthase CtaA } \\ \text { RCA23_c12860 } & \text { thermostable carboxypeptidase 1 } \\ \text { RCA23_c12870 } & \text { DNA gyrase subunit A } \\ \text { RCA23_c12880 } & \text { hypothetical protein } \\ \text { RCA23_c12890 } & \text { DedA family protein } \\ \text { RCA23_c12900 } & \text { hypothetical protein } \\ \text { RCA23_c12910 } & \text { putative snoaL-like polyketide cyclase } \\ \text { RCA23_c12920 } & \text { hypothetical protein, DUF1330 } \\ \text { RCA23_c12930 } & \text { hypothetical protein, DUF3303 } \\ \text { RCA23_c12940 } & \text { hypothetical protein, transmembrane } \\ \text { RCA23_c12950 } & \text { hypothetical protein, transmembrane } \\ \text { RCA23_c12960 } & \text { integrase } \\ \text { RCA23_c12970 } & \text { hypothetical protein } \\ \text { RCA23_c12980 } & \text { site-specific recombinase, resolvase family protein } \\ & \end{array}$

$\begin{array}{llrrr} & & \text { Gl 5 } & 0.00 & 0.00 \\ & & \text { Gl 5 } & 0.00 & 0.00 \\ \text { COG0491 } & \text { R } & & 100.00 & 100.00 \\ \text { COG0642 } & \text { T } & & 100.00 & 100.00 \\ & & & 100.00 & 100.00 \\ \text { COG0261 } & \text { J } & & 100.00 & 100.00 \\ \text { COG0211 } & \text { J } & & 100.00 & 100.00 \\ \text { COG1280 } & \text { E } & & 100.00 & 100.00 \\ \text { COG1670 } & \text { J } & & 100.00 & 100.00 \\ \text { COG1670 } & \text { J } & & 100.00 & 100.00 \\ \text { COG0536 } & \text { R } & & 100.00 & 100.00 \\ \text { COG0263 } & \text { E } & & 85.73 & 99.01 \\ \text { COG0014 } & \text { E } & & 80.35 & 88.94 \\ \text { COG5385 } & \text { S } & & 100.00 & 100.00 \\ & & & 100.00 & 100.00 \\ \text { COG3176 } & \text { R } & & 100.00 & 100.00 \\ \text { COG0204 } & \text { I } & & 100.00 & 98.29 \\ \text { COG0352 } & \text { H } & & 100.00 & 92.56 \\ \text { COG0565 } & \text { J } & & 100.00 & 100.00 \\ \text { COG1612 } & \text { O } & & 100.00 & 100.00 \\ \text { COG2317 } & \text { E } & & 100.00 & 97.64 \\ \text { COG0188 } & \text { L } & & 100.00 & 98.76 \\ \text { COG1495 } & \text { O } & & 100.00 & 100.00 \\ \text { COG1238 } & \text { S } & & 100.00 & 100.00 \\ & & \text { Gl 6 } & 100.00 & 98.00 \\ \text { COG3631 } & \text { R } & \text { Gl 6 } & 0.00 & 87.55 \\ \text { COG5470 } & \text { S } & \text { Gl 6 } & 0.00 & 100.00 \\ & & \text { Gl 6 } & 0.00 & 100.00 \\ \text { COG2801 } & \text { L } & \text { Gl 6 } 6 & 100.00 & 0.00 \\ \text { COG1961 } & \text { L } & \text { Gl 6 } & 100.00 & 0.00 \\ & & & 2.13 & 0.00 \\ & & 0.00 & 0.00 \\ & & 0.00 & 0.00\end{array}$




\begin{tabular}{|c|c|}
\hline RCA23_c12990 & hypothetical protein \\
\hline RCA23_c13000 & hypothetical protein \\
\hline RCA23_c13010 & transposase \\
\hline RCA23_c13020 & ribsomal protein S21 \\
\hline RCA23_c13030 & hypothetical protein \\
\hline RCA23_c13040 & integrase \\
\hline RCA23_c13050 & hypothetical protein \\
\hline RCA23_c13060 & putative phage integrase \\
\hline RCA23_c13080 & putative phage integrase \\
\hline RCA23_c13090 & hypothetical protein, GYD domain \\
\hline RCA23_c13100 & hypothetical protein \\
\hline RCA23_c13110 & hypothetical protein \\
\hline RCA23_c13120 & hypothetical protein \\
\hline RCA23_c13130 & integrase \\
\hline RCA23_c13140 & hypothetical protein \\
\hline RCA23_c13150 & hypothetical protein \\
\hline RCA23_c13160 & hypothetical protein \\
\hline RCA23_c13170 & hypothetical protein \\
\hline RCA23_c13180 & hypothetical protein \\
\hline RCA23_c13190 & hypothetical protein \\
\hline RCA23_c13210 & phosphoribosylformylglycinamidine cyclo-ligase PurM \\
\hline RCA23_c13220 & phosphoribosylglycinamide formyltransferase PurN \\
\hline RCA23_c13230 & ribonuclease D \\
\hline RCA23_c13240 & SufE-like protein \\
\hline RCA23_c13250 & hypothetical protein \\
\hline RCA23_c13260 & putative methionine synthase (B12 dependent) subunit 2 \\
\hline RCA23_c13270 & putative methionine synthase (B12 dependent) subunit 1 \\
\hline RCA23_c13280 & phosphoribosylaminoimidazole-succinocarboxamide synthase PurC \\
\hline RCA23_c13290 & phosphoribosylformylglycinamidine (FGAM) synthase PurS \\
\hline RCA23_c13300 & phosphoribosylformylglycinamidine synthase PurQ \\
\hline RCA23_c13310 & C4-dicarboxylate transport sensor protein DctB \\
\hline RCA23_c13320 & C4-dicarboxylate transport transcriptional regulatory protein DctD \\
\hline RCA23_c13330 & ribonuclease $\mathrm{E}$ \\
\hline
\end{tabular}

$\begin{array}{llrrr}\text { COG4731 } & \text { S } & \text { Gl 6 } & 0.00 & 100.00 \\ & & \text { Gl 6 } & 0.00 & 0.00 \\ \text { COG3415 } & \text { L } & \text { Gl 6 } & 0.00 & 0.00 \\ \text { COG0828 } & \text { J } & \text { Gl 6 } & 100.00 & 100.00 \\ & & \text { Gl 6 } & 100.00 & 45.83 \\ \text { COG2801 } & \text { L } & \text { Gl 6 } & 6.48 & 0.00 \\ & & \text { Gl 6 } & 100.00 & 85.99 \\ \text { COG0582 } & \text { L } & \text { Gl 6 } & 100.00 & 100.00 \\ \text { COG0582 } & \text { L } & \text { Gl 6 } & 100.00 & 98.71 \\ \text { COG4274 } & \text { S } & \text { Gl 6 } & 0.00 & 0.00 \\ & & \text { Gl 6 } & 0.00 & 12.95 \\ & & \text { Gl 6 } & 0.00 & 100.00 \\ \text { COG2801 } & \text { L } & \text { Gl 6 } 6 & 73.28 & 65.53 \\ \text { COG5586 } & \text { S } & \text { Gl 6 } & 0.00 & 0.00 \\ & & \text { Gl 6 } & 90.17 & 100.00 \\ & & \text { Gl 6 } & 100.00 & 84.93 \\ \text { COG4274 } & \text { S } & \text { Gl 6 } & 100.00 & 100.00 \\ & & \text { Gl 6 } & 84.67 & 100.00 \\ & & \text { Gl 6 } & 0.00 & 100.00 \\ \text { COG0150 } & \text { F } & & 90.87 & 100.00 \\ \text { COG0299 } & \text { F } & & 100.00 & 100.00 \\ \text { COG0349 } & \text { J } & & 100.00 & 100.00 \\ \text { COG2166 } & \text { R } & & 100.00 & 81.51 \\ & & & 100.00 & 100.00 \\ \text { COG5012 } & \text { R } & & 100.00 & 100.00 \\ \text { COG0646 } & \text { E } & & 100.00 & 100.00 \\ \text { COG0152 } & \text { F } & & 100.00 & 99.77 \\ \text { COG1828 } & \text { F } & & 100.00 & 100.00 \\ \text { COG0047 } & \text { F } & & 100.00 & 100.00 \\ \text { COG4191 } & \text { T } & & 100.00 & 100.00 \\ \text { COG2204 } & \text { T } & & 100.00 & 100.00 \\ \text { COG1530 } & \text { J } & & 100.00 & 99.28\end{array}$


RCA23_c13340

RCA23_c13360

RCA23_c13370

RCA23_c13380

RCA23_c13390

RCA23_c13400 glucosamine--fructose-6-phosphate aminotransferase GImS

RCA23_c13410 bifunctional protein GImU

RCA23_c13420 putative HAD-superfamily hydrolase

RCA23_c13440 MmgE/PrpD family protein

RCA23_c13430 putative pyridoxal-phosphate-dependent aminotransferase

RCA23_c13450 isovaleryl-CoA dehydrogenase

RCA23_c13460 hypothetical protein

RCA23_c13470 methylcrotonoyl-CoA carboxylase beta subunit MccB

RCA23_c13480 hypothetical protein

RCA23_c13490 methylcrotonoyl-CoA carboxylase alpha subunit MccA

RCA23_c13500 hydroxymethylglutaryl-CoA lyase MvaB

RCA23_c13510 putative methylglutaconyl-CoA hydratase

RCA23_c13520 NADH-quinone oxidoreductase subunit A

RCA23_c13530 NADH-quinone oxidoreductase subunit NuoB

RCA23_c13540 hypothetical protein DUF2158

RCA23_c13550 NADH-quinone oxidoreductase subunit C

RCA23_c13560 hypothetical protein

RCA23_c13570 NADH-quinone oxidoreductase subunit D

RCA23_c13580 NADH-quinone oxidoreductase subunit E

RCA23_c13590 hypothetical protein

RCA23_c13600 NADH-quinone oxidoreductase subunit F

RCA23_c13610 hypothetical protein

RCA23_c13620 NADH-quinone oxidoreductase subunit G

RCA23_c13630 hypothetical protein

RCA23_c13640 NADH-quinone oxidoreductase subunit $\mathrm{H}$

RCA23_c13650 NADH-quinone oxidoreductase subunit I

RCA23_c13660 NADH-quinone oxidoreductase subunit J

\begin{tabular}{|c|c|c|c|}
\hline COG0425 & $\mathrm{O}$ & 100.00 & 100.00 \\
\hline \multirow[t]{2}{*}{ COG0785 } & $\mathrm{O}$ & 100.00 & 100.00 \\
\hline & & 100.00 & 100.00 \\
\hline COG2124 & $Q$ & 100.00 & 100.00 \\
\hline COG4912 & $\mathrm{L}$ & 100.00 & 100.00 \\
\hline COG3153 & $\mathrm{R}$ & 100.00 & 100.00 \\
\hline COG0449 & $M$ & 100.00 & 100.00 \\
\hline COG1207 & $M$ & 100.00 & 100.00 \\
\hline COG0546 & $\mathrm{R}$ & 100.00 & 100.00 \\
\hline COG2079 & $\mathrm{R}$ & 100.00 & 99.16 \\
\hline COG0399 & $M$ & 94.55 & 87.12 \\
\hline \multirow[t]{2}{*}{ COG1960 } & I & 100.00 & 92.78 \\
\hline & & 100.00 & 100.00 \\
\hline \multirow[t]{2}{*}{ COG4799 } & 1 & 100.00 & 100.00 \\
\hline & & 100.00 & 94.08 \\
\hline COG4770 & 1 & 100.00 & 98.45 \\
\hline COG0119 & $E$ & 100.00 & 100.00 \\
\hline COG1024 & I & 100.00 & 100.00 \\
\hline COG0838 & $\mathrm{C}$ & 100.00 & 100.00 \\
\hline COG0377 & $\mathrm{C}$ & 100.00 & 100.00 \\
\hline COG5475 & $\mathrm{S}$ & 100.00 & 100.00 \\
\hline \multirow[t]{2}{*}{ COG0852 } & C & 100.00 & 100.00 \\
\hline & & 100.00 & 100.00 \\
\hline COG0649 & $\mathrm{C}$ & 100.00 & 97.94 \\
\hline \multirow[t]{2}{*}{ COG1905 } & $\mathrm{C}$ & 100.00 & 84.88 \\
\hline & & 100.00 & 100.00 \\
\hline \multirow[t]{2}{*}{ COG1894 } & $\mathrm{C}$ & 100.00 & 95.14 \\
\hline & & 100.00 & 96.79 \\
\hline \multirow[t]{2}{*}{ COG1034 } & $\mathrm{C}$ & 100.00 & 98.27 \\
\hline & & 100.00 & 88.76 \\
\hline COG1005 & C & 100.00 & 91.62 \\
\hline COG1143 & C & 100.00 & 100.00 \\
\hline COG0839 & C & 100.00 & 100.00 \\
\hline
\end{tabular}




\begin{tabular}{|c|c|}
\hline RCA23_c13670 & NADH-quinone oxidoreductase subunit $\mathrm{K}$ \\
\hline RCA23_c13680 & NADH-quinone oxidoreductase subunit L \\
\hline RCA23_c13690 & NADH-quinone oxidoreductase subunit M \\
\hline RCA23_c13700 & $\mathrm{NADH}$-quinone oxidoreductase subunit $\mathrm{N}$ \\
\hline RCA23_c13710 & biotin-[acetyl-CoA-carboxylase] ligase \\
\hline RCA23_c13720 & type III pantothenate kinase CoaX \\
\hline RCA23_c13730 & putative ribonuclease \\
\hline RCA23_c13740 & ATP-dependent RNA helicase RhIE \\
\hline RCA23_c13750 & peptide chain release factor 3 \\
\hline RCA23_c13760 & hypothetical protein \\
\hline RCA23_c13770 & putative short chain dehydrogenase \\
\hline RCA23_c13780 & arsenite methyltransferase \\
\hline RCA23_c13790 & $\mathrm{Fe}(3+)$ ions import ATP-binding protein FbpC \\
\hline RCA23_c13800 & putative helix-turn-helix protein \\
\hline RCA23_c13810 & sec-independent protein translocase protein TatA \\
\hline RCA23_c13820 & sec-independent protein translocase protein TatB \\
\hline RCA23_c13830 & sec-independent protein translocase protein TatC \\
\hline RCA23_c13840 & hypothetical protein DUF815 \\
\hline RCA23_c13850 & putative peptidoglycan-binding peptidase \\
\hline RCA23_c13860 & protein-L-isoaspartate O-methyltransferase Pcm \\
\hline RCA23_c13870 & 5'-nucleotidase SurE \\
\hline RCA23_c13880 & putative short chain dehydrogenase \\
\hline RCA23_c13890 & amidophosphoribosyltransferase PurF \\
\hline RCA23_c13900 & putative colicin $\mathrm{V}$ production protein \\
\hline RCA23_c13910 & DNA repair protein RadA \\
\hline RCA23_c13920 & ABC transporter ATP-binding protein \\
\hline RCA23_c13930 & hypothetical protein DUF140 \\
\hline RCA23_c13940 & alanine racemase, biosynthetic \\
\hline RCA23_c13950 & replicative DNA helicase DnaB \\
\hline RCA23_c13960 & orotate phosphoribosyltransferase PyrE \\
\hline RCA23_c13970 & dihydroorotase PyrC \\
\hline RCA23_c13980 & hypothetical protein \\
\hline RCA23_c13990 & hypothetical protein \\
\hline
\end{tabular}

$\begin{array}{llrr}\text { COG0713 } & \text { C } & 100.00 & 100.00 \\ \text { COG1009 } & \text { C } & 100.00 & 100.00 \\ \text { COG1008 } & \text { C } & 100.00 & 100.00 \\ \text { COG1007 } & \text { C } & 100.00 & 100.00 \\ \text { COG0340 } & \text { H } & 100.00 & 100.00 \\ \text { COG1521 } & \text { K } & 100.00 & 100.00 \\ \text { COG0595 } & \text { R } & 100.00 & 100.00 \\ \text { COG0513 } & \text { L } & 100.00 & 95.14 \\ \text { COG4108 } & \text { J } & 100.00 & 93.25 \\ & & 100.00 & 89.10 \\ \text { COG1028 } & \text { I } & 100.00 & 90.77 \\ \text { COG2226 } & \text { H } & 100.00 & 100.00 \\ \text { COG3842 } & \text { E } & 51.16 & 90.44 \\ \text { COG2378 } & \mathrm{K} & 76.75 & 100.00 \\ \text { COG1826 } & \text { U } & 100.00 & 100.00 \\ \text { COG1826 } & \text { U } & 36.47 & 100.00 \\ \text { COG0805 } & \text { U } & 4.94 & 97.98 \\ \text { COG2607 } & \mathrm{R} & 100.00 & 100.00 \\ \text { COG0739 } & \mathrm{M} & 100.00 & 100.00 \\ \text { COG2518 } & \mathrm{O} & 100.00 & 100.00 \\ \text { COG0496 } & \mathrm{R} & 100.00 & 100.00 \\ \text { COG1028 } & \mathrm{I} & 100.00 & 100.00 \\ \text { COG0034 } & \mathrm{F} & 100.00 & 98.57 \\ & & 100.00 & 100.00 \\ \text { COG1066 } & \mathrm{O} & 100.00 & 100.00 \\ \text { COG1127 } & \mathrm{Q} & 100.00 & 100.00 \\ \text { COG0767 } & \mathrm{Q} & 100.00 & 100.00 \\ \text { COG0787 } & \mathrm{M} & 100.00 & 100.00 \\ \text { COG0305 } & \mathrm{L} & 100.00 & 100.00 \\ \text { COG0461 } & \mathrm{F} & 100.00 & 100.00 \\ \text { COG0418 } & \mathrm{F} & 100.00 & 95.58 \\ & & 100.00 & 100.00 \\ & & 100.00 & 63.96\end{array}$


RCA23_c14000 hypothetical protein

RCA23_c14010 malate dehydrogenase Mdh

RCA23_c14020 citrate lyase beta subunit CitE

100.00

RCA23_c14030 putative mesaconyl-CoA hydratase

RCA23_c14040 succinate dehydrogenase cytochrome b556 subunit SdhC

RCA23_c14050 succinate dehydrogenase hydrophobic membrane anchor subunit SdhD

RCA23_c14060 succinate dehydrogenase flavoprotein subunit SdhA

RCA23_c14070 hypothetical protein

RCA23_c14080 succinate dehydrogenase iron-sulfur subunit SdhB

COG0039
COG2301
COG2030
COG2009
COG2142
COG1053
COG0479
COG0813
COG1246
COG0159
COG0012
COG1957
COG1664
COG0501
COG0123
COG3476
COG1961

RCA23_c14090 purine nucleoside phosphorylase deoD-type

RCA23_c14100 acetyltransferase

RCA23_c14110 tryptophan synthase alpha chain TrpA

RCA23_c14120 GTP-dependent nucleic acid-binding protein EngD

RCA23_c14130 Non-specific ribonucleoside hydrolase rihC

RCA23_c14150 hypothetical protein DUF583

RCA23_c14160 protease HtpX

RCA23_c14170 histone deacetylase

RCA23_c14180 peripheral-type benzodiazepine receptor/signal transduction protein TspO

RCA23_c14190 DNA-invertase Hin

RCA23_c14200 hypothetical protein

RCA23_c14210 hypothetical protein

RCA23_c14220 hypothetical protein, RmlC-like cupin family

RCA23_c14230 integrase

RCA23_c14240 hypothetical membrane protein

RCA23_c14260 hypothetical protein

RCA23_c14270 hypothetical protein DUF45

RCA23_c14280 HTH-type transcriptional regulator, GntR family

COG3450

COG4974

RCA23_c14290 dihydrolipoyl dehydrogenase Lpd

RCA23_c14300 dihydrolipoyllysine-residue succinyltransferase component of 2-oxoglutarate (

RCA23_c14310 2-oxoglutarate dehydrogenase E1 component SucA

RCA23_c14320 succinyl-CoA ligase [ADP-forming] alpha subunit SucD

RCA23_c14330 succinyl-CoA ligase [ADP-forming] beta subunit SucC

COG 4530

COG1451

COG1802

COG1249

COG0508

COG0567

COG0074

COG0045

RCA23_c14340 butyryl-CoA dehydrogenase

COG1960

\begin{tabular}{|c|c|c|c|}
\hline & & 100.00 & 87.67 \\
\hline \multicolumn{2}{|l|}{$C$} & 100.00 & 100.00 \\
\hline \multicolumn{2}{|l|}{ G } & 100.00 & 100.00 \\
\hline \multicolumn{2}{|l|}{1} & 100.00 & 100.00 \\
\hline \multicolumn{2}{|l|}{$C$} & 100.00 & 100.00 \\
\hline \multicolumn{2}{|l|}{$C$} & 100.00 & 100.00 \\
\hline \multirow{2}{*}{\multicolumn{2}{|c|}{ C }} & 79.62 & 100.00 \\
\hline & & 100.00 & 100.00 \\
\hline \multicolumn{2}{|l|}{$C$} & 100.00 & 100.00 \\
\hline \multicolumn{2}{|l|}{$\mathrm{F}$} & 100.00 & 91.91 \\
\hline \multicolumn{2}{|l|}{$E$} & 100.00 & 94.56 \\
\hline \multicolumn{2}{|l|}{$E$} & 100.00 & 95.03 \\
\hline \multicolumn{2}{|l|}{$J$} & 84.61 & 100.00 \\
\hline \multicolumn{2}{|l|}{$\mathrm{F}$} & 94.70 & 100.00 \\
\hline M & GI 7 & 100.00 & 61.64 \\
\hline 0 & GI 7 & 100.00 & 82.72 \\
\hline$B$ & GI 7 & 100.00 & 66.45 \\
\hline $\mathrm{T}$ & GI 7 & 100.00 & 48.84 \\
\hline \multirow[t]{3}{*}{ L } & GI 7 & 60.90 & 12.61 \\
\hline & GI 7 & 0.00 & 0.00 \\
\hline & GI 7 & 0.00 & 100.00 \\
\hline $\mathrm{R}$ & GI 7 & 0.00 & 77.25 \\
\hline \multirow[t]{2}{*}{$L$} & GI 7 & 99.30 & 63.65 \\
\hline & GI 7 & 100.00 & 89.26 \\
\hline \multicolumn{2}{|l|}{$S$} & 100.00 & 100.00 \\
\hline \multicolumn{2}{|l|}{$\mathrm{R}$} & 100.00 & 100.00 \\
\hline \multicolumn{2}{|l|}{ K } & 100.00 & 100.00 \\
\hline \multicolumn{2}{|l|}{ C } & 100.00 & 100.00 \\
\hline \multicolumn{2}{|l|}{$C$} & 100.00 & 96.66 \\
\hline \multicolumn{2}{|l|}{$C$} & 88.95 & 100.00 \\
\hline \multicolumn{2}{|l|}{$C$} & 100.00 & 100.00 \\
\hline \multicolumn{2}{|l|}{$C$} & 100.00 & 100.00 \\
\hline \multicolumn{2}{|l|}{1} & 100.00 & 100.00 \\
\hline
\end{tabular}


RCA23_c14350

RCA23_c14360 ferredoxin--NADP reductase Fpr

RCA23_c14370 hypothetical protein

RCA23_c14380 cysH'

RCA23_c14390 cysl/sir: sulfite reductase (ferredoxin)

RCA23_c14400 hypothetical protein

RCA23_c14410 siroheme synthase CysG

RCA23_c14420 HTH-type transcriptional regulator, AsnC family

RCA23_c14450 peptidase

RCA23_c14460 hypothetical protein

RCA23_c14470 4-hydroxy-3-methylbut-2-en-1-yl diphosphate synthase IspG

RCA23_c14480 TPR-repeat containing protein

RCA23_c14490 aspartate aminotransferase

RCA23_c14500 penicillin-binding protein 1A

RCA23_c14510 peptide chain release factor 2

RCA23_c14520 hypothetical protein DUF583

RCA23_c14530 putative peptidase, M23 family

RCA23_c14540 hypothetical protein DUF455

RCA23_c14550 peroxiredoxin Bcp

RCA23_c14560 hypothetical protein

RCA23_c14570 S-adenosylmethionine:tRNA ribosyltransferase-isomerase QueA

RCA23_c14580 MFS-type transporter

RCA23_c14590 hypothetical protein DUF924

RCA23_c14600 dihydrolipoyl dehydrogenase Lpd

RCA23_c14610 uvrABC system protein A

RCA23_c14620 MmgE/PrpD family protein

RCA23_c14630 3-hydroxyisobutyrate dehydrogenase MmsB

RCA23_c14640 3-hydroxyisobutyryl-CoA hydrolase

RCA23_c14650 isobutyryl-CoA dehydrogenase

RCA23_c14660 methylmalonate-semialdehyde dehydrogenase MmsA

RCA23_c14670 putative HTH-type transcriptional regulator, LysR family

RCA23_c14680 phosphopantetheine adenylyltransferase CoaD

RCA23_c14690 glyceraldehyde-3-phosphate dehydrogenase Gap

\begin{tabular}{|c|c|}
\hline COG0290 & \\
\hline COG1018 & \\
\hline COG3749 & \\
\hline COG0175 & \\
\hline COG0155 & \\
\hline COG0007 & \\
\hline COG1522 & \\
\hline COG0624 & \\
\hline COG1426 & \\
\hline COG0821 & \\
\hline COG4783 & \\
\hline COG0436 & \\
\hline COG5009 & \\
\hline COG1186 & \\
\hline COG1664 & \\
\hline COG0739 & \\
\hline COG2833 & \\
\hline COG1225 & \\
\hline COG0809 & \\
\hline COG3803 & \\
\hline COG1249 & \\
\hline COG0178 & \\
\hline COG2079 & \\
\hline COG2084 & \\
\hline COG1024 & \\
\hline COG1960 & \\
\hline COG1012 & \\
\hline COG0583 & \\
\hline COG0669 & \\
\hline COG0057 & \\
\hline
\end{tabular}

100.00

100.00

100.00

100.00

100.00

100.00

100.00

100.00

100.00

100.00

100.00

98.33

100.00

100.00

41.96

0.00

55.06

100.00

100.00

100.00

100.00

100.00

100.00

100.00

100.00

100.00

100.00

100.00

100.00

100.00

100.00

100.00

100.00
100.00

100.00

85.29

100.00

100.00

100.00

100.00

100.00

100.00

100.00

95.06

100.00

89.56

100.00

93.96

100.00

100.00

100.00

100.00

95.00

100.00

100.00

100.00

99.79

99.37

100.00

100.00

100.00

95.32

100.00

100.00

100.00

100.00 
RCA23 c14700

transketolase TktA

RCA23_c14720 hypothetical protein

RCA23_c14730 cell division protein ZapA

RCA23_c14740 putative glutaredoxin

RCA23_c14750 hypothetical protein

RCA23_c14760 hypothetical protein, BolA-like

RCA23_c14770 phosphoribosylformylglycinamidine synthase PurL

RCA23_c14780 HTH-type transcriptional regulator, LysR family

RCA23_c14790 hypothetical protein, pyruvate ferredoxin/flavodoxin oxidoreductase

RCA23_c14800 glutamate racemase Murl

RCA23_c14810 N-acetyl-gamma-glutamyl-phosphate reductase ArgC

RCA23_c14820 cytochrome c-type biogenesis protein CcmE

RCA23_c14830 cytochrome c-type biogenesis protein $\mathrm{CcmF}$

RCA23_c14840 cytochrome c-type biogenesis protein $\mathrm{CcmH}$

RCA23_c14850 putative enoyl-CoA hydratase FadB

RCA23_c14860 hypothetical protein

RCA23_c14870 citrate synthase GltA

RCA23_c14880 glutamyl-tRNA synthase 2

RCA23_c14890 hypothetical protein competence protein E

RCA23_c14900 LexA repressor

RCA23_c14910 molybdopterin biosynthesis protein MoeA

RCA23_c14920 molybdenum cofactor biosynthesis protein MoaC

RCA23_c14930 indole-3-glycerol phosphate synthase TrpC

RCA23_c14940 anthranilate phosphoribosyltransferase TrpD

RCA23_c14950 anthranilate synthase component TrpG

RCA23_c14960 hypothetical protein, divergent polysaccharide deacetylase

RCA23_c14970 hypothetical protein

RCA23_c14990 hypothetical protein

RCA23_c15000 putative L,D-transpeptidase YcbB

RCA23_c15010 UDP-3-O-[3-hydroxymyristoyl] glucosamine N-acyltransferase LpxD

RCA23_c15020 acyl carrier protein

RCA23_c15030 3-oxoacyl-[acyl-carrier-protein] synthase FabF

\begin{tabular}{|c|c|c|c|}
\hline COG0057 & G & 100.00 & 100.00 \\
\hline \multirow[t]{2}{*}{ COG0021 } & G & 95.09 & 95.93 \\
\hline & & 100.00 & 100.00 \\
\hline COG3027 & $S$ & 100.00 & 100.00 \\
\hline \multirow[t]{2}{*}{ COG0278 } & $\mathrm{O}$ & 100.00 & 100.00 \\
\hline & & 100.00 & 100.00 \\
\hline COG0271 & $\mathrm{T}$ & 100.00 & 100.00 \\
\hline COG0046 & $\mathrm{F}$ & 100.00 & 97.42 \\
\hline COG0583 & $\mathrm{K}$ & 100.00 & 100.00 \\
\hline COG4231 & $\mathrm{C}$ & 100.00 & 97.99 \\
\hline COG0796 & $M$ & 100.00 & 100.00 \\
\hline COG0002 & $E$ & 86.88 & 98.93 \\
\hline COG2332 & 0 & 54.53 & 100.00 \\
\hline COG1138 & 0 & 100.00 & 99.59 \\
\hline COG3088 & 0 & 100.00 & 100.00 \\
\hline \multirow[t]{2}{*}{ COG1024 } & I & 100.00 & 100.00 \\
\hline & & 100.00 & 100.00 \\
\hline COG0372 & $\mathrm{C}$ & 100.00 & 94.65 \\
\hline COG0008 & $\mathrm{J}$ & 100.00 & 100.00 \\
\hline COG0658 & $\mathrm{R}$ & 100.00 & 100.00 \\
\hline COG1974 & $\mathrm{K}$ & 100.00 & 100.00 \\
\hline COG0303 & $\mathrm{H}$ & 100.00 & 95.24 \\
\hline COG0315 & $\mathrm{H}$ & 100.00 & 100.00 \\
\hline COG0134 & $E$ & 100.00 & 100.00 \\
\hline COG0547 & $E$ & 100.00 & 91.67 \\
\hline \multirow[t]{3}{*}{ COG0512 } & $E$ & 100.00 & 99.48 \\
\hline & & 100.00 & 100.00 \\
\hline & & 100.00 & 100.00 \\
\hline COG3108 & $S$ & 100.00 & 100.00 \\
\hline COG2989 & $S$ & 100.00 & 100.00 \\
\hline COG1044 & $M$ & 100.00 & 100.00 \\
\hline COG0236 & I & 100.00 & 100.00 \\
\hline COG0304 & 1 & 100.00 & 100.00 \\
\hline
\end{tabular}


RCA23_c15040

RCA23_c15050

RCA23_c15060

RCA23_c15070

RCA23_c15080

RCA23_c15090

RCA23_c15100

RCA23_c15110

RCA23_c15120

RCA23_c15130

RCA23_c15140

RCA23_c15150

RCA23_c15160

RCA23_c15170

RCA23_c15180

RCA23_c15190

RCA23_c15200

RCA23_c15210

RCA23_c15220

RCA23_c15230

RCA23_c15240

RCA23_c15250

RCA23_c15260

RCA23_c15270

RCA23_c15280

RCA23_c15300 hypothetical protein

RCA23_c15310 cell cycle transcriptional regulator

RCA23_c15320 DNA ligase LigA

RCA23_c15330 ATP-dependent DNA helicase RecG

RCA23_c15340 hypothetical protein

RCA23_c15350 hypothetical protein

RCA23_c15360 phosphoribosyl-AMP cyclohydrolase Hisl

\begin{tabular}{|c|c|}
\hline COG5342 & \\
\hline COG4536 & \\
\hline COG4974 & \\
\hline COG0703 & \\
\hline COG0337 & \\
\hline COG0629 & \\
\hline COG0444 & \\
\hline COG1173 & \\
\hline COG0601 & \\
\hline COG0747 & \\
\hline COG0324 & \\
\hline COG0528 & \\
\hline COG0233 & \\
\hline COG0020 & \\
\hline COG0575 & \\
\hline COG0743 & \\
\hline COG0750 & \\
\hline COG4775 & \\
\hline COG0764 & \\
\hline COG1043 & \\
\hline COG3494 & \\
\hline COG0763 & \\
\hline COG0482 & \\
\hline COG0745 & \\
\hline COG0272 & \\
\hline COG1200 & \\
\hline COG0822 & \\
\hline COG0139 & \\
\hline
\end{tabular}

100.00

100.00

$90.76 \quad 96.61$

$100.00 \quad 100.00$

$100.00 \quad 100.00$

$100.00 \quad 100.00$

$100.00 \quad 100.00$

$100.00 \quad 100.00$

$100.00 \quad 100.00$

$100.00 \quad 98.51$

$100.00 \quad 94.69$

$100.00 \quad 100.00$

$60.90 \quad 100.00$

$74.97 \quad 100.00$

$100.00 \quad 100.00$

$100.00 \quad 100.00$

$100.00 \quad 100.00$

$100.00 \quad 100.00$

$100.00 \quad 98.71$

$100.00 \quad 100.00$

$100.00 \quad 92.25$

$70.97 \quad 100.00$

$0.00 \quad 100.00$

$83.33 \quad 100.00$

$100.00 \quad 94.03$

$100.00 \quad 100.00$

$85.49 \quad 99.56$

$100.00 \quad 92.98$

$77.73 \quad 100.00$

$100.00 \quad 89.77$

$98.76 \quad 100.00$

$100.00 \quad 100.00$

$100.00 \quad 100.00$

$100.00 \quad 100.00$ 


\begin{tabular}{|c|c|c|c|}
\hline COG0008 & $J$ & 86.90 & 100.00 \\
\hline COG4976 & $\mathrm{R}$ & 100.00 & 100.00 \\
\hline COG1206 & $J$ & 100.00 & 96.56 \\
\hline COG1024 & I & 100.00 & 94.04 \\
\hline COG2050 & $Q$ & 69.98 & 100.00 \\
\hline COG0102 & $\mathrm{J}$ & 0.00 & 100.00 \\
\hline \multirow[t]{2}{*}{ COG0103 } & $J$ & 0.00 & 100.00 \\
\hline & & 0.00 & 64.64 \\
\hline COG2303 & $E$ & 100.00 & 89.43 \\
\hline COG4662 & $\mathrm{H}$ & 100.00 & 100.00 \\
\hline COG1131 & V & 100.00 & 100.00 \\
\hline COG2998 & $\mathrm{H}$ & 100.00 & 100.00 \\
\hline COG1238 & $\mathrm{S}$ & 100.00 & 100.00 \\
\hline COG2962 & $\mathrm{R}$ & 100.00 & 100.00 \\
\hline COG2068 & $\mathrm{R}$ & 100.00 & 94.33 \\
\hline COG0404 & $E$ & 100.00 & 95.19 \\
\hline COG0404 & $E$ & 100.00 & 98.03 \\
\hline COG1028 & 1 & 100.00 & 100.00 \\
\hline COG3788 & $\mathrm{R}$ & 100.00 & 100.00 \\
\hline COG1309 & $\mathrm{K}$ & 100.00 & 100.00 \\
\hline \multirow[t]{2}{*}{ COG1897 } & $E$ & 100.00 & 100.00 \\
\hline & & 100.00 & 100.00 \\
\hline COG2510 & $S$ & 60.07 & 100.00 \\
\hline COG1670 & $J$ & 100.00 & 84.62 \\
\hline COG0519 & $\mathrm{F}$ & 100.00 & 100.00 \\
\hline \multirow[t]{2}{*}{ COG5598 } & $\mathrm{H}$ & 100.00 & 100.00 \\
\hline & & 100.00 & 100.00 \\
\hline \multirow[t]{2}{*}{ COG0320 } & $\mathrm{H}$ & 100.00 & 100.00 \\
\hline & & 100.00 & 100.00 \\
\hline COG0634 & $\mathrm{F}$ & 100.00 & 100.00 \\
\hline COG2867 & I & 100.00 & 100.00 \\
\hline COG0004 & $P$ & 100.00 & 100.00 \\
\hline COG1546 & $\mathrm{R}$ & 100.00 & 100.00 \\
\hline
\end{tabular}


RCA23_c15710 phosphatidylglycerophosphatase A

\begin{tabular}{|c|c|}
\hline COG1267 & \\
\hline COG0245 & \\
\hline COG0042 & \\
\hline COG3852 & \\
\hline COG2204 & \\
\hline COG5000 & \\
\hline COG2204 & \\
\hline COG0569 & \\
\hline COG0168 & \\
\hline COG1923 & \\
\hline COG2262 & \\
\hline COG2366 & \\
\hline COG2930 & \\
\hline COG0113 & \\
\hline COG1197 & \\
\hline COG2761 & \\
\hline COG0318 & \\
\hline COG1396 & \\
\hline COG0580 & \\
\hline COG4166 & \\
\hline COG1279 & \\
\hline COG2928 & \\
\hline COG2313 & \\
\hline COG0524 & \\
\hline COG1278 & \\
\hline COG0052 & \\
\hline COG0264 & \\
\hline COG1670 & \\
\hline COG0663 & \\
\hline COG0194 & \\
\hline
\end{tabular}

\begin{tabular}{rr}
100.00 & 100.00 \\
100.00 & 97.73 \\
100.00 & 95.22 \\
100.00 & 100.00 \\
100.00 & 100.00 \\
100.00 & 97.57 \\
100.00 & 100.00 \\
100.00 & 96.80 \\
100.00 & 99.73 \\
100.00 & 100.00 \\
100.00 & 100.00 \\
100.00 & 96.81 \\
100.00 & 93.91 \\
100.00 & 91.89 \\
100.00 & 100.00 \\
100.00 & 98.08 \\
100.00 & 66.67 \\
100.00 & 94.05 \\
100.00 & 100.00 \\
100.00 & 100.00 \\
100.00 & 100.00 \\
100.00 & 100.00 \\
100.00 & 99.43 \\
100.00 & 100.00 \\
100.00 & 100.00 \\
100.00 & 100.00 \\
100.00 & 100.00 \\
79.68 & 100.00 \\
95.07 & 79.32 \\
100.00 & 48.43 \\
\hline 59.81 & 73.52 \\
0.00 & 100.00 \\
91.12 & 83.02 \\
& \\
\hline
\end{tabular}


$\begin{array}{ll}\text { RCA23_c16040 } & \text { hypothetical protein, YicC-like } \\ \text { RCA23_c16050 } & \text { hypothetical protein, DUF1457 }\end{array}$

RCA23_c16060 phospho-2-dehydro-3-deoxyheptonate aldolase

RCA23_c16070 putative HTH-type transcriptional regulator, AraC family

RCA23_c16080 putative amino-acid binding protein

RCA23_c16090 putative branched-chain amino acid transport ATP-binding protein

RCA23_c16100 putative branched-chain amino acid transport ATP-binding protein

RCA23_c16110 putative branched-chain amino acid transport system permease protein

RCA23_c16120 putative branched-chain amino acid transport system permease protein

RCA23_c16130 GTP-binding protein TypA

RCA23_c16140 hypothetical protein DUF1330

RCA23_c16150 alanyl-tRNA synthase AlaS

RCA23_c16160 protein RecA

RCA23_c16170 hypothetical protein

RCA23_c16180 sensor transduction histidine kianse

RCA23_c16190 hypothetical protein

RCA23_c16200 hypothetical protein, NOL1/NOP2/sun family

RCA23_c16210 inosine-5'-monophosphate dehydrogenase GuaB

RCA23_c16220 hypothetical protein

RCA23_c16240 cysteine desulfurase SufS

RCA23_c16250 hypothetical protein

RCA23_c16260 hypothetical protein

RCA23_c16270 FeS assembly protein SufD

RCA23_c16280 FeS assembly ATPase SufC

RCA23_c16290 FeS assembly protein SufB

RCA23_c16300 putative cysteine desulfurase

RCA23_c16310 HTH-type transcriptional regulator Rrf2

RCA23_c16320 hypothetical protein

RCA23_c16330 putative oxidoreductase

RCA23_c16340 inosose dehydratase lolE

RCA23_c16350 putative oxidoreductase

RCA23_c16360 HTH-type transcriptional repressor, Lacl family

RCA23 c16370 hypothetical protein

\begin{tabular}{|c|c|c|c|}
\hline COG1561 & $S$ & 100.00 & 100.00 \\
\hline COG5388 & $S$ & 100.00 & 97.93 \\
\hline COG3200 & $E$ & 100.00 & 98.91 \\
\hline COG4977 & $\mathrm{K}$ & 100.00 & 98.52 \\
\hline COG0683 & $E$ & 100.00 & 80.88 \\
\hline COG0411 & $E$ & 84.49 & 93.46 \\
\hline COG0410 & $E$ & 100.00 & 79.13 \\
\hline COG0559 & $E$ & 100.00 & 82.35 \\
\hline COG4177 & $E$ & 100.00 & 97.53 \\
\hline COG1217 & $\mathrm{T}$ & 91.58 & 100.00 \\
\hline COG5470 & $S$ & 100.00 & 65.29 \\
\hline COG0013 & $\mathrm{J}$ & 77.92 & 100.00 \\
\hline \multirow[t]{2}{*}{ COG0468 } & $\mathrm{L}$ & 100.00 & 91.02 \\
\hline & & 100.00 & 100.00 \\
\hline \multirow[t]{2}{*}{ COG0642 } & $\mathrm{T}$ & 71.23 & 100.00 \\
\hline & & 40.23 & 92.64 \\
\hline COG0144 & $\mathrm{J}$ & 100.00 & 89.03 \\
\hline COG0516 & $\mathrm{F}$ & 100.00 & 100.00 \\
\hline COG3894 & $\mathrm{R}$ & 100.00 & 92.60 \\
\hline \multirow[t]{3}{*}{ COG0520 } & $\mathrm{E}$ & 100.00 & 100.00 \\
\hline & & 100.00 & 100.00 \\
\hline & & 100.00 & 95.60 \\
\hline COG0719 & $\mathrm{O}$ & 100.00 & 100.00 \\
\hline COG0396 & $\mathrm{O}$ & 100.00 & 100.00 \\
\hline COG0719 & $\mathrm{O}$ & 59.19 & 100.00 \\
\hline COG1104 & $E$ & 100.00 & 100.00 \\
\hline COG1959 & $\mathrm{K}$ & 100.00 & 100.00 \\
\hline COG2945 & $\mathrm{R}$ & 100.00 & 100.00 \\
\hline COG0673 & $\mathrm{R}$ & 100.00 & 100.00 \\
\hline COG1082 & G & 100.00 & 100.00 \\
\hline COG0673 & $\mathrm{R}$ & 100.00 & 100.00 \\
\hline \multirow[t]{2}{*}{ COG1609 } & $\mathrm{K}$ & 100.00 & 100.00 \\
\hline & & 100.00 & 100.00 \\
\hline
\end{tabular}


RCA23_c16380

RCA23_c16390

RCA23_c16400

RCA23_c16410

RCA23_c16420

RCA23_c16430

RCA23_c16440

RCA23_c16450

RCA23_c16460

RCA23_c16470

RCA23_c16480

RCA23_c16490

RCA23_c16500

RCA23_c16510

RCA23_c16520

RCA23_c16540

RCA23_c16550

RCA23_c16560

RCA23_c16570

RCA23_c16580

RCA23_c16590

RCA23_c16600

RCA23_c16610

RCA23_c16620

RCA23_c16630

RCA23_c16640

RCA23_c16650

RCA23_c16660

RCA23_c16670

RCA23_c16680

RCA23_c16690

RCA23_c16700 sugar (ribose) ABC-transport system ATP binding protein

sugar (ribose) $A B C$ transporter permease protein

sugar (ribose) $A B C$ transporter periplasmic binding protein

beta-glucosidase BgIA

maltose/maltodextrin import ATP-binding protein MalK

putative alpha-glucosidase AgIA

alpha-glucoside transport system permease protein AglG

$A B C$ transporter, membrane spanning protein

alpha-glucoside transport system permease protein AgIF

alpha-glucosides-binding periplasmic protein AgIE

HTH-type transcriptional regulator

oxidoreductase

alkanesulfonate monooxygenase SsuD

putative regulatory DNA binding protein

putative oxidoreductase

glucose-6-phosphate isomerase Pgi

6-phosphogluconolactonase $\mathrm{Pgl}$

\section{glucose-6-phosphate 1-dehydrogenase Zwf}

hypothetical protein, radical SAM

putative 5-methylcytosine-specific restriction enzyme McrA

putative phospholipase/carboxylesterase

HhH-GPD superfamily base excision DNA repair protein

precorrin-6A reductase CobK

cobalamin (vitamin B12) biosynthesis CbiDprotein CbiD

uroporphyrinogen-III C-methyltransferase CobA

cobyrinic acid A,C-diamide synthase CobB

putative major facilitator superfamily transporter

hypothetical protein

cysteinyl-tRNA synthase CysS

aspartate aminotransferase AspC

trimethylamine methyltransferase MttB

$A B C$ transporter ATP-binding protein Uup

hypothetical protein

\begin{tabular}{|c|c|}
\hline COG1129 & \\
\hline COG1172 & \\
\hline COG1879 & \\
\hline COG 2723 & \\
\hline COG3839 & \\
\hline COG0366 & \\
\hline COG0395 & \\
\hline COG0395 & \\
\hline COG1175 & \\
\hline COG1653 & \\
\hline COG1609 & \\
\hline COG4989 & \\
\hline COG2141 & \\
\hline COG2188 & \\
\hline COG0673 & \\
\hline COG0166 & \\
\hline COG0363 & \\
\hline COG0364 & \\
\hline COG0535 & \\
\hline COG1403 & \\
\hline COG0400 & \\
\hline COG0122 & \\
\hline COG2099 & \\
\hline COG1903 & \\
\hline COG0007 & \\
\hline COG1797 & \\
\hline COG1562 & \\
\hline COG0215 & \\
\hline COG0436 & \\
\hline COG5598 & \\
\hline COG0488 & \\
\hline COG3176 & \\
\hline
\end{tabular}

100.00

100.00

100.00

100.00

100.00

100.00

100.00

100.00

100.00

100.00

100.00

100.00

100.00

100.00

100.00

100.00

100.00

74.66

100.00

100.00

94.37

98.24

100.00

100.00

100.00

100.00

100.00

100.00

100.00

100.00

100.00

97.63

100.00
100.00

99.35

100.00

84.77

100.00

100.00

100.00

100.00

96.57

98.21

100.00

100.00

87.13

94.56

100.00

100.00

100.00

88.29

100.00

100.00

98.52

100.00

97.68

49.41

100.00

100.00

95.59

100.00

100.00

100.00

100.00

100.00

85.60 
RCA23_c16810 hypothetical protein, segregation and condensation protein A

RCA23_c16970 hypothetical protein

RCA23_c16980 glutamate-ammonia-ligase adenylyltransferase GInE

COG1391

RCA23_c16990 hypothetical protein

COG2606

RCA23_c17000 hypothetical protein

RCA23_c17010 hypothetical protein

RCA23_c17020 hypothetical protein

RCA23_c17030 putative aromatic-ring-hydroxylating dioxygenase

RCA23_c17040 putative acetolactate synthase small subunit IlvH 
RCA23 c17050

RCA23_c17060

RCA23_c17070

RCA23 c17080

RCA23 c17090

RCA23_c17100

RCA23 c17110

RCA23_c17120

RCA23_c17140

RCA23_c17150

RCA23_c17160

RCA23_c17170

RCA23_c17180

RCA23_c17190

RCA23 c17200

RCA23_c17210

RCA23 c17220

RCA23_c17230

RCA23_c17240

RCA23_c17250

RCA23_c17260

RCA23_c17270

RCA23 c17280

RCA23_c17290

RCA23_c17300

RCA23_c17310

RCA23_c17320

RCA23_c17330

RCA23_c17340

RCA23_c17350

RCA23_c17360

RCA23_c17370

RCA23 c17380 cetolactate synthase isozyme large subunit Ilv

hypothetical membrane protein, porin-like

TRAP dicarboxylate transporter, subunit DctP

TRAP dicarboxylate transporter, subunit DctQ

TRAP dicarboxylate transporter, subunit DctM

putative arginyl-tRNA--protein transferase Ate

vitamin B12-dependent ribonucleotide reductase $\mathrm{Nrd}$ J

hypothetical protein

hypothetical protein DUF192

cold shock protein

pyridoxine/pyridoxamine 5'-phosphate oxidase PdxH

enoyl-[acyl-carrier-protein] reductase Fabl

xanthine phosphoribosyltransferase Gpt

pyrimidine-specific ribonucleoside hydrolase RihA

hypothetical protein UPF0061

putative sodium/hydrogen exchanger

ferric uptake regulator protein Fur

putative S-adenosylmethionine uptake transporter

enolase Eno

anhydro-N-acetylmuramic acid kinase AnmK

tyrosyl-tRNA synthase TyrS

aspartate aminotransferase AspC

hypothetical protein

anthranilate synthase component TrpE

protein soxG

protein soxH

-aminolevulinate synthase HemA

sulfide dehydrogenase flavoprotein chain SoxF

domain of unknown function DUF1791

sulfite oxidase cytochrome subunit SoxD

sulfite oxidase molybdopterin subunit SoxC

sulfur oxidation protein SoxB

diheme cytochrome $\mathrm{c}$

\begin{tabular}{|c|c|}
\hline COG0028 & \\
\hline COG4663 & \\
\hline COG4665 & \\
\hline COG4664 & \\
\hline COG2935 & \\
\hline COG0209 & \\
\hline COG1430 & \\
\hline COG1278 & \\
\hline COG0259 & \\
\hline COG0623 & \\
\hline COG0503 & \\
\hline COG1957 & \\
\hline COG0397 & \\
\hline COG0025 & \\
\hline COG0735 & \\
\hline COG0697 & \\
\hline COG0148 & \\
\hline COG2377 & \\
\hline COG0162 & \\
\hline COG0436 & \\
\hline COG0760 & \\
\hline COG0147 & \\
\hline COG0491 & \\
\hline COG0491 & \\
\hline COG0156 & \\
\hline COG3439 & \\
\hline COG1416 & \\
\hline COG3474 & \\
\hline COG2041 & \\
\hline COG0737 & \\
\hline COG3258 & \\
\hline
\end{tabular}

100.00

100.00

100.00

100.00

100.00

100.00

95.29

100.00

100.00

100.00

100.00

100.00

100.00

100.00

100.00

100.00

100.00

100.00

100.00

100.00

100.00

100.00

100.00

100.00

100.00

100.00

100.00

100.00

100.00

100.00

100.00

100.00

100.00
92.98

100.00

94.50

84.97

100.00

97.45

97.51

100.00

100.00

100.00

100.00

99.11

100.00

88.35

100.00

100.00

100.00

94.63

100.00

100.00

100.00

95.63

99.35

99.74

100.00

96.72

72.73

100.00

100.00

100.00

100.00

82.16

100.00 


$\begin{array}{ll}\text { RCA23_c17390 } & \text { protein SoxZ } \\ \text { RCA23_c17400 } & \text { protein SoxY } \\ \text { RCA23_c17410 } & \text { cytochrome c } \\ \text { RCA23_c17420 } & \text { thioredoxin SoxW } \\ \text { RCA23_c17430 } & \text { cytochrome c-type biogenesis protein SoxV } \\ \text { RCA23_c17440 } & \text { protein SoxS } \\ \text { RCA23_c17450 } & \text { HTH-type transcriptional regulator, ArsR family } \\ \text { RCA23_c17460 } & \text { putative soxT, transmembrane protein DUF395 } \\ \text { RCA23_c17470 } & \text { hypothetical protein DUF395 } \\ \text { RCA23_c17480 } & \text { NAD-binding protein } \\ \text { RCA23_c17490 } & \text { glyoxylate reductase GyaR } \\ \text { RCA23_c17500 } & \text { glutamyl-tRNA(Gln) amidotransferase subunit A } \\ \text { RCA23_c17510 } & \text { TRAP dicarboxylate transporter, subunit DctM } \\ \text { RCA23_c17520 } & \text { TRAP dicarboxylate transporter, subunit DctQ } \\ \text { RCA23_c17530 } & \text { TRAP dicarboxylate transporter, subunit DctP } \\ \text { RCA23_c17540 } & \text { hypothetical protein } \\ \text { RCA23_c17550 } & \text { glycerol kinase GlpK } \\ \text { RCA23_c17560 } & \text { ribosomal RNA large subunit methyltransferase J } \\ \text { RCA23_c17570 } & \text { putative Ppx/GppA phosphatase family protein } \\ \text { RCA23_c17580 } & \text { hypothetical protein } \\ \text { RCA23_c17590 } & \text { hypothetical protein } \\ \text { RCA23_c17600 } & \text { pterin domain containing enzyme } \\ \text { RCA23_c17610 } & \text { HpcH/Hpal aldolase family protein } \\ \text { RCA23_c17620 } & \text { glucokinase Glk } \\ \text { RCA23_c17630 } & \text { hypothetical protein DUF1006 } \\ \text { RCA23_c17640 } & \text { reductive dehalogenase } \\ \text { RCA23_c17650 } & \text { hypothetical protein, XdhC and Coxl } \\ \text { RCA23_c17660 } & \text { 2-hydroxy-3-oxopropionate reductase GlxR } \\ \text { RCA23_c17670 } & \text { 3-hydroxybutyrate dehydrogenase } \\ \text { RCA23_c17680 } & \text { dihydroxy-acid dehydratase IlvD } \\ \text { RCA23_c17690 } & \text { fumarylacetoacetate hydrolase } \\ \text { RCA23_c17700 } & \text { hypothetical protein } \\ \text { RCA23_c17710 } & \text { nucleoside diphosphate kinase Ndk }\end{array}$

$\begin{array}{llrr} & & 100.00 & 89.09 \\ \text { COG5501 } & \text { S } & 100.00 & 81.32 \\ \text { COG2010 } & \text { C } & 100.00 & 64.22 \\ \text { COG2143 } & \text { O } & 100.00 & 71.86 \\ \text { COG0785 } & \text { O } & 100.00 & 100.00 \\ & & 100.00 & 100.00 \\ \text { COG0640 } & \text { K } & 100.00 & 100.00 \\ \text { COG2391 } & \text { R } & 100.00 & 100.00 \\ \text { COG2391 } & \text { R } & 100.00 & 100.00 \\ \text { COG2084 } & \text { I } & 100.00 & 100.00 \\ \text { COG1052 } & \text { C } & 100.00 & 96.82 \\ \text { COG0154 } & \text { J } & 100.00 & 99.25 \\ \text { COG4664 } & \text { Q } & 100.00 & 96.38 \\ \text { COG4665 } & \text { Q } & 100.00 & 100.00 \\ \text { COG4663 } & \text { Q } & 100.00 & 100.00 \\ & & 100.00 & 100.00 \\ \text { COG0554 } & \text { C } & 100.00 & 100.00 \\ \text { COG0293 } & \text { J } & 100.00 & 100.00 \\ \text { COG0248 } & \text { F } & 100.00 & 99.73 \\ & & 100.00 & 100.00 \\ \text { COG0685 } & \text { E } & 100.00 & 100.00 \\ \text { COG1410 } & \text { E } & 100.00 & 97.75 \\ \text { COG3836 } & \text { G } & 100.00 & 100.00 \\ \text { COG0837 } & \text { G } & 100.00 & 100.00 \\ \text { COG3214 } & \text { S } & 100.00 & 100.00 \\ \text { COG1018 } & \text { C } & 100.00 & 95.60 \\ \text { COG1975 } & \text { O } & 100.00 & 100.00 \\ \text { COG2084 } & \text { I } & 100.00 & 90.68 \\ \text { COG1028 } & \text { I } & 100.00 & 97.71 \\ \text { COG0129 } & \text { E } & 100.00 & 99.22 \\ \text { COG0179 } & \text { Q } & 100.00 & 100.00 \\ \text { COG0105 } & \text { F } & 100.00 & 100.00 \\ & & 100.00 & 100.00\end{array}$




$\begin{array}{ll}\text { RCA23_c17720 } & \text { hypothetical protein } \\ \text { RCA23_c17730 } & \text { ABC transporter ATP-binding protein } \\ \text { RCA23_c17740 } & \text { MarC family integral membrane protein } \\ \text { RCA23_c17750 } & \text { hypothetical protein } \\ \text { RCA23_c17760 } & \text { putative DNA polymerase III chi subunit, HolC } \\ \text { RCA23_c17770 } & \text { cytosol aminopeptidase PepA } \\ \text { RCA23_c17780 } & \text { puative permease, YjgP/YjgQ family } \\ \text { RCA23_c17790 } & \text { puative permease, YjgP/YjgQ family } \\ \text { RCA23_c17800 } & \text { putative organic solvent tolerance protein } \\ \text { RCA23_c17810 } & \text { hypothetical protein, SurA } \\ \text { RCA23_c17820 } & \text { 4-hydroxythreonine-4-phosphate dehydrogenase PdxA } \\ \text { RCA23_c17830 } & \text { dimethyladenosine transferase KsgA } \\ \text { RCA23_c17840 } & \text { hypothetical protein } \\ \text { RCA23_c17850 } & \text { modification methylase, hemK family } \\ \text { RCA23_c17860 } & \text { peptide chain release factor 1 } \\ \text { RCA23_c17870 } & \text { hypothetical protein } \\ \text { RCA23_c17880 } & \text { agmatinase SpeB } \\ \text { RCA23_c17890 } & \text { alpha/beta hydrolase } \\ \text { RCA23_c17900 } & \text { agmatinase SpeB } \\ \text { RCA23_c17910 } & \text { hippurate hydrolase HipO } \\ \text { RCA23_c17920 } & \text { protein MazG } \\ \text { RCA23_c17930 } & \text { ABC transporter periplasmic iron-binding protein FutA } \\ \text { RCA23_c17940 } & \text { putative peptidyl-prolyl cis-trans isomerase Ppi } \\ \text { RCA23_c17950 } & \text { putative peptidyl-prolyl cis-trans isomerase Ppi } \\ \text { RCA23_c17960 } & \text { phosphoglycerate kinase Pgk } \\ \text { RCA23_c17970 } & \text { fructose-bisphosphate aldolase class 1 } \\ \text { RCA23_c17980 } & \text { hypothetical protein, septum formation initiator } \\ \text { RCA23_c17990 } & \text { pyruvate dehydrogenase E1 component alpha subunit PdhA } \\ \text { RCA23_c18000 } & \text { pyruvate dehydrogenase E1 component beta subunit PdhB } \\ \text { RCA23_c18010 } & \text { dihydrolipoyllysine-residue acetyltransferase PdhC } \\ \text { RCA23_c18020 } & \text { serine acetyltransferase CysE } \\ \text { RCA23_c18030 } & \text { putative gene transfer agent protein } \\ \text { RCA23_c18040 } & \text { putative gene transfer agent large terminase part 1 } \\ & \end{array}$

\begin{tabular}{|c|c|c|c|}
\hline & & & \\
\hline COG0488 & $\mathrm{R}$ & 100.00 & 96.25 \\
\hline COG2095 & U & 100.00 & 100.00 \\
\hline COG3577 & $\mathrm{R}$ & 100.00 & 92.48 \\
\hline COG2927 & $\mathrm{L}$ & 100.00 & 100.00 \\
\hline COG0260 & $E$ & 100.00 & 100.00 \\
\hline COG0795 & $\mathrm{R}$ & 100.00 & 100.00 \\
\hline COG0795 & $\mathrm{R}$ & 100.00 & 100.00 \\
\hline COG1452 & $M$ & 91.88 & 100.00 \\
\hline COG0760 & $\mathrm{O}$ & 100.00 & 92.83 \\
\hline COG1995 & $\mathrm{H}$ & 100.00 & 100.00 \\
\hline COG0030 & J & 100.00 & 100.00 \\
\hline & & 100.00 & 100.00 \\
\hline COG2890 & $J$ & 100.00 & 100.00 \\
\hline COG0216 & $\mathrm{J}$ & 100.00 & 100.00 \\
\hline COG4446 & $S$ & 100.00 & 100.00 \\
\hline COG0010 & $\mathrm{E}$ & 100.00 & 100.00 \\
\hline & & 100.00 & 86.08 \\
\hline COG0010 & $\mathrm{E}$ & 100.00 & 100.00 \\
\hline COG1473 & $\mathrm{R}$ & 100.00 & 100.00 \\
\hline COG3956 & $\mathrm{R}$ & 100.00 & 96.06 \\
\hline COG1840 & $P$ & 93.77 & 95.75 \\
\hline COG0652 & 0 & 100.00 & 78.69 \\
\hline COG0652 & $\mathrm{O}$ & 100.00 & 100.00 \\
\hline COG0126 & G & 100.00 & 100.00 \\
\hline COG3588 & G & 100.00 & 100.00 \\
\hline COG2919 & $D$ & 100.00 & 100.00 \\
\hline COG1071 & $\mathrm{C}$ & 100.00 & 100.00 \\
\hline COG0022 & $\mathrm{C}$ & 100.00 & 100.00 \\
\hline COG0508 & $\mathrm{C}$ & 100.00 & 100.00 \\
\hline COG1045 & $E$ & 100.00 & 97.37 \\
\hline & & 50.04 & 58.62 \\
\hline COG5323 & $\mathrm{S}$ & 10.00 & 3.73 \\
\hline
\end{tabular}




$\begin{array}{ll}\text { RCA23_c18050 } & \text { putative gene transfer agent large terminase part } 2 \\ \text { RCA23_c18060 } & \text { aminodeoxychorismate lyase } \\ \text { RCA23_c18070 } & \text { 3-oxoacyl-[acyl-carrier-protein] synthase FabF } \\ \text { RCA23_c18080 } & \text { acyl carrier protein AcpP } \\ \text { RCA23_c18090 } & \text { 3-oxoacyl-[acyl-carrier-protein] reductase FabG } \\ \text { RCA23_c18100 } & \text { malonyl CoA-acyl carrier protein transacylase } \\ \text { RCA23_c18110 } & \text { 30S ribosomal protein S6 } \\ \text { RCA23_c18120 } & \text { 30S ribosomal protein S18 } \\ \text { RCA23_c18130 } & \text { 50S ribosomal protein L9 } \\ \text { RCA23_c18140 } & \text { trigger factor (TF) } \\ \text { RCA23_c18160 } & \text { nitrogen regulatory protein P-II 1 } \\ \text { RCA23_c18170 } & \text { glutamine synthase GlnA type I } \\ \text { RCA23_c18190 } & \text { hypothetical protein } \\ \text { RCA23_c18180 } & \text { dimethylpropiothetin dethiomethylase DddP } \\ \text { RCA23_c18200 } & \text { Biotin transporter BioY } \\ \text { RCA23_c18210 } & \text { hypothetical protein } \\ \text { RCA23_c18220 } & \text { adenylosuccinate lyase PurB } \\ \text { RCA23_c18230 } & \text { putative nitrile hydratase, beta subunit } \\ \text { RCA23_c18240 } & \text { hypothetical protein } \\ \text { RCA23_c18250 } & \text { nitrile hydratase alpha subunit NthA } \\ \text { RCA23_c18260 } & \text { hypothetical protein DUF6 transmembrane } \\ \text { RCA23_c18270 } & \text { putative lipid A biosynthesis lauroyl acyltransferase } \\ \text { RCA23_c18280 } & \text { hypothetical protein } \\ \text { RCA23_c18290 } & \text { aconitate hydratase AcnA } \\ \text { RCA23_c18300 } & \text { cytochrome c biogenesis protein CcmG } \\ \text { RCA23_c18310 } & \text { cytochrome c-type biogenesis protein CcmC } \\ \text { RCA23_c18320 } & \text { cytochrome c-type biogenesis protein CcmB } \\ \text { RCA23_c18330 } & \text { cytochrome c biogenesis ATP-binding export protein CcmA } \\ \text { RCA23_c18340 } & \text { hypothetical protein } \\ \text { hCA23_c18350 } & \text { protein export membrane protein SecF } \\ \text { pC18360 } & \text { protein export membrane protein SecD } \\ \text { putative immunogenic membrane protein YajC } \\ \text { seryl-tRNA synthase SerS }\end{array}$

$\begin{array}{llrr}\text { COG5323 } & \text { S } & 100.00 & 71.38 \\ \text { COG1559 } & \text { R } & 100.00 & 100.00 \\ \text { COG0304 } & \text { I } & 100.00 & 100.00 \\ \text { COG0236 } & \text { I } & 100.00 & 100.00 \\ \text { COG1028 } & \text { I } & 100.00 & 100.00 \\ \text { COG0331 } & \text { I } & 100.00 & 100.00 \\ \text { COG0360 } & \text { J } & 100.00 & 94.81 \\ \text { COG0238 } & \text { J } & 100.00 & 100.00 \\ \text { COG0359 } & \text { J } & 100.00 & 100.00 \\ \text { COG0544 } & \text { O } & 100.00 & 100.00 \\ \text { COG0347 } & \text { E } & 100.00 & 95.87 \\ \text { COG0174 } & \text { E } & 100.00 & 99.15 \\ & & 100.00 & 100.00 \\ \text { COG0006 } & \text { E } & 100.00 & 97.95 \\ \text { COG1268 } & \text { R } & 100.00 & 87.00 \\ & & 100.00 & 100.00 \\ \text { COG0015 } & \text { F } & 100.00 & 100.00 \\ & & 100.00 & 100.00 \\ & & 100.00 & 100.00 \\ \text { COG0697 } & \text { G } & 100.00 & 100.00 \\ \text { COG1560 } & \text { M } & 100.00 & 100.00 \\ \text { COG5429 } & \text { S } & 100.00 & 100.00 \\ \text { COG1048 } & \text { C } & 100.00 & 100.00 \\ \text { COG0526 } & \text { O } & 100.00 & 99.93 \\ \text { COG0755 } & \text { O } & 100.00 & 100.00 \\ \text { COG2386 } & \text { O } & 100.00 & 100.00 \\ \text { COG4133 } & \text { O } & 100.00 & 100.00 \\ \text { COG3737 } & \text { S } & 100.00 & 100.00 \\ \text { COG0341 } & \text { U } & 100.00 & 100.00 \\ \text { COG0342 } & \text { U } & 100.00 & 100.00 \\ \text { COG1862 } & \text { U } & 100.00 & 96.14 \\ & \mathrm{~J} & 100.00 & 100.00 \\ & & 100.00 & 99.15 \\ & & & \\ & & & \\ & & & \end{array}$




\begin{tabular}{|c|c|}
\hline RCA23_c18390 & hypothetical protein, alpha/beta hydrolase-like \\
\hline RCA23_c18400 & GTP-binding protein EngA \\
\hline RCA23_c18410 & putative quinoprotein \\
\hline RCA23_c18420 & hypothetical protein DUF2133 \\
\hline RCA23_c18430 & RND efflux transporter, MFP subunit \\
\hline RCA23_c18440 & RND efflux transporter, permease protein \\
\hline RCA23_c18450 & ABC transporter ATP-binding protein \\
\hline RCA23_c18460 & hypothetical protein, peptidoglycan-binding protein domain LysM \\
\hline RCA23_c18470 & protein RarD \\
\hline RCA23_c18480 & superoxide dismutase SodB \\
\hline RCA23_c18490 & sarcosine oxidase subunit SoxG \\
\hline RCA23_c18500 & sarcosine oxidase alpha subunit SoxA \\
\hline RCA23_c18510 & sarcosine oxidase subunit SoxD \\
\hline RCA23_c18520 & sarcosine oxidase beta subunit SoxB \\
\hline RCA23_c18530 & cytochrome c-type biogenesis protein $\mathrm{CycH}$ \\
\hline RCA23_c18540 & hypothetical protein \\
\hline RCA23_c18550 & hypothetical protein DUF1289 \\
\hline RCA23_c18560 & hypothetical protein \\
\hline RCA23_c18570 & hypothetical protein DUF81 \\
\hline RCA23_c18580 & tRNA-dihydrouridine synthase Dus \\
\hline RCA23_c18590 & putative peroxiredoxin (thioredoxin reductase) \\
\hline RCA23_c18600 & benzaldehyde dehydrogenase \\
\hline RCA23_c18610 & hypothetical protein \\
\hline RCA23_c18620 & hypothetical protein \\
\hline RCA23_c18630 & MFS-type transporter \\
\hline RCA23_c18640 & sorbitol dehydrogenase \\
\hline RCA23_c18650 & 6-hydroxynicotinate 3-monooxygenase \\
\hline RCA23_c18660 & hypothetical protein \\
\hline RCA23_c18670 & glycerate kinase \\
\hline RCA23_c18680 & putative carboxymuconolactone decarboxylase \\
\hline RCA23_c18690 & 2,4-dienoyl-CoA reductase [NADPH] \\
\hline RCA23_c18700 & thiamine pyrophosphate protein \\
\hline RCA23_c18710 & rffG/rfbB: dTDP-glucose 4,6-dehydratase \\
\hline
\end{tabular}

\begin{tabular}{|c|c|}
\hline COG2267 & \\
\hline COG1160 & \\
\hline COG1520 & \\
\hline COG4649 & \\
\hline COG0845 & \\
\hline COG0841 & \\
\hline COG5265 & \\
\hline COG1652 & \\
\hline COG2962 & \\
\hline COG0605 & \\
\hline COG4583 & \\
\hline COG0404 & \\
\hline COG4311 & \\
\hline COG0665 & \\
\hline COG4235 & \\
\hline COG0816 & \\
\hline CoG3313 & \\
\hline COG0730 & \\
\hline COG0042 & \\
\hline COG0678 & \\
\hline COG1012 & \\
\hline COG 2130 & \\
\hline COG2814 & \\
\hline COG1028 & \\
\hline COG0654 & \\
\hline COG2379 & \\
\hline COG0599 & \\
\hline COG1902 & \\
\hline COG0028 & \\
\hline COG1088 & \\
\hline
\end{tabular}

\begin{tabular}{rr}
0.00 & 86.50 \\
100.00 & 100.00 \\
100.00 & 100.00 \\
100.00 & 100.00 \\
100.00 & 100.00 \\
100.00 & 98.65 \\
100.00 & 97.90 \\
100.00 & 100.00 \\
100.00 & 100.00 \\
100.00 & 100.00 \\
100.00 & 100.00 \\
100.00 & 91.87 \\
100.00 & 100.00 \\
100.00 & 100.00 \\
100.00 & 100.00 \\
100.00 & 100.00 \\
100.00 & 100.00 \\
100.00 & 100.00 \\
100.00 & 100.00 \\
97.08 & 83.63 \\
0.00 & 0.00 \\
0.00 & 0.00 \\
0.00 & 0.00 \\
99.52 & 100.00 \\
100.00 & 100.00 \\
100.00 & 100.00 \\
100.00 & 85.61 \\
100.00 & 100.00 \\
100.00 & 90.19 \\
100.00 & 100.00 \\
100.00 & 97.17 \\
100.00 & 100.00 \\
91.97 & 100.00 \\
& \\
\hline
\end{tabular}


RCA23_c18720 hypothetical protein

RCA23_c18730 choline dehydrogenase BetA

100.00

94.02

RCA23_c18740 succinyl-CoA:3-ketoacid-coenzyme A transferase subunit ScoB

100.00

94.44

RCA23_c18750 succinyl-CoA:3-ketoacid-coenzyme A transferase subunit ScoA

100.00

100.00

100.00

RCA23_c18760 hypothetical membrane protein

RCA23_c18770 putative dimethyl sulfoniopropionate demethylase DmdA

100.00

100.00

RCA23_c18780 hydantoin utilization protein A

RCA23_c18790 hydantoin utilization protein B

100.00

100.00

100.00

COG0404

COG0145

COG0146

RCA23_c18800 FAD dependent oxidoreductase

RCA23_c18810 hypothetical protein, 3-beta hydroxysteroid dehydrogenase

COG0665

100.00

COG0451

RCA23_c18820 hypothetical protein, serine/threonine-protein kinase

COG1262

RCA23_c18830 hypothetical protein

RCA23_c18840 hypothetical protein DUF1989

RCA23_c18850 putative diaminopropionate ammonia-lyase

COG0457

COG3665

RCA23_c18860 hypothetical protein, metallopeptidase M24

COG1171

COG0006

RCA23_c18870 hypothetical protein, Asp/Glu/hydantoin racemase

COG3473

RCA23_c18880 putative 3-oxoadipate enol-lactonase 2, alpha/beta hydrolase family

COG0596

RCA23_c18890 hypothetical protein DUF1185

RCA23_c18900 limonene 1,2-monooxygenase LimB

RCA23_c18910 aldehyde dehydrogenase, cytosolic

COG 2141

COG1012

RCA23_c18920 ABC transporter, spermidine/putrescine import, permease protein PotC

RCA23_c18930 ABC transporter, spermidine/putrescine import, permease protein PotB

RCA23_c18940 ABC transporter, spermidine/putrescine import, substrate binding protein Pot

COG1177

COG1176

COG0687

RCA23_c18950 ABC transporter, spermidine/putrescine import, ATP-binding protein PotA

COG3842

RCA23_c18960 putative nitrilotriacetate monooxygenase component B

RCA23_c18970 hypothetical protein, DUF268

RCA23_c18980 hypothetical protein DUF28

COG1853

73.78

100.00

100.00

94.67

100.00

$\begin{array}{ll}100.00 & 100.00 \\ 100.00 & 100.00\end{array}$

$100.00 \quad 85.69$

$100.00 \quad 100.00$

$70.99 \quad 100.00$

$100.00 \quad 91.49$

$100.00 \quad 100.00$

$100.00 \quad 100.00$

$100.00 \quad 100.00$

$100.00 \quad 100.00$

$100.00 \quad 100.00$

$100.00 \quad 100.00$

$100.00 \quad 100.00$

$100.00 \quad 92.44$

$100.00 \quad 84.06$

$100.00 \quad 100.00$

COG0217

70.60

99.44

100.00

100.00

COG0471

100.00

96.98

RCA23_c19000 hypothetical protein

RCA23_c19010 hypothetical protein

COG0697

95.82

99.45

G1692

33.09

100.00

COG1764

100.00

100.00

RCA23_c19030 3-hydroxyacyl-CoA dehydrogenase, NAD-binding

COG1250

100.00

95.02

RCA23_c19040 putative transcriptional regulator

COG0703

100.00

97.50 


\begin{tabular}{|c|c|}
\hline RCA23_c19050 & thioesterase-like protein \\
\hline RCA23_c19060 & benzoyl-CoA oxygenase component A \\
\hline RCA23_c19070 & benzoyl-CoA oxygenase component B \\
\hline RCA23_c19080 & benzoyl-CoA-dihydrodiol lyase BoxC \\
\hline RCA23_c19090 & hypothetical protein DUF309 \\
\hline RCA23_c19100 & alpha/beta hydrolase \\
\hline RCA23_c19110 & benzoate-coenzyme A ligase \\
\hline RCA23_c19120 & putative 5 -formyltetrahydrofolate cyclo-ligase family protein \\
\hline RCA23_c19130 & magnesium transporter MgtE \\
\hline RCA23_c19140 & guanine deaminase GuaD \\
\hline RCA23_c19150 & putative hydroxydechloroatrazine ethylaminohydrolase \\
\hline RCA23_c19160 & putative inositol monophosphatase family protein \\
\hline RCA23_c19170 & putative helix-turn-helix protein \\
\hline RCA23_c19180 & putative alcohol dehydrogenase \\
\hline RCA23_c19190 & putative inner membrane protein \\
\hline RCA23_c19200 & hypothetical protein \\
\hline RCA23_c19210 & putative $\mathrm{N}$-acetylmuramoyl-L-alanine amidase amiD \\
\hline RCA23_c19220 & hypothetical protein \\
\hline RCA23_c19230 & glutamyl-tRNA(GIn) amidotransferase subunit $A$ \\
\hline RCA23_c19240 & aspartyl/glutamyl-tRNA(Asn/GIn) amidotransferase subunit GatC \\
\hline RCA23_c19250 & putative deaminase \\
\hline RCA23_c19260 & putative ribosomal large subunit pseudouridine synthase B \\
\hline RCA23_c19270 & molybdate $A B C$ transporter, ATP-binding protein ModC \\
\hline RCA23_c19280 & molybdate $A B C$ transporter, pemease protein ModB \\
\hline RCA23_c19290 & molybdate $A B C$ transporter, substrate binding protein ModA \\
\hline RCA23_c19300 & hypothetical protein, NUDIX hydrolase \\
\hline RCA23_c19310 & hypothetical protein DUF1178 \\
\hline RCA23_c19320 & aspartokinase LysC \\
\hline RCA23_c19330 & phosphoenolpyruvate-protein phosphotransferase Pstl \\
\hline RCA23_c19340 & hypothetical protein, acetyltransferase-like \\
\hline RCA23_c19350 & hypothetical protein \\
\hline RCA23_c19360 & putative sulfate transporter \\
\hline RCA23_c19370 & methylthioadenosine phosphorylase MtnP \\
\hline
\end{tabular}

COG0824
COG0369
COG3396
COG1024
COG0596
COG0318
COG0212
COG2239
COG0402
COG0402
COG0483
COG1396
COG0604
COG0670
COG3023
COG0154
COG0721
COG0590
COG1187
COG4148
COG4149
COG0725
COG0494
COG5319
COG0527
COG3605
COG3153
COG0655
COG0005

\begin{tabular}{rr}
31.07 & 100.00 \\
0.00 & 94.54 \\
86.65 & 98.01 \\
100.00 & 100.00 \\
100.00 & 100.00 \\
100.00 & 100.00 \\
100.00 & 100.00 \\
100.00 & 100.00 \\
100.00 & 97.82 \\
78.94 & 88.73 \\
100.00 & 100.00 \\
100.00 & 100.00 \\
100.00 & 100.00 \\
100.00 & 100.00 \\
100.00 & 100.00 \\
100.00 & 100.00 \\
100.00 & 100.00 \\
100.00 & 100.00 \\
100.00 & 100.00 \\
100.00 & 100.00 \\
100.00 & 66.90 \\
100.00 & 100.00 \\
100.00 & 97.94 \\
100.00 & 100.00 \\
92.51 & 100.00 \\
100.00 & 100.00 \\
100.00 & 100.00 \\
100.00 & 100.00 \\
100.00 & 99.02 \\
100.00 & 100.00 \\
100.00 & 100.00 \\
100.00 & 100.00 \\
100.00 & 100.00 \\
& \\
\hline
\end{tabular}


RCA23_c19380 adenine phosphoribosyltransferase Apt

RCA23_c19390 ribosomal-protein-alanine acetyltransferase RimJ

RCA23_c19400 uncharacterized zinc protease YmxG

RCA23_c19410 threonine synthase ThrC

RCA23_c19420 hypothetical protein, SURF1

RCA23_c19430 cytochrome c oxidase subunit 3

RCA23_c19440 cytochrome c oxidase assembly protein CtaG

RCA23_c19450 protoheme IX farnesyltransferase CtaB

RCA23_c19460 cytochrome c oxidase subunit 2 precursor

RCA23_c19470 protein TIdD

RCA23_c19480 SMF family protein

RCA23_c19490 DNA topoisomerase TopA

RCA23_c19500 fructose-bisphosphate aldolase Fba

RCA23_c19510 5-deoxy-glucuronate isomerase IolB

RCA23_c19520 5-dehydro-2-deoxygluconokinase lolC

RCA23_c19530 3D-(3,5/4)-trihydroxycyclohexane-1,2-dione hydrolase lolD

RCA23_c19540 hypothetical protein DUF989

RCA23_c19550 5-hydroxyisourate hydrolase UraH

RCA23_c19560 uric acid degradation bifunctional protein PucL

RCA23_c19570 putative allantoin catabolism protein YlbA

RCA23_c19580 sarcosine oxidase beta subunit SoxB

RCA23_c19590 sarcosine oxidase subunit SoxD

RCA23_c19600 sarcosine oxidase alpha subunit SoxA

RCA23_c19610 sarcosine oxidase subunit SoxG

RCA23_c19620 putative HTH-type transcriptional regulator, AraC family

RCA23_c19630 putative DNA-binding protein

RCA23_c19640 putative membrane protein

RCA23_c19650 hypothetical protein

RCA23_c19660 hypothetical protein, thioesterase

RCA23_c19670 hypothetical protein, calcineurin-like phosphoesterase-like

RCA23_c19680 putative DEAD/DEAH box helicase

RCA23_c19690 bidunctional enzyme FolD

RCA23_c19700 formate--tetrahydrofolate ligase Fhs

\begin{tabular}{|c|c|}
\hline COG0503 & \\
\hline COG1670 & \\
\hline COG0612 & \\
\hline COG0498 & \\
\hline COG3346 & \\
\hline COG1845 & \\
\hline COG3175 & \\
\hline COG0109 & \\
\hline COG1622 & \\
\hline COG0312 & \\
\hline COG0758 & \\
\hline COG0550 & \\
\hline COG0191 & \\
\hline COG3718 & \\
\hline COG0524 & \\
\hline COG3962 & \\
\hline COG3748 & \\
\hline COG2351 & \\
\hline COG3195 & \\
\hline COG3257 & \\
\hline COG0665 & \\
\hline COG4311 & \\
\hline COG0404 & \\
\hline COG4583 & \\
\hline COG4977 & \\
\hline COG1396 & \\
\hline COG2050 & \\
\hline COG1407 & \\
\hline COG1201 & \\
\hline COG0190 & \\
\hline COG2759 & \\
\hline
\end{tabular}

100.00

100.00

100.00

100.00

100.00

100.00

100.00

100.00

100.00

100.00

100.00

66.94

100.00

100.00

100.00

100.00

100.00

100.00

100.00

100.00

100.00

100.00

99.56

100.00

100.00

100.00

100.00

100.00

15.78

91.10

100.00

100.00

100.00
100.00

100.00

100.00

100.00

100.00

97.64

100.00

100.00

100.00

96.41

97.57

100.00

100.00

100.00

95.76

100.00

100.00

100.00

96.32

97.94

100.00

100.00

99.42

100.00

98.81

99.85

100.00

87.92

100.00

4.81

97.90

100.00

98.45 
RCA23_c19710 hypothetical protein

RCA23_c19720 cell division protease FtsH

100.00

100.00

RCA23_c19730 tRNA(Ile)-lysidine synthase Tils

100.00

100.00

RCA23_c19740 hypothetical protein

COG0037

100.00

100.00

RCA23_c19750 peptidoglycan-associated lipoprotein Pal

COG1729

100.00

100.00

RCA23_c19760 Tol-Pal system beta propeller repeat protein TolB

COG 2885

100.00

90.42

RCA23_c19770 hypothetical protein, TolA-like

RCA23_c19780 biopolymer transport protein TolR

COG0823

100.00

100.00

$100.00 \quad 86.45$

RCA23_c19790 biopolymer transport protein TolQ

COG0848

100.00

86.45
100.00

RCA23_c19800 acyl-CoA thioester hydrolase

COG0811

100.00

100.00

RCA23_c19810 hypothetical protein

RCA23_c19820 holliday junction ATP-dependent DNA helicase RuvB

COG0824

100.00

100.00

COG2255

RCA23_c19830 holliday junction ATP-dependent DNA helicase RuvA
RCA23_c19840 crossover junction endodeoxyribonuclease RuvC

COG0632

COG0817

100.00

100.00

putative ribosomal protein L11 methyltransferase

COG2264

100.00

100.00

100.00

COG0225

100.00

100.00

RCA23_c19870 hypothetical protein, major facilitator superfamily transporter

COG1304

100.00

COG1292

100.00

100.00

COG1825 J 100.00

100.00

COG0193

100.00
100.00

COG4427

100.00

COG0133

100.00

COG0135

100.00

100.00

COG0776

100.00

COG0539

100.00

100.00

COG1609

0.88

COG5285

RCA23_c20010

hypothetical protein, lacl family HTH-type regulatory protein

COG0667

100.00

100.00

100.00

100.00

100.00

100.00

100.00

100.00

91.01

87.26

100.00

100.00

99.22

100.00

100.00

100.00

100.00

100.00

100.00

100.00

100.00

100.00

100.00 


$\begin{array}{ll}\text { RCA23_c20040 } & \text { cytidylate kinase Cmk } \\ \text { RCA23_c20050 } & \text { 3-phosphoshikimate 1-carboxyvinyltransferase AroA } \\ \text { RCA23_c20060 } & \text { tRNA (guanine-N(7)-)-methyltransferase TrmB } \\ \text { RCA23_c20070 } & \text { S-adenosylmethionine synthase MetK } \\ \text { RCA23_c20080 } & \text { apolipoprotein N-acyltransferase Lnt } \\ \text { RCA23_c20090 } & \text { putative magnesium and cobalt efflux protein } \\ \text { RCA23_c20100 } & \text { hypothetical protein UPF0054 } \\ \text { RCA23_c20110 } & \text { PhoH-like protein } \\ \text { RCA23_c20120 } & \text { RNA modification enzyme, MiaB family } \\ \text { RCA23_c20130 } & \text { hypothetical protein } \\ \text { RCA23_c20140 } & \text { putative ferric uptake regulator family protein } \\ \text { RCA23_c20150 } & \text { 3-hydroxydecanoyl-[acyl-carrier-protein] dehydratase FabA } \\ \text { RCA23_c20160 } & \text { 3-oxoacyl-[acyl-carrier-protein] synthase FabB } \\ \text { RCA23_c20170 } & \text { enoyl-[acyl-carrier-protein] reductase FabI } \\ \text { RCA23_c20180 } & \text { threo-3-hydroxyaspartate ammonia-lyase SRY } \\ \text { RCA23_c20190 } & \text { 2-haloalkanoic acid dehalogenase } \\ \text { RCA23_c20200 } & \text { 3-oxoadipate enol-lactonase CatD } \\ \text { RCA23_c20210 } & \text { putative tetracycline resistance protein, class C } \\ \text { RCA23_c20220 } & \text { NAD/mycothiol-dependent formaldehyde dehydrogenase } \\ \text { RCA23_c20230 } & \text { D-galactonate dehydratase DgoD } \\ \text { RCA23_c20240 } & \text { dimethylglycine dehydrogenase } \\ \text { RCA23_c20250 } & \text { trimethylamine methyltransferase MttB } \\ \text { RCA23_c20260 } & \text { hypothetical protein } \\ \text { RCA23_c20270 } & \text { uncharacterized aminotransferase } \\ \text { RCA23_c20280 } & \text { aminomethyltransferase, mitochondrial } \\ \text { RCA23_c20290 } & \text { glycine cleavage system protein GcvH } \\ \text { RCA23_c20300 } & \text { glycine dehydrogenase GcvP } \\ \text { RCA23_c20310 } & \text { D-amino acid dehydrogenase small subunit DadA } \\ \text { RCA23_c20320 } & \text { putrescine ABC transport system putrescine-binding periplasmic protein PotF } \\ \text { RCA23_c20330 } & \text { putrescine ABC transport system ATP-binding protein PotG } \\ \text { RCA23_c20340 } & \text { putrescine ABC transport system permease protein Potl } \\ \text { RCA23_c20350 } & \text { putrescine ABC transport system permease protein PotB } \\ \text { RCA23_c20360 } & \text { rieske 2Fe-2S domain protein }\end{array}$

$\begin{array}{lc}\text { COG0283 } & \mathrm{F} \\ \text { COG0128 } & \mathrm{E} \\ \text { COG0220 } & \mathrm{R} \\ \text { COG0192 } & \mathrm{H} \\ \text { COG0815 } & \mathrm{M} \\ \text { COG1253 } & \mathrm{R} \\ \text { COG0319 } & \mathrm{R} \\ \text { COG1702 } & \mathrm{T} \\ \text { COG0621 } & \mathrm{J} \\ & \\ \text { COG0735 } & \mathrm{P} \\ \text { COG0764 } & \mathrm{I} \\ \text { COG0304 } & \mathrm{I} \\ \text { COG0623 } & \mathrm{I} \\ \text { COG1171 } & \mathrm{E} \\ \text { COG1011 } & \mathrm{R} \\ \text { COG0596 } & \mathrm{R} \\ \text { COG2814 } & \mathrm{G} \\ \text { COG1062 } & \mathrm{C} \\ \text { COG4948 } & \mathrm{M} \\ \text { COG0404 } & \mathrm{E} \\ \text { COG5598 } & \mathrm{H} \\ \text { COG0607 } & \mathrm{P} \\ \text { COG0161 } & \mathrm{H} \\ \text { COG0404 } & \mathrm{E} \\ \text { COG0509 } & \mathrm{E} \\ \text { COG1003 } & \mathrm{E} \\ \text { COG0665 } & \mathrm{E} \\ \text { COG0687 } & \mathrm{E} \\ \text { COG3842 } & \mathrm{E} \\ \text { COG1177 } & \mathrm{E} \\ \text { COG1176 } & \mathrm{E} \\ \text { COG4638 } & \mathrm{P} \\ & \end{array}$

94.05

100.00

100.00

100.00

100.00

100.00

100.00

100.00

100.00

96.92

100.00

100.00

100.00

100.00

97.47

100.00

97.51

100.00

97.88

100.00

100.00

99.88

99.42

100.00

100.00

98.18

100.00

99.96

100.00

100.00

100.00

100.00

100.00

100.00

100.00

100.00 
RCA23_c20370

RCA23_c20380

RCA23_c20390

RCA23_c20400

RCA23_c20410

RCA23_c20420

RCA23_c20430

RCA23_c20440

RCA23_c20450

RCA23_c20460

RCA23_c20470

RCA23_c20480

RCA23_c20490

RCA23_c20500

RCA23_c20510

RCA23_c20520

RCA23_c20530

RCA23_c20540

RCA23_c20550

RCA23_c20560

RCA23_c20570

RCA23_c20580

RCA23_c20590

RCA23_c20600

RCA23_c20610

RCA23_c20620

RCA23_c20630

RCA23_c20640

RCA23_c2065

RCA23_c20660

RCA23_c20670

RCA23_c20680

RCA23_c20690
TRAP dicarboxylate transporter, subunit DctM

TRAP dicarboxylate transporter, subunit DctQ

TRAP dicarboxylate transporter, subunit DctP

putative phytanoyl-CoA dioxygenase

putative phenylacetic acid degradation NADH oxidoreductase PaaE

phenylacetate-CoA oxygenase, subunit PaaD

phenylacetate-CoA oxygenase, subunit PaaC

phenylacetate-CoA oxygenase, subunit $\mathrm{PaaB}$

phenylacetate-CoA oxygenase, subunit PaaA

phenylacetic acid degradation operon negative regulatory protein PaaX

phenylacetic acid degradation protein PaaZ

putative enoyl-CoA hydratase PaaG

acyl-coenzyme A thioesterase Paal

beta-ketoadipyl CoA thiolase PaaJ

phenylacetate-CoA ligase PaaK

putative HTH-type transcriptional regulator, TetR family

3-dehydroquinate dehydratase AroQ

tyrosine decarboxylase

putative short chain dehydrogenase

hypothetical protein, acetyltransferase-like

protein CsaA

pyrroline-5-carboxylate reductase ProC

hypothetical protein DUF1790

hypothetical protein DUF526

prolipoprotein diacylglyceryl transferase Lgt

hypothetical protein DUF185

multi-copper polyphenol oxidoreductase laccase

hypothetical protein

leucine-responsive regulatory protein Lrp

thioredoxin reductase TrxB

bifunctional sulfate adenylyltransferase / adenylyl-sulfate kinase CysC

hypothetical protein DUF1150

small heat shock protein IbpA

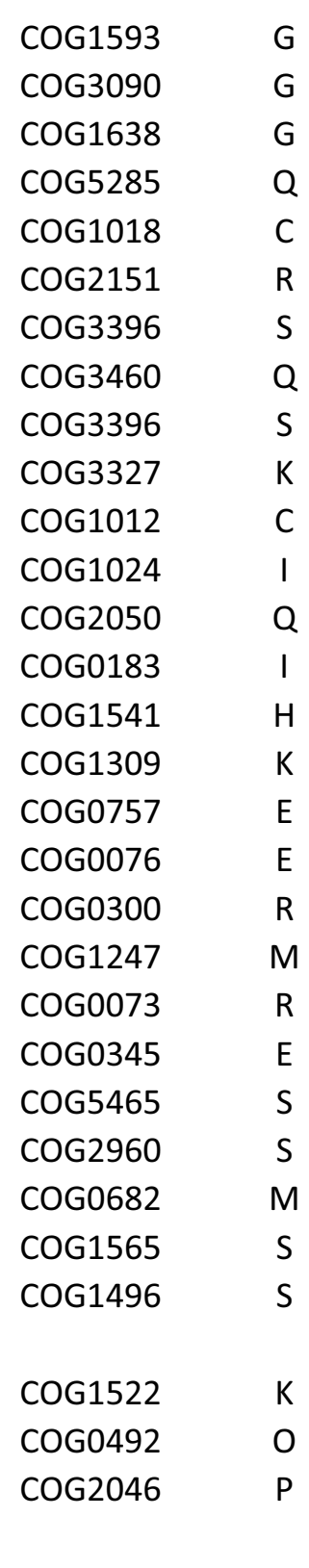

COG0071

$\begin{array}{rr}100.00 & 100.00 \\ 100.00 & 100.00 \\ 100.00 & 100.00 \\ 100.00 & 100.00 \\ 100.00 & 82.96 \\ 100.00 & 100.00 \\ 100.00 & 100.00 \\ 100.00 & 100.00 \\ 100.00 & 100.00 \\ 100.00 & 100.00 \\ 100.00 & 100.00 \\ 100.00 & 100.00 \\ 100.00 & 100.00 \\ 100.00 & 100.00 \\ 100.00 & 100.00 \\ 100.00 & 100.00 \\ 100.00 & 100.00 \\ 100.00 & 100.00 \\ 100.00 & 100.00 \\ 100.00 & 100.00 \\ 100.00 & 100.00 \\ 100.00 & 88.85 \\ 100.00 & 100.00 \\ 100.00 & 82.81 \\ 100.00 & 100.00 \\ 100.00 & 100.00 \\ 100.00 & 100.00 \\ 100.00 & 85.94 \\ 100.00 & 93.74 \\ 100.00 & 100.00 \\ 100.00 & 100.00 \\ 100.00 & 100.00 \\ 100.00 & 100.00\end{array}$


RCA23_c20700 hypothetical protein DUF465

\begin{tabular}{|c|c|c|c|}
\hline COG5481 & $S$ & 100.00 & 100.00 \\
\hline COG0041 & $\mathrm{F}$ & 100.00 & 100.00 \\
\hline COG0026 & $\mathrm{F}$ & 100.00 & 100.00 \\
\hline COG1075 & $\mathrm{R}$ & 100.00 & 84.51 \\
\hline COG0459 & 0 & 77.09 & 97.64 \\
\hline \multirow[t]{4}{*}{ COG0234 } & $\mathrm{O}$ & 3.82 & 100.00 \\
\hline & & 100.00 & 99.68 \\
\hline & & 100.00 & 86.83 \\
\hline & & 100.00 & 100.00 \\
\hline \multirow[t]{2}{*}{ COG0006 } & $E$ & 100.00 & 100.00 \\
\hline & & 100.00 & 100.00 \\
\hline COG5482 & $S$ & 100.00 & 100.00 \\
\hline COG1227 & $C$ & 100.00 & 100.00 \\
\hline COG0647 & G & 100.00 & 100.00 \\
\hline COG2030 & I & 100.00 & 100.00 \\
\hline COG0196 & $\mathrm{H}$ & 100.00 & 100.00 \\
\hline COG2983 & $\mathrm{S}$ & 100.00 & 100.00 \\
\hline COG2008 & $E$ & 100.00 & 100.00 \\
\hline COG3917 & $Q$ & 100.00 & 100.00 \\
\hline \multirow[t]{2}{*}{ COG0462 } & $\mathrm{F}$ & 79.31 & 100.00 \\
\hline & & 100.00 & 80.37 \\
\hline COG0355 & C & 100.00 & 100.00 \\
\hline COG0055 & C & 100.00 & 95.93 \\
\hline COG0224 & $C$ & 100.00 & 95.86 \\
\hline COG0056 & $C$ & 100.00 & 100.00 \\
\hline \multirow[t]{2}{*}{ COG0712 } & $C$ & 100.00 & 98.24 \\
\hline & & 88.98 & 100.00 \\
\hline COG0491 & $\mathrm{R}$ & 100.00 & 100.00 \\
\hline COG0542 & 0 & 100.00 & 100.00 \\
\hline \multirow[t]{2}{*}{ COG1360 } & $\mathrm{N}$ & 100.00 & 100.00 \\
\hline & & 100.00 & 100.00 \\
\hline COG3703 & $P$ & 100.00 & 93.41 \\
\hline COG1357 & $S$ & 88.91 & 90.70 \\
\hline
\end{tabular}




\begin{tabular}{|c|c|c|c|c|c|}
\hline RCA23_c21030 & protein TyrC & COG0287 & $E$ & 100.00 & 100.00 \\
\hline RCA23_c21040 & histidinol-phosphate aminotransferase HisC & COG0079 & $E$ & 100.00 & 100.00 \\
\hline RCA23_c21050 & 30 S ribosomal protein $\mathrm{S} 4$ & COG0522 & $\mathrm{J}$ & 100.00 & 91.17 \\
\hline RCA23_c21060 & cold-shock DEAD box protein A & COG0513 & $\mathrm{L}$ & 100.00 & 100.00 \\
\hline RCA23_c21070 & hypothetical protein DUF393 & COG3011 & $\mathrm{S}$ & 100.00 & 100.00 \\
\hline RCA23_c21080 & vitamin B12-dependent ribonucleoside-diphosphate reductase & COG0209 & $\mathrm{F}$ & 100.00 & 100.00 \\
\hline RCA23_c21090 & hypothetical protein & COG5458 & $\mathrm{S}$ & 100.00 & 100.00 \\
\hline RCA23_c21100 & ATP-phosphoribosyltransferase HisG & COG0040 & $\mathrm{E}$ & 100.00 & 100.00 \\
\hline RCA23_c21110 & ATP phosphoribosyltransferase regulatory subunit HisZ & COG3705 & $\mathrm{E}$ & 98.19 & 95.42 \\
\hline RCA23_c21120 & histidyl-tRNA synthase HisS & COG0124 & $\mathrm{J}$ & 73.57 & 100.00 \\
\hline RCA23_c21130 & hypothetical protein & COG 2900 & $\mathrm{~S}$ & 100.00 & 100.00 \\
\hline RCA23_c21140 & DNA polymerase III 1 alpha subunit DnaE & COG0587 & $\mathrm{L}$ & 100.00 & 98.86 \\
\hline RCA23_c21150 & xanthine dehydrogenase XdhA & COG4630 & $\mathrm{F}$ & 100.00 & 100.00 \\
\hline RCA23_c21160 & xanthine dehydrogenase $\mathrm{XdhB}$ & COG4631 & $\mathrm{F}$ & 95.14 & 98.87 \\
\hline RCA23_c21170 & xanthine dehydrogenase accessory protein $\mathrm{XdhC}$ & COG1975 & 0 & 100.00 & 100.00 \\
\hline RCA23_c21180 & sugar $A B C$ transporter, ATP-binding protein & COG3845 & $\mathrm{R}$ & 100.00 & 100.00 \\
\hline RCA23_c21190 & sugar $A B C$ transporter, permease protein & COG4603 & $\mathrm{R}$ & 100.00 & 91.90 \\
\hline RCA23_c21200 & $A B C$ transporter permease protein & COG1079 & $\mathrm{R}$ & 100.00 & 100.00 \\
\hline RCA23_c21210 & putative basic membrane protein & COG1744 & $\mathrm{R}$ & 100.00 & 100.00 \\
\hline RCA23_c21220 & putative FAD dependent oxidoreductase & COG0665 & $\mathrm{E}$ & 86.30 & 100.00 \\
\hline RCA23_c21230 & dimethylglycine dehydrogenase & COG0404 & $\mathrm{E}$ & 99.44 & 100.00 \\
\hline RCA23_c21240 & pantothenate synthase PanC & COG0414 & $\mathrm{H}$ & 100.00 & 80.00 \\
\hline RCA23_c21250 & 3-methyl-2-oxobutanoate hydroxymethyltransferase PanB & COG0413 & $\mathrm{H}$ & 100.00 & 100.00 \\
\hline RCA23_c21260 & hypothetical protein & COG3807 & $\mathrm{S}$ & 100.00 & 100.00 \\
\hline RCA23_c21270 & peptidyl-dipeptidase Dcp & COG0339 & $\mathrm{E}$ & 58.17 & 99.85 \\
\hline RCA23_c21280 & molybdopterin biosynthesis protein MoeB & COG0476 & $\mathrm{H}$ & 100.00 & 100.00 \\
\hline RCA23_c21290 & deoxyuridine 5 '-triphosphate nucleotidohydrolase Dut & COG0756 & $\mathrm{F}$ & 100.00 & 100.00 \\
\hline RCA23_c21300 & coenzyme $\mathrm{A}$ biosynthesis bifunctional protein CoaBC & COG0452 & $\mathrm{H}$ & 100.00 & 100.00 \\
\hline RCA23_c21310 & RNA polymerase sigma-32 factor RpoH & COG0568 & $\mathrm{K}$ & 100.00 & 98.63 \\
\hline RCA23_c21320 & bifunctional adenosylcobalamin biosynthesis protein CobP & COG2087 & $\mathrm{H}$ & 100.00 & 100.00 \\
\hline RCA23_c21330 & putative phosphoglycerate mutase family protein & COG0406 & G & 100.00 & 100.00 \\
\hline RCA23_c21340 & hypothetical protein, glutathione S-transferase & COG0625 & 0 & 100.00 & 100.00 \\
\hline RCA23_c21350 & glutathione S-transferase family protein & & & 100.00 & 100.00 \\
\hline
\end{tabular}


RCA23_c21430 putative ABC transporter, periplasmic substrate-binding protein

COG3845

RCA23_c21440

hypothetical protein, acetyltransferase-like

RCA23_c21450 NifU-like protein

RCA23_c21460 putative universal stress protein

RCA23_c21470 tryptophanyl-tRNA synthase TrpS

RCA23_c21480 hypothetical protein, rhomboid protease

RCA23_c21490 virulence factor MviN homolg

RCA23_c21500 uridylyltransferase GInD

RCA23_c21510 hypothetical protein

RCA23_c21520 putative tetrapyrrole methylase

RCA23_c21530 hypothetical protein UPF0102

RCA23_c21540 glutathione synthase GshB

RCA23_c21550 putative esterase/lipase

RCA23_c21560 NusB-like protein NusB

RCA23_c21570 6,7-dimethyl-8-ribityllumazine synthase RibH

RCA23_c21580 riboflavin biosynthesis protein RibB

RCA23_c21590 riboflavin synthase alpha chain RibE

RCA23_c21600 putative capsule polysaccharide export protein

RCA23_c21610 putative polysaccharide export protein

RCA23_c21620 putative capsule polysaccharide export protein

COG1744

COG0456

COG0694

COG0589

COG0180

COG0705

COG0728

COG2844

COG0683

COG0313

COG0792

COG0189

COG0657

COG0781

COG0054

COG0108

COG0307

COG3562

COG1596

COG3563

COG0117

COG1327

RCA23_c21640 transcriptional repressor NrdR

RCA23_c21650 RNA polymerase sigma factor RpoD

COG0568

COG0358

RCA23_c21660

RCA23_c21670

DNA primase DnaG

RCA23_c21680 sarcosine oxidase alpha subunit SoxA

COG4583

COG0404

$100.00 \quad 100.00$

$100.00 \quad 100.00$

$100.00 \quad 97.79$

$100.00 \quad 100.00$

$100.00 \quad 100.00$

$100.00 \quad 100.00$

$100.00 \quad 94.35$

$100.00 \quad 100.00$

$100.00 \quad 87.56$

$94.92 \quad 100.00$

$100.00 \quad 100.00$

$100.00 \quad 100.00$

$100.00 \quad 100.00$

$100.00 \quad 100.00$

$100.00 \quad 100.00$

$100.00 \quad 97.46$

$100.00 \quad 100.00$

$100.00 \quad 100.00$

$100.00 \quad 100.00$

$100.00 \quad 89.97$

$100.00 \quad 98.39$

$100.00 \quad 89.38$

$90.91 \quad 100.00$

$100.00 \quad 100.00$

$100.00 \quad 100.00$

$100.00 \quad 100.00$

$100.00 \quad 100.00$

$100.00 \quad 100.00$

$100.00 \quad 98.16$ 


\begin{tabular}{|c|c|}
\hline RCA23_c21690 & sarcosine oxidase subunit SoxD \\
\hline RCA23_c21700 & sarcosine oxidase beta subunit SoxB \\
\hline RCA23_c21710 & phosphatidylserine decarboxylase proenzyme Psd \\
\hline RCA23_c21720 & diacylglycerol kinase \\
\hline RCA23_c21730 & putative sulfatase \\
\hline RCA23_c21740 & hypothetical protein, CDP-alcohol phosphatidyltransferase-like \\
\hline RCA23_c21750 & hypothetical protein \\
\hline RCA23_c21760 & hypothetical protein \\
\hline RCA23_c21770 & hypothetical protein, DUF1705 \\
\hline RCA23_c21780 & glutamate dehydrogenase GluD \\
\hline RCA23_c21790 & hypothetical protein \\
\hline RCA23_c21800 & 2-hydroxy-3-oxopropionate reductase GarR \\
\hline RCA23_c21810 & reductive dehalogenase \\
\hline RCA23_c21820 & pirin \\
\hline RCA23_c21830 & transcriptional regulator \\
\hline RCA23_c21840 & hypothetical protein \\
\hline RCA23_c21850 & homoserine dehydrogenase Hom \\
\hline RCA23_c21860 & fructose-1,6-bisphosphatase class II \\
\hline RCA23_c21870 & putative single-stranded-DNA-specific exonuclease \\
\hline RCA23_c21890 & sulfopyruvate decarboxylase beta subunit ComE \\
\hline RCA23_c21900 & sulfopyruvate decarboxylase alpha subunit ComD \\
\hline RCA23_c21910 & zinc-type alcohol dehydrogenase \\
\hline RCA23_c21920 & gluconate 5-dehydrogenase Gno \\
\hline RCA23_c21930 & histidinol dehydrogenase HisD \\
\hline RCA23_c21940 & HTH-type transcriptional regulator, Lacl family \\
\hline RCA23_c21950 & HTH-type transcriptional regulator, IcIR family \\
\hline RCA23_c21960 & alcohol dehydrogenase AlkJ \\
\hline RCA23_c21970 & integral membrane protein TerC \\
\hline RCA23_c21980 & putative TRAP transporter, DctP subunit \\
\hline RCA23_c21990 & TRAP transporter, DctM/DctQ subunit \\
\hline RCA23_c22000 & trimethylamine methyltransferase \\
\hline RCA23_c22010 & putative HAD-family hydrolase \\
\hline RCA23_c22020 & hypothetical protein \\
\hline
\end{tabular}

$\begin{array}{llrr}\text { COG4311 } & \text { E } & 100.00 & 100.00 \\ \text { COG0665 } & \mathrm{E} & 100.00 & 100.00 \\ \text { COG0688 } & \mathrm{I} & 100.00 & 100.00 \\ \text { COG0818 } & \mathrm{M} & 100.00 & 100.00 \\ \text { COG2194 } & \mathrm{R} & 100.00 & 100.00 \\ \text { COG1183 } & \mathrm{I} & 100.00 & 100.00 \\ \text { COG0671 } & \mathrm{I} & 100.00 & 100.00 \\ \text { COG2194 } & \mathrm{R} & 100.00 & 100.00 \\ \text { COG2194 } & \mathrm{R} & 100.00 & 100.00 \\ \text { COG0334 } & \mathrm{E} & 96.73 & 99.23 \\ & & 100.00 & 100.00 \\ \text { COG2084 } & \mathrm{I} & 90.37 & 100.00 \\ \text { COG1600 } & \mathrm{C} & 26.15 & 100.00 \\ \text { COG1741 } & \mathrm{R} & 100.00 & 99.67 \\ \text { COG1309 } & \mathrm{K} & 100.00 & 100.00 \\ & & 100.00 & 100.00 \\ \text { COG0460 } & \mathrm{E} & 91.55 & 100.00 \\ \text { COG1494 } & \mathrm{G} & 100.00 & 100.00 \\ \text { COG0608 } & \mathrm{L} & 100.00 & 100.00 \\ \text { COG0028 } & \mathrm{E} & 100.00 & 100.00 \\ \text { COG4032 } & \mathrm{R} & 100.00 & 100.00 \\ \text { COG1063 } & \mathrm{E} & 100.00 & 100.00 \\ \text { COG1028 } & \mathrm{I} & 100.00 & 100.00 \\ \text { COG0141 } & \mathrm{E} & 100.00 & 100.00 \\ \text { COG1609 } & \mathrm{K} & 100.00 & 100.00 \\ \text { COG1414 } & \mathrm{K} & 100.00 & 100.00 \\ \text { COG2303 } & \mathrm{E} & 100.00 & 95.01 \\ \text { COG0861 } & \mathrm{P} & 100.00 & 86.40 \\ \text { COG4663 } & \mathrm{Q} & 33.69 & 100.00 \\ \text { COG4664 } & \mathrm{Q} & 89.37 & 100.00 \\ \text { COG5598 } & \mathrm{H} & 99.44 & 100.00 \\ \text { COG0546 } & \mathrm{R} & 98.57 & 77.40 \\ & & 0.00 & 100.00 \\ & & & \\ & & & \\ & & & \end{array}$




\begin{tabular}{|c|c|}
\hline RCA23_c22030 & hypothetical protein \\
\hline RCA23_c22040 & hypothetical protein \\
\hline RCA23_c22050 & hypothetical protein \\
\hline RCA23_c22060 & hypothetical protein, NUDIX hydrolase \\
\hline RCA23_c22070 & hypothetical protein \\
\hline RCA23_c22080 & putative fatty acid desaturase \\
\hline RCA23_c22090 & putative helix-turn-helix protein \\
\hline RCA23_c22100 & short chain dehydrogenase \\
\hline RCA23_c22110 & putative 3-hydroxyacyl-CoA dehydrogenase \\
\hline RCA23_c22130 & hypothetical protein, DUF849 \\
\hline RCA23_c22120 & transcriptional regulator, AraC family \\
\hline RCA23_c22140 & protein Tas \\
\hline RCA23_c22150 & hypothetical protein \\
\hline RCA23_c22160 & putative MFS-type transporter \\
\hline RCA23_c22170 & methionyl-tRNA synthase MetG \\
\hline RCA23_c22190 & integrase \\
\hline RCA23_c22200 & integrase \\
\hline RCA23_c22210 & putative nucleotidyl transferase \\
\hline RCA23_c22220 & hypothetical protein \\
\hline RCA23_c22230 & hypothetical protein \\
\hline RCA23_c22240 & putative replication factor $\mathrm{C}$, small subunit \\
\hline RCA23_c22250 & hypothetical protein \\
\hline RCA23_c22260 & hypothetical protein \\
\hline RCA23_c22270 & ParB-like nuclease \\
\hline RCA23_c22280 & cadmium-transporting ATPase CadA \\
\hline RCA23_c22290 & hypothetical protein \\
\hline RCA23_c22300 & putative lipoprotein signal peptidase \\
\hline RCA23_c22310 & putative ZIP zinc transporter \\
\hline RCA23_c22320 & hypothetical protein DUF411 \\
\hline RCA23_c22330 & SCO-like protein \\
\hline RCA23_c22340 & hypothetical protein \\
\hline RCA23_c22350 & hypothetical protein \\
\hline RCA23_c22360 & hypothetical protein, disulfide bond formation protein \\
\hline
\end{tabular}

\begin{tabular}{|c|c|c|c|c|}
\hline & & & & \\
\hline & & & 0.00 & 100.00 \\
\hline & & & 72.85 & 88.66 \\
\hline COG5349 & $S$ & & 100.00 & 100.00 \\
\hline COG0494 & $\mathrm{L}$ & & 100.00 & 100.00 \\
\hline & & & 100.00 & 100.00 \\
\hline COG3239 & I & & 100.00 & 100.00 \\
\hline COG1396 & $\mathrm{K}$ & & 100.00 & 100.00 \\
\hline COG1028 & I & & 100.00 & 100.00 \\
\hline COG1250 & 1 & & 100.00 & 100.00 \\
\hline COG3246 & $\mathrm{S}$ & & 100.00 & 100.00 \\
\hline COG4977 & $\mathrm{K}$ & & 100.00 & 98.15 \\
\hline COG0667 & $\mathrm{C}$ & & 100.00 & 100.00 \\
\hline COG4544 & $S$ & & 100.00 & 100.00 \\
\hline COG2211 & G & & 100.00 & 99.35 \\
\hline COG0143 & $\mathrm{J}$ & & 100.00 & 100.00 \\
\hline & & GI 8 & 65.69 & 100.00 \\
\hline COG4974 & $\mathrm{L}$ & GI 8 & 100.00 & 93.84 \\
\hline COG1210 & $M$ & GI 8 & 42.77 & 100.00 \\
\hline & & GI 8 & 0.00 & 92.08 \\
\hline & & GI 8 & 7.79 & 76.78 \\
\hline COG2256 & $\mathrm{L}$ & GI 8 & 100.00 & 100.00 \\
\hline & & GI 8 & 100.00 & 100.00 \\
\hline & & GI 8 & 100.00 & 98.44 \\
\hline CoG1475 & $\mathrm{K}$ & GI 8 & 100.00 & 97.83 \\
\hline COG2217 & $P$ & GI 8 & 94.20 & 92.03 \\
\hline COG3034 & $S$ & GI 8 & 0.00 & 100.00 \\
\hline COG0597 & $M$ & GI 8 & 0.00 & 100.00 \\
\hline COG0428 & $P$ & GI 8 & 3.41 & 100.00 \\
\hline COG3019 & $\mathrm{R}$ & GI 8 & 100.00 & 100.00 \\
\hline COG1999 & $\mathrm{R}$ & GI 8 & 100.00 & 100.00 \\
\hline COG2847 & $S$ & GI 8 & 100.00 & 100.00 \\
\hline COG1651 & 0 & GI 8 & 100.00 & 100.00 \\
\hline COG1495 & 0 & GI 8 & 100.00 & 100.00 \\
\hline
\end{tabular}




$\begin{array}{ll}\text { RCA23_c22370 } & \text { SCO-like protein } \\ \text { RCA23_c22380 } & \text { putative HTH-type transcriptional regulator } \\ \text { RCA23_c22390 } & \text { hypothetical protein UPF0060 } \\ \text { RCA23_c22400 } & \text { hypothetical protein } \\ \text { RCA23_c22410 } & \text { hypothetical protein } \\ \text { RCA23_c22420 } & \text { transposase } \\ \text { RCA23_c22430 } & \text { MORN motif precursor } \\ \text { RCA23_c22440 } & \text { transposase } \\ \text { RCA23_c22450 } & \text { hypothetical protein } \\ \text { RCA23_c22460 } & \text { hypothetical protein } \\ \text { RCA23_c22470 } & \text { hypothetical protein } \\ \text { RCA23_c22480 } & \text { hypothetical protein } \\ \text { RCA23_c22490 } & \text { hypothetical protein } \\ \text { RCA23_c22500 } & \text { transcriptional regulator, LuxR family } \\ \text { RCA23_c22510 } & \text { hypothetical protein } \\ \text { RCA23_c22520 } & \text { hypothetical protein, HTH-type transcriptional regulator, LuxR family } \\ \text { RCA23_c22530 } & \text { cysteine synthase CysK } \\ \text { RCA23_c22540 } & \text { hypothetical protein } \\ \text { RCA23_c22550 } & \text { hypothetical protein } \\ \text { RCA23_c22560 } & \text { hypothetical protein } \\ \text { RCA23_c22570 } & \text { hypothetical protein } \\ \text { RCA23_c22580 } & \text { hypothetical protein } \\ \text { RCA23_c22590 } & \text { coniferyl aldehyde dehydrogenase CalB } \\ \text { RCA23_c22600 } & \text { regulatory protein NocR } \\ \text { RCA23_c22610 } & \text { sn-glycerol-3-phosphate-binding periplasmic protein UgpB } \\ \text { RCA23_c22620 } & \text { sn-glycerol-3-phosphate transport system permease protein UgpA } \\ \text { RCA23_c22630 } & \text { sn-glycerol-3-phosphate transport system permease protein UgpE } \\ \text { RCA23_c22640 } & \text { sn-glycerol-3-phosphate import ATP-bindingprotein UgpC } \\ \text { RCA23_c22650 } & \text { putative glycerophosphoryl diester phosphodiesterase } \\ \text { RCA23_c22660 } & \text { aerobic glycerol-3-phosphate dehydrogenase GlpD } \\ \text { RCA23_c22670 } & \text { hypothetical protein, Na+/Pi-cotransporter } \\ \text { RCA23_c22680 } & \text { hypothetical protein, calcineurin-like phosphoesterase-like } \\ \text { RCA23_c22690 } & \text { ABC transporter permease protein } \\ & \end{array}$

\begin{tabular}{|c|c|c|c|c|}
\hline COG1999 & $\mathrm{R}$ & GI 8 & 100.00 & 100.00 \\
\hline COG0789 & K & GI 8 & 100.00 & 100.00 \\
\hline \multirow[t]{3}{*}{ COG1742 } & $S$ & GI 8 & 26.61 & 100.00 \\
\hline & & Gl 8 & 100.00 & 100.00 \\
\hline & & GI 8 & 90.61 & 88.57 \\
\hline COG3316 & L & Gl 8 & 1.98 & 0.00 \\
\hline COG4642 & S & GI 8 & 92.77 & 87.96 \\
\hline \multirow[t]{3}{*}{ COG3316 } & L & GI 8 & 87.01 & 0.00 \\
\hline & & GI 8 & 100.00 & 41.98 \\
\hline & & Gl 8 & 0.00 & 100.00 \\
\hline \multirow{3}{*}{ COG3295 } & $\mathrm{S}$ & GI 8 & 0.00 & 0.00 \\
\hline & & GI 8 & 0.00 & 0.00 \\
\hline & & GI 8 & 0.00 & 0.00 \\
\hline COG2197 & T & GI 8 & 0.00 & 0.00 \\
\hline COG3316 & $\mathrm{L}$ & GI 8 & 0.00 & 0.00 \\
\hline COG5616 & $\mathrm{S}$ & GI 8 & 0.00 & 43.46 \\
\hline \multirow[t]{5}{*}{ COG0031 } & $E$ & GI 8 & 0.00 & 23.80 \\
\hline & & GI 8 & 0.00 & 80.00 \\
\hline & & GI 8 & 0.00 & 0.00 \\
\hline & & GI 8 & 43.51 & 100.00 \\
\hline & & GI 8 & 100.00 & 98.38 \\
\hline COG5470 & $S$ & GI 8 & 100.00 & 15.00 \\
\hline COG1012 & C & GI 8 & 92.50 & 91.22 \\
\hline COG0583 & K & GI 8 & 97.88 & 47.60 \\
\hline COG1653 & G & GI 8 & 100.00 & 71.23 \\
\hline COG1175 & G & GI 8 & 100.00 & 100.00 \\
\hline COG0395 & G & GI 8 & 100.00 & 60.57 \\
\hline COG3839 & G & GI 8 & 100.00 & 30.18 \\
\hline COG0584 & C & GI 8 & 86.31 & 77.10 \\
\hline COG0578 & C & GI 8 & 100.00 & 36.21 \\
\hline COG1283 & $\mathrm{P}$ & GI 8 & 90.48 & 16.94 \\
\hline COG1409 & $\mathrm{R}$ & GI 8 & 100.00 & 27.78 \\
\hline COG0395 & G & GI 8 & 95.06 & 30.25 \\
\hline
\end{tabular}




\begin{tabular}{ll} 
RCA23_c22700 & ABC transporter permease protein \\
RCA23_c22710 & ABC transporter extracellular solute-binding protein \\
RCA23_c22720 & ABC transporter ATP-binding protein \\
RCA23_c22730 & HTH-type transcriptional regulator, DeoR family \\
RCA23_c22740 & HAD-superfamily hydrolase, subfamily IIB \\
RCA23_c22750 & putative inner membrane transporter \\
RCA23_c22760 & soluble aldose sugar dehydrogenase Ylil \\
RCA23_c22770 & putative FKBP-type peptidyl-prolyl cis-trans isomerase \\
RCA23_c22780 & putative NnrU family protein \\
RCA23_c22790 & hypothetical protein \\
RCA23_c22800 & putative adenine methyltransferase \\
RCA23_c22810 & hypothetical protein \\
RCA23_c22820 & phage uncharacterised protein \\
RCA23_c22830 & hypothetical protein, resolvase-like \\
RCA23_c22840 & putative prophage integrase \\
RCA23_c22850 & hypothetical protein, putative phage-like protein \\
RCA23_c22860 & hypothetical protein \\
RCA23_c22870 & hypothetical protein \\
RCA23_c22880 & hypothetical protein \\
RCA23_c22890 & DNA polymerase III \\
RCA23_c22900 & hypothetical protein, periplasmic binding protein-like \\
RCA23_c22910 & hypothetical protein \\
RCA23_c22920 & transposase \\
RCA23_c22930 & molybdopterin biosynthesis protein MoeA \\
RCA23_c22940 & molybdopterin-guanine dinucleotide biosynthesis protein MobB \\
RCA23_c22950 & hypothetical protein, MobA-like \\
RCA23_c22960 & formate dehydrogenase family accessory protein FdhD \\
RCA23_c22970 & molybdopterin-converting factor subunit MoaE \\
RCA23_c22980 & molybdopterin-converting factor subunit MoaD \\
RCA23_c22990 & transposase \\
RCA23_c23000 & molybdenum cofactor biosynthesis protein MoaA \\
RCA23_c23010 & transposase \\
RCA23_c23020 & ABC transporter, ATP-binding cassette protein \\
\hline &
\end{tabular}

\begin{tabular}{|c|c|c|c|c|}
\hline COG1175 & G & GI 8 & 21.59 & 0.00 \\
\hline COG1653 & G & GI 8 & 100.00 & 0.00 \\
\hline COG3839 & G & GI 8 & 100.00 & 0.00 \\
\hline COG1349 & K & GI 8 & 100.00 & 28.92 \\
\hline COG0561 & $\mathrm{R}$ & GI 8 & 100.00 & 33.58 \\
\hline COG0697 & G & GI 8 & 100.00 & 100.00 \\
\hline COG2133 & G & GI 8 & 100.00 & 97.17 \\
\hline COG0545 & 0 & GI 8 & 75.38 & 43.59 \\
\hline \multirow[t]{2}{*}{ COG4094 } & $S$ & GI 8 & 81.42 & 81.42 \\
\hline & & GI 8 & 98.28 & 44.44 \\
\hline \multirow[t]{2}{*}{ COG0863 } & $\mathrm{L}$ & GI 8 & 52.56 & 49.53 \\
\hline & & GI 8 & 100.00 & 0.00 \\
\hline COG5410 & $S$ & GI 8 & 40.93 & 0.00 \\
\hline COG1961 & $\mathrm{L}$ & GI 8 & 0.00 & 0.00 \\
\hline \multirow[t]{2}{*}{ COG0582 } & $\mathrm{L}$ & GI 8 & 0.00 & 0.00 \\
\hline & & GI 8 & 0.00 & 0.00 \\
\hline \multirow[t]{3}{*}{ CoG3311 } & K & GI 8 & 0.00 & 0.00 \\
\hline & & GI 8 & 0.00 & 0.00 \\
\hline & & GI 8 & 54.14 & 46.50 \\
\hline COG5545 & $\mathrm{R}$ & GI 8 & 100.00 & 89.39 \\
\hline \multirow[t]{2}{*}{ COG2998 } & $\mathrm{H}$ & GI 8 & 0.00 & 0.00 \\
\hline & & GI 8 & 0.00 & 81.13 \\
\hline COG3316 & $\mathrm{L}$ & GI 8 & 0.00 & 5.37 \\
\hline COG0303 & $\mathrm{H}$ & GI 8 & 0.00 & 75.38 \\
\hline COG1763 & $\mathrm{H}$ & GI 8 & 0.00 & 97.39 \\
\hline COG0746 & $\mathrm{H}$ & GI 8 & 0.00 & 75.08 \\
\hline COG1526 & $C$ & GI 8 & 0.00 & 96.01 \\
\hline COG0314 & $\mathrm{H}$ & GI 8 & 0.00 & 98.42 \\
\hline COG1977 & $\mathrm{H}$ & GI 8 & 0.00 & 92.68 \\
\hline COG3328 & $\mathrm{L}$ & GI 8 & 0.00 & 100.00 \\
\hline \multirow[t]{2}{*}{ COG2896 } & $\mathrm{H}$ & GI 8 & 0.00 & 76.98 \\
\hline & & GI 8 & 0.00 & 89.01 \\
\hline COG3839 & G & GI 8 & 0.00 & 76.75 \\
\hline
\end{tabular}




$\begin{array}{ll}\text { RCA23_c23030 } & \text { ABC transporter, permease protein } \\ \text { RCA23_c23040 } & \text { formate dehydrogenase, gamma subunit Fdhl } \\ \text { RCA23_c23050 } & \text { formate dehydrogenase, iron-sulfur subunit FdhB } \\ \text { RCA23_c23060 } & \text { formate dehydrogenase alpha subunit FdhA } \\ \text { RCA23_c23070 } & \text { putative twin-arginine translocation pathway signal sequence domain } \\ \text { RCA23_c23080 } & \text { hypothetical protein, cytoplasmic chaperon TorD } \\ \text { RCA23_c23090 } & \text { hypothetical protein } \\ \text { RCA23_c23100 } & \text { putative molybdopterin-guanine dinucleotide biosynthesis protein A } \\ \text { RCA23_c23110 } & \text { hypothetical protein, 4Fe-4S ferredoxin-like } \\ \text { RCA23_c23120 } & \text { hypothetical protein } \\ \text { RCA23_c23130 } & \text { hypothetical protein } \\ \text { RCA23_c23140 } & \text { hypothetical protein, Mrp/NBP35 family protein } \\ \text { RCA23_c23150 } & \text { hypothetical protein } \\ \text { RCA23_c23160 } & \text { hypothetical protein } \\ \text { RCA23_c23170 } & \text { putative phage terminase } \\ \text { RCA23_c23180 } & \text { transposase } \\ \text { RCA23_c23190 } & \text { putative phage helicase } \\ \text { RCA23_c23200 } & \text { hypothetical protein } \\ \text { RCA23_c23210 } & \text { putative pyridoxal 4-dehydrogenase } \\ \text { RCA23_c23220 } & \text { 2-dehydro-3-deoxy-D-gluconate 5-dehydrogenase KduD } \\ \text { RCA23_c23230 } & \text { putative L-rhamnonate dehydratase rhamD } \\ \text { RCA23_c23240 } & \text { ureidoglycolate lyase } \\ \text { RCA23_c23250 } & \text { D-3-phosphoglycerate dehydrogenase } \\ \text { RCA23_c23260 } & \text { uncharacterized oxidoreductase } \\ \text { RCA23_c23270 } & \text { putative rhamnose mutarotase RhaM } \\ \text { RCA23_c23280 } & \text { putative acetoacetate decarboxylase Adc } \\ \text { RCA23_c23290 } & \text { uncharacterized oxidoreductase } \\ \text { RCA23_c23300 } & \text { transcriptional regulator, GntR family } \\ \text { RCA23_c23310 } & \text { putative ribose ABC transport system, permease protein RbsC } \\ \text { RCA23_c23320 } & \text { putative ribose ABC transport system, permease protein RbsC } \\ \text { RCA23_c23330 } & \text { ribose import ABC transporter, ATP-binding protein RbsA } \\ \text { RCA23_c23340 } & \text { putative rhamnose ABC transport system, substrate-binding protein RhaS } \\ \text { RCA23_c23350 } & \text { galactonate dehydratase } \\ & \end{array}$

\begin{tabular}{|c|c|c|c|c|}
\hline COG4662 & $\mathrm{H}$ & GI 8 & 0.00 & 68.37 \\
\hline COG2864 & C & GI 8 & 0.00 & 97.17 \\
\hline COG0437 & $\mathrm{C}$ & GI 8 & 0.00 & 100.00 \\
\hline \multirow[t]{2}{*}{ COG0243 } & C & GI 8 & 7.36 & 98.65 \\
\hline & & GI 8 & 100.00 & 93.23 \\
\hline \multirow[t]{3}{*}{ COG3381 } & $\mathrm{R}$ & Gl 8 & 100.00 & 43.89 \\
\hline & & Gl 8 & 100.00 & 81.11 \\
\hline & & GI 8 & 47.65 & 51.60 \\
\hline \multirow[t]{3}{*}{ COG1148 } & $\mathrm{C}$ & GI 8 & 53.82 & 95.73 \\
\hline & & GI 8 & 0.00 & 82.64 \\
\hline & & GI 8 & 0.00 & 100.00 \\
\hline COG0489 & $D$ & GI 8 & 0.00 & 56.63 \\
\hline \multirow[t]{3}{*}{ COG0340 } & $\mathrm{H}$ & GI 8 & 0.00 & 100.00 \\
\hline & & GI 8 & 0.00 & 100.00 \\
\hline & & GI 8 & 0.00 & 0.00 \\
\hline COG3316 & $\mathrm{L}$ & GI 8 & 0.00 & 0.00 \\
\hline \multirow[t]{2}{*}{ COG3378 } & $\mathrm{R}$ & GI 8 & 0.00 & 58.97 \\
\hline & & GI 8 & 0.00 & 100.00 \\
\hline COG0667 & C & GI 8 & 0.00 & 0.00 \\
\hline COG1028 & I & GI 8 & 0.00 & 0.00 \\
\hline COG4948 & $\mathrm{M}$ & GI 8 & 0.00 & 0.00 \\
\hline COG0179 & $Q$ & GI 8 & 0.00 & 0.00 \\
\hline COG1052 & $\mathrm{C}$ & GI 8 & 0.00 & 0.00 \\
\hline COG1028 & I & GI 8 & 0.00 & 0.00 \\
\hline COG3254 & $S$ & Gl 8 & 0.00 & 0.00 \\
\hline COG4689 & $\mathrm{Q}$ & GI 8 & 0.00 & 0.00 \\
\hline COG0673 & $\mathrm{R}$ & GI 8 & 0.00 & 0.00 \\
\hline COG2186 & K & GI 8 & 0.00 & 0.00 \\
\hline COG1172 & G & GI 8 & 0.00 & 0.00 \\
\hline COG1172 & G & GI 8 & 0.00 & 0.00 \\
\hline COG1129 & G & GI 8 & 0.00 & 0.00 \\
\hline COG1879 & G & GI 8 & 0.00 & 0.00 \\
\hline COG4948 & $\mathrm{M}$ & GI 8 & 0.00 & 0.00 \\
\hline
\end{tabular}




\begin{tabular}{|c|c|}
\hline RCA23_c23360 & xylose isomerase-like \\
\hline RCA23_c23370 & putative aldo/keto reductase \\
\hline RCA23_c23380 & amidohydrolase \\
\hline RCA23_c23390 & hypothetical protein \\
\hline RCA23_c23400 & transposase \\
\hline RCA23_c23410 & L-rhamnose mutarotase RhaM \\
\hline RCA23_c23420 & ureidoglycolate lyase \\
\hline RCA23_c23430 & dihydrodipicolinate synthase DapA \\
\hline RCA23_c23440 & amidohydrolase \\
\hline RCA23_c23450 & 3-ketoacyl-(acyl-carrier-protein) reductase FabG \\
\hline RCA23_c23460 & L-rhamnonate dehydratase RhmD \\
\hline RCA23_c23470 & polyamine $A B C$ transporter, ATP-binding protein PotA \\
\hline RCA23_c23480 & polyamine $A B C$ transporter, permease protein \\
\hline RCA23_c23490 & polyamine $A B C$ transporter, permease protein \\
\hline RCA23_c23500 & polyamine $A B C$ transporter, substrate binding protein \\
\hline RCA23_c23510 & hypothetical protein \\
\hline RCA23_c23520 & hypothetical protein \\
\hline RCA23_c23530 & uncharacterized oxidoreductase \\
\hline RCA23_c23540 & L-rhamnonate dehydratase \\
\hline RCA23_c23550 & ribose $A B C$ transport system, permease protein $\mathrm{RbsC}$ \\
\hline RCA23_c23560 & ribose import $A B C$ transporter, ATP-binding protein RbsA \\
\hline RCA23_c23570 & ribose import $A B C$ transporter, substrate binding protein $\mathrm{RbsC}$ \\
\hline RCA23_c23580 & HTH-type transcriptional regulator, GntR family \\
\hline RCA23_c23590 & hypothetical protein \\
\hline RCA23_c23600 & putative DNA-binding protein \\
\hline RCA23_c23610 & glutamine amidotransferase-like protein GIxB \\
\hline RCA23_c23620 & glutamate synthase alpha subunit GlxC \\
\hline RCA23_c23630 & glutamate synthase large subunit GIxD \\
\hline RCA23_c23640 & glutamine synthase GInA type III \\
\hline RCA23_c23650 & hypothetical protein \\
\hline RCA23_c23660 & methyltrasnferase \\
\hline RCA23_c23670 & hypothetical protein \\
\hline RCA23_c23680 & putative terminase, large subunit \\
\hline
\end{tabular}

$\begin{array}{llrrr}\text { COG1082 } & \text { G } & \text { Gl 8 } & 0.00 & 0.00 \\ \text { COG0667 } & \text { C } & \text { Gl 8 } & 0.00 & 0.00 \\ \text { COG3618 } & \text { R } & \text { Gl 8 } & 0.00 & 0.00 \\ & & \text { Gl 8 } & 0.00 & 0.00 \\ \text { COG3316 } & \text { L } & \text { Gl 8 } & 0.00 & 5.79 \\ \text { COG3254 } & \text { S } & \text { Gl 8 } & 0.00 & 31.45 \\ \text { COG0179 } & \text { Q } & \text { Gl 8 } & 0.00 & 27.06 \\ \text { COG0329 } & \text { E } & \text { Gl 8 } & 0.00 & 0.00 \\ \text { COG3618 } & \text { R } & \text { Gl 8 } & 0.00 & 0.00 \\ \text { COG1028 } & \text { I } & \text { Gl 8 } & 0.00 & 0.00 \\ \text { COG4948 } & \text { M } & \text { Gl 8 } & 0.00 & 0.00 \\ \text { COG3842 } & \text { E } & \text { Gl 8 } & 0.00 & 0.00 \\ \text { COG1177 } & \text { E } & \text { Gl 8 } & 0.00 & 0.00 \\ \text { COG1176 } & \text { E } & \text { Gl 8 } & 0.00 & 0.00 \\ \text { COG0687 } & \text { E } & \text { Gl 8 } & 0.00 & 0.00 \\ & & \text { Gl 8 } & 0.00 & 0.00 \\ \text { COG1028 } & \text { I } & \text { Gl 8 } 8 & 0.00 & 0.00 \\ \text { COG4948 } & \text { M } & \text { Gl 8 } & 100.00 & 0.00 \\ \text { COG1172 } & \text { G } & \text { Gl 8 } & 9.20 & 0.00 \\ \text { COG1129 } & \text { G } & \text { Gl 8 } & 0.00 & 29.44 \\ \text { COG1879 } & \text { G } & \text { Gl 8 } & 1.80 & 0.00 \\ \text { COG1609 } & \text { K } & \text { Gl 8 } & 100.00 & 0.00 \\ \text { COG3311 } & \text { K } & \text { Gl 8 } & 100.00 & 0.00 \\ \text { COG1396 } & \text { K } & \text { Gl 8 } & 0.00 & 100.00 \\ \text { COG0067 } & \text { E } & \text { Gl 8 } & 0.00 & 97.88 \\ \text { COG0070 } & \text { E } & \text { Gl 8 } & 0.00 & 80.68 \\ \text { COG0069 } & \text { E } & \text { Gl 8 } & 0.00 & 96.35 \\ \text { COG0174 } & \text { E } & \text { Gl 8 } & 0.00 & 75.58 \\ & & \text { Gl 8 } & 0.00 & 0.00 \\ \text { COG0863 } & \text { L } & \text { Gl 8 } & 42.40 & 20.00 \\ \text { COG5410 } & \text { S } & \text { Gl } 8 & 100.00 & 4.43 \\ & & & 94.28 & 41.63\end{array}$




\begin{tabular}{|c|c|}
\hline RCA23_c23690 & hypothetical protein, DUF2924 \\
\hline RCA23_c23700 & hypothetical protein, resolvase-like \\
\hline RCA23_c23720 & signal transduction histidine kinase \\
\hline RCA23_c23730 & mercuric reductase MerA \\
\hline RCA23_c23740 & hypothetical protein \\
\hline RCA23_c23750 & putative ribonuclease $P$ \\
\hline RCA23_c23760 & hypothetical protein DUF37 \\
\hline RCA23_c23770 & hypothetical protein \\
\hline RCA23_c23780 & tRNA 2-thiocytidine biosynthesis protein TtcA \\
\hline RCA23_c23790 & putative diguanylate phosphodiesterase \\
\hline RCA23_c23800 & inner membrane protein OxaA \\
\hline RCA23_c23810 & hypothetical protein, molybdenum cofactor sulfurase \\
\hline RCA23_c23820 & putative GTP-binding protein EngB \\
\hline RCA23_c23830 & acetylglutamate kinase ArgB \\
\hline RCA23_c23840 & putative fatty acid hydroxylase \\
\hline RCA23_c23850 & hypothetical protein \\
\hline RCA23_c23860 & hypothetical protein, phosphogylcerate mutase \\
\hline RCA23_c23870 & glutamate/glutamine/aspartate/asparagine transport ATP-binding protein Bzt \\
\hline RCA23_c23880 & glutamate/glutamine/aspartate/asparagine transport system permease prote \\
\hline RCA23_c23890 & glutamate/glutamine/aspartate/asparagine transport system permease prote \\
\hline RCA23_c23900 & glutamate/glutamine/aspartate/asparagine-binding protein BztA \\
\hline RCA23_c23910 & ATP chaperone protein \\
\hline RCA23_c23920 & putative phosphoglycerate phosphatase \\
\hline RCA23_c23930 & ribosomal large subunit pseudouridine synthase $\mathrm{C}$ \\
\hline RCA23_c23940 & putative ccrb-like protein \\
\hline RCA23_c23950 & replication-associated recombination protein $A$ \\
\hline RCA23_c23960 & HTH-type transcriptional regulator, LuxR family \\
\hline RCA23_c23970 & $50 S$ ribosomal protein $\mathrm{L} 17$ \\
\hline RCA23_c23980 & DNA-directed RNA polymerase alpha subunit RpoA \\
\hline RCA23_c23990 & 30 S ribosomal protein S11 \\
\hline RCA23_c24000 & 30 S ribosomal protein S13 \\
\hline RCA23_c24010 & adenylate kinase Adk \\
\hline RCA23_c24020 & preprotein translocase subunit SecY \\
\hline
\end{tabular}

$\begin{array}{ll}\text { COG1961 } & \text { L } \\ \text { COG0642 } & \text { T } \\ \text { COG1249 } & \text { C } \\ \text { COG0398 } & \text { S } \\ \text { COG0594 } & \text { J } \\ \text { COG0759 } & \text { S } \\ & \\ \text { COG0037 } & \text { D } \\ \text { COG2200 } & \text { T } \\ \text { COG0706 } & \text { U } \\ \text { COG3217 } & \text { R } \\ \text { COG0218 } & \text { R } \\ \text { COG0548 } & \text { E } \\ \text { COG3000 } & \text { I } \\ \text { COG1148 } & \text { C } \\ \text { COG2062 } & \text { T } \\ \text { COG1126 } & \text { E } \\ \text { COG0765 } & \text { E } \\ \text { COG4597 } & \text { E } \\ \text { COG0834 } & \text { E } \\ \text { COG5387 } & \text { O } \\ \text { COG0546 } & \text { R } \\ \text { COG0564 } & \text { J } \\ \text { COG0239 } & \text { D } \\ \text { COG2256 } & \text { L } \\ \text { COG2197 } & \text { T } \\ \text { COG0203 } & \text { J } \\ \text { COG0202 } & \text { K } \\ \text { COG0100 } & \text { J } \\ \text { COG0099 } & \text { J } \\ \text { COG0563 } & \mathrm{F} \\ \text { COG0201 } & \text { U } \\ & \end{array}$

\begin{tabular}{|c|c|c|}
\hline GI 8 & 0.00 & 0.00 \\
\hline \multirow[t]{32}{*}{ GI 8} & 9.15 & 0.00 \\
\hline & 100.00 & 97.31 \\
\hline & 100.00 & 99.22 \\
\hline & 100.00 & 93.31 \\
\hline & 100.00 & 100.00 \\
\hline & 100.00 & 100.00 \\
\hline & 100.00 & 100.00 \\
\hline & 100.00 & 100.00 \\
\hline & 100.00 & 100.00 \\
\hline & 100.00 & 99.50 \\
\hline & 100.00 & 100.00 \\
\hline & 100.00 & 100.00 \\
\hline & 100.00 & 100.00 \\
\hline & 100.00 & 97.35 \\
\hline & 100.00 & 94.52 \\
\hline & 100.00 & 100.00 \\
\hline & 100.00 & 100.00 \\
\hline & 100.00 & 100.00 \\
\hline & 62.65 & 78.89 \\
\hline & 100.00 & 98.19 \\
\hline & 93.48 & 100.00 \\
\hline & 100.00 & 100.00 \\
\hline & 100.00 & 100.00 \\
\hline & 100.00 & 100.00 \\
\hline & 100.00 & 100.00 \\
\hline & 100.00 & 100.00 \\
\hline & 100.00 & 100.00 \\
\hline & 100.00 & 100.00 \\
\hline & 100.00 & 100.00 \\
\hline & 100.00 & 100.00 \\
\hline & 100.00 & 99.38 \\
\hline & 100.00 & 100.00 \\
\hline
\end{tabular}




\begin{tabular}{|c|c|}
\hline RCA23_c24030 & $50 S$ ribosomal protein L15 \\
\hline RCA23_c24040 & $50 S$ ribosomal protein $\mathrm{L} 30$ \\
\hline RCA23_c24050 & $30 S$ ribosomal protein S5 \\
\hline RCA23_c24060 & $50 S$ ribosomal protein L18 \\
\hline RCA23_c24070 & $50 S$ ribosomal protein L6 \\
\hline RCA23_c24080 & $30 S$ ribosomal protein S8 \\
\hline RCA23_c24090 & 30 S ribosomal protein S14 \\
\hline RCA23_c24100 & $50 S$ ribosomal protein L5 \\
\hline RCA23_c24110 & 50 S ribosomal protein L24 \\
\hline RCA23_c24120 & 50 S ribosomal protein L14 \\
\hline RCA23_c24130 & 30 S ribosomal protein S17 \\
\hline RCA23_c24140 & 50 S ribosomal protein L29 \\
\hline RCA23_c24150 & hypothetical protein \\
\hline RCA23_c24160 & $50 S$ ribosomal protein $\mathrm{L} 23$ \\
\hline RCA23_c24170 & $50 S$ ribosomal protein L4 \\
\hline RCA23_c24180 & 50S ribosomal protein L3 \\
\hline RCA23_c24190 & 30 S ribosomal protein S10 \\
\hline RCA23_c24200 & elongation factor Tu (EF-Tu) \\
\hline RCA23_c24210 & elongation factor FusA \\
\hline RCA23_c24220 & $30 S$ ribosomal protein S7 \\
\hline RCA23_c24230 & 30 S ribosomal protein S12 \\
\hline RCA23_c24240 & hypothetical protein \\
\hline RCA23_c24250 & $\mathrm{ABC}$ transporter ATP-binding protein \\
\hline RCA23_c24260 & $\mathrm{ABC}$ tansporter permease protein \\
\hline RCA23_c24270 & putative $A B C$ transporter periplasmic binding protein \\
\hline RCA23_c24280 & putative transcriptional repressor \\
\hline RCA23_c24290 & hypothetical protein, acyl-CoA thioesterase-like \\
\hline RCA23_c24300 & $\mathrm{ABC}$ transporter ATP-binding protein \\
\hline RCA23_c24310 & putative $A B C$ transporter permease protein \\
\hline RCA23_c24320 & hypothetical protein, gylcosyl transferase family 2 \\
\hline RCA23_c24330 & aminotransferase class-III \\
\hline RCA23_c24340 & putative ectoine utilization protein EutD \\
\hline RCA23 c24350 & putative integral membrane proein DUF6 \\
\hline
\end{tabular}

$\begin{array}{llrr}\text { COG0200 } & \text { J } & 100.00 & 100.00 \\ \text { COG1841 } & \text { J } & 100.00 & 100.00 \\ \text { COG0098 } & \text { J } & 100.00 & 100.00 \\ \text { COG0256 } & \text { J } & 100.00 & 100.00 \\ \text { COG0097 } & \text { J } & 100.00 & 100.00 \\ \text { COG0096 } & \text { J } & 100.00 & 100.00 \\ \text { COG0199 } & \text { J } & 100.00 & 100.00 \\ \text { COG0094 } & \text { J } & 100.00 & 100.00 \\ \text { COG0198 } & \text { J } & 100.00 & 100.00 \\ \text { COG0093 } & \text { J } & 100.00 & 100.00 \\ \text { COG0186 } & \text { J } & 100.00 & 100.00 \\ \text { COG0255 } & \text { J } & 70.53 & 100.00 \\ & & 71.98 & 95.65 \\ \text { COG0089 } & \mathrm{J} & 100.00 & 100.00 \\ \text { COG0088 } & \mathrm{J} & 100.00 & 100.00 \\ \text { COG0087 } & \mathrm{J} & 100.00 & 100.00 \\ \text { COG0051 } & \mathrm{J} & 100.00 & 100.00 \\ \text { COG0050 } & \mathrm{J} & 100.00 & 31.12 \\ \text { COG0480 } & \mathrm{J} & 100.00 & 100.00 \\ \text { COG0049 } & \mathrm{J} & 100.00 & 100.00 \\ \text { COG0048 } & \mathrm{J} & 100.00 & 100.00 \\ \text { COG1072 } & \mathrm{H} & 100.00 & 51.54 \\ \text { COG1129 } & \mathrm{G} & 100.00 & 94.47 \\ \text { COG1172 } & \mathrm{G} & 100.00 & 100.00 \\ \text { COG1879 } & \mathrm{G} & 100.00 & 96.82 \\ \text { COG1940 } & \mathrm{K} & 100.00 & 86.31 \\ \text { COG2755 } & \mathrm{E} & 100.00 & 100.00 \\ \text { COG1136 } & \mathrm{V} & 100.00 & 100.00 \\ \text { COG3127 } & \mathrm{Q} & 100.00 & 100.00 \\ \text { COG0463 } & \mathrm{M} & 95.78 & 100.00 \\ \text { COG0161 } & \mathrm{H} & 100.00 & 100.00 \\ \text { COG0006 } & \mathrm{E} & 100.00 & 100.00 \\ & & 100.00 & 100.00\end{array}$




\begin{tabular}{|c|c|c|c|c|c|c|}
\hline RCA23_c24360 & 4-coumarate--CoA ligase & COG0318 & \multicolumn{2}{|l|}{ I } & 100.00 & 100.00 \\
\hline RCA23_c24370 & hypothetical protein & COG0679 & \multicolumn{2}{|l|}{$\mathrm{R}$} & 100.00 & 100.00 \\
\hline RCA23_c24380 & hypothetical protein DUF125 & COG1814 & \multicolumn{2}{|l|}{$\mathrm{s}$} & 100.00 & 100.00 \\
\hline RCA23_c24390 & transcriptional regulator, AsnC family & COG1522 & \multicolumn{2}{|l|}{ K } & 100.00 & 86.95 \\
\hline RCA23_c24400 & arginase ArcA & COG0010 & \multicolumn{2}{|l|}{ E } & 100.00 & 100.00 \\
\hline RCA23_c24410 & ornithine cyclodeaminase ArcB & COG2423 & \multicolumn{2}{|l|}{ E } & 100.00 & 100.00 \\
\hline RCA23_c24420 & bifunctional protein PutA & COG4230 & \multirow{3}{*}{\multicolumn{2}{|c|}{ C }} & 100.00 & 100.00 \\
\hline RCA23_c24430 & hypothetical protein & & & & 0.00 & 100.00 \\
\hline RCA23_c24440 & hypothetical protein & & & & 0.00 & 100.00 \\
\hline RCA23_c24460 & hypothetical protein & & & & 100.00 & 100.00 \\
\hline RCA23_c24450 & creatinase & COG0006 & \multicolumn{2}{|l|}{$E$} & 100.00 & 100.00 \\
\hline RCA23_c24470 & putative hydrolase & COG0596 & \multicolumn{2}{|l|}{$\mathrm{R}$} & 95.99 & 0.00 \\
\hline RCA23_c24480 & glycine betaine/L-proline transport system permease protein ProW & COG4176 & \multicolumn{2}{|l|}{$\mathrm{E}$} & 100.00 & 46.78 \\
\hline RCA23_c24490 & glycine betaine/L-proline transport ATP-binding protein ProV & COG4175 & \multicolumn{2}{|l|}{$\mathrm{E}$} & 19.41 & 5.59 \\
\hline RCA23_c24500 & glycine betaine-binding periplasmic protein ProX & COG2113 & \multicolumn{2}{|l|}{ E } & 13.46 & 13.87 \\
\hline RCA23_c24510 & putative HTH-type transcriptional regluator, LysR family & COG0583 & \multicolumn{2}{|l|}{ K } & 100.00 & 85.20 \\
\hline RCA23_c24520 & D-cysteine desulfhydrase DcyD & COG2515 & \multicolumn{2}{|l|}{ E } & 100.00 & 100.00 \\
\hline RCA23_c24530 & hypothetical protein & & & & 100.00 & 86.27 \\
\hline RCA23_c24540 & high-affinity zinc uptake system protein ZnuA & COG4531 & \multicolumn{2}{|l|}{$\mathrm{P}$} & 100.00 & 100.00 \\
\hline RCA23_c24550 & zinc uptake regulator & COG0735 & \multicolumn{2}{|l|}{$P$} & 100.00 & 100.00 \\
\hline RCA23_c24560 & zinc import ATP-binding protein ZnuC & COG1121 & \multicolumn{2}{|l|}{$P$} & 100.00 & 100.00 \\
\hline RCA23_c24570 & high-affinity zinc uptake system membrane protein ZnuB & COG1108 & \multicolumn{2}{|l|}{$\mathrm{P}$} & 100.00 & 100.00 \\
\hline RCA23_c24580 & 4-hydroxyphenylpyruvate dioxygenase $\mathrm{Hpd}$ & COG3185 & \multicolumn{2}{|l|}{$\mathrm{E}$} & 100.00 & 97.53 \\
\hline RCA23_c24590 & hypothetical protein & & & GI 9 & 0.00 & 83.48 \\
\hline RCA23_c24600 & hypothetical protein & & & GI 9 & 0.00 & 64.23 \\
\hline RCA23_c24610 & hypothetical protein & COG1028 & 1 & GI 9 & 21.14 & 100.00 \\
\hline RCA23_c24620 & hypothetical protein & COG1402 & $\mathrm{R}$ & GI 9 & 100.00 & 77.28 \\
\hline RCA23_c24630 & putative gluconolactonase & COG3386 & G & GI 9 & 100.00 & 95.04 \\
\hline RCA23_c24640 & ribokinase RbsK & COG0524 & G & GI 9 & 100.00 & 100.00 \\
\hline RCA23_c24650 & ribose $A B C$ transporter protein $\mathrm{Rbs} D$ & COG4154 & G & GI 9 & 100.00 & 79.69 \\
\hline RCA23_c24660 & putative ribose $A B C$ transporter, $A T P$-binding protein $\mathrm{Rbs} A$ & COG3839 & G & GI 9 & 100.00 & 96.72 \\
\hline RCA23_c24670 & putative ribose $A B C$ transporter, substrate binding protein $R b s B$ & COG1653 & G & GI 9 & 100.00 & 92.16 \\
\hline RCA23_c24680 & putative ribose $A B C$ transporter, permease protein $\mathrm{Rbs} C$ & COG1175 & G & GI 9 & 100.00 & 100.00 \\
\hline
\end{tabular}


RCA23 c24690 putative ribose ABC transporter, permease protein RbsC

RCA23 c24700

RCA23_c24710

RCA23 c24720

RCA23 c24730

RCA23_c24740

RCA23_c24750

RCA23_c24760

RCA23_c24770

RCA23_c24780

RCA23 c24790

RCA23_c24800

RCA23_c24810

RCA23 c24820

RCA23_c24830

RCA23_c24840

RCA23 c24850

RCA23 c24860

RCA23_c24870

RCA23 c24880

RCA23_c24890

RCA23 c24900

RCA23_c24920

RCA23_c24930

RCA23_c24940

RCA23 c24950

RCA23_c24960

RCA23_c24970

RCA23_c24980

RCA23 c24990

RCA23_c25000

RCA23_c25010

RCA23 c25020

hypothetical protein, L-fucose isomerase-like

ugar isomerase

xylulose kinase XylB

aminopeptidase SgcX

photosystem I biogenesis protein BtpA

pyridoxal 4-dehydrogenase Pld

putative amidohydrolase

putative carbohydrate kinase, pfkB family

xylose isomerase family protein

putative HTH-type transcriptional regulator, GntR family

mandelate racemase/muconate lactonizing enzyme

atty acid desaturase

hypothetical protein

transposase

transporter, LysE family

hypothetical protein

putative transporter, periplasmic binding protein

ribitol 2-dehydrogenase RbtD

hypothetical protein

putative phage integrase

D-alanyl-D-alanine carboxypeptidase DacC

thymidylate kinase Tmk

hypothetical protein, DNA polymerase III delta subunit

TatD family deoxyribonuclease

hypothetical protein, metallo-beta-lactamase

membrane transport protein

FAD dependent oxidoreductase

UvrABC system protein B

hypothetical protein

hypothetical protein
UDP-N-acetylglucosamine--peptide N-acetylglucosaminyltransferase 110 kDa

hypothetical protein

\begin{tabular}{|c|c|c|c|c|}
\hline \multirow[t]{2}{*}{ COG0395 } & G & GI 9 & 100.00 & 80.61 \\
\hline & & GI 9 & 100.00 & 99.66 \\
\hline COG0794 & $M$ & GI 9 & 100.00 & 81.72 \\
\hline COG1070 & G & GI 9 & 24.61 & 100.00 \\
\hline COG1363 & G & GI 9 & 0.00 & 86.83 \\
\hline COG0434 & $\mathrm{R}$ & GI 9 & 0.00 & 100.00 \\
\hline COG0667 & C & GI 9 & 17.69 & 100.00 \\
\hline COG3618 & $\mathrm{R}$ & GI 9 & 100.00 & 100.00 \\
\hline COG0524 & G & GI 9 & 100.00 & 100.00 \\
\hline COG4952 & $M$ & GI 9 & 100.00 & 98.89 \\
\hline COG1802 & $\mathrm{K}$ & GI 9 & 100.00 & 100.00 \\
\hline COG4948 & $M$ & GI 9 & 100.00 & 100.00 \\
\hline \multirow[t]{2}{*}{ COG3239 } & I & GI 9 & 0.00 & 100.00 \\
\hline & & GI 9 & 0.00 & 41.32 \\
\hline COG3316 & $\mathrm{L}$ & GI 9 & 0.00 & 0.00 \\
\hline \multirow[t]{2}{*}{ COG 1280} & $E$ & GI 9 & 0.00 & 0.00 \\
\hline & & GI 9 & 0.00 & 68.85 \\
\hline COG2358 & $\mathrm{R}$ & GI 9 & 0.00 & 0.00 \\
\hline \multirow[t]{2}{*}{ COG4221 } & $\mathrm{R}$ & GI 9 & 0.00 & 0.00 \\
\hline & & GI 9 & 0.00 & 16.00 \\
\hline COG0457 & $\mathrm{R}$ & GI 9 & 0.00 & 24.22 \\
\hline COG4974 & $\mathrm{L}$ & GI 9 & 100.00 & 50.82 \\
\hline COG1686 & $M$ & & 69.53 & 100.00 \\
\hline COG0125 & $\mathrm{F}$ & & 100.00 & 98.54 \\
\hline COG2812 & $\mathrm{L}$ & & 100.00 & 100.00 \\
\hline COG0084 & $\mathrm{L}$ & & 100.00 & 100.00 \\
\hline COG1235 & $\mathrm{R}$ & & 100.00 & 100.00 \\
\hline COG0679 & $\mathrm{R}$ & & 100.00 & 88.92 \\
\hline COG0665 & $E$ & & 100.00 & 100.00 \\
\hline \multirow[t]{4}{*}{ COG0556 } & $\mathrm{L}$ & & 100.00 & 94.66 \\
\hline & & & 100.00 & 89.12 \\
\hline & & & 100.00 & 72.28 \\
\hline & & & 100.00 & 100.00 \\
\hline
\end{tabular}


RCA23_c25030 lysyl-tRNA synthase LysS

\begin{tabular}{|c|c|c|c|}
\hline \multirow[t]{2}{*}{ COG1384 } & $\mathrm{J}$ & 100.00 & 93.21 \\
\hline & & 100.00 & 100.00 \\
\hline \multirow[t]{2}{*}{ COG2027 } & $\mathrm{M}$ & 100.00 & 100.00 \\
\hline & & 100.00 & 100.00 \\
\hline COG1057 & $\mathrm{H}$ & 100.00 & 100.00 \\
\hline COG0488 & $\mathrm{R}$ & 100.00 & 100.00 \\
\hline COG1278 & $\mathrm{K}$ & 100.00 & 100.00 \\
\hline COG0008 & $\mathrm{J}$ & 100.00 & 100.00 \\
\hline COG0171 & $\mathrm{H}$ & 100.00 & 98.47 \\
\hline COG4642 & $S$ & 69.37 & 100.00 \\
\hline COG1028 & 1 & 100.00 & 100.00 \\
\hline COG0119 & $E$ & 100.00 & 100.00 \\
\hline COG1077 & $\mathrm{D}$ & 100.00 & 99.33 \\
\hline \multirow[t]{2}{*}{ COG1792 } & $M$ & 100.00 & 100.00 \\
\hline & & 100.00 & 96.48 \\
\hline COG0768 & $M$ & 100.00 & 100.00 \\
\hline COG0772 & $\mathrm{D}$ & 100.00 & 100.00 \\
\hline \multirow[t]{2}{*}{ COG0111 } & $\mathrm{H}$ & 100.00 & 100.00 \\
\hline & & 100.00 & 100.00 \\
\hline COG1573 & $\mathrm{L}$ & 100.00 & 100.00 \\
\hline COG3004 & $P$ & 100.00 & 100.00 \\
\hline COG1134 & G & 100.00 & 96.36 \\
\hline COG3524 & $M$ & 100.00 & 100.00 \\
\hline COG1832 & $\mathrm{R}$ & 100.00 & 100.00 \\
\hline \multirow[t]{2}{*}{ COG0633 } & $\mathrm{C}$ & 100.00 & 100.00 \\
\hline & & 100.00 & 100.00 \\
\hline COG1012 & $\mathrm{C}$ & 100.00 & 100.00 \\
\hline COG1804 & $\mathrm{C}$ & 100.00 & 100.00 \\
\hline COG0347 & $E$ & 100.00 & 100.00 \\
\hline COG0004 & $\mathrm{P}$ & 100.00 & 100.00 \\
\hline COG1846 & $\mathrm{K}$ & 100.00 & 100.00 \\
\hline COG1012 & $\mathrm{C}$ & 100.00 & 100.00 \\
\hline COG0346 & $E$ & 100.00 & 100.00 \\
\hline
\end{tabular}


RCA23_c25410 4-carboxymuconolactone decarboxylase PcaC

COG0599

RCA23_c25420 hypothetical protein

RCA23_c25430 transcriptional regulatory protein

RCA23_c25440 two component signal transduction histidine kinase ChvG

COG0745

RCA23_c25450 hypothetical protein

RCA23_c25460 $\mathrm{Na}(+)$-phosphate symporter Pit

$100.00 \quad 100.00$




\begin{tabular}{|c|c|c|c|c|c|}
\hline RCA23_c25700 & GTP-binding protein Era & COG1159 & $\mathrm{R}$ & 100.00 & 100.00 \\
\hline RCA23_c25710 & ribonuclease 3 & COG0571 & $\mathrm{K}$ & 100.00 & 100.00 \\
\hline RCA23_c25720 & signal peptidase I & COG0681 & $\mathrm{U}$ & 100.00 & 100.00 \\
\hline RCA23_c25730 & holo-[acyl-carrier-protein] synthase AcpS & COG0736 & 1 & 100.00 & 100.00 \\
\hline RCA23_c25740 & pyridoxine 5'-phosphate synthase PdxJ & COG0854 & $\mathrm{H}$ & 89.25 & 100.00 \\
\hline RCA23_c25750 & hypothetical protein DUF2062 & COG3216 & $\mathrm{S}$ & 0.00 & 100.00 \\
\hline RCA23_c25760 & guanosine-3',5'-bis(diphosphate) 3'-pyrophosphohydrolase SpoT & COG0317 & $\mathrm{T}$ & 97.23 & 96.31 \\
\hline RCA23_c25770 & DNA-directed RNA polymerase subunit omega & COG1758 & $\mathrm{K}$ & 100.00 & 100.00 \\
\hline RCA23_c25780 & putative 2-amino-4-hydroxy-6-hydroxymethyldihydropteridine pyrophosphok & COG0801 & $\mathrm{H}$ & 100.00 & 96.41 \\
\hline RCA23_c25790 & hypothetical protein DUF88 & COG1432 & $\mathrm{S}$ & 100.00 & 100.00 \\
\hline RCA23_c25800 & 4-hydroxy-3-methylbut-2-enyl diphosphate reductase IspH & COG0761 & 1 & 100.00 & 100.00 \\
\hline RCA23_c25810 & hypothetical protein, methyltransferase & COG2227 & $\mathrm{H}$ & 100.00 & 100.00 \\
\hline RCA23_c25820 & ribonuclease $\mathrm{H}$ & COG0328 & $\mathrm{L}$ & 100.00 & 100.00 \\
\hline RCA23_c25830 & hypothetical protein & & & 100.00 & 100.00 \\
\hline RCA23_c25840 & methionyl-tRNA formyltransferase Fmt & COG0223 & $\mathrm{J}$ & 100.00 & 100.00 \\
\hline RCA23_c25850 & peptide deformylase Def & COG0242 & $\mathrm{J}$ & 100.00 & 100.00 \\
\hline RCA23_c25860 & peptide deformylase Def & COG0242 & $\mathrm{J}$ & 100.00 & 97.46 \\
\hline RCA23_c25870 & aminotransferase & COG1168 & $\mathrm{E}$ & 100.00 & 95.20 \\
\hline RCA23_c25880 & hypothetical protein & & & 100.00 & 100.00 \\
\hline RCA23_c25890 & precorrin-4 C(11)-methyltransferase CobM & COG2875 & $\mathrm{H}$ & 100.00 & 100.00 \\
\hline RCA23_c25900 & precorrin-3B $C(17)$-methyltransferase CobJ & COG1010 & $\mathrm{H}$ & 100.00 & 100.00 \\
\hline RCA23_c25910 & precorrin-2 $C(20)$-methyltransferase Cobl & COG2243 & $\mathrm{H}$ & 100.00 & 100.00 \\
\hline RCA23_c25920 & precorrin-6Y $C(5,15)$-methyltransferase CobL & COG2242 & $\mathrm{H}$ & 100.00 & 100.00 \\
\hline RCA23_c25930 & precorrin-8X methylmutase CobH & COG2082 & $\mathrm{H}$ & 100.00 & 100.00 \\
\hline RCA23_c25940 & sirohydrochlorin cobaltochelatase CbiX & COG2138 & $\mathrm{S}$ & 100.00 & 100.00 \\
\hline RCA23_c25950 & methyltransferase, FkbM family & COG3774 & $\mathrm{M}$ & 45.28 & 7.19 \\
\hline RCA23_c25960 & hypothetical protein, glutathione S-transferase & COG0435 & 0 & 100.00 & 100.00 \\
\hline RCA23_c25970 & hypothetical protein DUF1636 & COG5469 & $S$ & 100.00 & 100.00 \\
\hline RCA23_c25980 & threonine-phosphate decarboxylase CobC & COG0079 & $\mathrm{E}$ & 100.00 & 100.00 \\
\hline RCA23_c25990 & cobalamin biosynthesis protein CobD & COG1270 & $\mathrm{H}$ & 100.00 & 100.00 \\
\hline RCA23_c26000 & putative peptidoglycan-binding lytic murein transglycosylase & COG2951 & M & 100.00 & 100.00 \\
\hline RCA23_c26010 & putative chromosome partition protein smc & COG1196 & $\mathrm{D}$ & 100.00 & 98.50 \\
\hline RCA23_c26020 & hypothetical protein & & & 100.00 & 100.00 \\
\hline
\end{tabular}




\begin{tabular}{|c|c|}
\hline RCA23_c26030 & hypothetical protein \\
\hline RCA23_c26040 & hypothetical protein DUF81 \\
\hline RCA23_c26050 & $50 S$ ribosomal protein $L 2$ \\
\hline RCA23_c26060 & 30 S ribosomal protein S19 \\
\hline RCA23_c26070 & $50 S$ ribosomal protein $\mathrm{L} 22$ \\
\hline RCA23_c26080 & $30 S$ ribosomal protein S3 \\
\hline RCA23_c26090 & $50 S$ ribosomal protein L16 \\
\hline RCA23_c26100 & hypothetical protein \\
\hline RCA23_c26120 & hypothetcial protein \\
\hline RCA23_c26130 & transcriptional regulator \\
\hline RCA23_c26140 & hypothetical protein \\
\hline RCA23_c26150 & hypothetical protein, UPF0311 \\
\hline RCA23_c26160 & transcriptional regulator, MarR family \\
\hline RCA23_c26170 & long-chain-fatty-acid-CoA-ligase \\
\hline RCA23_c26180 & TRAP dicarboxylate transporter, subunit DctM \\
\hline RCA23_c26190 & TRAP dicarboxylate transporter, subunit DctQ \\
\hline RCA23_c26200 & TRAP dicarboxylate transporter, subunit DctP \\
\hline RCA23_c26210 & 3-hydroxybutyryl-CoA dehydratase Crt \\
\hline RCA23_c26220 & metal-dependent hydrolase \\
\hline RCA23_c26230 & FAD dependent monooxygenase \\
\hline RCA23_c26240 & arylsulfatase \\
\hline RCA23_c26250 & transcriptional regulator, MarR family \\
\hline RCA23_c26260 & putative transporter, periplasmic binding protein \\
\hline RCA23_c26270 & TRAP transporter, 4TM/12TM fusion protein \\
\hline RCA23_c26280 & hypothetical protein, UPF0261 \\
\hline RCA23_c26290 & gamma-glutamylputrescine synthase PuuA \\
\hline RCA23_c26300 & cytochrome P450 \\
\hline RCA23_c26310 & glutamine amidotransferase class-I \\
\hline RCA23_c26320 & tripartite tricarboxylate transporter (TTT) protein TctC \\
\hline RCA23_c26330 & tripartite tricarboxylate transporter (TTT) protein TctA \\
\hline RCA23_c26340 & hypothetical protein, transmembrane \\
\hline RCA23_c26350 & gamma-glutamyl-gamma-aminobutyraldehyde dehydrogenase PuuC \\
\hline RCA23_c26360 & hypothetical protein \\
\hline
\end{tabular}

\begin{tabular}{|c|c|c|c|c|}
\hline COG1028 & I & & 100.00 & 95.56 \\
\hline COG0730 & $\mathrm{R}$ & & 100.00 & 100.00 \\
\hline COG0090 & J & & 100.00 & 98.31 \\
\hline COG0185 & $\mathrm{J}$ & & 100.00 & 100.00 \\
\hline COG0091 & J & & 100.00 & 100.00 \\
\hline COG0092 & J & & 100.00 & 100.00 \\
\hline \multirow[t]{2}{*}{ COG0197 } & J & & 100.00 & 100.00 \\
\hline & & GI 10 & 100.00 & 100.00 \\
\hline \multirow[t]{4}{*}{ COG0666 } & $\mathrm{R}$ & GI 10 & 0.00 & 0.00 \\
\hline & & GI 10 & 0.00 & 61.06 \\
\hline & & GI 10 & 0.00 & 54.41 \\
\hline & & GI 10 & 52.81 & 100.00 \\
\hline COG1846 & K & GI 10 & 100.00 & 100.00 \\
\hline COG0318 & 1 & GI 10 & 100.00 & 100.00 \\
\hline \multirow[t]{2}{*}{ COG1593 } & G & GI 10 & 100.00 & 89.01 \\
\hline & & GI 10 & 100.00 & 55.75 \\
\hline COG1638 & G & GI 10 & 100.00 & 98.36 \\
\hline COG1024 & I & GI 10 & 100.00 & 92.11 \\
\hline COG2159 & $\mathrm{R}$ & GI 10 & 100.00 & 94.61 \\
\hline COG0654 & $\mathrm{H}$ & GI 10 & 100.00 & 85.76 \\
\hline COG3119 & P & GI 10 & 100.00 & 82.21 \\
\hline COG1846 & K & GI 10 & 100.00 & 58.78 \\
\hline COG2358 & $\mathrm{R}$ & GI 10 & 100.00 & 86.08 \\
\hline COG4666 & $R$ & GI 10 & 100.00 & 70.89 \\
\hline COG5441 & $\mathrm{S}$ & GI 10 & 100.00 & 88.29 \\
\hline COG0174 & $\mathrm{E}$ & GI 10 & 100.00 & 100.00 \\
\hline COG2124 & Q & GI 10 & 77.02 & 64.97 \\
\hline COG0518 & $\mathrm{F}$ & GI 10 & 0.00 & 90.85 \\
\hline COG3181 & $\mathrm{S}$ & GI 10 & 41.28 & 95.46 \\
\hline \multirow[t]{2}{*}{ COG3333 } & $S$ & GI 10 & 47.59 & 100.00 \\
\hline & & GI 10 & 0.00 & 64.08 \\
\hline \multirow[t]{2}{*}{ COG1012 } & C & GI 10 & 51.89 & 100.00 \\
\hline & & GI 10 & 0.00 & 0.00 \\
\hline
\end{tabular}




\begin{tabular}{|c|c|c|c|c|c|c|}
\hline RCA23_c26370 & hypothetical protein & & & GI 10 & 0.00 & 0.00 \\
\hline RCA23_c26380 & hypothetical protein & & & GI 10 & 0.00 & 0.00 \\
\hline RCA23_c26390 & putative fucosyltransferase & & & GI 10 & 0.00 & 0.00 \\
\hline RCA23_c26400 & integrase & COG2801 & $\mathrm{L}$ & GI 10 & 0.00 & 91.19 \\
\hline RCA23_c26410 & putative extracellular solute-binding protein & COG1840 & $\mathrm{P}$ & GI 10 & 96.80 & 37.21 \\
\hline RCA23_c26420 & two-component system, sensor histidine kinase protein & COG0642 & $\mathrm{T}$ & GI 10 & 100.00 & 32.90 \\
\hline RCA23_c26430 & two-component system, response regulator protein & COG0745 & $\mathrm{T}$ & GI 10 & 100.00 & 47.68 \\
\hline RCA23_c26440 & tripartite tricarboxylate transporter (TTT) protein TctC & COG3181 & $\mathrm{S}$ & GI 10 & 80.50 & 100.00 \\
\hline RCA23_c26450 & tripartite tricarboxylate transporter (TTT) protein TctB & & & GI 10 & 100.00 & 100.00 \\
\hline RCA23_c26460 & tripartite tricarboxylate transporter (TTT) protein TctA & COG3333 & $\mathrm{S}$ & GI 10 & 100.00 & 99.07 \\
\hline RCA23_c26470 & hypothetical protein & & & GI 10 & 100.00 & 100.00 \\
\hline RCA23_c26480 & hypothetical protein & & & GI 10 & 100.00 & 100.00 \\
\hline RCA23_c26490 & transposase A & & & GI 10 & 7.56 & 86.83 \\
\hline RCA23_c26510 & hypothetical protein & & & GI 10 & 0.00 & 0.00 \\
\hline RCA23_c26520 & hypothetical protein & COG1709 & $\mathrm{K}$ & GI 10 & 0.00 & 0.00 \\
\hline RCA23_c26530 & hypothetical protein & & & GI 10 & 0.00 & 0.00 \\
\hline RCA23_c26540 & putative RTX toxin and hemolysin-type calcium binding protein & & & GI 10 & 0.00 & 0.00 \\
\hline RCA23_c26550 & putative RTX toxin and hemolysin-type calcium binding protein & & & GI 10 & 7.47 & 5.66 \\
\hline RCA23_c26560 & type I secretion outer membrane protein, TolC family & COG1538 & M & GI 10 & 94.05 & 90.27 \\
\hline RCA23_c26570 & type I secretion system ATP-binding component & COG2274 & $\mathrm{V}$ & GI 10 & 84.42 & 96.96 \\
\hline RCA23_c26580 & type I RTX secretion system membrane fusion protein, HlyD family & COG1566 & $\mathrm{V}$ & GI 10 & 100.00 & 100.00 \\
\hline RCA23_c26590 & hypothetical protein & & & GI 10 & 100.00 & 100.00 \\
\hline RCA23_c26600 & hypothetical protein & & & GI 10 & 100.00 & 99.21 \\
\hline RCA23_c26610 & hypothetical protein & & & GI 10 & 100.00 & 100.00 \\
\hline RCA23_c26620 & hypothetical protein & & & GI 10 & 100.00 & 100.00 \\
\hline RCA23_c26630 & hypothetical protein DUF2125 & & & GI 10 & 100.00 & 100.00 \\
\hline RCA23_c26640 & Asp/Glu racemase & COG3473 & Q & GI 10 & 88.47 & 100.00 \\
\hline RCA23_c26650 & cystathionine beta-lyase & COG0626 & $\mathrm{E}$ & GI 10 & 100.00 & 100.00 \\
\hline RCA23_c26660 & deoxyribodipyrimidine photo-lyase $\mathrm{PhrB}$ & COG0415 & $\mathrm{L}$ & GI 10 & 100.00 & 100.00 \\
\hline RCA23_c26670 & hypothetical protein & COG3380 & $\mathrm{R}$ & GI 10 & 100.00 & 100.00 \\
\hline RCA23_c26680 & O-sialoglycoprotein endopeptidase Gcp & COG0533 & $\mathrm{O}$ & GI 10 & 100.00 & 100.00 \\
\hline RCA23_c26690 & Sua5/YciO/YrdC/YwlC family protein & COG0009 & $\mathrm{J}$ & GI 10 & 100.00 & 100.00 \\
\hline RCA23_c26700 & putative glycoprotease family protein & COG1214 & $\mathrm{O}$ & GI 10 & 100.00 & 100.00 \\
\hline
\end{tabular}


RCA23_c26710 hypothetical protein UPF0079

RCA23_c26720 xylose isomerase family protein

RCA23_c26730 putative phage integrase

RCA23_c26740 hypothetical protein

RCA23_c26750 putative prophage regulatory protein

RCA23_c26760 hypothetical protein

RCA23_c26770 DNA polymerase

RCA23_c26780 hypothetical protein

RCA23_c26790 hypothetical protein, snoaL-like polyketide cyclase

RCA23_c26800 hypothetical protein

RCA23_c26810 glyoxalase/bleomycin resistance protein/dioxygenase superfamily protein

RCA23_c26820 hypothetical protein

RCA23_c26830 putative ABC transporter permease protein

RCA23 c26840 putative $A B C$ transporter permease protein

RCA23_c26850 putative ABC transporter extracellular solute binding protein

RCA23_c26860 ABC transporter ATP-binding protein

RCA23_c26870 histidinol dehydrogenase HisD

RCA23_c26880 hypothetical protein, snoaL-like polyketide cyclase

RCA23_c26890 short chain dehydrogenase

RCA23_c26900 putative HTH-type transcriptional regulator Lacl family

RCA23_c26910 hypothetical protein, snoaL-like polyketide cyclase

RCA23_c26920 hypothetical protein

RCA23_c26930 hypothetical protein, 2-hydroxypropyl-CoM lyase-like

RCA23 c26940 hypothetical protein, alpha/beta hydrolase-like

RCA23_c26950 hypothetical protein

RCA23_c26960 3-hydroxyisobutyrate dehydrogenase MmsB

RCA23_c26970 dihydroxy-acid dehydratase IlvD

RCA23_c26980 hypothetical protein

RCA23_c26990 putative choline (or alcohol) dehydrogenase

RCA23_c27000 aldehyde dehydrogenase

RCA23_c27010 transporter, LysE family

RCA23_c27020 TRAP dicarboxylate transporter, subunit DctM

RCA23_c27030 TRAP dicarboxylate transporter, subunit DctQ

\begin{tabular}{|c|c|c|c|c|}
\hline COG0802 & $\mathrm{R}$ & GI 10 & 100.00 & 100.00 \\
\hline COG3622 & G & GI 10 & 31.51 & 100.00 \\
\hline \multirow[t]{2}{*}{ COG0582 } & $\mathrm{L}$ & GI 10 & 0.00 & 79.94 \\
\hline & & GI 10 & 0.00 & 74.23 \\
\hline \multirow[t]{2}{*}{ COG3311 } & $\mathrm{K}$ & GI 10 & 0.00 & 0.00 \\
\hline & & GI 10 & 0.00 & 0.00 \\
\hline \multirow[t]{2}{*}{ COG0749 } & $\mathrm{L}$ & GI 10 & 0.00 & 67.34 \\
\hline & & GI 10 & 0.00 & 0.00 \\
\hline \multirow[t]{4}{*}{ COG5485 } & $\mathrm{R}$ & GI 10 & 0.00 & 0.00 \\
\hline & & GI 10 & 0.00 & 56.96 \\
\hline & & GI 10 & 0.00 & 0.00 \\
\hline & & GI 10 & 0.00 & 16.37 \\
\hline COG0395 & G & Gl 10 & 0.00 & 0.00 \\
\hline COG1175 & G & Gl 10 & 0.00 & 0.00 \\
\hline COG1653 & G & Gl 10 & 0.00 & 0.00 \\
\hline COG3839 & G & GI 10 & 0.00 & 0.00 \\
\hline COG0141 & $E$ & GI 10 & 0.00 & 0.00 \\
\hline COG5485 & $\mathrm{R}$ & GI 10 & 0.00 & 0.00 \\
\hline COG1028 & I & GI 10 & 32.12 & 34.95 \\
\hline \multirow[t]{3}{*}{ COG1609 } & $\mathrm{K}$ & GI 10 & 100.00 & 0.00 \\
\hline & & GI 10 & 30.64 & 1.00 \\
\hline & & Gl 10 & 80.64 & 23.91 \\
\hline COG0620 & $E$ & GI 10 & 73.76 & 0.00 \\
\hline COG0596 & $\mathrm{R}$ & GI 10 & 0.00 & 0.00 \\
\hline COG0684 & $\mathrm{H}$ & GI 10 & 0.00 & 0.00 \\
\hline COG2084 & I & GI 10 & 33.55 & 11.59 \\
\hline COG0129 & $E$ & GI 10 & 100.00 & 36.50 \\
\hline COG4091 & $E$ & GI 10 & 33.78 & 51.45 \\
\hline COG2303 & $E$ & GI 10 & 4.21 & 29.85 \\
\hline COG1012 & C & GI 10 & 100.00 & 76.74 \\
\hline COG1280 & $\mathrm{E}$ & GI 10 & 100.00 & 0.17 \\
\hline COG4664 & $Q$ & GI 10 & 100.00 & 24.34 \\
\hline COG4665 & $Q$ & GI 10 & 25.53 & 41.49 \\
\hline
\end{tabular}




\begin{tabular}{|c|c|}
\hline RCA23_c27040 & TRAP dicarboxylate transporter, subunit DctP \\
\hline RCA23_c27050 & transcriptional regulator, LysR family \\
\hline RCA23_c27060 & mandelate racemase/muconate lactonizing enzyme \\
\hline RCA23_c27070 & Zn-dependant oxidoreductase \\
\hline RCA23_c27090 & HTH-type transcriptional regulator, LysR family \\
\hline RCA23_c27100 & class II aldolase \\
\hline RCA23_c27110 & fatty acid desaturase \\
\hline RCA23_c27120 & 3-methyl-2-oxobutanoate hydroxymethyltransferase PanB \\
\hline RCA23_c27130 & putative rieske $[2 \mathrm{Fe}-2 \mathrm{~S}]$ protein \\
\hline RCA23_c27150 & hypothetical protein \\
\hline RCA23_c27160 & arginase family protein \\
\hline RCA23_c27170 & hypothetical protein \\
\hline RCA23_c27180 & putative HTH-type transcriptional regulator, AraC family \\
\hline RCA23_c27190 & hypothetical protein. fatty acid desaturase \\
\hline RCA23_c27200 & AMP-dependent synthase / ligase \\
\hline RCA23_c27210 & ABC transporter ATP-binding protein \\
\hline RCA23_c27220 & spore coat family protein \\
\hline RCA23_c27230 & PapD-like chaperone involved in fimbrial biogenesis \\
\hline RCA23_c27240 & fimbrial biogenesis outer membrane usher protein \\
\hline RCA23_c27250 & fimbrial biogenesis outer membrane usher protein \\
\hline RCA23_c27260 & hypothetical protein \\
\hline RCA23_c27280 & hypothetical protein \\
\hline RCA23_c27290 & DNA-directed RNA polymerase beta subunit RpoC \\
\hline RCA23_c27300 & DNA-directed RNA polymerase beta subunit RpoB \\
\hline RCA23_c27310 & 50S ribosomal protein L7/L12 \\
\hline RCA23_c27320 & $50 S$ ribosomal protein $\mathrm{L} 10$ \\
\hline RCA23_c27330 & $50 S$ ribosomal protein $\mathrm{L} 1$ \\
\hline RCA23_c27340 & $50 S$ ribosomal protein L11 \\
\hline RCA23_c27350 & transcription antitermination protein NusG \\
\hline RCA23_c27360 & preprotein translocase, subunit SecE \\
\hline RCA23_c27370 & hypothetical protein \\
\hline RCA23_c27430 & hypothetical protein \\
\hline RCA23_c27440 & hypothetical protein, transmembrane \\
\hline
\end{tabular}

\begin{tabular}{|c|c|c|c|c|}
\hline COG4663 & $Q$ & GI 10 & 0.00 & 0.00 \\
\hline COG0583 & K & GI 10 & 0.00 & 66.37 \\
\hline COG4948 & $M$ & GI 10 & 100.00 & 100.00 \\
\hline COG0604 & C & GI 10 & 56.06 & 97.66 \\
\hline COG0583 & K & GI 10 & 0.00 & 70.65 \\
\hline COG0235 & G & GI 10 & 0.00 & 29.10 \\
\hline COG3239 & I & GI 10 & 0.00 & 69.78 \\
\hline COG0413 & $\mathrm{H}$ & GI 10 & 0.00 & 30.86 \\
\hline COG2146 & $P$ & GI 10 & 0.00 & 89.00 \\
\hline COG1396 & K & & 100.00 & 100.00 \\
\hline COG0010 & $E$ & & 100.00 & 100.00 \\
\hline COG1082 & G & & 100.00 & 100.00 \\
\hline COG2169 & $\mathrm{F}$ & & 100.00 & 100.00 \\
\hline COG3239 & I & & 100.00 & 100.00 \\
\hline COG0318 & I & & 100.00 & 100.00 \\
\hline \multirow[t]{2}{*}{ COG1132 } & V & & 100.00 & 100.00 \\
\hline & & & 100.00 & 100.00 \\
\hline COG3121 & $\mathrm{N}$ & & 100.00 & 100.00 \\
\hline COG3188 & $\mathrm{N}$ & & 100.00 & 100.00 \\
\hline \multirow[t]{2}{*}{ CoG3188 } & $\mathrm{N}$ & & 100.00 & 100.00 \\
\hline & & & 100.00 & 100.00 \\
\hline COG0697 & G & & 100.00 & 100.00 \\
\hline COG0086 & K & & 86.33 & 100.00 \\
\hline COG0085 & K & & 100.00 & 100.00 \\
\hline COG0222 & J & & 100.00 & 100.00 \\
\hline COG0244 & J & & 100.00 & 100.00 \\
\hline COG0081 & J & & 100.00 & 100.00 \\
\hline COG0080 & J & & 100.00 & 100.00 \\
\hline COG0250 & K & & 100.00 & 100.00 \\
\hline \multirow[t]{4}{*}{ COG0690 } & U & & 100.00 & 100.00 \\
\hline & & & 100.00 & 100.00 \\
\hline & & & 100.00 & 100.00 \\
\hline & & & 100.00 & 100.00 \\
\hline
\end{tabular}




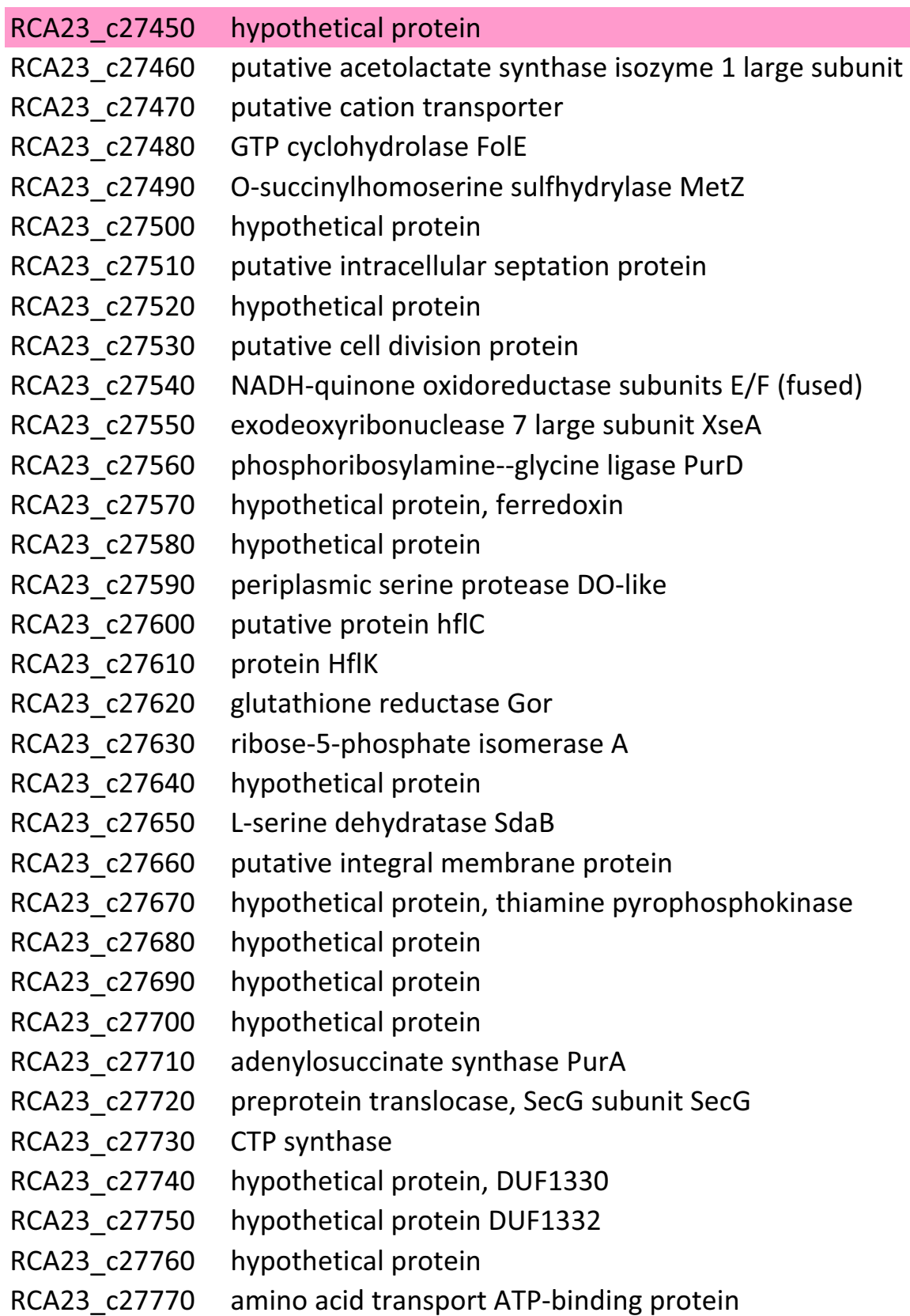

$\begin{array}{ll}\text { COG0028 } & \text { E } \\ \text { COG0168 } & \text { P } \\ \text { COG1469 } & \text { S } \\ \text { COG0626 } & \text { E } \\ \text { COG0625 } & \text { O } \\ \text { COG2917 } & \text { D } \\ \text { COG0697 } & \text { G } \\ \text { COG0552 } & \text { U } \\ \text { COG1894 } & \text { C } \\ \text { COG1570 } & \text { L } \\ \text { COG0151 } & \text { F } \\ \text { COG0633 } & \text { C } \\ \text { COG0587 } & \text { L } \\ \text { COG0265 } & \text { O } \\ \text { COG0330 } & \text { O } \\ \text { COG0330 } & \text { O } \\ \text { COG1249 } & \text { C } \\ \text { COG0120 } & \text { G } \\ & \\ \text { COG1760 } & \text { E } \\ \text { COG0697 } & \text { G } \\ \text { COG1564 } & \text { H }\end{array}$

COG0104

COG0504

COG5470

COG4103

COG3221

COG4598

$\begin{array}{rr}74.48 & 100.00 \\ 100.00 & 100.00 \\ 100.00 & 100.00 \\ 100.00 & 100.00 \\ 100.00 & 100.00 \\ 100.00 & 100.00 \\ 100.00 & 99.00 \\ 100.00 & 100.00 \\ 100.00 & 100.00 \\ 100.00 & 100.00 \\ 100.00 & 100.00 \\ 100.00 & 93.19 \\ 100.00 & 100.00 \\ 100.00 & 100.00 \\ 100.00 & 100.00 \\ 100.00 & 100.00 \\ 100.00 & 100.00 \\ 100.00 & 100.00 \\ 100.00 & 100.00 \\ 100.00 & 100.00 \\ 100.00 & 99.49 \\ 100.00 & 100.00 \\ 100.00 & 100.00 \\ 100.00 & 100.00 \\ 100.00 & 89.18 \\ 100.00 & 100.00 \\ 100.00 & 100.00 \\ 100.00 & 100.00 \\ 100.00 & 100.00 \\ 100.00 & 94.90 \\ 100.00 & 100.00 \\ 100.00 & 100.00 \\ 100.00 & 100.00\end{array}$


RCA23 c27780

RCA23 C27790

RCA23_c27800

RCA23 c27810

RCA23 c27820

RCA23_c27830

RCA23 c27840

RCA23_c27850

RCA23_c27860

RCA23_c27870

RCA23 c27880

RCA23_c27890

RCA23_c27900

RCA23 c27910

RCA23_c27920

RCA23_c27930

RCA23_c27940

RCA23_c27950

RCA23_c27960

RCA23_c27970

RCA23_c27980

RCA23_c27990

RCA23 c28000

RCA23_c28010

RCA23_c28020

RCA23_c28030

RCA23_c28040

RCA23_c28050

RCA23_c28060

RCA23_c28070

RCA23_c28080

RCA23_c28090

RCA23 c28100 putative amino acid transport extracellular solute binding protein

putative $A B C$ transporter inner membrane component

putative amino acid transport permease protein

gamma-glutamylputrescine synthase PuuA

hypothetical protein, glutamine amidotransferase class I

gamma-glutamylputrescine synthase PuuA

gamma-glutamylputrescine oxidoreductase PuuB

aminotransferase class III

putative PHB synthesis repressor protein

hypothetical protein

poly(R)-hydroxyalkanoic acid synthase PhaC

polyhydroxyalkanoate depolymerase PhaZ

putative ribosome biogenesis GTPase RsgA

hypothetical protein, alpha/beta hydrolase-like

hypothetical protein

hypothetical protein, alpha/beta hydrolase-like

threonyl-tRNA synthase ThrS

hypothetical protein, ArsC

thymidylate synthase

putative glyoxalase/bleomycin resistance protein/dioxygenase superfamily prı

hypothetical protein

putative transcriptional regulatorm marR family

hypothetical protein DUF339

hypothetical protein, DNA binding

aspartate aminotransferase AatA

hypothetical protein

multidrug resistance protein NorM

DNA topoisomerase 4 subunit B

hypothetical protein

putative malate/L-lactate dehydrogenase

lipoprotein-releasing system ATP-binding protein LolD

lipoprotein-releasing system transmembrane protein, IoIC/E family

prolyl-tRNA synthase ProS

\begin{tabular}{|c|}
\hline COG0834 \\
\hline COG4215 \\
\hline COG4160 \\
\hline COG0174 \\
\hline COG0518 \\
\hline COG0174 \\
\hline COG0665 \\
\hline COG0161 \\
\hline COG5394 \\
\hline COG3243 \\
\hline COG4553 \\
\hline COG1162 \\
\hline COG0596 \\
\hline COG0596 \\
\hline COG0441 \\
\hline COG1393 \\
\hline COG1351 \\
\hline COG0346 \\
\hline COG1846 \\
\hline COG2938 \\
\hline COG1813 \\
\hline COG0436 \\
\hline COG0534 \\
\hline COG0187 \\
\hline COG3238 \\
\hline COG2055 \\
\hline COG1136 \\
\hline COG4591 \\
\hline
\end{tabular}

100.00

100.00

100.00

(1)

100.00

100.00

100.00

100.00

100.00

100.00

100.00

100.00

100.00

98.97

100.00

100.00

100.00

100.00

100.00

100.00

100.00

100.00

100.00

100.00

100.00

100.00

100.00

100.00

100.00

100.00

100.00

100.00

100.00

100.00

100.00
100.00

100.00

98.51

100.00

100.00

97.62

100.00

100.00

100.00

100.00

99.60

100.00

100.00

100.00

100.00

95.74

100.00

100.00

100.00

100.00

100.00

100.00

100.00

100.00

100.00

100.00

100.00

100.00

99.90

100.00

100.00

100.00 


\begin{tabular}{|c|c|c|c|c|c|}
\hline RCA23_c28110 & hypothetical protein DUF20 & COG0628 & $\mathrm{R}$ & 100.00 & 100.00 \\
\hline RCA23_c28120 & hypothetical protein & COG0593 & L & 100.00 & 100.00 \\
\hline RCA23_c28130 & polyphosphate kinase Ppk & COG0855 & $\mathrm{P}$ & 100.00 & 100.00 \\
\hline RCA23_c28140 & putative phosphatase & COG0248 & $\mathrm{F}$ & 100.00 & 99.16 \\
\hline RCA23_c28150 & hypothetical protein, DnaJ & COG1076 & $\mathrm{O}$ & 100.00 & 100.00 \\
\hline RCA23_c28160 & hypothetical protein & & & 100.00 & 100.00 \\
\hline RCA23_c28170 & methylmalonyl-CoA mutase $\mathrm{McmA}$ & COG1884 & 1 & 100.00 & 100.00 \\
\hline RCA23_c28180 & hypothetical protein & & & 100.00 & 100.00 \\
\hline RCA23_c28190 & biotin carboxylase AccC & COG4770 & I & 100.00 & 100.00 \\
\hline RCA23_c28200 & hypothetical protein & & & 100.00 & 100.00 \\
\hline RCA23_c28210 & propionyl-CoA carboxylase beta chain, mitochondrial precursor & COG4799 & 1 & 100.00 & 100.00 \\
\hline RCA23_c28220 & putative major facilitator superfamily transporter & COG2814 & G & 100.00 & 100.00 \\
\hline RCA23_c28230 & hypothetical protein & COG3800 & $\mathrm{R}$ & 100.00 & 100.00 \\
\hline RCA23_c28240 & betaine aldehyde dehydrogenase BetB & COG1012 & C & 100.00 & 100.00 \\
\hline RCA23_c28250 & hypothetical protein & COG0697 & G & 100.00 & 100.00 \\
\hline RCA23_c28260 & TRAP dicarboxylate transporter, subunit DctM & COG1593 & G & 100.00 & 98.72 \\
\hline RCA23_c28270 & TRAP dicarboxylate transporter, subunit DctQ & COG4665 & Q & 100.00 & 87.46 \\
\hline RCA23_c28280 & TRAP dicarboxylate transporter, subunit DctP & COG1638 & G & 100.00 & 100.00 \\
\hline RCA23_c28290 & transcriptional regulator, Lacl family & COG1609 & K & 100.00 & 100.00 \\
\hline RCA23_c28300 & hypothetical protein, DUF81 family & COG0730 & $\mathrm{R}$ & 100.00 & 100.00 \\
\hline RCA23_c28310 & serine--glyoxylate aminotransferase SgaA & COG0075 & E & 100.00 & 99.66 \\
\hline RCA23_c28320 & D-lactate dehydrogenase Dld & COG0277 & $\mathrm{C}$ & 100.00 & 90.09 \\
\hline RCA23_c28330 & hypothetical protein & & & 100.00 & 79.22 \\
\hline RCA23_c28340 & AMP-binding enzyme & COG0318 & 1 & 100.00 & 80.01 \\
\hline RCA23_c28350 & succinate-semialdehyde dehydrogenase SucD & COG1012 & C & 100.00 & 100.00 \\
\hline RCA23_c28360 & hypothetical protein & COG3333 & $\mathrm{S}$ & 100.00 & 100.00 \\
\hline RCA23_c28370 & hypothetical protein & & & 100.00 & 100.00 \\
\hline RCA23_c28380 & putative tripartite tricarboxylate transporter family receptor & COG3181 & $\mathrm{S}$ & 18.15 & 89.84 \\
\hline RCA23_c28390 & putative ETC complex I subunit & & & 100.00 & 100.00 \\
\hline RCA23_c28450 & sulfoxide reductase heme-binding subunit YedZ & COG2717 & $S$ & 100.00 & 100.00 \\
\hline RCA23_c28460 & sulfoxide reductase catalytic subunit YedY & COG2041 & $\mathrm{R}$ & 100.00 & 100.00 \\
\hline RCA23_c28470 & 3-oxoacyl-[acyl-carrier-protein] reductase FabG & COG1028 & 1 & 100.00 & 100.00 \\
\hline RCA23_c28480 & putative haloacid dehalogenase-like hydrolase & COG0637 & $\mathrm{R}$ & 100.00 & 100.00 \\
\hline
\end{tabular}


RCA23_c28490

orotidine 5'-phosphate decarboxylase PyrF

RCA23_c28510 hypothetical protein

RCA23_c28520 SPFH domain/band 7 family protein

RCA23_c28530 DNA polymerase IV

RCA23_c28540 putative N-formylglutamate amidohydrolase

RCA23_c28560 hypothetical protein, phenylacetate-coenzyme A ligase

RCA23_c28570 high-affinity branched-chain amino acid transporter ATP-binding protein

RCA23_c28580 hypothetical protein

RCA23_c28590 high-affinity branched-chain amino acid transporter permease protein

RCA23_c28600 high-affinity branched-chain amino acid transporter permease protein

RCA23_c28610 high-affinity branched-chain amino acid transporter ATP-binding protein

RCA23_c28620 putative long-chain-fatty-acid-CoA ligase

RCA23_c28630 tRNA pseudouridine synthase B

RCA23_c28650 ribosome-binding factor A

RCA23_c28640 dihydrodipicolinate synthase DapA

RCA23_c28660 hypothetical protein DUF1674

RCA23_c28670 putative ribosomal RNA small subunit methyltransferase B

RCA23_c28680 hypothetical protein, heparinase II/III

RCA23_c28690 bifunctional purine biosynthesis protein PurH

RCA23_c28700 signal peptidase II

RCA23_c28710 uncharacterized zinc protease y4wA

RCA23_c28720 uncharacterized zinc protease y4wB

RCA23_c28730 DNA mismatch repair protein MutL

RCA23_c28740 putative RmuC family protein

RCA23_c28750 transcriptional activator ChrR

RCA23_c28760 RNA polymerase sigma factor SigK

RCA23_c28770 hypothetical protein

RCA23_c28780 hypothetical protein DUF1365

RCA23_c28790 hypothetical protein

RCA23_c28800 hypothetical protein

RCA23_c28810 putative short chain dehydrogenase

RCA23_c28820 saccharopine dehydrogenase (NAD+,L-lysine-forming)

\begin{tabular}{|c|c|}
\hline COG0542 & \\
\hline COG0284 & \\
\hline COG0330 & \\
\hline COG0389 & \\
\hline COG3741 & \\
\hline COG1541 & \\
\hline COG0410 & \\
\hline COG0683 & \\
\hline COG4177 & \\
\hline COG0559 & \\
\hline COG0411 & \\
\hline COG1022 & \\
\hline COG0130 & \\
\hline COG0858 & \\
\hline COG0289 & \\
\hline COG5508 & \\
\hline COG0144 & \\
\hline COG5360 & \\
\hline COG0138 & \\
\hline COG0597 & \\
\hline COG0612 & \\
\hline COG0612 & \\
\hline COG0323 & \\
\hline COG1322 & \\
\hline COG3806 & \\
\hline COG1595 & \\
\hline COG2907 & \\
\hline COG3496 & \\
\hline COG2211 & \\
\hline COG4221 & \\
\hline COG3288 & \\
\hline
\end{tabular}

100.00

100.00

100.00

100.00

100.00

100.00

100.00

100.00

100.00

100.00

100.00

100.00

100.00

100.00

100.00

100.00

100.00

100.00

79.28

100.00

100.00

100.00

100.00

100.00

100.00

100.00

100.00

100.00

100.00

100.00

100.00

100.00

100.00
100.00

100.00

100.00

100.00

100.00

100.00

100.00

99.64

57.30

71.22

90.82

100.00

100.00

100.00

100.00

100.00

100.00

100.00

100.00

93.76

100.00

100.00

100.00

100.00

100.00

100.00

100.00

100.00

100.00

100.00

100.00

100.00

99.34 
RCA23_c28830 putative glutathione S-transferase

\begin{tabular}{|c|c|c|c|}
\hline COG0625 & 0 & 100.00 & 100.00 \\
\hline COG0406 & $\mathrm{G}$ & 100.00 & 100.00 \\
\hline COG3383 & $\mathrm{R}$ & 100.00 & 100.00 \\
\hline COG1357 & $S$ & 75.52 & 54.92 \\
\hline COG4333 & $\mathrm{S}$ & 100.00 & 100.00 \\
\hline COG0596 & $\mathrm{R}$ & 100.00 & 100.00 \\
\hline COG0184 & $J$ & 100.00 & 100.00 \\
\hline COG0697 & G & 100.00 & 100.00 \\
\hline COG1185 & $\mathrm{J}$ & 100.00 & 100.00 \\
\hline COG1012 & $C$ & 97.85 & 100.00 \\
\hline \multirow[t]{4}{*}{ COG0564 } & $J$ & 100.00 & 96.43 \\
\hline & & 100.00 & 99.37 \\
\hline & & 27.08 & 100.00 \\
\hline & & 100.00 & 100.00 \\
\hline COG1087 & $\mathrm{M}$ & 100.00 & 100.00 \\
\hline COG0277 & $\mathrm{C}$ & 100.00 & 100.00 \\
\hline COG0541 & $\mathrm{U}$ & 100.00 & 96.66 \\
\hline COG1605 & $E$ & 100.00 & 100.00 \\
\hline COG0228 & $\mathrm{J}$ & 100.00 & 100.00 \\
\hline COG0806 & $\mathrm{J}$ & 100.00 & 100.00 \\
\hline COG0336 & $\mathrm{J}$ & 100.00 & 100.00 \\
\hline COG0335 & $\mathrm{J}$ & 100.00 & 100.00 \\
\hline COG0254 & $J$ & 100.00 & 100.00 \\
\hline COG1192 & $D$ & 100.00 & 100.00 \\
\hline COG0524 & G & 100.00 & 100.00 \\
\hline COG0654 & $\mathrm{H}$ & 100.00 & 98.64 \\
\hline COG3844 & $E$ & 100.00 & 100.00 \\
\hline COG1802 & $\mathrm{K}$ & 100.00 & 100.00 \\
\hline COG0625 & 0 & 100.00 & 100.00 \\
\hline COG0451 & $\mathrm{M}$ & 100.00 & 100.00 \\
\hline COG1024 & I & 100.00 & 100.00 \\
\hline COG1250 & 1 & 100.00 & 98.59 \\
\hline COG1028 & 1 & 100.00 & 100.00 \\
\hline
\end{tabular}




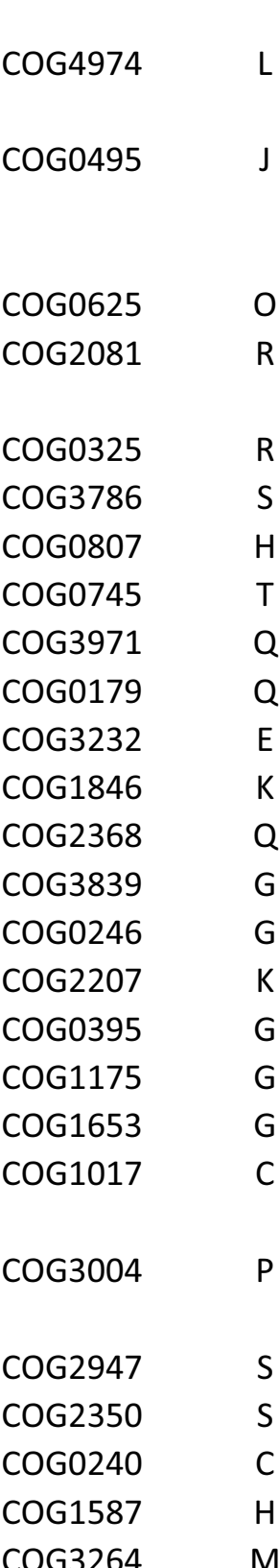

RCA23_c29200 hypothetical protein DUF2159

$100.00 \quad 73.20$

RCA23_c29210 hypothetical protein

RCA23_c29220 hypothetical protein, glutathione S-transferase

100.00

100.00

RCA23_c29230 hypothetical protein

RCA23_c29240 hypothetical protein, porin

RCA23_c29250 hypothetical protein, alanine racemase-like

RCA23_c29260 hypothetical protein, YkuD

RCA23_c29270 GTP cyclohydrolase II RibA

RCA23_c29280 response regulator receiver protein

RCA23_c29290 2-oxo-hepta-3-ene-1,7-dioic acid hydratase HpcG

RCA23_c29300 fumarylacetoacetate hydrolase family protein

RCA23_c29310 5-carboxymethyl-2-hydroxymuconate isomerase

RCA23_c29320 homoprotocatechuate degradation operon regulator HpaR

RCA23_c29330 4-hydroxyphenylacetate 3-monooxygenase oxygenase component $\mathrm{HpaH}$

RCA23_c29340 ABC sugar transporter, ATPase subunit

RCA23_c29350 mannitol 2-dehydrogenase MtIK

RCA23_c29360 transcriptional regulator, AraC family

RCA23_c29370 ABC sugar transporter, permease protein

RCA23_c29380 ABC sugar transporter, permease protein

RCA23_c29390 ABC transporter, periplasmic substrate-binding protein

RCA23_c29400 putative flavohemoglobin / bacterial hemoglobin

RCA23_c29410 hypothetical protein

RCA23_c29420 Na+/H+ antiporter NhaA

RCA23_c29430 hypothetical protein

RCA23_c29440 hypothetical protein DUF55

RCA23_c29450 protein Ycil

RCA23_c29460 glycerol-3-phosphate dehydrogenase GpsA

RCA23_c29470 hypothetical protein, uroporophyrinogen-III synthase HemD

RCA23_c29480 hypothetical protein

COG3264

$100.00 \quad 100.00$

$100.00 \quad 100.00$

$100.00 \quad 100.00$

$100.00 \quad 100.00$

$100.00 \quad 59.27$

$100.00 \quad 100.00$

$100.00 \quad 100.00$

$100.00 \quad 100.00$

$100.00 \quad 100.00$

$100.00 \quad 100.00$

$100.00 \quad 100.00$

$100.00 \quad 100.00$

$100.00 \quad 100.00$

$100.00 \quad 98.22$

$100.00 \quad 100.00$

$100.00 \quad 99.22$

$100.00 \quad 100.00$

$100.00 \quad 100.00$

$100.00 \quad 72.95$

$100.00 \quad 95.16$

$0.00 \quad 73.22$

$0.00 \quad 100.00$

$0.00 \quad 98.75$

$3.54 \quad 100.00$

$100.00 \quad 100.00$

$100.00 \quad 100.00$

$100.00 \quad 100.00$

$100.00 \quad 99.86$

$100.00 \quad 100.00$ 
RCA23 c29490 hypothetical protein, HemY

RCA23_c29500 transcriptional regulatory protein, Ars family

RCA23_c29510 magnesium-chelatase subunit BchO

RCA23_c29520 magnesium-chelatase subunit BchD

RCA23_c29530 magnesium-chelatase subunit Bchl

RCA23_c29540 spheroidene monooxygenase CrtA

RCA23_c29550 phytoene dehydrogenase Crtl

RCA23_c29560 phytoene synthase CrtB

RCA23_c29570 hydroxyneurosporene dehydrogenase CrtC

RCA23_c29580 methoxyneurosporene dehydrogenase CrtD

RCA23_c29590 geranylgeranyl pyrophosphate synthase CrtE

RCA23_c29600 hydroxyneurosporene methyltransferase CrtF

RCA23_c29610 2-desacetyl-2-hydroxyethyl bacteriochlorophyllide A dehydrogenase BchC

RCA23_c29620 chlorophyllide reductase BchX

RCA23_c29630 chlorophyllide reductase BchY

RCA23_c29640 chlorophyllide reductase subunit BchZ

RCA23_c29650 protein PufQ

RCA23_c29660 light-harvesting protein B-870 beta chain PufB

RCA23_c29670 light-harvesting protein B-870 alpha chain PufA

RCA23_c29680 reaction center protein L chain PufL

RCA23_c29690 reaction center protein M chain PufM

RCA23_c29700 protein PufX

RCA23_c29710 1-deoxy-D-xylulose-5-phosphate synthase Dxs

RCA23_c29720 isopentenyl-diphosphate delta-isomerase Idi

RCA23_c29730 geranylgeranyl reductase BchP

RCA23_c29740 bacteriochlorophyll synthase $44.5 \mathrm{kDa}$ chain

RCA23_c29750 bacteriochlorophyll synthase BchG

RCA23_c29760 cytochrome c-551

RCA23_c29770 uroporphyrinogen decarboxylase HemE

RCA23_c29780 porphobilinogen deaminase HemC

RCA23_c29790 hypothetical protein, NmrA-like

RCA23_c29800 5-aminolevulinate synthase HemA

RCA23_c29810 hypothetical protein

\begin{tabular}{|c|c|c|c|}
\hline COG3898 & $S$ & 100.00 & 100.00 \\
\hline COG0640 & $\mathrm{K}$ & 100.00 & 100.00 \\
\hline COG0596 & $\mathrm{R}$ & 100.00 & 100.00 \\
\hline COG1240 & $\mathrm{H}$ & 100.00 & 98.79 \\
\hline \multirow[t]{2}{*}{ COG1239 } & $\mathrm{H}$ & 100.00 & 100.00 \\
\hline & & 100.00 & 100.00 \\
\hline COG1233 & $Q$ & 100.00 & 100.00 \\
\hline \multirow[t]{2}{*}{ COG1562 } & I & 100.00 & 100.00 \\
\hline & & 100.00 & 84.93 \\
\hline COG1233 & $Q$ & 100.00 & 100.00 \\
\hline \multirow[t]{2}{*}{ COG0142 } & $\mathrm{H}$ & 100.00 & 91.37 \\
\hline & & 100.00 & 100.00 \\
\hline COG1063 & $E$ & 100.00 & 100.00 \\
\hline \multirow[t]{2}{*}{ COG1348 } & $P$ & 100.00 & 100.00 \\
\hline & & 100.00 & 100.00 \\
\hline \multirow[t]{7}{*}{ COG2710 } & $\mathrm{C}$ & 100.00 & 99.38 \\
\hline & & 100.00 & 100.00 \\
\hline & & 100.00 & 100.00 \\
\hline & & 100.00 & 100.00 \\
\hline & & 100.00 & 100.00 \\
\hline & & 100.00 & 100.00 \\
\hline & & 100.00 & 100.00 \\
\hline COG1154 & $\mathrm{H}$ & 100.00 & 100.00 \\
\hline COG1443 & 1 & 100.00 & 100.00 \\
\hline \multirow[t]{2}{*}{ COG0644 } & $\mathrm{C}$ & 100.00 & 100.00 \\
\hline & & 100.00 & 100.00 \\
\hline COG0382 & $\mathrm{H}$ & 100.00 & 100.00 \\
\hline COG3474 & $C$ & 100.00 & 100.00 \\
\hline COG0407 & $\mathrm{H}$ & 100.00 & 100.00 \\
\hline COG0181 & $\mathrm{H}$ & 100.00 & 100.00 \\
\hline COG0702 & $M$ & 100.00 & 90.83 \\
\hline \multirow[t]{2}{*}{ COG0156 } & $\mathrm{H}$ & 99.67 & 100.00 \\
\hline & & 43.99 & 100.00 \\
\hline
\end{tabular}


RCA23 c29820

RCA23 c29830

RCA23_c29840

RCA23 c29850

RCA23_c29860

RCA23_c29870

RCA23 c29880

RCA23_c29890

RCA23_c29900

RCA23_c29910

RCA23_c29920

RCA23_c29930

RCA23_c29940

RCA23 c29950

RCA23_c29960

RCA23_c29970

RCA23 c29980

RCA23 c29990

RCA23_c30000

RCA23_c30010

RCA23_c30020

RCA23_c30030

RCA23 c30040

RCA23_c30050

RCA23_c30060

RCA23_c30070

RCA23_c30080

RCA23_c30090

RCA23_c30100

RCA23_c3011

RCA23_c3012

RCA23_c30130

RCA23 c30140 aerobic Mg-protoporphyrin IX monomethyl ester oxidative cyclase AcsF

hypothetical protein

hypothetical protein

hypothetical protein

reaction center protein PuhA

protein PucC

magnesium-protoporphyrin O-methyltransferase BchM

light-independent protochlorophyllide reductase iron-sulfur ATP-binding prot

magnesium-chelatase subunit BchH

light-independent protochlorophyllide reductase subunit BchB

light-independent protochlorophyllide reductase subunit BchN

2-vinyl bacteriochlorophyllide hydratase BchF

putative transcriptional regulator PpaA

transcriptional regulator PpsR

hypothetical protein

transcriptional regulator protein FixJ

peripheral-type benzodiazepine receptor/signal transduction protein TspO

hypothetical protein, integral membrane proteins YeeE/YedE

hypothetical protein, integral membrane proteins YeeE/YedE

putative beta-lactamase hydrolase-like protein

hypothetical protein

sulphate transporter

amidase

hypothetical protein

aminoglycoside phosphotransferase Aph

hypothetical protein

chaperone protein DnaJ

chaperone protein DnaK

putative alpha-ketoglutarate-dependent dioxygenase AlkB

putative $A B C-2$ type transporter

$3^{\prime}\left(2^{\prime}\right), 5^{\prime}$-bisphosphate nucleotidase CysQ

UTP-glucose-1-phosphate uridylyltransferase GalU

hypothetical protein
COG3829

COG5012

COG4566

COG3476

COG2391

COG2391

COG0491

COG3453

COG0659

COG0154

COG2885

COG0484

COG0443

COG3145

COG1682

COG1218

COG1210

COG0463
100.00

100.00

100.00

90.92

22.87

100.00

100.00

100.00

100.00

100.00

100.00

100.00

100.00

100.00

100.00

100.00

100.00

100.00

100.00

100.00

100.00

100.00

100.00

100.00

100.00

100.00

100.00

100.00

100.00

100.00

100.00

100.00

4.59

100.00

100.00

100.00

100.00

100.00

100.00

100.00

100.00

100.00

100.00

100.00

100.00

100.00

100.00

100.00

100.00

100.00

100.00

100.00

100.00

100.00

100.00

100.00

100.00

100.00

100.00

100.00

100.00

100.00

100.00

100.00

M

M

26.43 


$\begin{array}{ll}\text { RCA23_c30150 } & \text { hypothetical protein } \\ \text { RCA23_c30160 } & \text { hypothetical protein beta-1,6-N-acetylglucosaminyltransfer } \\ \text { RCA23_c30170 } & \text { hypothetical protein } \\ \text { RCA23_c30180 } & \text { nitrogen regulatory protein PtsN } \\ \text { RCA23_c30190 } & \text { putative sigma } 54 \text { modulation protein } \\ \text { RCA23_c30200 } & \text { lipopolysaccharide export system ATP-binding protein LptB } \\ \text { RCA23_c30210 } & \text { putative lipopolysaccharide export system protein LptA } \\ \text { RCA23_c30220 } & \text { hypothetical protein } \\ \text { RCA23_c30230 } & \text { putative 3'-5'-exonuclease } \\ \text { RCA23_c30240 } & \text { glycine amidinotransferase } \\ \text { RCA23_c30250 } & \text { hypothetical protein } \\ \text { RCA23_c30260 } & \text { hypothetical protein, metal-dependent phosphohydrolase } \\ \text { RCA23_c30270 } & \text { S-adenosyl-L-homocysteine hydrolase AhcY } \\ \text { RCA23_c30280 } & \text { photosynthetic apparatus regulatory protein RegA } \\ \text { RCA23_c30290 } & \text { protein SenC } \\ \text { RCA23_c30300 } & \text { sensor histidine kinase RegB } \\ \text { RCA23_c30310 } & \text { hypothetical protein } \\ \text { RCA23_c30320 } & \text { hypothetical protein, aminoglycoside phosphotransferase } \\ \text { RCA23_c30330 } & \text { hypothetical protein, nucleotidyl transferase } \\ \text { RCA23_c30340 } & \text { double-strand break repair protein AddB } \\ \text { RCA23_c30350 } & \text { double-strand break repair helicase AddA } \\ \text { RCA23_c30360 } & \text { thioredoxin TrxA } \\ \text { RCA23_c30370 } & \text { ATP-dependent protease HsIV } \\ \text { RCA23_c30380 } & \text { ATP-dependent hsl protease ATP-binding subunit HslU } \\ \text { RCA23_c30390 } & \text { MFS-type transporter } \\ \text { RCA23_c30400 } & \text { hypothetical protein, Smr protein/MutS2 } \\ \text { RCA23_c30410 } & \text { putative lytic murein transglycosylase } \\ \text { RCA23_c30420 } & \text { hypothetical protein, TIM44 } \\ \text { RCA23_c30430 } & \text { putative cytoplasmic membrane protein FxsA } \\ \text { RCA23_c30440 } & \text { protein-export protein SecB } \\ \text { RCA23_c30450 } & \text { DNA polymerase III subunit epsilon } \\ \text { RCA23_c30460 } & \text { dephospho-CoA kinase CoaE } \\ \text { RCA23_c30470 } & \text { shikimate 5-dehydrogenase AroE } \\ & \end{array}$

$\begin{array}{ll}\text { COG1762 } & \text { G } \\ \text { COG1544 } & \text { J } \\ \text { COG1137 } & \text { R } \\ \text { COG1934 } & \text { S } \\ & \\ \text { COG0349 } & \text { J } \\ \text { COG1834 } & \text { E } \\ \text { COG4123 } & \text { R } \\ \text { COG1896 } & \text { R } \\ \text { COG0499 } & \text { H } \\ \text { COG4567 } & \text { T } \\ \text { COG1999 } & \text { R } \\ \text { COG0642 } & \text { T } \\ & \\ \text { COG3178 } & \text { R } \\ \text { COG1208 } & \text { M } \\ \text { COG3893 } & \text { L } \\ \text { COG1074 } & \text { L } \\ \text { COG3118 } & \text { O } \\ \text { COG5405 } & \text { O } \\ \text { COG1220 } & \text { O } \\ \text { COG2814 } & \text { G } \\ \text { COG2840 } & \text { S } \\ \text { COG2821 } & \text { M } \\ \text { COG4395 } & \text { S } \\ \text { COG3030 } & \text { R } \\ \text { COG1952 } & \text { U } \\ \text { COG0847 } & \text { L } \\ \text { COG0237 } & \text { H } \\ \text { COG0169 } & \text { E } \\ & \end{array}$

$\begin{array}{rr}0.00 & 53.82 \\ 0.00 & 6.85 \\ 14.99 & 36.27 \\ 100.00 & 100.00 \\ 100.00 & 100.00 \\ 100.00 & 100.00 \\ 100.00 & 100.00 \\ 100.00 & 100.00 \\ 100.00 & 94.63 \\ 100.00 & 100.00 \\ 100.00 & 100.00 \\ 100.00 & 100.00 \\ 100.00 & 100.00 \\ 100.00 & 100.00 \\ 100.00 & 100.00 \\ 100.00 & 100.00 \\ 100.00 & 100.00 \\ 100.00 & 98.19 \\ 100.00 & 100.00 \\ 100.00 & 100.00 \\ 97.97 & 100.00 \\ 100.00 & 100.00 \\ 100.00 & 100.00 \\ 100.00 & 96.87 \\ 100.00 & 100.00 \\ 100.00 & 100.00 \\ 100.00 & 100.00 \\ 100.00 & 100.00 \\ 100.00 & 100.00 \\ 100.00 & 100.00 \\ 100.00 & 100.00 \\ 100.00 & 100.00 \\ 100.00 & 100.00\end{array}$


RCA23_c30480

RCA23_c30490

RCA23_c30500

RCA23_c30510

RCA23_c30520

RCA23_c30530

RCA23_c30540

RCA23_c30550

RCA23_c30560

RCA23_c30570

RCA23_c30580

RCA23_c30590

RCA23_c30600

RCA23_c30610

RCA23_c30620

RCA23_c30630

RCA23_c30640

RCA23_c30650

RCA23_c30660

RCA23_c30670

RCA23_c30680

RCA23_c30690

RCA23_c30710 hypothetical protein

RCA23_c30720 ion transport protein

RCA23_c30730 hypothetical protein

RCA23_c30740 hypothetical protein, SCP-like extracellular protein

RCA23_c30750 hypothetical protein

RCA23_c30760 ferrochelatase HemH

RCA23_c30770 hypothetical protein

RCA23_c30780 hypothetical protein, ComF/GntX family

RCA23_c30790 glutaredoxin GrxC

RCA23_c30800 putative carbon-nitrogen hydrolase

\begin{tabular}{|c|c|}
\hline COG1158 & K \\
\hline COG0486 & $\mathrm{R}$ \\
\hline COG0445 & $\mathrm{D}$ \\
\hline COG0357 & $\mathrm{M}$ \\
\hline COG1192 & $\mathrm{D}$ \\
\hline COG1475 & K \\
\hline COG0635 & $\mathrm{H}$ \\
\hline COG0127 & $\mathrm{F}$ \\
\hline COG0689 & $\mathrm{J}$ \\
\hline COG1420 & K \\
\hline COG0576 & $\mathrm{O}$ \\
\hline COG0249 & $\mathrm{L}$ \\
\hline COG0281 & C \\
\hline COG0524 & G \\
\hline COG0115 & $E$ \\
\hline COG0137 & $\mathrm{E}$ \\
\hline COG1171 & $\mathrm{E}$ \\
\hline COG0494 & $\mathrm{L}$ \\
\hline COG1281 & $\mathrm{O}$ \\
\hline COG0494 & $\mathrm{L}$ \\
\hline COG0617 & $\mathrm{J}$ \\
\hline COG1132 & V \\
\hline COG2265 & $\mathrm{J}$ \\
\hline COG3034 & $\mathrm{S}$ \\
\hline COG2340 & $\mathrm{S}$ \\
\hline COG1376 & $\mathrm{S}$ \\
\hline COG0276 & $\mathrm{H}$ \\
\hline COG1040 & $\mathrm{R}$ \\
\hline COG0695 & $\mathrm{O}$ \\
\hline COG0388 & $\mathrm{R}$ \\
\hline
\end{tabular}

100.00

100.00

100.00

100.00

100.00

100.00

100.00

100.00

100.00

100.00

100.00

100.00

100.00

100.00

100.00

100.00

100.00

100.00

100.00

100.00

100.00

100.00

100.00

95.06

2.89

100.00

100.00

100.00

100.00

100.00

100.00

100.00

100.00
100.00

100.00

99.84

100.00

100.00

100.00

100.00

100.00

100.00

100.00

100.00

100.00

98.05

100.00

100.00

100.00

100.00

100.00

100.00

100.00

100.00

100.00

100.00

100.00

100.00

100.00

100.00

100.00

100.00

100.00

100.00

100.00

100.00 


\begin{tabular}{|c|c|c|c|c|c|}
\hline RCA23_c30810 & putative HTH-type transcriptional regulator, MarR family & COG1846 & K & 100.00 & 100.00 \\
\hline RCA23_c30820 & 3-demethylubiquinone-9 3-O-methyltransferase UbiG & COG2227 & $\mathrm{H}$ & 100.00 & 100.00 \\
\hline RCA23_c30830 & proline iminopeptidase Pip & COG0596 & $\mathrm{R}$ & 100.00 & 94.74 \\
\hline RCA23_c30840 & putative peptide transport system permease protein & COG0601 & $\mathrm{E}$ & 100.00 & 100.00 \\
\hline RCA23_c30850 & putative peptide transport system permease protein & COG1173 & $\mathrm{E}$ & 100.00 & 100.00 \\
\hline RCA23_c30860 & peptide transport system ATP-binding protein & COG1123 & $\mathrm{R}$ & 100.00 & 100.00 \\
\hline RCA23_c30870 & putative periplasmic peptide-binding protein & COG0747 & $\mathrm{E}$ & 100.00 & 97.48 \\
\hline RCA23_c30880 & hypothetical protein UPF0090 & COG0779 & $\mathrm{S}$ & 100.00 & 100.00 \\
\hline RCA23_c30890 & transcription elongation protein NusA & COG0195 & K & 100.00 & 100.00 \\
\hline RCA23_c30900 & hypothetical protein DUF448 & $\operatorname{COG} 2740$ & K & 100.00 & 100.00 \\
\hline RCA23_c30910 & translation initiation factor IF-2 & COG0532 & $J$ & 100.00 & 100.00 \\
\hline RCA23_c30920 & putative mutator MutT protein & COG1051 & $\mathrm{F}$ & 100.00 & 100.00 \\
\hline RCA23_c30930 & arginine biosynthesis bifunctional protein ArgJ & COG1364 & $\mathrm{E}$ & 100.00 & 100.00 \\
\hline RCA23_c30940 & putative peptidylprolyl isomerase & COG0760 & $\mathrm{O}$ & 100.00 & 100.00 \\
\hline RCA23_c30950 & protein translocase subunit SecA & COG0653 & $U$ & 100.00 & 100.00 \\
\hline RCA23_c30960 & putative O-acetyltransferase OatA & COG1835 & I & 87.06 & 100.00 \\
\hline RCA23_c30970 & hypothetical protein & COG4922 & $\mathrm{S}$ & 100.00 & 100.00 \\
\hline RCA23_c30980 & hypothetical protein, transcriptional regulator-like & COG1733 & K & 100.00 & 100.00 \\
\hline RCA23_c30990 & UDP-glucoronate 5'-epimerase LspL & COG0451 & M & 62.96 & 96.49 \\
\hline RCA23_c31000 & hypothetical protein & & & 100.00 & 98.60 \\
\hline RCA23_c31010 & phosphoglucosamine mutase GImM & COG1109 & G & 100.00 & 100.00 \\
\hline RCA23_c31020 & putative ubiquinone biosynthesis protein UbiB & COG0661 & $\mathrm{R}$ & 100.00 & 100.00 \\
\hline RCA23_c31030 & ubiquinone/menaquinone biosynthesis methyltransferase UbiE & COG2226 & $\mathrm{H}$ & 100.00 & 100.00 \\
\hline RCA23_c31040 & formamidopyrimidine-DNA glycosylase MutM & COG0266 & $\mathrm{L}$ & 100.00 & 100.00 \\
\hline RCA23_c31050 & enoyl-CoA hydratase/isomerase & COG1024 & I & 100.00 & 100.00 \\
\hline RCA23_c31060 & 30 S ribosomal protein S20 & COG0268 & $\mathrm{J}$ & 100.00 & 100.00 \\
\hline
\end{tabular}


STUDY 6:

\title{
COMPOSITION AND ACTIVITY OF THE BACTERIOPLANKTON Communities in the Drake Passage and Antarctic Peninsula REGION WITH A SPECIAL EMPHASIS ON THE ROSEOBACTER CLADE AND DISSOLVED ORGANIC MATTER
}

\author{
SimOn $\mathrm{M}^{1}$, BILlERBECK $\mathrm{S}^{1}$, BRINKHOFF $\mathrm{T}^{1}$, DOGS $\mathrm{M}^{1}$, \\ Müllenmeister $\mathrm{S}^{1}$, SeibT $\mathrm{M}^{1}$, Seidel $\mathbf{M}^{1}$, SMits $\mathrm{M}^{2}$, WAGNER- \\ DÖBLER I ${ }^{3}$, WANG $\mathrm{H}^{3}$, WeMHEUER B ${ }^{2}$, AND WURST $\mathbf{M}^{1}$ \\ REPORTS ON POLAR AND MARINE RESEARCH 653: 49-54. \\ (hdl: 10013/epic.4037) \\ ${ }^{1}$ INSTITUTE FOR CHEMISTRY AND BIOLOGY OF THE MARINE ENVIRONMENT \\ (ICBM), CARL-VON-OSSIETZKY-UNIVERSITY OF OLDENBURG, CARL-VON- \\ OSSIETZKY-STR. 9-11, D-26111 OLDENBURG, GERMANY; ${ }^{2}$ INSTITUTE OF \\ Microbiology And Genetics, GeOrG-August-University GötTingen, \\ GRISEBACHSTR. 8, D-37077 GÖTTINGEN, GERMANY; ${ }^{3}$ HelmHOLTZ CENTRE FOR \\ INFECTION RESEARCH, INHOFFENSTRAßE 7, D-38124 BRAUNSCHWEIG, GERMANY
}

Author contributions to the work: all Contributed data: all Wrote the publication: MS 


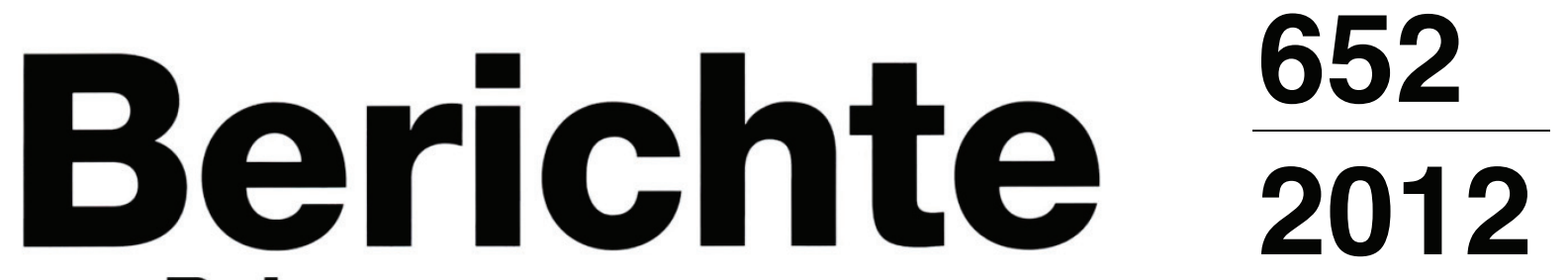

\section{zur Polar-}

und Meeresforschung

\section{Reports \\ on Polar and Marine Research}

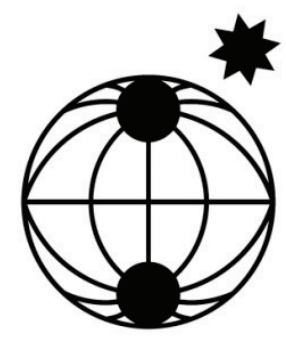

The Expedition of the Research Vessel "Polarstern" to the Antarctic in 2012 (ANT-XXVIII/4)

Edited by

Magnus Lucassen

with contributions of the participants

HELMHOLTZ

| GEMEINSCHAFT
ALFRED-WEGENER-INSTITUT FÜR

POLAR- UND MEERESFORSCHUNG

in der Helmholtz-Gemeinschaft

D-27570 BREMERHAVEN

Bundesrepublik Deutschland 


\title{
13. COMPOSITION AND ACTIVITY OF THE BACTERIOPLANKTON COMMUNITIES IN THE DRAKE PASSAGE AND ANTARCTIC PENINSULA REGION WITH A SPECIAL EMPHASIS ON THE ROSEOBACTER CLADE AND DISSOLVED ORGANIC MATTER
}

\author{
Meinhard Simon ${ }^{1}$, Sara Billerbeck ${ }^{1}$, \\ Thorsten Brinkhoff ${ }^{1}$, Marco Dogs ${ }^{1}$, Swaantje \\ Müllenmeister ${ }^{1}$, Maren Seibt ${ }^{1}$, Michael \\ Seidel $^{1}$, Maike Smits ${ }^{3}$, Irene Wagner- \\ Döbler², Hui Wang², Bernd Wemheuer' ${ }^{3}$, \\ Mascha Wurst1
}

\author{
${ }^{1} \mathrm{ICBM}$ \\ ${ }^{2} \mathrm{HZI}$ \\ ${ }^{3}$ University of Göttingen
}

\section{Objectives}

We aim at a comprehensive assessment of the bacterioplankton community in the Drake Passage and the Peninsula region of the Southern Ocean with a special emphasis on the Roseobacter clade and its major bacterioplankton subclusters. This project is part of a key work package of the Transregional Collaborative Research Center Ecology, Physiology and Molecular Biology of the Roseobacter clade: Towards a Systems Biology Understanding of a Globally Important Clade of Marine Bacteria (TRR 51). The work includes investigations of the biogeography, growth and population dynamics, the genomic potential (metagenomics) and actively expressed genes (metatranscriptomics) and the impact on the decomposition of dissolved organic matter (DOM) and cycling by the bacterioplankton communities. Our investigations can only be done in a concerted action in which also the other members of the bacterioplankton communities are considered, as well as bulk parameters of the entire bacterioplankton communities and relevant biogeochemical parameters such as chlorophyll and the composition and concentration of DOM. Previous studies dealing with some of these aspects have been carried out in this region before (Manganelli et al. 2009, Straza et al. 2010). However, one particular group of marine bacteria and in particular the Roseobacter clade have not been investigated before in such great detail.

A list of investigated parameters is given in table 13.1. 
Tab. 13.1: List of parameters studied for assessing bacterioplankton communities during cruise ANT-XXVIII/4.

\begin{tabular}{|c|c|c|c|c|c|c|c|c|c|}
\hline \multirow[t]{2}{*}{ Parameter } & \multicolumn{9}{|c|}{ Water depths (m) } \\
\hline & 20 & 40 & 60 & 100 & 200 & 500 & 1000 & 2000 & $>3000$ \\
\hline POC & + & + & + & + & & + & + & + & + \\
\hline Chlorophyll & + & + & + & + & + & & & & \\
\hline Phytoplankton & + & + & + & + & & & & & \\
\hline Inorganic nutrients & + & + & + & + & + & + & + & + & + \\
\hline Bacterial abundance & + & + & + & + & + & + & + & + & + \\
\hline Bacterial production & + & + & + & + & + & + & + & & \\
\hline Glucose turnover rate & + & + & + & + & + & + & + & & \\
\hline $\begin{array}{l}\text { Amino acid turnover } \\
\text { rate }\end{array}$ & + & + & + & + & + & & & & \\
\hline FISH & + & & + & + & & & & & \\
\hline $\begin{array}{l}\text { Aerobic anoxygenic } \\
\text { bacteria }\end{array}$ & + & + & + & + & + & & & & \\
\hline DGGE & + & + & + & + & + & + & + & + & + \\
\hline $\begin{array}{l}\text { 16S rRNA gene } \\
\text { Pyrosequencing }\end{array}$ & + & + & + & + & + & + & + & + & + \\
\hline Metagenomics & + & & + & & & & & & + \\
\hline Metatranscriptomics & + & + & + & + & + & + & + & + & + \\
\hline DOC & + & + & + & + & + & + & + & + & + \\
\hline DOM & + & + & + & + & + & + & + & + & + \\
\hline Vitamins & + & + & + & + & + & + & + & + & + \\
\hline
\end{tabular}

\section{Work at sea}

Our main work on shipboard was the collection and processing of water samples from depths between 20 and 3500 m. Samples were collected with Niskin bottles mounted on a CTD rosette from the mixed layer, the mesopelagic and bathypelagic zones (for details on the CTD see Badewien et al., chapter 18, this volume). Our sampling scheme included fixed depths between 20 and $200 \mathrm{~m}$ and at deep stations also at 500 and $1000 \mathrm{~m}$. Below, sampling depths were identified according to the temperature and salinity profile. In total 16 stations were visited, five deep stations on the continental slope and in the Drake Passage and 11 stations on the continental shelf. For exact locations and further details see table 13.2 and Fig. 13.1.

Tab. 13.2: List of stations and depths investigated for studies of the bacterioplankton and dissolved organic matter during cruise ANT-XXVIII/4.

\begin{tabular}{lrrrrl}
\hline Station & Date & Ship time & $\begin{array}{c}\text { Depth } \\
(\mathrm{m})\end{array}$ & & Sampled Depths $(\mathrm{m})$ \\
\hline PS79/178 & 16.03 .12 & $1: 30$ & 3994 & $20-200$ & \\
PS79/179 & 16.03 .12 & $15: 19$ & 4210 & $20-200$ & 500,1000 \\
PS79/193 & 18.03 .12 & $22: 10$ & 2095 & $20-200$ & $500,1000,2000$ \\
PS79/205 & 20.03 .12 & $20: 30$ & 3540 & $20-200$ & $500,1000,2000,3500$ \\
PS79/217 & 22.03 .12 & $20: 30$ & 1845 & $20-200$ & \\
PS79/232 & 24.03 .12 & $20: 30$ & 331 & $20-200$ &
\end{tabular}




\begin{tabular}{lcrrll}
\hline Station & Date & Ship time & $\begin{array}{c}\text { Depth } \\
(\mathrm{m})\end{array}$ & Sampled Depths $(\mathrm{m})$ \\
\hline PS79/235 & 25.03 .12 & $13: 00$ & 316 & $20-200$ & \\
PS79/241 & 26.03 .12 & $13: 30$ & 1845 & $20-200$ & $500,1000,1800$ \\
PS79/244 & 27.03 .12 & $12: 30$ & 394 & $20-200$ & \\
PS79/247 & 28.03 .12 & $10: 30$ & 316 & $20-200$ & \\
PS79/251 & 29.03 .12 & $08: 30$ & 436 & $20-200$ & \\
PS79/262 & 30.03 .12 & $20: 30$ & 4420 & $20-200$ & $500,1000,2000$ \\
PS79/267 & 01.04 .12 & $04: 00$ & 2190 & $20-200$ & \\
PS79/277 & 02.04 .12 & $21: 00$ & 1484 & $20-200$ & \\
PS79/281 & 03.04 .12 & $23: 00$ & 740 & $20-200$ & 350,600 \\
PS79/287 & 04.04 .12 & $22: 00$ & 3644 & $20-200$ & $500,1000,2500,3600$ \\
\hline
\end{tabular}

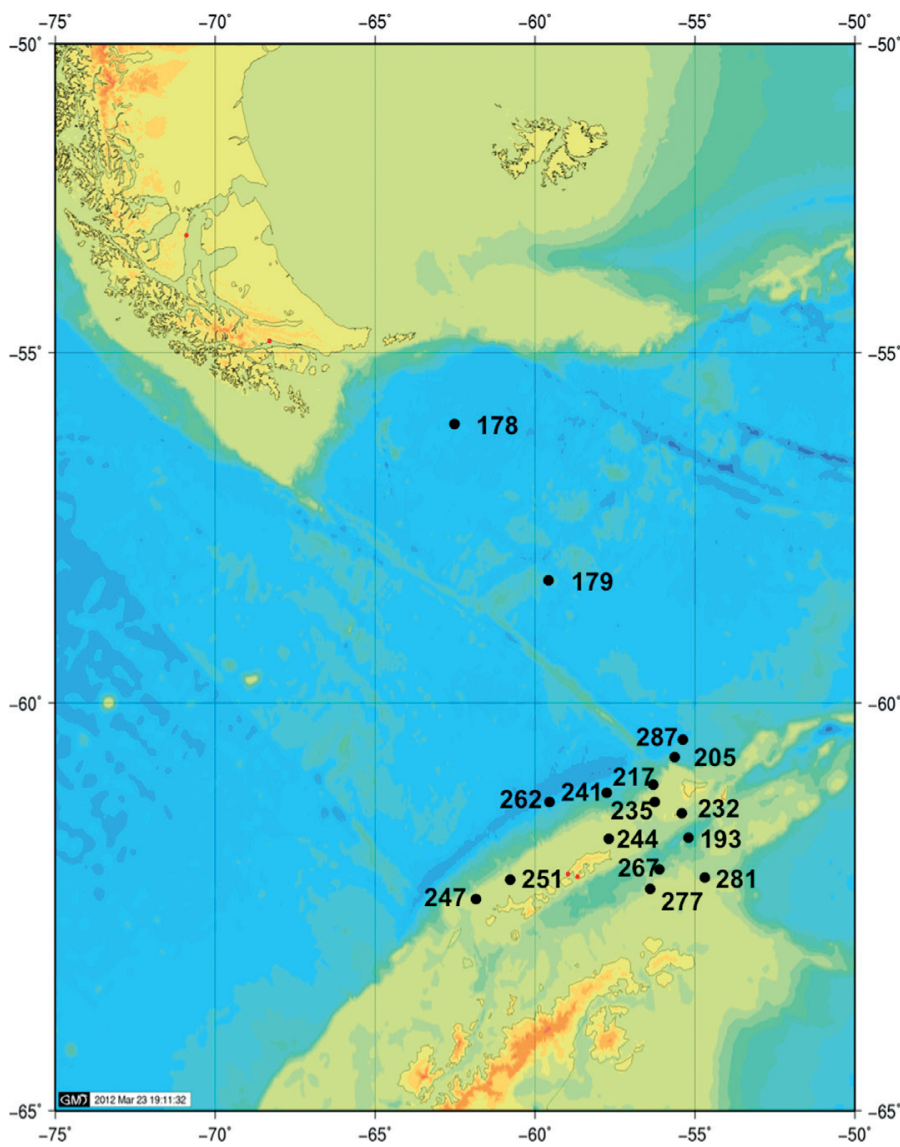

Fig. 13.1: Map with stations where samples for this study were collected during cruise ANTXXVIII/4
In most cases, samples were filtered onto membrane filters of various type and size, frozen at -20 or $-80^{\circ} \mathrm{C}$. Further processing will be done in the home laboratories. Samples for phytoplankton and nutrient analyses were fixed with Lugol's solution and $\mathrm{HgCl}$, respectively, and will be analyzed further at home. Samples for the analyses of dissolved amino acids, carbohydrates, vitamins, DOC and DOM were prefiltered and frozen or acidified (DOC). Samples for bacterial abundance, production and turnover of dissolved free amino acids and glucose were analyzed on shipboard. Bacterial abundance was assessed by flow cytometry and bacterial production and substrate turnover by radiotracer techniques and applying 14C-leucine, 3H-leucine, -glucose and -amino acids. For details on the methods see Simon and Azam (1989) and Simon and Rosenstock (2007). 


\section{Preliminary results}

The analysis of the water masses from the CTD and sigma-T data showed that we sampled quite different water masses (Badewien et al., chapter 18 this volume). The data on bacterial abundance, production and turnover rates of amino acids and glucose in most cases did not reflect these water masses, but rather differences between the stations on the continental shelf, the slope and Drake Passage. The more productive stations on the shelf exhibited consistently higher rates of bacterial biomass production and also shorter generation times of the bacterioplankton communities than those on the continental slope and the Drake Passage (Fig. 13.2 and 13.3). Whereas the values of bacterial biomass production on the continental slope and in the Drake Passage are similar to data from a previous study in this region (Manganelli et al. (2009) the values on the shelf are on average significantly higher than those of previous studies (Manganelli et al.2009, Straza et al. 2010). Bacterioplankton bulk generation times of as fast as 1 - 2 days in the mixed layer of this cold, but obviously very productive region were most remarkable. These findings are surprising, considering that the study was carried out in the late austral fall and at in-situ temperatures of $0-1{ }^{\circ} \mathrm{C}$ and including stations close to the ice edge. We might have encountered a particularly productive situation, reflected also by a surprisingly high abundance of fin wales and krill in this region (chapter 3, 16 this volume). Below $100 \mathrm{~m}$, bacterial activity, as shown in the form of generation time, was much lower than above as a result of the much lower substrate supply below the mixed layer. The data on concentrations of chlorophyll, dissolved amino acids and carbohydrates and DOC will provide us with further details on the availability of substrates to the bacterioplankton.

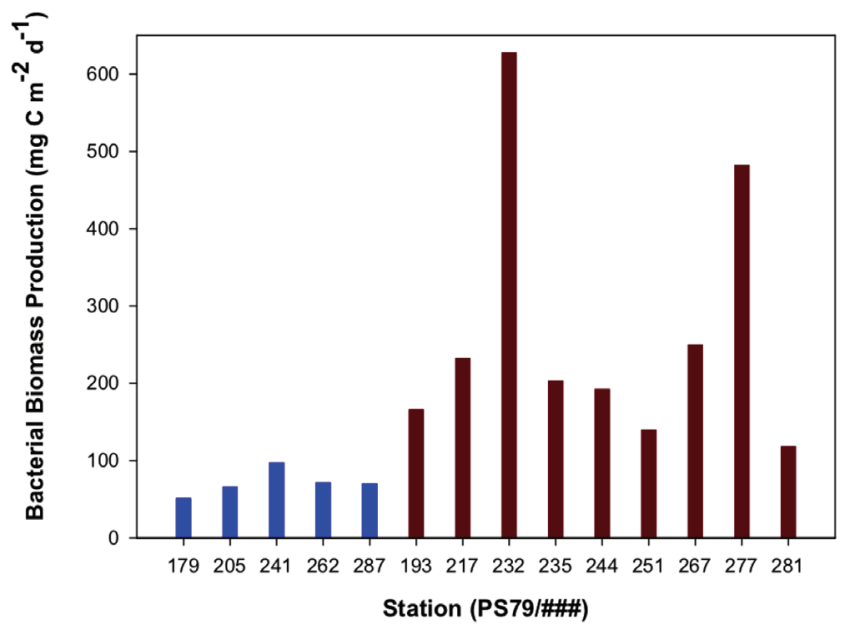

Fig. 13.2: Bacterial biomass production integrated from 0 to $200 \mathrm{~m}$ at all stations visited during cruise ANT-XXVIII/4. Stations on the continental slope and the Drake Passage (179-287) are shown on the left in blue and those on the continental shelf on the right in dark red (193-281). 


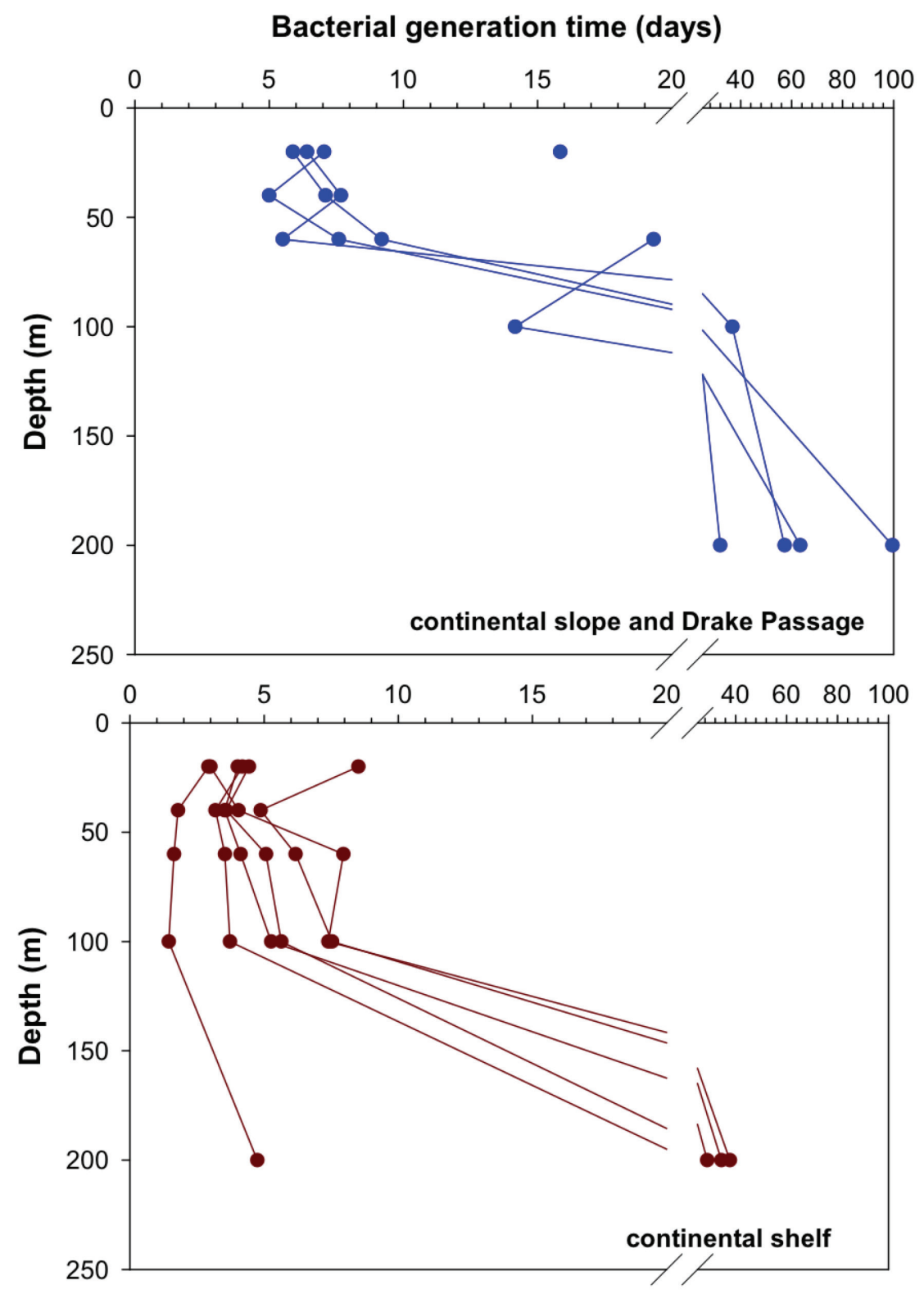

Fig. 13.3: Bacterioplankton bulk generation times of various profiles on the continental slope and the Drake Passage (upper panel) and on the continental shelf (lower panel) during cruise ANT-XXVIII/4.

The most interesting question is whether and how these differences will be reflected in the composition and metabolic activities of the bacterioplankton communities at these stations. Our analyses hopefully will shed light on this issue.

These results and those of all other parameters for which samples were collected, however, will become available only after processing of the samples in the home laboratories after several months to years. 


\section{Data management}

All finally processed data will be stored on a server at ICBM and of TRR 51 and will be available on request if not otherwise mentioned. Data on the pyrosequencing and metagenomics and metatranscriptomics will be processed and stored on a server of the Göttingen Genomics lab at the University of Göttingen and at HZI. The final data of the metagenomics and metatranscriptomics and on sequenced genes will be made publicly available via GenBank and NCBI. Most of the data will be published in international peer-reviewed journals.

\section{References}

Manganelli M, Malfatti F, Samo TJ, Mitchell BG, Wang H, Azam F (2009) Major role of microbes in carbon fluxes during Austral winter in the Southern Drake Passage. PLoS ONE 4, e6941.

Simon M, Azam F (1989) Protein content and protein synthesis rates of planktonic marine bacteria. Marine Ecology Progress Series 51, 201-213.

Simon M, Rosenstock B (2007) Different coupling of dissolved amino acid, protein, and carbohydrate turnover to heterotrophic picoplankton production in the Southern Ocean in austral summer and fall. Limnology and Oceanography 52, 85-95.

Straza TRA, Ducklow HW, Murray AE, Kirchman DL (2010) Abundance and single-cell activity of bacterial groups in Antarctic coastal waters. Limnology and Oceanography $55,2526-2536$. 


\title{
STUDY 7:
}

\section{HIGH ABUNDANCE OF HETEROTROPHIC PROKARYOTES IN HYDROTHERMAL SPRINGS OF THE AZORES AS REVEALED BY A NETWORK OF 16S RRNA GENE-BASED METHODS}

\author{
SAHM K ${ }^{1}$, JOHN $\mathrm{P}^{1}$, NACKE $\mathrm{H}^{2}$, WeMHEUER $\mathbf{B}^{2}$, GROTE $\mathrm{R}^{1}$, DANIEL $\mathrm{R}^{2}$, \\ AND ANTRANIKIAN $\mathrm{G}^{1}$
}

EXTREMOPHILES 17(4): 649-62.

INSTITUTE FOR TECHNICAL MICROBIOLOGY, HAMBURG UNIVERSITY OF TECHNOLOGy, KASERnENSTR. 12, 21073 HAMBURG, GERMANY; ${ }^{2}$ Institute OF Microbiology And Genetics, GeORG-August-University GötTINGEN, GRISEBACHSTR. 8, D-37077 GÖTTINGEN, GERMANY;

\footnotetext{
Author contributions to the work:

Performed the experiments: PJ

Analyzed data: KS, HN, BW

Contributed data on environmental properties and analysis of these data: PJ Contributed to sampling: $\mathrm{RG}$ Wrote the publication: KS

Conceived and designed the experiments: KS, GA
} 


\title{
High abundance of heterotrophic prokaryotes in hydrothermal springs of the Azores as revealed by a network of 16S rRNA gene-based methods
}

\author{
Kerstin Sahm • Patrick John • Heiko Nacke • \\ Bernd Wemheuer • Ralf Grote · Rolf Daniel • \\ Garabed Antranikian
}

Received: 21 March 2013/ Accepted: 12 May 2013/Published online: 26 May 2013

(C) Springer Japan 2013

\begin{abstract}
Two hydrothermal springs (AI: $51^{\circ} \mathrm{C}, \mathrm{pH} 3$; AIV: $92{ }^{\circ} \mathrm{C}, \mathrm{pH} 8$ ) were analysed to determine prokaryotic community composition. Using pyrosequencing, 93,576 partial 16S rRNA gene sequences amplified with V2/V3specific primers for Bacteria and Archaea were investigated and compared to $16 \mathrm{~S}$ rRNA gene sequences from direct metagenome sequencing without prior amplification. The results were evaluated by fluorescence in situ hybridization (FISH). While in site AIV Bacteria and Archaea were detected in similar relative abundances (Bacteria $40 \%$, Archaea $35 \%$ ), the acidic spring AI was dominated by Bacteria (68\%). In spring AIV the combination of $16 \mathrm{~S}$ rRNA gene sequence analysis and FISH revealed high abundance $(>50 \%)$ of heterotrophic bacterial genera like Caldicellulosiruptor, Dictyoglomus, and Fervidobacterium. In addition, chemolithoautotrophic Aquificales were detected in the bacterial community with Sulfurihydrogenibium being the dominant genus. Regarding Archaea, only Crenarchaeota, were detected, dominated by the family Desulfurococcaceae $(>50 \%)$. In addition, Thermoproteaceae made up almost $25 \%$. In the acidic spring (AI) prokaryotic diversity was lower than in the hot, slightly alkaline spring AIV. The bacterial community of site AI
\end{abstract}

Communicated by M. da Costa.

K. Sahm $(\bowtie) \cdot$ P. John · R. Grote · G. Antranikian Institute for Technical Microbiology, Hamburg University of Technology, Kasernenstr. 12, 21073 Hamburg, Germany e-mail: sahm@tuhh.de

H. Nacke · B. Wemheuer · R. Daniel

Department of Genomic and Applied Microbiology and Göttingen Genomics Laboratory, Institute of Microbiology and Genetics, Georg-August University Göttingen, Göttingen, Germany was dominated by organisms related to the chemolithoautotrophic genus Acidithiobacillus (43\%), to the heterotrophic Acidicaldus (38\%) and to Anoxybacillus (7.8\%). This study reveals differences in the relative abundance of heterotrophic versus autotrophic microorganisms as compared to other hydrothermal habitats. Furthermore, it shows how different methods to analyse prokaryotic communities in complex ecosystems can complement each other to obtain an in-depth picture of the taxonomic composition and diversity within these hydrothermal springs.

Keywords Biodiversity - Thermoacidophile ecology · Thermophile ecology $\cdot$ Metagenome

\section{Introduction}

With regard to their physicochemical conditions, terrestrial hydrothermal springs are highly diverse habitats, offering a wide range of ecological niches. These niches exhibit extreme conditions, such as high temperature, low or high $\mathrm{pH}$, and the presence of toxic ions. Their extreme features are expected to lead to limited biodiversity, making hydrothermal habitats ideal model systems to study principles of community structure and function. Prokaryotic diversity in hydrothermal ecosystems has been extensively studied, in particular at Yellowstone National Park repeatedly revealing characteristic taxonomic groups like Aquificales and specific groups of Crenarchaeota, in particular (among others Hamamura et al. 2012; MeyerDombard et al. 2005; Spear et al. 2005).

The abundant, often predominant occurence of Aquificales has led to the hypothesis that $\mathrm{H}_{2}$-based chemolithoautotrophic processes play a dominant role in hot-temperature ecosystems, in which photosynthesis is no longer possible (Spear 
et al. 2005; Inskeep et al. 2010; Hugenholtz et al. 1998). Aquificales often form the basis for chemolithotrophic biofilm or mat structures, e.g. the pink filaments of Thermocrinis ruber and the white sausage-shaped filaments found in sulphur-turf mats of Japanese hot springs (Blank et al. 2002; Yamamoto et al. 1998).

Estimates on community composition, however, have been performed mainly on the basis of clone libraries with the known bias of cloning-based technologies and relatively low sample size taken into account (among others Blank et al. 2002; Hugenholtz et al. 1998; Reysenbach et al. 1994; Swingley et al. 2012). With next generation sequencing methods the analysis of larger 16S rRNA genedata sets has become feasible, making it possible to increase the extent of sequence-based biodiversity studies, leading to a higher degree of reliability. Analysis of large sets of short rRNA gene fragments comprising variable regions has been applied to infer community composition and biodiversity estimates in terrestrial and marine habitats (Huse et al. 2008; Miller et al. 2009; Nacke et al. 2011; Roesch et al. 2007; Will et al. 2010; Youssef et al. 2009). However, the analysis is usually based on PCR-amplified DNA fragments, which still suffers from potential primer bias. Direct sequencing of metagenomic DNA can circumvent this bias, reducing, however, the amount of data available for analysis since non-16S rRNA gene sequences are also generated (Inskeep et al. 2010). To obtain an indepth picture of prokaryotic hydrothermal spring communities, we combined both sequencing of short variable rRNA gene fragments and phylogenetic analysis of the metagenome, evaluating it with fluorescence in situ hybridization (FISH), which allows direct quantification of specific microbial lineages in the sample, directly. Our study was conducted with samples from the Furnas Valley, situated on São Miguel, Azores.

The Azores are a group of geographically isolated islands in the Atlantic Ocean. They are almost exclusively of volcanic origin, with the main hydrothermal area being the Furnas Valley on the Island of Sao Miguel. However, compared to other hydrothermal zones like Yellowstone National Park and Iceland the overall amount of data available is still limited. Brock and Brock (1967) gave a detailed description of the hot springs of Furnas Valley pointing out the thermal and chemical complexity of the Furnas springs and a major difference with regard to other terrestrial hydrothermal areas: in Furnas “... the largest spring is at the highest elevation and is alkaline, whereas some of the lower springs are smaller and more acidic. This is completely opposite to the situation found in Yellowstone National Park and Iceland... (Allen and Day 1935; Barth 1950)". Here the higher springs are small and acidic and the lower ones large and alkaline. The hot springs of
Furnas Valley have been a valuable source for thermophilic microorganisms and thermostable enzymes with useful features for biotechnological applications (among others Albuquerque et al. 2008, 2010, 2012; Franca et al. 2006; Riessen and Antranikian 2001; Friedrich and Antranikian 1996). However, only little data are available on overall diversity (Hamamura et al. 2012).

Applying different 16S rRNA gene-based and metagenomic approaches, we provide an in-depth study of bacterial and archaeal diversity as a quantitative basis for understanding ecological interactions within the prokaryotic community. The study reveals the wealth of biocatalytic potential for enzymes from heterotrophic organisms still waiting to be recovered from these challenging extreme habitats.

\section{Materials and methods}

Study site and sampling

Sediment, biofilm, and water samples were collected from various hydrothermal springs at Furnas Valley, São Miguel, Azores, in September 2010. All necessary permits were obtained for the described field studies from the regional government of the Azores (LICENCA No 107/2010/DRA). A description of the different sampling sites is provided in Table 1. Several samples were collected at a solfataric field (sampling site A) (Fig. 1). Additional samples were collected from the hydrothermal vents Caldeirão (sampling site B) and Caldeira do Asmodeu (sampling site C). With the exception of the solfatara sample AIV (water sample) mainly sediments, muds or biofilms were collected and supplemented with water from the respective hydrothermal spring. Sediments and mud were characterized by brownish, ochre, grey, black or green appearance. The biofilms were black, white or light-grey, and the microbial mats encountered along the effluent stream of one hydrothermal vent exhibited green, orange, yellowish or brownish colours (Fig. 1).

Each sample was transferred to a sterile serum bottle, preventing exposure to air as far as possible. After sampling, the bottles were closed immediately with a butyl rubber stopper and a screw cap and $0.01 \%$ w/v (final concentration) sodium sulphide was added by means of a syringe to counteract potential oxygen intake. Within $4 \mathrm{~h}$ after sampling, aliquots of $500 \mu \mathrm{L}$ per sample were fixed for $1 \mathrm{~h}$ with $3 \%$ (final concentration) paraformaldehyde for subsequent FISH analyses as described by Ravenschlag et al. (2000) and stored at $-20{ }^{\circ} \mathrm{C}$. The original samples were stored at $4{ }^{\circ} \mathrm{C}$. 
Table 1 Sampling site characteristics

\begin{tabular}{lllll}
\hline Site & $T\left({ }^{\circ} \mathrm{C}\right)$ & $\mathrm{pH}$ & Biotope & Sample \\
\hline A & 51 & 3 & $\begin{array}{l}\text { Small shallow hydrothermal spring at solfataric field near Caldeira do } \\
\text { Esguicho }\end{array}$ & AI \\
& 84 & $2.5-3$ & $\begin{array}{c}\text { Small shallow hydrothermal spring at solfataric field near Caldeira do } \\
\text { Esguicho }\end{array}$ & AII \\
& 85 & 8 & $\begin{array}{l}\text { Small shallow hydrothermal spring at solfataric field near Caldeira do } \\
\text { Esguicho }\end{array}$ & AIII \\
& 92 & 8 & Solfatara (Caldeira do Esguicho), effluent stream & AIV \\
B & 60 & 6 & Hydrothermal spring (Caldeirão) & BI \\
& 65 & 7 & Small stream near Caldeirão (Chalet Quente) & BII \\
& 70 & 6 & Hydrothermal spring (Caldeirão, paved basin) & BIII \\
C & 55 & 8 & Effluent of Caldeira do Asmodeu & CI \\
& 76 & 8 & Hydrothermal spring (Caldeira do Asmodeu), edge zone & CII \\
\hline
\end{tabular}

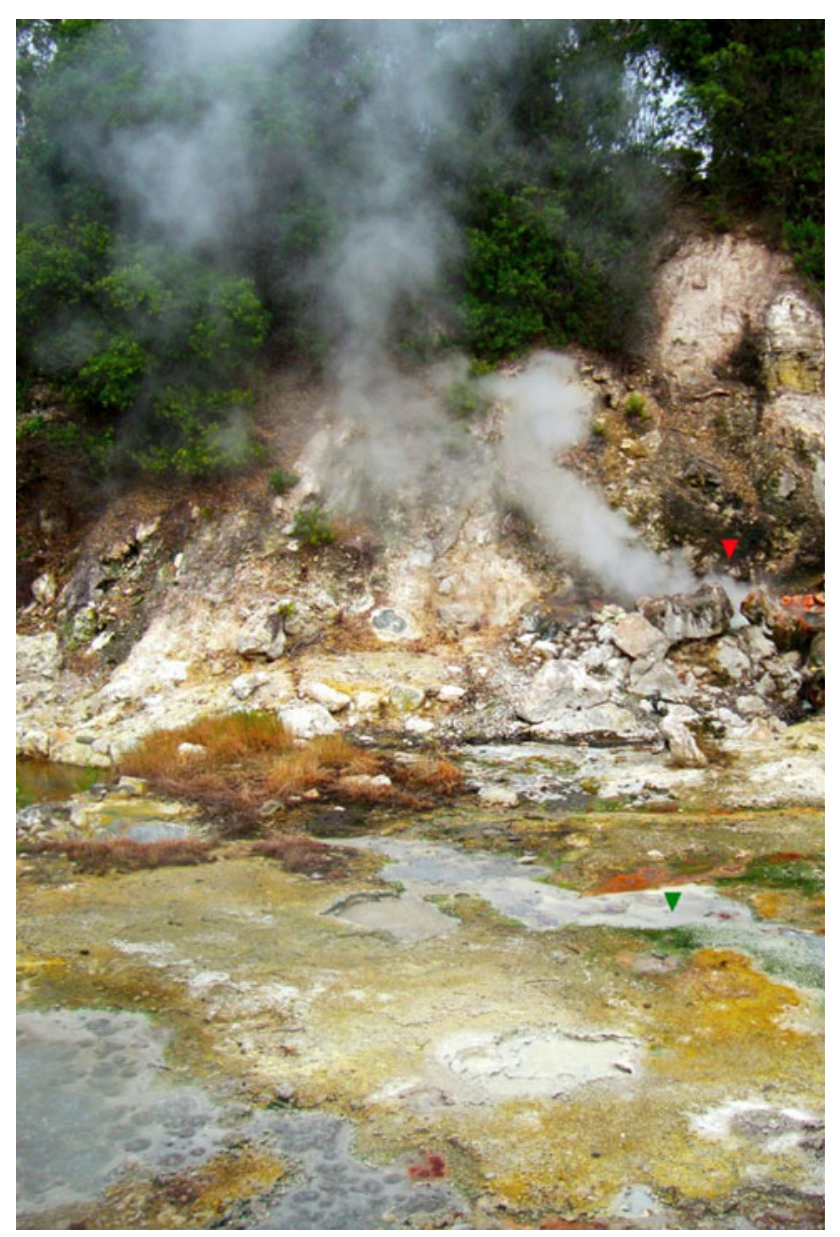

Fig. 1 Solfataric field (study site A) with sulphur deposits and various hydrothermal springs of temperatures up to $97^{\circ} \mathrm{C}$ and $\mathrm{pH}$ values varying between 2.5 and 8 . The rising gases (mainly water vapour and hydrogen sulphide) originate from a solfatara, Caldeira do Esguicho (red arrow, sample AIV). Several sediment and water samples were collected at this site. The green arrow depicts site AI
Determination of chemical parameters

Aliquots of approx. $120 \mathrm{~mL}$ of the original samples were centrifuged at $3,800 \times g$ for $40 \mathrm{~min}$. The supernatants were filtered (pore size of the filters $<0.45 \mu \mathrm{m}$ ) and analysed for chemical parameters applying the following methods/ instruments: optical emission spectroscopy with inductively coupled plasma (Optima 7000 DV OES/ICP, PerkinElmer, Inc.) ( $\mathrm{Na}, \mathrm{K}, \mathrm{Mg}, \mathrm{Ca}, \mathrm{Fe}, \mathrm{S}$ ), ultraviolet-visible spectrophotometry (Lambda 25 UV-VIS, PerkinElmer, Inc.) $\left(\mathrm{NH}_{4}{ }^{+}, \mathrm{Fe}^{2+}, \mathrm{NO}^{2-}\right)$, ion chromatography (Metrohm AG, Germany) $\left(\mathrm{Cl}^{-}, \mathrm{NO}_{3}{ }^{-}, \mathrm{SO}_{3}{ }^{2-}, \mathrm{SO}_{4}{ }^{2-}, \mathrm{PO}_{4}{ }^{3-}\right)$ and TOC analyser (highTOC, Elementar Analysensysteme GmbH, Germany) (DOC, TIC).

\section{Isolation of DNA}

Total community DNA was isolated as described by Zhou et al. (1996), based on lysis with high-salt extraction buffer and extended heating in the presence of sodium dodecyl sulphate (SDS). The samples were centrifuged at $3,939 \times g$ for $1 \mathrm{~h}$ and 2-3 g of the pellet was resuspended in DNA extraction buffer, containing $1 \%$ hexadecylmethylammonium bromide (CTAB). Prior to DNA isolation, three freeze-and-thaw cycles in liquid nitrogen and a water bath at $65^{\circ} \mathrm{C}$ were conducted. The precipitated DNA was dissolved in $120 \mu \mathrm{L}$ sterile water and analysed spectrophotometrically at 260/280 nm and by agarose gel electrophoresis ( $0.4 \%$ agarose). DNA solutions derived from samples with high proportions of sediments appeared intensively orange or yellowish, indicating the coextraction of humic substances which interfere with UVphotometric measurement of DNA concentration. Thus, quantification of DNA extracted from these samples was merely done by agarose gel electrophoresis. 
In addition, we applied the PowerMax ${ }^{\mathrm{TM}}$ Soil DNA Isolation Kit (MO BIO Laboratories, Inc., Carlsbad, USA) as an alternative method for isolation of genomic DNA from all samples. Microorganisms were lysed by a combination of SDS and further disruption agents, and mechanical force using beads. Approx. $2 \mathrm{~g}$ of sediment was used for DNA extraction. The DNA was eluted in $2 \mathrm{~mL}$ sterile water and quantified as described above. Pooled DNA from both methods was used for metagenomic pyrosequencing or PCR amplification.

Denaturing gradient gel electrophoresis

PCR amplification and DGGE were performed as described by Muyzer et al. (1998). We routinely added $3 \mu \mathrm{g} / \mu \mathrm{L}$ (final concentration) bovine serum albumin to the PCR reaction mixture to prevent inhibition of the DNA polymerase by humic substances. The sequences of the primers used for amplification of 16S rRNA gene-fragments were as follows: Arc334F: 5'-CGCCCGCCGCGCCCCGCGCCCGTC CCGCCGCCCCCGCCCGACGGGGYGCAGCAGGCGC GA-3'，Arc915R: 5'-GTGCTCCCCCGCCAATTCCT-3' (Archaea); 314F: 5'-CGCCCGCCGCGCCCCGCGCCCGT CCCGCCGCCCCCGCCCGCCTACGGGAGGCAGCAG3', 907R: 5'-CCGTCAATTCMTTTGAGTTT-3' (Bacteria). Taq DNA polymerase (Fermentas GmbH, St. LeonRot, Germany) was used in PCR. The touchdown PCR protocol by Muyzer (annealing temperatures ranging from 65 to $55^{\circ} \mathrm{C}$ ) was applied for both primer pairs. We used the Dcode $^{\mathrm{TM}}$ System (Bio-Rad Laboratories GmbH, Munich, Germany) for DGGE. Electrophoresis was carried out using a $6 \%$ polyacrylamide gel with a denaturing gradient of $20-80 \%$, at $55{ }^{\circ} \mathrm{C}, 200 \mathrm{~V}$ for $5 \mathrm{~h}$ (BacteriaDGGE), and a denaturing gradient of $30-80 \%$ at $60{ }^{\circ} \mathrm{C}$, $150 \mathrm{~V}$ for $2 \mathrm{~h}$ (Archaea-DGGE). After electrophoresis, the gels were stained in Roti $^{\circledR}$-Gel Stain (Carl Roth $\mathrm{GmbH}+\mathrm{Co}$. KG, Karlsruhe, Germany) and photographed on a UV transilluminator.

Amplification of 16S rRNA gene fragments and pyrosequencing

DNA preparations from both isolation approaches were used as template for individual PCR amplification of 16S rRNA gene fragments. The PCR products derived from either DNA preparation were combined for sequencing in equal amounts. The sequences of the bacterial and archaeal V2/V3 regionspecific primers used in respective PCRs are as follows: Bacteria, V2f: 5'-AGTGGCGGACGGGTGAGTAA-3'; V3r, 5'-CCGCGGCTGCTGGCAC-3' [(Will et al. 2010) V3r modified]; Archaea, Arc113f: 5'-ACKGCTSAGTAACACG TGG-3'; Arc520r, 5'-TACCGCGGCKGCTGGCA-3' [Arc1 13f, (Baker and Cowan 2004); Arc520r, this study]. The template-specific primer sequences were complemented with a GS FLX Titanium primer sequence including the sequence adaptor, a four-base library key sequence, and a MID (multiplex identifier) sequence at the $5^{\prime}$ end of the specific primer. The Amplicon Fusion Primers were commercially synthesized (Fermentas GmbH, St. Leon-Rot, Germany).

The PCR mixtures (final volume $50 \mu \mathrm{L}$ ) contained $10 \mu \mathrm{L}$ fivefold Phusion HF buffer (New England Biolabs $\mathrm{GmbH}$, Frankfurt am Main, Germany), $300 \mu \mathrm{g}$ BSA, $0.2 \mathrm{mM}$ final concentration of each dNTP, $0.4 \mu \mathrm{M}$ final concentration of each primer, 0.5 U Phusion High-Fidelity DNA polymerase (New England Biolabs GmbH, Frankfurt am Main, Germany), and 30-70 ng DNA. For Archaeaspecific PCR the following steps were conducted: initial denaturation at $98{ }^{\circ} \mathrm{C}$ for $30 \mathrm{~s}$ and 28 cycles of denaturation at $98{ }^{\circ} \mathrm{C}$ for $10 \mathrm{~s}$, primer annealing for $20 \mathrm{~s}$ using a temperature gradient ranging from $68{ }^{\circ} \mathrm{C}$ to $55^{\circ} \mathrm{C}\left(1{ }^{\circ} \mathrm{C}\right.$ touchdown every two cycles) and extension at $72{ }^{\circ} \mathrm{C}$ for $15 \mathrm{~s}$, followed by a final extension period at $72{ }^{\circ} \mathrm{C}$ for 10 min. For Bacteria-specific PCR the cycling scheme deviated from the one described above by the annealing temperature gradient which was from 68 to $58{ }^{\circ} \mathrm{C}$ over 22 cycles and six additional cycles at a constant annealing temperature of $58{ }^{\circ} \mathrm{C}$. Subsequently, the PCR products were purified by employing the GeneJet ${ }^{\mathrm{TM}}$ Gel Extraction Kit (Fermentas GmbH, St. Leon-Rot, Germany) and quantified spectrophotometrically.

The isolated metagenomic DNA was used to create a 454-shotgun library following the GS Rapid library protocol (Roche). The library was sequenced with the Genome Sequencer FLX (Roche, Mannheim, Germany) using Titanium chemistry. Sequencing was performed by the Göttingen Genomics Laboratory. In total, 2,044,797 shotgun reads were generated by two complete sequencing runs.

The partial 16S rRNA gene amplicons were sequenced using the unidirectional sequencing protocol (Roche) and Titanium chemistry. One medium lane of a Titanium Picotiter plate was used for sequencing, resulting in 125,702 shotgun sequences.

The sequences have been deposited at NCBI database under the accession number: SRA059339.

Analysis of pyrosequencing-derived data

All pyrosequencing reads obtained from partial 16S rRNA gene amplicons were reassigned to samples AI and AIV based on the unique MIDs. Different scripts of the QIIME software pipeline (Caporaso et al. 2010) and additional programs were applied to perform pyrosequencing data preprocessing and downstream analyses. Removal of sequences $<200 \mathrm{bp}$, and sequences containing more than two primer mismatches or long homopolymers ( $>8 \mathrm{bp}$ ) was performed by applying the script "split_libraries.py". 
Pyrosequencing noise was removed by using the scripts "denoise_wrapper.py" and "inflate_denoiser.py". Subsequently, the programs cutadapt (Martin 2011) and UCHIME (Edgar et al. 2011) (reference database: Greengenes gold database) were applied to remove remaining primer sequences and chimeras, respectively.

Operational taxonomic units (OTUs) were identified at genetic distances of 3 and $20 \%$, representing the species and phylum level, respectively, according to Schloss and Handelsman (2005) by applying the QIIME script "pick_otus.py" (Schloss and Handelsman 2005). In addition, taxonomic classification of OTUs as well as calculation of rarefaction curves, the Shannon index and the Chaol index were performed using QIIME (Shanon and Weaver 1949; Chao and Bunge 2002). With respect to the script "assign_taxonomy.py", related to taxonomic classification of OTUs, preprocessed sequences were compared to the SILVA ribosomal RNA database (release 108) using BLASTN (Pruesse et al. 2007). Furthermore, a customized script to remove all OTUs from the OTU table that have been classified as chloroplasts was applied.

Metagenomic 16SrRNA gene sequences with a minimum length of $100 \mathrm{bp}$ were analysed in the same way by comparing them to the SILVA ribosomal RNA database (release 108) using BLASTN (Pruesse et al. 2007).

Fluorescence in situ hybridization

An $80 \mu \mathrm{L}$ aliquot of the fixed sample was diluted 1:10 in PBS/ethanol and treated by sonication using Branson Sonifier 450 (Branson Ultrasonics Corporation, Danbury, USA) at a setting of 1 min, duty cycle 20 and output control 2, three times with $60 \mathrm{~s}$ lapse between each sonication step while cooled on ice. Subsequently, the sample was resuspended in $400 \mu \mathrm{L} \mathrm{PBS/ethanol.} \mathrm{In} \mathrm{situ} \mathrm{hybrid-}$ ization was conducted following the protocol by Snaidr et al. (1997). An aliquot of $2.5 \mu \mathrm{L}$ was applied to a poly-Llysine-coated microscopic slide. After dehydration, hybridization of the respective $5^{\prime}$-cyanine 3 -labelled oligonucleotide probe to the ribosomal sequence in the target cells was carried out at $46{ }^{\circ} \mathrm{C}$ for $100-120 \mathrm{~min}$. The slide was washed and stained with $2 \mu \mathrm{g} / \mathrm{mL} 4^{\prime}, 6^{\prime}$-diamidino-2phenylindol (DAPI) for $5 \mathrm{~min}$ on ice. Cells were counted using a fluorescent microscope (Zeiss Axioplan) and means were calculated by counting 10-20 randomly chosen fields for each analysis, which corresponded to at least 1,000 Dapi-stained cells.

The FISH probes applied in this study were Eub338 (5'-GCTGCCTCCCGTAGGAGT-3', specificity: domain Bacteria, $35 \%$ formamide in hybridization buffer) (Amann et al. 1990), Arc915 (5'-GTGCTCCCCCGCCAATTCCT $-3^{\prime}$, specificity: domain Archaea, $35 \%$ formamide in hybridization buffer) (Stahl and Amann 1991), Cal450 (5'- CTCCCCGTCCAAAGAGGT-3', specificity: genus Caldicellulosiruptor, $30 \%$ formamide in hybridization buffer) (O-Thong et al. 2007), SHyd540 (5'-TCGCGCAAC GTTCGGGACC-3', specificity: genus Sulfurihydrogenibi$u m, 60 \%$ formamide in hybridization buffer), and Fer660 (5'-GTTCCGTCTGCCTCTGCC-3', specificity: genus Fervidobacterium, $20 \%$ formamide in hybridization buffer). Probes were commercially synthesized as $5^{\prime}$-indocyanine 3-labelled oligonucleotides (Fermentas $\mathrm{GmbH}$, St. Leon-Rot, Germany). Specificity for the newly designed oligonucleotide probes SHyd540 and Fer660 was verified by hybridization to control strains that possess one mismatch position within the ribosomal target sequence (SHyd540: Rhodothermus marinus (DSMZ 4252); Fer660: Fervidobacterium gondwanense (DSMZ 13020) and F. nodosum (DSMZ 5306)). Under the given stringency discrimination of one mismatch was possible.

\section{Results}

Sampling site and sample characteristics

Samples were collected in September 2010 in the Valley of Furnas from nine sites with a wide variety of physicochemical characteristics. In situ temperatures ranged from 51 to $92{ }^{\circ} \mathrm{C}$, whereas $\mathrm{pH}$ values varied between 8 and 2.5 (Table 1). Two sampling sites (AI and AIV) were selected for in-depth analysis, including the determination of several chemical parameters (Table 2). Site AI had a temperature of $51{ }^{\circ} \mathrm{C}$ and an acidic $\mathrm{pH}$ of 3 . The greyish muddy hot spring exhibited oxidized conditions with high concentrations of sulphate $(12.5 \mathrm{mM})$ and iron, which was mainly present as $\mathrm{Fe}^{3+}(1,400 \mu \mathrm{M})$. Site $\mathrm{AIV}$, with a temperature of $92{ }^{\circ} \mathrm{C}$ and a $\mathrm{pH}$ of 8 , exhibited reduced conditions, indicated by the proportion of $\mathrm{Fe}^{2+}$ to $\mathrm{Fe}^{3+}$, which can be taken as a proxy for redox conditions (Mathur et al. 2007). The concentrations of sulphate and iron were low $(100$ and $20 \mu \mathrm{M})$ and iron was mainly present as $\mathrm{Fe}^{2+}$. Organic carbon content was high with $0.006 \%(60 \mathrm{mg} / \mathrm{L})$ at site $\mathrm{AI}$ and $0.03 \%(300 \mathrm{mg} / \mathrm{L})$ at site $\mathrm{AIV}$.

\section{Community fingerprinting using DGGE}

Prokaryotic diversity was estimated using denaturing gradient gel electrophoresis (DGGE) based on 16S rRNA gene fragments amplified with Bacteria- and Archaea-specific primers. Results are shown in Figs. 2 and 3. Taking the number of bands in the DGGE-profile as diversity indicator, the highest bacterial diversity was detected at sites with temperatures between 55 and $85{ }^{\circ} \mathrm{C}$ and $\mathrm{pH}$ values between 7 and 8. Analysis of the DGGE-profiles revealed a 
Table 2 Chemical analysis of sampling sites AI and AIV

\begin{tabular}{llllllllll}
\hline & $\mathrm{Na}(\mathrm{mM})$ & $\mathrm{K}(\mathrm{mM})$ & $\mathrm{Mg}(\mathrm{mM})$ & $\mathrm{Ca}(\mathrm{mM})$ & $\mathrm{Fe}^{2+}(\mu \mathrm{M})$ & $\mathrm{Fe}^{3+(1)}(\mu \mathrm{M})$ & $\mathrm{Fe}(\mu \mathrm{M})$ & $\mathrm{NH}_{4}^{+}(\mu \mathrm{M})$ & $\mathrm{Cl}^{-}(\mathrm{mM})$ \\
\hline $\mathrm{AI}$ & 6.0 & 1.5 & 0.7 & 1.1 & 152 & 1391 & 1543 & 388 & 1.0 \\
$\mathrm{AIV}$ & 19.7 & 0.7 & 0.1 & 0.3 & 22 & 2 & 25 & 26 & 5.4 \\
\hline & $\mathrm{NO}_{2}{ }^{-}(\mu \mathrm{M})$ & $\mathrm{NO}_{3}{ }^{-}(\mu \mathrm{M})$ & $\mathrm{SO}_{3}{ }^{2-}(\mu \mathrm{M})$ & $\mathrm{SO}_{4}{ }^{2-}(\mathrm{mM})$ & $\mathrm{S}(\mathrm{mM})$ & $\mathrm{PO}_{4}{ }^{2-}(\mathrm{mM})$ & $\mathrm{TIC}(\%)$ & $\mathrm{DOC}(\%)$ \\
\hline $\mathrm{AI}$ & $<200$ & $<16$ & $<13$ & 12.5 & 12.6 & 0.01 & $<0.0005$ & 0.006 \\
$\mathrm{AIV}$ & $<200$ & $<16$ & & $<13$ & 0.1 & 0.3 & 0.1 & 0.009 & 0.028 \\
\hline
\end{tabular}

$\mathrm{Fe}^{3+}$ was calculated as the difference of $\mathrm{Fe}$ and $\mathrm{Fe}^{2+}$

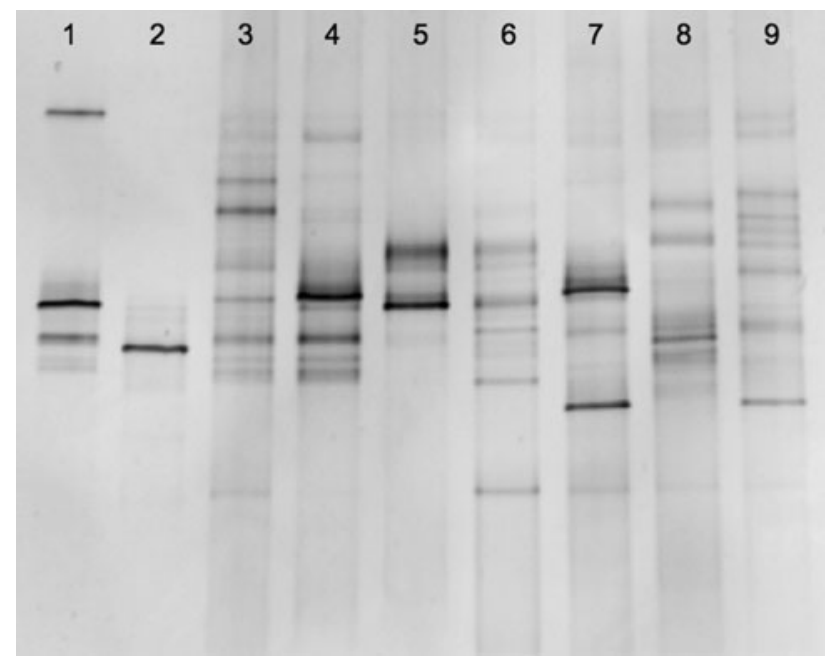

Fig. 2 DGGE analysis of 16S rRNA gene fragments amplified with Bacteria-specific primers. PCR products were analysed on a denaturing gradient from 20 to $80 \%$. The samples were grouped according to sampling site (A, B, C) and increasing temperature. The lanes can be attributed to the following sites: $1 \mathrm{AI}\left(51^{\circ} \mathrm{C}, \mathrm{pH} 3\right), 2 \mathrm{AII}\left(84^{\circ} \mathrm{C}, \mathrm{pH}\right.$ 2.5-3), 3 AIII $\left(85^{\circ} \mathrm{C}, \mathrm{pH} 8\right), 4$ AIV $\left(92{ }^{\circ} \mathrm{C}, \mathrm{pH} 8\right), 5 \mathrm{BI}\left(60^{\circ} \mathrm{C}, \mathrm{pH}\right.$ 6), 6 BII $\left(65^{\circ} \mathrm{C}, \mathrm{pH} 7\right), 7$ BIII $\left(70{ }^{\circ} \mathrm{C}, \mathrm{pH} 6\right), 8 \mathrm{CI}\left(55^{\circ} \mathrm{C}, \mathrm{pH} 8\right), 9$ CII $\left(76^{\circ} \mathrm{C}, \mathrm{pH} 8\right)$

prominent effect of $\mathrm{pH}$. In particular, the combination of acidic $\mathrm{pH}$ and high temperature $\left(\mathrm{pH} 2.5-3\right.$ and $\left.84^{\circ} \mathrm{C}\right)$ led to a very low bacterial diversity (Fig. 2 , lane 2 ) while at moderate temperature of $51{ }^{\circ} \mathrm{C}$ and $\mathrm{pH} 3$ more bacterial bands were detected (Fig. 2, lane 1). Analysis of archaeal 16S rRNA genes using DGGE revealed an overall lower number of bands (Fig. 3). Sites AIII and AIV exhibit an almost identical band-pattern despite the difference in temperature $\left(85\right.$ vs. $\left.92{ }^{\circ} \mathrm{C}\right)$.

Based on site-specific characteristics and the DGGE results we selected two sites (AI and AIV) for further analysis. Both sites are connected, with the outflow of AIV running into AI. Furthermore, they exhibit medium diversity and particularly challenging conditions with regard to $\mathrm{pH}$ (AI: $\mathrm{pH} 3$ ) or temperature (AIV: $92{ }^{\circ} \mathrm{C}$ ).

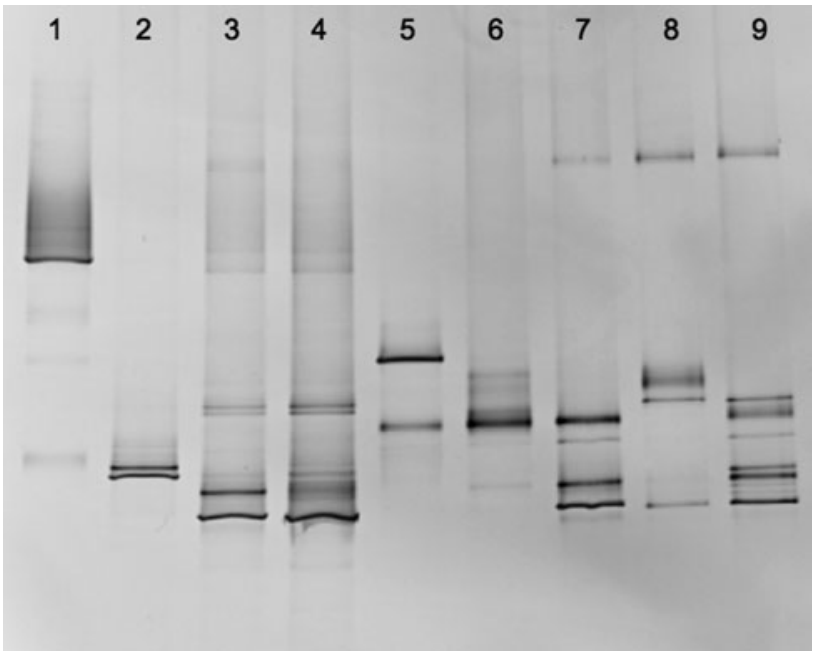

Fig. 3 DGGE analysis of 16S rRNA gene fragments amplified with Archaea-specific primers. PCR products were analysed on a denaturing gradient from 30 to $80 \%$. The samples were grouped according to sampling site (A, B, C) and increasing temperature. The lanes can be attributed to the following sites: $1 \mathrm{AI}\left(51^{\circ} \mathrm{C}, \mathrm{pH} 3\right), 2 \mathrm{AII}\left(84^{\circ} \mathrm{C}, \mathrm{pH}\right.$ 2.5-3), 3 AIII $\left(85^{\circ} \mathrm{C}, \mathrm{pH} 8\right), 4$ AIV $\left(92{ }^{\circ} \mathrm{C}, \mathrm{pH} 8\right), 5$ BI $\left(60{ }^{\circ} \mathrm{C}, \mathrm{pH}\right.$ 6), 6 BII $\left(65^{\circ} \mathrm{C}, \mathrm{pH} 7\right), 7$ BIII $\left(70{ }^{\circ} \mathrm{C}, \mathrm{pH} 6\right), 8 \mathrm{CI}\left(55^{\circ} \mathrm{C}, \mathrm{pH} 8\right), 9$ $\mathrm{CII}\left(76^{\circ} \mathrm{C}, \mathrm{pH} 8\right)$

Community composition determined by fluorescence in situ hybridization

To quantify the relative contributions of Bacteria and Archaea to the communities of sites AI and AIV, we applied FISH using domain-specific probes (Fig. 4). The acidic hydrothermal spring AI was dominated by Bacteria (68\%). Archaea could not be detected at all and $32 \%$ of the cells could only be stained with DAPI. At the hightemperature site AIV $\left(92{ }^{\circ} \mathrm{C}\right) 75 \%$ of all cells could be detected by FISH. The relative contribution of the specific domains was almost even with $35 \%$ Archaea and $40 \%$ Bacteria. Total cell number determined by DAPIstaining was $4.6 \times 10^{7} / \mathrm{ml}$ for AI and $2.6 \times 10^{8} / \mathrm{ml}$ for AIV. 
Fig. 4 Domain-level composition of microbial communities $\mathrm{AI}$ and $\mathrm{AIV}$ as determined by FISH. For Bacteria EUB333 was used and for Archaea probe Arch915. Relative abundance is based on the total cell number determined by DAPI-staining. a Depicts the results for site $\mathrm{AI}$ and $\mathbf{b}$ for site AIV
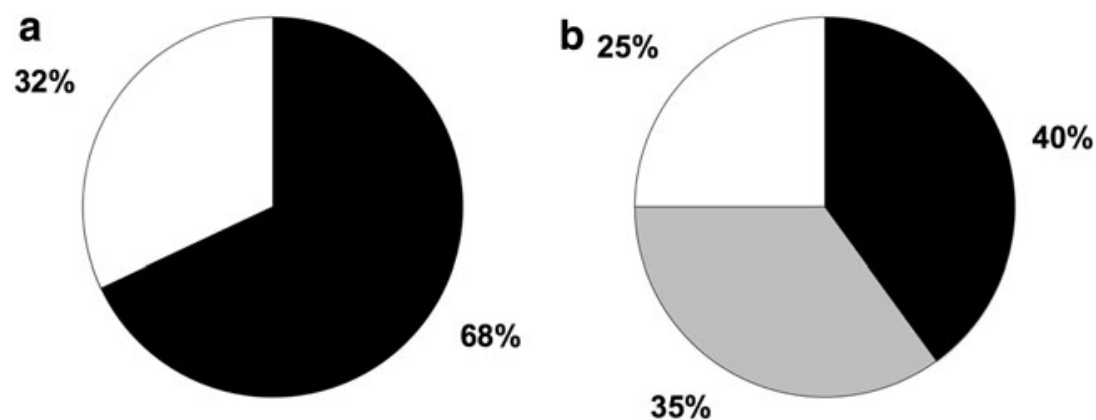

Bacteria

Archaea

Only DAPI

Phylogenetic analyses based on 16S rRNA gene sequences

To evaluate prokaryotic diversity of the selected sites, partial 16S rRNA genes were amplified from metagenomic DNA and sequenced by pyrosequencing. Based on former studies, we decided to amplify the V2/V3 region for both, Bacteria and Archaea, comprising 435 bp (Nacke et al. 2011; Yu et al. 2008; Will et al. 2010; Kysela et al. 2005). While primers for Bacteria were already available, new primers to amplify the corresponding region in the archaeal 16S rRNA gene had to be designed. The forward primer was based on the data of Baker and Cowan with slight modifications (Baker and Cowan 2004) while the reverse primer was designed de-novo. A total number of 125,702 sequences were generated. After preprocessing including quality filtering and denoising, 93,576 sequences with an average length of 390 bases could be obtained for further analyses. The number of total reads of every sample and remaining numbers of reads after quality filtering and denoising are depicted in Table 3. Amplification was specific, yielding the expected domain-specific sequences apart from archaeal amplification of DNA from site AIV.

Furthermore, metagenomic DNA derived from site AIV was analysed using direct pyrosequencing without prior amplification. Of the data generated $0.1 \%$ represented partial 16S rRNA genes. The 16S rRNA gene fragments $f \geq 100 \mathrm{bp}$ were extracted from the dataset. The resulting 725 partial 16S rRNA gene sequences were analysed by comparing them to the SILVA ribosomal RNA database using BLASTN.

\section{Comparison of the sequencing approaches}

Combined results of the two sequencing approaches are shown in Tables 4, 5 and 6 . The acidic spring AI was dominated by Proteobacteria $(>80 \%)$ and Firmicutes $(10 \%)$ (Table 4) while site AIV was dominated by bacteria belonging to 4 different phyla: Thermotogae,
Table 3 Evaluation of V2/V3 pyrosequencing data

\begin{tabular}{llllll}
\hline & $\begin{array}{l}\text { Total } \\
\text { sequences }\end{array}$ & $\begin{array}{l}\text { Preprocessed } \\
\text { sequences }\end{array}$ & $\begin{array}{l}\text { Average } \\
\text { read } \\
\text { length }\end{array}$ & $\begin{array}{l}\text { Assigned } \\
\text { to } \\
\text { Bacteria } \\
(\%)\end{array}$ & $\begin{array}{l}\text { Assigned } \\
\text { to } \\
\text { Archaea } \\
(\%)\end{array}$ \\
\hline AI-Bact. & 37,044 & 28,565 & 385 & 97.0 & 3 \\
AI-Arch. & 49,573 & 35,607 & 386 & 1.3 & 98.7 \\
AIV-Bact. & 39,085 & 29,404 & 400 & 99.9 & 0.1 \\
\hline
\end{tabular}

Firmicutes, Dictyoglomi, and Aquificae (Table 5). Each of these phylum-groups mainly consisted of one dominating genus. The acidic spring AI was dominated by Proteobacteria known for their acidophilic properties: the heterotrophic genus Acidicaldus (38\%) and the chemolithoautotrophic Acidithiobacillus (43\%). In addition, almost $8 \%$ of the sequences was related to Anoxybacillus (Table 4). Within site AIV $\left(92{ }^{\circ} \mathrm{C}, \mathrm{pH} 8\right)$ members of Dictyoglomus, Caldicellulosiruptor, and Fervidobacterium constituted up to $61 \%$ of the bacterial community according to data resulting from non-amplified pyrosequencing of metagenomic DNA, whereas analysis of the amplified V2/V3 16S rRNA gene region indicated an even higher abundance of these heterotrophic genera (88\%) (Table 5). Data from direct metagenome sequencing also revealed high abundance of two genera from the phylum Aquificae, with the chemolithoautotrophic Sulfurihydrogenibium being the dominant genus $(22 \%)$.

The archaeal community of the hot spring AIV $\left(92^{\circ} \mathrm{C}\right)$ was almost exclusively composed of Crenarchaeota while in the acidic spring AI only Euryarchaeota were detected. Table 6 depicts the detailed composition. The archaeal community of site AI mainly harboured Thermoplasma (89\%), while clone group BLSdp215 represented the second largest group ( $9 \%$ of all sequences). Site AIV was dominated by Desulfurococcaceae $(75 \%)$ with the genera Sulfophobococcus, Desulfurococcus being most abundant within this family. Furthermore, the genus Pyrobaculum of the Thermoprotaceae made up $25 \%$ of the sequences. 
Table 4 Composition of the bacterial community of AI determined by V2/V3 sequencing

Only genera that occur at an abundances of above $0.5 \%$ are shown

Dominant taxa are given in bold

\begin{tabular}{llll}
\hline Phylum & Family & Genus & $\begin{array}{l}\text { Rel. abundance (\%) } \\
\text { AI V2/V3 }\end{array}$ \\
\hline Proteobacteria $(\boldsymbol{\alpha})$ & Acetobacteraceae & Acidicaldus & $\mathbf{3 8}$ \\
& & Uncultured & 0.6 \\
Proteobacteria $(\gamma)$ & Acidithiobacillaceae & Acidithiobacillus & $\mathbf{4 3}$ \\
Firmicutes & Bacillaceae & Anoxybacillus & $\mathbf{7 . 8}$ \\
& Clostridiaceae & Caloramator & 1.2 \\
& & Clostridium & 0.5 \\
Nitrospirae & Nitrospiraceae & Leptospirillum & 0.9 \\
Actinobacteria & Acidimicrobiaceae & Acidimicrobium & 0.7 \\
\hline
\end{tabular}

Table 5 Detailed comparison of the bacterial community composition of AIV determined by V2/V3 or metagenome sequencing

\begin{tabular}{|c|c|c|c|c|}
\hline \multirow[t]{2}{*}{ Phylum } & \multirow[t]{2}{*}{ Family } & \multirow[t]{2}{*}{ Genus } & \multicolumn{2}{|c|}{ Rel. abundance (\%) } \\
\hline & & & AIV V2/V3 & AIV metagenome \\
\hline \multirow[t]{2}{*}{ Aquificae } & Hydrogenothermaceae & Sulfurihydrogenibium & 0.4 & 22 \\
\hline & Aquificaceae & Hydrogenobacter & 0.1 & 6 \\
\hline Dictyoglomi & Dictyoglomaceae & Dictyoglomus & 22 & 27 \\
\hline Deinococcus-Thermus & Thermaceae & Thermus & 0.8 & 2 \\
\hline \multirow[t]{4}{*}{ Firmicutes } & Thermoanaerobacteraceae & Caldicellulosiruptor & 19 & 21 \\
\hline & Clostridiaceae & Clostridium & 4.9 & 0.6 \\
\hline & Peptococcaceae & Desulfosporosinus & ND & 1 \\
\hline & Ruminococcaceae & Incertae Sedis & 1.63 & ND \\
\hline \multirow[t]{2}{*}{ Thermotogae } & Thermotogaceae & Fervidobacterium & 47 & 13 \\
\hline & & Thermotoga & 0.7 & 0.8 \\
\hline Thermodesulfobacteria & Thermodesulfobacteriaceae & Thermodesulfobacterium & ND & 1 \\
\hline Nitrospirae & Nitrospiraceae & Thermodesulfovibrio & 0.72 & 0.4 \\
\hline
\end{tabular}

Only genera that occur at an abundances of above $0.5 \%$ in at least one of the two approaches are shown

Dominant taxa are given in bold

$N D$ not detected

Table 6 Detailed comparison of the archaeal community composition of AI and AIV determined by metagenome sequencing and V2/V3 sequencing, respectively

\begin{tabular}{|c|c|c|c|c|}
\hline \multirow[t]{2}{*}{ Phylum } & \multirow[t]{2}{*}{ Family } & \multirow[t]{2}{*}{ Genus } & \multicolumn{2}{|c|}{ Rel. abundance of archaea (\%) } \\
\hline & & & $\mathrm{AI}$ & $\mathrm{AIV}^{\mathrm{a}}$ \\
\hline \multirow[t]{5}{*}{ Crenarchaeota } & \multirow[t]{4}{*}{ Desulfurococcaceae } & Sulfophobococcus & ND & 55 \\
\hline & & Desulfurococcus & ND & 19 \\
\hline & & Staphylothermus & ND & 0.5 \\
\hline & & Stetteria & ND & 0.5 \\
\hline & Thermoproteaceae & Pyrobaculum & ND & 25 \\
\hline \multirow[t]{3}{*}{ Euryarchaeota } & \multirow[t]{3}{*}{ Thermoplasmataceae } & Thermoplasma & 89 & ND \\
\hline & & BSLdp215 uncultured & 9 & ND \\
\hline & & A10 uncultured & 1 & ND \\
\hline
\end{tabular}

Only genera that occur at an abundances of above $0.5 \%$ are shown

Dominant taxa are given in bold

$N D$ not detected

${ }^{a}$ Data are based on the metagenome analysis 
Microbial diversity indices

Hot springs are usually referred to as low-diversity habitats. Diversity indices are well established measures to quantify diversity on a parametric (Shanon) or non-parametric (Chao1) basis. While the Shanon index takes species richness and species evenness into account, the Chao index is based on species richness, with the obtained value giving the number of expected operational taxonomic units (OTUs). To calculate rarefaction curves, richness, and diversity indices, OTUs at genetic distances of 3 and $20 \%$ were determined. With respect to the Bacteria, OTU-based analyses were performed at the same level of surveying effort by using 22,100 randomly selected sequences per sample to enable accurate OTU-based comparisons between site $\mathrm{AI}$ and $\mathrm{AIV}$.

Comparison of the rarefaction analyses with the number of OTUs determined by Chao 1 richness estimator revealed that $76.2-90.6 \%$ (20\% genetic distance) and $54.5-77.7 \%$ (3\% genetic distance) of the taxonomic richness were covered by the surveying effort (Fig. 5; Table 7). Thus, we did not survey the full extent of taxonomic diversity at these genetic distances, but especially at the phylum level a substantial fraction of the estimated richness was assessed by the surveying effort. The bacterial diversity at sites AI and AIV exhibits an interesting difference: on the phylum level the acidic spring is more diverse than the slightly alkaline high-temperature site AIV, with 50 versus 30 OTUs (Table 7), whereas on the species level the opposite pattern was discovered (AI: 178 OTUs, AIV: 236 OTUs).

Using Chao1 richness estimator, the maximum number of OTUs for the acidic spring bacterial community predicted at $3 \%$ genetic distance was 229 belonging to 59 predicted phyla. With respect to site AIV $\left(92^{\circ} \mathrm{C}, \mathrm{pH} 8\right)$, 371 bacterial OTUs on species level and 33 OTUs on the phylum level were predicted by Chaol richness estimator. The Shanon index $\left(H^{\prime}\right)$, determined for both habitats, indicated a slightly lower diversity in site AI than in site AIV (3\% genetic distance: AI: 1.8 , AIV: $2.3 ; 20 \%$ genetic distance: AI: 0.8, AIV: 1.0).

Archaeal diversity could only be estimated for site AI and was very low $\left(H^{\prime}: 0.54\right.$ at $3 \%$ and 0.09 at $20 \%$ genetic distance) as expected due to the high dominance of Thermoplasma (Table 6). At $3 \%$ sequence divergence a maximum number of 99 OTUs were predicted while 21

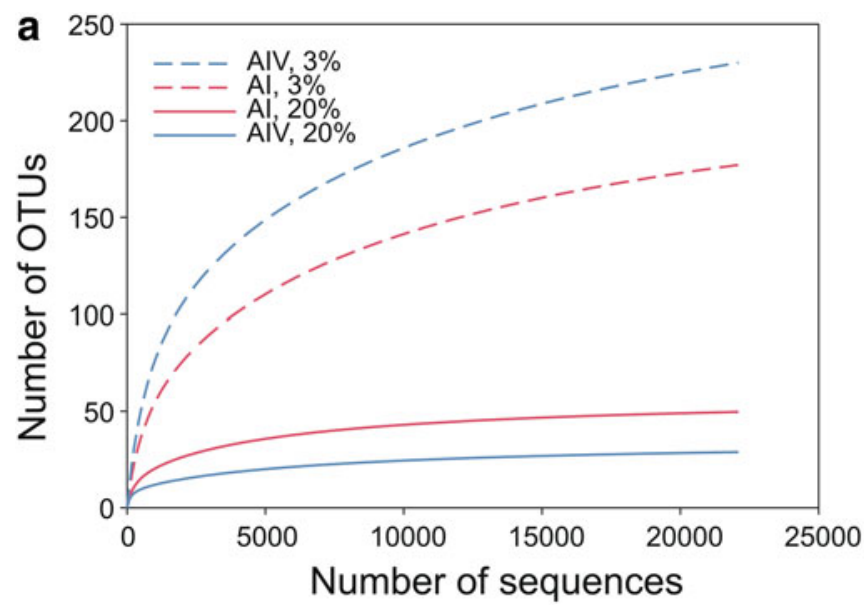

Fig. 5 Rarefaction analysis of V2/V3 sequencing results for Bacteria and Archaea. Rarefaction curves were calculated on the basis of 22,100 sequences for Bacteria (a) and based on 35,200 sequences for

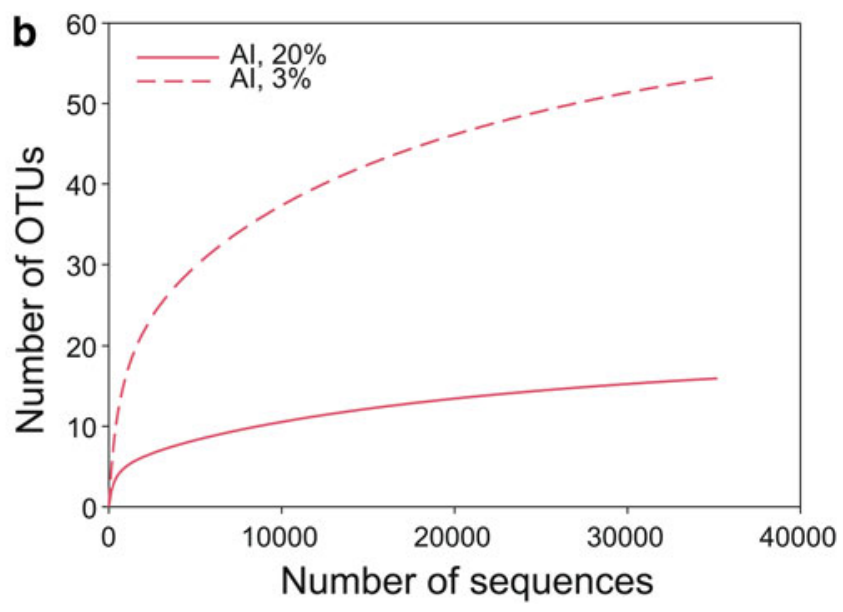

Archaea (b). The curves indicate the observed number of OTUs within the two samples AI $\left(51^{\circ} \mathrm{C}, \mathrm{pH} 3\right)$ and $\operatorname{AIV}\left(92{ }^{\circ} \mathrm{C}, \mathrm{pH} 8\right)$. OTUs are shown at the level of 3 and $20 \%$ genetic distance

Table 7 Diversity estimates based on V2/V3 sequencing

\begin{tabular}{|c|c|c|c|c|c|c|c|c|}
\hline \multirow[t]{2}{*}{ Distance } & \multicolumn{2}{|c|}{ Shannon index $\left(H^{\prime}\right)$} & \multicolumn{2}{|c|}{ Rarefaction (no. of OTUs) } & \multicolumn{2}{|c|}{ Chao1 (no. of OTUs) } & \multicolumn{2}{|c|}{ Coverage $(\%)$} \\
\hline & $3 \%$ & $20 \%$ & $3 \%$ & $20 \%$ & $3 \%$ & $20 \%$ & $3 \%$ & $20 \%$ \\
\hline AI Bacteria ${ }^{a}$ & 1.80 & 0.83 & 178 & 50 & 229 & 59 & 77.7 & 84.7 \\
\hline AI Archaea ${ }^{b}$ & 0.54 & 0.09 & 54 & 16 & 99 & 21 & 54.5 & 76.2 \\
\hline AIV Bacteria ${ }^{a}$ & 2.29 & 1.04 & 231 & 29 & 337 & 32 & 68.5 & 90.6 \\
\hline
\end{tabular}

a No. of sequences analysed 22,100
b No. of sequences analysed 35,200 
OTUs were predicted at $20 \%$ sequence divergence using Chao1 richness estimator.

Evaluation of the pyrosequencing-based analyses by group-specific fluorescence in situ hybridization

At site AIV relative abundance of Sulfurihydrogenibium and Fervidobacterium differed depending on the sequencing approach (Table 5). While sequencing of non-amplified metagenomic DNA indicated high abundance of Aquificae (approx. $28 \%$ ), in particular Sulfurihydrogenibium, the sequencing of partial 16S rRNA gene amplicons hardly detected any. On the other hand, amplicon sequencing indicated dominance of Fervidobacterium (approx. $47 \%$ ). We applied FISH to quantify and further analyse these specific groups including also Caldicellulosiruptor, which represented approx. $21 \%$ of the bacterial community according to data derived from direct sequencing and pyrosequencing of the V2/V3 16S rRNA gene region. Dictyoglomus, the fourth dominant genus in sample AIV could not be evaluated because no specific probe could be designed.

Two probes had to be designed de-novo. The probes specific for Sulfurihydrogenibium and Fervidobacterium were developed on the basis of signature sequences described by Harmsen et al. (1997), which had been specific for Hydrogenobacter and Thermotoga. An exchange of one and two bases, respectively, allowed to change the specificity to the genera in question. Primer specificity was confirmed in-silico using ProbeMatch of the RDP Database Project and hybridization conditions were experimentally verified using controls with one mismatch. At the stringency conditions applied, no signal could be detected in cells with 1 mismatch to the probe. A comparison of all three approaches to quantify dominant bacterial genera is shown in Fig. 6. Quantification by FISH underlined the high abundance of Caldicellulosiruptor, revealing that this genus represented $28 \%$ of all Bacteria (detected with EUB-specific probe) as compared to 19 and $21 \%$ detected by sequencing of partial $16 \mathrm{~S}$ rRNA gene amplicons and direct sequencing of metagenomic DNA, respectively. Furthermore, FISH indicated that Fervidobacterium accounted for $22 \%$ of the bacterial community and thus had been overestimated by analysis of the V2/V3 $16 \mathrm{~S}$ rRNA region (47\%) and underestimated according to data derived from direct sequencing of metagenomic DNA (14\%). While Sulfurihydrogenibium was almost undetected by sequencing of the V2/V3 16S rRNA gene region $(0.4 \%)$, the genus was overestimated by direct sequencing of metagenomic DNA (17\%) since FISH revealed it to account for $9 \%$ of the Bacteria. Altogether, almost $60 \%$ of the bacterial cells could be assigned to the three genera

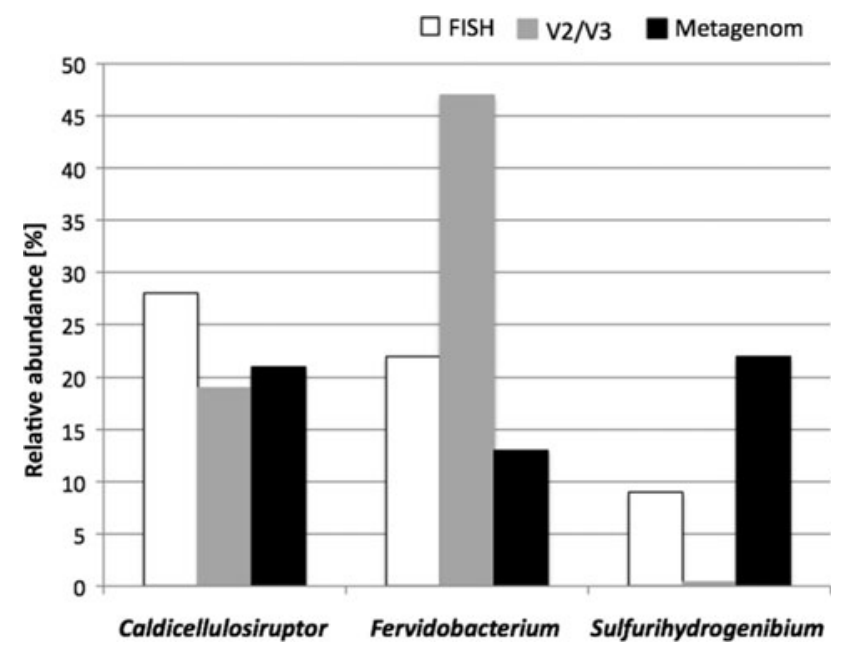

Fig. 6 Comparative quantification using FISH, V2/V3 and metagenome sequencing. The relative abundance relates to $\%$ of bacterial cells for FISH, \% of bacterial rRNA gene sequences for V2/V3 and metagenome sequences

Caldicellulosiruptor, Fervidobacterium, and Sulfurihydrogenibium using FISH.

\section{Discussion}

Prokaryotic diversity

Hot springs are considered low-diversity habitats due to the high physicochemical constraints and the high degree of geographical isolation (Papke et al. 2003). The effect of temperature on prokaryotic diversity has been studied and results are contradictory. Yim et al. (2006) did not find a linear correlation between prokaryotic diversity and temperature in mats and streamers at temperatures between 52 and $69^{\circ} \mathrm{C}$ in alkaline geothermal springs from Tibet. On the other hand, Miller et al. suggested that bacterial diversity along a temperature gradient from 39 to $72{ }^{\circ} \mathrm{C}$ in two alkaline hot springs from Yellowstone National Park is primarily controlled by temperature in photosynthetically active microbial mats which has also been shown by Hiraishi et al. in hot springs in Japan (Yim et al. 2006; Miller et al. 2009; Hiraishi et al. 1999). Furthermore, Skirnisdottir et al. (2000) found the lowest bacterial diversity at the highest temperature $\left(80{ }^{\circ} \mathrm{C}\right)$ and highest sulphide concentration when comparing hot springs in Iceland with low and high concentration of sulphide. Based on DGGE analysis of nine sites, we found high bacterial diversity over a range of temperature between 55 and $85^{\circ} \mathrm{C}$ as long as the $\mathrm{pH}$ was neutral to slightly alkaline. With respect to Archaea, the temperature range was slightly shifted upwards from 70 to $92{ }^{\circ} \mathrm{C}$. In the 
hydrothermal springs investigated here, lowest bacterial diversity was detected at acidic $\mathrm{pH}$ and high temperature.

If phylogenetic distance is taken into account, sites AI and AIV display a distinctive difference. OTU-based analyses showed that bacterial diversity was more phylum rich in site AI compared to site AIV. However, site AIV was more species rich than site AI. Similar observations have been published previously (Roesch et al. 2007; Yim et al. 2006). Yim et al. suggested that extreme stress might inhibit the survival of large numbers of closely related guild taxa in microbial population from hot spring sediments and streamers leading to higher phylum numbers (Yim et al. 2006). Roesch et al. (2007) found that agricultural soil was phylum poor and species rich, whereas undisturbed forest soil showed the opposite pattern. However, the authors could not find a clear explanation for this. The factors causing the differences between the two habitats AI and AIV investigated here remain elusive. It is possible that coping with low $\mathrm{pH}$ is a property more widespread in the phylogenetic tree on phylum level than coping with temperatures above $90{ }^{\circ} \mathrm{C}$. On the other hand it could also mean, that a habitat with temperature above $90{ }^{\circ} \mathrm{C}$ allows faster speciation than the low $\mathrm{pH}$ habitat. As long as there is no additional data available to show that this is not a coincidental observation, we can only speculate. Further comparative studies will be needed to evaluate this and to establish, whether it also holds for archaeal populations.

Diversity indices help to compare habitats. However, only few data are available on diversity indices from hot springs. For circumneutral springs at temperatures between 73 and $86^{\circ} \mathrm{C}$ Costa et al. (2009) calculated Shanon indices between 2.02 and 2.37 at $3 \%$ genetic distance for Bacteria and between 1.18 and 2.7 for Archaea. At a genetic distance of $20 \%$, the values were between 1.82 and 2.29 for Bacteria and between 0.95 and 2.16 for Archaea. For slightly alkaline springs along a temperature gradient from 52 to $69{ }^{\circ} \mathrm{C}$ Lau et al. (2009) calculated slightly higher Shanon indices between 3 and 4 at $3 \%$ genetic distance for Bacteria. In acidic springs at temperatures between 60 and $75{ }^{\circ} \mathrm{C}$ Mathur et al. (2007) calculated Shanon indices for bacteria at $3 \%$ genetic distance between 0.83 and 3.28 at springs with high sulphide and low iron concentration and between 2.1 and 3.6 in springs with high iron and low sulphide concentration. Shanon indices for bacteria calculated for sites AI and AIV fall within the same range. The acidic spring AI, which contained high iron and low sulphide concentrations, exhibited a Shanon index of 1.8 for Bacteria and 0.54 for Archaea at $3 \%$ sequence divergence and values of 0.83 and 0.09 at $20 \%$ sequence divergence. The slightly alkaline high-temperature $\left(92{ }^{\circ} \mathrm{C}\right)$ spring AIV shows a Shanon index of 2.29 at $3 \%$ and 1.04 at $20 \%$ sequence divergence for Bacteria. These values are, as expected, lower than in terrestrial soils, which are considered the most complex microbial ecosystems on Earth, with Shanon indices of 5-7 at $3 \%$ sequence divergence and 2.5-4.5 at $20 \%$ sequence divergence (Will et al. 2010; Nacke et al. 2011). Shanon indices calculated for another extreme environment, glacier ice (3.4 and 1.7 for 3 and $20 \%$ sequence divergence, respectively) (Simon et al. 2009), were in the same range as in our study.

Dominant metabolic pathways in the hot springs of Furnas

Inferring physiology from 16S rRNA gene phylogeny is inherently biased (Jaspers and Overmann 2004), in particular if the closest relatives are sequences from uncultured organisms. Keeping this in mind we suggest putative physiology on the basis of the closest cultivated 16S rRNA gene relatives for our habitat, in particular for AIV because a large proportion of the partial sequences is more than $99 \%$ identical to sequences from cultivated organisms. For Fervidobacterium $91 \%$ of the sequences were more than $99 \%$ identical to $F$. islandicum, for Dictyoglomus $88 \%$ of the sequences were more than $99 \%$ identical to $D$. thermophilum, and for Caldicellulosiruptor $85 \%$ of the sequences were more than $99 \%$ identical to $C$. lactoaceticus. Altogether only the rare members of the sequence pool amounting to $11 \%$ were $<97 \%$ identical to cultivated or related to uncultivated species. The situation is different for AI and here in particular for Acidicaldus. $94 \%$ of the Acidicaldus-specific sequences were related to uncultivated organisms. However, $99 \%$ of the Acidithiobacillus-sequences were $99 \%$ identical to Acidithiobacillus caldus. This is in contrast to the majority of other environmental studies, in which the largest proportion of sequences does not affiliate with cultivated species (MeyerDombard et al. 2005; Hugenholtz et al. 1998; Ivanova et al. 2011; Pagaling et al. 2012).

Although differing for two groups (Sulfurihydrogenibium and Fervidobacterium), both 16S rRNA gene sequencebased approaches indicated the dominance of heterotrophic bacterial genera in both springs. This is in contrast to many other studies in hot spring-environments where Aquificales have been repeatedly found to dominate 16S rRNA genelibraries, e.g. from Yellowstone National Park, Iceland, New Zealand, and Japan (Hall et al. 2008; Meyer-Dombard et al. 2005; Blank et al. 2002; Jackson et al. 2001; Skirnisdottir et al. 2000; Hetzer et al. 2007; Yamamoto et al. 1998). These findings led to the hypothesis that chemolithotrophic physiology probably based on the oxidation of $\mathrm{H}_{2}$ or reduced sulphur compounds is the major metabolic pathway in hot springs. Skirnisdottir et al. compared results from different studies on hot spring microbial mats and sediments and found that, depending on the chemical characteristics of the 
spring, different subgroups of Aquificales dominated (Yamamoto et al. 1998; Reysenbach et al. 2000; Hugenholtz et al. 1998). In high-sulphide and sometimes iron-rich habitats groups, $\mathrm{J}$ and $\mathrm{S}$ were dominating and the related sequences can today be attributed to Sulfurihydrogenibium. The high abundance (21\%) of Sulfurihydrogenibium-related sequences within the metagenome from site AIV fitted into the picture. However, evaluation with FISH revealed that Sulfurihydrogenibium had been overestimated and was only accounting for $9 \%$ of the bacterial cells.

The comparatively low abundance of chemolithoautotrophic organisms at site AIV might be related to the high concentration of dissolved organic carbon (DOC) of $284 \mathrm{mg} / \mathrm{L}(0.028 \%)$. Only little data are available on the DOC content of hot springs. Yamamoto et al. measured a DOC content of $0.41-0.72 \mathrm{mg} / \mathrm{L}$ within the microbial sulphur-turf mat, while Hetzer et al. determined $0.7 \mathrm{mg} / \mathrm{L}$ in Champagne Pool, New Zealand, and Hall et al. described a DOC content of $10 \mathrm{mg} / \mathrm{L}$ in Coffee Pot hot spring (YNP) (Yamamoto et al. 1998; Hetzer et al. 2007; Hall et al. 2008). All sites showed clear dominance of Aquificales. The more than 20-fold or even 400-fold higher concentration of DOC in the Furnas spring could well be a reason for the abundant occurence of heterotrophic bacteria. Regarding autotrophic processes at site AIV, however, also Archaea have to be taken into account, since FISH detected $35 \%$ of the cells to be of archaeal origin. Metagenomic rRNA data suggest that the heterotrophic genera Sulfophobococcus spp. and Desulfurococcus spp. account for approx. $74 \%$ of the sequences while the remaining $26 \%$ may well be related to chemolithotrophic genera. Further studies will show, if high abundance of heterotrophic microorganisms is a common feature for springs with higher organic carbon content.

The dominant genera in site AIV (Caldicellulosiruptor, Dictyoglomus, and Fervidobacterium) have also been detected in in situ enrichment cultures in hot springs from Kamchatka (Kublanov et al. 2009). While Caldicellulosiruptor sp. and Dictyoglomus sp. grew on polysaccharides like cellulose and chitin, Fervidobacterium sp. was enriched on proteinaceous substrates. Although dominated by one OTU, all groups show additional sequence diversity in particular Dictyoglomus with 44 OTUs at $3 \%$ divergence. For Fervidobacterium and Caldicellulosiruptor the number of specific OTUs is 18 and 14, respectively. These results suggest that the hot springs of Furnas are a valuable source to retrieve new polymer-degrading organisms.

\section{Conclusions}

The microbial community of two hot springs of Furnas Valley was characterized on the basis of different rRNA gene-based methods. The combination of different primer- dependent and independent methods revealed major differences, emphasizing the importance of combining different methodological approaches. A large dataset of short rRNA gene sequences and metagenome analysis revealed that the habitats were dominated by three to four genera, both for the bacterial and the archaeal population. Archaeal diversity was particularly limited in the acidic spring AI ( $\left.\mathrm{pH} 3,51{ }^{\circ} \mathrm{C}\right)$, in which Thermoplasma represented almost $90 \%$. However, overall abundance of Archaea in this acidic environment was low as revealed by FISH, while the hot slightly alkaline spring AIV $(\mathrm{pH} 8$, $92{ }^{\circ} \mathrm{C}$ ) had almost even abundances of Archaea and Bacteria. Unlike other hydrothermal habitats, the hightemperature slightly alkaline low-sulphate spring AIV was dominated by heterotrophic bacteria, probably due to a high content of dissolved organic carbon, suggesting that not all hydrothermal habitats are dominated by chemolithoautotrophs and that a wide range of chemical characteristics needs to be taken into account when analysing hot springs. This supports the efforts of the Earth Microbiome Project which states the importance of careful and comprehensive metadata collection for each and in particular for metagenomic environmental studies in order to improve comparability, so that general patterns can be identified on the basis of different studies (Knight et al. 2012; Yilmaz et al. 2011).

Our results suggest a natural enrichment of heterotrophic, polymer-degrading genera in the Furnas springs which make them particularly promising for the search of novel thermostable enzymes for application in biotechnology and biorefinery of the second generation.

Acknowledgments The authors gratefully acknowledge Milton da Costa for supporting their sampling on a field trip to the Valley of Furnas.

\section{References}

Albuquerque L, Rainey FA, Nobre MF, da Costa MS (2008) Elioraea tepidiphila gen. nov., sp. nov., a slightly thermophilic member of the Alphaproteobacteria. Int J Syst Evol Microbiol 58:773-778

Albuquerque L, Rainey FA, Nobre MF, da Costa MS (2010) Meiothermus granaticius sp. nov., a new slightly thermophilic red-pigmented species from the Azores. Syst Appl Microbiol $33: 243-246$

Albuquerque L, Rainey FA, Nobre MF, da Costa MS (2012) Hydrotalea sandarakina sp. nov., isolated from a hot spring runoff and emended description of the genus Hydrotalea and the species Hydrotalea flava. Int J Syst Evol Microbiol 62:1603-1608

Allen ET, Day AL (1935) Hot springs of Yellowstone National Park. Carnegie Institution of Washington Publication no. 466

Amann RI, Krumholz L, Stahl DA (1990) Fluorescent-oligonucleotide probing of whole cells for determinative, phylogenetic, and environmental studies in microbiology. J Bacteriol 172:762-770

Baker GC, Cowan DA (2004) 16 S rDNA primers and the unbiased assessment of thermophile diversity. Biochem Soc Trans 32:218-221 
Barth TFW (1950) Volcanic geology, hot springs and geysers of Iceland. Carnegie Institution of Washington Publication no. 587

Blank CE, Cady SL, Pace NR (2002) Microbial composition of nearboiling silica-depositing thermal springs throughout Yellowstone National Park. Appl Environ Microbiol 68:5123-5135

Brock TD, Brock ML (1967) The hot springs of Furnas Valley, Azores. Int Revue ges Hydrobiol 52:545-558

Caporaso JG, Kuczynski J, Stombaugh J, Bittinger K, Bushman FD, Costello EK, Fierer N, Pena AG, Goodrich JK, Gordon JI, Huttley GA, Kelley ST, Knights D, Koenig JE, Ley RE, Lozupone CA, McDonald D, Muegge BD, Pirrung M, Reeder J, Sevinsky JR, Turnbaugh PJ, Walters WA, Widmann J, Yatsunenko T, Zaneveld J, Knight R (2010) QIIME allows analysis of highthroughput community sequencing data. Nat Methods 7:335-336

Chao A, Bunge J (2002) Estimating the number of species in a stochastic abundance model. Biometrics 58:531-539

Costa KC, Navarro JB, Shock EL, Zhang CL, Soukup D, Hedlund BP (2009) Microbiology and geochemistry of great boiling and mud hot springs in the United States Great Basin. Extremophiles 13:447-459

Edgar RC, Haas BJ, Clemente JC, Quince C, Knight R (2011) UCHIME improves sensitivity and speed of chimera detection. Bioinformatics 27:2194-2200

Franca L, Rainey FA, Nobre MF, da Costa MS (2006) Tepidicella xavieri gen. nov., sp. nov., a betaproteobacterium isolated from a hot spring runoff. Int J Syst Evol Microbiol 56:907-912

Friedrich AB, Antranikian G (1996) Keratin Degradation by Fervidobacterium pennavorans, a novel thermophilic anaerobic species of the order Thermotogales. Appl Environ Microbiol 62:2875-2882

Hall JR, Mitchell KR, Jackson-Weaver O, Kooser AS, Cron BR, Crossey LJ, Takacs-Vesbach CD (2008) Molecular characterization of the diversity and distribution of a thermal spring microbial community by using rRNA and metabolic genes. Appl Environ Microbiol 74:4910-4922

Hamamura N, Meneghin J, Reysenbach AL (2012) Comparative community gene expression analysis of Aquificales-dominated geothermal springs. Environ Microbiol

Harmsen H, Prieur D, Jeanthon C (1997) Group-specific 16S rRNAtargeted oligonucleotide probes to identify thermophilic bacteria in marine hydrothermal vents. Appl Environ Microbiol 63:4061-4068

Hetzer A, Morgan HW, McDonald IR, Daughney CJ (2007) Microbial life in Champagne Pool, a geothermal spring in Waiotapu, New Zealand. Extremophiles 11:605-614

Hiraishi A, Umezawa T, Yamamoto H, Kato K, Maki Y (1999) Changes in quinone profiles of hot spring microbial mats with a thermal gradient. Appl Environ Microbiol 65:198-205

Hugenholtz P, Pitulle C, Hershberger KL, Pace NR (1998) Novel division level bacterial diversity in a Yellowstone hot spring. J Bacteriol 180:366-376

Huse SM, Dethlefsen L, Huber JA, Mark Welch D, Relman DA, Sogin ML (2008) Exploring microbial diversity and taxonomy using SSU rRNA hypervariable tag sequencing. PLoS Genet 4:e1000255

Inskeep WP, Rusch DB, Jay ZJ, Herrgard MJ, Kozubal MA, Richardson TH, Macur RE, Hamamura N, Jennings R, Fouke BW, Reysenbach AL, Roberto F, Young M, Schwartz A, Boyd ES, Badger JH, Mathur EJ, Ortmann AC, Bateson M, Geesey G, Frazier M (2010) Metagenomes from high-temperature chemotrophic systems reveal geochemical controls on microbial community structure and function. PLoS ONE 5:e9773

Ivanova I, Atanassov I, Lyutskanova D, Stoilova-Disheva M, Dimitrova D, Tomova I, Derekova A, Radeva G, Buchvarova V, Kambourova M (2011) High Archaea diversity in Varvara hot spring, Bulgaria. J Basic Microbiol 51:163-172
Jackson CR, Langner HW, Donahoe-Christiansen J, Inskeep WP, McDermott TR (2001) Molecular analysis of microbial community structure in an arsenite-oxidizing acidic thermal spring. Environ Microbiol 3:532-542

Jaspers E, Overmann J (2004) Ecological significance of microdiversity: identical $16 \mathrm{~S}$ rRNA gene sequences can be found in bacteria with highly divergent genomes and ecophysiologies. Appl Environ Microbiol 70:4831-4839

Knight R, Jansson J, Field D, Fierer N, Desai N, Fuhrman JA, Hugenholtz P, van der Lelie D, Meyer F, Stevens R, Bailey MJ, Gordon JI, Kowalchuk GA, Gilbert JA (2012) Unlocking the potential of metagenomics through replicated experimental design. Nat Biotechnol 30:513-520

Kublanov IV, Perevalova AA, Slobodkina GB, Lebedinsky AV, Bidzhieva SK, Kolganova TV, Kaliberda EN, Rumsh LD, Haertle T, Bonch-Osmolovskaya EA (2009) Biodiversity of thermophilic prokaryotes with hydrolytic activities in hot springs of Uzon Caldera, Kamchatka (Russia). Appl Environ Microbiol 75:286-291

Kysela DT, Palacios C, Sogin ML (2005) Serial analysis of V6 ribosomal sequence tags (SARST-V6): a method for efficient, high-throughput analysis of microbial community composition. Environ Microbiol 7:356-364

Lau MC, Aitchison JC, Pointing SB (2009) Bacterial community composition in thermophilic microbial mats from five hot springs in central Tibet. Extremophiles 13:139-149

Martin M (2011) Cutadapt removes adapter sequences from highthroughput sequencing reads. EMBnetjournal 17:10-12

Mathur J, Bizzoco RW, Ellis DG, Lipson DA, Poole AW, Levine R, Kelley ST (2007) Effects of abiotic factors on the phylogenetic diversity of bacterial communities in acidic thermal springs. Appl Environ Microbiol 73:2612-2623

Meyer-Dombard DR, Shock EL, Amend JP (2005) Archaeal and bacterial communities in geochemically diverse hot springs of Yellowstone National Park, USA. Geobiology 3:211-227

Miller SR, Strong AL, Jones KL, Ungerer MC (2009) Bar-coded pyrosequencing reveals shared bacterial community properties along the temperature gradients of two alkaline hot springs in Yellowstone National Park. Appl Environ Microbiol 75: $4565-4572$

Muyzer G, Brinkhoff T, Nübel U, Santegoeds C, Schäfer H, Wawer C (1998) Denaturing gradient gel electrophoresis (DGGE) in microbial ecology. In: Akkermans ADL, van Elsas JD, de Bruijn FJ (eds) Molecular microbial ecology manual. Kluwer Academic Publishers, London, pp 3.4.4.1-3.4.4.27

Nacke H, Thurmer A, Wollherr A, Will C, Hodac L, Herold N, Schoning I, Schrumpf M, Daniel R (2011) Pyrosequencing-based assessment of bacterial community structure along different management types in German forest and grassland soils. PLoS ONE 6:e17000

O-Thong S, Prasertsan P, Karakashev D, Angelidaki I (2007) Specific detection of Thermoanaerobacterium spp., Thermoanaerobacterium thermosaccharolyticum and Caldicellulosiruptor spp. in thermophilic biohydrogen reactor using fluorescent in situ hybridization (FISH). Int J Hydrogen Energy 33:6082-6091

Pagaling E, Grant WD, Cowan DA, Jones BE, Ma Y, Ventosa A, Heaphy S (2012) Bacterial and archaeal diversity in two hot spring microbial mats from the geothermal region of Tengchong, China. Extremophiles 16:607-618

Papke RT, Ramsing NB, Bateson MM, Ward DM (2003) Geographical isolation in hot spring cyanobacteria. Environ Microbiol 5:650-659

Pruesse E, Quast C, Knittel K, Fuchs BM, Ludwig W, Peplies J, Glockner FO (2007) SILVA: a comprehensive online resource for quality checked and aligned ribosomal RNA sequence data compatible with ARB. Nucleic Acids Res 35:7188-7196 
Ravenschlag K, Sahm K, Knoblauch C, Jorgensen BB, Amann R (2000) Community structure, cellular rRNA content, and activity of sulfate-reducing bacteria in marine arctic sediments. Appl Environ Microbiol 66:3592-3602

Reysenbach AL, Wickham GS, Pace NR (1994) Phylogenetic analysis of the hyperthermophilic pink filament community in Octopus Spring, Yellowstone National Park. Appl Environ Microbiol 60:2113-2119

Reysenbach AL, Ehringer M, Hershberger K (2000) Microbial diversity at $83{ }^{\circ} \mathrm{C}$ in Calcite Springs, Yellowstone National Park: another environment where the Aquificales and "Korarchaeota" coexist. Extremophiles 4:61-67

Riessen S, Antranikian G (2001) Isolation of Thermoanaerobacter keratinophilus sp. nov., a novel thermophilic, anaerobic bacterium with keratinolytic activity. Extremophiles 5:399408

Roesch LF, Fulthorpe RR, Riva A, Casella G, Hadwin AK, Kent AD, Daroub SH, Camargo FA, Farmerie WG, Triplett EW (2007) Pyrosequencing enumerates and contrasts soil microbial diversity. ISME J 1:283-290

Schloss PD, Handelsman J (2005) Introducing DOTUR, a computer program for defining operational taxonomic units and estimating species richness. Appl Environ Microbiol 71:1501-1506

Shanon WE, Weaver W (1949) The mathematical theory of communication. MD Comput 14:306-317

Simon C, Wiezer A, Strittmatter AW, Daniel R (2009) Phylogenetic diversity and metabolic potential revealed in a glacier ice metagenome. Appl Environ Microbiol 75:7519-7526

Skirnisdottir S, Hreggvidsson GO, Hjorleifsdottir S, Marteinsson VT, Petursdottir SK, Holst O, Kristjansson JK (2000) Influence of sulfide and temperature on species composition and community structure of hot spring microbial mats. Appl Environ Microbiol 66:2835-2841

Snaidr J, Amann R, Huber I, Ludwig W, Schleifer KH (1997) Phylogenetic analysis and in situ identification of bacteria in activated sludge. Appl Environ Microbiol 63:2884-28896

Spear JR, Walker JJ, McCollom TM, Pace NR (2005) Hydrogen and bioenergetics in the Yellowstone geothermal ecosystem. Proc Natl Acad Sci USA 102:2555-2560

Stahl DA, Amann RI (1991) Development and application of nucleic acid probes. In: Stackebrandt E, Goodfellow M (eds) Nucleic acid techniques in bacterial systematics. Wiley, Chichester, pp 205-248

Swingley WD, Meyer-Dombard DR, Shock EL, Alsop EB, Falenski HD, Havig JR, Raymond J (2012) Coordinating environmental genomics and geochemistry reveals metabolic transitions in a hot spring ecosystem. PLoS ONE 7:e38108
Will C, Thürmer A, Wollherr A, Nacke H, Herold N, Schrumpf M, Gutknecht J, Wubet T, Buscot F, Daniel R (2010) Horizonspecific bacterial community composition of German grassland soils, as revealed by pyrosequencing-based analysis of $16 \mathrm{~S}$ rRNA genes. Appl Environ Microbiol 76:6751-6759

Yamamoto H, Hiraishi A, Kato K, Chiura HX, Maki Y, Shimizu A (1998) Phylogenetic evidence for the existence of novel thermophilic bacteria in hot spring sulfur-turf microbial mats in Japan. Appl Environ Microbiol 64:1680-1687

Yilmaz P, Kottmann R, Field D, Knight R, Cole JR, Amaral-Zettler L, Gilbert JA, Karsch-Mizrachi I, Johnston A, Cochrane G, Vaughan R, Hunter C, Park J, Morrison N, Rocca-Serra P, Sterk $\mathrm{P}$, Arumugam M, Bailey M, Baumgartner L, Birren BW, Blaser MJ, Bonazzi V, Booth T, Bork P, Bushman FD, Buttigieg PL, Chain PS, Charlson E, Costello EK, Huot-Creasy H, Dawyndt P, DeSantis T, Fierer N, Fuhrman JA, Gallery RE, Gevers D, Gibbs RA, San Gil I, Gonzalez A, Gordon JI, Guralnick R, Hankeln W, Highlander S, Hugenholtz P, Jansson J, Kau AL, Kelley ST, Kennedy J, Knights D, Koren O, Kuczynski J, Kyrpides N, Larsen R, Lauber CL, Legg T, Ley RE, Lozupone CA, Ludwig W, Lyons D, Maguire E, Methe BA, Meyer F, Muegge B, Nakielny S, Nelson KE, Nemergut D, Neufeld JD, Newbold LK, Oliver AE, Pace NR, Palanisamy G, Peplies J, Petrosino J, Proctor L, Pruesse E, Quast C, Raes J, Ratnasingham S, Ravel J, Relman DA, Assunta-Sansone S, Schloss PD, Schriml L, Sinha R, Smith MI, Sodergren E, Spo A, Stombaugh J, Tiedje JM, Ward DV, Weinstock GM, Wendel D, White O, Whiteley A, Wilke A, Wortman JR, Yatsunenko T, Glockner FO (2011) Minimum information about a marker gene sequence (MIMARKS) and minimum information about any (x) sequence (MIxS) specifications. Nat Biotechnol 29:415-420

Yim LC, Hongmei J, Aitchison JC, Pointing SB (2006) Highly diverse community structure in a remote central Tibetan geothermal spring does not display monotonic variation to thermal stress. FEMS Microbiol Ecol 57:80-91

Youssef N, Sheik CS, Krumholz LR, Najar FZ, Roe BA, Elshahed MS (2009) Comparison of species richness estimates obtained using nearly complete fragments and simulated pyrosequencinggenerated fragments in 16S rRNA gene-based environmental surveys. Appl Environ Microbiol 75:5227-5236

Yu Z, Garcia-Gonzalez R, Schanbacher FL, Morrison M (2008) Evaluations of different hypervariable regions of archaeal $16 \mathrm{~S}$ rRNA genes in profiling of methanogens by Archaea-specific PCR and denaturing gradient gel electrophoresis. Appl Environ Microbiol 74:889-893

Zhou J, Bruns MA, Tiedje JM (1996) DNA recovery from soils of diverse composition. Appl Environ Microbiol 62:316-322 


\title{
STUDY 8:
}

\section{METAGENOME SURVEY OF A MULTISPECIES AND ALGAE-ASSOCIATED BIOFILM REVEALS KEY ELEMENTS OF BACTERIAL-ALGAE INTERACTIONS IN PHOTOBIOREACTORS}

\author{
Krohn-Molt I ${ }^{1,2}$, Wemheuer B ${ }^{3}$, Alawi $\mathbf{M}^{4,5}$, Poehlein $A^{3}$, \\ Güllert $\mathrm{S}^{1}$, SCHMEISSER $\mathrm{C}^{1}$, POMMERENING-RÖSER A, \\ GRUNDHOFF $\mathrm{A}^{4}$, DANIEL $\mathrm{R}^{3}$, HANELT $\mathrm{D}^{2}$, AND STREIT WR ${ }^{1}$
}

APPliED AND EINVIRONMENTAL MiCROBIOLOGY 79 (20): 6196-6206

\begin{abstract}
${ }^{1}$ Microbiology and Biotechnology, Biocenter Klein FlottbeK, University of Hamburg, HAMBURG, Germany; ${ }^{2}$ Cell Biology AND PhyCOlOGy, Biocenter KleIn FlotTBeK, University of HAMBURG, HAMBURG, Germany; ${ }^{3}$ GenOmiC And ApPlied Microbiology and Goettingen GenOMics LABrotory, Institute of Microbiology and Genetics, GeORG-AugustUNIVERSITY GOETTINGEN, GOETTINGEN, GERMANY; ${ }^{4}$ VIRUS GENOMICS LEIBNIZ, INSTITUTE FOR EXPERIMENTAL VIROLOGY, HEINRICH-PETTE-INSTITUTE, HAmburg, Germany; ${ }^{5}$ University MedicAl CENTER Hamburg-EPPENdORF, BIOINFORMATICS SERVICE FACILITY, HAMBURG, GERMANY
\end{abstract}

\footnotetext{
Author contributions to the work:

Performed the experiments: IKM

Analyzed data: IKM, BW, MA

Contributed data on bioreactor properties and analysis of these data: IKM, APR, CS, WRS

Wrote the publication: IKM, BW, WRS

Conceived and designed the experiments: IKM, WRS
} 


\title{
Metagenome Survey of a Multispecies and Alga-Associated Biofilm Revealed Key Elements of Bacterial-Algal Interactions in Photobioreactors
}

\author{
Ines Krohn-Molt, ${ }^{a, b}$ Bernd Wemheuer, ${ }^{c}$ Malik Alawi, ${ }^{d, e}$ Anja Poehlein, ${ }^{c}$ Simon Güllert, ${ }^{a}$ Christel Schmeisser, ${ }^{a}$ \\ Andreas Pommerening-Röser, ${ }^{a}$ Adam Grundhoff, ${ }^{d}$ Rolf Daniel, ${ }^{c}$ Dieter Hanelt, ${ }^{b}$ Wolfgang R. Streit ${ }^{a}$ \\ University of Hamburg, Biocenter Klein Flottbek, Microbiology and Biotechnology, Hamburg, Germanya; University of Hamburg, Biocenter Klein Flottbek, Cell Biology and \\ Phycology, Hamburg, Germany ${ }^{\text {; }}$; Georg-August-University Goettingen, Institute of Microbiology and Genetics, Goettingen, Germanyc; Heinrich-Pette-Institute, Leibniz \\ Institute for Experimental Virology, Virus Genomics, Hamburg, Germany'; University Medical Center Hamburg-Eppendorf, Bioinformatics Service Facility, Hamburg, \\ Germany
}

Photobioreactors (PBRs) are very attractive for sunlight-driven production of biofuels and capturing of anthropogenic $\mathrm{CO}_{2}$. One major problem associated with PBRs however, is that the bacteria usually associated with microalgae in nonaxenic cultures can lead to biofouling and thereby affect algal productivity. Here, we report on a phylogenetic, metagenome, and functional analysis of a mixed-species bacterial biofilm associated with the microalgae Chlorella vulgaris and Scenedesmus obliquus in a PBR. The biofilm diversity and population dynamics were examined through $16 \mathrm{~S}$ rRNA phylogeny. Overall, the diversity was rather limited, with approximately 30 bacterial species associated with the algae. The majority of the observed microorganisms were affiliated with Alphaproteobacteria, Betaproteobacteria, and Bacteroidetes. A combined approach of sequencing via GS FLX Titanium from Roche and HiSeq 2000 from Illumina resulted in the overall production of $350 \mathrm{Mbp}$ of sequenced DNA, $165 \mathrm{Mbp}$ of which was assembled in larger contigs with a maximum size of $0.2 \mathrm{Mbp}$. A KEGG pathway analysis suggested high metabolic diversity with respect to the use of polymers and aromatic and nonaromatic compounds. Genes associated with the biosynthesis of essential B vitamins were highly redundant and functional. Moreover, a relatively high number of predicted and functional lipase and esterase genes indicated that the alga-associated bacteria are possibly a major sink for lipids and fatty acids produced by the microalgae. This is the first metagenome study of microalga- and PBR-associated biofilm bacteria, and it gives new clues for improved biofuel production in PBRs.

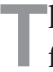
he increasing global $\mathrm{CO}_{2}$ concentrations and the resulting effects of global warming have led to the development of novel and alternative technologies for the production of non-fossilbased biofuels and methods of $\mathrm{CO}_{2}$ capture. Since photobioreactors (PBRs) allow the continuous cultivation of microalgae under relatively controlled conditions, they have been the focus of many research projects, often linked to large-scale biofuel production (1-3). The microalgae in the PBRs produce significant amounts of lipids that are the basis of biofuel production $(1,2,4,5)$. Unfortunately the technology is not yet sustainable (6), and certainly, more research is needed, not only to improve the technology, but also to better understand the complex biology and interactions of microalgae with their environment.

The term microalgae comprises a phylogenetically very heterogeneous group of prokaryotic and eukaryotic microorganisms. They all employ oxygenic photosynthesis and thereby convert atmospheric $\mathrm{CO}_{2}$ to biomass (7-9).

PBRs are usually vessels with varying volumes $(3,10,11)$. Despite their advantages, however, PBRs suffer from several drawbacks, and biodiesel production with microalgae in PBRs faces many challenges $(11,12)$. One major problem associated with PBRs is linked to biofouling and the growth of microbial biofilms within the reactor. Bacterial growth in running PBRs results in disrupted flow, increased pressure, and reduced light intensities and ultimately affects algal productivity (13). While it is well known that microalgae are often associated with diverse bacteria in their natural aquatic ecosystems and in experimental cultures (14-16), only very few studies have addressed a detailed phyloge- netic characterization of the associated microbes (17-19). Bacteria observed in these nonaxenic cultures belong to the classes Alphaproteobacteria, Betaproteobacteria, and Gammaproteobacteria, but bacteria affiliated with the phylum Bacteroidetes are also often observed. Additionally, many uncultivated bacteria are noted. However, no archaeal species have been detected, and only one study has reported the presence of an uncultivated fungus (18). Two very recent studies have addressed a partial phylogenetic characterization of the alga-associated microbial community within PBRs $(16,20)$. The authors of these studies show that the microalga Chlorella vulgaris is associated mainly with the Alphaproteobacteria (i.e., the genus Sphinogomonas) and Dunaliella tertiolecta is associated with the Alphaproteobacteria and Gammaproteobacteria.

Microalgae are in general believed to be auxotrophic for vitamin $B_{12}$, and a significant fraction of microalgal species appear to be auxotrophic for thiamine, while some are also auxotrophic for biotin (21-24). Within this framework, it is also possible that

Received 20 May 2013 Accepted 19 July 2013

Published ahead of print 2 August 2013

Address correspondence to Wolfgang R. Streit, wolfgang.streit@uni-hamburg.de. Supplemental material for this article may be found at http://dx.doi.org/10.1128 /AEM.01641-13.

Copyright $\odot$ 2013, American Society for Microbiology. All Rights Reserved. doi:10.1128/AEM.01641-13 
other bacterial factors or metabolic activities have a positive influence on algal growth (25). Only very few studies have suggested that there is actually a negative impact on the population dynamics of the algae (26).

Metagenome technologies have proven to be powerful tools for the analysis of complex microbial communities and have led to a tremendous increase of knowledge about the functions, protein families, biotechnology, and ecology of microbial communities within the last decade (27-29). Recent examples from metagenome studies have given us a first insight into the complex interactions of microorganisms with their environments and hosts (29-33). Surprisingly, only very few studies have focused on metagenomes associated with algae $(34,35)$, and to date, no study is available that has addressed aquatic microalgae and their bacterial communities in PBRs.

Therefore, here, we have analyzed the phylogenetic and metagenomic diversity of a mixed-species biofilm grown in a PBR. The data suggest that the microbial community is composed of approximately 30 different microbial species and is capable of supporting algal growth by the production of $\mathrm{B}$ vitamers (cobalamin $\left[\mathrm{B}_{12}\right]$ and biotin $\left[\mathrm{B}_{7}\right]$ ) and possibly other cofactors not yet identified. Remarkably, our data also suggest that at least some of the bacteria within the PBR biofilm cannot be cultivated without the microalgae and that the bacteria encode the potential to affect biofuel production.

\section{MATERIALS AND METHODS}

Microorganisms used in this study and cultivation media. Scenedesmus obliquus strain U169 and Chlorella vulgaris strain U126 were obtained from the collection of algae at the University of Hamburg, Hamburg, Germany (http://www.biologie.uni-hamburg.de/bzf/zeph/zephsvcke $. \mathrm{htm})$. The defined medium for cultivation of algae was composed of $2 \mathrm{~g}$ liter $^{-1}$ Flory Basis Fertilizer 1 (Euflor, Germany) and supplemented with $3.22 \mathrm{~g} \mathrm{liter}^{-1} \mathrm{KNO}_{3}$. Flory Basis Fertilizer 1 is solely based on mineral compounds and was not supplemented with any vitamins. The $\mathrm{pH}$ was adjusted to 7.0. The algae were cultivated at $17^{\circ} \mathrm{C}$ in liquid medium at a natural light intensity in polyethyleneterephthalate flat-panel photobioreactors. The culture medium circulated at 1 liter $\mathrm{min}^{-1}$ in the PBR system. The PBR was aerated with compressed air and flue gas obtained from a combined block heat and power station. Physical parameters and culture conditions were monitored continuously (WTW IQ Sensor Net; System 2020 XT, Germany). The light intensity was determined with a LI-190 sensor (Li-Cor, USA). For a detailed description of the reactor, see Fig. S1 in the supplemental material and reference 36 .

Escherichia coli strains were grown at $37^{\circ} \mathrm{C}$ in lysogenic broth (LB) medium ( $1 \%$ tryptone, $0.5 \%$ yeast extract, $1 \% \mathrm{NaCl})(37)$ supplemented with appropriate antibiotics. Lactobacillus plantarum ATCC 8014 and Lactobacillus delbrueckii subsp. lactis DSM 20335 for B vitamin detection were obtained from the DSMZ, Braunschweig, Germany. Lactobacillus strains were grown on MRS medium (38) under anaerobic conditions.

Media for cultivation of individual bacterial isolates derived from the PBR biofilm community were prepared as follows. R2A medium was prepared as described previously (39), and M9, TSB, and NB media were prepared according to the method of Sambrook and Russell (37). To stimulate microbial growth, the media were in part supplemented with algal culture extracts ranging from $5 \%$ to $50 \%$ (vol/vol). The inoculated plates were incubated for 5 to 7 days at $22^{\circ} \mathrm{C}$ under aerobic and anaerobic conditions.

Scanning electron microscopy. For scanning electron microscopy (SEM), biofilm samples were fixed in paraformaldehyde (1\%) and glutaraldehyde $(0.25 \%)$, dehydrated by ascending alcohol series, and dried at the critical point with Balzers CPD 030 Critical Point Dryer (Bal-Tec, Schalksmühle, Germany). After coating samples with gold using an SCD
050 sputter coater (Bal-Tec), scanning electron micrographs were taken with a Leo 1525 (Zeiss, Germany).

PBR biofilm DNA extraction and molecular technologies. Total nucleic acids were extracted from the biofilm samples using a previously published enzymatic cell lysis protocol with some modifications (40). The samples were stirred $(200 \mathrm{rpm})$ overnight in $10 \mathrm{ml}$ of extraction buffer (100 mM Tris-HCl, pH 8.0, 100 mM sodium EDTA, pH 8.0, $1.5 \mathrm{M} \mathrm{NaCl}$, $0.1 \%$ Tween 80 ) with the addition of $5 \mathrm{mg}$ lysozyme and $0.5 \mathrm{mg}$ proteinase $\mathrm{K}$ at $37^{\circ} \mathrm{C}$. Subsequently, SDS $(1 \mathrm{ml} ; 20 \%)$ was added and incubated at $65^{\circ} \mathrm{C}$ for $90 \mathrm{~min}$. The sample was centrifuged for $10 \mathrm{~min}$ at room temperature and $6,000 \times g$. The pellet was resuspended in $10 \mathrm{ml}$ extraction buffer, incubated for $10 \mathrm{~min}$ at $65^{\circ} \mathrm{C}$, and centrifuged again. The supernatant was collected and mixed with 1 volume polyethylene glycol (PEG) $6000(30 \%)$ and $1.6 \mathrm{M}$ sodium chloride. After $2 \mathrm{~h}$ of incubation at room temperature, the mixture was centrifuged again for $20 \mathrm{~min}$ at $10,000 \times g$. The resulting pellet was resuspended in $2 \mathrm{ml} \mathrm{TE}$ buffer $(10 \mathrm{mM}$ Tris-HCI, $1 \mathrm{mM}$ sodium EDTA, pH 8.0). For separating proteins and polysaccharides, $7.5 \mathrm{M}$ potassium acetate was added to the mixture, achieving a final concentration of $0.75 \mathrm{M}$. After $5 \mathrm{~min}$ of incubation on ice, proteins and polysaccharides were centrifuged at $16,000 \times g$ and $4^{\circ} \mathrm{C}$ for $30 \mathrm{~min}$. The DNA was finally extracted with phenol-chloroform-isoamyl alcohol and precipitated overnight at $-20^{\circ} \mathrm{C}$ after adding 0.7 volume isopropanol with $1 / 10$ volume of $3 \mathrm{M}$ sodium acetate. The isolated DNA was used for PCR amplifications, as well as metagenomic analyses.

For the phylogenetic characterization, 16S rRNA genes were amplified using the standard primers $27 \mathrm{f}$ and $1492 \mathrm{r}$ (41). The amplified genes were ligated into the pDrive cloning vector (Qiagen, Hilden, Germany) and transformed into chemically competent TOP10 E. coli cells (Invitrogen, Karlsruhe, Germany). The $16 \mathrm{~S}$ rRNA gene was sequenced with automated ABI377 technology following the manufacturer's instructions.

The large-insert fosmid library was constructed according to the Copy Control fosmid library production kit manual (Epicentre Biotechnologies, Madison, WI, USA). A total of 14,976 fosmid clones harboring inserts with an average size of $35 \mathrm{~kb}$ were generated. The insert rate was approximately $98 \%$.

Sequencing of metagenomic DNA. For sequencing of metagenomic DNA on the GS FLX platform (Roche Applied Science), libraries were constructed by applying the GS Rapid Library Prep kit (Roche Applied Science) according to the manufacturer's protocol. A single library was sequenced in half a PicoTiter Plate on the GS FLX system using the titanium sequencing chemistry (Roche Applied Science, Mannheim, Germany). Raw data were processed by employing the analysis pipeline for whole-genome shotgun sequence reads and applying GS FLX System Software (version 2.3). Illumina sequencing was done using a single lane of a HiSeq 2000 paired-end run (2 sets of 100 cycles). De novo assembly of these short reads was performed using the Velvet assembly program version 1.2.08 (42).

For the sequences' functional characterization, we used the Integrated Microbial Genomes (IMG) pipeline. To further analyze the biological processes linked to the individual genes and open reading frames (ORFs), we mainly employed the KEGG (43), COG (44), and Pfam (45) databases, using a cutoff of $10^{-5}$.

Phylogenetic analysis of bacteria associated with algae. 16S rRNA genes were amplified using oligonucleotide primers (27f, 5' $5^{\prime}$ AGA GTT GAT CMT GGC TCA G-3', and 1492r, 5' -GGY TAC CTT GTT ACG ACT T-3') (41). PCR mixtures contained 100 ng of template DNA per $\mu l, 0.2$ $\mathrm{mM}$ each of the four deoxynucleoside triphosphates, $1.5 \mathrm{mM} \mathrm{MgCl}, 1$ $\mu \mathrm{M}$ (each) primer, and $2.5 \mathrm{U}$ of Taq DNA polymerase. The thermocycling conditions were $45 \mathrm{~s}$ of denaturation at $94^{\circ} \mathrm{C}, 45 \mathrm{~s}$ of primer annealing at $50^{\circ} \mathrm{C}$, and $1 \mathrm{~min} 30 \mathrm{~s}$ of primer extension at $72^{\circ} \mathrm{C}$. This cycle was repeated 30 times.

Denaturing gradient gel electrophoresis (DGGE) analyses were carried out with a DCode system (Bio-Rad, Munich, Germany) using denaturing gradients of 40 to $70 \%$ denaturants. For the amplification of the $16 \mathrm{~S}$ rRNA gene fragments, the primers 341F-GC (5'-GCA CGG GGGG CCT ACG 
GGA GGC AGC AG-3', containing a 30-bp GC-rich sequence at the 5' end) and 907R ( $5^{\prime}$-CCG TCA ATT CCT TTR AGT TT- $\left.3^{\prime}\right)$ were used (46, 47). The thermocycling conditions were $40 \mathrm{~s}$ of denaturation at $96^{\circ} \mathrm{C}, 40 \mathrm{~s}$ of primer annealing at $56^{\circ} \mathrm{C}$, and $1 \mathrm{~min}$ of primer extension at $72^{\circ} \mathrm{C}$. This cycle was repeated 30 times. DGGE bands were sampled for reamplification and sequencing by punching into individual bands with sterile pipette tips and were transferred to $1.5-\mathrm{ml}$ microcentrifuge tubes that contained $50 \mu \mathrm{l}$ of distilled water. The reamplified PCR products were cleaned up using the Gel/PCR DNA Fragments Extraction kit (Qiagen, Hilden, Germany) and finally sequenced using standard technologies.

For restriction fragment length polymorphism (RFLP) analysis, the amplified (27f and 1492r) 16S rRNA genes were cloned into pDrive and transformed in E. coli cells. The insert DNA of 100 clones of each sample (T0 to T5) was amplified using oligonucleotide primers (M13-20-f, 5' GTA AAA CGA CGG CCA GT-3', and M13-r, 5' -CAG GAA ACA GCT ATG ACC- $\left.3^{\prime}\right)$. The thermocycling conditions were $45 \mathrm{~s}$ of denaturation at $94^{\circ} \mathrm{C}, 45 \mathrm{~s}$ of primer annealing at $57^{\circ} \mathrm{C}$, and $1 \mathrm{~min} 45 \mathrm{~s}$ of primer extension at $72^{\circ} \mathrm{C}$. This cycle was repeated 30 times. The fragments were digested by the restriction enzyme HpaII. Clones that showed different patterns were sequenced using standard technologies.

Furthermore, to investigate the composition of the microbial community in the photobioreactor, rRNA sequences of the small subunit (SSU) were extracted from the unassembled FLX 454 and Illumina data using SortMeRna (48). Low-quality $(<20 \mathrm{Ns})$ and short $(<80$-bp) reads were removed prior to further analysis. To gain insight into the community composition, sequences were directly mapped onto the most recent Silva database (SSURef 111 NR) using Bowtie2 (49). The Silva taxonomy of the best hit in the database was affiliated to the respective query sequence. For deeper analysis of the bacterial community structure, the hypervariable regions V3 and V6 of the bacterial 16S rRNA genes were extracted using V-Xtractor (50) and were also mapped on the most recent Silva database.

EPS characterization. Exopolymeric substances (EPS) from the biofilm sample were extracted according to the method of Wingender et al. (51) with minor modifications. For this purpose, the biofilm samples were carefully removed from the PBR surface, weighed, and subsequently suspended in a ratio of 1:16 (wt/vol) in $0.14 \mathrm{M} \mathrm{NaCl}$ solution and homogenized by stirring at room temperature for $60 \mathrm{~min}$. The suspension was centrifuged for $30 \mathrm{~min}$ at $20,000 \times g$ and $10^{\circ} \mathrm{C}$. The supernatants were twice sterile filtered using membrane filters (cellulose acetate; pore size, $0.20 \mu \mathrm{m})$. The filtrates were either processed immediately or aliquoted and stored until use at $-20^{\circ} \mathrm{C}$.

The lipid content was measured by extraction with $n$-hexane (52). To $0.5 \mathrm{ml}$ of the EPS sample, $0.5 \mathrm{ml} n$-hexane was added and homogenized for $30 \mathrm{~min}$ by shaking at room temperature following a centrifugation step at $12,000 \times g$ for $90 \mathrm{~s}$. The upper phase (hexane and lipids) was transferred to a preweighed glass tube while avoiding the interphase. The solution was dried, and the glass vessel was weighed again.

The total carbohydrate content was determined using a phenol-sulfuric acid method (53) with dextran (neutral polysaccharides) and alginate (acidic polysaccharides) standards. To $0.5 \mathrm{ml}$ of sample, $0.5 \mathrm{ml}$ of phenol solution was added and mixed. Following this, $2.5 \mathrm{ml}$ of concentrated sulfuric acid $\left(\mathrm{H}_{2} \mathrm{SO}_{4}\right)$ was added, and the sample was mixed again following an incubation step at room temperature $(10 \mathrm{~min})$ and incubation at $30^{\circ} \mathrm{C}$ for $15 \mathrm{~min}$. After a further 5-min incubation at room temperature, the absorbance of the samples was measured spectrophotometrically as the optical density at $480 \mathrm{~nm}\left(\mathrm{OD}_{480}\right)$ for acidic polysaccharides (alginate) and the $\mathrm{OD}_{490}$ for neutral polysaccharides (dextran).

Uronic acids were determined according to the method of FilisettiCozzi and Carpita (54) with glucuronic acid as a standard. To $0.4 \mathrm{ml}$ of each sample, $40 \mu$ l solution 1 ( $4 \mathrm{M}$ sulfamic acid $\left[\mathrm{H}_{3} \mathrm{SO}_{3} \mathrm{~N}\right]$, $\mathrm{pH} 1.6$ ) was added and mixed. After this step, $2.4 \mathrm{ml}$ of solution $2[0.075 \mathrm{M}$ $\mathrm{Na}_{2}\left(\mathrm{~B}_{4} \mathrm{O}_{5}(\mathrm{OH})_{4}\right) \times 8 \mathrm{H}_{2} \mathrm{O}$ dissolved in $\left.\mathrm{H}_{2} \mathrm{SO}_{4}\right]$ was added, mixed, and then incubated for $20 \mathrm{~min}$ at $100^{\circ} \mathrm{C}$. The samples were cooled in an ice bath for $5 \mathrm{~min}$. Then, $80 \mu \mathrm{l}$ of solution $3(0.15 \%$ [wt/vol] $m$-hydroxybiphenyl $\left[\mathrm{C}_{12} \mathrm{H}_{10} \mathrm{O}\right]$ dissolved in $0.5 \%[\mathrm{wt} / \mathrm{vol}] \mathrm{NaOH}$ ) was added. Finally, the samples were thoroughly mixed and incubated for $10 \mathrm{~min}$ at room temperature, and the absorbance was recorded as $\mathrm{OD}_{525}$.

The protein content was measured using a modified Lowry assay $(55,56)$.

Furthermore, the total DNA within the EPS solution was detected spectrophotometrically after extraction from the EPS using the UltraClean Microbial DNA Kit (Dianova, Hamburg, Germany).

Lipase and esterase activities were assayed using various p-nitrophenyl (pNP) substrates and following previously published protocols (57).

Vitamin $B_{12}$ and biotin detection. For the determination of cobalamin the Difco $B_{12}$ assay medium was used, and vitamin $B_{12}$ was extracted and assayed according to the protocol published by Denter and Bisping (58) employing the L. delbrueckii subsp. lactis DSM 20335 indicator strain.

To determine the biotin content of the sample, the culture supernatant was centrifuged and sterile filtered. The biotin detection was done as described previously using the Lactobacillus growth assay and L. plantarum strain ATCC 8014 (59).

Nucleotide sequence accession numbers. This project has been assigned the GenBank BioProject number PRJNA197241. The sequences derived from Illumina and FLX454 sequencing were deposited in the NCBI Short Read Archive under the study accession number SRP021903. The genome assembly, together with predicted gene models and annotations, is available from www.jgi.doe.gov (DOE Joint Genome Institute) under the IMG Project ID 9992.

The 16S rRNA gene sequences obtained have been deposited in the GenBank database under accession numbers KC994651 to KC994663, KC994664 to KC994680, KC994681 to KC994881, and KC994882 to KC994889.

\section{RESULTS AND DISCUSSION}

Biofilm development and chemical analysis. PBRs are commonly inoculated with nonaxenic cultures of eukaryotic microalgae (14-16). In the current study, we examined a microbial biofilm in a PBR, which was inoculated with an S. obliquus and C. vulgaris culture. We monitored biofilm development over a period of 12 weeks by analyzing a total of six time points (T0 to T5) (Fig. 1). As early as 14 days after the initial transfer of the starter culture into the reactor, extensive biofilm formation was observed. The biofilm was tightly attached to the surface of the reactor and spread over the entire reactor within a period of 10 to 12 weeks, thereby strongly affecting the overall photosynthesis rates of the algae. This strong biofilm development resulted in shutdown of the PBR. Microscopic examinations of biofilm samples using SEM suggested that the bacteria were tightly attached to the algae (Fig. 2A to D). Additionally, EPS and nanowire-like filamentous structures were visible in the SEM images (Fig. 2). It is well known that EPS in biofilms mainly consists of polysaccharides, proteins, nucleic acids, and lipids (60). The concentrations of the individual components, however, vary and depend to a large extent on the different microorganisms and their medium and environmental conditions (61-63). EPS has diverse functions during biofilm development: it provides mechanical stability, builds up a threedimensional network of polymers, and plays a role in cell-cell communication and defense against biocides $(60,64)$. A detailed chemical analysis of the PBR biofilm exopolymeric matrix suggested that it consisted mainly of fatty acids $(10.4 \mathrm{mg} /$ $\mathrm{g})$, acidic and neutral polysaccharides (11.6 mg/g), and proteins $(3.8 \mathrm{mg} / \mathrm{g})$. However, only small amounts of uronic acid $(<1 \%)$ and only traces of DNA were observed (Fig. 3 ). Since microalgae are well known to produce and release lipids 

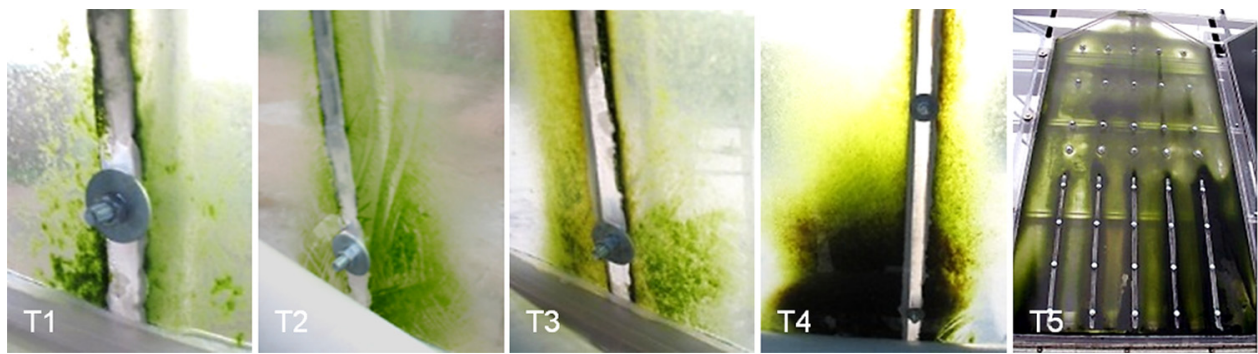

FIG 1 Development of a microbial biofilm over 12 weeks in a flat-panel PBR. T1, after 2 weeks; T2, after 4 weeks; T3, after 6 weeks; T4, after 8 weeks; T5, after 12 weeks of incubation. No microbial biofilm was observed at T0 (data not shown). Shortly after inoculation of the PBR at T0, a light intensity of approximately $150 \mu \mathrm{mol} / \mathrm{m}^{2} \mathrm{~s}$ was measured at the backside of the reactor. The light intensities with a fully developed biofilm were in the range of $10 \mu \mathrm{mol} / \mathrm{m}^{2} \mathrm{~s}$ or lower (T5).

$(2,5)$, it is not surprising that the EPS consisted largely of fatty acids.

Population structure of the alga-associated bacterial community. For phylogenetic analysis, DNA from the mature biofilm (T5), the different biofilm developmental stages (T1 to T4), and the nonaxenic starter culture (T0) was extracted. The quality of the isolated DNA was sufficiently high for the construction of a large-insert metagenome library and DNA-sequencing analysis using pyrosequencing and Illumina-based technologies.

We used different strategies to estimate the microbial diversity within the developing biofilm samples and the established biofilm. We amplified 16S rRNA genes using standard primers (27f and 1492r [41]) and cloned the amplified DNA fragments. Inserts of these clones were completely sequenced. After removal of potential chimeras and duplicates, we analyzed a total of 201 unique $16 \mathrm{~S}$ rRNA gene sequences from the mature biofilm (T5) (KC994681 to KC994881). In order to identify unique phylotypes and to estimate the bacterial richness, a rarefaction analysis using QIIME
(65) was performed. This analysis suggested that the 16S rRNA gene sequences represented 28 operational taxonomic units (OTUs) based on a $>99 \%$ identity cutoff for bacterial $16 \mathrm{~S}$ rRNA genes. Rarefaction curves reached saturation at distance levels of 20\% (phylum level) and 3\% (species level) (Fig. 4). This analysis also suggested that the overall diversity within the biofilm community was rather limited. In addition, a Shannon-Weaver index (66) of 3.01 at a genetic distance of $1 \%$ was observed. These results, together with abundance-based coverage estimators (ACE) (67) and Chaol richness estimates (68), indicated that a significant fraction of the bacterial species diversity was assessed. The analyzed bacterial $16 \mathrm{~S}$ rRNA gene sequences were mainly affiliated with members of the classes Alphaproteobacteria, Betaproteobacteria, and Gammaproteobacteria (Fig. 5; see Table S1 in the supplemental material). Additionally, a significant number of $16 \mathrm{~S}$ rRNA gene hits were associated with the phylum Bacteroidetes. Bacteroidetes are among the main colonizers of the guts of humans and animals, but they are also found in many other habitats and are
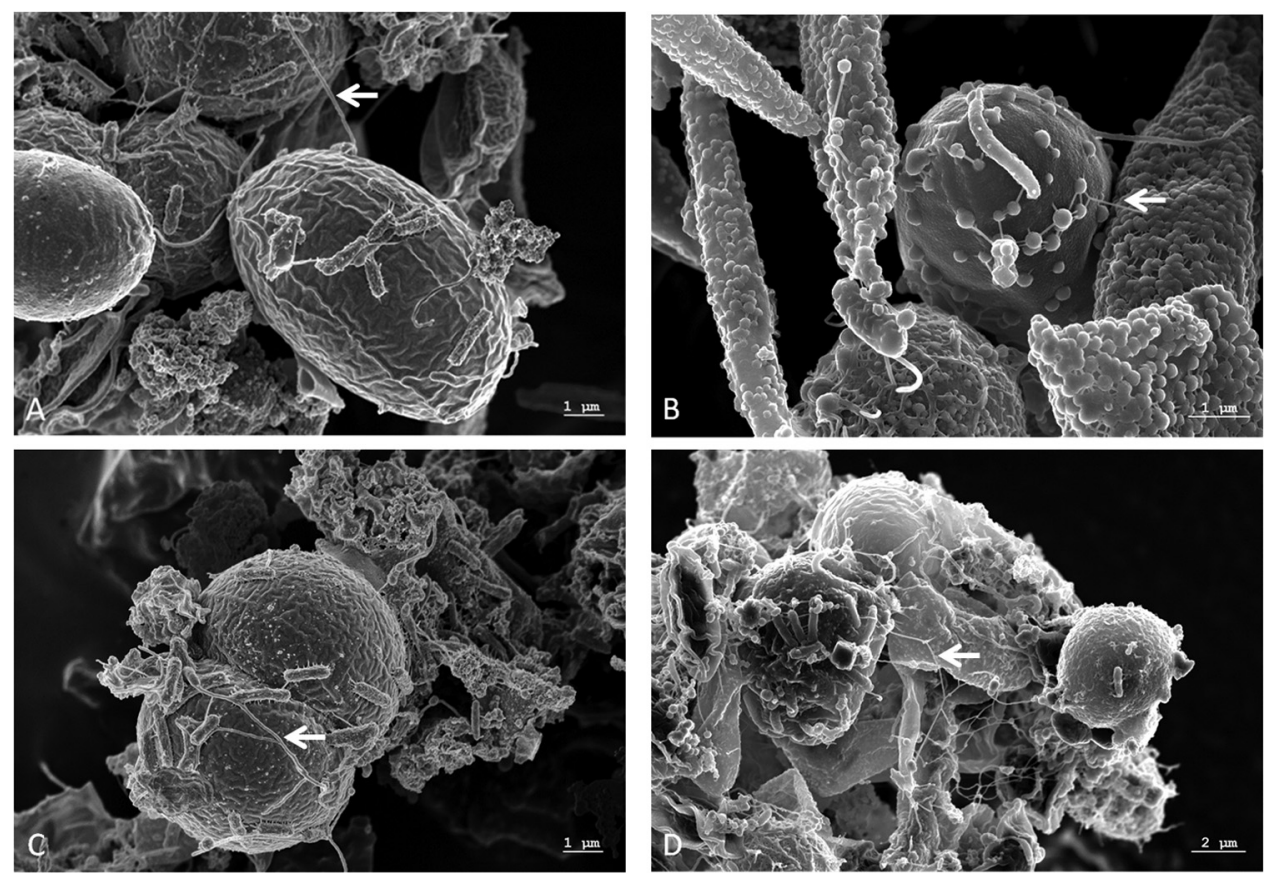

FIG 2 Scanning electron micrographs of a network of microalgae and bacteria in a PBR. Scale bars are indicated in the images (REM Leo 1525; $5.00 \mathrm{kV})$. The arrows point to nanowire-like structures that were identified. The large round cells (5 to $6 \mu \mathrm{m})$ are $C$. vulgaris, and the lemon-shaped cells $(8$ to $9 \mu \mathrm{m})$ are $S$. obliquus. 


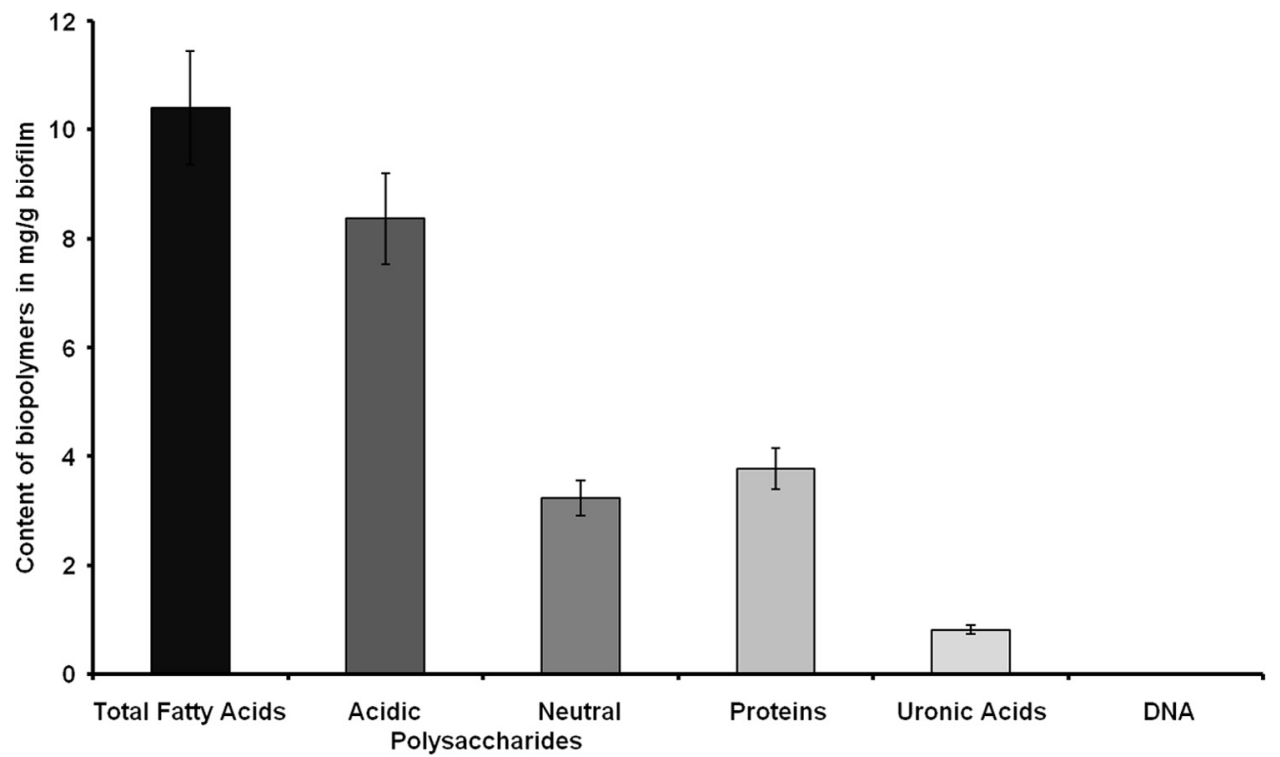

FIG 3 Contents of biopolymers of the extracellular polymeric substances from biofilm samples harvested at T5. The DNA content was $<4 \mathrm{ng} / \mathrm{mg}$ wet weight. The data are mean values of at least three replicates. The error bars indicate simple standard deviations.

regarded as specialists in the degradation of high-molecularweight organic matter (34). Overall, the most abundant bacterial organisms were members of the families Sphingomonadaceae, Caulobacteraceae, Rhizobiaceae, Comamonadaceae, Xanthomonadaceae, Sphingobacteriaceae, and Flavobacteriaceae.

Additional data from DGGE and RFLP analysis from the different time points during biofilm development and the nonaxenic starter culture supported these findings (see Fig. S2 and S3 in the supplemental material). The DGGE profiles and RFLP analysis, in combination with 16S rRNA gene sequences (DGGE, KC994651 to KC994663; RFLP, KC994664 to KC994680) derived from T0 to T5 further suggested that the phylogenetic structure of the biofilm population was rather stable over the entire time. The data also indicated that the microbes observed within the PBR biofilm were mostly already present in the starter culture used to inoculate the PBR at T0.

To further verify these data, we analyzed the DNA sequences of the mature PBR biofilm obtained by pyrosequencing and Illumina-based sequencing for the presence of hypervariable regions of rRNA gene fragments. Analysis of the V3 and V6 regions has been applied to study bacterial communities in diverse ecosystems (69-71). In total, 226 sequences from the FLX 454 (see Fig. S4A in the supplemental material) and 137,506 sequences from the Illumina (see Fig. S4C in the supplemental material) data sets were directly mapped onto the Silva database. For the analysis of the bacterial population, the hypervariable region V6 of the bacterial

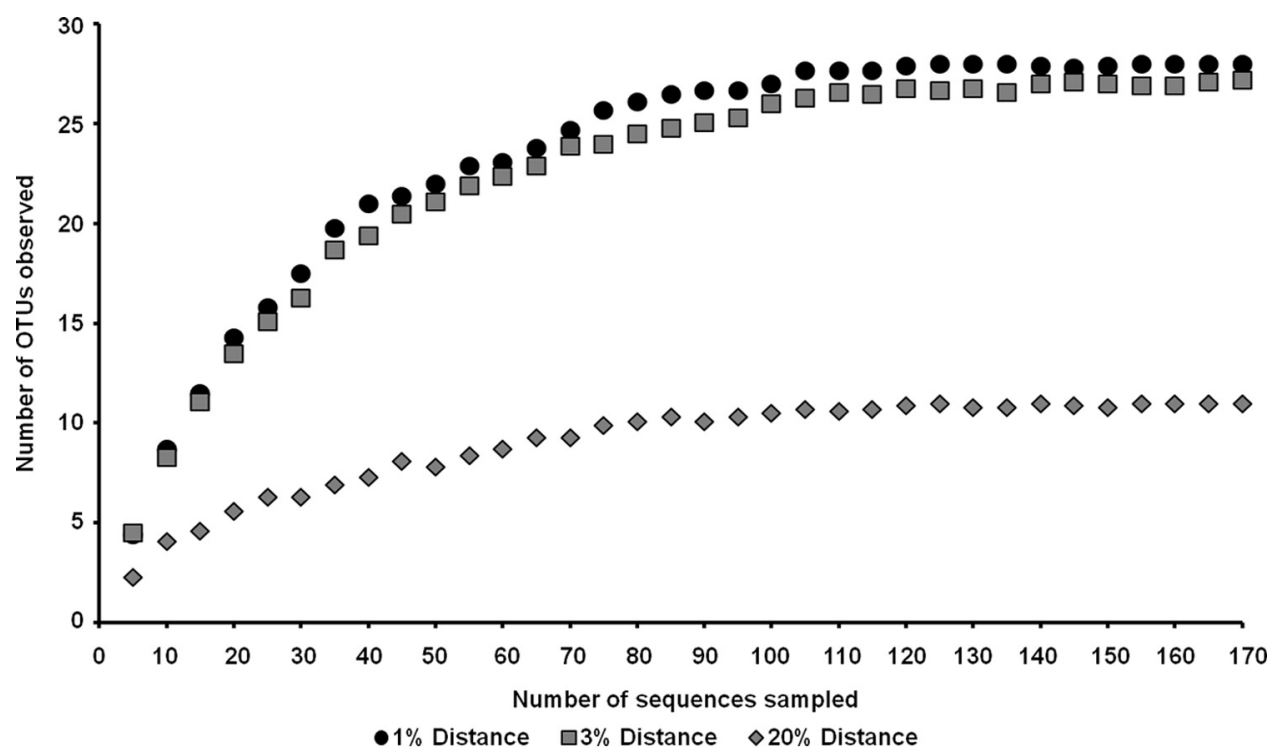

FIG 4 Rarefaction curves indicating the observed numbers of OTUs within the 16S rRNA gene libraries derived from the PBR biofilm at T5 after filtering of the chloroplast sequences. The curves were calculated with QIIME (65). OTUs are shown at 1,3, and 20\% genetic-distance levels. 


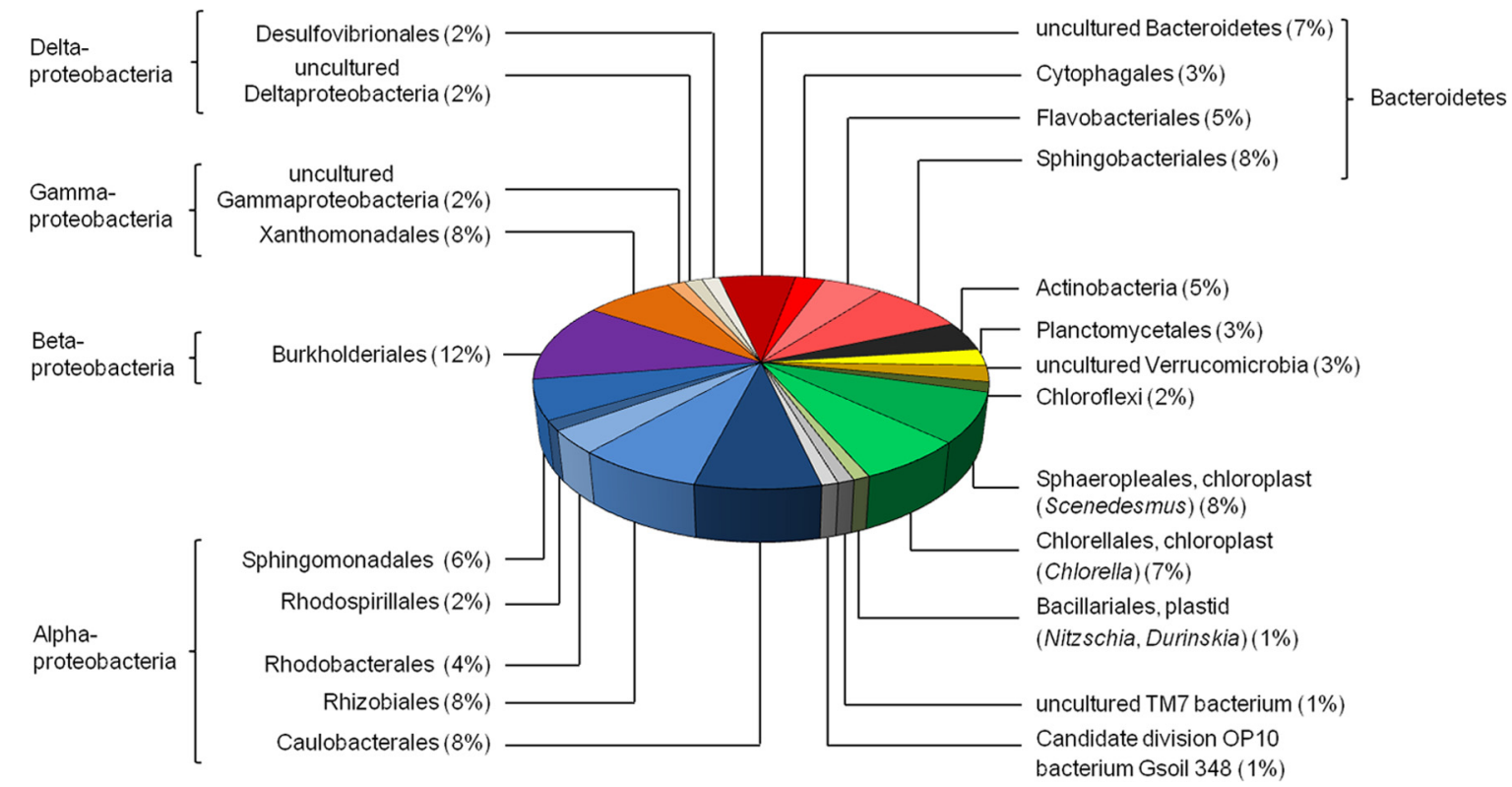

FIG 5 Phylogenetic assignment of the 16S rRNA clone library derived from the PBR biofilm by using the reference sequences stored in the NCBI database. The 16S rRNA gene sequences were analyzed with Finch TV (Geospiza) and BioEdit (http://www.mbio.ncsu.edu/bioedit/bioedit.html).

16S rRNA gene was analyzed. Altogether, 41 sequences from the FLX 454 (see Fig. S4B in the supplemental material) and 558 sequences from the Illumina (see Fig. S4D in the supplemental material) data sets were included in the analysis.

In total, the results from the analysis (see Fig. $\mathrm{S} 4$ in the supplemental material) largely confirmed the results and the phylogenic composition estimated by using the $16 \mathrm{~S}$ rRNA gene clone library.

However, it is notable that primer biases occurring during amplification of 16S rRNA genes (72) and the relatively high copy number of the microalgal plastid genomes, including $16 \mathrm{~S}$ rRNA genes, resulted in slightly different species counts. The observed fungi, diatoms, and golden algae most likely are contaminants resulting from previous use of the PBRs.

Cultivation of microorganisms from the PBR. Initial attempts to isolate bacteria associated with the algae by plating on different solid media (LB, tryptone-yeast [TY], Reasoner's 2A [R2A], TSB, and NB) under aerobic and anaerobic conditions, resulted in only two pure cultures. 16S rRNA gene sequencing suggested that the two isolates were affiliated with the genera $\mathrm{Bre}$ vundimonas (JQ661035.1; isolate A) and Paracoccus (JQ404485.1; isolate B) (see Table S2 in the supplemental material). Members of these genera have been frequently isolated from soil and aquatic environments, but various clinical isolates are also known. Interestingly, tests in which we added various amounts of algal culture supernatant, including living cells, to the solid media did stimulate growth of another six bacterial organisms. These isolates were phylotyped by $16 \mathrm{~S}$ rRNA gene sequencing (see Table S2 in the supplemental material). The $16 \mathrm{~S} \mathrm{rRNA}$ gene sequence of isolate $\mathrm{C}$ is most similar to that of Chryseobacterium taichungense YNB68 (JQ071521.1). C. taichungense belongs to the Flavobacteriales and was only recently described as a novel species able to hydrolyze many chromogenic substrates (73). Isolate D could be associated with a Brevibacterium species that was not further characterized (GQ199748.1). Brevibacteria are strictly aerobic Gram-positive microorganisms. Both isolates $\mathrm{C}$ and $\mathrm{D}$ were isolated on R2A agar plates supplemented with $50 \%$ (vol/vol) algal culture. The closest relative of isolate $\mathrm{E}$ is a member of the genus Roseomonas. The $16 \mathrm{~S}$ rRNA gene sequence revealed a similarity of 78\% to Roseomonas sp. (HQ588850.1). Isolate $\mathrm{E}$ was cultivated in the presence of $25 \%$ ( $\mathrm{vol} / \mathrm{vol}$ ) algal culture on NB agar plates. 16S rRNA analysis of isolate $\mathrm{F}$ indicated that this strain is associated with the yet-uncultured Cytophaga-Flavobacteria-Bacteroides (CFB) group bacterial clone S15D-MN13 (AJ583211.1). The 16S rRNA gene sequence was $96 \%$ similar to the $\mathrm{S} 15 \mathrm{D}-\mathrm{MN} 13 \mathrm{GenBank}$ entry. Isolate $\mathrm{G}$ was similar to a hitherto uncultured gammaproteobacterium, clone L4 (EU887990.1). 16S rRNA sequencing of isolate $\mathrm{H}$ suggested that the isolate is affiliated with Rhodococcus sp. strain $3 / 2$ (EU041710.1). Isolates $\mathrm{F}$ to $\mathrm{H}$ were grown on NB medium supplemented with $50 \%$ ( $\mathrm{vol} / \mathrm{vol}$ ) algal culture.

Altogether, these data suggest that only a minor fraction of the bacteria within the PBR are easily cultivable in laboratory media (KC994882 to KC994889).

Analysis of the metabolic potential encoded by the PBR bacterial metagenome. Today, our knowledge of the physiology and metabolism of complex microbial communities associated with eukaryotic microalgae is very limited. Therefore, we analyzed the partial metagenome sequences of the PBR biofilm microbial community with respect to possible gene functions. We established and assembled 164.7 Mbp of DNA sequences for the PBR biofilm community in contigs ranging from $165 \mathrm{bp}$ to $203,650 \mathrm{bp}$ (Table 1). Approximately 347,000 protein-coding genes could be assigned. Of all possible ORFs predicted, a total of 55,767 were similar to ORFs and genes in the KEGG database; 125,999 ORFs matched the COG database, and 35,935 ORFs could be analyzed by a MetaCyc pathway analysis (74). In addition, it should be noted that up to $1.5 \%$ of all ORFs were derived from eukaryotic DNA in the sample. Within this framework, it should be taken into account that most likely a small but significant number of ORFs are not correctly predicted due to overlapping genes/ORFs and noncorrected frame shifts. Based on the assumption that most 
TABLE 1 Overall numbers of sequences and contigs generated for PBR biofilm analysis

\begin{tabular}{ll}
\hline Parameter & Value \\
\hline Reads FLX 454 (filtered) & \\
No. & 569,233 \\
Total length (bp) & $322,201,969$ \\
Mean length (bp) & 566 \\
Range (bp) & $20-1,637$ \\
GC mean (\%) & 54 \\
& \\
Reads Illumina (filtered) & \\
No. & $217,902,594$ \\
Total length (bp) & $21,136,551,618$ \\
Mean length (bp) & 97 \\
Range (bp) & 97 \\
GC mean (\%) & 51 \\
& \\
Contigs-assembly (velvet) & \\
No. & 165,176 \\
Total length (bp) & $164,776,921$ \\
Mean length (bp) & $997 \pm 2,780$ \\
No. $\geq 400$ bp & 86,050 \\
N50 size (bp) & 2,410 \\
Largest (bp) & 203,650 \\
GC mean (\%) & $52 \pm 10$ \\
\hline
\end{tabular}

of these 30 different bacterial species have genomes ranging from 3 to $8 \mathrm{Mbp}$, it is reasonable to speculate that the overall bacterial biofilm metagenome ranges from $90 \mathrm{Mbp}$ to $240 \mathrm{Mbp}$. Therefore, the 164.7-Mbp assembled DNA represents a significant fraction of the overall bacterial biofilm metagenome. Although the available sequences do not allow a complete analysis of the physiological and metabolic functions within this bacterial community, the sequences give a good estimate of the biofilm genome structure and its metabolic potential.

The KEGG analysis suggested that the metabolic and catabolic potential of the microbes living in the PBR biofilm is highly diverse and flexible (Table 2). Genes for many of the classical pathways linked to the degradation of polysaccharides, proteins, and cellulose, but also for the degradation of aromatic compounds, were identified. With respect to the degradation of biopolymers, at least 64 amylases, 57 cellulases (mainly GH5 and M-family cellulose), 22 genes linked to the depolymerization of poly- $\beta$-hydroxybutyrate $(\mathrm{PHB})$, and a high number of proteases $(2,419)$ were observed.

Many genes involved in lipid and fatty acid catabolism could be identified. Altogether, at least 1,137 genes and ORFs encoded esterolytic and/or lipolytic enzymes, suggesting a high hydrolytic activity for fatty acids within the analyzed microbial community. This observation was supported by data from a metagenome fosmid library screening. Altogether, 14,976 clones with an average insert size of $35 \mathrm{kbp}$ were screened in tributyrin-containing indicator plates. This equals about $524 \mathrm{Mbp}$ of screened DNA. From this screen, a surprisingly large number of lipolytic clones were identified. A total of 68 clones were identified in a first screen using the outlined screening procedures. Further tests with cell extracts of 16 of these clones confirmed that a wide range of fatty acids with various chain lengths were turned over by extracts of the fosmid clones (Fig. 6). The majority of the clones were active on the pNPlaurate $\left(\mathrm{C}_{12}\right)$ but had almost negligible activities on the pNP-
TABLE 2 Key features observed in the PBR biofilm metagenome using a KEGG-based analysis

\begin{tabular}{ll}
\hline Trait & \% of all hits \\
\hline Amino acid metabolism & 16.6 \\
Polysaccharide degradation and metabolism & 16.1 \\
Energy metabolism & 8.1 \\
Vitamin and cofactor biosynthesis & 6.7 \\
Secondary-metabolite synthesis & 4.9 \\
Lipid metabolism & 4.8 \\
Transport mechanisms & 4.7 \\
Xenobiotic- and aromatic-compound degradation & 4.2 \\
Exopolysaccharide biosynthesis and modification & 1.9 \\
Cell appendages and motility & 1.8 \\
Secretion systems & 1.6 \\
Others & 14.2 \\
Total & 100 \\
\hline
\end{tabular}

palmitate $\left(\mathrm{C}_{16}\right)$ and pNP-stearate $\left(\mathrm{C}_{18}\right)$ and thus most likely encoded esterases acting preferentially on shorter-chain fatty acids. However, very few clones also hydrolyzed the longer-chain fatty acid substrates and are perhaps more likely to encode true lipases (i.e., pFOS73A2, pFOS108D6, and pFOS131A4). Additional tests with culture supernatants supported this hypothesis. In these tests, we observed small but significant hydrolytic activities ranging from 0.0732 to 0.3373 milliunits per $\mathrm{ml}$ in the cell-free culture supernatant of the PBR. Lipolytic enzymes, including lipases (EC 3.1.1.3) and carboxylesterases (EC 3.1.1.1), are of general cell importance for membrane and fatty acid metabolism, and they are well known to be important during various pathogenic and nonpathogenic host-microbe interactions $(75,76)$. Thus, we speculate that the relatively high number of esterolytic and lipolytic genes is perhaps a result of the known production of lipids and fatty acids by the algae and thus has possibly resulted in an enrichment of highly lipolytic and esterolytic microbes. It is further notable that many short-chain fatty acid oxidoreductases and oxidoreductases without an assigned substrate $(>600)$ were identified within the PBR metagenome. Some of these will most likely be important for the oxidation/reduction of the lipids derived from algae.

The metagenome sequences further suggest that the bacteria associated within the PBR were mainly heterotrophs metabolizing a wide range of carbon and energy sources provided by the algae.

The microbial lifestyle in the PBR biofilm most likely included aerobic, as well as microaerobic, growth. Altogether, 1,844 cytochrome-encoding genes were counted, suggesting that highly diverse and branched electron transport chains are encoded by the bacteria living within the PBR biofilm. Branched electron transport chains are an adaptation to varying oxygen concentrations (77) and are observed in the majority of all bacterial genomes. In addition, all the genes needed for nitrate respiration were identified. The occurrence of these genes will certainly allow a wide range of metabolic activities under varying oxygen concentrations and could be an adaptation to life in biofilms that are known to include gradients of oxygen and often even have anoxic pockets $(78,79)$.

Biosynthesis genes of $\mathrm{B}$-group vitamins. Vitamin $\mathrm{B}_{12}$ is one of the most complex cofactors and an essential vitamer that is required for molecular rearrangements of hydrogen or methyl groups in prokaryotic and eukaryotic cells, and it is involved in the 


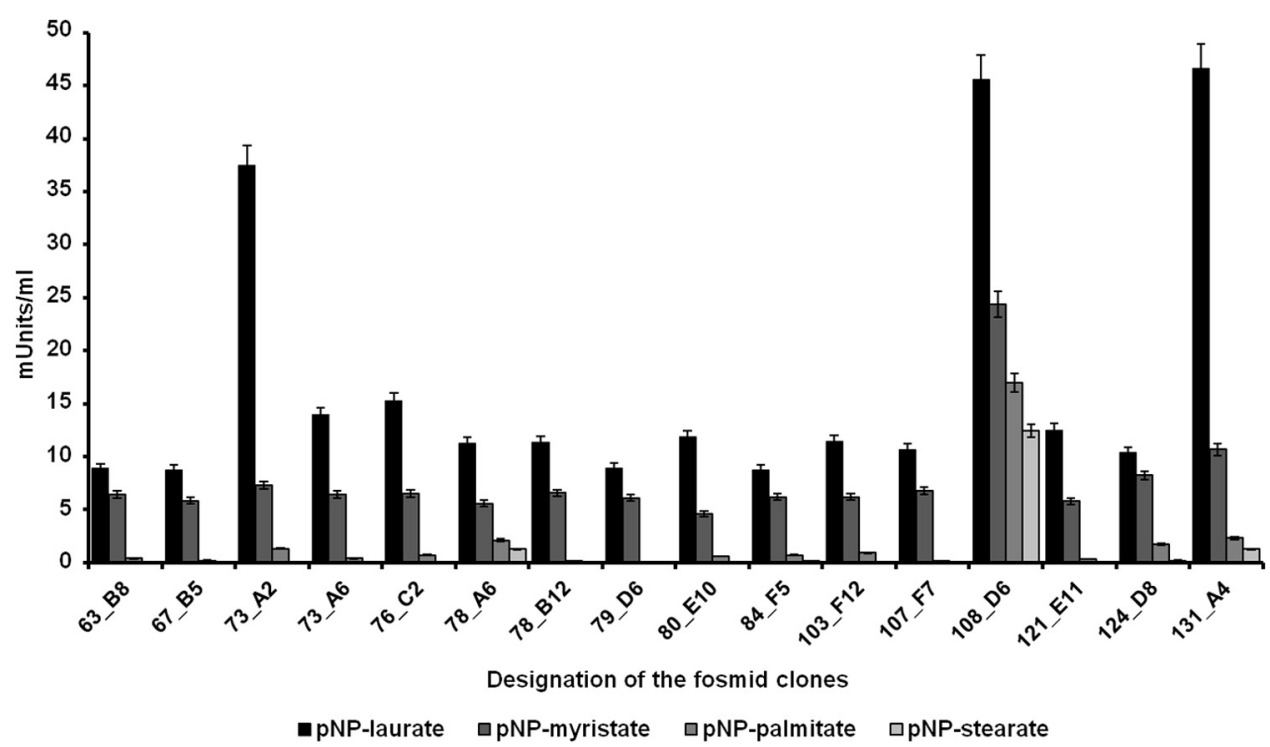

FIG 6 Lipolytic and esterolytic activities of 16 PBR- and metagenome-derived fosmid clones. Activities were assayed in the presence of various pNP substrates (pNP-laurate, pNP-myristate, pNP-palmitate, and pNP-stearate) at a final concentration of $1 \mathrm{mM}$. Extinction was measured at $405 \mathrm{~nm}$ against an enzyme-free blank after $30 \mathrm{~min}$ of incubation at $37^{\circ} \mathrm{C}$. The data are mean values of at least three replicates. The error bars indicate simple standard deviations.

reduction of ribonucleotide triphosphate to $2^{\prime}$-deoxyribonucleotide triphosphate $(80,81)$. Higher eukaryotes (i.e., animals, humans, and protists) require $B_{12}$ but do not synthesize the vitamer, and plants and fungi neither synthesize it nor use it. While plants have evolved a $B_{12}$-independent methionine synthase, algae require the vitamer for the function of $\mathrm{B}_{12}$-dependent methionine synthase $(22-24,82,83)$. Vitamin $B_{12}$ is synthesized by bacteria and archaea, which have evolved two distinct routes for biosynthesis under aerobic and anaerobic conditions (22). More than 20 different steps are required for the biosynthesis of the corrinoid ring structure from uroporphyrinogen III $(80,81)$.

The KEGG-based analysis of the predicted genes and ORFs in the PBR biofilm metagenome suggested that all the genes with relevance to $B_{12}$ vitamin biosynthesis were present, and many of them in multiple copies (see Fig. S5 in the supplemental material). Within this framework, it is notable that many algae are auxotrophic with respect to the production of thiamine and biotin, as well (21). Thiamine (vitamin $B_{1}$ ) is essential for some of the key enzymes in the primary carbohydrate and branched-chain amino acid metabolism. Altogether, we have identified at least 218 genes in the biofilm metagenome that are involved in thiamine biosynthesis (see Fig. S6 in the supplemental material) $(84,85)$. Biotin is a cofactor of biotin-dependent carboxylase reactions, among them acetyl coenzyme A (CoA) carboxylase, which is essential for fatty acid synthesis $(86,87)$. For all major genes involved in biotin biosynthesis, multiple copies were detected (see Fig. S7 in the supplemental material). Based on the KEGG analysis, almost $6.7 \%$ of all ORFs and genes encoded metabolism of cofactors and vitamin biosynthesis. Additional tests in an experimental test reactor confirmed that small amounts of the two vitamers $B_{12}$ and biotin could already be detected in the PBR culture supernatant $48 \mathrm{~h}$ after inoculation (Fig. 7 and 8). The pico- and nanomolar amounts observed were certainly sufficient to support algal growth.

$\mathrm{N}$-Acyl-homoserine lactone-dependent signaling plays a minor role in PBR biofilm formation. Microbial biofilm formation depends to a large extent on the attachment of bacteria to surfaces, microcolony formation, and maturing of the biofilm structure $(64,88,89)$. Within the PBR metagenome, many genes were identified that are essential to biofilm formation. Biofilm formation is regulated by a wide range of factors, including signaling molecules, such as autoinducer involved in quorum-sensing-dependent gene regulation. Interestingly, we have identified only a small number of genes that are involved in the synthesis of autoinducer I-type ( $N$-acyl-homoserine lactone) molecules. $N$-Acyl-homoserine lactones are the key signaling molecules in the cell densitydependent system of gene regulation in many Gram-negative bacteria, and they are usually synthesized through a LuxI-like protein $(90,91)$. Employing the amino acid sequences of various LuxI homologues for Blastp searches, we could not detect more than a few homologues $(<10)$ in the PBR metagenome. This finding is intriguing, and it might suggest that autoinducer I-dependent sig-

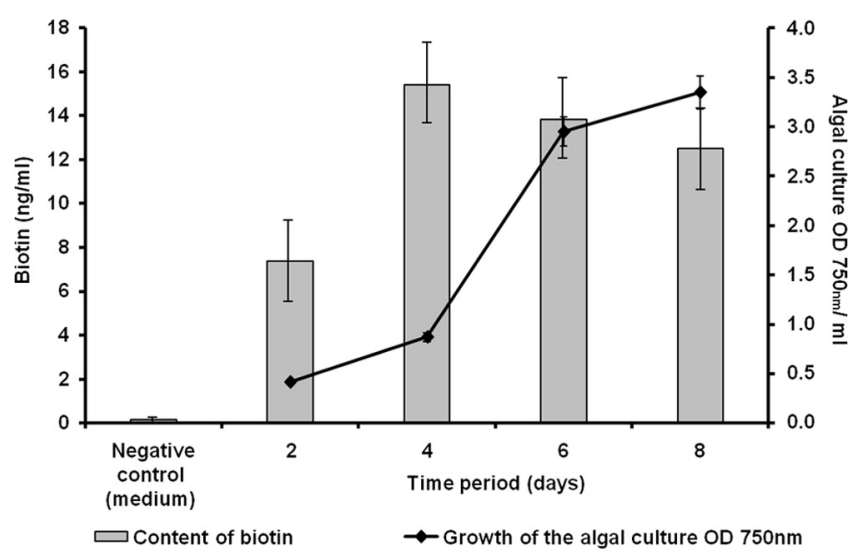

FIG 7 Biotin $(\mathrm{ng} / \mathrm{ml})$ detected in a PBR culture supernatant. Biotin was determined at different periods of growth of the algal culture. The data represent values of at least three replicates. The error bars indicate simple standard deviations. 


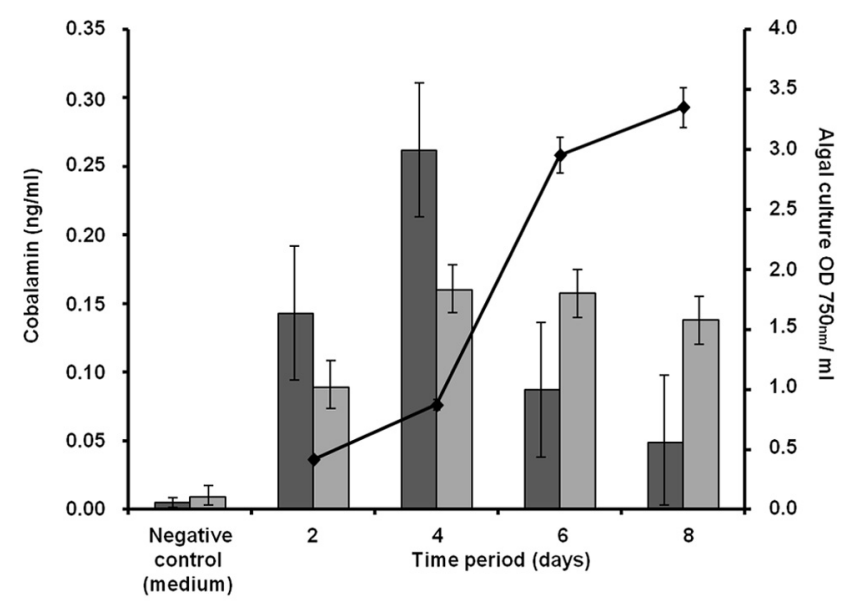

$\square$ Content of cobalamin (active form) $\sim$ Growth of the algal culture OD $750 \mathrm{~nm}$

FIG 8 Content of cobalamin $(\mathrm{ng} / \mathrm{ml})$ in a model PBR. The cobalamin content (active and inactive forms) of the algal culture supernatant was determined at different time points during algal growth. The data represent values of at least three replicates. The error bars indicate simple standard deviations.

naling may play only a minor role within the observed ecological niche.

Summary and conclusions. Sequencing-based metagenome analyses in combination with function-based studies have in general significantly increased our knowledge of microbial communities and their phylogenetic makeup and genetic potential. Finally, these studies provided insight into the ecology of the analyzed communities and thereby enriched our understanding of biodiversity and biochemical functions. Many of these studies have been summarized previously $(29,92-94)$. Surprisingly, only a few studies have addressed metagenome technologies for the analysis of mixed-species biofilms in nonhuman interactions. The earliest studies dealt with the acid mine drainage biofilm (95) and a drinking water biofilm (96). More recently, studies have addressed microbial biofilm metagenomes of hydrothermal vent chimneys, biofilms on concrete water pipes, and an extremely acidophilic sulfur-oxidizing biofilm (97-99). Although not all studies have been listed here, it is evident that many different biotic and abiotic factors shape each of these communities and that each community clearly differs in its phylogenetic structure and genomic-information content.

In summary, our data give detailed insight into the microbial community and the metagenome of a PBR-associated microbial biofilm. Altogether, we observed 28 OTUs within the analyzed biofilm, and DGGE and RFLP analyses suggested that the community was rather stable over time. The sequence-based data and the laboratory measurement data clearly support earlier findings with respect to the bacterially produced B vitamins. Our data also suggest that bacterial growth depends in part on compounds released by the algae or bacteria within the community.

Finally, it is interesting that the bacteria in the PBR studied here encode many esterolytic and lipolytic enzymes. This finding was supported by extracting active lipolytic clones and by measuring the hydrolytic activities in the culture supernatants. Future work will have to use these data to further improve the efficiencies of PBRs with respect to $\mathrm{CO}_{2}$ fixation and downstream processing of biofuels and/or other valuable compounds produced and released by the algae.

\section{ACKNOWLEDGMENTS}

This work was supported by the research and development project Technologies for Exploiting the Resource Microalgae (TERM) and the BMBF Project ChemBiofilm and was funded by the Federal Graduate School "C1-Chemistry in Resource and Energy Management" (C1-REM) (Hamburg, Germany).

\section{REFERENCES}

1. Chisti Y. 2007. Biodiesel from microalgae. Biotechnol. Adv. 25:294-306.

2. Williams PJLB, Laurens LML. 2010. Microalgae as biodiesel and biomass feedstocks: review and analysis of the biochemistry, energetics and economics. Energy Environ. Sci. 3:554-590.

3. Ugwu CU, Aoyagi H, Uchiyama H. 2008. Photobioreactors for mass cultivation of algae. Bioresour. Technol. 99:4021-4028.

4. Gouveia L, Oliveira A. 2009. Microalgae as a raw material for biofuels production. J. Ind. Microbiol. 36:269-274.

5. Abomohra AF, Wagner M, El-Sheekh M, Hanelt D. 2012. Lipid and total fatty acid productivity in photoautotrophic fresh water microalgae: screening studies towards biodiesel production. J. Appl. Phycol. 2012:1-6.

6. Waltz E. 2013. Algal biofuels questioned. Nat. Biotechnol. 31:12.

7. Andersen RA. 2004. Biology and systematics of heterokont and haptophyte algae. Am. J. Bot. 91:1508-1522.

8. Falkowski PG, Katz ME, Knoll AH, Quigg A, Raven JA, Schofield O, Taylor FJ. 2004. The evolution of modern eukaryotic phytoplankton. Science 305:354-360.

9. Falkowski PG, Raven JA. 2007. Aquatic photosynthesis, 2nd ed. Princeton University Press, Princeton, NJ.

10. Lee YK. 2001. Microalgal mass culture systems and methods: their limitation and potential. J. Appl. Phycol. 13:307-315.

11. Lehr F, Posten C. 2009. Closed photo-bioreactors as tools for biofuel production. Curr. Opin. Biotechnol. 20:280-285.

12. Scott SA, Davey MP, Dennis JS, Horst I, Howe CJ, Lea-Smith DJ, Smith AG. 2010. Biodiesel from algae: challenges and prospects. Curr. Opin. Biotechnol. 21:277-286.

13. Carvalho AP, Meireles LA, Malcata FX. 2006. Microalgal reactors: a review of enclosed system designs and performances. Biotechnol. Prog. 22:1490-1506.

14. Cole JJ. 1982. Interactions between bacteria and algae in aquatic ecosystems. Annu. Rev. Ecol. Syst. 13:291-314.

15. Lakaniemi AM, Hulatt CJ, Wakeman KD, Thomas DN, Puhakka JA. 2012. Eukaryotic and prokaryotic microbial communities during microalgal biomass production. Bioresour. Technol. 124:387-393.

16. Lakaniemi AM, Intihar VM, Tuovinen OH, Puhakka JA. 2012. Growth of Chlorella vulgaris and associated bacteria in photobioreactors. Microb. Biotechnol. 5:69-78.

17. Otsuka S, Abe Y, Fukui R, Nishiyama M, Sendoo K. 2008. Presence of previously undescribed bacterial taxa in non-axenic Chlorella cultures. J. Gen. Appl. Microbiol. 54:187-193.

18. Watanabe K, Takihana N, Aoyagi H, Hanada S, Watanabe Y, Ohmura N, Saiki H, Tanaka H. 2005. Symbiotic association in Chlorella culture. FEMS Microbiol. Ecol. 51:187-196.

19. Ueda H, Otsuka S, Senoo K. 2009. Community composition of bacteria co-cultivated with microalgae in non-axenic algal cultures. Microbiol. Cult. Coll. 25:21-25.

20. Lakaniemi AM, Intihar VM, Tuovinen OH, Puhakka JA. 2012. Growth of Dunaliella tertiolecta and associated bacteria in photobioreactors. J. Ind. Microbiol. Biotechnol. 39:1357-1365.

21. Croft MT, Warren MJ, Smith AG. 2006. Algae need their vitamins. Eukaryot. Cell 5:1175-1183.

22. Warren MJ, Raux E, Schubert HL, Escalante-Semerena JC. 2002. The biosynthesis of adenosylcobalamin (vitamin B12). Nat. Prod. Rep. 19: $390-412$.

23. Helliwell KE, Wheeler GL, Leptos KC, Goldstein RE, Smith AG. 2011. Insights into the evolution of vitamin B12 auxotrophy from sequenced algal genomes. Mol. Biol. Evol. 28:2921-2933.

24. Giovannoni SJ. 2012. Vitamins in the sea. Proc. Natl. Acad. Sci. U. S. A. 109:13888-13889.

25. Mouget JL, Dakhama A, Lavoie MC, de la Noüe J. 1995. Algal growth 
enhancement by bacteria: is consumption of photosynthetic oxygen involved? FEMS Microbiol. Ecol. 18:35-43.

26. Berger PS, Rho J, Gunner H. 1979. Bacterial suppression of Chlorella by hydroxylamine production. Water Res. 13:267-273.

27. Handelsman J. 2004. Metagenomics: application of genomics to uncultured microorganisms. Microbiol. Mol. Biol. Rev. 68:669-685.

28. Simon C, Daniel R. 2011. Metagenomic analyses: past and future trends. Appl. Environ. Microbiol. 77:1153-1161.

29. Streit WR, Schmitz RA. 2004. Metagenomics-the key to the uncultured microbes. Curr. Opin. Microbiol. 7:492-498.

30. Simon C, Daniel R. 2009. Achievements and new knowledge unraveled by metagenomic approaches. Appl. Microbiol. Biotechnol. 85:265-276.

31. Tremaroli V, Bäckhed F. 2012. Functional interactions between the gut microbiota and host metabolism. Nature 489:242-249.

32. Weinstock GM. 2012. Genomic approaches to studying the human microbiota. Nature 489:250-256.

33. Lewin A, Wentzel A, Valla S. 2013. Metagenomics of microbial life in extreme temperature environments. Curr. Opin. Biotechnol. 24:516-525.

34. Burke C, Steinberg P, Rusch D, Kjelleberg S, Thomas T. 2011. Bacterial community assembly based on functional genes rather than species. Proc. Natl. Acad. Sci. U. S. A. 108:14288-14293.

35. Williams TJ, Wilkins D, Long E, Evans F, Demaere MZ, Raftery MJ, Cavicchioli R. 2013. The role of planktonic Flavobacteria in processing algal organic matter in coastal East Antarctica revealed using metagenomics and metaproteomics. Environ. Microbiol. 15:1302-1317.

36. Hindersin S, Leupold M, Kerner M, Hanelt D. 2013. Irradiance optimization of outdoor microalgal cultures using solar tracked photobioreactors. Bioprocess Biosyst. Eng. 36:345-355.

37. Sambrook J, Russell DW. 2001. Molecular cloning: a laboratory manual, 3rd ed. Cold Spring Harbor Laboratory Press, Cold Spring Harbor, NY.

38. De Man J, Rogosa M, Sharpe M. 1960. A medium for the cultivation of lactobacilli. J. Appl. Bacteriol. 23:130-135.

39. Reasoner DJ, Geldreich EE. 1985. A new medium for the enumeration and subculture of bacteria from potable water. Appl. Environ. Microbiol. 49:1-7.

40. Yeates C, Gillings MR, Davison AD, Altavilla N, Veal DA. 1998. Methods for microbial DNA extraction from soil for PCR amplification. Biol. Proced. Online 1:40-47.

41. Lane DJ. 1991. 16S/23S rRNA sequencing, p 115-175. In Stackebrandt E, Goodfellow MD (ed), Nucleic acid techniques in bacterial systematics. John Wiley and Sons, New York, NY

42. Zerbino DR, Birney E. 2008. Velvet: algorithms for de novo short read assembly using de Bruijn graphs. Genome Res. 18:821-829.

43. Nakaya A, Katayama T, Itoh M, Hiranuka K, Kawashima S, Moriya Y, Okuda S, Tanaka M, Tokimatsu T, Yamanishi Y, Yoshizawa AC, Kanehisa M, Goto S. 2013. KEGG OC: a large-scale automatic construction of taxonomy-based ortholog clusters. Nucleic Acids Res. 41:D353-D357.

44. Tatusov RL, Natale DA, Garkavtsev IV, Tatusova TA, Shankavaram UT, Rao BS, Kiryutin B, Galperin MY, Fedorova ND, Koonin EV. 2001. The COG database: new developments in phylogenetic classification of proteins from complete genomes. Nucleic Acids Res. 29:22-28.

45. Finn RD, Tate J, Mistry J, Coggill PC, Sammut SJ, Hotz HR, Ceric G, Forslund K, Eddy SR, Sonnhammer ELL, Bateman A. 2008. The Pfam protein families database. Nucleic Acids Res. 36:281-288.

46. Buchholz-Cleven BEE, Rattunde B, Straub KL. 1997. Screening for genetic diversity of isolates of anaerobic $\mathrm{Fe}(\mathrm{II})$-oxidizing bacteria using DGGE and whole-cell hybridization. Syst. Appl. Microbiol. 20:301-309.

47. Muyzer G, de Waal EC, Uitterlinden AG. 1993. Profiling of complex microbial populations by denaturing gradient gel electrophoresis analysis of polymerase chain reaction-amplified genes coding for 16S rRNA. Appl. Environ. Microbiol. 59:695-700.

48. Kopylova E, Noe L, Touzet H. 2012. SortMeRNA: fast and accurate filtering of ribosomal RNAs in metatranscriptomic data. Bioinformatics 28:3211-3217.

49. Langmead B, Salzberg SL. 2012. Fast gapped-read alignment with Bowtie 2. Nat. Methods 9:357-359.

50. Hartmann M, Howes CG, Abarenkov K, Mohn WW, Nilsson RH. 2010. V-Xtractor: an open-source, high-throughput software tool to identify and extract hypervariable regions of small subunit (16S/18S) ribosomal RNA gene sequences. J. Microbiol. Methods 83:250-253.

51. Wingender J, Strathmann M, Rode A, Leis A, Flemming HC. 2001. Isolation and biochemical characterization of extracellular polymeric substances from Pseudomonas aeruginosa. Methods Enzymol. 336:302-314.
52. Hara A, Radin NS. 1978. Lipid extraction of tissues with a low-toxicity solvent. Anal. Biochem. 90:420-426.

53. Dubois M, Gilles KA, Hamilton JK, Rebers PA, Smith F. 1956. Colorimetric method for determination of sugars and related substances. Anal. Chem. 28:350-356.

54. Filisetti-Cozzi TM, Carpita NC. 1991. Measurement of uronic acids without interference from neutral sugars. Anal. Biochem. 197:157-162.

55. Lowry OH, Rosebrough NJ, Farr AL, Randall RJ. 1951. Protein measurement with the Folin phenol reagent. J. Biol. Chem. 193:265-275.

56. Frølund B, Palmgren R, Keiding K, Nielsen PH. 1996. Extraction of extracellular polymers from activated sludge using a cation exchange resin. Water Res. 30:1749-1758.

57. Elend C, Schmeisser C, Leggewie C, Babiak P, Carballeira JD, Steele HL, Reymond JL, Jaeger KE, Streit WR. 2006. Isolation and biochemical characterization of two novel metagenome-derived esterases. Appl. Environ. Microbiol. 72:3637-3645.

58. Denter J, Bisping B. 1994. Formation of B-vitamins by bacteria during the soaking process of soybeans for tempe fermentation. Int. J. Food. Microbiol. 22:23-31.

59. Entcheva P, Liebl W, Johann A, Hartsch T, Streit WR. 2001. Direct cloning from enrichment cultures, a reliable strategy for isolation of complete operons and genes from microbial consortia. Appl. Environ. Microbiol. 67:89-99.

60. Flemming HC, Wingender J. 2010. The biofilm matrix. Nat. Rev. Microbiol. 8:623-633.

61. Branda SS, Vik S, Friedman L, Kolter R. 2005. Biofilms: the matrix revisited. Trends Microbiol. 13:20-26.

62. Sutherland IW. 2001. The biofilm matrix: an immobilized but dynamic microbial environment. Trends Microbiol. 9:222-227.

63. Flemming HC, Neu TR, Wozniak DJ. 2007. The EPS matrix: the house of biofilm cells. J. Bacteriol. 189:7945-7947.

64. Stoodley P, Sauer K, Davies DG, Costerton JW. 2002. Biofilms as complex differentiated communities. Annu. Rev. Microbiol. 56:187-209.

65. Kuczynski J, Stombaugh J, Walters WA, Gonzalez A, Caporaso JG, Knight R. 2011. Using QIIME to analyze 16S rRNA gene sequences from microbial communities. Curr. Protoc. Bioinformatics 10:10.7. doi:10 .1002/0471250953.bi1007s36.

66. Shannon CE, Weaver W. 1949. The mathematical theory of communication, p 379-423. University of Illinois Press, Urbana, IL.

67. Chao A, Lee SM. 1992. Estimating the number of classes via sample coverage. J. Am. Stat. Assoc. 87:210-217.

68. Chao A. 1984. Nonparametric estimation of the number of classes in a population. Scan. J. Statist. 11:265-270.

69. Christen R. 2008. Global sequencing: a review of current molecular data and new methods available to assess microbial diversity. Microbes Environ. 23:253-268.

70. Gloor GB, Hummelen R, Macklaim JM, Dickson RJ, Fernandes AD, MacPhee R, Reid G. 2010. Microbiome profiling by Illumina sequencing of combinatorial sequence-tagged PCR products. PLoS One 5:e15406. doi:10.1371/journal.pone.0015406.

71. Huse SM, Dethlefsen L, Huber JA, Welch DM, Relman DA, Sogin ML. 2008. Exploring microbial diversity and taxonomy using SSU rRNA hypervariable tag sequencing. PLoS Genet. 4:e1000255. doi:10.1371/journal .pgen.1000255.

72. Klindworth A, Pruesse E, Schweer T, Peplies J, Quast C, Horn M, Glockner FO. 2013. Evaluation of general 16S ribosomal RNA gene PCR primers for classical and next-generation sequencing-based diversity studies. Nucleic Acids Res. 41:e1. doi:10.1093/nar/gks808.

73. Shen FT, Kämpfer P, Young CC, Lai WA, Arun AB. 2005. Chryseobacterium taichungense sp. nov., isolated from contaminated soil. Int. J. Syst. Evol. Microbiol. 55:1301-1304

74. Caspi R, Altman T, Dreher K, Fulcher CA, Subhraveti P, Keseler IM, Kothari A, Krummenacker M, Latendresse M, Mueller LA, Ong Q, Paley S, Pujar A, Shearer AG, Travers M, Weerasinghe D, Zhang P, Karp PD. 2012. The MetaCyc database of metabolic pathways and enzymes and the BioCyc collection of pathway/genome databases. Nucleic Acids Res. 40:D742-D753.

75. Arpigny JL, Jaeger KE. 1999. Bacterial lipolytic enzymes: classification and properties. Biochem. J. 343:177-183.

76. Jaeger KE, Ransac S, Dijkstra BW, Colson C, van Heuvel M, Misset O. 1994. Bacterial lipases. FEMS Microbiol. Rev. 15:29-63.

77. Anraku Y. 1988. Bacterial electron transport chains. Annu. Rev. Biochem. 57:101-132. 
78. Stewart PS, Franklin MJ. 2008. Physiological heterogeneity in biofilms. Nat. Rev. Microbiol. 6:199-210.

79. Williamson KS, Richards LA, Perez-Osorio AC, Pitts B, McInnerney K, Stewart P, Franklin MJ. 2012. Heterogeneity in Pseudomonas aeruginosa biofilms includes expression of ribosome hibernation factors in the antibiotic-tolerant subpopulation and hypoxia-induced stress response in the metabolically active population. J. Bacteriol. 194:2062-2073.

80. Martens J, Barg H, Warren MJ, Jahn D. 2002. Microbial production of vitamin B12. Appl. Microbiol. Biotechnol. 58:275-285.

81. Roth J, Lawrence J, Bobik T. 1996. Cobalamin (coenzyme B12): synthesis and biological significance. Annu. Rev. Microbiol. 50:137-181.

82. Croft MT, Lawrence AD, Raux-Deery E, Warren MJ, Smith AG. 2005. Algae acquire vitamin B12 through a symbiotic relationship with bacteria. Nature 438:90-93.

83. Duda J, Pedziwilk Z, Zodrow K. 1957. Studies on the vitamin B12 content of the leguminous plants. Acta Microbiol. Pol. 6:233-238.

84. Begley TP, Ealick SE, McLafferty FW. 2012. Thiamin biosynthesis: still yielding fascinating biological chemistry. Biochem. Soc. Trans. 40:555560.

85. Jurgenson CT, Begley TP, Ealick SE. 2009. The structural and biochemical foundations of thiamin biosynthesis. Annu. Rev. Biochem. 78:569603.

86. Streit WR, Entcheva P. 2003. Biotin in microbes, the genes involved in its biosynthesis, its biochemical role and perspectives for biotechnological production. Appl. Microbiol. Biotechnol. 61:21-31.

87. Lin S, Cronan JE. 2011. Closing in on complete pathways of biotin biosynthesis. Mol. Biosyst. 7:1811-1821.

88. Monds RD, O'Toole GA. 2009. The developmental model of microbial biofilms: ten years of a paradigm up for review. Trends Microbiol. 17:73-87.

89. Klausen M, Gjermansen M, Kreft JU, Tolker-Nielsen T. 2006. Dynamics of development and dispersal in sessile microbial communities: examples from Pseudomonas aeruginosa and Pseudomonas putida model biofilms. FEMS Microbiol. Lett. 261:1-11.

90. LaSarre B, Federle MJ. 2013. Exploiting quorum sensing to confuse bacterial pathogens. Microbiol. Mol. Biol. Rev. 77:73-111.

91. Galloway WR, Hodgkinson JT, Bowden SD, Welch M, Spring DR. 2011. Quorum sensing in Gram-negative bacteria: small-molecule modulation of AHL and AI-2 quorum sensing pathways. Chem. Rev. 111:28-67.

92. Gilbert JA, Dupont CL. 2011. Microbial metagenomics: beyond the genome. Annu. Rev. Mar. Sci. 3:347-371.

93. Tringe SG, von Mering C, Kobayashi A, Salamov AA, Chen K, Chang HW, Podar M, Short JM, Mathur EJ, Detter JC, Bork P, Hugenholtz P, Rubin EM. 2005. Comparative metagenomics of microbial communities. Science 308:554-557.

94. Simon C, Wiezer A, Strittmatter AW, Daniel R. 2009. Phylogenetic diversity and metabolic potential revealed in a glacier ice metagenome. Appl. Environ. Microbiol. 75:7519-7526.

95. Tyson GW, Chapman J, Hugenholtz P, Allen EE, Ram RJ, Richardson PM, Solovyev VV, Rubin EM, Rokhsar DS, Banfield JF. 2004. Community structure and metabolism through reconstruction of microbial genomes from the environment. Nature 428:37-43.

96. Schmeisser C, Stöckigt C, Raasch C, Wingender J, Timmis KN, Wenderoth DF, Flemming HC, Liesegang H, Schmitz RA, Jaeger KE, Streit WR. 2003. Metagenome survey of biofilms in drinking-water networks. Appl. Environ. Microbiol. 69:7298-7309.

97. Gomez-Alvarez V, Revetta RP, Santo Domingo JW. 2012. Metagenome analyses of corroded concrete wastewater pipe biofilms reveal a complex microbial system. BMC Microbiol. 12:122.

98. Brazelton WJ, Baross JA. 2009. Abundant transposases encoded by the metagenome of a hydrothermal chimney biofilm. ISME J. 3:1420-1424.

99. Jones DS, Albrecht HL, Dawson KS, Schaperdoth I, Freeman KH, Pi Y, Pearson A, Macalady JL. 2012. Community genomic analysis of an extremely acidophilic sulfur-oxidizing biofilm. ISME J. 6:158-170. 


\section{SUPPORTING INFORMATION FOR STUDY 8}

\section{CONTENTS:}

Fig. S1: A:Photobioreactors mounted on a solar tracker.B:Flow chart of the microalgae pilot plant's function

Fig S2: DGGE analysis of PCR-amplified 16S rRNA gene fragments obtained from six biofilm samples.

Fig. S3: Assignment of phylogenetic classes and orders of 16S rRNA sequences from the RFLP analysis. Per sample (T0-T5), 100 clones were analysed.

Fig. S4. Distribution of phylogenetic classes and orders of the metagenome-derived sequences in the PBR biofilm community.

Fig. S5. Gene count for cobalamin metabolism.

Fig. S6: Gene count for thiamine metabolism.

Fig. S7: Gene count for biotin metabolism.

TABLE S1.Phylogenetic analysis of 171 16S rRNA clones sequences derived from thebiofilm's fully established microbial community (T5).

TABLE S2.Bacteria cultivated from the PBR microbial community on solid media. 


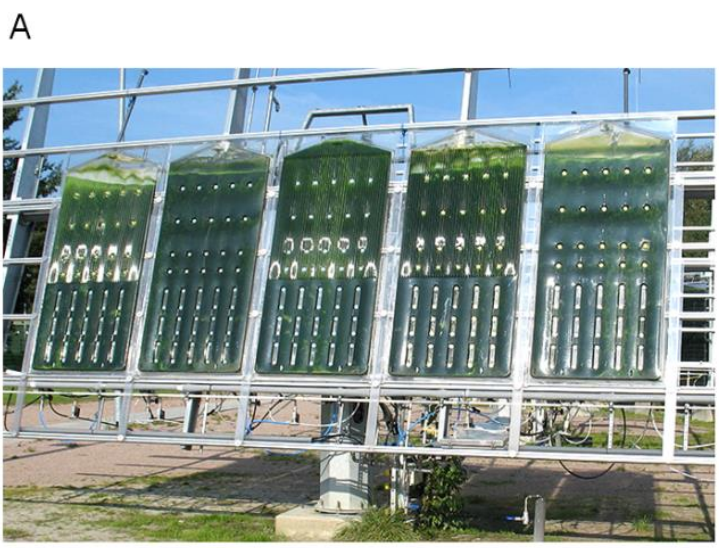

B
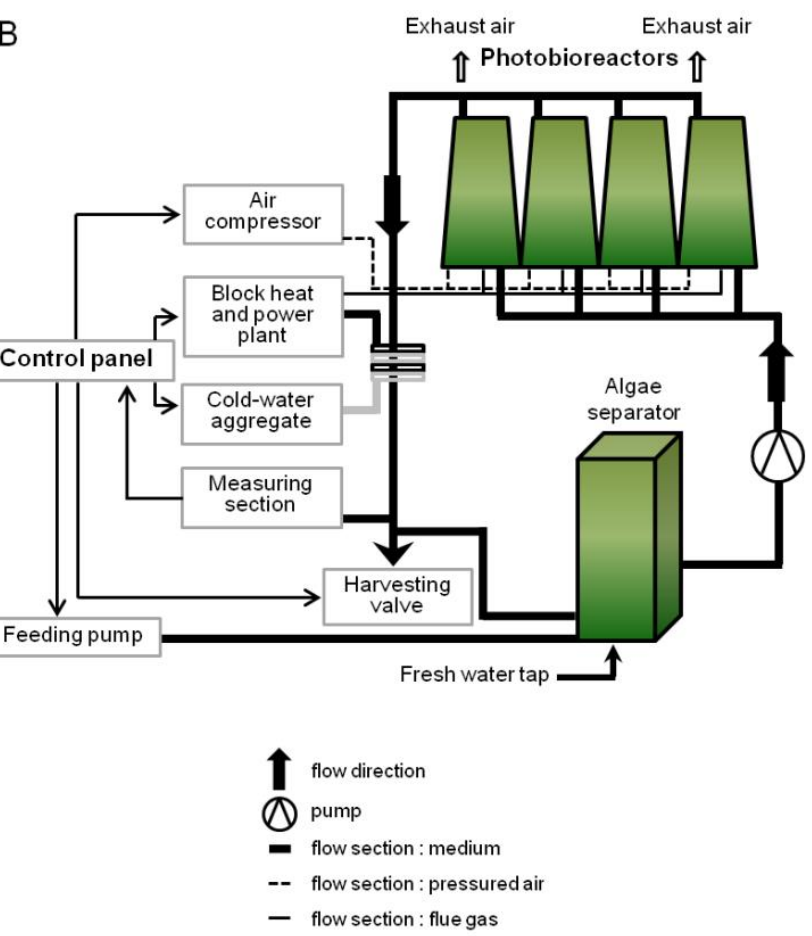

FIGURE S1, Krohn-Molt et al 2013,

Fig. S1:A:Photobioreactors mounted on a solar tracker.B:Flow chart of the microalgae pilot plant's function(modified from S. Hindersin, M. Leupold, M. Kerner, and D. Hanelt, "Irradiance optimization of outdoor microalgal cultures using solar tracked photobioreactors," Bioprocess Biosyst. Eng. 36:345-355, 2013, Fig. 2, with kind permission from Springer Science and Business Media [copyright 2013 Springer-Verlag]). For the duration of cultivation, part of the culture medium circulates through an external circuit. The algal biomass was harvesting continuously, which adjusts cell density to a constant value. The process parameters were monitored by measuring thetemperature, turbidity, $\mathrm{pH}, \mathrm{O}_{2}, \mathrm{NH}_{4}^{+}$, $\mathrm{NO}_{3}{ }^{-}$, and $\mathrm{K}^{+}$.Above a set value, nutrients were added automatically.A heat exchanger within the circular flow allowed temperature control. 


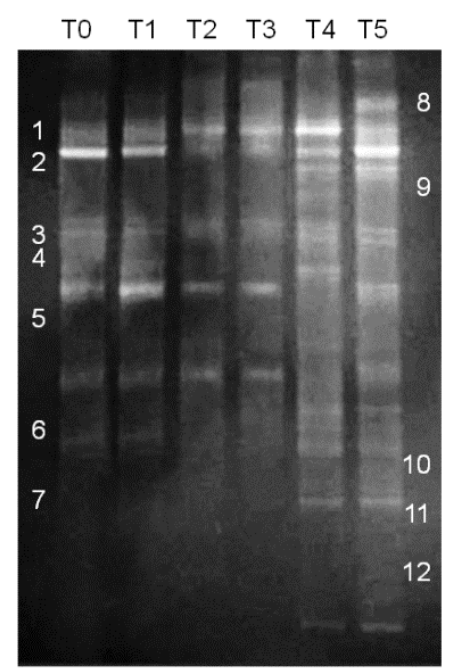

FIGURE S2, Krohn-Molt et al 2013

Fig S2: DGGE analysis of PCR-amplified 16S rRNA gene fragments obtained from six biofilm samples. Lanes 1-6 represent the different time points (T0-T5) of sampling, which were taken in 14 day intervals. The different DGGE bands (1-13) represent the 16S rRNA fragments of associated microorganisms, which could be assigned to sequences stored in the NCBI database. (1) Pedobacter sp. (EU585748.1), (2) Flavobacterium sp. (JX827624.1), (3) Acidovorax sp. (KC464816.1), (4) Rhodobacter sp. (KC157045.1), (5) plastid gene of Nitzschiafrustulum (AY221721.1), (6) chloroplast of Scenedesmusobliquus (DQ396875.1), (7) chloroplast of Chlorella vulgaris (AB001684.1), (8) Bacteroidetes bacterium (HM205113.1), (9) Sinorhizobium sp. (JQ316267.1), (10) Caulobacter sp. (EF020225.1), (11) uncultured Bacteroidetes bacterium (DQ463716.2), (12) uncultured Bacteroidetes bacterium (AY874003.1), (13) Gemmatimonadetes bacterium (JQ177808.1). 


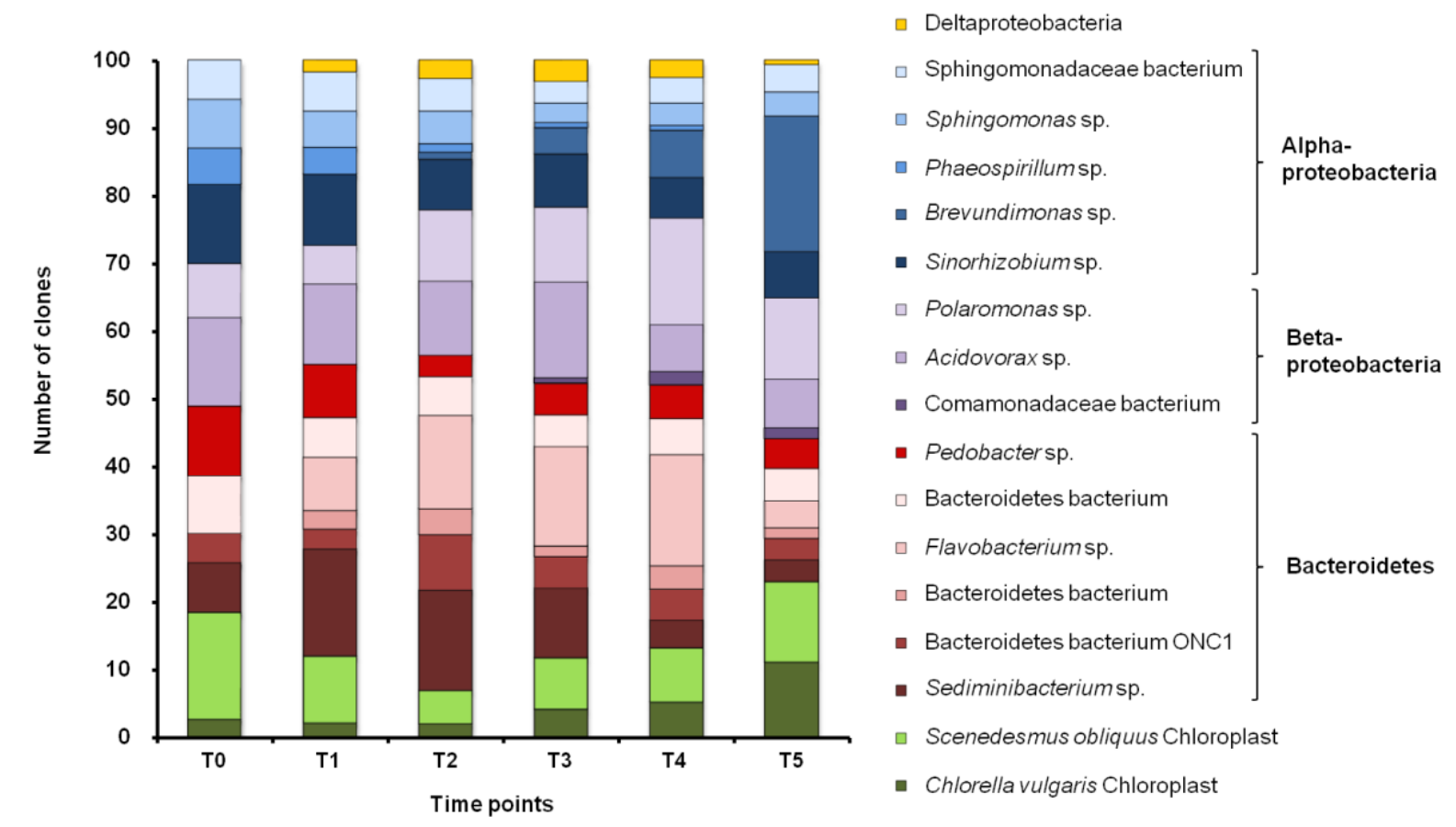

FIGURE S3, Krohn-Molt et al 2013

Fig. S3: Assignment of phylogenetic classes and orders of 16S rRNA sequences from the RFLP analysis. Per sample (T0-T5), 100 clones were analysed. 

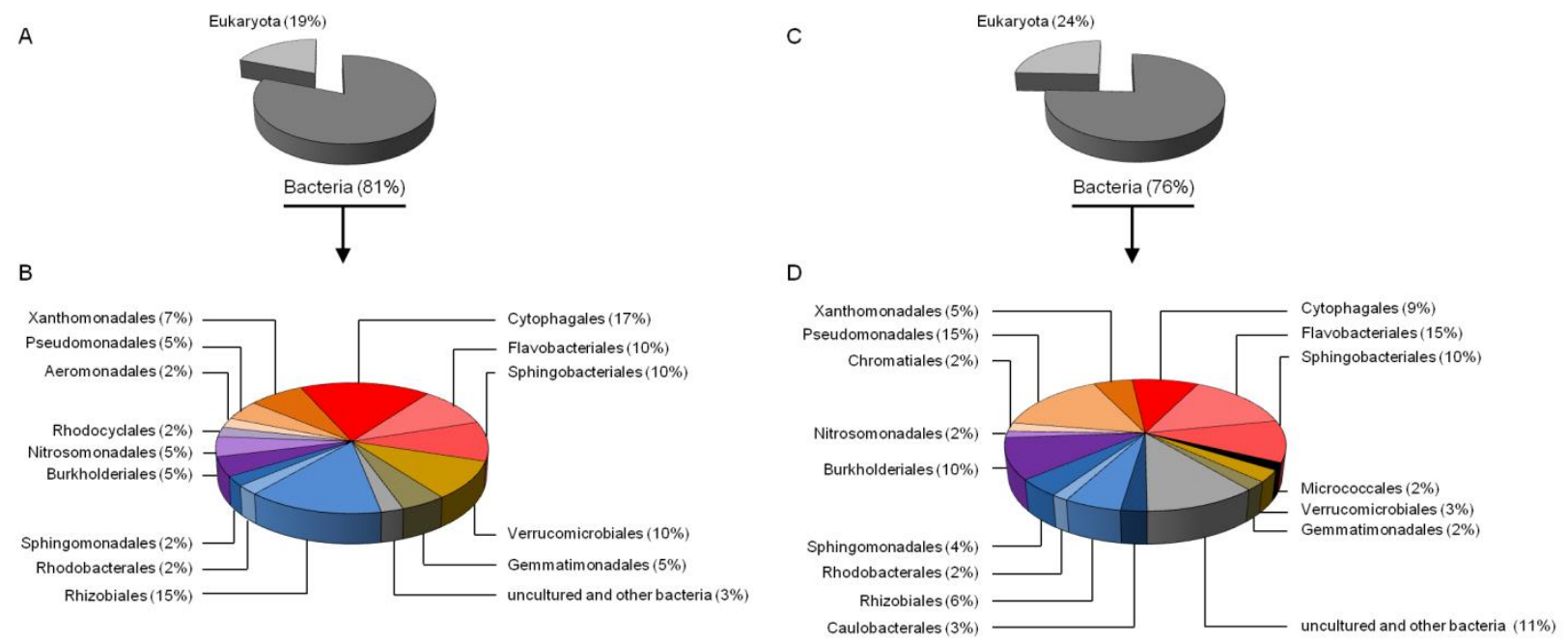

FIGURE S4, Krohn-Molt et al 2013

Fig. S4. Distribution of phylogenetic classes and orders of the metagenome-derived sequences in the PBR biofilm community. A:Overall diversity of 226 sequences from the FLX 454 dataset (Eukaryota 19\%, Bacteria 81\%), B: Phylogenetic classification of the V6 region of the $16 \mathrm{~S}$ rRNAfrom the FLX 454 dataset (41 sequences). Alphaproteobacteria are represented by Sphingomonadales (2\%), Rhodobacterales (2\%), and Rhizobiales (15\%).Betaprotebacteria were composed of Rhodocyclales (2\%), Nitrosomonadales (5\%), and Burkholderiales (5\%).Gammaproteobacteriaconsistedof Xanthomonadales (7\%), Pseudomonadales (5\%), and Aeromonadales (2\%). Bacteroidetes included Cytophagales (17\%), Flavobacteriales (10\%), and Sphingobacteriales (10\%). 10\% could be assigned to Verrucomicrobia(Verrucomicrobiales), and $5 \%$ could be classified asGemmatimonadetes(Gemmatimonadales). C:Overall diversity of 137,506 sequences from the Illumina dataset (Eukaryota 24\%, Bacteria 76\%),D: Phylogenetic classification of the V6 region of the $16 \mathrm{~S}$ rRNA from the Illumina dataset (558 sequences).Alphaproteobacteria are represented by Sphingomonadales (4\%), Rhodobacterales (2\%), Rhizobiales (6\%), and Caulobacterales (3\%). Betaprotebacteria were composed of Nitrosomonadales (2\%), and Burkholderiales (10\%). GammaproteobacteriaconsistedofXanthomonadales (5\%), Pseudomonadales (15\%), and Chromatiales (2\%). Bacteroidetes included Cytophagales (9\%), Flavobacteriales (15\%), and Sphingobacteriales (10\%). 2\% were represented by Actinobacteria(Micrococcales). $3 \%$ could be assigned to Verrucomicrobia(Verrucomicrobiales), and $2 \%$ could be classified asGemmatimonadetes(Gemmatimonadales).Phylogenetic groups accounting for $<1 \%$ of the sequences and sequences which were not assigned to a specific taxonomic group were summarized in the artificial groups "uncultured and other bacteria". 


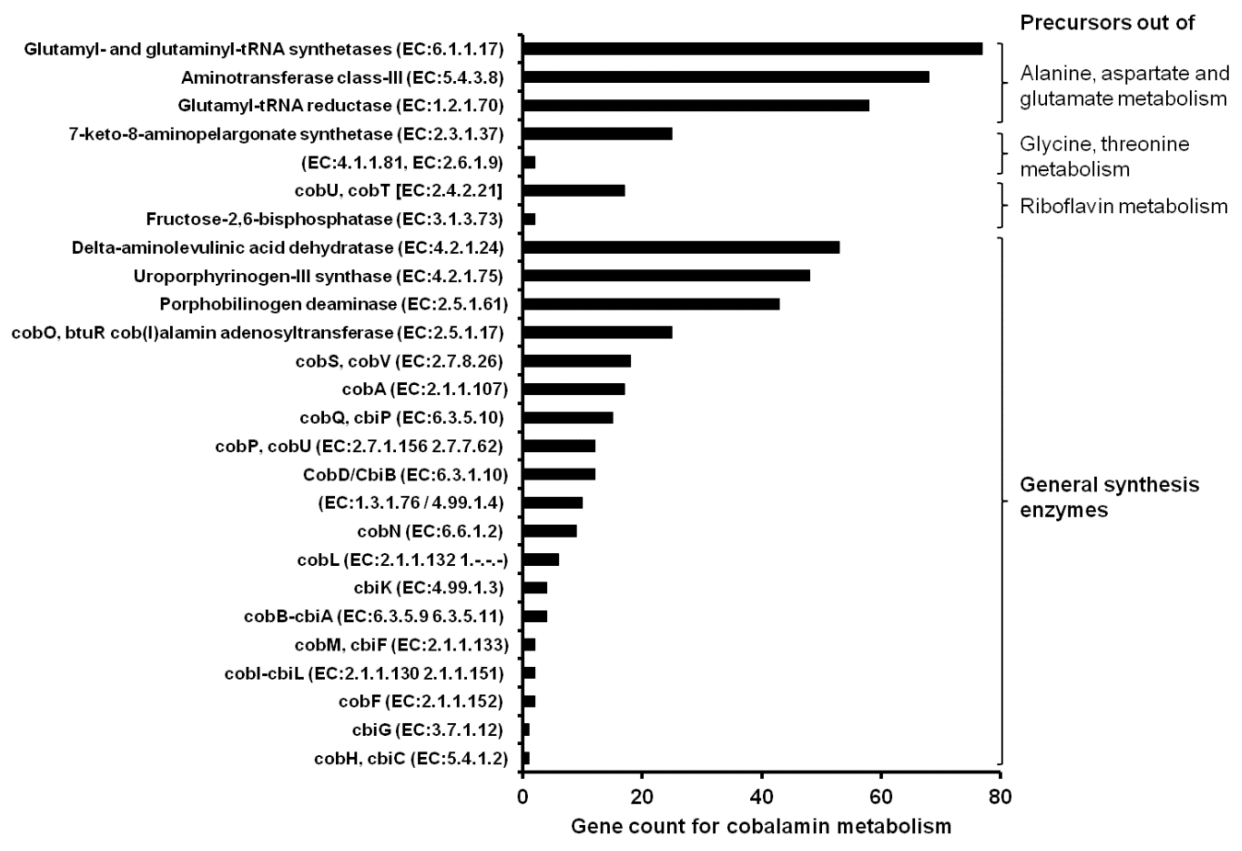

FIGURE S5, Krohn-Molt et al 2013

Fig. S5. Gene count for cobalamin metabolism. Analysis of the metagenome-derived sequences was done using the KEGG database. In total 533 sequences were assigned to the metabolism cobalamin. 


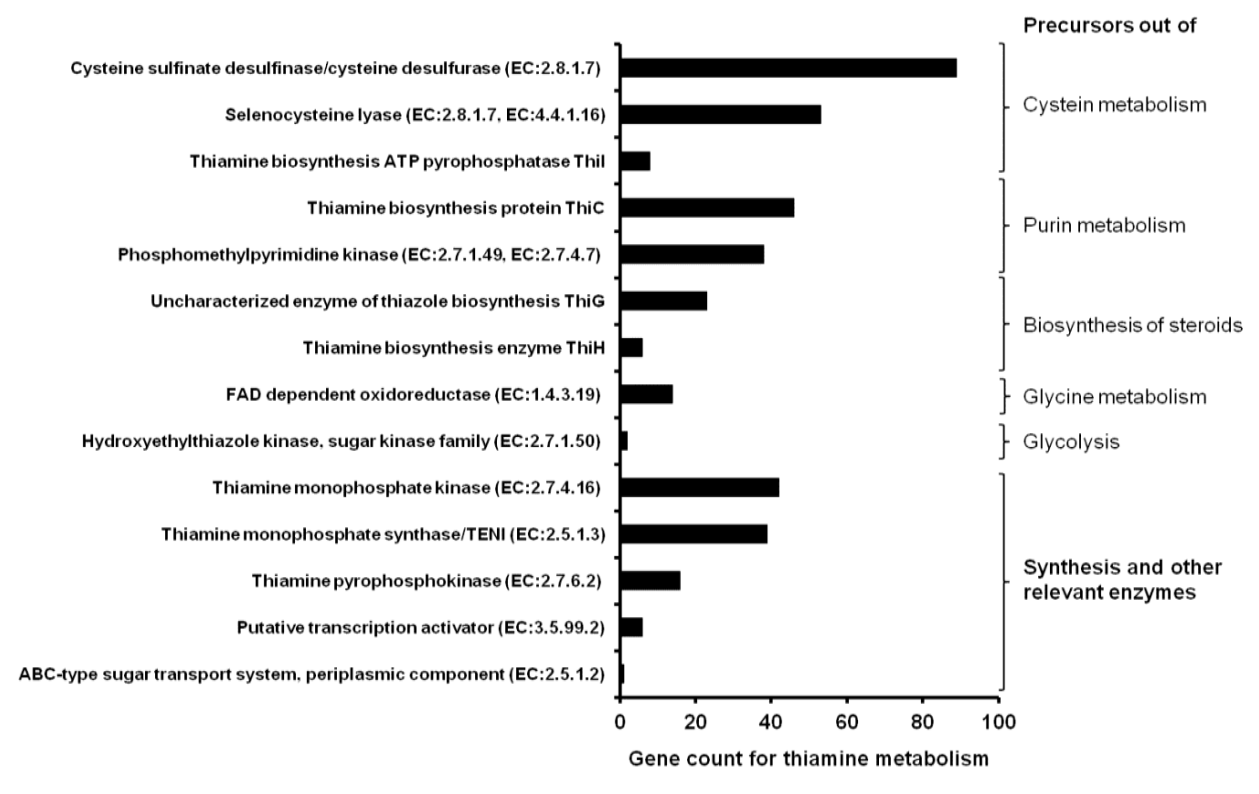

FIGURE S6, Krohn-Molt et al 2013

Fig. S6: Gene count for thiamine metabolism. Analysis of the metagenome-derived sequences was done using the KEGG database. In total 383 sequences were assigned to the metabolism of thiamine. 


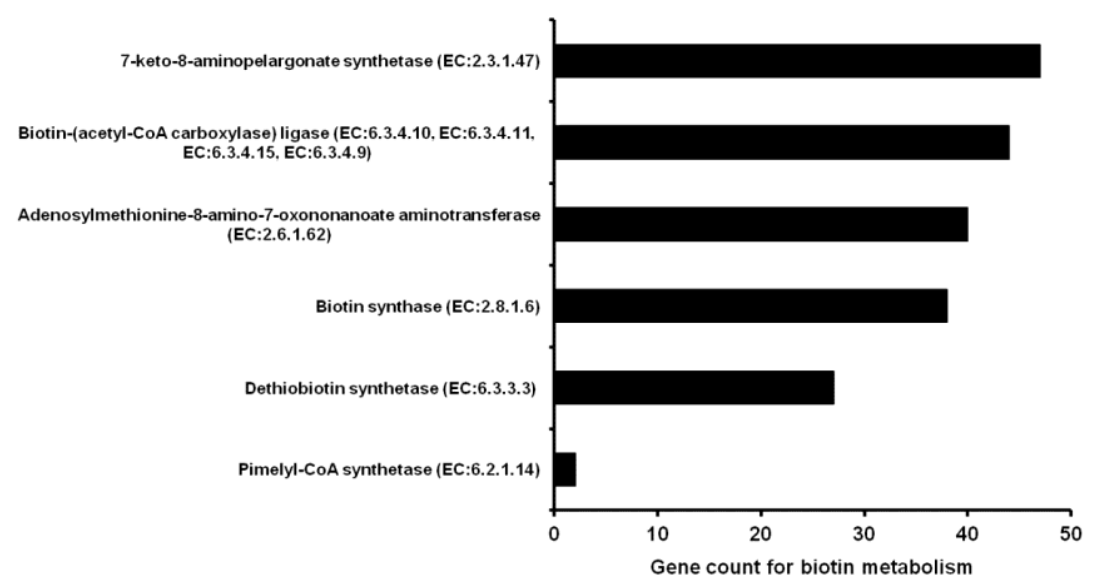

FIGURE S7, Krohn-Molt et al 2013

Fig. S7: Gene count for biotin metabolism. Analysis of the metagenome-derived sequences was done using the KEGG database. In total 198 sequences were assigned to the various biosynthesis steps of the vitamer biotin. 
SUPPLEMENTAL TABLES

TABLE S1.Phylogenetic analysis of 171 16S rRNA clones sequences derived from thebiofilm's fully established microbial community (T5).

$\begin{array}{llll}\text { Phyla/Class Sequence count } & \text { Order/Family }\end{array}$

\begin{tabular}{|c|c|c|c|}
\hline Alphaproteobacteria & 48 & Sphingomonadales & 12 \\
\hline & & Rhodobacterales & 7 \\
\hline & & Rhodospirillales & 3 \\
\hline & & Rhizobiales & 15 \\
\hline & & Caulobacterales & 11 \\
\hline Betaproteobacteria & 26 & $\begin{array}{l}\text { Burkholderiales } \\
\text { uncultured }\end{array}$ & 15 \\
\hline & & Comamonadaceae & 11 \\
\hline Deltaproteobacteria & 6 & $\begin{array}{l}\text { Desulfovibrionales } \\
\text { uncultured }\end{array}$ & 3 \\
\hline & & Deltaproteobacteria & 3 \\
\hline Gammaproteobacteria & 19 & $\begin{array}{l}\text { Xanthomonadales } \\
\text { uncultured }\end{array}$ & 16 \\
\hline & & Gammaproteobacteria & 3 \\
\hline & & Flavobacteriales & 10 \\
\hline & & $\begin{array}{l}\text { Cytophagales } \\
\text { uncultured }\end{array}$ & 5 \\
\hline & & Bacteroidetes & 13 \\
\hline Actinobacteria & 9 & Acidimicrobiales & 2 \\
\hline & & $\begin{array}{l}\text { Actinomycetales } \\
\text { uncultured }\end{array}$ & 3 \\
\hline & & Actionobacteria & 4 \\
\hline Planctomycetes & 7 & Planctomycetales & 7 \\
\hline Verrucomicrobia & 5 & uncultured & \\
\hline Chloroflexi & 3 & $\begin{array}{l}\text { Verrucomicrobia } \\
\text { uncultured }\end{array}$ & 5 \\
\hline & & Chloroflexi bacterium & 3 \\
\hline unknown Bacteria & 4 & Candidate division & \\
\hline & & $\begin{array}{l}\text { OP10 bacterium } \\
\text { uncultured }\end{array}$ & 2 \\
\hline & & TM7 bacterium & 2 \\
\hline
\end{tabular}


TABLE S2.Bacteria cultivated from the PBR microbial community on solid media.

\section{Bacterial Isolate Closest relatives}

$16 S$ rRNA gene

identity (\%)

\begin{tabular}{lll}
\hline & & \\
A & Brevundimonassp. (JQ661035.1) & 94 \\
B & Paracoccussp. (JQ404485.1) & 96 \\
C & Chryseobacteriumtaichungense(JQ071521.1) & 99 \\
D & Brevibacteriumsp. / Arthrobacter sp. (GQ199748.1) & 99 \\
E & uncultivated / Roseomonassp. (HQ588850.1) & 78 \\
F & uncultivated CFB affiliated bacterium (AJ583211.1) & 96 \\
G & Xanthomonassp. (EU887990.1) & 99 \\
H & Rhodococcussp. (EU041710.1) & 99 \\
\hline
\end{tabular}




\title{
STUDY 9:
}

\section{IMPACT OF GRASSLAND MANAGEMENT REGIMES ON BACTERIAL ENDOPHYTE DIVERSITY DIFFERS WITH GRASS SPECIES AND SEASON}

\author{
WeMHEUER $\mathrm{F}^{1}$, KRETZSCHMAR D ${ }^{1}$, WEMHEUER $\mathbf{B}^{2}$, DANIEL $\mathrm{R}^{2}$, AND \\ VIDAL $S^{1}$
}

(IN PREPARATION)

${ }^{1}$ DePARTMENT OF CROP SCIENCES, GEORG-AUguSt-UniVERSITY GÖTtINGEN, GrisebACHSTR.6, D-37077 GÖTTINGEN, GERMANY; ${ }^{2}$ InSTITUTE OF MiCROBIOLOGY And Genetics, GeORG-August-University Göttingen, Grisebachstr. 8, D37077 GÖTTINGEN, GERMANY

Author contributions to the work:

Performed the experiments: FW, DK

Analyzed data: FW, BW

Wrote the publication: FW, RD, SV

Conceived and designed the experiments: FW, SV 


\section{Abstract}

Most plant species are colonized by a diverse number of microorganisms including endophytic bacteria. Despite their importance for plant health and yield, the response of these bacteria to grassland management regimes is still largely unexplored. This study aimed at assessing the bacterial endophytic community structure in the agricultural important grass species Lolium perenne L., Dactylis glomerata L., and Festuca rubra L. with regard to different fertilizer and mowing treatments. For that purpose, above-ground plant material from the Grassland Management Experiment (GrassMan) in Germany was collected in September 2010 and 2011. To evaluate seasonal effects, additional samples were taken in April and July 2011. DNA was extracted from the plant material and subjected to $16 \mathrm{~S}$ rRNA gene PCRs. The endophytic community structure was subsequently studied by Denaturing Gradient Gel Electrophoresis (DGGE). Management regimes did not impact the endophytic community structure in the grasses in the same manner. Fertilization and mowing frequency significantly altered the endophytic communities in L. perenne and F. rubra but not in D. glomerata. On the other hand, season significantly affected the community structure in all three grass species. Moreover, as community structures were subjected to temporal variations, the recorded impact of management regimes differed between the two investigated years.

\section{Introduction}

Almost all plant species are colonized by a high number of microorganisms including endophytic bacteria (Senthilkumar et al., 2011). Endophytic bacteria are defined as bacteria that can be extracted from within plants or isolated from surfacedisinfested plant tissue, and that have no visibly harmful effects on the plant (Hallmann et al., 1997). They are found in a wide range of plants (Sturz et al., 2000).

Many biotic factors including plant species, plant age, plant tissue, or the presence of phytopathogenic fungi, as well as abiotic factors such as soil conditions, temperature, or crop rotation influence the bacterial endophytic community (e.g., Hallmann et al., 1997; FuentesRamírez et al., 1999; Sessitsch et al., 2002; Seghers et al., 2004; Hardoim et al., 2012). Moreover, plant species vary in their biochemical composition, which may affect the endophytic bacterial community (Hallmann \& Berg, 2006). As endophytic bacteria rely on the nutritional supply offered by the plant, any factor influencing the nutritional or physiological status of the plant may consequently have an impact on the endophytic community (Hallmann et al., 1997; FuentesRamírez et al., 1999).

Several endophytic bacteria have been reported to promote plant growth, plant yield, and the overall plant health by a number of mechanisms. These include the production of phytohormones and antibiotics (Bacon \& Hinton, 2006; Compant et al., 2010) as well as enhanced nutrient availability and nitrogen fixation (Stoltzfus et al., 1997; Rosenblueth \& Martinez-Romero, 2006). Furthermore, plants infected with endophytic bacteria have a higher resistance to plant pathogens (e.g., Hallmann et al., 1998; Hallmann, 2001; Krechel et al., 2002; Siddiqui \& Shaukat, 2003; Compant et al., 2005) and environmental stresses (Sturz \& Nowak, 2000; Bacon \& Hinton, 2006; Bacon \& Hinton, 2011).

Although their important role in agricultural cropping systems is frequently appreciated (e.g., Hallmann et al., 1997; Kobayashi \& Palumbo, 2000; Bacon \& Hinton, 2006; Maksimov et al., 2011; Senthilkumar et al., 2011), the diversity of interactions between endophytic bacteria, plant species, and management regimes is not fully understood. Previous studies on the impact of different management regimes, such as fertilizer application, have mainly focused on root endophytic bacteria (Tan et al., 2003; Seghers et al., 2004; Kuklinsky-Sobral et al., 2005), and nitrogen-fixing (diazotrophic) bacteria (FuentesRamírez et al., 1999; Sturz et al., 2000; Tan et al., 2003; Doty et al., 2009; Prakamhang et al., 2009).

The aim of this study was to investigate the influence of combined fertilizer applications and mowing regimes as well as the effect of season on the overall diversity of bacterial endophytes in three abundant and important agricultural grass species (Dactylis glomerata L., Festuca rubra L., and Lolium perenne L.). We hypothesized (1) that the overall endophytic community structure is different between the three examined grass species as the grasses differ in their physiological state. We further hypothesized (2) that the overall bacterial endophytic community structure of the investigated grasses is influenced by fertilizer application and different mowing frequencies as these management regimes affect the host plants and, thus, indirectly 
the endophytes in the grasses. Moreover, we hypothesized (3) that the endophytic community in the grass species is influenced by season as the physiological state of the plant is altered with season.

For this purpose, above-ground plant material was taken from the Grassland Management Experiment (GrassMan), a long-term experimental field on a semi-natural, moderately species-rich grassland site. The aim of this experiment was to investigate the effects of fertilizer application, mowing frequencies, and sward composition on diversity and ecosystem functioning. For this purpose, ten samples per grass species and plot were collected in both September 2010 and 2011. To investigate the influence of season on the endophytic communities, 10 samples per grass species were collected from fertilized plots in April and July 2011. DNA was extracted from the plant material and subjected to 16S RNA gene PCR. Obtained PCR products were subsequently studied by DGGE analysis. In addition to the cultureindependent approach, non-specialized endophytes were isolated from the grass species and classified by $16 \mathrm{~S}$ rRNA gene analysis.

\section{Materials and Methods}

\section{Study site}

The Grassland Management Experiment (GrassMan) is a long-term field experiment with different management intensity treatments. It was established in spring 2008 at a semi-natural, moderately species-rich grassland site in the Solling Mountains in Lower Saxony, central Germany (51 44'53" N, 9³2'43" E, $490 \mathrm{~m}$ a.s.l.). At least since the late $19^{\text {th }}$ century, this grassland site has been traditionally used as pasture or for hay making (Geological Map of Prussia 1910 (based on the topographic inventory of 1896), topographic maps of Sievershausen and Neuhaus/Solling 1924, 1956 and 1974). The pasture has been improved by annual fertilization ( $80 \mathrm{~kg} \mathrm{~N} \mathrm{ha}^{-1} \mathrm{yr}^{-1}$ ), liming, and overseeding with high value forage species (farm records Relliehausen since 1966). The moderate fertilization stopped two years before the first experiments started. The vegetation consists of a nutrient poor, moderately wet Lolio-Cynosuretum (Petersen et al., 2012). The mean annual temperature is $6.9^{\circ} \mathrm{C}$ and the mean annual precipitation is $1028 \mathrm{~mm}$ (Deutscher Wetterdienst 1960-1990, Station Silberborn-Holzminden, 440 m a.s.1.). During the study period, mean temperature and precipitation were $11.42^{\circ} \mathrm{C}$ and $93.6 \mathrm{~mm}$ in September $2010,11.26^{\circ} \mathrm{C}$ and $41.75 \mathrm{~mm}$ in April $2011,14.48^{\circ} \mathrm{C}$ and $110.85 \mathrm{~mm}$ in July 2011 , and $14.75^{\circ} \mathrm{C}$ and $54.75 \mathrm{~mm}$ in September 2011, respectively. The dominating soil type of the experimental area has been determined as a shallow (40-60 cm), stony Haplic Cambisol (Keuter et al., 2013) with a $\mathrm{pH}_{\mathrm{KCl}}$ ranging from 4.18 to 5.47.

\section{Experimental design}

The three-factorial design of this study included two mowing frequencies (once per year in July vs. three times per year in May, July, and September) and two fertilizer treatments (no vs. NPK fertilizer application). All plots were cut to a height of $7 \mathrm{~cm}$ with a Haldrup ${ }^{\circledR}$ harvester. The $\mathrm{N}$ fertilizer was applied as calcium ammonium nitrate N27 in two equal doses (180 kg N ha $\left.{ }^{-1} \mathrm{yr}^{-1}\right)$ in April and end of May. In addition, $30 \mathrm{~kg} \mathrm{P}^{-1} \mathrm{yr}^{-1}$ plus $105 \mathrm{~kg} \mathrm{~K}^{-}$ $1 \mathrm{yr}^{-1}$ as Thomaskali® $\left(8 \% \mathrm{P}_{2} \mathrm{O}_{5}, 15 \% \mathrm{~K}_{2} \mathrm{O}\right.$, $20 \% \mathrm{CaO}$ ) were also applied at the end of May. A third parameter manipulated was the sward composition (monocot-reduced, dicot-reduced, species-rich). This was achieved by selective herbicide application which either reduced dicot (Mecoprop-P and Fluroxypyr/ Triclopyr; 31 ha $^{-1}$ each) or monocot species diversity (Clethodim; $\left.0.51 \mathrm{ha}^{-1}\right)$. One third of the plots was left untreated as control (species-rich). The application of herbicides took place on $31^{\text {st }}$ July 2008 resulting in significant changes in species richness and in functional group abundances (Petersen et al., 2012). Each treatment was replicated six times, resulting in 72 plots of $15 \times 15 \mathrm{~m}$ size arranged in a Latin rectangle.

\section{Sampling}

Above-ground plant material was collected on $19^{\text {th }}$ September 2010 and on $12^{\text {th }}$ September 2011 (shortly before the third annual mowing application) from dicot-reduced plots. To investigate seasonal effects on the bacterial endophytic community structure in the three investigated grass species, samples from the intensively managed (fertilized, thrice mown), dicot-reduced plots were additionally collected on $12^{\text {th }}$ April 2011 (prior to fertilizer application or mowing) and on $18^{\text {th }}$ July 2011 (after fertilizer application and shortly before the second annual mowing application). Ten plants per grass species and plot were randomly selected for sampling, with one exception: due to the low number of $L$. perenne in the plots mown once a year in September 2010, 
above-ground plant material was collected only from two non-fertilized and from three fertilized plots.

Collected plants did not show obvious disease symptoms, such as leaf spots, chlorosis, or other types of pathogen-induced lesions. Following cutting of above-ground plant material with sterilized scissors, the collected plant samples were immediately cooled down (below $4^{\circ} \mathrm{C}$ ), transported to the laboratory, and kept frozen at $-80^{\circ} \mathrm{C}$ until further use. Plant material derived from the same plot and plant species was pooled prior to DNA extraction.

\section{Surface sterilization of plants}

Surface-sterilization of plant tissues was performed according to Schulz et al. (1993), with slight modifications. Plant material was immersed in $37 \%$ formaldehyde for $3 \mathrm{~min}$ and rinsed two times with autoclaved and sterile-filtered water. To remove DNA, samples were rinsed with DNA-Exitus (Applichem, Darmstadt, Germany) for $30 \mathrm{~s}$ and subsequently washed three times in autoclaved and sterile-filtered distilled water. The surface-sterilized plant material was triturated with an autoclaved mortar and pestle or directly used for an isolation experiment. Until DNA extraction, the powdered samples were stored at $-80^{\circ} \mathrm{C}$.

\section{Isolation of non-specialized endophytes}

For the isolation experiment, surface-sterilized plant material from 9 plots (at least 2 of each treatment) was cut into several pieces of approximately 5 to $15 \mathrm{~mm}$ length. Ten to 15 plant fragments were placed on malt extract agar (MEA), Luria-Bertani-Agar (LB), and potato dextrose agar (PDA) plates. Moreover, at least 10 plant fragments were incubated in $1 \mathrm{~mL} \mathrm{NaCl}$-solution (1\% (w/v). The tubes were extensively shaken for $10 \mathrm{~s}$ and then incubated for 20 to $30 \mathrm{~min}$. Prior to shaking, five to six glass beads $(3 \mathrm{~mm})$ were added to increase the extraction efficiency. $400 \mu \mathrm{l}$ of the resulting solution were pipetted onto an agar plate. The plates were incubated in the dark at $25^{\circ} \mathrm{C}$ for at least two weeks. Colonies were further cultivated in liquid culture (LB media). After one day growing at $25^{\circ} \mathrm{C}$, DNA was extracted using the peqGold Plant DNA Mini Kit (Peqlab, Erlangen, Germany) were subjected to PCR-based amplification targeting the bacterial 16S rRNA gene.

\section{Amplification of the 16S rRNA genes of isolated endophytic strains}

PCR amplification of bacterial 16S rRNA genes was performed with the primers $8 \mathrm{~F}$ 5'AGAGTTTGATCMTGGC-3 (Muyzer et al., 1995) and 1114R 5'-GGGTTGCGCTCGTTRC-3' (Wilmotte et al., 1993). The PCR reaction mixture $(25 \mu \mathrm{l})$ contained $2.5 \mu \mathrm{l}$ of 10 -fold $\mathrm{Mg}$-free Taq polymerase buffer (Fermentas), $200 \mu \mathrm{M}$ of each of the four desoxynucleoside triphosphates, $2 \mathrm{mM}$ $\mathrm{MgCl}_{2}, 0.4 \mu \mathrm{M}$ of each primer, 5\% DMSO, $0.5 \mathrm{U}$ of Taq DNA polymerase (Fermentas), and approximately $10 \mathrm{ng}$ of the DNA sample as template. Negative controls were performed by using the reaction mixture without template. The following thermal cycling scheme was used: initial denaturation at $95^{\circ} \mathrm{C}$ for $2 \mathrm{~min}$ and 25 cycles of: $1 \mathrm{~min}$ at $95^{\circ} \mathrm{C}, 1 \mathrm{~min}$ at $55^{\circ} \mathrm{C}$ and $1.5 \mathrm{~min}$ at $72^{\circ} \mathrm{C}$. The final extension was carried out at $72^{\circ} \mathrm{C}$ for $5 \mathrm{~min}$. The resulting PCR products were checked for appropriate size and then purified using the peqGOLD Gel Extraction Kit (Peqlab) as recommended by the manufacturer. Sequences of the purified PCR products were determined by Sanger sequencing at the Göttingen Genomics Laboratory.

\section{Extraction of total community DNA}

Total microbial community DNA was extracted employing the peqGOLD Plant DNA Mini Kit (Peqlab) according to the manufacturer's instructions with two modifications. Glass beads were used in the first step to grind plant material. Furthermore, $10 \mu \mathrm{l}$ Proteinase $\mathrm{K}\left(20 \mathrm{mg} \mathrm{mL}^{-1}\right)$ were added to improve initial cell lysis. DNA was eluted in $30 \mu \mathrm{l}$ DEPC water.

\section{Amplification of the 16S rRNA genes for DGGE analysis}

For DGGE analysis, a nested PCR approach was applied. In the first PCR, the primers $799 \mathrm{f}$ (AACMGGATTAGATACCCKG) and 1492R (GCYTACCTTGTTACGACTT) were used to suppress co-amplification of plant chloroplast $16 \mathrm{~S}$ rRNA gene DNA (Chelius \& Triplett, 2001). PCR amplification with this primer pair resulted in two PCR products: a mitochondrial product with approximately $1.1 \mathrm{kbp}$ and a bacterial product of approximately $735 \mathrm{bp}$.

The PCR reaction mixture $(25 \mu \mathrm{l})$ for amplification of the target gene contained $2.5 \mu \mathrm{l}$ of 10-fold Mg-free Taq polymerase buffer (Fermentas, St. Leon-Rot, Germany), $200 \mu \mathrm{M}$ of each of the four desoxynucleoside triphosphates, $1.75 \mathrm{mM}$ $\mathrm{MgCl}_{2}, 0.4 \mu \mathrm{M}$ of each primer, 5\% DMSO, $1.5 \mathrm{U}$ 
of Taq DNA polymerase (Fermentas), and approximately $25 \mathrm{ng}$ of the DNA sample as template. Negative controls were performed by using the reaction mixture without template. Three independent PCR reactions were performed per sample and obtained PCR products were pooled in equal amounts. The following thermal cycling scheme was used: initial denaturation at $95^{\circ} \mathrm{C}$ for 5 min and thirty cycles of: $1 \mathrm{~min}$ at $94^{\circ} \mathrm{C}, 1 \mathrm{~min}$ at $53^{\circ} \mathrm{C}$ and $1 \mathrm{~min}$ at $72^{\circ} \mathrm{C}$. The final extension was carried out at $72^{\circ} \mathrm{C}$ for $8 \mathrm{~min}$. The resulting PCR amplicons were electrophoretically separated and bands specific for bacteria were excised from the gel. DNA was subsequently purified using the peqGOLD Gel Extraction Kit (Peqlab) according to manufacturer's instructions.

Purified products were subjected to nested PCR with the primer pair F968-GC (5'AACGCGAAGAACCTTAC-3') and R1401 (5'CGGTGTGTACAAGACCC-3') (Nübel et al., 1996). To prevent complete denaturation of the fragment, a GC-rich sequence (5'CGCCCGCCGCGCCCCGCGCCCGTCCCGCCG CCCCCGCCCG-3') was attached at the 5'- end of the primer F968-GC (Muyzer et al., 1993). The same PCR reaction mixture as for the first PCR was used for nested PCR with one modification: only $1 \mathrm{U}$ of Taq DNA polymerase (Fermentas) was added to the mixture. The thermal cycling scheme of the nested PCR was as follows: initial denaturation at $94^{\circ} \mathrm{C}$ for $5 \mathrm{~min}, 11$ cycles of: $1 \mathrm{~min}$ at $94^{\circ} \mathrm{C}, 1 \mathrm{~min}$ at $60^{\circ} \mathrm{C}$ (minus $1^{\circ} \mathrm{C}$ per cycle) and $2 \mathrm{~min}$ at $72^{\circ} \mathrm{C}$, followed by 17 cycles of: $1 \mathrm{~min}$ at $94^{\circ} \mathrm{C}, 1 \mathrm{~min}$ at $53^{\circ} \mathrm{C}$ and $2 \mathrm{~min}$ at $72^{\circ} \mathrm{C}$. The final extension was carried out at $72^{\circ} \mathrm{C}$ for $10 \mathrm{~min}$. The resulting PCR products were checked for appropriate size by agarose gel electrophoresis. Three independent PCR reactions were performed per sample and obtained PCR products were pooled in equal amounts.

Denaturing Gradient Gel Electrophoresis (DGGE) To investigate the bacterial endophytic diversity, the products derived from 16S rRNA gene PCRs were studied by DGGE analysis. DGGEs were carried out by using a PhorU2 machine (Ingeny, Goes, the Netherlands) with a double gradient. The first gradient ranged from 55 to $68 \%$ denaturant with a second gradient of 6.2 to $9 \%$ acrylamide. The acrylamide gradient was applied to enhance band sharpness and resolution (Cremonesi et al., 1997). The denaturant (100\%) contained $7 \mathrm{M}$ urea and $40 \%$ formamide. Approximately $100 \mathrm{ng}$ of the
PCR product were loaded. The DGGE run was performed in 1xTris-acetate-EDTA buffer $(40 \mathrm{mM}$ Tris, $20 \mathrm{mM}$ sodium acetate, $1 \mathrm{mM} \mathrm{Na} \mathrm{N}_{2}$ EDTA [pH $7.4])$ at $60^{\circ} \mathrm{C}$. Following electrophoresis for $16 \mathrm{~h}$ at $100 \mathrm{~V}$, the gels were stained for $60 \mathrm{~min}$ with SYBRGold (Invitrogen, Darmstadt, Germany) and subsequently photographed on a UV transillumination table. To compare the reproducibility of the statistical analysis of the DGGE profiles, at least two independent DGGE runs were performed.

\section{DGGE data analysis}

Analysis of DGGE profiles was carried out using the software package GELCOMPAR II, version 5.1 (Applied Math, Ghent, Belgium). Cluster analyses (UPGMA) based on Jaccard correlation indices considering band presence and absence were performed to evaluate the percentage of similarity shared among the samples from the different treatments and sampling dates. Due to the low plant number obtained for L. perenne in September 2010, these data were excluded from the cluster analysis. To further evaluate the impact of management regimes and sampling time, the results of the DGGE were analysed in $\mathrm{R}$ employing the vegan package (version 3.0.1). For this purpose, similarity matrices exported from GelCompare were converted into dissimilarity objects and subsequently analysed by Permutational Multivariate Analysis of Variance Using Distance Matrices (adonis) [http://cran.rproject.org/web/packages/vegan/vegan.pdf].

\section{Identification of abundant bacterial community members by $D G G E$}

To identify the most abundant members of the bacterial endophytic community, several dominant bands were excised from DGGE gels, re-amplified, and sequenced. Excised bands were incubated in $30 \mu l$ sterile TE buffer ( $\mathrm{pH} 8$ ) overnight at $4^{\circ} \mathrm{C}$. One $\mu l$ of the resulting solution was subjected to PCR reaction to re-amplify the $16 \mathrm{~S}$ rRNA gene fragment. The PCR was performed as described for the nested PCR reaction with one exception: the forward primer F968 did not carry the GC clamp. The resulting PCR products were checked for appropriate size and purified using the peqGOLD Gel Extraction Kit (Peqlab) as recommended by the manufacturer. The Göttingen Genomics Laboratory determined the sequences of the purified PCR products by Sanger sequencing. 
Further Analysis of 16S rRNA gene sequences All obtained 16S rRNA gene sequences were further analyzed employing the QIIME software package (version 1.6) (Caporaso et al., 2010) and other tools. The Uchime algorithm implemented in Usearch (version 6.0.152) was initially applied in reference mode to identify and remove putative chimeric sequences using the most recent SILVA database (SSURef $115 \mathrm{NR}$ ) (Quast et al., 2013) as reference dataset. Afterwards sequences were clustered into operational taxonomic units (OTUs) at $99 \%$ genetic similarity by BLAST alignment against the above-mentioned SILVA database using the pick_otus.py script (QIIME). The phylogenetic composition was determined by classifying the sequences with respect to the silva taxonomy of their closest match.

\section{Nucleotide sequence accession numbers}

Nucleotide sequences of the isolated strains and sequenced DGGE bands were deposited in GenBank under accession numbers KF699892 to KF699947 and KF699948 to KF700039, respectively.

\section{Results and Discussion}

\section{Community structure differs with grass species and analysis approach}

To assess endophytic community structures in the three grass species, DNA was extracted from plant material and subjected to $16 \mathrm{~S}$ rRNA gene PCRs. Obtained PCR products were studied by DGGE analysis. DGGE fingerprints revealed patterns with 10 to 20 bands for each sample (Figs. S1-3). Prominent bands were excised and sequenced. Analysis of the obtained sequences revealed that bacterial diversity on class level was lowest and highest in L. perenne and D. glomerata (Fig. 1), respectively. Gammaproteobacteria were the most dominant bacterial phylum in both D. glomerata and F. rubra. This is in agreement with other studies (Chelius \& Triplett, 2001; Sun et al., 2008; Gottel et al., 2011). Endophytic bacteria in L. perenne were dominated by Betaproteobacteria. The second most dominant groups were Bacilli (D. glomerata), Betaproteobacteria (F. rubra), or Gammaproteobacteria (L. perenne). Within the Gammaproteobacteria, we identified Pseudomonas as the most common genus (Table S1). One interesting species identified was Herbaspirillum seropediacae which is known as a nitrogen-fixing endophyte in sorghum, maize, sugarcane, and other plants (Baldani et al., 1986; Olivares et al., 1996).

We further examined how similar/dissimilar the endophytic communities are between the three investigated grass species. The number of calculated operational taxonomic units (OTUs) shared between the species was lower than the number exclusively found in one species (Fig. 2) which may refer to the different physiological states of the grass species investigated. Whereas 10 of the 29 identified OTUs of D. glomerata were also detected in F. rubra and L. perenne, the latter species shared 7 OTUs. Only 5 OTUs were found being present in all three grass species: one uncultured bacterium of the Comamonadaceae, Staphylococcus aureus, S.epidermidis, Janthinobacterium lividum, and Pseudomonas balearica (Table S1). The recorded findings support our first hypothesis that the grass species differ in their endophyte community structure. This is in accordance with a study of McInroy and Kloepper (1995A) who found differences in the

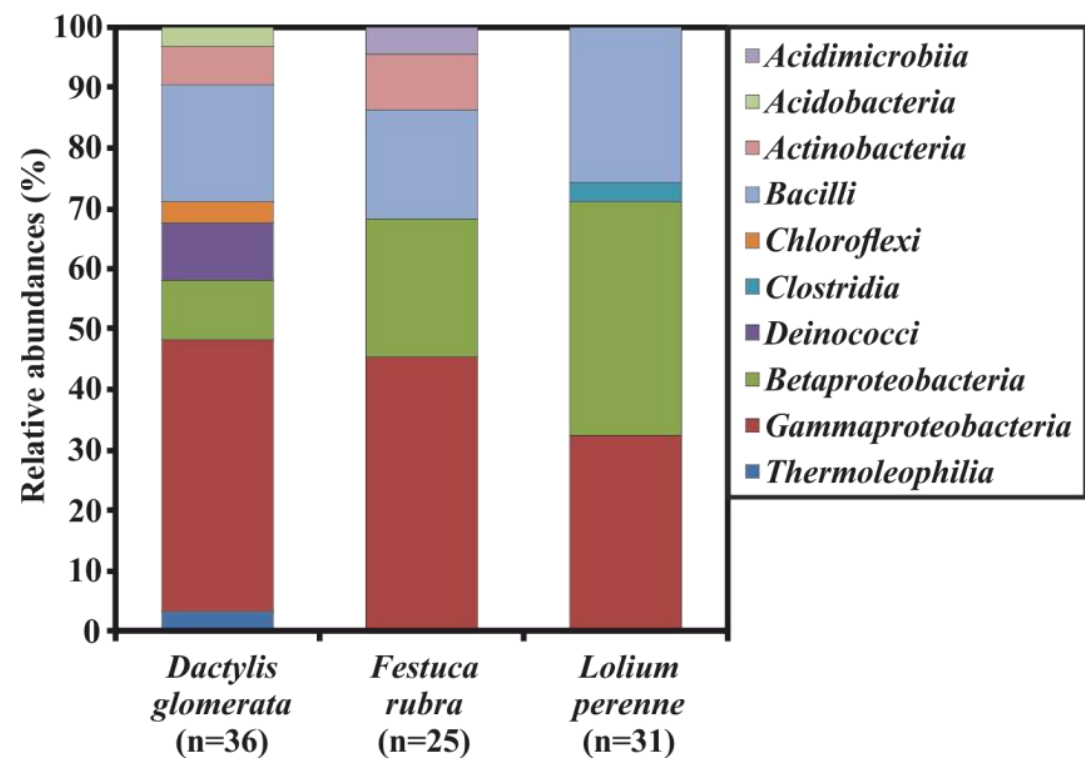

Fig. 1. Composition of the endophytic bacterial communities in the three grass species as revealed by sequencing of prominent DGGE bands. The number below the species name refers to the number of $16 \mathrm{~S}$ rRNA genes sequences used in the analysis. 


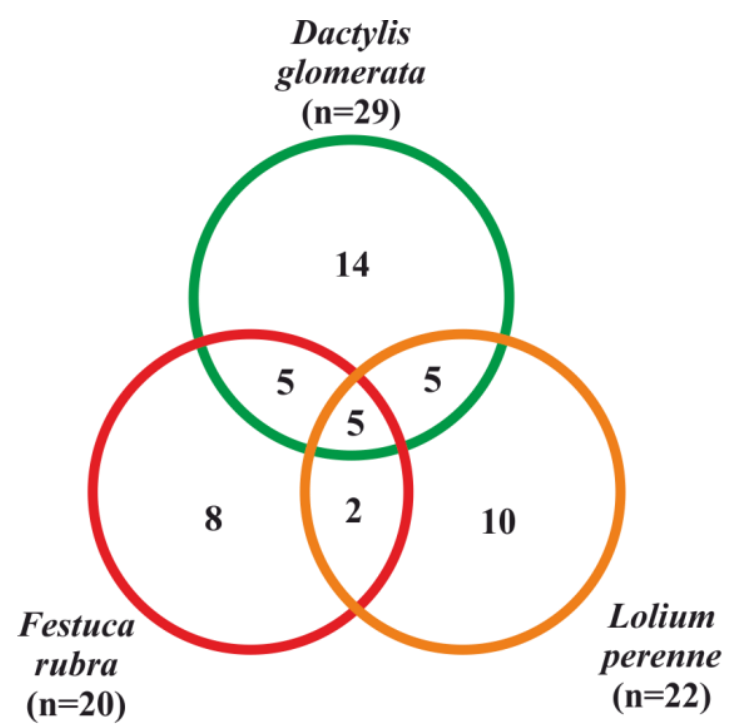

Fig. 2. Number of shared operational taxonomic units (OTUs) at $1 \%$ genetic distance. The number below the species name refers to the number of OTUs used in the analysis.

bacterial endophyte population in field-grown sweet corn and cotton grown side by side. They suggested that internal plant niches are colonized by a wide variety of bacteria. According to Hallmann (2001), the differences in bacterial endophytic community structures between different plant species growing next to each other can only be explained by plant species-specific selection mechanisms. Different plant species vary in their biochemical composition, which may affect bacterial endophyte community (Hallmann \& Berg, 2006).

Moreover, the spectrum of indigenous endophytic bacteria in roots is not only affected by niche specialization, but also by differences in colonization pathway (Hallmann \& Berg, 2006). According to Hallmann and Berg (2006), the soil and the rhizosphere are the main sources of endophytic colonizers. Many bacteria in these environments are able to penetrate and colonize root tissues (Quadt-Hallmann et al., 1997; Reinhold-Hurek \& Hurek, 1998). Plant wounding either by abiotic (e.g., tillage, extreme temperature fluctuations) or by biotic factors (e.g., fungi, plant-parasitic nematodes, insects) can also result in microbes entering the plant tissue (reviewed in Siddiqui \& Shaukat, 2003). Other possible sources for endophytic bacteria include the anthosphere, the seeds, and the phyllosphere (Hallmann et al., 1997; Hallmann, 2001; Compant et al., 2010).
We also tried to assess the endophytic community structure by isolating strains from the three grass species. The most dominant groups isolated from the grasses were members of the Bacilli and Gammaproteobacteria, with Pseudomonas and Bacillus being the most abundant genera (Table S1). This is in accordance with other studies (as reviewed in Hallmann \& Berg, 2006). However, a comparison of OTUs calculated for the $16 \mathrm{~S}$ rRNA gene datasets obtained from the culturing-dependent and from the culturingindependent approach exhibited no overlap of the endophytic communities (Table S1). Consequently, the isolated strains do not necessarily represent the dominant endophytes in the three grasses which is supported by other studies (e.g., Chelius \& Triplett, 2001; Garbeva et al., 2001; Araujo et al., 2002; Conn \& Franco, 2004). For example, Araujo et al. (2002) showed that some endophytic bacteria in citrus plants were only observed by DGGE and not by the culture-dependent approach. In a study with potato plants, several non-culturable or so far uncultured endophytic organisms were detected. According to Chelius and Triplett (2001), the culturable component of the bacterial community reflected a community composition different from that of the clone library. Thus, only the community structures assessed by the metagenomic approach were further examined for their response to different management regimes and season.

\section{Fertilizer application and mowing regimes differently shape bacterial endophytic community composition in D. glomerata, L. perenne, and F. rubra}

In order to validate our second hypothesis that different fertilizer application and mowing regimes alter the bacterial endophytic communities, we compared DGGE band patterns with respect to the different management practises. UPGMA dendrograms of endophytic bacterial communities in D. glomerata, L. perenne, and F. rubra revealed differences with regard to fertilizer treatments and mowing frequencies (Figs. 3-5). Plants of D. glomerata sampled in September 2010 (Fig. 3A) and 2011 (Fig. 3B) did not cluster with respect to the applied management regimes. Furthermore, a significant influence of fertilizer application or mowing frequency was not recorded (Table 1). In contrast to D. glomerata, cluster analysis for F. rubra revealed a strong impact of the fertilizer treatment on bacterial endophytic community in September 2010 (Fig. 4A), but to a lesser extend in 
A

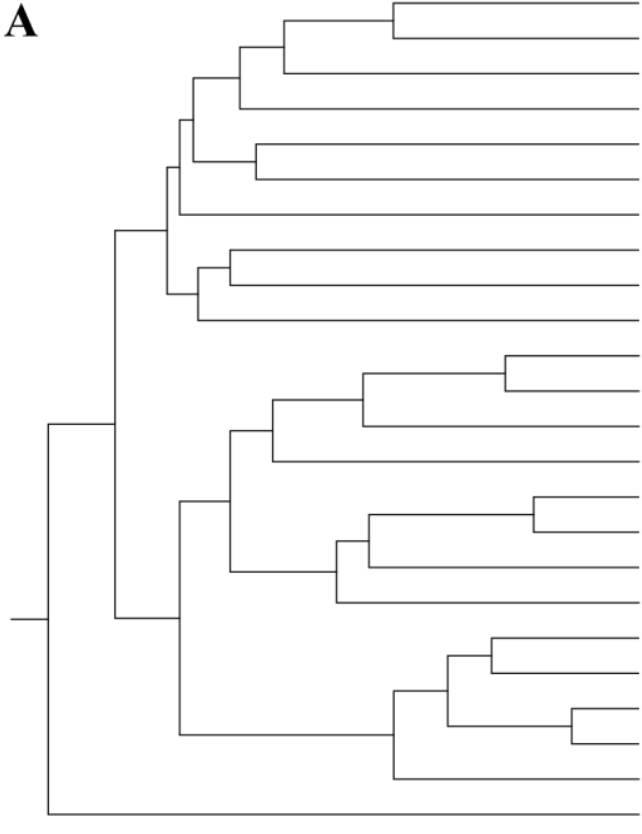

20

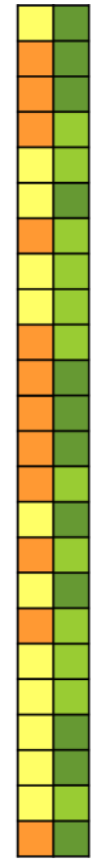

B

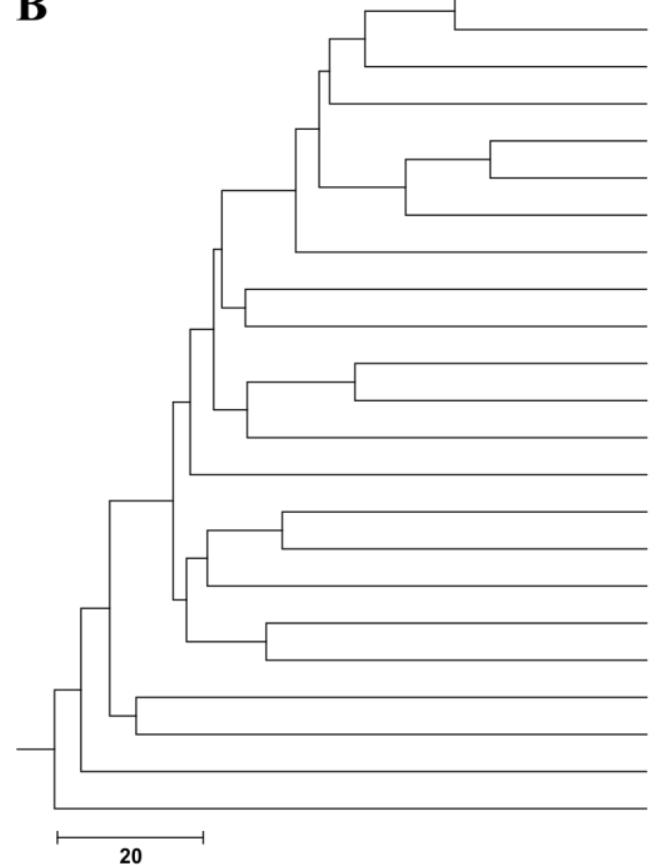

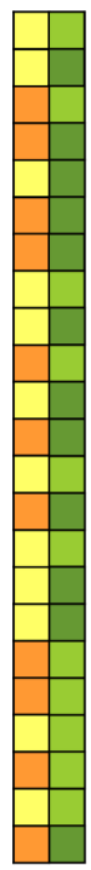

Fertilized: no $\square$ yes $\square \quad$ Mowing: once $\square$ three times $\square$

Fig. 3. UPGMA dendrogram generated by cluster analysis of DGGE fingerprints on the influence of different fertilization and mowing regimes on bacterial endophyte communities in above-ground plant parts of $D$. glomerata. Plant samples were taken in September 2010 (A) and 2011 (B). The dendrogram was constructed using the Jaccard correlation coefficient. The scale shows similarity values.

2011 (Fig. 4B). Furthermore, fertilizer application affected the community structure of bacterial endophytes in plants of L. perenne in September 2011 (Fig. 5). Such clear patterns were not recorded for the mowing regime. These results are in concordance with the statistical evaluation: fertilization and the interaction of fertilizer application and mowing frequency but not of mowing itself significantly influenced the structure of the endophytic community in F. rubra in
September 2010 and in L. perenne in September 2011 (Table 1).

It is well-known that different management practices have an impact on bacterial endophytic communities, but most previous research has focused on root endophytes (Tan et al., 2003; Seghers et al., 2004; Kuklinsky-Sobral et al., 2005) or on nitrogen-fixing (diazotrophic) endophytes (Fuentes-Ramírez et al.; 1999, Sturz et al., 2000; Tan et al., 2003; Doty et al., 2009; Prakamhang et

Table 1. Statistical evaluation of the influence of management regimes and season towards the bacterial endophyte community in D. glomerata, F. rubra, and L. perenne. Abbreviation: Fert.:Mow. = the interaction of fertilization and mowing.

\begin{tabular}{|c|c|c|c|c|c|c|}
\hline \multirow[t]{2}{*}{ Species } & & \multicolumn{3}{|c|}{ Management regimes } & \multicolumn{2}{|c|}{ Time } \\
\hline & & Fertilization & Mowing & Fert.:Mow. & Season & Year \\
\hline \multirow[t]{3}{*}{ D. glomerata } & 2010 & - & - & - & & \\
\hline & 2011 & - & - & - & & \\
\hline & - & & & & $* * *$ & $* *$ \\
\hline \multirow[t]{3}{*}{ F. rubra } & 2010 & $* *$ & - & $* * *$ & & \\
\hline & 2011 & - & - & - & & \\
\hline & - & & & & $* * *$ & $* * *$ \\
\hline \multirow[t]{3}{*}{ L. perenne } & 2010 & NA & NA & NA & & \\
\hline & 2011 & $*$ & - & $* *$ & & \\
\hline & - & & & & $* * *$ & $* * *$ \\
\hline
\end{tabular}

not significant (-); significant with $\mathrm{P}<0.05(*), \mathrm{P}<0.01(* *)$, and $\mathrm{P}<0.001(* * *)$ 

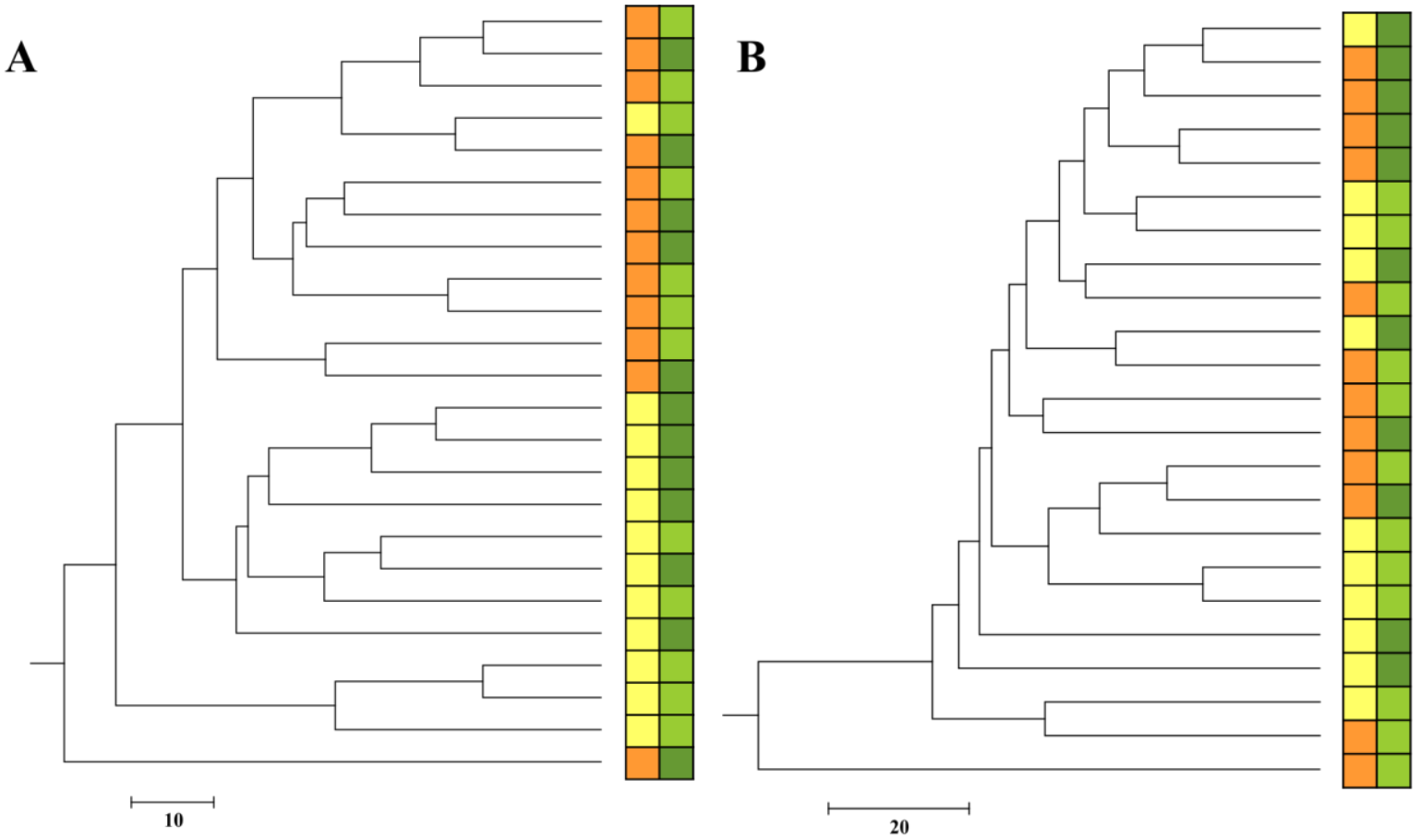

Fertilized: no $\square$ yes $\square \quad$ Mowing: once $\square$ three times $\square$

Fig. 4. UPGMA dendrogram generated by cluster analysis of DGGE fingerprints on the influence of different fertilization and mowing regimes on bacterial endophyte communities in above-ground plant parts of F. rubra. Plant samples were taken in September 2010 (A) and 2011 (B). For details see Fig. 3.

al., 2009). For example, endophytic populations in cotton roots are affected by application of nitrogencontaining chitin as an organic amendment (Hallmann et al., 1999). Moreover, a higher diazotrophic bacterial diversity in the roots of rice cultivated in unfertilized and previously uncultivated soil than in paddy soil amended with nitrogen fertilizer were recorded by Prakamhang $e t$ al. (2009). According to Tan et al. (2003), a rapid change of both the population and the activity of nitrogen-fixing bacteria in rice roots were observed within 15 days after $\mathrm{N}$-fertilization. Although these studies investigated the endophytic community in cotton and rice roots, they are in accordance with the results of the present study. Plant samples of D. glomerata in both years investigated and plant samples of F. rubra taken in September 2011 showed no significant impact of any management regime. This result is concordant with a study of Seghers et al. (2004), which showed that mineral fertilizer as well as herbicide application exhibited no impact on bacterial endophytic community structure in maize kernels. The recorded findings partly support our initial hypothesis as some but not all investigated plant samples were affected by the applied management regimes.

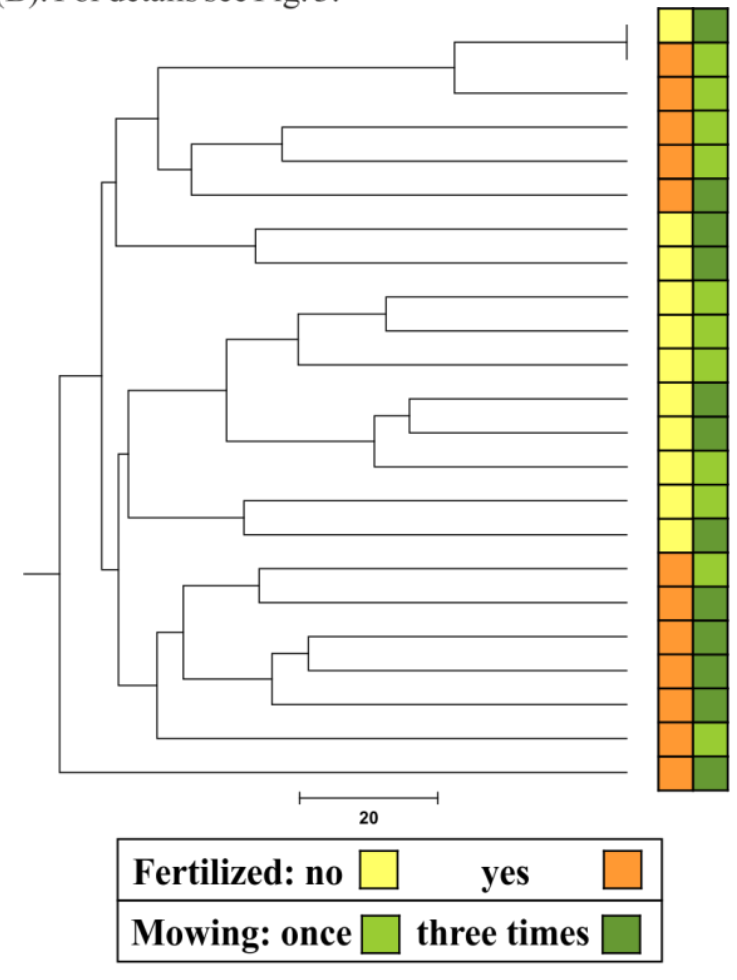

Fig. 5. UPGMA dendrogram generated by cluster analysis of DGGE fingerprints on the influence of different fertilization and mowing regimes on bacterial endophyte communities in above-ground plant parts of L. perenne. Plant samples were taken in September 2011. For details see Fig. 3. 
Moreover, as the recorded effects on endophytic communities were different between the three grass species examined in this study, it is most likely that also the grasses are affected differently by management regimes which is in concordance with our second hypothesis. This was supported by an experiment in the Fraser Valley of British Columbia (Parish et al., 1990). In five consecutive years, the authors investigated the effects of two different fertilizer levels (non-fertilized, fertilized) and four frequencies of mowing on the botanical composition of a pasture. At the end of the study, only D. glomerata was found in all treatments, while the abundance of Lolium spp. declined considerably. Mowing and fertilizer application every 3 weeks had a significant impact on the abundance of all investigated species. Furthermore, there was a significant fertilization - mowing interaction effect on all species except Festuca sp. The authors suggested that the plants differ in their growth rates and tolerance to shading and fertilizer application.

Additionally, the grass species investigated in this study differ in their indicator values such as tolerance against mowing or grazing (Dierschke \& Briemle, 2002). Both D. glomerata and L. perenne have a higher tolerance against mowing compared to $F$. rubra. In contrast, L. perenne shows a higher indicator value for nitrogen than the other two grass species. As mentioned earlier, plants vary in their biochemical composition which might explain differences in the bacterial endophytic community (Hallmann \& Berg, 2006). Hallmann et al. (1999) suggested that changes in plant physiology may result in the development of distinct bacterial endophytic communities. Moreover, endophytic bacteria rely on the nutritional supply offered by their host plant. As a consequence, changes in the nutritional or physiological status of the host plant may have an influence on the plant's endophytic community (Hallmann et al., 1997; FuentesRamírez et al., 1999).

\section{Seasonal impact on the abundance of bacterial endophytic community in the three grass species D. glomerata, F. rubra, and L. perenne}

To verify our third hypothesis that the season has an effect on the bacterial endophytic community structure, we compared DGGE band patterns obtained from plant samples collected in September 2010 and April, July, and September 2011 (Figs. 6 and S4). Band patterns of F. rubra samples taken during the same season clustered together indicating a more similar community composition at the same season (Fig. 6B). Four of the six July samples cluster together with samples taken in September 2011. The other two samples showed higher similarities to samples taken in April 2011 and September 2010. This may indicate that the bacterial community composition in F. rubra followed a within year pattern. Plant species that propagate vegetatively are able to transmit their endophytes to the next generation so that no infection is required (Rosenblueth \& Martinez-Romero, 2006). Festuca rubra is propagated mainly by rhizomes. Therefore, this propagation pattern might explain our findings that endophytic communities were quite similar in July and September 2011 in this grass species.

Moreover, three of the six samples taken in September 2010 and all samples from April 2011 formed a coherent cluster suggesting that they harbor a similar endophytic community. This distinct cluster pattern might be explained by seed transfer although this mechanism was not specifically tested in our study. It is known for some perennial plant species that several bacterial endophytes are seed-borne. These species are transferred from one plant generation to the next through the seeds of many plant species such as tobacco (Mastretta et al., 2009), rice (Hardoim et al., 2012), or Norway spruce (Cankar et al., 2005). In a study of endophytic bacteria in switchgrass, some bacterial species were found in plants that originated from seeds sampled a year earlier (Gagne-Bourgue et al., 2013). The authors regarded this as evidence for a vertical transmission to the next generation within this host plant.

Cluster analysis of the bacterial endophytic community in L. perenne revealed a clear separation of groups based on sampling year and season (Fig. 6C). Samples taken in 2011 formed a coherent cluster and exhibit a higher similarity to each other compared to samples taken in 2010. This finding suggests that the community structures in this grass species were different between both investigated years. Interestingly, samples collected in April 2011 and September 2011 were more similar to each other compared to samples taken in July 2011. This indicates that endophytic communities in L. perenne followed a seasonal pattern and that endophytic communities respond to changing climatic conditions. 
DGGE band patters derived from D. glomerata samples revealed that samples taken in April 2011 clustered together, suggesting that they harbor a homogenous community composition (Fig. 6A). In accordance with L. perenne, three of the six samples taken in September 2011 were more similar to samples taken in April 2011. The other three samples of September 2011 were related to samples taken in July 2011. Such a pattern was already reported for $F$. rubra. Furthermore, samples taken in September 2010 were more similar to some of the samples taken in September 2011. These data suggested that the bacterial endophytic community in D. glomerata was less variable over consecutive years as, for example, the community in L. perenne. This might be explained by the higher endophytic diversity (number of OTUs) observed in $D$. glomerata compared to L. perenne; the smaller the community size the stronger the impact of seasonal fluctuations of single species on community structure.

The different seasonal patterns recorded for the three grass species confirm our first hypothesis that the overall endophytic community structure is different between the three examined grass species. Moreover, statistical analysis supported our third hypothesis that the season has an effect on the bacterial endophytic community in the three grasses as both season and year significantly influenced the composition of these communities (Table 1). This result is consistent with other studies. According to McInroy and Kloepper (1995B), the bacterial endophytic population in sweet corn and cotton fluctuated seasonally. The season also influenced the bacterial endophytic community in elm (Mocali et al., 2003) and in soybean (Kuklinsky-Sobral et al., 2004). However, only cultivable endophytes were investigated in these studies.

During the year, plants undergo physiological changes that probably increase nutrient availability and thus bacterial diversity in the roots (Hallmann \& Berg, 2006). This might also play a role for endophytic bacteria in the above-ground plant tissues and could explain the high similarity of F. rubra and D. glomerata samples from September and July 2011 compared to samples from April 2011. Tan et al. (2003) showed that environmental conditions strongly influenced the diazotrophic endophytic community structure in rice roots. Several factors, such as temperature or precipitation, have a direct effect on the plant physiology and thus an indirect impact on the colonization and the survival of bacteria in the endosphere (Hallmann et al., 1997; Hardoim et al., 2012). This might explain the fact that the endophytic community structure in L. perenne in spring and autumn showed a higher similarity compared to the community in summer due to higher precipitation in summer.

In conclusion, our results demonstrate that different management regimes affect certain bacterial endophyte communities in grass species. However, this influence varies between the applied management regimes as the effect of the fertilizer application is clearer visible compared to the impact of different mowing frequencies. In addition, the influence of the management regimes can alter with time as seasonal changes also have an impact on the endophytic community composition. Interestingly, the effect of different management regimes and season is dependent on the host species as differences between the three investigated grass species were recorded. So far, the majority of the studies examined the effect of only one management regime in one single year, or focused on culturable endophytes or one functional group only. This study provides first insights into structural changes of endophyte communities in three agricultural important grass species as response to combined fertilizer application and mowing regimes as well as season. More studies targeting the influence of management regimes in combination with the impact of season and plant species are required to unravel the diversity of interactions between endophytic bacteria, plant species and management regimes.

\section{Acknowledgments}

We thank the technical staff of the Department of Crop Sciences and the Department of Genomic and Applied Microbiology at the University of Göttingen for help with experimental maintenance. In addition, we are grateful to Birgit Pfeiffer for providing assistance with the DGGE. This study was funded by the Ministry of Science and Culture of Lower Saxony and the 'Niedersächsisches Vorab' as part of the Cluster of Excellence 'Functional Biodiversity Research'. 


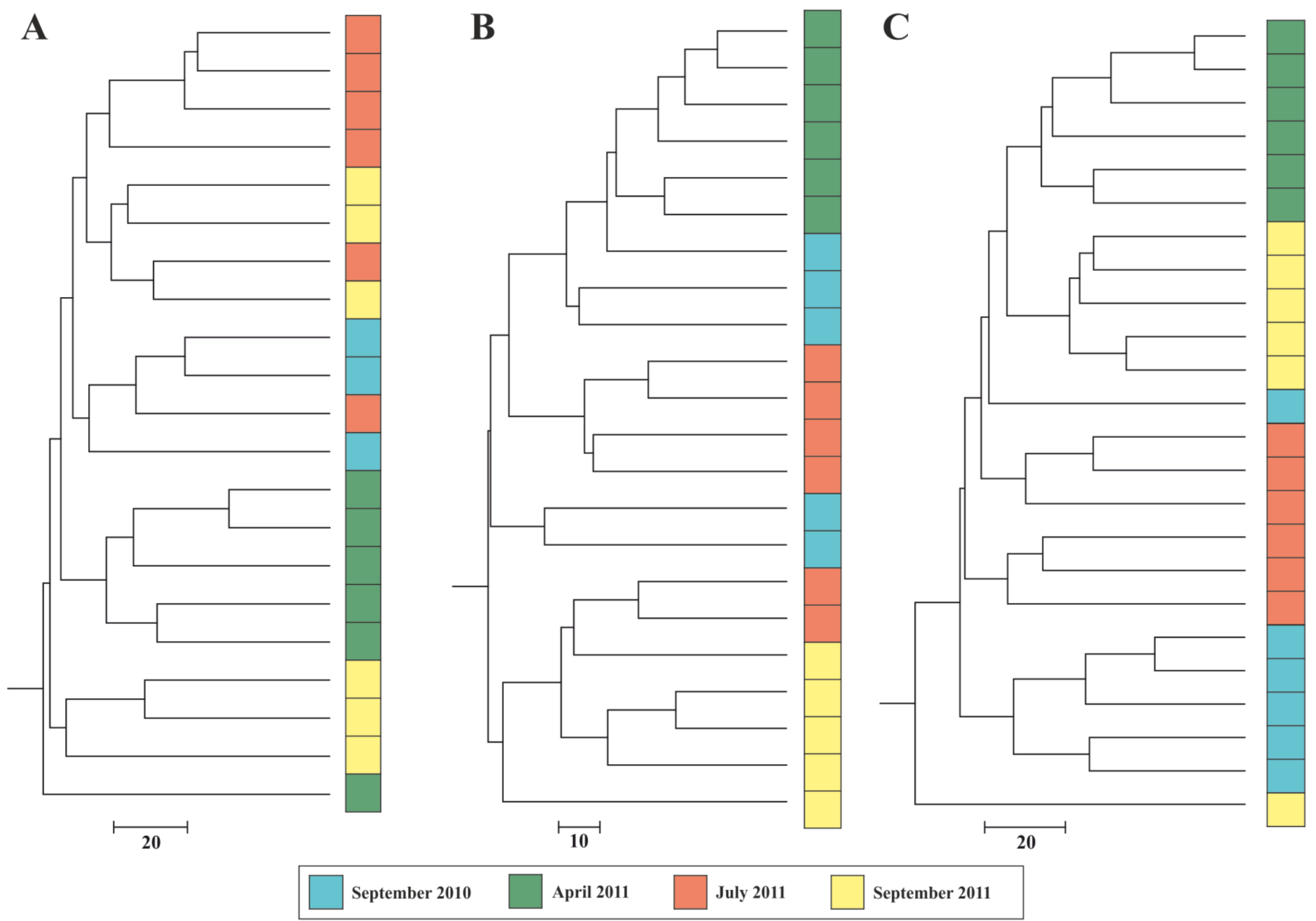

Fig. 6. UPGMA dendrogram generated by cluster analysis of DGGE fingerprints on the seasonal effect on the bacterial endophytic community composition in above-ground plant parts of D. glomerata (A), F. rubra (B), and L. perenne (C). For details see Fig. 3 


\section{References}

Araujo WL, Marcon J, Maccheroni W, Jr., Van Elsas JD, Van Vuurde JW \& Azevedo JL (2002) Diversity of endophytic bacterial populations and their interaction with Xylella fastidiosa in citrus plants. Appl Environ Microbiol 68: 4906-4914.

Bacon C \& Hinton D (2006) Bacterial endophytes: The endophytic niche, its occupants, and its utility. Plant-Associated Bacteria (Gnanamanickam S, ed), pp. 155-194. Springer Netherlands.

Bacon C \& Hinton D (2011) Bacillus mojavensis: Its Endophytic Nature, the Surfactins, and Their Role in the Plant Response to Infection by Fusarium verticillioides. Bacteria in Agrobiology: Plant Growth Responses (Maheshwari DK, ed), pp. 21-39. Springer Berlin Heidelberg, Germany.

Baldani J, Baldani V, Seldin L \& Döbereiner J (1986) Characterization of Herbaspirillum seropedicae gen. nov., sp. nov., a rootassociated nitrogen-fixing bacterium. Int $J$ Syst Bacteriol 36: 86-93.

Cankar K, Kraigher H, Ravnikar M \& Rupnik M (2005) Bacterial endophytes from seeds of Norway spruce (Picea abies L. Karst). FEMS Microbiol Lett 244, 341-345.

Caporaso JG, Kuczynski J, Stombaugh J, et al. (2010) QIIME allows analysis of highthroughput community sequencing data. Nat Methods 7: 335-336.

Chelius MK \& Triplett EW (2001) The Diversity of Archaea and Bacteria in Association with the Roots of Zea mays L. Microbial Ecol 41: 252-263.Compant S, Clément C \& Sessitsch A (2010) Plant growth-promoting bacteria in the rhizo- and endosphere of plants: Their role, colonization, mechanisms involved and prospects for utilization. Soil Biol and Bioch 2: 669-678.

Compant S, Duffy B, Nowak J, Clement C \& Barka EA (2005) Use of plant growth-promoting bacteria for biocontrol of plant diseases: principles, mechanisms of action, and future prospects. Appl Environ Microbiol 71: 49514959.

Conn VM \& Franco CM (2004) Analysis of the endophytic actinobacterial population in the roots of wheat (Triticum aestivum L.) by terminal restriction fragment length polymorphism and sequencing of $16 \mathrm{~S}$ rRNA clones. Appl Environ Microbiol 70: 17871794.

Cremonesi L, Firpo S, Ferrari M, Righetti PG \& Gelfi C (1997) Double-gradient DGGE for optimized detection of DNA point mutations. Biotechniques 22: 326-330.

Dierschke H \& Briemle G (2002) Kulturgrasland. Eugen Ulmer, Stuttgart, Germany.

Doty S, Oakley B, Xin G, Kang J, Singleton G, Khan Z, Vajzovic A \& Staley J (2009) Diazotrophic endophytes of native black cottonwood and willow. Symbiosis 47: 2333.

Fuentes-Ramírez LE ， Caballero-Mellado J , Sepúlveda J \& Martínez-Romero E (1999) Colonization of sugarcane by Acetobacter diazotrophicus is inhibited by high $\mathrm{N}$ fertilization. FEMS Microbiol Ecol 29: 117128.

Gagne-Bourgue F, Aliferis KA, Seguin P, Rani M, Samson R \& Jabaji S (2013) Isolation and characterization of indigenous endophytic bacteria associated with leaves of switchgrass (Panicum virgatum L.) cultivars. J Appl Microbiol 114: 836-853.

Garbeva P, Overbeek LS, Vuurde JW \& Elsas JD (2001) Analysis of Endophytic Bacterial Communities of Potato by Plating and Denaturing Gradient Gel Electrophoresis (DGGE) of $16 \mathrm{~S}$ rDNA Based PCR Fragments. Microb Ecol 41: 369-383.

Gottel NR, Castro HF, Kerley M, et al. (2011) Distinct microbial communities within the endosphere and rhizosphere of Populus deltoides roots across contrasting soil types. Appl Environ Microbiol 77: 5934-5944.

Hallmann J (2006) Plant Interactions with Endophytic Bacteria. Biotic Interactions in Plant-pathogen Associations (Jeger MJ \& Spence NJ, eds), pp. 87-119. CABI, Wallingford.

Hallmann J \& Berg G (2006) Spectrum and Population Dynamics of Bacterial Root Endophytes. Microbial Root Endophytes, Vol. 9 (Schulz BE, Boyle CC \& Sieber T, eds.), pp. 15-31. Springer Berlin Heidelberg, Germany.

Hallmann J, Rodríguez-Kábana R \& Kloepper JW (1999) Chitin-mediated changes in bacterial communities of the soil, rhizosphere and within roots of cotton in relation to nematode control. Soil Biol and Bioch 31: 551-560. 
Hallmann J, Quadt-Hallmann A, Mahaffee WF \& Kloepper JW (1997) Bacterial endophytes in agricultural crops. Can J Microbiol 43: 895914.

Hallmann J, Quadt-Hallmann A, Rodríguez-Kábana R \& Kloepper JW (1998) Interactions between Meloidogyne incognita and endophytic bacteria in cotton and cucumber. Soil Biol and Bioch 30: 925-937.

Hardoim PR, Hardoim CCP, van Overbeek LS \& van Elsas JD (2012) Dynamics of SeedBorne Rice Endophytes on Early Plant Growth Stages. PLoS ONE 7: e30438.

Keuter A, Hoeft I, Veldkamp E \& Corre M (2013) Nitrogen response efficiency of a managed and phytodiverse temperate grassland. Plant Soil 364: 193-206.

Kobayashi DY \& Palumbo JD (2000) Bacterial endophytes and their effects on plants and uses in agriculture. Microbial endophytes (Bacon CW,White JF, eds), pp. 199-236. Marcel Dekker, New York.

Krechel A, Faupel A, Hallmann J, Ulrich A \& Berg G (2002) Potato-associated bacteria and their antagonistic potential towards plantpathogenic fungi and the plant-parasitic nematode Meloidogyne incognita (Kofoid \& White) Chitwood. Can J Microbiol 48: 772786.

Kuklinsky-Sobral J, Araújo W, Mendes R, Pizzirani-Kleiner A \& Azevedo J (2005) Isolation and characterization of endophytic bacteria from soybean (Glycine max) grown in soil treated with glyphosate herbicide. Plant Soil 273: 91-99.

Kuklinsky-Sobral J, Araujo WL, Mendes R, Geraldi IO, Pizzirani-Kleiner AA \& Azevedo JL (2004) Isolation and characterization of soybean-associated bacteria and their potential for plant growth promotion. Environ Microbiol 6: 1244-1251.

Maksimov IV, Abizgil'dina RR \& Pusenkova LI (2011) Plant growth promoting rhizobacteria as alternative to chemical crop protectors from pathogens. Appl Biochem Micro+ 47: 333-345.

Mastretta C, Taghavi S, van der Lelie D, Mengoni A, Galardi F, Gonnelli C, Barac T, Boulet J, Weyens N \& Vangronsveld J (2009) Endophytic bacteria from seeds of Nicotiana tabacum can reduce cadmium phytotoxicity. Int J Phytoremediat 11: 251-267.
McInroy J \& Kloepper J (1995A) Survey of indigenous bacterial endophytes from cotton and sweet corn. Plant Soil 173: 337-342.

McInroy JA \& Kloepper JW (1995B) Population dynamics of endophytic bacteria in fieldgrown sweet corn and cotton. Can $J$ Microbiol 41: 895-901.

Mocali S, Bertelli E, Di Cello F, Mengoni A, Sfalanga A, Viliani F, Caciotti A, Tegli S, Surico G \& Fani R (2003) Fluctuation of bacteria isolated from elm tissues during different seasons and from different plant organs. Res Microbiol 154: 105-114.

Muyzer G, de Waal EC \& Uitterlinden AG (1993) Profiling of complex microbial populations by denaturing gradient gel electrophoresis analysis of polymerase chain reactionamplified genes coding for 16S rRNA. Appl Environ Microbiol 59: 695-700.

Muyzer G, Teske A, Wirsen CO \& Jannasch HW (1995) Phylogenetic relationships of Thiomicrospira species and their identification in deep-sea hydrothermal vent samples by denaturing gradient gel electrophoresis of $16 \mathrm{~S}$ rDNA fragments. Arch Microbiol 164: 165-172.

Nübel U, Engelen B, Felske A, Snaidr J, Wieshuber A, Amann RI, Ludwig W \& Backhaus H (1996) Sequence heterogeneities of genes encoding $16 \mathrm{~S}$ rRNAs in Paenibacillus polymyxa detected by temperature gradient gel electrophoresis. J Bacteriol 178: 56365643.

Olivares F, Baldani VD, Reis V, Baldani J \& Döbereiner J (1996) Occurrence of the endophytic diazotrophs Herbaspirillum spp. in roots, stems, and leaves, predominantly of Gramineae. Biol Fert Soils 21: 197-200.

Parish R, Turkington R \& Klein E (1990) The influence of mowing, fertilization, and plant removal on the botanical composition of an artificial sward. Can J Bot 68: 1080-1085.

Petersen U, Wrage N, Köhler L, Leuschner C \& Isselstein J (2012) Manipulating the species composition of permanent grasslands - A new approach to biodiversity experiments. Basic Appl Ecoly 13: 1-9.

Prakamhang J, Minamisawa K, Teamtaisong K, Boonkerd N \& Teaumroong N (2009) The communities of endophytic diazotrophic bacteria in cultivated rice (Oryza sativa L.). Appl Soil Ecol 42: 141-149. 
Quadt-Hallmann A, Kloepper JW \& Benhamou N (1997) Bacterial endophytes in cotton: mechanisms of entering the plant. Can $J$ Microbioly 43: 577-582.

Quast C, Pruesse E, Yilmaz P, Gerken J, Schweer T, Yarza P, Peplies J \& Glöckner FO (2013) The SILVA ribosomal RNA gene database project: improved data processing and webbased tools. Nucleic Acids Res 41: D590D596.

Reinhold-Hurek B \& Hurek T (1998) Life in grasses: diazotrophic endophytes. Trends Microbiol 6: 139-144.

Rosenblueth M \& Martinez-Romero E (2006) Bacterial endophytes and their interactions with hosts. Mol Plant Microbe Interact 19: 827-837.

Schulz B, Wanke U, Draeger S \& Aust HJ (1993) Endophytes from herbaceous plants and shrubs: effectiveness of surface sterilization methods. Mycol Res 97: 1447-1450.

Seghers D, Wittebolle L, Top EM, Verstraete W \& Siciliano SD (2004) Impact of agricultural practices on the Zea mays L. endophytic community. Appl Environ Microbiol 70: 1475-1482.

Senthilkumar M, Anandham R, Madhaiyan M, Venkateswaran V \& Sa T (2011) Endophytic Bacteria: Perspectives and Applications in Agricultural Crop Production. Bacteria in Agrobiology: Crop Ecosystems (Maheshwari DK, ed), pp. 61-96. Springer Berlin Heidelberg, Germany.

Sessitsch A, Reiter B, Pfeifer U \& Wilhelm E (2002) Cultivation-independent population analysis of bacterial endophytes in three potato varieties based on eubacterial and Actinomycetes-specific PCR of $16 \mathrm{~S}$ rRNA genes. FEMS Microbiol Ecol 39: 23-32.

Siddiqui IA \& Shaukat SS (2003) Endophytic bacteria. Prospects and opportunities for the biological control of plant-parasitic nematodes. Nematologia Mediterranea 31: 110-120.

Stoltzfus JR, So R, Malarvithi PP, Ladha JK \& de Bruijn FJ (1997) Isolation of endophytic bacteria from rice and assessment of their potential for supplying rice with biologically fixed nitrogen. Plant Soil 194: 25-36.

Sturz AV \& Nowak J (2000) Endophytic communities of rhizobacteria and the strategies required to create yield enhancing associations with crops. Appl Soil Ecol 15: 183-190.

Sturz AV, Christie BR \& Nowak J (2000) Bacterial Endophytes: Potential Role in Developing Sustainable Systems of Crop Production. CRC Cr Rev Plant Sci 19: 1-30.

Sun L, Qiu F, Zhang X, Dai X, Dong X \& Song W (2008) Endophytic bacterial diversity in rice (Oryza sativa L.) roots estimated by $16 \mathrm{~S}$ rDNA sequence analysis. Microb Ecol 55: 415-424.

Tan Z, Hurek T \& Reinhold-Hurek B (2003) Effect of $\mathrm{N}$-fertilization, plant genotype and environmental conditions on nifH gene pools in roots of rice. Environ microbiol 5: 1009-1015.

Wilmotte A, Van der Auwera G \& De Wachter R (1993) Structure of the $16 \mathrm{~S}$ ribosomal RNA of the thermophilic cyanobacterium Chlorogloeopsis HTF ('Mastigocladus laminosus HTF') strain PCC7518, and phylogenetic analysis. FEBS Lett 317: 96100. 


\section{SUPPORTING INFORMATION FOR STUDY 9}

\section{Contents:}

Fig. S1. 16S-DGGE profile showing the influence of different fertilization and mowing regimes on bacterial endophyte communities in above-ground plant parts of D. glomerata.

Fig. S2. 16S-DGGE profile showing the influence of different fertilization and mowing regimes on bacterial endophyte communities in above-ground plant parts of $F$. rubra.

Fig. S3. 16S-DGGE profile showing the influence of different fertilization and mowing regimes on bacterial endophyte communities in above-ground plant parts of L. perenne.

Fig. S4. 16S-DGGE profile showing the seasonal effect on bacterial endophyte communities in above-ground plant parts of D. glomerata (A), F. rubra (B), and L. perenne (C).

Table S1. Overview about all OTUs obtained by analysis of 16S rRNA sequences derived from the isolation and the DGGE analysis. 
A
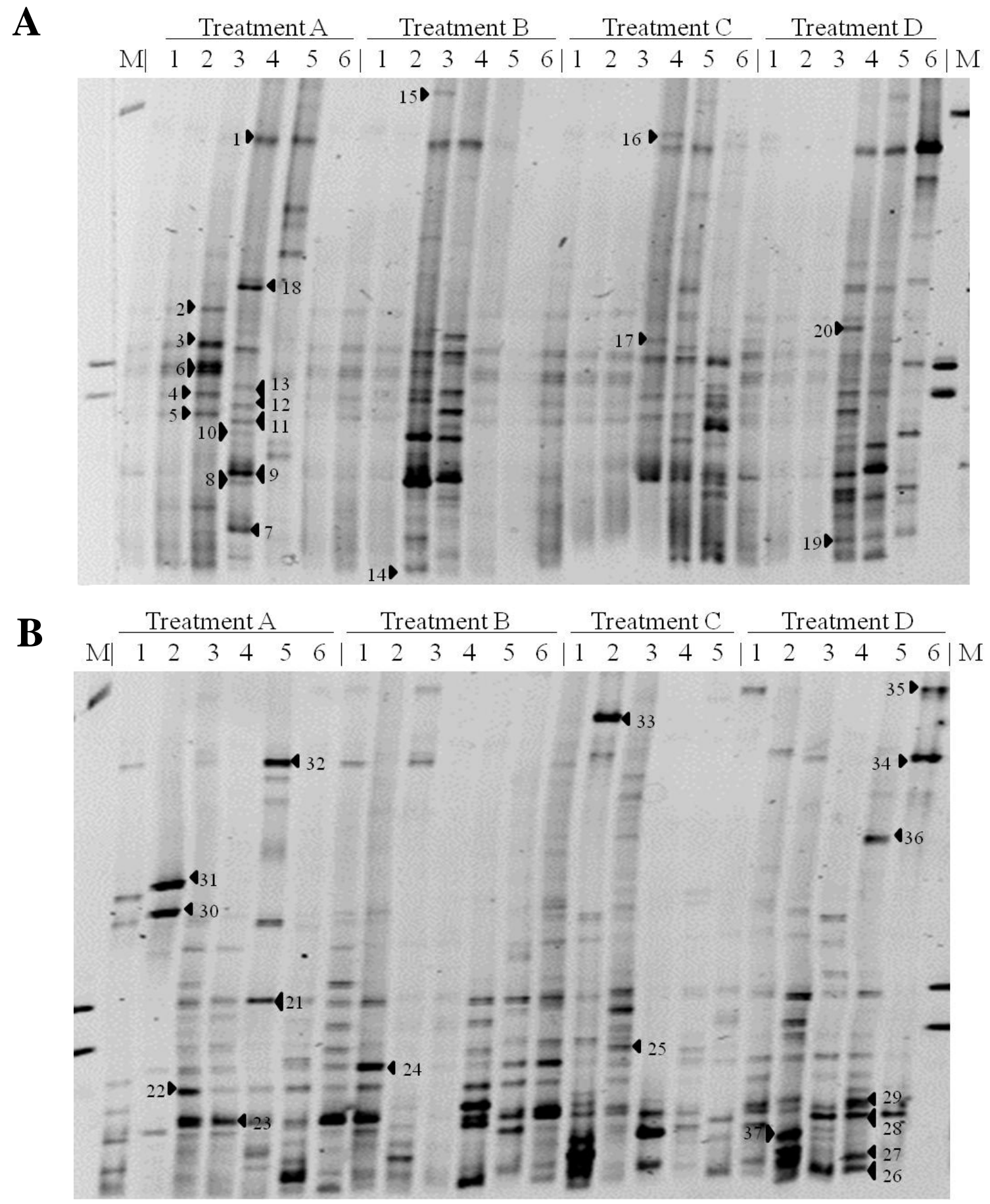

Fig. S1. 16S-DGGE profile showing the influence of different fertilization and mowing regimes on bacterial endophyte communities in above-ground plant parts of D. glomerata. Plant samples were taken in September 2010 (A) and 2011 (B). Independent replicates are indicated with numbers from 1 to 6 . Excised bands are labelled with numbers.

Treatment A: 1 x mowing/ year, no NPK; treatment B: 3 x mowing/ year, no NPK; treatment C: $1 \mathrm{x}$ mowing/ year, NPK; treatment D: $3 \mathrm{x}$ mowing/ year, NPK. M: GeneRuler $1 \mathrm{~kb}$ DNA Ladder (Fermentas, St. Leon-Rot, Germany). 

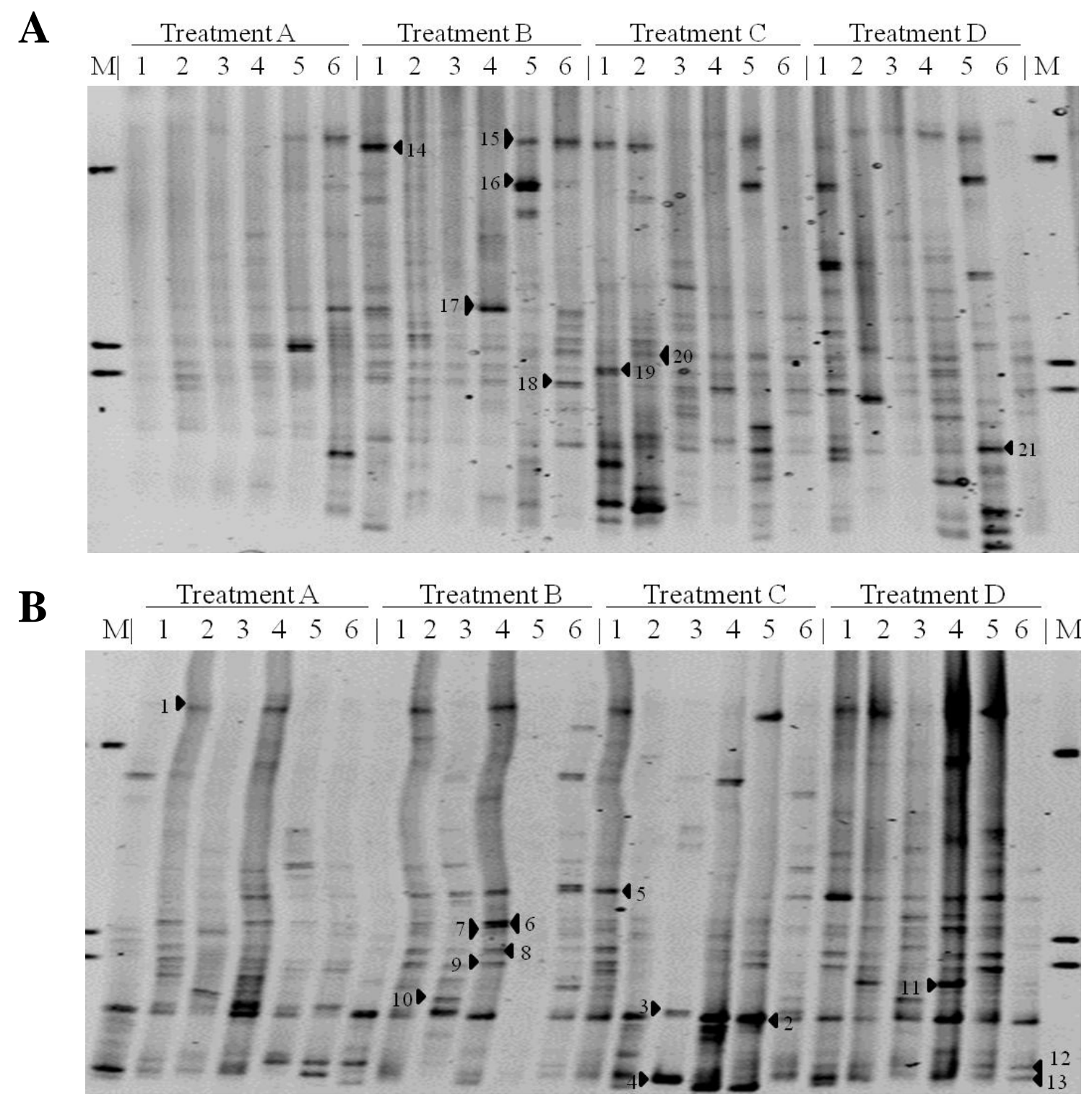

Fig. S2. 16S-DGGE profile showing the influence of different fertilization and mowing regimes on bacterial endophyte communities in above-ground plant parts of $F$. rubra. Plant samples were taken in September 2010 (A) and 2011 (B). Independent replicates are indicated with numbers from 1 to 6 . Excised bands are labelled with numbers, respectively.

Treatment A: 1 x mowing/ year, no NPK; treatment B: 3 x mowing/ year, no NPK; treatment C: 1 x mowing/ year, NPK; treatment D: 3 x mowing/ year, NPK. M: GeneRuler $1 k b$ DNA Ladder (Fermentas, St. Leon-Rot, Germany). 
A

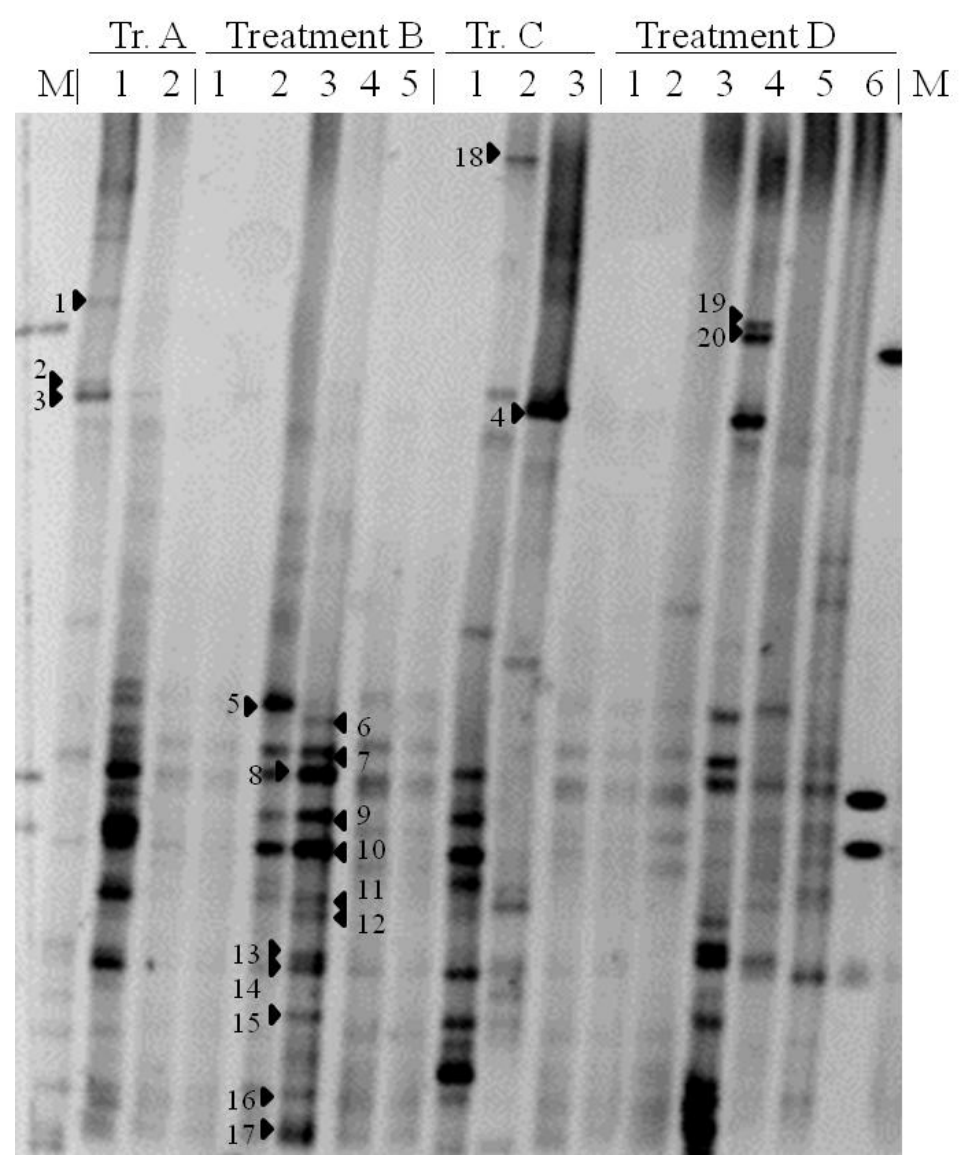

B

Treatment A Treatment $\mathrm{B}$ Treatment $\mathrm{C}$ Treatment D

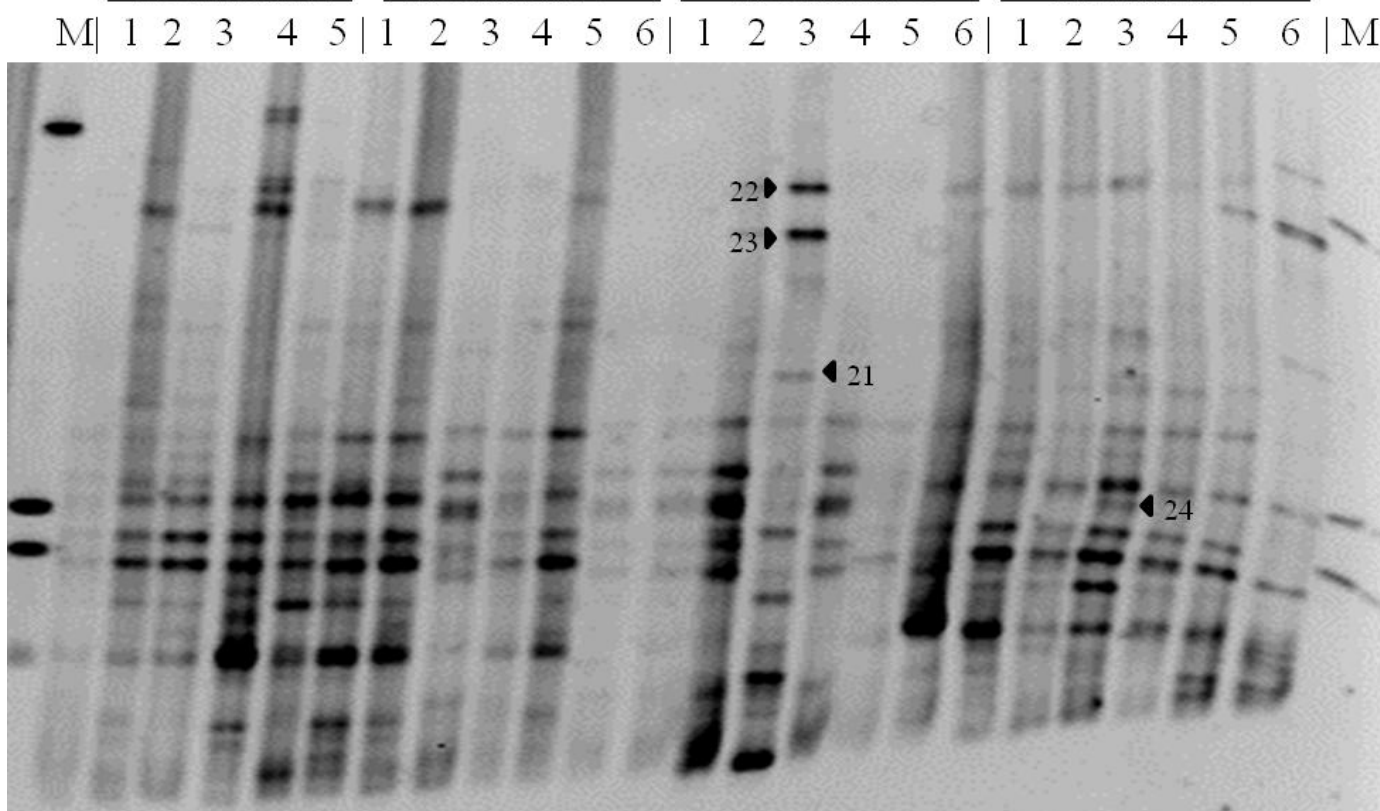


Fig. S3. 16S-DGGE profile showing the influence of different fertilization and mowing regimes on bacterial endophyte communities in above-ground plant parts of L. perenne. Plant samples were taken in September 2010 (A) and 2011 (B). Independent replicates are indicated with numbers from 1 to 6 . Excised bands are labelled with numbers.

Treatment A: 1 x mowing/ year, no NPK; treatment B: 3 x mowing/ year, no NPK; treatment C: 1 x mowing/ year, NPK; treatment D: 3 x mowing/ year, NPK. M: GeneRuler $1 k b$ DNA Ladder (Fermentas, St. Leon-Rot, Germany). 
A

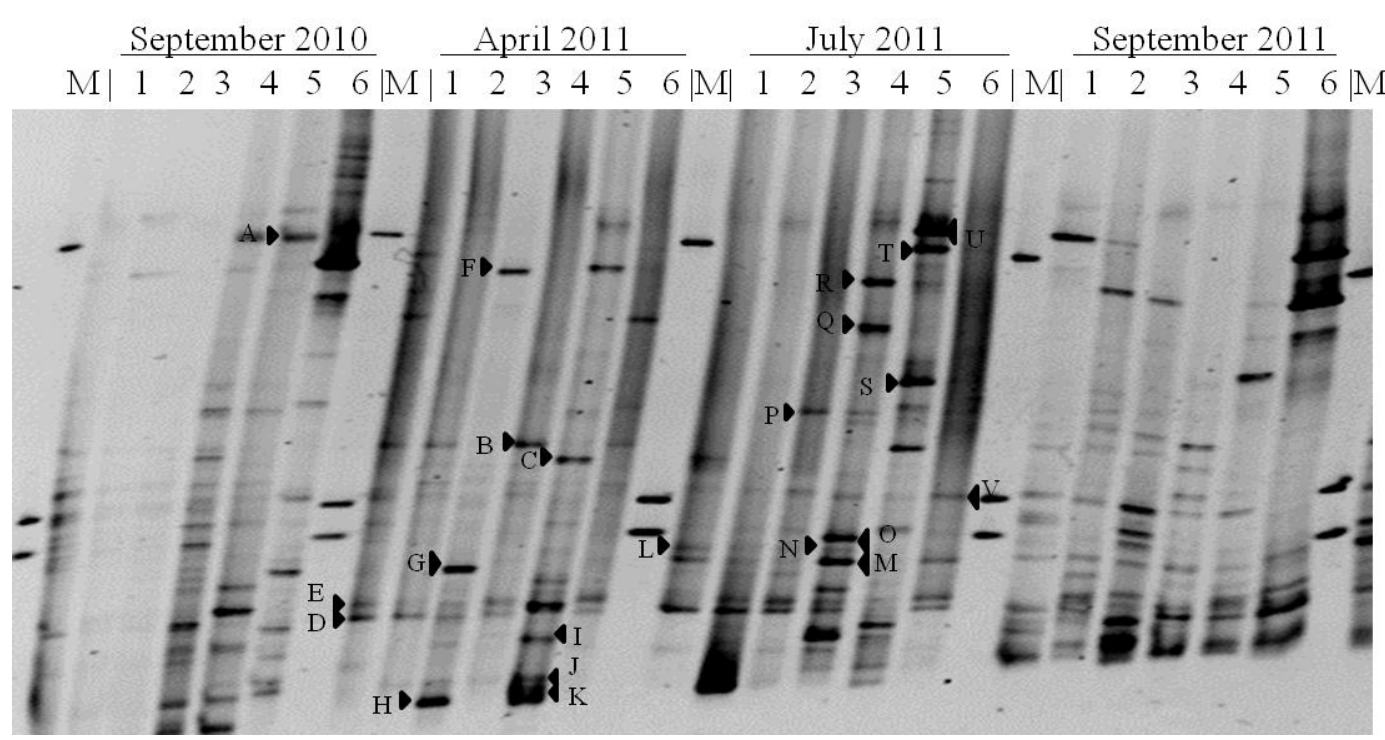

B

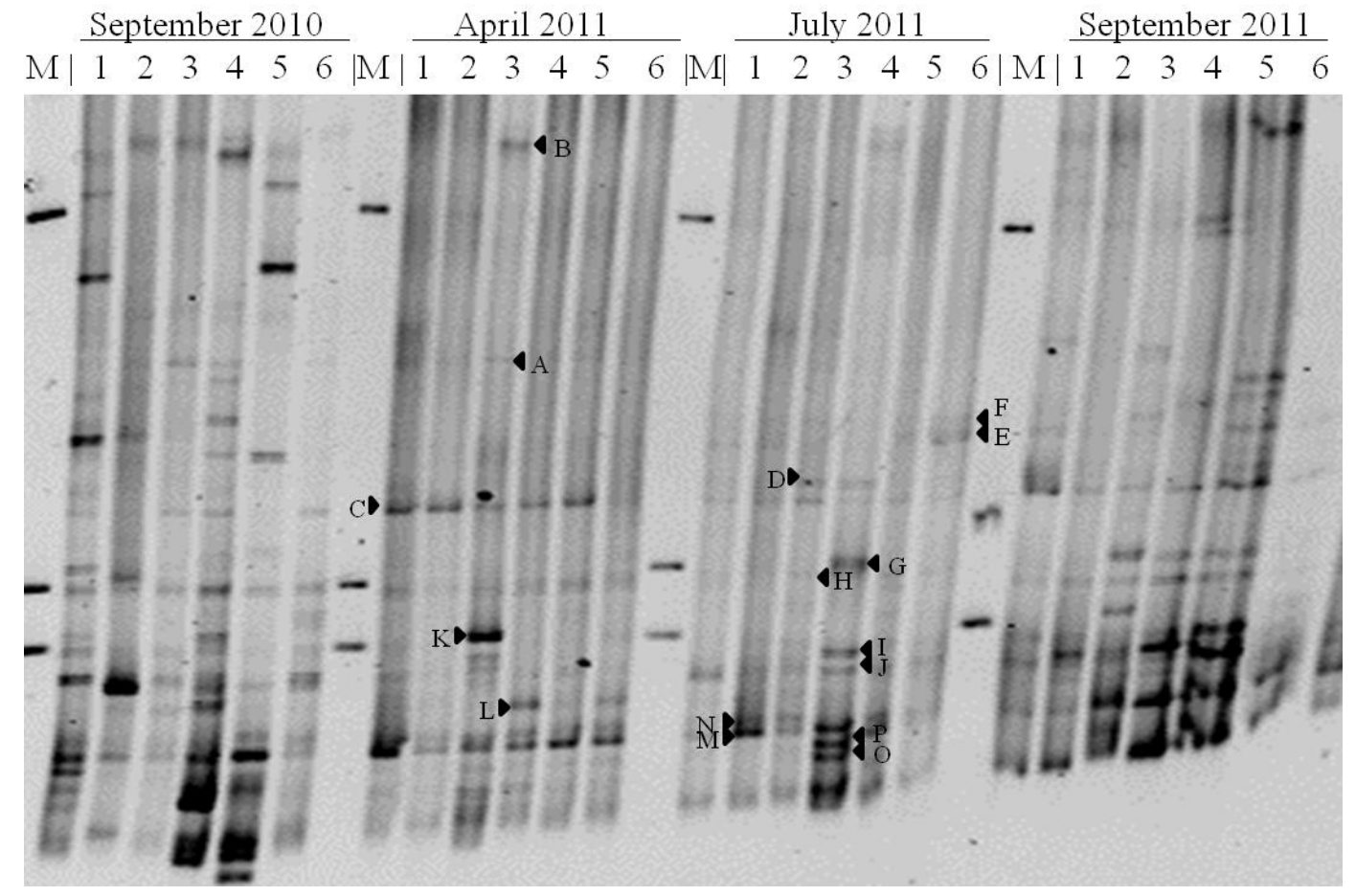




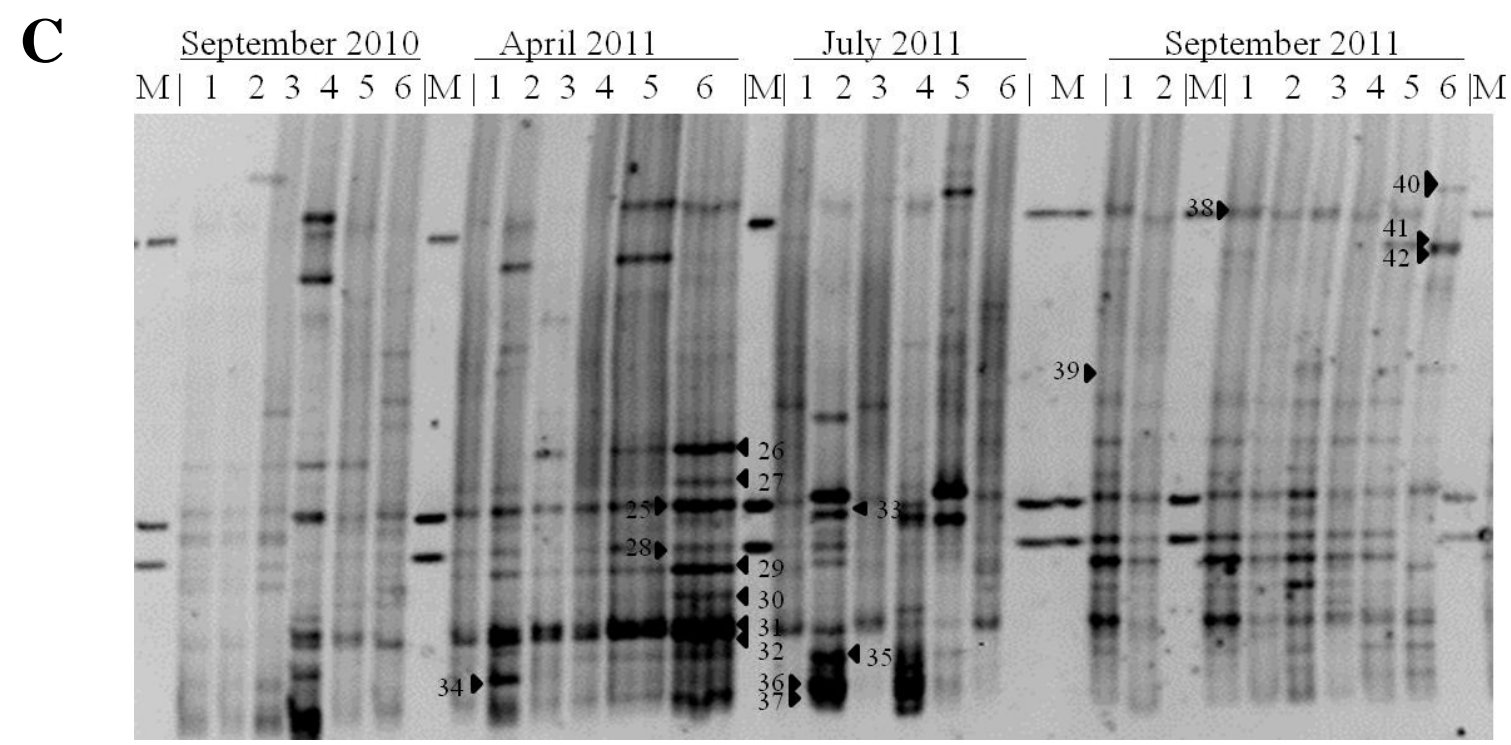

Fig. S4. 16S-DGGE profile showing the seasonal effect on bacterial endophyte communities in above-ground plant parts of D. glomerata (A), F. rubra (B), and L. perenne (C). Independent replicates are indicated with numbers from 1 to 6. M: GeneRuler $1 \mathrm{~kb}$ DNA Ladder (Fermentas, St. Leon-Rot, Germany). Excised bands are labelled with numbers and letters, respectively. Samples were taken on fertilized plots three times a year in September 2010 as well as in April, July, and September 2011. 
Table S1. Overview about all OTUs obtained by analysis of 16S rRNA sequences derived from the isolation and the DGGE analysis.

\begin{tabular}{|c|c|c|c|c|c|c|c|}
\hline \multirow[t]{2}{*}{$I D$} & \multicolumn{3}{|c|}{ Sequences affiliated } & \multirow[b]{2}{*}{ Isolates } & \multicolumn{3}{|c|}{ Closest hit in the SILVA database } \\
\hline & Dactylis & Festuca & Lolium & & acession & e value & SILVA taxonomy \\
\hline 1 & 1 & 0 & 0 & 0 & HQ598842 & 0 & Bacteria; Acidobacteria; Acidobacteria; Subgroup 3; Family IncertaeSedis; Bryobacter; uncultured Acidobacteria bacterium \\
\hline 2 & 0 & 0 & 1 & 0 & JF176919 & 0 & Bacteria; Actinobacteria; Acidimicrobiia; Acidimicrobiales; Acidimicrobiaceae; CL500-29 marine group; uncultured bacterium \\
\hline 3 & 0 & 0 & 0 & 1 & KC236620 & 0 & Bacteria; Actinobacteria; Actinobacteria; Micrococcales; Microbacteriaceae; Curtobacterium; Curtobacterium sp. 4136 \\
\hline 4 & 0 & 0 & 1 & 0 & Y17233 & 0 & Bacteria; Actinobacteria; Actinobacteria; Micrococcales; Microbacteriaceae; Microbacterium; Microbacteriumkeratanolyticum \\
\hline 5 & 1 & 0 & 1 & 0 & KC169799 & 0 & Bacteria; Actinobacteria; Actinobacteria; Micrococcales; Microbacteriaceae; Microbacterium; Microbacterium sp. CC-AMFLN-3 \\
\hline 6 & 1 & 0 & 0 & 0 & Y17240 & $1 \mathrm{E}-168$ & Bacteria; Actinobacteria; Actinobacteria; Micrococcales; Microbacteriaceae; Microbacterium; Microbacteriumtrichothecenolyticum \\
\hline 7 & 0 & 0 & 0 & 1 & JX133202 & 0 & Bacteria; Actinobacteria; Actinobacteria; Micrococcales; Microbacteriaceae; Plantibacter; Plantibactercousiniae \\
\hline 8 & 0 & 0 & 0 & 1 & JQ071511 & 0 & Bacteria; Actinobacteria; Actinobacteria; Micrococcales; Micrococcaceae; Micrococcus; Micrococcus yunnanensis \\
\hline 9 & 1 & 0 & 0 & 0 & AB672179 & 0 & Bacteria; Actinobacteria; Thermoleophilia; Gaiellales; uncultured; uncultured bacterium \\
\hline 10 & 1 & 0 & 0 & 0 & JX091739 & 0 & Bacteria; Chloroflexi; S085; uncultured bacterium \\
\hline 11 & 1 & 0 & 0 & 0 & AM696939 & $2 \mathrm{E}-158$ & Bacteria; Deinococcus-Thermus; Deinococci; Deinococcales; Trueperaceae; Truepera; uncultured bacterium \\
\hline 12 & 1 & 0 & 0 & 0 & AB374378 & 0 & Bacteria; Deinococcus-Thermus; Deinococci; Deinococcales; Trueperaceae; Truepera; uncultured endolithic bacterium \\
\hline 13 & 1 & 0 & 0 & 0 & KC120646 & 0 & Bacteria; Deinococcus-Thermus; Deinococci; Thermales; Thermaceae; Thermus; uncultured bacterium \\
\hline 14 & 0 & 0 & 0 & 3 & KC441733 & 0 & Bacteria; Firmicutes; Bacilli; Bacillales; Bacillaceae; Bacillus; Bacillus licheniformis \\
\hline 15 & 0 & 0 & 0 & 1 & КC434960 & 0 & Bacteria; Firmicutes; Bacilli; Bacillales; Bacillaceae; Bacillus; Bacillus safensis \\
\hline 16 & 0 & 0 & 0 & 1 & КC434960 & 0 & Bacteria; Firmicutes; Bacilli; Bacillales; Bacillaceae; Bacillus; Bacillus safensis \\
\hline 17 & 0 & 0 & 0 & 2 & KC310814 & 0 & Bacteria; Firmicutes; Bacilli; Bacillales; Bacillaceae; Bacillus; Bacillus sp. A8(2013) \\
\hline 18 & 0 & 0 & 0 & 1 & FN395277 & 0 & Bacteria; Firmicutes; Bacilli; Bacillales; Bacillaceae; Bacillus; Bacillus sp. FR-W2C1 \\
\hline 19 & 0 & 0 & 0 & 3 & KC441785 & 0 & Bacteria; Firmicutes; Bacilli; Bacillales; Bacillaceae; Bacillus; Bacillus subtilis \\
\hline 20 & 0 & 0 & 0 & 11 & JX436372 & 0 & Bacteria; Firmicutes; Bacilli; Bacillales; Bacillaceae; Bacillus; Firmicutes bacterium Man17 \\
\hline 21 & 0 & 0 & 2 & 0 & HE974809 & 0 & Bacteria; Firmicutes; Bacilli; Bacillales; Bacillaceae; Bacillus; uncultured Bacillus sp. \\
\hline 22 & 0 & 0 & 0 & 2 & EU282459 & 0 & Bacteria; Firmicutes; Bacilli; Bacillales; Family XII IncertaeSedis; Exiguobacterium; Exiguobacterium sp. TC38-2b \\
\hline 23 & 0 & 0 & 0 & 1 & AB363733 & 0 & Bacteria; Firmicutes; Bacilli; Bacillales; Paenibacillaceae; Paenibacillus; Paenibacilluslautus \\
\hline 24 & 0 & 0 & 0 & 10 & JX897938 & 0 & Bacteria; Firmicutes; Bacilli; Bacillales; Paenibacillaceae; Paenibacillus; Paenibacillusxylanexedens \\
\hline 25 & 0 & 0 & 0 & 1 & FM173819 & 0 & Bacteria; Firmicutes; Bacilli; Bacillales; Paenibacillaceae; Paenibacillus; Pseudomonas sp. CL4.14 \\
\hline 26 & 0 & 0 & 0 & 1 & JX990163 & 0 & Bacteria; Firmicutes; Bacilli; Bacillales; Planococcaceae; Lysinibacillus; Bacillales bacterium Cul_0304 \\
\hline 27 & 0 & 0 & 0 & 1 & JX898015 & 0 & Bacteria; Firmicutes; Bacilli; Bacillales; Planococcaceae; Lysinibacillus; Bacillus sp. FBst09 \\
\hline 28 & 0 & 0 & 0 & 1 & JN208189 & 0 & Bacteria; Firmicutes; Bacilli; Bacillales; Planococcaceae; Lysinibacillus; Lysinibacillus sp. DT3 \\
\hline 29 & 0 & 0 & 0 & 1 & JX996174 & 0 & Bacteria; Firmicutes; Bacilli; Bacillales; Planococcaceae; Solibacillus; Solibacillussilvestris \\
\hline 30 & 0 & 0 & 0 & 1 & JX996174 & 0 & Bacteria; Firmicutes; Bacilli; Bacillales; Planococcaceae; Solibacillus; Solibacillussilvestris \\
\hline 31 & 3 & 5 & 1 & 0 & X70648 & 0 & Bacteria; Firmicutes; Bacilli; Bacillales; Staphylococcaceae; Staphylococcus; Staphylococcus aureus \\
\hline 32 & 1 & 2 & 1 & 0 & L37605 & 0 & Bacteria; Firmicutes; Bacilli; Bacillales; Staphylococcaceae; Staphylococcus; Staphylococcus epidermidis \\
\hline 33 & 1 & 1 & 0 & 0 & KC153285 & 0 & Bacteria; Firmicutes; Bacilli; Bacillales; Staphylococcaceae; Staphylococcus; Staphylococcus sp. G2-10 \\
\hline 34 & 0 & 0 & 0 & 1 & KC012992 & 0 & Bacteria; Firmicutes; Bacilli; Bacillales; Staphylococcaceae; Staphylococcus; Staphylococcus sp. JP44SK55 \\
\hline 35 & 1 & 0 & 0 & 0 & HQ792508 & 0 & Bacteria; Firmicutes; Bacilli; Bacillales; Staphylococcaceae; Staphylococcus; uncultured organism \\
\hline 36 & 0 & 1 & 0 & 0 & JQ901473 & 0 & Bacteria; Firmicutes; Clostridia; Clostridiales; Family XI IncertaeSedis; Peptoniphilus; uncultured bacterium \\
\hline 37 & 0 & 0 & 0 & 1 & КC003398 & 0 & Bacteria; Proteobacteria; Betaproteobacteria; Burkholderiales; Burkholderiaceae; Ralstonia; unidentified marine bacterioplankton \\
\hline 38 & 0 & 2 & 0 & 0 & JN713899 & 0 & Bacteria; Proteobacteria; Betaproteobacteria; Burkholderiales; Comamonadaceae; Tepidimonas; Tepidimonas sp. AT-A2 \\
\hline 39 & 1 & 2 & 1 & 0 & JX271982 & 0 & Bacteria; Proteobacteria; Betaproteobacteria; Burkholderiales; Comamonadaceae; uncultured; uncultured bacterium \\
\hline 40 & 1 & 0 & 0 & 0 & HQ222272 & 0 & Bacteria; Proteobacteria; Betaproteobacteria; Burkholderiales; Comamonadaceae; uncultured; Variovorax sp. enrichment culture clone Van 40 \\
\hline 41 & 0 & 1 & 0 & 0 & KC286834. & 0 & Bacteria; Proteobacteria; Betaproteobacteria; Burkholderiales; Comamonadaceae; Variovorax; uncultured bacterium \\
\hline 42 & 0 & 1 & 0 & 0 & X74914 & 0 & Bacteria; Proteobacteria; Betaproteobacteria; Burkholderiales; Oxalobacteraceae; Duganella; Zoogloearamigera \\
\hline 43 & 0 & 1 & 0 & 0 & Y10146 & 2E-129 & Bacteria; Proteobacteria; Betaproteobacteria; Burkholderiales; Oxalobacteraceae; Herbaspirillum; Herbaspirillumseropedicae \\
\hline
\end{tabular}


Table S1 continued.

\begin{tabular}{|c|c|c|c|c|c|c|c|}
\hline \multirow[t]{2}{*}{$\overline{I D}$} & \multirow[b]{2}{*}{ Dactylis } & \multicolumn{2}{|c|}{ Sequences affiliated } & \multirow[b]{2}{*}{ Isolates } & \multirow{2}{*}{\multicolumn{3}{|c|}{ 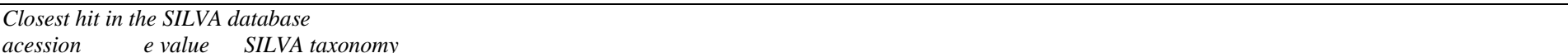 }} \\
\hline & & Festuca & Lolium & & & & \\
\hline 44 & 1 & 2 & 1 & 0 & Y08846 & 0 & Bacteria; Proteobacteria; Betaproteobacteria; Burkholderiales; Oxalobacteraceae; Janthinobacterium; Janthinobacteriumlividum \\
\hline 45 & 0 & 1 & 2 & 0 & JN024091 & 0 & Bacteria; Proteobacteria; Betaproteobacteria; Burkholderiales; Oxalobacteraceae; Massilia; uncultured bacterium \\
\hline 46 & 0 & 0 & 1 & 0 & JQ278953 & 0 & Bacteria; Proteobacteria; Betaproteobacteria; Neisseriales; Neisseriaceae; uncultured; uncultured beta proteobacterium \\
\hline 47 & 0 & 2 & 0 & 0 & KC331513 & 0 & Bacteria; Proteobacteria; Betaproteobacteria; Rhodocyclales; Rhodocyclaceae; Azospira; uncultured bacterium \\
\hline 48 & 1 & 0 & 1 & 0 & Z96082 & 0 & Bacteria; Proteobacteria; Gammaproteobacteria; Enterobacteriales; Enterobacteriaceae; Pantoea; Pantoeaagglomerans \\
\hline 49 & 0 & 1 & 0 & 0 & HQ801751 & 0 & Bacteria; Proteobacteria; Gammaproteobacteria; Pasteurellales; Pasteurellaceae; Haemophilus; uncultured organism \\
\hline 50 & 0 & 0 & 0 & 1 & JX849037 & 0 & Bacteria; Proteobacteria; Gammaproteobacteria; Pseudomonadales; Moraxellaceae; Enhydrobacter; Moraxella osloensis \\
\hline 51 & 0 & 1 & 0 & 0 & JX849037 & 0 & Bacteria; Proteobacteria; Gammaproteobacteria; Pseudomonadales; Moraxellaceae; Enhydrobacter; Moraxella osloensis \\
\hline 52 & 0 & 0 & 0 & 2 & HQ178997 & 0 & Bacteria; Proteobacteria; Gammaproteobacteria; Pseudomonadales; Pseudomonadaceae; Pseudomonas; bacterium OC25(2011) \\
\hline 53 & 0 & 0 & 1 & 0 & X99541 & 0 & Bacteria; Proteobacteria; Gammaproteobacteria; Pseudomonadales; Pseudomonadaceae; Pseudomonas; Pseudomonas anguilliseptica \\
\hline 54 & 1 & 1 & 1 & 0 & AF054936 & 0 & Bacteria; Proteobacteria; Gammaproteobacteria; Pseudomonadales; Pseudomonadaceae; Pseudomonas; Pseudomonas balearica \\
\hline 55 & 1 & 1 & 0 & 0 & KC342251 & 0 & Bacteria; Proteobacteria; Gammaproteobacteria; Pseudomonadales; Pseudomonadaceae; Pseudomonas; Pseudomonas chlororaphis \\
\hline 56 & 1 & 0 & 0 & 0 & Z76673 & $7 \mathrm{E}-114$ & Bacteria; Proteobacteria; Gammaproteobacteria; Pseudomonadales; Pseudomonadaceae; Pseudomonas; Pseudomonas chlororaphis \\
\hline 57 & 1 & 0 & 1 & 0 & FJ976601 & 0 & Bacteria; Proteobacteria; Gammaproteobacteria; Pseudomonadales; Pseudomonadaceae; Pseudomonas; Pseudomonas putida \\
\hline 58 & 0 & 0 & 1 & 0 & KC310832 & 0 & Bacteria; Proteobacteria; Gammaproteobacteria; Pseudomonadales; Pseudomonadaceae; Pseudomonas; Pseudomonas sp. C2(2013) \\
\hline 59 & 1 & 1 & 0 & 0 & KC310832 & 0 & Bacteria; Proteobacteria; Gammaproteobacteria; Pseudomonadales; Pseudomonadaceae; Pseudomonas; Pseudomonas sp. C2(2013) \\
\hline 60 & 0 & 0 & 1 & 0 & JX899644 & $6 \mathrm{E}-174$ & Bacteria; Proteobacteria; Gammaproteobacteria; Pseudomonadales; Pseudomonadaceae; Pseudomonas; Pseudomonas sp. REm-amp_189 \\
\hline 61 & 0 & 1 & 1 & 0 & U65012 & 0 & Bacteria; Proteobacteria; Gammaproteobacteria; Pseudomonadales; Pseudomonadaceae; Pseudomonas; Pseudomonas stutzeri \\
\hline 62 & 1 & 0 & 1 & 0 & Z76669 & 0 & Bacteria; Proteobacteria; Gammaproteobacteria; Pseudomonadales; Pseudomonadaceae; Pseudomonas; Pseudomonas syringae \\
\hline 63 & 1 & 1 & 0 & 0 & DQ469202 & 0 & Bacteria; Proteobacteria; Gammaproteobacteria; Pseudomonadales; Pseudomonadaceae; Pseudomonas; uncultured bacterium \\
\hline 64 & 0 & 0 & 0 & 5 & HM261524 & 0 & Bacteria; Proteobacteria; Gammaproteobacteria; Pseudomonadales; Pseudomonadaceae; Pseudomonas; uncultured bacterium \\
\hline 65 & 1 & 0 & 1 & 0 & GQ262820 & 0 & Bacteria; Proteobacteria; Gammaproteobacteria; Xanthomonadales; uncultured; uncultured bacterium \\
\hline 66 & 1 & 0 & 0 & 0 & JN023904 & 0 & Bacteria; Proteobacteria; Gammaproteobacteria; Xanthomonadales; uncultured; uncultured bacterium \\
\hline 67 & 1 & 0 & 0 & 0 & EF018613 & 0 & Bacteria; Proteobacteria; Gammaproteobacteria; Xanthomonadales; uncultured; uncultured proteobacterium \\
\hline \multirow[t]{2}{*}{68} & & & & & & & Bacteria; Proteobacteria; Gammaproteobacteria; Xanthomonadales; Xanthomonadaceae; Luteibacter; Xanthomonadaceae bacterium \\
\hline & 1 & 1 & 0 & 0 & JN872548 & 0 & SAP40_3 \\
\hline 69 & 1 & 0 & 0 & 0 & FJ164060 & 0 & Bacteria; Proteobacteria; Gammaproteobacteria; Xanthomonadales; Xanthomonadaceae; Rhodanobacter; gamma proteobacterium CH $23 i$ \\
\hline 70 & 0 & 1 & 0 & 0 & FJ380140 & $2 \mathrm{E}-170$ & Bacteria; Proteobacteria; Gammaproteobacteria; Xanthomonadales; Xanthomonadaceae; Rhodanobacter; uncultured bacterium \\
\hline 71 & 0 & 0 & 1 & 0 & JF180263 & $2 \mathrm{E}-151$ & Bacteria; Proteobacteria; Gammaproteobacteria; Xanthomonadales; Xanthomonadaceae; Rhodanobacter; uncultured bacterium \\
\hline 72 & 0 & 0 & 0 & 2 & JN897284 & 0 & Bacteria; Proteobacteria; Gammaproteobacteria; Xanthomonadales; Xanthomonadaceae; Stenotrophomonas; Pseudomonas poae \\
\hline 73 & 0 & 1 & 0 & 0 & JX205209 & 0 & Bacteria; Proteobacteria; Gammaproteobacteria; Xanthomonadales; Xanthomonadaceae; Stenotrophomonas; Pseudomonas sp. MLB-42 \\
\hline 74 & 1 & 0 & 0 & 0 & X95923 & $2 \mathrm{E}-155$ & Bacteria; Proteobacteria; Gammaproteobacteria; Xanthomonadales; Xanthomonadaceae; Stenotrophomonas; Stenotrophomonasmaltophilia \\
\hline
\end{tabular}


CHAPTER D

\section{GENERAL DISCUSSION}


Bacteria and Archaea are the most abundant organisms on Earth (Oren, 2004). They have been found in every environment that has been investigated so far. Moreover, these prokaryotes are responsible for various key processes in many globally important biogeochemical cycles (Lengeler et al., 1999, Madigan et al., 2008). As they influence types and rates of nutrient cycling, Bacteria and Archaea play a crucial role in ecosystem structuring (Azam \& Malfatti, 2007). However, the knowledge about their ecological contribution is still limited as most prokaryote species cannot be cultivated and characterized (Oren, 2004). The development of culture-independent molecular approaches has greatly advanced the understanding of microbial diversity including bacterial and archaeal communities in marine ecosystems (e.g., Giebel et al., 2009, Giebel et al., 2011, Sperling et al., 2012). However, most studies so far used DNA-based techniques which are not able to distinguish between active and inactive community members. Recent developments, expanding culture-independent approaches to RNA and proteins, were applied to overcome this limitation and allowed conclusion on active players, their ecological contributions, and putative key functions (e.g., Teeling et al., 2012, Gifford et al., 2013, Ottesen et al., 2013).

In this thesis, the diversity and ecology of archaeal and bacterial communities in the pelagic realm of the North Sea was studied using different culture-independent approaches. In particular, the abundance and ecological role of the Roseobacter clade in the North Sea was investigated. In addition, the response of the prokaryotic communities to changing environmental conditions was examined. Contrary to most previous studies, mainly metatranscriptomic approaches were applied and thus the active community players were studied. 


\section{MARINE MicrobeS}

\subsection{MICROBIAL ECOLOGY OF MARINE ECOSYSTEMS}

The majority of studies presented in this thesis investigated microbial diversity in the pelagic realm of the North Sea (studies 1-4). The examined bacterial communities were dominated by different marine groups affiliated to the Bacteroidetes as well as Alpha- and Gammaproteobacteria including different subclusters of Roseobacter clade and members of the SAR116 clade. Moreover, Cyanobacteria were found in minor abundance with Synechococcus as the dominant genus.

During the past decades, marine communities in the North Sea have been frequently studied (Schmidt et al., 1991, Eilers et al., 2000, Zubkov et al., 2001, Brakstad \& Lødeng, 2005, Alderkamp et al., 2006, Rink et al., 2011). These studies showed that distinct lineages of Alpha- and Gammaproteobacteria as well as Flavobacteria constitute the majority of these communities (Alderkamp et al., 2006, Rink et al., 2011, Teeling et al., 2012, Sintes et al., 2013). The Alphaproteobacteria mainly composed of the SAR11 clade and the Roseobacter clade with the Roseobacter clade affiliated (RCA) cluster (Selje et al., 2004, Giebel et al., 2011, Sperling et al., 2012). Although being concordant with the results presented in this thesis, most previous studies used DNA-based approaches and thus analyzed the total biodiversity but not the active fraction. Moreover, these surveys mainly used traditional techniques such as Sanger sequencing-based analysis of $16 \mathrm{~S}$ rRNA gene libraries to examine bacterial community structures. Consequently, they failed to investigate the full extent of bacterial diversity due the size and complexity of marine bacterial communities.

In addition to bacteria, the archaeal diversity in the North Sea was studied in this thesis. The investigated archaeal communities were dominated by Halobacteria and minor proportions of Thermoplasmata as well as members of the Marine Group I. Recent metagenomic studies provided evidence for ammonium-oxidizing archaea capable of nitrification (Cavicchioli et al., 2007). Some marine crenarchaeal lineages are thought to be important nitrifiers in the pelagic realm (Auguet et al., 2009). These studies indicated that Archaea are important players in the global nitrogen cycle. However, detailed comparative 
studies to understand archaeal community patterns and ecology as well as environmental drivers that shape these communities are missing (Auguet et al., 2009).

\subsection{ECOLOGY OF THE ROSEOBACTER CLADE}

In the fifth study, an abundant Roseobacter clade member in the North Sea was investigated to elucidate its ecological role and to identify putative key traits contributing to the success of this clade in marine ecosystems. The Roseobacter clade is an abundant marine group constituting up to $25 \%$ of the total prokaryote community in pelagic realm (Brinkhoff et al., 2008). The success of this group is usually referred to the use of a multitude of organic compounds, the production of secondary metabolites, and other metabolic pathways such as aerobic anoxygenic photosynthesis or carbon monoxide oxidation as most of the sequenced genomes contain genes for at least one of these features (Buchan et al., 2005). However, only one genome of an abundant Roseobacter subcluster, the genome of Planktomarina temperata RCA23, is currently available (Giebel et al., 2013). Consequently, our knowledge about the ecology of the Roseobacter clade mainly derives from genome analyses of isolates, which do not represent abundant subclusters (Fig. 8). 
A

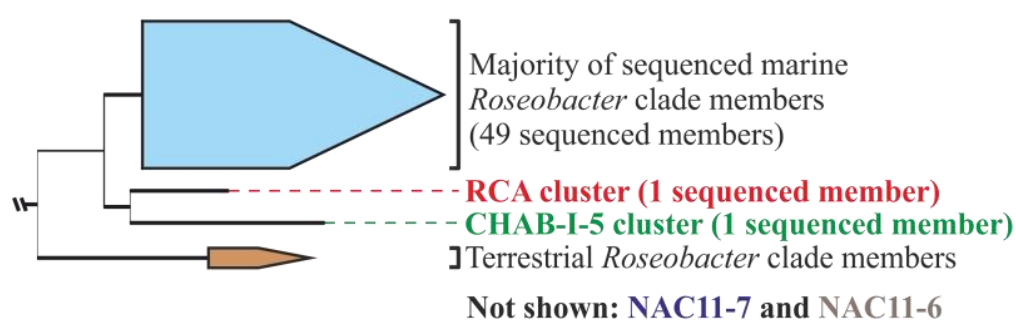

Fig. 8. Gene content tree of sequenced Roseobacter clade members (as from July 2013) (A) and the average composition of this clade based on the results from studies 2 and 3 (B). The colors in (B) refer to the colors in (A).

Despite the high 16S rRNA gene similarity within the Roseobacter clade, inferring physiology from $16 \mathrm{~S}$ phylogeny is inherently biased (Jaspers \& Overmann, 2004). One example of such a bias is the genus Octadecabacter which is abundant in polar regions. Both type strains O. arcticus 238 and O. antarcticus 307 share more than $99 \%$ identity on 16S level (Vollmers et al., 2013). Although sharing some features unusual for other Roseobacter clade members, they also show remarkable differences. Unique genes of each strain comprise $20 \%$ and $23 \%$ of the genome in O. antarcticus and O. arcticus, respectively, indicating a high potential for individual adaptations (Vollmers et al., 2013). A similar result was found for two other closely related Roseobacter clade members, Roseobacter litoralis and Roseobacter denitrificans (Kalhoefer et al., 2011). The comparative analysis of both genomes showed that 1122 of the 4537 (24.7\%) genes predicted for $R$. litoralis were not present in the genome of $R$. denitrificans (Kalhoefer et al., 2011). This includes several potential heavy metal resistance genes. Moreover, some genomic regions were exclusively detected in these two strains but not in other Roseobacter clade members.

To investigate the gene expression of Planktomarina temperata in situ, environmental mRNA was sequenced and the retrieved sequencing information were mapped on the genome of this species (see study 5). Almost $86 \%$ of the 
entire genome was transcribed. Active features included the photosynthetic operon, reflecting the biosynthesis of bacteriochlorophyll $a(\mathrm{Bchl} a)$, which is an indicator for energy harvesting via aerobic anoxygenic photosynthesis. Moreover, both $\mathrm{CO}$ dehydrogenase systems were fully transcribed, suggesting an active carboxidovoric metabolism. In addition, transcripts for the assimilatory sulfate reduction pathway were identified. The observed presence of transcripts of the cleavage and demethylase pathways reflected a versatile metabolism of dimethylsulfoniopropionate, a major organosulfur compound in marine ecosystems.

Mapping of environmental mRNA sequences on available genomes or genetic data stored in public databases is a common approach to study gene expression and active contribution of single marine groups to ecosystem functioning (Frias-Lopez, 2008, McCarren et al., 2010, Hollibaugh et al., 2011, Gifford et al., 2013, Ottesen et al., 2013). An early study analyzed gene expression in the open ocean and found active genes associated with key metabolic pathways including genes involved in photosynthesis, carbon fixation, and nitrogen acquisition (Frias-Lopez, 2008). Ottesen et al. (2013) studied transcriptome profiles of eukaryotic (Ostreococcus) and bacterial (Synechococcus) photosynthetic picoplankton as well as proteorhodopsin-containing heterotrophs, including Pelagibacter, SAR86-cluster Gammaproteobacteria, and marine Euryarchaea. The investigated photosynthetic picoplankton exhibited strong circadian rhythms over thousands of gene transcripts which was remarkably consistent with observations from pure cultures experiments. Investigated heterotrophs did not follow such a daily routine.

Although novel insights into gene expression patterns and functions of an abundant Roseobacter clade member were gained, our knowledge about the active ecological contribution of the Roseobacter clade is still very limited. Further research is needed addressing this issue. 


\subsection{MICROBIAL RESPONSE TO A CHANGING ENVIRONMENT}

Four studies presented in this thesis analyzed changes of microbial community structures as a response to changing environments conditions (studies 1-4). The structure and function of microbial communities in marine ecosystems is largely driven by environmental conditions. Many biotic factors including phytoplankton blooms (West et al., 2008, Teeling et al., 2012) as well as abiotic factors such as salinity, temperature, and depth (Thompson et al., 2011, Campbell \& Kirchman, 2013) influence the structure and function of marine microbial communities.

The first two studies presented in this thesis investigated the impact of a phytoplankton bloom on the active archaeal and bacterial community structure in the southern North Sea employing different metatranscriptomic approaches (studies $1 \& 2$ ). Both prokaryotic communities responded to the presence of the bloom or environmental parameters correlated with bloom presence. The number of studies examining the impact of a phytoplankton bloom on microbial community structures is limited especially for Archaea. Herfort et al. (2007) studied archaeal communities in the southwestern North Sea via denaturing gradient gel electrophoresis and showed a positive correlation between the abundance of Euryarchaeota and chlorophyll concentrations, whereas the abundance of Crenarchaeota was negatively correlated. Teeling et al. (2012) investigated the impact of a phytoplankton bloom bacterial communities near Helgoland. They demonstrated that the structure of these communities followed the development stages of the examined bloom. In a study from the Southern Ocean, community structures were different in and outside of a natural ironfertilized algal bloom (West et al., 2008).

In the third and fourth study, bacterial communities along a latitudinal gradient ranging from the German Bight to the coast of Norway were investigated. Community structures significantly changed along the examined latitudinal gradient. The abundance of certain marine groups such as the Roseobacter CHAB-I-5 and NAC11-7 clusters either decreased or increased with rising latitude. This is supported by other studies. For example, high numbers of Proteobacteria in coastal bacterioplankton communities along a latitudinal 
gradient in Latin America were observed by Thompson et al. (2011). Another study showed that the SAR11 clade as well as the genus Prochlorococcus were the dominant phylogenetic groups in oceanic surface waters on a latitudinal gradient ranging from South Africa to the English Channel (Schattenhofer et al., 2009). According to Lefort \& Gasol (2013), marine surface bacterioplankton groups varied along gradients of salinity, chlorophyll, and temperature. The authors suggested that both different niche preferences and a coherent response to environmental factors were responsible for the observed patterns. Another study examined total and active bacterial communities along a salinity gradient in Delaware Bay by pyrotag sequencing of $16 \mathrm{~S}$ rRNA and found significant structural changes in surface water communities along the investigated gradient (Campbell \& Kirchman, 2013). Fuhrman et al. (2008) investigated community patterns of marine planktonic bacteria worldwide by amplified ribosomal intergenic spacer analysis (ARISA). Geographic patterns similar to those of higher organisms were recorded. The authors concluded that the kinetics of metabolisms strongly influenced bacterial diversity and global distribution.

Although being intensively studied over the past years, our knowledge about prokaryotic communities in marine ecosystems and their response to changing environmental conditions is still limited. However, it is of fundamental importance to understand how they react as the reaction can have global implications. 


\section{FURTHER STUDIES ON MICROBIAL ECOLOGY}

\subsection{MICROBIAL DIVERSITY AND ECOLOGY OF TWO HYPERTHERMAL SPRINGS}

In one of the studies presented in this thesis, the prokaryotic community composition and ecology of two hyperthermal springs (AI: $51^{\circ} \mathrm{C}, \mathrm{pH} 3$; $\mathrm{AIV}$ : $92^{\circ} \mathrm{C}, \mathrm{pH} 8$ ) on the Azores was investigated (study 7). Bacterial and archaeal communities were dominated by a limited number of genera and lineages. This is not surprising as hyperthermal springs are considered to be low-diversity habitats due to the high physicochemical constraints and the high degree of geographical isolation (Papke et al., 2003).

Several studies revealed that the abundance and diversity of diverse microbial communities in terrestrial hot springs is influenced by chemical compositions, $\mathrm{pH}$, temperature, dissolved hydrogen sulfide levels, and biogeography (Ward \& Castenholz, 2002, Whitaker et al., 2003, Purcell et al., 2007). It is known that temperature is one major driver of the prokaryotic diversity in hot springs. For example, Hiraishi et al. (1999) showed that the microbial diversity of sulfide-containing neutral $\mathrm{pH}$ hot spring mats in Japan decreased as the temperature of the environment increased. Skirnisdottir et al. (Skirnisdottir et al., 2000) found the lowest bacterial diversity at the highest temperature $\left(80^{\circ} \mathrm{C}\right)$ and at the highest sulfide concentration when comparing hot springs in Iceland with low and high concentration of sulfide. These findings were also supported by a study about the bacterial diversity of microbial mats in two alkaline hot springs from Yellowstone National Park Park (Miller et al., 2009). On the other hand, no statistical correlation between prokaryotic diversity and temperature was observed in almost $\mathrm{pH}$ neutral hot springs in Central and CentralEastern Tibet (Huang et al., 2011) or in microbial mats and streamers in alkaline geothermal springs from Tibet (Yim et al., 2006).

Interestingly, the prokaryotic diversity on species level was lower in the acidic spring AI compared to the hot, slightly alkaline spring AIV. This result is supported by one of our previous studies of two hot springs on the Kamchatka peninsula (Wemheuer et al., 2013). We showed that the prokaryotic community in the thermophilic $\left(81^{\circ} \mathrm{C}, \mathrm{pH} 7.2-7.4\right)$ spring was more diverse than in the 
thermoacidophilic $\left(70^{\circ} \mathrm{C}, \mathrm{pH} 3.5-4\right)$ spring. The $\mathrm{pH}$ value was the major driver of the prokaryotic diversity in the investigated hot springs.

Geothermal springs are windows in the plant's past. Therefore, studies about these springs provide a unique inside in the early days of our planet and might help us to understand the evolution of life on Earth. Additionally, the low diversity found in these springs makes them ideal systems to study principles of community structure and function

\subsection{DIVERSITY, GENOMIC POTENTIAL, AND FUNCTION IN A PHOTOBIOREACTOR}

The community structure of algae-associated bacteria in a photobioreactor was analyzed in one of the presented studies (study 8). Furthermore, the microbial potential and function was evaluated. The bacterial diversity within the bioreactor was low with approximately 30 algae-associated bacterial species. Moreover, the analysis suggested that the catabolic and metabolic potential of the microbes living in the photobioreactor biofilm is highly flexible and diverse.

Microalgae comprise a large and phylogenetically very heterogeneous group of microorganisms. They carry out oxygenic photosynthesis and thereby convert $\mathrm{CO}_{2}$ to significant amounts of cellular lipids as potential source of biofuels (Abomohra et al., Chisti, 2007, Gouveia \& Oliveira, 2009, Williams \& Laurens, 2010, Wiley et al., 2011). Since photobioreactors allow the continuous cultivation of microalgae under relatively controlled conditions, they have been in the focus of many research projects often linked to algal fuel production (Chisti, 2007, Ugwu et al., 2008, Scott et al., 2010, Williams \& Laurens, 2010).

In this study, the metagenome sequences suggest that the bacteria associated within the photobioreactor were mainly heterotrophs metabolizing a wide range of carbon and energy sources provided by the algae. In addition, the relatively high number of predicted and functional esterase and lipase genes indicated that the algae-associated bacteria might be a major sink for lipids and fatty acids released by the microalgae. Heterotrophic organisms in algal cultures are generally considered as contaminants. Moreover, they are harmful for algal 
growth in microalgal biomass production systems (Belay, 1997, Huntley \& Redalje, 2007). According to Joint et al. (2002), bacteria and microalgae in a photobioreactor compete for the available nutrients such as N and P. Furthermore, bacteria may produce metabolites that are inhibitory to microalgal growth. On the other hand, certain bacteria may have positive impacts on growth of microalgae (Watanabe et al., 2005, Park et al., 2008), for example by increasing the solubility of nutrients and trace elements for algae (Keshtacher-Liebso et al., 1995) or by supplying vitamin B12 (Croft et al., 2005). One example for such a close mutualistic relationship is Dinoroseobacter shibae, another member of the Roseobacter clade. It is associated with dinoflagellates and supplies its algal host with vitamin B12 (Wagner-Döbler et al., 2010).

Photobioreactors can be used to produce algal fuel which is a promising alternative to fossil fuel and thus a putative solution for the global energy crisis. Moreover, photobioreactors can be used for the reduction of anthropogenic carbon dioxide. However, there is still a knowledge gap on the physiology and metabolism of complex microbial communities associated with eukaryotic microalgae. Therefore, a better understanding of the complex biology and interactions of microalgae with the environment is crucial to bypass known problems of photobioreactors and to improve this technology.

\subsection{ENDOPHYTIC COMMUNITIES IN THREE GRASS SPECIES}

The last study presented in this thesis evaluated the impact of different management regimes and seasons on the endophytic bacterial community composition in three agricultural important grass species, L. perenne, F. rubra, and D. glomerata (study 9). Community structures were significantly influenced by the applied management regimes. This is in accordance with other studies. For example, a higher diazotrophic bacterial diversity in the roots of rice cultivated in unfertilized and previously uncultivated soil than in paddy soil amended with nitrogen fertilizer were recorded by Prakamhang et al. (Prakamhang et al., 2009).

Moreover, differences in the community structures of the analyzed grass species and their response to the examined management regimes were recorded. 
According to Hallmann \& Berg (Hallmann \& Berg, 2006), plants vary in their biochemical composition which might explain differences in the bacterial endophytic community. Hallmann et al. (Hallmann et al., 1999) suggested that changes in plant physiology may result in the development of distinct bacterial endophytic communities. Several factors including temperature or precipitation have a direct effect on the plant physiology and thus an indirect impact on the colonization and the survival of bacteria in the endosphere (Hallmann et al., 1997, Tan et al., 2003, Hardoim et al., 2012). During the year, plants undergo physiological changes that probably increase nutrient availability and thus bacterial diversity (Hallmann \& Berg, 2006). This might explain the effect of season on the endophytic community composition recorded in this study.

As endophytes can promote plant growth, yield, and health, understanding what drives the composition of these microbes is important for agricultural production systems. However, the complex interaction between plant and endophyte is still not fully understood. 


\section{CONCLUDING REMARK}

The majority of studies presented in this thesis investigated the diversity and dynamics of prokaryotic communities in diverse ecosystems using a network of different culture-independent approaches. Our knowledge about the dynamics of these communities and their contribution to ecosystem functioning is still limited. Therefore, the results presented in this thesis might pave the way for a better understanding of these dynamics and the ecological role of prokaryotic communities. Moreover, the presented results also support the conclusion that only a combination of different, culture-dependent and culture-independent as well as DNA- and RNA-based ,approaches is able to draw a more comprehensive and realistic picture of a prokaryotic community. 
CHAPTER E

\section{GENERAL REFERENCES}


Abomohra AE-F, Wagner M, El-Sheekh M \& Hanelt D Lipid and total fatty acid productivity in photoautotrophic fresh water microalgae: screening studies towards biodiesel production. Journal of Applied Phycology 1-6.

Alderkamp AC, Sintes E \& Herndl GJ (2006) Abundance and activity of major groups of prokaryotic plankton in the coastal North Sea during spring and summer. Aquat Microb Ecol 45: 237-246.

Atlas RM \& Bartha R (1993) Microbial Ecology: Fundamentals and Applications. Benjamin Cummings, Redwood City, CA.

Auguet J-C, Barberan A \& Casamayor EO (2009) Global ecological patterns in uncultured Archaea. ISME J 4: 182-190.

Azam F \& Malfatti F (2007) Microbial structuring of marine ecosystems. Nat Rev Microbiol 5: 782-791.

Bacon C \& Hinton D (2006) Bacterial endophytes: The endophytic niche, its occupants, and its utility. Plant-Associated Bacteria,(Gnanamanickam S, ed.) pp. 155-194. Springer Netherlands.

Bacon C \& Hinton D (2011) Bacillus mojavensis: Its Endophytic Nature, the Surfactins, and Their Role in the Plant Response to Infection by Fusarium verticillioides. Bacteria in Agrobiology: Plant Growth Responses,(Maheshwari DK, ed.) p.^pp. 21-39. Springer Berlin Heidelberg.

Belay A (1997) Mass culture of Spirulina outdoors: the Earthrise Farms experience. Spirulina platensis (Arthrospira): Physiology, cell-biology and biotechnology London, Taylor and Francis 131-158.

Bolhuis H \& Stal LJ (2011) Analysis of bacterial and archaeal diversity in coastal microbial mats using massive parallel 16S rRNA gene tag sequencing. The ISME journal 5: 1701-1712.

Brakstad OG \& Lødeng AG (2005) Microbial diversity during biodegradation of crude oil in seawater from the North Sea. Microb Ecol 49: 94-103.

Brinkhoff T, Giebel HA \& Simon M (2008) Diversity, ecology, and genomics of the Roseobacter clade: a short overview. Arch Microbiol 189: 531-539.

Brinkmeyer R, Knittel K, Jürgens J, Weyland H, Amann R \& Helmke E (2003) Diversity and structure of bacterial communities in Arctic versus Antarctic pack ice. Appl Environ Microbiol 69: 6610-6619. 
Britschgi TB \& Giovannoni SJ (1991) Phylogenetic analysis of a natural marine bacterioplankton population by rRNA gene cloning and sequencing. Appl Environ Microbiol 57: 1707-1713.

Buchan A, González JM \& Moran MA (2005) Overview of the marine roseobacter lineage. Appl Environ Microbiol 71: 5665-5677.

Buchan A, Gonzalez JM \& Moran MA (2005) Overview of the marine roseobacter lineage. Applied and environmental microbiology 71: 56655677.

Campbell BJ \& Kirchman DL (2013) Bacterial diversity, community structure and potential growth rates along an estuarine salinity gradient. ISME $J$ 7: 210-220.

Cavicchioli R, DeMaere MZ \& Thomas T (2007) Metagenomic studies reveal the critical and wide-ranging ecological importance of uncultivated archaea: the role of ammonia oxidizers. BioEssays 29: 11-14.

Chisti Y (2007) Biodiesel from microalgae. Biotechnology advances 25: 294-306.

Compant S, Clément C \& Sessitsch A (2010) Plant growth-promoting bacteria in the rhizo- and endosphere of plants: Their role, colonization, mechanisms involved and prospects for utilization. Soil Biology and Biochemistry $\mathbf{4 2}$ : 669-678.

Compant S, Duffy B, Nowak J, Clement C \& Barka EA (2005) Use of plant growth-promoting bacteria for biocontrol of plant diseases: principles, mechanisms of action, and future prospects. Appl Environ Microbiol 71: 4951-4959.

Croft MT, Lawrence AD, Raux-Deery E, Warren MJ \& Smith AG (2005) Algae acquire vitamin B12 through a symbiotic relationship with bacteria. Nature 438: 90-93.

Curtis TP, Sloan WT \& Scannell JW (2002) Estimating prokaryotic diversity and its limits. Proc Natl Acad Sci U S A 99: 10494-10499.

Doty S, Oakley B, Xin G, Kang J, Singleton G, Khan Z, Vajzovic A \& Staley J (2009) Diazotrophic endophytes of native black cottonwood and willow. Symbiosis 47: 23-33. 
Eilers H, Pernthaler J, Glockner FO \& Amann R (2000) Culturability and In situ abundance of pelagic bacteria from the North Sea. Applied and environmental microbiology 66: 3044-3051.

Elend C, Schmeisser C, Leggewie C, Babiak P, Carballeira JD, Steele HL, Reymond JL, Jaeger KE \& Streit WR (2006) Isolation and biochemical characterization of two novel metagenome-derived esterases. Appl Environ Microbiol 72: 3637-3645.

Frias-Lopez J (2008) Microbial community gene expression in ocean surface waters. Proc Natl Acad Sci USA 105: 3805-3810.

Fuentes-Ramírez LE, Caballero-Mellado J, Sepúlveda J \& Martínez-Romero E (1999) Colonization of sugarcane by Acetobacter diazotrophicus is inhibited by high N-fertilization. FEMS Microbiology Ecology 29: 117128.

Fuhrman JA, Steele JA, Hewson I, Schwalbach MS, Brown MV, Green JL \& Brown JH (2008) A latitudinal diversity gradient in planktonic marine bacteria. Proceedings of the National Academy of Sciences 105: 77747778.

Giebel H-A, Kalhoefer D, Gahl-Janssen R, et al. (2013) Planktomarina temperata gen. nov., sp. nov., belonging to the globally distributed RCA cluster of the marine Roseobacter clade, isolated from the German Wadden Sea. International Journal of Systematic and Evolutionary Microbiology 63: 4207-4217.

Giebel HA, Brinkhoff T, Zwisler W, Selje N \& Simon M (2009) Distribution of Roseobacter RCA and SAR11 lineages and distinct bacterial communities from the subtropics to the Southern Ocean. Environ Microbiol 11: 21642178.

Giebel HA, Kalhoefer D, Lemke A, Thole S, Gahl-Janssen R, Simon M \& Brinkhoff T (2011) Distribution of Roseobacter RCA and SAR11 lineages in the North Sea and characteristics of an abundant RCA isolate. ISME J 5: 8-19.

Gifford SM, Sharma S, Booth M \& Moran MA (2013) Expression patterns reveal niche diversification in a marine microbial assemblage. ISME $J$ 7: 281298. 
Giovannoni SJ \& Stingl U (2005) Molecular diversity and ecology of microbial plankton. Nature 437: 343-348.

Giovannoni SJ, Britschgi TB, Moyer CL \& Field KG (1990) Genetic diversity in Sargasso Sea bacterioplankton. Nature 345: 60-63.

Gouveia L \& Oliveira AC (2009) Microalgae as a raw material for biofuels production. Journal of industrial microbiology \& biotechnology 36: 269274.

Hallmann J \& Berg G (2006) Spectrum and Population Dynamics of Bacterial Root Endophytes. Microbial Root Endophytes, Vol. 9 (Schulz BE, Boyle CC \& Sieber T, eds.), pp. 15-31. Springer Berlin Heidelberg.

Hallmann J, Rodríguez-Kábana R \& Kloepper JW (1999) Chitin-mediated changes in bacterial communities of the soil, rhizosphere and within roots of cotton in relation to nematode control. Soil Biology and Biochemistry 31: $551-560$.

Hallmann J, Quadt-Hallmann A, Mahaffee WF \& Kloepper JW (1997) Bacterial endophytes in agricultural crops. Canadian Journal of Microbiology 43: 895-914.

Hallmann J, Quadt-Hallmann A, Rodríguez-Kábana R \& Kloepper JW (1998) Interactions between Meloidogyne incognita and endophytic bacteria in cotton and cucumber. Soil Biology and Biochemistry 30: 925-937.

Hardoim PR, Hardoim CCP, van Overbeek LS \& van Elsas JD (2012) Dynamics of Seed-Borne Rice Endophytes on Early Plant Growth Stages. PLoS ONE 7: e30438.

Heidelberg KB, Gilbert JA \& Joint I (2010) Marine genomics: at the interface of marine microbial ecology and biodiscovery. Microb Biotechnol 3: 531543.

Herfort L, Schouten S, Abbas B, Veldhuis MJW, Coolen MJL, Wuchter C, Boon JP, Herndl GJ \& Sinninghe Damsté JS (2007) Variations in spatial and temporal distribution of Archaea in the North Sea in relation to environmental variables. FEMS Microbiology Ecology 62: 242-257.

Hiraishi A, Umezawa T, Yamamoto H, Kato K \& Maki Y (1999) Changes in quinone profiles of hot spring microbial mats with a thermal gradient. Appl Environ Microbiol 65: 198-205. 
Hollibaugh JT, Gifford S, Sharma S, Bano N \& Moran MA (2011) Metatranscriptomic analysis of ammonia-oxidizing organisms in an estuarine bacterioplankton assemblage. ISME J 5: 866-878.

Huang Q, Dong C, Dong R, et al. (2011) Archaeal and bacterial diversity in hot springs on the Tibetan Plateau, China. Extremophiles 15: 549-563.

Hugenholtz P, Pitulle C, Hershberger KL \& Pace NR (1998) Novel Division Level Bacterial Diversity in a Yellowstone Hot Spring. Journal of Bacteriology 180: 366-376.

Huntley ME \& Redalje DG (2007) CO2 mitigation and renewable oil from photosynthetic microbes: a new appraisal. Mitigation and adaptation strategies for global change 12: 573-608.

Jaspers E \& Overmann J (2004) Ecological Significance of Microdiversity: Identical 16S rRNA Gene Sequences Can Be Found in Bacteria with Highly Divergent Genomes and Ecophysiologies. Applied and Environmental Microbiology 70: 4831-4839.

Joint I, Henriksen P, Fonnes GA, Bourne D, Thingstad TF \& Riemann B (2002) Competition for inorganic nutrients between phytoplankton and bacterioplankton in nutrient manipulated mesocosms. Aquatic Microbial Ecology 29: 145-159.

Kalhoefer D, Thole S, Voget S, Lehmann R, Liesegang H, Wollher A, Daniel R, Simon M \& Brinkhoff $\mathrm{T}$ (2011) Comparative genome analysis and genome-guided physiological analysis of Roseobacter litoralis. BMC Genomics 12: 324.

Keshtacher-Liebso E, Hadar Y \& Chen Y (1995) Oligotrophic Bacteria Enhance Algal Growth under Iron-Deficient Conditions. Applied and environmental microbiology 61: 2439-2441.

Kobayashi D \& Palumbo J (2000) Bacterial endophytes and their effects on plants and uses in agriculture. Microbial endophytes Marcel Dekker, New York 199-236.

Krechel A, Faupel A, Hallmann J, Ulrich A \& Berg G (2002) Potato-associated bacteria and their antagonistic potential towards plant-pathogenic fungi and the plant-parasitic nematode Meloidogyne incognita (Kofoid \& White) Chitwood. Canadian Journal of Microbiology 48: 772-786. 
Kuklinsky-Sobral J, Araújo W, Mendes R, Pizzirani-Kleiner A \& Azevedo J (2005) Isolation and characterization of endophytic bacteria from soybean (Glycine max) grown in soil treated with glyphosate herbicide. Plant and Soil 273: 91-99.

Kvist T, Ahring BK \& Westermann P (2007) Archaeal diversity in Icelandic hot springs. FEMS Microbiology Ecology 59: 71-80.

Lee OO, Wang Y, Yang J, Lafi FF, Al-Suwailem A \& Qian P-Y (2011) Pyrosequencing reveals highly diverse and species-specific microbial communities in sponges from the Red Sea. ISME J 5: 650-664.

Maksimov IV, Abizgil'dina RR \& Pusenkova LI (2011) Plant growth promoting rhizobacteria as alternative to chemical crop protectors from pathogens (review). Applied Biochemistry and Microbiology 47: 333-345.

McCarren J, Becker JW, Repeta DJ, Shi Y, Young CR, Malmstrom RR, Chisholm SW \& DeLong EF (2010) Microbial community transcriptomes reveal microbes and metabolic pathways associated with dissolved organic matter turnover in the sea. Proceedings of the National Academy of Sciences 107: 16420-16427.

Meyer-Dombard DR, Shock EL \& Amend JP (2005) Archaeal and bacterial communities in geochemically diverse hot springs of Yellowstone National Park, USA. Geobiology 3: 211-227.

Miller SR, Strong AL, Jones KL \& Ungerer MC (2009) Bar-coded pyrosequencing reveals shared bacterial community properties along the temperature gradients of two alkaline hot springs in Yellowstone National Park. Appl Environ Microbiol 75: 4565-4572.

Olsen GJ, Woese CR \& Overbeek R (1994) The winds of (evolutionary) change: breathing new life into microbiology. J Bacteriol 176: 1-6.

Ottesen EA, Young CR, Eppley JM, Ryan JP, Chavez FP, Scholin CA \& DeLong EF (2013) Pattern and synchrony of gene expression among sympatric marine microbial populations. Proceedings of the National Academy of Sciences.

Papke RT, Ramsing NB, Bateson MM \& Ward DM (2003) Geographical isolation in hot spring cyanobacteria. Environ Microbiol 5: 650-659. 
Park Y, Je K-W, Lee K, Jung S-E \& Choi T-J (2008) Growth promotion of Chlorella ellipsoidea by co-inoculation with Brevundimonas sp. isolated from the microalga. Hydrobiologia 598: 219-228.

Prakamhang J, Minamisawa K, Teamtaisong K, Boonkerd N \& Teaumroong N (2009) The communities of endophytic diazotrophic bacteria in cultivated rice (Oryza sativa L.). Applied Soil Ecology 42: 141-149.

Purcell D, Sompong U, Yim LC, Barraclough TG, Peerapornpisal Y \& Pointing SB (2007) The effects of temperature, $\mathrm{pH}$ and sulphide on the community structure of hyperthermophilic streamers in hot springs of northern Thailand. FEMS Microbiol Ecol 60: 456-466.

Quast C, Pruesse E, Yilmaz P, Gerken J, Schweer T, Yarza P, Peplies J \& Glöckner FO (2013) The SILVA ribosomal RNA gene database project: improved data processing and web-based tools. Nucleic Acids Research 41: D590-D596.

Rink B, Seeberger S, Martens T, Duerselen C-D, Simon M \& Brinkhoff T (2011) Regional patterns of bacterial community composition and biogeochemical properties in the southern North Sea. Aquatic Microbial Ecology 63: 207222.

Rosenblueth M \& Martinez-Romero E (2006) Bacterial endophytes and their interactions with hosts. Mol Plant Microbe Interact 19: 827-837.

Rusch DB, Halpern AL, Sutton G, et al. (2007) The Sorcerer II Global Ocean Sampling expedition: northwest Atlantic through eastern tropical Pacific. PLoS biology 5: e77.

Sahm K, John P, Nacke H, Wemheuer B, Grote R, Daniel R \& Antranikian G (2013) High abundance of heterotrophic prokaryotes in hydrothermal springs of the Azores as revealed by a network of 16S rRNA gene-based methods. Extremophiles 17: 649-662.

Schattenhofer M, Fuchs BM, Amann R, Zubkov MV, Tarran GA \& Pernthaler J (2009) Latitudinal distribution of prokaryotic picoplankton populations in the Atlantic Ocean. Environ Microbiol 11: 2078-2093.

Schmidt TM, DeLong EF \& Pace NR (1991) Analysis of a marine picoplankton community by $16 \mathrm{~S}$ rRNA gene cloning and sequencing. J Bacteriol 173: 4371-4378. 
Scott SA, Davey MP, Dennis JS, Horst I, Howe CJ, Lea-Smith DJ \& Smith AG (2010) Biodiesel from algae: challenges and prospects. Current Opinion in Biotechnology 21: 277-286.

Seghers D, Wittebolle L, Top EM, Verstraete W \& Siciliano SD (2004) Impact of agricultural practices on the Zea mays L. endophytic community. Appl Environ Microbiol 70: 1475-1482.

Selje N, Simon M \& Brinkhoff T (2004) A newly discovered Roseobacter cluster in temperate and polar oceans. Nature 427: 445-448.

Senthilkumar M, Anandham R, Madhaiyan M, Venkateswaran V \& Sa T (2011) Endophytic Bacteria: Perspectives and Applications in Agricultural Crop Production. Bacteria in Agrobiology: Crop Ecosystems,(Maheshwari DK, ed.) p.^pp. 61-96. Springer Berlin Heidelberg.

Sessitsch A, Reiter B, Pfeifer U \& Wilhelm E (2002) Cultivation-independent population analysis of bacterial endophytes in three potato varieties based on eubacterial and Actinomycetes-specific PCR of 16S rRNA genes. FEMS Microbiol Ecol, Vol. 39 p.^pp. 23-32. England.

Siddiqui I \& Shaukat S (2003) Endophytic bacteria. Prospects and opportunities for the biological control of plant parasitic nematodes. Nematologia Mediterranea 31.

Simon C \& Daniel R (2011) Metagenomic analyses: past and future trends. Appl Environ Microbiol 77: 1153-1161.

Sintes E, Witte H, Stodderegger K, Steiner P \& Herndl GJ (2013) Temporal dynamics in the free-living bacterial community composition in the coastal North Sea. FEMS Microbiology Ecology 83: 413-424.

Skirnisdottir S, Hreggvidsson GO, Hjorleifsdottir S, Marteinsson VT, Petursdottir SK, Holst O \& Kristjansson JK (2000) Influence of sulfide and temperature on species composition and community structure of hot spring microbial mats. Appl Environ Microbiol 66: 2835-2841.

Sperling M, Giebel HA, Rink B, Grayek S, Staneva J, Stanev E \& Simon M (2012) Differential effects of hydrographic and biogeochemical properties on the SAR11 clade and Roseobacter RCA cluster in the North Sea. Aquatic Microbial Ecology 67: 25-34. 
Stoltzfus JR, So R, Malarvithi PP, Ladha JK \& de Bruijn FJ (1997) Isolation of endophytic bacteria from rice and assessment of their potential for supplying rice with biologically fixed nitrogen. Plant and Soil 194: 25-36.

Sturz AV \& Nowak J (2000) Endophytic communities of rhizobacteria and the strategies required to create yield enhancing associations with crops. Applied Soil Ecology 15: 183-190.

Sturz AV, Christie BR \& Nowak J (2000) Bacterial Endophytes: Potential Role in Developing Sustainable Systems of Crop Production. Critical Reviews in Plant Sciences 19: 1-30.

Tan Z, Hurek T \& Reinhold-Hurek B (2003) Effect of N-fertilization, plant genotype and environmental conditions on nifH gene pools in roots of rice. Environmental microbiology 5: 1009-1015.

Teeling H, Fuchs BM, Becher D, et al. (2012) Substrate-controlled succession of marine bacterioplankton populations induced by a phytoplankton bloom. Science 336: 608-611.

Thompson F, Bruce T, Gonzalez A, et al. (2011) Coastal bacterioplankton community diversity along a latitudinal gradient in Latin America by means of V6 tag pyrosequencing. Archives of Microbiology 193: 105-114.

Ugwu C, Aoyagi H \& Uchiyama H (2008) Photobioreactors for mass cultivation of algae. Bioresource Technology 99: 4021-4028.

Venter JC, Remington K, Heidelberg JF, et al. (2004) Environmental genome shotgun sequencing of the Sargasso Sea. Science 304: 66-74.

Vila-Costa M, Gasol JM, Sharma S \& Moran MA (2012) Community analysis of high- and low-nucleic acid-containing bacteria in NW Mediterranean coastal waters using $16 \mathrm{~S}$ rDNA pyrosequencing. Environmental Microbiology 14: 1390-1402.

Vollmers J, Voget S, Dietrich S, Gollnow K, Smits M, Meyer K, Brinkhoff T, Simon M \& Daniel R (2013) Poles Apart: Arctic and Antarctic Octadecabacter strains Share High Genome Plasticity and a New Type of Xanthorhodopsin. PLoS ONE 8: e63422.

Wagner-Döbler I, Ballhausen B, Berger M, et al. (2010) The complete genome sequence of the algal symbiont Dinoroseobacter shibae: a hitchhiker's guide to life in the sea. ISME J 4: 61-77. 
Ward D \& Castenholz R (2002) Cyanobacteria in Geothermal Habitats. The Ecology of Cyanobacteria,(Whitton B \& Potts M, eds.), p.^pp. 37-59. Springer Netherlands.

Waschkowitz T, Rockstroh S \& Daniel R (2009) Isolation and characterization of metalloproteases with a novel domain structure by construction and screening of metagenomic libraries. Appl Environ Microbiol 75: 25062516.

Watanabe K, Takihana N, Aoyagi H, Hanada S, Watanabe Y, Ohmura N, Saiki H \& Tanaka H (2005) Symbiotic association in Chlorella culture. FEMS microbiology ecology 51: 187-196.

Wemheuer B, Wemheuer F \& Daniel R (2012) RNA-Based Assessment of Diversity and Composition of Active Archaeal Communities in the German Bight. Archaea,vol. 2012, Article ID 695826.

Wemheuer B, Taube R, Akyol P, Wemheuer F \& Daniel R (2013) Microbial Diversity and Biochemical Potential Encoded by Thermal Spring Metagenomes Derived from the Kamchatka Peninsula. Archaea, vol 2013, Article ID 136714.

Wemheuer B, Güllert S, Billerbeck S, Giebel H-A, Voget S, Simon M \& Daniel R (2013) Impact of a phytoplankton bloom on the diversity of the active bacterial community in the southern North Sea as revealed by metatranscriptomic approaches. FEMS Microbiology Ecology (accepted)

West NJ, Obernosterer I, Zemb O \& Lebaron P (2008) Major differences of bacterial diversity and activity inside and outside of a natural ironfertilized phytoplankton bloom in the Southern Ocean. Environ Microbiol 10: $738-756$.

Whitaker RJ, Grogan DW \& Taylor JW (2003) Geographic barriers isolate endemic populations of hyperthermophilic archaea. Science 301: 976-978.

Whitman WB, Coleman DC \& Wiebe WJ (1998) Prokaryotes: The unseen majority. Proceedings of the National Academy of Sciences 95: 65786583.

Wiley PE, Campbell JE \& McKuin B (2011) Production of biodiesel and biogas from algae: a review of process train options. Water Environment Research 83: 326-338. 
Williams PJIB \& Laurens LM (2010) Microalgae as biodiesel \& biomass feedstocks: Review \& analysis of the biochemistry, energetics \& economics. Energy \& Environmental Science 3: 554-590.

Yim LC, Hongmei J, Aitchison JC \& Pointing SB (2006) Highly diverse community structure in a remote central Tibetan geothermal spring does not display monotonic variation to thermal stress. FEMS Microbiol Ecol 57: 80-91.

Zubkov MV, Fuchs BM, Archer SD, Kiene RP, Amann R \& Burkill PH (2001) Linking the composition of bacterioplankton to rapid turnover of dissolved dimethylsulphoniopropionate in an algal bloom in the North Sea. Environ Microbiol 3: 304-311. 
APPENDIX 


\section{Other Publications}

\section{JOURNAL ARTICLES (PEER-REVIEWED)}

- Wemheuer B, Taube R, Akyol P, Wemheuer F, Daniel R. Microbial diversity and biochemical potential encoded by thermal spring metagenomes derived from the Kamchatka peninsula. Archaea, vol. 2013: Article ID 136714, 2013. doi:10.1155/2013/136714.

- Mientus M, Brady S, Angelov A, Zimmermann P, Wemheuer B, Schuldes J, Daniel R, Liebl W (2013) Thermostable xylanase and $\beta$-glucanase derived from the metagenome of the Avachinsky Crater in Kamchatka (Russia). Current Biotechnology 2: 284-293. 


\section{TALKS AND POSTER PRESENTATIONS}

\section{TALKS AT CONFERENCES}

- Wemheuer B (2013): Metagenomics and Metatranscriptomics at the Göttingen Genomics Laboratory (invited speaker). German Conference on Bioinformatics (GCB), Göttingen (10.-13.09.2013).

- Wemheuer F, Wemheuer B, Kretzschmar D, Daniel R, Vidal S (2013): Multitrophic interaction between microorganisms, plant and herbivores: Does fertilizing, mowing or herbivory on plants alter the microbial community diversity in the rhizosphere? Annual Conference of the Association for General and Applied Microbiology (VAAM), Bremen (10.-13.03.2013).

\section{POSTERS AT CONFERENCES (SELECTION)}

- Wemheuer B, Güllert S, Meier D, and Daniel R (2013). Diversity, ecology, and physiology of the Roseobacter clade and other marine microbes in the North Sea. Annual Conference of the Association for General and Applied Microbiology (VAAM), Bremen (10.-13.03.2013).

- Wemheuer B, Güllert S, Meier D, and Daniel R (2012). Metatranscriptomics of the Roseobacter clade. "International Symposium on Microbial Ecology”, Copenhagen, 19.-24.08.2012.

- Wemheuer B and Daniel R, (2010): Characterization of metagenomes derived from volcanic sites of Kamchatka. Annual Conference of the Association for General and Applied Microbiology (VAAM), Hannover (28.-31.03.2010). 


\section{ACKNOWLEDGEMENTS}

It would not have been possible to write this thesis without the help and support of many kind people around me.

First of all, I would like to thank Prof. Dr. Rolf Daniel for giving me the opportunity to work on this interesting, interdisciplinary topic as well as for the continuous support and supervision during my thesis. Many thanks for letting me work independently on my thesis but providing valuable advice when needed, and for the critically and constructive reading of my manuscripts.

I am very grateful to Prof. Dr. Stefanie Pöggeler for accepting to co-examine this thesis and always having a friendly ear.

This study is part of the TRR51'Ecology, Physiology and Molecular Biology of the Roseobacter clade'. I want to thank the Deutsche Forschungsgesellschaft (DFG) for funding. I am very grateful to Prof. Dr. Meinhard Simon, the speaker of the TRR, for helpful comments and feedbacks on my manuscripts and the cookies during the various research cruises. I also appreciated the cooperation with so many people in the TRR: Sara Billerbeck, Marco Dogs, Bert Engelen, HelgeAnsgar Giebel, Saranya Kanukollu, Judith Lucas, and all the other people. It was a great time!

I was not able to conduct all this work by myself and thus I want to thank: Simon Güllert, Peggy Klempert, and Dimitri Meier who wrote their master theses under my supervision and contributed significantly to this work, Pinar Akyol and Robert Taube who wrote their Bachelor theses under my supervision, and Sonja Voget and John Vollmers, the other 'Roseobacters' in our group.

I would also like to thank my colleagues of the Department of Genomic and Applied Microbiology and the Göttingen Genomics Laboratory for the pleasant atmosphere. I want to thank: Mechthild Bömeke, Silja Brady, Sarah Herzog, Heiko Nacke, Birgit Pfeiffer, Dominik Schneider, Tanja Waschkowitz, and all the 
other people. A special thanks to Andrea Thürmer, Frauke-Dorothee Meyer, and Kathleen Gollnow for all the sequencing stuff. I would also like to thank some former members of our group: Jenny Hüpeden, Boris Nowka, Steffi Rockstroh, Juliane Schnabel, Marie Schnapp, Carola Schröder, Carola Simon, and Jörn Voss.

Finally, I am very grateful to my wife Franziska for the love and understanding during all the time, the critical reading of my manuscripts, and the statistical advice. I am also grateful to my son Erik who kept me successfully away from sleeping and to my parents for their patience (direct quote: "Wann wirst du endlich fertig?!!"). 


\section{Curriculum Vitae}

\section{Personal information}

Name

Nationality

Date of birth

Place of Birth

Marital status

\section{Education}

$04 / 2010-01 / 2014$

$10 / 2003-09 / 2009$

$09 / 1990-06 / 2003$
Bernd Wemheuer

German

21 April 1984

Northeim, Germany

Married with one child

$\underline{\text { PhD candidate in the TRR51: "Ecology, Physiology }}$ and Molecular Biology of the Roseobacter clade"

Genomic and Applied Microbiology and Göttingen

Genomics Laboratory, University of Göttingen

Study of Biology at the University of Göttingen

Degree obtained: Dipl.-Biol. Univ

Main subject: Microbiology

Minor subjects: Human Genetics and Physical Chemistry

Diploma thesis: „Characterization of microbial metagenomes derived from extreme habitats of the Kamchatka peninsula"

$\underline{\text { High school graduation (Allgemeine Hochschulreife) }}$

Ernst-Moritz-Arndt Gymnasium, Herzberg am Harz 
Work Experience

$10 / 2009-03 / 2010$

$\underline{\text { Research assistant }}$

Genomic and Applied Microbiology, University of

Göttingen

$09 / 2010$

$\underline{\text { Student assistant }}$

Genomic and Applied Microbiology, University of

Göttingen

Other Experiences

$03 / 2012-04 / 2012$

Research trip in the Southern Ocean on board of the

$\underline{\text { RV Polarstern (AntXXVIII-4) }}$

$07 / 2011$

Research trip in the North Sea on board of the RV

Heincke (HE361)

$05 / 2010$

Research trip in the North Sea on board of the RV

Heincke (HE327)

09/2009

$\underline{\text { Research trip to South Africa }}$

University of the Free State, Bloemfontein, South Africa 